Slavistische Beiträge · Band 418

(eBook - Digi20-Retro)

\title{
Lenka Bayer
}

\section{Sprachgebrauch \\ vs. Spracheinstellung \\ im Tschechischen}

\section{Empirische und soziolinguistische Untersuchung in Westböhmen und Prag}

Verlag Otto Sagner München - Berlin - Washington D.C.

Digitalisiert im Rahmen der Kooperation mit dem DFG-Projekt „Digi20“

der Bayerischen Staatsbibliothek, München. OCR-Bearbeitung und Erstellung des eBooks durch den Verlag Otto Sagner:

http://verlag.kubon-sagner.de

( $)$ bei Verlag Otto Sagner. Eine Verwertung oder Weitergabe der Texte und Abbildungen, insbesondere durch Vervielfältigung, ist ohne vorherige schriftliche Genehmigung des Verlages unzulässig. 


\section{Lenka Bayer}

Sprachgebrauch vs. Spracheinstellung im Tschechischen 


\title{
SLAVISTISCHE BEITRÄGE
}

\author{
Herausgegeben von \\ Peter Rehder
}

\author{
Beirat: \\ Tilman Berger · Walter Breu · Johanna Renate Döring-Smirnov \\ Walter Koschmal - Ulrich Schweier · Miloš Sedmidubský · Klaus Steinke
}

\section{BAND 418}

\section{VERLAG OTTO SAGNER MÜNCHEN 2003}




\section{Lenka Bayer}

\section{Sprachgebrauch vs. Spracheinstellung im Tschechischen}

Eine empirische und soziolinguistische Untersuchung in

Westböhmen und Prag

\section{VERLAG OTTO SAGNER MÜNCHEN 2003}


ISBN 3-87690-838-8

(C) Verlag Otto Sagner, München 2003 Abteilung der Firma Kubon \& Sagner

D-80328 München

Gedruckt auf alterungsbeständigem Papier

\section{Bayeriacho}

Stentabibliothok

Minchen 


\section{Danksagung}

Die vorliegende Arbeit entstand in den Jahren 1998-2002 als Dissertation am Institut furr Slavistik der Friedrich-Alexander-Universität Erlangen-Nürnberg unter der Anleitung von Herrn Prof Dr. Dr. h.c. KLAUS STEINKE. Ihm gebührt an dieser Stelle herzlicher Dank für die Betreuung meiner Arbeit, fur wertvolle Ratschlage und Anregungen. Die Erfahrungen von Herrn Prof. STEINKE auf dem Gebiet des empirischen wissenschaftlichen Arbeitens sowie seine Unterstützung beim experimentellen Anwenden interdisziplinärer Methoden standen nicht nur an der Wiege dieser Studie, sondern begleiteten ihre gesamte Entstehung.

Weiter sei an dieser Stelle gedankt den Bohemisten an der Karlsuniversität in Prag, die diese Studie mit großem Interesse verfolgten und unterstützten, Frau Prof. Dr. R. BRABCovA, Herrn Prof. Dr F. CERmak, Frau Dr. E. HÁJKOVA und Herrn Prof. Dr. O. Ulí́NÝ.

Für ihre Unterstützung beim Durchführen der direkten sowie der indirekten Enquete in Pilsen danke ich an dieser Stelle Frau Dr. V. CHMELIKOVÁ, Bohemistin und Germanistin an der Pädagogischen Fakultät der Westböhmischen Universität in Pilsen, und Herm Prof. Dr. SovA, Dozenten an der Technischen Fakultät der Westböhmischen Universität in Pilsen.

Herrn J. PERLINGER, der unter unserer Anleitung bei der direkten und indirekten Enquete in Prag mitwirkte, gebührt unser herzlicher Dank. Herm Rechtsanwalt H. NERLICH, der die juristische Grundlage unserer Enqueten überprüfte und überwachte, sowie meinen Kollegen, Herrn Dr. H. REINSTEIN und Herrn J. ACHTERBERG, die mir mit Rat und Tat bei Problemen mit der Textverarbeitung zur Seite standen, sei an dieser Stelle ebenso herzlich gedankt.

Nicht zuletzt möchte ich meinem Sohn LUDWIG, meinem Lebensgefahrten HARALD und meinen Eltern von Herzen danken. Sie teilten mit mir die Augenblicke der Schaffensfreude aber auch des manchmal aufkommenden Frustes. Mit ihrer Geduld und ihrem Verständnis fur meine wissenschaftliche Arbeit trugen sie in großem Maße zur Entstehung dieser Studie bei

Schließlich gilt mein Dank Herrn Prof. Dr PFTER REHDER, Ludwig-Maximilians-Universität München, der diese Arbeit in seine wissenschaftliche Reihe Slonistische Beiträge aufnahm. 


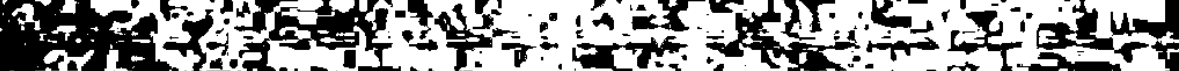

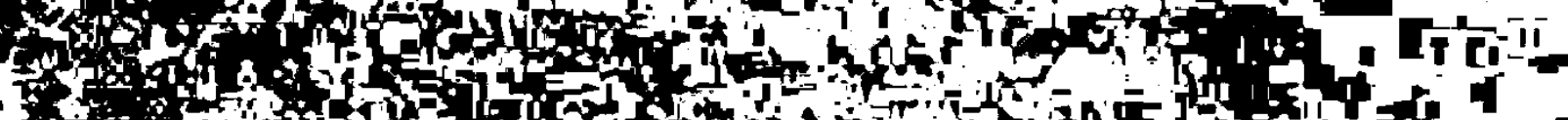

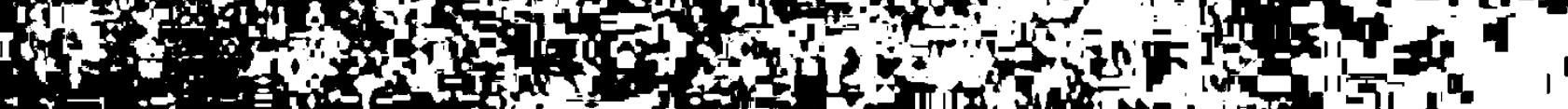

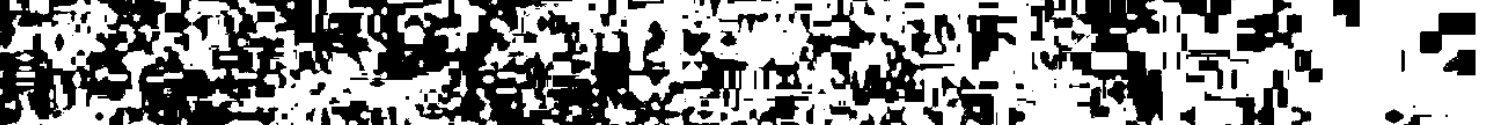
a

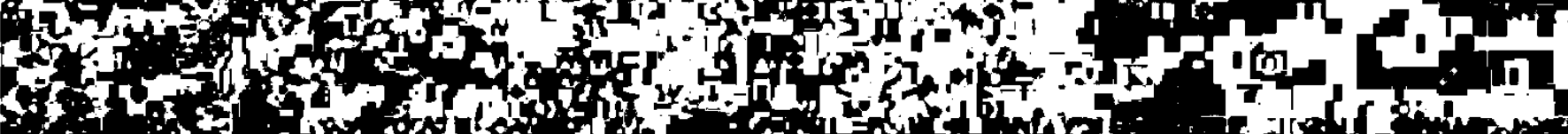

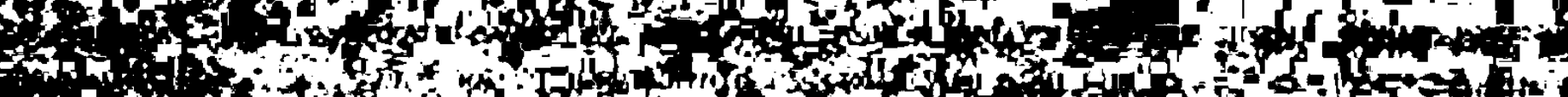

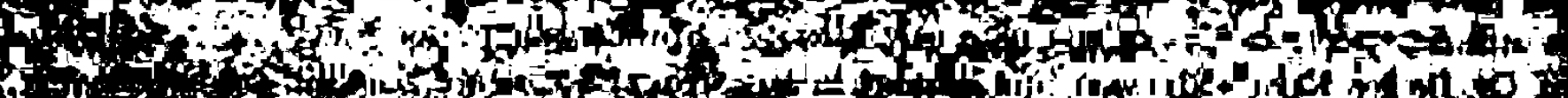

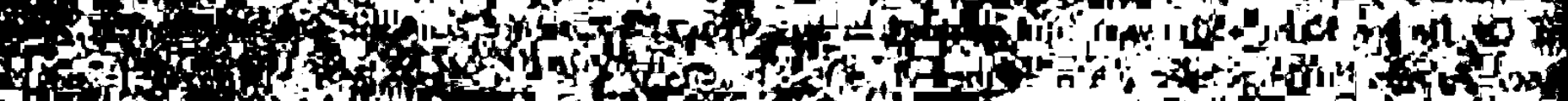

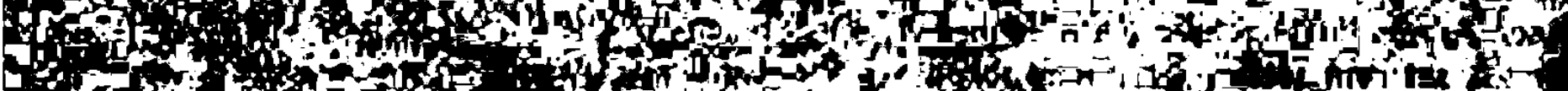
4.5.56\%

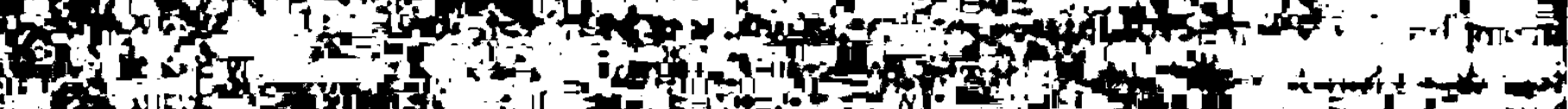

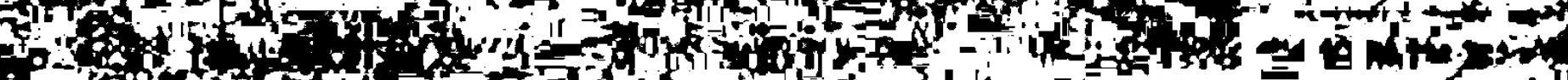
14tom B Fon

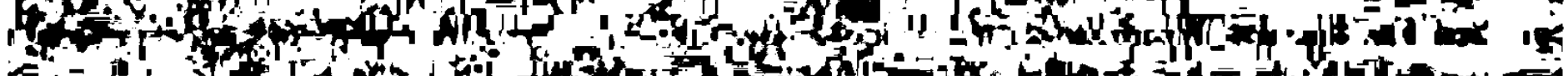
$E=$ id: (1) 1 of

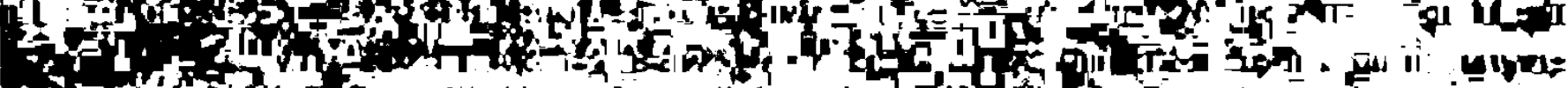

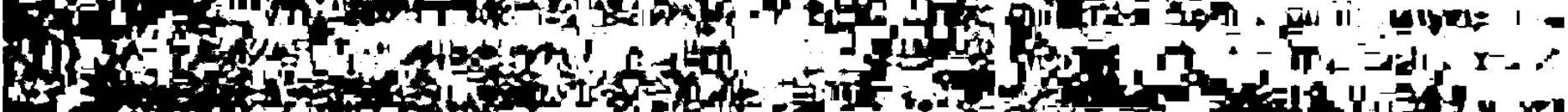

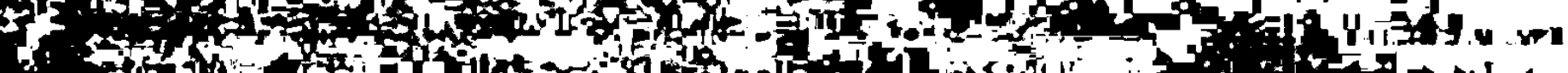
ald

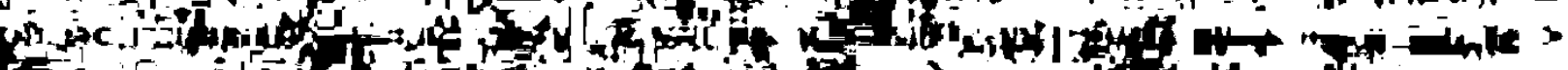

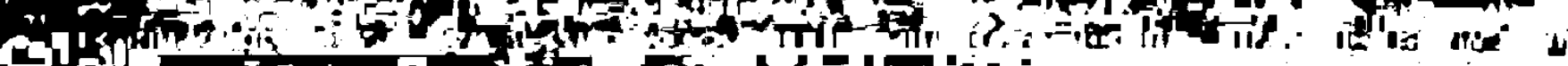

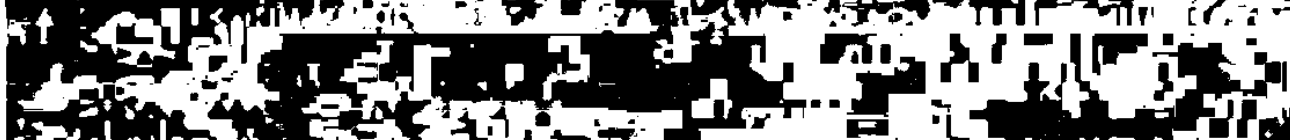
Fon

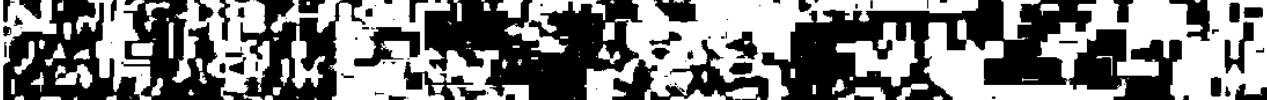
A. Hif (4) 4 (n) Kl for 150

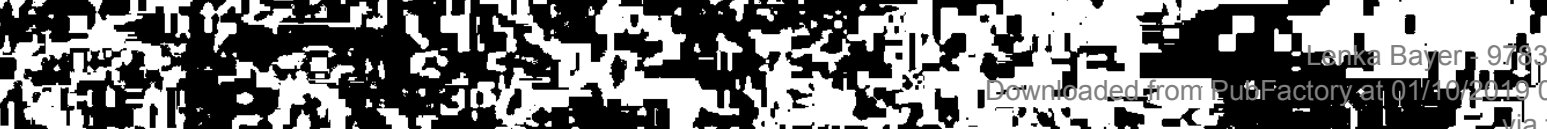
all 


\section{Inhaltsverzeichnis}

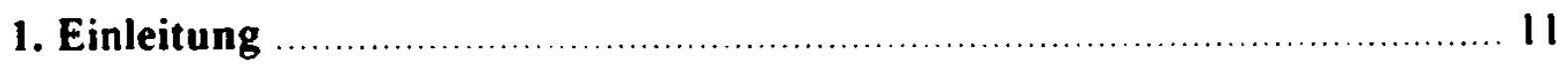

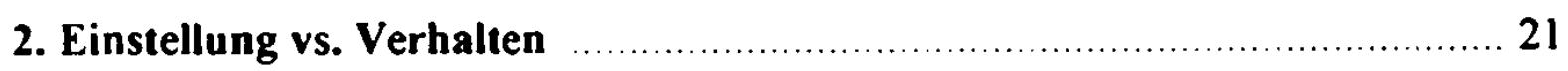

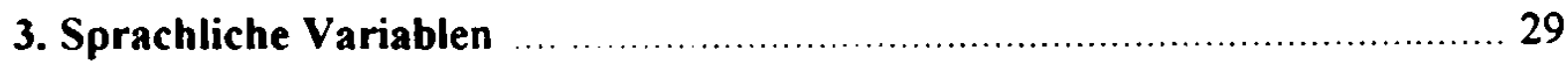

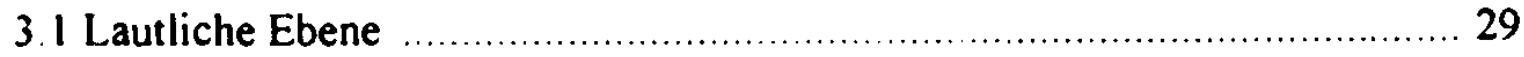

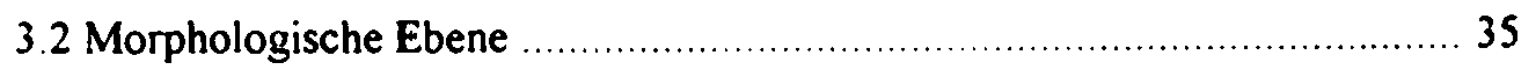

4. Soziologische und diatopische Variablen ……….................................. 39

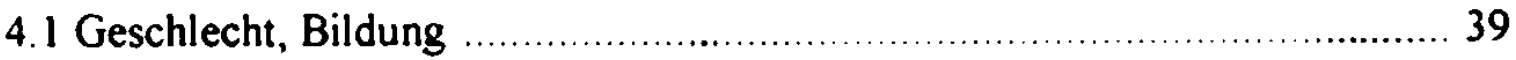

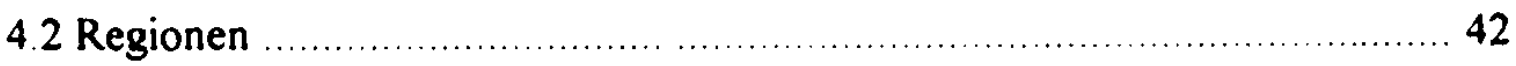

5. Untersuchungs- und Auswertungsmethoden …................................. 45

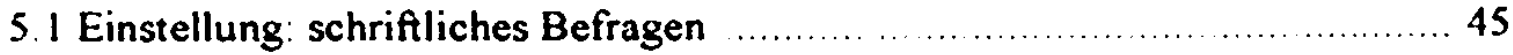

5 1.1 Das kognitive Subsystem ....................................................... 48

5.1.2 Das affektive Subsystem ................................................... 53

5.1.3 Das konative Subsystem .......................................................... 56

5.2 Situationbezogenes sprachliches Verhalten ....................................... 60

5.2.1 Verhalten in einer informellen Situation ......................................6 60

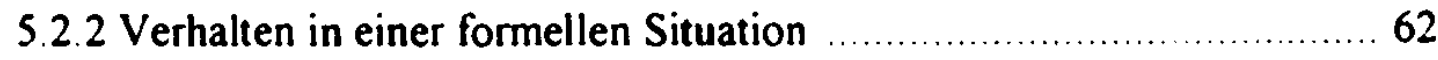

5.2.3 Auswertung im Bereich des Sprachverhaltens ..............................63 63

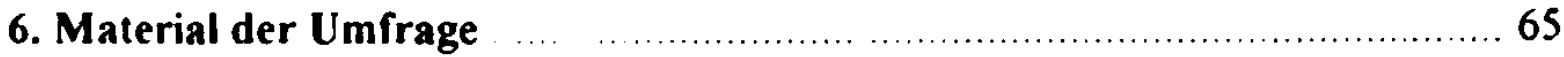

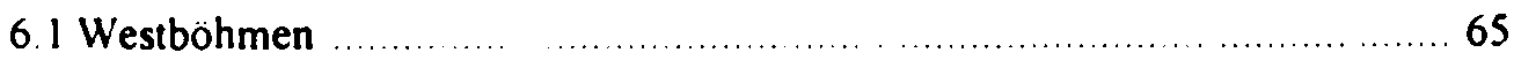

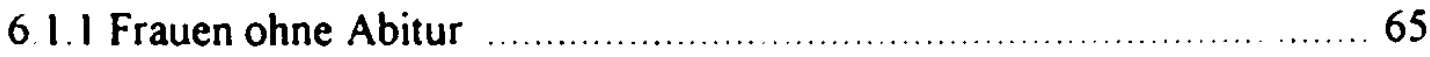

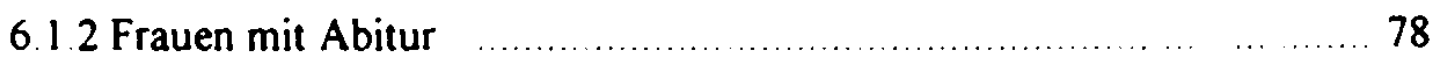

6.1.3 Frauen mit Hochschulabschluß ......................................... 89

61.4 Männer ohne Abitur ....................................................... 100

61.5 Männer mit Abitur ............................................................. 113

61.6 Männer mit Hochschulabschluß ........................................... 129 


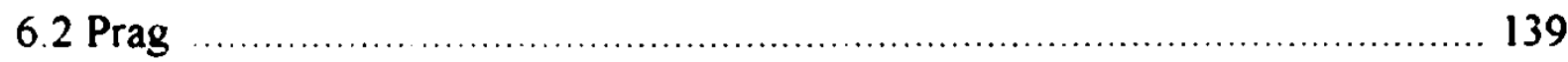

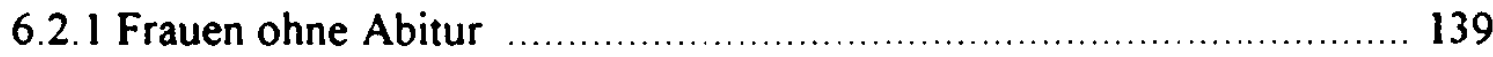

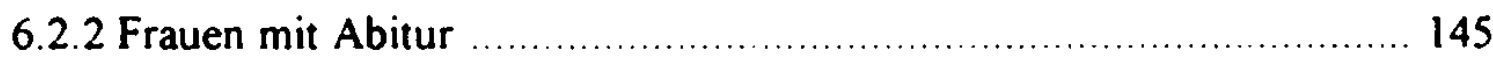

6.2.3 Frauen mit Hochschulabschluß .......................................... 153

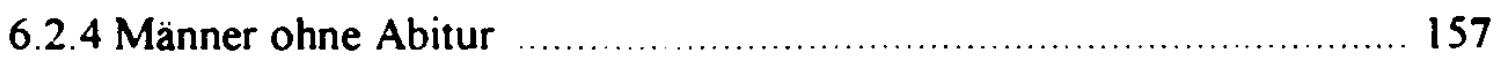

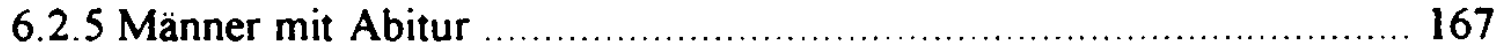

6.2.6 Männer mit Hochschulabschluß .............................................. 176

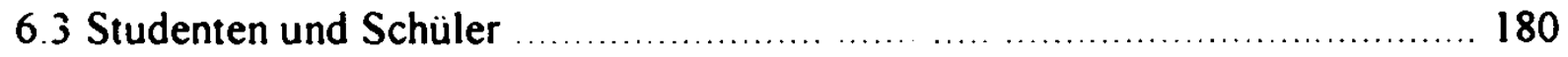

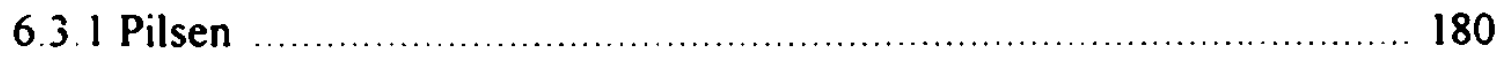

6.3.1.1 Jurastudent und -studentin .......................................... 180

6.3.1.2 Studenten der Technischen Fakultät ................................. 183

6.3.1.3 Studentinnen der Pädagogischen Fakultät, Bohemistik ........... 190

6.3.1.4 Studenten der Pädagogischen Fakultät, Bohemistik ................ 197

6.3.1.5 Schüler der Technischen Oberschule, Verkehrswesen ............ 201

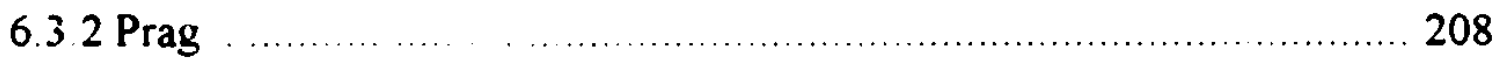

6.3.2.1 Studentinnen der Philosophischen Fakultat, Bohemistik ........ 208

6.3.2.2 Studenten der Philosophischen Fakultät, Bohemistik ........... 215

6.3.2.3 Studentinnen der Pädagogischen Fakultät, Bohemistik ........... 218

6.3.2.4 Studenten der Pädagogischen Fakultät, Bohemistik ... ......... 225

7. Exkurs: Sprache der audiovisuellen Medien ...................................... 229

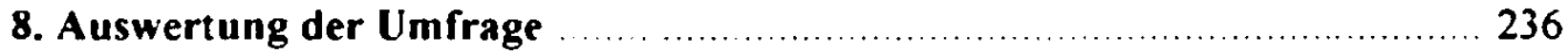

8.1 Ermittlung der Durchschnittswerte .......................................... 236

8.1.1 Erste Working-up-Ebene: Westböhmen ……........................... 238

8.1.2 Erste Working-up-Ebene: Prag …................................. 248

8.1.3 Zweite Working-up-Ebene. Westböhmen ……....................... 256

8.1 4 Zweite Working-up-Ebene: Prag ......................................... 263

8.15 Dritte Working-up-Ebene: Westböhmen, Prag ........................... 270

8.2 Vergleich des kognitiven und des affektiven Subsystems ..................... 278

8.3 Sprachverhalten vs. konatives Subsystem der Einstellung ................. 286 
9. Beobachtungen und Respondentenkommentare .................................. 294

10. Zusammenfassung und Ausblick auf die weitere Forschung ..................299

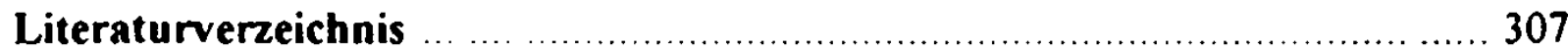

Anlage 


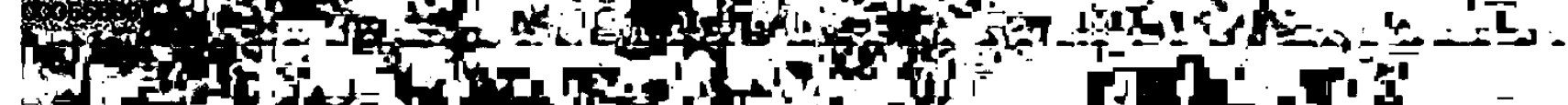
;)

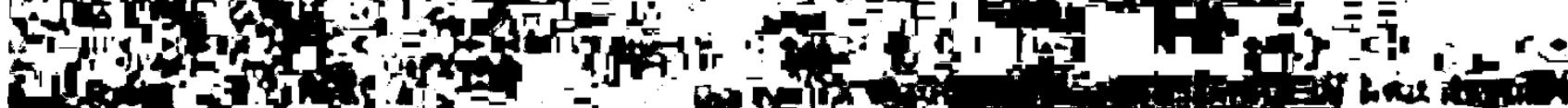

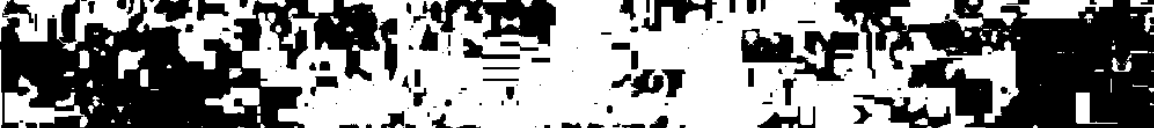

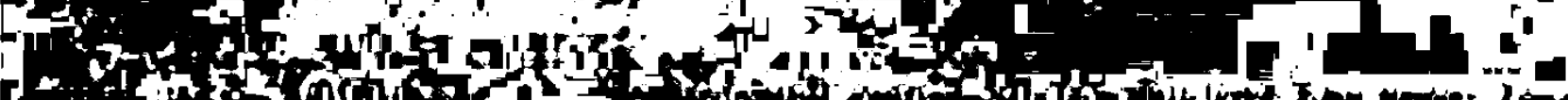

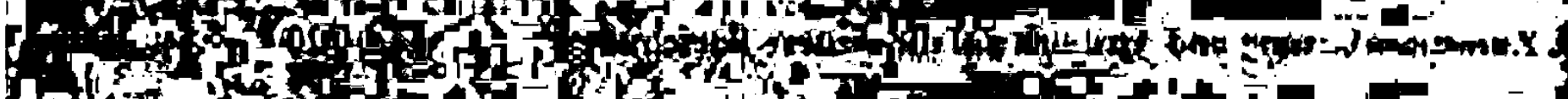

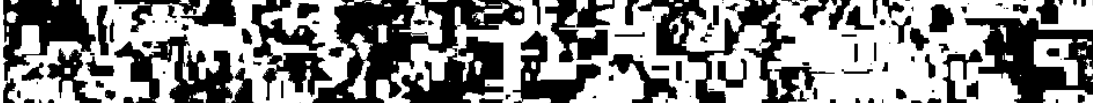

6 of

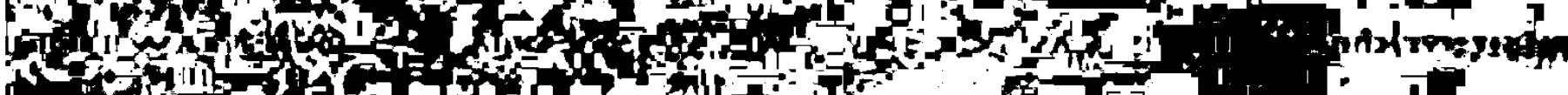

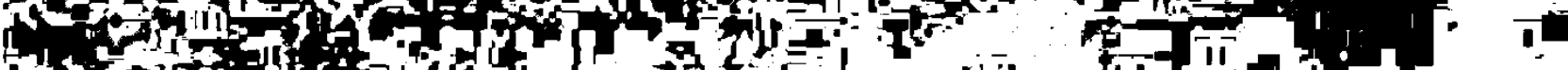

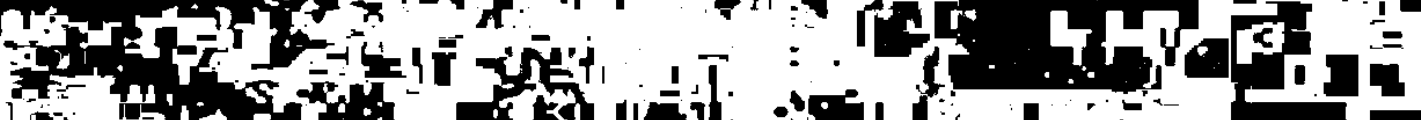

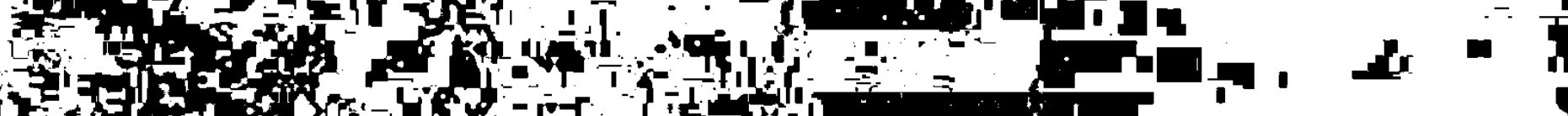

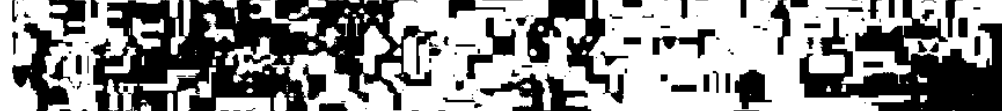

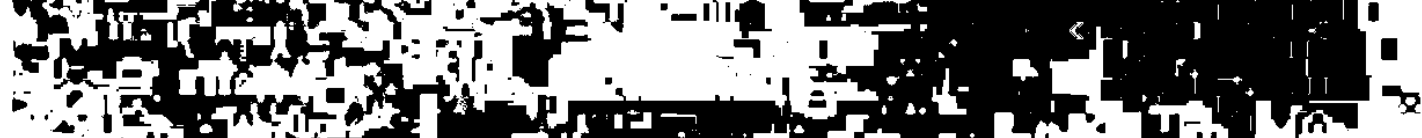

1.

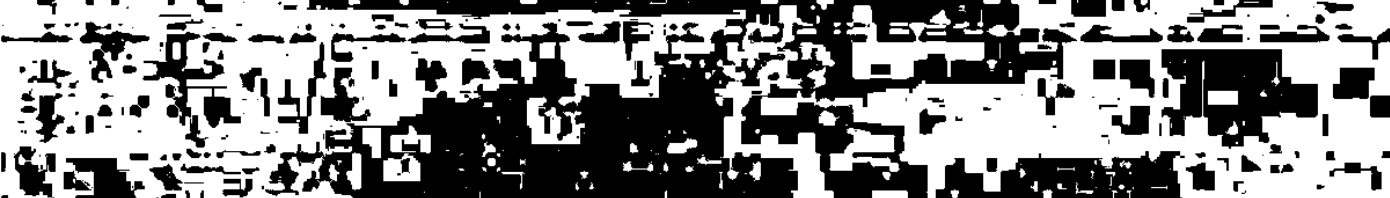

The

$\therefore$ (15)

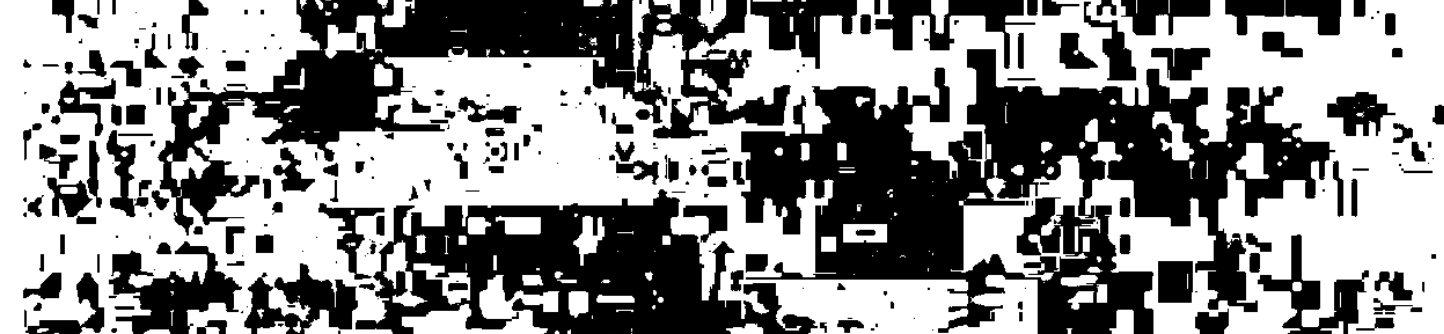

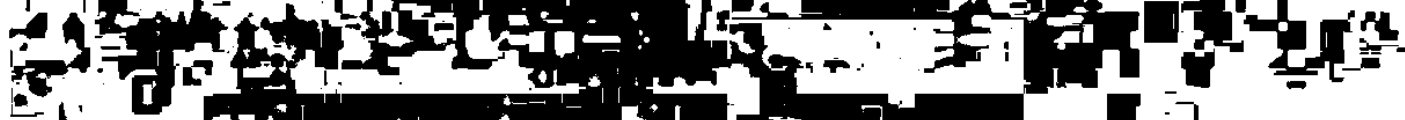

(a)

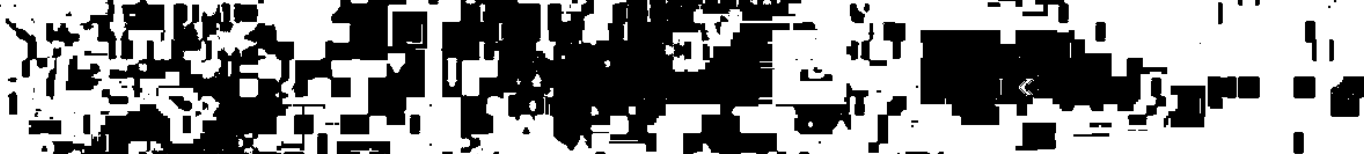

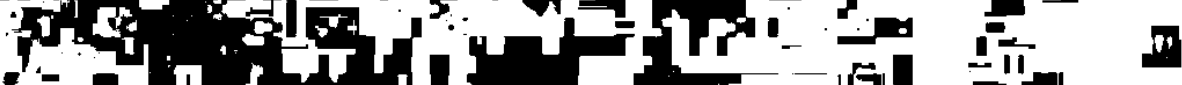

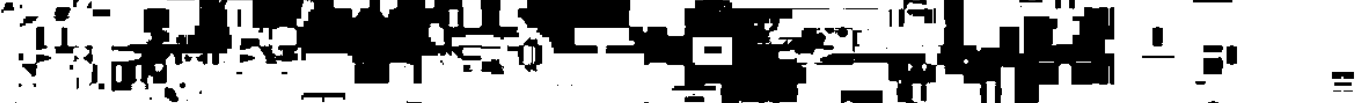

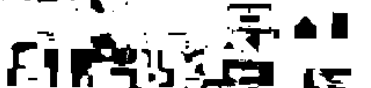

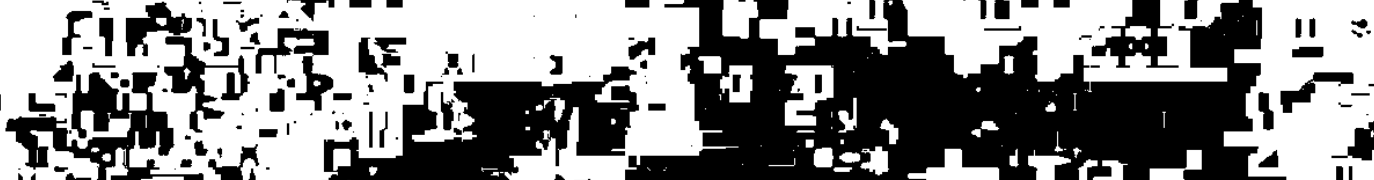

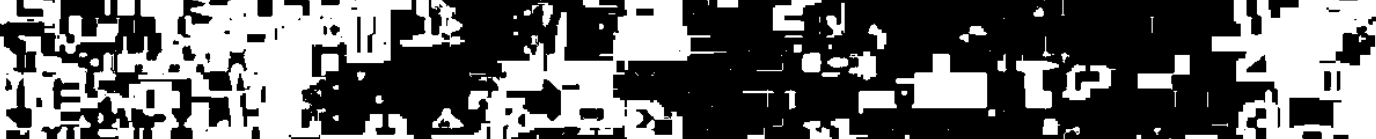

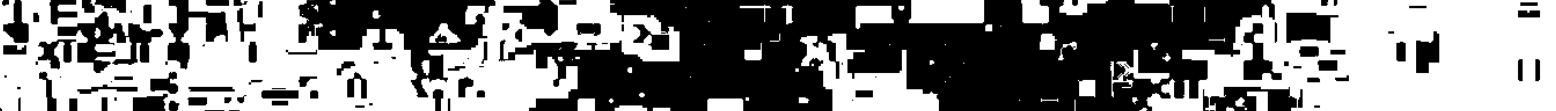

1

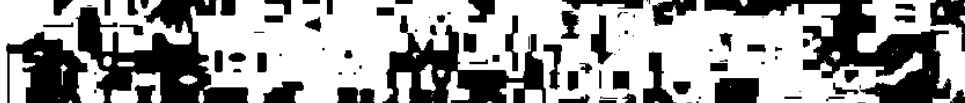

ofrat a

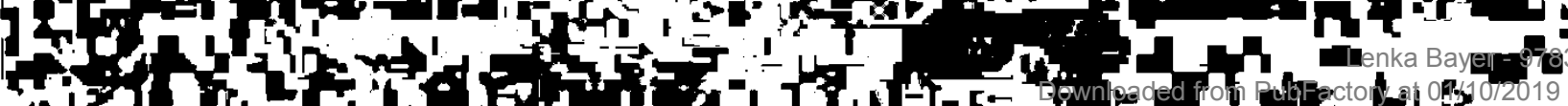

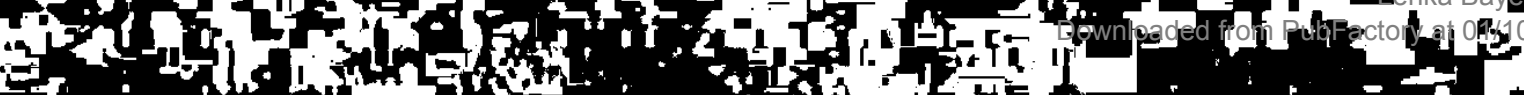




\section{Einleitung}

Im Jahre 1989 leitete die "Sametová revoluce"1, mit der im Jahre 1989 das mehr als vierzigjährige sozialistische Regime in der ehemaligen Tschechoslowakei zu Ende ging, tiefgehende Änderungen im öffentlichen Leben der Tschechen und Slowaken ein. Politische, wirtschaftliche und rechtliche Reformen brachten neue bzw. stark modifizierte gesellschaftiche Strukturen hervor, die nicht zuletzt auch wichtige Bereiche der Wissenschaft und Forschung erfaßten.

Die Sprachwissenschaft gehört zu den Disziplinen, die nach dem Fall des eisernen Vorhangs zusammen mit der Pädagogik und Didaktik etliche neue Aufgaben erhielt. In erster Linie wurde der Fremdsprachenunterricht an Schulen und in der Erwachsenenbildung ausgebaut und neue Methoden eingefuhrt. Der politisch diktierte und daher für die meisten Schüler und Studenten wenig attraktive Russischunterricht wurde von einem erfrischenden FremdsprachenPluralismus abgelöst.

Für die Bohemistik bedeutete die Öffnung nach dem Westen neue Herausforderungen im Bereich des Tschechischunterrichts für Ausländer. Der Einzug der freien Marktwirtschaft löste eine fur die marode tschechische Wirtschaft gewinnbringende Immigrationswelle auslandischer Geschäftsleute aus, die das Tschechische schnell und effizient erlernen wollten. Das Wirtschaftstschechische mußte rasch didaktisch konzipiert und in den praktischen Sprachunterricht eingefuhrt werden. Das Erarbeiten neuer Lehrmethoden sowie die Herstellung modernen Lehrmaterials gehörten in den 90er Jahren zu den wichtigsten Aufgaben der Bohemistik

Parallel zu diesen praktischen Aufgaben und Problemen wurde die Bohemistik der 90er Jahre zum Epizentrum einer heftigen Diskussion um die sprachliche Situation und Kultur im Tschechischen, konkret um die Funktion und Zukunft des Standardtschechischen (ST) und der in ganz Böhmen verbreiteten nonstandardlichen Varietät, des Gemeimeintschechischen (GT) ${ }^{2}$. Es ist sicherlich kein Zufall, dass in den liberalen Phasen der tschechischen Geschichte das Verhältnis dieser beiden wichtigsten Varietäten des Tschechischen von den Bohemisten aufgegriffen und diskutiert wird, während in den Zeiten der Diktatur diese Problematik entweder nur marginal behandelt oder ganz ignoriert wird.

Als J. DOBROvSKY im Jahre 1809 während des Auflebens des tschechischen Nationalgeistes ${ }^{3}$ und im Sinne des Historizismus seine auf der Grundlage des zur damaligen Zeit völlig veralteten humanistischen Tschechisch ${ }^{4}$ basierende Grammatik ,Ausfiihrliches

1 Dies ist die traditionelle Bezeichnung des politischen Umbruchs in der chemaligen Tschechoslowakei Im

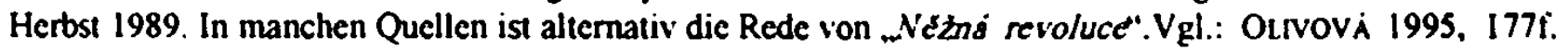

2 Ähnlıche Diskussionen um die Standardvarietăten und ihre Entwicklungstendenzen fanden in den $90 \mathrm{er}$ Jahren in den Lándern des ehemaligen Ostblocks statt. Die von dem politischen Diktat gepragten Sprachkulturen wurden unter den neuen politischen Aspekten diskutient bzw. revidiert. Vgl.: MArTHEIER 1997. Iff.

3 Die wichtigste Intention dieses Werkes war die Demonstration der nationalen Identităt der Tschechen. Nach der Zeit der deutschen Übermacht. die stark von uneinheidichem barocken Schriftschochisch geprägt wurde. gewann Anfang des 19. Jh. die alte tschechische humanistische Sprachtradition stark an Bedeutung. Vgl. ECNERT 1993. 7.

- DobrovskY wăhlte als die unmittelbare Vorlage seines Werkes die Sprache der .Niralitzer Biber" aus den Jahren 1579-1593. Diese beinhaltet die erste vollstăndige Übersetzung aller biblischen Bücher aus dem Lateinischen ins Tschechische. Vgl.: JEDLICKA 1949, 10. 
Lehrgebaude der bohmischen Sprache" verfaßte, ahnte er nicht, daß die Folgen dieses mehr politisch als sprachwissenschaftlich ausgerichteten Unternehmens noch am Ende des $20 \mathrm{Jh}$. ein heftiges Nachbeben verursachen werden. DOBROVSKYYs Normierung und Kodifizierung der Anfang des 19. Jh. in Böhmen bereits ausgestorbenen lautlichen und morphologischen Merkmale des Alttschechischen führte Ende des 19. Jh. und später auch im 20. Jh. zu einer Kluft zwischen der sich in Folge der Alphabetisierung verbreitenden geschriebenen Sprachnorm und der böhmischen Koine. Aufgrund dieser Entwicklung stellt das heutige Standardtschechisch eine auf der mündlichen Ebene funktional eingeschränkte Varietät dar, die bis auf wenige Bereiche des öffentlichen Lebens ${ }^{s}$ vom Gemeintschechischen dominiert wird:

Eime Akkultivierung und l'erschrıfunng des zeitgenössischen vitaien Tschechisch hälte sogar zweifellos zu einer schnelleren und breiteren Offnumg der Schriftsprache auch für die umteren sozialen Strata fïhren kömmen. (JACHNOW 1994, 360)

Als erster stellte B. HAVRANEK im Jahre 1934 fest, daß die böhmischen Mundarten nicht wie erwartet sukzessive von der Standardsprache abgelöst werden, sondern von einer expansiven auf dem zentralbohmischen Dialekt basierenden überregionalen Sprachform, der sog. ..obecina cestina":

... pri mlıveni jimym jazykem neż mistmim nárécim. (...), ani se vlasme casto neuživa spisonmeho jazyka v podobe vice nebo mene presne, nÿbrž se jen predevšim stiraji mistmi zllaky náre ini; tylo znaky totiž neustupuji pritom văty snad formám spisovmeho jazyka. mybrż casto jen formám jimeho lidoveho jazyka. t.zv. obecneho jazyka. totiz lidového jazyka - ve vzlahu $k$ jazyku spisoviemu - ale bez izkeho vymezeni. Timto obecnym jazykem je " podstaté stiedodeské náreci (v hlavnich rysech), které isak prekrocilo urcité izemi a šiń se i za hranice zeme č ceské. (HAVRÁNEK 1934, 13)

HAVRANFKS Abhandlungen über die funktionale Ebene des GT prägten neben seinen Beitragen zur Prager Theorie der Standardsprache die tschechische Linguistik der dreißiger und vierziger Jahre ${ }^{t}$. In der Nachkriegszeit und verstarkt nach dem kommunistischen Umsturz im Jahre 1949 wurde HAVRANEKs ,famlastické vzepetti ducha" (SUK 1993, 8), bedingt durch die Ideologisierung der Sprachwissenschaff ${ }^{7}$, unterbunden und geriet fur mehr als ein Jahrzehnt in Vergessenheit ${ }^{8}$.

Erst in Folge der Liberalisierungswelle in der tschechischen Politik der 60er Jahre griff $P$ SGALL. die Problematik ST vs. GT erneut auf. In der Zeitschrift .. Ioprosy' jazykoznamija"

S Das ST wird als Spraclic der Medien und in hochformellen Situationen venvendet. .Jde zprovidla o projerv

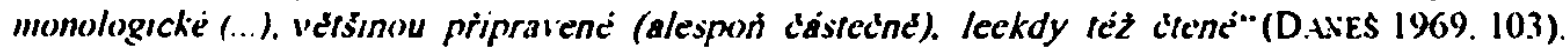

6 Neben HAlrivek befaBte sich ein weiteres wichtiges Mitglied des Prager linguistischen Zirkels. V. MATHESII's (1933). mit der Problematik des GT.

7 Am Ende der vierziger Jahre wurde die tschechische Linguistik vom "M/arrschen Programm" gepragt. das jedocli bald darauf voin "Stalmschen" abgelost wurde. Im Jahre 1951 stanteten P. SGALL und F. TR.AiNicEK die Kampagne "boj proti ceskiemu strukiuralismu". die u.a. gegen HAlR.iNE.his linguistische Arbeit gerichtet war. SGALL widerrief spater (1956) scinen antistrukturalistischen Standpunkt. Der starke politische Einfluß von TR.tiviceK (er wurde Vorsitzender der linguistischen und literatunvissenschaftlichen Sektion der Tscheclioslowakisclicn Akademic der Wissenschaften) hinderte jedoch HAliRivek weiterhin an der Fortsetzung seiner in den dreiBiger Jahren begonnenen Arbeit. Unter diesein Druck ordnete sich HAlR.tiEk der polıtisclien Fühnung TR.tIXiCEKS unter (NOVAK 1991. 183m)

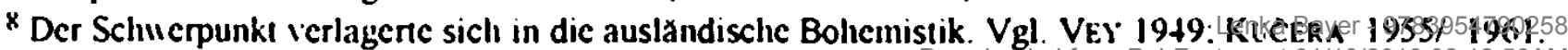


veröffentlichte er den Aufsatz „Obichodno-razgovornyj óešskjj jazyk“ (SGALL 1960), in dem er sich der Havránekschen Charakteristik des GT aus den 30er Jahre anschließt und in dem er betont, daß diese ursprünglich ausschließlich böhmische Varietät bereits auch in Südwestmähren die gesprochene Sprache dominiert. Statt der in der Bohemistik der 50er Jahre vertretenen Zweiteilung - Standardsprache (schriftlich, mündlich) vs. Dialekte (mündlich) stellt SGALL eine Dreiteilung fest:

\begin{tabular}{|l|l|l|}
\hline $\begin{array}{l}\text { Standardsprache } \\
\text { (vonviegend schriftlich) }\end{array}$ & $\begin{array}{l}\text { Gcmeintschechisch } \\
\text { (mündlich) }\end{array}$ & $\begin{array}{l}\text { Dialekte } \\
\text { (mündlich) }\end{array}$ \\
\hline
\end{tabular}

Das umgangssprachliche Tschechisch "razgovornaja forma literaturnogo jazyka", bezeichnet SGALL als eine hybride Varietät, "... skoree idet rec o kolebanii meżhı literaturnym iessskim jazykom i obichodno-razgovornym jazykom" (SGALL. 1960, 16), die einer neutralen kolloquialen Umgangsform nicht gerecht sei:

Vozmon̆y sitmacii, kogda upotreblenie literaturnoj normy proizvodit vpedatlenie iskusstremmosti $i$ dałe pedantizma, $v$ drugich sludajach formy obichodmorazgovornogo jazyka zuncàt sliškom famil'jarno. (SGALL 1960, 11)

Zusammenfassend bezeichnet SGALL die sprachliche Situation im Tschechischen als "jav/leniem iskljucitel'nym i nezdorovym" und fordert eine institutionalisierte "demokratizacij" literaturnogo čsskogo jazyka" (SGAlL 1960, 19), eine Normierung und Kodifizienung gemeintschechischer lautlicher und morphologischer Elemente.

SGALls neue Stratifikation des Tschechischen sowie seine Reformforderungen riefen innerhalb der tschechischen Bohemistik eine ablehnende Reaktion hervor. Bereits ein Jahr nach SGiAl.LS Veröffentlichung verfaßten die vier namhaften tschechischen Bohemisten J. BÉLIĆ, B. HAVRANEK, A. JEDLICKA und F. TRÁVNICEEK einen gemeinsamen Arikel', in dem sie SGAlLs Ansätze und Intentionen als subjektiv und ohne jeglichen wissenschaftlichen Hintergrund bezeichnen (BÉLIC et al. 1961, 99). Nach ihrer Auffassung stellt das GT innerhalb der tschechischen Nationalsprache den quantitativ stärksten Interdialekt dar, der zwar einige expansive Merkmale aufweise, der jedoch das ST aus dem mündlichen sprachlichen Umgang nicht verdrängen könne:

... má dokonce obecná čšstina nad ostatmimi interdialekty krantitativmi i kvalitativni

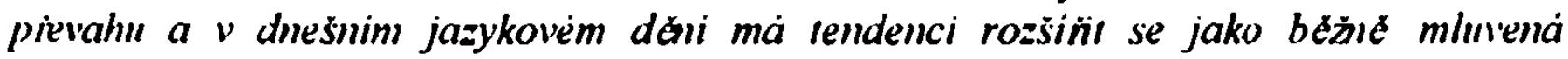
nespisouna iec po celém izemi (...). Tato tendence ovšem neni dovršena a jeji pronikani neni primocaré a jen tak jednoduché. (BÉLIĆ et al. 1961, 100)

Als das größte Hindernis für die Verbreitung des GT bezeichnen SGALLs Opponenten die mährischen Dialekte, die nach wie vor auch in den großen mährischen Kulturzentren wie

9 Ursprünglıch erschien dieser Beitrag auf Russisch in "I oprosy jazykoznanija" unter deın Titel "K' voprosu oh 'obichoino-razgovornom' \&sskiom jazuke i jego otnosenii k literaturnomu cesskomu jazvku". Noch im sclben Jahr wurde derselbe Artikel ins Tschechische übersetzt und in der vom Prager Zirkel gegnündeten ischechischen Zeitschrift "Slovo a slovesnost" unter dem Titel "K otázce obecne cestiny a jejiho pom cru k' cystinc" sptsovne" veroffentlicht (BÉLiC et al. 1961). 
Ostrava, Gottwaldov (heute Zlin) und Prostějov fest verwurzelt seien, und dem GT nur in begrenztem Maße - oft überhaupt nicht - weichen. SGALLs Charakterisienung des Umgangstschechischen (UT) als eine nicht selbständige Ebene zwischen dem ST und dem GT schließen sich die Autoren nicht an. Sie bezeichnen die Varietät des Tschechischen, die den mündlichen Umgang dominiert, als "spisorná čeština hovorovä", eine Varietät, die auf der Norm des ST basiere und das GT nur marginal berühre. Auf dieser Ebene wird die sog. ..demokratizace spisomé iestriny" realisiert, d.h. nur solche Elemente des GT, die sich im UT auf Dauer etablieren, können sukzessive institutionell in der Kodifizienung des ST stabilisiert werden (BÉLIĆ et al. 1961, 105). Auch umgekehrt können auf der Ebene des UT Elemente aus dem ST in das GT eindringen, so daß die Unterschiede zwischen den beiden Varietäten allmählich schwinden und das kolloquiale Tschechisch immer einheitlicher werde, mit deutlicher Tendenz zum ST:

Pokud jde o otázku tzv. demokratizace spisowne deštiny, má temto proces troji stránku. Jednak jate o to. te se s rozvojem spole chosti aktivmi użuámi spisovného jazyka (i v jeho mhnene poxtobe) se vzrüstajici imtenziton sin̈ do siále širšich ursłev (...). je to odraz demokratizace celèho spolécenského dări. (BÉl.ľ́ et al. 1961, 102)

Zum Abschluß ihres Artikels lehnen die Autoren SGALLs Reformforderungen vehement ab. Eine von SGALL geforderte Korrektur der Kodifizierung in Richtung GT wäre laut BÉLIC et al. anachronistisch, denn ihren Prognosen nach - obwohl empirisch nicht untermauert - gewinnen die standardtschechischen Formen im mündlichen Umgang immer mehr an Bedeutung. Somit werden in absehbarer Zeit die im 19. Jh. entstandenen Differenzen zwischen den beiden Varietaten zu Gunsten des ST getilgt werden (BÉl.IČ et al. 1961, 105).

Die beiden oben skizzierten Artikel rückten die Problematik um die aktuelle sprachliche Situation im Tschechischen zum ersten Mal in den Mittelpunkt des breiten bohemistischen Interesses und entfachten somit eine fruchtbare Diskussion in der vom Prager Zirkel gegründeten Zeitschrift .S/ov'o a slovesnos/," die erst im Jahre 1963 durch HAVRANEKS Schlußwort .Na ziv'r diomlere diskuse o obeche a hovorove cestminc.: abgeschlossen wurde. Als Fazit kristallisierte sich heraus, daß das GT sowie das UT innerhalb der tschechischen Bohemistik unterschiedlich aufgefaßt werden und somit die tatsachliche sprachliche Situation im Tschechischen nur schwerlich umfassend beschrieben werden kann Trotz verschiedener Standpunkte und Ansätze einigten sich schließlich alle an der Diskussion beteiligten Bohemisten 10 in dem Punkt, daß eine breit angelegte empirische Untersuchung als Basis für weitere theoretische Ansätze auf diesem Gebiet notwendig sei. Erst dann könne die Bohemistik zu einem sinnvollen Abschluß der Diskussion gelangen

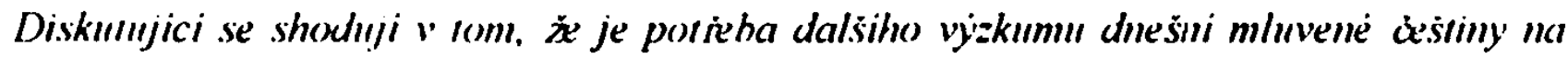
pexlklade primcienc rozscihleho maleriàlı. (HAVRANEK 1963, 254)

Fünf Jahre später publizienten KRAVCISINOVA் BEDNAROVÁ als Resonanz auf HAVRANEKS Appell aus dem Jahre 1963 die Ergebnisse der ersten tschechischen empirischen Studie zum 
Verhältnis ST vs. GT ${ }^{11}$. In dieser Studie werden Aufzeichnungen ${ }^{12}$ von 79 Respondenten aus verschiedenen Regionen Böhmens, verschiedenen Alters und Berufs, in formellen (Rundfunkdiskussion) und informellen Situationen lautlich und morphologisch analysiert. Die jeweiligen Anteile der ST- und der GT-Elemente stellen die Autorinnen tabellarisch mit prozentuellen Angaben dar. Aus den Ergebnissen dieser Untersuchung geht deutlich hervor, $\mathrm{da} ß$ das GT nicht nur für die informelle Sprache in Böhmen signifikant ist, sondern auch in formellen Kontexten häufig verwendet wird'3 (KRAVČIŚINOVÁ/ BEDNÁŔovÁ 1968, 307ff). Durch das soziolinguistisch angelegte Konzept dieser Studie konnte darüber hinaus zum ersten Male gezeigt werden, daß das GT keine nur auf untere soziale Strata beschränkte Varietät darstellt, sondern von allen Gesellschaftsschichten verwendet wird:

... a zameñit pozornost na to, zda by nekteré rozdily mezi promluvami mohly být

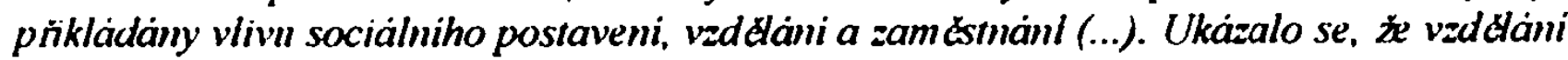
a zamestmáni mlıvciho charakter projevu skuteç⿰丿⿱⺊⺂七七 ovlivñuje, ovsem pouze do urcité miry. Nejvice nespisovnych prvkú totiž obsahuje promluva zemádłskè dènice, ale na druhe strane jsou nespisovne prvky dasté " spisovatelü novinárü hercü ... (KRAVCISINOVÁ/ BEDNAROVÁ 1968, 309)

Leider wurde der für die 60er Jahre überaus progressive soziolinguistische Ansatz von den Verfasserinnen nicht konsequent verfolgt: „Tæchto fakt jsme si vsimli spiše pro zajimarost a pro vyzkoušseni jedné z możiosti, jak $k$ této otázce pristupovat " (KRAVČISINOVẢ BEDNÁROVÁ $1968,309)$.

Mit dem gewaltsamen Ende der Liberalisierungsprozesse in der Tschechoslowakei nach dem Prager Frühling blieben die wertvollen Forschungsansätze und empirischen Untersuchungen, die durch die Diskussion der 60er Jahre angeregt wurden, in ihren Anfangen stecken $^{14}$. Publikationen zur Problematik des GT bzw. zu dessen Verhältnis zum ST wurden in den folgenden zwei Jahrzehnten äußerst rar's ${ }^{15}$. Erst die liberale politische Atmosphäre am Ende der 80er und Anfang der 90er Jahre schuf erneut einen fruchtbaren Boden für neue Beiträge und Ansatze, die sich mit der sprachlichen Situation im Tschechischen sowie der bisherigen bzw. zukunftigen Sprachkultur und -politik auseinandersetzen

Im Jahre 1990 leitete SGALL mit seiner rhetorischen Frage, die er im Titel seines Artikels in ..Slovo a slovesnosr" formulierte "Chceme spisovnou ceśtimu ochuzorat a cinit nem/uvnou?" (SGAl.L 1990, 60), eine Wiederaufnahme seiner Ansätze aus den 60er Jahren ein und setzte damit schnell eine neue Diskussionswelle in Bewegung. Die anfangs nur innerhalb der tschechischen Bohemistik geführte Auseinandersetzung nahm nach der Veröffentlichung "lariation in Language" (SGALl et al. 1992) internationale Dimensionen an. Während die

1 Die Untersuchungen. die bis Anfang der sechziger Jahre durchgefühn wurden. stammen von auslăndischen Bohemisten: VEY (1946) untersuchte nur die morphologische Ebene im gesprochenen Tscheehisch in Prag und der nahen Umgebung. KI'CERA (1955) analysiene die Sprache der in den USA lebenden Tschechen.

12 Dic Aufzeichnungen wurden in der Studic leider nicht abgedruckt.

13. Dies bestâtigten auch spatere kleinere regionale Studien. Vgl.: BrabCovi 1973: DEJMEK 1981. 1987: H.AIINER 1985. 1986.

it In den 6)er Jahren wurde sprachliches Material gesammelt. Leider blicb diese Sammlung olnne ș stematische Auswertung. MCLEROVi 1994. 213.

Is HRONEK 1971/ 1972: BR.BBCON A 1973: DENEK 1981/ 1987: SG.UL 1981: H.MMER 1985/Bl9866.9783954790258 
meisten tschechischen Bohemisten SGALl.s Ansätze kritisch betrachten, ist im Wesen eine deutlich positivere Resonanz zu verzeichnen ${ }^{16}$.

In ihrer umfangreichen Publikation setzen sich SGALL et al. in erster Linie für ene neue Stratifikation der tschechischen Nationalsprache ein, fur eine vierstufige Varietätenskall:

"The highest degree in the scale is (...) the literary language, by which we refor to the norm characterized by an overall observance of codified rules. This norm is used at sch(o)l, in official discourses in the mass media, and in official primted texts, including kechnical literature.

The next degree is that of standard speech. which is generally used in seniformal colloquial silmations and differs from the literary norm in some lexical phonomena (neologisms, occasional new loan words, abbreviations ...). as well as in specific grammatical items ("colloquialisms").

The substandard speech displays even more relaxed wordformation restrictions (with suffixes lacking the full status of standard morphemes) and is used mostly in nformal dialogues and discourses.

Only after all these central degrees there come the locally restricted dialects." (SCiAL et al. 1992,7$)$

Ein weiteres wichtiges Moment in der Veröffentlichung ist die Charakterisierıng der sprachlichen Situation im Tschechischen als diglossieähnlich (SGALl. et al. 1992, 18). Die Autoren betonen, daß durch die Koexistenz eines standardsprachlichen und eines starken uberregionalen nichtstandardsprachlichen Kodes oft Situationen entstehen, in denen ein Sprecher nicht abschätzen konne, welchen Kode er ad hoc anwenden sollte. So entsteht „cocte swikhmin" bzw. "oscillanom beween Standard ("zech and (ommon ("zech, which concerns first of all phomemics and morphemics" (SGiall et al. 1992, 20). Bedingt durch die Unsicherheit der Sprecher, in einer Situation den adäquaten Kode anzuwenden, und durch die daraus resultierende starke Konzentration auf die sprachliche Form statt auf den Inhalt entstehen oft hyperkorrekte und hybride Formen, die sowohl den Inhalt als auch die Form verunstalten (SciAl.l. et al. 1992, 182ff). Im letzten Kapitel „Perspectives on the Siratification of Czech" betonen die Autoren - wie S(iALI. bereits in den 60er Jahren -, daß die Behebung dieser Defizite nur durch eine Korrektur der Kodifizierung zu erreichen sei (SGALL et al. 1992, 232ff).

Als Hauptopponent SGali.s gilt in erster Linie O. HAUSEnBlas. Er kritisiert SGall.s Intentionen und erklart diese für sprachlich destabilisierend. HAUSENBLAS bringt die von SciAlL hervorgehobenen Mißstände im Tschechischen mit der durch das sozialistische Regime verursachten Krise des tschechischen Schulsystems sowie mit " 10 let mlceni a sirachi" (O HAIJSENIBLAS 1993a, 101) in Verbindung. Er betont, daß die jahrzehntelange sprachliche Propaganda fur das ST dazu fuhrte, daß diese Varietät heute als "kox̀mý a odcizenj jazyk" empfunden werde (O. HAISFNBI.AS 1993a, 97). Eine Reform des ST nach SGALl.s Vorschlägen wurde jedoch als "revolucini zcisah do kulturmi tradice" zu einer tiefgreifenden

$16 \mathrm{Vgl}$ : JACHNOW 1994: LFECWEN-TIRNONCONA I: 1994: STEINKE 1995. 
Destabilisierung innerhalb der ganzen tschechischen Gesellschaft füren und einen "zlom ve inimaini visech textú psanych pred reformou" (O. HAUSENBLAS 1993a, 98) mit sich bringen. Die Lösung der von SGALL geschilderten Probleme sieht HAUSENBLAS in einem allmählichen Wandlungsprozeß in Richtung ST. In diesem Prozeß der sukzessiven Anpassung an die neuen gesellschaftlichen Verhältnisse und der damit verbundenen neuen sprachlichen Orientierung benötige jedes Mitglied der Gesellschaft eine sich über Jahre erstreckende Anpassungszeit. Die Bohemistik sollte die Sprecher in dieser Phase unterstützen, anstatt sie mit neuen Vorschriften und Regeln zu belasten:

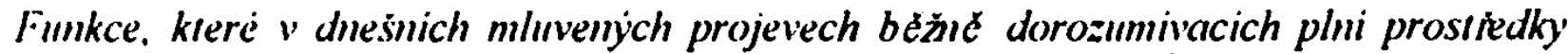
mespison'me, mohou byt realizovany i prostiedky spisovinimi. (...) Ukolem jazykovddy tedy

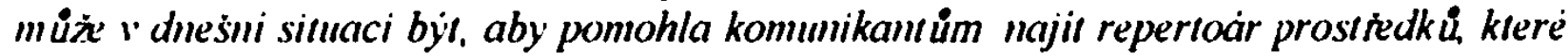
jsoll ve spisovmem jazyce vhodne $k$ vyjadrovani icch poloh. jeż pro spisovny jazyk pưvodné charakteristicke nebyly: prostredky uvolnăısti, nezáiaznost, osobniho konlakı", pros/iedky vyjädreni urcitych druhü pocitu ... (O. HAUSENBLAS 1993a, 102/104)

Anschließend betont HAUSENBLAS, daß die neu geformte tschechische Gesellschaft in der Zukunft stärker als in den letzten Jahrzehnten "nadregionálni. (...) neafektovamý nástroj verejmeho dorozumivani" (O. HAUSENBLAS 1993a, 105) benötigen werde, falls sie sich in den neuen europäischen politischen und wirtschaftlichen Verhältnissen behaupten wolle. Nur das ST in der heutigen Form könne als die repräsentative Varietät der tschechischen Nationalsprache anhand seiner beinahe zweihundertjährigen Tradition den neuen gesellschaftlichen und internationalen Anforderungen standhalten (O. HAUSENBLAS 1993b, 72ff).

Zu den namhaften Bohemisten, die sich in Anlehnung an SGALls Ansätze kritisch zur gegenwartigen sprachlichen Situation und Politik in Tschechien äußern, gehor der Leiter des Korpus der tschechischen Nationalsprache, F. CERMAK. In seinen neuesten Beiträgen betont er, daß das GT die einzige Varietät ist, die in der Periode der primären Sozialisation aktiv verwendet wird. Erst in der Schule werden die Kinder in den aktiven Gebrauch des ST eingefuhrt Diese Umstellung der vom GT dominierten Sprachwelt des Kindes bewertet Cl:RMAK als zu autoritativ und oft dauerhaft traumatisierend

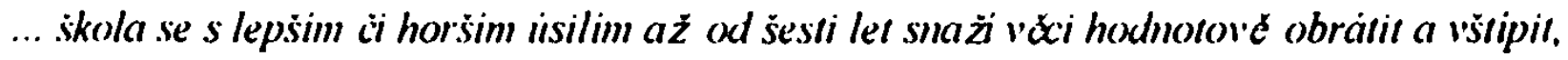

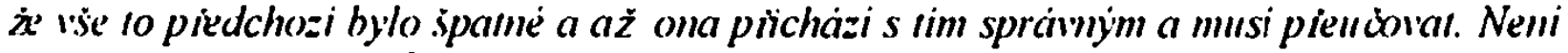

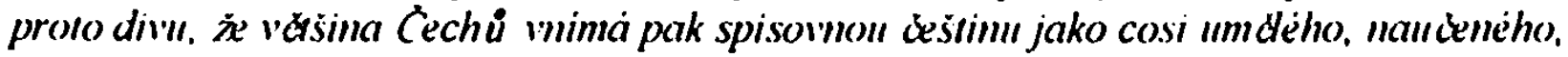
popr. imuceneho, ale take hlidaneho s käravym prstem v pozadi. (...): vwolàva se v nich absurdmi nejistota a dojem, jakoby neum sli spränn desky. (CERMAK 1996, 14)

Die Ursache für "nemhwmosr" der Standardvarietät sieht CERMAK neben den schulischen Methoden auch in den Praktiken, die der Normierung zu Grunde liegen. .. Traditiomal lingussic emphasis is still laid on codification, while only minor interest is taken in actual usage (...) there is no up-10-date sociolinguistic research in usage..." (ČERMAK 1993, 31). Das Ausbleiben der empirischen Untersuchungen und der dadurch bedingte willkürliche Zug der Kodifikation bzw. ihrer sukzessiven Veränderungen betrachtet ČERMAK als dem neuen Selbstbeuußtsein der Tschechen nach der Wende nicht adäquat. ..Bez rakoveho skuteimieho materialového vyzkumu cokoliv tvrdit, resp. predpisovat, a to at o forme. it viznamu aj..

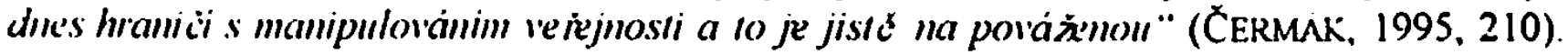


Solange die tschechische Sprachpolitik autoritäre und präskriptive Züge beibehält, muß sie die Konsequenz tragen, daß nach diesem alten Prinzip "se spisovma ḋeština nikcty mlunnon nestane" (CERMAK 1996, 17).

Gegenwartig entstehen etliche Publikationen, die sich unter verschiedenen Aspekten mit der oben geschilderten Problematik auseinandersetzen. Leider wird auch diesmal ohne eine systematisch analysierte empirische Basis polemisiert. Somit sind die Worte, die die erste kurz nach der Wende publizierte Textsammlung des gesprochenen Tschechisch einleiten, aktueller denn je:

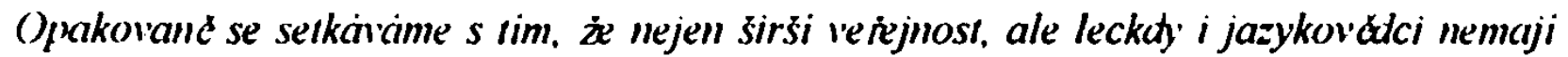
piedstav'u. 'jak vlasmé mluvime': a pï setkäni s autentickymi texty mluvené iestriny' bjraji sokovaini. (MULLEROVA et al. 1992, 1) 17

An der Philosophischen Fakultät der Karlsuniversität ${ }^{18}$ arbeitet seit 1994 ein Linguistenteam unter der Leitung von F. CERMAK an der bisher umfangreichsten Sammlung geschriebener tschechischer Texte, dem „Cesky närodni korpus"19. Künftig soll dieses Mammutwerk um ein Korpus des gesprochenen Tschechisch erweitert werden. Doch bereits heute befurchten die Wissenschaftler größere Hindernisse, v.a. finanzieller Art:

Poridit visak korpus mlureneho jazyka je mnohonásobne, rädov'e drazisi (...) Dokud mebuctou $k$ dispozici prostredky $k$ automatickèmu prevodu zvukové stránky jazyka do psamé a pocitaible citelme podoby. je proto treba 'dobre hospodarit' uż pri volbe sond a povahy mensich korpusú mlunemeho jazyka. (ČERMAK/ SGALL. 1997, 19)

Die erste Ebene der vorliegenden Arbeit tangiert in methodischer Hinsicht das geplante Prager Korpus des gesprochenen Tschechisch ${ }^{20}$. Gesprochene Texte werden aufgenommen, schriftlich fixien und nach sprachlichen und soziologischen Kriterien geordnet und ausgewertet Das Ziel ist es, anhand der Aufnahmen die aktuelle Situation im gesprochenen Tschechisch zu skizzieren und somit einen Beitrag zur oben geschilderten Diskussion um das Verhaltnis ST vs GT zu leisten. Die Betonung liegt dabei in erster Linie auf der empirischen und soziolinguistischen Vorgehensweise, die in der modernen Varietatenforschung sicherlich in den Vordergrund genickt werden sollte. Behauptungen und Vermutungen ${ }^{21}$ nämlich, die ausschließlich auf theoretischer Induktion aufgestellt werden, könnten die sprachliche Realität in verzerter Weise wiedergeben und in Folge dessen die Sprachpolitik und -kultur in eine falsche Richtung lenken 22

17 Die Texie der Autorinnen sınd Texte oline cingeliende Analyse.

18 In Zusamumenarbeıt mit der Mathematiscli-phỵsikalisclıcn Fakultảt der Karlsunisersität und der Masaṛ̂kUniversitat in Brunn (CE.RN.iN SG.AL.L 1997. 17).

19 Der geplante Untang ist I(0) Millionen Wörter (CERM.w/ SG.MU. 1997. 19).

20) Trotz der lliematischen Nähe eltstand diese Arbeit gănzlich unabliàngig von dem genannten Prager Projekt Erst nacli ilirer Fertigstellung wurde das Material unserer Unufagen dem Tschechisclien Nationalkorpus zur Verfugung gesiellt.

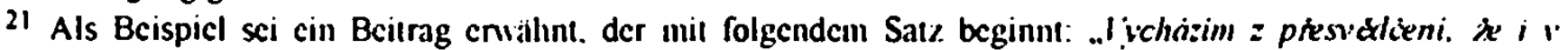
miluene forms' jazika..." (P.V.kOV. 1995. 76).

22 An diescr Stelle drangt sich dic Frage auf. auf welcher Grundlage in der Ietzten Grammatik des Tscheclissclien die bıslier als gemeintschechisch definierten Endungen der Verben der I. und VI Klasse 
Theorie und Empirie sind namlich durchaus zwei Seiten einer Medaille, delm was hilft die theoretische Aussage, welche keinen Bezug zur realen Welt hat, also blind ist ... (WII.DCEN 1987, 45)

Die zweite Ebene unserer Studie komplementiert die Auswertung des sprachlichen Materials. Mit per Fragebögen erhobenen soziologischen Daten und Angaben derselben Sprecher werden im Bereich des ST:

1. Kenntnisse (Kognition),

2. Grad der positiven Evaluation,

3. vor allem aber die Bereitschaft (Konation) der Sprecher zur Verwendung des ST untersucht.

Die Einstellung der Tschechen zu ihrer Standardsprache, sekundär zu ihrer Koine, steht hier im Vordergrund.

Das sprachliche Material sowie die soziologischen Daten und Sprecherangaben, die von insgesamt 105 Respondenten aus Westböhmen (Umfrage im Frühjahr 1998) und aus dem Großraum Prag (Umfrage im Frühjahr 1999) bilden in dieser interdisziplinar ausgerichteten soziolinguistischen Studie zwei äquivalente komplementäre Ebenen. Die primäre Zielsetzung dieser Studie ist:

\section{Dokumentation}

Zusammenhangende situationsabhängige Texte des zeitgenössischen gesprochenen Tschechisch werden schriftich fixien und nach soziolinguistischen Kriterien (Region, Geschlecht und Bildung der Sprecher) sowie nach situativen Faktoren systematisch geordnet

\section{Sprachliche Analyse}

In den Texten werden die fur unsere Studie relevanten lautlichen bzw. morphologischen Variablen des ST sowie des GT markiert und in Verbindung mit soziologischen (Geschlecht, Bildung), diatopischen (Region) und diaphasischen (Situation) Aspekten nach der Häufigkeit ihres Vorkommens ausgewertet. Das quantitative Verhältnis der beiden wichtigsten Varietäten des Tschechischen steht hier im Vordergnund

\section{Experimentelle sozialpsychologische Analyse}

Die Einstellung der Tschechischsprecher zu ihrer Standardsprache bzw. zu ihrer Koine ist ein wichtiger, in der Bohemistik bisher kaum untersuchter sozio- bzw. psycholinguistischer Faktor. Mit Hilfe moderner Methoden aus der Sozialpsychologie soll hier experimentell versucht werden, die ersten Ansätze in der Erforschung dieses sprachlich-psychologischen Bereiches zu schaffen. Anhand der in der Einstellungsforschung häufig vertretenen Drei-KomponentenKonzeption der Einstellungserfassung werden alle drei Subsysteme der Einstellung zum ST

(Differenzicnung nach dem Infimitivstamm. Vgl.: KaRLik et. al. 1995. 326/331). I. P. Sg. -u und 3. P.Pl. ou als Dubletten mit den ursprunglichen $-i /-i$ (sielie Kap. 3.2) kodifizicrt wurden. Aindere stark verbreitete Elcmente des GT. z. B. Konditional. 1. P. PI. husme (siche Kap. 3.2) bleiben dagegen nacli wic vor aus der Kodifizicrung ausgeschilossen. Argumente gegen dic Kodifizienung des Konditionals: ..l/luviti : Cech hude

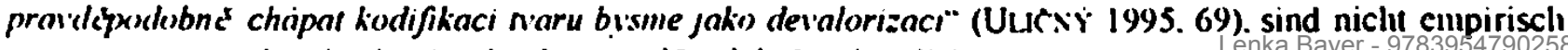
untermatkrn. "as bercits der Ausdnuck .prmelćpodobns" signalissichtoaded from PubFactory at 01/10/2019 02:12:56AM 
bzw. zum GT - das kognitive, affektive und konative - einzeln ausgewertet ${ }^{23}$. Die Ergebnisse im konativen Subsystem, das in der sprachlichen Einstellung sicherlich das signifikanteste ist, sollen schließlich direkt den Ergebnissen im Sprachgebrauch gegenüber gestellt werden. Der direkte Vergleich sprachliches Verhalten der Tschechen vs. ihre sprachliche Einstellung ${ }^{24}$ steht hier im Vorcergrund.

Zum Absihluß dieser Studie wird versucht, die Ergebnisse des experimentellen Vergleichs sprachliches Verhalten vs. Einstellung - bzw. die eventuellen Diskrepanzen zwischen den beiden Varizblen zumindest im Ansatz, unter Berücksichtigung der Respondentenkommentare, Beobachtungen während unserer Feldstudie sowie weiterer soziologischer und sprachpolitischer Aspekte zu begründen.

Der experimentelle Zug der dieser Untersuchung zugrunde liegenden Feldstudie sei an dieser Stelle betont. Es handelt sich um keine standardisierte Datenerhebung, um keine Laboruntersichung mit exakt ausgesuchten Probanden. Vielmehr stellt diese Studie ein Design dar, das in Form einer regional und soziosituativ determinierten natürlichen Felduntersuchung angelegt wurde $2 s$. Im präexperimentellen Stadium der Studie wurden lediglich die Vorgehensweise bzw. die einzelnen Komponenten der Untersuchung umrissen: sprachliche Variablen. etwaige Anzahl und das soziale Spektrum der Respondenten, Befragungssituationen. Regionen und schrifliche vs. mündliche Befragungsweise per Fragebogen und Mikrofon.

2.3 Von der Darstcllung der summarischen Einstellung (ein abstraktes Konglomeral aller drei Subsysteme. stelie Kap. 2) wird in unserer Sludic abgeschen.

24 Explizit das konalive Subsy stem der Einstellung

$25 \mathrm{Vgl}$.: Al'W'ARTF. 1988. $923 \pi$. 


\section{Einstellung vs. Verhalten}

In diesem Kapitel werden die wichtigsten, unsere Studie tangierenden Grundlagen und Theorien der Einstellungsforschung umrissen. Im Vorfeld ist zu betonen, daß menschliche Einstellungen und ihr Verhältnis zum menschlichen Verhalten bereits seit Jahrzehnten zu den meistdiskutierten ${ }^{26}$ Themen in der Sozialpsychologie gehören. In sprachwissenschaftlichen Untersuchungen dagegen werden diese Begriffe erst seit Anfang der 80er Jahre im Rahmen der interdisziplinär ausgerichteten Sozio- bzw. Psycholinguistik thematisiert ${ }^{27}$.

Die Erforschung und Messung menschlicher Einstellungen (attitudes ${ }^{28}$ ) bildete sich nach dem Zweiten Weltkrieg zu einem wichtigen Forschungsbereich der amerikanischen Sozialpsychologie heraus ${ }^{29}$. In der anfanglichen Annahme. Einstellungen seien Korrelate bzw. Prädiktoren des Handelns, wurden zahlreiche Untersuchungen durchgeführt, die zum besseren Verständnis und eventueller Tilgung von Vorurteilen und Stereotypen im Verhalten der Amerikaner gegenüber Minderheitengruppen und Rassenangehörigen führen sollten (GRAUMANN 1987, 489). Das primäre Ziel dieser Untersuchungen war das programmatische Vorhersagen von Verhaltensweisen anhand der Einstellungsbestimmung. Gegen alle Erwartungen wurden bereits in den ersten Untersuchungen Diskrepanzen zwischen Einstellungen und dem Handeln der Amerikaner registriert. Es stellte sich heraus, daß die Korrelation zwischen Einstellungs- und Verhaltensvariablen nur gering ist bzw. überhaupt nicht vorhanden ${ }^{30}$. Zuerst erklärte man dieses Phänomen durch Mängel in den Erhebungsmethoden, Ende der 60er Jahre mußte jedoch das Postulat. Einstellungen und Verhalten eines Individuums seien Korrelate, aufgrund eindeutiger Beweise endgültig aufgegeben werden. Die gemeinsame Varianz zwischen Einstellungs- und Verhaltensmaßen wurde auf höchstens $10 \%$ festgelegt (MI MMMFNDEY 1988, 2):

Taken as a whole. these studies suggest that it is considerably more likely that atritudes will be unrelated or only slightly related to overt behaviors than that antitudes will be closely related to actions. Product - momem correlation coefficients relating the nio kImds of responses are rarely above .30, and often are near zero. (WICKFR 1969.65)

:. .Der Begriff Finstellung ist ein sehr schillernder. Es finden sich kaum alei futoren. die ihn in gleicher "Ieise definieren" (ROTH 1967. 11).

$\because$ Vgl.: Gli.ts ct al. 1987. 585f

* Der Ausdruck Altitude ist cine Zusammensetzung zweier Begriffe: des spätlatcimsclicn ..nptrtucle" (Bercitsclaft. Neigung) und des latcinischen ..nclus" (Aktion. Verhalten) (DepreZ/ PERS(x)Ns 1987. 125)

$\because$ Die crsien Arbeiten zum Thema Einsicllung entstanden in den 20er Jaliren: THL RSTONE 1927: THI RSTONE/ CHAlE. 1929. Bis zum Jalıre 19+0 erschienen in Amerika mindestens 1500 Arbeiten zu diescm Thema (Roth 1967. 26). Vgl. auch: PeterM.tiN 1980. 9.

"' Bereits im Jahre 1934 konnte L.PIERE Diskrepanzen zwischen Einstellung und Verlalten anlaand sciner Studie nachwciscn: .EIn II eißer hesuchte zusammen mit einem gut gekledieten und gebildeten (hinesen-liheparr Restaurants und Hotels in den LSA. Lur in $0.5 \%$ der Falle konnte eine thweisung des Ehepares beohachtet werden. Bei einer nachiraglichen Befragung in Form einer direkten Frage gaben 92\% der Gasiro. nommebetriebe an. daß sie Chinesen nicht bedienen wirden. Thnliche Inkonsistenzen beohachrele .I/Inard 19.5:) he' der. Irheit in den Kohlengruben. IJahrend der .Irheitszeit kooperierten Ileiße und . Shwarze. nach Fescrabend aher gah es eine sirenge Trennung. Die negarive Einstellung von Ireißen gegenither den

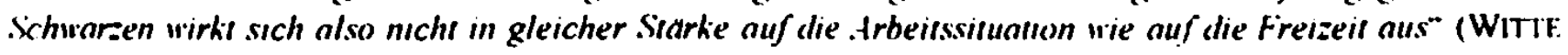
(1889. 382). 
Diese Erkenntnis führte in den 70er und 80er Jahren zu einer Fülle von Ansätzen und Modellen, die sich einerseits mit den Interdependenzen zwischen Einstellung und Verhalten, andererseits mit der Definition, Klassifizierung. Entstehung. Funktionen und Struktur von Einstellungen befaßten. $\mathrm{Zu}$ den wichtigsten Beiträgen aus dieser Zeit gehört die heute noch meist zitierte Definition der menschlichen Einstellung

Fishbein and Ajzen $(1975,6)$ define 'attitude' as 'a predisposition to respond in a consistently favourable or infavourable manmer with respect to a given object. ' (zitiert nach DEPREZJ PERSO(INS 1987, 125)

Die Einstellungen eines Individuums liegen dem sozialen und psychischen Verhalten jedes Menschen zu Grunde und können dessen Reaktionen auf verschiedene Objekte: Personen, Ereignisse, Situationen, Fakten, Handlungen aber auch auf Sprachen, Varietäten etc. hic et nunc determinieren. Sie bilden drei Grundkategorien: negativ, neutral oder positiv" und sind in einem komplexen, äußerlich nicht erkennbaren System, auf das nur bedingt durch das Verhalten eines Menschen geschlossen werden kann, integriert (HFRKNER 1981, 209).

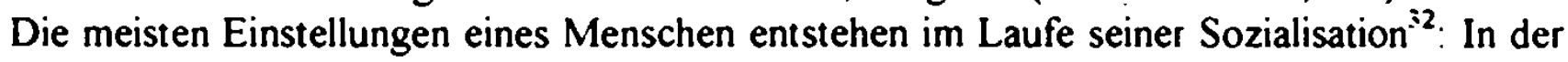
primären Sozialisation definiert fast ausschließlich die Familie die Welt des Kindes und damit auch die Entstehung und Entwicklung von Einstellungen ${ }^{33}$, in der sekundären Sozialisation kommen weitere Faktoren hinzu: Freunde, Schule und Medien (DEPREZ/ PERSOONs 1987. 128). Das System der Einstellungen ist auch im Erwachsenenalter kein statisches Gebilde. Die Einstellungsobjekte einer Person sind ebenso wie die einzelnen Einstellungen keine isolierten Elemente, sondern stehen zum Großteil miteinander in Verbindung (HERKNER 1981, 210). Demnach ist das Einstellungssystem ein kompliziertes, ständig mutierendes, sich weiterentwickelndes Paradigma von Objekten und Relationen, dessen momentane Struktur von vielen Variablen abhängt. Aufgrund dieser Variabilität ist es in der Einstellungsforschung notwendig. die einzelnen Untersuchungen unter dem synchronischen bzw. diachronischen Aspekt durchzufuhren (WITTE 1992, 46ff).

Aus der funktionalen Sicht bilden Einstellungen die zentrale Verbindung zwischen Anpassung eines Individuums an die Gesellschaft und dessen Selbstverwirklichung (Individualisierung). Sie erfullen vier motivationale Funktionen, die die Existenz und Integrierung eines Individuums in der Gesellschaft sichern.

1. Lime Anpassingsfunknon, indem die Indwidnen soziale Inhalıe identifizieren und dazu. Siellung zu nehmen lerne"n und sich damit einer Referensgruppe zugehörig. fiihlen:

${ }^{31}$ Einc Einstcllung ist immer subjcktiv ..Eıne Person .A. die von B fur intelligent, schon und ehrlich gehallen wird, wird ion B possitiv bewertet, gleichgullig. ob sie intelligent, schon und ehrlich ist oder nicht" (HFRKNER 1991. 210).

"..The process whereby people are led to internalize the beliefs. values. attitudes, and expectutions of a specific culture" (S.Mrth 1977. 206. ziticn nach: DE.PRE.7/ PERSOXNs 1987. 128).

"Bereits bei Kleinkindern entstehen Einstellungen durcli natürliche Reiz-Reaktionsterbindungen. Z.B. beim Fültern kann man klassische Musik als konditionientı Reiz cinsetzen. So kann das Kind sehr früh cine positwe Bewertung klassischer Musik enverben (WiTTE 1989. 370). 
2. eine Individualisierungsfunktion, indem man seine persönliche Einstellung zeigen kamm und sich damit von anderen abhebt:

3. eine Funktion der Komplexitätsreduktion, indem Wahrnehmungs- und Erklärungshypothesen zur lerfügung gestellt w'erden:

t. eime Funktion des Selbstwertschutzes, indem man wichtige und umichtige Einstellungsobjekte fir sich unterscheidet und diese entsprechend bewertet und damach handelt. (WITTE 1992, 36f)

Der heutige Begriff „Einstellung“ ist auf drei Ansätze zurückzuführen, die von unterschiedlichen Einstellungsstrukturen ausgehen: Der erste Ansatz beschäftigt sich mit der physiologischen Bereitschaft des Körpers, Reize aufzunehmen und in Handlungen umzusetzen. Al.LPORT (1924) benutzte hierfür das Bild des Schnelläufers beim Start. In diesem Ansatz wird die enge Verbindung zwischen der kognitiven (Startschuß) und der konativen Komponente (Bereitschaft zum Loslaufen) der Einstellung betont. Der zweite Ansatz ${ }^{34}$ stellt die Kognition in den Vordergrund und sieht von der kognitiven Komponente gänzlich ab und letztlich stellt DARWIN (1987) die enge Verbindung zur affektiven Komponente her, wobei er die Einstellung als Ausdruck eines Gefühls sieht (WrTTE 1989, 361). Aus diesen drei Ansätzen entstand die sog. Drei-Komponenten-Konzeption ${ }^{35}$, in deren Rahmen die Einstellung als "systematische l'erbindung der drei Subsysteme, eines handelnden Individualsystems zur Verarbeitung von Informationen und zur Festlegung von Handlungstendenzen auf der Basis allgemeingültiger sozialer Inhalle" (WITTE 1989, 395) verstanden wird:

1) The cognitive compoment of the atritude includes all kinds of knowledge one has about the attitude object. This knowledge is composed of so-called beliefs. Beliefs are the smallest cogmitive units of the conceptual structure.

2) The evaluative component is the central component. Here emotional values are related to the beliefs.

3) Together, the cognitive and evaluative componems determine the conative componemt of attitude. In the conative component the relevam beliefs and emotional values are transformed imro more or less specific behavioural imtemions. (DEPREZ/ PERSOONS 1987, 125fm)

Die einzelnen Subsysteme können an der Struktur einer Einstellung in unterschiedlichem Ausmaß beteiligt sein, so lassen sich Einstellungen danach klassifizieren, welches der Subsysteme im Gesamtgefüge dominiert (BIERHOFF 1984, 197):

1. Affektive Assoziationen: Einstellungen, in denen die affektive Komponente deutlich uberwiegt

2. Intellektualisierte Einstellungen zeichnen sich durch ein Überwiegen der kognitiven Komponente aus.

\footnotetext{
"Dicser Ansalz gcht zurück auf THOM.tS/ ZNANIECNI (1918) (WITTE 1989. 361).

36 Diesc Konzeption aus dem Jahre 1959 stamme von KATZ/ STOTL.WD (BIERHOF 1984. 195).
} 
3 Handlungsorientierte Einstellungen sind im hohen Ausmaß verhaltensabhängig.

+ Balancierte Einstellungen sind durch eine Konsistenz zwischen Bewertung. Meinung unc Verhaltensintension gekennzeichnet.

Die ersten Arbeiten, die systematisch und komplex die Interdependenzen zwischer. Einstellung und Verhalten untersuchen, stammen von FISHBEIN' AJZEN. Die beiden Wissenschaftler konzipienten im Jahre 1980 die "Theorie der ïberlegten Handlungen (Theory of reas(med action), in der sie zum ersten Male die zwischen Einstellung und Verhalten intervenierenden Elemente, die sog. Drittvariablen, berücksichtigen:

Die Ausfiihrung einer Handllung ist das Ergebnis der Absicht des Handlungsobjekts, diese Handlung aus:ufiihren. Die Handlungsabsicht wird von zwei Fakıren determiniert. nümlich eimmal von der Einstellung des Handlungsobjekts zur Handlung, sowie von seinen die Handling betreffenden subjektiven Normen. (zitient nach LINDENLAUB 1984, 48)

Die Einstellung zu einer Handlung und die subjektiven Normen des Individuums konnen die Ausführung bzw. Unterlassung einer Handlung hic et nunc beeinflussen. Die Einstellung zu einer Handlung wird dadurch bestimmt, welche tuswirkungen der Handlung das Individuum erwartet und dadurch, wie es diese Auswirkungen bewertet. Die subjektiven Normen werden durch die Kombination zweier Faktoren bedingt: 1 von den normativen Überzeugungen (beliefs) des Individuums, d.h. durch seine Auffassungen, daß bestimmte fur ihn bedeutende Personen bzw. Gruppen von ihm die Ausfuhrung bzw. Unterlassung der Handlung erwaren und 2. von der Stärke seiner Motivation, den Enwartungen dieser Persoren bzw. Gruppen entsprechend zu handeln.

Abbildung 1 Veranschaulichung der Theorie von FISHBEIN/ AJZEN durch ein Pfaddiagramm (ubernommen von LINDENI.AUB3 1984, 49)
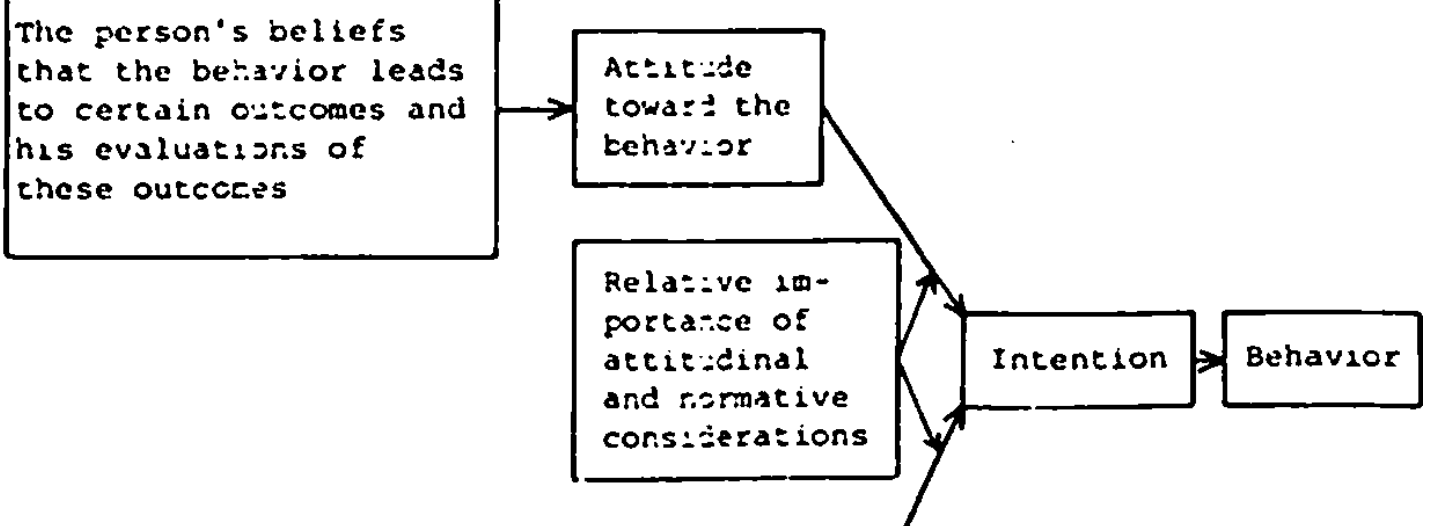
Die Einstellung-Verhalten-Relation, primär die folgenden Fragen, wurden in den letzten zwei Jahrzehnten in zahlreichen Beiträgen diskutiert ${ }^{36}$.

1. Unter welcher Bedingungen gibr es besonders enge Beziehungen zwischen Einstellumgen und Verhalten?

2. Wie laßß sich mit Hilfe von Einstellungen und unter Berïcksichtigung anderer relevanter l'ariablen l'erhalien vorhersagen? (SIX 1992, 13)

Als Fazit dieser Diskussion kristallisierten sich in der modernen Sozialpsychologie zwei Postulate heraus, die die wichtigsten Erkenntnisse wiedergeben:

1. Postulat: Aus Einstellungen lassen sich nur Handlungstendenzen über verschiedene Situationen oder Zeitpunkte vorhersagen. Eine wichtige Rolle bei der Vorhersage des individuellen Verhaltens spielen Einstellungen nur dann, wenn das Verhalten selber individuell gestaltet werden kann. Je größer die Abhängigkeit des Individuums von externen Einflüssen ist, desto weniger kann die Einstellung als Prädiktor des Verhaltens berücksichtigt werden, d.h. das Verhalten kann unabhängig von der Einstellung in verschiedenen Situationen und zu unterschiedlichen Zeitpunkten variieren (WITTE 1989, 395 / 1992, 49).

2. Postulat: Je differenzierter, integrierter, zentraler der Inhalt und je breiter der Handlungsspielraum ist, je stärker der Inhalt eine Immenorientierung fordert und je kognitivaffekıi konsistenter die Elemente des Einstellungsbegriffs ausfallen. desto größer ist die Einstellung-l erhalien-Konsistenz. (WITTE 1989, 395)

Zu den neuesten Beiträgen in der Einstellungsforschung zahlt das Einstellung-VerhaltenModell von E.H. WITTE, das auf der Drei-Komponenten-Konzeption basiert und die internen und externen Drittvariabien berücksichtigt. WITTE versteht in seinem Modell die drei Subsysteme einer Einstellung als eigenständige Modalitäten, die sich zu einem Konglomerat mit einem höheren Abstraktionsniveau, der summarischen Einstellung, zusammenschließen. Er betont, daß abhängig vom Einstellungsobjekt nicht alle Modalitäten für die Messung der summarischen Einstellung von gleicher Bedeutung sein müssen und plädiert bei der Einstellungserfassung für die Fokussierung der individuellen Mittelwerte pro Subsystem (WITTE 1992, 41ff).

${ }^{36}$ Einige Ansäize und Modelle sichı SIN 1992 
Abbildung 2 Interne Strukturierung und hierarchischer Aufbau der Einstellungskonzeption von WilT: $(1992,44)$

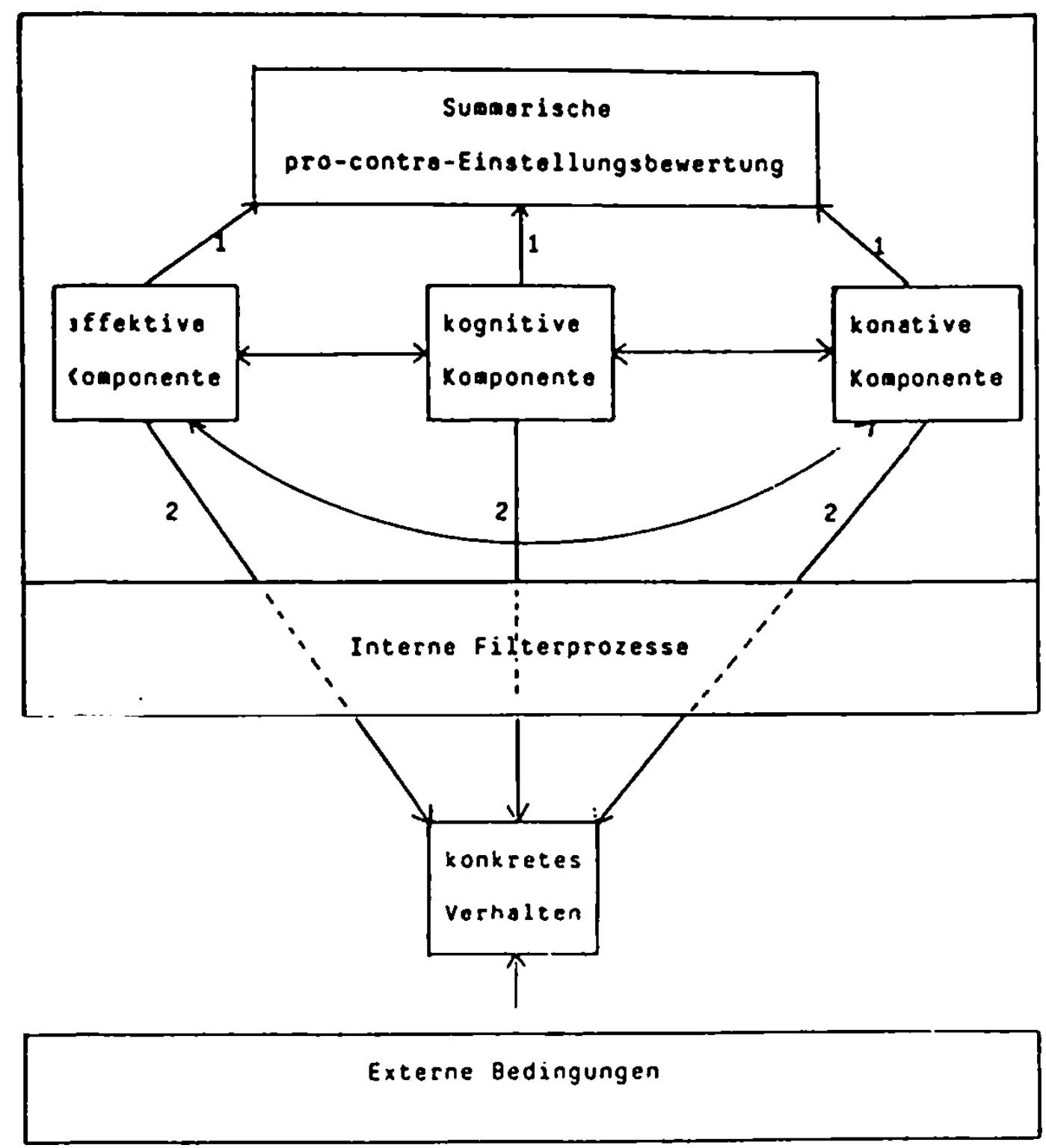

I. Prozeß Jer Abstraktion und Integration

2. Prozeß Jer Konkretisierung und Differenzierung

WIrTE konkretisier seinen Ansatz am Beispiel des Umweltschutzes: die Schulbildung, Massenmedien und die entsprechende Literatur vermittelten in den letzten Jahren viele neue Erkenntnisse uber die Umwelt und den Umweltschutz (kognitive Komponente), gleichzeitig mit der allgemeinen Aufklarung wurden Container fur Flaschen und Papier aufgestellt (konative Komponente), so daß gewisse Verhaltensmoglichkeiten erst ermöglicht wurden. Das Verhalten vieler Menschen anderte sich, wobei nicht auszuschließen ist. daß die summarische 
Einstellung zum Umweltschutz konstant geblieben ist, und nur die beiden Komponenten modifiziert wurden (WITTE 1992, 46f). Umgekehrt besteht die Möglichkeit, daß sich die summarische Einstellung nur aufgrund der Modifikation einer Komponente ändert. Die beiden Prozesse sind jedoch für die Forschung ..außerordentlich schwer nachollziehbar" (WITTE 1992, 47).

Parallel zur Trichotomie der Einstellungskomponenten akzentuiert WITTE auch die bereits von FISHBEIN/ AJZEN thematisierten zwischer. der Einstellung und dem Verhalten intervenierenden Drittvariablen. In seinem Modell wird das konkrete Verhalten neben der Einstellung durch interne Filterprozesse (Bequemlichkeit, momentane Gemütsverfassung, Bewertung der Handlung und der Konsequenzen der Handlung etc.) und/ oder externe Bedingungen (Konvention in der Wohngegend, momentanes Fehlen oder Überlastung der Container etc.) bestimmt.

Die ersten sozialpsychologischen Arbeiten im sprachlichen Bereich wurden in den 60er Jahren in den USA durchgeführt. Ihr primäres Ziel war es, Einstellungen von Angehörigen verschiedener Strata und sprachlicher Gruppen zu standard- und nonstandardsprechenden Personen zu untersuchen um däbei festzustellen, ob und in welchem Maße der Gebrauch einzelner Varietäten als Mittel soziologischer Stratifizierung anwendbar ist ${ }^{37}$.

Empirical studies in a range of simations and across the world reveal a generally consistem pattern of results in their differential evaluations of standard and nonstandard speakers. A standard variety is that most often associated with status, the media, power and those of the higher socioeconomic bracket. (Gll.Es et al. 1987, 585)

In die Soziolinguistik, deren Grenzen zur Sozialpsychologie im Bereich der Einstellungsforschung fließend sind, drang der Begriff Einstellung erst in den 80er Jahren ein. Obwohl mit der sozialpsychologischen Theorie und Methodologie eng verknüpft, wurde in den linguistischen Arbeiten der Akzent von den primär soziologischen auf die sprachlichen Probleme verlagert ${ }^{38}$. Die meisten soziolinguistischen Untersuchungen prägt die Frage „to what extem are people's language attitudes predictive of their linguistic belkniour?" (GILES et al. 1987. 591). Bei der Antwort auf diese Frage stützen sich die Wissenschaftler auf die dem sprachlichen Bereich angepaßten "Theory of reasoned action" von FISHBBEIN/ A.ZEN (1980), die bei der Einstellungs- vs. Sprachverhaltensanalyse folgende zwei intervenierende Drittvariablen berücksichtigt:

1. die Einstellung zu der konkreten Sprechhandlung sowie

2. subjektive sprachliche Normen eines jeden Individuums

Eine wichtige subjektive Norm bei der Wahl einer sprachlichen Varietat ist die Erwartung der Konsequenzen der sprachlichen Handlung und deren subjektive Einschätzung:

\footnotetext{
3. In Deutscliland entstanden in den 7()er Jahren im Zusammenhang mit der Gastarbeiterproblematik dic ersten Studıeı uber Einstellungen zur Spraelıe ausländischer Arbeiter. Auch hier wurde miltels Spraclıe dic Einstelung zu anderssprechenden - hier danüber hinaus einer sozialen Seliclı angeliorenden - Menschen unterSuclit. Vgl.: SCHONB.tCH 1970.

"Einige Arbetten siche: Glı.Es ct al. 1987. 585
} 
A given language variety will be used if, for example, it is seen as very probably leading to a highly valued consequence ('My speaking Received Pronounciation in this context will improve my chances of leading the job, something I would evaluate very favourahly: \%. (Glles et al. 1987, 591f)

Das zentrale Problem der vorliegenden Arbeit ist die Einstellung der Tschechen zu ihrer Standardsprache, bedingt auch zu ihrer Koine, dem Gemeintschechischen vs. der konkrete Gebrauch der beiden Varietäten. Auf der Grundlage des Drei-Komponenten-Modells von WITTE werden bei verschiedenen sozialen Gruppen das kognitive, affektive und konative Subsystem der sprachlichen Einstellung einzeln untersucht und ausgewertet. Da es sich im Falle des sprachlichen Bereiches um einen ausgeprägten Handlungsbereich handelt, stellt hier das konative Subsystem der Einstellung das zentrale Untersuchungsobjekt ${ }^{39}$ dar Auf den Umriß der summarischen Einstellung wird in unserer Untersuchung verzichtet:

Die globale Einstellung. die ein höheres Abstraktionsnivean im V'ergleich z" den Komponemten besitzt. läßt sich auf das angenommene Zutreffen verschiedener Komponemen und deren Bewernungen als Produktsummen zuriickzufiihren. (WITTE 1989, 370)

Das konative Subsystem der Einstellung wird ebenso wie das sprachliche Verhalten in einer formellen und bei den meisten Respondenten auch in einer informellen Situation untersucht. Die Ergebnisse werden verglichen und die evtl. Diskrepanzen hervorgehoben. Auf der theoretischen Grundlage der Theory of reasomed action von FISHIBEIN/ AJZEN (Abbildung 1) sowie des Drei-Komponenten-Modells von WITTE (Abbildung 2) sull anschließend versucht werden, mit Hilfe der Respondentenkommentare, Beobachtungen während der Feldstudie und eigener Erfahrungen ${ }^{\text {th }}$, die Gründe für die festgestellten Diskrepanzen näher zu erläutern.

\footnotetext{
${ }^{39} \mathrm{Vgl}$. Bit.RHOFF 1998. 197f.

"Die Verfasscrin dieser Studie isı Ischechische Muttersprachılerin. Während ilırer primären und sekundăren Sozialisition lebıe sic in der chemaligen Tsclicelioslowakei. Wăhrend der Studic befand sic siclı melırere Wochen in der Tschechischen Republik und konnte so die Sprecher in verschiedenen Situationen geziclt bcobacliten
} 


\section{Sprachliche Variablen}

$\mathrm{Zu}$ den wichtigsten Variablen in dieser Arbeit gehört die sprachliche Substanz, die im heutigen Tschechisch in der standard- und der gemeintschechischen Form vorliegt. Bereits HAVRANEK hob in seiner dialektologischen Abhandlung die lautlichen Merkmale des GT hervor. Die standardtschechischen Sätze: „Naši ješté dneska mláti pśenici, ale zitra pưjdou "İ̈ orat na pole. Kam jdeș? Ale teté pro mléko. Dej na vozik "u mouku ze mlyna." gab er im GT folgendermaßen wieder: „Naši ešlé dneska mlátej pšeñici, ale zejtra pudou uš vorat na pole. Kam deś? E. te te pro mliko. Dej na vozejk I" mouku ze mlejna" (HAVRÁNEK 1934, 84/ 104).

In den 90er Jahren wurde die im ST und im GT variierende sprachliche Substanz ausfuihrlich von SGAl.L et al. beschrieben. Die Autoren befaßten sich mit der phonologischen, morphologischen, syntaktischen und lexikalischen Ebene der beiden Varietäten und demonstrieren die verschiedenen standardlichen und gemeintschechischen Merkmale an zahlreichen Beispielen (SGiall. et al. 1992).

Die vorliegende Untersuchung beschränkt sich auf die lautliche und morphologische Ebene des ST bzw des GT. In folgenden Kapiteln werden in Anlehnung an SGALL et al. (1992) die 8 signifikantesten und wichtigsten sprachlichen Variablen, vorgestellt ${ }^{4}$.

\subsection{Lautliche Ebene}

Auf der lautlichen Ebene des Tschechischen werden insgesamt 4 Variablen untersucht. Drei von ihnen bezeichnen SGALL et al. $(1992,82 \mathrm{ff})$ als die Hauptdifferenzen zwischen dem ST und GT. Eine weitere Variable, die von den Autoren nicht zu den markantesten gezählt wird. zeichnete sich im Verlauf der Felduntersuchungen als ein häufig verwendetes und signifikantes Merkmal des GT und wurde aus diesem Grund ebenfalls in unsere Studie aufgenommen.

Tabelle 1: Ubersicht der lautlichen Variablen ${ }^{42}$

\begin{tabular}{|l|l|l|}
\hline ST & GT & \multicolumn{1}{|c|}{ Position } \\
\hline$i$ & $i$ & $\begin{array}{l}\text { Nach allen nichtpalatalisierten Konsonanten in Wortstämmen und } \\
\text { Endungen. }\end{array}$ \\
\hline$\therefore$ (i) & $\dot{j}$ & $\begin{array}{l}\text { Für das alte /y/ nach allen nichtpalatalisierten Konsonanten in } \\
\text { Wortstämmen und Endungen: selten im Präfix vy-. Für das alte } i: \\
\text { nach Zischlauten z, c. s in Wortstämmen und im Suffix -ik. }\end{array}$ \\
\hline
\end{tabular}

"Die Selektion erfolgte mit Rücksiclı auf den Umfang und die Intention unserer Untersuchung

"Anmerkung zur Transkription: Das lieutige Tschechisch besitzt zwei Grapheme (i, v) fur cinen Laut. Der altisclieclusclie breite. hintere Vokal i $y$ bzw: y:l, der bereits zwischen Ende des 14 . und Anfang des 17. Jh mit deın Vokal $i$ bzw. $i$ : verschmolz. existiert heute nur noch in cinigen măhrischen Mundarten. Die heutige rein orthographisclie Unterscheidung $i, v / i, \dot{y}$ fußt in der tschechischen humanistischen Tradition. Vgl.: Tr.tixiceK 1940. 210 In unserer Studie werden phonologische Klammern nur bei $i$ i. y. $i$ auf der diachronischen Ebene venwendet. um diese beiden Laute im Alt- und Neutschechischen wiederzugeben. In allen anderen Fällen. auch bei der Wiedergabe des GT wird die traditionelle standardischechische Sclireibweise ubernommen. 


\begin{tabular}{|l|l|l|}
\hline \multicolumn{1}{|c|}{ ST } & GT & \multicolumn{1}{c|}{ Position } \\
\hline$o$ & $v o$ & $\begin{array}{l}\text { Der prothetische Laut v kommt im GT in den Positionen vor dem } \\
\text { anlautenden } o-\text { bzw: im Hiat vor o im Wortinneren vor als Ersatz für } \\
\text { den Glottislaut (fester Einsatz). }\end{array}$ \\
\hline$i \quad \dot{a}$ & $i a$ & Nach allen Konsonanten in der letzten Silbe vor $-m$. \\
\hline
\end{tabular}

\section{1. $\dot{e}$ im ST vs. $i$ im GT}

Die lautliche Reduktion $\dot{e}>1: /$ nach allen Konsonanten setzte in Böhmen im 15. Th. ein und wurde anfangs des 17. Jh. abgeschlossen. Im $19 \mathrm{Jh}$. war im mündlichen Umgang in Böhmen die neue Form bereits fest etabliert (HUNR 1934, 46). DOBROVSK $\dot{Y}$ orientiente sich dennoch in seiner Grammatik zum größten Teil an der älteren Form. Nach palatalisierten Konsonanten und $j$ kodifizierte er $i$, nach allen anderen Konsonanten $\dot{e}$ (CURIN 1975, 55ff):

$\ddot{r} c i$ aus dem alttschechischen $\ddot{r} c i$ vajicko aus dem alttschechischen vajécko

In neuerer Zeit werden immer mehr Ausdrücke, die das gemeintschechische $i$ nach nichtpalatalisierten Konsonanten aufweisen, als Dubletten kodifiziert (KRAUS et al. 1981, 232): kameinek kaminek; polevka polivka Die meisten Formen gelten jedoch nach wie vor als gemeintschechisch.

Die Variable $\dot{e}$ vs. $i$ tritt im heutigen Tschechisch in drei Positionen auf ${ }^{\text {s: }}$

Position 1: im Wortauslaut

Im Auslaut harter Adjektive, Neutr. Sg. Nom./Akk./Vok. und Fem. Sg. Gen., Dat., Präp. sowie Mask. unbelebt $\mathrm{Pl}$. Nom./Akk./Vok. (bei belebten Mask. nur Pl. Akk.) und Fem. PI. Nom./Akk./Vok.

\begin{tabular}{|c|c|c|}
\hline & Beispiele im ST & Beispiele im GT \\
\hline Neutr. Sg. Nom./Akk./Vok. & dershé & cersnit \\
\hline Fem. Sg. Gen./Dat./Präp. & mladi & mlacti \\
\hline Mask. unb. PI. Nom./Akk./Vok. & $t^{c}$ ’̈ki & $1^{k} \not \mathrm{kj}^{j}$ \\
\hline Mask. bel. Pl. Akk. & silmi & silmi: \\
\hline Fem. PI. Nom./Akk./Vok. & nove & noiy \\
\hline
\end{tabular}

Position 2 in den Endungen

In den Endungen harter Adjektive, Mask. Sg. Gen./Dat./Präp. (bei belebten Mask. auch im Akk.) und Neutr. Sg. Gen./Dat./Präp.:

43 Dicsi lautliche Ándenung wird aufgnund ihres Vorkommens im Paradigma harter Adjektive hauufig als morphologisch beıcichnet. In der Wirklichkeit handelt es sich aus der sỵnchronischen Siclı um cin morphophonctisclics Merkmal. 


\begin{tabular}{|c|c|c|}
\hline & Beispiele im ST & Beispiel im GT \\
\hline Mask./Neutr. Sg. Gen. & nového & novyho \\
\hline Mask./Neutr. Sg. Dat. & novému & novyimu \\
\hline Mask./Neutr. Sg. Präp. & novém & novym \\
\hline Mask. belebt Sg. auch im Akk. & nového & noviho \\
\hline
\end{tabular}

\section{Position 3: im Wortstamm}

\begin{tabular}{l|l} 
Beispiele im ST & Beispiele im GT \\
\hline mléko & mliko \\
\hline chlev & chliv \\
\hline mést & nyst \\
\hline létat & litat \\
\hline péct & pict \\
\hline ménd & miñ
\end{tabular}

Obwohl die gemeintschechische Reduktion in den Stämmen weit verbreitet ist, existieren Ausdrucke, die nur die é-Variante führen (léta, lekkar, nicméné. scéna, téma) ${ }^{\text {th }}$. Solche Fälle sind 1. von unklarer Etymologie, 2. etymologisch einer anderen lautlichen Entwicklung zuzuweisen, 3. Fremdwörter oder 4. im Rahmen des ST gebildete Neologisments.

\section{2. $y i$ im ST vs. $e j$ im GT}

Bereits im 14. Jh. setzte in Böhmen die Diphthongierung des langen hinteren Vokals $y:$ (nach nichtpalatalisierten Konsonanten) bzw. des langen vorderen Vokals $i$ : (nach $z, c, s$ ) $\mathrm{ein}^{16}$ Bis Mitte des 17. $\mathrm{Jh}^{{ }^{77}}$ wurden in Bohmen diese Laute in der oben angegebenen sprachlichen Umgebung zum Diphthong ej. Der Anfang des 19. Jh. in der böhmischen Ungangssprache bereits fest etablierte Diphthong ej für das alttschechische $y:$ bzw. $i$ : wurde von DOBROVSKY nicht kodifiziert.

Die Variable $y$ vs. ej tritt im heutigen Tschechisch in vier Positionen auf ${ }^{8 .}$.

\footnotetext{
"VgI KR.MCISINON:W BEDN.ARONA 1968. 307.

"Eine nälıere Untersuchung auf diesem Gebiet ist nicht Gegenstand dieser Arbeit. sie würde ihren Rahmen sprengen.

* Laut Gebat'ER veranderte sich der alttschechische Vokal y:/bzw. $i$ : zuerst zu aj und erst im Laufe des 15. Jh. zu ej. Vgl.: Gebalier. ed. 1963. 281: HejJER nimmt dagegen an. daB diesc lautliclie Entwicklung oline jeglıclic Zwisclienstufe ablicf. daB aber die lautliche Form $e j$ in der Anfangsplase (1t. Jh.) als aj geschricbcil wurde. Vgl.: HLIJER 1934. 48.

"Ersı naclı dem aufgrund der politischen Gegebenheiten allmăhlich untergehenden humanistischen Tschecliscli aus dem ausgelienden 16. Jh.

1* Ähnlich wic dic Änderung $\dot{e}>i$ wird auch diesc Variable haüfig als morphologisch bezcichnel. Auclı hier handelt es sicli aufgrund des Vorkommens in Paradigma harter Adjektive un ein morphophonetisclics Merkmal
} 
Position 1: im Wortauslaut

Im Auslaut harter Adjektive Mask. Sg. Nom./Vok. (bei unbelebten Mask. auch im Akk ):

\begin{tabular}{l|l} 
Beispiele im ST & Beispiele im GT \\
\hline Stastmi & stasmej \\
\hline relki & velkej \\
\hline dobry & dohrej
\end{tabular}

Position 2: in den Endungen

In den Endungen harter Adjektive, alle Genera des PI. im Gen./Dat./Präp./Instr:

\begin{tabular}{l|l|l} 
& Beispiele im ST & Beispiele im GT \\
\hline Gent.Präp. PI. & dobrjich & dobrejch \\
\hline Dat. PI. & dobrim & dobrejm \\
\hline Inst. PI. & dobrimi & dobrejmat
\end{tabular}

Position 3 im Wortstamm

\begin{tabular}{l|l} 
Beispiele im ST & Beispiele im GT \\
\hline mlint & mlejn \\
\hline kichmont & kejchmout \\
\hline midllo & mejdlo
\end{tabular}

Position 4: im Präfix vej- (ST vi-)

\begin{tabular}{l|l} 
Beispiele im ST & Beispiele im GT \\
\hline biskut & rejskut \\
\hline ysitrih & rejairih
\end{tabular}

Die altschechische lautliche Entwicklung /i: $>e j$ nach den Zischlauten $z, c, s$ setzte im 15 Jh ein und wurde in der Mitte des 17. Jh parallel zu /y: > ej nach nichtpalatalisierten Konsonanten ${ }^{\text {st }}$ abgeschlossen.

Die Variable $i$ vs. $e j$ tritt im heutigen Tschechisch in zwei Positionen auf:

\footnotetext{
"Zur Variablen -mi vs. -ma siclic Kap. 3.2./1.

"In den meisten Fällen wird das Prafix in sciner monophthongischen Form vertreten: vichova. vin'os. ristrédni. vistma. Dic meisten Ausdnicke. die mit Hilfe des Prafixes yi-gebildet werden. entstanden crst im Rilhmeı der Standardspraclie als Neologismen. sie sind niclıt natürlich gewachsen. Aus diesem Grund wird in unserer Auswertung des sprachlichen Materials von allen Ausdrücken mit viv-abgeselien.

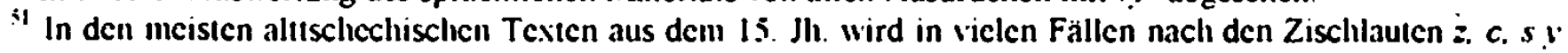
gescliricben Gr.B.ll rer nimmt an. daB der Vokal , bzw. i: nach $z, c, s$ im Laufe des 15 . Jh. zum hinteren Vokal !' bzu. ." mutienc. Das gedelinte :". , wurde dann bis Mitte des 17. Jh. obligatorisch zu ej. Erst im 19. Jh. fiulıne Dobrotshi (in den meisten Fällen) die Sclıreibucise mu dem Graphem i nach z. c. $s$ cil. Vgl. GRB IIER. ed 1963. $211 \pi$.
} 
Position 1: im Wortstamm

\begin{tabular}{l|l} 
Beispiele im ST & Beispiele im GT \\
\hline zirra & zejtra \\
\hline cirit & cejtit \\
\hline sito & sejto
\end{tabular}

Position 2: im Suffix -ejk (ST -ik)

Als Suffix einiger maskulinen substantiven Diminutive, 1. Stufe ${ }^{52}$ :

\begin{tabular}{l|l} 
Beispiele im ST & Beispiele im GT \\
\hline rozik & vozejk \\
\hline mosik & nosejk \\
\hline mrazik & mrazejk
\end{tabular}

Ähnlich wie bei der Variablen $\dot{e}$ vs. $i$ weisen auch hier viele Stämme nur ihre monophthongische Variante auf. KRAVČISINOVÁ BEDNÁR̉OVẢ begründen das häufige Ausbleiben der gemeintschechischen Form $e j$ in den Stämmen, im Präfix $v \dot{y}$ - bzw. im Suffix -ik durch den starken Einfluß des ST. Sie betonen, daß die Ausdrücke, die innerhalb des mündlichen Umgangs häufig in ihrer standardsprachlichen Form verwendet werden - z.B. bei offiziellen Anlässen als Phrasen oder im Berufsleben als fachbezogene Begriffe -, auch im privaten Umgang ihre gemeintschechische Variante verlieren (KRAVĆISINOVA BEDNARORA 1968, 319) Der starke Einfluß des ST auf das GT stellt zweifellos einen wichtigen Faktor dar, dennoch sollten auch hier, ähnlich wie bei $\operatorname{der}$ Reduktion $\dot{e}>i$, in erster Linie die Wortetymologie überprüft werden ${ }^{\text {s3 }}$.

2. Die gemeintschechische $v$-Prothese vor $o$

Bereits im 14. Jh. wurde in Böhmen $v$ - vor dem anlautendem o bzw. im Hiat ausgesprochen. Es handelte sich um eine Entwicklung, die den bis dahin obligatorischen Glottisschlag vor $o$ ablöste. Bis Ende des 16. Jh. setzte sich die $v$ - Prothese im mündlichen Umgang in Böhmen durch (LAMPRECHT/ ŚLOSAR 1962, 77). Zur Zeit der Wiedergeburt ignorierte DOBROVSKY diese Entwicklung und kodifizierte die ältere Form. Somit verbannte er die $v$-Prothese auch im heutigen Tschechisch in den Bereich des GT (CURiN 1975, 58).

Die Variable $o$ vs. vo tritt im heutigen Tschechisch in zwei Positionen auf:

\footnotetext{
5gl:: H.WRitien JedLICKa 1960, 97. Der kommunikative Wen dieses Suffixes isl gering

3 TOW'NSEND dokumentien dic Absenz der gemeintschechischen Variante anhand einiger Beispiele olne jegliche Erklärung. Vgl.: TOW'xsEND 1990. 32. Eine kurze etymologisclie Recherche maclit jedoch deutlich. daß cinige der aufgeführten Ausdrücke nicht der Entwicklung y: bzw: /i:/ > cj zuzuschreiben sind. Z.B. ..lika" "urde ins Altlschechische aus dem Deutsclien .Degen” übernommen (Hol.L'B/LiER 1978. 145). Das $\dot{e}$ wurde zwischen dem 15. und 17. Jh. ganz regulär zu i:/ und in dieser Form kodifizien. Der Ausdruck .mivar" "urde crst im Rahmen der standardischechischen Wortbildung aus dem Deutschen (IIaschioar > m!raß) übcrsctzt (HOLUB/ LIER 1978. 327).
} 
Position 1: im Anlaut

\begin{tabular}{l|l} 
Beispiele im ST & Beispiele im GT \\
\hline on & ron \\
\hline okno & rokno \\
\hline odejii & rodejii \\
\hline okolo & rokolo
\end{tabular}

Auch bei dieser Variablen existieren einige wenige Ausdrücke, die keine $v$-Prothese aufweisen - orrce, olec, ovisem, oxaza, oficiálme - und die von KRAVČISINOVÁ BEDNÁROVA $(1968,307)$ auf den starken Einfluß des ST zurückgefuihrt werden ${ }^{\text {st }}$

Position 2 im Hiat

\begin{tabular}{l|l} 
Beispiele im ST & Beispiele in GT \\
\hline pootevít & porotevrit \\
\hline lyorat & vvorat \\
\hline kokm! kokm! & krokm! \\
\hline maopak & naropak
\end{tabular}

4. Die gemeintschechische Reduktion bei $i$ und $\dot{a}$ im Auslaut vor $-m$

Bereits im 16. Jh. schwand in Bohmen die vokalische Quantitat bei $i$ und $\dot{a}$ (GEBAUER, ed 1963, 207ff) Von DOBROVSKY nicht kodifiziert, bildet im heutigen GT der Verlust der Quantitä von $-i$ und $-a$ in der letzten Wortsilbe ${ }^{56}$ sehr häufig vor $-m^{57}$ - eine häufig verwendete lautliche Variable.

\begin{tabular}{|c|c|}
\hline Beispiele in ST & Beispiele in GT \\
\hline$-i m$ & $-\mathrm{im}$ \\
\hline$m / i i m$ & m/cim \\
\hline rim merim & im nevim \\
\hline plarim & plarim \\
\hline$-\mathrm{i} i m$ & $-a m$ \\
\hline mcim & mam! \\
\hline zeplám se & zepram se \\
\hline
\end{tabular}

"s Auch hier imußıc cine genaucre Recherche durchgefuhrt werden. die jedoch nicht den Gegenstand diescr Arbeil darsiclil.

"Niclısilbisclic Prapositionen $(s, z, v, k)$ werden im Tschichischen mit dem nachfolgenden Won als cine Einheit ausgesproclen (H.WR.LIEN JEDt.ICKA 1960, 30).

${ }^{4}$ Sci.U.L. ct al. besehen dic Reduktion niclıl nur auf dic letzic Silbc. Sic führen als Bcispicle an: uprimnej vs.

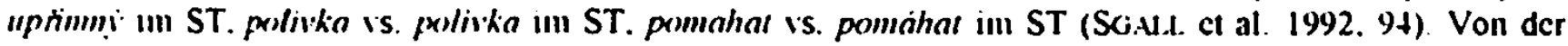
Reduklion im Wortimeren wurde in dieser Arbcil abgesclien.

"Dies helrilli vor allem dic 1. P. Sg. Prisens der Verben der III.. IV. und V. Klasse (Differenzienung nach dem Infinitis stamm. Vgl.: K.tRt.ik el al. 1995. 329m 


\subsection{Morphologische Ebene}

Auf der morphologischen Ebene fuihren SGall et al. (1992) einige Variablen an, die anhand ihrer seltenen Verwendung für unsere Untersuchung irrelevant $\operatorname{sind}^{38}$. Wir übernehmen nur solche, die in der gesprochenen Sprache relativ häufig verwendet werden, mit dem Vorbehalt, daß ihre Anzahl im Vergleich zu den lautlichen Variablen deutlich geringer ist ${ }^{39}$.

Tabelle 2: Übersicht der morphologischen Variablen

\begin{tabular}{|c|c|}
\hline \multicolumn{2}{|c|}{ Deklination } \\
\hline Standardtschechisch & Gemeintschechisch \\
\hline $\begin{array}{l}\text { Substantivendungen im Instr. PI., alle } \\
\text { Genera, variieren gemäß ihrer Stamm- } \\
\text { zugehörigkeit. Die Endung harter und } \\
\text { weicher Adjektive, Instr. Pl., alle } \\
\text { Genera, ist einheitlich: }-m i .\end{array}$ & $\begin{array}{l}\text { Substantivendungen im Instr. PI, alle } \\
\text { Genera, sowie die Endungen harter und } \\
\text { weicher Adjektive, Instr. PI., alle } \\
\text { Genera, sind einheitlich: -ma. }\end{array}$ \\
\hline $\begin{array}{l}\text { Endungen harter Adjektive, Nom./Akk. } \\
\mathrm{Pl} \text {. werden nach Genera differenziert. }\end{array}$ & $\begin{array}{l}\text { Endungen harter Adjektive, Nom./Akk. } \\
\text { Pl., alle Genera, sind einheitlich: }-y \text {. }\end{array}$ \\
\hline \multicolumn{2}{|c|}{$\begin{array}{l}\text { Konjugation } \\
\end{array}$} \\
\hline Standardtschechisch & Gemeintschechisch \\
\hline $\begin{array}{l}\text { Die Endungen der I. und VI. Verbklasse } \\
\text { in der I. P. Sg. Präs. Akt. und in der } 3 \text {. } \\
\text { P. Pl. Präs. Akt. sind: - } i \text { - } i \text { (Typ: ja } \\
\text { kryji. kupuji oni kryji, kupuji). }\end{array}$ & $\begin{array}{l}\text { Endungen der I. und VI. Verbklasse in } \\
\text { der l. P. Sg. Präs. Akt. und in der 3. P. } \\
\text { Pl. Präs. Akt. sind: -u -ou (Typ: já kryju, } \\
\text { kupuju voni kryjou, kupujoui). }\end{array}$ \\
\hline $\begin{array}{l}\text { Die Form des Verbs být im Konditional } \\
\text { Prasens. } 1 \text { P Pl. ist bychom. }\end{array}$ & $\begin{array}{l}\text { Die Form des Verbs být (GT bejt) im } \\
\text { Konditional Präsens, 1. P. PI. ist bysme. }\end{array}$ \\
\hline
\end{tabular}

I Die gemeintschechische Nominalendung -ma im Instr. Pl.

Uberliefert aus dem Urslavischen, existierte im Alttschechischen etwa bis Ende des 15 . Jh. der Dual als dritter Numerus. Zwischen dem 16. und 19. Jh. wurde der Dual bis auf wenige Ausnahmen vom Plural abgelöst ${ }^{60}$. In der böhmischen Umgangssprache blieb jedoch die uniforme substantivische Dualendung - $m a$ im Instr. Pl., alle Genera, erhalten. Dieses signifikante Merkmal wurde von DOBROVSKY nicht kodifiziert. Somit bildet es im heutigen Tschechisch das gemeintschechische Äquivalent zu den polyformen standardtschechischen Instrumentalendungen harter und weicher Substantive:

\footnotetext{
" Einige Bcispicle: Substantive mask. PI.. die auf cinen Velarlaut enden. sind äußerst rar: im ST mit der Endung -ich. im GT mit der Endung - ich. Der Vokativ kommt nur in speziellen Kontexten vor: im GT wird der Vokativ of durch den Nom. erset7t. Vgl.: SGall et al. 1992. 105.

${ }^{<9} \mathrm{Vgl}$.: SGilll. ct al. $199210+\mathrm{fr}$.

"' III heutigen ST blieben die Reste des nominalen Duals in einigen Ausnahmen erlatten. So haben z. B. dic paanicise vorkommenden Körpencile wic Arne. Beine. Schulter. Augen usw im Instr. PI die Endung -mIa. Beispicic: nohama, ocima, kolenama (HAIRAVEN JEDLCKA 1960. 106).
} 
Tabelle 3: Substantivendungen im Instr. PI. im ST ${ }^{61}$

\begin{tabular}{|c|c|c|c|}
\hline Genus & Endungen & Beispiele im ST & Beispiele im GT \\
\hline Maskulin & $-y-i$ & $\begin{array}{c}\text { pany muzi } \\
\text { hrady/stroji }\end{array}$ & $\begin{array}{l}\text { panama mużema } \\
\text { hradama strojema }\end{array}$ \\
\hline Feminin & $-a m i^{\prime}-\mathrm{em} i^{\prime}-m i$ & żnami rüzemi kosimi & Žnama rix̌ma kostma \\
\hline Neutrum & $-y-i-m i$ & mesty mori stavenims & méstama moícma/stavenima \\
\hline
\end{tabular}

Parallel zur Erhaltung der alten substantivischen Dualendung - $m a$ im Plural Instr. etablierte sich im Laufe des 17. Jh. die gleichformige adjektivische Dualendung im Paradigma harter und weicher Adjektive, Adjektivpronomina. Ordinalia Instr. Pl., alle Genera (GEBAUER, ed. 1960, 560). In der Kodifizierung von DOBROvSKY nicht berücksichtigt, gehört diese Endung gemeinsam mit der substantivischen Endung -ma zu den signifikanten morphologischen gemeintschechischen Merkmalen.

\begin{tabular}{l|l} 
Beispiele im ST & Beispiele im GT \\
\hline mladymi & mladejma \\
\hline nonymi & novejma \\
\hline jarnimi & jarnima \\
\hline jakymi & jakejma \\
\hline kterimi & kterejma \\
\hline prnmimi & prvnima
\end{tabular}

2 Die gemeintschechische Adjektivendung $-i$ im Nom./Akk PI

Der Entstehung der morphologischen Variablen $i$ im Paradigma harter Adjektive. Nom./Akk.PI., alle Genera, im GT vs. polyforme Endungen im ST liegt die lautliche Reduktion $\dot{e} \quad i:$ zu Grunde. Noch bis ins 15. Jh. endeten harte Adjektive im Nom. Pl., Mask. unbelebt/Fem. sowie im Akk Mask./Fem. auf $\dot{e}$. Bis Anfang des 17. Jh. mutierte diese Endung regular zu i: (Huslt: 1934, 67). Im 17. Jh. wurde die neu entstandene Endung analog auf harte Adjektive im Nom. Mask. belebt - ursprunglich " $-i$ - und später auch auf harte Adjektive im Nom./Akk. Pl. Neutr. - ursprünglich $\dot{a}$ - übertragen. Anfang des 19. Jh. ließ D.MBROVSK $Y$ in seiner Kodifizierung diese lautliche und analoge Entwicklung unberücksichtigt und kodifiziente die ausgestorbenen heterogenen Adjektivendungen. Die dadurch entstandene Diskrepanz existien im Tschechischen bis heute:

\footnotetext{
${ }^{61} \mathrm{Vgl}$ : HalRANEN JEDLCKA 1960. 114.

6: Das Verhălınis $y i>e j$ siclıc Kap. 3.1/2.
} 
Tabelle 4: Endungen harter Adjektive, Nom./Akk. ${ }^{63}$

\begin{tabular}{c|c|c|c}
\multicolumn{5}{c}{ Nominativ } \\
\hline Genus & Endungen & Beispiele im ST & Beispiele im GT \\
\hline Mask. belebt & $-i$ & mladi & mlacty \\
\hline Mask. unbelebt & $-\dot{e}$ & mladé & mladj $\dot{~}$ \\
\hline Fem. & $-\dot{e}$ & mladé & mlady \\
\hline Neutr. & $-\dot{a}$ & mlad $\dot{a}$ & mlacty
\end{tabular}

\begin{tabular}{c|c|c|c}
\hline Genus & Endungen & Beispiele im ST & Beispiele im GT \\
\hline $\begin{array}{c}\text { Mask. } \\
\text { (belebt und unbelebt) }\end{array}$ & $-\dot{e}$ & mladi & mlady \\
\hline Fem. & $-\dot{e}$ & mlad $\dot{~}$ & mlady \\
\hline Neutr. & $-\dot{a}$ & mladá & mlady
\end{tabular}

3. Verbalendungen, Präs., 1. und 3. P. -i-i im ST vs. -u-ou im GT

Die Tendenz zur morphologischen Vereinheitlichung im GT ist nicht nur bei den substantivischen bzw. adjektivischen Deklinationen zu beobachten, sondem auch bei der I. und VI. Verbklasse, 1. P. Sg. und 3. P. Pl. im Präs. Aktiv Ind.

Bis Ende des 16. Jh. endeten aufgrund der lautlichen Entwicklung " $>/ i$, $i>/ i: /$ nach $j$ (Ende des 14. Jh.) die Verben der I. Klasse Typ ,kry' ' und VI. Verbklasse, 1. P. Sg. bzw. 3 P. PI. Präs. Akt. Ind. auf $/-i$ bzw. /-i:/. Im Laufe des 17. Jh. drangen die Endungen - 11 -ou der 11 .

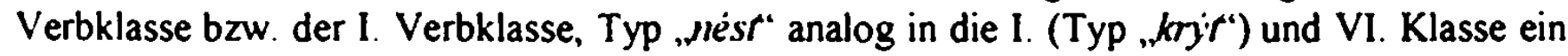
und etablierten sich in ganz Böhmen. (GEBAUER, ed. 1958, 204/399f) DOBROVSKY kodifizierte die bereits in der Sprache ausgestorbenen Endungen $/-i$ bzw. $/-i: /$ die dennoch bis heute in der gesprochenen Sprache nicht verwendet werden ${ }^{64}$.

\begin{tabular}{l|l|l} 
& Beispiele im ST & Beispiele im GT \\
\hline I. KI., 1. P. Sg. Präs. Akt. Ind. & kryji. biji & kryju, biju \\
\hline I. Kl., 3. P. PI. Präs. Akt. Ind. & kryji. biji & kryjou, bijou \\
\hline VI. KI., 1. P. Sg. Präs. Akt. Ind. & kupuji. pracuji & kupuju, pracuju \\
\hline VI. KI., 3. P. PI. Präs. Akt. Ind. & kupuji, pracıji & kupujou, pracujou
\end{tabular}

6) Vgl: HAlR.ANEN JEDLICKA 1960. 166.

ot Die Verbalendungen - $u$-ou werden in Tschechischen in manchen Kontexten als standardischechiscli aufgcfaßı und bilden somit Dubletlen zu -i -i. . lzor KRIT piedstaruje slovesa s jedinos/abichim infinitnem.

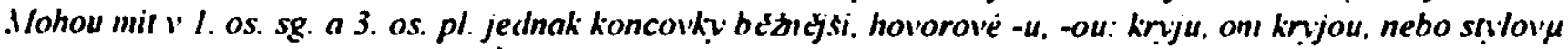

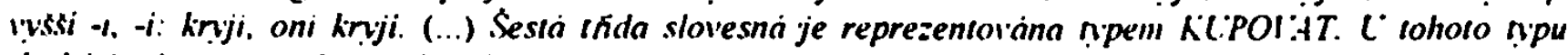
dochazi v l. os. sg. a 3. os. pl. Indhk. prèz. ke zmche ve prospech koncovek -u. ou proli -i. -i. le livssim sñlu

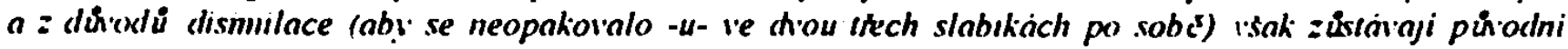
koncoik! chsto zachovin!." (K.URI.ik et al. [Hrsg.] 1995. 327/332). 
4. Konditional vom Verb byı, 1.P.PI. bychom im ST vs. bysme im GT

Bereits im 15. Jh. entwickelte sich der Konditional Präsens und später auch Konditional Präteritum aus der synthetischen Form des ursprünglichen Aorist-Plusquamperfekt (Aorist von $b \dot{y} t+$ Part.Perf.Akt.- L-Partizip) durch die semantische Verschiebung Vergangenheit > Konditional. Die ursprünglich uneinheitliche Aoristform des Hilfsverbs být, 1.P.PI. - bychom, bychme, bychmy - stabilisierte sich im $17 \mathrm{Jh}$. analog zu der 2.P.PI. byste zu bysme (GEBAUER, ed. 1958, 429). Diese Form, obwohl im 19. Jh. allgemein gebräuchlich, wurde von DoBROVSKY nicht kodifiziert, er griff zu der älteren Form bychom. Im heutigen GT wird die 1.P.PI. Konditional Präsens durch die Form bysme vertreten, was sich auch in den zwei häufig verwendeten Konjunktionen widerspiegelt:

\begin{tabular}{l|l} 
Beispiele im ST & Beispiele im GT \\
\hline chteli bychom & chicli bysmc \\
\hline abychom & abysme \\
\hline kdybychom & kdyby:smc
\end{tabular}




\section{Soziologische und diatopische Variablen}

\subsection{Geschlecht, Bildung}

Für die Wahl der Respondenten waren zwei soziologische Variablen relevant: das Geschlecht und der Bildungsgrad. Angestrebt wurde eine möglichst repräsentative Respondentengruppe, die sich in etwa zum gleichen Teil aus Frauen und Männern mit verschiedenem Bildungsniveau zusammensetzt. Das Alter bildet in unserer Studie keine relevante Variable ${ }^{65}$, denn bereits in den ersten Phasen der Felduntersuchung stellte sich heraus, daß die meisten Vertreter der jungen Generation ${ }^{66}$ nicht bereit waren, sich den Anforderungen der Enquete zu stellen. Sie weigerten sich ins Mikrofon zu sprechen oder beantworteten alle Fragen mit "nevim". Eine Ausnahme bildet eine Gruppe von 6 Schülern, die Dank guter Kontakte zur Technischen Fachoberschule in Pilsen direkt in der Schule befragt werden konnten und auch bereit waren ${ }^{67}$, die ihnen vorgelegten Fragebögen auszufüllen. Auch die Zusammenarbeit mit älteren Personen ${ }^{68}$ erwies sich bis auf wenige Ausnahmen als problematisch. Die meisten verhielten sich den Interviewern gegenüber mißtrauisch und weigerten sich, ins Mikrofon zu sprechen. Somit bewegt sich das Alter der Befragten bis auf wenige Ausnahmen zwischen 20 bis 60 Jahren $^{69}$.

In der Soziolinguistik gilt die Zugehörigkeit zu einem Geschlecht als eine wichtige, die Sprache determinierende Variable. Bereits in den 70er Jahren wurden die ersten Versuche durchgeführt, die auf biologischer Prädisposition sowie unterschiedlicher Sozialisation und nicht zuletzt historischer Entwicklung der einzelnen Nationen basierenden sprachlichen Spezifika bei Frauen und Männern zu untersuchen. Die bisher durchgeführten Untersuchungen weisen formale geschlechtsspezifische Differenzen auf allen sprachlichen Ebenen auf und machen darüber hinaus deutlich, daß das sprachliche Verhalten von Frauen und Männern in Verbindung mit verschiedenen Situationen variiert:

Thus the conclusion can be drawn that language use differs for women and men and, that sex-specific ways of using language might have become incorporated in language structure in the course of its historical development. (KLANN-DELIUS 1987. 767)

In der vorliegenden Studie werden die sprachlichen Aufnahmen sowie die Angaben in den Fragebögen nach dem Geschlechtskriterium ausgewertet und die eventuellen geschlechtsbedingten Spezifika hervorgehoben.

"Im präcxperimentellen Stadium war das Alter der Sprecher noch als cine auszuwertende Variable vorgesehen.

" Es handelt sich um die Sprechergnuppe bis 20 Jahre. In der Entwicklungspsychologic wird das ..Fertigsein des. Menschen" im Alter zw. 20 und 25 Jahren angesetzl (M.tTTHE.JER 1987. 79).

$\because$ Die Umfrage an dieser Schule verlief wăhrend des Unterrichts. Die sich beteiligenden Schüler durften für ca. 30 min den Unterricht verlassen.

* Es handelı sich um die Sprechergruppe ab 60 Jahre. Diese Phase wird in der Entwicklungspsychologic als dic ..Phase der .I hlosung rom Leben" genannt (M.tTrHEIER 1987. 80).

${ }^{69}$ Das Alter von 20 bis 60 Jahren wird als das Envachsenenalter definiert: 1. Plase: Selbstbestimmung und Zicisetzung im Provisorischien (20 - 30 Jahre). 2. Pliase: Spezielle Bindungen mit übervicgen des Sachlichen (30 - 50 Jahre). 3. Phase: Einordnung in cinen höheren Zusammenhang (50 - 60) Jahre) (M.ITTifiFR 1987. 80). 
Die soziale Ungleichheit stellt ein traditionelles Forschungsobjekt dar. Bereits in der antiken Philosophie und in der frühchristlichen Theologie beschäftigten sich Denker mit den .Angesehemen und lerachreten, Reichen und Armen. Mächtigen und Ohnmächtigen" (WIEHN 1987, 109). Diese sozialen Dichotomien spiegeln sich auch in den ersten soziolinguistischen Ansätzen der 60er Jahre wider. Die Bernsteinsche Aufteilung der Sprecher in Träger des .elaborierten" und ,restringierten" Kodes (BERNSTEIN, 1972) ist auf die traditionelle Aufteilung zunuckzufuhbren. In der modernen Soziolinguistik wird die Problematik der vertikalen Stratifikation viel komplexer und unter Berücksichtigung zahlreicher Klassifikationskriterien behandelt. Von einer strengen Trennung zwischen einzelnen sozialen Gruppen wird dabei immer öfter abgesehen (WIEHN 1987, 112).

Für die Auswertung der Daten in dieser Studie ist lediglich eine vertikale soziologische Variable relevant: der erreichte Bildungsgrad der Respondenten. Unterschieden werden drei Kategorien: ohne Abitur, mit Abitur und Hochschulabsolventen. Von einer detaillierten Abstufung sowie von der Fachrichtung der Ausbildung - technisch, kaufmännisch etc. - wird abgesehen. Ausnahme bilden Schüler und Studenten. Bei dieser Sprechergruppe wurde die Schul- bzw. Studienfachrichtung berücksichtigt ${ }^{70}$.

In Westböhmen wurden im Frühjahr 199815 Studenten, 5 Schüler und 46 Sprecher verschiedener sozialer Gruppen interviewt und an der indirekten Enquete beteiligt In Prag waren es im Frühjahr 199915 Studenten und 24 Sprecher verschiedener sozialer Gruppen. Insgesamt beteiligten sich an unserer Untersuchung 105 Respondenten.

Graphische Darstellung 3a: Westböhmen

10

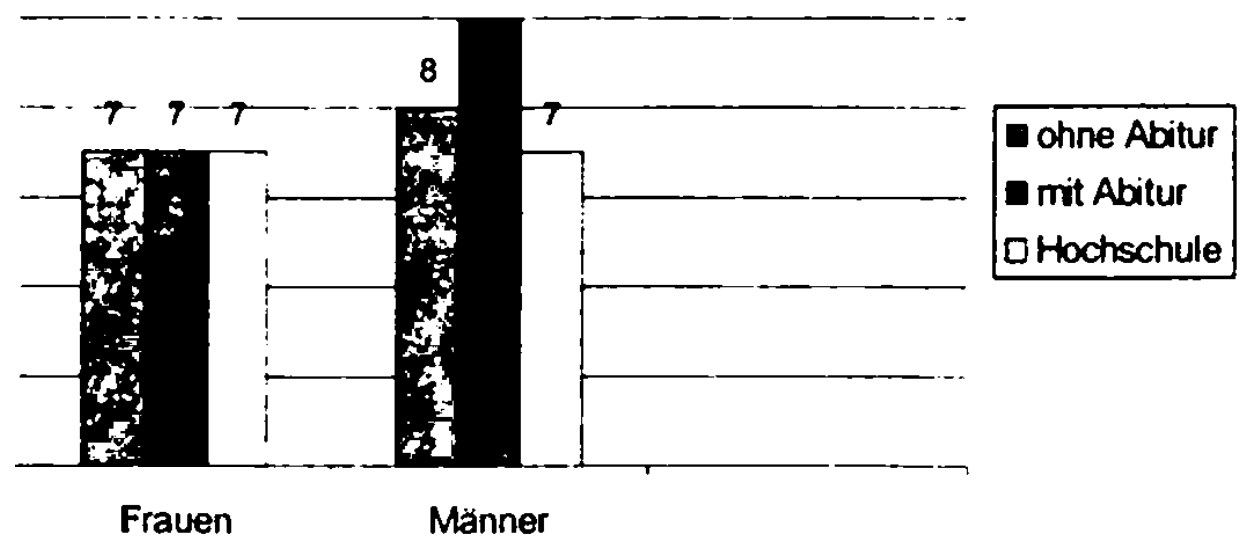

"Bei der Wiedergabe der Aufnahmen sowie der Angaben in den Fragebögen wird jeweils auch der Beruf angegeben. Bei der Auswertung bleibt dieser jedoch unbenicksiclitigt. Die vier Studentengruppen und eine Schulcrgnuppe werden dagegen auch fachrichtungsspezifisch ausgewertet und miteintandervergfietwen 0258 
Studenten der Geisteswissenschaften

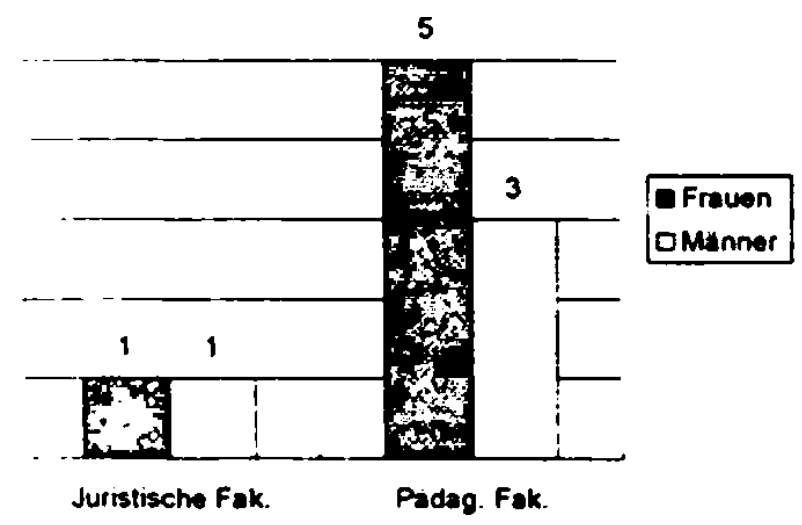

Graphische Darstellung 3b: Prag

Studenten der Geisteswissenschaften

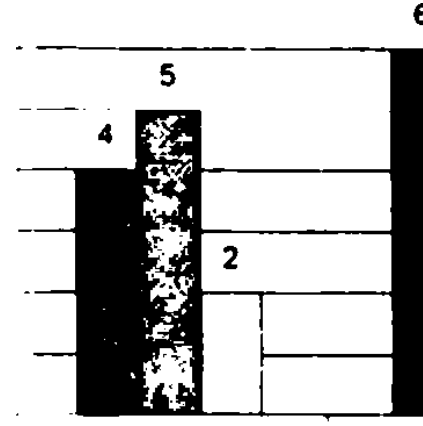

Fraven

6
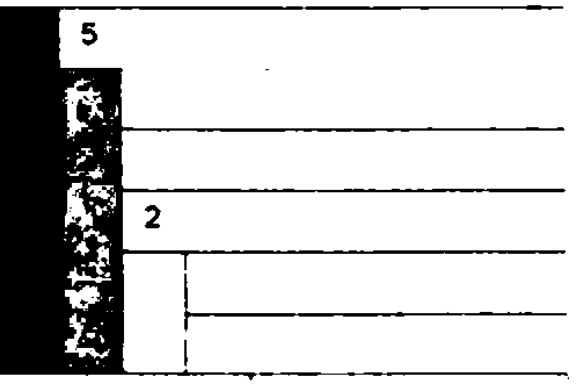

Ohne Abitur
mi Abrur
Oochschule

Manner

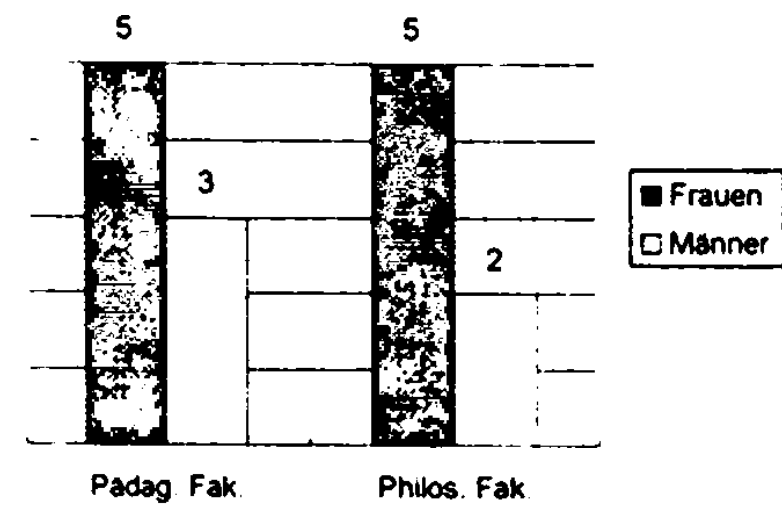

Studenten und Schüler, Technik

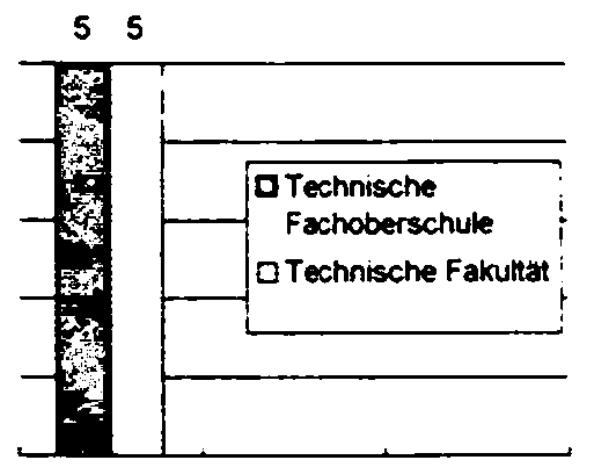


Die Schüler und Studenten wurden jeweils nur in einer formellen Situation unter dem Einfluß des spezifischen Setting ${ }^{71}$, direkt an ihrer Ausbildungsstelle, befragt. Sie werden separat ausgewertet und die einzelnen Gruppen unter ihnen in Verbindung mit den Variablen Region, Geschlecht, und Studienfachrichtung - verglichen. Die Schüler werden ebenfalls als eine separate Gruppe ausgewertet und in etwa der Kategorie mit Abitur zugeordnet.

\subsection{Regionen}

Im dialektologischen Standardwerk des Tschechischen unterscheidet J. BELIC (1972) die vier Haupt- bzw. Interdialekte des Tschechischen

Karte 1: Zàkladni rozvrženi českých náreči (BÉLIČ 1972, mapka ċ. 1)
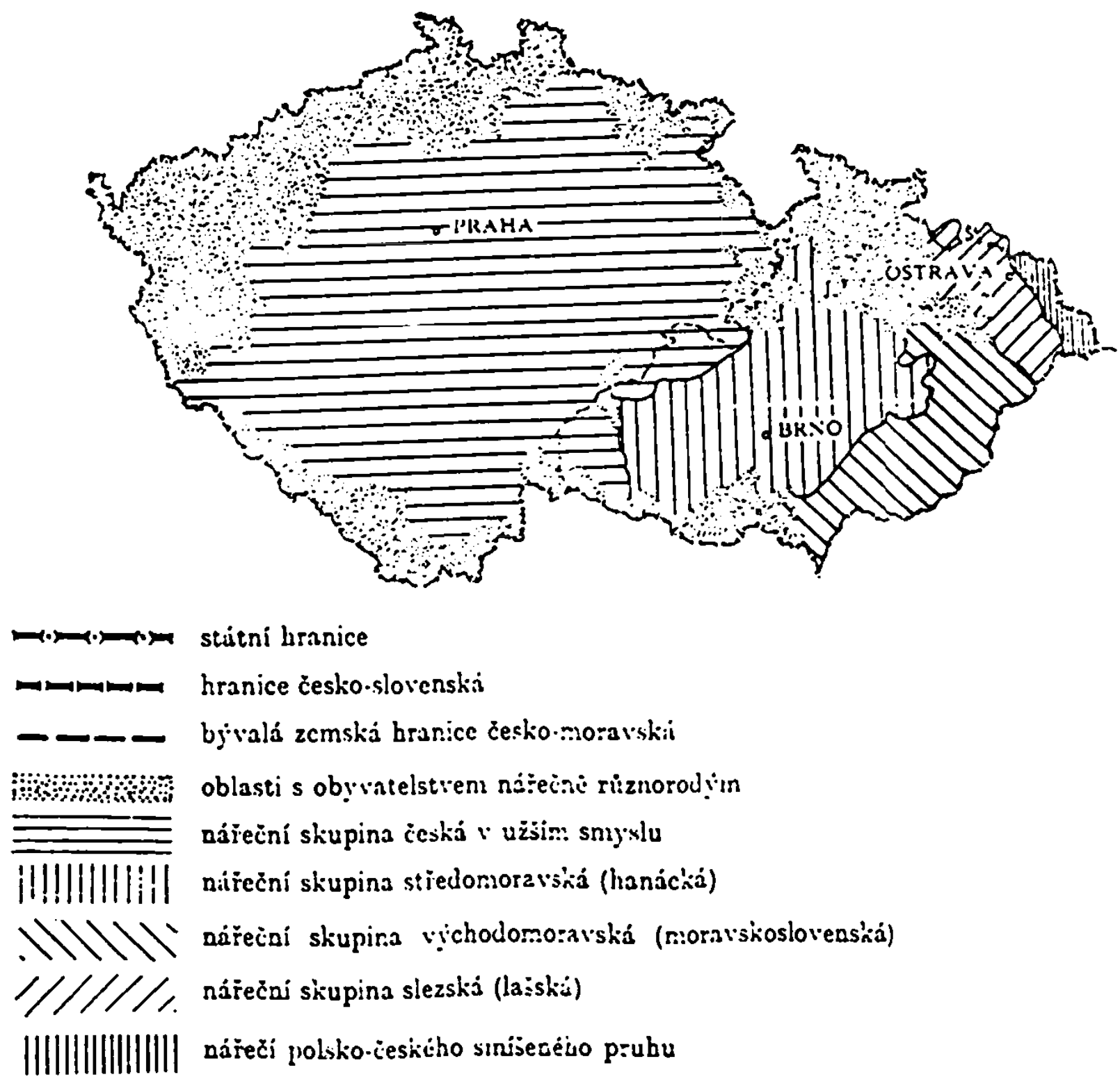

"Scltings werden in unserer Studic in Anlchnung an GIMPPER (1975. +9) als Lokalităın definicr. in dic Spreclicr iliren Lebensraum cintcilen (Heim. Arteilstelle. Ausbildungssiclle. Kirclie cic.). .Dies crmogylicht

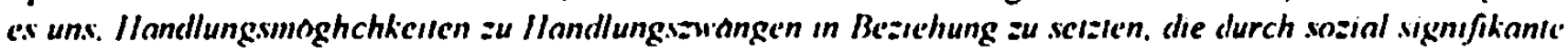

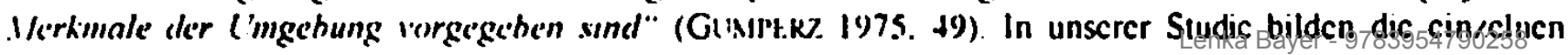
Scilings kcine Variablen 
Den bohmischen Interdialekt, „náréchi skupina ǐská v utsim smys/u" (BELLC 1972, 217). gliedert er weiterhin in vier regionale Mundarten - Zentral-, Nordost-. Südwestböhmisch und sprachliche Mischgebiete

Karte 2. Bohmische und mährische Mundarten (übernommen von HOLUB/JANECKOVA 1993, 51, modifiziert $)^{73}$

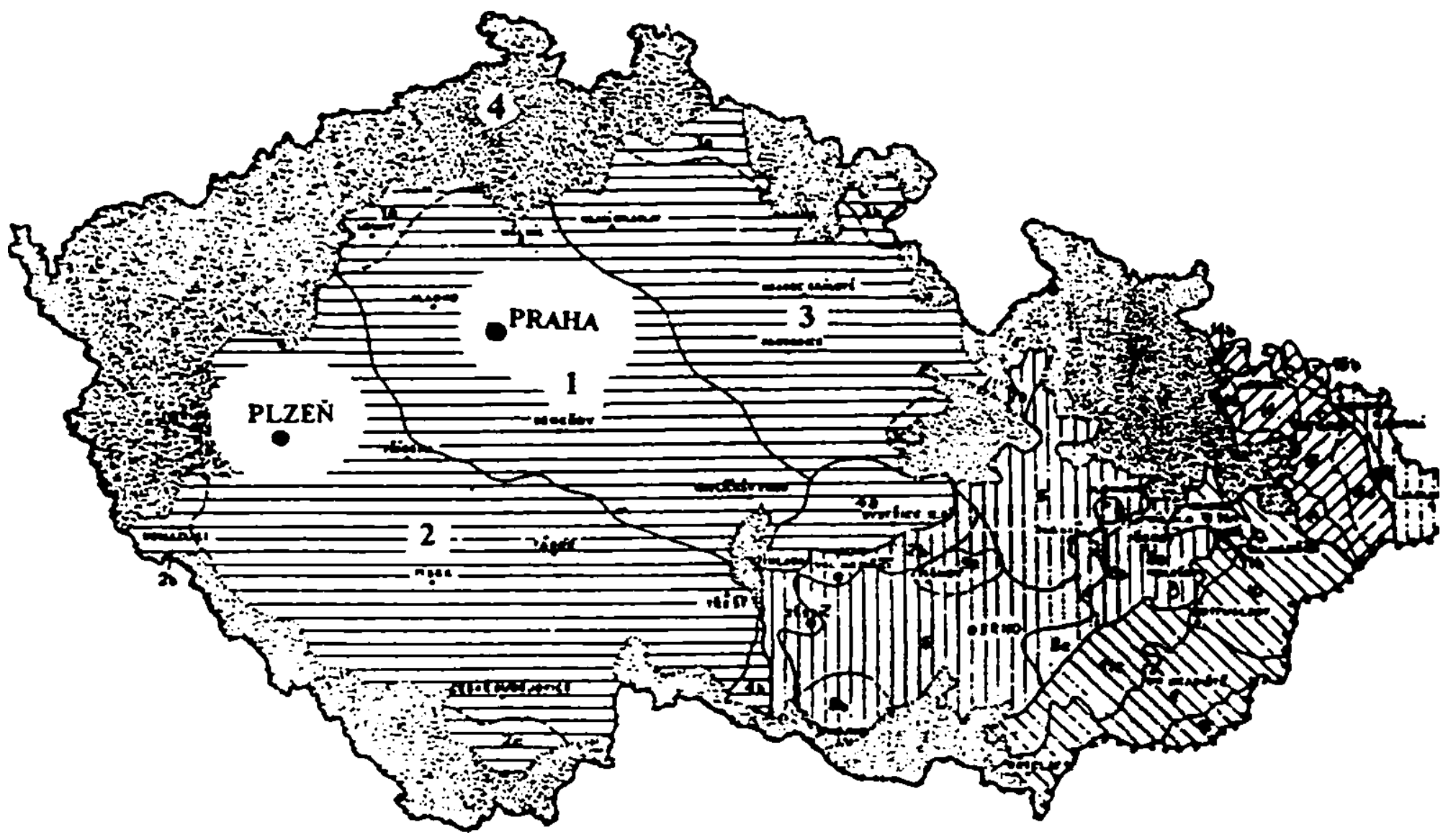

\section{Zentralbohmische Variante des GT}

2 Sudwestbohmische Variante des GT

3 Nordostbohmische Variante des GT

4 Sprachliche Mischgebiete

\footnotetext{
": Es lanndelt sich uin das urspringliche Sudetenland. das im 12. Jh. von den Deutsclien besiedelt wurde. Nach dem Zinciler Weltkrieg wurden diese Gebiete von Tseleechen aus verschiedenen Regionen sekundär besiedelt (Belic 1972.331).

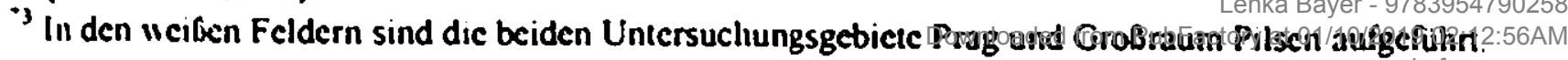


Die nur noch rudimentär erhaltenen böhmischen Mundarten unterscheiden sich in wenigen lexikalischen, morphologischen ${ }^{74}$ und syntaktischen Merkmalen ${ }^{75}$, die für unsere Studie irrelevant sind. Die für unsere Umfrage ausgewählten lautlichen und morphologischen Variablen sind in Böhmen überregional (Bél.lC 1972, $11 \mathrm{ff}$ ), so daß sie für die Untersuchung in den beiden Regionen verwendet werden konnten ${ }^{76}$ :

1. die Hauptregion: Großraum Pilsen (insg. 66 Respondenten)

2. die Kontrollregion Prag. (insg. 39 Respondenten)

Aus dialektologischer Sicht handelt es sich um die südwest- und zentralböhmische Mundart (BÉliC 1972, 224ff) bzw. Variante des $\mathrm{GT}^{77}$

Graphische Darstellung 4: Respondentenanteile in den untersuchten Regionen

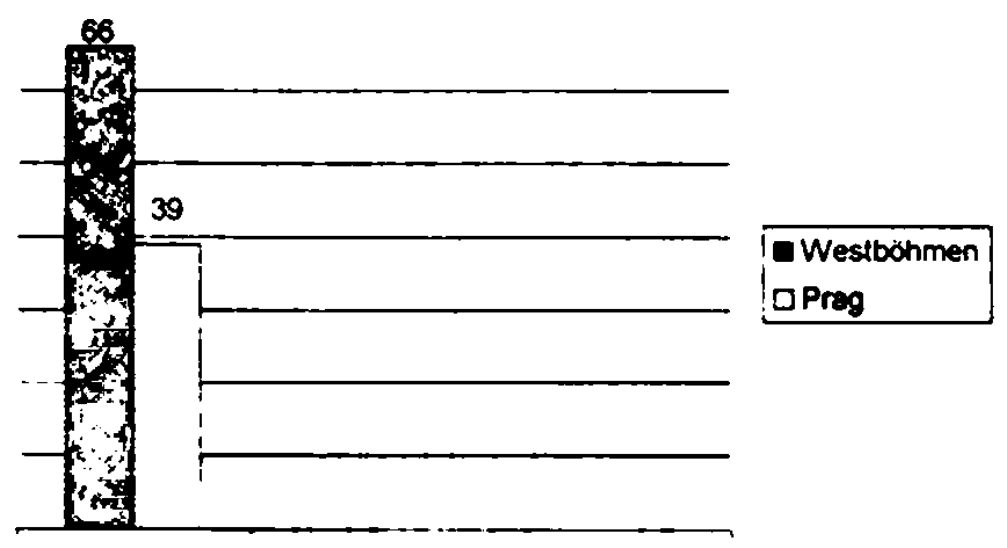

Da unsere Feldstudien in Prag und im Großraum Pilsen, der größten westbohmischen Stadt. durchgefünt wurden, bilden die Unterschiede zwischen Stadt- und Landsprache, obwohl auch Sprecher einiger anliegender Gemeinden befragt wurden, in der vorliegenden Untersuchung keine Variablen ${ }^{78}$.

${ }^{-}$Ein signifikantes Merkmal ist das starte Posscssivadjektiv ovo statt - in: ova. ovo in Südwestböhmen (BELI.IC 1972. 225).

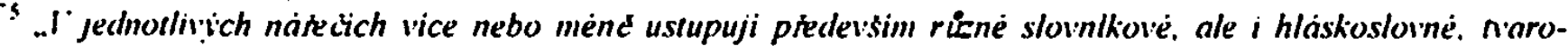

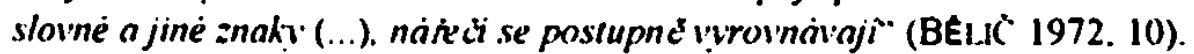

"Im neiten Sinne könnten dic Ergebnisse unserer Studic auf das ganze bolımische Sprachgebict übertragen werden

SG.U.1/ Hronex (1992. 20) teruenden diesen Begriff sỵnonym zur Bezcichnung bohlınische Mundarten.

- Durclı die Zentrallage und -funktion Prags und durcli den Einfluß größerer Industriestädte. zu denen auch Pilsen geliör. wurden in Bölımen die Unterschiede zwischen der Stadt- und Landsprache minimalisiert: .. I

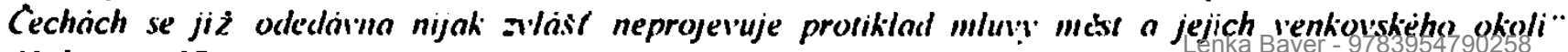
(UTESENI 1979. 167). 


\section{Untersuchungs- und Auswertungsmethoden}

\subsection{Einstellung: schriftliches Befragen}

Schriftliche Befragungen zählen zu den in der psychologischen und soziologischen Forschung am meisten angewendeten Untersuchungsverfahren: In den Sozialwissenschaften werden seit 1865 sozialstatistische Erhebungen per Fragebogen durchgefuihrt (WILDGEN, 1987, 46), in der Persönlichkeitspsychologie stellt der Fragebogen das wichtigste Instrument für die Persönlichkeits-Eigenschaften-Untersuchungen dar und in der Sozialpsychologie bildet er in erster Linie die Grundlage für die Erforschung der Einstellungen und Einstellungsänderungen (MUMMENDEY, 1987, 14).

Die Sprachwissenschaft bediente sich der Methode der schriftlichen Befragung lange Zeit fast ausschließlich im Bereich der Dialektforschung. Erst nach der Entstehung der interdisziplinär ausgerichteten Soziolinguistik werden von den Sprachwissenschaftlern zunehmend soziologische und psychologische Methoden übernommen" und somit auch die Methode der schriftlichen Befragung. Grundsätzlich kann schriftliches Befragen in drei Kategorien unterteilt werden

1 Bei der Fragebogenmethode „werden den antwortenden Personen (...) sprachlich klar strukturierte Vorlagen zur Beurteilung gegeben. (...) Es geht niemals um Fragen, deren Beantwortung offen ist, sondern es geht stets um das Ankreuzen festgelegter Antwortmoglichkeiten auf klar vorgegebene Fragen oder Feststellungen" (MUMMENDEY 1987, 15f).

2. Die schriftliche Befragungsmethode beruht dagegen auf dem Prinzip Frage - Antwort. Die Beantwortung jeder Frage ist offen.

3. Der schriftliche Test wird ,in der Regel mit Hilfe quantitativer, vom Testbemutzer umahhängiger Methoden entwickelt, geskort und imterpretiert" (MUMMENDEY 1987, 19)".

In unserer Untersuchung dient das schriftiche Befragen als Instrument für die Messung der kognitiven. affektiven und konativen Subsysteme der Einstellung. Obwohl wir für die Grundlage der schriftlichen Befragung den Begriff Fragebogen ${ }^{81}$ verwenden, handelt es sich de facto um eine Kombination aller drei oben aufgefürten schriftlichen Meßverfahren. Die in unserem Fragebogen dem Respondenten vorgelegten Aufgaben waren:

1. einen Sprachtest durchführen,

2 einige Fragen frei beantworten und

3. vorgegebene Antwortmöglichkeiten markieren

\footnotetext{
${ }^{-9}$ In den liordergrund treten die Probleme der lenurklichung der ständigen gesellschafilichen Kuntrolle in den Bereichen des Funktionierens und der Ennicklung der Sprache sowie die gegenseitige Beeinflussung ivon Sprachen. die Fragen der Prognostizierung. der Planung von sprachlicher Ennvicklung. die unter schwierigen Bedingungen ablaufen und enorme Dimensionen aufieisen. Alles das machte es erforderlich. die Soziolinguistik zu schaffen und weiterzuennwickeln, d.h. eine neue Disziplin, einen neuen .Ispekt des sprachlichen Lehens der Gesellschaft. der verschiedenen sozialen Einheiten sowie der gesamten .1Jenschhell. eine Dissiplin. in der die Haupibedeutung den sozialen Faktoren sowie den inneren Ennwicklungs- und Funkilionsgeserzen der Sprachen bergemessen wird (DESERIEY 1987. 3).

" In der Linguistik und v.a. im Bereich des praktischen Sprachunterrichts werden Sprach- bzw. GrammatikICsis hăufig als Mittel fur die Sprachkenntnisbeurteilung verwendet.

" Der komplette Fragebogen ist diescr Studie als Anlage beigefügt. 
Bereits im präexperimentellen Stadium wurde sowohl der Befragungsablauf als auch die Grundlage der Enquete sorgfaltig geplant und vorbereitet. Damit alle Anforderungen der Enquete von den Respondenten vollständig und gewissenhaft erfült werden, wurden folgende Regeln aufgestellt und während der Befragung konsequent eingehalten ${ }^{8:}$ :

1. Die einzelnea Punkte des Fragebogens wurden klar und allgemein verstandlich formulien.

2. Für die Bearseitung der Fragebögen wurde jeweils eine solche Situation gewählt, in der sich die Respondenten gut konzentrieren konnten.

3. Die Respondenten wurden vor der schriftlichen Befragung seitens des Interviewers motiviert, dibei wurde die strenge Anonymität der Enquete betont. Im Falle einer mangelnden Motivation seitens des Respondenten wurde auf die Befragung verzichtet.

4. Die Fragebozen wurden jeweils ausschließlich in Anwesenheit des Interviewers ausgefüllt, so daß es des Respondenten jeder Zeit möglich war, Rückfragen zu stellen.

5. Für die Bearseitung wurde kein Zeitlimit gesetzt.

Der Fragebogen für unsere Untersuchung besteht aus 5 DIN A4 - Seiten. Der Überschrift

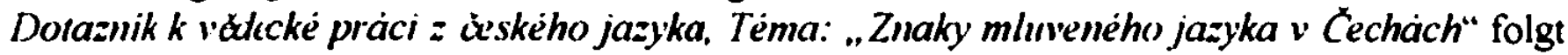
die Bitte um ene sorgfältige Bearbeitung der einzelnen Punkte und eine Danksagung im voraus:

Prosime rsechny icinstmiky tero akce o svałomite zpracoväni tohoto dotazniku a o uvedemi prandivych iddajü Predem diknjeme všem za vynaložnou námahu a obcrovany' ias.

Sindenii filozoficke fakulty (obor bohemistika)

Einen wichtiget Bestandteil des Fragebogens bilden persönliche Daten, die der Respondent, nachdem ihm atsolute Anonymität zugesichert wurde, in ein Kästchen eintragen sollte

„Naje anketc je naprosto anomymmi, jen náskedujici ridaje json pro yyhodmoceni doraznik velmi düle zixi:"

stîñ:_let pohlavi: ixnskej $O$

$m u$ skie $O$

povolani:

$\begin{array}{lll}\text { vzldaini: } & \text { základni } & \text { o } \\ & \text { středni (maturita) } & O \\ & \text { vysokoskolské } & O\end{array}$

bydlište v poslalnich 15 letech:

misto narozeni (mésto, oblast)

\begin{tabular}{|c|c|}
\hline$o d$ & (1) \\
\hline $\mathrm{ox}$ & (b) \\
\hline$(x)$ & (1) \\
\hline$(x)$ & (4) \\
\hline$(x)$ & (1) \\
\hline & \\
\hline
\end{tabular}


Diese Daten dienen der Unterteilung der Respondenten in Gruppen nach dem Kriterium der soziologischen und diatopischen Variablen. Sie werden bei jedem Respondenten angegeben. Die Angabe des Wohnorts in den letzten 15 Jahren war ein wichtiges Kriterium für die Auswahl der Respondenten. Nur solche Respondenten, welche seit mindestens 10 Jahren in dem untersuchten Gebiet wohnten, wurden in unsere Studie aufgenommen und deren Daten ausgewertet. Nach der Angabe der persönlichen Daten folgten:

1. ein Sprachtest für die Untersuchung des kognitiven Subsystems der Einstellung.

2. Fragen sowie ein tabellarisches multiple choice Verfahren für die Untersuchung des kognitiven, affektiven und konativen Subsystems der Einstellung.

Zum Abschluß des Fragebogens wurden die Respondenten aufgefordet, ihren Kommentar zu unserer Enquete sowie zur sprachlichen Situation im Tschechischen abzugeben:

V'elmi by nás pot Ėilo. kdybyste nám napsali Vás osobni názor na tuto anketu a na sonciasnou situaci v destine. Co byste ly osobne v deśtine zmenili a co se Vám libi. Budeme läm vdechi za każdy komentát a rádi prijmeme jakoukoliv kritiku.

Diese Kommentare werden zusammen mit einigen Beobachtungen während aber auch außerhalb der Enquete berücksichtigt, um die Relationen Sprachgebrauch vs. sprachliche Einstellung im Tschechischen zumindest ansatzweise zu erklären.

Um Einstellungen messen zu können wurden in der Geschichte der Sozialpsychologie zahlreiche Modelle zur F.rstellung von Finstellungsskalen ${ }^{83}$ entwickelt. Das Ziel solcher Modelle war festzustellen, wie stark negativ oder positiv eine Einstellung ist bzw. wie sie sich auf der diachronischen Achse entwickelt (HERKNER 1981, 215). Eine der bekanntesten und am weitesten verbreitete Methode zur Einstellungsmessung - auch auf unsere Untersuchung anwendbar - ist die personenorientierte Meßmethode .. subject-cemtered approach", die die individuellen Unterschiede zwischen den Versuchspersonen interpretiert (PETERMANN 1980, 99). Innerhalb dieser Konzeption etablierte sich in erster Linie die von LIKERT begründete Merhode der summierten Einschäzungen ${ }^{84}$ :

In einem Fragebogen muß zunächst eine ausreichende Anzahl von Items zusammengestellt werden. In der Regel sind es 80 bis 120 . Jedem Item werden dann je nach Charakter bis zu funf Antworkategorien zugeordnet (PETERMANN 1980, 99f):

völlige Ablehmung

Ablehming

unentschieden

Zustimmung

völlige Zustimmmung

${ }^{83}$ Eine Einstellungsskala ist cine Liste von Fragen und/oder Feststellungen (Items) in Bezug auf ein Einstellungsobjekt. Die Person. deren Einstellung zu einem bestimmten Objekt gemessen wird. muß bei jedem Item der Einstellungsskala angeben. ob sie diesen bejaht bzw. akzeptiert oder verneint bzw. ablelınt. Aus der Anzahl und Art der akzeptierten und abgelchnten ltems kann dann auf die Riclitung (posıtiv oder negativ) und Stärke der untersuchten Einstellung geschlossen werden (HF.RKN.F.R 1981. 216)

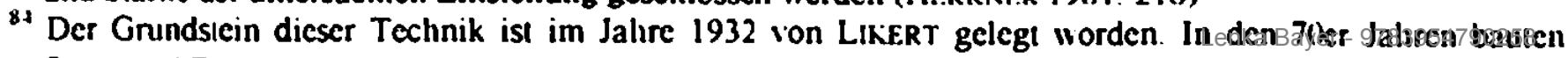

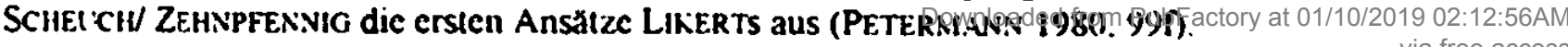


Den einzelnen Antwortkategorien werden dann die Zahlenwerte 0-5 zugeteilt. Du:ch die Addition der fur die einzelnen Items erreichten Punktwerte wird daraufhin ein Gesam:punktwert für jeden Respondenten errechnet. Je höher der Gesamtpunktwert, um so positiver die Einstellung des Respondenten gegenüber dem Einstellungsobjekt (MUMMENDEY 1987, 7 Iff).

Die Methode der summierten Einschätzungen sowie weitere in der Sozialpsychologie verwendete Methoden zur Einstellungsmessung ${ }^{85}$ beziehen sich primär auf das EinKomponenten-Modell der Einstellung, d.h. sie bewerten ausschließlich das affektive Subsystem der Einstellung. Der Auswertung in dieser Studie liegt jedoch das Drei-Komponenten-Modell zu Grunde. Dies bedeutet, daß alle drei Subsysteme der Einstellung zum ST, bedingt auch zum GT, ausgewertet und graphisch dargestellt werden. Im Vordergnund steht dennoch die Bereitschaft, das Standardtschechische im mundlichen Gebrauch zu verwenden - das konative Subsystem der Einstellung.

\subsubsection{Das kognitive Subsystem}

Das kognitive Subsystem der Einstellung bezieht sich auf das Wissen, die Überzeugungen und Meinungen, die ein Individuum mit einem Einstellungsobjekt verbindet. Es wird mit Hilfe kognitiver Urteile operationalisiert. Solche Urteile enthalten Aussagen, die eine objektive oder wenigstens intersubjektiv vergleichbare Grundlage haben. Für die Bildung kognitiver Urteile sind externe Informationsquellen sowie die interne Disposition eines Individuums, Informationen wahrzunehmen und zu interpretieren, verbunden (KLAUER 1991, 2). Da der Mensch nur im begrenzten Maße Informationen aufnehmen, verarbeiten und speichern kann, verfugt er uber komplexe Selektionsmechanismen, die darüber entscheiden, welche Informationen aufgenommen und gespeichert werden bzw. welche unbeachtet bleiben. Demnach kann das kognitive Subsystem der Einstellung erst dann entstehen, wenn das Einstellungsobjekt:

1. sensorisch aufgenommen wird,

2 durch das Selektionssieb bis ins Bewußtsein durchdringt

3. und dort wahrgenommen und gespeichert wird

Der Ablauf der Selektions- und Wahrnehmungsprozesse wird von internen Denkprozessen determiniert. Sie bestimmen die individuelle Interpretation einer Wahrnehmung und der mit ihr verbundenen Qualitat des kognitiven Subsystems der Einstellung (HFRKNFR, 1981, 238)

Mit dem Erlernen und sicheren Beherrschen der Standardsprache in Wort und Schrift sind komplizierte Selektions- und Denkprozesse verbunden, die vorwiegend während der sekundären Sozialisation ablaufen. In der Schule sollten die Schüler nicht nur den praktischen Umgang mit der Standardsprache üben. Sie sollten hier auch theoretische Basiskenntnisse über die Standardsprache. nichtstandardliche Varietaten der Nationalsprache sowie Sprachstruktur. Sprachgeschichte, Sprachgeographie etc. erwerben.

Das schriftliche Befragen, das in unserer Studie fur die Messung des kognitiven Subsystems konzipiert wurde, gliedert sich in zwei Teile. Im ersten Teil wurden praktische Kenntnisse im

\footnotetext{
"Mcthode der gleicliabständigen Intenalle. Methode der kumulatıen Skalicrung dis semanujsclyg Differen-
} tial (TiK) IIS 1991. 137m). 
Umgang mit dem schriftlichen Standardtschechisch untersucht, im zweiten Teil sollten die Respondenten 5 einfache theoretische Fragen über das Tschechische beantworten.

Um die praktischen Kenntnisse im schriftlichen ST zu untersuchen, wurde den Respondenten ein kurzer Sprachtest vorgelegt. Sie sollten den folgenden Text, der insgesamt 23 Fehler beinhaltet, nach ihrem eigenen Ermessen korrigieren:

Pŕedstavte si, že jste učitel nebo učitelka, a že máte opravit následujici text - jsou y něm totiž cluyby:

Naši mástský pożärnici koupili tỉ nové požärnické auta $s$ nanyjjecima hadicema a poloautomatickymi regulatorami tlaku vody.

Starosıa mesta rekl v rozhlası: „.Naši chlapci pracujou nad miru spolehlivè. jsme stastıý. ze je máme. a jsme ma né velmi hrdy. Mé osobnè se libi jejich objetanost. l'elmi jsi váz̈m jejich präce, vătyd" oni chräni naše mésto pred vohnén a zachrañujou lidský žvoty. Bez nich bysme nemdy klidnej z̈vor. Doufám. žx si budeme i nadàle dob ré rozummer.

Die Fehler werden in zwei Kategorien unterteilt:

1. Kategorie: Ausdrücke mit untersuchten lautlichen und morphologischen gemeintschechischen Variablen (siehe Kap. 3).

\begin{tabular}{|c|c|}
\hline falsch & richtig \\
\hline$m c s t s k \dot{~}$ & $m e^{s} s t s ̌ t i ́$ \\
\hline nov'é & nová \\
\hline pojárnické & pozárnická \\
\hline navijecima & navijecimi \\
\hline hadicema & hadicemi \\
\hline regulàror'ami & regulàtory \\
\hline pracujou & pracuji \\
\hline sfasimý & stastni \\
\hline$h r d y$ & hrdi \\
\hline vătyim & vázím \\
\hline vohncm & ohnem \\
\hline zachrañujou & \begin{tabular}{|l} 
zachrañují \\
\end{tabular} \\
\hline liclski & lidské \\
\hline bysme & bychom \\
\hline klidmej & klidmý \\
\hline
\end{tabular}

2. Kategorie: Rechtschreibfehler auf dem Niveau der abgeschlossenen Schulausbildung ohne Abitur

\begin{tabular}{l|l} 
falsch & richtig \\
\hline navyjecima & navijecimi \\
\hline nad miru & nadmiru \\
\hline
\end{tabular}




\begin{tabular}{l|l}
\hline falsch & richtig \\
\hline me & mnd (im Dativ) \\
\hline objetcnost & obdtavost \\
\hline jsi & si \\
\hline vzdyd & vżdyt \\
\hline ncmely & nemeli (Belebtheitskategorie) \\
\hline rozumndt & rozumet \\
\hline
\end{tabular}

Die Bewertung der theoretischen Kenntnisse erfolgte nach dem Prinzip der schriftichen Befragungsmethode. Die Respondenten sollten fünf Fragen schriflich beantworten:

\section{Prosime Vais o zolpovečeni následujicich otázek:}

Kcty si myslite, ze venikla spisomia cestina?

Kdo zaloz̆l spisonnou céstimu a na jakè základe?

Jakà náréci existıji na Mora'c??

Jak se mazyva mlwieny nespisomý jazyk. klerym se mhwi v Cechäch?

I kleri ohlasti v Cechäch nebo na Moran'e se mhivi jen spisovne?

In unserer Studie wurde die Erfassung des kognitiven Subsystems um einen zusätzlichen Aspekt erweitert um die subjektive Evaluation der eigenen - v.a. in der Schule erworbenen Kenntnisse im Bereich des mündlichen und schriftichen Standardtschechisch. Den Respondenten wurden im Fragebogen vier Fragen gestellt, die sie nach der Fragebogenmethode mit ja oder ncin beantworten sollten. Die Antworten auf dicse cvaluativen Fragen dienen zum Vergleich mit der tatsächlichen untersuchten Kognition im ST. Sie werden separat ausgewertet und graphisch dargestellt:

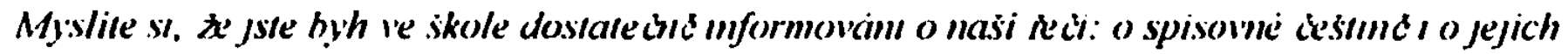
ne.spisomyich formách, o vanikil a vivoji cx.s.tiny?
() ano
One

Myslite si. ¿x jste se ve skole nancili dobre ovladat pisemnou formu spisov'me ceštilly?"
$O$ ano
O ne

Myslite si, ¿̇̉ jste se ve skole naucili dobre ovladat mluvenou formu spisovie cestiny?
$O$ ano
$O$ ne

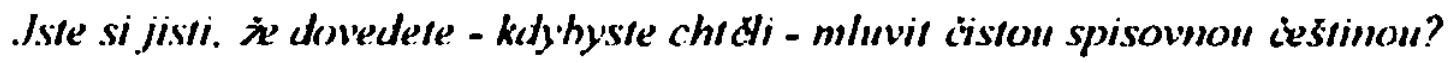
$O$ ano
One

Fur die Auswertung des kognitiven Subsystems wurden in unserer Untersuchung zusätzlich zur Anwendung der Methode der summierten Einschärzungen folgende methodische Erweiterungen vorgenommen:

Der Sprachtest als das Kriterium für die Bewertung der praktischen Kenntnisse im ST (Praxis) wurde nach einer mathematischen Formel ausgewertet, die sowohl die Kognition auf der Ebene der gemeintschechischen Variablen (ST vs. GT) als auch auf der Ebene der 
Orthographie (Orthogr.) berücksichtigt. Da die Kognition in der ersten Kategorie (ST vs. GT) im Vordergrund dieser Arbeit steht, wird sie zur zweiten Kategorie (Orthogr.) in Relation 2:1 gerechnet:

$$
\begin{gathered}
\text { Kognition in der Praxis (Prozentangaben) } \\
(\text { Praxis })=\{2 \times[(\text { erkannt in STvs.GT }): 0,15]+[(\text { erkannt in Orthogr. }): 0,08]\}: 3
\end{gathered}
$$

\section{Demonstration am Beispiel:}

Ein Respondent erkannte (markierte) von den insgesamt $15(=100 \%)$ gemeintschechischen (zu markierenden) lautlichen bzw. morphologischen Items 10 und von den insgesamt 8 falsch aufgeführten orthographischen Items $(=100 \%) 2$. Nach der obigen Formel ergibt sich folgende Berechnung: Der Respondent erkannte das Einstellungsobjekt im ersten Fall (ST vs. GT) zu 66.7\% und im zweiten Fall (Orıhogr.) zu 25\%. Die gesamte Kognition im praktischen Bereich (Praxis) ergibt der obigen Formel nach:

$\{2 \times 66,7+25\}: 3=52,8 \%$

Zur besseren Demonstration der Ergebnisse wird nach jeder Berechnung der Angaben jeweils eine graphische Auswertung aufgefuihrt: Die Angaben unter erkamm geben den Grad der Kognition wieder (in der Grafik werden die Zahlen nach dem Komma jeweils ab- bzw. aufgerundet):

Graphische Darstellung des obigen Beispiels:

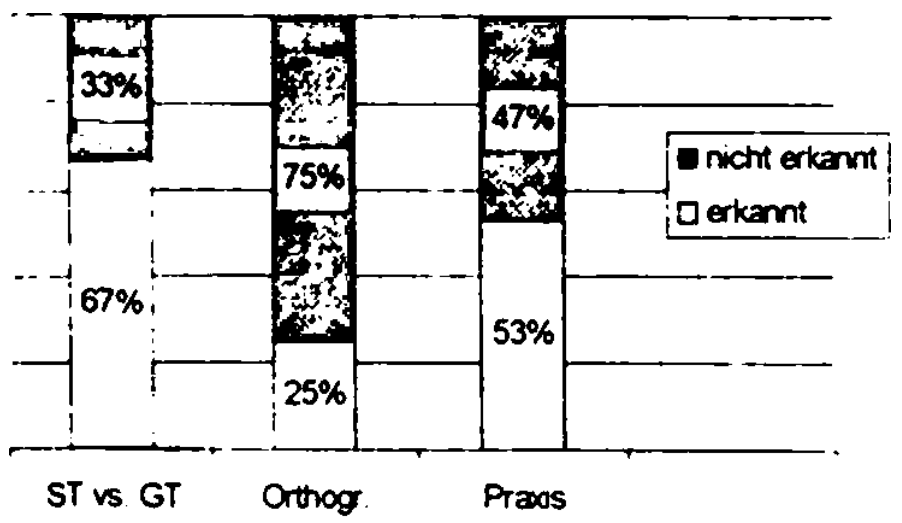

Die funf theoretischen Fragen in Form der schriflichen Befragung dienten als Kriterium für die Bewertung der Kognition im theoretischen Bereich der Standardsprache (Theorie). Für diese Auswertung wurde die Methode der summierten Einschätzungen verwendet. Jede Frage wurde mit einer Punkteskala versehen:

Kdy si myslite. tze vinikla moderni spisonna à.štima?

4 Punkte: 1809, 1819. zaciarlek 19. stoleti

3 Punkte: 19. siol., v dobe deskeho obrozeni

2 Punkte 16. stol., cesky humanizmus

I Punkt: 15. stol., doba husitska

0 Punkte andere Antworten 
Kdo zalożl spisovmou čeśtimm?

4 Punkte: Dobrovski

3 Punkte: Jingmaim!

2 Punkte: humaniste (Blahoslav)

1 Punkt: Jan Hus

0 Punkte: andere Antworten

Jakà náre ii existuji na Morave?

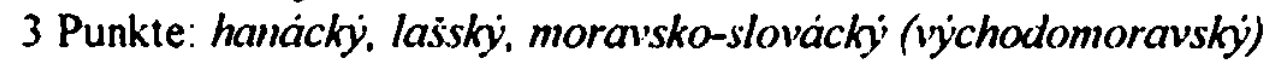

2 Punkte: zwei Angaben richtig

I Punkt: eine Angabe richtig

0 Punkte: keine Angabe/falsche Angaben

Jak se nazjva m/mvenyं nespisonyy jazyk, klerym se mhwi v Cechäch?

3 Punkte: obecriá óšrina

2 Punkte: mlinvená cesstina. hovorová iesśtina

I Punkt: stredoceská cesstina

0 Punkte: andere Antworten

¡kıeré oblasti v Cechách nebo na Morave se mluvi jen spisovne?

I Punkt: mikde

0 Punkte: andere Antworten

Bei der Berechnung der Kenntnisse im theoretischen Bereich des ST (Theorie) gingen wir von der hochsten Punktezahl (15 Punkte) als von 100\% aus. Sollte ein Respondent z.B. 7 Punkte erreicht haben, bewerteten wir seine theoretischen Kenntnisse (Theorie) als $46.7 \%$ (aufgerundet $47 \%$ ).

Wie bereits erwähnt, stellen wir den Ergebnissen im kognitiven Subsystem die subjektive Evaluation der eigenen Kenntnisse gegenüber. Bei der Auswertung der vier evaluativen Fragen wurde jedes ja mit jeweils $25 \%$ bewertet. Die komplette Auswertung im kognitiven Subsystem setzt sich aus folgenden Komponenten zusammen:

Einstellung, kognitives Subsystem:

Evaluation der eigenen Kenntnisse. (Beispiel für eine positive Beantwortung von zwei Fragen)
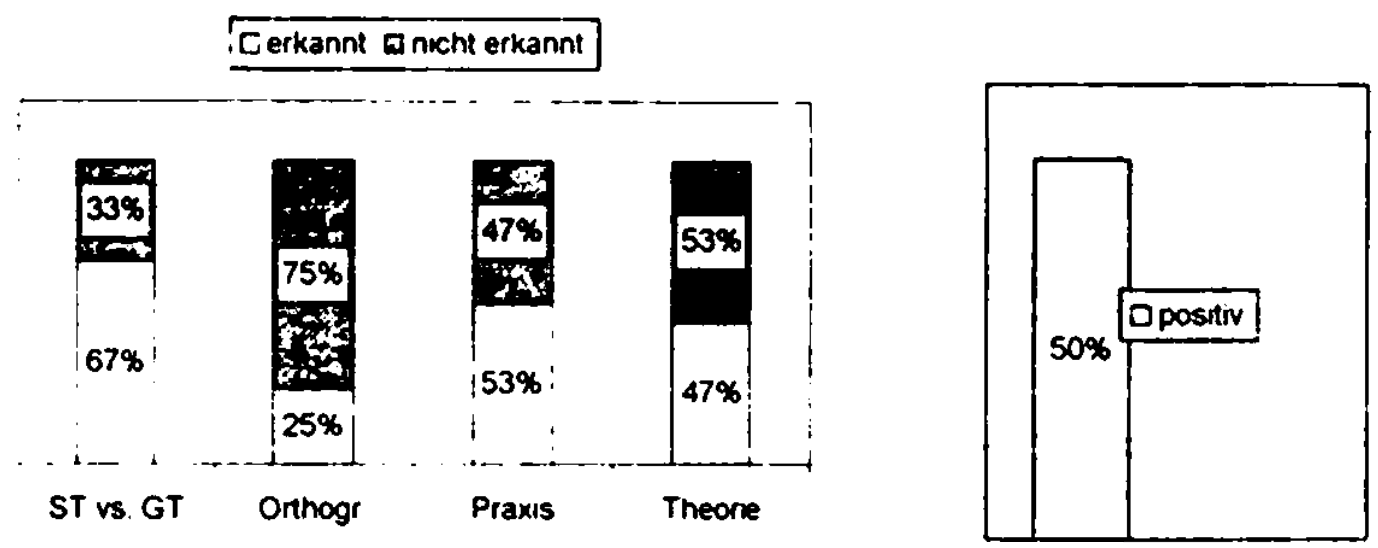


\subsubsection{Das afjektive Subsystem}

Das affektive Subsystem der Einstellung wird von der "Disposition der Person, sich ablehmend oder zlnvendend, mit positiv oder negativ getöntem Affekt. dem Einstellıngsobjekt gegemiber z" verhalten" (KLAUER 1991, 1). Es wird mit Hilfe affektiver Urteile operationalisiert. Affektive Urteile sind wertende Urteile, die ein Einstellungsobjekt nach subjektiver Sympathie bzw. Antipathie einordnen. Die Herausbildung des affektiven Subsystems der Einstellung korrespondiert mit dem kognitiven Subsystem. Nach dem Modell von SHIFFRIN/ SCHINEIDER aus dem Jahre 1977 wird nach der Kenntnisnahme des zu beurteilenden Objekts sehr schnell und automatisch die affektive Konnotation aktiviert (KLAUER 1991, 27).

Die tschechische Standardsprache wurde bereits nach ihrer Entstehung im 19. Jh. zu einem wichtigen. mit positiven Attributen besetzten Politikum Die neu kodifizierte Sprache ermöglichte den Tschechen, sich innerhalb der Habsburger Monarchie als eine Ethnie zu präsentieren und ihren nationalen Stolz und Zusammengehörigkeit über die Grenzen hinaus zu demonstrieren.

Die wichtigen Momente in der tschechischen Geschichte in der ersten Hälfte des 20 Jhs. die Entstehung der Tschechischen Republik im Jahre 1918 und die Befreiung von der faschistischen Diktatur im Jahre 1945 -, denen ein erneutes Aufleben des tschechischen Nationalgeistes folgte, brachten die tschechische Standardsprache zu neuen Höhen. Stärker denn je wurde sie als das Symbol der nationalen Unabhängigkeit gelobt und besungen ${ }^{8 \mathrm{t}}$.

Am Anfang der 90er Jahre, kurz nach dem Fall des kommunistischen Regimes, wurden in einer Umfrage 41 Schuler eines Prager Gymnasiums nach ihrer Finstellung zum ST befragt. Obwohl - oder gerade deshalb - dies in einer Zeit der intensiven Öffnung nach dem Westen und den westlichen Sprachen geschah, äußerten sich die Schüler in jede Richtung positiv. Aus ihren Aussagen wird deutlich, daß die emotionale Verbindung zwischen der Standardsprache und der nationalen Identität der Tschechen - auch bei der jungen Generation - nach wie vor vorhanden ist (DANES/ CME.JRKOVA 1993, 25ff)

Unabhängig von den früheren Untersuchungen sollte in unserer Studie die indirekte und direkte Evaluation des ST ermittelt werden. Anhand von 5 Fragen, die der Respondent nach der Fragebogenmethode beantworten sollte, wurde der Grad der indirekten Evaluation des ST errechnet. Die letzte dieser funf Fragen zielt direkt auf die gegenwärtig innerhalb der Bohemistik diskutierte Reform des ST:

ladi läm. když̀ l'ämi cizi clov mlavi nespisone?

$$
\text { Oano One }
$$

I'adi läm. kdyzz televizmi a rozhlasovi hlasatele mlwi pri yysilami nespisovme?

$$
\text { O ano One }
$$

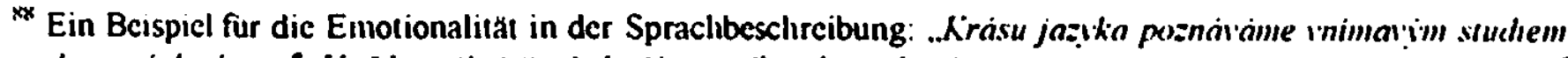

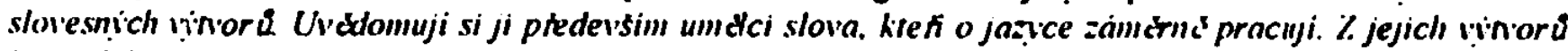

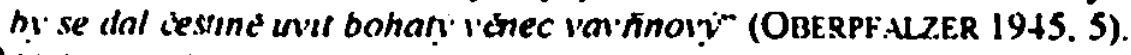

${ }^{* 9} \mathrm{Vgl}$ dazU: NEMEC 1993. 9-17. 


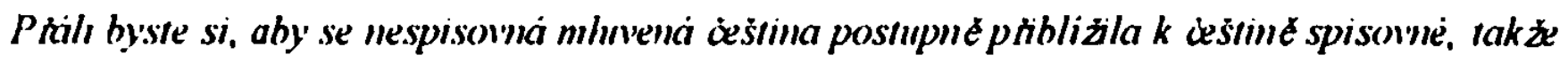
by' jedinon zanikla?

$$
\text { O ano One }
$$

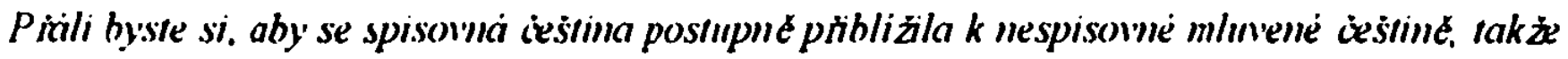
bychom jednou psali tak, jak dnes m/nnime?

$$
\text { Oano One }
$$

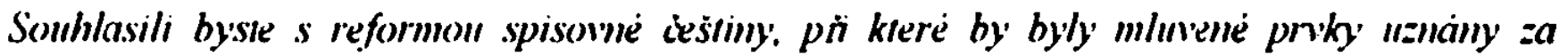
spison'me, rak ż by rozdily mezi spisommon a miln'enou cesstinou rychle zamikly?

$$
\text { O ano } O \text { ine }
$$

Die Markierung eines der vier Grade der Evaluierung des ST bildete die Grundlage für die Berechnung der expliziten Evaluation dieser Varietät. Kontrastiv wurde auf die gleiche Art die Evaluation des GT in Erfahrung gebracht:

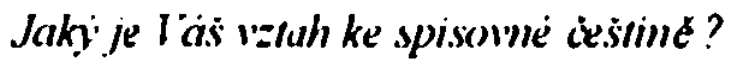

relmi pozinimio pozirimio nentrámio negainmio

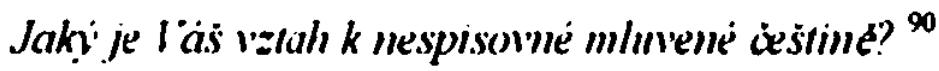

relmi posinimio pozllimio meutrálmio negativnio

Die Auswertung im affektiven Subsystem basiert auf der binaristischen Methode der summmierten Einschatzumgen von LIKERT ${ }^{9}$ Die funf Fragen (Items) zur indirekten Evaluation des ST wurden je nach Antwort mit einem Punkt bzw. 0 Punkten bewertet:

Iadi läim. ketyżs lämi cizi cilon'ck mhni nespisonme?

(ino I Punkt ne O Punkte

Iadi läm, kcţż televizni a rozhlasoni hlasatele mhni pri uysiläni nespisovme?

(ino I Punkt ne 0 Punkte

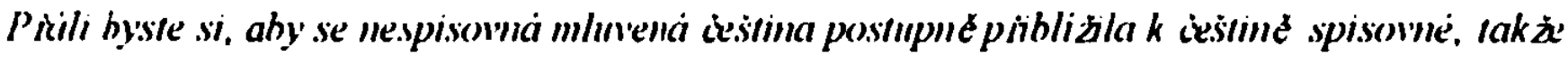
by jection zanikla?

ano I Punkt ne 0 Punkte

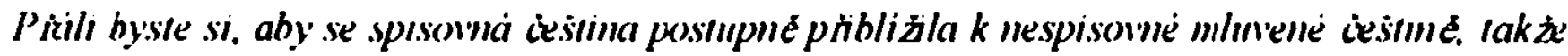
bychom jednou psali tak. jak dnes mhwime?

ano O Punkte me I Punkt

Somhlassli byste s reformon spisonme ixstiny. pï klere by byly mlwene proky uziany za

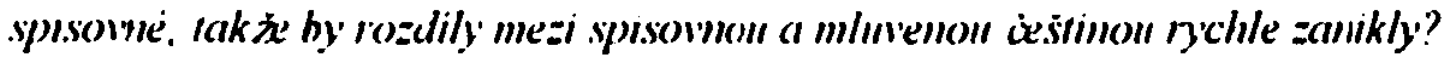

ano 0 Punkte me l Punkt

"Der Begriff ..ohecna ce.stma" Ist den meisien Tscheclien unbekannt.

" VgI PETERMANX 1980. \%)f 
Die explizite Evaluation des ST bzw. des GT wird nach der Methode der summierten Finschätzungen anhand einer einfachen Punkteskala ausgewertet und graphisch dargestellt:

Jakyj je l'ás valah ke spisovné (nespisovné mluvené) destine?

relmi kladmy 3 Punkte kladny 2 Punkte

neutrilmi 1 Punkt sáporny' 0 Punkte

Der Respondent konnte also bei der indirekten Evaluation des ST maximal 5 Punkte und bei der direkten Evaluation des ST bzw. des GT maximal 3 Punkte erreichen. Bei jeder Punktzahl gingen wir jeweils von $100 \%$ aus.

Beispiel:

Ein Respondent erreichte bei der indirekten Evaluation des ST 4 Punkte (80\%), bei der expliziten Evaluation des ST 2 Punkte $(66,7 \%)$ und bei der expliziten Evaluation des GT 1 Punkt $(33,3 \%)$ (in der Graphik werden die Zahlen nach dem Komma jeweils ab- bzw. aufgerundet):

Einstellung affektives Subsystem: Grad der positiven Einstellung

indir.Ev.ST: indirekte Evaluation des Standardtschechischen dir.Ev.ST: direkte Evaluation des Standardtschechischen dir.Ev.GT: dirckte Evaluation des Gemeintschechischen

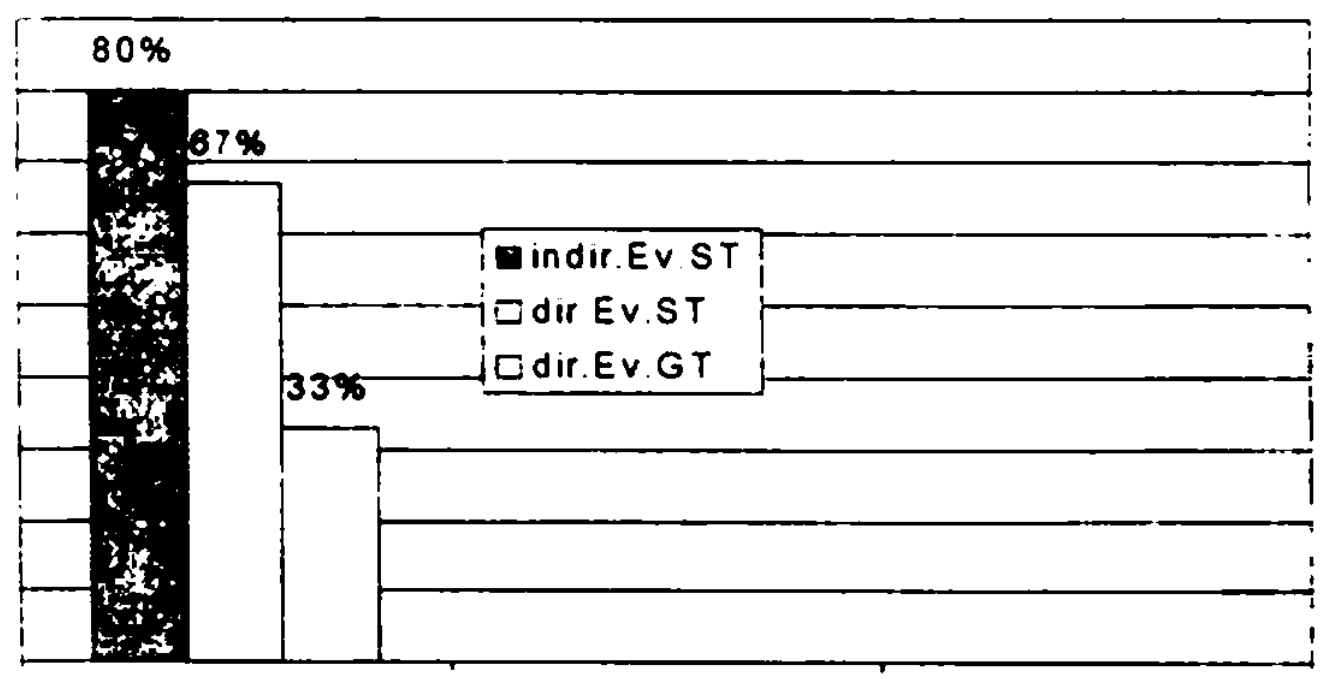




\subsubsection{Das konative Subsystem}

Das konative Subsystem der Einstellung stellt die Bereitschaft eines Individuums dar, auf eine bestimmte Art und Weise auf ein Einstellungsobjekt zu reagieren. Es besteht aus dem Selbstbild eines Individuums, so zu handeln, wie es denkt (BIERHOFF 1998, 210). Die Verhaltensintentionen können als Spezialfall von Meinungen aufgefaßt werden:

Dabei ist das Objekt der Meimungsbildung immer der Befragte selbst und das Attribut eime Ierhaltensweise. Die Stärke der Imemtion kam durch die subjektive Wahrscheinlichkeit, ein bestimmies lerhalten auszufuihren, angegeben werden. (SCHriFFIF: 1990, 12)

Wie bereits erwähnt, wird in unserer Untersuchung im Rereich der Einstellung dem konativen Subsystem die größte Gewichtung beigemessen. Die Bereitschaft der Respondenten das ST bzw. das GT anzuwenden":, steht unserer Auffassung nach im direkten Zusammenhang mit dem sprachlichen Verhalten derselben. Das primäre Ziel unserer Untersuchung ist, die beiden Variablen zu analysieren und kontrastiv nebeneinander zu stellen. Das Verhältnis der beiden Variablen stellt den thematischen Kern unserer Untersuchung dar.

Für die Untersuchung des konativen Subsystems erhielten die Respondenten folgende Instruktionen.

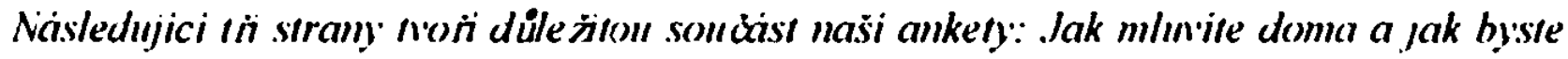

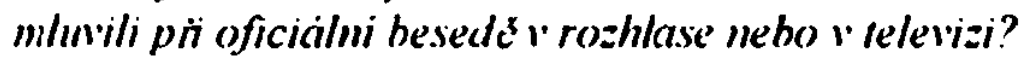

Den Respondenten wurden in Form einer Tabelle standard- und gemeintschechische Variablen vorgelegt. Sie sollten nach der Fragebogenmethode (multiple choice) markieren, in welchem Kontext sie das ST bzw das GT verwenden wurden. Als Orientienungshilfe diente ihnen das folgende Muster

Priklud vyplnčni:

\begin{tabular}{|l|c|c|}
\hline & doma & $\begin{array}{c}v \text { televizi /v } \\
\text { rozhlase }\end{array}$ \\
\hline $\begin{array}{l}\text { 1 dobrý vecicr } \\
2 \text { dobrej veicr } \\
\text { 3. misto pro Vaši osobni variantu, napí. } \\
\text { dobrej vecir }\end{array}$ & 3 & \\
\hline $\begin{array}{l}\text { 1. stare myddlo } \\
\text { 2. stary mejdlo } \\
\text { 3 (stary myddlo) }\end{array}$ & 3 & 1 \\
\hline
\end{tabular}

9: In unscrer Sludic in ciner informellen und clicer formellen Simbationtrom PubFactory at 01/10/2019 02:12:56AM 
Da die gemeintschechischen Ausdrücke mit orthographischen Mitteln des ST dargestellt werden $^{93}$, was für den Tschechen visuell irritierend sein kann, werden die Respondenten in dem Fragebogen gebeten, die Ausdrücke für sich auszusprechen um parallel zum visuellen auch den auditiven Ausdruck wahrzunehmen:

Nespisovné nary se lám jisté zdaji na primi pohied ponkud neziyklé. To je zpúsobeno tim. zo je nejste zuykli vnimat vizuálne. t.j. v pisemné podobe Proto je düleżié vyslovit si każty spisovmyं i nespisovny vyraz pro sebe nahlas, abyste ho vnimali akusticky. Pritom je mumé vcitit se v dané situaci (doma, pri besedè v rozhlase nebo televizi) do role miluvici osoby.

Mit der etwas aufheiternden Aufforderung ..S chuti do toho a pull je hotovo!" sollten nun die Respondenten folgende Variablen wählen:

\begin{tabular}{|c|c|c|}
\hline & Doma & $\begin{array}{l}v \text { televizi / } \\
\text { rozhlase }\end{array}$ \\
\hline $\begin{array}{l}\text { 1. kulaţi stưl } \\
\text { 2. kulatej stül } \\
\text { 3. }\end{array}$ & & \\
\hline $\begin{array}{l}\text { 1. pracuji kazdý tiden } \\
\text { 2. pracuju kazdej tejden } \\
\text { 3. }\end{array}$ & & \\
\hline $\begin{array}{l}\text { 1. mluvil o novem aute } \\
\text { 2. mluvil o novym aure } \\
\text { 3. mluvil vo novym aute } \\
\text { 4. }\end{array}$ & & \\
\hline $\begin{array}{l}\text { 1. dưm s malymi okny } \\
\text { 2.düm s malejma oknama } \\
\text { 3. düm s malimma voknama } \\
\text { t. }\end{array}$ & & \\
\hline $\begin{array}{l}\text { 1. ráno piji repli mliko } \\
\text { 2. ráno piju teplì mliko } \\
\text { 3. }\end{array}$ & & \\
\hline $\begin{array}{l}\text { 1. prisli bychom } \\
\text { 2. prisli b!sme } \\
\text { 3. }\end{array}$ & & \\
\hline $\begin{array}{l}\text { 1. s mladimi painy } \\
\text { 2. s mladejma painama } \\
\text { 3. s mladima pinama } \\
\text { t. }\end{array}$ & & \\
\hline $\begin{array}{l}\text { 1. bez velkich problemí } \\
\text { 2. bez velkejch problémú } \\
\text { 3. }\end{array}$ & & \\
\hline
\end{tabular}

93 Dic standardischechische Orhographie ist die Ieserfreundliclste Darstellungsform von nichtstandardlichen Tevien. Dicse Darstcllungsform wurde in unserer Studie von SGALU HRONEK übernommen: ..C'zuváme tah.

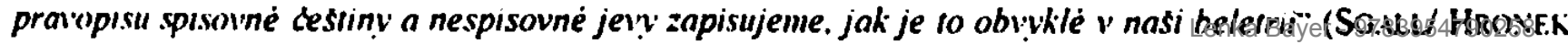
1992. 29). 


\begin{tabular}{|c|c|c|}
\hline & Doma & $\begin{array}{c}v \text { televizi 'v } \\
\text { roshlase }\end{array}$ \\
\hline $\begin{array}{l}\text { 1. rodice pracuji doma } \\
\text { 2. rodic'c pracujou doma } \\
\text { 3. }\end{array}$ & & \\
\hline $\begin{array}{l}\text { 1. jdeme ke známim } \\
\text { 2. deme ke známejm } \\
\text { 3. deme ke známym } \\
\text { 4. }\end{array}$ & & \\
\hline 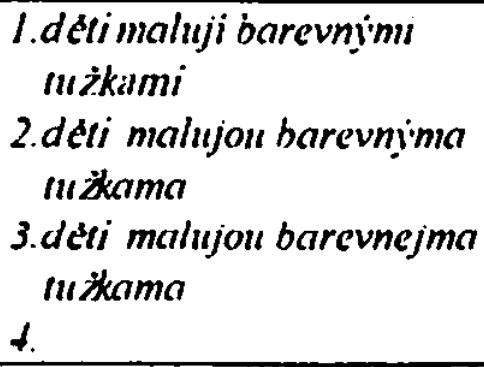 & & \\
\hline $\begin{array}{l}\text { 1. pocrebuji nové bryile } \\
\text { 2. poirebuyu novy brejle } \\
\text { 3. }\end{array}$ & & \\
\hline $\begin{array}{l}\text { 1. miluji ruchlá auta } \\
\text { 2. miluji nychle auta } \\
\text { 3. miluju nychlỵ auta } \\
\text { f. }\end{array}$ & & \\
\hline $\begin{array}{l}\text { 1. mladi custi maliñi } \\
\text { 2. mladì cicský malitíi } \\
\text { 3. }\end{array}$ & & \\
\hline $\begin{array}{l}\text { 1. musim bit doma } \\
\text { 2. musim bejt doma } \\
\text { 3. musim bejt doma } \\
\text { 4. }\end{array}$ & & \\
\hline $\begin{array}{l}\text { 1. màn hodného kolegu } \\
\text { 2. mìm hodnụho kolegu } \\
\text { 3. }\end{array}$ & & \\
\hline $\begin{array}{l}\text { 1. mliwila o svem bivote } \\
\text { 2. minvila o svim zivote } \\
\text { 3. mhivila vo svim zivote } \\
\text { 4. }\end{array}$ & & \\
\hline $\begin{array}{l}\text { 1. videlijsme staré hrady' } \\
\text { 2. vidsli sme staryi hrady. } \\
\text { j. }\end{array}$ & & \\
\hline $\begin{array}{l}\text { 1. znam dobré kuchare } \\
\text { 2. znam dobri kuchare } \\
\text { 3. }\end{array}$ & & \\
\hline $\begin{array}{l}\text { 1. boli } m e^{d} \text { oci } \\
\text { 2. bolcji me oci } \\
\text { 3. bolej } \mathrm{me}^{\mathrm{s}} \text { voci } \\
\text { 4. }\end{array}$ & & \\
\hline $\begin{array}{l}\text { 1. kahà je v nové skriml } \\
\text { 2. kabà je v novì skrimi } \\
\text { 3. }\end{array}$ & & \\
\hline
\end{tabular}




\begin{tabular}{|c|c|c|}
\hline & doma & $\begin{array}{l}\text { velevizi / } \\
\text { rozhlase }\end{array}$ \\
\hline $\begin{array}{l}\text { 1. musim prinést pivo } \\
\text { 2. musim prinýst pivo } \\
\text { 3. }\end{array}$ & & \\
\hline $\begin{array}{l}\text { 1. Irvá to déle } \\
\text { 2. ıná to dyll } \\
\text { 3. }\end{array}$ & & \\
\hline $\begin{array}{l}\text { 1. nemohu dichat } \\
\text { 2. nemüż dejchat } \\
\text { 3. }\end{array}$ & & \\
\hline $\begin{array}{l}\text { 1. male déti piji caj } \\
\text { 2. malý déti pijou caj } \\
\text { 3. }\end{array}$ & & \\
\hline
\end{tabular}

Die Auswertung des konativen Subsystems ist im Bereich der Einstellung die umfangreichste. Insgesamt wurden 54 Items - 27 Variablen in zwei Situationen - ausgewertet. Als Methode für die Auswertung wählten wir die binaristische Variante der Likertschen Methode der summierten Einschätzungen. Separat in jeder Situation bewerteten wir die Wahl des ST mit einem Punkt, die Wahl des GT mit 0 Punkten. So wurde die Konation in der informellen bzw. in der formellen Situation mit maximal je 27 Punkten (100\%) berechnet. Die Zahlen nach dem Komma werden in den Auswertungen auf- bzw. abgenundet:

Beispiel:

Ein Respondent wählte in der informellen Situation 12 von 27 Variablen in ihrer standardtschechischen Form, den Rest im GT:
$27: 100=0,27(=1 \%$ von 27$)$
$12: 0,27=44,4 \%$ (abgerundet $44 \%$ )

Der Respondent würde in der informellen Situation das ST zu $44 \%$ verwenden, das GT zu $56 \%$.

In der formellen Situation wählte der Respondent 25 von 27 Variablen in ihrer standardtschechischen Form, den Rest im GT:
$27: 100=0,27(=1 \%$ von 27$)$
$25: 0,27=92,6 \%$ (aufgerundet $93 \%$ )

Der Respondent würde in der formellen Situation das ST zu 93\% verwenden, das GT zu 7\%.

Graphische Darstellung des obigen Beispiels: Einstellung, konatives Subsystem

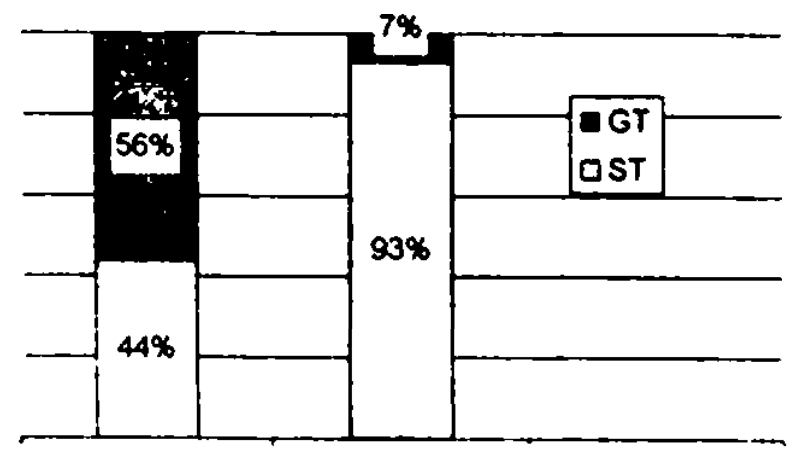

inform Sit form Sit 


\subsection{Situationbezogenes sprachliches Verhalten}

Über die ersten Ansätze bei BÜHLER, in seiner ,hier-jelzt-ich-Origo “ (BOHLER 1934/1965, 79-148, ubernommen von SCHOTZE 1987, 159), etablierte sich der Terminus "Silmation" in den 70 er Jahren zuerst in der Sprechakttheorie. Nach der ersten Feststellung, "daß die grammatische Siruktur eines Sprachsystems (...) nicht umabhängig vom Situationsrahmen von Außcrungen formulierbar ist " (SCHUTZE 1987, 159), wurden in den Folgejahren in der Textund Soziolinguistik komplexe Modelle und Theorien vorgestellt, die versuchen, möglichst viele situative und kontextuelle Komponenten des Schreibens bzw. Sprechens zu erfassen.

Nach dem anfanglichen Enthusiasmus stellte sich dennoch bald heraus, daß eine exakte Bestimmung der Sprechsituation mit größeren Problemen verbunden ist. So mußten die meisten Ansätze ..aporetisch bleiben, weil kein Konzept für die erlebıe Danter und Wandlung von Sitmationskontexten zur l'erfügung stand" (SCHUTZE 1987, 160).

In unserer Untersuchung wird "Sitmation als typisierter Imteraktionsanla $\beta$, der an einen bestimmmen Schauplatz. einen bestimmten Enwartungsfahrplan und eine bestimmte Akleurskonstellation gebunden ist" (SCHOTZE 1987, 160) verstanden. Unterschieden werden zwei Arten von Situationen:

\subsubsection{Terhalten in einer informellen Sintation}

In Westböhmen wurden 36 Respondenten in der informellen Situation aufgenommen. In Prag konnten aus organisatorischen Grunden nur 4 Aufnahmen $^{\text {s4 }}$ in der informellen Situation durchgeführt werden. Da die Studenten und Schüler in der jeweiligen Fakultät bzw. in der Schule interviewt wurden, ergab sich zu persönlichen Gesprächen leider keine Gelegenheit. Im Rahmen unserer Untersuchung zeichnet sich eine informelle Situation durch folgende Merkmale aus

Die Aufnahmen wurden in informellen Settings - in den meisten Fällen zu Hause, seltener während eines Besuchs bei Freunden/ Bekannten, am Arbeitsplatz während der Mittagspause oder in einem Café/ Restaurant - durchgeführt. Die Gesprächspartner und die sprachliche Umgebung waren den Respondenten vertraut. Die Konversation war rein privater und zwangloser Natur Der wichtigste Faktor bei den Aufnahmen in der informellen Situation war ihre verdeckte Durchführung, d.h. die Uniformiertheit der Sprecher uber das unauffallige Einschalten des kleinen Diktiergeräts, das mit einem starken eingebauten Mikrofon ausgestattet war und in der Nähe der Sprechenden plaziert wurde. Meistens befand sich das Diktiergerat in einer leichten Stofftasche. die unauffallig vor bzw. neben den Respondenten gelegt wurde ${ }^{95}$ Die Verfasserin bzw. der Tutor waren in allen informellen Kontexten anwesend als:

21 Dic Uilfrage in Prag unter den Niclitstudenten wurde zumn großen Teil von cinem Tutor durchgefühn. Trot/. sciner Bemühungen gelang es ihm bis auf wenige Ausnahmen nicht. dic verdeckten Aufnahmen in der informelicn Situation durch/uführen.

95 Zur cthischen Scite dicser Aufnahmen: .. Es besteht heute ein allgemeiner Nonsens daraber, daß hier das Prin:ip der . Schadensmmmmierung auf Seiten der Betroffenen - ganz nach arallichem lorbild: primum minl mocere - absoluten Iorrang hat" (GOEß3. 1988. 859). Im Falle unserer Untersuchung wurde das Material streng vertraulich behandelt. Die Aufnahımen wurden jewcils mit Nummern verschen, um sie spater mit den

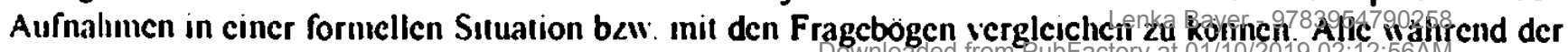
Aufnahmen genannten Eigennamen wurden im Text ausgelassen. Dic ganze Untersuchupg adecist somit 
1. passive, dem Respondenten bekannte Zuhörer oder

2 passive, dem Respondenten nur flüchtig bekannte Zuhörer oder

3. aktive, dem Respondenten bekannte Gesprächspartner oder

4. aktive, dem Respondenten nur flüchtig bekannte Gesprächspartner ${ }^{\%}$

In der informellen Situation äußerten sich die Respondenten entweder monologisch in einer kontinuierlichen Rede (Erzählung, Monolog) oder dialogisch (Gespräch zweier bzw. mehrerer Personen). Im Falle eines Dialogs wurde nur ein Respondent akzentuiert, der Ausdruck anderer Teilnehmer wurde nur teilweise der semantischen Kohärenz wegen aufgezeichnet und in Klammern aufgefuhrt. Jede Aufnahme wird in unserer Studie schriftlich einzeln reproduziert. Abschnitte, deren Aufnahmequalität durch starke Nebengeräusche so gemindert ist, daß die einzelnen Laute nur undeutlich zu verstehen sind, wurden ausgelassen. Solche Textlücken werden in der Textwiedergabe mit drei Punkten markiert. Die dadurch entstandenen inhaltlichen Risse stören zwar die semantische Kohärenz der Texte, für unsere Untersuchung sind sie jedoch nicht von Bedeutung ${ }^{97}$. Obwohl jeweils die in etwa gleiche Aufnahmedauer angestrebt wurde, variiert die Länge. Dies resultiert aus den Details der jeweiligen Situation, dem Spektrum der Gesprächsteilnehmer bzw. Akteure und der natürlichen bzw. momentanen Eloquenz des einzelnen Respondenten. Der zeitliche Ablauf der Aufnahmen wurde so festgelegt. daß während der Unterhaltung in der informellen Situation den Sprechern nicht bekannt war, daß sie später ${ }^{98}$ aufgefordert werden, sich ins Mikrofon zu äußern und einen Fragebogen auszufüllen. Eine Ausnahme bilden die Respondenten, die fur das formelle Interview mit Mikrofon direkt auf der Straße oder an ihrem Arbeitsplatz angesprochen wurden. Bei diesen erfolgte die Reihenfolge: Aufnahme in der formellen Situation. Ausfullen des Fragebogens, verdeckte Aufnahme in der informellen Situation.

einen streng anonymen Charakter auf. Die juristische Seite der verdeckten Aufnahmen wurde von einem Rechtsanwalt überprüf. Dieser bestătigte. daß die Venwendung der Aufnahmen nicht gegen die deutsche Rechtsordnung verst6Bt.

* Die hier nur schematisch dargestellten Bezichungen Verfasserin bzw. Tutor - Sprecher bilden in unserer Untersuchung keine Variablen. denn in jeder Situation müBte die Konstellation (Länge der Bekanntschaft. Verhăltınis Sprecher - Zuhörer etc.) detaillien besclırieben und separat ausgewertet werden. Solche situativen Variablen sind nur schwer erfaßbar und würden den Rahmen unserer Untersuchung sprengen. Die wichtigsten situativen Merkmale werden vor jeder Aufnahme beschrieben. von der Auswertung wird dennoch abgesehen. In allen informellen Situationen verhielten sich die Verfasserin bza: Tutor in der Rolle der Gesprächsteilnchmer/ Muttersprachler gemaß ihrer sprachlichen Norm und ventendeten zum großßen Teil das GT.

9: Die Inhalte können meistens nur als marginale sozialpsychologisch-politologische Information von Interesse sein. Sic dokumentieren den Gesprächsstoff. Theinen und Probleme sowie Meinungen und Ansichten der Tschechen am Ende des 20. Jh. In einigen Fallen uurden Meinungen über das Tschechische aufgenommen. Diesc werden. falls für die Studie relevant. berucksichtigt. um die entl. Diskrepanzen zwischen der Eınsıellung und dem Sprachverhalien zu erklären.

* Die jetieilige Festlegung dieses Zeitpunktes bildete die schwierigste Phase der Untersuchung. denn die meistens angenelıme gescllige Unterhaltung muBte mit viel Rücksicht auf die Mitteilungsbenpitschafo der Respondenten in eine formelle Situation umgewandelt werden. Downloaded from PubFactory at 01/10/2019 02:12:56AM 


\subsection{2 l'erhalten in einer formellen Situation}

Die absolute Mehrheit der Respondenten wurde sowohl in Westböhmen als auch in Prag in einer formellen Situation aufgenommen. Im Rahmen unserer Untersuchung zeichnet sich eine formelle Situation durch folgende Merkmale aus:

Die Sprecher wurden künstlich in eine formelle Situation versetzt, indem sie um ein kurzes Rundfunkinterview ${ }^{99} \mathrm{zu}$ aktuellen Themen gebeten wurden. Obwohl die Interviews meistens in einem informellen Setting durchgefuhrt wurden und die Verfasserin bzw. der Tutor in vielen Fällen bekannt waren, ist es mit Hilfe:

1. des Mikrofons,

2. der formellen Frage: „Mohl a byste nám pro naši rozhlasovou anketu sdelit vás názor ..."."

3. des konsequenten Gebrauchs des ST seitens der Interviewer,

4. des formellen Auftretens und

5. der für das Interview gewählten Themen

sehr gut gelungen, eine formelle Situation herzustellen. Der anfängliche Streß, der sich nach der Ankündigung des Interviews bei den meisten Respondenten breitmachte, wurde mit beruhigenden Worten und mit der Betonung, $\mathrm{da} B$ es sich nur um eine kurze und völlig anonyme Aufnahme handelt, überwunden. Das Verhalten der Respondenten war unterschiedlich. Die meisten Befragten empfanden das Mikrofon als unangenehm. Viele befurchteten. daß sie nicht ins Mikrofon sprechen könnten. Einige jedoch begrüßten die Gelegenheit, sich öffentlich über die politische Situation in ihrer Heimat äußern zu können. Im Allgemeinen zeigten jüngere Männer die größte Courage.

Die Respondenten wurden zuerst nach ihrer Meinung zu einigen aktuellen politischen Problemen in der Tschechischen Republik gefragt. Damit sich jedoch das Interview nicht ausschließlich in diese Richtung entwickelte, sollten sich die Respondenten anschließend zu ebenso aktuellen klimatischen Veränderungen in Europa äußern ${ }^{100}$.

Die Aufnahmen in der formellen Situation stellen jeweils einen Dialog dar. Aufgenommen und schriftlich reproduziert wurden sowohl Fragen des Interviewers als auch die Antworten der Respondenten. Obwohl die Antworten auf aktuelle politische Probleme in der Tschechischen Republik zweifellos wertvolle politologische und soziologische Aspekte liefern, ist die inhaltliche Seite der Aufnahmen für unsere Untersuchung ganzlich irrelevant. Nur Äußerungen, die die sprachliche Situation sowie das Schulsystem, Sprachpolitik, Sprache der Medien etc. tangieren, werden für die Erfassung der Drittvariablen, die zwischen der sprachlichen Einstellung und dem Sprachverhaiten intervenieren, verwendet.

${ }^{99}$ Es handelt sıch uın eine fiklisc Sendung. denn dic Aufnahmen wurden nur für die Zwecke unserer Studic veniendet.

'(11) Bereits all Anfang des Experiments stellie sich heraus. daß dicse Themen dic ineisten Respondenten ansprochen. In einigen Fallen wurden aufgrund der Interessen der Respondenten oder aufgnund der gegebenen Situation andere Themen gewahlt. 


\subsubsection{Auswertung im Bereich des Sprachverhaltens}

Die Aufnahmen in der formellen sowie in der informellen Situation wurden schriflich fixier. Die Umschrift der Texte wurde im Rahmen unserer Untersuchung wie folgt festgelegt:

1. Die Grundlage für die Umschrift bilden die orthographischen Mittel des ST. Die standardtschechische Orthographie wird auch in den nichtstandardlichen Ausdrücken beibehalten. Die Grapheme $i, i / y, \dot{y}$ werden dementsprechend jeweils nach der standardtschechischen Norm eingesetzt.

2. Die Interpunktion erfolgt ebenfalls nach den Regeln des Standardtschechischen. Sprechpausen werden mit Gedankenstrichen oder Kommata markiert.

3. Die für diese Studie relevanten gemeintschechischen lautlichen und morphologischen Variablen werden in den Texten fett, die standardtschechischen unterstrichen markiert.

4. In der Reproduktion der Aufnahmen in einer formellen Situation wird der sprachliche Ausdruck der Interviewer kursiv dargestellt.

5. Wenn bei den Aufnahmen in einer informellen Situation mehrere Personen an einem Gespräch beteiligt waren, wird jeweils nur eine ausgewertet. Der semantischen Kohärenz wegen werden dennoch die Beiträge der übrigen Gesprächsteilnehmer - zumindest partiell in Klammem aufgefuhrt.

6. Textausschnitte, die wegen schlechter Aufnahmequalität nicht wiedergegeben werden konnten sowie längere für die Auswertung und die semantische Kohärenz nicht relevante Beiträge werden durch drei Punkte ersetzt.

Der Auswertung der schriftlich fixierten Aufnahmen wurde folgende Berechnung zu Grunde yelegt:

Die Gesamtsumme aller von einem Respondenten verwendeten und für unsere Untersuchung relevanten sprachlichen Variablen (Items) bildete den Ausgangspunkt fur die Erfassung und graphische Darstellung dessen sprachlichen Verhaltens in der gegebenen Situation. Wenn z B der sprachliche Ausdruck eines Respondenten in einer informellen Situation insgesamt 36 Items beinhaltete, gingen wir von der Zahl 36 als $100 \%$ aus. Wenn der Respondent in dieser Situation z.B. 32 gemeintschechische und 4 standardtschechische Variablen verwendete, setzt sich sein sprachliches Verhalten in der gegebenen Situation gemäß folgender Berechnung zusammen

36 Items $=100 \% \quad 1 \%=0.36 \quad$ GT-Variablen $=32: 0.36=88,9 \%$ (aufgerundet $89 \%$ ) Der Anteil des GT in der informellen Situation ist $89 \%$. Folglich ist der Anteil des ST (100\% $89 \%) 11 \%$

Wenn z.B. derselbe Respondent in der formellen Situation insgesamt 20 Items verwendete. davon 8 gemeintschechische und 12 standardischechische, gehen wir ebenfalls von 20 als $100 \%$ aus 
Wenn z.B. derselbe Respondent in der formellen Situation insgesamt 20 Items verwendete, davon 8 gemeintschechische und 12 standardtschechische, gehen wir ebenfalls von 20 als $100 \%$ aus:

20 Items $=100 \% \quad 1 \%=0,20 \quad$ GT-Variablen $=8: 0,20=40 \%$ Der Anteil des GT in der formellen Situation ist 40\%. Folglich ist der Anteil des ST $(100 \%-40 \%) 60 \%$.

Graphische Darstellung des obigen Beispiels: Sprachverhalten

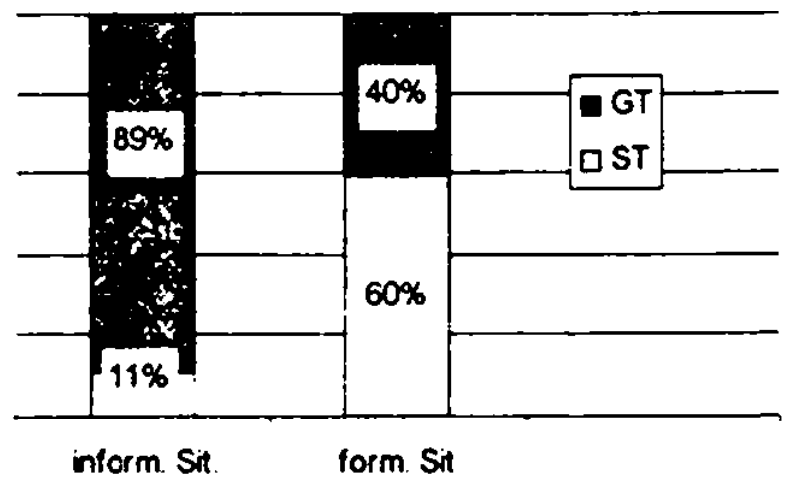




\section{Material der Umfrage}

\subsection{Westböhmen}

\subsubsection{Framen ohne Abirur}

Alter der Respondentinnen: 38 bis 65 Jahre, insg. 7 Aufnahmen

\section{Näherin, 38 Jahre}

Siprachrerhalten, informelle Sitnation: in der Wohnung der Respondentin im Gespräch mit der Nachbarin (Buchhalterin, 65 Jahre, ohne Abitur), mit ihrem Sohn (Schüler, 8 Jahre) und der Verfasserin (flüchtige Bekannte)

- To jako nás Honzik - ne. U nás plaval vajgl v záchodẻ a voni mé presvédicovali, że priplaval. Já jak jsem byla vzteklá, tak jsem tady zacala kticet: 'Jo - hovno taky priplavalo?' Pak jsem si uvẻdomila, že nčkdo je na chodbé. Pak jsem si łikala: 'Ty bláho!'(...)

- Tak se mrkncte do katalogu, von je tedy poškozenej - jo.

(.) (a ho mam doma.)

- Jà myslela jinej, no. Jo, von je ale dobrej

(To je sijicarskej nebo sivedskej?)

- To vám nereknu - švédskej. Vyberete si to - jo. Voni vám to privezou až domú, jo. Tam je jako vobálka - u toho. Já si vobjednávaci listek - já si to tam jako napišu na ten vobjednávaci listek. Pošlu to tam normálne posstou. A voni asi za tejden nebo tak za vosm dni to pošlou. A voni to normálné prinesou aż domú.

(Ale je io kvalimi??)

- Já bych jako rekla, žc docela jo.

(Byli kluci pro ly vejce dineska?)

- Jo, ale rijkal mi Petr̂ik, że prej jindy nebo co. Já nevim. Petriiku! Jakpa jsi dopad u téch lidi s těma vajičkama? Dneska jsi je dostal? Kolipa? (...)

- Ja jsem si jednou koupila - jả vám vokážu potom, jakou z tý ṙady, a vủbec jako mi nedčlal jako dobre. Mčla jsem takovou masnou pusu, takovou jako upatlanou, jo. Ten mi jako nesedell. jo. Ale co jsem si treba vobjednávala jiný kremy, tak jako jsou docela dobrý.

(A laky jako : Avomu, jo?)

- Jak kterej, ale tamten byl taky jako z Avonu, jo.

(Te'l Ponds je ale raky dohrej - ren Ponds.)

- Já ù̀ jsem míla i ty s tou kyselinou, jo. Jak - ten mi dẻlal docela taky dobre. Ale tadyten je taky s tčma kyselinama. Ten je taky dobrej. (...)

- Vono - jả vám dam tr̉eba normálni - jako bez tý kyseliny. Kdybyste si chtčla zkusit - jako, jo. Normálné si udéláte - jako si to rozetrete po puse, necháte chvilku, a vono to jako uschne, jako kdyż. jste si - dẻlala jste si nêkdy z bilku - pletovou masku? Tak vono se to jako uceli a vy jdete a takhle to sloupnete

Syracherhaltell, formelle Simation: in der Wohnung der Respondentin

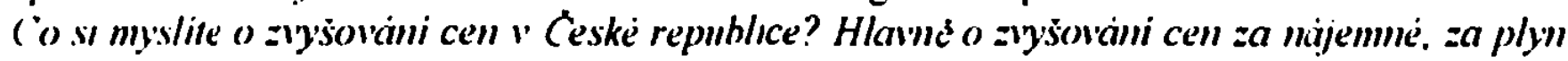
a za elektrimm? 
- Jả platim za näjem trì tisice tr̆i sta, samozrejmé bez elektriiny, bez plynu, bez telefon. Já si myslim. że je to hodné. Samoziejmé já vim, že se traduje, že to neni jako $v$ jinejch zenich, že daji polovinu platu za to, ale u nás si myslim, że to je hodnè.

Máte obany: że se ceny budou i nadále zyysovat?

- Mám, myslim si, že ano.

A ¿x by se tim mohla snižnval z̈votmi uroveñ?

- Ne, myslim si, že ne. Chtěla bych vêrit tomu, že ne. (...) Těžko ríct, jestli bude lẹpe, ale myslim si, že je dostatečnà sociälni sit.

A ješt éjiná otázka. Co si myslite o posledni teplè zime?

- Nemam ráda zimu, takže já teplou zimu uvitám.

Sprachverhalten:

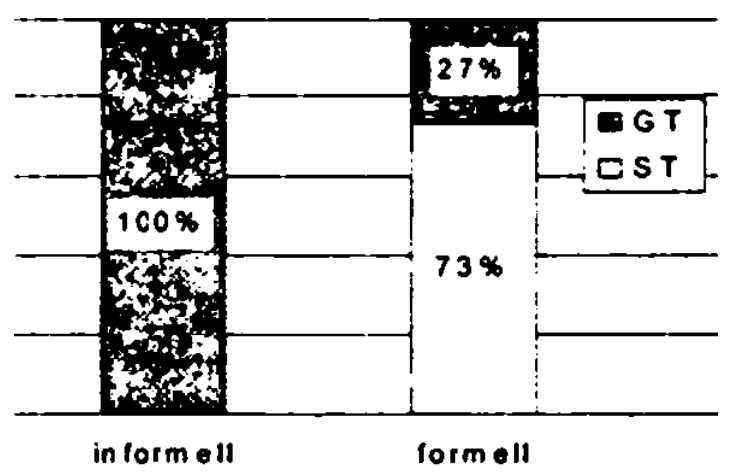

Einstellung, kognitives Subsystem:

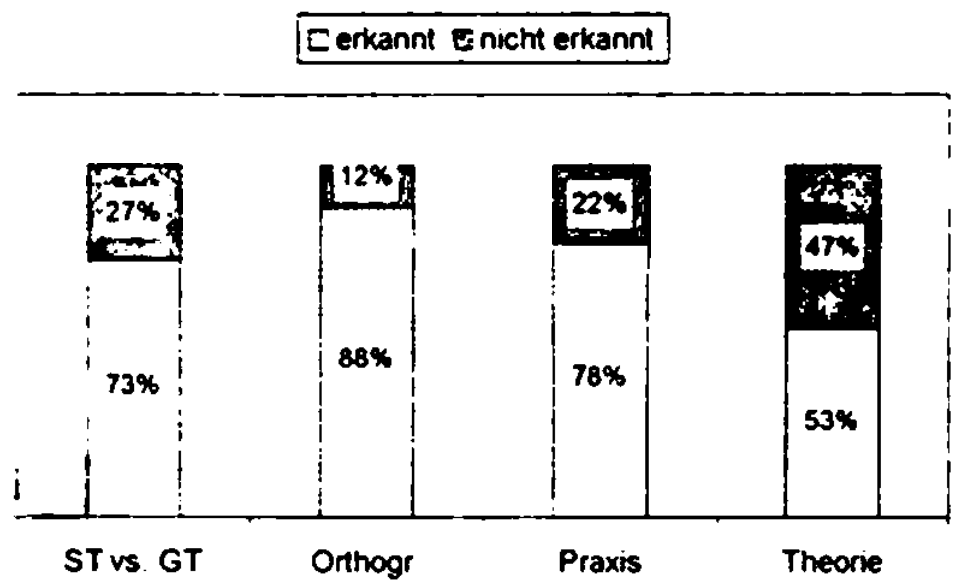

Einstellung, konatives Subsystem:

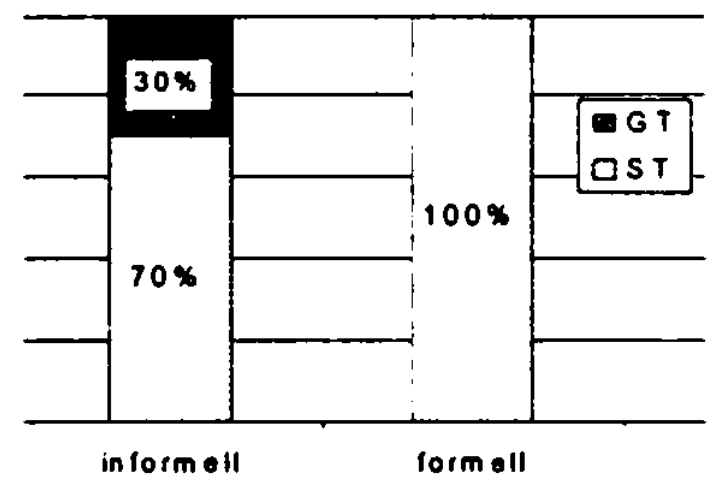

Evaluation der eigenen Kognition:

Einstellung, affektives Subsystem Grad der positiven Einstellung

(100\%




\section{Fräserin, 51 Jahre}

Sprachverhalten, informelle Simation: während eines Besuchs bei Nachbarn im Gespräch mit dem Nachbar (pensionierter Elektriker, 65 Jahre, ohne Abitur) und seinem Hund

- Jé - jà jsem si myslela, bůhvi jak velkej pes na mẻ vyleze - a ty jsi takovej pucliček. A tady se máš dobrie, vid', tady vo tebe budou pečovat - to viš.(..)

- No mnè minulej tejden taky - ne - to už je vlastné étrnàct dni. Holka vodjela na lyže a v nedẻli jsem - ráno jsem eště uvarila snidani - v kuchyni, koupiła jsem řizky a řikam: budu dẻlat vobẽd Pustim plyn a udẻlà to psss. Druhej den ale potom jsem mẻla - jsem si rikala: pudu za tim, nćjak jsem ani to nepotrebovala - ten plyn. V útery volam na plynämy: to prej jste mohla zavolat $v$ nedéli hned. Hodiny to byly. No vono jako $v$ nedéli - jako když potom vic lidi vaŕi. tak nẻkdy jako to jde miñ, tak jsem si rikala: 'pude to'. Eště że màme mikrovlnku, kterou jsme si teda koupili pred mésicem - tak tam jsme uvařili brambory, votevřela jsem konzervu a vohŕáli jsme konzervu.

Sprachierhalten. formelle Sirmation: in der Wohnung der Nachbarn

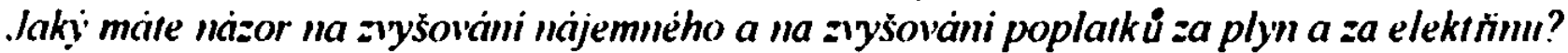

- No tak to je katastrofa, to je hrozný - to je hrozný, protože to furt stoupa - jako byty, vlastné ceny bytů. No, to kupováni bytů - tak to je pro ty mladý úplná katastrofa. Protoże ty koupi bytủ, teda - pro ty mladý dneska - i když děti maji tak, no tak prưmérnej vejdčlek treba tecch dvanáct tisic. No a ty pronajmy nebo ty podnajmy - ty jsou zase strašně drahý - no vưbec už nevime, jak to s nima dopadne, no a - jả zase trebas mam družstevni byt, když jsem si mysleła. že už jako na starý kolena - jak se riká - budu mit klid, tak eštẻ mam zase doplàcet.

A co si myslite o posledmi zimc v Cechách? Byla podle láseho názoru normálhi?

- No, spiš byla teplà, moc jsme si ji neužili.

Myslite si, the se pelmebi virope mbi?

- No, tekla bych, že hodnč Mẻni, mèni. Ted’ko je zima jako spiš nad nulou, málo snčhu, dẻti si toho málo užijou. Driv byla zima pro nás lepši - jako déti Vic jsme si ji užili. Déti jezdily na sanich, bruslily, délal se led pred domem - treba umšlej led - udržoval, že nohly bruslit a ted'ko teda už. to ani nejde.

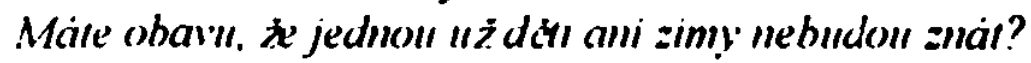

- To uplné ne tak doslova, no - ale jako - ty déti, který tteba nemaji možnost jezdit na hory, aby tam užily toho snchu nebo takhle - tak ho užijou tady u nàs na Plzeñsku asi teda mảlo.

Sprachverhaiten:

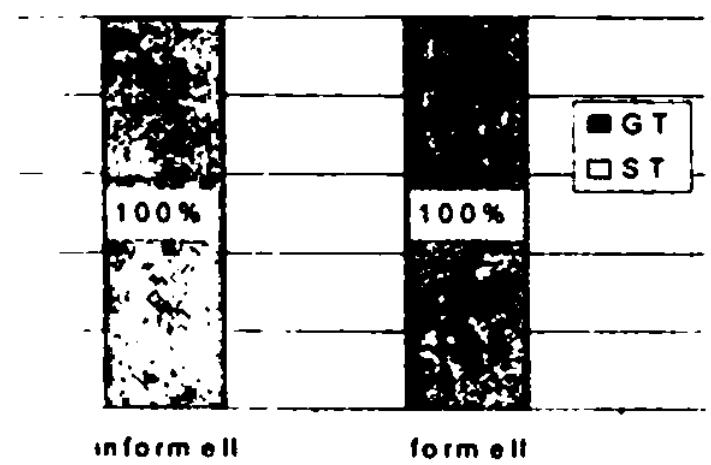

\section{Einstellung, konatives Subsystem}

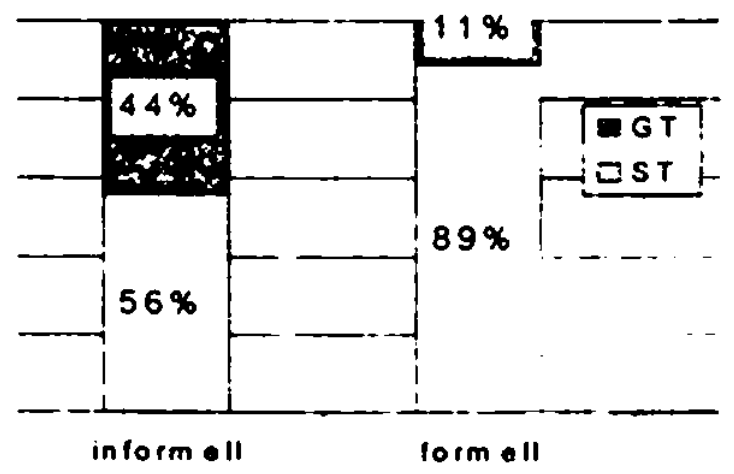


Einstellung kognitives Subsystem:

Serkannt Dnicht erkannt

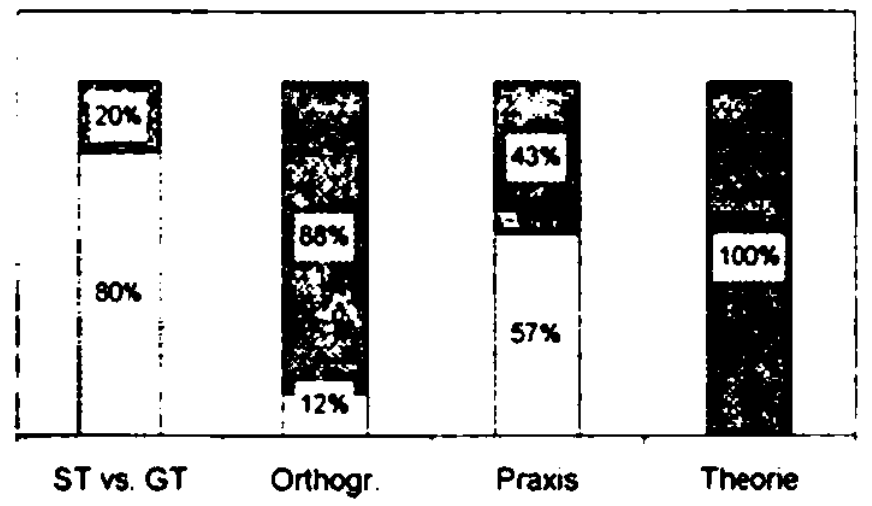

Evaluation der eigenen Kognition

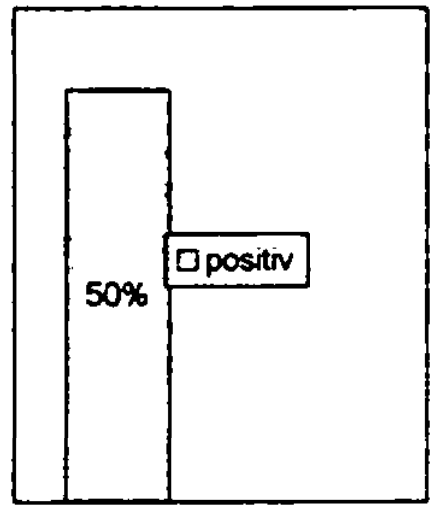

Einstellung, affektives Subsystem: Grad der positiven Einstellung

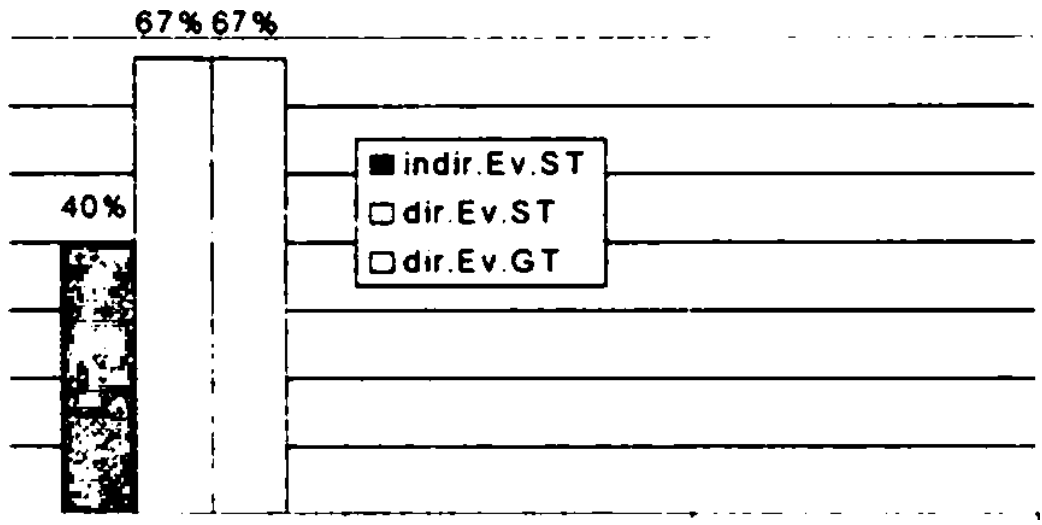

Kommentar: V televizi a $v$ rozhlase mnè vadi, když se mluvi nespisovně.

\section{Briefträgerin, 52 Jahre}

Spracherhalten, informelle Situation: im Haus der Respondentin im Gespräch mit einer Freundin (Arbeiterin, 55 Jahre, ohne Abitur), ihrem Ehemann (Lagerarbeiter, 53 Jahre, ohne Abitur) und der Verfasserin (flüchtige Bekannte)

- No. tak vemte si, že my jsme se sem nastčhovali - loni jsme se sem nastčhovali v prosinci No, ted'ko to bylo $v$ prosinci rok, jo - to bylo. Ctrnáctýho jsme se sem nastěhovali - prosince. No, a za tejden nato zaciala zima. A to bylo krutý, to bylo mésic. My jsme ráno vstávali, klepali jsme kosu, my jsme tady mẻli pêt stupñů. (...) Ted’ko tady jsme mẻli kamna, takový tady zůstali po nich - takovej sporák. To nehoŕelo, my jsme mêli tam mokrý dìevo, ted'ko no prosté to bylo hrozný. Záchod byl zamrzlej, voda byla zamrzlà. (...) Prostě jsme sem vlitli rovnejma nohama. (...)

- Ale jo, ted'ko už si človčk na to vzpominá tak ñảk s humorem. Ale ted' naše Petra, ta je ted' chudảk. Hale viš. Andulko, když tak ted'ko zatim eštž ne. Když tak až potom - jả bych ji. Ale hele. vždyt vona sem prijede $v$ pátek s klukama. Vona sem vodveze kluky, protože vona bude delat. 
Spracherhalten, formelle Simation: im Haus der Respondentin

Jakj' máte názor na kriminalitı v soudasné dobé v Ceské republice?

- No, po svý zkušenosti, když jsme tadydle - tady byli rok, sebrali jsme se, vodešli jsme ráno do prace kolem pátý hodiny - tak nás vykradli. Prìšli jsme domu kolem púl čtvrtý, mèli jsme byt - veškerou elektroniku jsme méli pryċ. Roztrískali vokno. A co se stalo? Nic. Reklo se, že se vezme, že se zkusi, pokusi se nékoho chytit, ale do dnešniho dne nic.

A viš nazor na momentálni stoupáni cen?

- No, je to špatný. Ne, że bych - ale za komoušủ bylo to prosté takový lepši. Bylo prosté taková jistota, byly pevný ceny, co se tỷkalo tadydlenc jidla, co se týkalo tadydlenc oblećeni jo. všechno. Byly pevný ceny - no a ted’konc holt si to udélá každej kdo jak chce.

A ješl é otázka z jiné oblasti. Jak se uám libila posledni mirná zima?

- Jo, tak to - nebylo to špatný. Aspoñ jsme tolika neprotopili. Jinak takhlenc - Ioni to bylo krutý. to jsme tady byli pruni rok, no to bylo krutý loni.

Sprachverhalten:

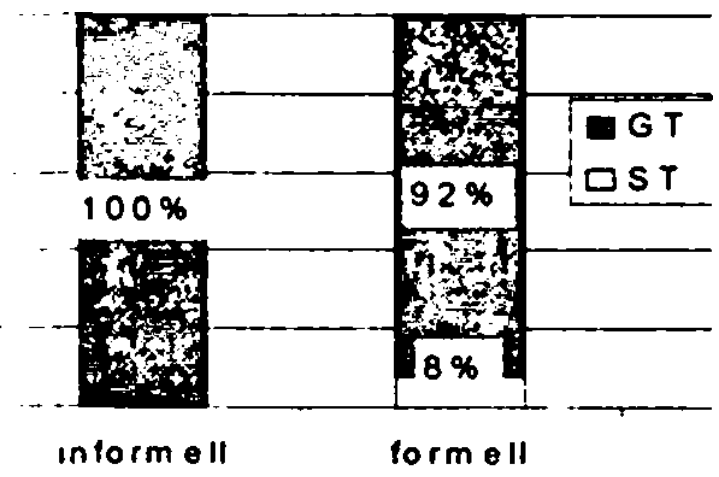

Einstellung, kognitives Subsystem:
Einstellung, konatives Subsystem:

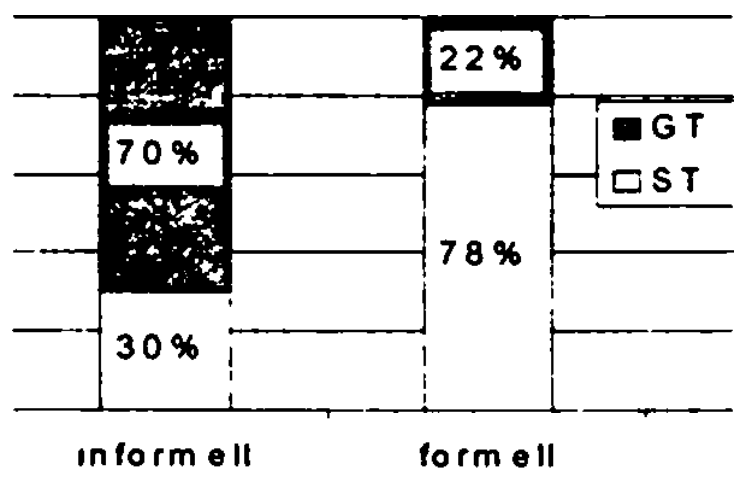

Evaluation der eigenen Kognition:

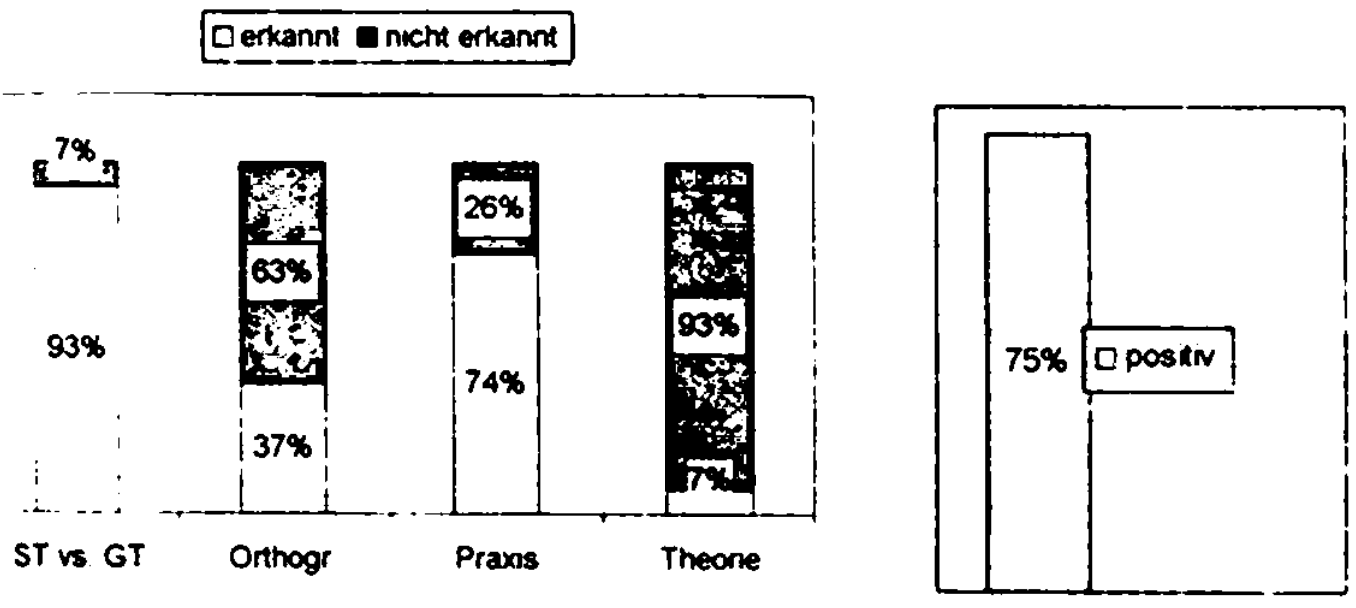


Einstellung, affektives Subsystem: Grad der positiven Einstellung

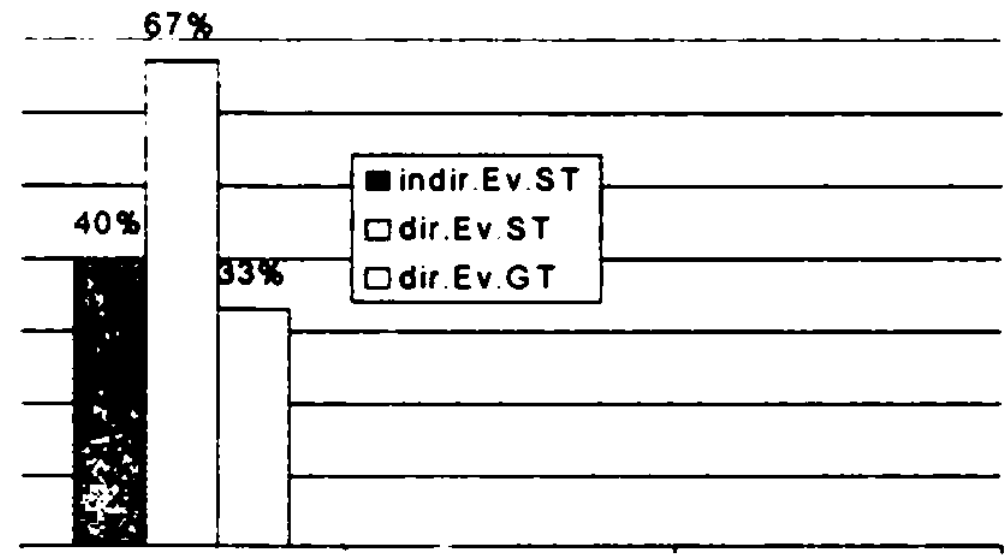

Kommentar: ohne Kommentar

\section{Arbeiterin, 55 Jahre}

Sprachierhalten, informelle Situation: Gespräch im Haus der Respondentin mit der Verfasserin (Bekannte)

- To samý je, jako když se bavime ne̊co spolu a vona riká: 'Jả kdykoliv - tak v̌̌echno zapriu' Jo - jà tikam: 'Vite, to já zase ne. Když řeknu pravdu, tak teknu pravdu a tim to konči - jo.' A hnedka utikala $k$ vašim a hnedka to tam všechno vypovidala. (...)

- Tak vite, to je takový to. A tak jsme se bavili tady vo tom. A tuhle jsem ji taky asi tala, protože von mel šedesátku a vona začala - jako - jak je nemocnej. A rikala 'Vite, vy už to máte tak krásný tady.' A já povidam. 'Co vy furt narikate.' 'Vite, co my mame za vydaje? Ted' von slavi šedesátku a tảmhle a támhle.' Všude jaký dẻlaj honorace Jả povidam: 'Tak když na to nemam, tak to neslavim. Proć to tedy déláte? A když nemáte penize, no tak nevoslavujte.' 'No - to se musi.' Ja povidam: 'Taky dostanete zase zpátky, tak proto to asi dêlate.' Mnẽ je to jedno, at si vo mnè mysli, co chce. A to samý jsem riikala - jako - vaši mámé. Já fikam: 'Vite, nelibi se mi to. Jả jsem asi na tohle hrozné blbá. Kamaradi spolu takovejch let, až jsem to rikala mužovi. Když von se stčhuje, tak běhá sem pro rady, tady donȧ̧̉i, votađ̛ si puçuje vozejk. No - nechtecjte slyšet to vostatni tady z tý strany. A potom, když to, tak riká: 'Já ne, já se do ničeho nepletu, ne, ne, ne. Já jsem kamarádka, já chci mit klid. A kdyż tak, já to zapru.' Tak to je kamaradstvi Já jsem to rikala vaši mamince: 'To se mné nelibi. Af́ už je to, jak je to. Už jsme dospcli lidi. Tak bud' si teda rekneme: 'Tak hale nazdar a jdeme vod toho, ale abych jako dêlala kamaradku a na druhej stranè potom tak. (...)

- To Mrivý more mčlo základ. Pak jsem dostala ten Psorkutan - tu mast novou, co ted'ka je. A ted'ka eš̀tč jako von do toho - já nevim

(A kulybysle jeli k mori?)

- No, vono to u nás stoji. Je to hroznè drahý a pojištovna vám vlastné nic nedá. V Nèmecku to plati. Nejak dost velkou ċảstku. A my jsme se takhle mezi lupenkářema. Ty velký cástky se plati v Nêmecku, protože prišli na to, že je to prijde levnèjš, než když ten pacient nékde leži $v$ nemocnicich anebo kdyż nckkdo omarodi. 
Sprachverhalten, formelle Situation: im Haus der Respondentin

Co si myslite o stoupáni cen v Ceské republice?

- No, že je to hrozný. Hlavné pro mladý lidi a pro dưchodce, že by se to trochu mèlo na ñáký hranici ustálit, aby sociálni podminky pro určitý věkový kategorie byly takový prijatelný. A co si myslite o stoupáni najjemného, plymu a elekt riny.

- No, że to nikdo za chvilku nebude moct zaplatit a że mladý lidi budou bydlet pod mostem. protože nemaj byty, nemaj nic a na né mit nebudou. Že byty - jako ceny bytư jsou nehoraznể vysoký a nevyteši to ani ñáký zdražováni plynu, elektriky a nájemnýho. To bude zase jenom pro horni vrstvy a ty malý vrstvy budou bydlet pod mostem. A dủchodci zmrznou.

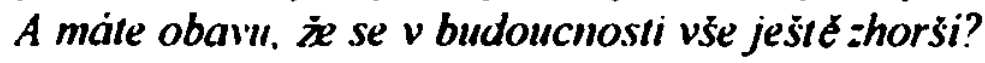

- Mám mám. protoże to tak nẻjak tomu napovidà - všechno.

A ješt

- Kdyby bylo jich vic - takovejch teplejch zim. To by bylo dobre, spottebovalo by se miñ energie - $v$ domácnostech.

Máte dojem. ż budouci zimy budou ješt ¿ mimejsi anebo zase chladne?

- Jo, tak tohleto já nevim. Podle meteorologủ tikaji, že má bejt dvacet rokủ zima velká. Tak jả nevim, jestli se to zase zmeni.

Sprachverhalten:

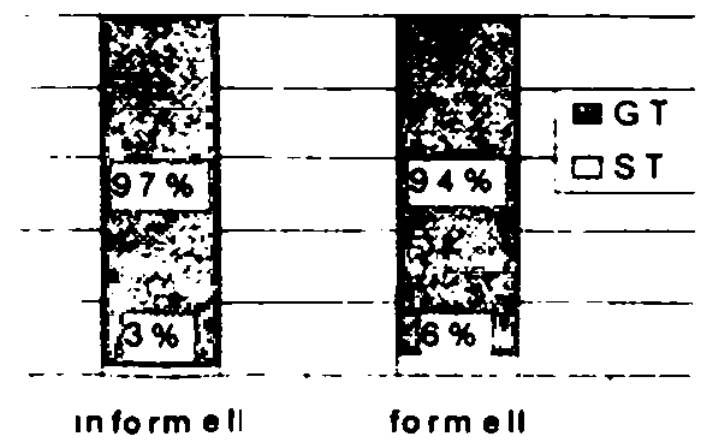

Einstellung, kognitives Subsystem:

Derkank I richt erkann

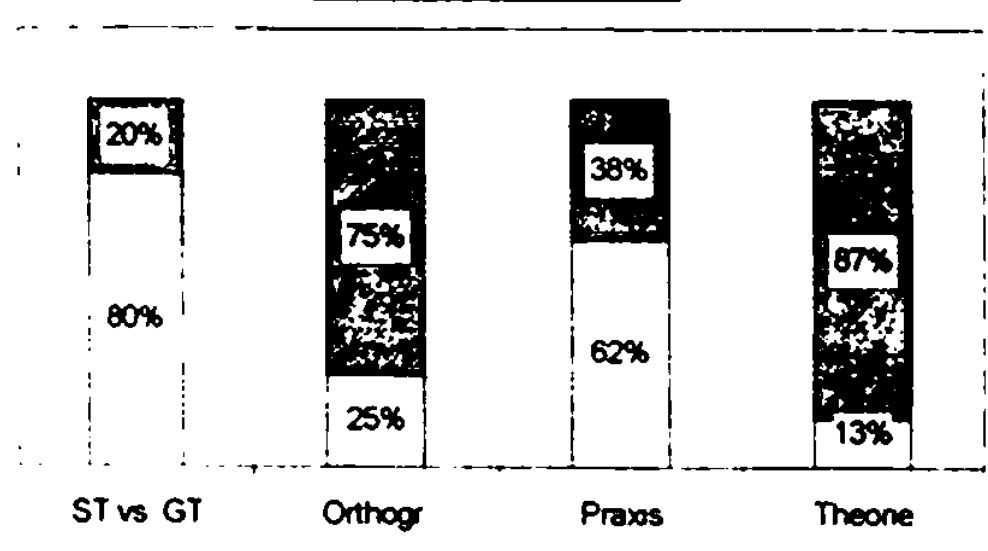

Einstellung konatives Subsystem:

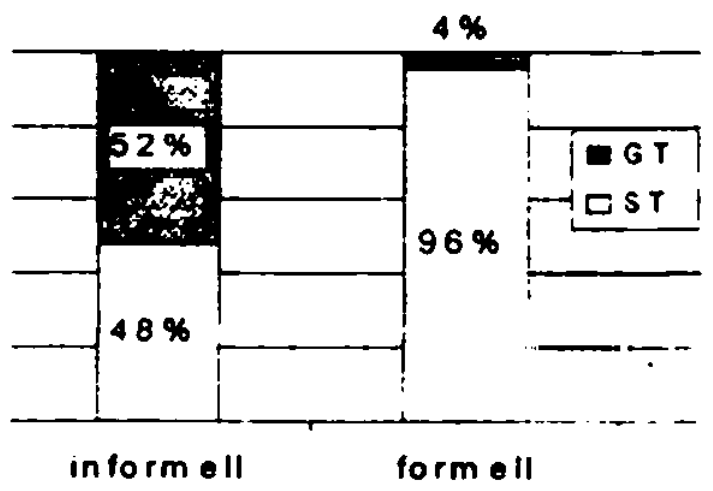

Evaluation der eigenen Kognition: 
Einstellung, affektives Subsystem:

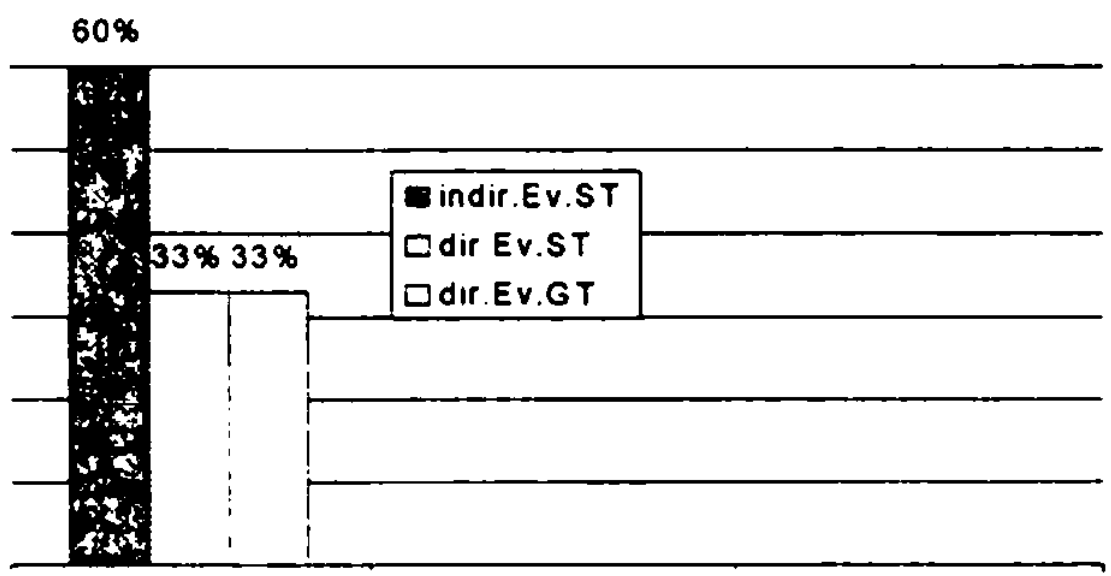

Kommentar Nelibi se mi dvojsmyslné komentảie. V televizi by mèli mluvit spisovnè. Ve škole by se déti mêly vèst ke spisovnému jazyku.

\section{Putzfrau, 56 Jahre}

Sprachverhalten, informelle Situation: während eines Besuchs bei einer Freundin im Gespräch mit der Freundin (pensionierte Buchhalterin, 65 Jahre, ohne Abitur) und mit der Verfasserin (Bekannte)

(Kưle más Jirku?)

- No - ten, co se ted' voženil, tak na mé hodil bobek. (...)

- Ale viš Boženko, to jsou takový rodový znaky, někdo má pružnou plet dlouho a nemusi se namazat - tr̉eba jả se nekrémuju, já to nesnášim - krẻmy mně nedêlaj dobr̉e. I když bych méla - taky - i ruce, protože mam je drsný - jo - takový hrubý. Ale jả krémy nemanı ráda. Takže ted’ jsem začala - ṙikala jsem si - vỉera jsme právẻ šli si nčkam sednout - a já povidam: jả mam ruce jak - hrubý jak drevorubec. Tak jsem si je tam masirovala. Eštê $\vee$ divadle teda - jo. Ale Ivana - ta naše - taky má sklony. Takže ta bude mit plet do Vaškovic rodu - jo - a ty méli suchou plet. A Ivana řikala taky, že bude mit brzo jako - viš. A když se smčje, tak taky se ji dêlaj takový vräseciky.

(A kolik je liane?)

- Ivanè bylo tricet pèt Bylo ji tricet pèt - letos ji bude šestatticet - $v$ èervnu. Takže vona taky jako kolem têch voči, když se sméje. Tak to já jsem eštê nemèla ani ċárečku - oproti tr̉eba lvanč Taky jako už se ji dêlá - ale ta méla citlivou plet vod dêtstvi - hele. A celej život se maže obličej - riká: mami, jả kdybych se nenamazala, tak mnè ta kủže, jo, se stáhne - a jako ditě se ji loupala. jo, kdeżto jả rikam: já nepotřebuju na krém šahnout. Protože ho nemam ani ráda.

Sprachverhalten. formelle Simation: während des obigen Besuchs

Jakj máre názor na soucasné zuysováni cen v Ceské republice?

- No, nelibi se mi to. Špatný nàzor.

Z jakiho divodu?

- No, $z$ jakèho dủvodu. Životni úroveň je teda nizkả a mảme se hủr, no. Musi se moc šetrìt

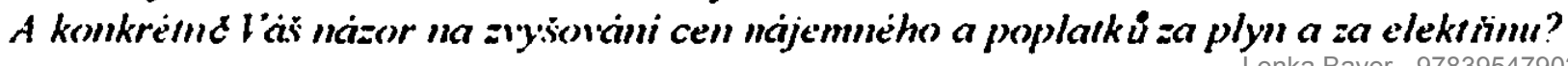


- Tak nájemneho, to se na mé nevztahuje. Bydlim v domku. Ale jako elektrika, plyn - tak to už se $\mathrm{m} \mu$ moc dotýká. Protože prece jenom jako důchodce to pocituju velmi.

A budou se ceny podle Vašeho názoru nadále zvyšovat?

- Myslim si, že budou se zvyšovat, ale předpokládam, že i ty důchody se zvýši, no takže to nèjak prežijeme. A jelikož si umim ještẻ vydẻlat. Teda do práce chodim, tak to nějak płeživám jakž takż dobie.

A ted'otázka z jiné oblasti. Jak se V'ám libila posledni teplá zima?

- Posledni teplá zima? Ted' jsou spiš takové teplejši zimy - nelibi. Já mam ráda takový ty zimy - opravdu hodnê snèhu a prosté takovou pravou chumelenici. Mam to ráda z dètstvi - tu romantiku

A ta posledni zima?

- No. byla spiš teplejši. Blàto a takový teplo, no.

A máte dojem, ¿̇e chripková epidemie, která rádi v Evrope. má s touto zimou nஷco spolecineho?

- No, já si nemyslim, że ta chłłipka je každjym rokem asi ňáká - se vyskytne - a v každý oblasti.

Sprachverhalten:

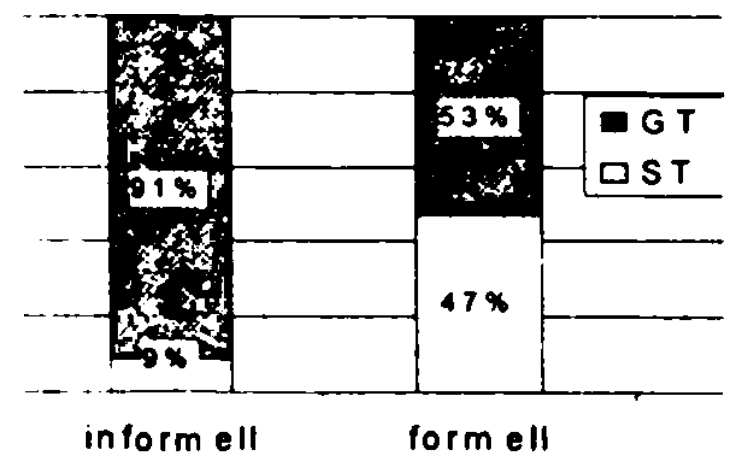

Einstellung, kognitives Subsystem:

Derkannt E ncht erkannt

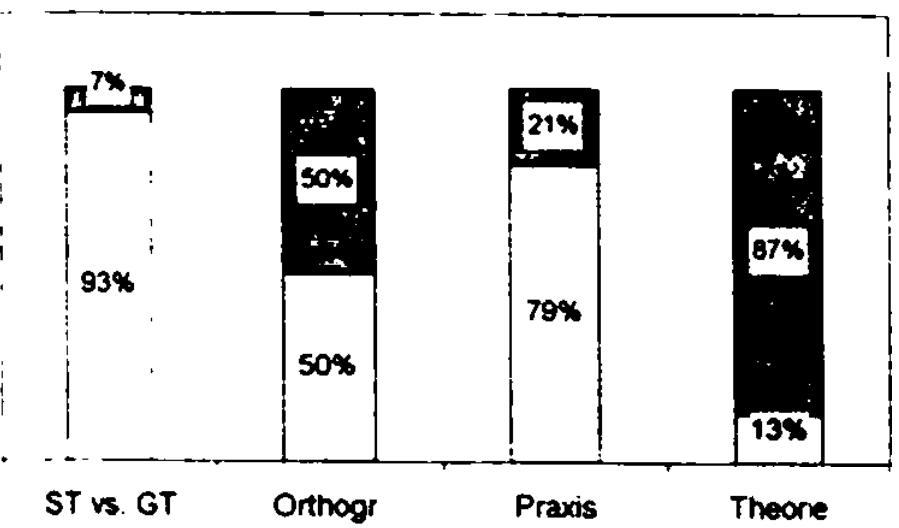

Einstellung, konatives Subsystem:

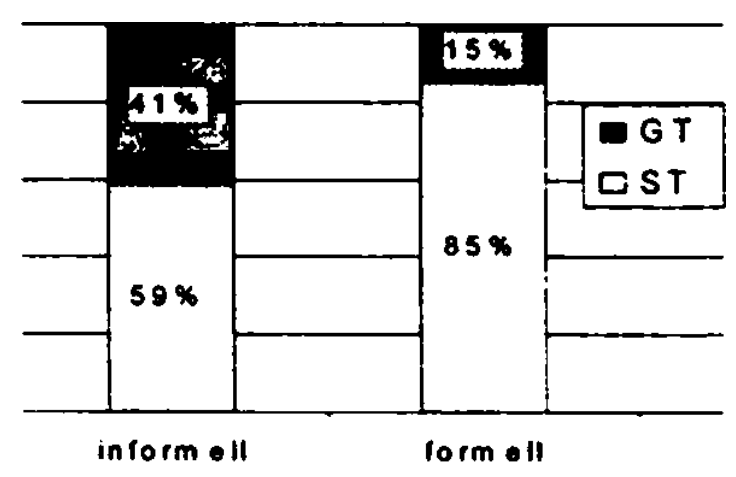

Evaluation der eigenen Kognition: 
Einstellung, affektives Subsystem: Grad der positiven Einstellung

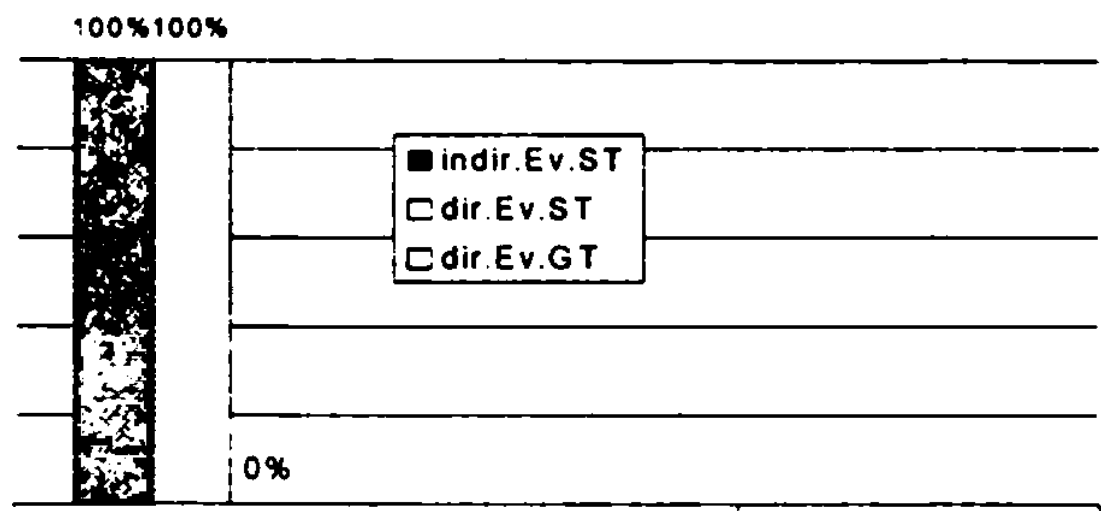

Kommentar: Spisovnà čeština se mi velmi libi.

\section{Pensionierte Verkäuferin, 57 Jahre}

Sprachrerhalten, informelle Sitıation: in der Wohnung des Sohnes beim Erzählen vor Zuhörern: Sohn (Elektromechaniker, 29 Jahre, mit Abitur), Schwiegertochter (Verkäuferin, 25 Jahre, ohne Abitur), Verfasserin (Bekannte)

- No podle některejch těch dèti - no - tak to jsou všechny děti - že rozbijou všechno. Jití když byl malej. tak si vopravdu. Ten tu má ještẻ nękde ty hračky, ktery vưbec - z mateřský školky tu má autičko. Ilonka si s nim hraje. Prostæ prines to v krabičce - dostali to na Mikulaše - a když jsem mu vzala krabičku a hodila do koše, tak hledal a plakal. Hiedal krabičku, že - jà jsem rikala: 'prosim tě, co $s$ tim.' 'No maminko, to je garaž.' Tak jsme mu potom koupili takovou drevènou garáż na trì autička. (...)

- Jà jsem tady prišla vo práci. Nám prodali prodejnu - pred dủchodem - tak, nakonec potom nás dali ešté Jolủ, do nákupáku - protože to byly jako potraviny. Rok - a po roce to prievzal Nord a ten nam dal dva tisice hrubej plat. Potom to prodali, a ten, co to koupil, tak chtęl, abych tady zủstala - a jả jsem r̉ekla, že ne. Protože jsem vêdẻla: začiná, tak copa mi múže dảt za vejplatu. Tak jsem rekla: ne, jả ešté zủstanu u podniku, pokad je ješté závod - a to méli eště jako nảkupni stredisko - Radynẻ byla. To bylo eště státni, ten eště nebyl v privatizaci. Tak jsem tam Šla, ale jenomże to vydrželo rok. A po roce to prodali a koupila to společnost Nord. To byli vlastnẻ papalaši, co byli nahore - jo - ty holt méli penize. A ty nám dali dva tisice hrubýho a vic nàm nedali.(..)

- Napied to mêl Patron dva tisice - tu drogerii - a von prostê jim dal vyjpovêd' a chtêl to celý. Tak ty potom sli pryc். My jsme byli pod nim - von si vzal prostč celou budovu. Von mél napred ċást dole - prostê elektro, domáci potr̉eby - a vpravo byly potraviny už zprivatizovaný vod toho Nordu. Tak po têch trech mésicich - prostê to vzal a dal nám kolem šestnácti korun na hodinu. No, bylo to strašný. A jả jsem rikala: jestli taky dostaneme ten plat, co nám dal Nord. tak $z$ toho je tedy vopravdu vzit si mašli - jo.

- Plat se nezvyšoval, než tak vo těch dvacet halérự, vo padesát halèrü - jo. Takže prostể jsem byla rozhodnutá - jsem rikala: když mi ten plat dáte, co mi nabizi v Plzni, ráda zủstanu -

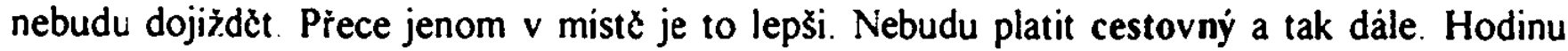
ztráta ìasu tảm, hodinu zpátky. $\Lambda$ von rek: to vảm dat nemủžu. (...) 
- Ale łikam, že na tom nejsem zase tak špatnẻ - po stránce finančni, protože já jsem vlastnẻ celejch těch deset let mêla docela péknej plat. Tady jako vedouci. akorát mi to prostě zkazilo. že u toho Nordu jsme dostali než ty dva tisice, a vic nám dát nechtêli - a to byl ješté hrubej plat. Takže my jsme taky méli sedmnáct set cistýho na ruku - a to jako bylo katastrofa. To jsme ỉekli, že na podporu nẻkterii berou vic než my. (...)

- Chodim ted"ka zase na kréni - nevim, no - špatnê se mi dejchá, protože i tu sliznici v nosu mam jako krvavou - bude to chronický. A pani doktorka mi iekla - a iekla mi - ted", kdyż jsem tam byla minulej týden.

Sprachverhalien, formelle Situation: in der Wohnung des Sohnes

Co si myslite o souçasném zyyseni najemného a poplatki za elcktrinu a plyn?

- No, jà si myslim, że je to pomérné - prosté, że to je jako vêtši ...

Tak xu celly' stoupaji a platy' zistónaji na stejne irovni?

- Skoro jsou - prostê tak nàak - nepatrné ho tedy zvýsi, ale to je jak kde - a hlavnex pro dîchodce je to špatný. (...) No - vểim, že snad - ptijde snad dobrá vlàda, která vlastně tuto pochopi, a že bysme to mêli mit jako - drobièek abysme byli na úrovni západu.

A co si myslite o posledni zime byla podle l'ajeho nazoru prilis mirná?

- No, myslim si, že je dost mirná na to, že je zima, że by to mẻlo bejt studenéjł̌i, protože hlavné je to na - prostě - zemédêlstvi, prirodu - že to je úplná katastrofa. Protože nèkterý ty teploty jsou neobvyklý, který by mély bejt pod nulou misto nad nulou.

Myslite si. \# v budoucmu budou simy teplejsi?

- No, tak tuto je těžko rict, protože ptiroda se nenechá ňákym zpủsobem ovlivnit.

Sprachverhalten:

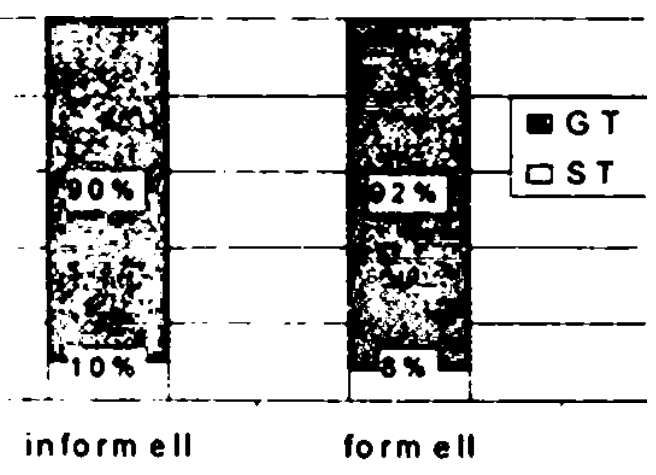

Einstellung, kognitives Subsystem:

Derkannt I nicht erkannt

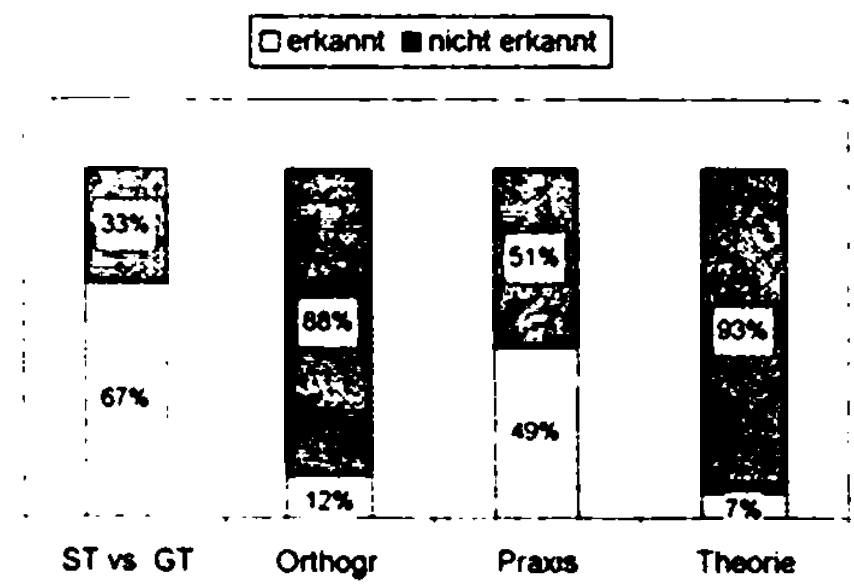

Einstellung konatives Subsystem:

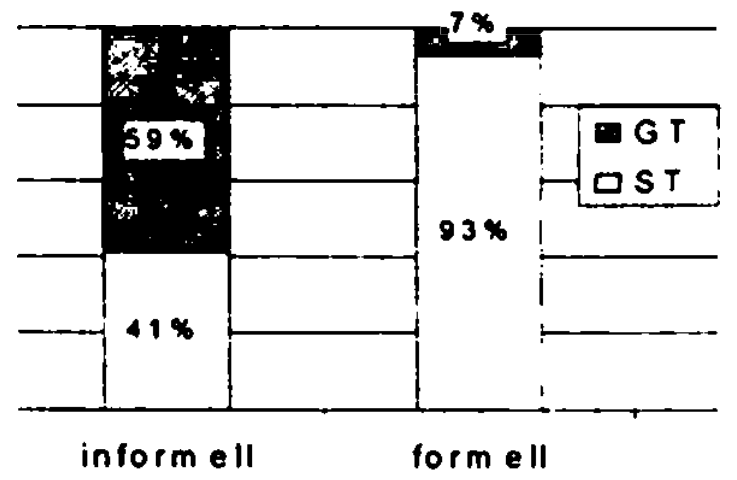

Evaluation der eigenen Kognition:

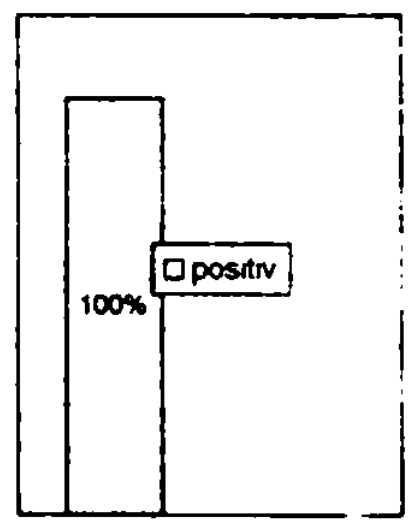


Einstellung, affektives Subsystem: Grad der positiven Einstellung

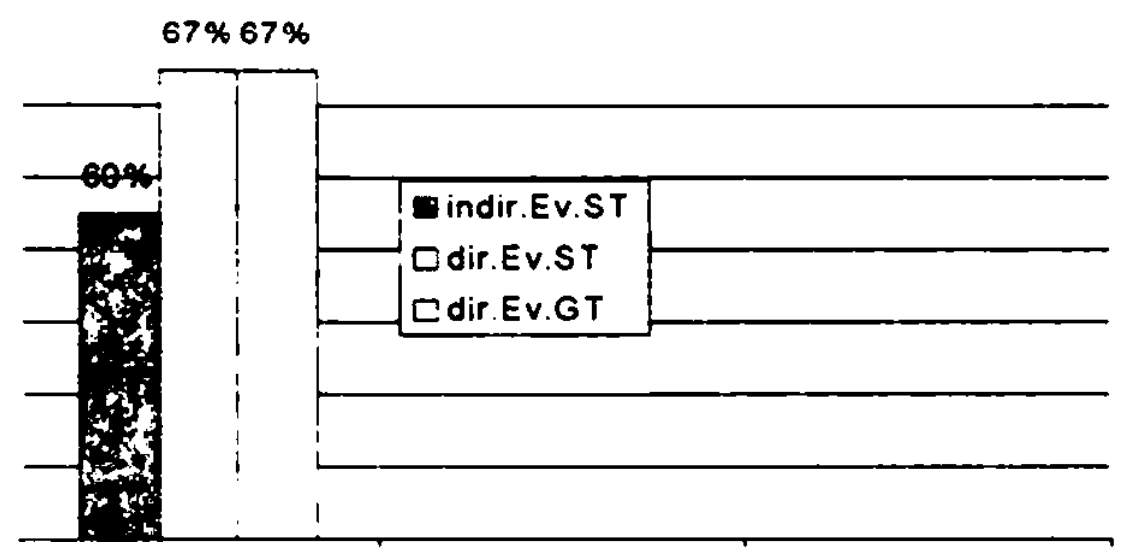

Kommentar: Mêlo by se odmalička mluvit na dêti spisovnè. Když se mluvi spisovnè, tak si na to déti zvyknou a taky tak mluvi. Je porad vètši trend $k$ náreči [hier ist das GT gemeint]. $V$ televizi náreci vadi, méli by mluvit spisovine.

\section{Pensionierte Buchhalterin, 65 Jahre}

Sprachverhalten. informelle Sitmation: im Haus der Respondentin beim Erzählen vor Zuhörern: Ehemann (pensionierter Elektriker, 65 Jahre, ohne Abitur), Verfasserin (Tochter)

- No, v televizi - tam byly nékolik rodin, a mladý lidi - a rikali, že tam dali veškerý svoje uspory. Jedny lidi rikali, že tam dali tr̉i sta tisic, protože chtéli si prostê koupit byt - jo - a voni tam jim rikali - voni rikali: taky zhodnoceni, jak veliký zhodnoceni - já uż si to ted' nepamatuju - jo - ale veliký zhodnoceni - a - ted'kon, voni ty lidi rikali: my nemáme ani penize. ani byt - a ữ. takovejch, tolika peñzz nenašetrime Druhy - dvè stẻ tisic - no - a ted'kon - co se stalo tady s tim - tou agenturou Zvonek. To jste slyšeli, ne?

Náká agentura realitni to byla - nebo já nevim - no prostẽ - prodávala byty a shánéla pro lidi byty - je zprostredkovávala. Ted'kon lidi - nčkolik lidi - asi dvacet - tanı dali zálohy na byty. Jedna rodina, ty jako to zaplatili celý, nedali jenom zálohu - dali asi pét set dvacet tisic. Jiný nejmiñ dávali dvê stê padesát tisic - a ted'kon naráz prosté agentura zaviela kancelár, zmizela. No jistê, vytunelovali to. No, a voni potom tam $v$ televizi to jako rozvádéli - vysvêtlovali to. Vona ta agentura Zvonek koupila - jả nevim - vod vojenskejch staveb Praha - koupila tady v Plzni ňakou ubytovnu a že ji - že to pìedélaji na byt - na byty. Jenomže vona ta agentura Zvonek zaplatila jenom ċást těm vojenskejm stavbám. A ted'kon prvniho brezna nebo prostě vod určitýho datumu méla dát druhou splátku - a voni už nedali nic. Tim pádem - ty vojenský stavby vod toho vodstoupily, ale ta agentura Zvonek ty penize vod têch lidi vybrala - a ted'kon - barák samozrejmé neni, lidi penize taky nemaj - a nikdo nevi, kde jsou. A voni rikaji ty postižený - $i$ kdyby je našli a vodsoudili, tak penize už stejné nedostanou. No, dneska mluvi vo miliónech, ċovec̀e Dneska r̀eknou: trì chlapi, bejvalý vysoký dủstojnici, který mčli spojeni s poslancema a prostês s vysokejma - têma - politikama, zpronevêtili pưl miliardy

Sprachverhalien, formelle Silmation: im Haus der Respondentin (o si my:slite o zyysouáni najjmú a poplatkú za plyn a elektrïm? 
- No, rozhodné to neni nic dobrýho pro důchodce. Protože důchody se zvyšujou minimálnę a neúmèrnè se zvyšujou najmy a elektrika.

Myslitc si. że ceny budou nadále stoupat?

- Ano - ne, myslim - ale $\mathbf{v}$ televizi se $k$ tomu dokonce priznali, že budou zase stoupat ceny i potravin. A to je oproti zajadnim zemím - to u nás to nejhorší. Protože $v$ západnich zemich potraviny jsou pomèrnẻ levný. Tak pak múžou bejt vo to zvýšený nájmy a energie. Myslite si, že z̈uotmi urroven bude klesat?

- Už klesla dost, a jestli bude dál klesat, pak nevim, jäk nás múžou prijimout do Evropské unie. A ješté orázka z jiné oblasti. Jaky máte názor na posledni mirnou zimu?

Poćasi je nevyzpytatelný. Nemam na to názor. Posledni dobou vủbec je počasi tak nepochopitelný, że - to neni jenom posledni zima.

Sprachverhalten.

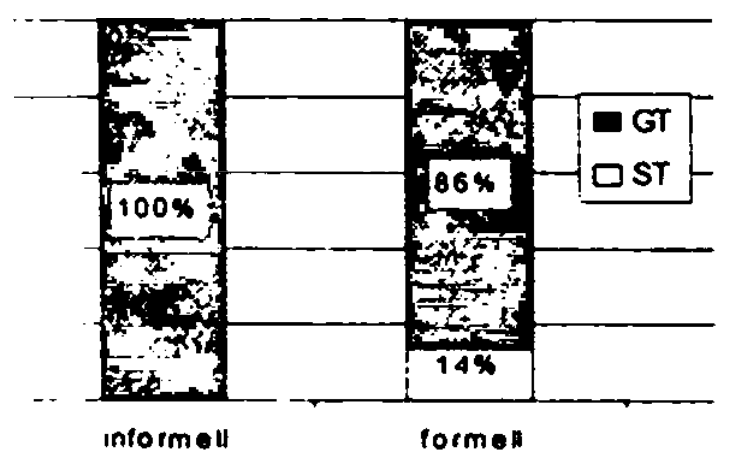

Einstellung kognitives Subsystem:
Einstellung, konatives Subsystem:

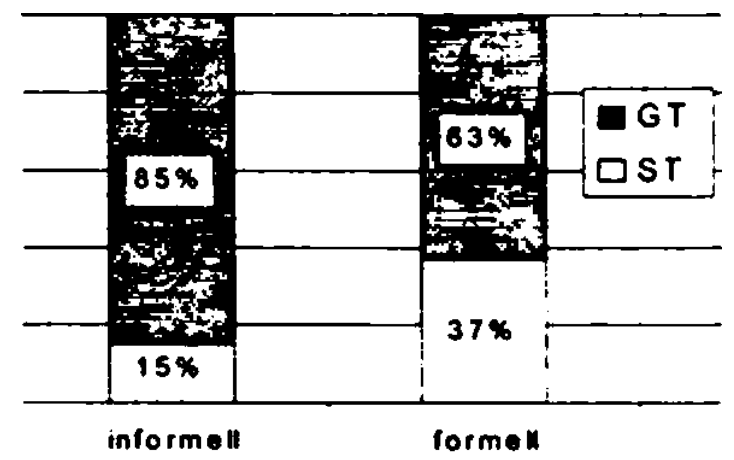

Evaluation der eigenen Kognition:
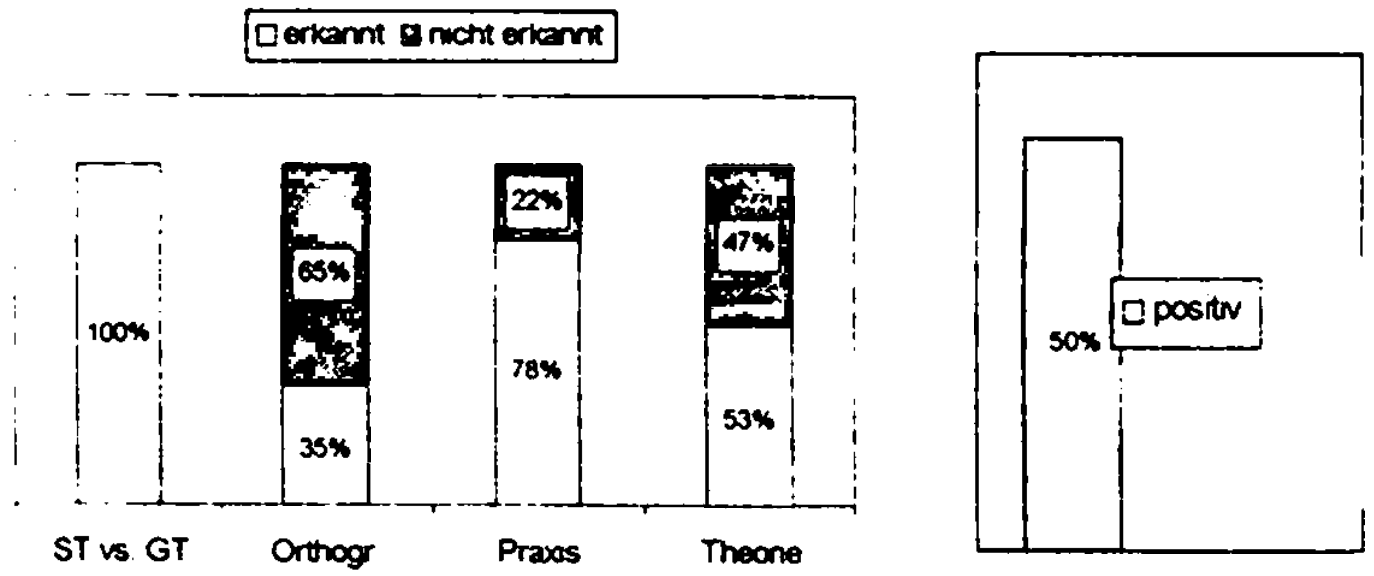

Finstellung, affektives Subsystem: Grad der positiven Einstellung

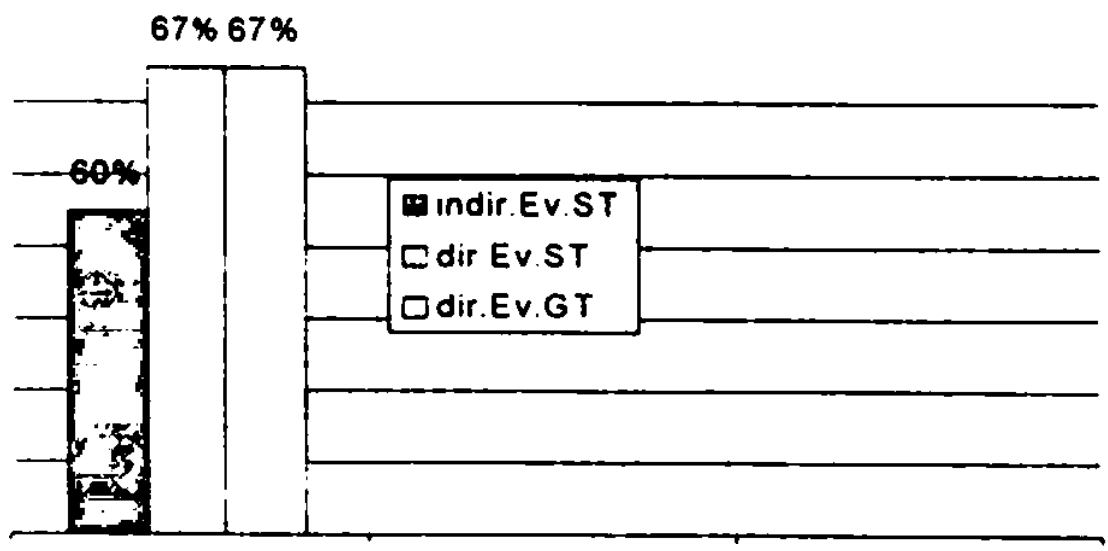

Kommentar: Nevadi mi, jestli se mluvi spisovnè, ale zảleži na dobrèm vyjadìovíni. 9783954790258 


\subsubsection{Frauen'it Abitur}

Alter der Resondentinnen: 20 bis 62 Jahre, insg. 7 Aufnahmen

\section{Kaufmänısche Angestellte (z.Z. als Boutiqueverkäuferin tätig), 20 Jahre}

Sprachverhal:n, formelle Situation: in der Boutique

Jakj máre nóor na momentálmi stoupáni cen " Ceské republice?"

- No, tak ja :myslim, że ty ceny - je to hrozný, že je tolika zvedaji. Vlastnè, oni zvedaji ceny, ale uźnezvedaji dủchody. Także si myslim, że taková prủmủrná rodina s jednim ditêtem, cožje $\vee$ dnešni dobè takhle jasný, tak jako, že se nemủžc naảk uživit nebo se nemúże svyn důchodem pokrỵt všechny ty ceny.

A jestiz otaza z jiného oboru. Co si myslite o posledni zime?

- No, posledi zima nebyla taková, jaká by mela bejt. Nebyl žádnej sníh, led taky ne, takže nic mc.

Máte ráda irné zimy. nebo radéji ty studené?

- No, já $\mathbf{m m}$ radši poráadnou zimu, kdy vopravdu je všude krảsně zasněženo. Mủžu jezdit na hor.

Sprachierha'n, informelle Sitwation: Gespräch mit der Verfasserin in der Boutique nach dem Interview

- Eštê sc taq podivam na tuto, jo. Já nevim, no - tak (...)

(A jakou jis delala skolu?)

- Soukromoubchodni Tady je i statni, ale potom tady v Plzni jsou eštc dvè soukromý (A kolik toho.idy prokicite?)

- No, tak von jak kdy, treba nčkdy to jde - nčkterej den - a nčkterej zase ani korunu. A kór, $k$ dyż. ied'ko ude hezky, tak prostẻ lidi budou chodit ven. A my jsme teda až. na konci. a treba lidi prijdou a eknou si: 'No punçocháce'. Já jako vim, že tohleto neni zrovna nejvhodnčjši misto (...).

- Já myslimako celkové, żc všude se mluvi jako jinak. Já vim vždycky, když jedem na Moravu, tak rostê se aklimatizujem. To prostê okamżitê zainu mluvit moravsky. Ale prostę hned. A muj amarád rikal - von je z Mariánských Lázni - von rỉkal: 'já mluvim, jak chci, no. Jednou tak a odruhý tak'

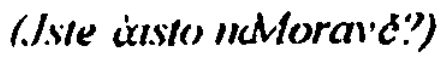

- No, já jsentam byla jako dite, tak trii roky. Jako - jenom, protože mé tam vždycky jako soupli - a hlicjte mé tam. Ale tam je to hezký, mnẽ se to libi na Moravê. Tam jsou uplnê jiný lidi. Choaji se $k$ vàm hezky (...).

- Jà uż jsem rodávala $v$ textilu, prosté brigády. Protožc když. ta prodavačka nemá náladu dobric - ale tosou precc jako osobni dủvody. Ale já prosté nechápu, když já mám nčjaký problemy, talproc bych méla bejt neprijemná na toho zákaznika, kterej za to nemúže jako, kterej sprišsel koupit to zboži. 
Sprachverhalten:

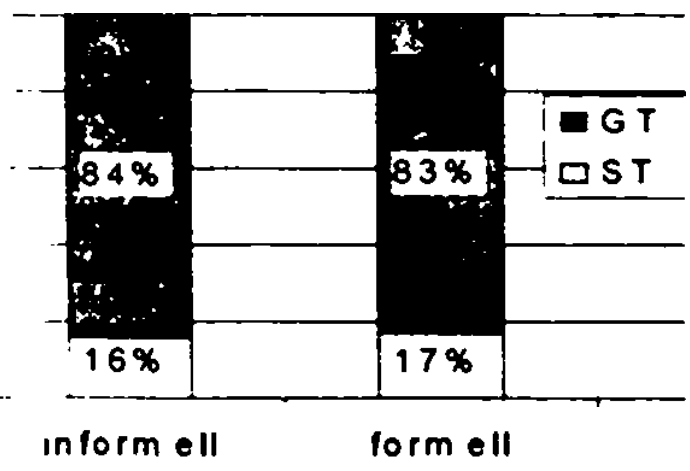

Einstellung, kognitives Subsystem:

Cerkannt E nicht erkannt

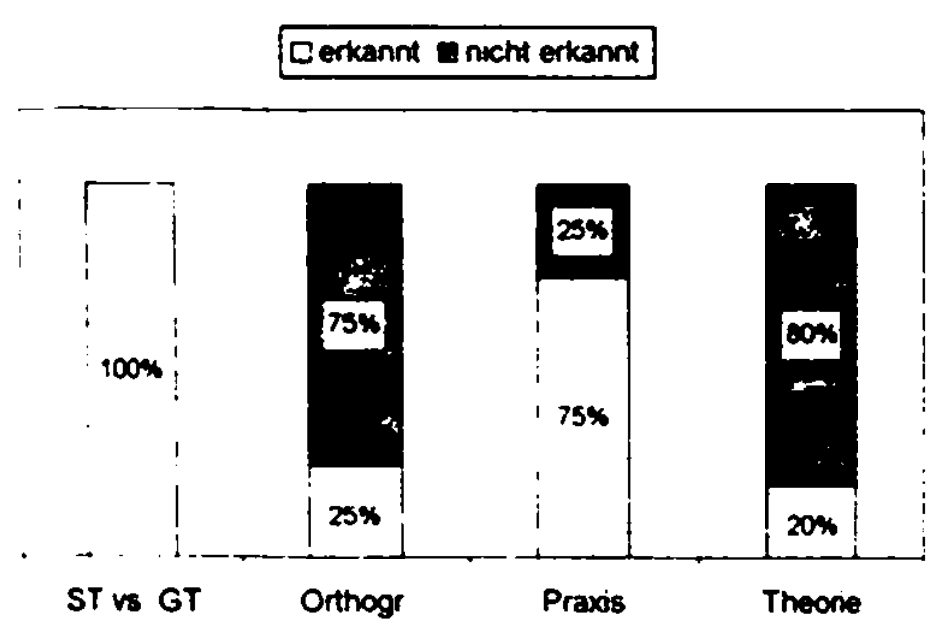

Einstellung, konatives Subsystem:

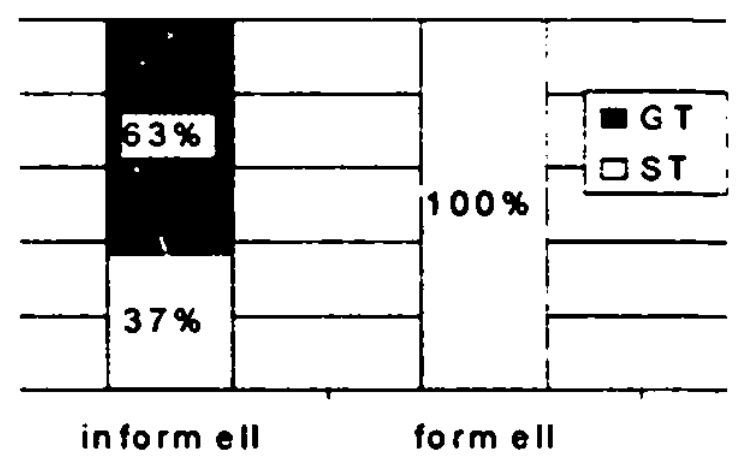

Evaluation der eigenen Kognition:

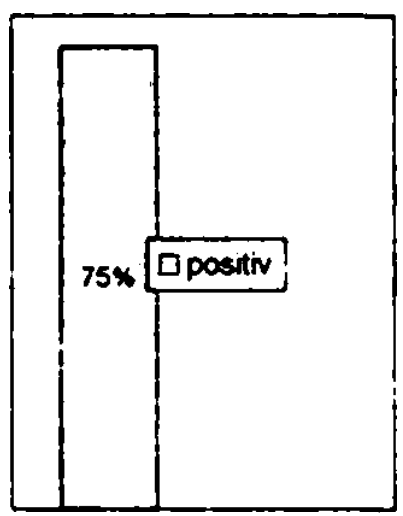

Einstellung, affektives Subsystem: Grad der positiven Einstellung

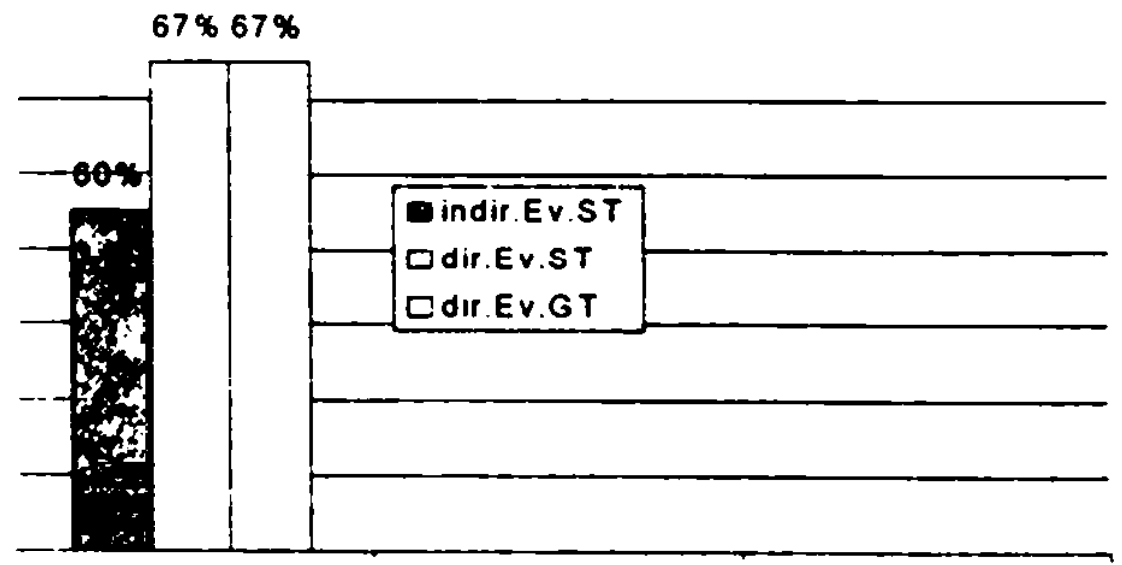

Kommentar Zanášeni vulgarizmủ do ceskèho jazyka je mnohdy až. nechutné, protože tim lidé hanobi ceskyj jazyk. 


\section{Sekretärin. 33 Jahre}

Sprachverhalten, formelle Simation: am Arbeitsplatz der Respondentin

Jakj máte názor na zvyšováni cen v Céské republice?

- Můj názor na zvyšováni cen v Ceské republice je asi takový, že si myslim, že to nutný je. Otázka je to tempa - jestli to tempo vyhovuje nebo nevyhovuje primèrenẻ k platům. Asi tak. A jaky' je l'áă názor na zryšsováni nájemného a poplatkủ za elektrimu? Tỷka se Vảs to?

- No, samoż̉ejmč, zvyšovảni nájmů a poplatků se tỷká každýho. A jả si myslim, že je dobrie, abysme co nejdrive dohnali tu hranici, na kterou se mà občan dostat s poplatkama, ale jako je zase nutný, aby ty poplatky nepokrivaly některý náklady firem, který se vlastnê nemčly by dotỳkat toho občana - zvýšené nẻjaké vnitřni režijni nảklady.

Dckıji. A jiná otázka: Libila se Vàm posledni teplá zima?

- Nelibila, podle mé má být zima studená. Nemá být teplá. Člověk je takovej pořád unavenej. $\mathrm{V}$ zimé mả bỳt zima a má se lyžovat - a prostẻ mit tu zimni vnitřni náladu.

Sprachverhalten, informelle Situation: Gespräch mit der Verfasserin (bekannt nur durch das Interview) am Arbeitsplatz der Respondentin

- No, co jste s tim chudảkem udělala, vżdył byl jako rak ċervenej (...).

- No, to je jako dost težkyy. Jả jako když jsem doma, tak mluvim jako vic nespisovnè, ale kdyż jsem jako tady $v$ zamèstnáni, tak vic spisovné. Vono to nejde jako mluvit tak, jako mluvim doma

\section{Sprachverhalten:}

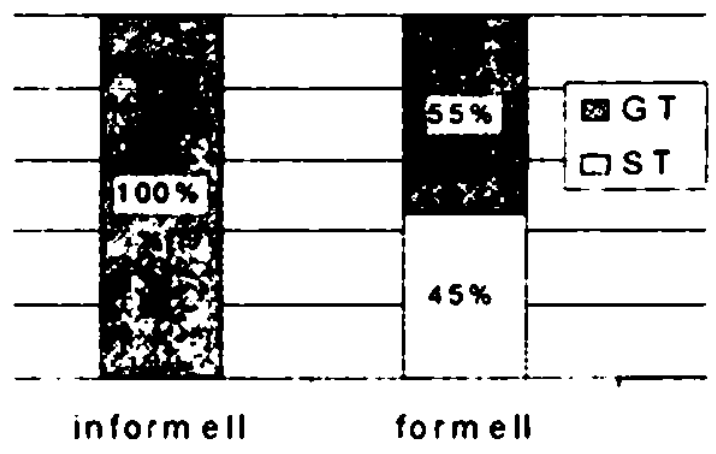

Einstellung, kognitives Subsystem:

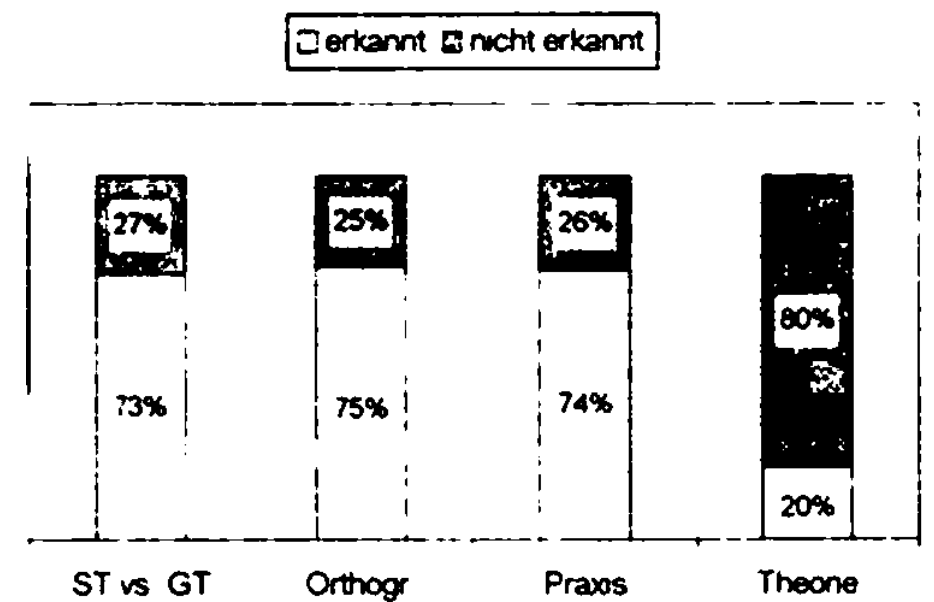

Einstellung konatives Subsystem:

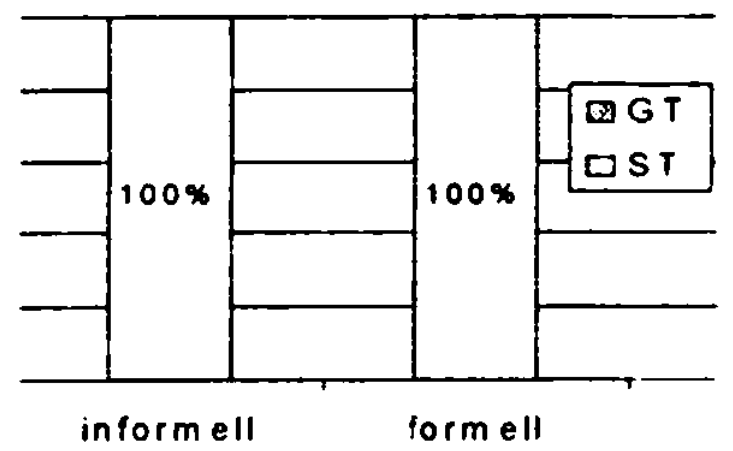

Evaluation der eigenen Kognition: 
Einstellung affektives Subsystem: Grad der positiven Einstellung

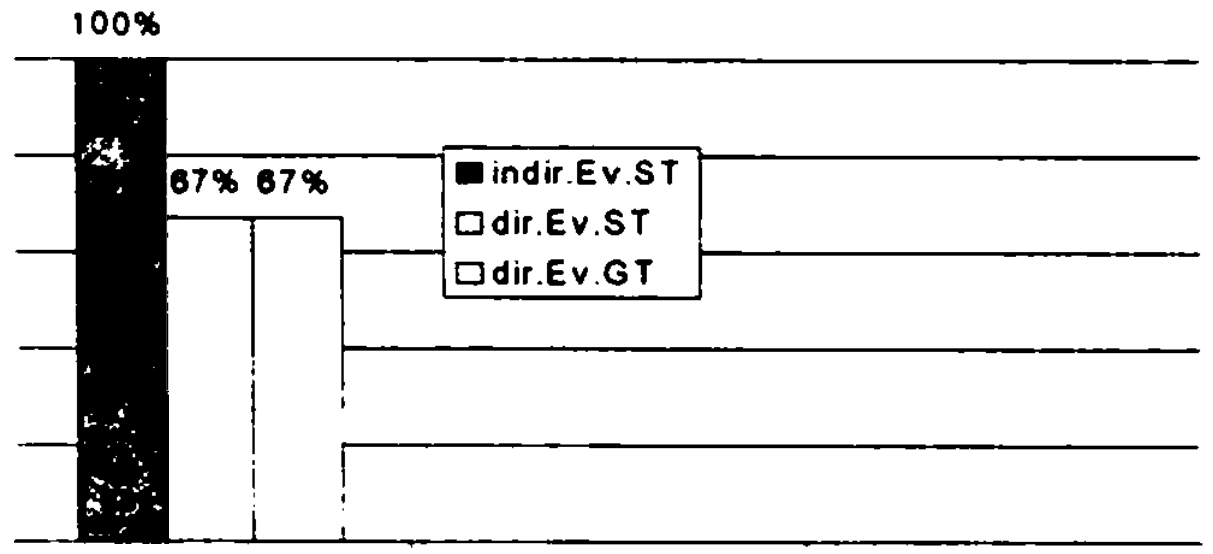

Kommentar: ohne Kommentar

\section{Selbständige Buchhalterin, 50 Jahre}

Siprachverhalten, formelle Simation: in der Firma der Respondentin

Jaky máte názor na zvyšoväni cen $v$ České republice?

- No, názor. Nevim, jak bych to vyjädrila. Myslim si, že ty ceny nékde se zvyšujou jako neadekvátnč teda têm nákladům. A že by tomu zvyšováni asi nemuselo $v$ téhle miře docházet. A konkrétmé ke ży:šováni nájemného a poplatkủ za plyn a za elekttim!?

- No, rozhodl nčkdo nahore a s tim jako těžko my tady mưžeme néco dêlat, jo.

A ješst otázka = jimé oblasti. Jaky máte názor na posledni zinm!?

- No, zima byla velmi mirná. Pro mé to bylo prijemnè, protože ve messte - pokud je nçjaký snih nebo prostê ta breçka - tak to je velmi nepríijemný. Takže vzhledem $k$ mýmu pracovnimu vytiženi, tak ta zima pro mé byla letos velmi prijemná.

A máte dojem. ic ta replà zima somisi nejak s chripkorou epidemii?

- Asi ano, protože tohleto je podnebi - ty teploty jsou takový proste - ani zima ani mráz, jo. Takže je to docela dobrie možný.

\section{Sprachverhalten:}

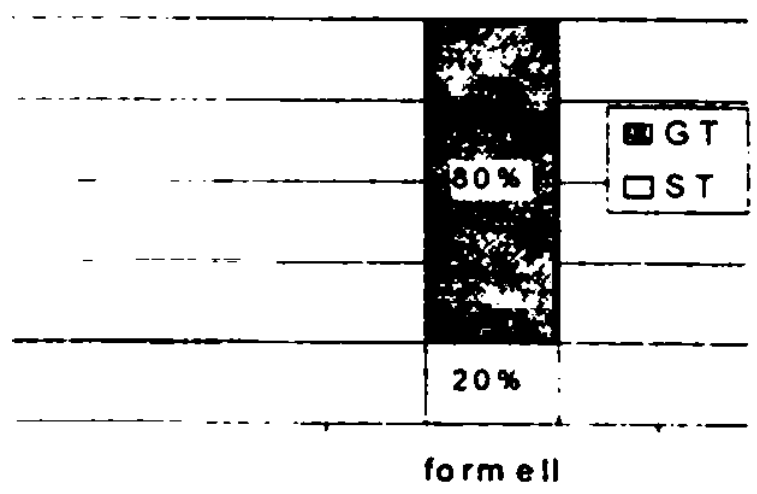

Einstellung, konatives Subsystem.

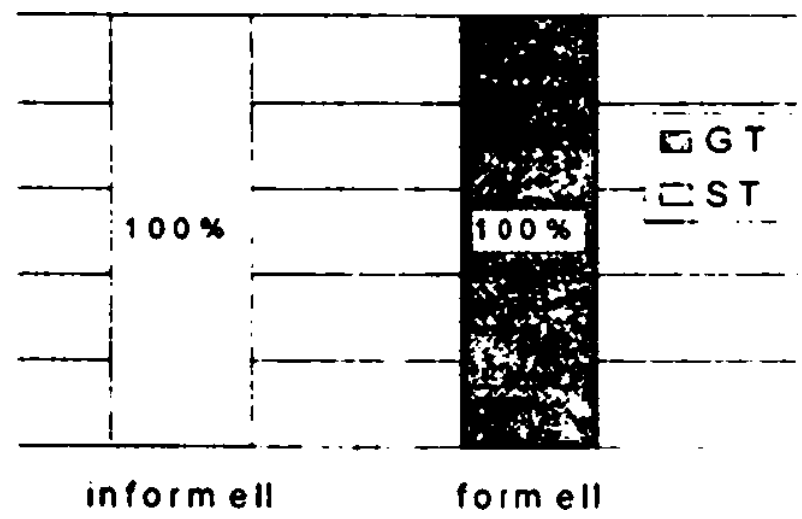


Einstellung, kognitives Subsystem: Dekant Dridt efart

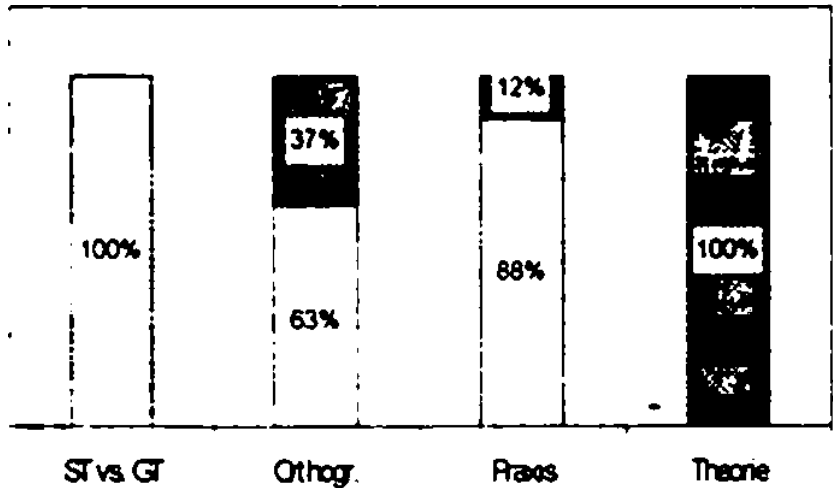

Evaluation der eigenen Kognition:

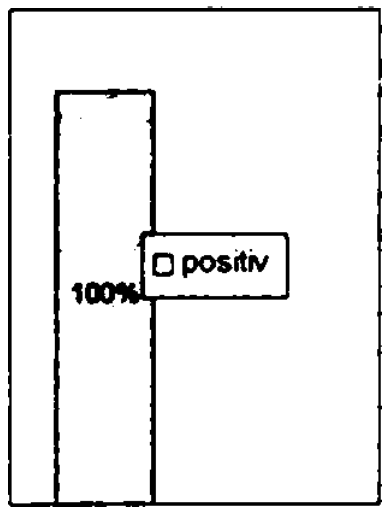

Einstellung, affektives Subsystem: Grad der positiven Einstellung

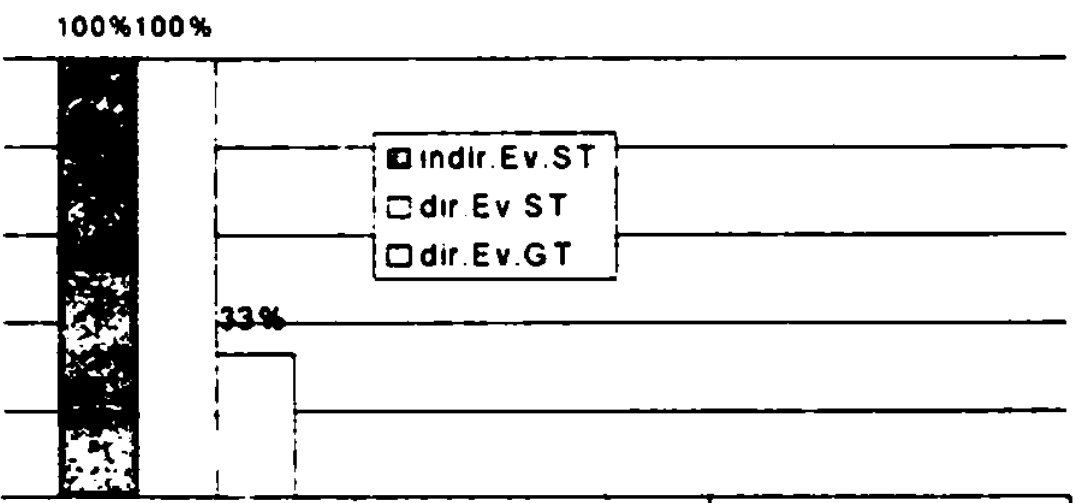

Kommentar: Človêk si nad touto anketou uvẻdomi, jak nepêknè zni dialekt, kterým hovori. Ale dlouholeté vlivy prostredi, ve kterèm komunikuje, zanechávaji stopy. Piesto je nemilé. když. slyši nespisovny jazyk $z$ rủznych medii. Kèž by tato anketa priméla hodnẻ lidi, aby se snažili upravit svoji mluvenou icei na prijatelnou miru.

\section{Buchhalterin, 55 Jahre}

Sprachierhalıen. formelle Situation: am Asbeitsplatz der Respondentin

Co si myslite o somiasmin zyysováni cen v Ceské republice?

- Myslim si, že je dost vysokè - pro normálniho človčka - jak bych to ìckla, neúnosnè. A konkrimuco zyysovaini najemmiho a poplatkü za plyn a za elektrimu?

- Najjemné mé osobné se netyká, ale myslim si, że je vysoké, plyn, elektrika - tèž.

A orázka zjime oblasti. Jakj máte nȧor na posledni mirnou zimu?

- Nebylo to špatny.

lám osobne 10 vyhovovalo?

- Man rada zimu, ale mam ràda i teplo. Radši mam teplo.

A läs uazor na souciasmon chripkovou epidemii?

- No. letos mi to postihlo po dlouhý dobz - a zabralo to doccla

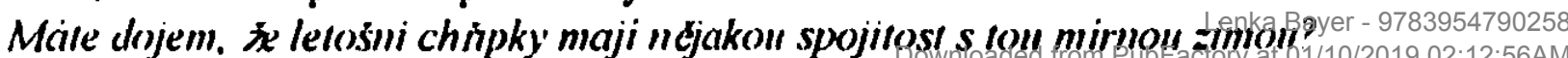

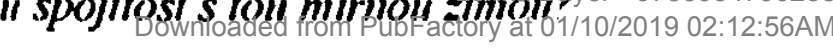


- Myslim si, že je to asi spojený s tim, že zima byla mimá. No, tikả se že bude oteplováni. takže bude asi stejný ten cyklus, jako byl letošni. Protože posledni dva roky je ta zima stejná.

Sprachierhalten, informelle Simation: Anmerkungen beim Ausfullen des Fragebogens am Arbeitsplatz der Respondentin

- Tak na tohle já vám nevodpovim, to já nevim. Ale pane mistr, nedellejte tady na mé ksichty. Protože to je takovej - jo - šprýmaŕ. (...) Ježišmarjà - Ceštinu. No jo, no tak - Mistr Jan Hus. To to takhle mam škrtnout, když to nevim, jo? Ježiš - jả už si to nepamatuju, jả už jsem ze školy taky asi dvacet let $(. .$.$) .$

No, to už si nepamatuju - a vnoučata zase už jsou velký. (...) Ale, tak - to jsem teda nemêla ale jo, dobrý, v pohode.

Sprachverhalten:

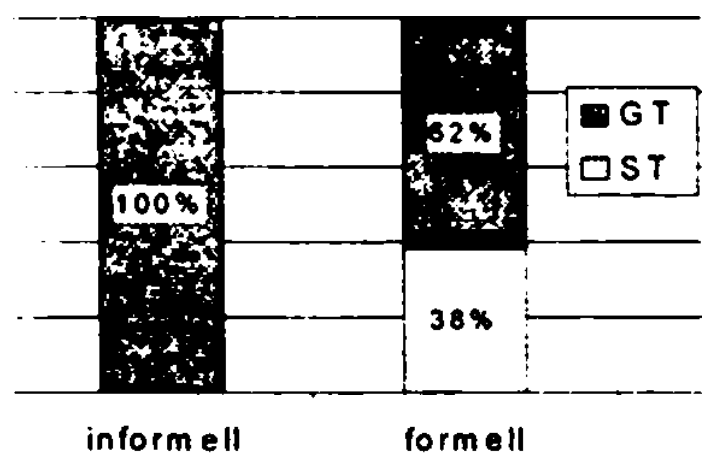

Einstellung, kognitives Subsystem:

Derkarnt B nictit erkant

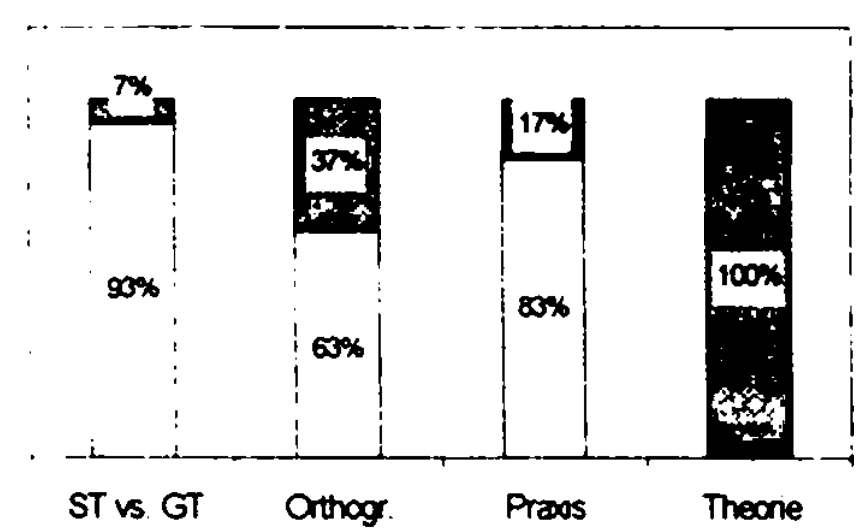

Einstellung, konatives Subsystem:

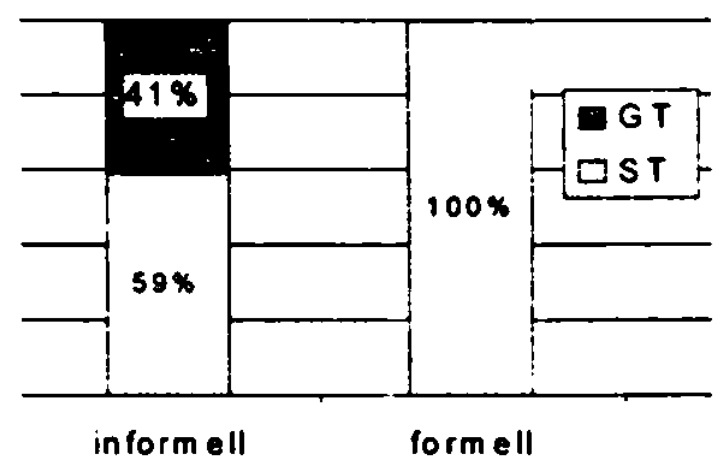

Evaluation der eigenen Kegnition:

Einstellung, affektives Subsystem: Grad der positiven Einstellung

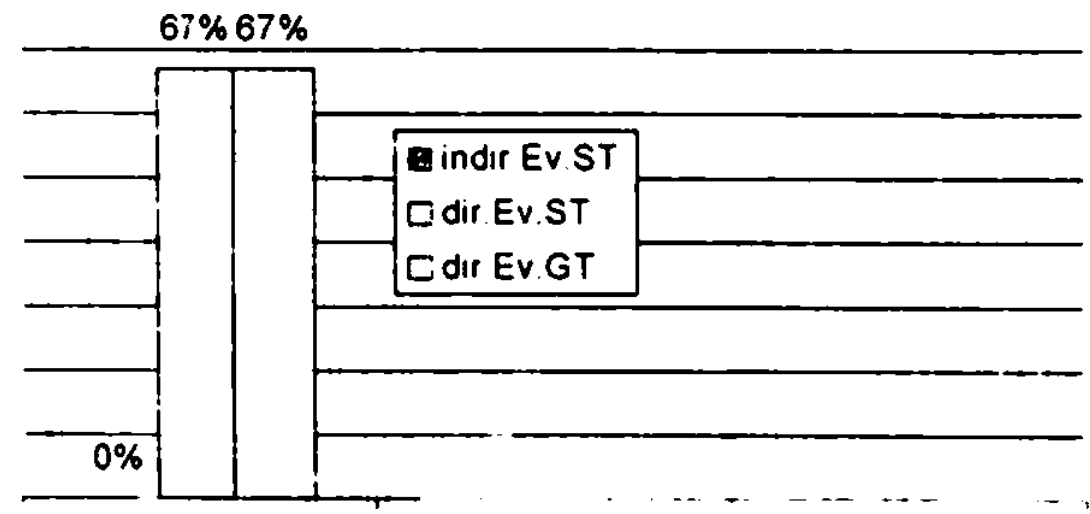

Kommentar Kritizuji castẻ použiváni cizich slov $\mathrm{v}$ televizi. 


\section{Verwalterin im Lager, 55 Jahre}

Sprachverhalten, formelle Simation: am Arbeitsplatz der Respondentin

Jakj máte názor na żyšováni cen momentälnè ve Ceské republice?

- No, je to fascinujici. Pro stredni vrsturu je to eště jakž takž ucházejici, ale pro lidi, který maji nižši prijimy - tak je to až nckdy nechutný. Asi tak bych rekla $\mathrm{k}$ tomu. A konkrérné te d' - akıualmi zuýšeni nájemmého a poplatki za plyn a elektrimu?

- No, taky s tim nesouhlasim, protože napred lidi - bych řekla - bláznili tim, aby si každy் dával elektrický topeni, ekologický topeni, a nakonec, kdyż si to tr̉eba dủchodci, protože už nemaji tolik sil, aby mohli topit uhlim - dali si primotopy, dali si elektrická topeni - tak jim to zvedli tak vysoko, že aby ted' chodili a dali jedny kamna a chodili nčkam do lesa na šš̌ky a topili si tak. Protože je to neúnosný, na ty platy, který se berou, je to neúnosný

A jes̀t

- Já dobrý, protože mné to vyhovovalo, zvlášt tedy na to topeni mi to vyhovovalo. A zimu osobné iá moc rảda neman, takže jsem byla rảda, že byla zima mirná.

A do budoucna? Mále dojem. ż̉ budou zimy replejsi ane bo zase prijdou krute zimy?

- No, nejlepši by bylo, kdyby byly zimy takové, jako byly $z$ détstvi, kdy se skuteċnè stridalo to léto, jaro, léto, podzim, zima a byly ty zimy se sněhem a s mrazy a nebylo tolik nemoci, ale tak jak se dovidame, že zemčkoule se otepluję, tak zrejmẻ ty zimy nebudou už tak krutý anebo prijdou takový kalamity, že to jako nikdo asi nedokáže předpovêdèt dopìedu.

Syrachrerhalten. informelle Situation: Gespräch mit der Verfasserin (bekannt nur durch das Interview) am Arbeitsplatz der Respondentin

(Aha. Iy jste zahradnice. To je vsechmo l'ase?)

- To je všechno moje. Sklenik.

(No. rak roje pckinj).

- No. pæknný. Tady to jsou rajský. Tuto jsou rajský a tuto jsou papriky. Tuto všechno (lo je perrislka, ne?)

- Ne, to je celer. Von napied je takhle ze semineček a porom se musi prepichat, aby zesilit. To je hrozná prace - podivejte, jak je to maličký (...).

- Tohle nevim teda. ježiš - to je vostudy. Tohle já si vủbec nepamatuju. Ale tu cešstinu - ježiš - vìdyt to jsme se všechno uciili.

\section{Sprachverhalten:}

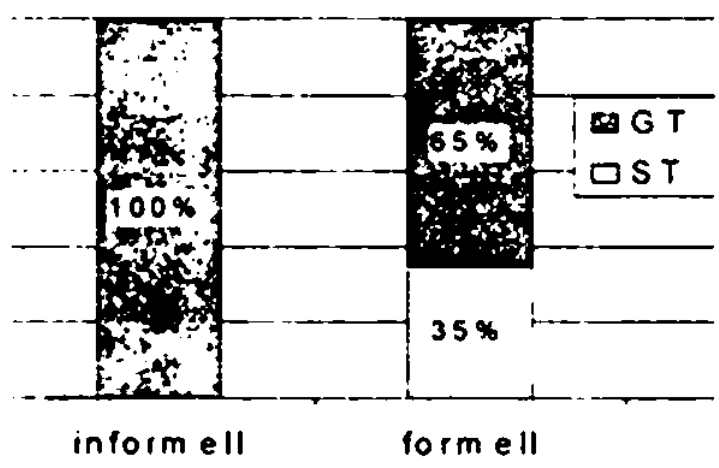

Einstellung, konatives Subsystem:

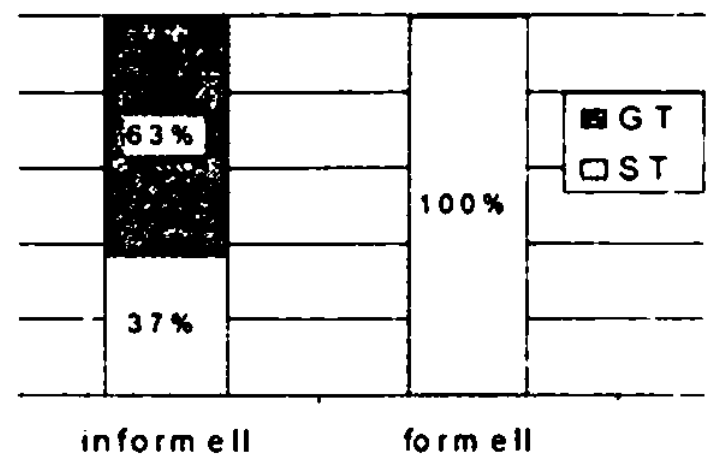


Einstellung kognitives Subsystem:

Dorkannt E nicht erkannt

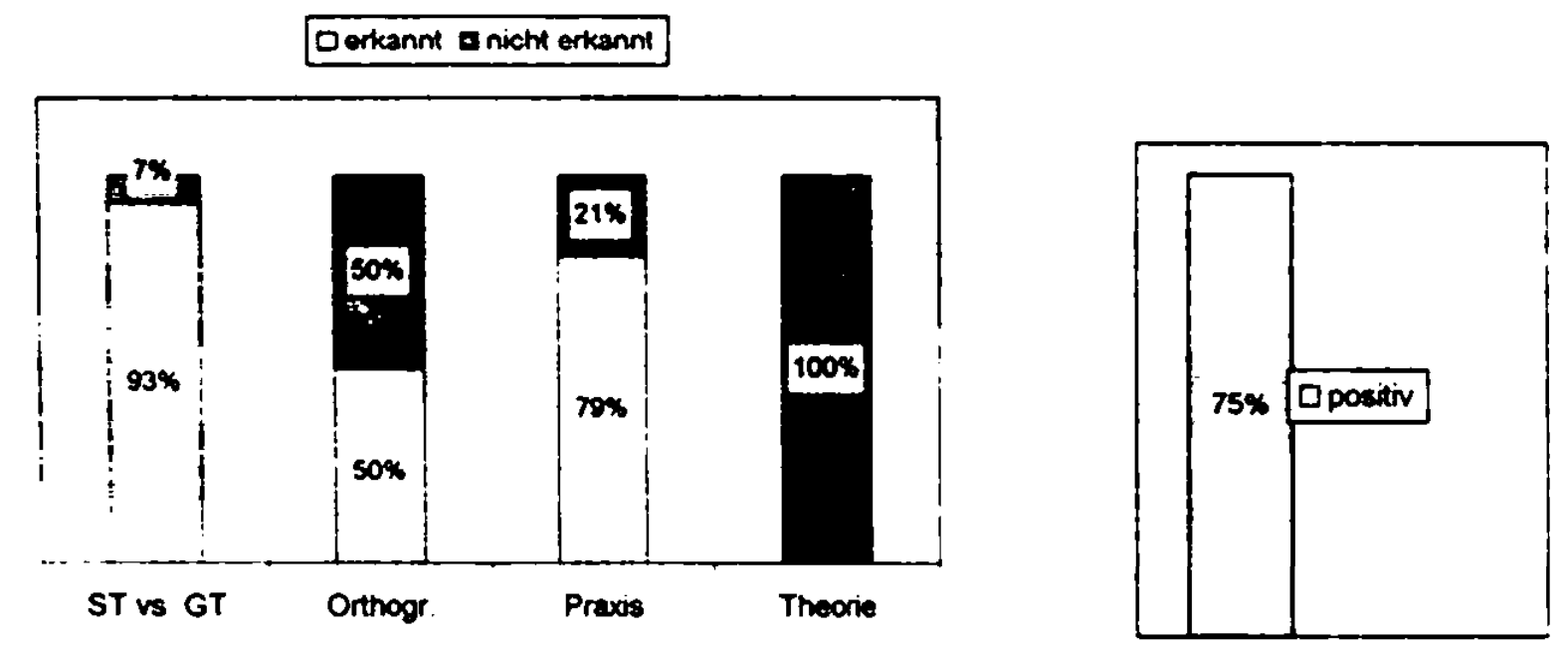

Evaluation der eigenen Kognition:

Einstellung, affektives Subsystem: Grad der positiven Einstellung

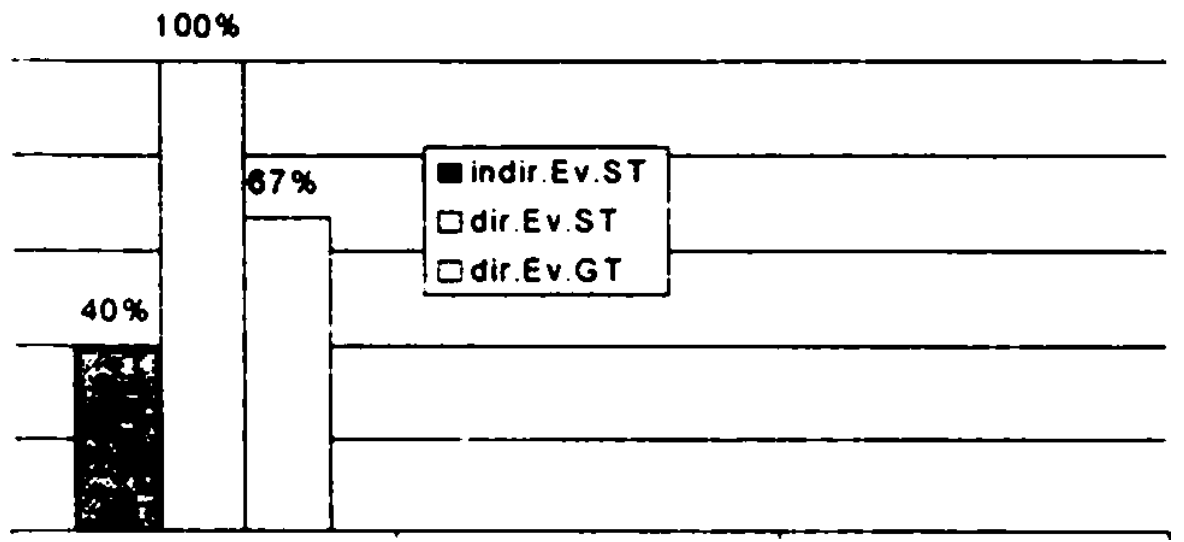

Kommentar: ohne Kommentar

\section{Krankenschwester, 58 Jahre $^{101}$}

Sprachverhalten. informelle Situation: Telefongespräch mit der Verfasserin (Bekannte)

- Jè, ahoj!

(Já j.sem stras̀né zvólavá, co má lladka.)

- Chlapecika A je strašné hodnej - no.

(Tak ix ma radost?)

- No tak má to viš - no Jả byla z toho celá špatnà, no ale, už je to dobrý (..) - No. byl pěknej, jenže musela jit na cisałskej ṙez.

(To hyl primi cisaskej iez?)

- Pruni. no. No, méla to takový špatný. Von mêl trì kila - trii a pủl kila - a furt cekali do posledni chvile - no. a potom už museli, protože už prestal dýchat. a tak museli. Tak to viš, ze zacàtku byla $z$ toho úplné špatnà, až. jsem ji nadávala. No tak, už je to dobrý

(No - lak to mita tejky: A jimak - jak se jim dari??)

- Ale jo. jde to, no. Protoże musi se setkávat s tim prunim. no.

I'"' Dieser Respondentin wurde der Frageboden ausnahınsweise zugeschickl 
(Já na ni tak casto myslela. Jà taky byla nemocná kolem Vänoc.)

- A už je to dobrý?

(Já jsem ted' momemáhe zutravá. ale bylo to dost zly.)

- A neviš, jestli tatinek má zitra volno? Nemá, vid'? Já totiž jedu s Michálkem do Plznè.

Má zitra volno.)

- Von Michálek vodjiždi v šestnáct dvacet pêt. Takže bych možná stihla se na nẽj mrknout.

Má wolno. my jdeme zitra do divadla vod sedmi. Także bude doma. Tak prijd'.)

- No, uvidim, jak já budu na tom casově - no. Kolik já tam mam ċasu. Asi hodinu, no. Vono je blbý, že nemá telefon.

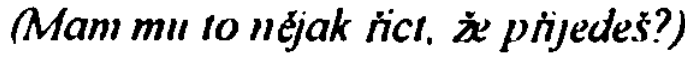

- Nojo, $v$ šestnáct dvacet - $v$ pủl pátý tam určité budu - na nádraži.

(A jimak je " vás v'sechmo v' porídku?)

- No, von strašné má rád toho malýho. No, a jinak, že s tim druhym - viš - se musi stýkat. ( $A$ maminka je " porádku?)

- No, tak maminka sem tam. No, někdy jako nemúže dejchat - viš - a takový

(Hale, moc v'sechmy' krásné pozdraiıj. Já to táıovi dneska rekmu.)

- No, v pưl pátý já tam jsem.

\section{Sprachverhalten:}

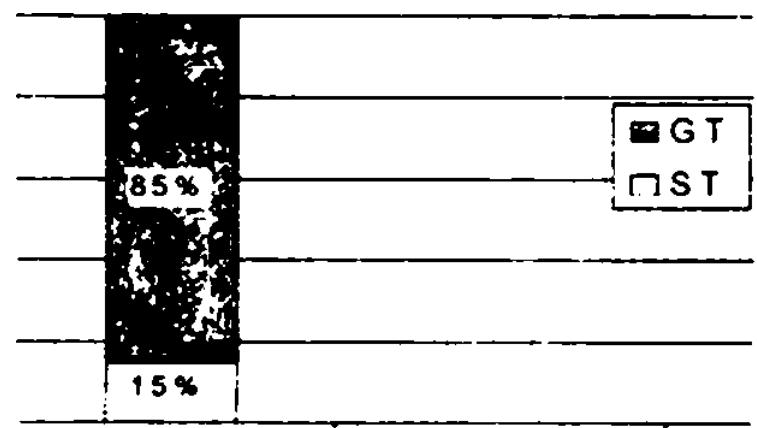

in form ell

Einstellung, kognitives Subsystem:

Gerkannt E nicht erkannt

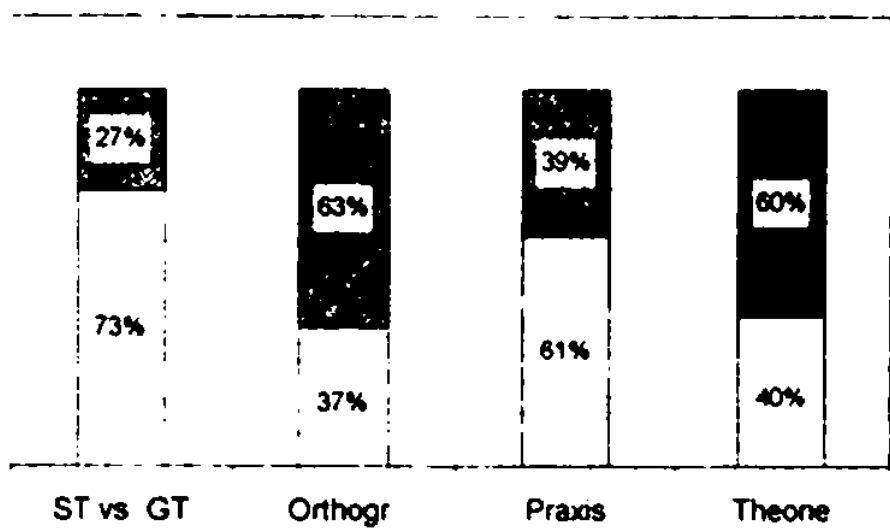

Einstellung, konatives Subsystem:

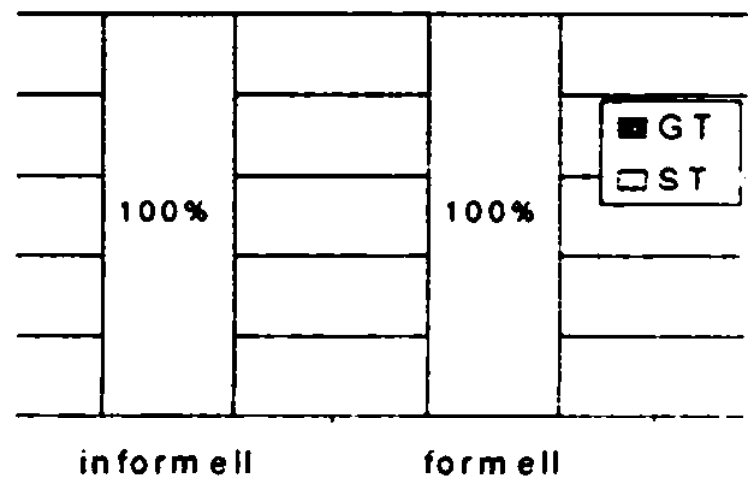

Evaluation der eigenen Kognition: 
Einstellung, affektives Subsystem: Grad der positiven Einstellung

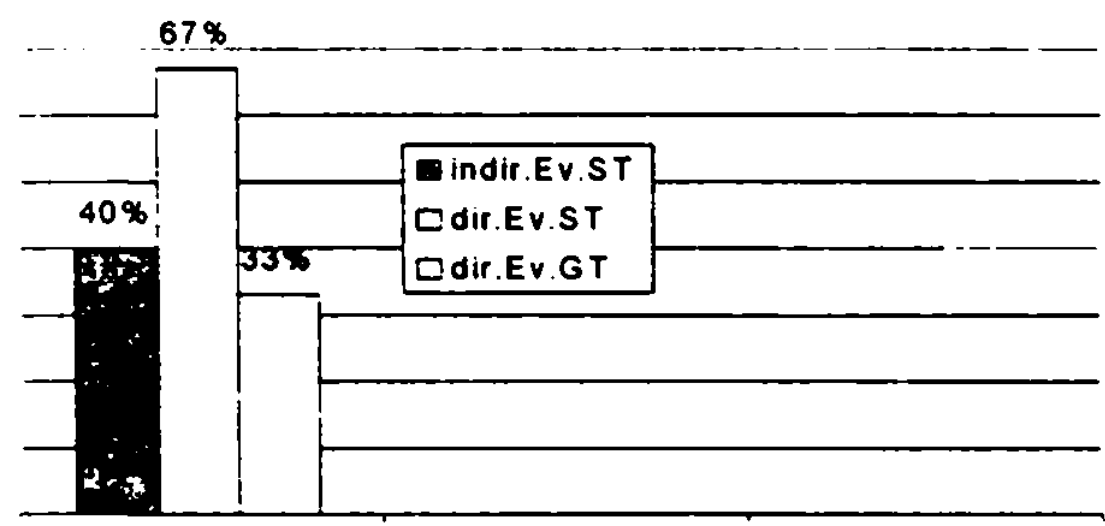

Kommentar: ohne Kommentar

\section{Pensionierte kaufmännische Angestellte, 62 Jahre}

Sprachverhalien, formelle Silmation: im Haus der Respondentin

('o si myslite o momemálnim suyšsoväni cen v Ceské republice?

- No, vo zvyšováni cen si myslim to, že pro ty nižši vrstvy je to jako dost těžký. No, a nedà se nic dèlat, protože naše republika ty penize nemá.

.lakj máte názor konkrétmé na zyysováni nájemneho a poplatkü za plyn a elektrinu?

- No, to je to samý. Jestliže ten stát na to nemá, no tak to musi ty uživatelé a spotrebitelé uhradit Stát dá jenom tolik, kolik mủže.

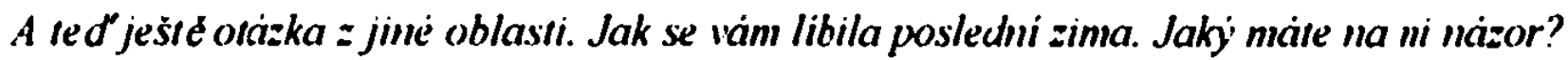

- Posledni zima byla špatná, ponévadż nebyl snih. Hlavné dêti to neužily. Kdy všechny déti maji vlastné nakoupeno za plno penezz ty lyże a boty a všechno, no a naši treba byli lyżovat dvakrát za celou zimu.

Myslite si. ze letošni chripkove obdobi s touto mirnou zimou nejak souvisi?"

- No, já bych rekla, że ano. Ponévadž kdyż je porádná zima, jako byla tr̉eba loni, kdyż to všechno vymrzlo, tak prece jenom tẻch bacilü asi je menê.

Sprachverhalten, informelle Sitmation: im Haus der Respondentin im Gespräch mit der Verfasserin (flüchtige Bekannte)

- Tatinek mi dal tady trii čokoládový vajička, tak mam $i$ vejplatu. (...) Jà to $v$ żádnym pripadê. Já to za prvé vủbec nejim, vübec ne. Ježišmarjà, já to netikam proto, jako abyste mi nẻco dala. Vždył já jsem vám dlužna ešté jak jste mi tenkrát privezli domú tuhle s têma ť̉̌kkejma taškama. Tak se nevzrušujte.

(Tak 10 meni pro vás, ale pro holky.)

- No, voni jsou na horách. Teda, vráti se až. v nedêli. Jcžiš, tak děkuju.

Nechcete aspoñ uvarit kafe? 
Sprachverhalten:

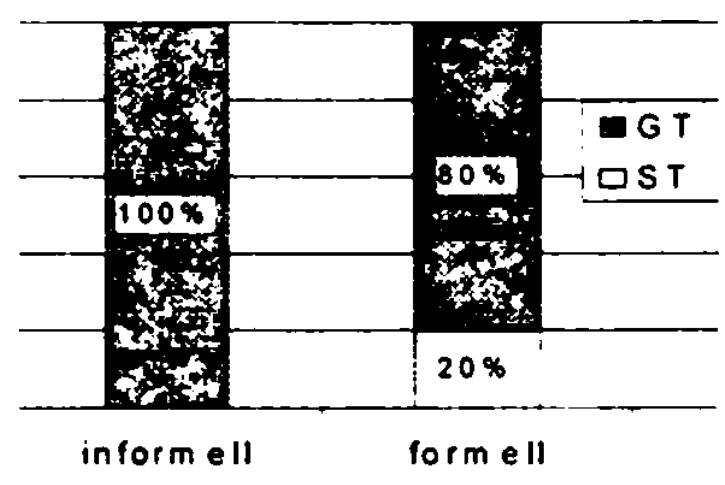

Einstellung, kognitives Subsystem:

Cerkannt a nicht erkannt

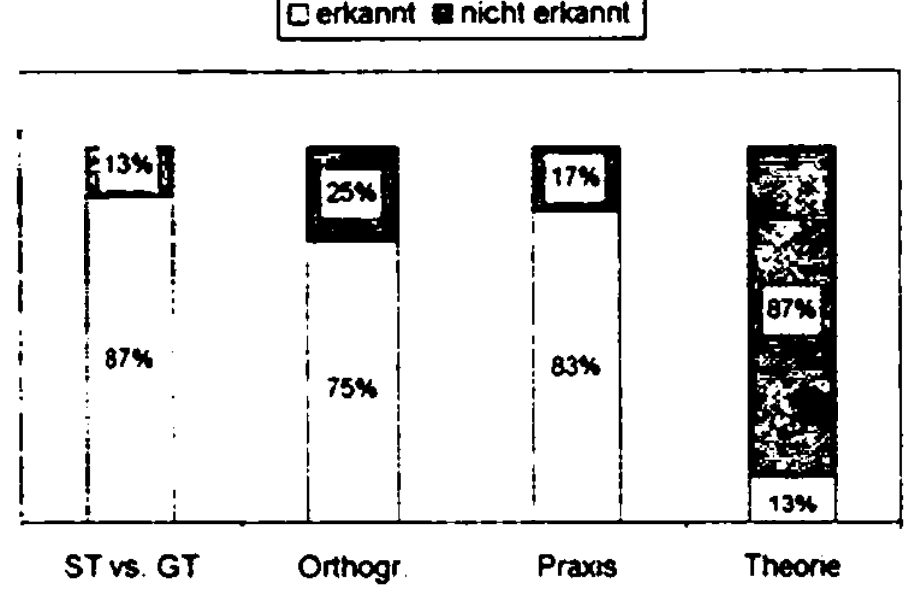

Einstellung, konatives Subsystem:

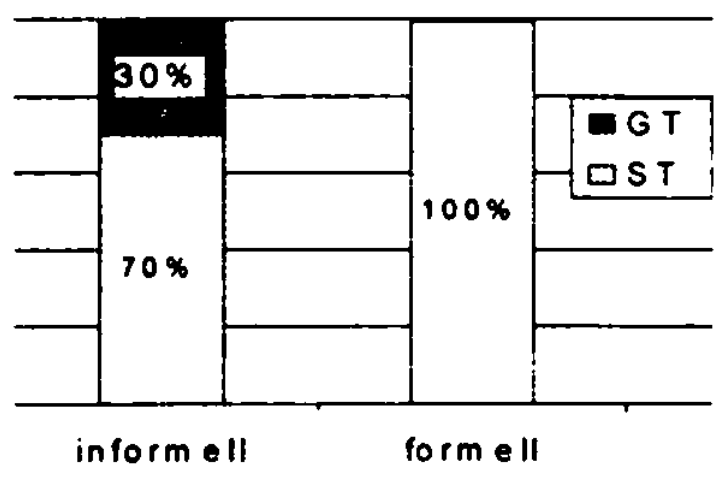

Evaluation der eigenen Kognition:

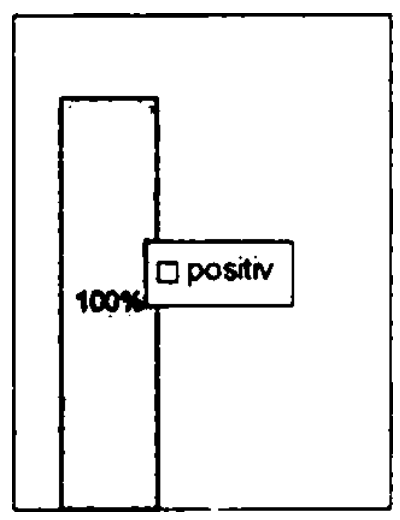

Einstellung, affektives Subsystem. Grad der positiven Einstellung

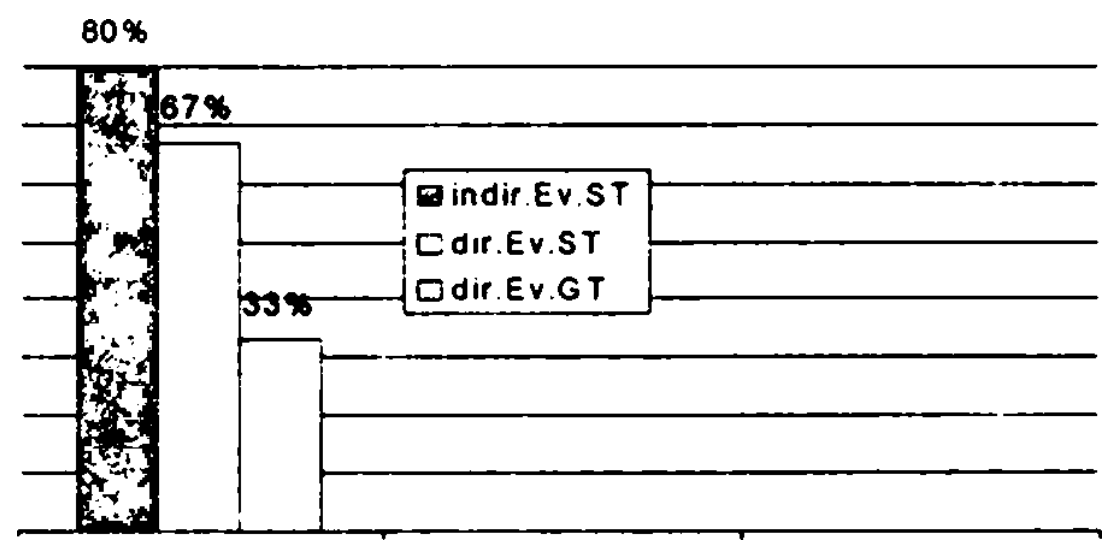

Kommentar: ohne Kommentar 


\subsubsection{Frauen mit Hochschulabschluß}

Alter der Respondentinnen: 25 bis 63 Jahre, insg. 7 Aufnahmen

\section{Betriebswirtin, 25 Jahre}

Sprachverhalten, formelle Situation: angesprochen mit Mikrofon auf der Straße

Jakj máte názor na posledni zimu. Byla studená nebo teplá?

- Tak, byla rozhodné lepši než ta loňskả, protože loni jsem byla teda nemocná. Takže jsem ven nevycházela - a letos se mi docela libila.

Màte ráda teple zimy?

- No. ja nemam ràda vỉbec zimu, takže

A jaké jsou vase výhledy do budoucna? Myslite si, be budou zimy teplejsi nebo studenejsi?

- Tak má se teda oteplovat - skJenikovej efekt. Ale nevim. Taky se to projevuje spiš v našich sférách asi naopak, že jo. Jsou vêtši zimy, je miň slunička.

Sprachverhalten, informelle Situation: Gespräch mit der Verfasserin über die bevorstehende Feier in Prag zum 650. Jubiläum der Karlsuniversität

- Jak jsou ty oslavy, tak to bude celej rok, nebo

(Tak to vám nepovim.)

- Já jsem ted' sice v Praze, ale že by se s tim nèco délalo. Já myslela, že to bude trošku vic, no. No a ted'ka, ted'ka o tomhle vikendu má bejt nẻco - den oteviených dveri nebo tak néco. (...) Jsem myslela. že jako když je to šest set padesát let, že to bude nějak

\section{Sprachverhalten:}

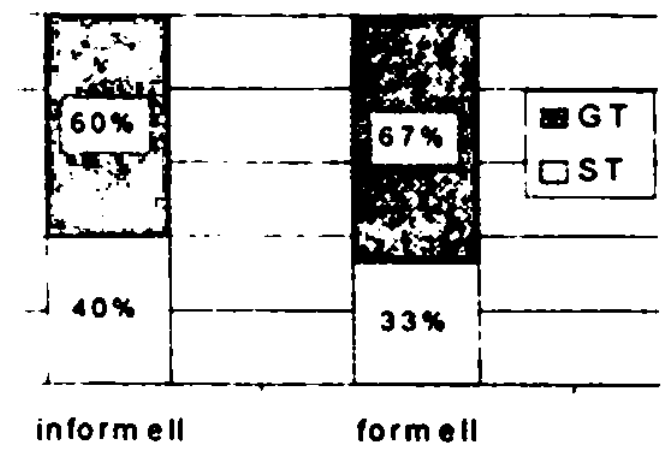

Einstellung, kognitives Subsystem:

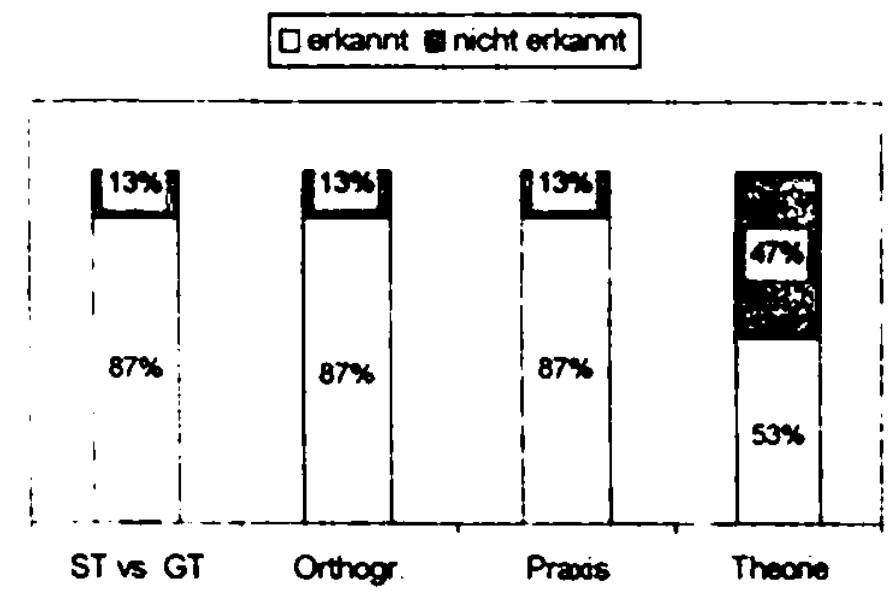

Einstellung, konatives Subsystem.

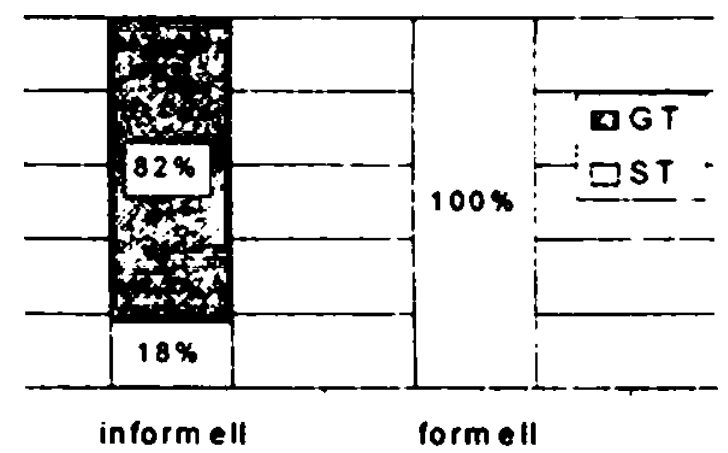

Evaluation der eigenen Kognition:

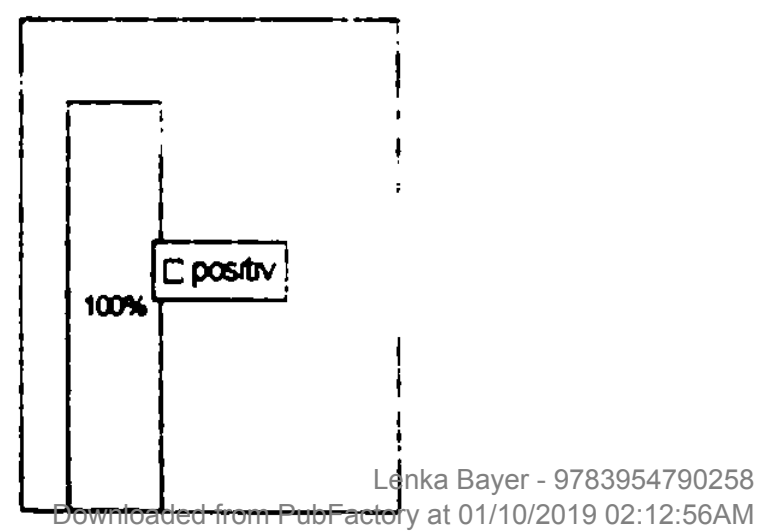


Einstellung, affektives Subsystem: Grad der positiven Einstellung

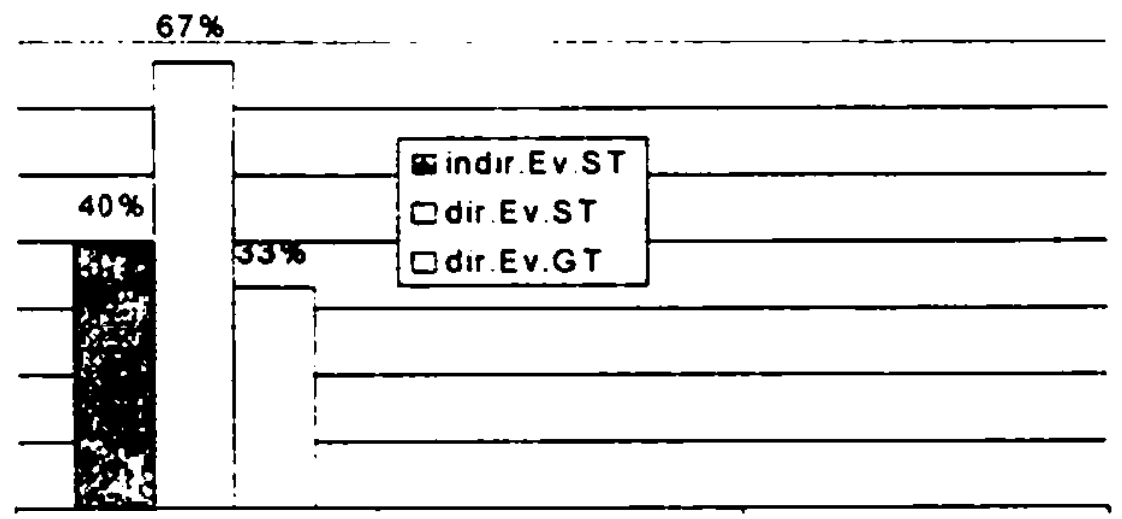

Kommentar: ohne Kommentar

\section{Ingenieurin, 32 Jahre}

Sprachverhalten, mformelle Sitmation: in der Wohnung der Mutter im Gespräch mit der Verfasserin (fluchtige Bekannte)

Aj mále ale krasingiho Sarpeje.)

- No, von je takovej hodnej

(A l'y se ucile srowna?)

- Ne, já pracuju. (...) No, jả uż nejsem tak mladá. Mně už bylo tr̛icet dva let.

(Ale ly nemále żadny' vrásky.)

- Jà mam vrásek kolem voči. Jả to mam hlavné vod slunicka a taky z tý zimy - my jezdime ċasto na hory, no. (...) Ja jsem si zase vzala práci domu, protože my prìšti pátek vodjiždíme na hory - a pak - co jä budu na horach. (...)

- Jà kdyż se podívam u nás v práci, tak jenom Jolana - ta je z Moravy - mluvi spisovnè. (...) To jako pronajmy, to jako už. samotnej najem - jako takovej - ne. (...)

- A mcla jsem šilenej nákup. Už jsem to neprepočitávala, że jo. Že to je jako pétistovka ted’ je to - nebo šest stovek. Tak jsem riikala: triicet marek, ježišmarja - co já si koupim u nás za tricet korun. Jako když. to vezmu - jako v tom prepoc̀tu na plat, tak to bysem nekoupila nic.

Sprachverhalten, formelle Simation: im Haus der Mutter der Respondentin Jaky máte názor na ziysoráni nájemmeho a poplatkü za plyn a za elektrinu?

- V Ceské republice - myslim si, že je to neưnosný počin od naši vlàdy, a myslim si, že zvýšeni cen näjmủ a elektrriny a energie je neúmčrný ke zvyšováni platů $v$ České republice. Także si myslite. ¿̇u hy z̈ivolmi iroveñ mohla klesat?

- Rozhodnè se nebude zvyšovat, pokud, teda, se nebude snižovat, protože už i u nás existuji nizné vrstvy, a myslim si, że stredni vrstva, která má bỳt, teda, údajné nejvice početná - tak urcitể v této stredni vrstvě se bude snižovat żivotni úroveñ.

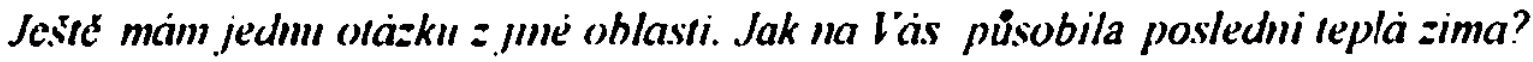

- Tepla zima? Tak to budou asi deprese, stavy úzkosti, nervozita, človčk už se těsi, že bude por̀ádný jaro.

Myslite si, be hudouci zimy hudou rake rakove reple? 
Sprachverhalten:

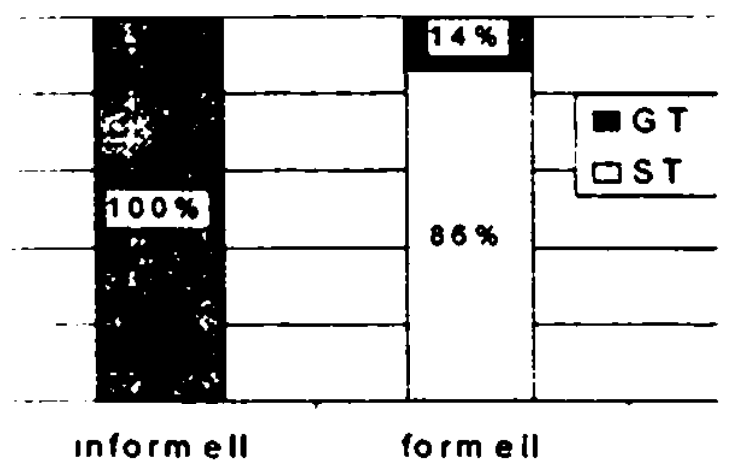

Einstellung, kognitives Subsystem:

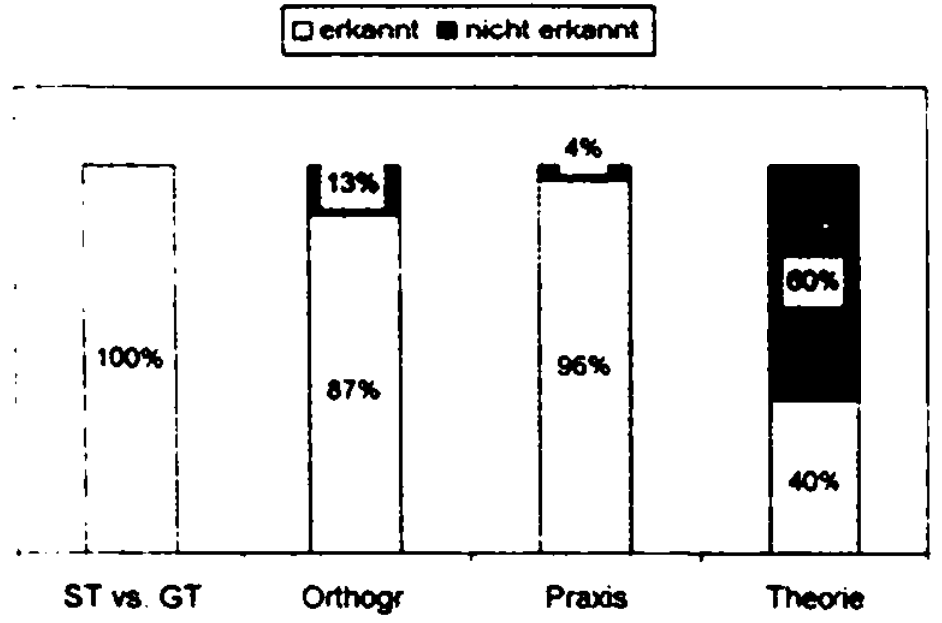

Einstellung, konatives Subsystem:

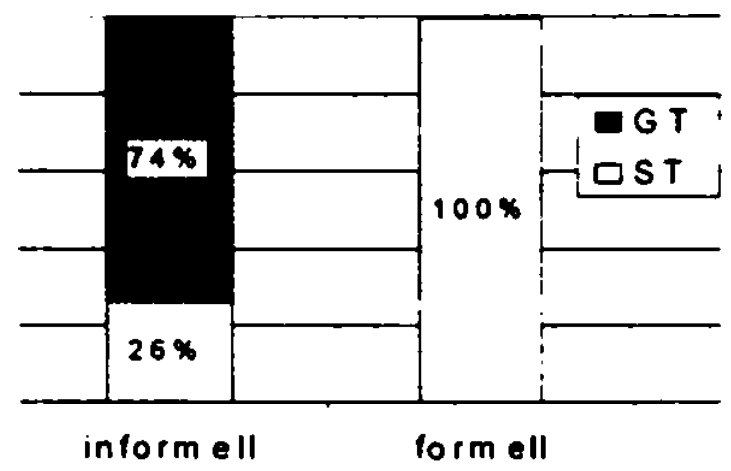

Evaluation der eigenen Kognition:

Einstellung, affektives Subsystem: Grad der positiven Einstellung

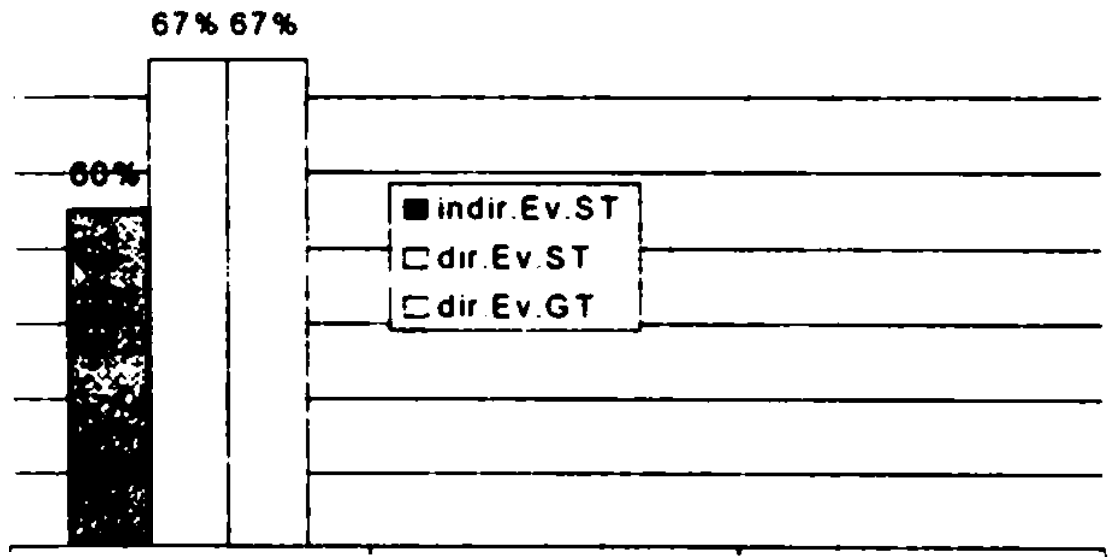

Kommentar: Myslim si, že spisovná cešstina by mêla prevládat zejména v pisemném projevu. ale $i v$ rozhlase a televizi.

\section{Grundschullehrerin, 35 Jahre}

Sprachverhatten, informelle Situation: Gespräch in der Wohnung der Respondentin mit der Verfasserin (Schulfreundin) u. a beim Ausfullen des Fragebogens

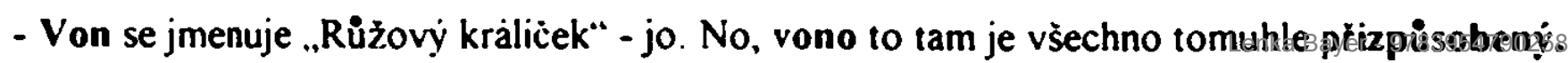


- A viš, že jsem si myslela, že tam bylo žlutý. Já jsem to sama dostala vod tý mami - teda. No, voni právè holky to nemaji rádi. (...)

- Takže jako mam vopravit chyby, jo? Jako jenom pravopisný chyby, jo?

Nechceš ty pamtofle. náhodou?)

- No, jä je nenosim. Jà chodim furt úplnê bosa. Mnẻ to je pràvě płíjemný, no. (..)

- No, jà nevim. Já bych napsala tłeba $v$ parlamentu. No, to neni oblast. Já napišu tedy hlavni mèsto. To je blbost ale. Podle mè se nemluvi nikde. No, nemyslim si, že by se někde mluvilo. Nikde se nemluvi spisovnè, ani ve škole. Jà jo - teda. Ale dẻsnẻ mi to zatežuje. Ale taky se mi vod zári stává. že na svý holky zar̀u nèco spisovnè, ale hned na tu hovorovou, viš. A to jako i když pišu dopisy. Ty pišu taky spisovnè a ani mnè to neprijje. (...)

- No, covecie - jako dokázali, ale vobčas tady s tẻma hadicema. To je jako ċtyìmi, dvěma - to se mi furt plete - jako, jo.

(Ale dokážeš tak mluvit, ne?)

- No, nékdy jo, nẻkdy ne. (...)

- Ten mastif je podle mé hezči - teda, když je jako velkej. No my jsme viděli s tátou krásnýho. A takovej krásnẻ bẻžovo-zrzavej. Ten byl tak nádhernej Malýho bych mit nemusela, to teda radši už tu kočku, než malýho psa. (...)

- Kritiku na anketu? Viš, co si myslim? Jak je tam takový to „starýmu, novymu“ - to že se spiš v Praze asi použivá. Než tady v Plzni - jako, jo. Jà tł̌eba nemluvim doma tak spisovné, ale tuto zrovna nepouživam. No, jả to nevim, já si to myslim, když tr̉eba slyšim Bohdalku v televizi, tak mi to docela i vadi.

Sprachierhalten, formelle Siluation: in der Wohnung der Respondentin

Co si myslite o naristini cen v Ceske republice? Konkrèmé o ziysovaini najemmèho a poplatkú za plyn a za elektrimu?

- No. že je to hroznè. K tomu nic jinýho rict nemúžu, je to fakt zoufaly

Jaky máte pocil do budoucha?

- No, vzhledem $k$ tomu, ze muž zacal podnikat, tak když. to pưjde dobłe, tak snad by to teda jako nás nemuselo nčjak ohrozit, ale jestli bude muset délat normální práci, tak - my jsme byli do ted'ka na podpore - a myslim, že to bude pokraciovat.

A ješlé otcizka z jime oblasii. ('o si mysliti o posledmi zime?

- Strašnẻ nàs mrzelo. že nebyl snih, protože jsme nemohli chodit sáňkovat.

A jake hudou polle vajeho nazoru budouci zimy"?

- No, já doufam, že to bude lepši, protoże rádi máme snih a koulovačky.

\section{Sprachverhalten:}

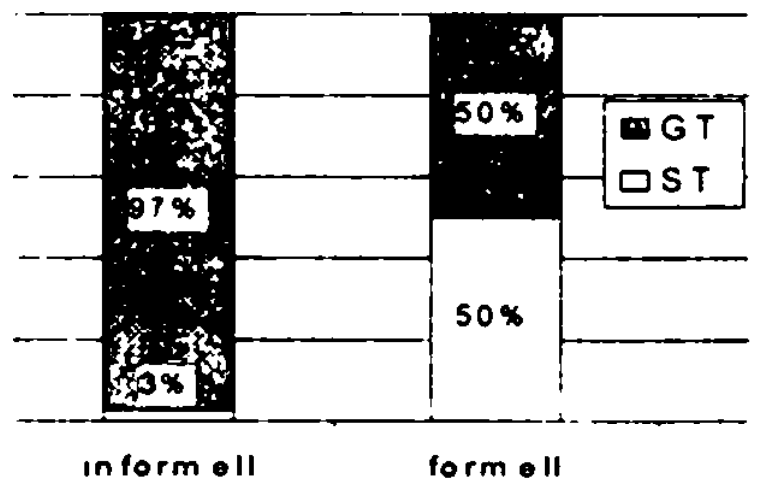

Einstellung, konatives Subsystem.

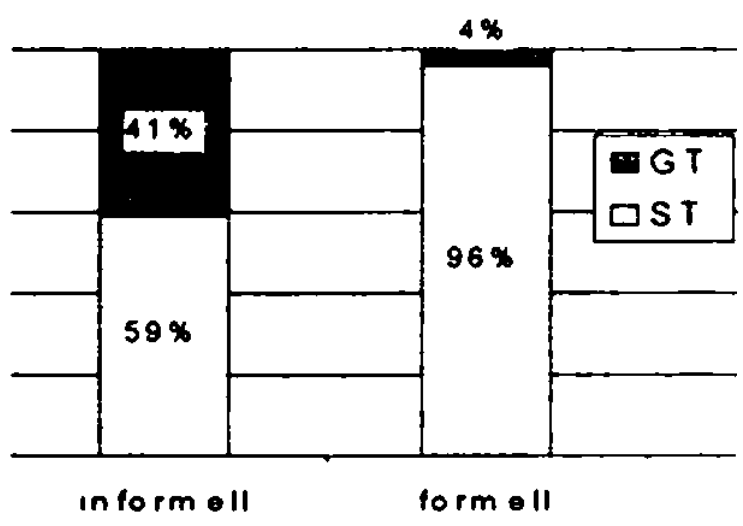


Einstellung, kognitives Subsystem:

Uerkann wicht erkannt

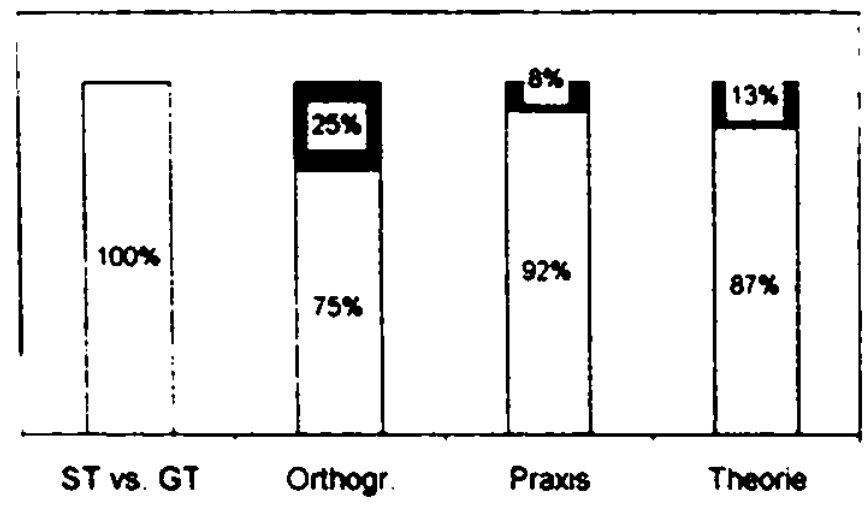

Evaluation der eigenen Kognition:

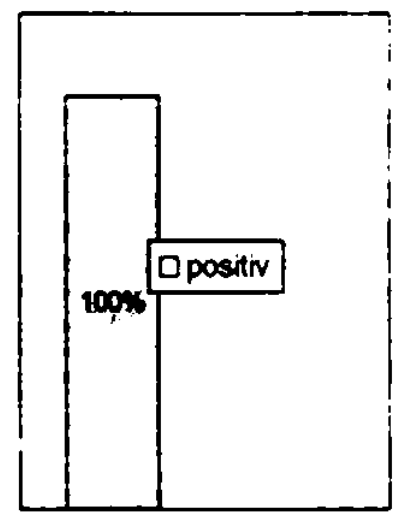

Einstellung, affektives Subsystem: Grad der positiven Einstellung

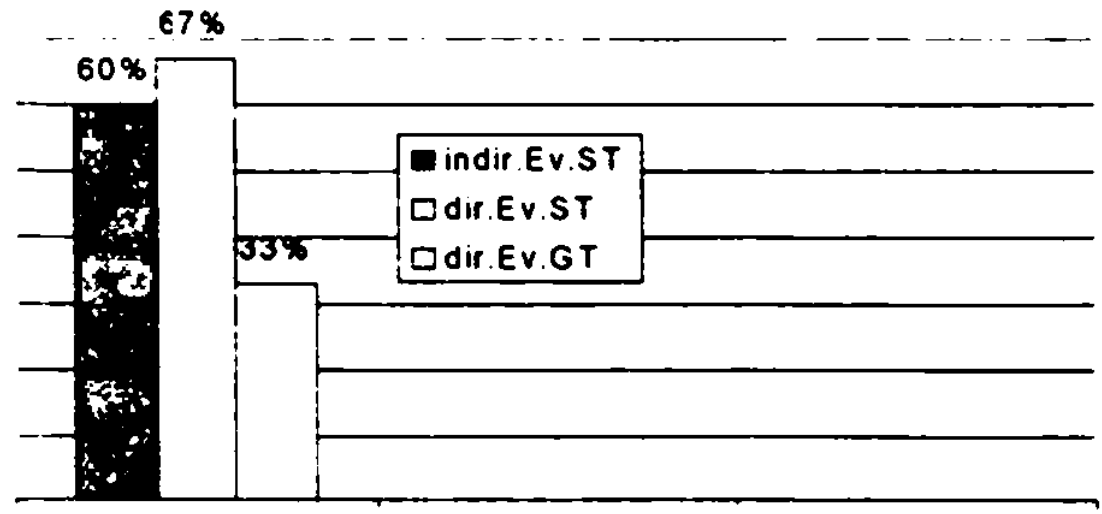

Kommentar: Pod bodem 2 jsou většinou pražské varianty. V Plzni se mluvi spisovnèji.

\section{Richterin, 35 Jahre}

Spracher/malten. formelle Simation: Bei verschiedenen Gerichtsverhandlungen (konnten leider nicht aufgenommen werden) sprach die Respondentin ausschließlich Standardtschechisch $(100 \%)$.

Sinrachererhalıen. informelle Simation: Gespräch mit der Verfasserin (ehemalige Mitschülerin) am Arbeitsplatz der Respondentin

- Tak pojd' dál, dáš si kafe?

(No. lak jo.)

- Slabý nebo silný?

(Rad'si slabši.)

- Mam tady kapucino nebo rozpustný. Nechceš džus napit? Kdepa mam tu lžicku? Jà nemam lz̧icku. Tak zejtra, jak se domluvime? Copa tady na námésti u Andêlickia? Viš kde. u Andělička? Na námésti, jak je kostel, $z$ jedný strany máš vchod a $z$ druhý strany je mrìż. Andêlicek (...)

- No. voni rikaji. že pìed revoluci byly vètši sociálni jistoty. To je pravda. to byly. Ale jak

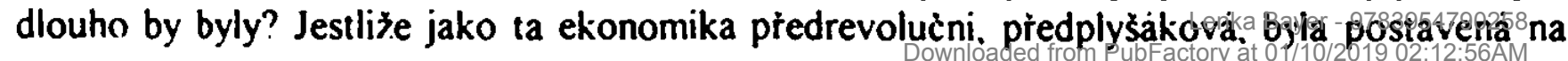


tr̉ech podnikàch - Škodovka, CKD a tamhle nèjaký Východoslovenský zelezärny, který to držely - tu ekonomiku, tak je to dost krušný, protože třeba jenom Škodovka jela pét let na dluh. Także jak dlouho by vydržely ty socialni jistoty, který tenkrát byly? Vono to moc dlouho vydržet nemohlo. (...)

- No, vono, kdybysme ty cityry roky stagnovali, tak by to eště šlo, ale jenom aby to nešlo zase zpátky. (...)

- Jako tyhle problèmy, který máme my, tak ty méli všude. Jako - to obdobi se musi preklenout. Ale prưšvih je $v$ tom, že my se nemúžeme poučit $z$ těch chyb, který udêlali voni, a nčkde začit. Ne, my je musime zvopakovat celý. A problèm byl $v$ tom, že teda, ać teda Klaus je vynikajici ekonom, politik - to všechno, ale bohužel - jako je to jeho vina. Takže, v pruni tradě ekonomickou reformu, ale jako - podle mé mèla jit bud' ruku v nuce s právni reformou, nebo ta právni mčla jit vo krok napred. To by nebyly takový problémy jako vytunelováni firem a podobně. A u nás to bylo vobráceñ̌ a dneska už se na ně nedostaneš (...).

- Tady byl šilenej humbuk kolem toho, že teda vláda podala demisi $v$ čele s premiérem a że najednou bysme méli mit prozatimni vládu. Jako - $v$ Itálii to je normálni, tam je vżdycky vláda na rok. (...)

- To je ale jako naše mentalita, jo. My jsme ċtyricet let šli $v$ jednom pangejtu, takže ted' pudeme nijakou dobu $v$ druhym pangejtu.

Sprachverhalten:

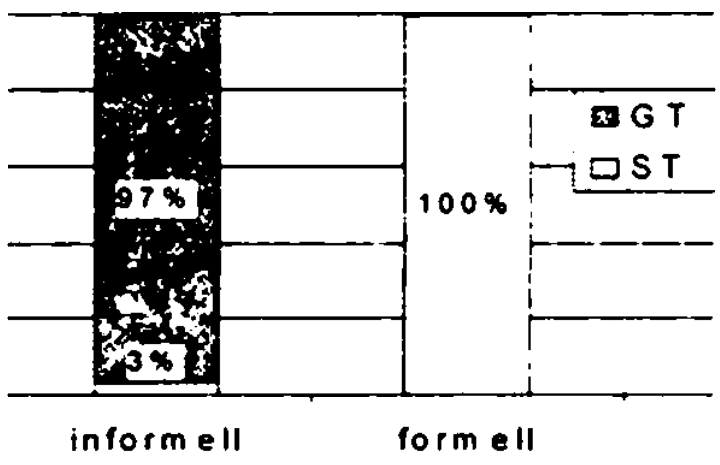

Einstellung, kognitives Subsystem:

Derkannt a nicht erkannt

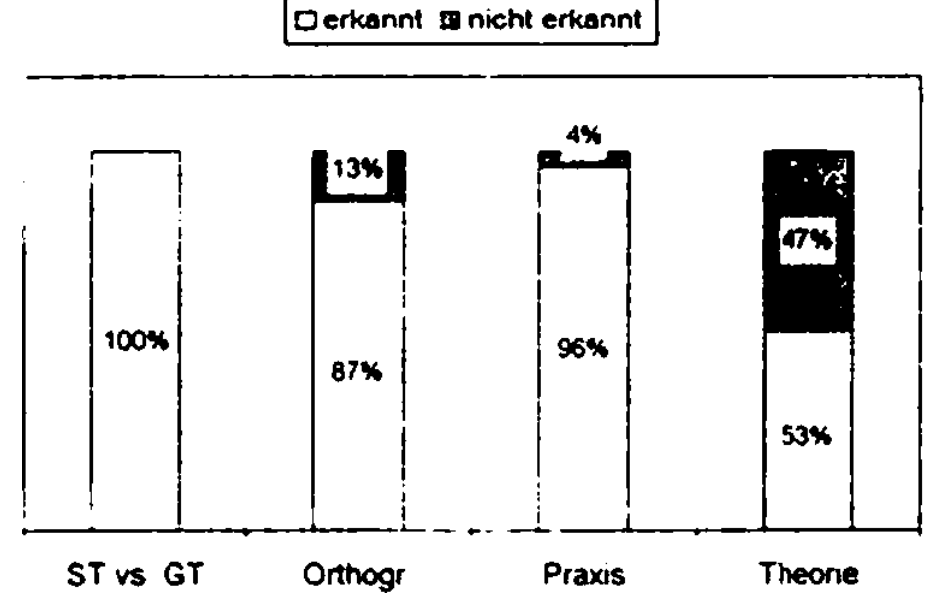

Einstellung, konatives Subsystem:

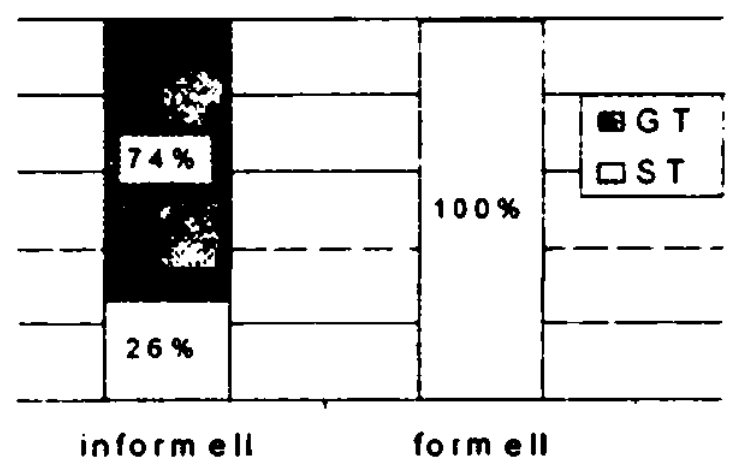

Evaluation der eigenen Kognition:

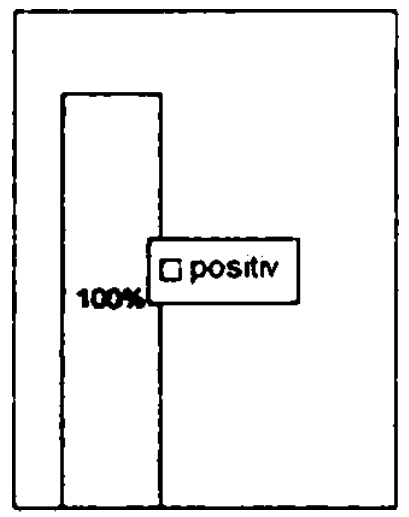


Einstellung, affektives Subsystem: Grad der positiven Einstellung

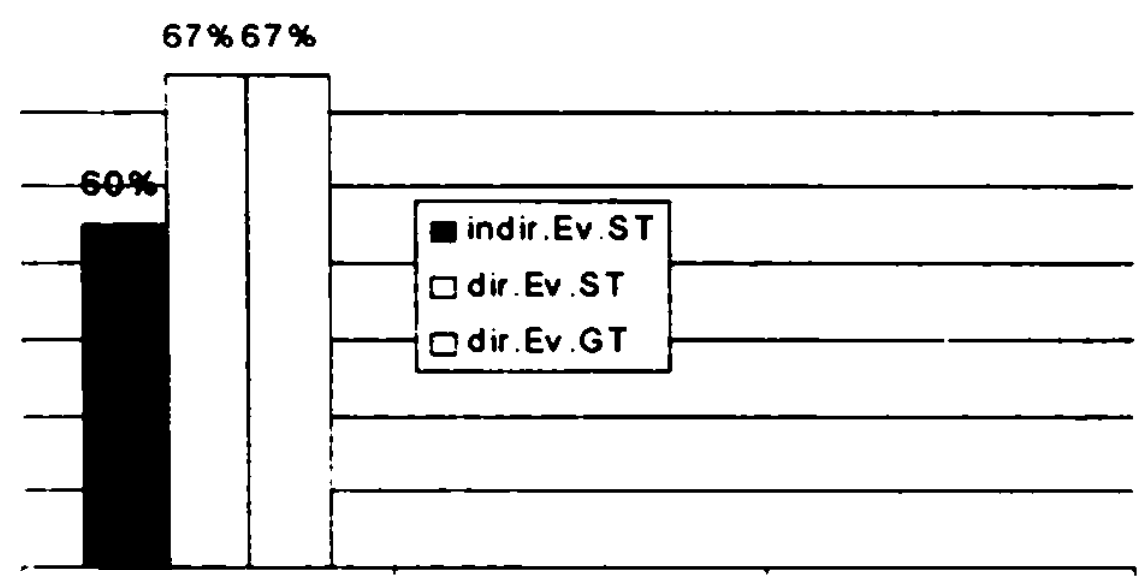

Kommentar: I mezi advokaty jsou lidé, kteti maji problémy se spisovnou ceštinou. Mnohdy to nepůsobi priliš negativnè, dủležitý je obsah.

\section{Hochschuldozentin (Bohemistik und Germanistik) und Deutschlehrerin an der Technischen Fachoberschule, 45 Jahre}

Sprachverhalten, informelle Sitmation: Gespräch mit der Verfasserin (Bekannte) vor dem Deutschunterricht an der Technischen Fachoberschule in Pilsen

- No, já se vomlouvam, ujel mi autobus pred nosem. (...)

- Voni vo vás nevi, protože já je učim v pondéli, ctvrtek a pátek, jo. Čili, my jsme se vidéli v pondêli, ale (...)

- No, vona rada mlsá, vona to má s tou štitnou ìlàzou. (...)

- Takže jako tu trasu tý dvaadvacitky změnili, takže jà musim ject vod nemocnice $k$ námèsti Milady Horakové. Takže tam musim doject a (...)

- No, nepoika - tr̉eba, kdyż. tam má napsáno toleranci dvě minuty, tak treba má ject večer $v$ osmnáct dvacet devêt, tak viera jel ossmnáct dvacet ċtyti. No to je jako trošku brzy. To je pèt minut, a to neni malo. No, tak ted’ už mam nacvičeno, že když z toho kurzu jdu, a protože chvátảm - treba večer. Takže prostě vopravdu ve ćtyri - tedy - v patnact to tedy zakončim. Reknu, že koncime. No a vohromnym tryskem, protože nejsem si jistá, jestli tam eštž bude.

Sprachrerhalten, formelle Sirnation. Aufnahme wahrend des Deutschunterrichts an der Technischen Fachoberschule in Pilsen

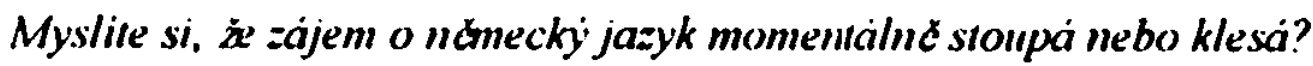

- No. klesá, podobné jako ptii vyuce ruštiny je to stejnè jako pri vyuce všech cizich jazyků.

Takže klesà

Jaká je morálka ve vyucováni ncmeckèho jazyka?

- Tak, jak si to ucitel zaridi.

Mohlo by to bỳ lepsis?

- Mohlo, no ale to by na tom museli všichni asi participovat, obe strany.

Jak se divàte do hududoucna? Myslite si, ze zájem bude stoupat nebo stagnovat? 
- No, ż̉ejmě asi bude spiš klesat, protože nakonec žảk vidi, že to uplatnèni nemà, a že stejnê se

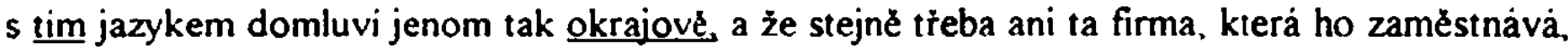
tak jeho znalosti nevyužjje. Takže si myslim, že bude asi klesat. Jakou radu byste dala studemiom. kieti se uci nómecky jazyk?

- No, aby se to neucili otrocky, ale hlavnè aby se to ucili komunikativně.

Sprachverhalten:

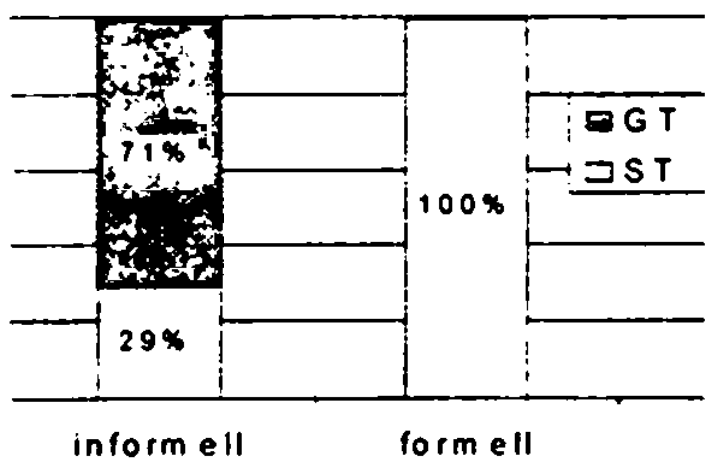

Einstellung kognitives Subsystem:

Cerkannt a nicht erkannt

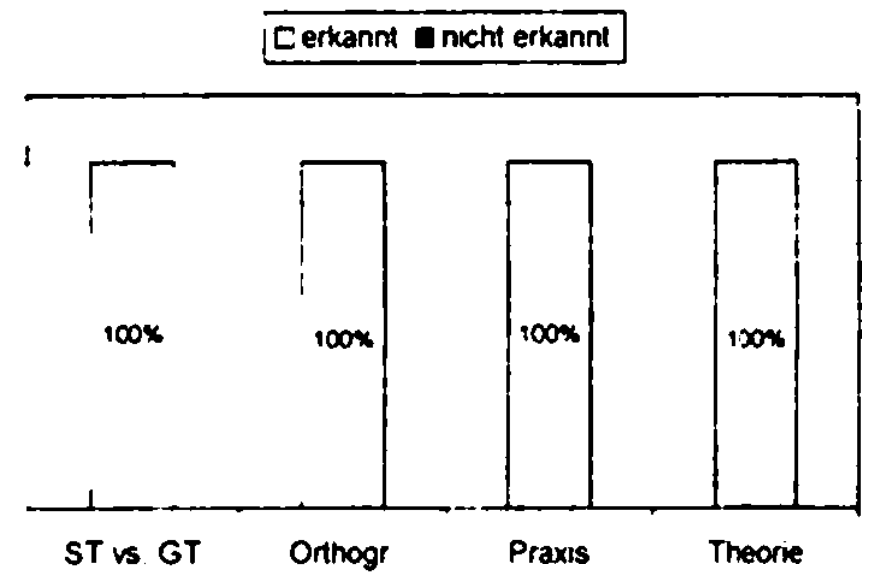

Einstellung, konatives Subsystem:

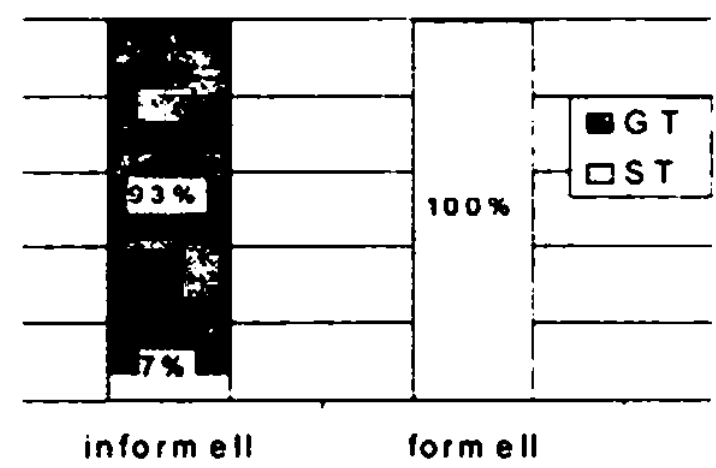

Evaluation der eigenen Kognition:

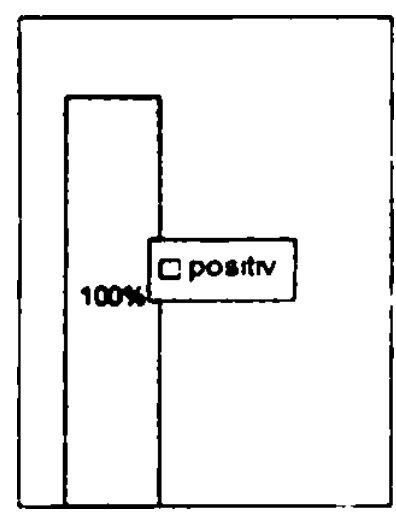

Einstellung, affektives Subsystem: Grad der positiven Einstellung

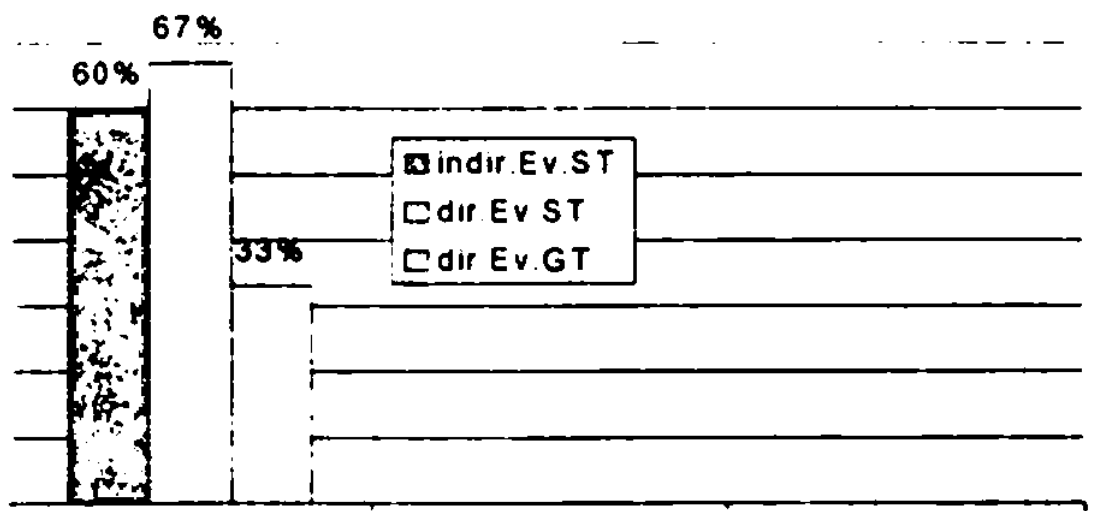

Kommentar Jak mluvime - problèmy spiše vzrůstaji v rovine̊ jazykové kulteary - 9783954790258 


\section{Betriebswirtin an der Technischen Fakultät in Pilsen, 45 Jahre}

Sprachverhalten, formelle Simation: am Arbeitsplatz der Respondentin Jaky máte názor na posledni teplou zimu?

- Na posledni teplou zimu. No, názor mám takový, że zima by predevšim neméla bỹt teplá, takže chybêl mi snih, chybẻla mi prosté taková ta opravdová zima s velkỷmi mrazy a hodné snchem na horàch. Asi tak.

Jaky je l'ás uyhled do budoucna. Budou zimy poulle Vašeho názoru teplejsi anebo se zase budou ochlazovar?

- No, já na to moc sviji názor nemám, jả bych spiše dala na odborniky a tị tikaji, že spiše se bude asi oteplovat. Celková ta situace, že smèruje $\mathrm{k}$ oteplováni. Vypadá to tak posledni roky.

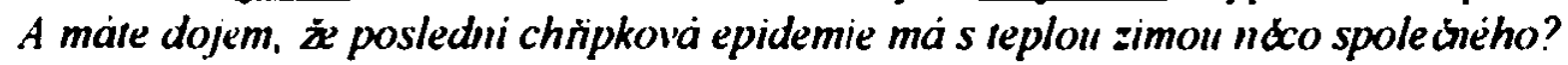

- Určitě, urcitič, protože jakmile se otepli, tak vlastné všechna nečistota, která tady kolem nás je pritomná, tak vlastnê dostává vêtši šanci - bych r̉ekla - ano. Protože vlastné je - ví̛i se prach po té. vlastnẻ po té zimé - $i$ když teda nebyla velká, tak vlastné. No tak - jak bych to - jak bych to upiesnila. Prostě je prostor - je pro to prostor, že se vlastně múžou rozšitovat bakterie.

Sprachverhalten, informelle Simation: Kommentar der Respondentin beim Ausfülen des Fragebogens

- To je taková smésice - skoro spisovná čeština a do toho najednou néco a to je jako pár facek. Jo. prostê, a já jsem si to ani neuvêdomila vủbec, jak by to tak pủsobilo, jo. Urěitę od tê doby se jako to zménilo. Určitê už nemluvim tak - jako pohoršilo se to - jo - určitê teda - to si uvêdomuju. Ale jako tehdy jsem si to nemyslela - jo. Já jsem v podstaté mluvila dost spisovné a $v$ podstatê jsem $s$ tim docela méla problemy, takže jsem se spiš učila mluvit tak náa - jak bych to rekla - nespisovne. A i vlastnê na tom pracovišti. No, fakt to je, že samozrejmé, kdyż clovêk je $\checkmark$ domácim prostredi, tak je to néco jinèho. Ale jako treba spousta kolegú - kdyż chodime na prednášky - tak spousta kolegú se ani nesnaži mluvit spisovnè. Ani na té prednašce.

- Tadyhle teda Vảm r̉eknu, że se úplnč stydim, protože, co se tỷkả tadyhle - my jsme určitê se tudleto učili - jo. Spisovná čeština - ale já prostê - já to radši nenapišu, protože, kdo založil spisovnou ceštinu - jako mysli se tim - jako já to beru, że jako prostě - Cyril a Metoděj - že sem teda vlastné privedli takovou tu - ten základ - jo Ale potom jako - spisovnou ċeštinu prostć já tak jako si vủbec nejsem teda jistá. Ani stoletim - prostě ani - fikam - až se stydim, protože určitê jsme se to ve škole uciili

(No. já l'ám io rekmu.)

- No, tak reknète - no.

(No. je to zaçatek devatenacty'ho stoleti - Dobrovskj.)

- Devatenáctýho! Já jsem chtêla napsat osmaáctý, ale Dobrovský - to jsem si už vưbec nebyla jistá - jo. Fakt nebyla. To reknu úplnć uprimnč - a jako stydim se, protože jsme se to stoprocentnê učili na tom gymnáziu. To $v$ žádnym pripadẻ neni tim, že by $(\ldots)$

(No clovis laky zapommene. te jo.)

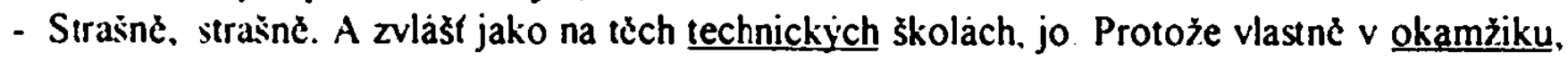
$k d y$ ċlovék skoncil to gymnazium, tak vlastne ta humanitni cást - já to łikam i studentủm. protoże jako nákou kulturu nebo tak - ale stejnê mnê to chybęlo. Chybèla mi prostê - néco jako humanitniho - jako treba - já nevim - néco vod psychologie, vod pedagogiky - aby to nebyla taková jenom ta technika. jo. Já si myslim. że ten technik to potrebuje a że prostè jako - kdyż. to srovnam - protoże mam déti, který ted" - dcera akorát bude konciit devátou tridu - a jako myslim si. że fakt ta vyuka ceštiny je naprosto (...) 
No ve škole mluvený projev takìka neni, protože se zkouši pisemně. Vždyt pŕece na základnich školách vždycky jsem to považovala - j̇e vlastně to zkoušeni neni jenom ziskáváni toho, abyste zjistila, co to ditě umi, ale že se uči i mluvit. Oni dneska tu možnost prakticky nemaji. Oni pišou - jenom pisemně, takže tahle možnost se zminimalizovala. Takže oni na to prostč vuibec jako nemaji prostor. Nebo si ho vưbec neudšlaj.

Sprachverhalten:

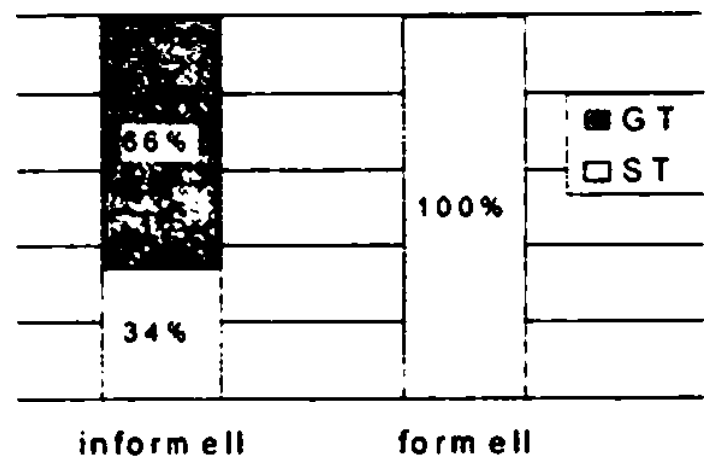

Einstellung, kognitives Subsystem:

\section{Eerkannt of nicht erkannt}

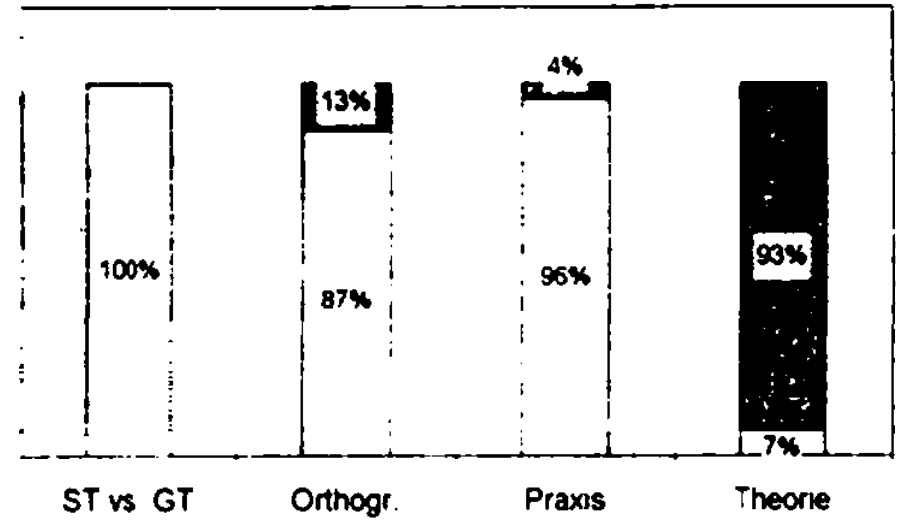

Einstellung, konatives Subsystem:

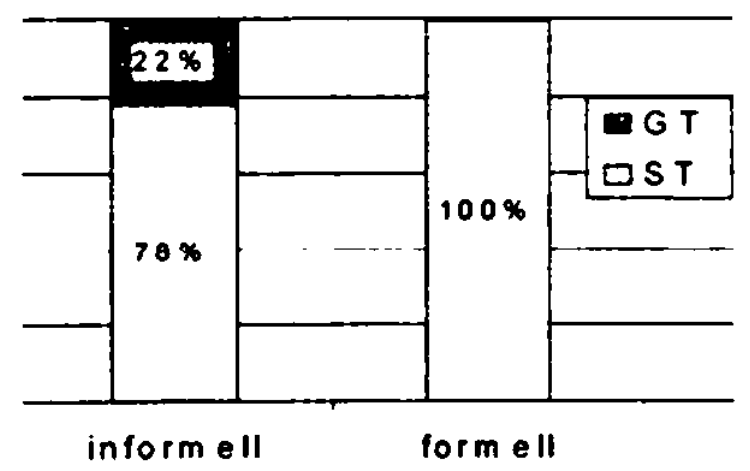

Evaluation der eigenen Kognition:

Einstellung, affektives Subsystem: Grad der positiven Einstellung

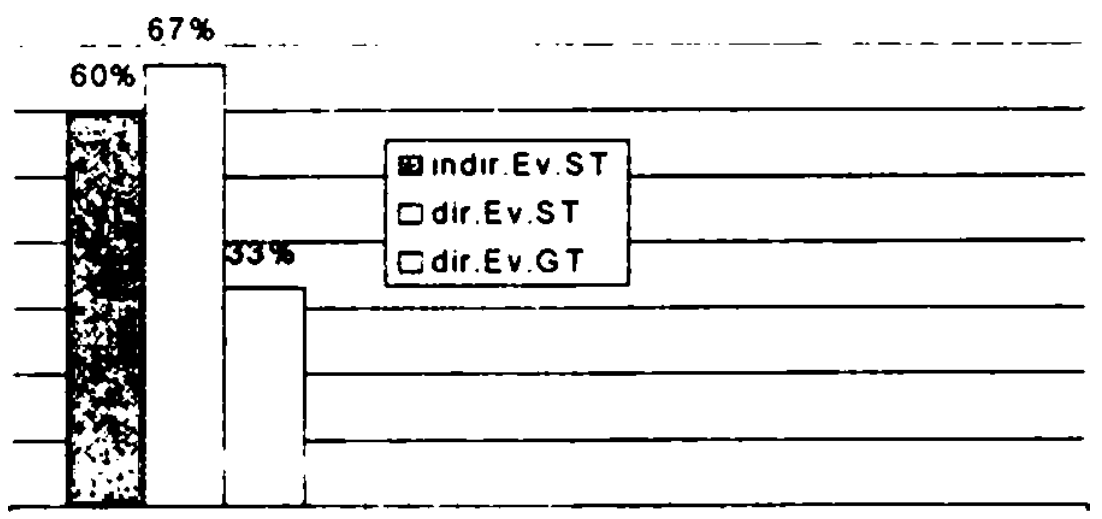

Kommentar Anketa je jistç velmı użıteiná, všichni potrebujeme kultivovat svi̊j projev 


\section{Pensionierte Gymnasiallehrerin (z.Z. Theaterkassiererin), 63 Jahre}

Sprachverhalıen, informelle Sitmation: ein kurzes Gespräch mit einem Schauspieler im Theaterfoyer

(Tacty to vưbec nefunguje. Müäı si zaplatil z vrátmice? Tady to nedrä vúbec).

- Prosim vas, támle tý pani Ale když to dẻláte, když točite pomalinku, zatim jste proni, kdo riká, že to nejde. Zkuste to hrozně pomalu, tak jak vám tam radi, co mate udélat, tak to šlo.

(To propadà. Asi je plnej.)

- A že už jste volal, a že vám to šlo. Anebo to napsat.

Sprachverhalten, formelle Sitmation: im Theaterfoyer Jaky máte názor na momentálni stoupáni cen v Ceské republice?

- No, pochopitelnẽ, že se mi vủbec nelibi současný ceny. Zejmena ne ceny potravin a celá ta cenová politika, myslim, že neni momentálné vủbec dobrá. Protože trebas prvovýrobci, to je, zemedẻlci dostávaji minimum. Zatimco zpracovatelskej prumysl, to je, ty c̀lanky mezi tim tedy $-z$ toho vlastne bohatnou. Takže to si myslim, że to neni $v$ porádku.

A konkrèmx na ziyšováni nájemného a cen za elektrimu a plyn?

- Tak, ty ceny za ty energie - si myslim, że je nutný, aby byly vyšši, ale je taky nutný, aby mèli lidi vyšsi platy, aby se to dalo zaplatit, jo.

Ještẻ dalši otäzka. Jaky máte názor na posledni zimu? Libila se Vám osobnz??

- Ta se mnẻ strašnè libila, protože nebyla krutá jako ta loňská, takže ta zima se mi libila. A märe dojem. zh chripková epidemie souvisi s posledni teplou zimou?

- No. to si myslim. że jo.

\section{Sprachverhalten:}

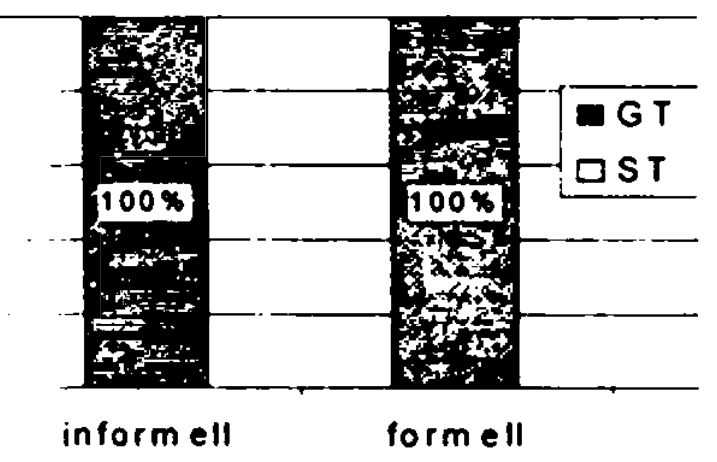

Einstellung, kognitives Subsystem:

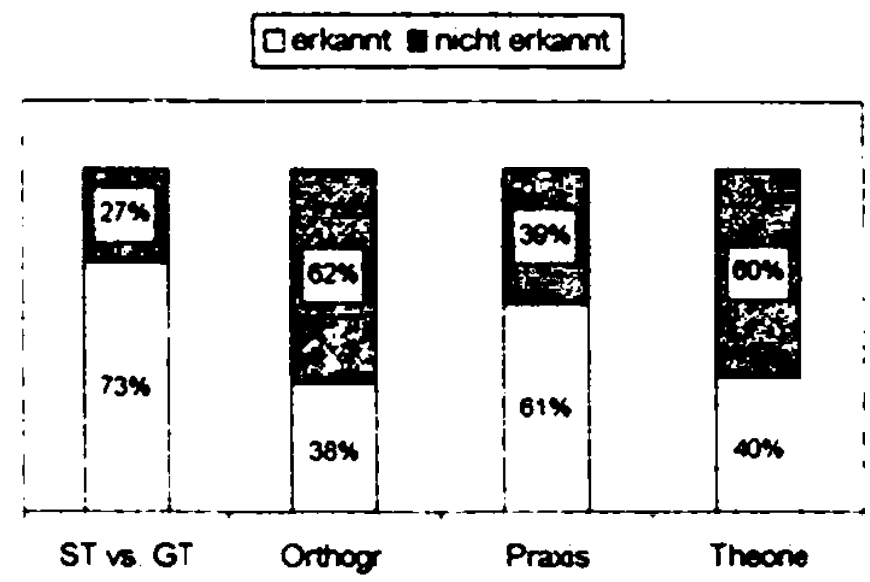

Einstellung, konatives Subsystem:

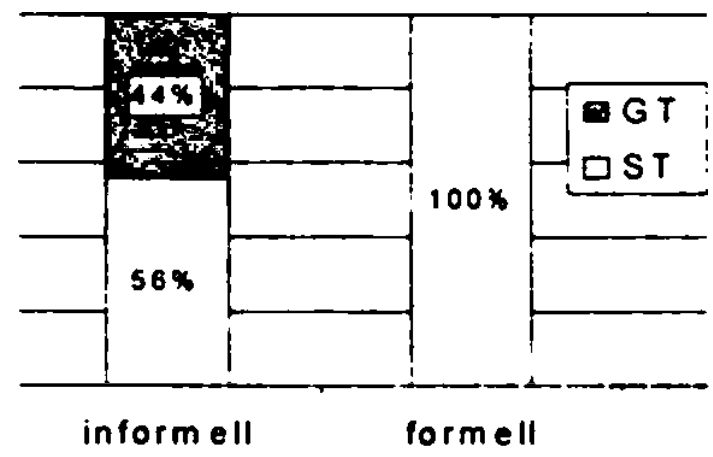

Evaluation der eigenen Kognition:

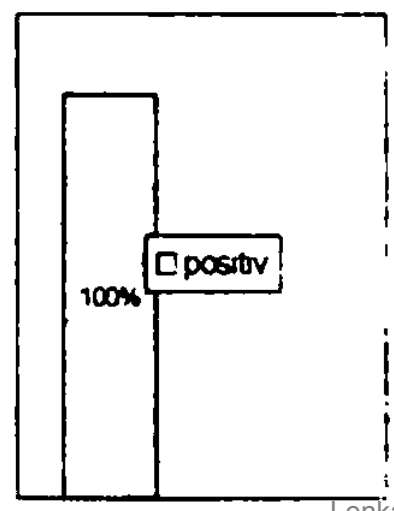

enka Bayer - 9783954790258 
Einstellung, affektives Subsystem: Grad der positiven Einstellung

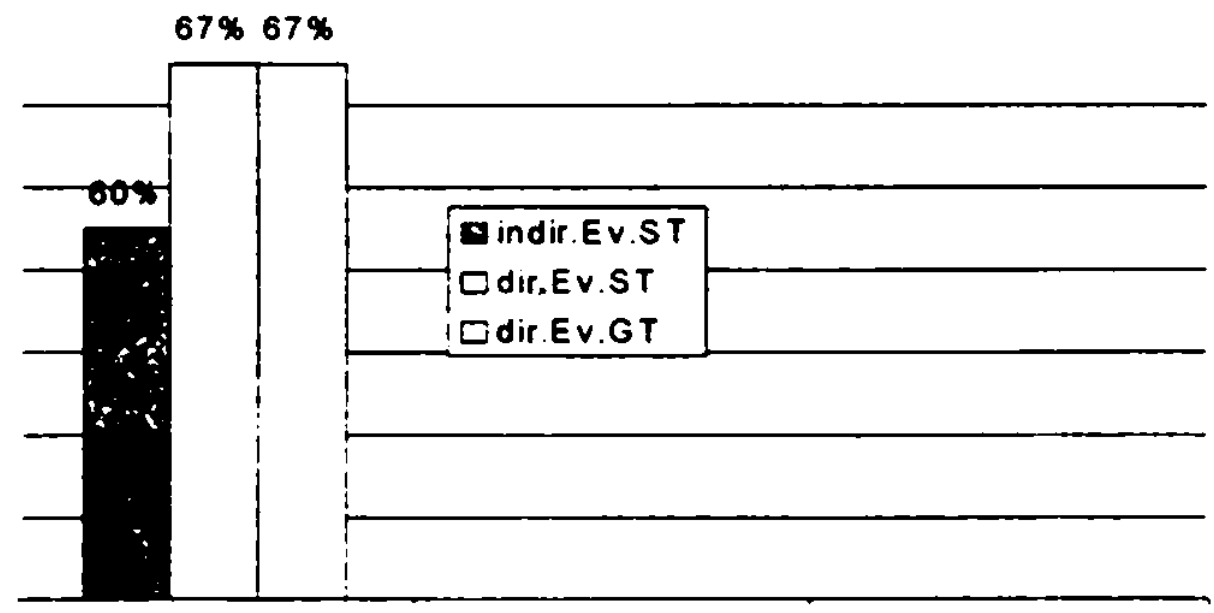

Kommentar: ohne Kommentar

\section{1.t Männer ohne Abitur}

Alter der Respondenten: 26 bis 68 Jahre, insg. 8 Aufnahmen

\section{Fräser, 26 Jahre}

Sprachverhalten, formelle Situation: am Arbeitsplatz des Respondenten

Jaky mäte názor na zvysovaini cen v Ceské republice?

- Tragedie. Nic vic.

Mále "çjakj' dalši komentair k tomato témutu?

- Jakpa to chcete rozvést? Nebo - jak vám to mủžu specifikovat?

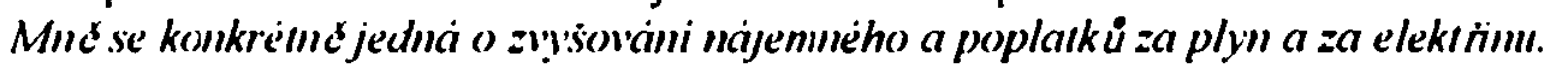

- No tak. kdyż si vemu vo trii roky z.pátky ceny a ted', tak je to jasný, ne. Je to jako triikrát aż. štyrykrat vic - je to, je to jasný, kam to spšje. Jestli to za - do roka se uvidi, jak se to v tutom státẻ vyvine. To bude jak za války pred padesáti, šedesáti lety.

Mate dojem. ix bucle klesal żivotmi uroveri?

- Ano. Sice budou - bude to kapitalismus - tvrdej. Budou periférie, tam budou bydlet ty - a budou bohatý. Ty budou bydlet ve stredu, no. Takže se to rozdẻli na takový trì dost rapidné takový - nevim, jak bych to komentoval - vrstvy, no. Na takový trii dost vodlišný vrstvy, který budou po sobè klesat. Ta nejnižši bude dost - dost bidná.

A led ješstc otázka z jime oblasti. Jak se l'ám libila posledni teplà zima?

- Teplá byla - ta byla za dvê sté let. Je to - je to tou ozónovou dirou. Bude to çim dál tim horši

- no. Furt budou teplejši, dýl budou trvat Bude to jako je to ted' - no. 
Sprachverhalten:

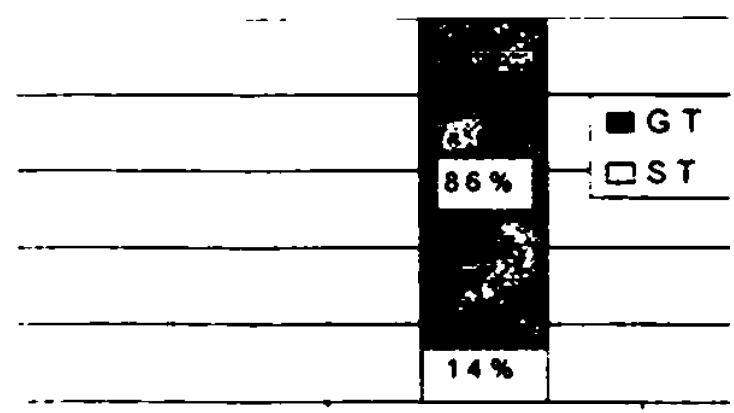

form ell

Einstellung, kognitives Subsystem:

Derkannt unicht erkennt

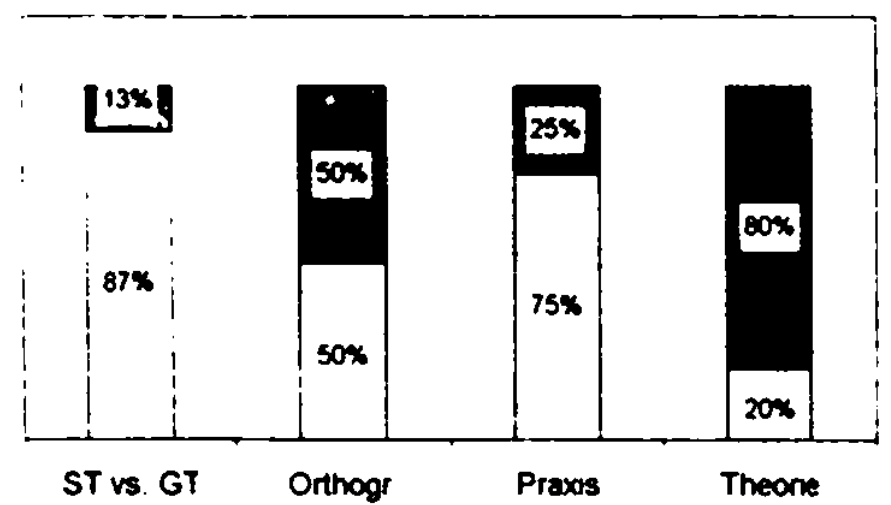

Einstellung, konatives Subsystem:

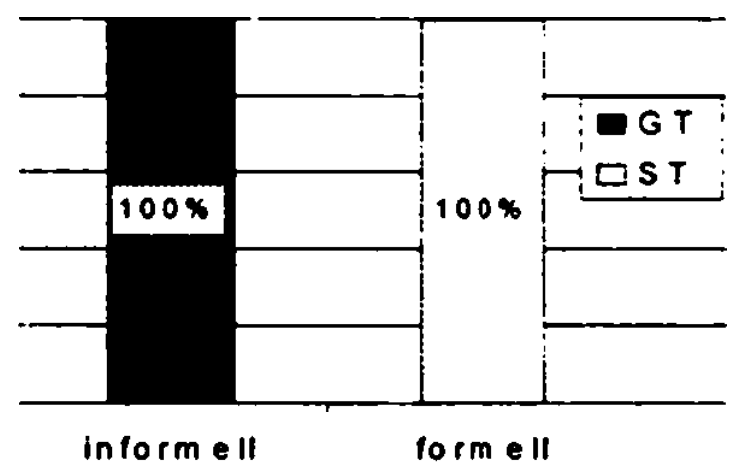

Evaluation der eigenen Kognition:

Einstellung, affektives Subsystem: Grad der positiven Einstellung

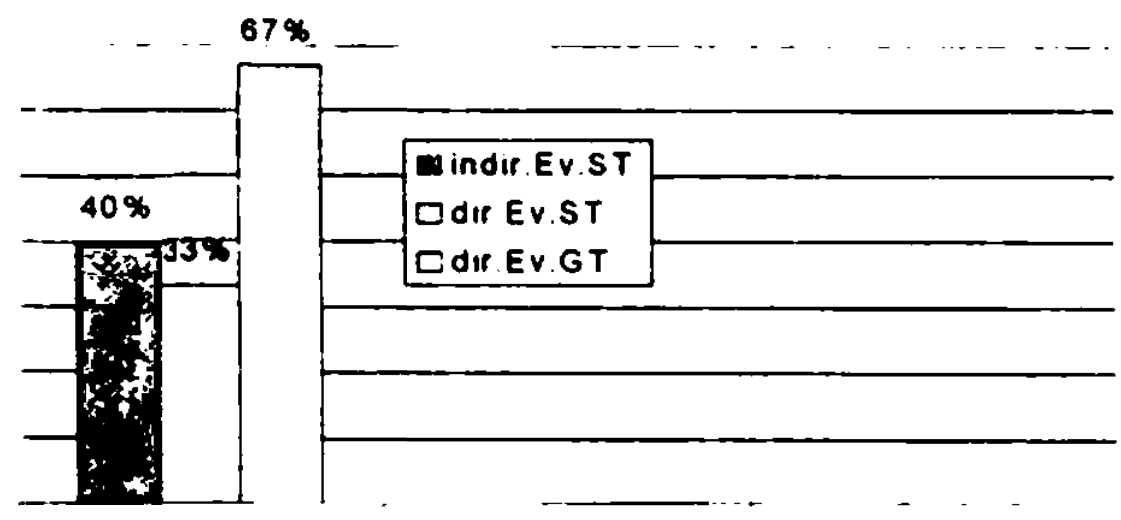

Kommentar: ohne Kommentar

\section{Arbeiter, 40 Jahre}

Sprachverhalten, formelle Sirmation: am Arbeitsplatz des Respondenten

Jakji mále názor na soucasne zuysováni cen ৩ Ceské republice?

- No, zdà se mi, že pro normálni lidi - jako - se zvyšujou ceny jako neủmèrnè. Bych rek - podle mýho minžni Jà to pocituju na vlastni kủži, manželka skončila materskou dovolenou a my 
jako velkou ést mzdy utratime vlastnè jako za nájem, za poplatky. S tim mikrofonem - to mé hroznẻ znervózñuje.

Jaky mále názor konkrétme na zyšováni nájemmèho a poplatkủ za plyn a elektrimu? $V$ soncasne dobè se hodné mlıni o zyysováni tachto cen.

- Jak už jsem rikal. Myslim si, že je to dost jako velká zátěž pro - pro lidi s běžným prijimem.

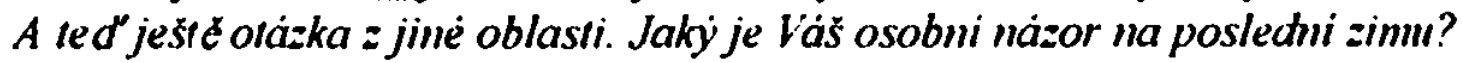

- No, mnex celkem jako vyhovuje tedy ta mirná zima, protože já vlastnê provozuju cyklistiku, takže mnẽ to jako vyhovuje - tady žádnej snih. Když bych byl jako treba fanda do lyžováni, tak samoziejmé bych to uvital - vice snẻhu. Ale takhle, když prostẻ nemáme možnosti někam jezdit - na hory - a także mnè tady ta mirná zima - jako - vyhovuje perfektnè.

A jaky máte nazor na budouci zimy? Budou se oteplovat nebo zase ochlazovat?

- No, tak vzledem $k$ tomu, že $k$ tomu skleníkovýmu efektu. Takže si myslim, že ty zimy budou mirnejjši. Že bude mirnsjjši to klima - že se jako otepli - a že mi to celkem vyhovuje.

Siprachverhalten, informelle Sitmation: Gespräch mit der Verfasserin (bekannt nur durch das Interview) am Arbeitsplatz des Respondenten

My' jezdice na kole? A jezdite i ' zime?

- Já jezdim i $v$ zimé, no. No, to mé jako bavi. Snažil jsem se tedy i manželku do toho zatahnout. ale marnž, no. Já už učil jako malou taky jezdit s těma postranníma kolečkama. Já si myslim, že vona na to bude mit jako taky takový buňky. (...) No, já když to vidim, ty partickky têch mladejch klukủ, jak se tady poflakujou. Tak doufam, že dcera takhle neskonc̈i. Budu se ji prostě snażit takhle vést. Aby prostě aspoň nèco dělala. (...) No, to bylo hrozný do toho mikrofonu. Člověk nemůže najit to správný slovo.

Sprachverhalten:

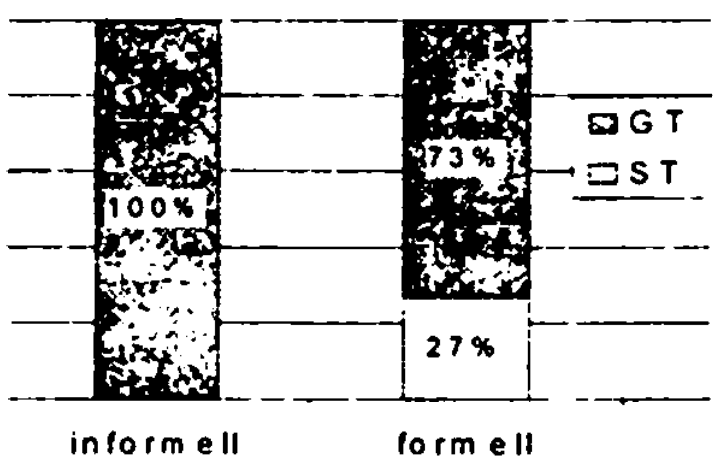

Einstellung, kognitives Subsystem:

Eerkannt 0 nicht erkannt

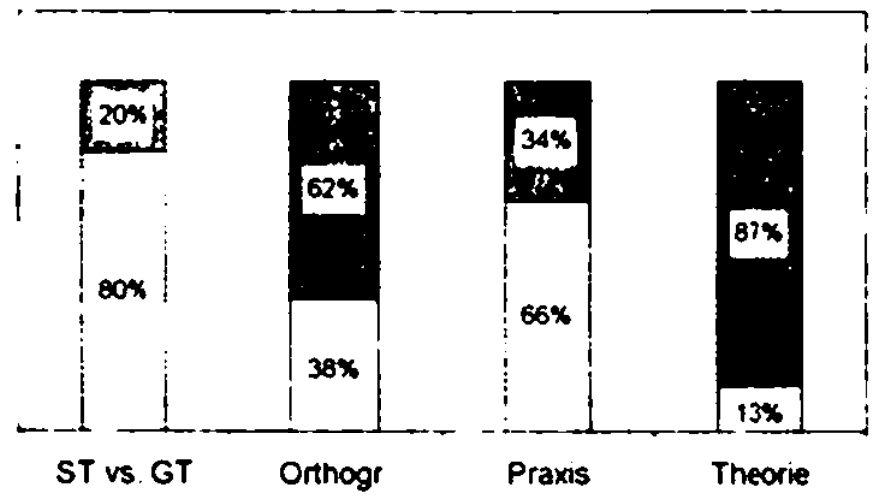

Einstellung, konatives Subsystem

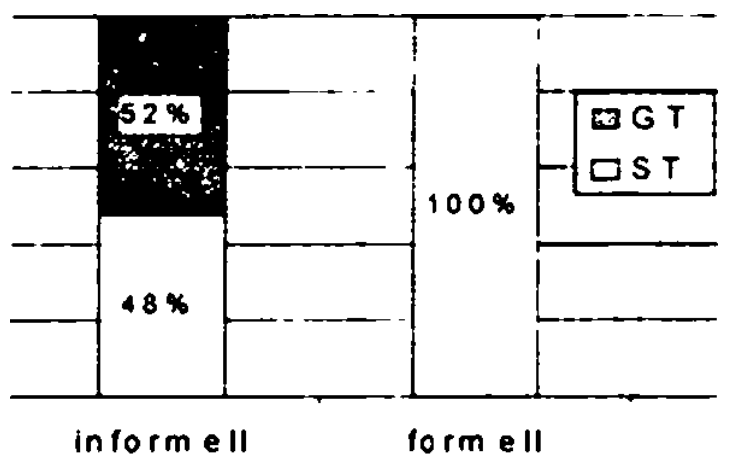

Evaluation der eigenen Kognition:

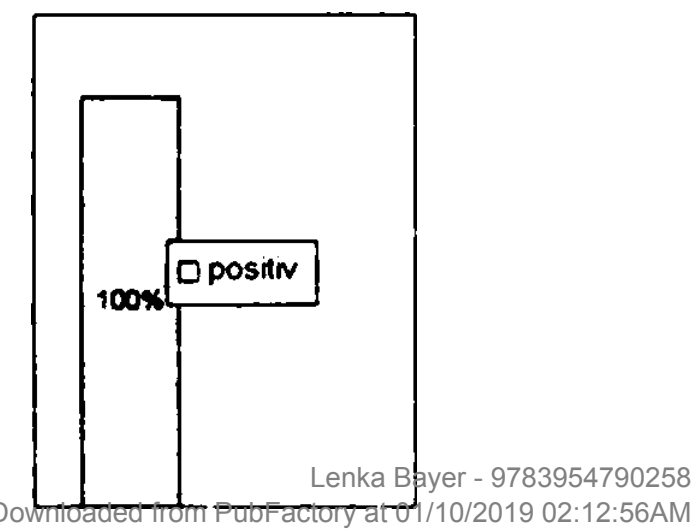


Einstellung, affektives Subsystem: Grad der positiven Einstellung

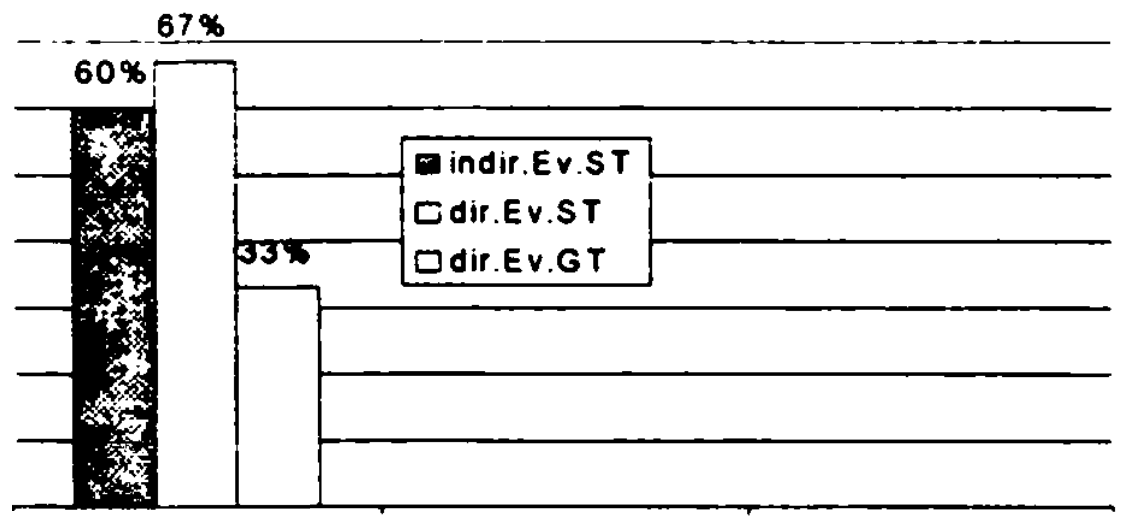

Kommentar: ohne Kommentar

\section{Schlosser, 46 Jahre}

Sprachierhalten. formelle Situation: mit Mikrofon auf der Straße angesprochen

Jakj' máte názor na zvyšováni cen v Ceské republice, hlavnẻ na zyyšováni nájemmého a poplatkú za elekıtimu a plyn?

- V situaci pro současnýho občana - pracujiciho - je to trošku vêtši ceny, neż by mêly bỳt.

Myslite si. że ceny budou i nadále stoupar?

- Určité budou.

I ceny za základmi potraviny?

- Taky budou.

A jak to vidite iy osobnd? Jste s tim srozumbr?

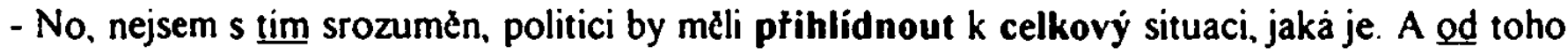
by se asi mêlo - mêlo potom vodvinout ty dalši vêci, co se tỷče $i$ ceny - ceny pro potraviny,

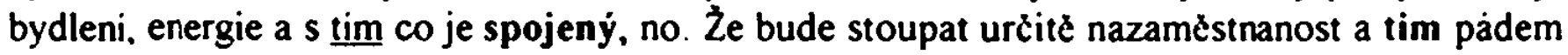
vlastnê to je celej rozhodujici - asi podle mề rozhodujici vêc, že bude stoupat nezamèstnanost a tim pádem lidi budou mit, jak se fekne, hluboko do kapsy.

A ješlı otäka z jiné oblasti. Jaky máte nàzor na posledni zimu?

- No jako, jak to myslite?

Byla podle vás mirná nebo chladina?

- No, únor byl teplej, leden byl normálni. Takže asi se to méni, určitě se mẻni, jako pred třiceti lety. Co já si pamatuju jako ditě, tak dnešni dêti asi zimu takovou jako už my jsme Omêli. nemaji a asi, nevim. Nemúžu odpovêdêt zatim.

Sprachverhalten, informelle Sitmation: Gespräch mit der Verfasserin (bekannt nur durch das Interview) im Café beim Ausfüllen des Fragebogens

- Zimu mam rảd. Jo, ale ted' už ne, ted’ už ne. Teđ" už by mohlo bejt trochu teplejš (...)

- To se podarilo. Ja jsem právê dneska slyšel v rádiu vo knižce 'Stredni školy v USA' - jako, jo. Co se tam vlastnè dẻje. Tak to bylo celkem zajimavý. A ted', že já ted' jdu a ted' se potkam s váma, jo. Że jsem si pustil Vltavu - jo - Že jsme se dostali jako, jak se tikáa zase. jo. 
Vltava je celkem, že jo, pro druh lidi, který jako zaméteni maji. A že je to jako v návaznosti, i ta stanice Vltava mi zaujala, jaký tam byly celkem zajímavý věci. (...)

- No, byl jsem na Sportpragu - na veletrhu v Praze a bylo mi tečeno, że v Plzni jako sportovni - co se týče spontovni obuvi - jako obuvi na kolo - chci. Jako aby to bylo takový dvojitý. Tak prej jako, že tady byly. Tak jsem se šel podivat.

Máte horsky kolo?)

- No, já mam dvẻ kola. Já jsem cykloturista, jo. Takže takhle spiš - jako, jo.

(Tak ze vy jste sportosec?)

- Jo, jezdime na kolech. Tak jezdime právé jako na ty zajezdy, jo. (...)

- Zase vim možnosti tr̉eba. Tuhle za hranicema se jede do Německa. Vlakem jsme si dojeli do Železný rudy. Takže tr̉eba takový ty zimni - jako i podzimni doplňky, jo Kompletně bundu (...) A ted' tam vznikly dvè zase, jo.

(Takı. vblizkosti?)

- Jo, tam v blizkosti. Je to zajímavý, no. Sortiment s přislušenstvím, jako jo.

(Ale to jenom na kolo, jo?)

- Jenom kolo, jo. Já mluvinı jenom vo kolech.

Sprachverhalten:

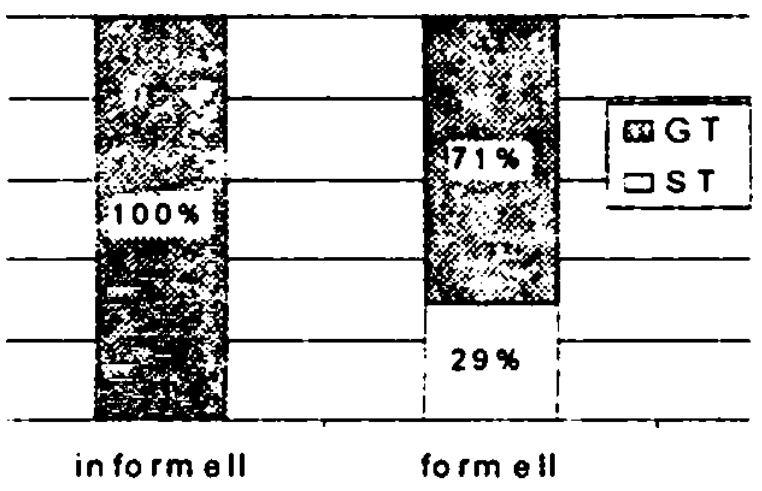

Einstellung kognitives Subsystem:
Einstellung, konatives Subsystem

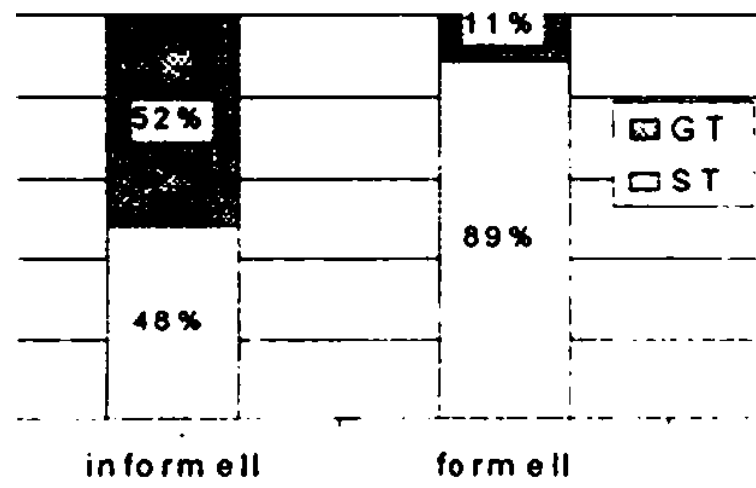

Evaluation der eigenen Kognition.
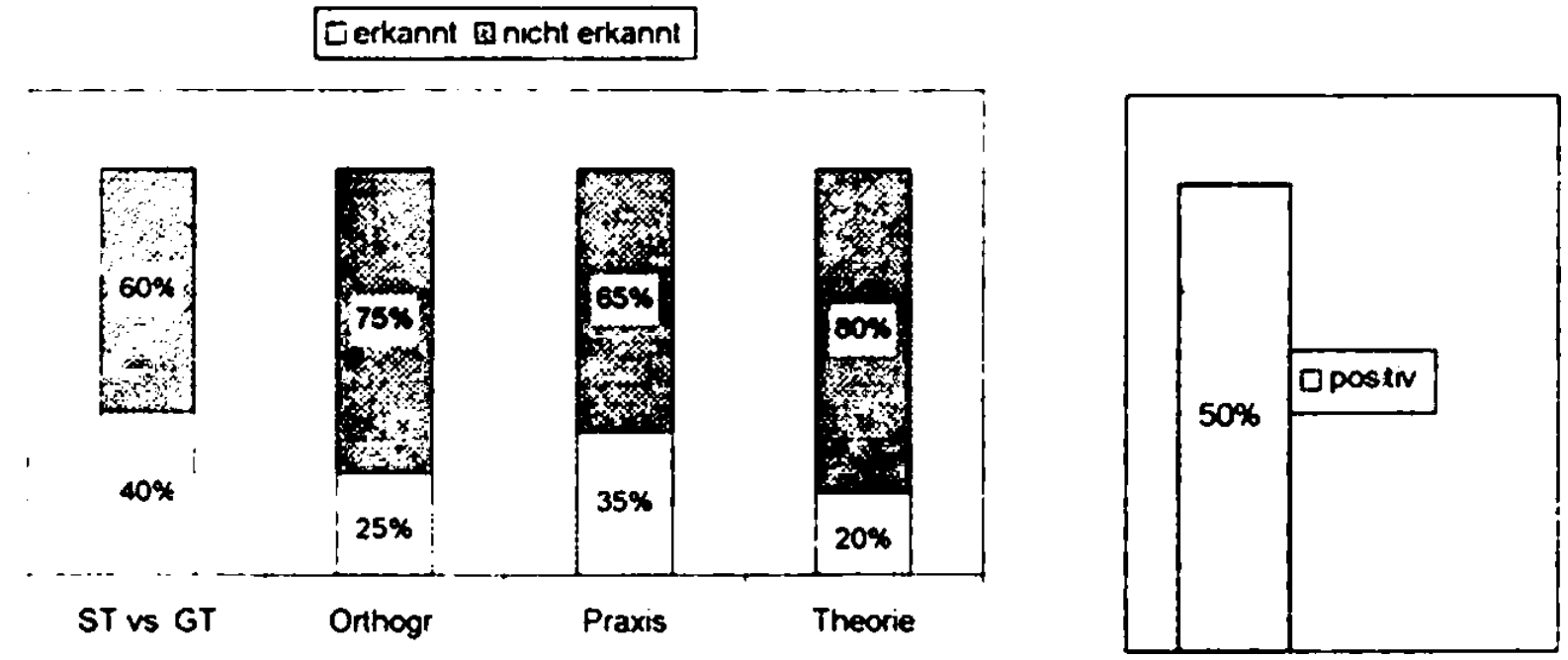
Einstellung, affektives Subsystem: Grad der positiven Einstellung

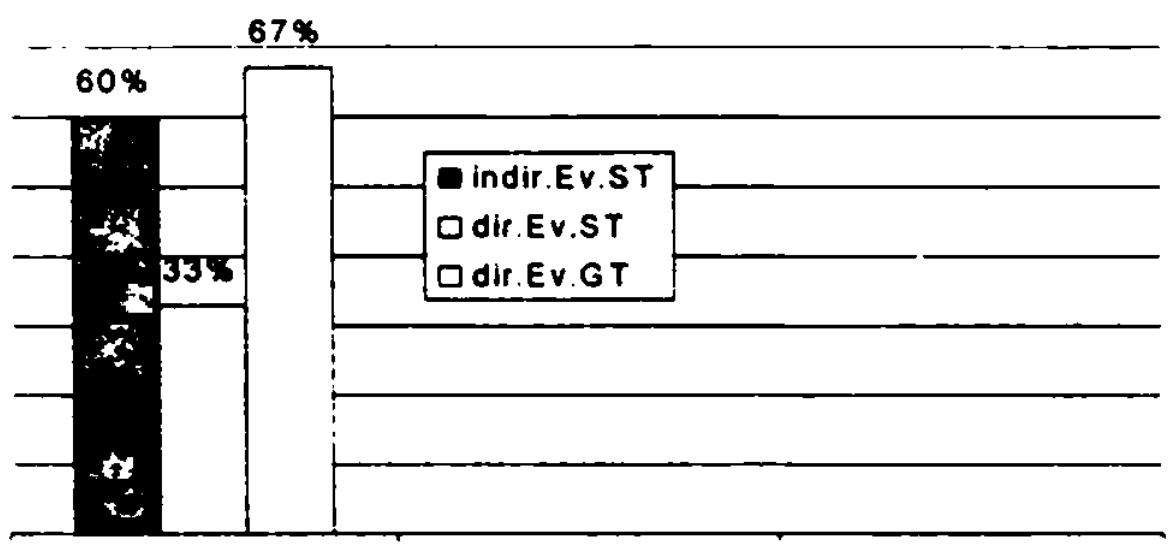

Kommentar: Ceština v současné dobẻ v soukromých rảdiich jest špatnà. V̌̌eobecnẻ by se mêla ¿eština zlepšovat.

\section{Lagerarbeiter, 53 Jahre}

Sprachverhalıen, informelle Situation: Gespräch mit seiner Ehefrau (Briefträgerin, 52 Jahre) und einer Bekannten (Arbeiterin, 55 Jahre) im Haus des Respondenten

(Dás si kafír)? Kapucino?)

- Ne, jà si dam vobyčejný, ale slabý, jo.(...)

- Ticho budeš! No - von si lehne a bude klid. [Gemeint ist der Hund des Respondenten](...)

- No, von porad napovida. Von je takovej ukecanej. Nenapovidej! [Gemeint ist der Wellensittich des Respondenten] (...)

- No, my máme tady takovej krb a ten taky tak coudi. (...)

- To mi jako nevadi. Kdyż se mnou jako nékdo mluvi normálné lidově, tak mi to nevadi. (...)

- No, tady bylo jako topeni - normálné všechno. Ale von to vytrhal a vyházel. Także tady nebylo moż.ný topit - vübec, no. A než jsme se stačili dát do toho, tak prišly ty hrozný mrazy. (...) No, my jsme ten barák vlastnẻ ani neznali. My jsme se sem nastěhovali z paneläku. jo. A to je vo to horši

Sprachverhalten. formelle Situation: beim Respondenten zu Hause

Co si myslite o soucóasnim zuysováni cen v Ceské republice?

- No tak, zvyšováni, to je éim dal tim horši věc. Myslim, že pro hodnè lidi tady v republice. Że na to nikdo neni zvyklej, a že si to každej płedstavoval jinak a začinà to bohužel bejt čim dal horši pro lidi.

A co si myslite konkrétmé o syysoväni nájemného a poplatkú sa plyn a za elektrim!?

- No, tim to zaciná vrcholit - si myslim - ale bohužel to nebude ešté asi konečný. A pro lidi už to zaciná bejt hodnè neúnosný.

A jakyj je väs nazor na kriminalitu v Ceské republice?

- No tak, s kriminalitou to je ešté horši, bych tek pomalu. To aby se clovêk pomalu bál vyjit ven, protože to je - co se dneska déje - a i když se nèco stane a dopadnou pachatele nebo néco. tak prakticky se mu nestane nic $v$ dnešni dohẻ Jako nedávno - no ted' vlastné - chytli - prepadli

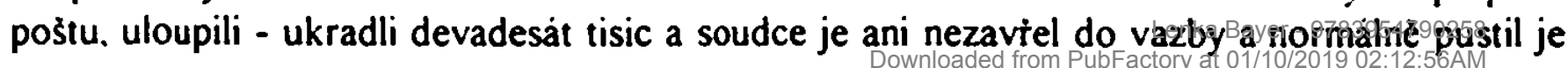


ven. Hned, okamžitę. Takže co, co se jim stane? Nic. Voni si $z$ toho akorát dělaj srandu lidovẽ ṙč̀cno - a ncmuscj sc prakticky - ty pachatele - obávat. Kdežto obyčejnej c̀lověk pomalu jo. Aby se bál vyjit - jak jsem řikal - ven.

\section{Sprachverhalten:}

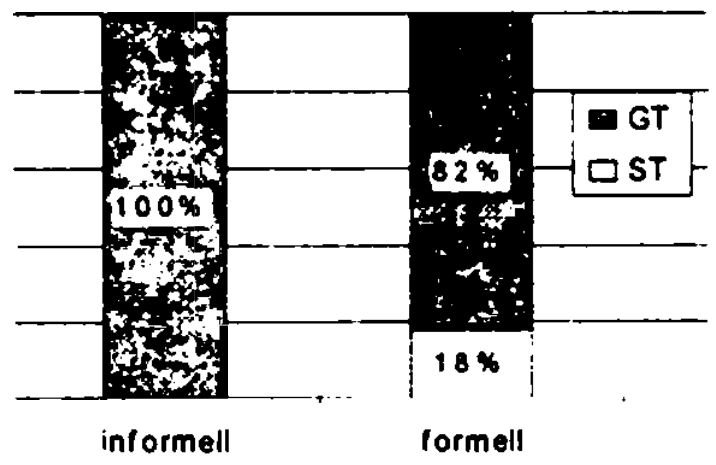

Einstellung, kognitives Subsystem:

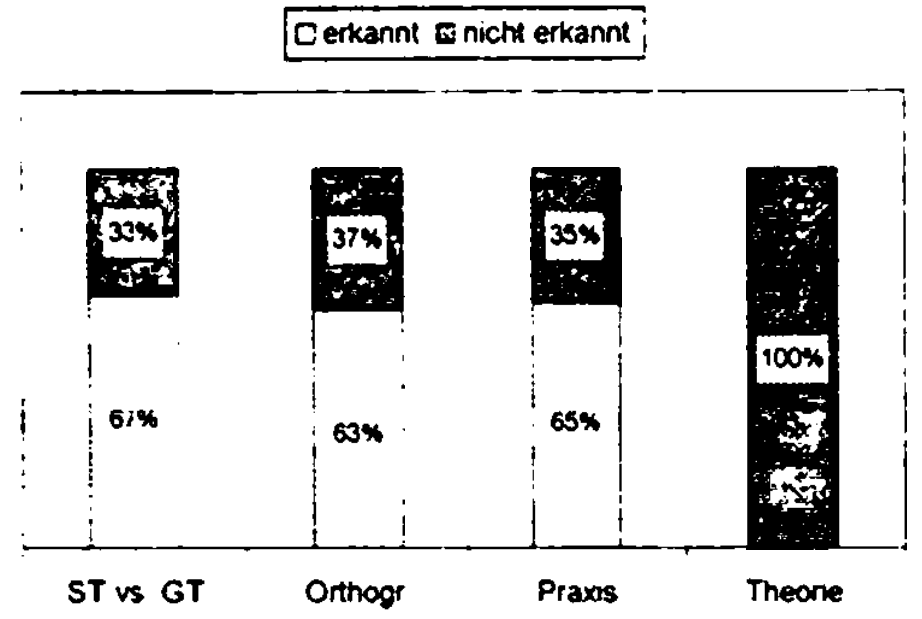

Einstellung, konatives Subsystem:

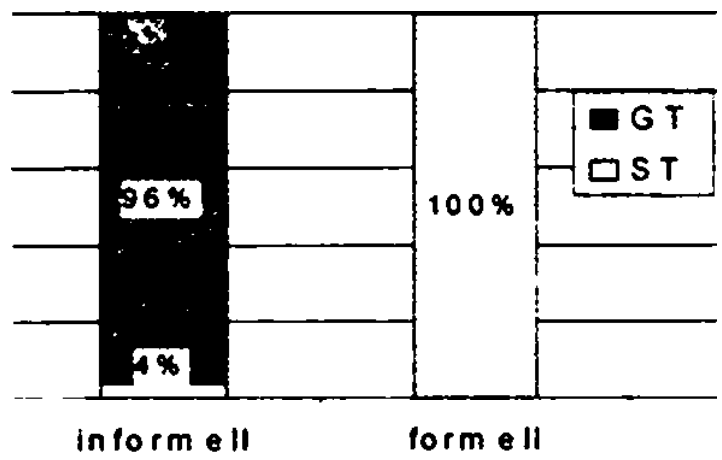

Evaluation der eigenen Kognition:

Einstellung, affektives Subsystem: Grad der positiven Einstellung

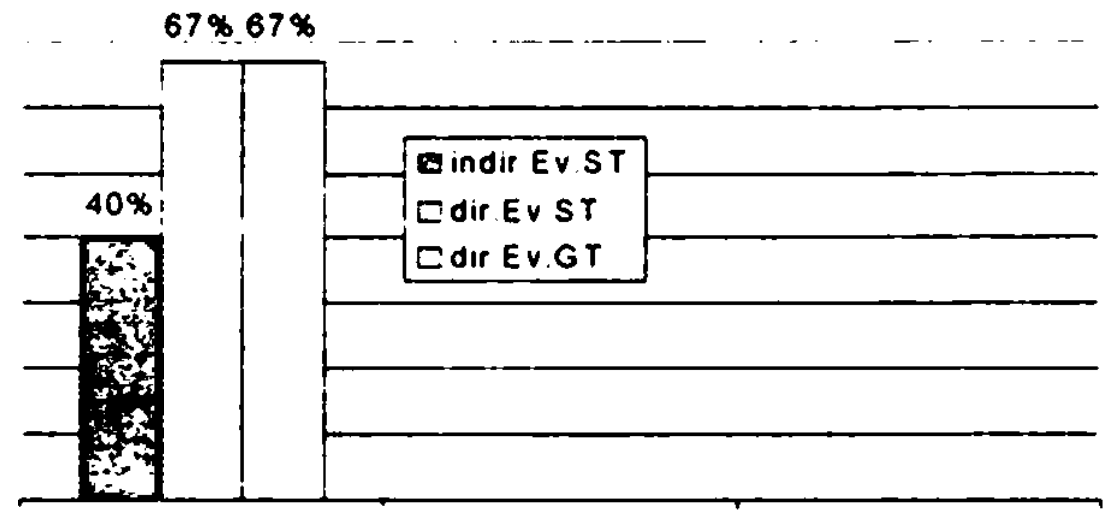

Kommentar. Podle mèho názoru je taková anketa dobrá vèc. Zjisti se a udèlá se prủzkum mezi lidnıa, jak si národ stoji se svoji mateřštinou.

Ve školàch by se méla ¿eština ̇̇ảkủm vice ..spopularizovat”, aby jak se tiká ji prišsli vice na chut. Ceština je dobry jazyk i kdyż ne lehký ${ }^{102}$.

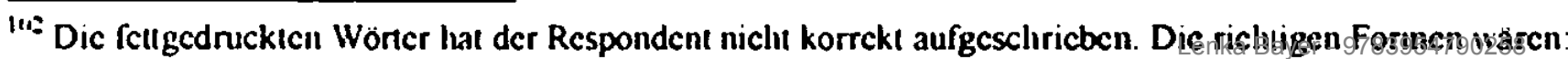




\section{Fahrer, 60 Jahre}

Sprachierhalten, informelle Silmation: Gespräch mit seiner Frau (Arbeiterin, 55 Jahre) und mit der Verfasserin (flüchtige Bekannte) beim Respondenten zu Hause

- A se stejnýma lékama jako vostatni - tak ñảk se stejnejma, ale protože je néjaká norma pro toho člověka - každýho. Takže to má vlastnể včtš̉i ửinnost, ale jaký to má dalši následky, to už je u Boha - že jo. (...)

- Za nás se všechno zmènilo. Když se veme blbej sirup - sirop. Ale vemete matematiku postupy úplnẻ jiný. Jà jsem se učil s děckama. Když jsem jim to chtěl zkontroloval, tak jsem to napsal nejdriv po svým a když jsem jim mel poradit, tak jsem rikal:'napiš to takhle'. 'Ale my to takhle nedélàme'. A jả povidam: 'A jak to dẻlate?’ Tak jsme tedy museli dotảhnout knižku a jet pěkně poporaadku, ał̌ jsem se dostal $k$ tomu.

Spracherhalten, formelle Situation: beim Respondenten zu Hause

Co si myslite o momemailmim stoupaini cen v Ceské republice?

- No tak, hlavnè důchodci nemaji żádný zázemi. $Z$ toho, co dostanou - důchod, ne - z toho se

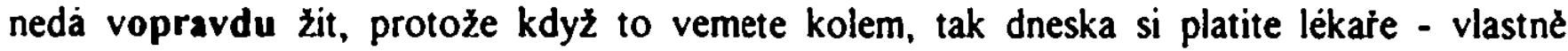
všechno. A mladý lidi jsou na tom stejnè, protože když jsou závislý teda na práci ve fabrikách a tak. Kdo nepodniká primo a teda nevydirà ty druhý, tak neni schopen tu rodinu potom uživit Nehledě, že nemả kde bydlet, takže sociälni jistoty pro tydle dva typy lidi u nảs nejsou. A jinàc - no to trikàm, nemaj byty, nemaj nic. A jinác - potom ta stredni vrstva, ta možná. Ne asi všichni. protože dneska je to u nás tak, že nemaji s çim platit. Prosté jeden neplati druhýmu To znamená, že neni schopen uhradit prostě nảkup zboži, materiälu, cehokoliv Tr̉eba $v$ tom zemědčlstvi hnojiv a takový, protože jemu zase neplati mlikárna, jatky. Jako tej'ka zroma tady v Plzni vybouchly ty jatky. Tak dluži - jä nevim - kolik milionư, prostę dodavatelưm No, a jak ten mả pokračovat dảl. że jo. Aby moh sảm teda existovat. No, a to si myslim, že tohle zmẻnit bude asi na dlouhý lokte.

Sprachverhalten:

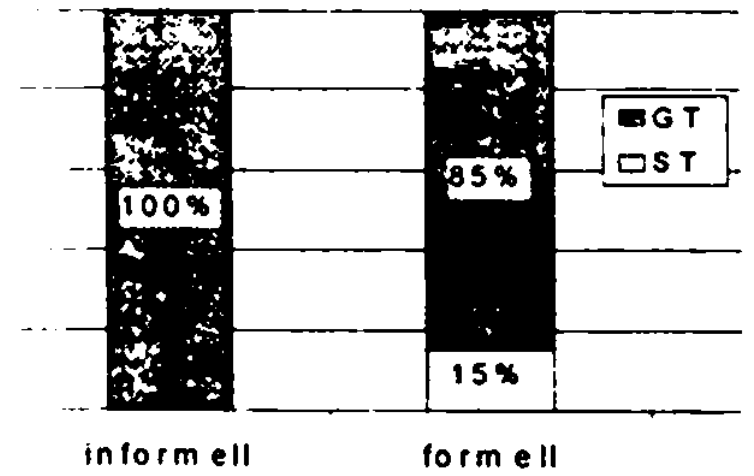

Einstellung, konatives Subsystem:

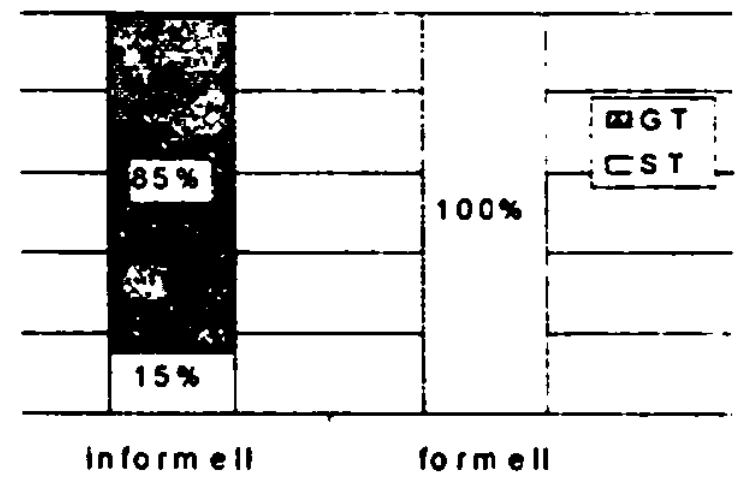


Einstellung, kognitives Subsystem:

Evaluation der eigenen Kognition:
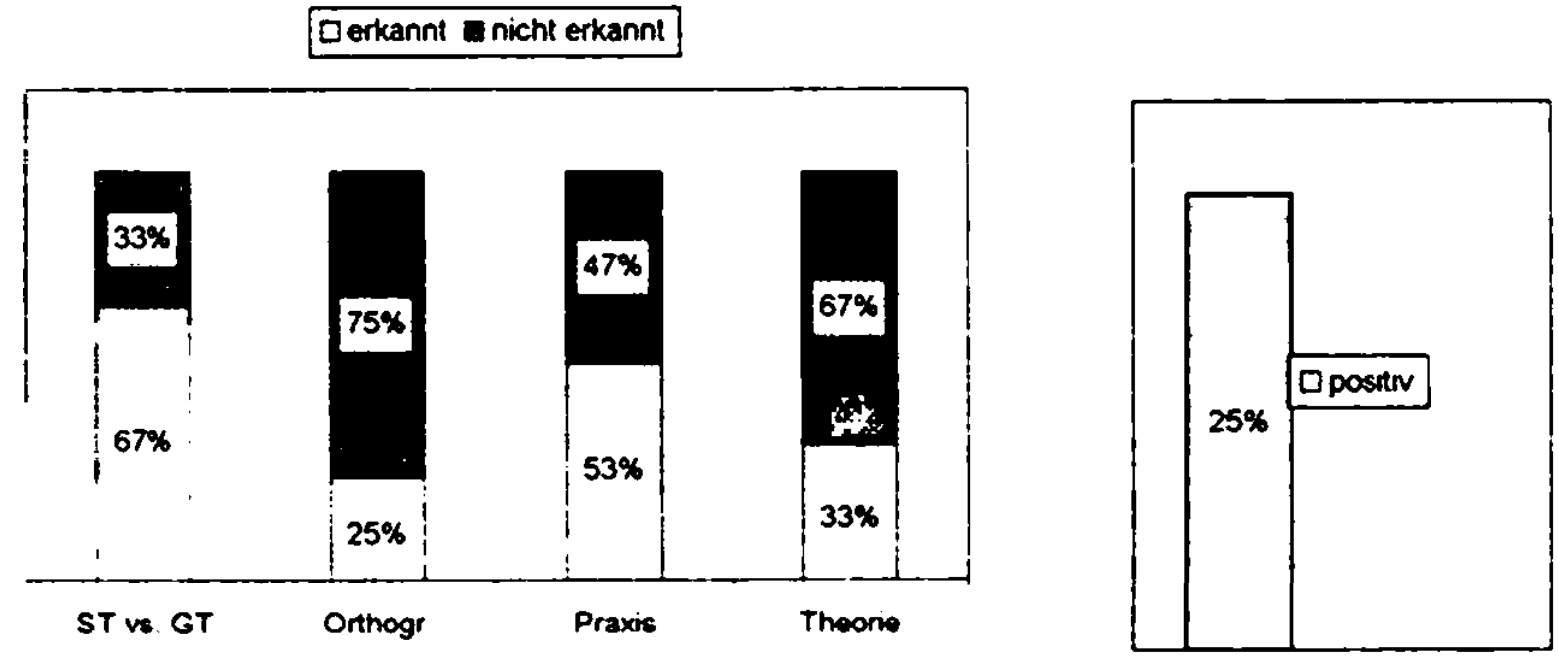

Einstellung, affektives Subsystem: Grad der positiven Einstellung

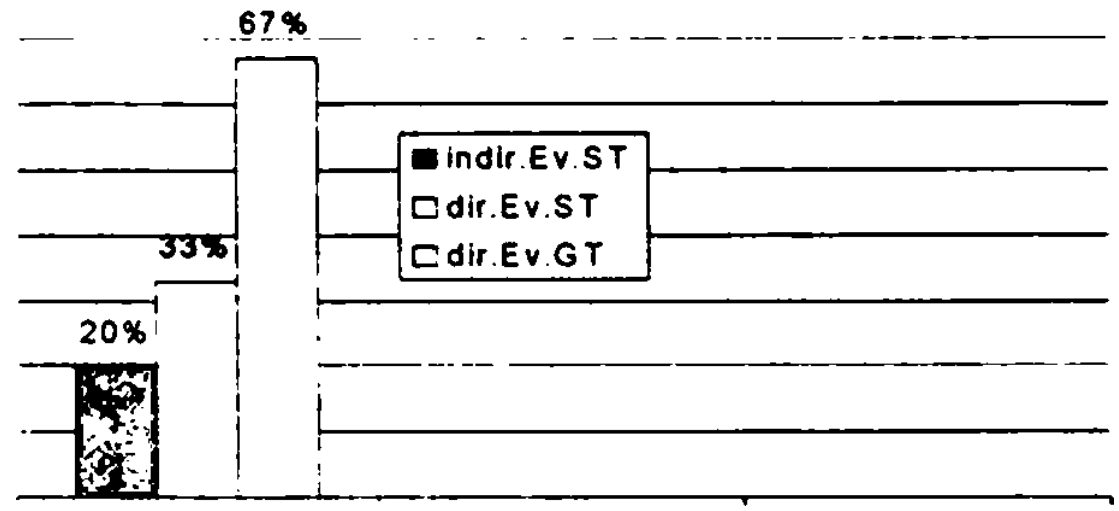

Kommentar: Blbost, co jsem se naučil, dávno jsem zapomcl ${ }^{103}$. Ale nevzdảvejte to!

\section{Technischer Zeichner, 63 Jahre}

Spracherhalten, informelle Situation: Gespräch mit seinem Kollegen (Kaufm. Angestellter mit Abitur) und mit der Verfasserin (flüchtige Bekannte) in der Wohnung des Respondenten

- Já kourim tak vod takovejch šestnácti let - bych rek. Jsem krad cigarety pro mýho kamaráda, pać matka méla trafiku tam, kde bydli, jo. Tak jsem je tam ukrad, no a von mi rikal: 'Dej si, dej si, dej si'. Tak jsem si dal, no - si vodkašlu. (...)

('o jsi to koupil, jak tam bylo vevnitr' tak hodnè masa?)

- Bủcek, bủček Ale libovej, libovej. Uzenej, ale libovej. Ted' jsem koupil koleno. Ted' jsem délal sulc. Jà ho učim varit. (...)

- Základ je cibulka, i $\vee$ tej rajskej pitomej vomáčce. Ted' to nakrajiš na kousky, dáš ji vosmažit do - aby byla taková skelnatá, potom do toho šoupni maso. Potom - až potom. když

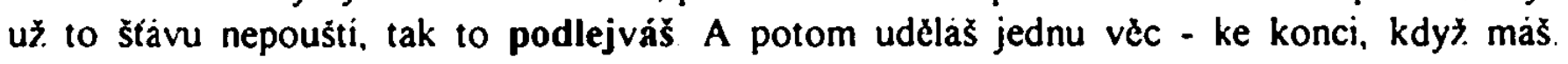

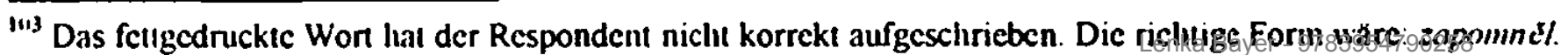


Zobneš maso - je měkký, všechno $v$ pohodě, tak potom vemeš tu mouku, dáš tam trochu tý mouky Nemusi dávat jiłku, to nemusi. To staci mouka a zalejt vodou. No - ta se snad zahuštuje sama, já to nekupuju.

Sprachverhalten, formelle Situation: beim Respondenten zu Hause

Co si myslite o zvyšovani cen $v$ Ceskè republice?

- Je to silenstvi, naprostý šlenstvi. To je pravda a to teknu každýmu na ulici. A co bych eštč $k$ tomu chtèl rict: Nebyl jsem nikdy komunista, ani moje rodina - nikdo, ale když tahle vláda prebrala tu moc, tak včera zrovna $v$ televizi rikali, že byli bez dluhü. Ted’ jsme zadlužený a nemáme ani na penze. Na zdravotnictvi a takovýdle věci, který jsou nutný pro ty lidi, vobzvlášl starši. Možná, že člověk ìekne: 'Tak si postav barák'. Dobře, dneska vydčlam dvacet tisic, ale zejtra mẻ múže podnikatel vyhodit, a nemam z čeho platit. Takže tohleto je neúnosnej - podle mè - podepišu se pod to se všim všudy. To je neúnosncj - já nevim, jak bych to rek - neunosná vẻc prosté. Divim se teda Klausovi. Kdysi jsem mu fandil, ale divim se, že tohle moh dopustit. Tak, takle zdegradovat tak tu republiku, vždył už nás nebere vủbec nikdo. Uż jsme za Polskem, pomalu za Rumunskem. Co to je za - jà prosté nevim. Já se $k$ tomu nemúżu naák vyjádrit, prostč neni to normálni. Takovej stát, $v$ kterým jsme méli vysokou kulturu, vysokou vzdẻlanost lidi v práci, jo. Rikalo se: 'Naše český ručičky', jo. Dneska z toho nezbylo nic a bojujeme vo holý prežití.

Myslite si, ze vechách bude klesat żvomi uroven?

- Já nevêrim ani tejhle vládẻ, abych vám rek. Ale vlastné takhle to reknu. jestli Zeman do nčieho jde, tak strká hlavu pod żilotinu. To znamená, že $v$ takovýmle stavu prevzit vládu. nebo tohle, tak to je nemožny. To já bych, kdybych byl politik, tak bych to neudêlal. Nevim, co už $k$ tomu dảl rict. Je to údẻsný.

\section{Sprachverhalten:}

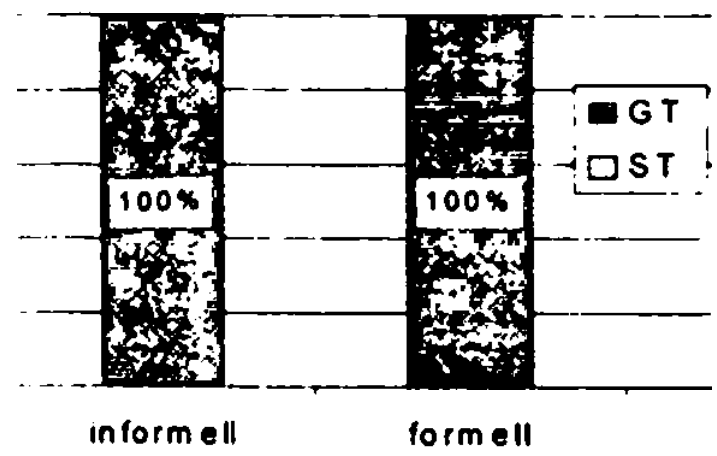

Einstellung kognitives Subsystem:

Jerkarnt I nuche erkanth

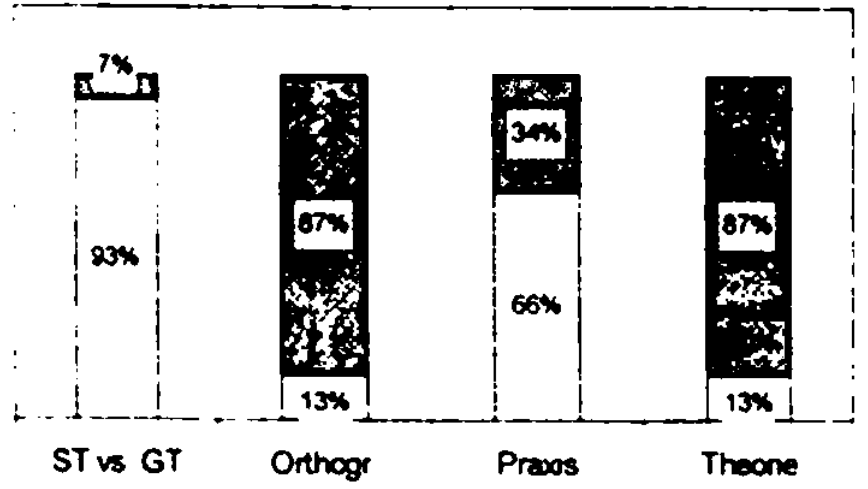

Einstellung, konatives Subsystem.

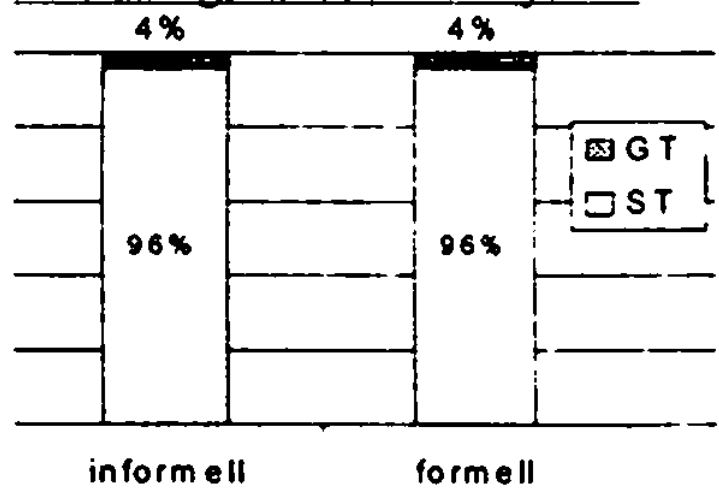

Evaluation der eigenen Kognition:

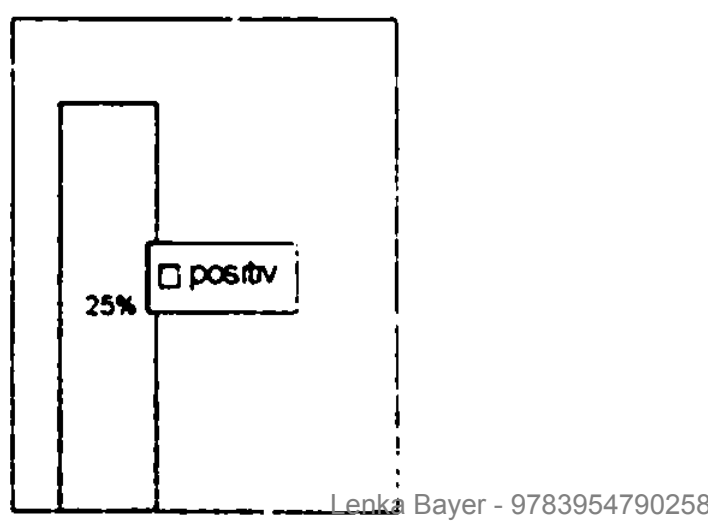

Downloaded from PubFactory at 01/10/2019 02:12:56AM 
Einstellung, affektives Subsystem: Grad der positiven Einstellung

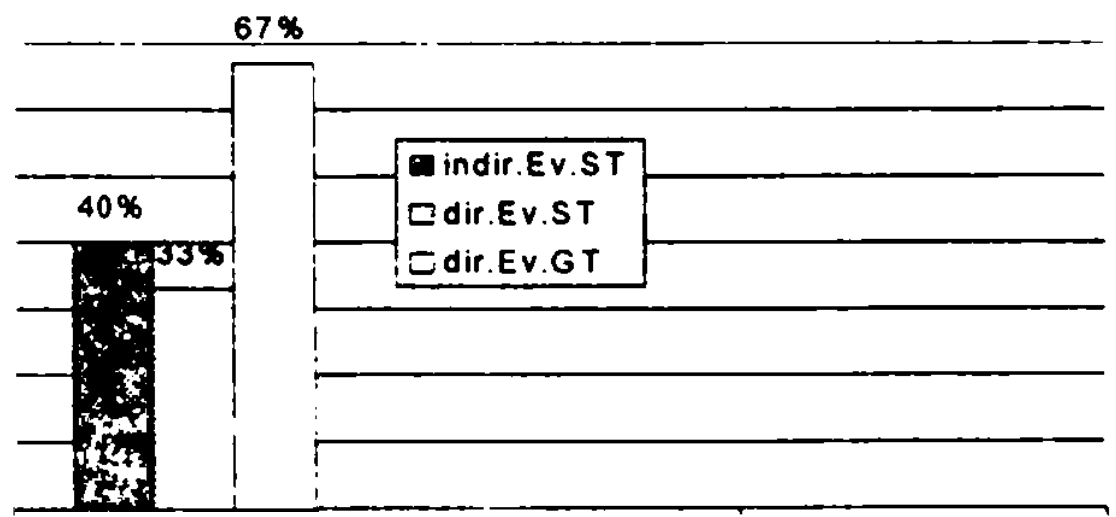

Kommentar: Tato anketa je velmi pozitivni. Jsem rảd, że jsem mohl pr̃ispět k zäjmu o poznáni ¿eskeho jazyka.

\section{Elektriker, 65 Jahre}

Sprachrerhalten, informelle Simation: im Haus des Respondenten beim Gespräch mit seiner Ehefrau

- No, udélala normálni rizoto hotovíy. A tudleto tak jak to măš ted’, tak tr̉ebas to do toho potom promichat.

(Já tam do rizola dávam hrásek.)

No, ale vona kupuje tudlecto, to $s$ tou kukurici. To mi rikala prave, to musi bejt to $s$ tou kukurici. Ta zelenina, ta prej je dobrá. Kde se to dostane koupit? (...)

To je vodpoved' tuto. To jsem se nemusel ptát retizku, to moh rict vuil, retizek moh zủstat doma. (...)

(A kdy pojedele lam na in svarbu?)

No aż ve ċtyry, v pủl pátý. No jà nevim, aż prijede, no. (...)

No vidiš kocoura, jak chrảpe. jak je vospalej? Mả tváre jako kíeček. (...)

To by se clovék divil. No jo, vono by se to asi mélo udelat. Kdyby ty pojistky byly špatný a šlo to, tak lidi budou topit zadarmo. Tak to asi je tam ňákej zpट̌tnej ventil. Kdyby se tam nčco porouchalo, tak to zablokuje. Tam jsou koleika $z$ umèlejch hmot.

Spracherhalien, formelle Situation: beim Respondenten zu Hause (o) si myslite o soucasnem zyysovani cen v Ceske republice?

- V Ceskè republice mé to úpInc̉ neprekrapuje, protože je to system politiky, která je dneska u nàs Pokud byli komunisti - tedy - u moci, tak se držela určitá disciplina, na všechno se reagovalo, aby byl porádek. Dneska je volná - ta demokracie - prostč. Każdej si délá, co chce No, a i ta vláda. Eštę takhle - pokud byly penize a privatizovalo se, jo - tak bylo z ìeho brát. Majetek je prodanej, penizky došly, no a ted' neni z čeho brát, a proto se musi zdražovat. A jakj' máte názor konkrémé na zvyšováni nájemmého a poplatkú za plyn a elekırinm?

- No, nevim, proċ se zvyšuje trebas poplatky za nájemıný, když baráky stoji, nikdo do nich nic nepridàă, žádný to - zlepšeni. Takže nájemný by se zvyšovat nemèlo, protože to uż jednou stoji a to je zaplacený - snad. A pokud se týka elektriky, tak je to mpožng் 
zvýšený náklady na výrobu elektriny, no anebo - pokud nebudou uvedeny do provozu jaderný elektrảrny, także se zdražovat bude. Nevim, jestli by elektrárny jaderný stačily, aby elektrina byla lacinějši - no, ale věrim spiš vodnim elektrárnám, kde elektfina by mohla bỵt lacinęjši. A ted' ješt é otázka z jine oblasti. Co si myslite o posledni zime?

- No tak, každy rok je - nějak ta zima proběhne. Letošni tr̉ebas byla tak - chvili bylo hezky, pár dnủ bylo tak kolem těch pêti stupñu - no, ale riiká se, že se zemé otepluje. Ale vêtim tomu, že cyklus têch jedenácti let dycky se - že se opakuje. Prostẻ po těch jedenácti letech pituhne ta zima. A jinak ty dalši leta jsou trošku mirnějši, a protože si pamatuju, že to tak bylo ve dvaačtyłicátým roce, potom $\mathbf{v}$ tł̉iapadesátým roce nebo $\mathrm{v}$ šestapadesátým. To bylo vỉdycky po urcitých letech - mam dojem, že je to têch ċtrnáct let - że vždycky se to opakuje a že ta zima je ostr̂ejši a krutejǰi mrazy.

Sprachverhalten:

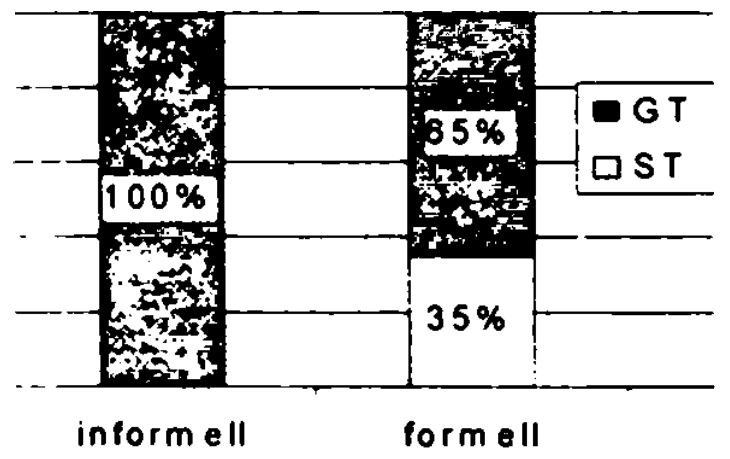

Einstellung, kognitives Subsystem: Derkarm I nictk erkarm

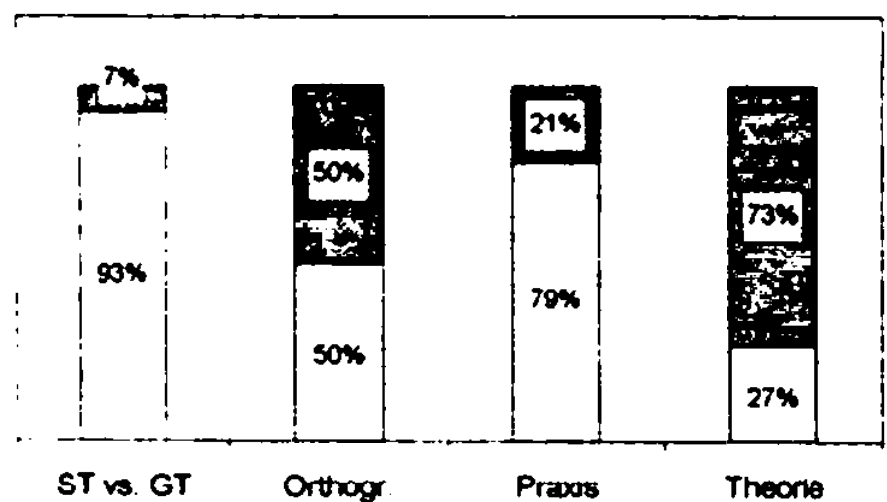

Einstellung, konatives Subsystem:

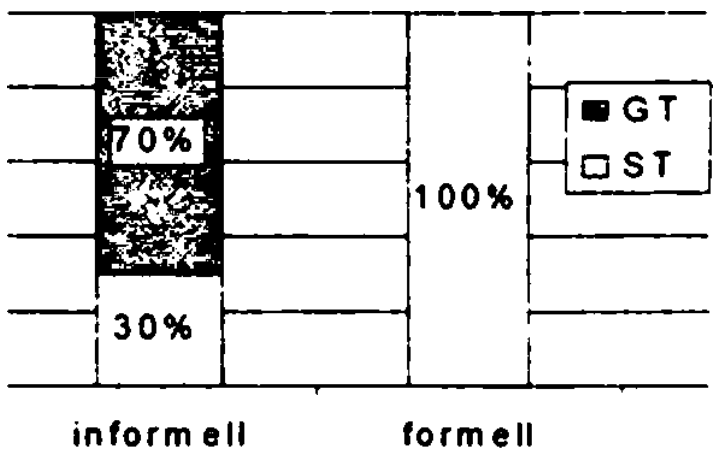

Evaluation der eigenen Kognition:

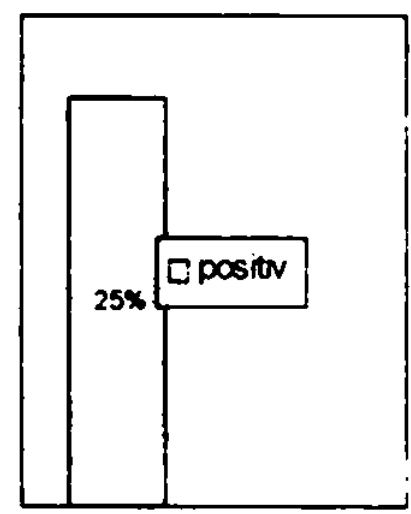

Einstellung, affektives Subsystem: Grad der positiven Einstellung $80 \%$

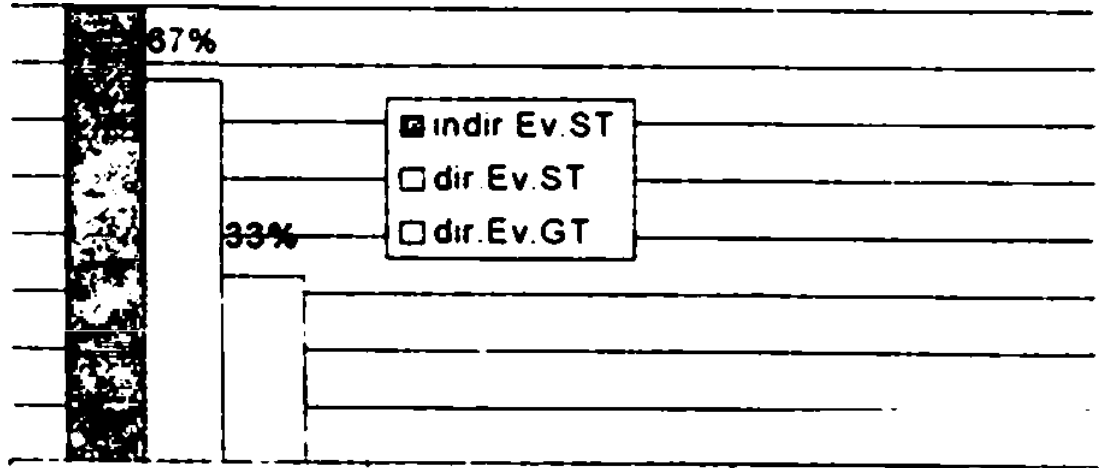


Kommentar: Pochybuji o nejjakè zmèně mezi spisovnou ceštinou a mluvenou. Je to již dlouholety zvyk mluvenèho slova na vesnicich (dialektech) a spisovnou ceštinou na úradech, $i$ když. se leckde mluvi i na úradech obvyklou mluvenou eeštinou.

\section{Tischler, 68 Jahre}

Sprachierhalten, formelle Silıation: mit Mikrofon auf der Straße angesprochen

Co si myslite o soucasném ziyšováni cen y Ceskè republice? Konkrémé o zuyšováni "ájemmiho a poplatkü za plyn a za elekırimu?

- No tak, pockejte, ja si to musim promyslet drobiček. Protože to nájemný jako mé nezajimá, pac jsem $v$ rodinnym domku a tim pádem se mi zdá dost nespravedlivý, abych já dotoval bydleni - jako - jinejm, který dostali tr̉eba státni byt. A jả bych jim mêl znova - pac̀ jsem si musel sám pristavêt $v$ rodinnym domku, abych moh bydlet. To je takovej jeden dủvod Elektrriny - no - a tomu nerozumim, no. Protože neznam ty vstupy. Jestli je to vopravdu drahý, jestli je to nutný

A rübec nárüst cen $v$ Ceské republice, i za potraviny?

- No, pakliže je to kompenzovaný - jako u mex - zvýšenim důchodu dycky, tak to beru. Já jsem dost pozitivnè naladẻnej na to, ale - to jste si asi vybrala špatnýho

A te d' ješstě otázka z jimé oblasti. Jaký máte názor na posledni zimu?

- Na posledni zimu? No - byla si tak v normálu, no. Nejsem ten staromilec, kterej si mysli, žc za mladi bylo hodné snchu a - to, to ne. Asi to bylo porád stejný.

Sprachverhalten informelle Situation: Gespräch mit der Verfasserin (bekannt nur durch das Interview) im Café beim Ausfüllen des Fragebogens

- No, u nás byl malér hroznej. protože jả jsem prìnes ċtyriku $z$ ceštiny a jednotku $z$ némčiny $\mathrm{Ne}$. jä jsem vżdycky $v$ tom plaval, ale dost jsem cet. Takže vidin, když nejjak mi to nejde do voka. tak

(A asi dneska ješld citele hoxlme, ne?)

- No, c̀tu. c̀tu. (...)

- Vy jste vodbornik. Mluvi se tady špatné nebo. Mnẻ by scházel ten krajovej kurs. Driv když jsem nékam prišel, tak jsem poznal, kde jsem, kdybyste mi zavázala voči. (...)

- No, vono taky zálcži na tom originalu, jak to preloži. Bylo by bibý, když budou natácet ncjjaky่ho James Bonda a von tam mluvi spisovné.

\section{Sprachverhalten:}

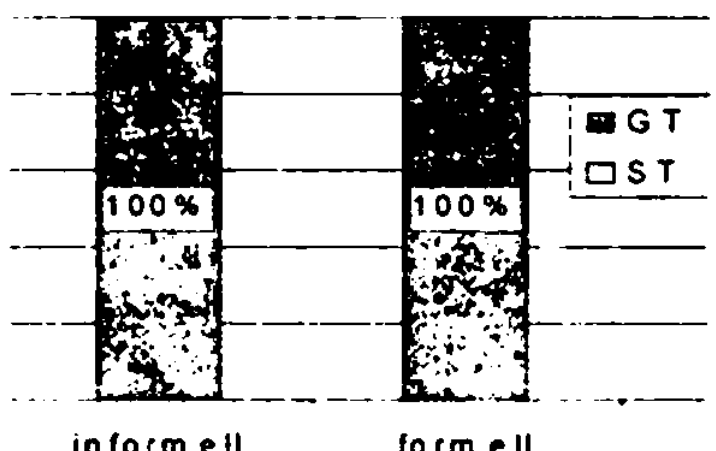

Einstellung, konatives Subsystem

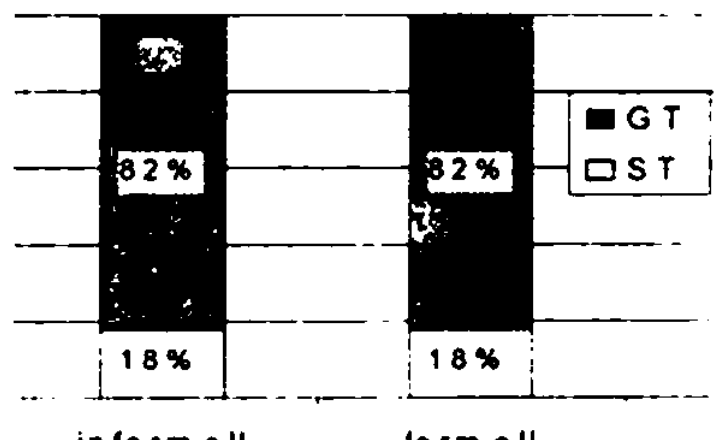

lorm ell 
Einstellung, kognitives Subsystem:

Derkannt 1 nicht erkannt

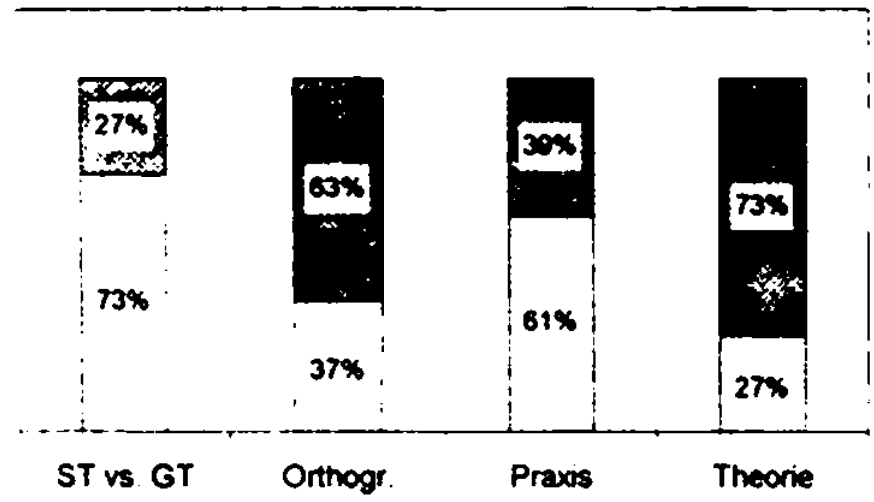

Evaluation der eigenen Kognition:

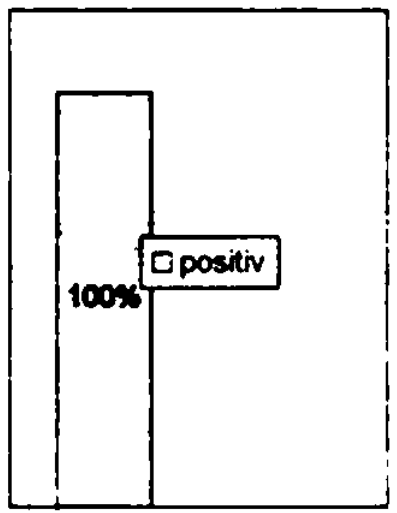

Einstellung, affektıves Subsystem: Grad der positiven Einstellung

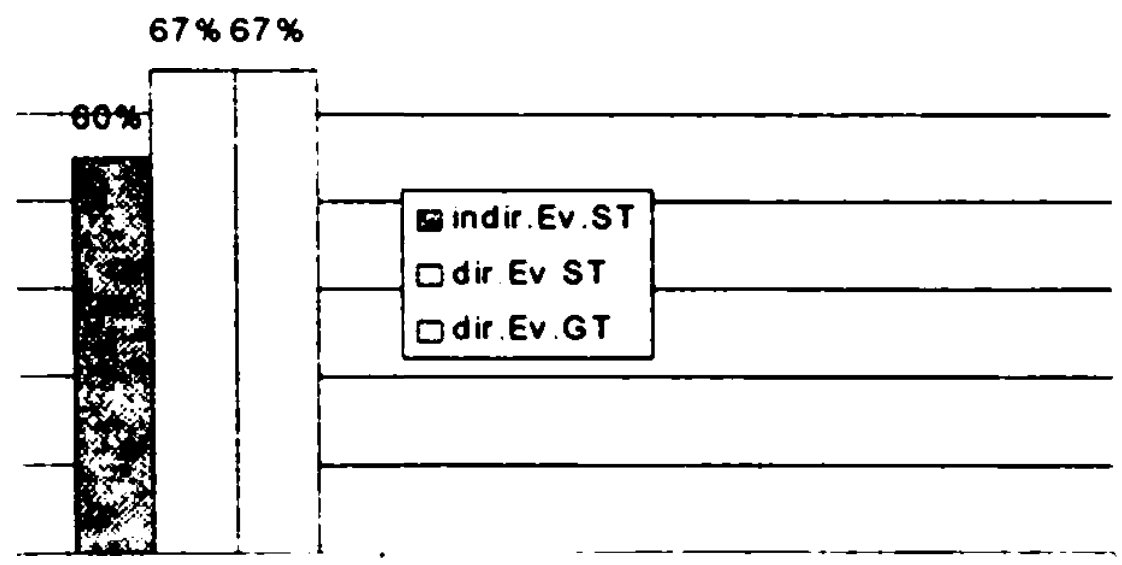

Kommentar: Je skoda, že se mistni nárecii ztráci. Rèč̀ mèla mistni kolorit.

\section{1.5 Mämmer mit Abitur}

Alter der Respondenten: 29 bis 69 Jahre, insg. 10 Aufnahmen

\section{Elektromechaniker, 29 Jahre}

Sprachverhalten. informelle Sitmation in der Wohnung des Respondenten beim Gespräch mit seiner Mutter (pensionierte Verkäuferin, 57 Jahre, ohne Abitur) und der Verfasserin (flüchtige Bekannte)

- Ne llonko, ted' k tomu nemúžeš - ne, ne, ne. Vona by to totiž zvrhla.

- Mam zan'tit to vokno?)

- No, zaviti to vokno.

- (.le żsimarja. co se stalo?)

- Vona totiž nevi, co chce, jo. To vona takhle vżdycky brecii, kdyż néco chce - a ted' to nedostane. (...)

- Tady to - zkratka to áčko je treba jako vopravit - vopravit chyby, jo? No. je jich tam hodnd, no. A kdyż to nebudu vèdżt, tak tam nebudu psat nic. Protože tohle vim, ̌e jsme se to učili ve 
škole, ale už si to nepamatuju. Chyby jenom voznačit nebo i vopravit? Jả bych treba tudleten text jako formuloval upplně jinak, protože to bych radši treba napsal nexkterý slova ujplné jinak jo. Jinak než tady - jo. Jinak bych to seradil. Tak jà to udělam tak - já jenom voznačim chyby. (Banila läs mlwinice?)

- No, jako, ne že by mẻ bavila, ale šla. A literatura - vždycky jsme mẻli - vona to do nás vždycky dvẻ hodiny hustila - tu poezii. Tu prózu ani tak ne - vona spiš tu poezii.

(Ty jste dellal primyslowku?)

- Ne, ne - jà dêlal jako s maturitou - ale učebni obor. To bylo lepši vlastné neż prưmyslovka. protože jà - vlastně prì̌̌l někam - a už jsem mẻl praxi. (...)

- Jà jsem nemêl množiny. Jả mẻl množiny, až když jsem prì̌̌el na učñàk. Tam jà na to koukal jako tele na nový vrata. Po nás už je potom chtẻli, když jsme priišli na učnảk. To byly pěkný blbiny. To už se dneska vưbec neuci. Tam se uci takový vêci - jako co to je datum, co to je mésic nebo jaký jsou názvy mésiců - jak se jmenujou.

Sprachuerhalıen, formelle Sirwation: in der Wohnung des Respondenten

(o si myslite o somcasném zujišeni najjenmého a poplatkú za elektrimm a plyn?

- Co si myslim - no, že to je asi svextovej trend, no.

My:slite si. ż budou ceny i nadale stoupar?

- Asi jo.

Takze se bude Żvorini iroveñ neustäle zhoršovat?

- Pocitam, że ty platy taky porostou. Soucasnè s tẻma cenama.

Doufáte. ż se siluace zhorisovat nebucle?

- No, to zảleži, v každym stảtẻ to bude asi individuelni. V každej republice.

A co rikcint posledmi zime?

- Zime? To nevim.

Byla poulle lä̀cho nazoru neobrykle teplá?

- No, asi takhle, no tak. Každý obdobi je jiný, že jo. Na tuto nevim, co rict.

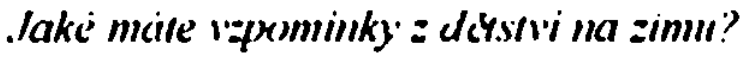

- No myslim, że byla dost - jako - studená, no. Bylo vic snchu.

My:slite si. ¿x prisili zımy budou raky tak mirmé?

- No, tak takovej prorok zase nejsem. Takže nevim.

A co byste si pràl pro siou malou dcerku do budoucma?

- No, aby byla živá a zdravà a aby na ni neprišly nčjaký těžkosti - jak - jako prirodni katastrofy, tak jako politický nebo ñáký - aby to zkrảtka ñảk klapalo.

Sprachverhalten:

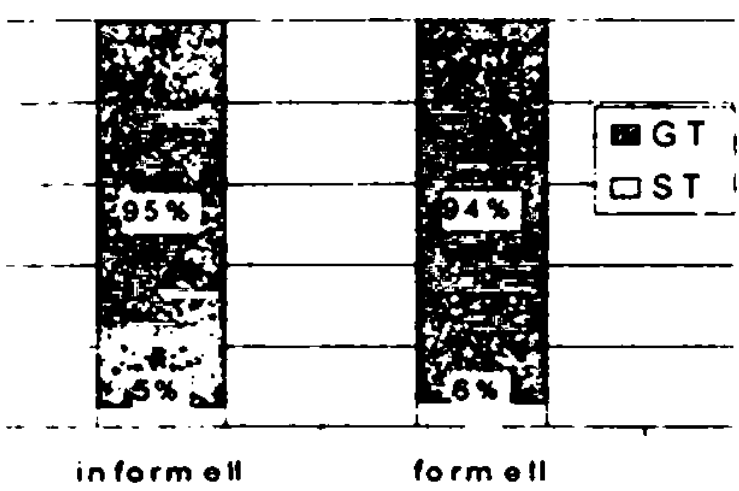

Einstellung, konatives Subsystem.

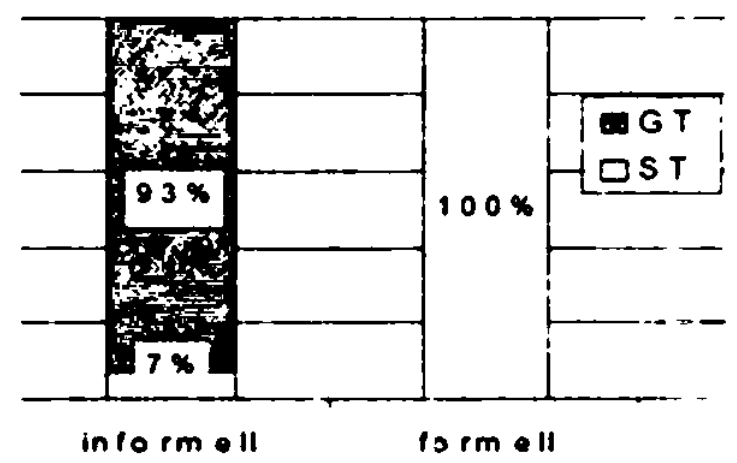


Einstellung, kognitives Subsystem:

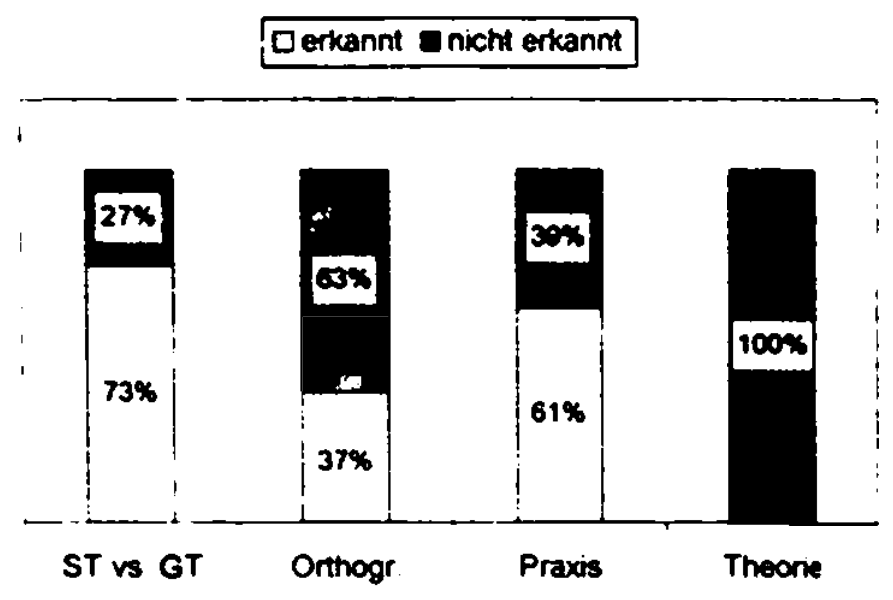

Evaluation der eigenen Kognition:

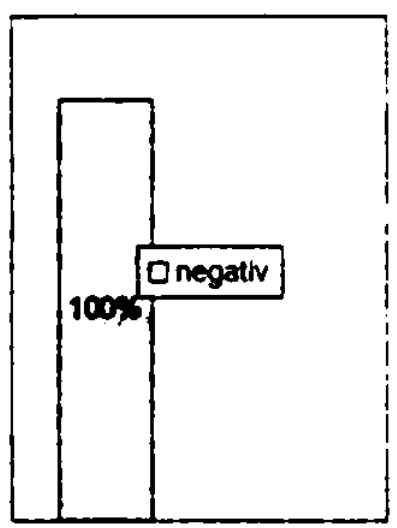

Einstellung, affektives Subsystem: Grad der positiven Einstellung

\begin{tabular}{l|l}
$100 \times 100 \%$ \\
\end{tabular}

Kommentar ohne Kommentar

\section{Kaufmännischer Angestellter, 32 Jahre}

Sprachverhalten. formelle Simation: beim Respondenten zu Hause

('o si myslite o souciasném zyšováni najemmiho a poplatkü za plyn a elektrinu?"

- No, asi je to nutný, ale - jako - asi by to nemello bejt tak vysoký

A jak to vidue do budoncria?

- No, tak spiš optimisticky - jo, protože tak ñák - jako - je mi ñákejch tticet dva, a tak eštê nejsem takovej pesimista.

A le d" ješst otázka z jimé oblasti. Jaky' máte näzor na posledni teplou zimu?

- No, zimy byly vždycky - někdy krutý, nêkdy teplý.

.lake byly' zimly', kctyżjsle byl maly??

- No, co si pamatuju. taky nic moc

Nebylo vic snchur?

- No, tady ve mèstẻ - jako - nikdy moc snèhu nebylo. Jo - když jsme jeli tr̉eba do Krkonoš. tak tam bylo asi vic snehu. neż. jsou posledni zimy. 
A jezdite na hory lyžovat?

- No, v posledni dobẻ uż jenom do Francie.

Takı̉ lyăıjele rád?

- No, to jo. Dřiv jsem byl teda zvyklej spiš na bežzky, ale když jako - do tý Francie, tak jedinę na ty sjezdovky.

Także mirne zimy v Cechách l"äm nevadi, zajedete si na lyże do Francie.

- No, to jo, ale radši - jako - jsem, když je v lednu zima - a pak vod toho března když už je teplejc. To už jako - vic se mi to libi.

Sprachverhalten:

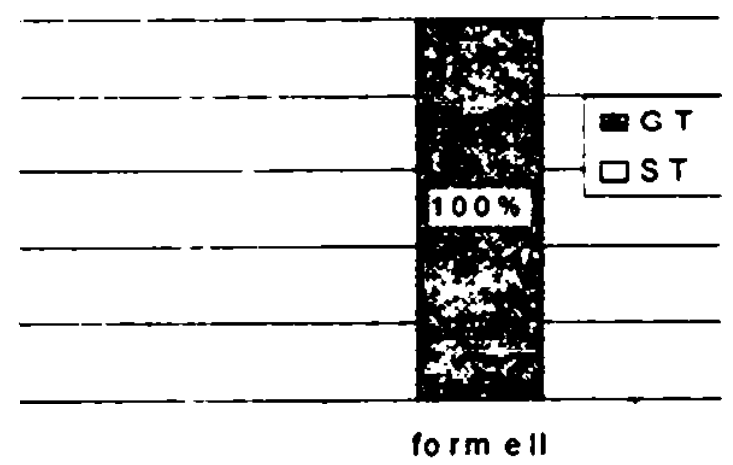

Einstellung, kognitives Subsystem:

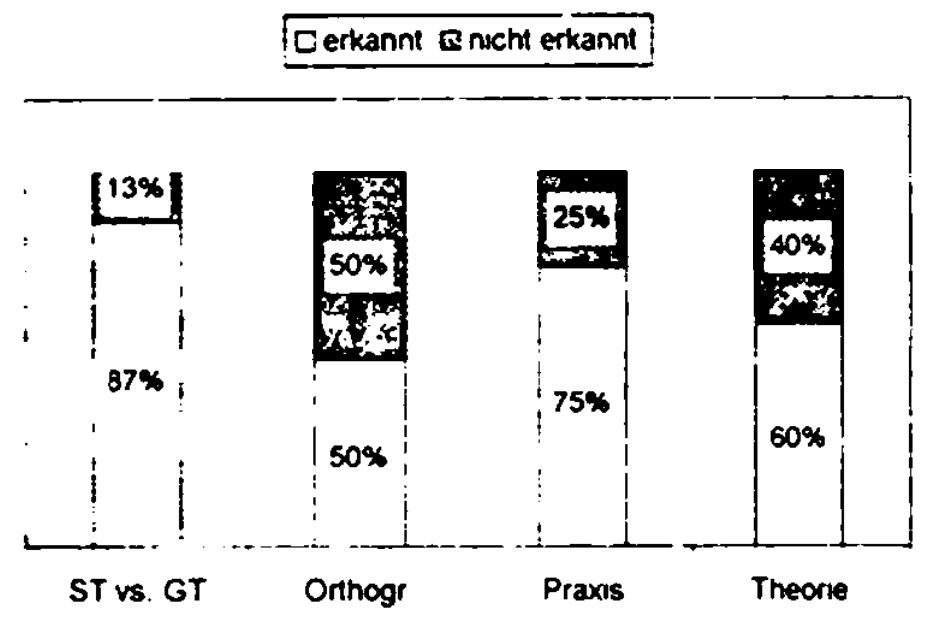

Einstellung, konatives Subsystem.

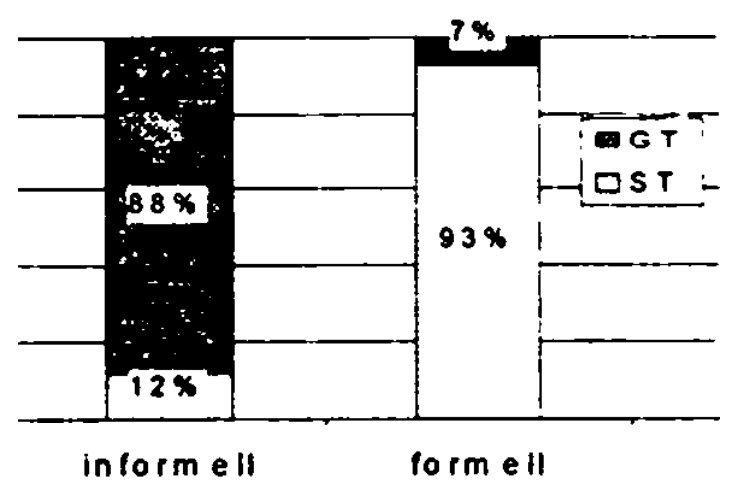

Evaluation der eigenen Kognition:

Einstellung. affektives Subsystem Grad der positiven Einstellung
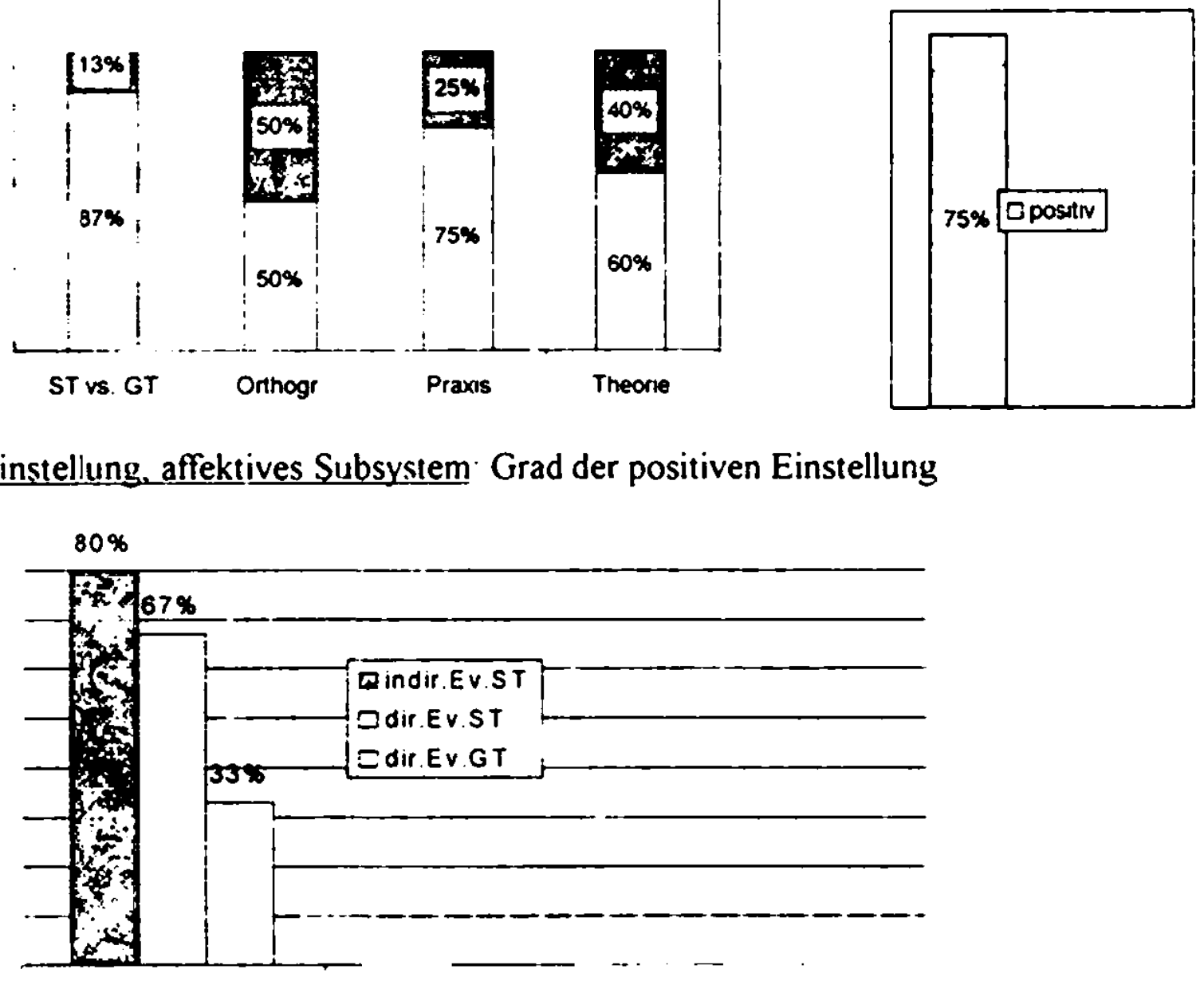


\section{Chemiker, 36 Jahre}

Sprachverhalten. formelle Sitmation: an der Arbeitsstelle des Respondenten

Co si myslite o souciasném zryšsováni cen v Ceské republice?

- Je to neumèrne - to zvyšováni cen.

Konkrètmé o zyyšováni najemmého a poplatkủ za plyn a elektrimm?

- No, to je jako - pro nékterý rodiny už to bude jako neúnosný - teda. Jsou to velký ceny, vysoký ceny.

Myslite si, zu bucle klesat tivomi iroven?

- No, v nékterých pripadech ano.

A led' ješl č otázka z jimi oblasti. Vyhovovala Vám posledni zima? Jaký mu ni mále názor. Co jsie delal?

- Co jsem dèlal, no, vêtšinou jsem byl v práci

Byl jste letos na horách?

- Na horách jsem nebyl, pouze doma. Dle možnosti teda.

Mohly by zimy' podle laseho piani tiplné zaniknout? Co byste potom deal?

- Co bych dẻal. Věnoval bych se asi nějakýmu jinýmu sportu, no. Dêlal bych asi nějakou tu turistiku horskou. Možná horský kolo.

Sprachverhalten:

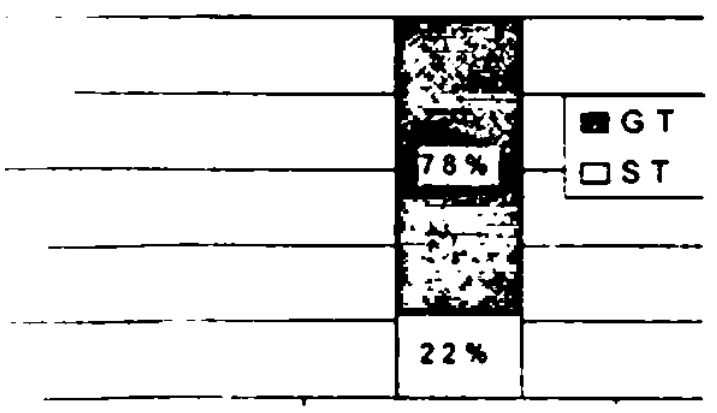

form ell

Einstellung, kognitives Subsystem:

Cerkannt Inicht erkannt

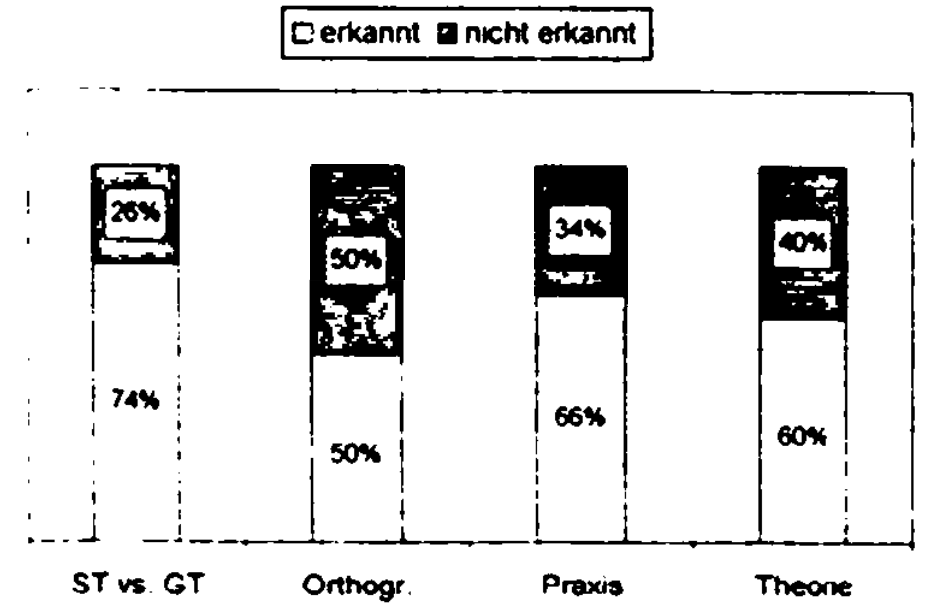

Einstellung, konatives Subsystem:

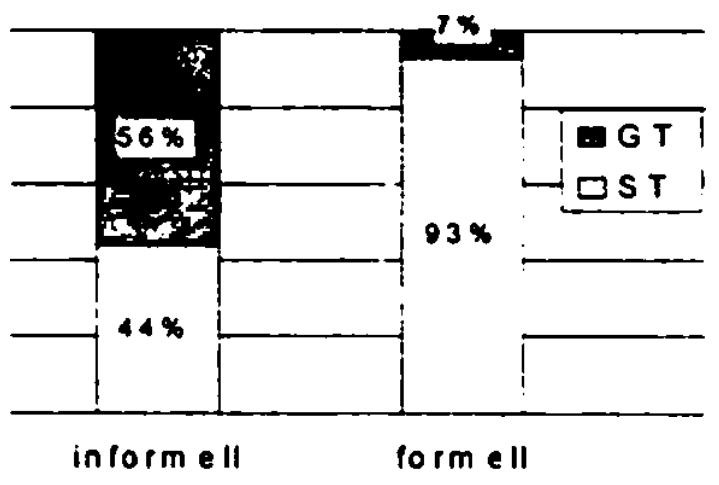

Evaluation der eigenen Kognition:

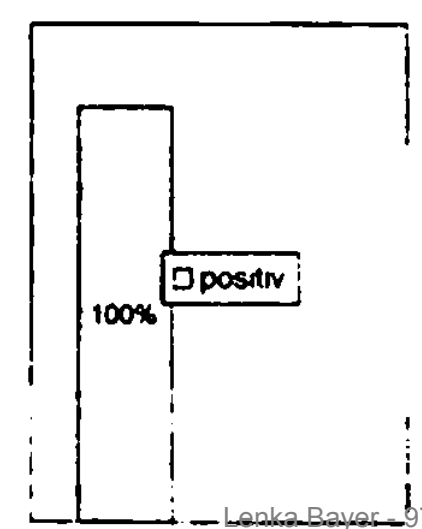


Einstellung, affektives Subsystem: Grad der positiven Einstellung

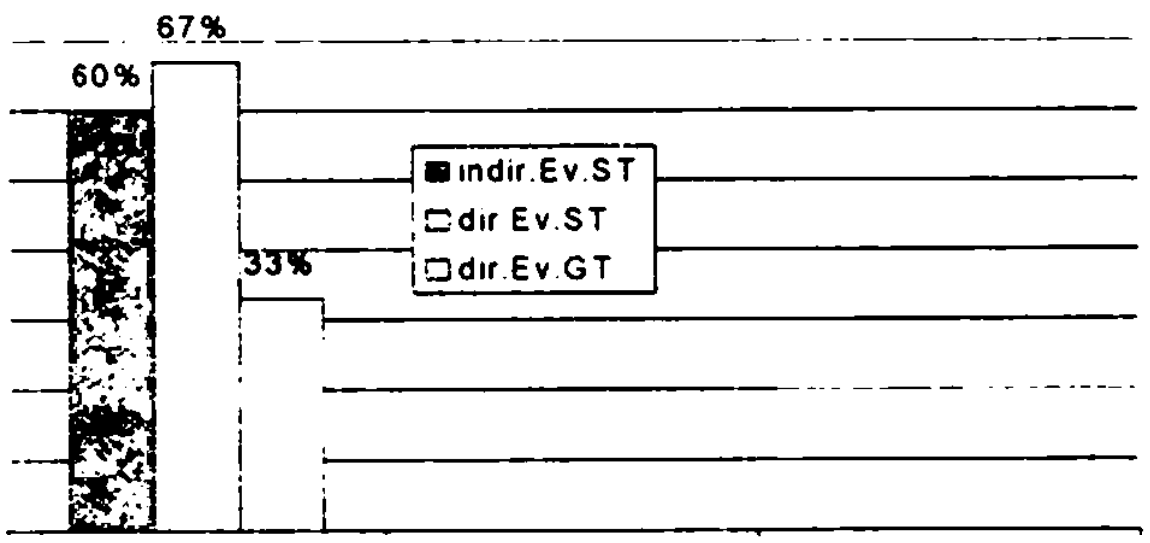

Kommentar: ohne Kommentar

\section{Elektromechaniker, 38 Jahre}

Sprachierhallen, formelle Simarion: mit Mikrofon auf der Straße angesprochen

Co si my:slite o zıyśováni najjemného a poplatkí za plyn a za elekt rimm?

- No, muj nảzor je takovej, že $v$ podstaté jako tuto navyšováni už $v$ podstaté jako je dost teda jako neúnosný pro urẻitý - jako dcjmc tomu jednak teda sociálnế slabši vrstvy, mezi který teda jako nepattrim. Já pattrim jako do tý středni cásti, středni vrstvy. Ale i tak jako - já nevim - pri mym platu - dejme tomu jedenácti tisic čistýho už jako pri najjmu, kterej platim dneska tři tisice c̀tyři sta za byt. plus ešte $k$ tomu navyšováni energie. Tak to se mi zdá jako už. dost neúnosny. Pokud by tohleto byl konec a dả už by se to nezvedalo. Teda dejme tomu ňakym určitym procentem by se zvedaly platy - od tudletý chvile, tak dejme tomu, je to ínosný, ale pokavad' to bude takhle pokraçovat dál, už jako $v$ tom nevidin żádnou perspeitivu - jako, jo.

Sprachicrhalten informelle Silluation. Gespräch mit der Verfasserin (bekannt nur durch das Interview) im Café beim Ausfullen des Fragebogens

(lïe, kdy rzmikla spisonma izestima?)

- Tak. myslim si, že brzy, ale jako kdy presnè vznikla - to nevim.

(A vile, kele ji zalozil?)

- No, asi ñákej ten Palackej. Ale vopravdu, to jako stŕilim, jo. (...) To bych jako byl pro, jako jo. Že prostě, použivat spisovnou češtinu jako ve zpravodajstvi, ve všem, ale jako nezachàzet jako do nějakejch extrémú. Tu hovorovou ceštinu jako použivat klidnš. A tu spisovnou ćeštinu, já nevim, dejme tomu, $v$ tej úředni reči. Jako, já nevim - spisovnej projev já nevim pro ửad, jo. Jako vyplñovat cokoliv, jako jo, prosté jakýkoliv lejstro. Psaná, jako jo - psanej podmét - jako jo - tou spisovnou ceštinou. Jako dejme tomu napsat: 'Zaplat mi fakturu', že jo, misto: 'Zaplatte fakturu'. To by bylo asi - jako tam bych teda tu hovorovou cesštinu jakio vypustil, jo. To by asi to mčlo bejt $v$ tej psanej forme. 
Sprachverhalten:

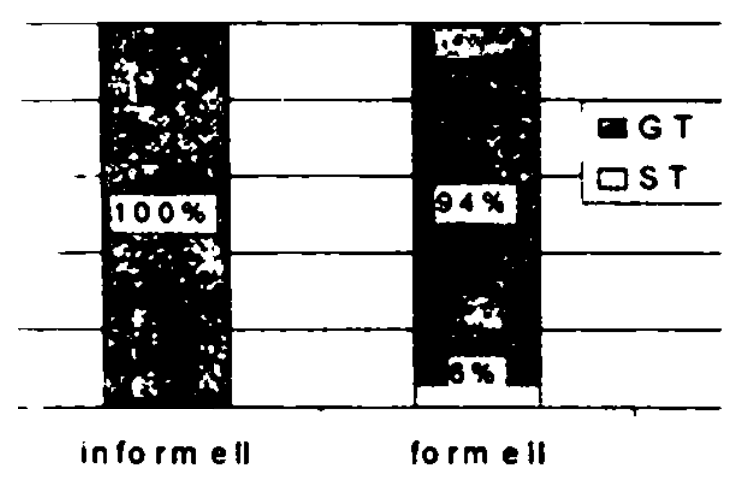

Einstellung, kognitives Subsystem:

Derkann D nicht erkannt

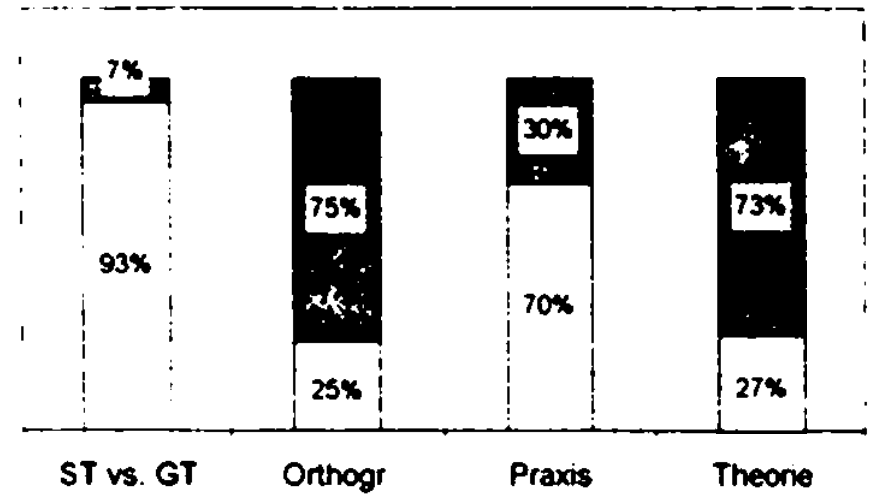

Einstellung, konatives Subsystem:

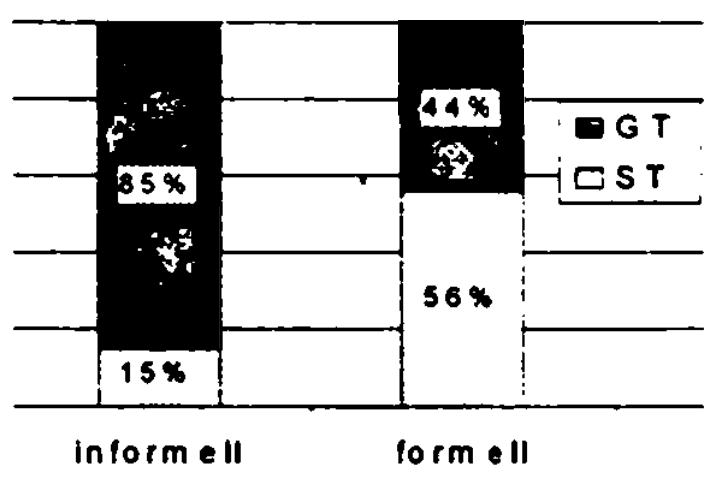

Evaluation der eigenen Kegnition:

Einstellung, affektives Subsystem: Grad der positiven Einstellung

$67 \%$

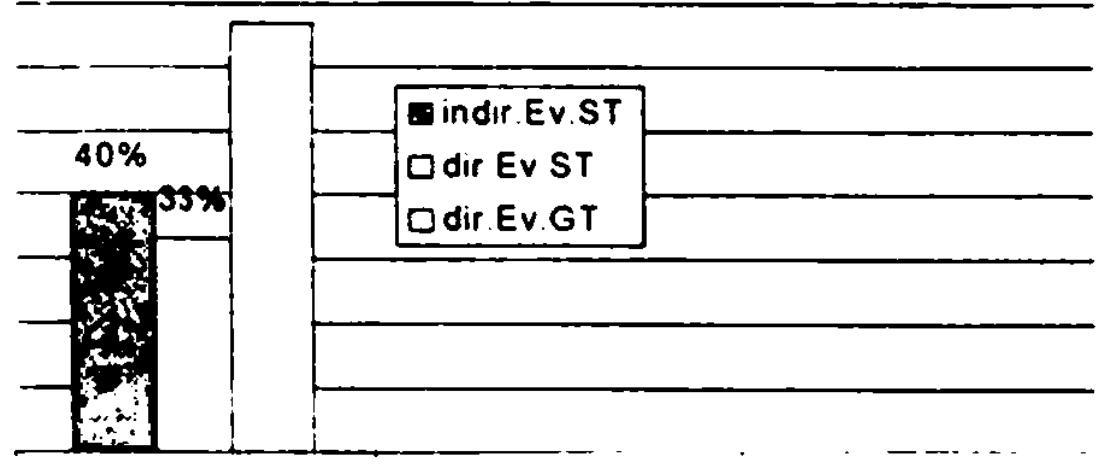

Kommentar Rozdil mezi mluvenou a psanou formou mi vyhovuje. Mluva $v$ televizi - v mluvené formé by se mẻla použivat hovorová c̀eština [gemeint ist hier das GT]. Úredni rè poużjvat spisovnou cešstinu.

\section{Technischer Angestellter, 47 Jahre}

Sipracherhalten, formelle Sirmalion: an der Arbeitsstelle des Respondenten

('o si myslite o somiansnem zyysováni cen v Ceské republice?

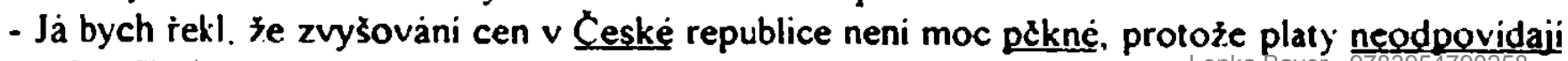
cenàm To je všechno - asi. 
A jaký máte názor na myni akmálni zvyšováni nájemmého a poplatkủ za plyn a elektrimm?

- Jà bych řckl, żc to je to samé. co zvyšováni cen, platy neodpovidaji požadovaným cenám. A ted' ješl or ázka z jime oblasti. Jaký máte názor na posledni mirnou zimu?

- Posledni mirná zima prekvapila mnoho lidi, no, a takový je svêt.

A ly osobne máte rád mirme zimy anebo jsou Vám ty studené milejsi?

- Tak, jả mám radši teplo $\mathrm{Za}$ zimou si múžu dojet.

A myslite si. ž soucasne chripkove obdobi je spojene s mirnou zimou?

- Myslim že to neni spojene s mirnou zimou, že chřipkový obdobi je daný, że prostè chripka prícházi $v$ epidemiich anebo vodcházi. Je to každoročnč. Jak to vypadá - tak vypadá. że asi budou zimy teplejši - taková je priroda.

Sprachverhalten:

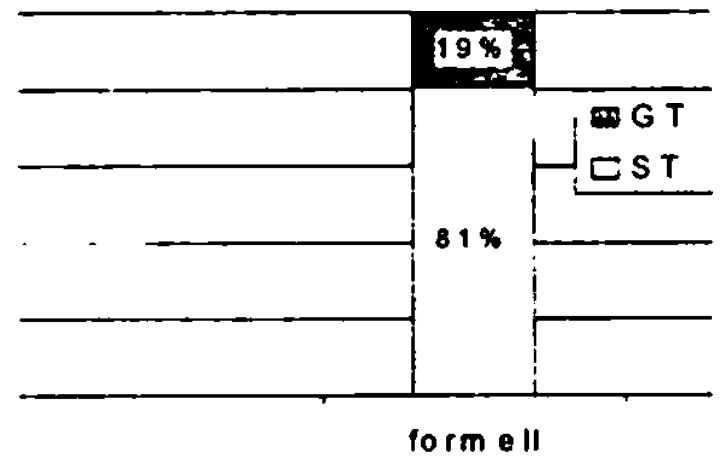

Einstellung, kognitives Subsystem:

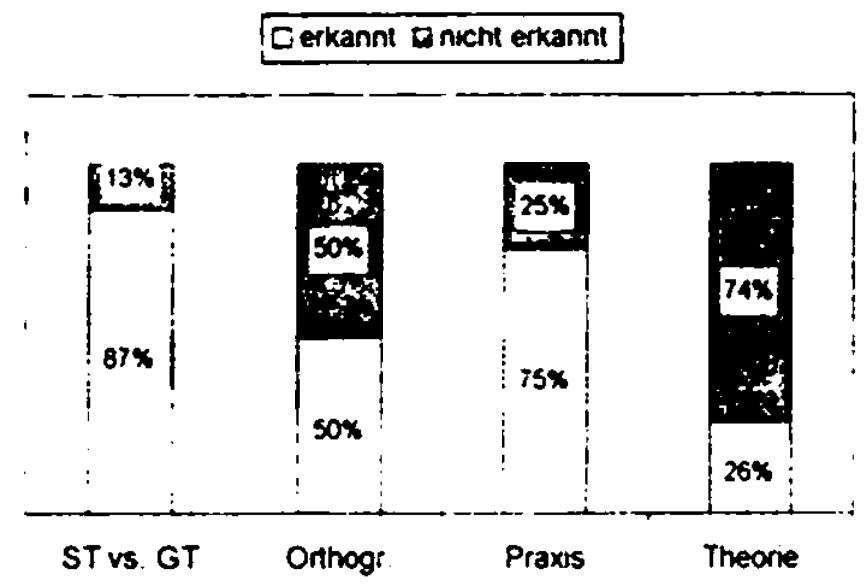

Einstellung, konatives Subsystem:

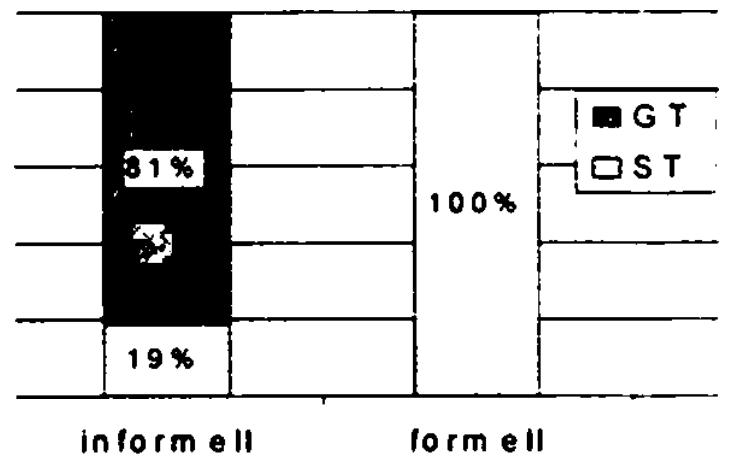

Evaluation der eigenen Kognition:

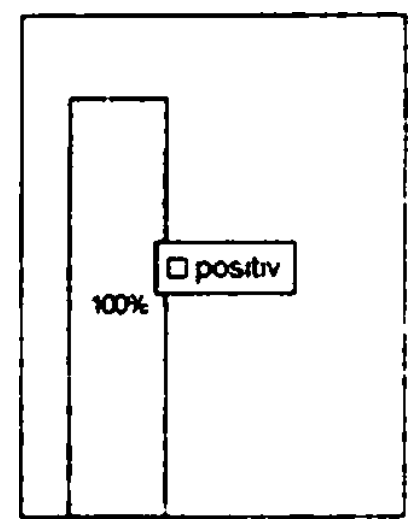

Einstellung, affektives Subsystem: Grad der positiven Einstellung

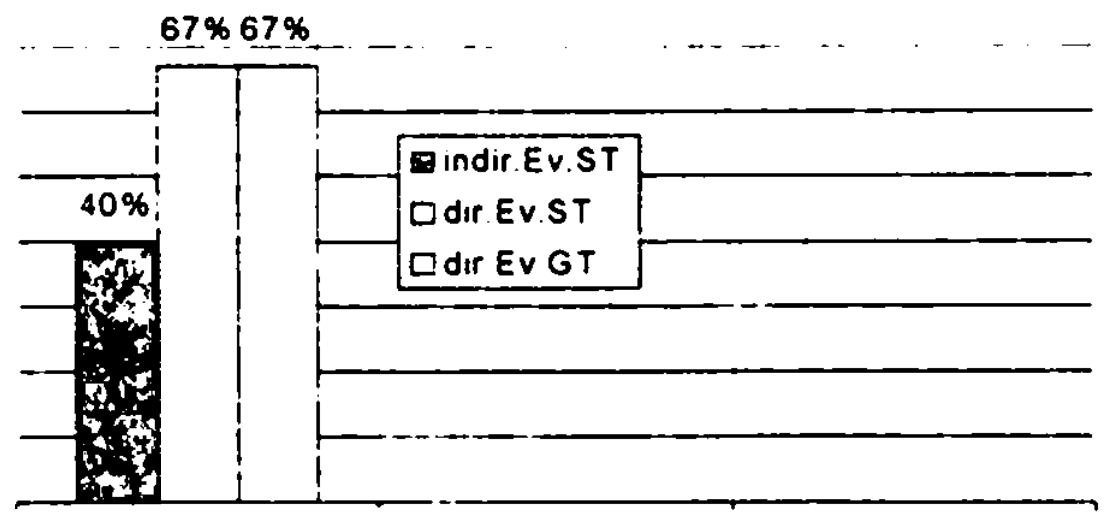




\section{Kulissenbauer, 47 Jahre}

Sprachverhalten. informelle Situation: Gespräch mit seiner Kollegin und der Verfasserin (unbekannt) im Theaterfoyer

Máte chvilku cas?)

- A co to je za dotaznik?

(Z íšrtiny.)

- Jà neumim cesky.

(Kdybyste mal chvilku ias, byla bych ráda.)

- To bysme museli do kavarmy. Tak počkejte, já si musim zavolat. Abych vám do toho. (...)

- Ne. ne, ne - to někdy bydlel ve Škvrñanech? Nebydlel? Jả ho vodněkud - no, to je jedno.

Sprachverhalten, formelle Simation: im Theaterfoyer

Jaky máte názor na stoupáni cen v Ceské republice?

- Jà si myslim, že stoupảni cen je úplné zbytečné, protože to nevede $k$ ničemu jinýmu než $k$ ochuzovảni určitý vrstvy lidi, kterii maji vỷdélky nižši než deset tisic. Ty, co maji nad deset tisic, to tak nepociti. A je to hlavnè stoupáni cen v neprospěch lidi, který maji déti a který by mêli svüj život žit, a ne ho jenom - prostě - žit tim, že budou šetrit a odpirat dêtem to, že jim mủžou koupit vêtši množstvi ovoce anebo cukrovi a tak dảle. Dneska dêti vlastné jsou ochuzovaný $Q$ to, že jim neni dopłáno, aby cestovaly, protože se zvyšuje nesmyslnẻ i drảha. kde vrstvy, který nemaji na to, aby jezdily autama, nemúžou dneska ani jezdit vlakem, protože je to dražši - $v$ podstatě než auto. A tim pádem $i$ ekologie $v$ tomto státé je až na poslednim mistç, protože hromadný dopravni prostředky jsou $v$ podstatě pro tti- až ityričlenou rodinu dražši než je to autama - vlastnè osobni dopravou. To je všechno.

A ješl jimá otázka. Jaký máte názor ma posledmi zimu?

- No. posledni zima byla priznivá pro celej tento národ, protože mu zdražujou topeni, takže aspoǹ ta zima doprảla $v$ tom, že nemuseli tolik topit a ušetrili na topeni. Ale jinak si myslim, ż.e zima by méla byyt se snçhem, aby zase se mohly rodiny vỉetné déti vyžit $v$ zinnnich sportech a aby mohly proste̊ užit si zase jinýho roc̉niho obdobi, který prosté je $v$ tomto státé, že je léto. zima - a což teda tỉeba $v$ Africe neni, že jo. No, ale s̉patná zima byla, protože nebyl snih a led a déti si nemohly dovolit bruslit. Byly odkázaný jenom tỉeba na zimni stadiony a zase je ta otảzka, že všechno je drahý a $v$ podstatẻ tẻm rodinảm, který nemaji velký výdẻlky - vlastnê $i$ ty déti nemohly na ty zimni stadiony, což. je politika této zemć velice špatná.

Sprachverhalten:

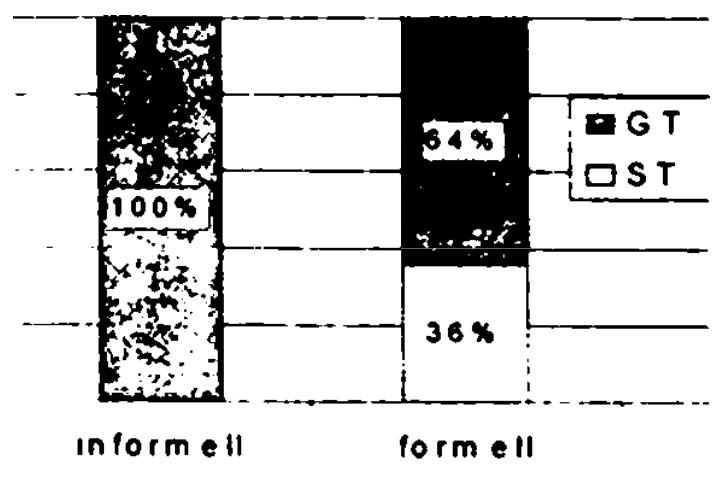

Einstellung, konatives Subsystem

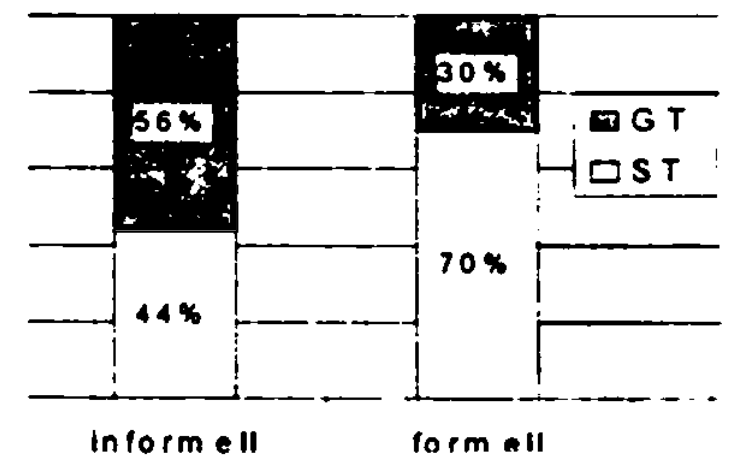

Lenka Bayer - 9783954790258 
Einstellung, kognitives Subsystem:

Derkannt I nicht erkannt

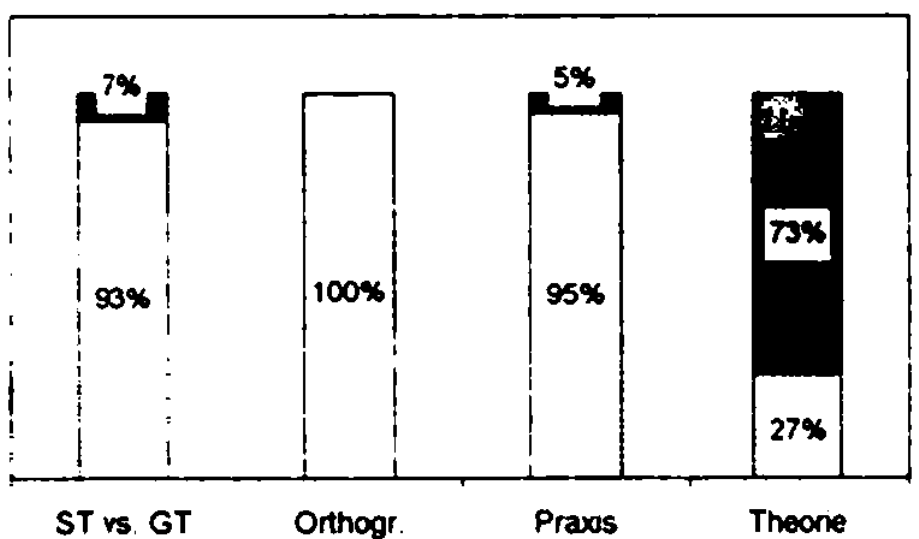

Evaluation der eigenen Kognition

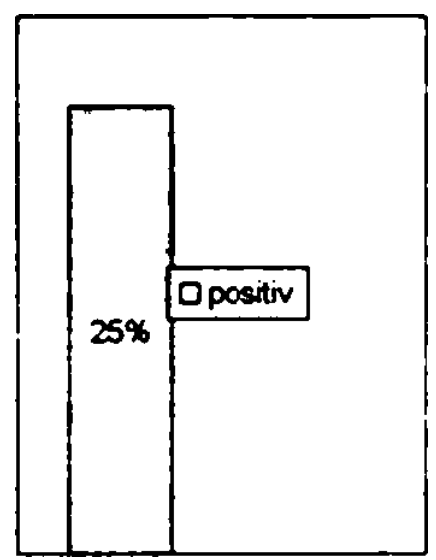

Einstellung, affektives Subsystem: Grad der positiven Einstellung

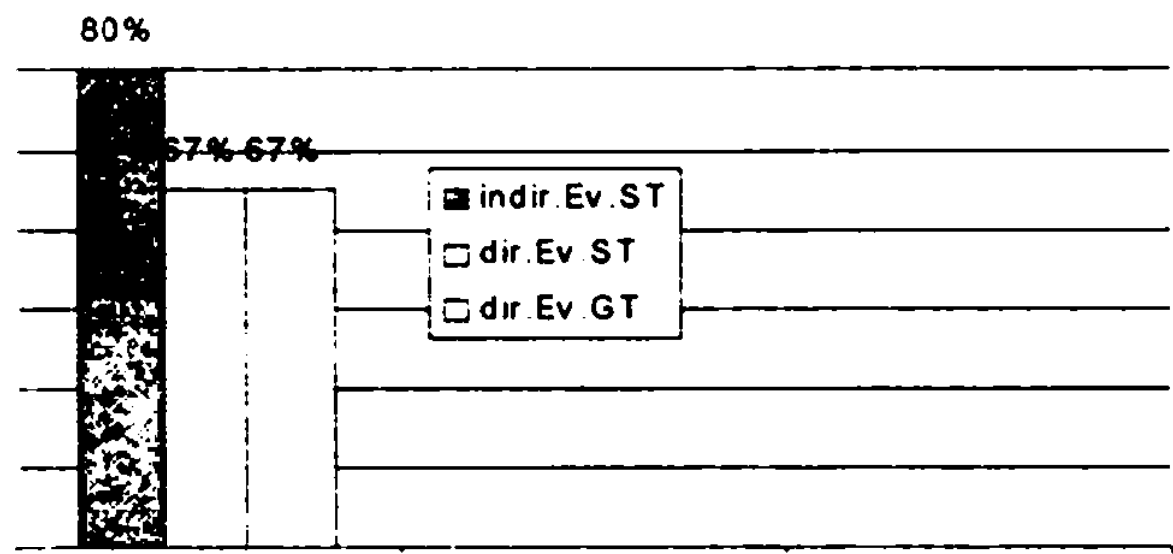

Kommentar: Tato anketa je velmi prospéšná a méla by se uskutečnit i v televizi a rozhlase, pro zlepšeni ceskèho jazyka. V televizi a rozhlase jsou hlasatalè, kteri neznaji spisovnou mluvenou ¿eštinu. Co je nejhorši, že někdy úmysinê mluvi nespisovně. Noviny a ċasopisy maji tolik chyb. te je to ostuda celeho naroda.

\section{Pensionierter Büroangestellter, 62 Jahre}

Sprachverhalsen, formelle Situation: in der Wohnung seiner Freundin

Jakj mále názor na soucasnié zyyšováni cen?

- No, nèkdy je dobrý - je to nutný - a nékdy to neni nutný. Nêkdy je to tr̉ebas ñákej - ten - ty podniky chtêj vydẻlat. A nêkdy je to nutný oprávnèný.

A konkrétmé na zvyšováni nájemného a poplatkú za elekı rimm a za plyn?

- No, je skutecinost ta, že u nás jsou - najem - że jsou nizký, že ty skutec̀nẻ nestacii na ưdržbu a opravy téch domủ. Plyn je dost vysokej. Možná, že monopol to délá, że se musi - neman takovej eštč názor vyhrančnej na to. Na nájemný - asi se musi zvỷšit v každym prípadž. A jakj mále názor na posledmi zimu?

- No, posledni zima byla kolisavá - mrazy, zima a tim pádem byly chripky a takaý̇ Także souvisi to s tim - s pocasim to souvisi. 
Sprachverhalten:

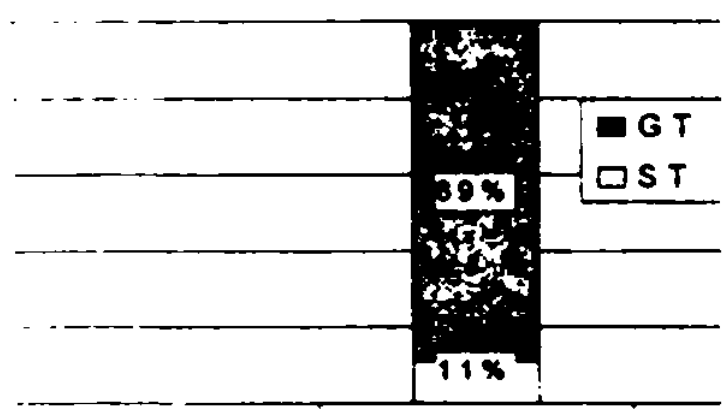

form ell

Einstellung, kognitives Subsystem:

Derkannt In nicht erkannt

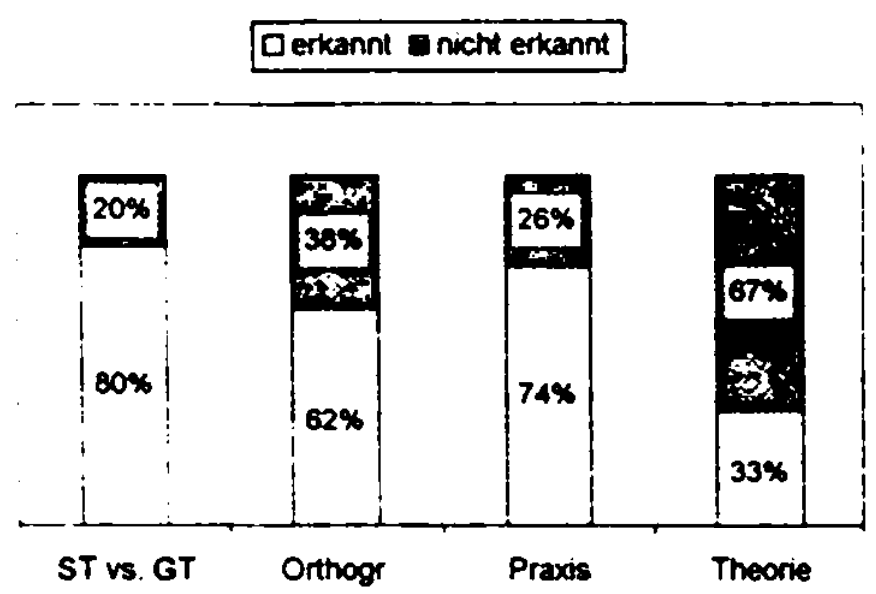

Einstellung, konatives Subsystem:

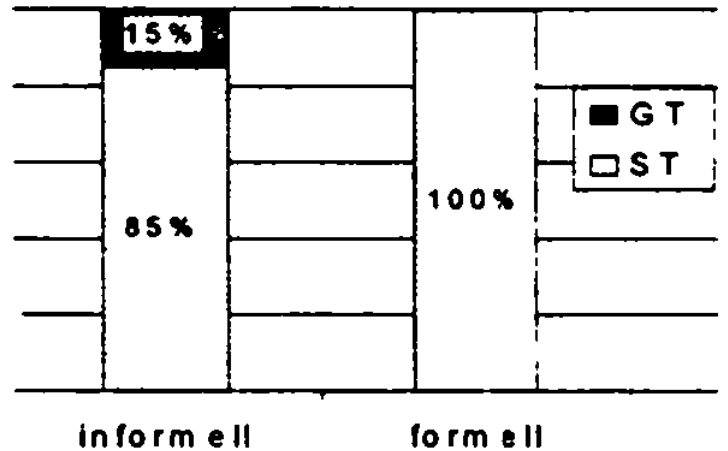

Evaluation der eigenen Kognition:

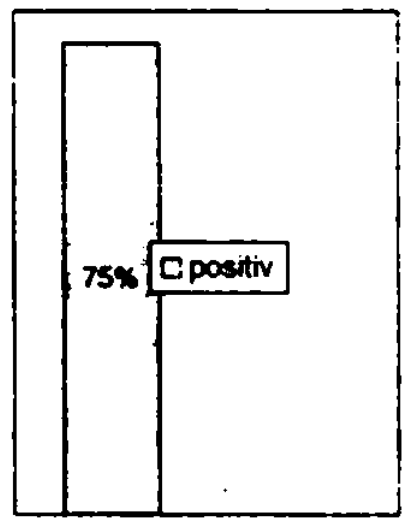

Einstellung, affektives Subsystem: Grad der positiven Einstellung

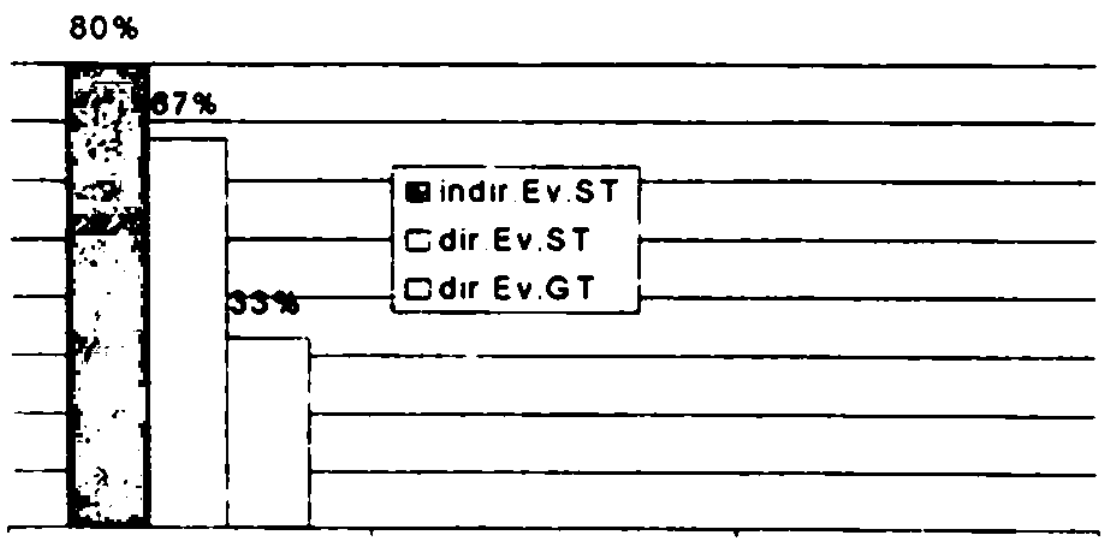

Kommentar: Nêkdy použivám i nespisovné vyrazy $v$ běžnèm hovorovém jazyce. $V$ rozhlase a $v$ televizi by se melo mluvit spisovně.

\section{Gebäudeverwalter, 62 Jahre}

Siprachverhalien, informelle Sitmation: Gespräch mit der Verfasserin (flüchtige Bekannte) am Arbeitsplatz des Respondenten

(No. la replá zima uam zase prinesla spoustu chriphy:)

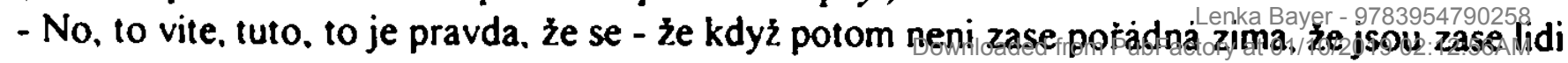


nemocný. Ale ušetrì se zase za topeni.

(To mate pravdu.) (...)

- To byl slovnik, to kdybyste slyšela, to byste vzala jak vodstrašujici priklad. Já jsem mu tam dal. A von eštê: Promiňte, promiňte. Tak eštč chtêl podat takovou tu žádost. (...) Protože mê i to dožralo. To udélal taky už jeden taxikár. A ten byl taky tak pitomej, ten do mč narazil (...)

To i tak potom ta moje žena nadávala. (...)

- To jsou momenty, kdy skuteine, jo. To povolej nervy.

(A naboural Vám to moc?)

- Ne, nebylo tam nic. No, kdybych to bejval vidêl - takhle - že tam nic neni, tak bych pribrzdil, no. (...)

To jsou nervy, taky. A to jsem to tak, taky asi v takovej tej miře nebo trošku ešti vic. No. vono se rikà (...)

Spracherhallen, formelle Simation: am Arbeitsplatz des Respondenten

Jakj' máte nazor na soucasné stoupaini cen v Ceské republice?

- No, neni to dobrý tady u nás ted'ka. protože nejvic tim trpi ty lidi, který jsou nižšiho zarazeni nebo nižši vrstvy a i tý str̉edni vrstvy. Protože at se to týká bydleni, at se to týkà energii - a i vlastnich životnich - żivotně dưlężitých - prostě - potṙeb. Když, jestliže rikáme, že musime vyrovnat ceny i vưci zahraniči, tak by ovšem mẻlo bejt taky zase vidêt nékde ñáký zlevnẻni nčkterejch têch věci, protože je rozdil - v zahraniči, když zaplati za byt treba pomérnè dost velkou éástku - u nás už je to ted'ka taky. Za energii taky zaplati velkou částku $u$ nás taky - no, ale $v$ zahranici to - ty żivotni potreby, co se týkả toho jidla a tak dále. Tak ty jsou pomérné lacinżǰ̌i, kdežto u nás jsou drahý zrovna tak jako ty vostatni věci.

A ješt č otäza z jime oblasti. Jakỷ mále názor na posledni mirnou zimu? lyhovovala lä́m?

- No, tak vêtšinou lidi, kterii už jsou trošku starši, tak, kdyż je mirnà zima, tak jim vyhovuje. Když byl ċlověk mladši, tak chtêl radši, aby byla ta zima tuhá. už kvưli ñákýmu tomu sportu. ale čim je človšk starši, tak pricházi - tak má - tak se mu lepši libi, kdyż je tý zimy miñ. Nevêrì tomu, když byl mladej, protože to znal vždycky $z$ těch - vod têch drivęjšich - vod têch staršich lidi taky. že riikali: jè, to je špatný, zase už je zima. A pricházi $k$ tomu - $k$ tomu názoru taky

Sprachverhalten:

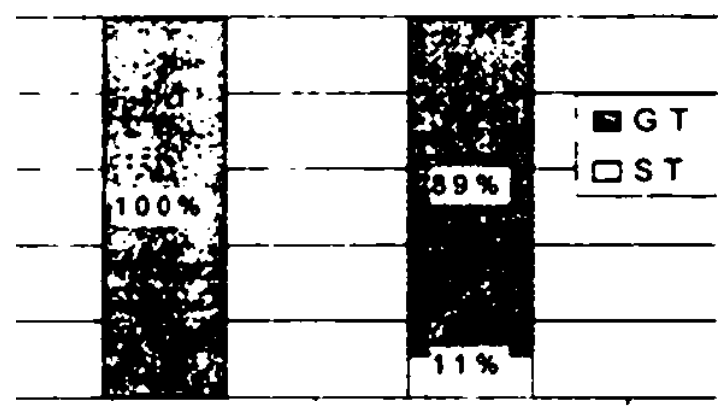

inform ell

formell
Einstellung, konatives Subsystem.

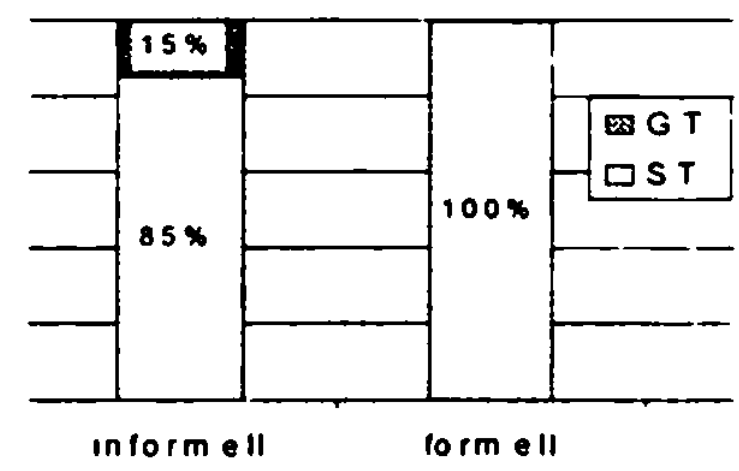


Einst ellung, kognitives Subsystem:

Derkannt Enicht erkannt

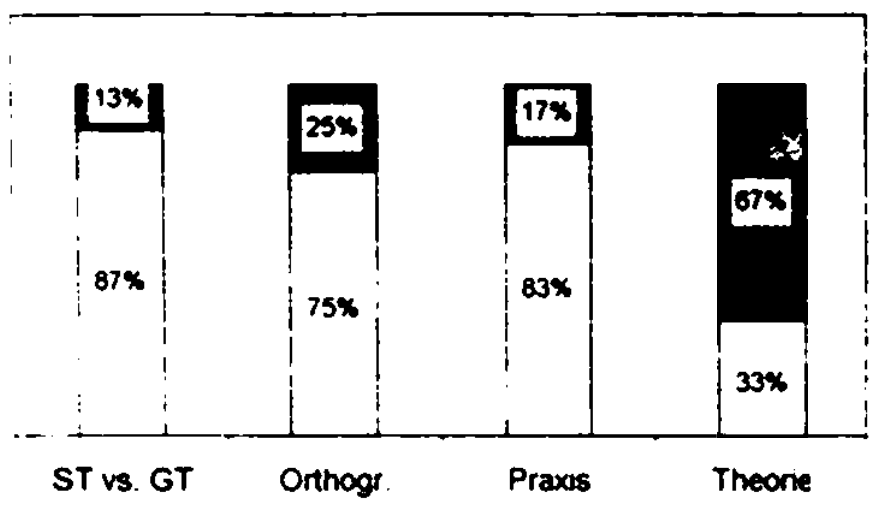

\section{Evaluation der eigenen Kognition}

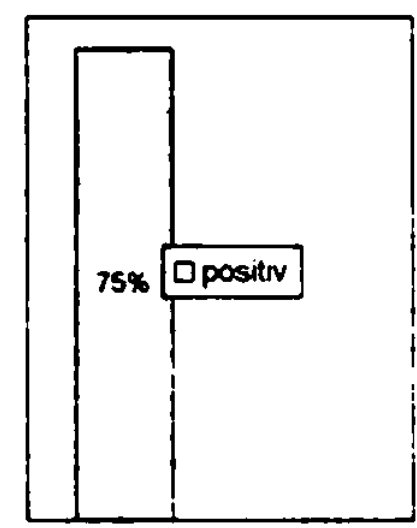

Einstellung, affektives Subsystem: Grad der positiven Einstellung

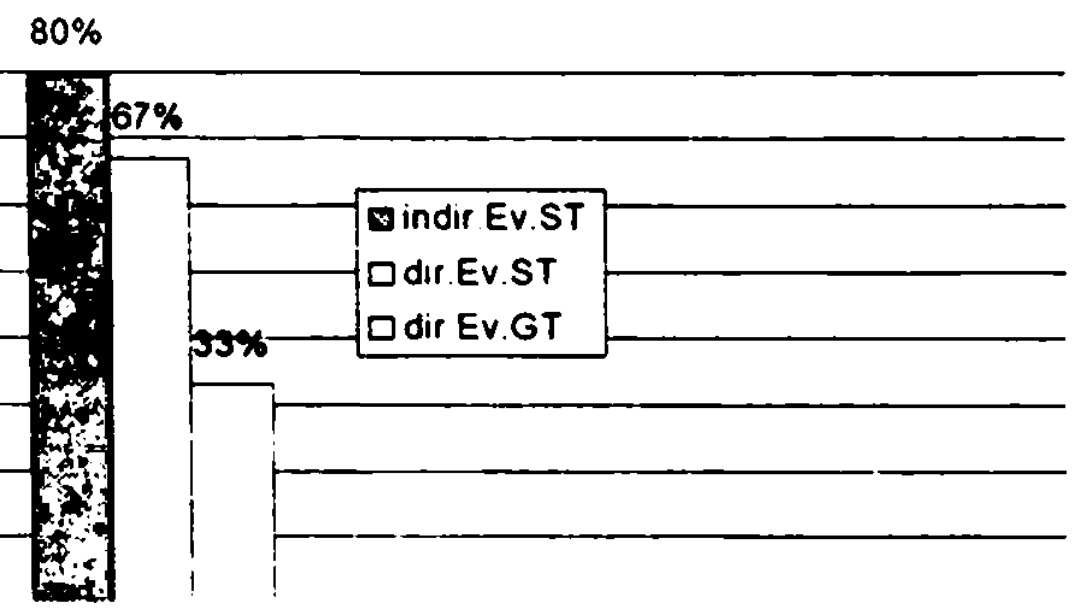

Kommentar ohne Kommentar

\section{Pensionierter technischer Buchhalter, 6+ Jahre (z.Z. als Hilfsarbeiter tätig)}

Sprachierhalien, formelle Situation: Interview am Arbeitsplatz des Respondenten

Jakj mäı názor na stoupini cen v Ceské republice?

- No, sanoztejme, ze stoupáni cen se nikomu zrejmé asi nebude libit. No ale, stoupáni nêkterych cen je nêkdy nutnosti, že jo. Prostê to si vyžádala doba - že jo - a tim nabejvaji vlastnè správný hodnoty, že jo - taky. No, to bych $k$ cenam moh tict, že jo.

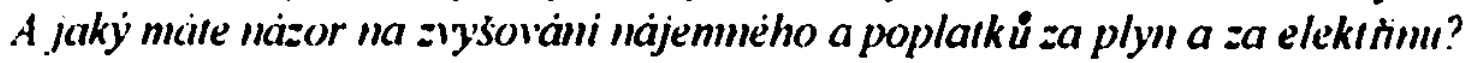

- No, to je právê néco podobnèho, že jo. Tak $i$ nékdy docházi $k$ narovnáni tẻch cen. že jo Ponévadž - ponévadž nêkteré - prostě - ceny neodpovidaly skutec̀nosti. No ovšem, na druhè stranê je zase nutno tict, że nékteti lidé tedy złejmé - a zejména starši - jak bych tak chtêl tict nemaji prostê, nemaji čim platit - pak, že jo - no. To je všechno, co bych moh rict $k$ tomuhle

A red" jestck oräka z jine oblasti. Jakyं máte uázor na posledni replou zimu?

- No, letošni - tr̉eba - zima je svým zpủsobem trochu podivná, že jo. Tr̉eba únor se vyznacioval velice teplym - velice vysokou teplotou, zejmena ta druha polovina. že jo. No ovšem, potom 
nakonec, ponèvadż ta teplota se nèjakým zpủsobem musi vyrovnat, docházi třeba $v$ breznu $k$ nižšim teplotam. Ale to je kolobẻh, že jo, neni to zase nic mimoráadnèho.

Myslite si, ž v budoucuu budou zimy mirnejši?

- No, já myslim, že se to bude cástečné tak nẻjak opakovat, jo, že nebude, nebude nęjaký metr, Že se bude vyskytovat zima chladnějši nebo tak nějak. Řikà se, že se neustále teplota jako - zvyšuje, ale myslim, že to neni nijak poznat, že spiš dost dochäzi k takovym vỳkyvưm A když si nakonec někdy zvykneme na tu vyšši teplotu, pak se nám to třeba zajidá, jak se riká To tak v kostce, co bych moh rict o teploté.

Sprachuchalten, imformelle Sitmation: Gespräch mit der Verfasserin (bekannt nur durch das Interview) am Arbeitsplatz des Respondenten

- No tak, já nejsem żadnej rečnik, jo. Nepouživam ty slova správnê. $V$ televizi by se mêlo mluvit správné. Tam by se mêlo mluvit spisovné. (...)

(A co clescite?)

- No, já jsem dủchodce, no. Driv jsem tady byl jako technickej účetni, że jo, a ted’ dělam u stroje.

Sprachverhalten:

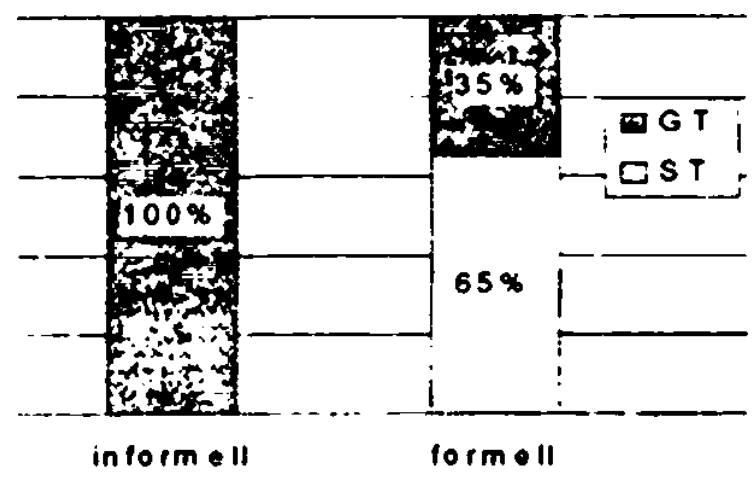

Einstellung kognitives Subsystem:

CE erkannt B nicht erkannt
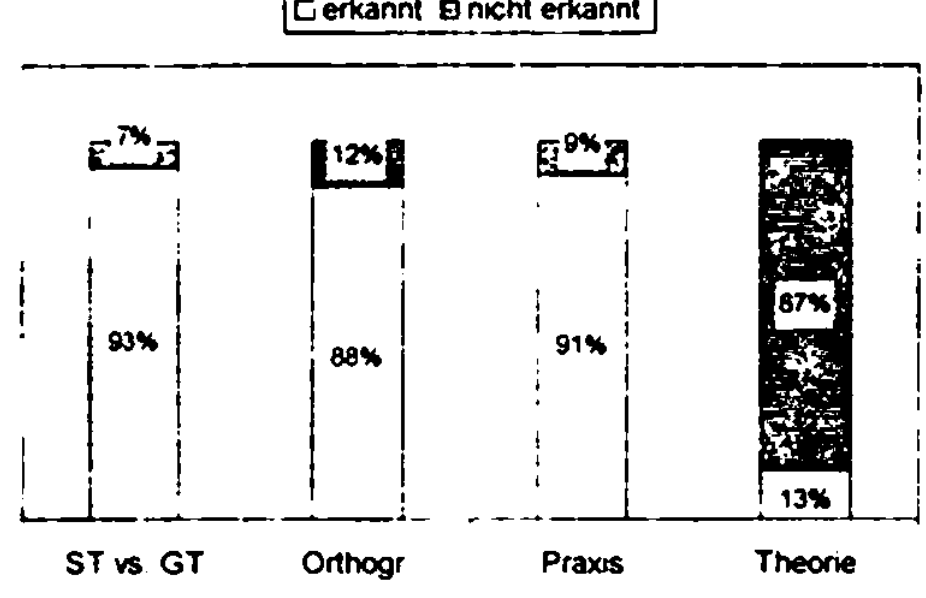

Einstellung, konatives Subsystem:

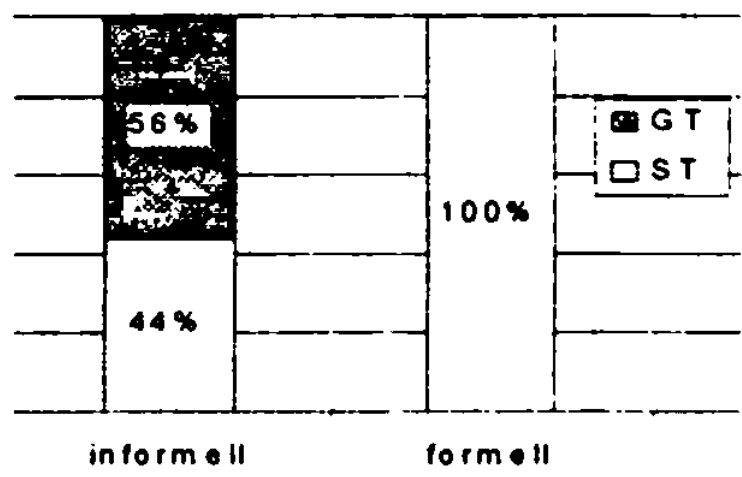

Evaluation der eigenen Kognition

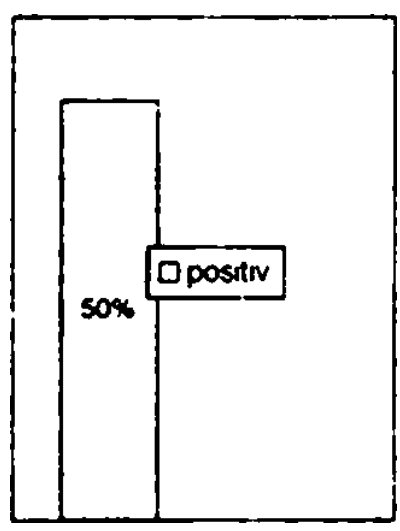


Einstellung, affektives Subsystem: Grad der positiven Einstellung

年

Kommentar: Každá anketa nuti k zamyšleni, což je jen pozitivni. Anketa se vyhnula faktu, že naše mateřstina je zaplavována cizimi výrazy. Hodnota psaného či predneseného projevu je żejmè mêrena poìtem použitých cizich výrazu. Totéż plati o kởenèni umèleckých projevư vulgarismy. Mohlo by jich bỳt o špetku méné

\section{Pensionierter Betriebswirt, 69 Jahre (2.Z. als Nachtwächter tätig)}

Spracherhalten, informelle Situation: Gespräch mit der Verfasserin (Tochter) zu Hause

- Jak jsem mêl noc̀ni. a ve dvê hodiny - takhle co je tam ulice hned vedle ostrahy naši. Neřikam vrátnice, to ne - jedno hasičský auto blikalo, houkalo - druhý, tłeti, cturtý. Ctyry auta se tam prititily - a úplnê jsem je vidèl v tý ulici - prosté pár metrú vod vrátnice - vod sträžnice. A sanitka houkala - všechny tam narvaly se a ted'kon ty blikaly - a ted'kon jsem neviddsl, to bude nčco velkýho. Tak jsem tam potom šel a tak asi po deseti minutäch - a voni ti méli visutej žcbrik do druhýho patra - to byl takovej vysokej barak - čtyřposchớ ovej. Do druhýho patra méli vysunutej ten - ten hasičskej žebriik. A akorát jsem videll, jak jeden hasic ti má v ruce - lez pozpátku po žebriku a držel - no, to ti bylo dvouletý dité. Prdel nahou. nożiciky nahý, jenom košilku to mélo. A tăh ti ho po tom žebriku dolì. A za chvilku tam druhej a za nim pani v pyžamu taky. Taky lezla dólu. To je záslužná práce jo, vopravdu jo. Vono se riká: hasič - a tó, ale když pak je ouvej, tak to maji lidi prdelku takhle a hới lidi, że jo.

Sprachierhalten, formelle Simation: zu Hause

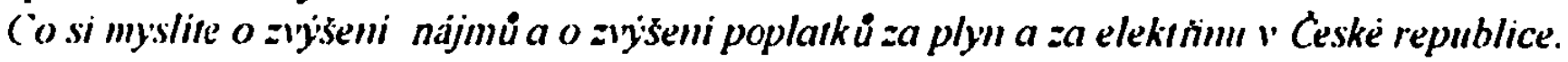

- No, zvýšeni najjmú, to nás dost prekvapilo, protože - sice se mluvilo vo šedesáti aż. sedmdesáti procentech, který ovšem ṅàk vlivem - zảsluhou Nảrodniho shromážděni se postupnẽ mínilo, klesalo - ta cástka klesala. A ted'kon se to ustálilo na takový dost prijatelný íastce $-v$ prüméru kolem pètadvaceti procent. Je to sice ešté dost, pac̉ je to dalక̌i postupný snižovani żivotni ürovné lidi, obzvläšt nižsich vrstev, ale z toho zla je to to zlo nejmensi.

A co si myslite o letośni teple zime?

- Letošni zima byla vopravdu mimotadné teplá, tẻšili jsme se, že preci jenom dêticky budou moc na téch lyžich a na sañkảch vyrazit do hor, ale bylo priliš teplo, snih se neudržel, hory byly vétšinou holè. Ty sjezdy a ty lanovky, co jsou na horảch, prodêlàvaly - nariikaly, že prodélàvaly 
velký penize, že letošni sezóna, že bude pro nẻ ztrátová. No sem tam pár dni byl poprašek, ale jinak prakticky sczóna lyżałská nebyla żảdná - letos.

Myslite si. te budou v pristich letech zimy take tak teple?

- Ne, nemyslim si - jo teplé? Jo, je všeobecnẽ známo, že podnebi Evropy i púlky naši polokoule se postupnẻ otepluje. A jsou prognózy, że za sto, dvě stě snad - možná i dýl - tady bude - zimy prakticky nebudou - a bude tu skoro cely rok mimé pásmo.

Tak zu se budou ztrácet rozdily mezi létem zimon?

- Ano, to rozhodné ano, to už je poslednich deset let nazpátek - možná dvacet let už zź ejmý, że skutečné rozdily mezi lètem a zimou - spiš mezi podzimem a jarem se vytráci. Čili vopravdu ty teplotni rozdily nejsou tak vysoký jako byly pred lety.

Sprachverhalien:

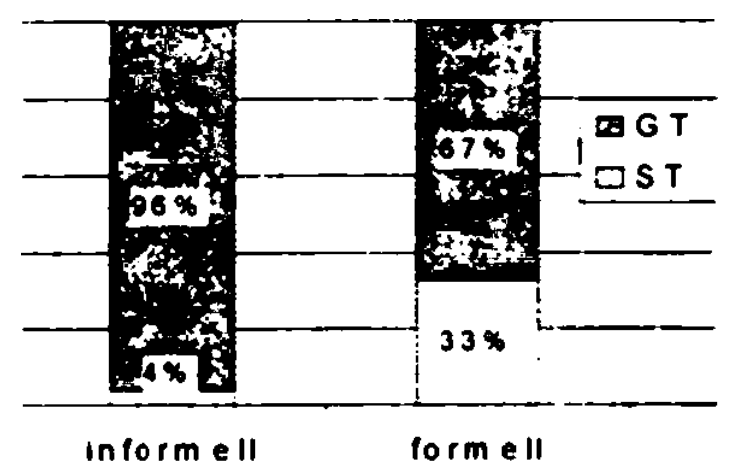

Einstellung, kognitives Subsystem.

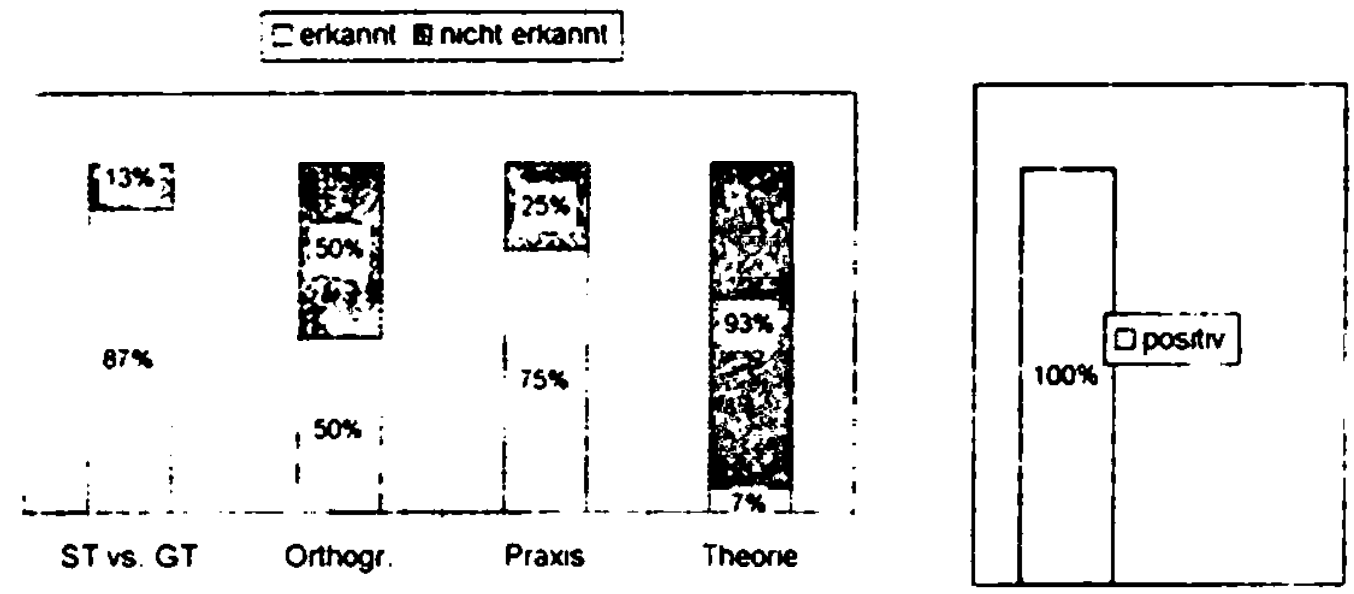

Einstellung, konatives Subsystem:

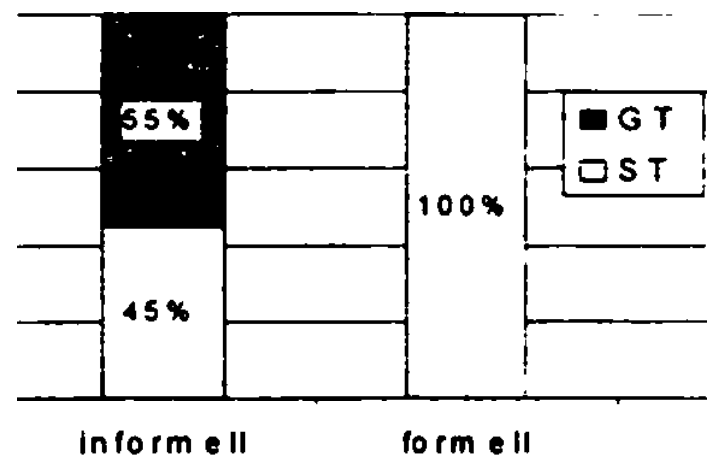

Evaluation der eigenen Kognition.

Einstellung, affekitives Subsystem Grad der positiven Einstellung

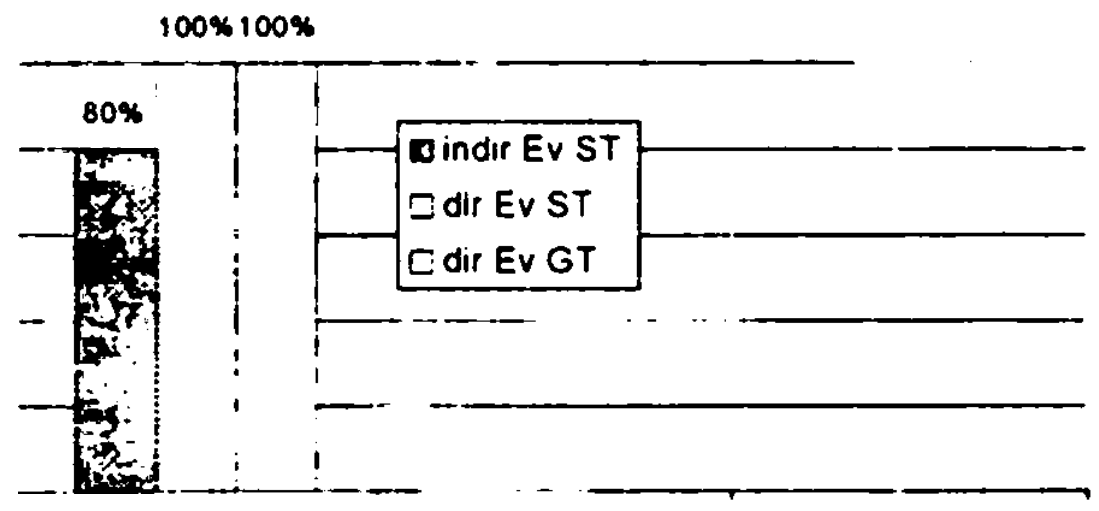




\section{I.6 Mämmer mit Hochschulabschluß}

Alter der Respondenten: 25 bis 61 Jahre, insg. 7 Aufnahmen

\section{Grundschullehrer, 25 Jahre}

Sprachverhalten, formelle Situation: mit Mikrofon auf der Straße angesprochen

Co si myslite o zyłsováni cen $v$ Ceské republice?

- No, tak já si myslim, že asi je to ñákej vy̛voj tẹ ekonomiky, že to asi musi bejt, no. Jako pro mé jako pro obciana je to hrozný, strašný. To je všechno, co k tomu mủžu povêdét, no.

A jaky máte vihhled do hudoucna, budou podle Vás ceny i nadále ver istat?

- Vzrústat jako ceny myslite? No, určite̊ budou, no. Tak já nevim, jak se budou vyvijet ty platy nàk, nebo takhle - nevim. Jako asi - nevidim to rủzovè tu budoucnost. Rozhodnè ne, no. Jako, pro nékoho to bude složitejši, pro nékoho to bude to skok takovej razantni, protože - to vite, nčkdo si vydẻlàvá vic, nčkdo podniká a podobnè. Pro nékoho ty zmèny jako nejsou tak razantni, no.

Sprachverhalten:

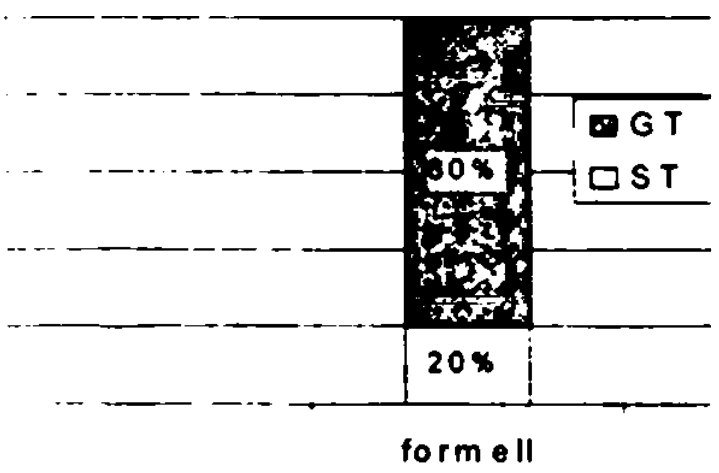

Einstellung, kognitives Subsystem:

Clerkannt E nicht erkannt

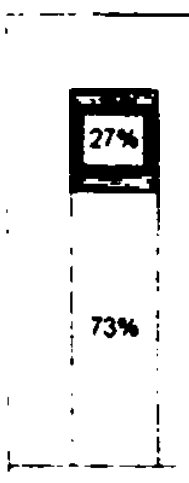

ST vs. GT

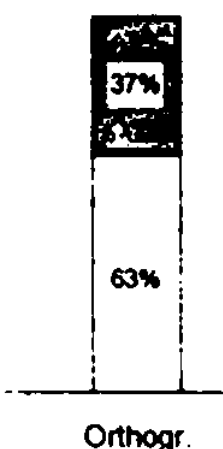

Orthogr.

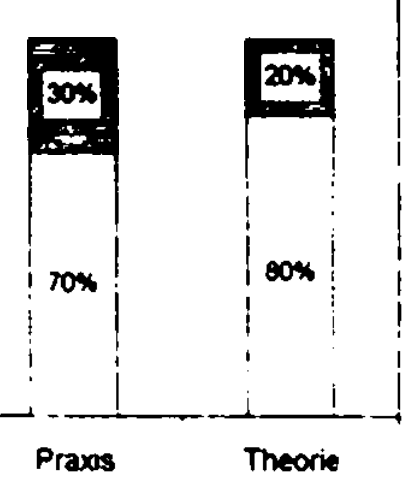

Einstellung, konatives Subsystem.

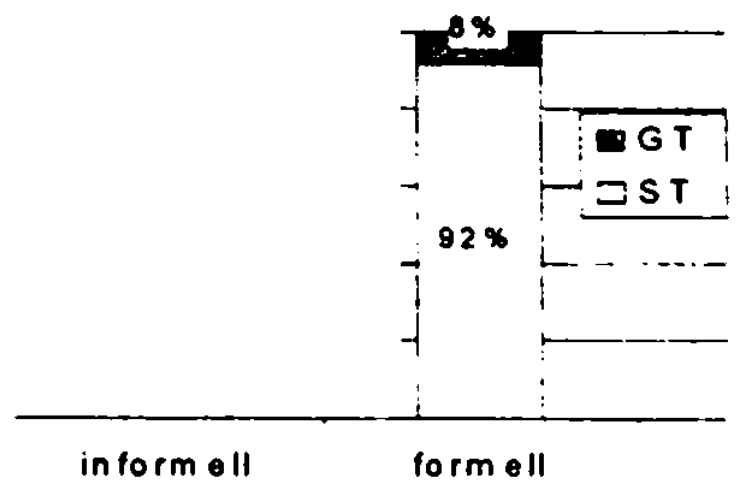

Evaluation der eigenen Kognition: 
Einstellung, affektives Subsystem: Grad der positiven Einstellung $60 \%$

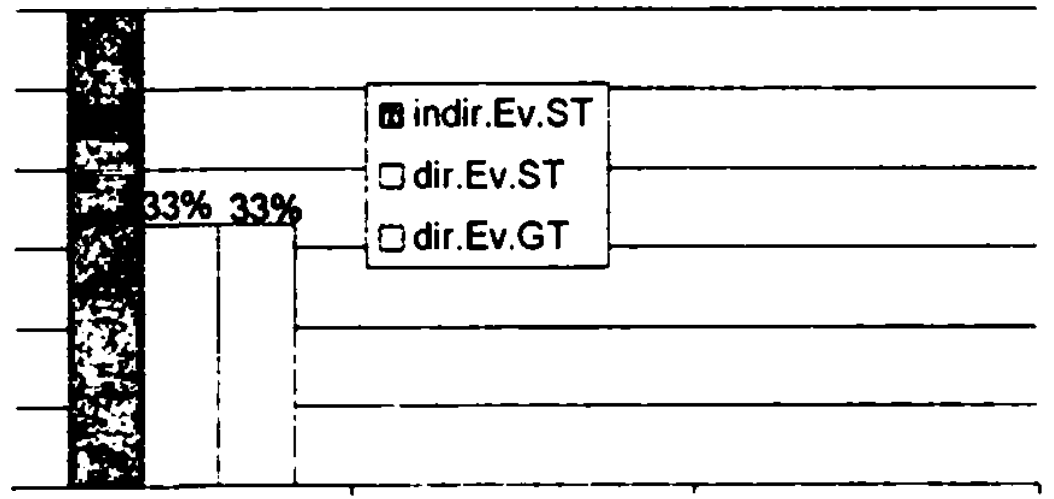

Kommentar: Současna ċeština je zamoŕcna amerikanizmy a nèmčinou apod. No a? Učil jsem se ve škole, ̌̌e vỹvoj jazyka neni nikdy ukonc̀en $\Rightarrow$ stále se vyviji nová slova + nová slova prejatá apod. Ale kdo je vytvári ty ${ }^{104}$ nová slova $\Rightarrow$ nová generace $\Rightarrow$ nový żivotni styl. Učitele sedi ve skole a mluvi o slangu a argotu, ale jak doopravdy mluvi mladi lide ted' tady $v$ klubech, na mejdanech apod., o tom nedaji žadne výzkumy zprávu. Protože takové dotazniky by mladi lidi $v$ klubu - ożrali a zfetovani - použili tak akorat na pripáleni jointa. $\Rightarrow$ Některé nové výrazy jsou absolutnè vystižne $\Rightarrow$ napri, „tajm“, .těžkej šit“, „fakr" apod.

\section{Nervenarzt, 39 Jahre}

Spracherhallen, formelle Silluaiom: im Haus des Respondenten

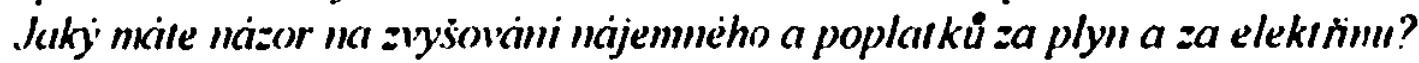

- Mé by zajimalo, kde na to brali komunisti, když jsme żili tak dlouhý léta na úkor budoucnosti - jak se tvrdilo. Ted' se všechno vyvazżi do ciziny, nežijeme na úkor budoucnosti, takže si to musime všichni zaplatit. Kdyż se dostanou $k$ moci nové politické strany, tak razantné. Co si ještể nenahrabaly, si budou muset nahrabat.

Lihila se vam posledmi mirná zima?

- Ani jsem si nevšiml, že byla tak mirná. Byl jsem totiž stále v práci.

Myslinc si, te se zimy budou i nadale oteplovar?

- To nikdo nevi. Ale za osmdesát tisic - ne - za dvacet tisic let - prijde opèt doba ledová. Stridá se oteplováni a ochlazováni atmosféry.

Sprachverhalten

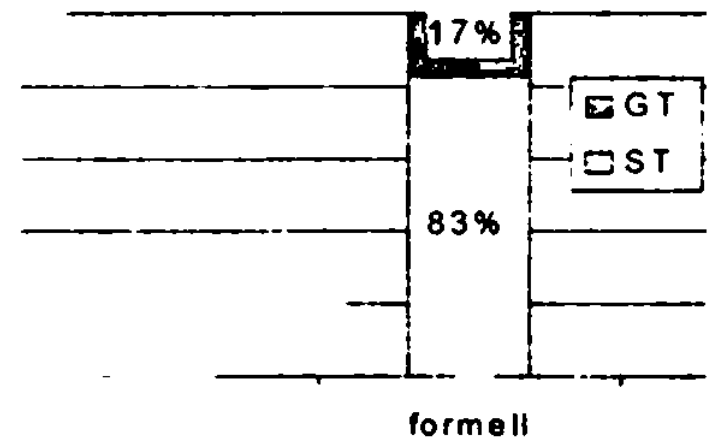

Einstellung, konatives Subsystem:

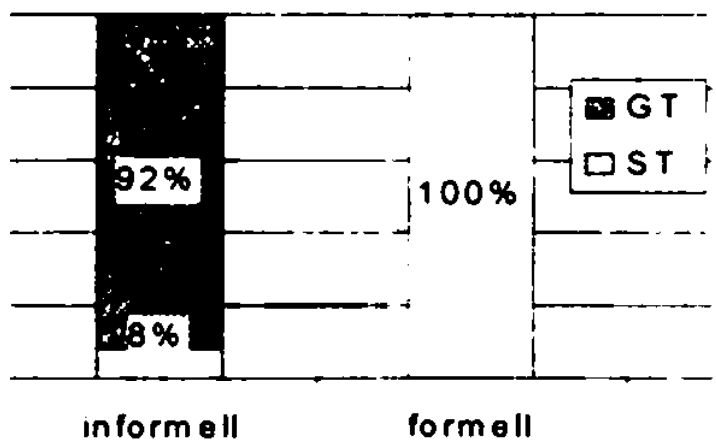

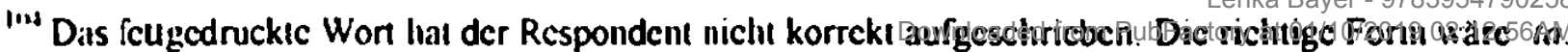


Einstellung, kognitives Subsystem:

Dorkanme Incht erkannt

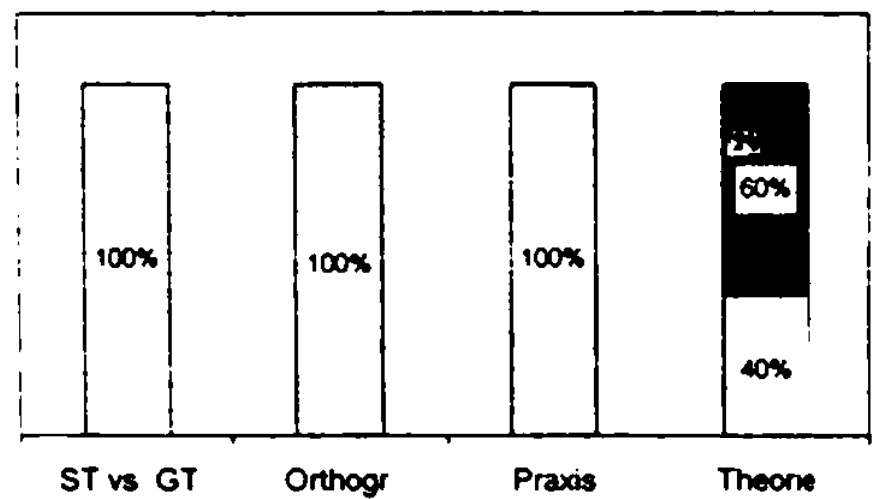

Evaluation der eigenen Kognition:

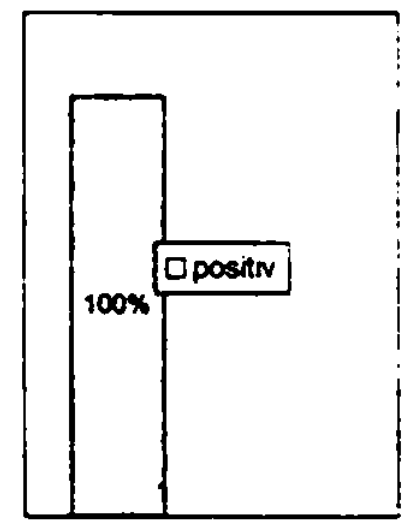

Einstellung, affektives Subsystem: Grad der positiven Einstellung

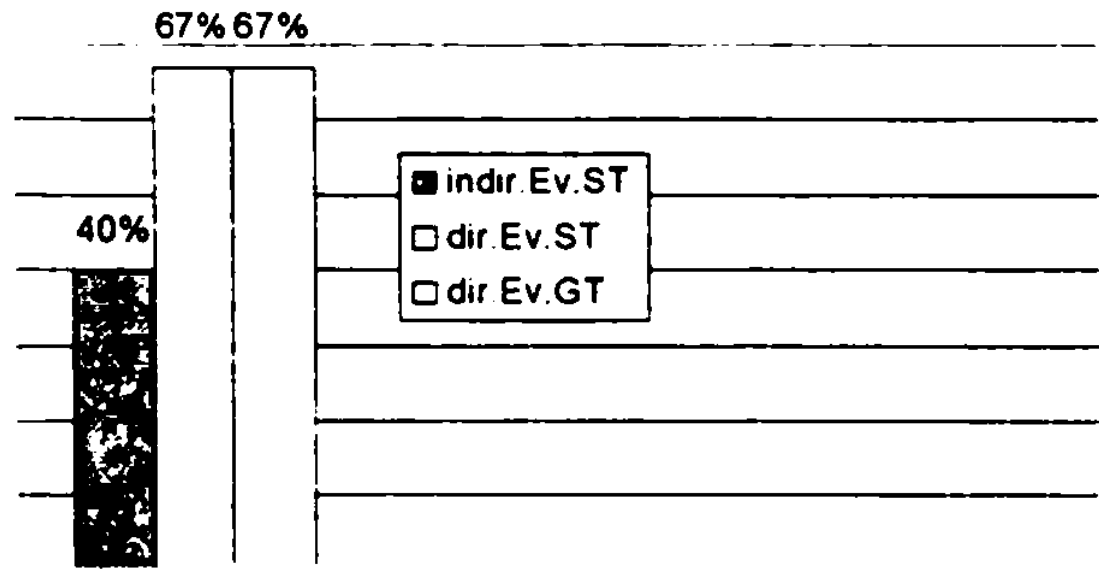

Kommentar Nikdo neni dokonalý

\section{Betriebswirt, selbständig, 39 Jahre}

Sprachrerhalten, formelle Simation: am Arbeitsplatz des Respondenten

Jakj: máre názor na souciasné stoupáni cen v Ceské republice?

- Jestliže je stoupáni cen ekonomicky podlożeno, tak je to $v$ poŕadku, protože, aby - já nevim dvacet procent nemajetnych obċanů na tom bylo stejné jako osmdesát procent majetných obcianủ neni možnè. Także osmdesát procent majetných obianủ by mélo platit näjmy a energie

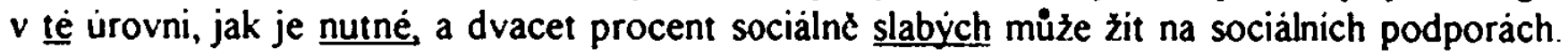
Pokud na né maji jako nárok.

Máte oban'u, żx żvotmi uroven by mohla v budoucich letech kle.sat?

- Nemam obavu. myslim si, že kdo délá a dêlá dobr̀e, tak se bude mit stejné - a myslim si, že i lépe neż ted".

A ted" ješld otäza z jime oblasti. Jaký je l'áš näzor na posledni replon zimm?

- No, pro $\mathrm{m}^{\mathrm{k}}$ jako lyżare a spontovce je to neprijemne. Ve mésté by zima nemusela bỹt vübec. ale na horách je to pro sportovce a i podnikatele katastrofa.

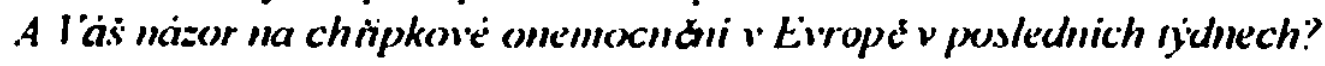


- No, naši rodinu nepostihla żádná epidemie ani nemoc, a co vim ze sdêlovacich prostředkü, tak byly oblasti, kde byly epidemie i byly vyhlảšeny prázdniny - chripkové, ale naši rodinu to nezasảhlo - primo.

Sprachierhalten, informelle Simation: Gespräch mit der Verfasserin (bekannt nur durch das Interview) unmittelbar nach dem Interview

- Tak jsme vám pomohli, že jo. Vono to bylo i vzájemný, že jo. (...) Já se priznam, že kdyby mi nékdo na ulici takhle zastavil, tak bych ner̉ek ani slovo. No, ìeknu, že nemam čas, protože vêtš̌inou vopravdu nemam. No, ted' je tady spousta takovejch anket na rủzný pripravky, na kosmetiku, na čaje - no, všechno možný.

Sprachverhalten:

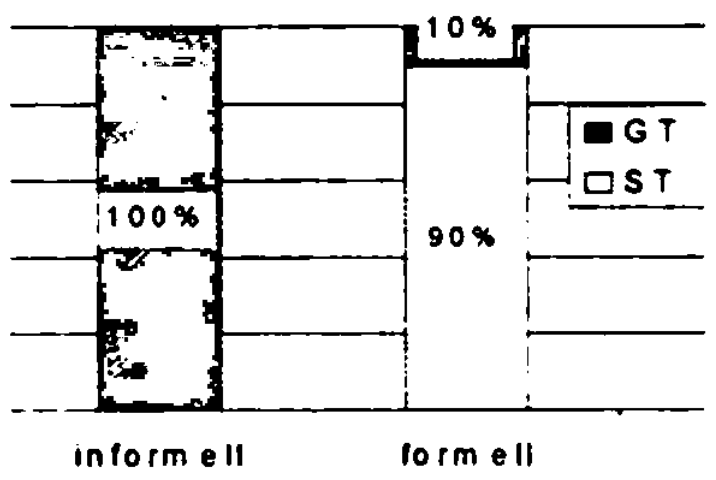

Einstellung, kognitives Subsystem:

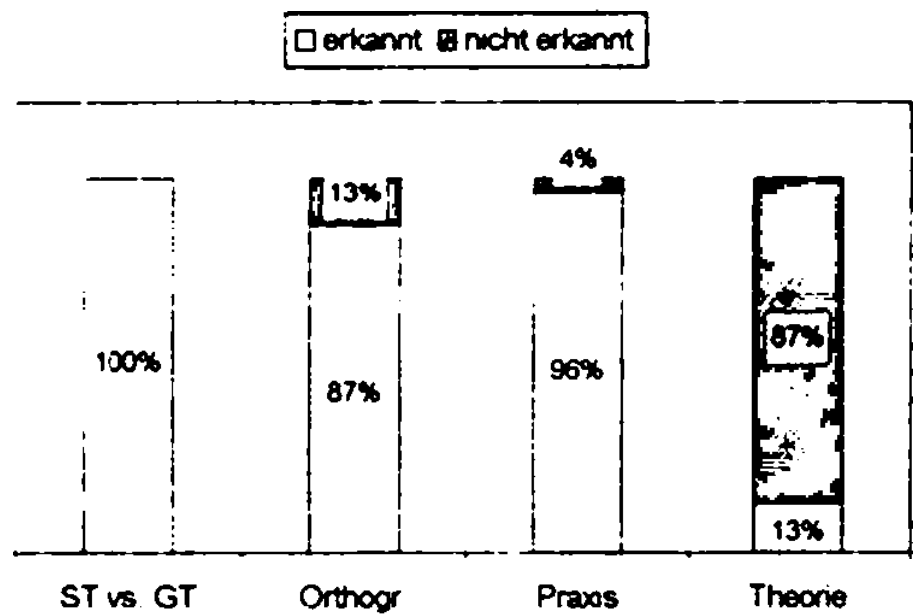

Einstellung, konatives Subsystem:

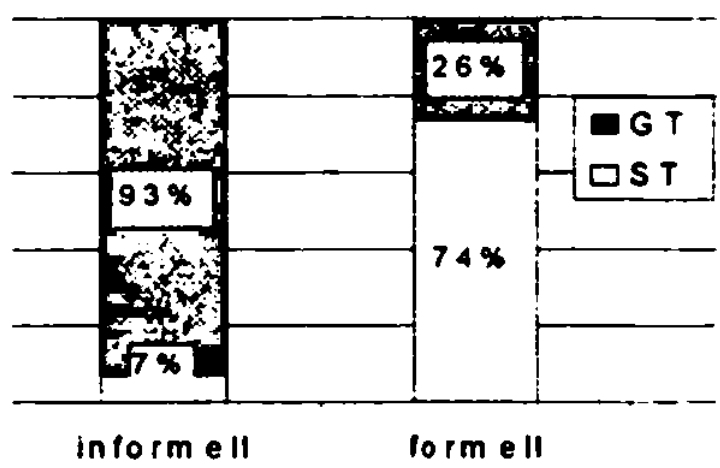

Evaluation der eigenen Kognition:

Einstellung, affektives Subsystem: Grad der positiven Einstellung

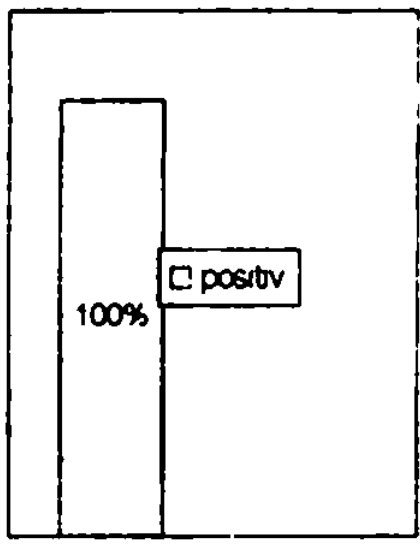
$100 \%$

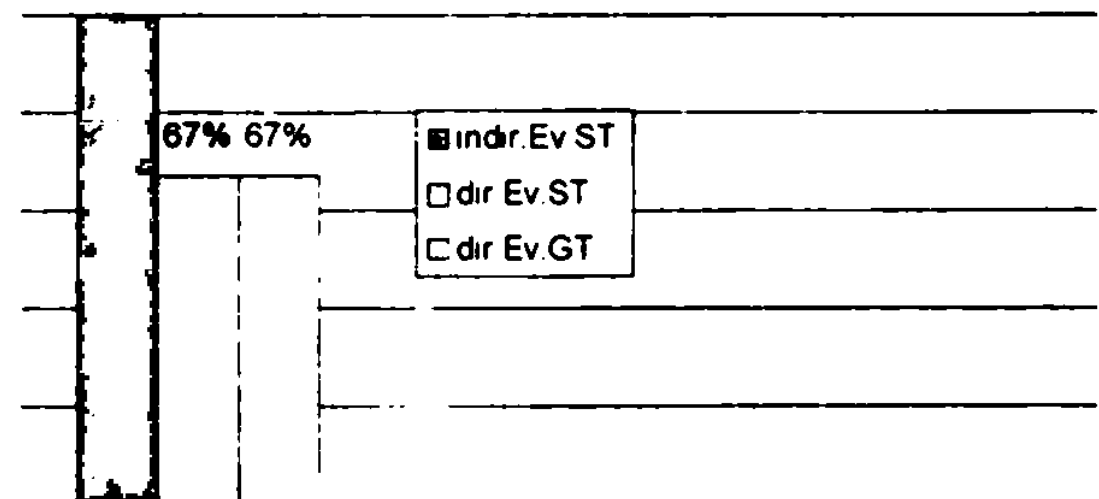




\section{Maschinenbauingenieur, selbständig, 53 Jahre}

Sprachverhalten, formelle Simation: am Arbeitsplatz des Respondenten

Co si myslite o sou casnem zvyšsovani cen v Ceské republice?

- No, jà si myslim, że je to dủsledek toho minulýho obdobi.

A jakj máte názor konkrétmé na zyyšováni najemného a poplatkủ za plyn a za elekt timu?

- No, $k$ tomu nejsem asi nestrannej, já jsem pro zvyšováni cen nájemnýho na takovou úroveñ, aby se vyplatilo dům postavit a dủm provozovat. To znamená najimat tam teda byty a vydelat na tom, a ne jako je to $v$ tomto obdobi, kdy teda nikdo nemá zajem byty stavêt, protože näjmem se ani neudrži - nedá udržet ten byt prìi žjotê. Ale $k$ têm energiim mam podobny názor. Je to trend, že se musime dostat na ceny, tak jak jsou.

A ted' ješté otázka z jiné oblasti. Jaký máte názor na posledni teplou zimu?

- No, myslim, že nám vytrhla trn z paty, protože jinak bysme méli asi obrovský problémy naše ekonomika. Zaplat pánbủ za ni, teda. Myslim si, že prišsti zimy budou zcela určité studençǰ̌i, než byla tuta, protože ta byla opravdu neobvykle teplá.

Sprachverhalten, informelle Sitıation: Gespräch mit der Verfasserin (bekannt nur durch das Interview) nach dem Interview

- No, to jsem teda šikovnej. Jà to uklidim, moment. Vezmu druhej - prinesu vám kafe do druhýho. (...)

- Já vám tady dam vizitku.

(A utj.jste lam byl?)

- Ne, nebyli jsme tam. Takhle bych to rek na ưvod: vo naši firmẻ asi vite. Von váš tati tady (...)

- Vona nemá jako ty kontakty takový ptímý, takže je vyhledává takovým tim dost anonymnim zpủsobem. To je vždycky nepłíjemný, to asi znáte - když se volá nékam nablind, tak je tẻmêt stoprocentni šance, że vás vodbudou, že jo. (...)

- No, takhle - technickou nèmčinou se domluvim - jo. (...)

- No, my pracujeme vêtšinou s oceli, ale - formy jsou ocelový, ale leje se do nich hlinik, jo. (...)

- Nikdy jsem ho nevide̋l, já znảm jenom vašeho tatiho. (...) Takže tim pádem jsme to vypotrèbovali - a my máme tu druhou filiálku v Rokycanech. Tak jà nevim - vy tady jste autem nebo?

(Já jsem tady autem, no.)

- No tak, já vám to namaluju, jak se tam dostanete a na koho se tam obrátite. Takže, mluvil jsem $s$ panem (...). To je jako mistr, tam $v$ tý naši nárad'ovné. Člověk, kterej je primo spoleinikem firmy, se jmenuje Ing. (...), jo.

Sprachverhalten:

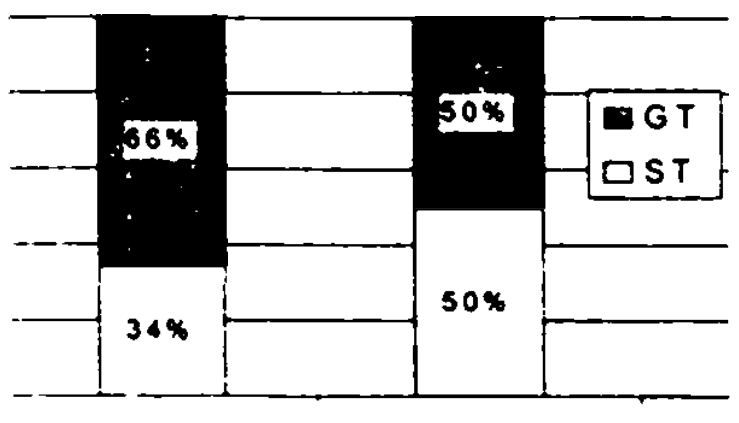

informell

formell
Einstellung, konatives Subsystem:

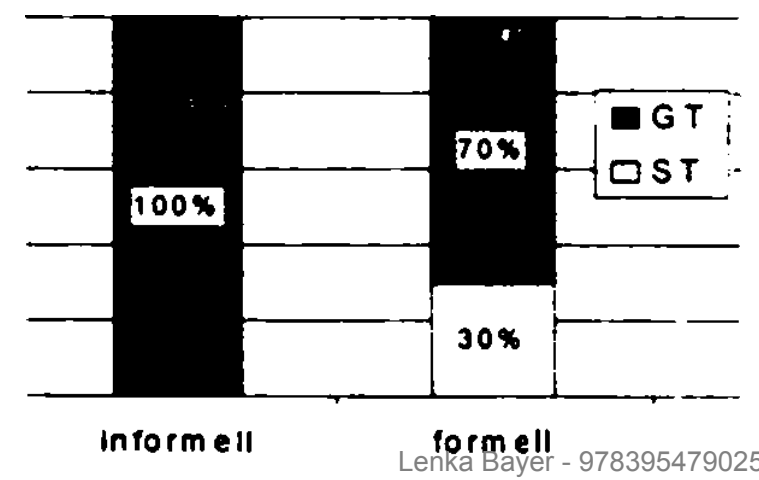


Einstellung, kognitives Subsystem:

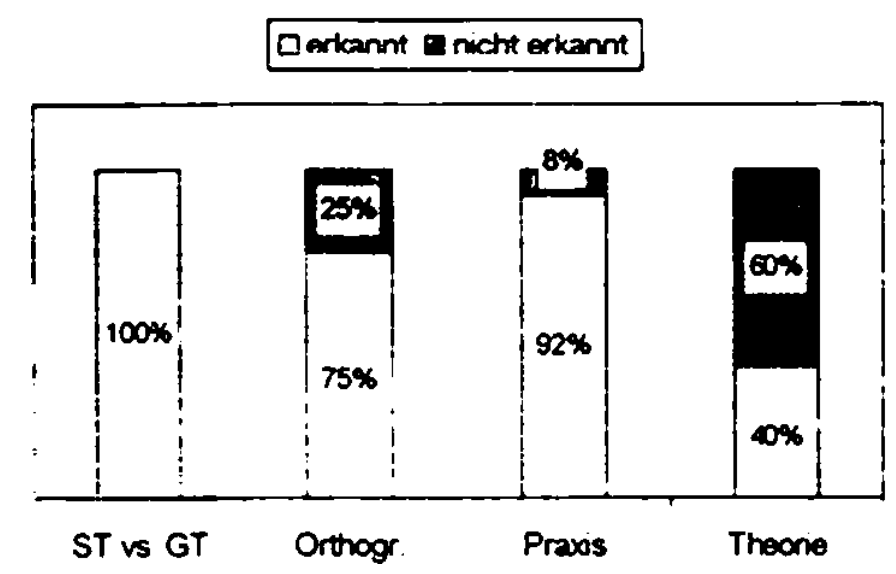

Evaluation der eigenen Kognition:

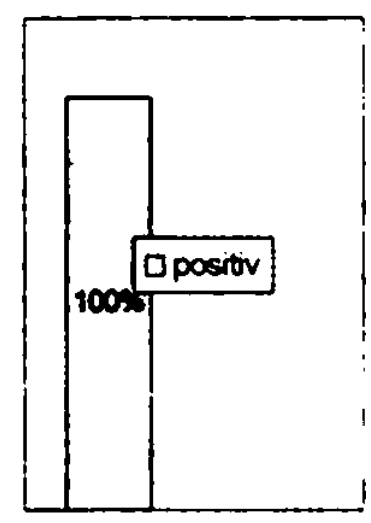

Einstellung, affektives Subsystem: Grad der positiven Einstellung

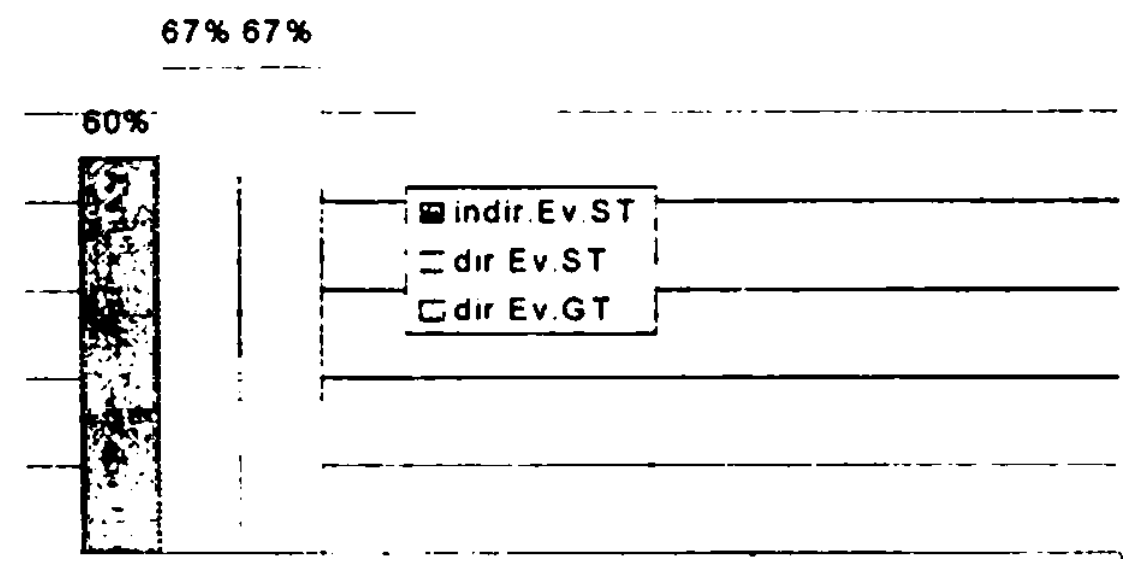

Kommentar: ohne Kommentar

\section{Hochschuldozent an der Technischen Fakultät in Pilsen, 54 Jahre}

Sprachrehalien. formelle Sirmation: am Arbeitsplatz des Respondenten

Jak se laim osobma libilo masto Mmichor? (Diese Frage ergab sich aus der vorausgehenden Erzahlung des Respondenten von seinem Besuch in München)

- Mnichov, jižni Bavorsko. No tak, je to hezké mésto - velkoměsto, rozložené na brezich Izaru - a podle mého vkusu leži priliš $v$ rovinč Sice má hezkou kulisu Alp $v$ okoli GarmišPartenkirchenu a potom jižnęji smèrem $k$ Insbruku a tam $v$ tẻch $-v$ tèchto konèinäch Ale samotné mèsto je polożeno dosti $v$ roviné. Jinak, mèsto je to hezkè i̇isté upravené. lidè prijemni ochotni odpovêdčt na otázky Hezkè parky jsou tam - oceñoval jsem tam stezky pro cyklisty, kde se mủże kdekoliv jezdit - a podél toho mésta. Takže takový ten automobilový provoz se tam potom velice - no - je omezen nebo je zmenšen. No, Olympiapark a okoli. Jà jsem hlavne jezdil do okoli, do toho okoli Garmiš-Partenkirchenu. No a do oblasti Alp. A Iupúvohilo na l'às másio prilis hekricky. priliš chaoticky?

- Pokud se týka architektury, tak myslim si. že ano. Myslim si, że po stránce architektonické je tam sneseno všechno możnè ze svesta, hlavnè $z$ rịmské kultury - a tak $z$ toho vyplýva tak trošku snaha v tomto regionu se podobat vlastné Rimu a vibec rimské riši byjvalé. I $z$ té architektury, têch chramů a $z$ têch staveb to tam taky pủsobi na ċlovêka. 
Sprachverhalten:

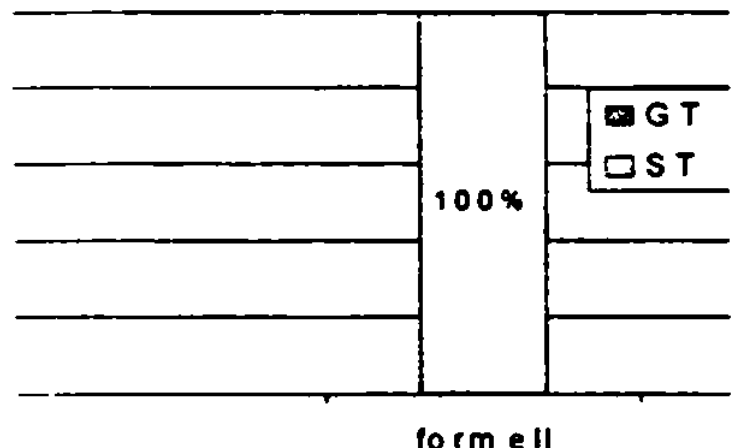

Einstellung, kognitives Subsystem:

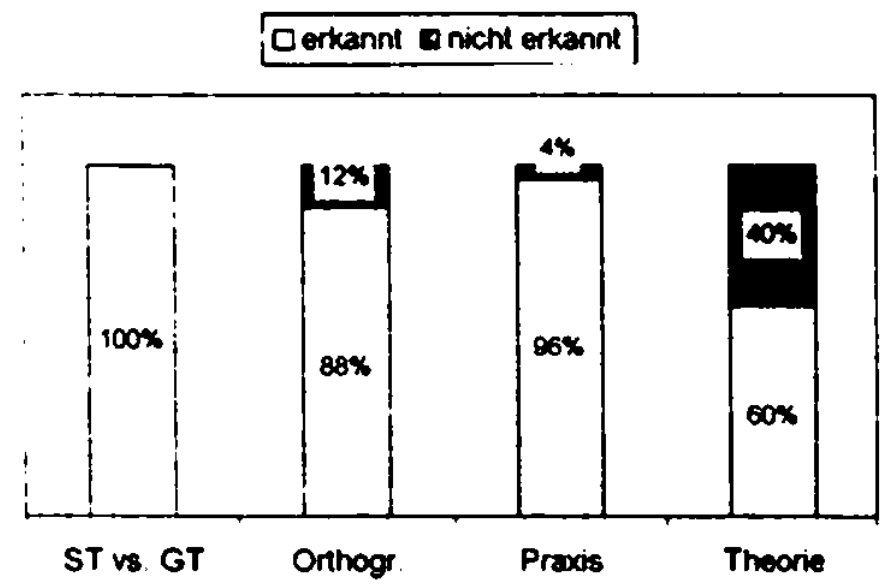

Einstellung, konatives Subsystem:

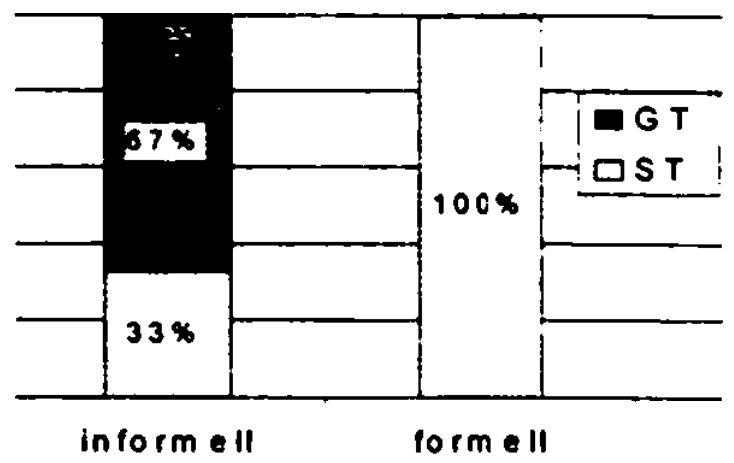

Evaluation der eigenen Kognition.

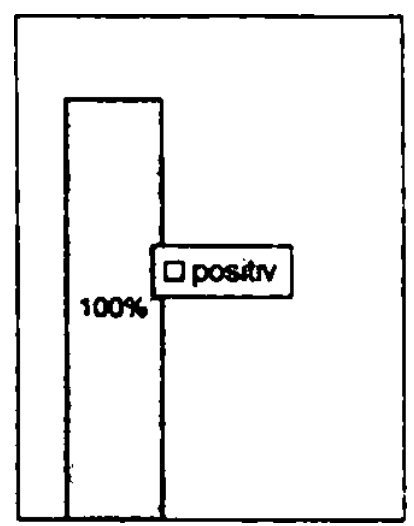

Einstellung, affektives Subsystem: Grad der positiven Einstellung

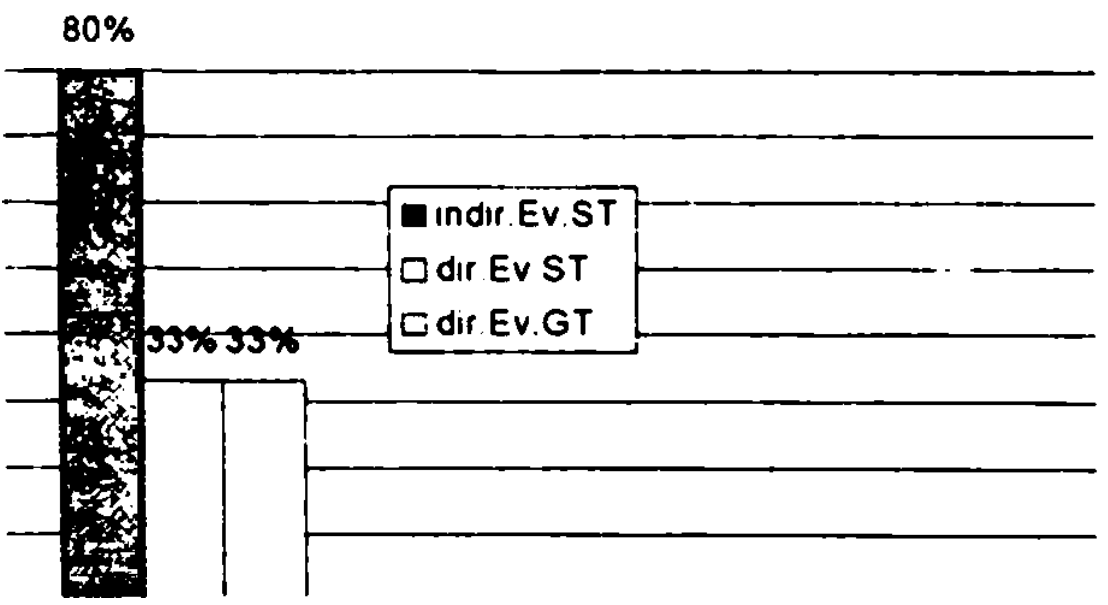

Kommentar: Dobł̌c, že se provádi. Hodnoceni některých otȧzek je priliš hrubé.

\section{Elektroingenieur, 56 Jahre}

Sprachierhalien, formelle Situation: am Arbeitsplatz des Respondenten

Jaky' máte názor na soucàsmé ayšováni cen v Ceské republice?

- Zvyšováni cen. $V$ zásadé je nutné, $v$ posledni dobẻ aktualni - zvyšováni cen, no najemnèho.

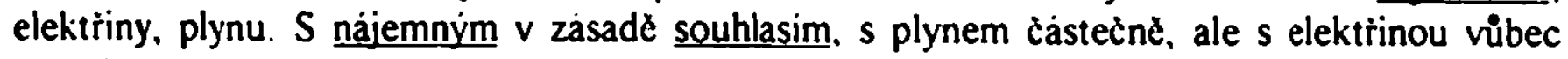
nemohu southlasit. To je asi vše. 
Jake json láse vihledy do budoucna v tomto smeru. Myslite si, že ceny budou $i$ nadále stompat?

- Nadảle stoupat. Otázka. Ceny nájemnýho určitẻ, plynu by už nemusely a elektriny taky ne. A ted'otazka z jime oblasti. Jaky máte nazor na posledmi teplou zimu?

- No, posledni teplà zima. Vono už i predchàzejici byly teplý. Je to daň civilizaci. Znecisténi ovzduši. Je to dañ za znecišsténè ovzduši a naše bezohlednost $\mathrm{k}$ prirodè.

A màtc ly osobné rád teplejši zimy anebo ty poradiné studene??

- No, mival jsem rád studené zimy spojené se sněhem. Diky bohu, kdyż jsem byl mladej, tak byly. A v posledni dobẻ už mi to tolik nevadi. Uż mam rád teplo, jsem starši.

A Iắe vihledy' do budoucna. Jaké si myslite, te budou prišsti zimy? Teple jako ta letošni, a nebo zase stmdene jako diri??

- Myslim si, że studené zimy uż dlouho nebudou, to by znamenalo zménit život, zménit postoj $k$ prirode.

Sprachverhalten, informelle Sirmation: Anmerkungen beim Ausfullen des Fragebogens am Arbeitsplatz des Respondenten gegenüber einer Kollegin (Buchhalterin mit Abitur)

- Von tam je nèjakej pán. Tak to asi udćláme tady. (...)

- Je. tak tohleto jà vủbec nevim, na ċeštinu jả byl vżdycky blbej. Já psal ryba s mêkkým i, že jo. Jà mỏl nejhorši známku z ċeštiny - vżdycky. (...)

- Tám je teda chyb, to je $v$ každym tom slovẻ. Možná, že to je i dobrie, a jà to tady vopravuju. (...)

- No, to bych musel strilet. To bych tam napsal nexjaký stoleti a to nema žádnou cenu. Je to divný - takoví. (...)

- Cizi slova, to je móda, ł̌e jo. Všude ted slyšite cizi slova - a lidi tomu nerozumi - potom. To se mi nelibi. (. .)

- Ja prej mluvim úplnẻ nespisovné. (..)

- Je to sranda, zjistiš, jak mluviš. Já zjištuju strašný vęci Řikam treba 'potrebuju nový brejle', nerieknu: 'potrebuji nové brýle'. (..)

- Ukażte mi tak jenom, co to tám máte - jenom takhle na dálku. Né - já nebudu vopisovat. Jenom, kolik tám toho máte - takhle. (...) Jà to ale nad to nepsal, já to jenom podtrh. Także to je blby.

Sprachverhalten:

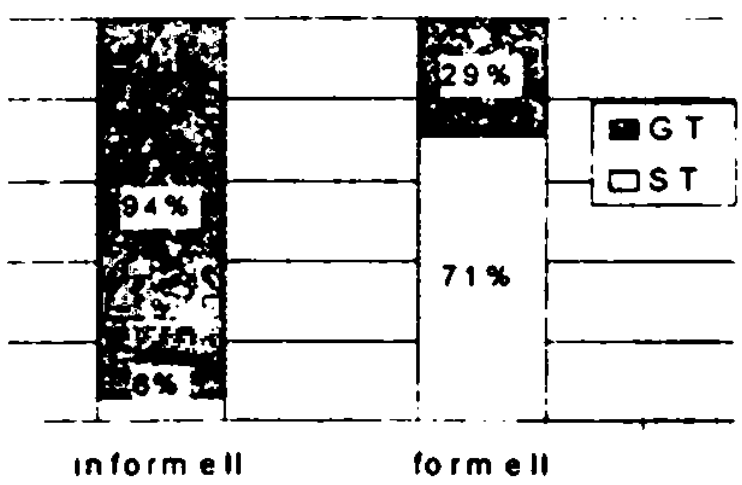

Einstellung, konatives Subsystem:

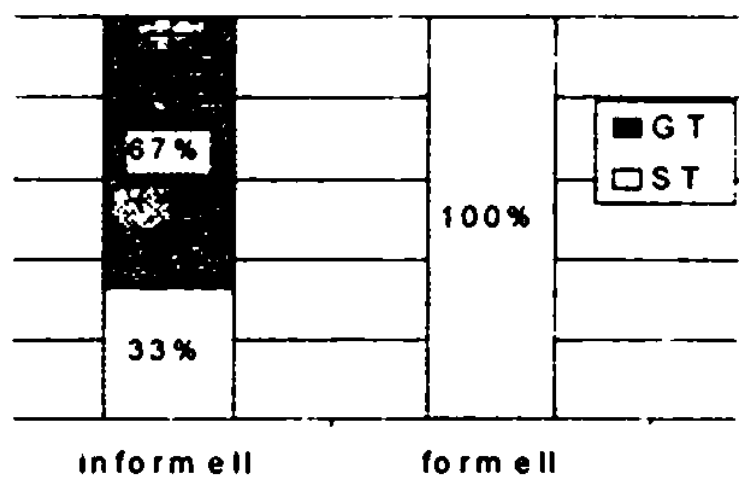


Einstellung, kognitives Subsystem:

Derkannt Enicht erkannt

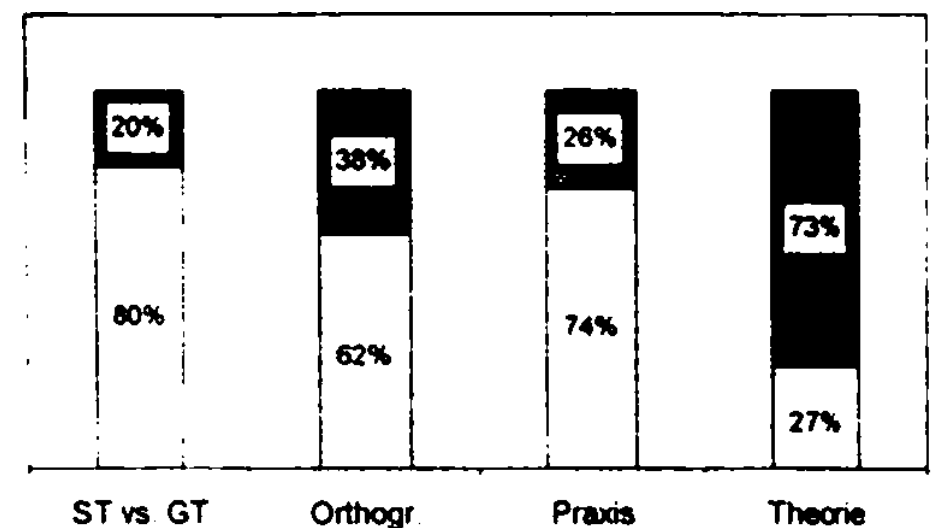

Evaluation der eigenen Kognition:

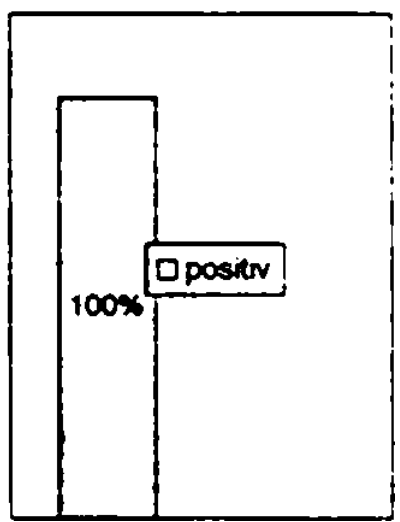

Einstellung, affektives Subsystem: Grad der positiven Einstellung

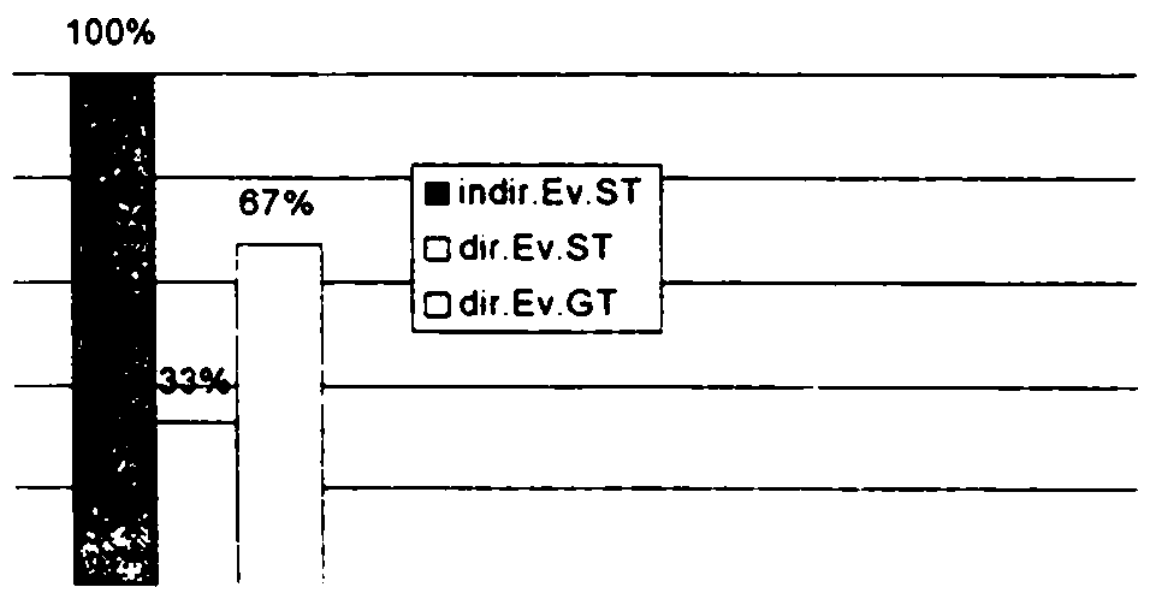

Kommentar: Použiváni cizich slov v rozhlase a televizi je nevhodnè

\section{Hochschuldozent an der Technischen Fakultät in Pilsen, 61 Jahre \\ Sprachierhalien, formelle Silluation: am Arbeitsplatz des Respondenten}

Jakj je l'ás názor na posledmi teplou zimu?

- No, nazor na teplou zimu. Ušetrili jsme $v$ nakladech na topeni, ovšem nevim, co tomu rekne priroda. protože na nékterých mistech jaro už pokročilo a chladnè dny, které ješté oc̉ekáváme. tento proces zase zpomali a bude to mit určitê neptiznivy vliv na úrodu a toho se obávám. Protože casto jezdim na venkov, tak mam možnost tyto véci pozorovat. Zima nebyla ta nejlepši, kterou jsme prożili. 
Sprachverhalten:

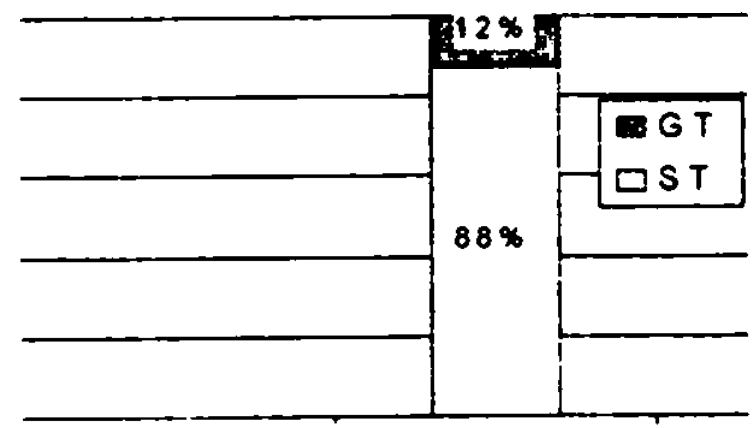

formell

Einstellung, kognitives Subsystem:

Derkannt E nicht erkannt

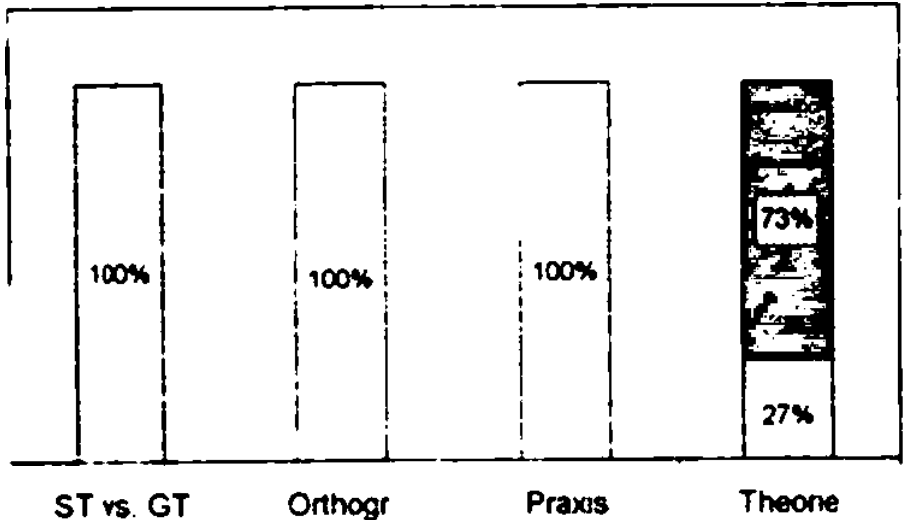

Einstellung, konatives Subsystem:

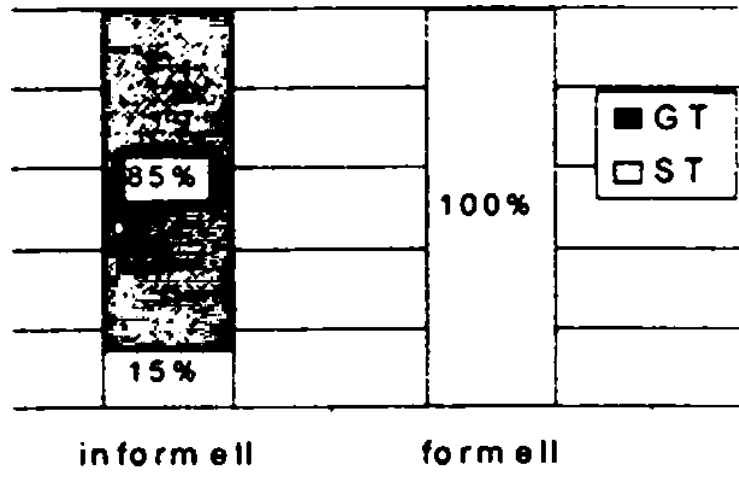

Evaluation der eigenen Kognition:

Einstellung, affektives Subsystem: Grad der positiven Einstellung

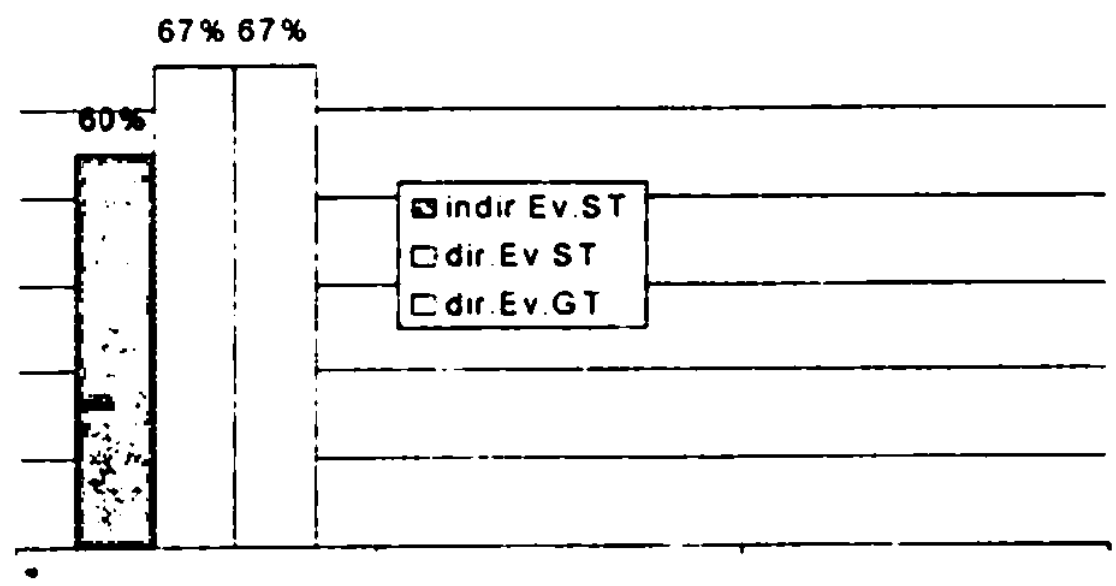

Kommentar: ohne Kommentar 


\subsection{Prag}

\subsubsection{Franen ohme Abiur}

Alter der Respondentinnen: 20 bis 39 Jahre, insg. 4 Aufnahmen. Die ersten drei Respondentinnen wurden jeweils an ihrem Arbeitsplatz interviewt.

\section{Aushilfsbürokraft, 20 Jahre}

Sprachierhalien, formelle Situation:

Co rikáte zyłsováni cen $v$ Ceské republice?

- No tak, zvyšováni cen se mi moc nelibi, bylo by dobrý, kdyby se to tak ñák ustálilo, anebo kdyby to bylo trošku levnejšis.

A konkrétmé osobni pot řby, telekomumikauni poplatky. cinžs, móda?

- No tak u mé se asi jednà nejvic vo tu módu, boty a takovýdle, takže tłeba já nevim. nemúžu si koupit to, co se mi libi všechno.

Tak to lla plat zdaleka nestaci?

- No, to urcité nestaci.

A jake jsou platy ve státmi správe?

- No, asi tak průmèrný nebo kolem průmèru, tak.

A myslite si. zu na to má vliv politik, anebo zahraniáni vlivy, válka v Kosovu?

- Jà nevim.

A co rikáte cenám jizdneho?

- No, to je dost drahý. Kolikrát premejšlim, jak to udelat, abych nemusela potád štipat listky. A vy máte auto?

- No, rodiče maj, ale jả nemam Mam tidičàk, takže - musim si vobčas pučit.

A mäle "cjake konicky. "cjaky nadstandard?

- Tak, mam. No, treba ráda chodim cvicit na aerobik, a to je taky dost drahý. Takže nemúžu si to dovolit tak, jak bych chtêla, že jo.

('hodite pravidelne?

- No, chodim vżdycky jednou tỹdnè. Chtêla bych treba trikrát, ale nejde to.

A kolik stoji hodina aerobiku rady?

- Clyricet korun.

Sprachverhalten:

Eimstellung, konatives Subsystem:

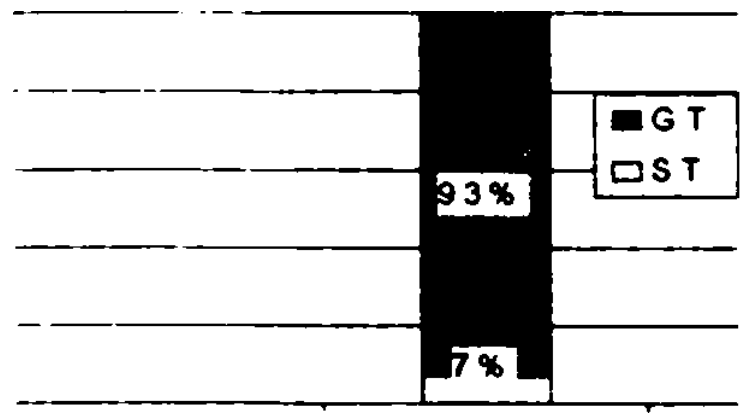

torm ell

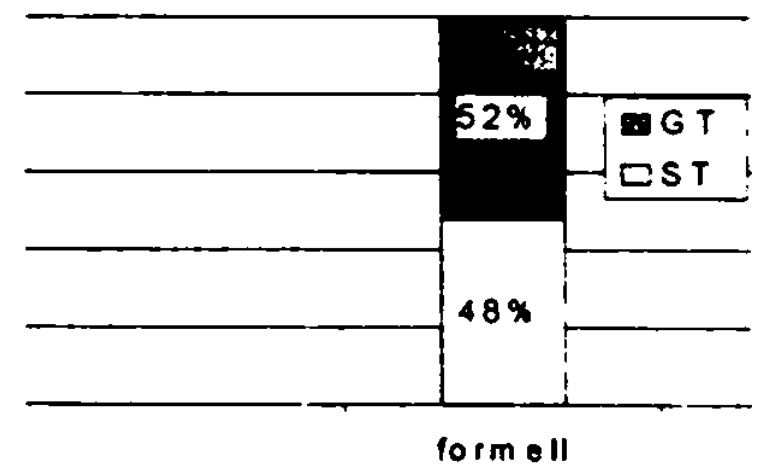

Lenka Bayer - 9783954790258 
Einstellung kognitives Subsystem:

Ci erkannt E nicht erkannt

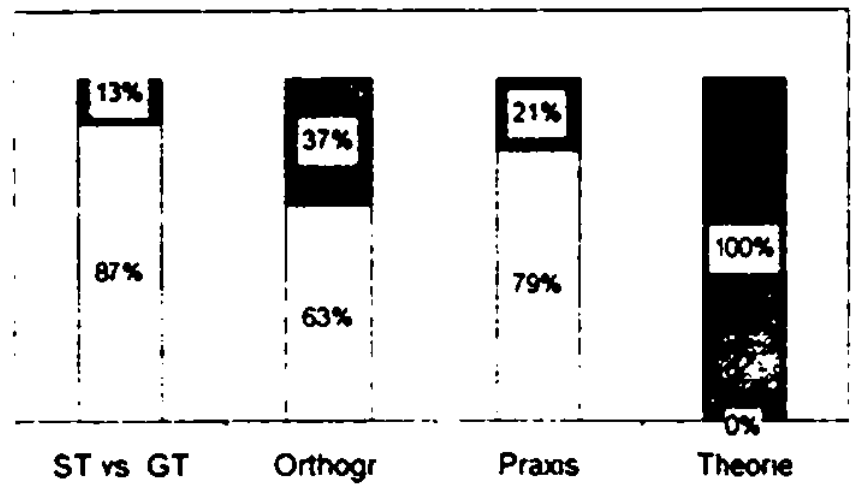

Evaluation der eigenen Kognition:

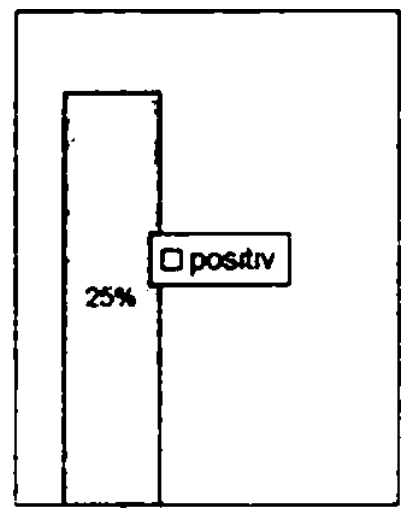

Einstellung, affektives Subsystem: Grad der positiven Einstellung

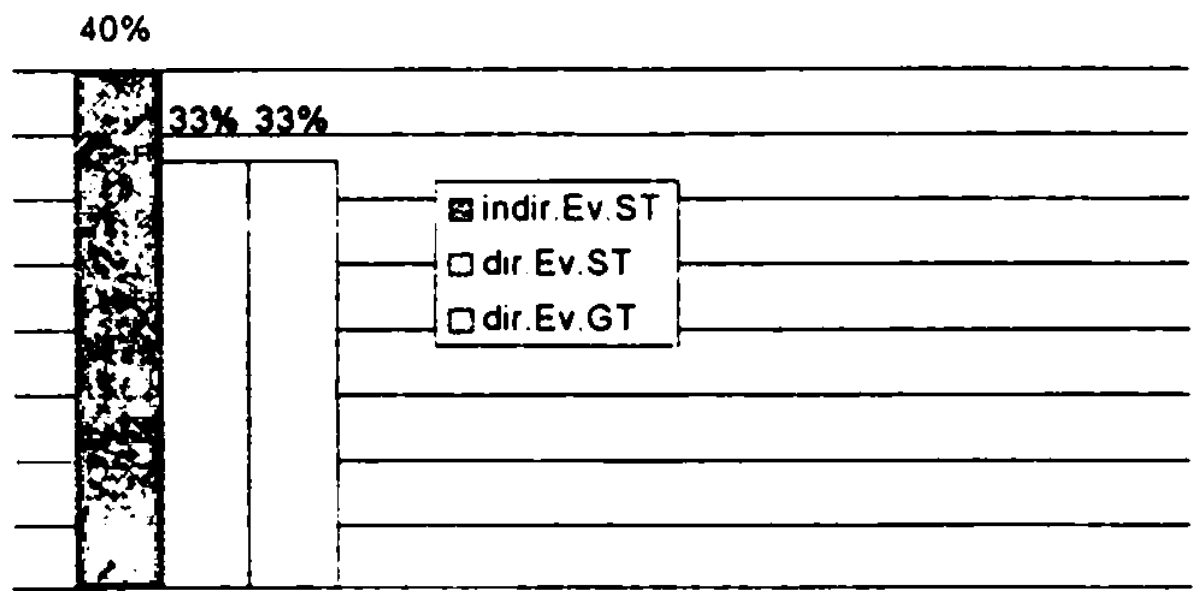

Kommentar ohne Kommentar

\section{Verkäuferin, 31 Jahre}

Spracherhallen, formelle Sirnation:

Co rikcile zlysowaini cen v Ceské republice a sociälni simaci ceskjch obiamü?

- Tak jako podle toho, koho se to tỷká, że jo. Když se zvyšujou ceny, tak se to hodnê dotýká rodin $s$ malỷmi détmi, protože si myslim, že tahleta skupina je vic ješté ohrožcnèjši než tr̉eba skupina dưchodcủ. Protože vlastnẻ rodiny s malými dětmi maji vêtš̉ požadavky a vêttši nároky, jak na stravováni, vlastné, tak na oblikáni a i na tráveni volnýho casu.

A iiracty jim dinaji injake prispetiky?

- No, nékterý útady. Nčkterý ửady se snaži pomähat, ale pokud jsou $v$ têch ửadech nčjaký strikıni ưrednice, který se držej čisté jenom zakonủ a nekoukaji tr̉eba na lidský hledisko, tak jsou $i$ útady, který nepomúžou. Takže vlastné musi to vlastnê prevzit potom nejenom stätni spràva ale i nčjaký jiný sdruženi - občanský sdruženi a podobnè.

Tak $x=$ toho yypliva. $\dot{x}$ dmeska mit rodimu a déri je docela financinc narocine.

- To je hodnè nárociný. To je dost velký nadstandard teda $v$ dnešni dobẻ. A jako, ješté když se ċlovék kouká vlastñ do budoucna, tak jả sama jsem teda pesimistická v tomhle ohledu. 


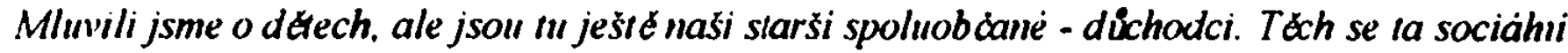
pomoc raky' "zjak tijká.

- Ta se jich týká tolik, ale co jsem si takhle všimla, anebo co vim z praxe, tak nejsou na tom tak špatně, jako rodiny, který maji děti, který chodi do školy. Spiš ty dủchodci se ještê prostę vejdou do toho životniho minima. Nemúžou si treba dovolit nejaký velký nadstandard nebo si vyskakovat nebo néco takovýho, ale je fakt, že za ten svüj žvot už prece jenom maji nějakou tu jistotu, maji kde bydlet, nemaji takový velký nároky na - já nevim - na ošaceni tr̉eba, nebo už ani na to jidlo. Kdežto třeba rodiny, který maji déti - já nevim - trinácti-, čtrnáctiletý, kde vopravdu ten plat se proji, takže si myslim, že nejsou na tom tak špatné.

Ale penize nejsou všechno. Jsou výkommi podnikatele, kde oba pracuji. ale zase za to zaplati

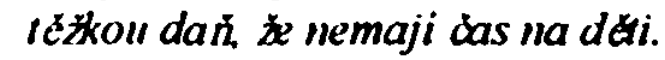

- No, to už je potom jejich problém, ale kdyż si takovou práci, vlastne, vybrali, że jo. Mưže tam jeden $z$ rodiny se vlastnê obêtovat a vênovat se vic dêtem a pritom nekoukat na ty penize tolik.

Takx souhlasite se mmou, žx penize nejsou vsechno?

- Penize určitê nejsou všechno, no ale jsou dủležitý.

Sprachverhalten:

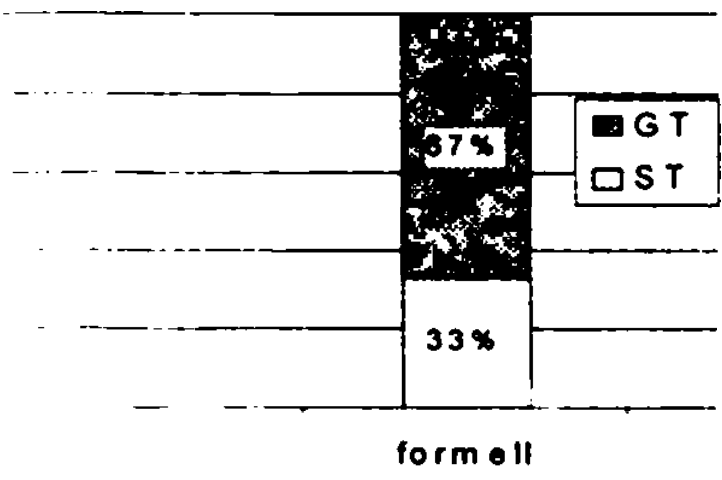

Einstellung, kounitives Subsystem:

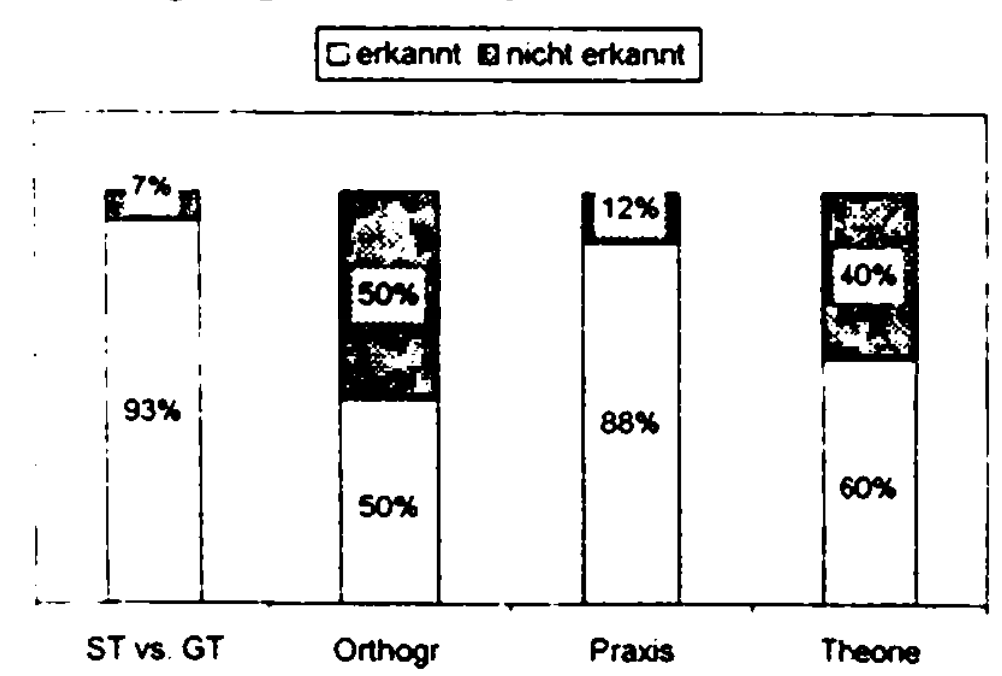

Einstellung konatives Subsystem:

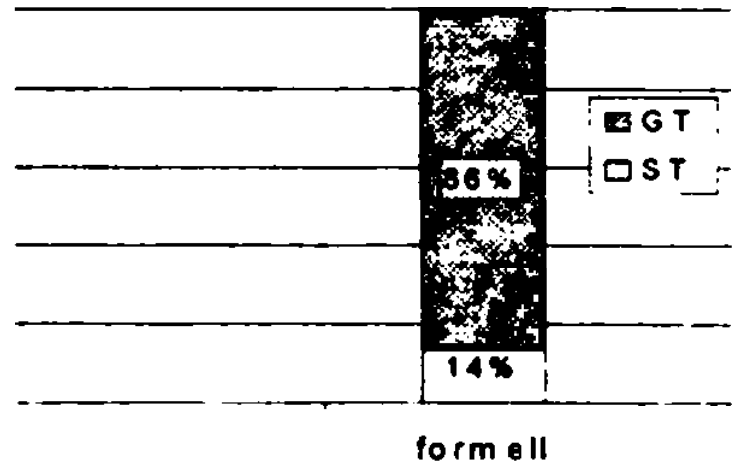

Evaluation der eigenen Kognition: 
Einstellung, affektives Subsystem: Grad der positiven Einstellung

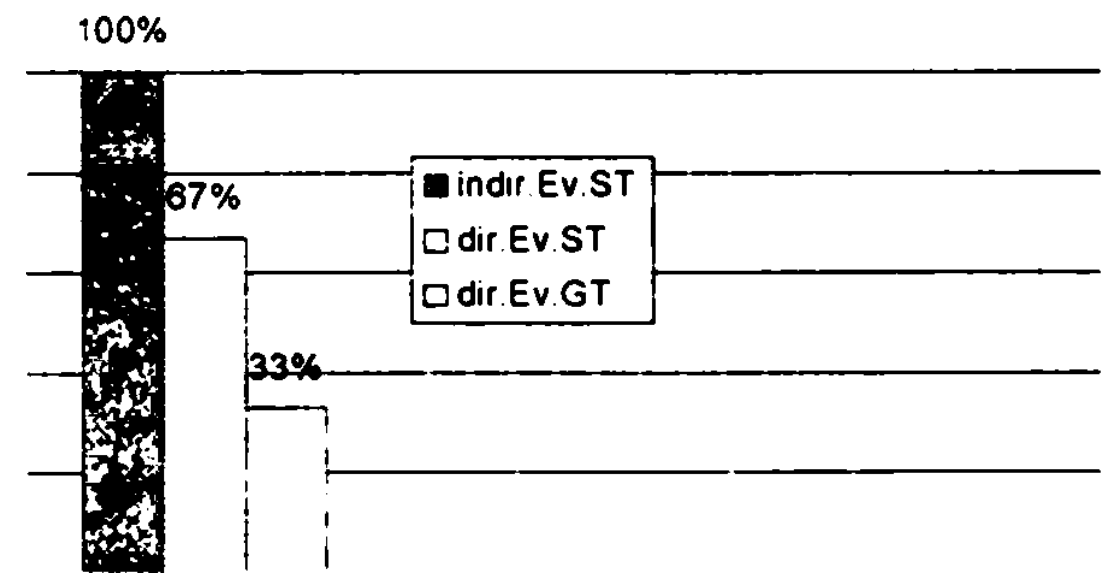

Kommentar: ohne Kommentar

\section{Lagerarbeiterin, 39 Jahre}

Spracherhalten, formelle Sirnation:

Co ïkacke zuysovaini cen Y Ceské republice?

- Vủbec nic.

l'ás se lo netýká, kctyż nakupujete vobchodd a ceny se ziysuji?

- Moc ne, já všechno dostávam vod našich z Moravy.

Tak ze mále na Morav'e rodimme sponzory?

- Ano. mam tam rodice.

A se siym platem jste spokojena?

- No, to moc nejsem, ale když mi nezajimaji ceny, tak bych mohla byjt.

Tak y.y.jste jedna z mála lidi, kle ì j.son spokojeni? A máte nçjake konicky?

- Ne, nemam żádný.

A máte deti, rexlim?

- Man dvẽ.

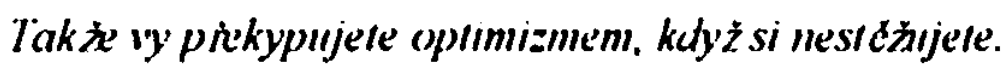

- Jà myslim, že to je jedno, jestli si stčżuju nebo ne. protože ono to vyjde nastejno. Tak co viml radi? Theba viscivani do prace?

- No, to mi vadi, hlavné to vstavaani, ve trii čturté na šest. To je údésný

A dotykajji se vás nçjak poplarky za lelefon?

- To se mi dotýká, protože telefonuju dost ċasto na Moravu.

A jsme zase zpà na Mora'ć Dostávale i to zname moravske vino?

- To moravske vino taky dostávam, ale já ho nepiju

A co likcile letošnimu jaru? Usmivàle se.

- Hlavne, že mluvite vic než já, to se mi libi

No jo, protox̌ yj jste málo sdilmá.

- Ne, co je hezky, jaro, vopravdu. Mám ráda slunicko, teplo, mor̀e, prirodu.

A kam pojedele leos na dowolenon?

- My vètšinou jezdime do Chorvatska, tak nevim, možná asi tam, ale neni to tam ňáký jistý, protoże tam se péknč vảiči ted'ka v tý Jugoslàvii. Także nevim ešttčcenka Bayer - 9783954790258 
Sprachverhalten:

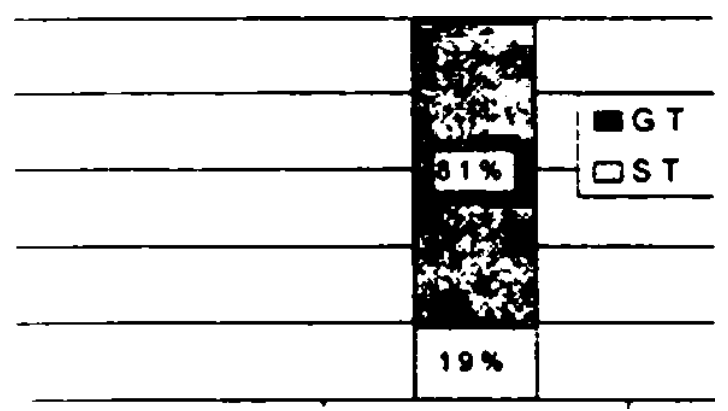

form ell

Einstellung, kognitives Subsystem:

Derkannt E nicht erkannt

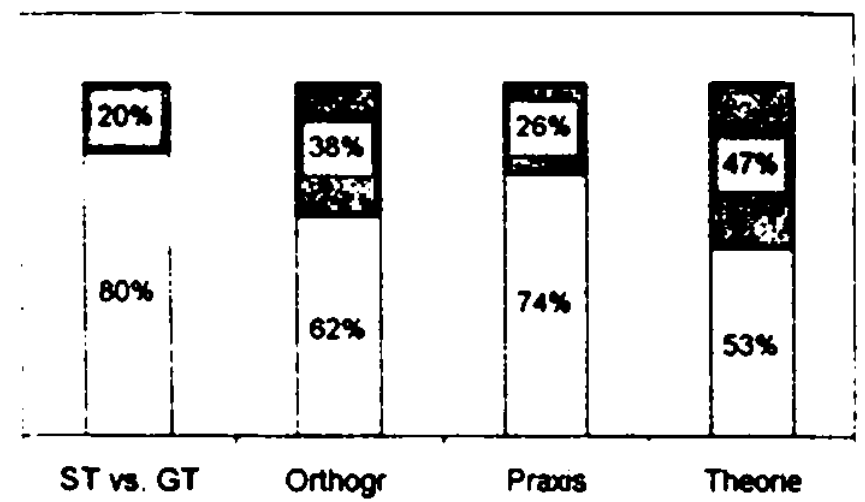

Einstellung affektives Subsystem: Grad der positiven Einstellung

$100 \%$

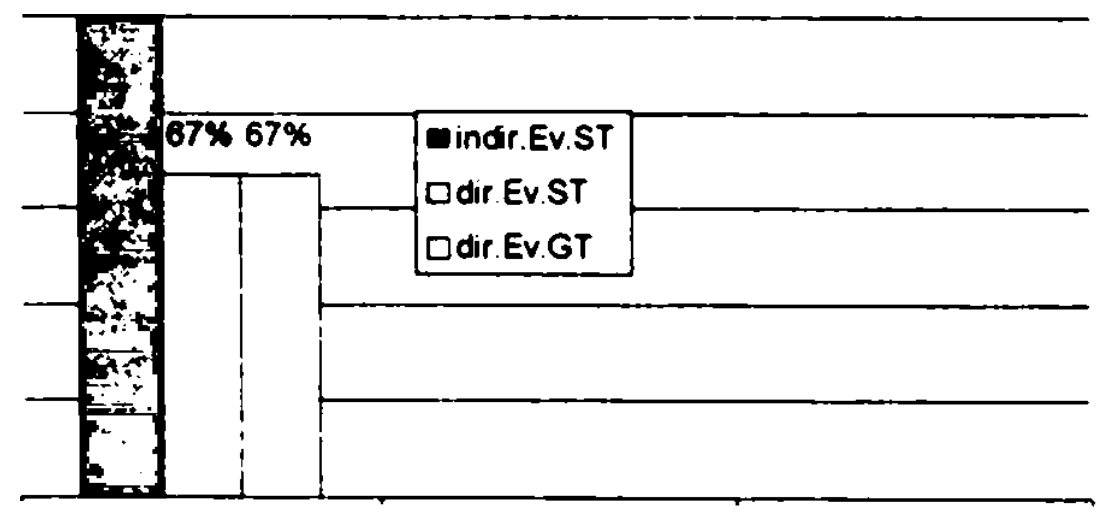

Kommentar: ohne Kommentar

\section{Unternehmerin, Vertrieb im Baubereich, 39 Jahre $^{105}$}

Sprachverhatten, informelle Simuation: privates Telefongespräch mit der Verfasserin

- A máš už to dobrý, jo?

(No, nemam ešt $e_{\text {pràve.) }}$

"1"S Dieser Respondentin wurde der Fragebogen ausnalımsweise zugeschickt. 
- Jà taky nemam, abych ti pravdu tekla, ale vim, že uż taky jedna prekladatelka - spolu jsme bydlely. Bydlela u mé pobliž a šla taky, że (...) jả tenkrát když jsem rodila, tak jsem chodila na tu gymnastiku. viš. Ale to už je taky dávno, viš. (...) No, budeš to mit nékde mezi praci a domú. A v který ulici bydliš? (...) Aha, to je jako ten spisovatel nèjakej, ňákej básnik to byl. (...) A ted" tł́eba pres tejden tam budeš - Vikend? A já ti ted" - jako - zavolam predem. Protože ted' je taky svátek, že jo. A uvidime. (...)

- No nic, pokud možno technika ñảká, jakákoliv, jo. A dám ti teda, eštẻ ti zavolam, kdybysme se. Já bych prỉšla za tebou. A kde to asi je, teda? No, jä mam plán, tak já to jako najdu, viš. To mné jako nedẻlá problémy. Tak dobře. (...) Já jsem ti volala snad už včera, takhle kolem desátý.

Sprachverhalten:

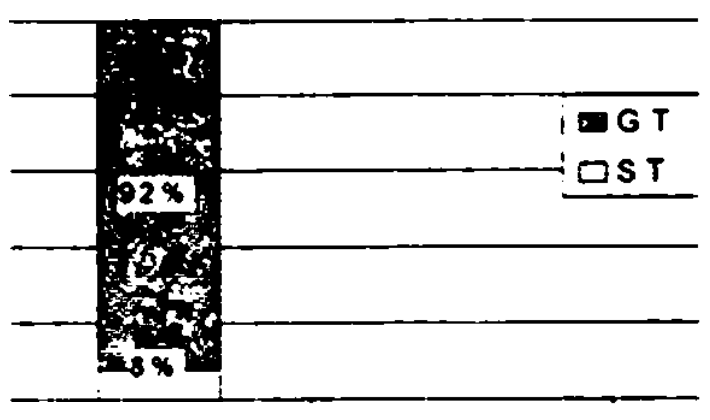

in form ell

Einstellung kognitives Subsystem:

\section{Eerkannt Enxht erkannt}

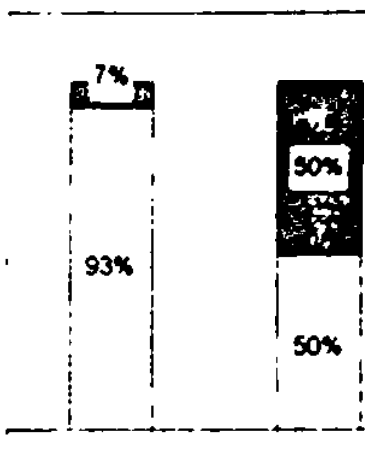

ST vs GT Orthogr

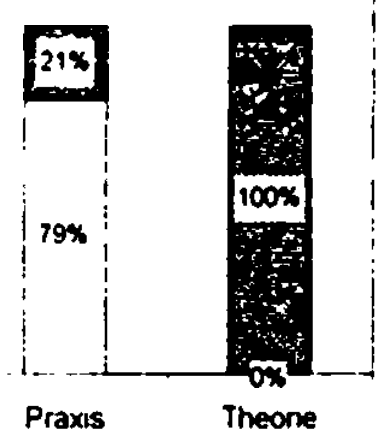

Praxis
Einstellung, konatives Subsystem:

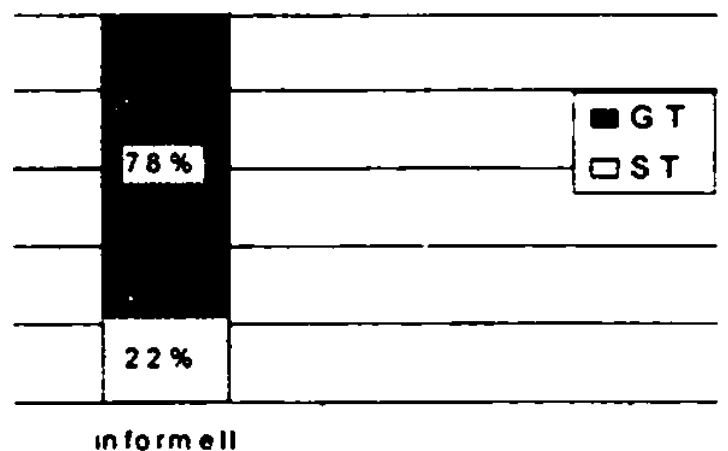

Evaluation der eigenen Kognition:

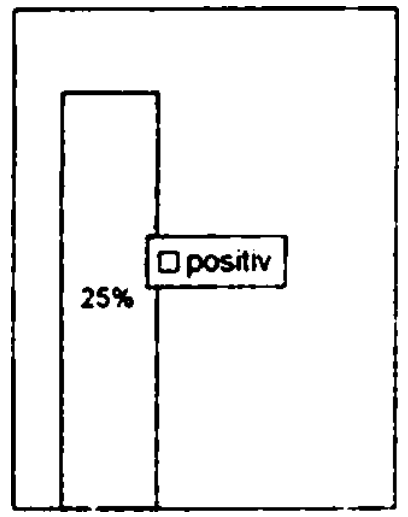

Einstellung, affektives Subsystem: Grad der positiven Einstellung

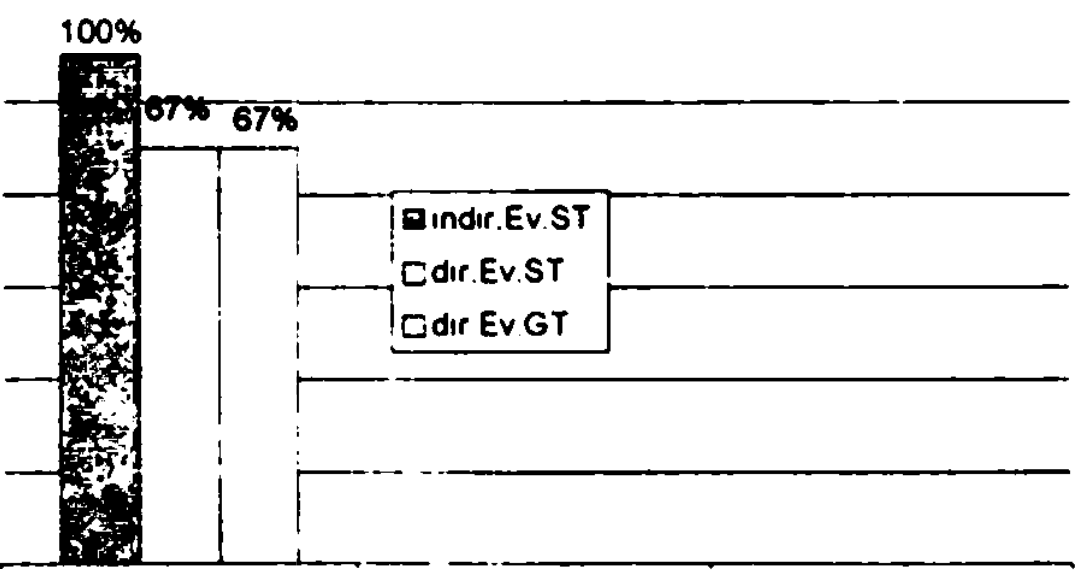




\subsubsection{Frauen mir Abitur}

Alter der Respondentinnen: 29 bis 54 Jahre, insg. 5 Aufnahmen. Alle Respondentinnen wurden jeweils an ihrem Arbeitsplatz interviewt.

\section{Referentin im Bereich Umweltschutz, 29 Jahre}

Sprachverhalten, formelle Sinuation:

Co rïkáte zvyšováni cen v Ceskè republice?

- Tomu nerozumim. (...)

Jsou ješle jimé poplatky, tjkajici se żvotmiho prost tedi?

- Samożejmé jsou. Jsou to vlastné poplatky za znečištováni ovzduši. Jsou to takzvané malè zdroje znečištêni, který každý provozovatel musi do patnąctěho unora prislušneho roku dát na prislušný nảrodni vỷbor nebo mistni národni víbor s udánim poplatku.

To snad nejsou poplatky, to jsou spis penále?

- Ne, to jsou poplatky, který jsou daný zákonem. Já bych spiš chtěla mluvit $Q$ svoji pràci, kterou $v$ souciasne dobẻ teda délám. a to je to, že vyzjuám občany, fyzické a právnické osoby, $\mathrm{k}$ tomu, aby predlożili, jakým zpúsobem nakládaji s komunálnim odpadem.

A nejsou " vas stiżosti na psy. na jejich vykkaly?

- Na psy tady samozŕejmẻ jsou stižnosti. Na psi exkrementy. Samoztejmè ty nám tady znecišśuji żivotni prostredi, a rekla bych, že to je dalši otázkă dost taková problematická. V současne dobẻ mi rada odsouhlasila cedule, na kterých bude nápis, že - samoztejmé - zákaz vstupu se psy na dẻtskả hr̉ištẻ pod pokutou pêt set korun a budou $v$ naši méstské cásti instaluvány odpadkovè koše na psi exkrementy.

Takove odpadkove kose budou opatkny reklamou?

- Ne. instalace byla vlastnê darovana mèstské ėásti zdarma. (...)

A co byste jes̀ile rekla k swoji práci?

- K svoji práci uź jsem rikala, że se zabjivàm têma popelnicema, který mnẻ teda zaberou. bych rekla. puilku moji pracovni doby

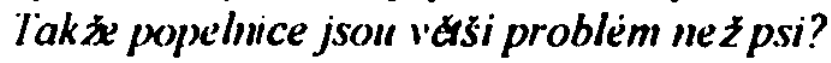

- Jả bych rekla. že se to asi spiš rovná - popelnice a psi, protože psủ - podle informaci finanìni

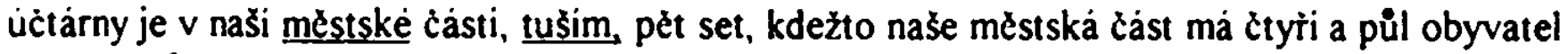
- ċtyri a púl tisice obyvatel - znamená to, że téch popelnic tady bude daleko a daleko vic.

Sprachverhalten:

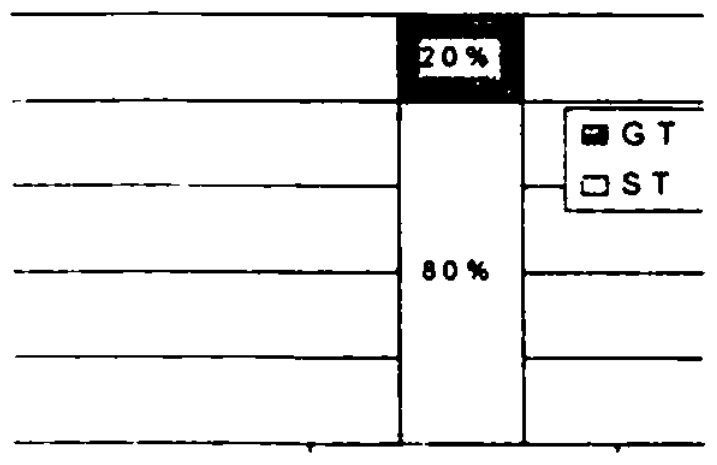

form ell
Einstellung, konatives Subsystem.

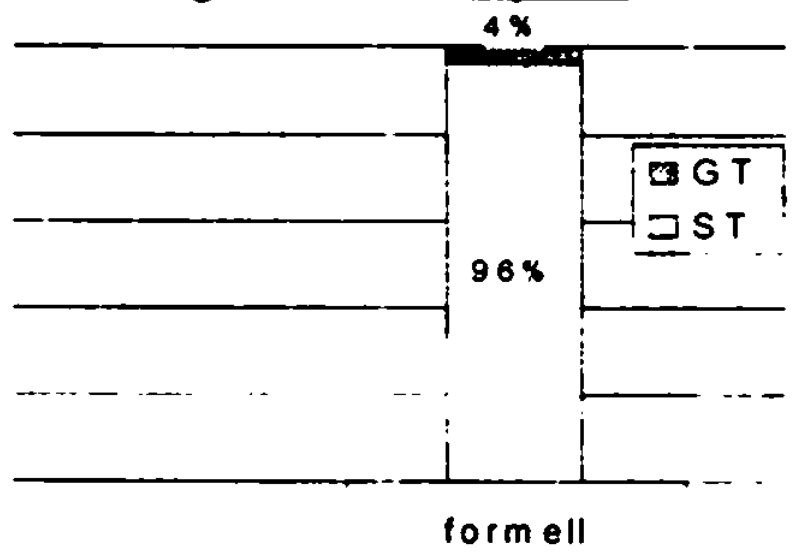


Einstellung kognitives Subsystem:

Cerkannt $\mathbf{n}$ nicht erkannt

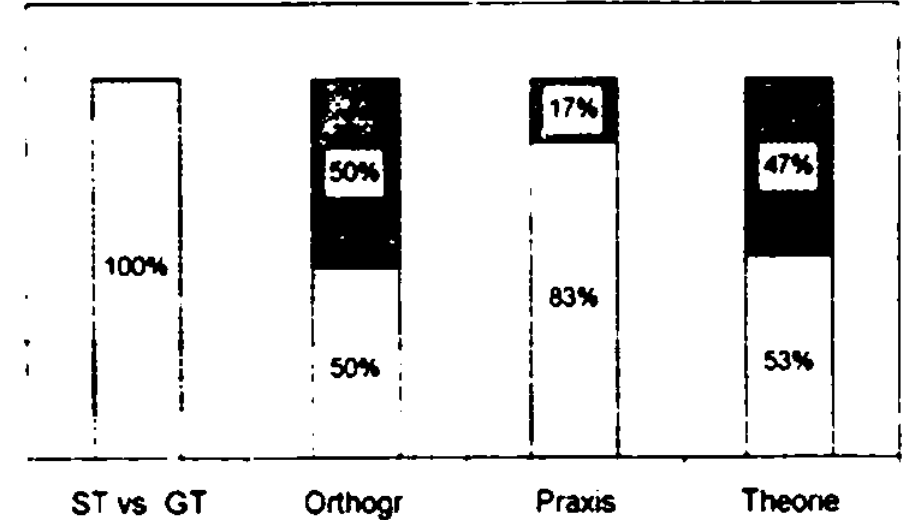

Evaluation der eigenen Kognition:

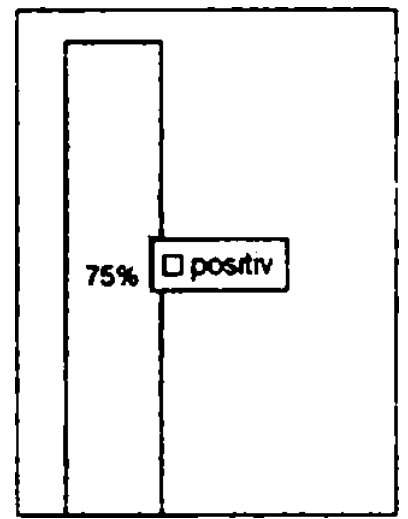

Einstellung, affektives Subsystem: Grad der positiven Einstellung $80 \%$

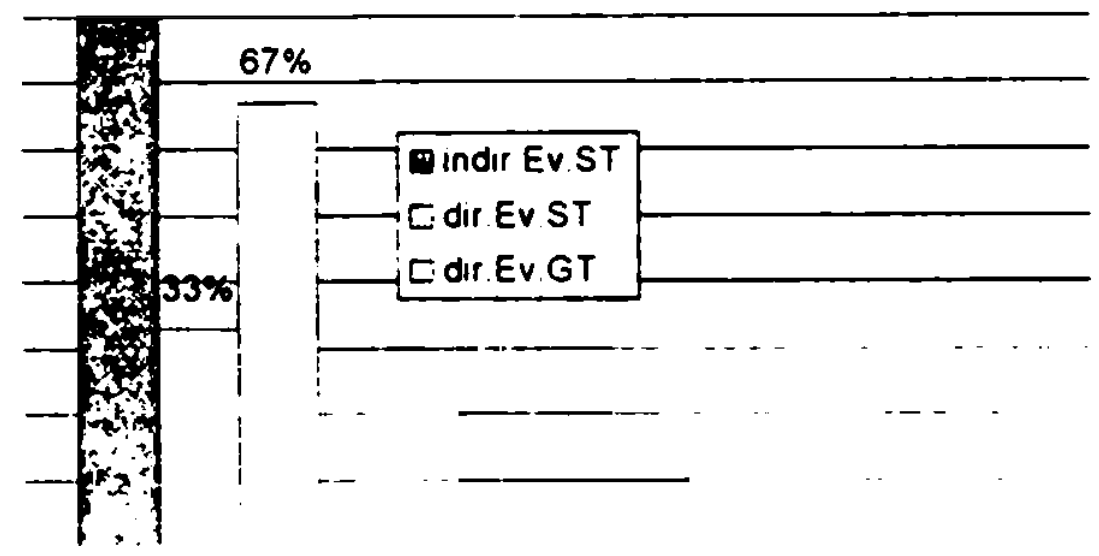

Kommentar ohne Kommentar

\section{Beamtin am Finanzamt, 37 Jahre}

Spracherhalien. formelle Simation:

('o rikcile ziysovaini cen v Ceske republice?

- Zvyšováni cen $v$ Českè republice. No, nevim, co $k$ tomu rict. Zvyšováni je realitou a musime

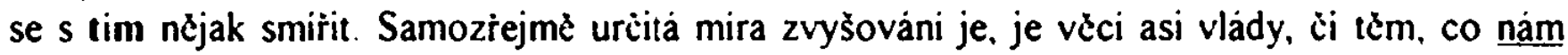

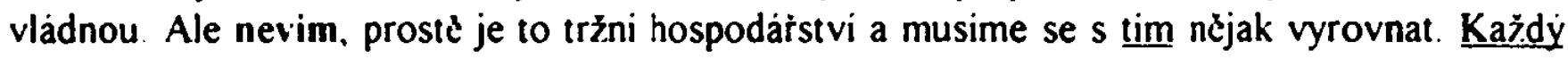
má na to svoje, svoje metody.

Ale " moci je sociálmi demokracie a ta by mốla mir spis socialmi program.

- No, to je to, to jsem rikala predtim, že určitá, určitá mira závisi na tèm, co nám, co nám vládnou. a pokud nčkdo špatn̊̌ hospodari, jako zrejme, jako zrejme se domnivám. Že sociálni demokracie to neumi, tak si myslim, že, że se zvyšováni cen a urçitemu kolotoči nevyhneme. A co ceny porran'm, ceny mijemmeho. ceny za relekommmikaci?

- No, samoziejme tyto - socialni demokracie to skryvá pod, pod jiné zvyšováni. Samoziejme neni pro ni popularni zvyšovat základni, základni veci, jako voda, elektřina, potraviny. Proto to 
zvyšuje něčim jiným, jako jsou třeba daně z terminovaných vkladủ, kde si to vybere úplné jinak. Nebo zpưsob, zpưsob zvyšováni poplatkủ jiných - nevim, nevim, co $k$ tomu ešté. co $k$ tomu eštẻ dodat, protože je to - má to souvislost i s jinými, is jinými danèmi. Ne jenom, ne jenom - se to neprojevuje i $v$ cenách, těch primo. Nevim, nevim - ted' jsem se do toho zamotala. A ted' taková netypickà otázka. Myslite, maji penize vliv na lásku? A v jakèm ohledu? - No, samožrejmé. Asi v každym věku je to trošku jiný. Čim je člověk mladši. asi je to - má to ten vliv trošku menši, ale domnivám se, že i dnešni, dnešni mladež se na to divá skrz penize.

Sprachverhalten:

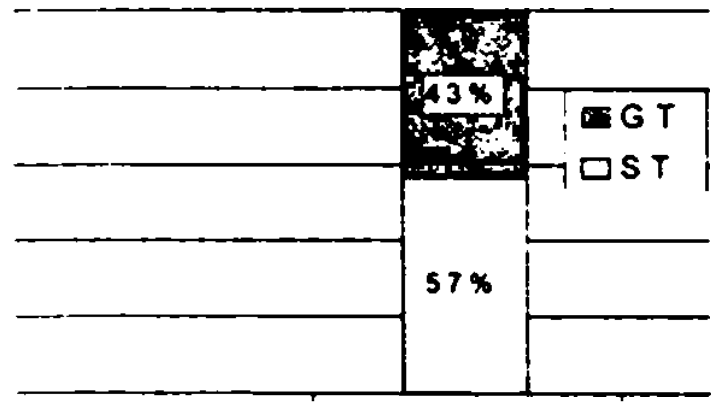

form ell

Einstellung, kognitives Subsystem:

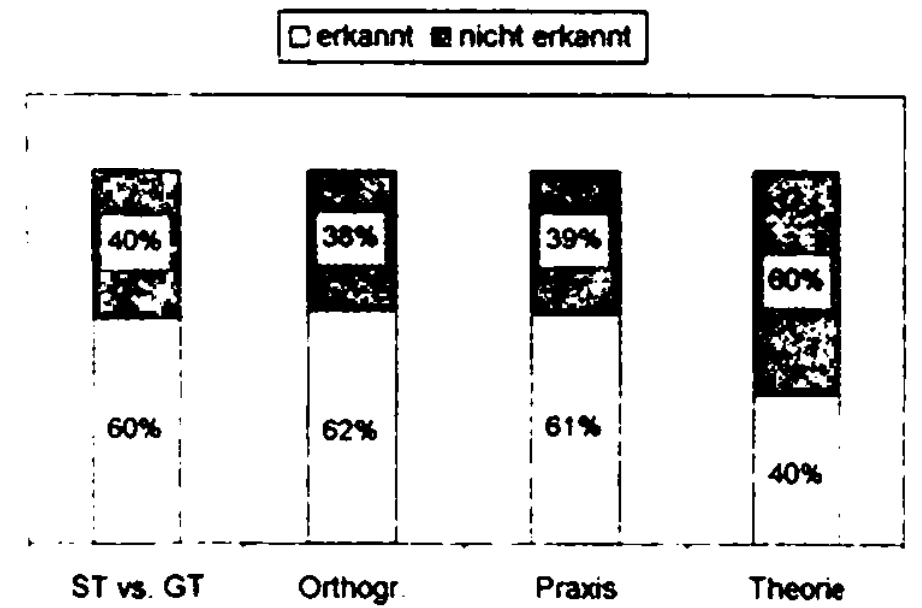

Einstellung, konatives Subsystem:

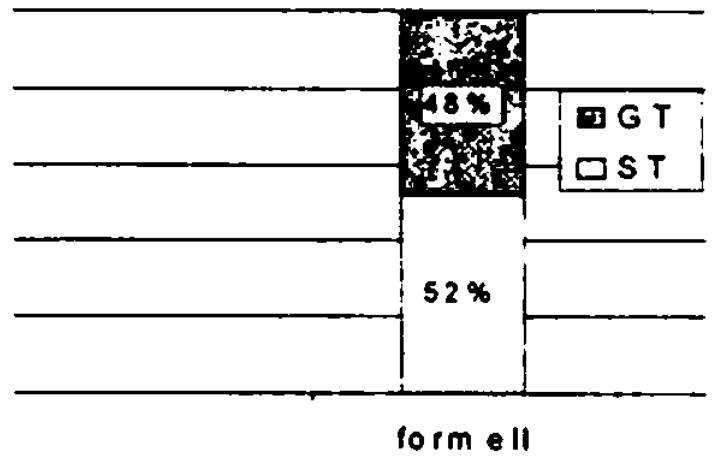

Evaluation der eigenen Kognition:

Einstellung, affektives Subsystem: Grad der positiven Einstellung

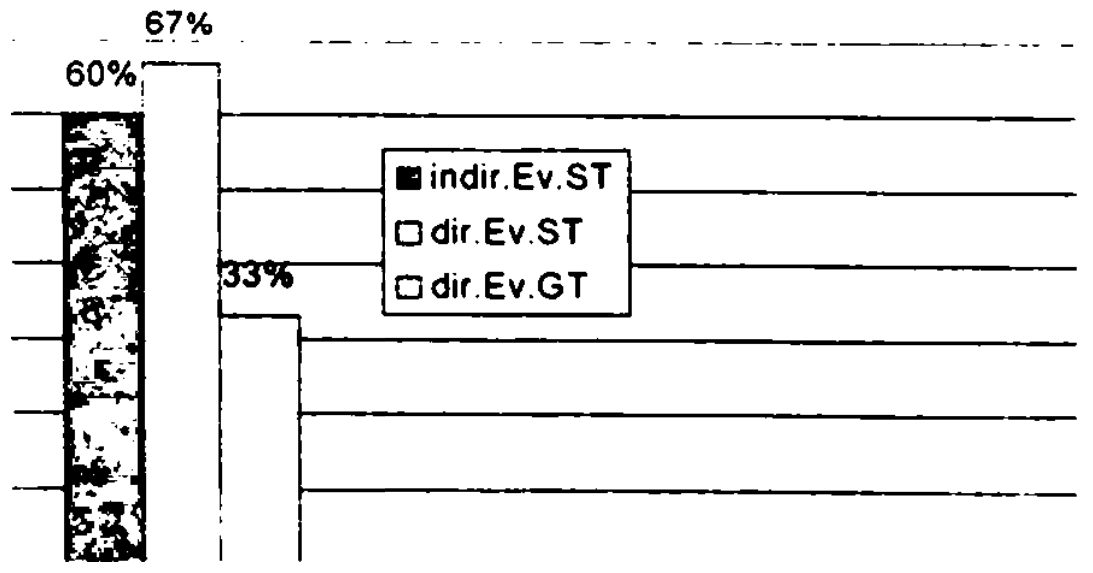




\section{Büroangestellte, 38 Jahre}

Sprachverhalten, formelle Simation:

Co rïkite zuysoráni cen $v$ Ceské republice?

- No, nelibi se mi, no.

Co se ram konkreinc nelibi?

- No, jä teda hlavnê pres to jidlo, protože mảm dvẽ malý dêti a mlíko je každej den dražši.

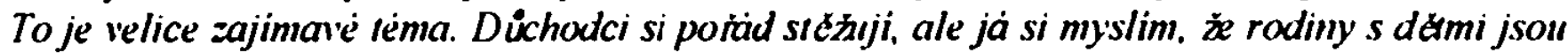
na lom mohem hür.

- No, to asi ano, protoże kdyż koupite ditéti boty za sedm set, tak mu vydrżej tţi mésice, když si koupi düchodce boty za sedm set, tak mu vydrżi tr̉i roky.

A bydllire v rodinmem domku, anebo v sidlisimi zástavbe?

- V paneläku, $v$ klasickym nảjemnim bytc.

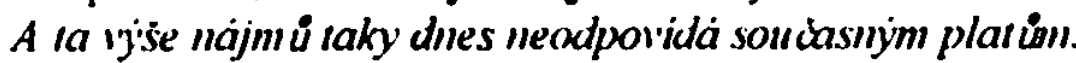

- No. ona samotná výše najjmu by nebyla tak hroznà, ale ty služby $k$ tomu. Protože je sice pravda, że najemne se zvedlo jako zhruba trikrat od toho roku devadesát, ale porád je to

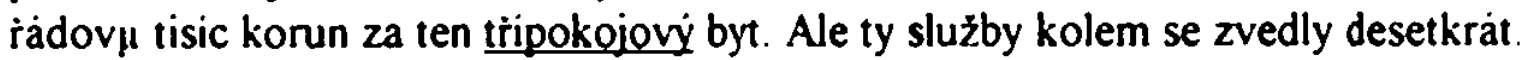

Oràzka je. jestli ra kvalita oxtpovidá zujseni cen?

- No, u vody určitě ne. Voda je cim dál horši. Stávala osmdesát halíxủ, dneska stoji trìcet korun se stočnym, że jo

Zase ropeni je ekologicke. a prolo je dražsi.

- No, tak je pravda, że - $\mathrm{i}$ kdyż ne. My jsme $v$ sidlišti, které bylo postavený $v$ roce sedmdesát. Uż tehdy bylo na plyn a dneska je zase na plyn. Takže $u$ nás teda żádný - żádnà zména $k$ lepšimu nedošla

A osobmi dotaz. Máte anio?

- Tý plechovce kovošrotu se snad ani auto rikat nedá

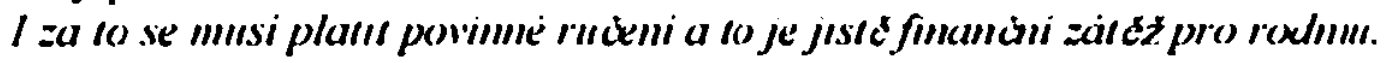

- No, já to mam $z$ toho titulu, że obcias - prece jenom dvê malý déti - v Brandýse napriklad teda dostat sanitku, to musel mit kluk zlämanou nohu, aby nám dali sanitku, że jo A co rikále visi priplatki na dasi?

- No tak zaplat pänbủ za nẽ, i když by mohly byjt vêt ši.

Sprachverhalten:

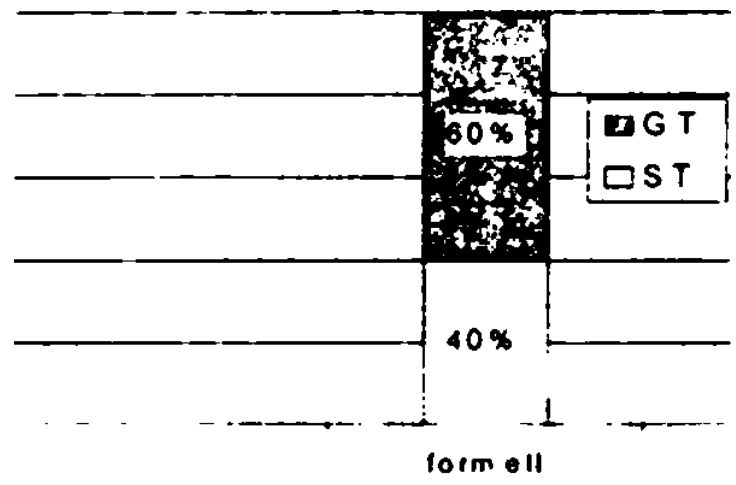

Einstellung, konatives Subsystem:

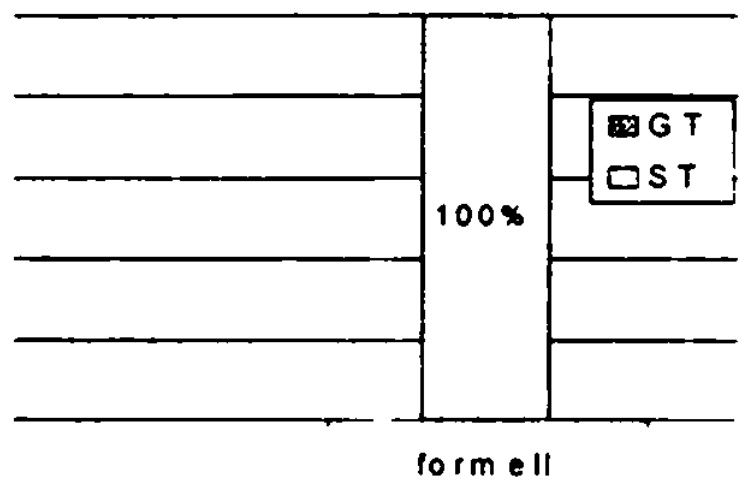


Einstellung, kognitives Subsystem:

Cerkannt E nicht erkannt

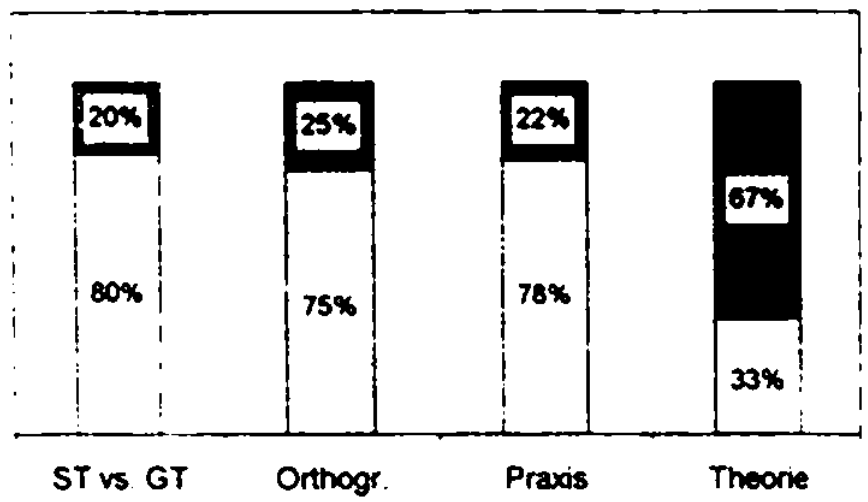

Evaluation der eigenen Kognition:

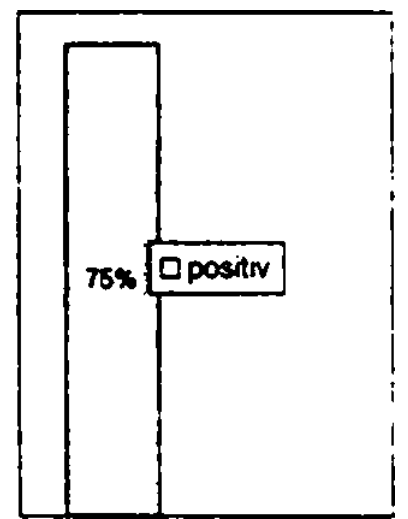

Einstellung, affektives Subsystem: Grad der positiven Einstellung

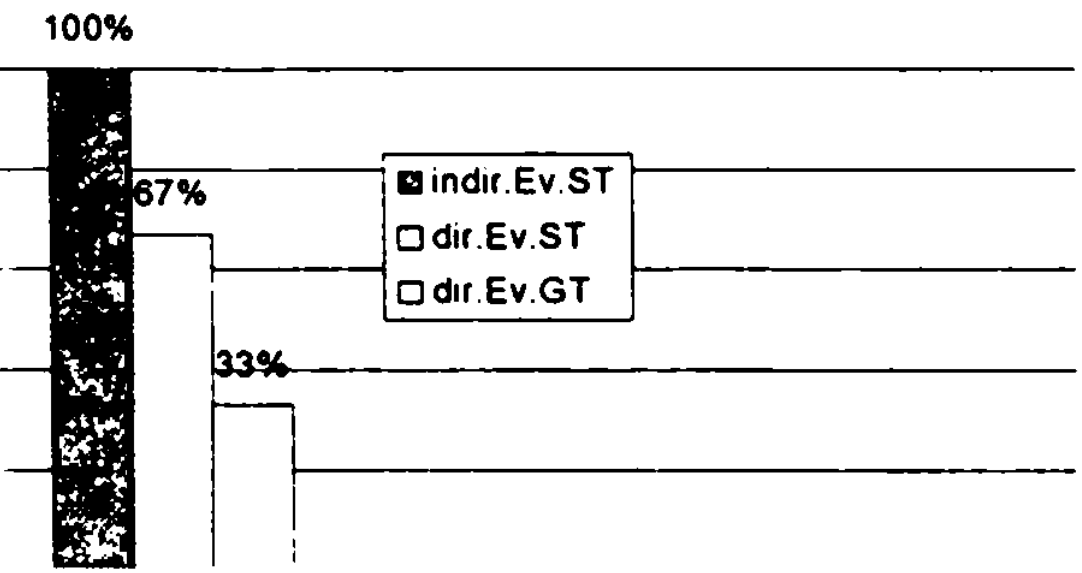

Kommentar Syn se práve̊ pripravuje na životni zkoušku, prijimaci pohovory na 8-leté gymnásium. Pokud bych se mśla vyjädtit $k$ zjednodušeni spisovné ċeštiny, tak jen u płejatých

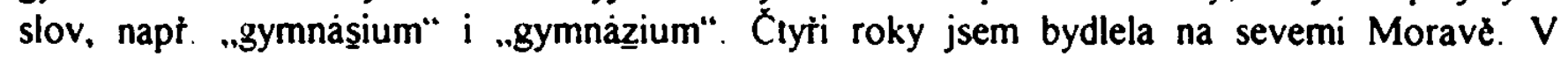
kanceláti mnè vyhovovalo, že vêtš̉inou mluvili spisovnè, ale na venkovè už ne: „ona usla“ (ona usnula); nikdy nešli „k lékarii”, ale „do doktora"; nešli "na kopec", ale „do hory“. P.S. Když byl

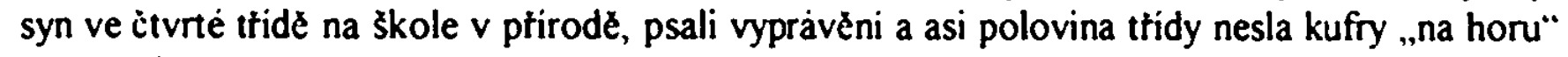
do pruniho patra chaty, misto ,nahoru“.

\section{Standesbeamtin, 52 Jahre}

Sprachierhalien, formelle Sitnation:

('o rikate zuysováni cen $v$ Ceskè republice?

- Zvyšováni cen $v$ České republice podle mèho názoru probihả rychleji neż zvyšováni platů.

Myslite konkrime na iradech nebo kdekoli?

- No, na úradech samoż̉ejmê vždycky - vždy se bylo pozadu, ale myslinı, že i kdekoli

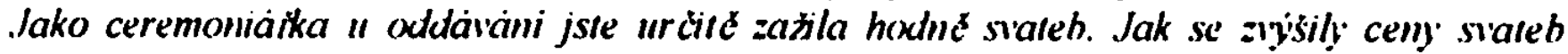
bihem posledinich deseti let?

- Ceny svateb se vỉbec nezvýšly, $v$ żadnèm pripadś. Stále stoji svatebni obìad šest set korun

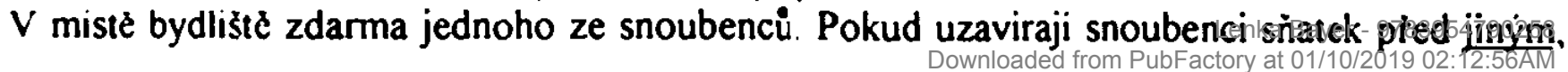


než v mistě priislušným nảrodnim výborem, šest set korun. Pokud chtêji uzavřit snoubenci mimo sianovenou dobu nebo mimo stanovenou obradni mistnost, tisic korun. Poplatky se nezvýšily za poslednich osm let.

Tak to je prijjemmá zpráva, ale zato roziodové poplatky se urcit é zvysisly.

- $\underline{O}$ rozvodovych poplatcich nemám samozíejmé vyhranèný názor, protože do rozvodu celkem moc jako matrikári nezasahuji. Pokud vim, bylo to ctyrii sta korun, kdo dával návrh na rozvod. A co je ješlı̌ mimo svateb a statistiky obianú v popisu práce matrikárky?

- No, matrikárka má velice rozsáhlý obsah své pủsobnosti. Samožrejmé kromé svateb také vede rodnou matriku, úmrni matriku, vỷpisy do Brna déti narozených mimo územi naši republiky, snoubencủ oddaných mimo naše územi a úmrti mimo naše územi. Tam se vede zvlàšni matrika pro naše obiany narozené, oddané a zemrelé $v$ cizinž. Tak $i$ to. Dále samoż̉ejmé matrikár - mủže pred matrikárem uznat otcovstvi $k$ narozenému ditěti i matka, která nechce uzavìit manželstvi. V tom prípadé si prìvede tatinka a múže pr̉ed matrikárem uzavirit - udêlat dohodu o prijmeni ditête.

A jako slanma osobmost jste kdysi na Staromàtské radnici asistovala " svateb zlnamyich osobnosti. Kteri to napriklad byly?

- Kdybych mèla udélat výcet, výčet známých osobnosti, tak by to byla celkem velká plejáda Zaìneme Waldemarem Matuškou, Bárou Bazikovou, Žbirka, Ivanka Devảtả, Josef Vinklár. Chudik Ted' momentálnê dalši mi nenapadaji. Ljuba Hermanová - to bych se musela podivat do své statistiky osobni.

Sprachverhalten:

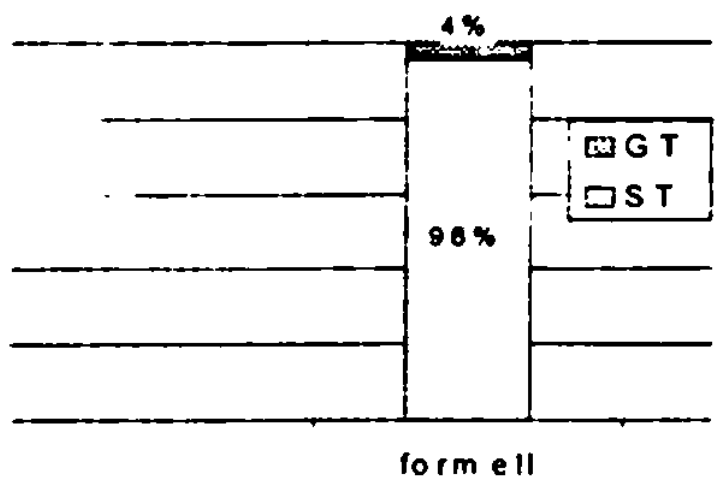

Einstellung, kognitives Subsystem:

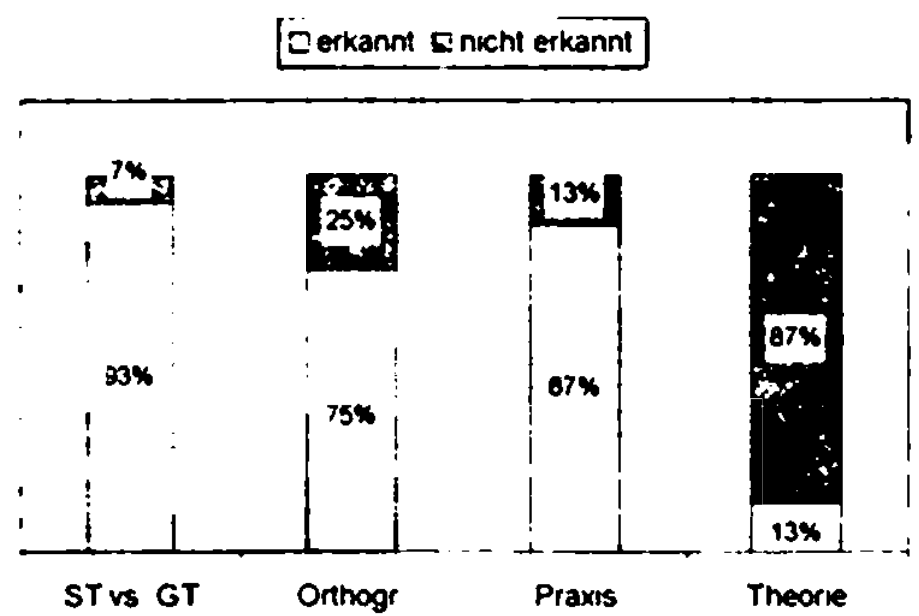

Einstellung, konatives Subsystem:

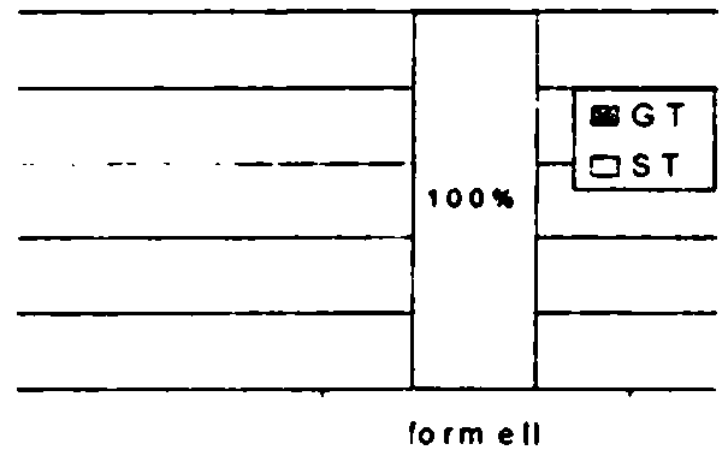

Evaluation der eigenen Kognition:

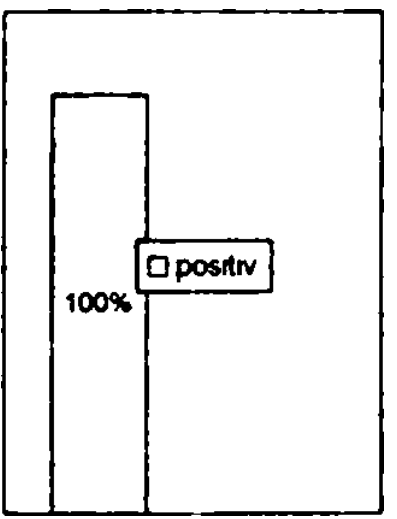




\section{Einstellung, affektives Subsystem: Grad der positiven Einstellung}

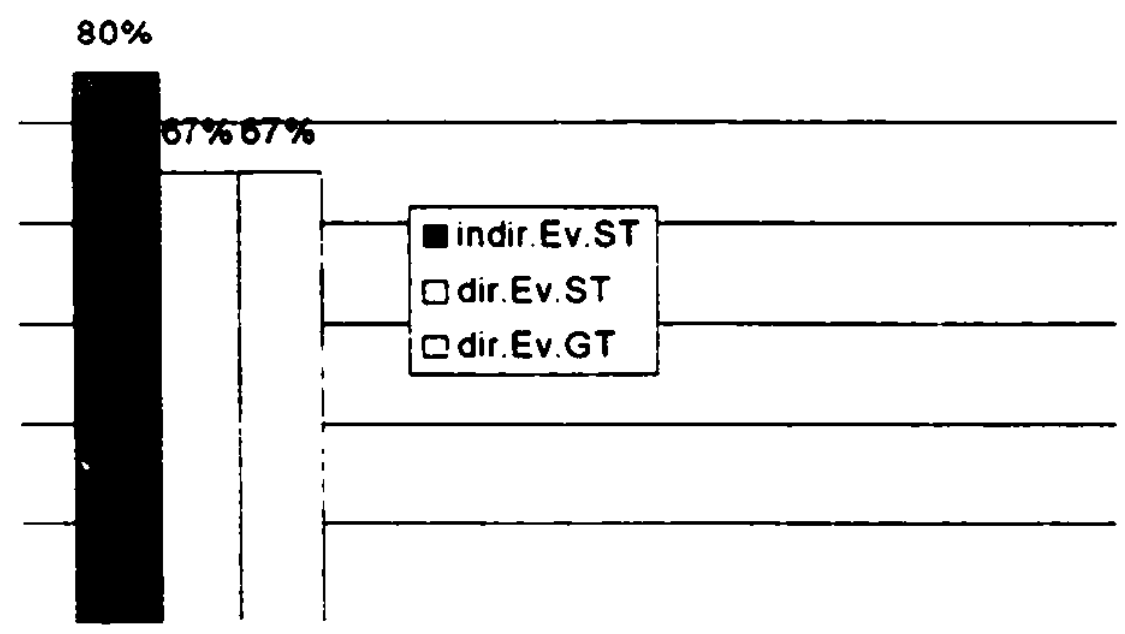

Kommentar: Osobnê si myslim, že tak jak mluvime doma je osobni dialekt každèho jedince ( $v$ mém prípadè prażského). Pokud osobné jednám $s$ úcastniky tizeni płripadné budu vystupovat $v$ nèkterem ze sdẻlovacich prostriedkủ budu samozłejmé uživati spisovnou češtinu. Jinak by mi to ani nenapadlo. Dost mi mrzi a někdy $i$ trochu povyskočim na židli, když slyšim nékteré naše reporterry $v$ televizi ${ }^{106}$.

\section{Leitende Verwaltungsangestellte, 54 Jahre}

Spracherhalten, formelle Simation:

('o ïkäle zuysovani cen v Ceskè republice?

- No, jả bych rekla, že ceny se zvyšuji, dả se ríct. pro - ze strany starých obcianů pomèrnè dost. Stari obiane nariikaji, że nemaji $z$ ceho platit najemné, i potraviny jsou vètsinou zásahem do jejich rozpoitu. Dủchody se nezvyšuji tak, jak by bylo potroba. Životni minimum je tak nizké. že to je opravdu jenom na prežiti. Myslim si, že dalši skupinou, kterả je dosti, jak bych rekla.

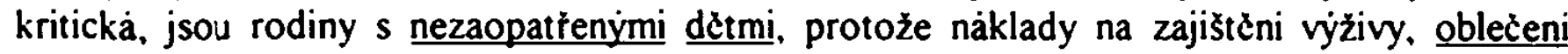
rodiny s dêtmi bych rekla. że je ještẻ horši než teda dủchodci.

Zuysowaini lelefomich poplatkú Dotykà se vás to nejak?

- Mé osobnê? Osobne, no dotýká, protože vlastnê jsme platili telefon mẽsičnẽ okolo stokonuny. Ted' telefon se plati okolo trì set, êtyr̃ set korun. Neni vyjimka i vice, pêt set, šst set korun. Zajimavi jsou také ceny potranin.

- No tak, když si rekneme, tak za sto korun vlastné żádný nákup neni. $Z$ toho ani neuvarime Tak jsme se už museli naucit vybirat si obchody, kde jsou sezonni slevy, jak se tỷká oblečeni i potravin a umet asi lépe hospodarit.

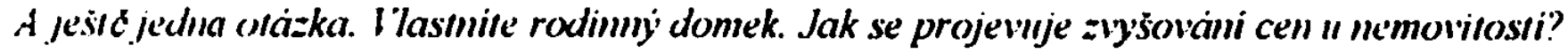

- Rodinny domek vlastnime, domovni danž, jak jsem se dozvẽdẻla $z$ tisku by mély narüstat, což si myslim, że neni sprảvný. Mluvim z pozice vlastnika domku. Protože nảklady vynakladané do údržby rodinnèho domku jsou již $v$ dnešni dobè dosti vysoké a ještế platit domovni dañ za néco, co jsme si museli vlastnimi silami postavit. Jà osobné jsme platili leta pủjỉku, méli jsme sporeni. a po dvaceti letech żjistuji. že musime do nemovitosti dàvat dalši penize na opravy, tak

1"w Dieser Kommentar weist cinige Schwachen in der lnıctpunhtion auf und beınhaltet cinein morplıologısclien Archaismus .. ubivat" stall ..ubivor. 
ještě teda mit vyšši daně než jsou ted'ko - myslim, že už je to velký zásah do rodinnèho rozpoctu

Jes̀tç posledni otäzka. (o rikäte cenàm ve zdrarotmctvi?

- Zdravotnictvi. No, prekvapuje mê, že stále se piše, že ceny lèkủ, nebo že některè léky se sice na nê dopláci, ale vêtšina lèkủ, že maji občané zdarma. Já se tady setkávám s občany, vêtš̉inou teda dủchodci, kterì jsou ochotni nebo i mi nosi úċty z lekáren. Jejich, zvlášté když to jsou diabetici nebo jsou vice nemocni (...) Doplatky na léky délaji teda v prủměru tti sta, čtyťi sta korun. A bohužel jim nemúžeme léky nebo vynaloženi - vynaložené cástky za léky počitat do vydaných ċastek, co se tỷká životniho minima, protože léky podle tisku jsou bezplatné. Občan si mủže udajné vybrat mezi lèky $z$ tuzemské vyroby a léky dovozové ale myslim, že záleži na ošetriujici lékarce, aby doporuciila takový lèk, na který obcian má. Já múžu mluvit z vlastni zkušenosti. že na lèky doplácin taky. A ještě bych chtčla upozornit na déti i pro starši obciany, že vlastnè vitaminy si všichni všechny vlastnê plati v hotovosti. A i to, myslim, kdyż jsou dêti malè, że to taky je zásah do rozpocitu.

Sprachverhalten:

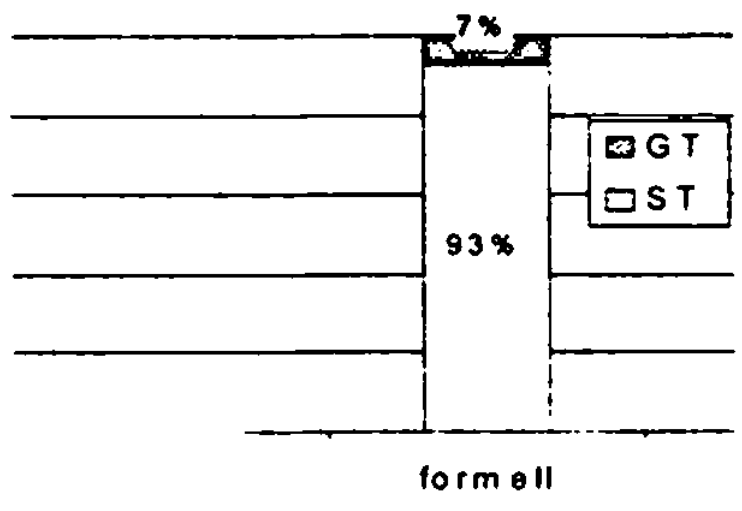

Einstellung, kognitives Subsystem.
Einstellung, konatives Subsystem:

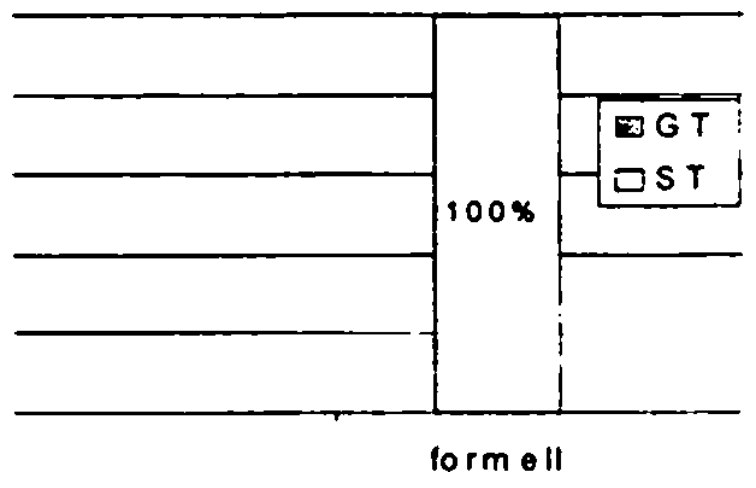

Evaluation der eigenen Kognition

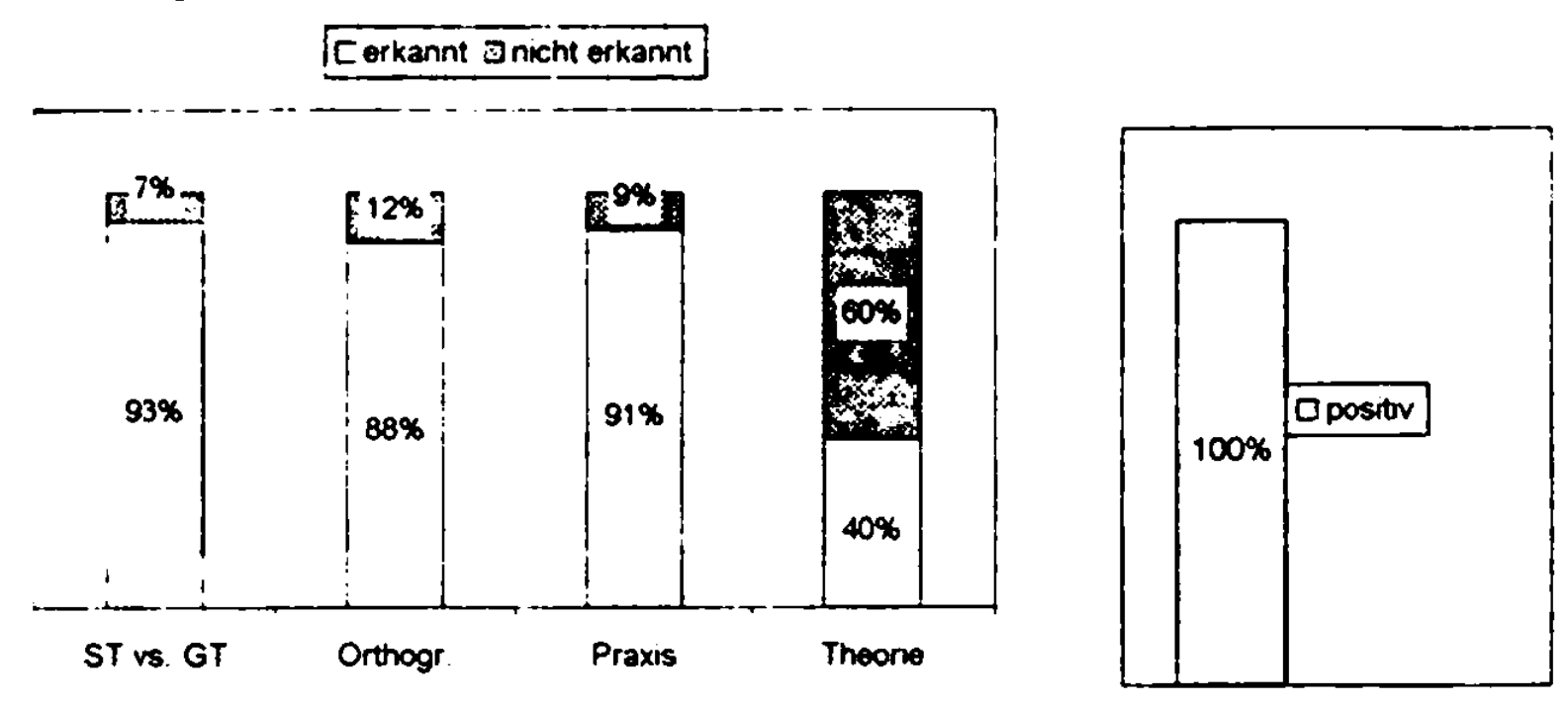


Einstellung, affektives Subsystem: Grad der positiven Einstellung

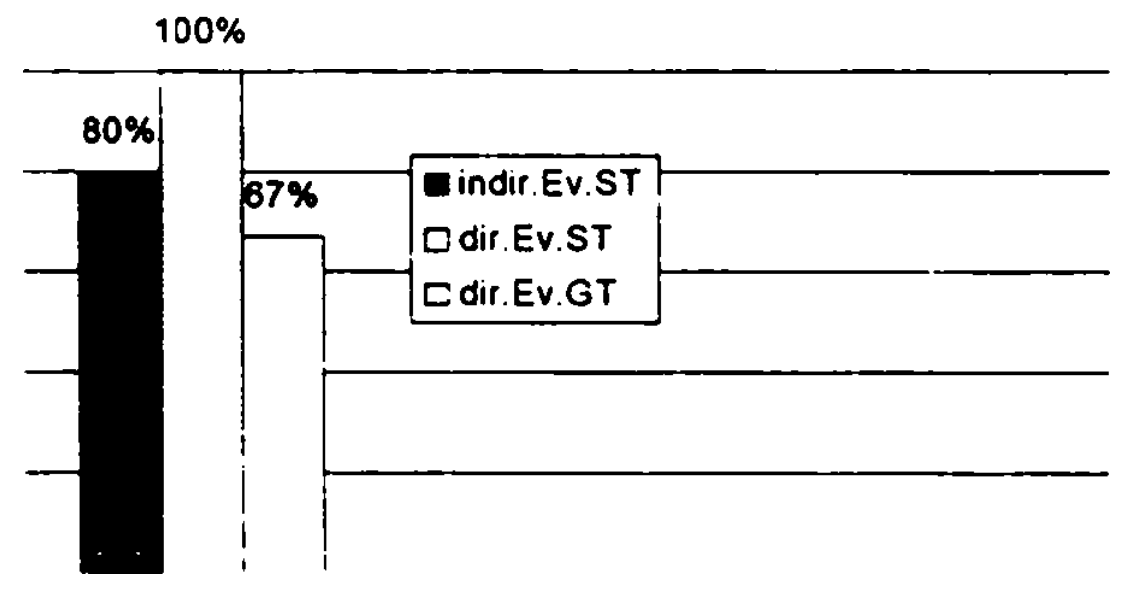

Kommentar: ohne Kommentar

\subsubsection{Frauen mit Hochschulabschluß}

Alter der Respondentinnen 37 und 39 Jahre, insg. 2 Aufnahmen. Beide Respondentinnen wurden jeweils an ihrem Arbeitsplatz interviewt.

\section{Leitende Verwaltungsangestellte, 37 Jahre}

Sprachierhalien. formelle Situation:

Co rikále zuysováni cen $v$ Ceské republice?

- Jo, ceny $\vee$ Ceské republice jsou nevyzpytatelne. Asi to musi být, nékdy je potreba zvednout ceny, kdyż jsou nảklady vysoký, ale nčkdy si myslim, że to je spiš otázka zisku toho kterèho obchodnika c̀i lèpe rečeno prekupnika.

A co treha takhle ziysit platy?

- Tak to se budou zvyšovat platy a zvyšovat ceny a budeme pomalu jak $v$ Itálii nebo $v$ Polsku kdysi, że budeme brát platy ve statisicich a možnả $v$ miliónech. Budou ze všech $z$ nás milionári a nic za to nekoupime

('o rikàte zyysováni cen za telefommi poplatky?

- No, to je, myslim si, dost svérázná kapitola, protože máme tady jeden podnik Tclckom, a pokud nékomu se nebudou libit, że se zvyšuji poplatky, tak mà smủlu. Protože nemúže jit nćkam jinam, aby si zaplatil tr̉eba jinou spoleinost nebo aby - aby prosté rek: ,já s váma nechci, jà si vemu nékoho levnejjšiho."

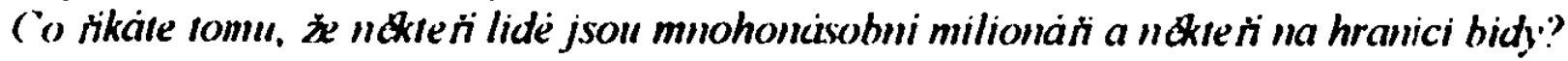

- Pokud ten mnohonásobnej milionár prijide ke svemu zisku Łim, že néco vymysli nebo najde penize, jak se riká, na ulici, protože vidi to, co jini nevidi, tak zaplat pánbỉ za né. Ale pokud to ziská na - hlouposti jinych nebo na tom, že nékoho podvede, tak to je trestný

A jes̀te jimá otázka. Je vaše práce na iríade zajimavá?

- No, velice zajimavà. Kdyż jsem sem pred dvêma a pủl lety nastupovala, tak byla jsem taková - ted' to zmènim. ted' budu všechno délat spravné, jediné jà to dokảžn. Je pravda, že jsme tady za ty dva a púl roku udélali spoustu práce, ale i jsem prišla $Q$ iluze, co se tỷe lidi Myslite mezilidske vatahy? 
- Tak. A takovả ta, když ne závist, tak aspoñ informačni šum. Protože jedna pani povidala, a pak se to za trikrát otočený stává pravdou.

Tak se dotykaji pomliny i vas osobne, ano?

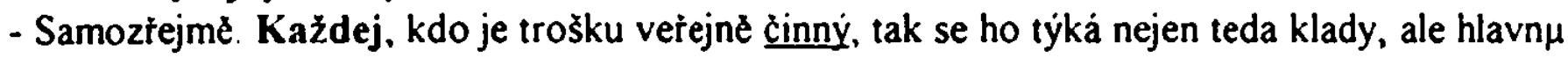
i zapory, protože když nékdo vystrči trošku hlavu vejš, tak vždycky musi bejt sražen a každỳ dobry skutek musi bỳt po zásluze potrestàn. A ted" trosku jiné téma. Co rikáte cenám potranin?

- No, protože jsem pracujici žena, tak nemám čas sledovat, kde je co levnějšiho a kam bych mêla pro urciitý druh výrobkủ zajet, takže já mám svưj oblibený krám s milou pani prodavaikou. A jestli je tam mliko o pêt korun dražši, tak bohužel, já si ho koupim.

A iyplati se kupovat v ich hypermarketech spiše nežv tady lách malych obchodech " Prahy?

- Je fakt, że kdyż je néjaký vètši nảkup, tak kde se koupi trii oleje a dvê baleni mlika a zásoby tèstovin. ale pro ty běžný nákupy človẻk nemá c̀as jezdit jinam. A na druhou stranu tyto velké obchody pretahnou svý zákazniky a až zkrachuji ti drobni, tak ty ceny stejnê pudou nahoru.

Sprachverhalten:

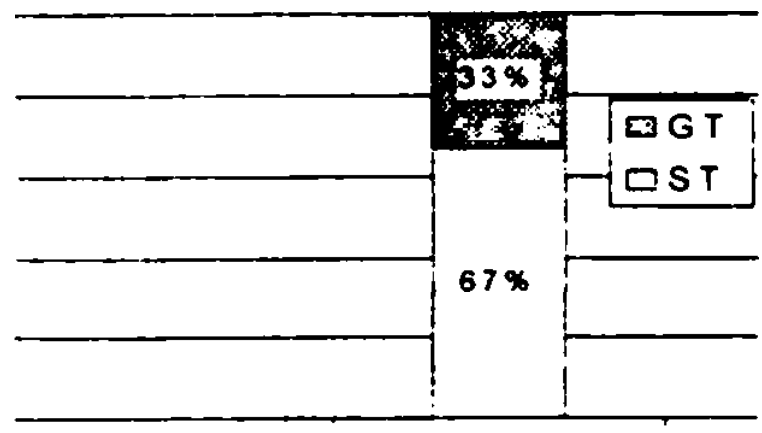

formell

Einstellung, kognitives Subsystem:

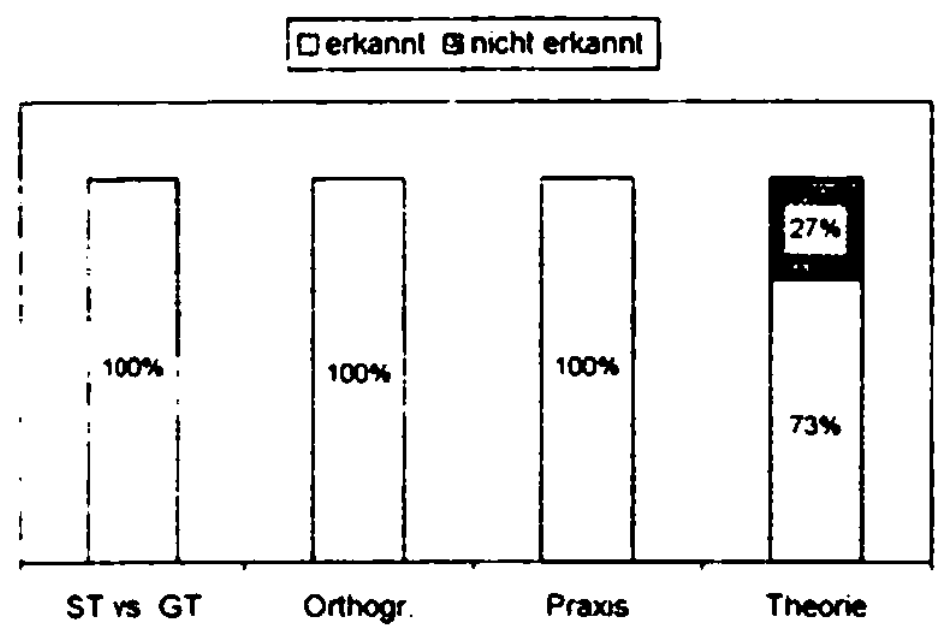

Einstellung, konatives Subsystem:

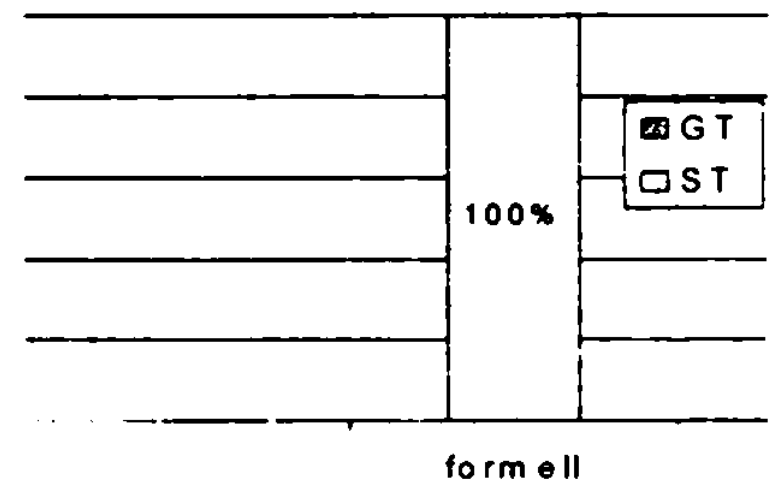

Evaluation der eigenen Kognition. 
Einstellung, affektives Subsystem: Grad der positiven Einstellung

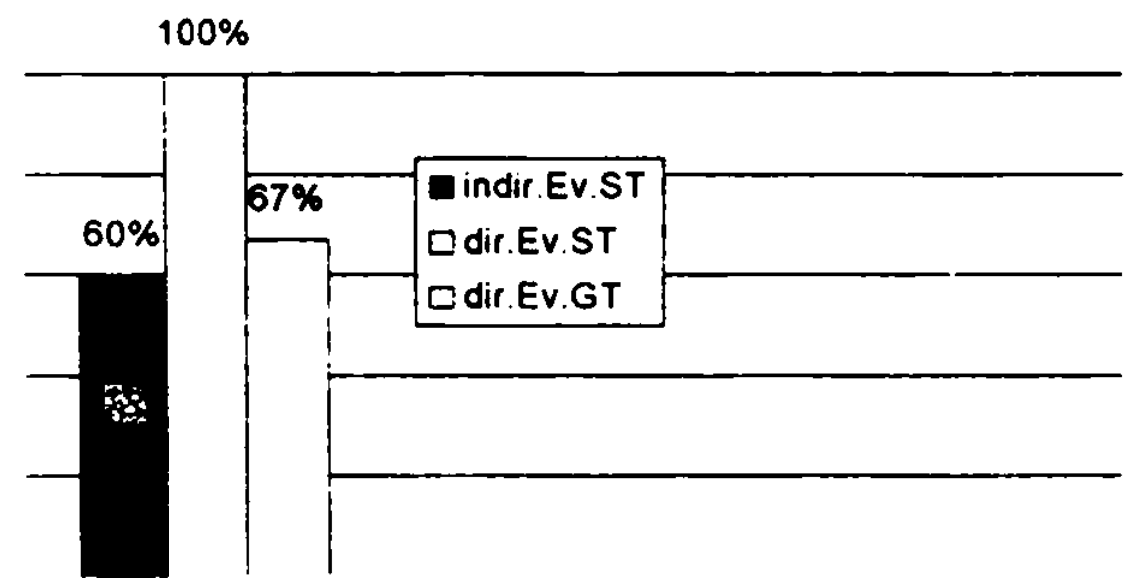

Kommentar: Vadi mi, když se ve sdẻlovacich prosttedcich piše, di mluvi nespisovnè. Alespoǹ nékde by se méla spisovná forma uživat. I jả osobnè mluvim doma a mezi práteli nespisovné, ale psát by se mèlo správnè. Tato anketa mi pripadả velice správná. Libi se mi i obçasné diktáty pana Svêráka v televizi.

\section{Bauingenieurin, 39 Jahre}

Sprachverhalten, formelle situation:

('o rikkàte zuyšováni cen v Ceské republice?

- No, zvyšovảni cen $v$ Ceské republice je hrozný. Możná by bylo dobłe, kdyby se $k$ tomu zvyšovaly i platy.

Dotyika se vás to silne osobne?

- Ano, velmi se me to dotýká. Byla bych radši, kdyby ceny zủstávaly a platy rostly.

A myslite. $\dot{x}$ je 10 vlivem mimulé politiky nebo sonciasné?

- Do politiky já se plist nebudu.

A co tikáte zyyšoväni telefommich poplatk u??

- No, telefonni poplatky, ty se zvyšujou teda hroznè. Jả si pamatuju, když jsem ležela dlouho $\checkmark$ posteli a dlouho telefonovala. Dneska bohużel telefonuji krátce a zanedbávám své prátele. Už jenom základni poplatek je drahej

I' pracujele na irade. Jak je tam placemá práce?

- No, práce je placená celkem slušnc, akorát je práce moc.

A je moǹie z tohoto plat" "żivit rodim!?

- Samozrejme, že možný to je. Nejen, že je to možný, ale je to i nutný.

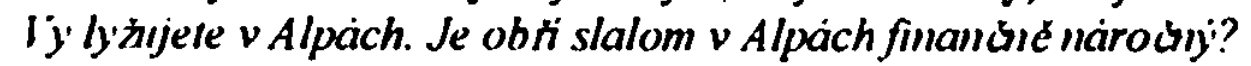

- Ne, neni - neni finančnè náročný. Samozłejmé jednou za rok si takový vỷlet múżeme dovolit a lyžováni je tam ve srovnáni s našima horama nesrovnatelnè lepši. Podminky, úroveñ, volný vleky, upravený sjezdovky.

A zpaiky' $k$ ien cenam. Co treba ceny potrai'in?

- Samozrejmé je výhodný jet do supermarketu a nakoupit na delši dobu. Jet tam jednou za ittrnáct dnú. udélat velký nảkup a pak $s \underline{m m}$ hospodarit a dokupovat jen vẻci potłebný $k$ dennimu ỉivotu. 
Sprachverhalten:

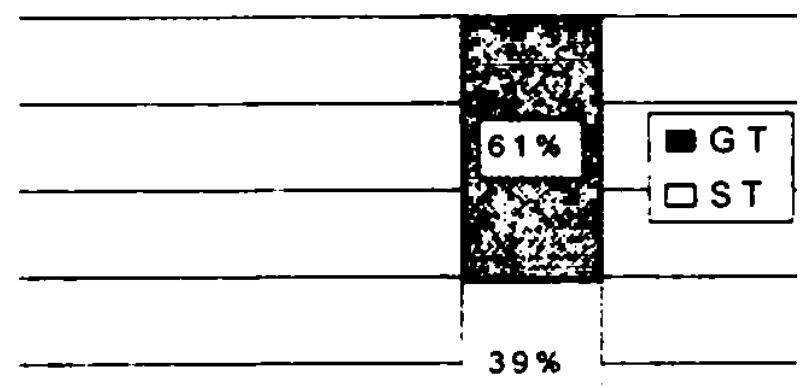

form ell

Einstellung, kognitives Subsystem:

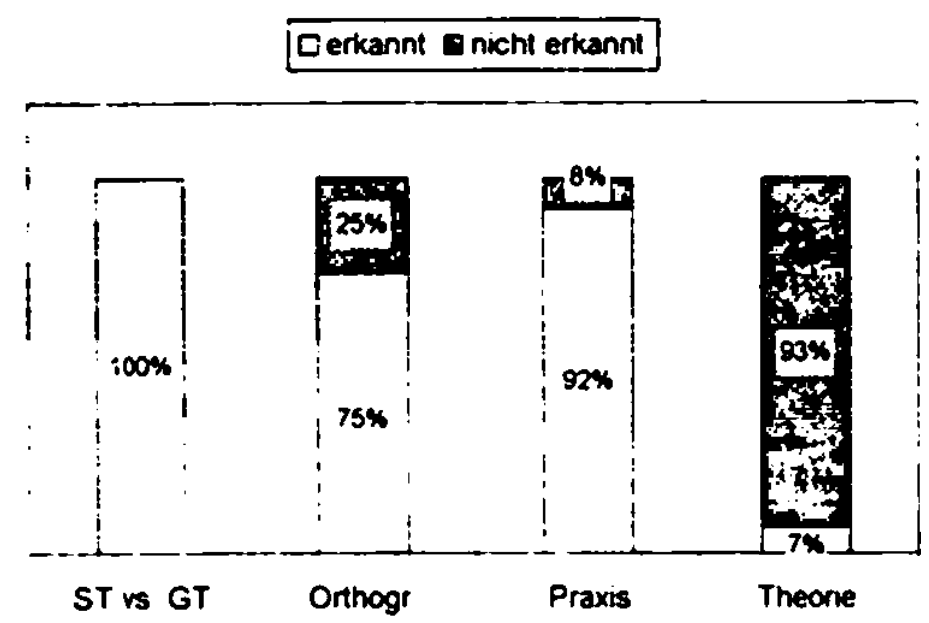

Einstellung, konatives Subsystem.

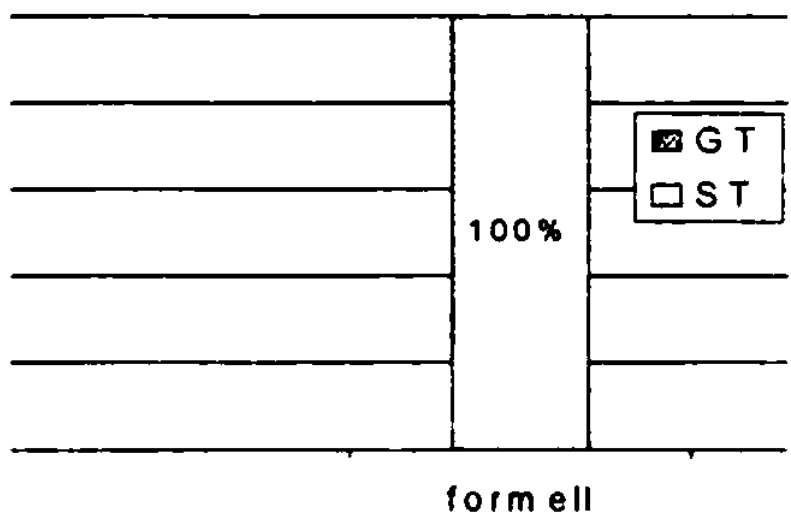

Evaluation der eigenen Kognition:

Einstellung, affektives Subsystem: Grad der positiven Einstellung

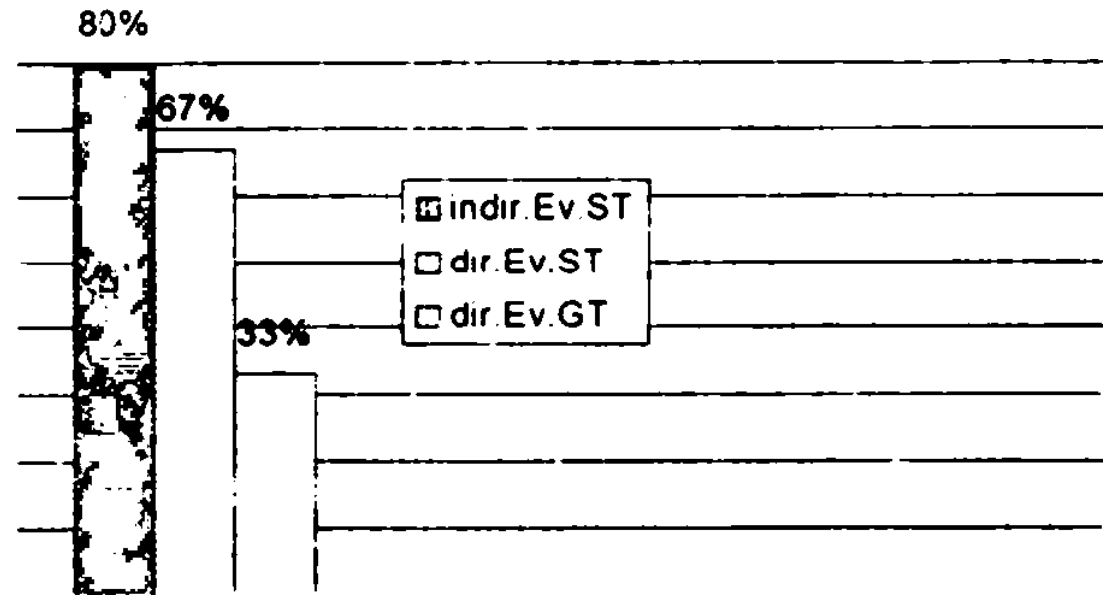

Kommentar Predevšim ve sdèlovacich prostredcich by mêli hovorit spisovné. Nápadné je to napri pri čteni éisel „sto trii body, sto trí bodü“ 107

"Es ist niclı ganz. klar. " as dic Informantin mu den rormen der Zalılenangaben meıu. Beide Formen

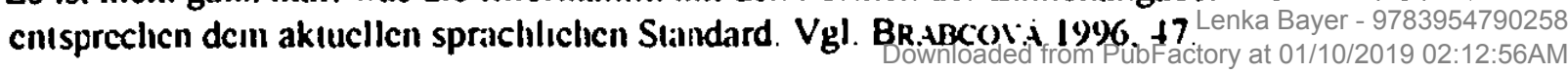




\subsection{Mämmer ohne Abitur}

Alter der Respondenten: 37 bis 49 Jahre, insg. 6 Aufnahmen

\section{Installateur, 37 Jahre}

Sprachverhalten, informelle Simation: Gespräch mit einem Freund (Verleger örtlicher Zeitung mit Abitur) in einer Bierkneipe

(Jaky máte názor na zvyšováni cen v Ceské republice? Tak pänové, co rikáte zvyšováni cen v Ceské republice?)

- Stoji to za hovno. Co mam na to tict jinýho, no.

(A cena piva?)

- Když jsme taky vývozci, tak bysme to méli mit levnéjsi, ne.

(A ceny vsmpenek?)

- No, tak to už je úplnè $v$ pytli, to už nemá cenu mluvit. To na tom jsou hlavné škodný ty dủchodci. ne. Protože ty byli celej zivot zvykli chodit treba na sport a ted' jim to zvedli tak, že si nemúžou dovolit na každej zápas chodit, protože $z$ toho malýho dủchodu na to nemaj, prostę. Mysliš. zo to je neim triny $k$ plat im?)

- Samozłejme. jasný.

(A myslis, zu je to vinou politiku?)

- To je hotový.

(A co treba ceny benzimu?)

- No, je to bezvadný. Zase to zdražili, jsem koukal, vo korunu vosmdesát až vo dvè dvacet. Jestli to takhle pude dál, tak budeme chodit pessky, aspoñ my normálni lidi. Ty nahớe, têm je to jedno, že jo.

$n^{\circ}$ Cine se jezdi na bicyklech.)

- V Ciné je v Cinê, ale tady se bicykly kradou. Tady si kolo nechảš u hospody a máš ho v pytli.

I kdyż bylo privázaný.

(S hidou stoupa kriminalita.)

- No, to dá rozum, taky. A kór u nás tady. V posledni dobẻ je to hrozný

(A policii nevertis??)

- Vủbec, v żádnym pripadè. Jsou to šmejdi. (...)

(Staci te plat na noje osobni požitky?)

- Nestači, protuže jả jsem na podpoře, já nedélam. No, mam Havaj. No nedxllam, no. Ted' zaìnu délat, ted' vod prišstiho tejdne.

(A chodis na melouchy?)

- A já ne. já jsem línej. Já radši chodim na ryby.

( $A$ = ixho żjes??)

- No, nevim, no. Vobčas si ňảkou korunu vydêlam nẻkde. no.

Mühu (i zaplatit jedno pivo?)

- Tŕeba deset. To se zlobit nebudu. 
Sprachverhalten:

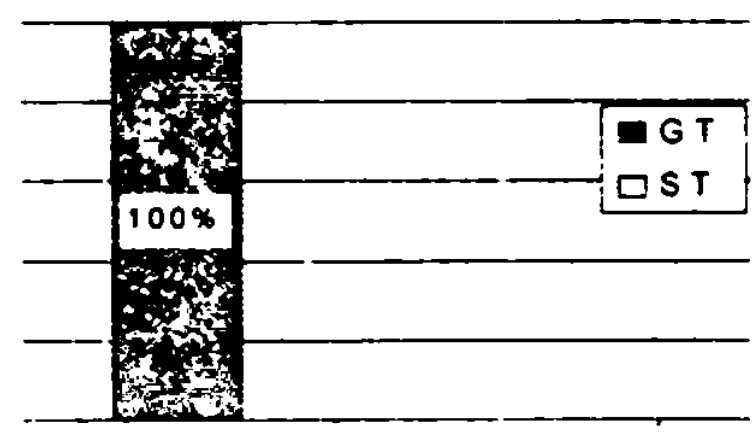

in form ell
Einstellung, konatives Subsystem:

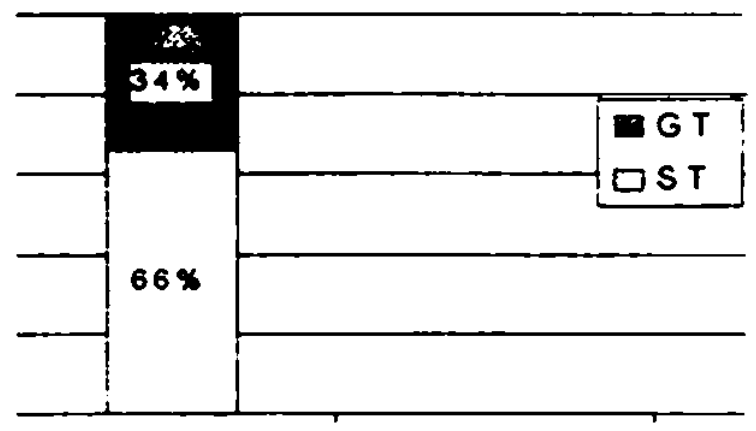

in form ell

Einstellung kognitives Subsystem:

Evaluation der eigenen Kognition

Cerkannt Is nucht erkannt
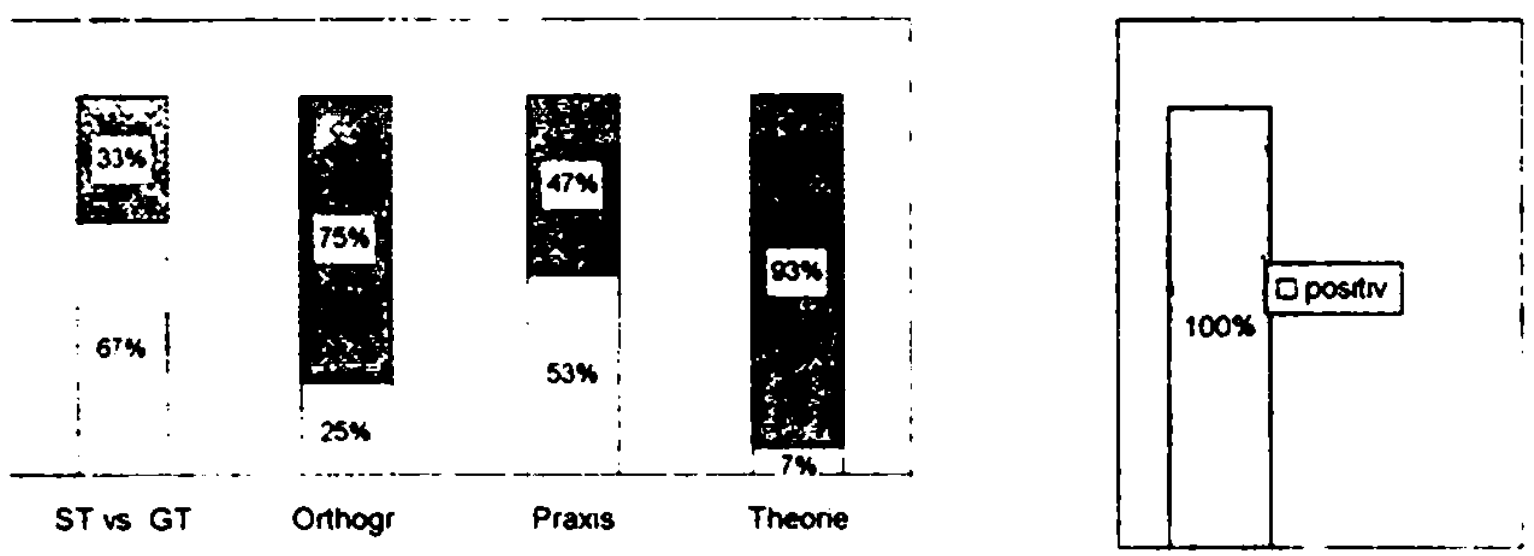

Einstellung, affektives Subsystem. Grad der positiven Einstellung

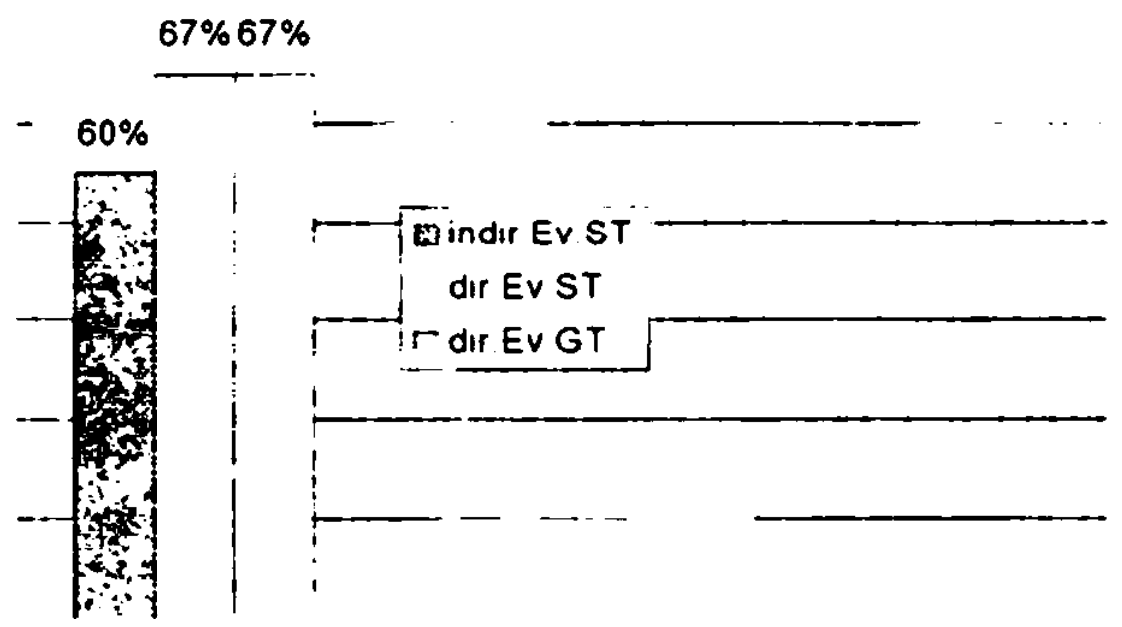

Kommentar Pripada mi to jako test na výzkum cešstiny Ćloveck si aspoñ oživi a ovčìi své védomosti $z$ cieskèho jazyka. 


\section{Elektriker, 41 Jahre}

Sprachverhalten, formelle Situarion: am Arbeitsplatz des Respondenten Co rikáre syyšováni cen $v$ Ceské republice?

- No, vúbec se mi to nelibi. Jako nevim teda, jestli to pude dál, tak hodne lidi bude nespokojenejch. No, hlavně têch, co člověk nejvic použjvá - potravin. At si je dražši to, co člověk potrebuje jednou za deset let, ale ne takový ty běžný věci, aby nešli furt nahón, že jo. A co treba ceny nájmú a ceny telefonư?

- To je taky dủležitý, ano. Tyhlety dvě, ceny jidla a ceny näjmú.

A jako majitel auta? To se vás taky dotyká. zvỷseni cen kolem auta?

- No, tak jả auto teda vlastnim, jo, ale na mym starym auté už jako, nevim, no. Mêly by bejt levnejjši, ale pochybuju, že budou levnèjši.

Màre financine narociniho konicka? Co 10 je?

- Mám. lludba, hudba.

A projevuje se. ż stoupa marka a dolar ke korumé i na cend, tízba cédéciek nebo kazet?

- Ano, projevuje a dost silné. Ted' treba stoupla zase vo takovejch tricet procent.

Ale sajem neupadá?

- No, zajjem neupadà, ale musim se (...) nẻkde jinde no, kor na tom jidle, no.

A iste spokojen se svymi platovymi podminkami?

- No, melo by to bejt lepši.

l.epsi poxdminky platové nebo pracovni?

- No, tak platový.

A múzete si tícba dovolit dovolenou na Mallorce?

- Ne, v żádnym pripadé.

Sprachverhalten:

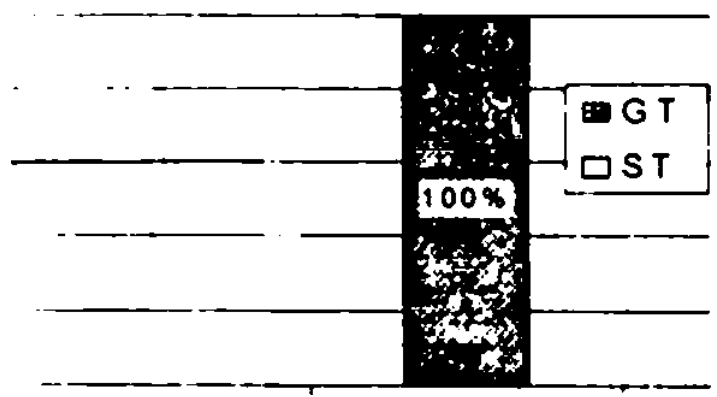

form ell

Einstellung, kognitives Subsystem:

Gerkannt I nucht erkannt

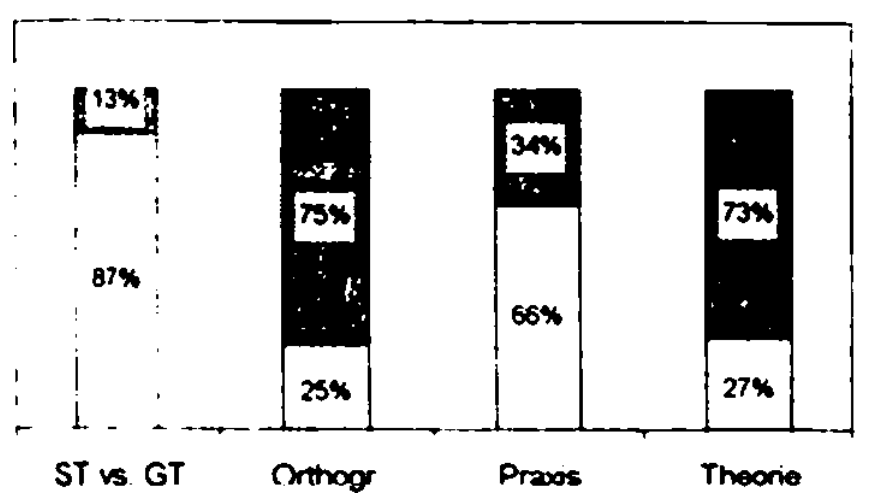

Einstellung, konatives Subsystem:

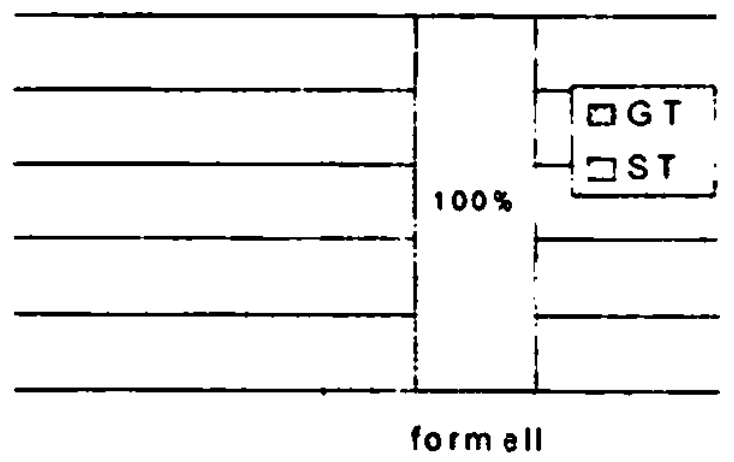

Evaluation der eigenen Kognition:

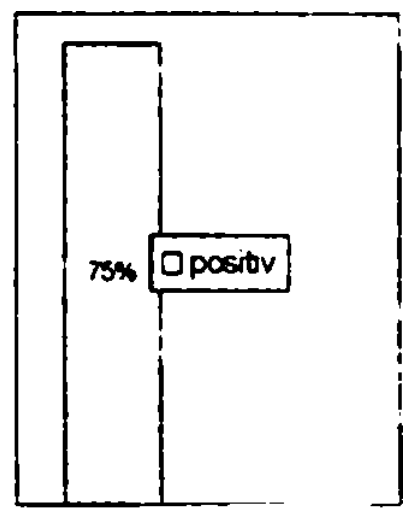

Lenka Bayer - 9783954790258 
Einstellung, affektives Subsystem: Grad der positiven Einstellung

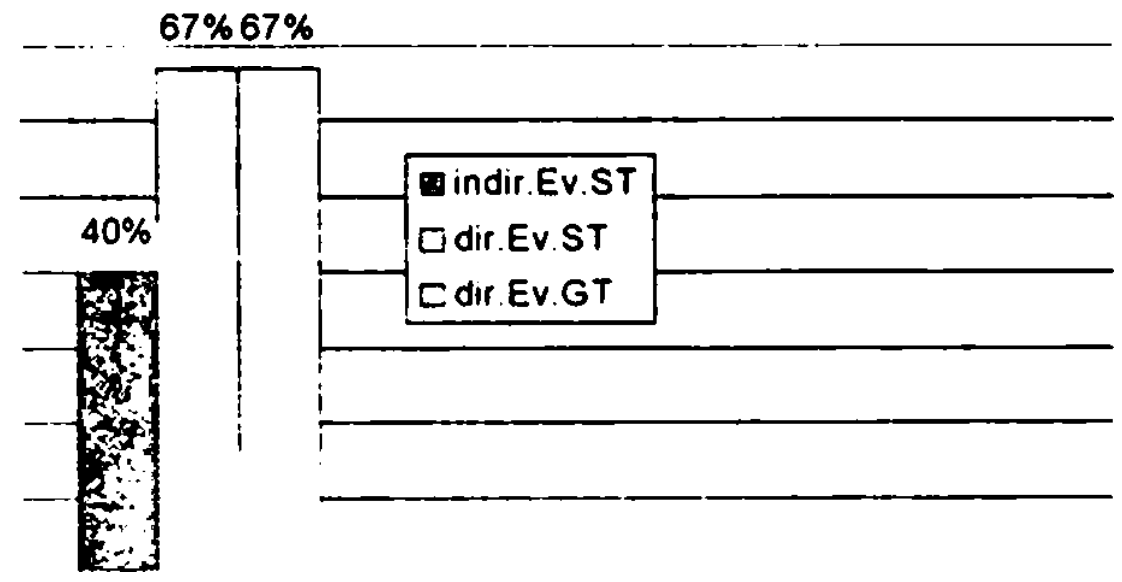

Kommentar. Ještč że to neni moc složitý. Dobrý češtinč zdar ${ }^{107}$.

\section{Reinigungskraft, selbständig, 43 Jahre}

Sprachurhalten. formelle Sirnalion: Gespräch in einer Gaststätte

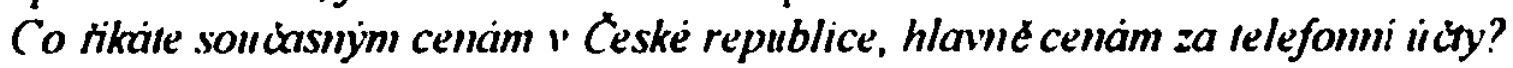

- No, jsem na to nasranej - a pékné teda. jo. Protože jsem podnikatel a já musim teda natahovat taky ceny, abych vübec uživil rodinu a moh zaplatit tydlety véci. Jelikož. telefon je vlastnè muij - moje živobyti.

liy mire relefolly dia?

- Ano, mam i mobil, no a ten je taky drahej. $Z$ toho radši nevolám

Ale jako poxtmikatel bez mobilu nemüxte prece fungovat?

- No. nemưžu fungovat, tak proto si to necham, aby lidi volali spiš mnê, než abych jà volal z mobilu lidem.

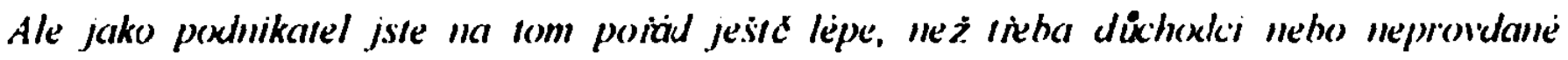
maminky s dami.

- No, teoreticky jo, ale prakticky vlastne je to nárazový povolani - todleto, to co délan já - to je takovej ten úklid. No, a to jsou taky hluchý messice, kdy jả vlastnè musin si našetrit na mésice - $z$ têch bohatejch mésicủ si musim našetrit na ty chudỷ mésice. abych moh žit

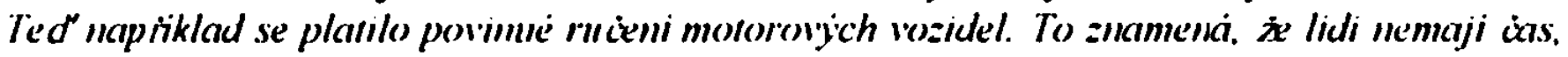
aby si sjedicivali zakazky; jo 10 rak?

- Ano, protože tydlety zakảzky se zacinaji sjednàvat až po zaplaceni dani a všech têhletêch akutnich složenek.

Ale jak je monie, ixe kedyri lide nemaji pe'nize, a presto json hospody plne. Na to maji, aby. iysedairah " pira?

- No, tak to nevim. Asi nčkde kradou, nebo co, ale prostč berou na to nẻkde, no. Musej na to nékde vzit. Vochudéj rodinu

A jakou roli hraji pujicks?

- Pủjçky, to jsem zásadné proti, protože potom jsou takový úroky, že to ċovck ani nemúže splatit

10"- Dic beiden fell gedruckicn Ausdricke wcisen gemeintschechische Endungen auf. die standardichechischen 
Ale velci podmikatele to "ccjak delat musi, protoxe jinak by všichni zkrachovali, a volnj' trh rady funguje.

- No jo, tak ty velký podnikatele jim to zase nesplácej, protože jsou tak silný v kramflekảch.

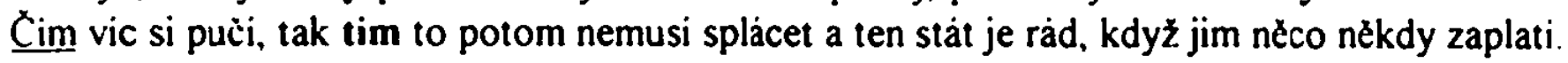
A jaky ' 'y máte rozpodet rodiny?

- No, rozpocet rodiny, to znamenà jenom složenky mnê vyjdou pres vosm tisic mêsičné. Plus jidlo a tohleto, tak je to kolem tý desitky, jedenactky.

To zlamena, the kdybyste byl nezamesmany, lak ani podpora v nezamesmanosti vám nestaci, abyste pokryl tyto rodinme naklacty?

- Ne, to by mnè nestaciilo. To bych musel jit krást nékam eštê.

A myslite si, ze talo situace vinikla vlivem politiky?

- Jo, to by tak mélo bejt, protože ty to rozkradli, no a ted'kon se to snažej zase nékde nahrabat a zase to je na nás malejch podnikatelich a na obycejnejch lidech, který to musej zaplatit.

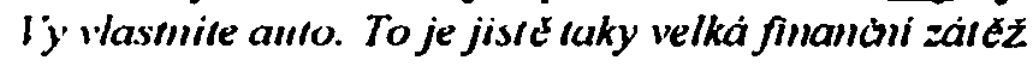

- No, ja bych bez auta bejt nemoh, proto mam sice starýho žigulika, kterej ešte jezdi. Držim ho silou vưle prí životé a na nový se asi nezmúžu, pakliže to takhle dál bude pokračovat.

Myslite si, ¿ź taky na této situaci má vliv priliv zahranianich pracovnich sil. To znamená I/krajincú l'ietmamcü Cinani a dalsich?

- No tak, vo Ciñanech ne, ty na mé jako vliv nemaj - na to moje podnikảni. Ale ty Ukrajinci a tydlety vyčủraný ćeský firmy jo. Ty mủžou jit pod cenu a protože tẻm Rusákủm dávaj pár haliťu a jà hold taky musim pod tu cenu, abych jả se vủbec uživil.

A taky ve raši cimmosti pocihujete konkurenoin boj?

- Snažim se vo to, snažim.

Sprachverhalten.

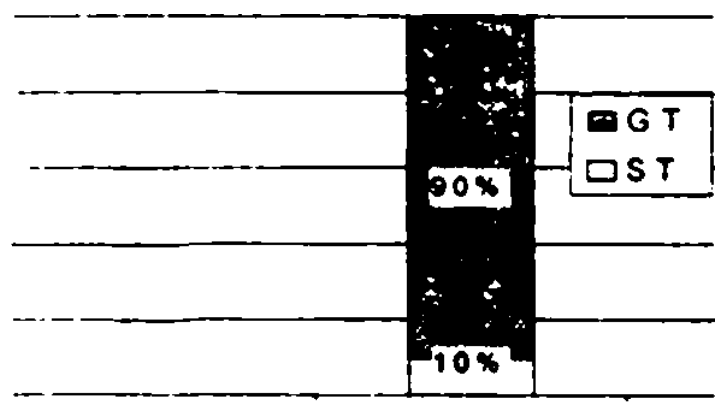

form ell

Finstellung, kognitives Subsystem:

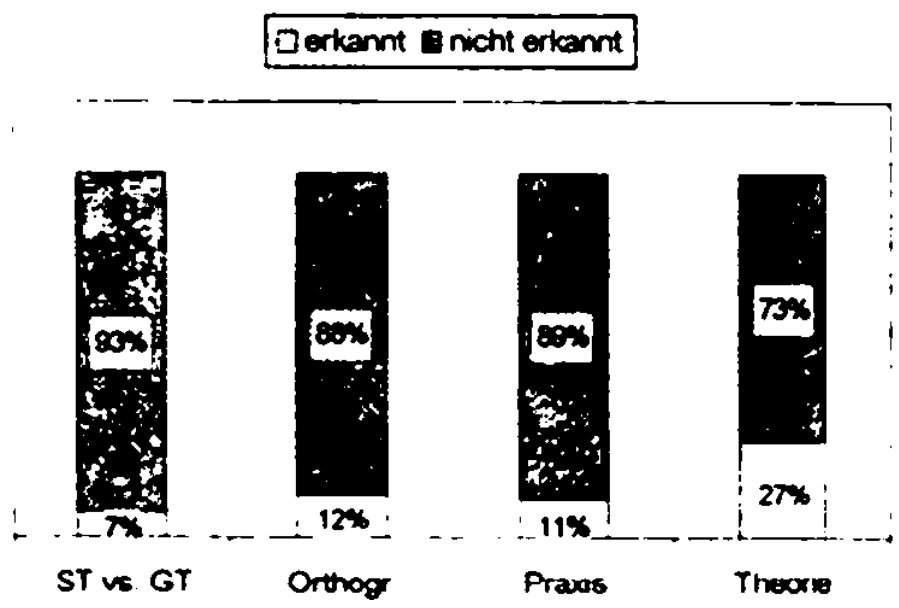

Einstellung, konatives Subsystem:

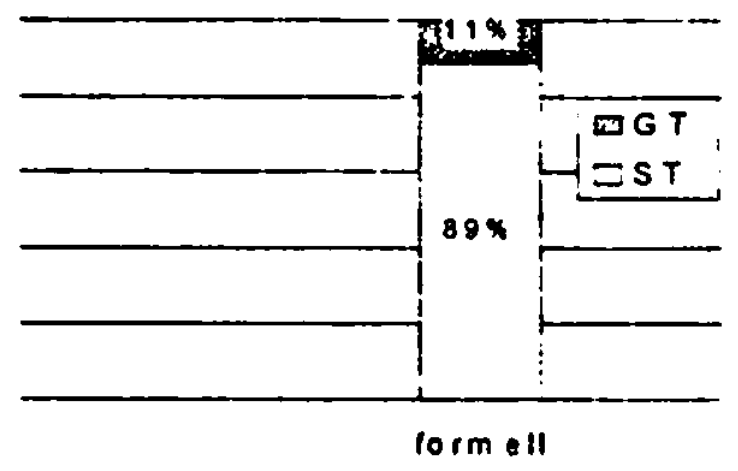

Evaluation der eigenen Kognition: 
Einstellung, affektives Subsystem: Grad der positiven Einstellung

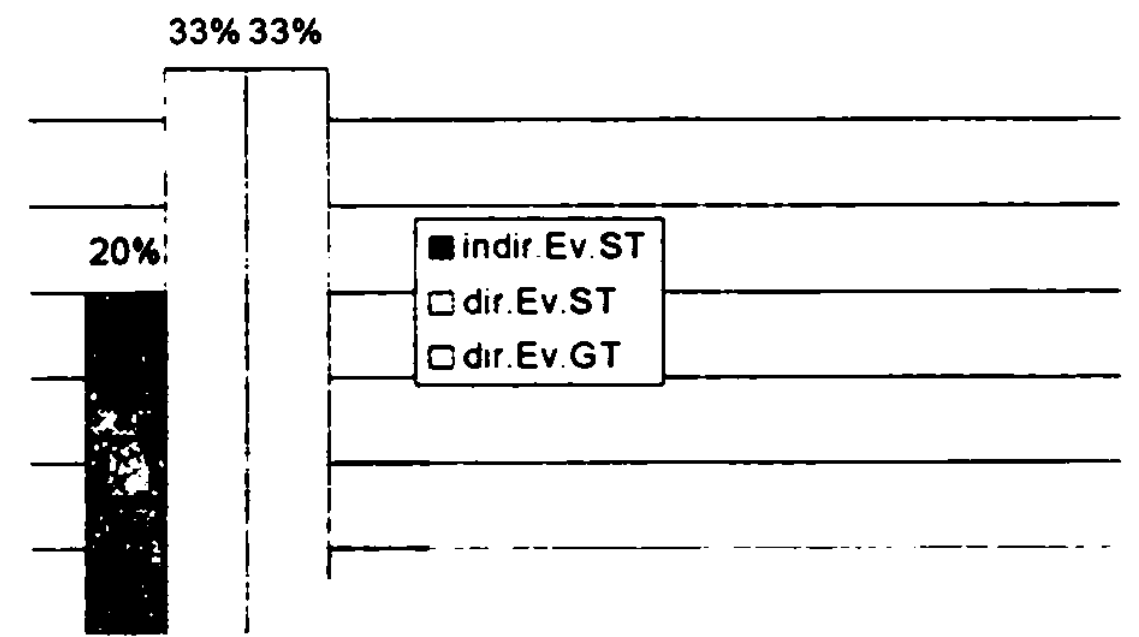

Kummentar: Anketa se me libi a doufäm, že têchto anket bude vic ${ }^{108}$.

\section{Wächter, 45 Jahre}

Sprachvirhalien, formelle Simation: Gesprach auf der Straße

Co rikäre zuyšováni cen y Ceské republice, napriklad zyysováni cen za relefon a tak dále?

- No tak, pro mê $v$ dnešni situaci už je to úplnẽ neúnosný, protoże jả si myslim, že prímèrnej člověk, kterej neni aspoń pripraven na todleto, že by mêl ñákou zálohu nebo ñákej kapităl, tak se to nedà prostê z dnešniho platu udržet, vủbec. Takže, myslim, že todlento se jako tý vládż néjak moc nepovedlo.

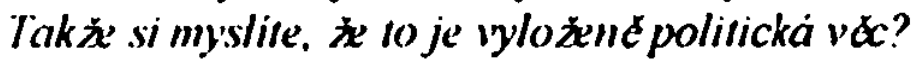

- No, myslim, že politická, protože driv to bylo všechno daleko levnęjši, ale zase jsme se neméli tak, nebyli jsme tak volný, jako jsme dneska, že jo, ale už to jako precházi. Mné to pripadà, i.e to precházi jako nékam tam, kde to bylo a bojim se, aby se to nezvrtlo zpátky.

Myslite. ze pexdstandardmi pr um tr ob cana je zméren opravdu vykonanon praci?

- To určité ne, protože znam priklady, kde by méli mit lidi daleko vic, že jo. který bojujou vo żivot. Ale na druhou stranu jsou tady špičky, který jsou za vodou a vlastne nemusej dêlat vủbec nic. To je pràvê ten paradox, že, kdyż má èlověk penize, tak vlastnẻ nemusi dêlat nic.

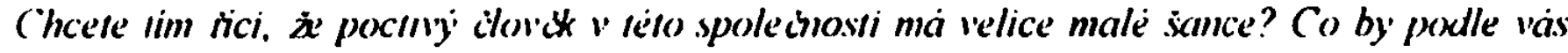
$m c^{2} d c^{2}(a r$ ?

- Pokud má możnosti a je na to psychicky a nčjak fyzicky disponovanej, tak myslim. že neni problem jako se do toho angažovat a prosté se vervat do toho kolotoċe, ale jsou lidi, který na to nemaj, jak psychicky, tak fyzicky.

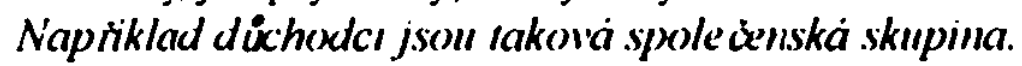

- No jistẽ, tam už jako ty dủchodci uż vlastnê nemúžou, pokud neziskali nčjakej kapitàl dopredu a nemủżou investovat a nemủżou podnikat, tak vlastné nemaj vủbec jảdnou šanci a mủžou skonciit tak jako jiný, který nemaj vủbec žádný penize.

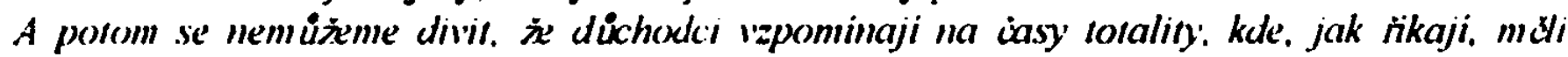
isechmo.

- No, tak zase bych to asi rek tak, že ty dủchodci vlastnê, vlastnè ty už to nęjak se snažej jako preżit. jo. Tady jde vo to, jesli mysli, jesli mysli eštẻ na svoji rodinu nebo nemysli na svoji

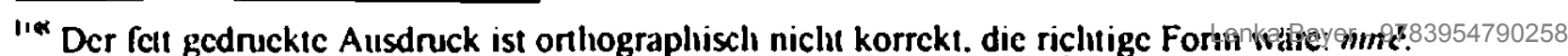


rodinu, na svoje potomky. Takže, jesli treba si predstavi, že jejich vnuci $v$ budoucnu se budou mit daleko lip, tak treba to podpor̀i. A zase dủchodci, kterii si mysli, že nemaji žádnou šanci, tak to vlastne hazi za hlavu, no.

A myslite, ž soucasmy' z̈ior stoji pouze na pentrich?

- No tak, na penézich - takhle, co se týče mè, tak na penézich stoji. Ale jinak si myslim, že, nevim, možnà. že by tam mèlo bejt eště nẻco jinýho kromè tẻch penèz

Myslite tim sdravi nebo mezilidske vatahy?

- No, tak to určitě, no. Vono, ta euforie, co byla $v$ tom devětavosmdesátym, tak nějak cástećné vopadala, vopadala. A ted' je problèm $v$ tom, jestli se náhodou vlastnê $-v$ tý vlàdé jestli nejsou ty, co tam byli. Protože se to zase podle mé se to ñák vraci $k$ tomu, co tam bylo.

\section{Sprachverhalten:}

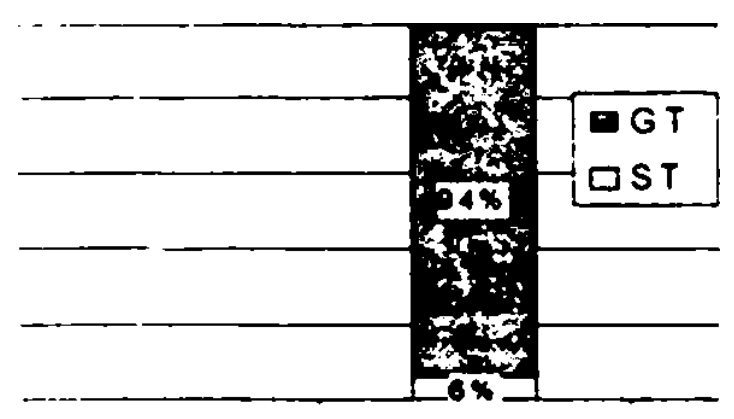

form ell

Einstellung, kognitives Subsystem:

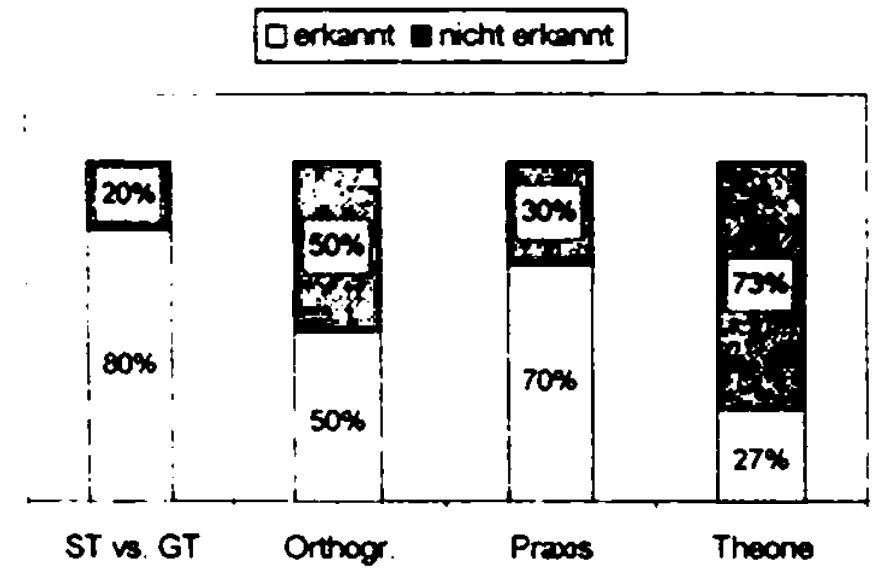

Einstellung, konatives Subsystem:

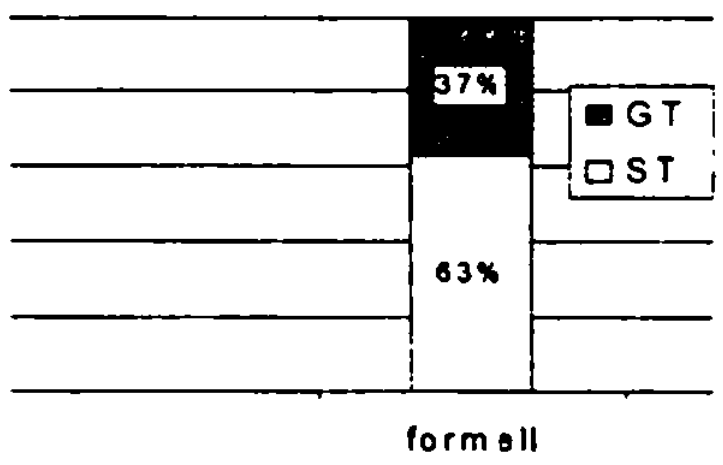

Evaluation der eigenen Kognition:

Einstellung, affektives Subsystem: Grad der positiven Einstellung

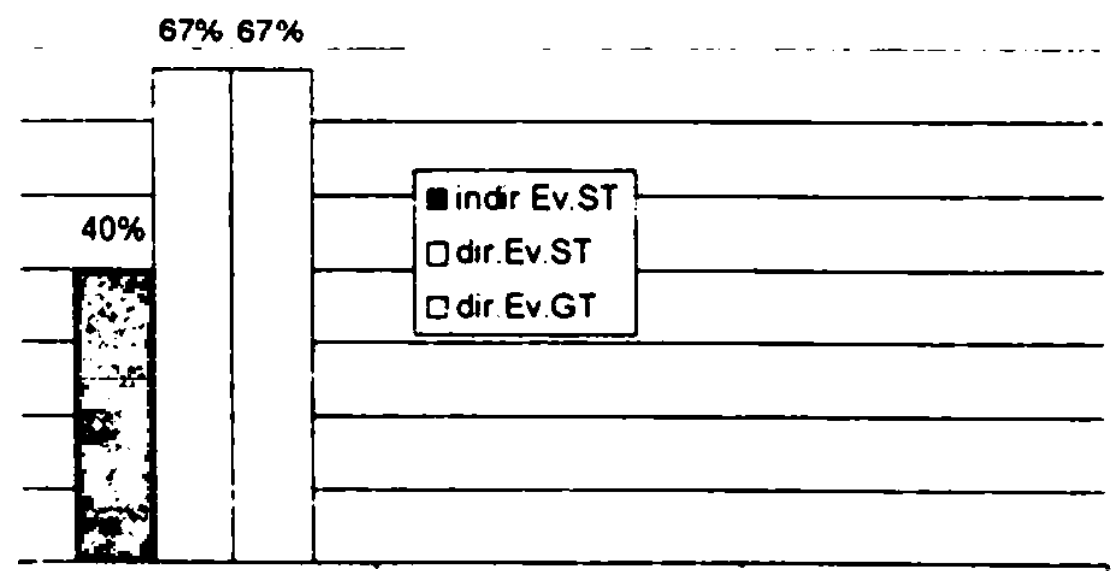

Kommentar Myslim si, že pro obyčejnèho, prümérné vzdẻlaneho clověka se anketa zda bỳt sbyteiná, protože lidé stejnê nezac̀nou mluvit jinak, než dosud. 


\section{Einsteller, 48 Jahre}

Sprachverhalten, informelle Simation: Gespräch mit einem Freund (Verleger der örlichen Zeitung mit Abitur) in einer Bierkneipe

(Zuyssili cenly' piva.)

- At mi vyližou prdel, vole.

(Pockej, to je trochu neshusiny. $2 x$ jo?)

- Tady más ten listek a to pivo zaplat. Że brácha rikal: „To se tam vožerete jako dobytkove.“ Hovno, je to jenom 130 korun.

(Dej si cigaro a bude ic hmed lip.)

- Kdyż. se špatné dejchá. tak si zapảliš jednu Marsku a už to jde lip. Fernet a rum jsou taky medikamenty. Na každýho to pủsobi jinak. Nêkdo si dá dva panáky, nčkdo jich dá deset a je to $v$ pohode a nékdo se po jednom svali. Už jsme dlouho nevidelli ..., ty vole. (...) Já mu dam pres držku, ty vole. Co von ty pneumatiky, že si pro né prïjde, vid’. Jsme se dohodli a von se vuibec nestavil, ty vole.

(Mci asi vostrou manxzlku, klerá má pízdivku ..(ieneräl".)

- Tu ma vostrou, to jo Zakaz vychazek dostal, no. (...)

(Pive cko po práci, 10 jo.)

- Mủze bejt - jedno, dvê - domủ. S „Pid'alkou“ ven a nakoupime a ...

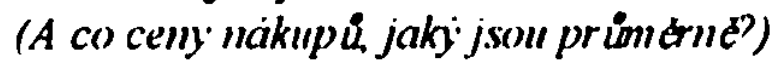

- Parádni, paradni jsou. No, furt to eštê jde, no. To viš, neni to, jako to bylo driv, ale s tim se covêk musi ňàk smiřit

(To se upplati nakupoval i supermarkelech, $\ddot{x}$ jo?)

- To jo. To nákup tỉeba na celej mésic, to se vyplati no, ale takový ty denni, abys tam jel pro pro chleba. To se nevyplati, to koupiš tady, vid'. To tam nepojedu, vole. To je drahý jak (A jakej hyl letos.leñisek?. Jakej hyl letos?)

- Dobrej. letos byl dobrej Letos byl parádni Ježišek - náhodou To. co bylo potreba. no

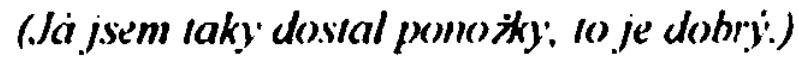

- Ponožky, slipy a takový voloviny, viđ, to jako jo, no Nadélili video, jsme si nadélili, protože jsme ho doted'ka nemêli. Nêkdo už má pátý, šestý, ty vole, tak my jsme si nadélili pruni, no, abych rek pravdu.

(lak te nahraicile.)

- No, déti hlavné, vid' Holka má vodpoledni nebo manželka má vodpoledni, vid', tak ňáký filmy si nahrajou takhle a to, vid'.

Sprachverhalten

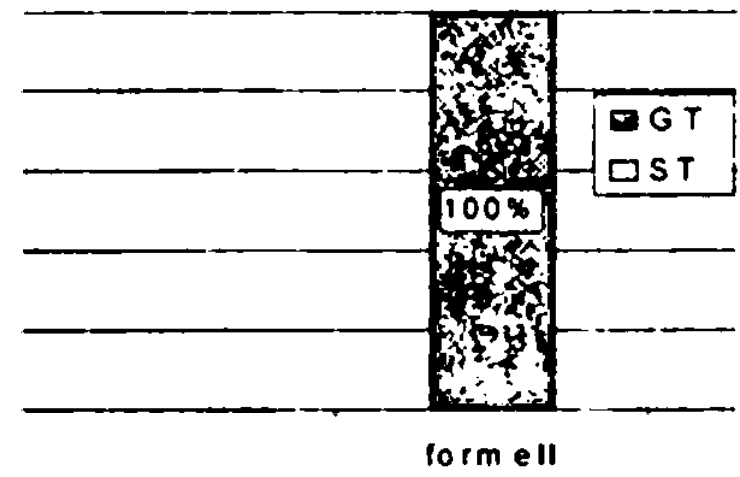

Einstellung, konatives Subsystem

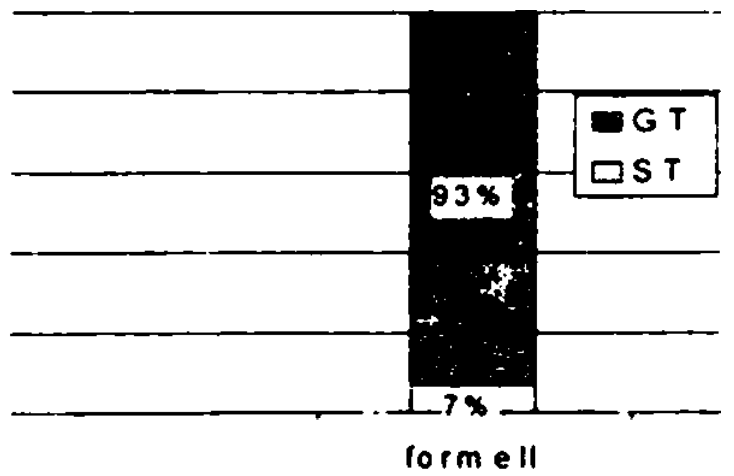




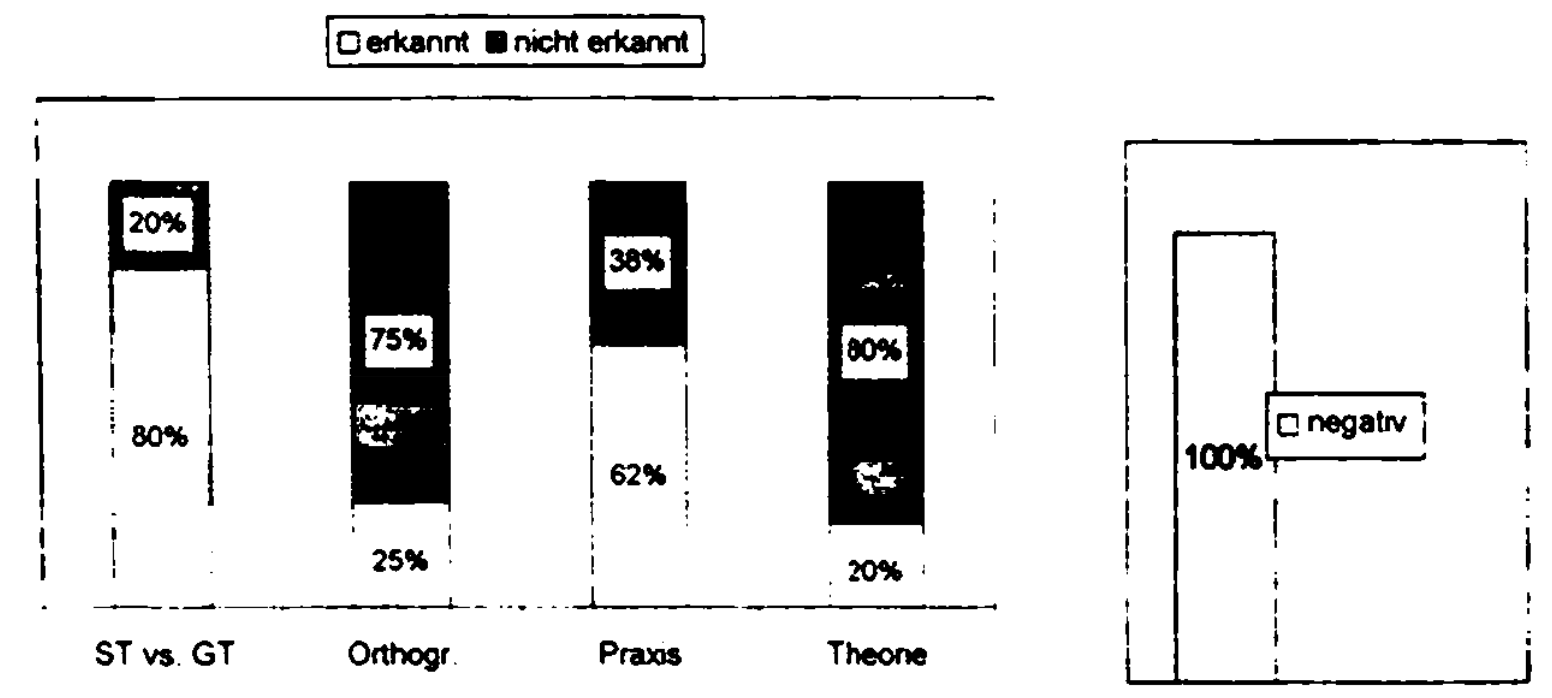

Einstellung, affektives Subsystem: Grad der positiven Einstellung

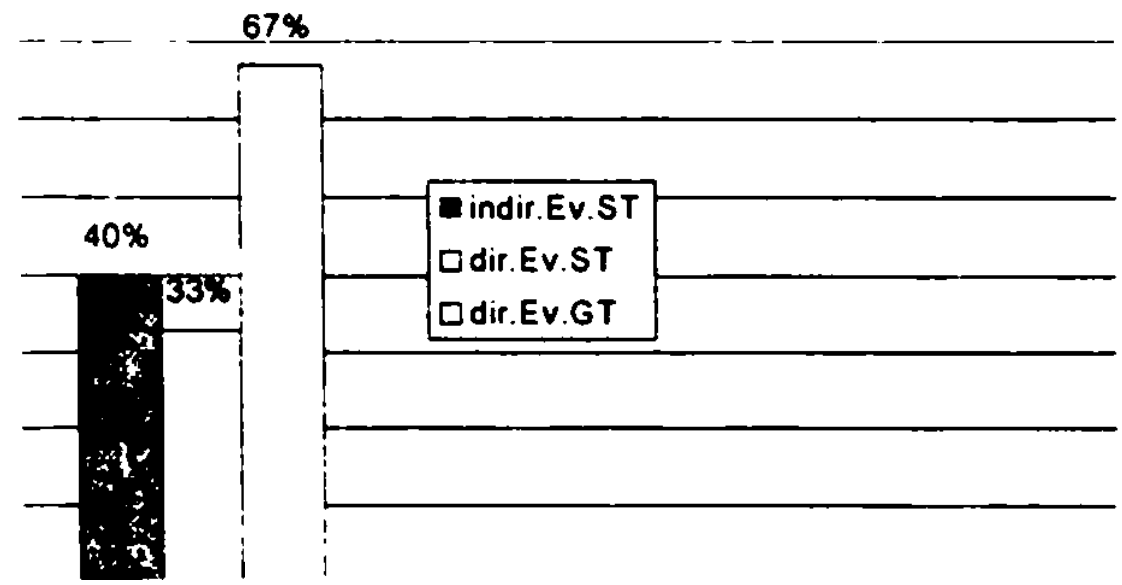

Kommentar Pripadá mi to jako test nebo hra na zkoumáni svèho IQ

\section{Landwirt, selbständig, 49 Jahre}

Sprachverhallen. formelle Sirmation: Gespräch in einer Gaststätte Co rikcile somiasniemu zyysovaini cen v Ceské republice?

- (...) Tak se sem treba dováži konkretné z Polska za ityry koruny kilo a tady se realizuje vod patnácti do pètadvaceti konun pro spotrebitele.

A co ceny' vimych oblastech? Jak se projevije zuysováni cen i mimo zemdidsni?

- No. mimo zemédêlstvi to dẻlá tercièrni sféra, která si sama diktuje svoje ceny. To znamená velkoobchod a supermarkety nebo hypermarkety. To znamená, že hypermarkety nariději našim zpracovatelüm. který berou vod našich prvovyrobcú, urcitou cenu. A jelikoż to voni berou dotovaný suroviny nebo dotovaný výrobky, hotový pochopitelnž, takže se stává. że sem jde výrobek tieba s osmdesátiprocentni dotaci, který se projevuje tim stylem. že my to nemúżeme $\checkmark$ žádnym pripadé - jako náš prủmysl a - zachránit. Protoże od státu jak prvovýrobce, tak zpracovatel dostává minimálni dotaci nebo vübec żádnou.

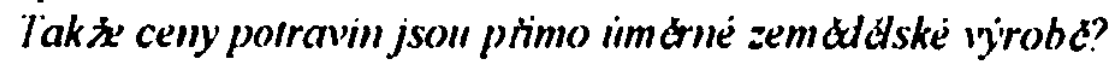

- No, nejsou. $V$ żádnym pripadẻ. Nemúžou bejt úmérný, protože vstupy, to znamená pohonný hmoty, herbicidy a veškery chemikálie a hnojiva a ceny strojủ jsou na svečtoyym 
svêtovejch cenảch. To znamená, že $\mathbf{v}$ žádnym pripadẻ nemủže se náš zemědělec rovnat bez evropskejch dotaci současnýmu trendu, kterej tady je.

Takž Evropská unie bude mit v budoucmu vliv na ceny nasich potravin?

- V každym pripadê, protože voni maj silnčjši hospodářský potenciäl

Także smčrem nahoru?

- Ne, naopak. protože voni maji silnou ekonomiku a s tou ekonomikou si múžou dovolit silný dotace. A ve svêtovym méritku je to nemožný.

A myslite si. ž na ceny má také vliv naše politika?

- Pochopitelně, pochopitelně, když tam seď̉li nebo sedêj a nic nedělaji nebo dêlaj minimálnè naši politici - a udẻlaj takový smlouvy s EU, který jsou naprosto nevyvážený a neracionálni

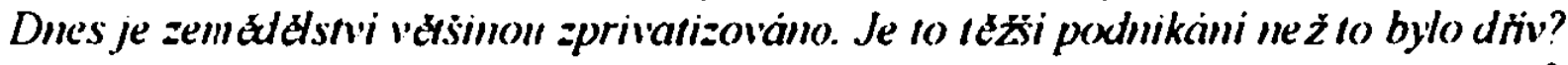

- No, pochopitelné, že to je těžši ted", protože tady jsou - tady je nékolik subjektủ. Tady jsou bejvalý JZD, dneska ZD Jsou tady akciový spolecinosti. Jsou tady soukromnici, jako jednotlivci, no a pochopitelnê, ל̌e tam určitý - takhle startovaci ėăru nemêl nikdo stejuej Nêkdo mêl nadhodnocenej, nêkdo podhodnocenej. Totiž tam jsou rủzný vỷkyvy a smèry. A za druhý byl zajišténej za bejvalehho režimu odbyt dycky. I když se to mẻlo hodit tłeba, ja nevim, prasatủm. Suchý mliko, konkrètné.

Projevinje se zvyiseni telefomich poplatkú take v zematdstvi?

- Pochopitelné. To je komunikaćni pristroj, ne, jako každej ... No tak pochopitelnè se to projevuje, no ale bohužel ten zemédělec si nemúže třeba dovolit internet.

A jako zemciddec si jiste odbirále odbormy lisk. A tam se ty ceny taky projevily.

- No ano, pochopitelné. To je celý trend, $v$ celym hospodàìstvi.

$A$ znisila se krimimalita $v$ zemaddstri?

- No, to tėżko rict. Ale pochopitelné jako $v$ celym národnim hospodàrstvi, tak ta kriminalita asi stoupla, i kdyż. byla za minulýho reţimu takzvané skrytà. To znamená, že kdyż. tłeba, já nevim, pan nebo soudruh predseda JZD nicco to, tak byl dobry stranik, tak mu to na okrese zaretušovali. A dostal treba vêtši dotace. Protože treba nesklidil cibuli, vona mu, já nevim. treba pomrzla, nebo pomrzlo mu néco, tak se to naak takhle ututlalo a skrylo. To byl jinej ale smèr kriminality než dnešni Dneska se prostč. jede se do šedý ekonomiky, jak se to dneska rikà. To je nemčřitelný

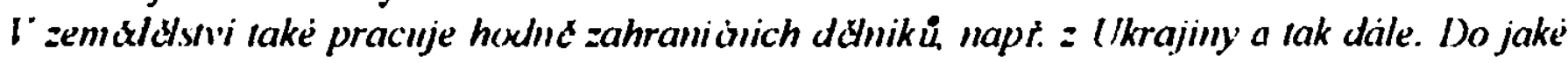
miry je to iyhodme?

- No, pakliže je prihlášenej. tak pracuje. Musi bejt pochopitelnê přihlášenej - ten dotyìnej dẻınik nebo dêlnice. No, a protože to je rảana složka této spoleìnosti i minoritni složky, který nemaji vzdéláni a nemaji, já nevim, nic - jenom ty ruce. Tak nemaj vo to zajem, tak musi brát to, coje.

Sprachverhalten:

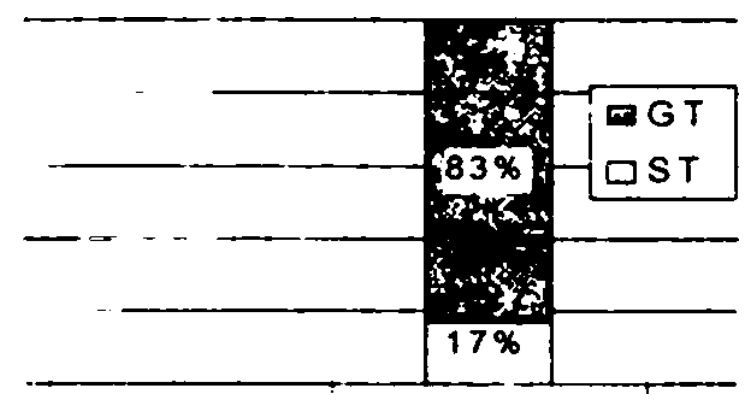

form ell
Einstellung, konatives Subsystem:

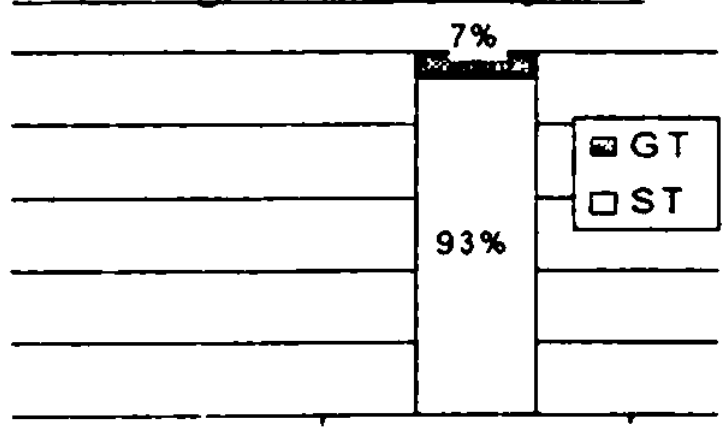

form ell 
Einstellung kognitives Subsystem:

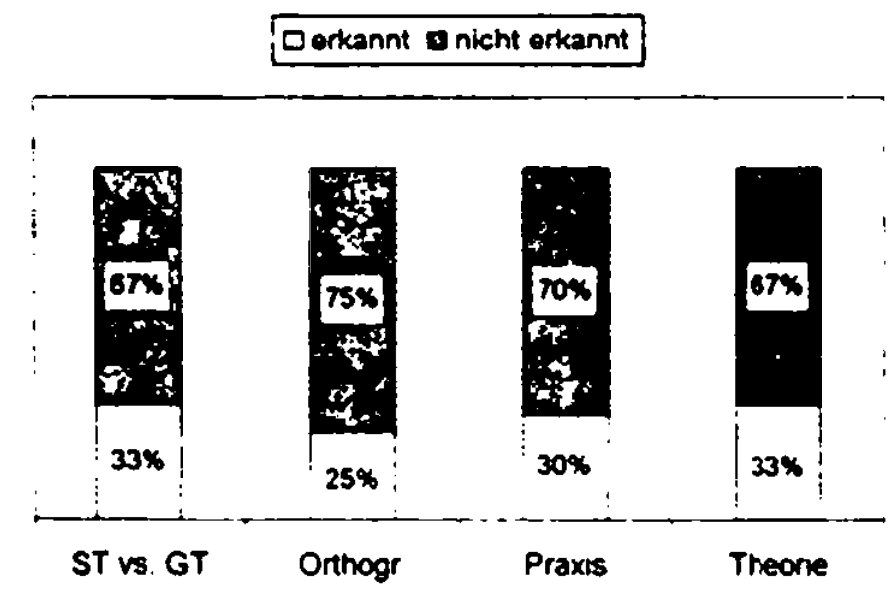

Evaluation der eigenen Kognition:

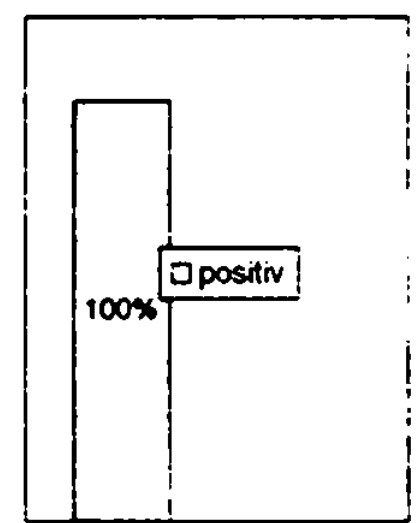

Einstellung, affektives Subsystem: Grad der positiven Einstellung

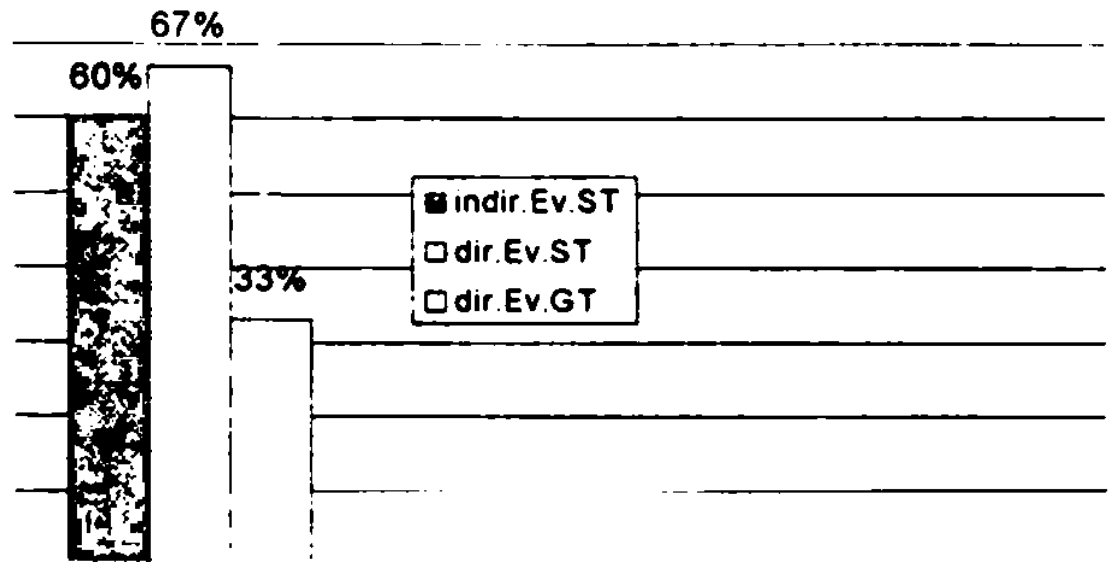

Kommentar: ohne Kommentar

\subsubsection{Mämmer mit Abitur}

Alter der Respondenten: 33 bis 67 Jahre, insg. 5 Aufnahmen

\section{Ober im Restaurant, 33 Jahre}

Sprachverhalıen. formelle Situation: Gespräch am Arbeitsplatz des Respondenten

Co rikäte zuysonaini cen v Ceské republice?

- Zvyšováni cen je neúmêrné $k$ vỷši platu. Na výši platu se všechno zdražuje strašnes moc Je o vás znamo, ix jste aktivmi sportovec. Jak se to projevuje ve sporm?

- Projevuje se to na vỷši nakupováni jako materialu, kopaček napriklad, dresủ. Pro ty menši

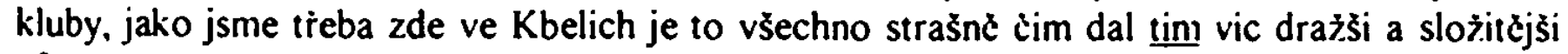
vübec udržet klub finančne $v$ cinnosti.

A lleni mosice hrá v kopackach domáci viroby?

- Ale je możne hrát v kopačkách domáci výroby, ale ty uż se dostaly skoro na stejne ceny jako jsou zahranični kvalitni vyrobky.

Ale ve kralite musi bji méjaky' rozdil. 
- No, żejmê ve kvalitě rozdil je, proto taky každej kupuje značky zahraniěni, protože ¿̇eskà zatim zrejmè nedosảhla takov'y úrovnè.

Kazty nrdi, te je racty bida, ale obchody json zatim porad pline. Cim to je?

- Tak už záleži żejmè na těch lidech, jak se rozhodnou - situaci svoji financ̀ni. Nčkteri se uskromni, nèkteři pottebujou chodit do tý hospody. Tak chodèj.

A myslite si, ¿̇e ve sporlu rozhoduji hodmé penize?

- Samoziejmè že rozhoduji penize, protože bez penčz se v současný dobè sport zřejmé vủbec nedà dêlat.

To zmi tak. ze sport dmeska nemi cisty?

- Sport samozỉejmè neni čistý. Vždyt se koukněte všude vokolo.

To zmamena. że i rozhodìi se dá koupir?

- Rozhodi se kupuje. (...)

- To je výhodný, ale zase záleži, jak klub se $k$ tomu postavi, jestli má schopnýho, jak se riká menežera. nebo jestli je schopnej jakoby výbor nebo něco takovýho, kterej se postará vo .. A na nižšich úrovnich to tak ż̉ejmè nefunguje, kde penize nejsou.

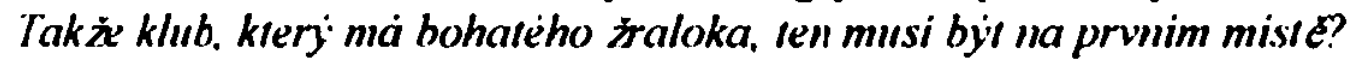

- No, dyt to vidite podle soućasný ligy fotbalový, kam se dostaly takový vesnice jako Plšany, Trnovice. Tam záleži na tom menedżmentu

A raky na rom sponzorovi.

- Samozìejmé. protože ziskali bohaté sponzory, který to všechno zaplati

A co rikäe cenam potravin?

- No, ceny potravin jsou podle mýho tak ñak relativni k cenám - zatim slušný.

To znamerki imcrié $k$ platu?

- Rek bych, że jo. Protože kdo chce si to koupit, tak si to nakoupi. (..)

A co rikate zy'seni cen telekommikacmich, teiefomm?

- No, tak to nevim, ale iek bych, że by to melo, jako $v$ současný dobé, tak by to mélo zưstat na têch cenàch. że by se to už zvedat nemẻlo. (...)

- To pivo by mèlo zůstat na normálnich cenàch, protože je to vlastnè českej dar, pije ho celej narod, tak by to mẻlo zůstat $v$ normälnich cenàch a ne to prehànct. Protože kupovat si nékdy pivo za ctyricet, padesát korun, to už je moc a moc drahý.

A co takouy' sportovec po skonceni aktiwmi kariery, co mu zbýn'a?

- To už záleži na nčm. Zảleži, jestli študoval, jestli mả ňáký zaopatíeni za sebou, jestli má dost finaninich prostredkủ. Prostě záleži, jak von se pripravil na to ukonċeni svý karièry.

Sprachverhalten:

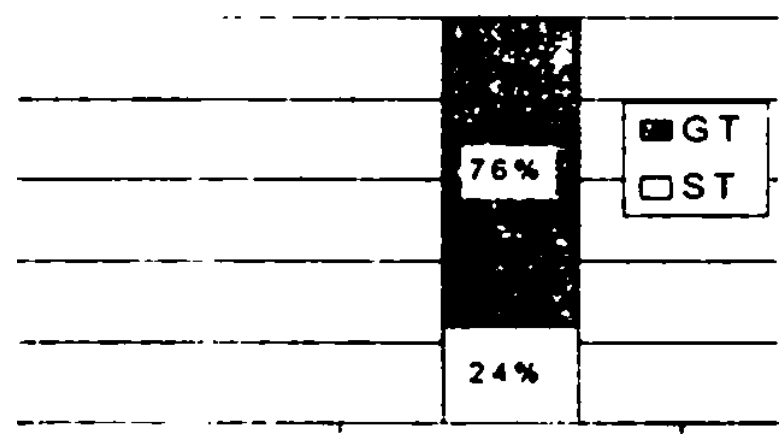

form ell
Einstellung, konatives Subsystem

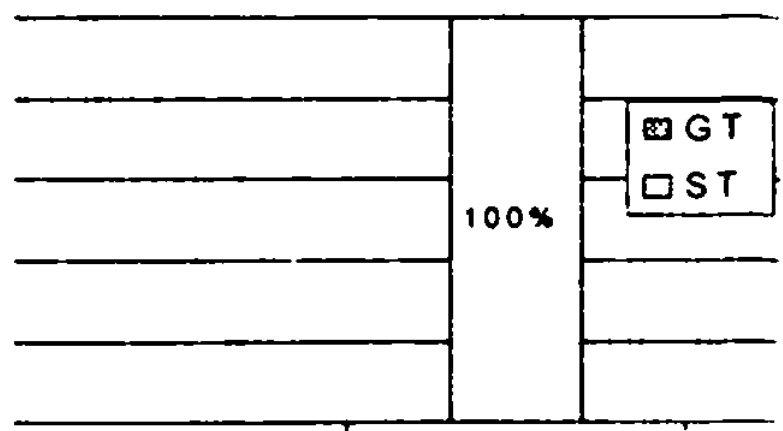

formell 
Einstellung, kognitives Subsystem:

Evaluation der eigenen Kognition:
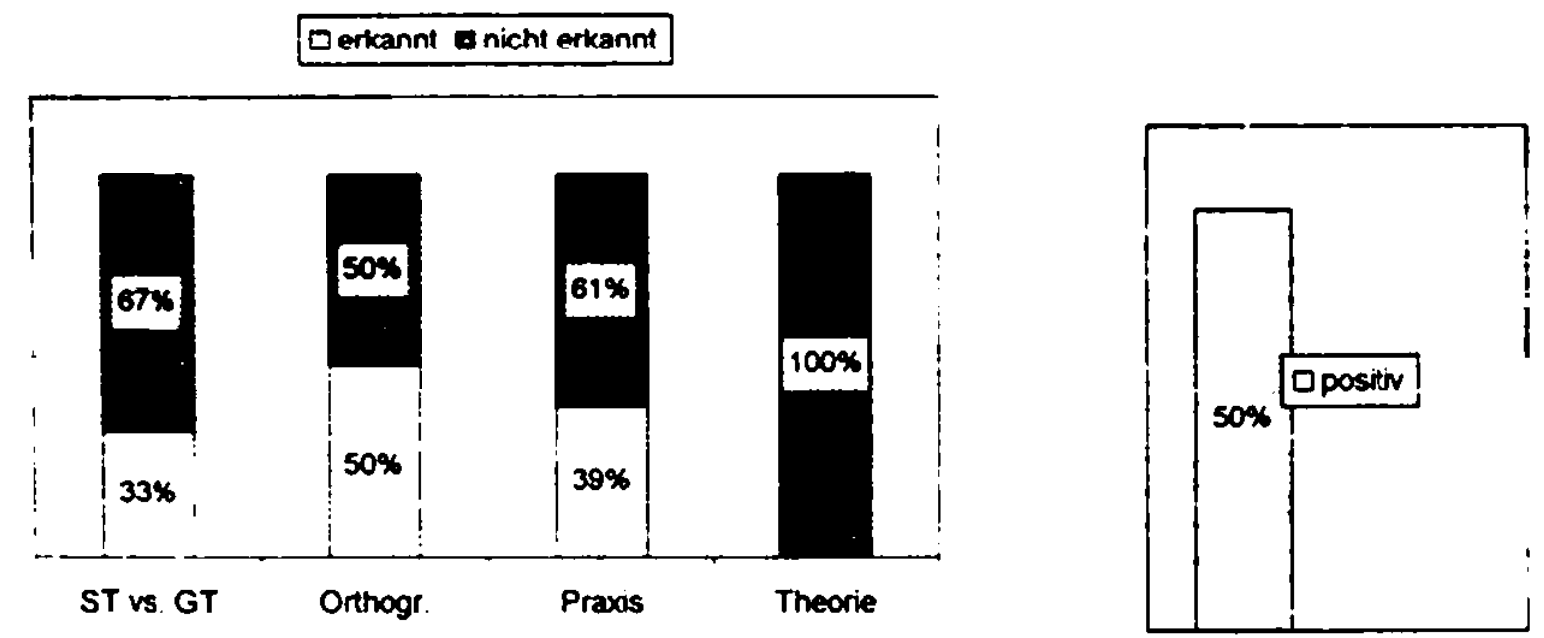

Einstellung, affektives Subsystem: Grad der positiven Einstellung

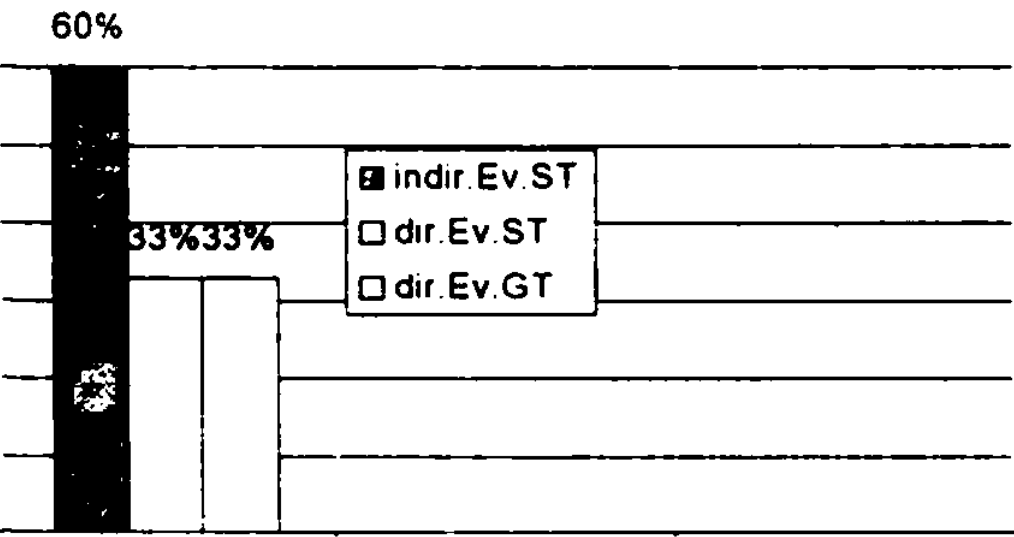

Kommentar Této anketê nerozumim, vypadá to tak, že si stejnẻ každý mluvi podle svèho a Cechy stejnể začinà ovlàdat ruština.

\section{Schauspieler, 36 Jahre}

Sprachverhalten. formelle Sitmation: Gespräch am Arbeitsplatz des Respondenten

(o) iikcile zuysowaini cen " Ceske republice?

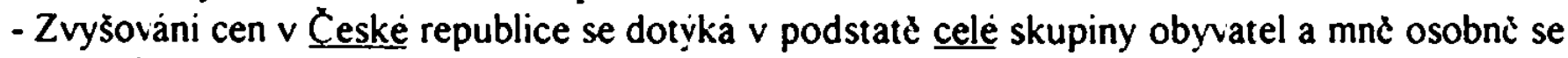
zdà, že je neúnosné

Myslite im ceny potravin?

- V podstate je to od cen potravin pres všechny možné poplatky a lekkaŕstvi a socialni jistoty. läm je nejhliżi kullura. Jak se zvysováni cen projevuje v kullurni oblasti. ve vašem pripads"v provozoraini divadelmi spole conosti?

- V provozu divadelni spoleỉnosti je samozrejme problém zvyšováni cen velkým problémem. protože zvỷšnou cenou benzinu se zvyšuje doprava zajezdové cinnosti. to znamená. ie se

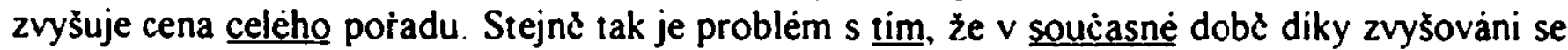
narokủ na finance se zavirá ỉada kulturnich zarizeni, nebo nejsou dotovány $\vee$ takových mirách jako byly $v$ minulosti. Tak je ta cinnost omezená a omezujici. My zvyšovat honoràre $v$ podstates mnoho nemúžeme, abysme si valorizovali veškeré ty zdražovaci procesy, protoże $v$ okamżiku. kdy se dostaneme na unosnou miru pro naši kapsu, tak se staneme neunosne drahymi 
A jakyj je vás názor na zuyšováni telefomnich poplatkü?

- Zvyšováni cen telefonnich poplatkủ se pochopitelnẽ promitá i zase do naši činnosti, kdyż. vezmu tu divadelni činnost. Protože otázka manadžingu, která je odkảzaná na telefonni služby, tak samoziejmè už se to načita do nákladủ a tyto náklady neúmérné rostou.

A jak se divàte na platy poslancü? To asi neni zrovna sociálnè slabá skupina.

- Já nevim. já mam takový pocit, že $v$ okamżiku, kdy se daný élovêk dostane na post poslance, tak zapomene, $v$ cem żije.

$A$ relace platú poslancú $k$ dưchnd im a platưm matek $s$ dami?

- Samozíejmé otázka dủchodovèho zabezpečeni nebo vúbec dủchodcủ a matek $s$ détmi je - to je stránka sama pro sebe. Co se týče obyvatel $v$ dủchodovém vêku - je to problèm, protože už si nemohou vydélávat $\vee$ pripadé, že to - takže jsou odkázáni pouze na vỷši dủchodu, který, ac̀ se valorizuje, tak je $v$ nepoméru. To znamená, když se na valorizaci padesáti korun zdraži nájem o sto korun, tak je to nepomér. A u matek $s$ dêttmi je to to samé. Zvláště kdyż ceny výrokủ neboli ušaceni pro déti, pro ty nejmenši, je $v$ cenách $v$ podstaté jako pro nás, pro dospêlè A nemyslite, ż zásadmi hodnoty. jako jsou zdravi a sioboda, zo jsol prebijeny pentemi?

- To je problém současné doby nejen $v$ civilnim žjvoté, nejen $v$ práci, prostê všude a ve všech

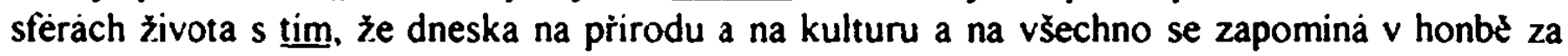
penčzmi. Je strašné tě̉zkẻ rict, že penize nejsou všechno, ale oni osvobozuji. A to je právê už ta debata zase na to - $Q$ té svobodé

Tak ze pì nedostalku pence lide omezuji kuluuru - divadla, kulturni poracty?

- To rozhodnč. To rozhodnć, protože když manželé maji jit do divadla, kde vstupenka stoji trii sta korun. dohromady je to šest set. A z toho rodinnèho rozpoctu šest set korun už neni zanedbatelný obnos. To znamená, że do toho divadla se vydaji jednou za pủl roku.

\section{Sprachverhalten:}

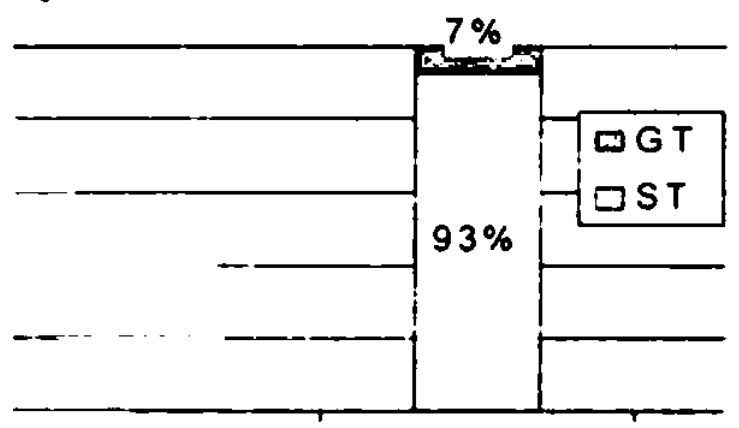

form ell

Einstellung kognitives Subsystem:

Derkannt G nucht erkannt

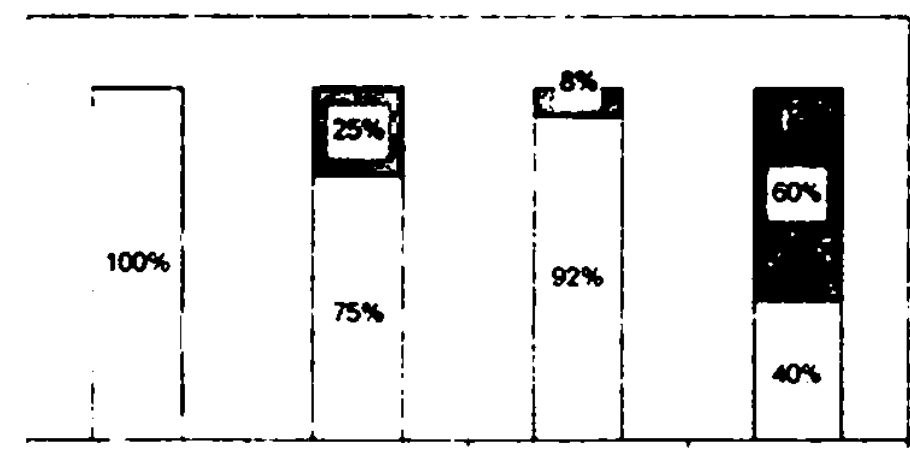

ST rs GT Orthog Praos Theone
Einstellung, konatives Subsystem:

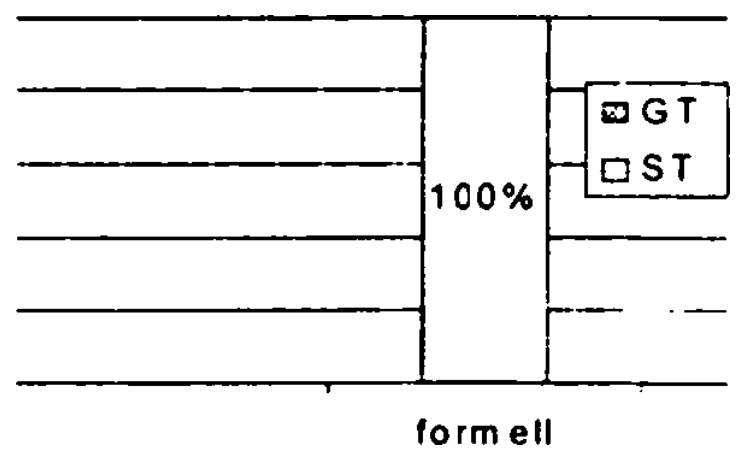

Evaluation der eigenen Kognition

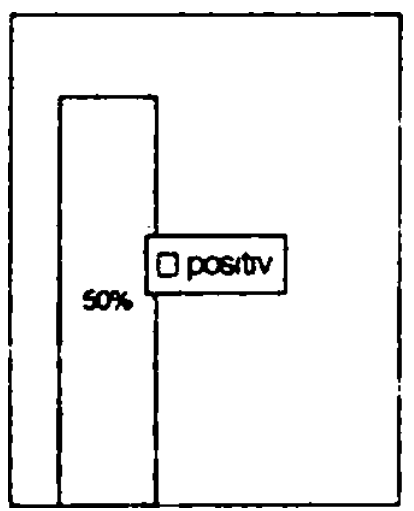

Lenka Bayer - 9783954790258 
Einstellung, affektives Subsystem: Grad der positiven Einstellung

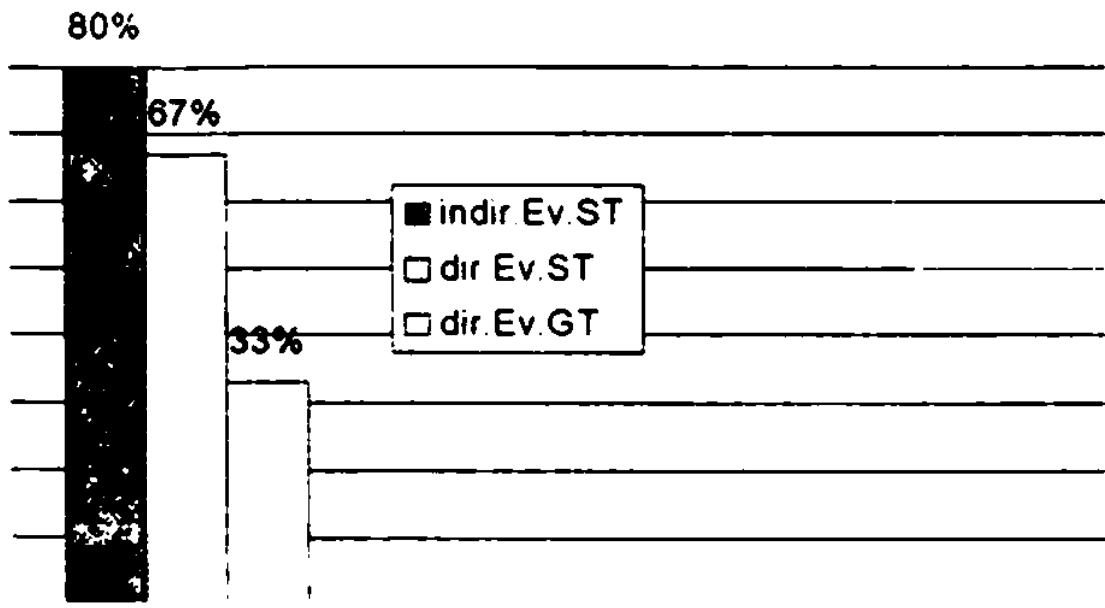

Kommentar: ohne Kommentar

\section{Bautechniker, 47 Jahre}

Sprachierhalien. formelle Situation: Gespräch am Arbeitsplatz des Respondenten

('o rikáte avy:šovani cen ' Ceské republice?

- Zvyšovani cen $v$ Ceskè republice je asi nezbytně nutnè, protože vzhledem $\mathrm{k}$ tomu, že podniky vyrábęj strašně málo a ekonomika neni na takový úrovni, aby teda se mohly držet stabilni ceny a podniky maji malo penez na vyrobu, na vstupy. Także se to musi promitnout i do cen, to znamená, že se zvyšuje energie, zvyšujou se veškeny vstupy do výroby, takže potom to vodnesou vlastnç $i$ ceny výrobkủ $v$ naši republice

A tika se to raky cen ve starebnictvi?

- Samoziejmé Ceny ve stavebnictvi rostou neustále Mưžeme vidèt, že ceny se mẻni treba każdỳm mésicem. Stavebnik. který začne stavèt jeden rok a než stavbu dokonẻi, tak dejme tomu to trvá rok, a ceny bèhem toho roku rapidné stoupaji. A ten, kdo stavi rychle, stavi vlastnè levnèjc.

A co rïkäre zlyysoráni cen relekommikainich poplatkü?

- No, to je kapitola sama pro sebe. Myslim, že zvyšováni telekomunikainich poplatkủ asi neni vopodstatnéný, protože monopol Telekomu diktuje veškeré ceny na našem trhu a když. se dozvidaime vo odmènách a mzdách pracovnikú Telekomu, tak to vůbec nekoresponduje $s$ cenama a zvyšovánim A když vidime tr̉eba $v$ zahraniči, kde tỉeba Telekom $v$ Nèmecku snižuje naopak ceny, takł̌e choväni našeho Telekomu je jednak $v$ cenách vỷrobkủ - jejich služeb - tak $i \vee$ cenách prostę zaváděni novejch siti - to vidime $\vee$ obci, kdy teda jsou nehorázný ceny za zaváděni siti, tak to se mi nelibi.

A ted"otazka, která se tyka visech obcamú Zvysovánl cen potranin.

- No, když se podivame na vývoj cen potravin za loňskej rok a za letošni rok, tak vidime, že rapidnc nestoupaji ceny potravin. Naopak klesaji ceny potravin. Je to daný asi tim, že $v$ naši republice funguje - velké retęzce - kterii se snaži udržet si zákaznika. zlikvidovat menši podniky, a proto drži ceny. A naopak nčkerý ceny $i$ snižuji, takže $v$ tomletom narust velkej $v$ potravinach asi nebude takovej, jako $\mathbf{v}$ jinejch vyrobcich.

To. jste docela oprimista. Kolik vim zlyde z iyplaty? 
- No, z výplaty mi moc nezbyde. Když poplatim veškerý poplatky, co mảm, že jo, protože bydlim $\checkmark$ rodinnym domku - to znamená voda, elektriina, telefon a ruizný ty poplatky, samozrejmẻ auto $\mathrm{k}$ tomu - takže jako těch penèz mi moc nezbyde, proto potom vyhledávám tyhlety velký obchodni domy, kde si teda mủžu nakoupit ve vêtšsim množstvi. Nemusim chodit každej den do obchodu. No, proti mistnim krámkủm ušetrim, i když pojedu autem, projedu néco benzinu, tak pờàd ta cena bude nižši $v$ tom velkym objemu toho nákupu, treba tỳdennim. itrnáctidennim.

A myslite si, za soucasné cenove relaci potravin a veskerém zdražováni má vinu i la mimulà politika?

- No, samozłejmê, že jo, protože za minulèho režimu byly potraviny dotovaný, byly $s$ pevnejna cenama a neprihliželo se prostę ke vstupủm a produktivité a výnosủm tẻch podnikủ. Dneska, když si ten podnik, soukromej podnik, musi hospodarit sảm, tak prosté mu musi zbejvat na ten rozvoj, takže se to musi někde vobrátit.

Máte taky' "cjjakj' komicek?

No. koniçek, mám konicka. Práci na svý zahradě, ùprava kolem domku, no, moje auto, rodina. A co rikćle ziysováni cen benzinu. cen za povimie ruceni automobilü Auto je nadstandard?

- To je nadstandard, ale jako v současný dobẻ asi bez auta - jednak když ho člověk má asi už delši dobu, tak je zvyklej na auto - cena povinnýho ručeni, to je kapitola, která teda hejbe celou republikou asi, protože mi to pripadá nehorázný - takovýhle ceny povinnýho ruceni. Pokud by to bylo správné udẻlaný, aby teda bezškodni prúbẻh byl zohledněnej, to dneska neni. A zase je to něco jako Telekom. Ceská pojištovna - monopolni podnik, a jak se riká, że až bude vic podnikủ. moc - vybirat povinný ručeni - moc tomu nevểim, że by se cena snižila. protože určité budou držet ñákou tu cenu a vo moc dolu nepudou.

Sprachverhalten:

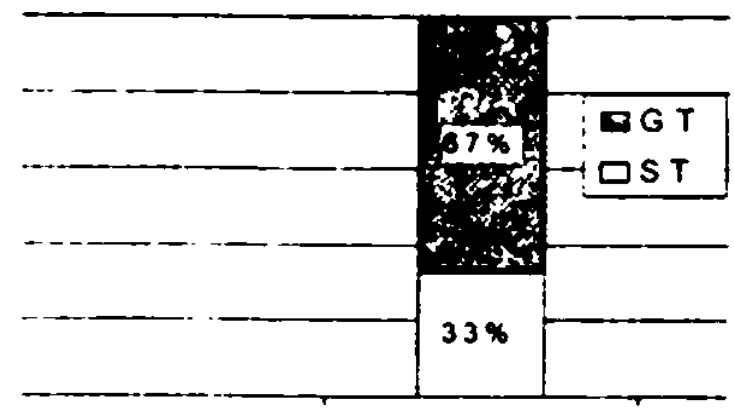

form ell

Einstellung, kognitives Subsystem:

Derkannt is nicht erkannt

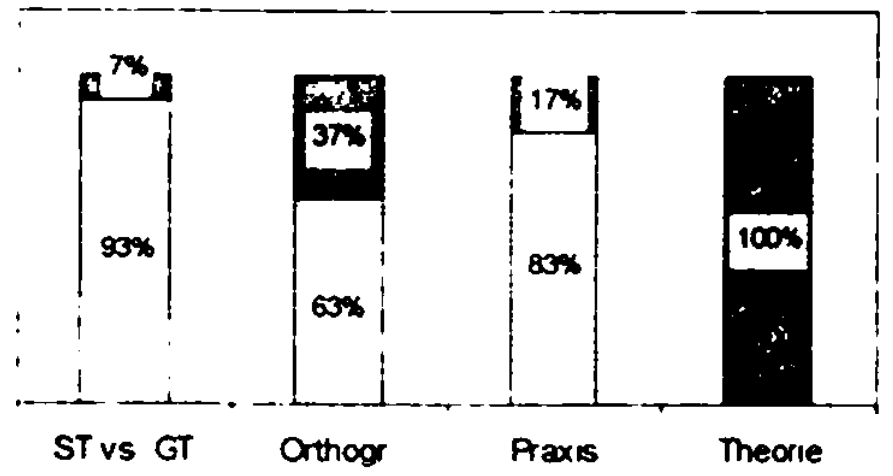

Einstellung, konatives Subsystem:

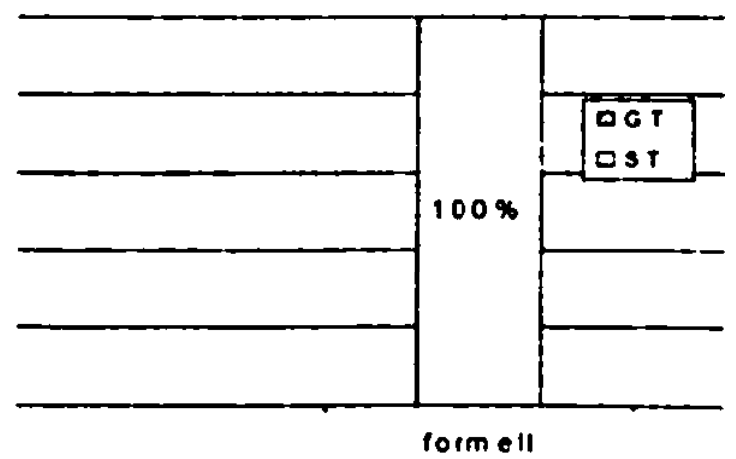

Evaluation der eigenen Kognition

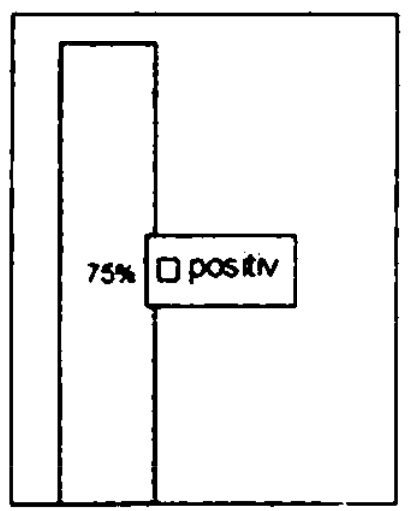


Einstellung, affektives Subsystem: Grad der positiven Einstellung

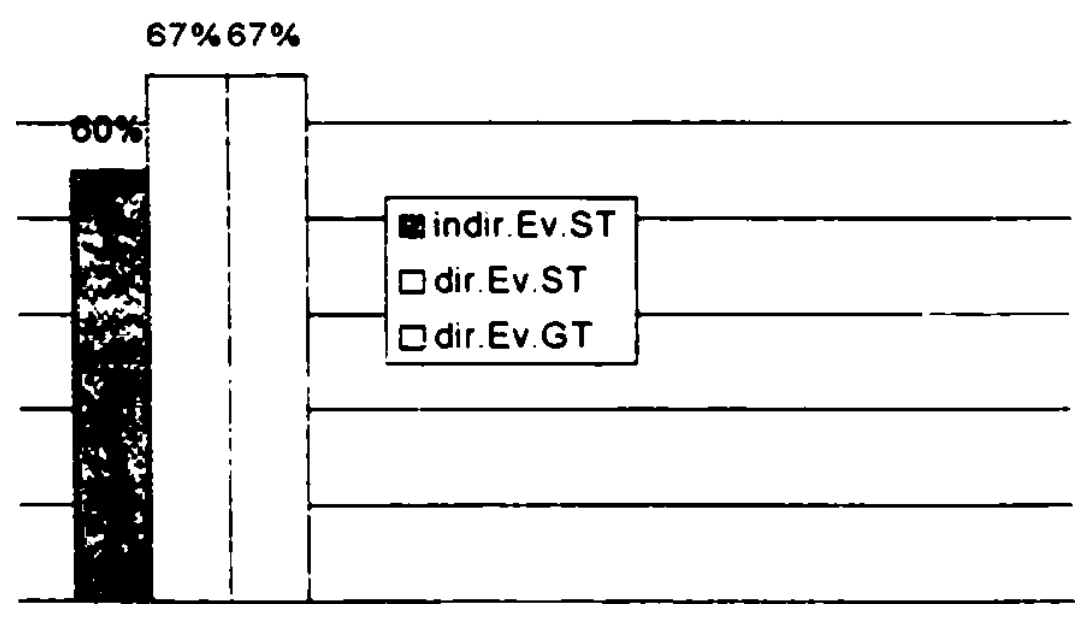

Kommentar: ohne Kommentar

\section{Immobilienmakler, 48 Jahre}

Sprachverhalten, informelle Sitmation: Gespräch mit der Verfasserin in einem Restaurant

(Tak si objedname. Jà bych si dala daj s citronem. jestli máte.)

- Jà si dam kolu.

(A k jidll ...) (...)

- To jsou ty sedačky ñáký úzký nebo se mi to zdá.

(.)sés posvame). jo. Ty si dej co chceš.)

- Jo, jả si dam nčjakej vobẻd normảlni.

(Naco dobriho. Tady maj docela dobriy jidlo...)

- No, už je dvanáct. Takže na obęd.

(Acite vybrano?)

- Jà si dam ty veprový výpečky.

(.Isou k tomu asi bramborovy knedliky nebo houskovy?)

(Bramborovy nemam.)

- A $k$ têm vyjpeckám?

(.Jenom houskouy:)

- A jsou se zelim nebo se špenatem? (...)

- Jak jsou lidi spokojený s pražskou dopravou. To se týkả prostč każdýho

Spracherhalten, formelle Situation: im Restaurant

Jakj mále názor na momemálmi situaci doprannich prostiedk ù v Praze?

- Müj nazor je velice negativni.

Z.jakiho din'cxh?

- $Z$ dỉvodu toho, že dnes rảno jsem cekal na autobus ve stanici, a bohužel nejel podle jizdniho ràdu. Vlastnim jizdni ràd dopravniho podniku a zjistil jsem, że autobusy nejezdi presne̊ A co ry byste zlepsil?

- Vyminil bych reditele dopravnich podnikủ

A jaký je vás osobmi názor na letošni zimu. Byla teplá mebo stmdena'? 
- Posledni zima byla vỷborná, protoże konec̉né po nékolika letech se objevil snih a bylo możno na horách lyžovat.

Byl jste na lyzich?

- Na lyžich jsem nebyl, ale byly dêti. Mám déti dvê. Vêk sedmnact, patnáct. A obẻ jezdi.

Takze privitaly letošni snih.

- $\underline{0}$ jarnich prázdminách určité.

A o simnich?

- Q zimnich? Zimni prázdniny bohužel u nás ve škole nejsou, jenom $Q$ Vánocich a to jsou déti u rodiny.

Sprachverhalten:

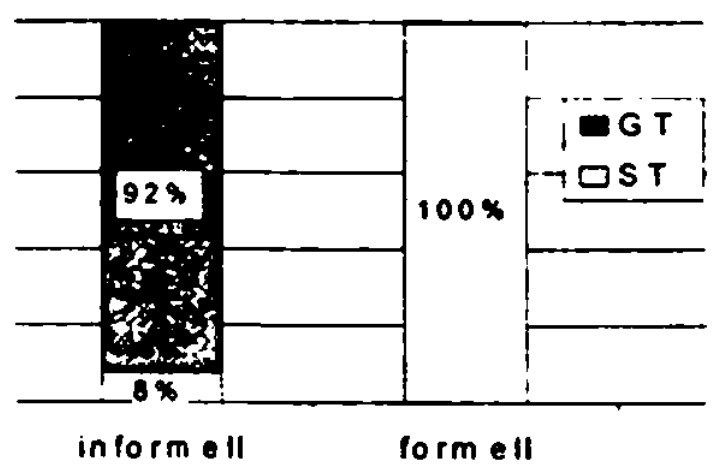

Einstellung, kognitives Subsystem:

C erkarm I nicht erkent

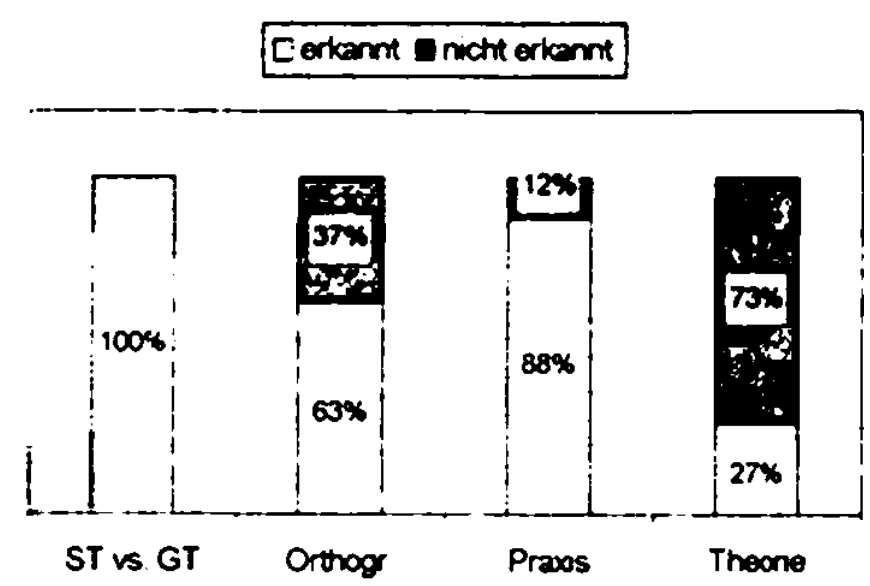

Einstellung, konatives Subsystem.

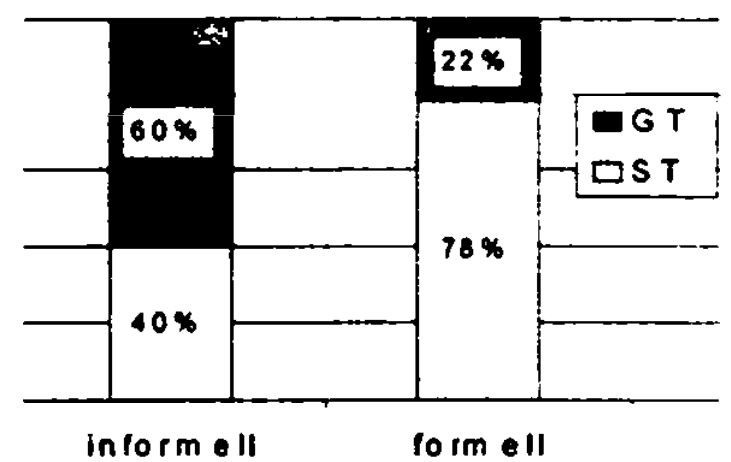

Evaluation der eigenen Kognition:

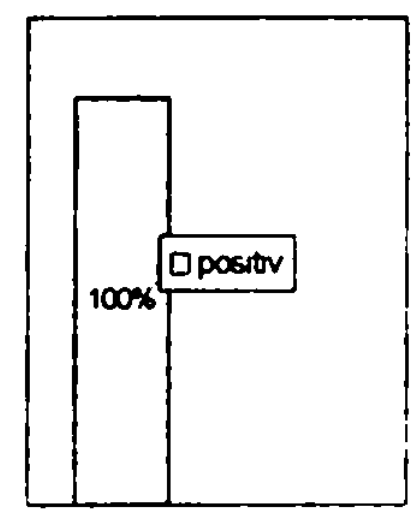

Einstellung, affektives Subsystem Grad der positiven Einstellung

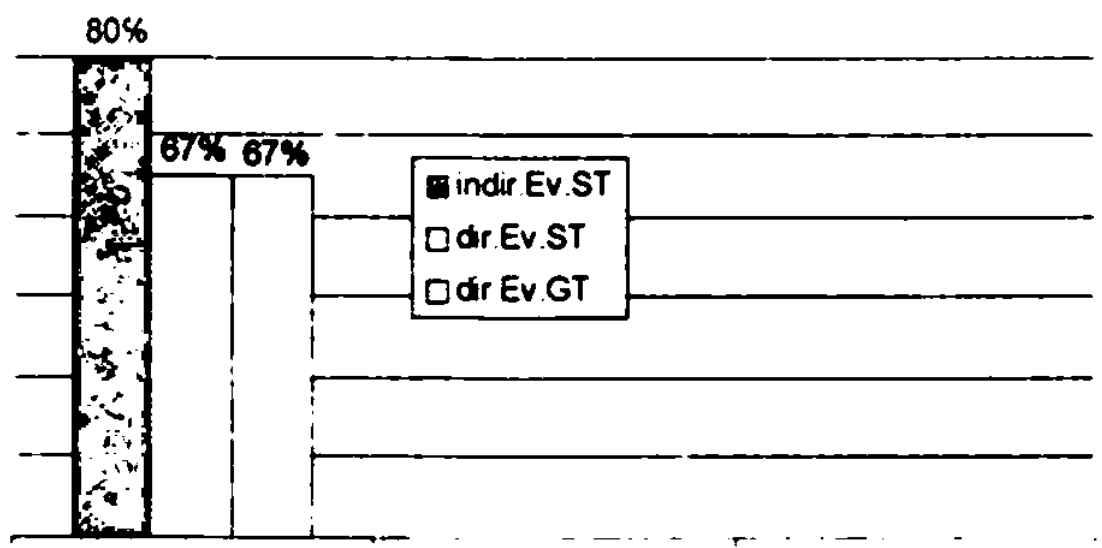

Kommentar. Pri tomto testu si človêk uvêdomi, jaká je ceština pestrá a jaký je to tęzký jazyk a kdo mluvi jen spisovnou ceštinou - takovy clovêk se snad ješté nenarodil - musel by to bỳt naprogramovany robot spisovnè ceštiny. 


\section{Unternehmer in der Landwirtschaft, 67 Jahre}

Sprachverhalten, formelle Simation: Gespräch beim Respondenten zu Hause Co rikàte zuyšovani cen v Čskè republice?

- Jả se domnivám, že se nějak moc zvlášt nezvyšuji. Zemédělské výrobky jdou dolů a bohužel $i$ ceny zemèdélských produktů a jiné zvyšovảni je zpủsobeno żejmé pouze inflaci.

Ale lide nrdi. žx ceny potranin stoupaji.

- To nevim, to nevim, ale všeobecnẻ se vi, že ceny treba masa i mouky a tak jdou dolü. No, kupni sila klesá. Taky to asi prispelo $k$ tomu, że ty ceny jdou dolu - nevim.

A myslite si, ż dovoz tréba oroce zemi Evropské umie se na tom taky projevuje?

- No, to se projevuje určitě, ale na tom dovozu má asi nejvètši vinu právě to naše zemèdêlstvi. że to neumi tak šikovné zpracovat jako na západé.(...) No, na mym osobnim standardu se to neprojevuje, ponévadż já bydlim sám a kupuju si, já nevim, jednou za ċtrnáct dni nějakej nakup domú. Já, mê to nezajimá - potraviny takhle.

Ale jste majitelem pozemkú které byly v restituci. S rim souvisi hodné starosti.

- No, samoztejmé s tim starosti souvisi a pomérné dost velkè. Dostali jsme sice pozemky, ale nedostali jsme żádné možnosti k tomu, abysme je sami obdélávali - stroje, zviłata domáci - to. No, a my na to nemame, abysme si to zakoupili. Tak jsme byli nuceni to pronajmout. A co ireba ziyšrovani telefommich poplatkü?

- Zvyšovảni telefonnich poplatkủ mě štve. Myslim si, že je to zlodějna vod Telekomu. Telekom rady' zatim má monopol. Myslite, ze v budoucmu tady bude i jiná firma?

- Pídpokladám. że ano a mèla by bejt co nejdriv.

ly máte firmu se sidlem mimo Prahu. Myslite, zu mimo Prahu je podnikàni jednodušši?

- Ne, je to úplnê stejný.

Sprachverhalten:

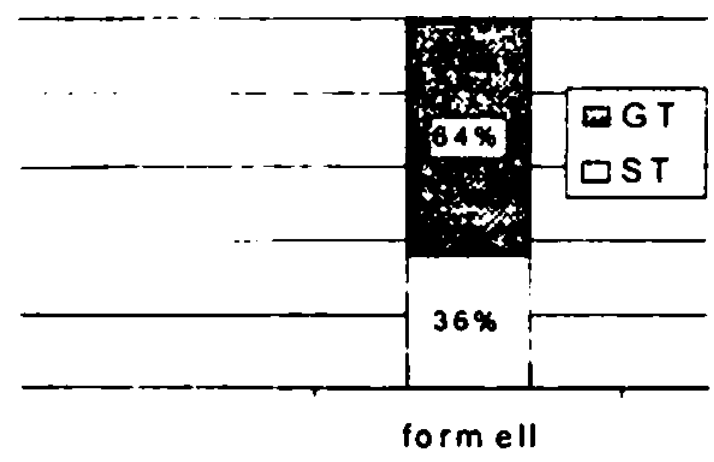

Einstellung, kognitives Subsystem:

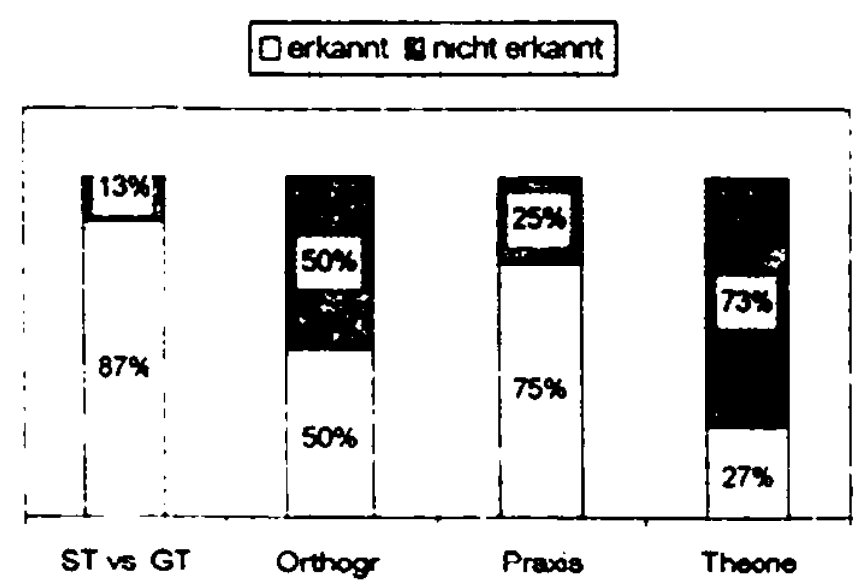

Einstellung, konatives Subsystem

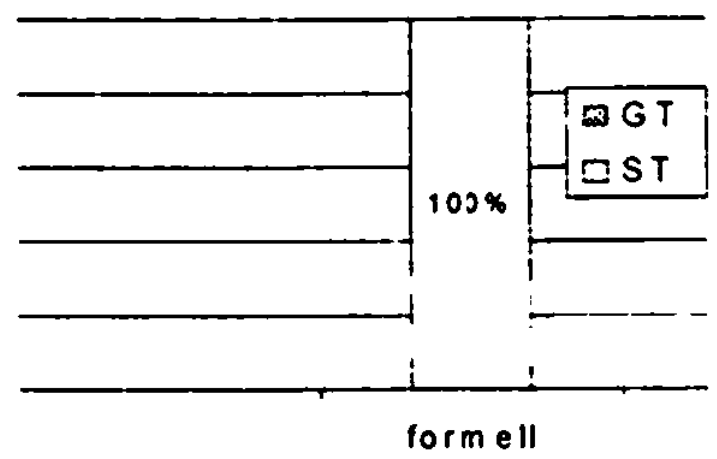

Evaluation der eigenen Kognition:

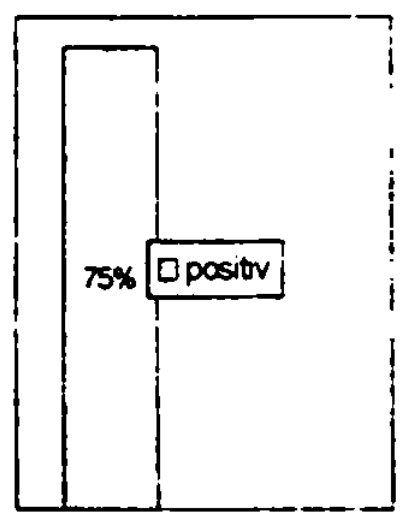


Einstellung, affektives Subsystem: Grad der positiven Einstellung

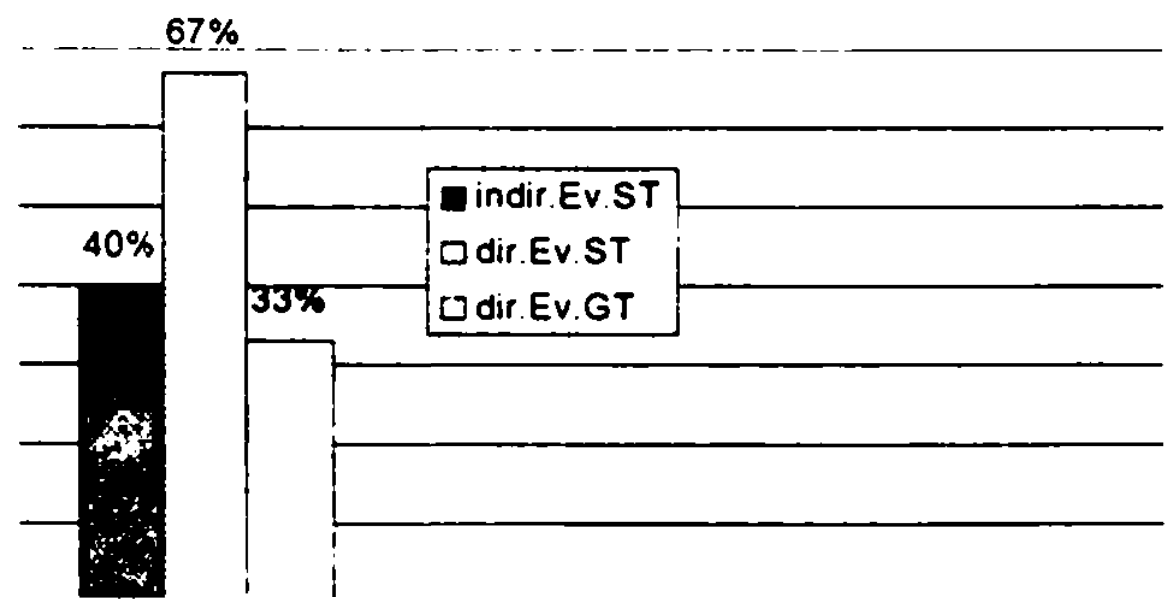

Kommentar: Tésilo by me, kdyby anketa prispěla ke sbliženi spisovné a lidové češtiny a jejiho dalšiho vìvoje.

\subsubsection{Männer mit Hochschulabschlıß}

Alter der Respondenten 49 und 60 Jahre, insg. 2 Aufnahmen

\section{Architekt, 49 Jahre}

Sprachverhalien. formelle Simation: Gespräch beim Respondenten zu Hause

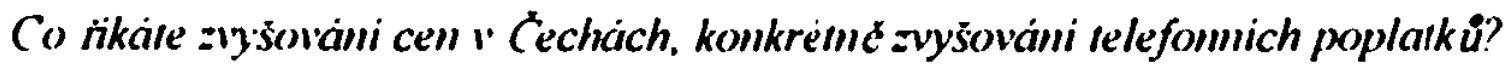

- Tak je to asi urçitym zpủsobem nezbytná vẽc. Jde o mẻnovou strukturu cenovych - zvýšeni cen

A rás se to dotyká?

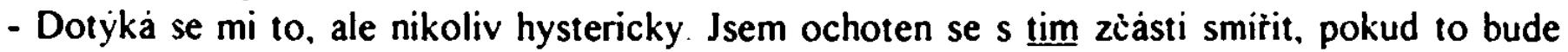
mit racionalni základ

l'ảs obor je archirektura. Jak se projevuje zuysoväni cell ve stavebnictvi, projektováni a dalšich pribuznych oborech?

- $V$ podstatč pozitivnè, protoże stoupla cena projektů vzhledem $k$ tomu, že se cena počitá jako procentueini náklad $z$ ceny stavby. Vzhledem $k$ tomu, že stoupá rychleji - rychleji náklady stavby nežli moje prijmy, tak mne to vlastne zvyšuje ptijem

A pomúcky: které potrebujete $k$ vykomáváni práce, jako treba, dam triviálni priklad, pravitka. Jejich cena stoupla desateronásobma Neprojevuje se to nejak na vaši práci?

- To se neprojevuje. protoże jaksi v pomén nemúže to hrát vẏraznou roli. Protože ty náklady jsou relativné malý percentuelné.

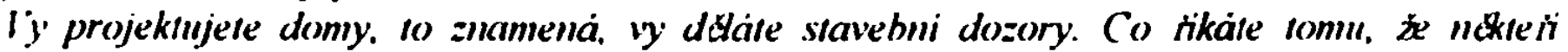
podmikatele najimaji za levnyं peniz zahrami bni delniky. Je to podle vás správne?

- Urieitým zpưsobem jo, protože je to nezbvtný dủsledek uvolnčni soutčże.

Matre jako poxdmikatel mobilmi relefon?

- Nemám ho a je mi protivny.

Tak ze máte konzervativni prissup k ićmo pristrojüm. Máte pocitac?

- Pocitać potfebuju, ale jsem liný se naucit pracovat na nêm. 


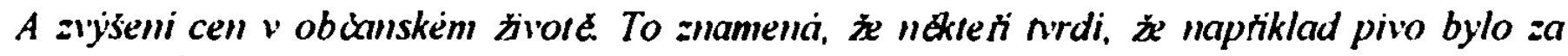
kommmistü za korrum padesát a ted' je za deset korım. Co vy tomu rikáte?

- No, tak zéàsti je to názor naivni, protože se mèni skladba ptijmủ. Zéásti je to spontánni odpor a nechut. To nelze brát ċistou numerickou hodnotu a srovnávat $\mathrm{v}$ rüzných dobách.

Dnes se rika. 20 auto je prepych. Nyni prešla hore čka placeni povimmeho ručeni. Co k tomu muixte rict?

- Povinné ručeni se mé do té miry - zvỷšeni - nedotklo vzhledem $\mathrm{k}$ malému obsahu, ale obecnê protivnè je, že se to zvyšuje neúmèrnejji, zejmena u vjššsich obsahů vozidel.

Máte "çjake konicky; které stoji penize?

- No, u rybärstvi to neni tak zlè, ale horši je to u çernobilé fotografie, kde se neúmérné zvýšila základni cena materialu. A tam to už doopravdy vadi.

Ḱdyż Ceská republika vstoupi do Eıropské unie, budou ceny asi ješle vy̌šsi.

- Je to pravdępodobné. že budou vyšsi, ale snad to vyrovnaji dalši klady, který z toho vyplynou.

A jaky máte názor na podnikatele. tak zrane tumeläru, kleñ, jak se dozvidáme z nisku, "iechäraji zmizet miliony z rürnych firem?

- No tak, byla to nezvládnutá legislativni záležitost, která umožnila těmto lidem se dostat do pozic, $v$ kterych byli.

Sprachverhalten:

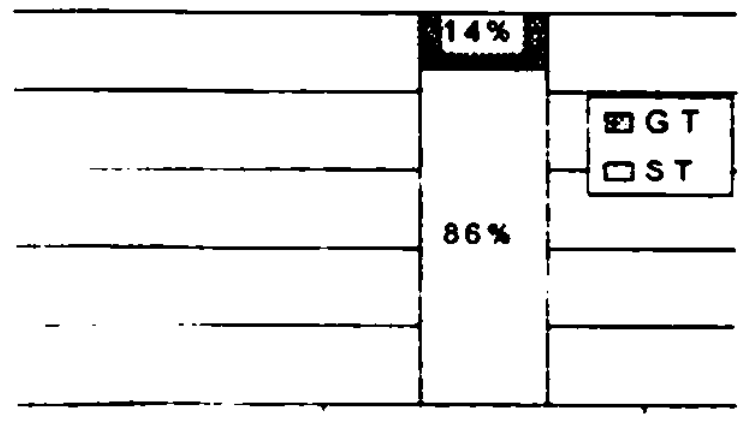

formell

Einstellung kognitives Subsystem:

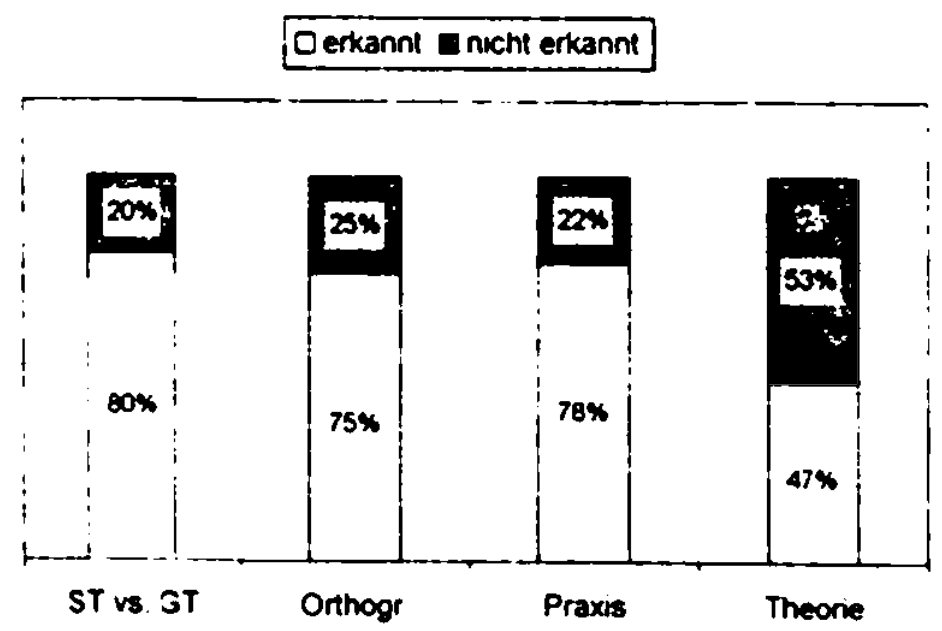

Einstellung, konatives Subsystem.

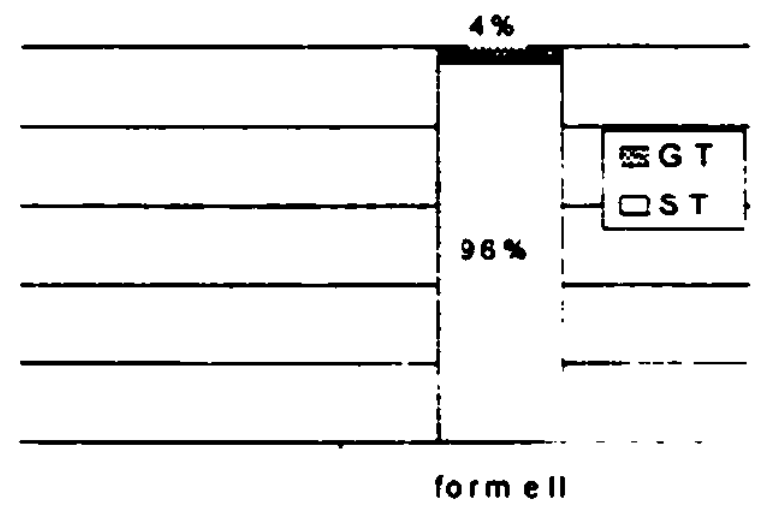

Evaluation der eigenen Kognition: 
Einstellung, affektives Subsystem: Grad der positiven Einstellung

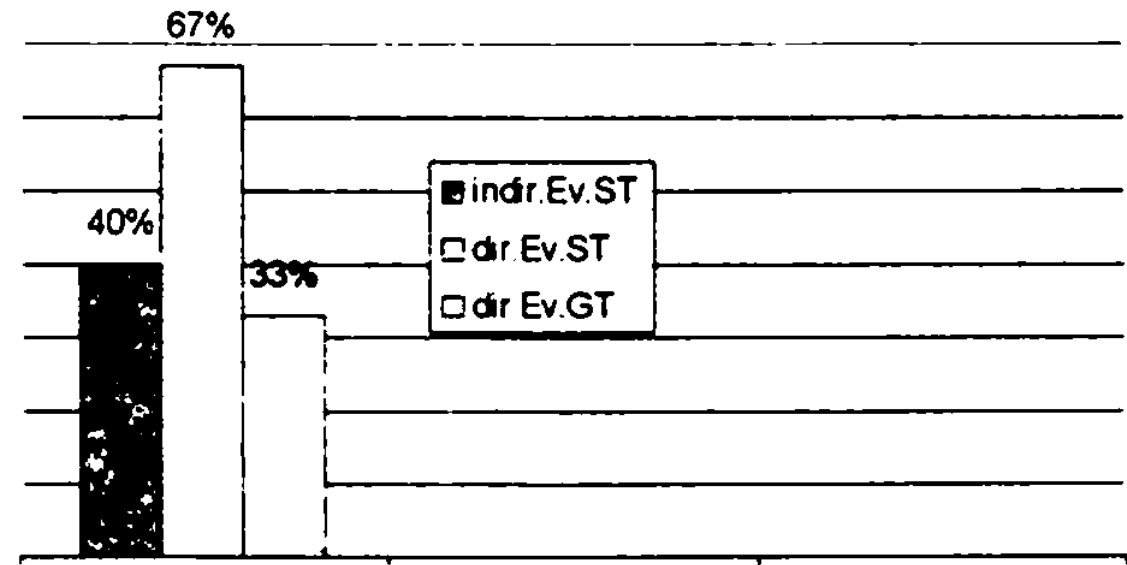

Kommentar: Zajimalo by mé, jakè závêry vyvodite, zda se je pokusite uplatnit a jak; jakou máte spolupráci s Ústavcm pro jazyk ¿̇cský; zda budete publikovat v Čechảch.

\section{Betriebswirt, 60 Jahre}

Sprachierhalıen, formelle Silıation: Gespräch beim Respondenten zu Hause

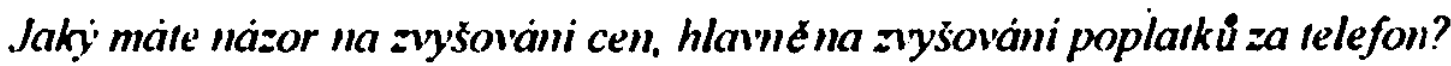

- No tak. to je zajimavá otázka. Jà bych začal u toho telefónu. Domnivám se, že telefon podražil zhruba od roku devatenáct set osmdesát devêt asi trtikrät, jo. To je ovšem docela prijatelný a myslim si, že telefony celkové asi tak nahoru nešly, a že jestliže to srovnám se zvyšovánim cen ostatnich. tak tam to prícházelo až pètkrát nebo i osmkrát. Takže relativnè by se dalo rici, że na telefonech se dá vlastnč vydêlat Pokud jde $Q$ otázku o zvyšovảni cen vủbec. anebo pohybu cen. tak tam si myșlim, że sehràaa - i kdyż se nčkomu to bude zdát nepravdẻpodobný - roli morálni hledisko. Jà se domnivám, že ceny by nešly asi nahoru, nebo $u$ nás by nebyla recese $v$ ekonomice, pokud by lidi daleko poctiveji pracovali a pokud by méné kradli a podvảdéli a tak dále. Ono jedno souvisi s druhým. Samozìejmé, łe jsou zde i situace. kdy docházi vlastně ke snižováni cen. Je to $v$ pripadé zaváděni - zaváděni teda provozu obchodnich retězcủ. jako je Penny Market nebo jako je Bêl, anebo Delvita. Tam jdou ceny vlastnê dolu, i když. pochopitelnê je tam určitej rủst, ale $v$ podstatẻ nižši. A je to prostê situace, $k$ dy docházi $k$ likvidaci malých prodejcú. $\mathrm{Na}$ jednu stranu $z$ hlediska toho maleho podnikàni je to smutne. jo Ale fakt je ten, że zákaznik spotrebitel, ten na tom vydélává. Asi tolik.

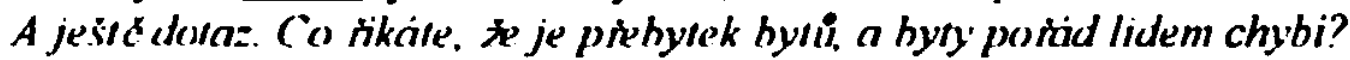

- No, fakt je ten, že todle je taky dủsledek - to je dủsledek prostě toho celkového vývoje od roku devatenáct set devadesát. A fakt je ten, že za takové situace, kdy mladi lidè vlastnè nemaji možnost prostę si pơ̌idit byt, nebo si ho koupit nebo tak, tak zde by skuteinnè mêl daleko vic tudle uricitou roli teda sehrát stat, jo. A myslim si, že je dneska dostatek zpủsobü, jak na to Jenomże stát má prázdnou pokladnu, a takže asi nčjak rozumné vyíešeni tohoto problému - na rozumnè vyìešeni tohoto problému si budeme muset ješté nçjakou chvili poikat.

Ale je lacty ješr é jeden prohlem. a sice osobni finance lidi.

- No, asi tolik, že je treba vymyslet systém, který by prinutil lidi poctivè pracovat, a potom budou i vyšši vyddellky. Ale zatim lidi jsou takovi, jaký jsou. Prostê jsou morảlnč spiše na nižši ùrovni. Takže jả se domnivám, že pokud se nenajde dostatečnẻ düraznỳ systèm na to, aby lidi prinutil $k$ práci. no tak to asi nepưjde. Domnivám se. že zde porád scházi daleko vic úcasti zahranicnich investoru. zahranic̈nich firem, které prece jenom maji možnost,-jakso54rebo maji 
propracovaný systemy - jak daleko lépe využit pracovni silu. Zvy̌sit produktivitu práce a zvy̌šit samoż̉ejmẻ potom i následnẻ żivotni ưroveñ.

A neni to trochu prehnane. vsechno svade jen na obcany?

- Ta otázka, myslim si, že má svoje misto. Pochopitelné, že na obiany se to nedá svádèt anebo jenom na obcany ne. Samozjejme, že pokud jde $Q$ jejich morálni ủroveñ, jejich morálni profit, tak to je néco jinýho. To si myslim, że tam by méli zapracovat sami. Ale fakt je jeden, że. dejme tomu, predchozi vlàda se snažila nèco vymyslet, a je pravda, že i když ta snaha tady byla, tẻch možnosti - protože jde fakticky o úplné novou situaci, která neexistovala nikde na světě. Takže je nutno i do jisté miry to zkoušet. No, a takže lidi maji jednu možnost. Prostě volit si politiky takové. kteri budou i z hlediska rozvoje národniho hospodárstvi pristupovat velice zodpovědně $k$ tẻmto otảzkám. Domnivám se, że zde nás taky čeká eště dlouhá doba, než dojde $k$ určitým vỷraznçjšim zmènàm. Je pravda, že pokud jde $\mathbf{Q}$ morälni kodex. jo, prostě $\mathbf{Q}$ tydle otázky. tak to mủžeme počitat $s \underline{\text { tim }}$, že musi se změnit několik generaci, než teda nastane situace. kdy by opravdu lidi dokázali bjt tekněme, na určitý morálni úrovni.

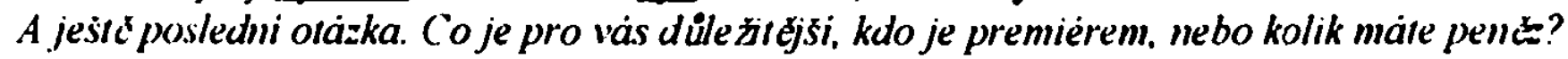

- Tak samożejmè, že kolik mám penčz v kapse. Ale fakt je ten, že, jả se domnivám. že penize poŕàd nejsou všechno. Jả se domnivàm. že lidè, kterii, dejme tomu, maji miliardy na kontech, co jim je to platný, pokud nemaji treba zdravi. Takže ono porad jsou i hodnoty mimo to. A potom - prosté lidskej život je tr̉eba využivat nejen po strảnce nêjaké hmotné, že - neznamená to, že musim za každou cenu bojovat $Q$ to, abych mèl lepši finančni situaci, ale za určitých okolnosti je človêk tr̉eba - nacházi prostê smysl života i v tom, že je hezky, že je krásná priroda. Jà tam jdu, podivám se tam. Že jdu na houby a tak dảle. Neni všechno jenom to, že nemám dostatek penčz, a jenom na to se vymlouvat. Prostè je treba život brat i $z$ jinýho konce.

Sprachverhalten

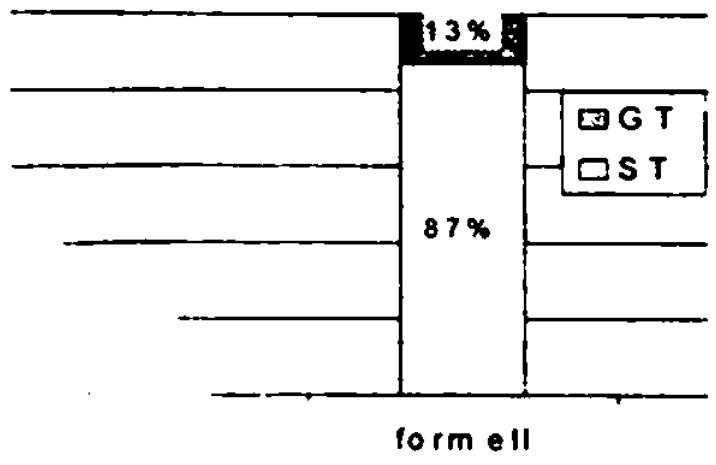

Einstellung kognitives Subsystem:

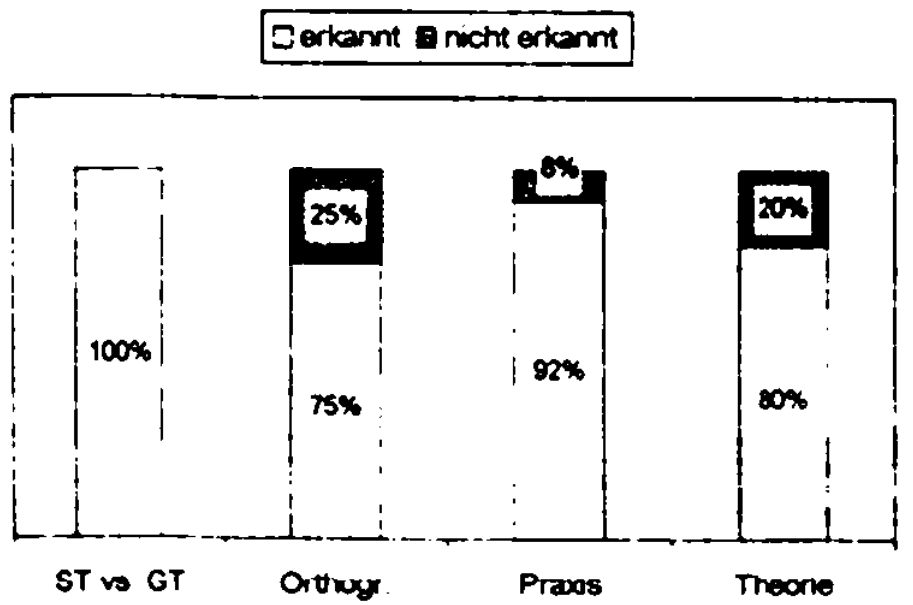

Einstellung, konatives Subsystem

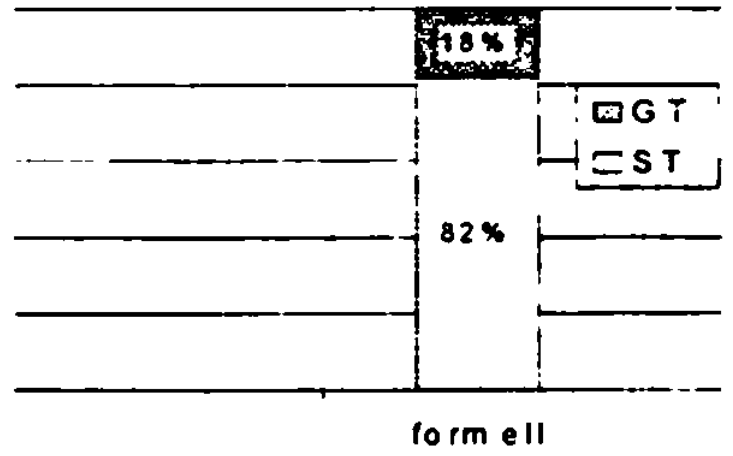

Evaluation der eigenen Kognition 
Einstellung, affektives Subsystem: Grad der positiven Einstellung

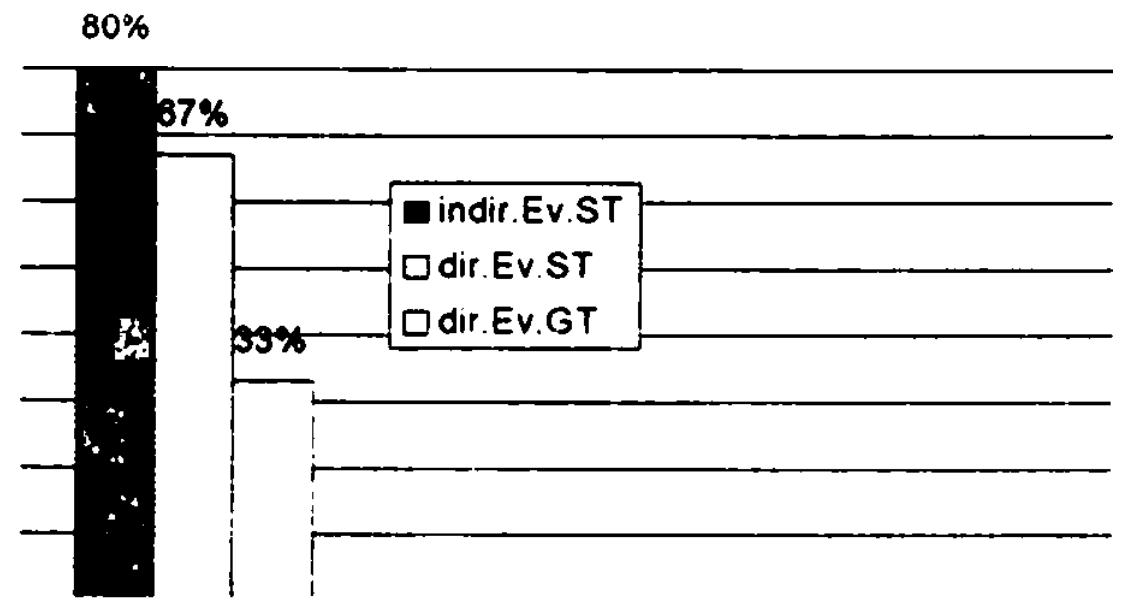

Kommentar: Domnivám se, że Vaše ankcta je smysluplný cin. Zakousli jste do priliš vclkého sousta. Bude to chtit mnoho trpélivosti, dotáhnout vše do konce. Pŕeji hodnẻ sil a elánu.

\subsection{Studenten und Schüler}

Alle sich an unserer Enquete beteiligten Studenten und Schüler konnten aus organisatorischen Gründen nur in einer formellen Situation, direkt an der Ausbildungsstätte, mit Mikrofon interviewt werden. Aus diesem Grund wurde bei dieser Sprechergruppe von der Auswertung des konativen Subsystems der sprachlichen Einstellung in einer inoffiziellen Situation - obwohl diese Angabe in den Fragebögen von den Sprechern gemacht wurde abgesehen. Alle Studenten gaben in den Fragebögen an, in welchem Studienjahrgang ${ }^{110}$ sie sich zur Zeit der Enquete befinden Diese Angabe folgt bei jedem Respondenten nach der Angabe seines Alters in den Klammern

\subsubsection{Pilsen}

\subsubsection{Jurasindent und -studemin}

Die beiden Studierenden wurden nach einer Gerichtsverhandlung vor dem Gerichtssaal aufgenommen

\section{Studentin, 23 Jahre (3. Studienjahrgang)}

Procijste si iybrala pràvė studium práv?

- Protože si myslim, że za prvé je to perspektivni obor a je to asi jedna z mála věci, ktera by mé asi mohla bavit $v$ životé.

A jake maile konkremi vihledy do budoucra?

- Konkrètnê vỷhledy do budoucna, no, vêtrim, že se mi podar̀i dokončit školu dobre a uvidim, co bych chtêla dẻlat, možná soudce, možná advokáta. Kdo vi, až podle profilace tedy $v$ tý skole

"I" Die gàngige Studieneinheit des tschechischen Hochschulsystems ist cin Studienjahrgang. Diese Einheit entspriclit in ctwa der Dauer von 2 Studienseınestern in Deutschliand. 
A jake studujete cizi jazyky?

- No tak, domluvim se anglicky, domluvim se némecky. Postupnẻ se néjak tak zdokonaluju, uvidim, co bude $\mathrm{v}$ budoucnosti.

Proc práve tyto dva jazyky?

- No tak, protože, jelikož nejsme daleko od hranic s Nêmeckem, a tak se tady dost mluvi nẻmecky. Takže tohleto byl pruni popud, no a anglicky, protože se po premènê poméni vlastnê mluvi anglicky a je to perspektivni jazyk.

A red' ješt ó otázka z jiné oblasti. Jaky máte názor na posledni zimu?

- Jako na povêtrnostni podminky, na klimatický? Śpatný - velký teplo a nedá se sportovat. Podle mê je to netypický a nesprávný.

Sprachverhalten:

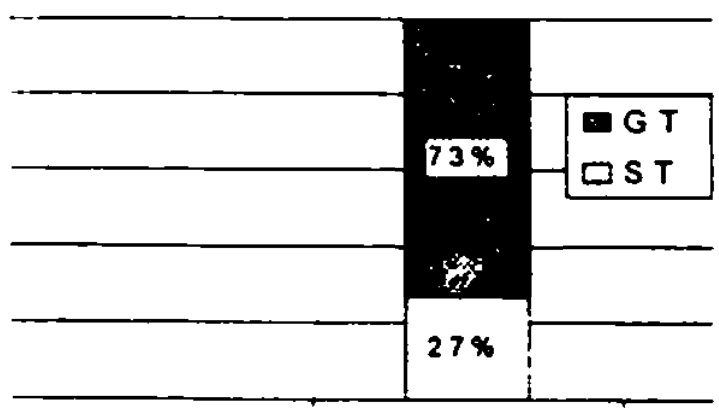

form ell

Einstellung, kognitives Subsystem:

Derkannt D nicht erkannt

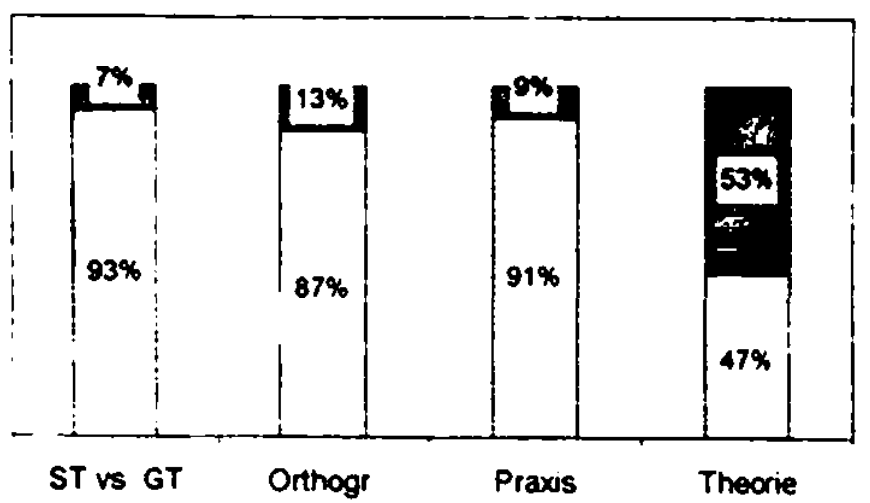

Eimstellung, affektives Subsystem: Grad der positiven Einstellung $67 \% 67 \%$

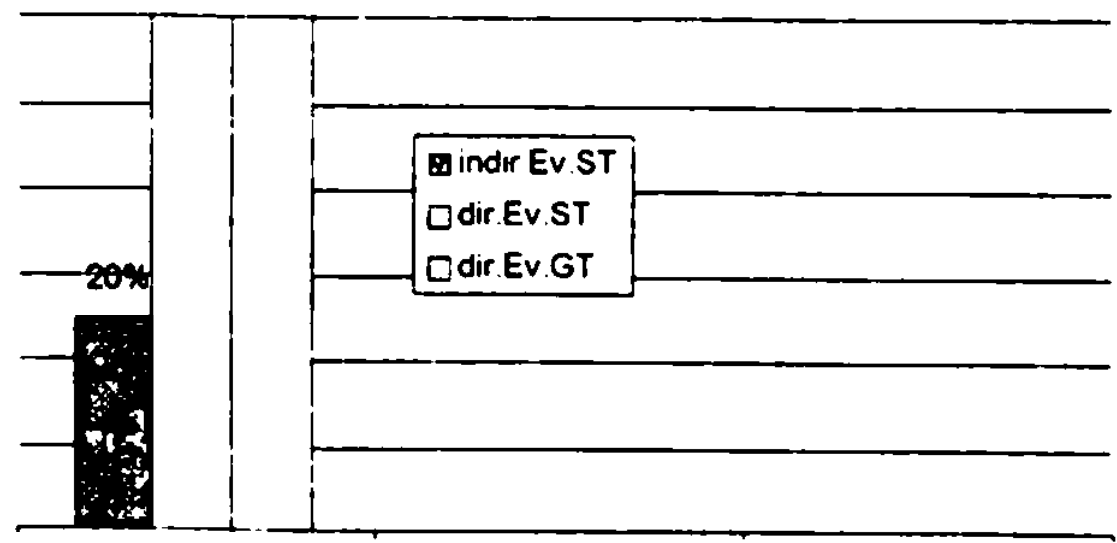




\section{Student, 25 Jahre (5. Studienjahrgang)}

Procijste si uybral práve studium práv?

- No. vybral jsem si to proto, že mê tenhleten obor zajimá, chtěl bych trošičku do budoucna vêdèt $Q$ čem to je. A zkusit to taky jako advokát nebo soudce. To se ještè uvidi.

Takx jaké máte konkremini výhledy do budoucna?

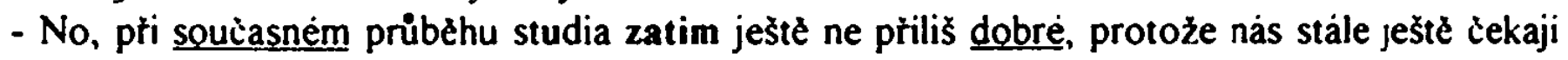
dva roky. Ale doufäm, že to zdárné dokonciom. a že pak teda uvidim, kam se hnu.

A jake cri jazyky studujere?

- Jeden už jsem teda dostudoval. Mam státnici $z$ angličtiny. A jinak jsem dêlal talštinu po dobu dvou let a rảd bych se vênoval pozdejji, aż bude vice casu švédštiné.

Proc prai'e tylo jazyky?

- Angličtina mè vždycky zajimala. italština se mi libi. protože je taková melodickả, a švédština proto. że jsem tam po nejaký cas pobjual, a takè se mi libi.

A red'ješíc otázka z jimé oblasti. Jaký je vás názor na posledni zimu?

- Posledni zima je taková rozpacitá - podle mého názoru. Dva roky už nebyl snih. Lividime, jak to bude prišti rok.

Maite pocit, te se zimy otepliji?

Myslim si, że se budou oteplovat. Podle toho, co ctteme $v$ dennim tisku $v$ rámci globalniho oteplováni zemékoule si myslim że ten trend bude pớad stejny.

Sprachverhalten:

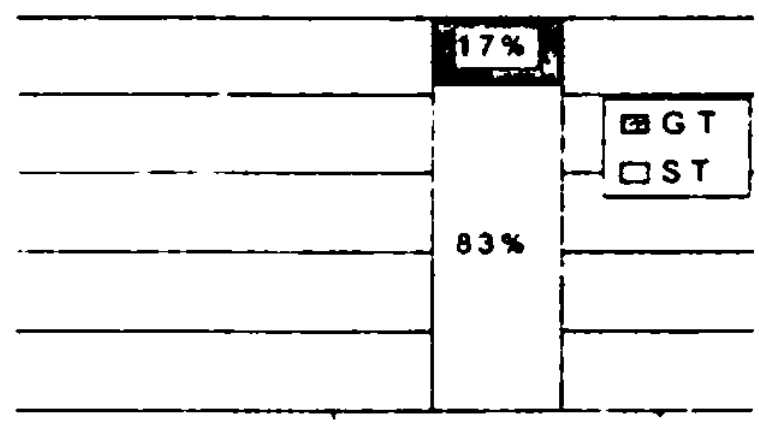

rorm ell

Einstellung. kognitives Subsystem

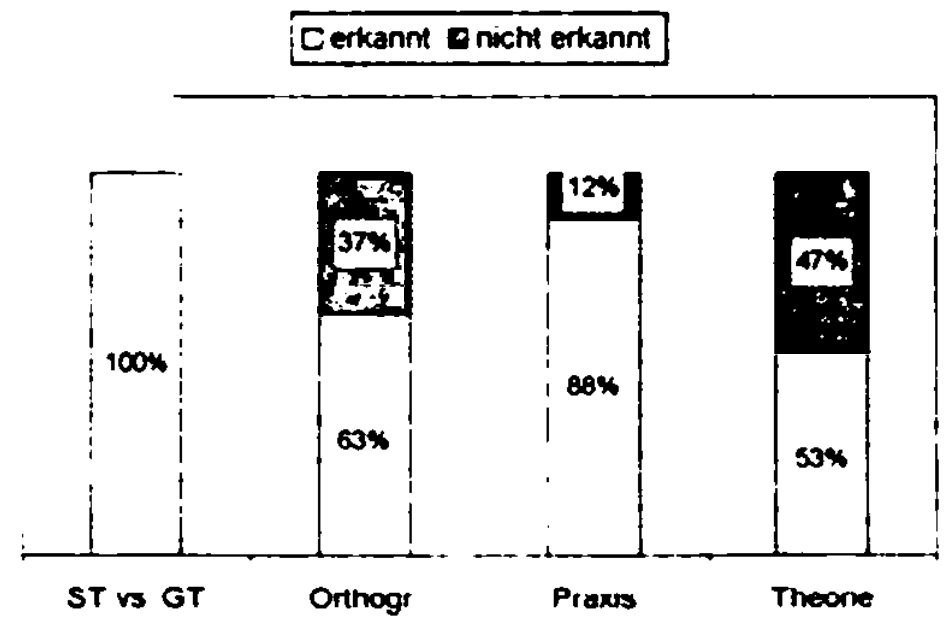

Einstellung, konatives Subsystem.

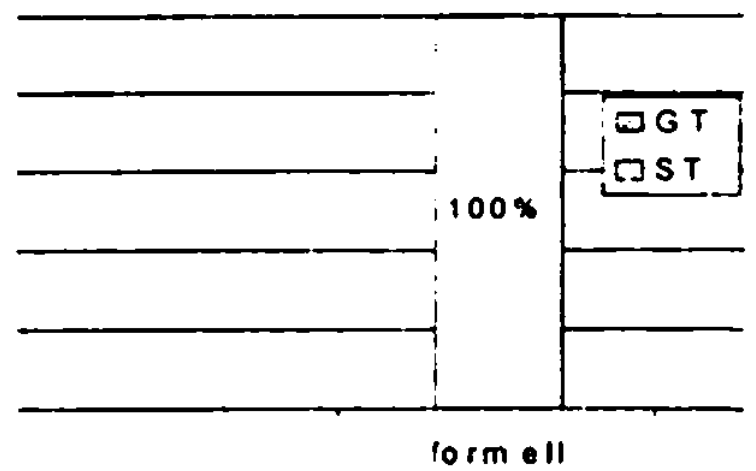

Evaluation der eigenen Kognition. 
Einstellung, affektives Subsystem: Grad der positiven Einstellung

$67 \% 67 \%$

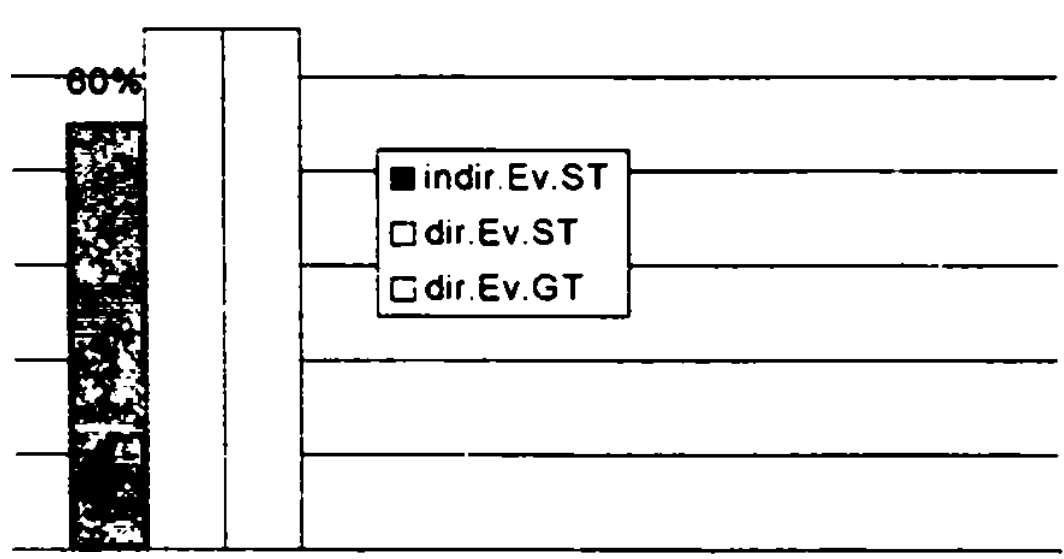

Kommentar: ohne Kommentar

\subsubsection{Sindemen der Technischen Fakultät}

Diese Studentengruppe wurde in der Fakultät während einer Lehrveranstaltung aufgenommen. Insgesamt wurden 5 Aufnahmen durchgefuihrt.

\section{Student, 22 Jahre (3. Studienjahrgang)}

Proc jste si uybral právè tento studijni obor?

- Protože si myslim, že - že to je perspektivni obor, że v naši spolec̉nosti je treba strojare, jelikoż vyioj jde neustále dopŕedu a za poslednich čtyticet let tady dost zaostalo.

Allo. a jahy mále vihled do budoncna?

- Výhled do budoucna v současný dobé v Plzni neni moc nủžový, jelikož Śkodovka jako nejvêtši tady možnost zamèstnáni má ekonomický problemy, ale na druhou stranu se objevilo plno novych soukromých firem, $v$ kterých uplatnèni, si myslim, že je.

Ulive se clzim jazyk um?

- Učim se némecky - bohužel ne moc úspěšnê - a anglicky

A proi zroina tylo die re ie i?

- No. tak nẻmecky jsem začal vlastně už na stredni škole a ted'ka jsem začal anglictinu, protože to je vlastnè celosvétovy jazyk.

Sprachverhalten

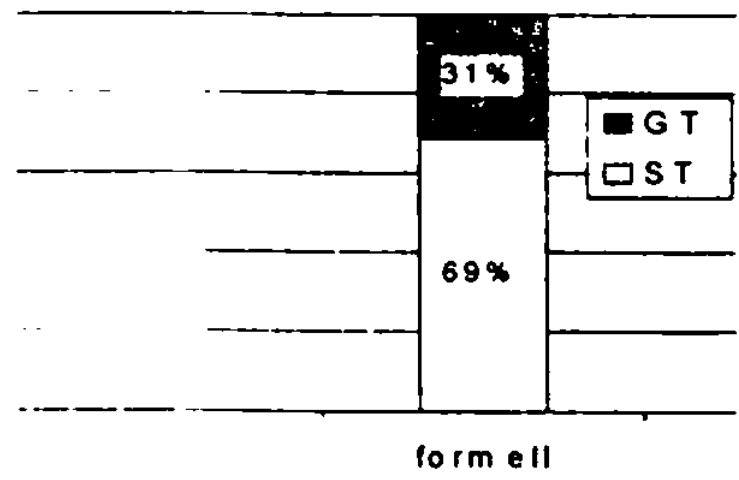

Einstellung, konatives Subsystem:

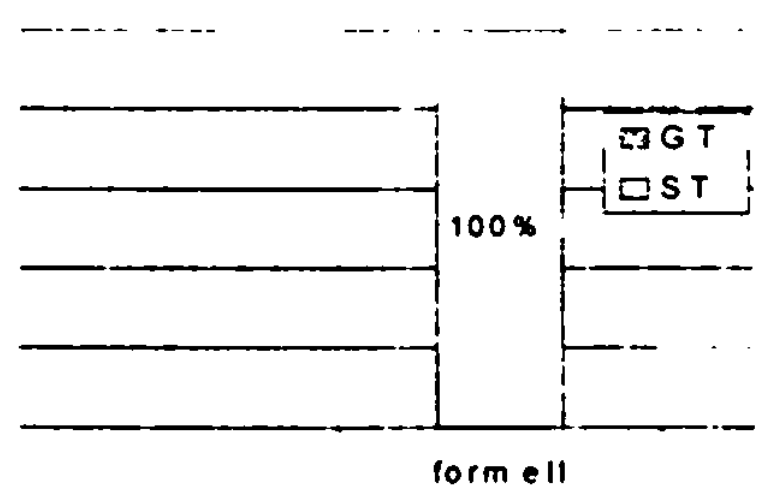


Einstellung, kognitives Subsystem:

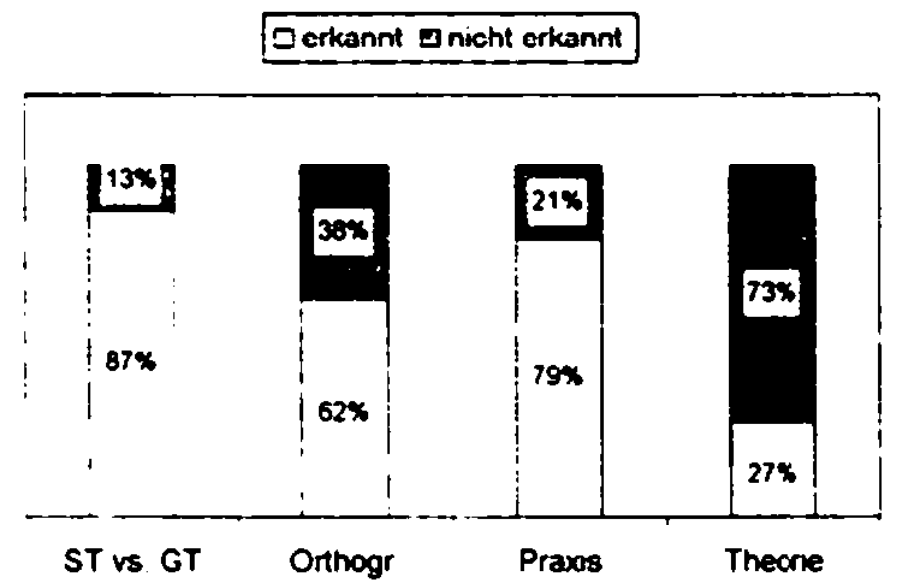

\section{Evaluation der eigenen Kognition:}

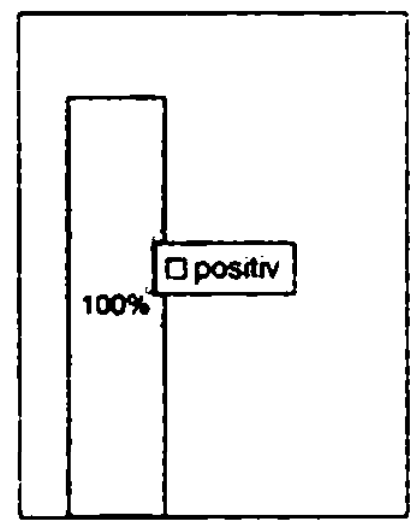

Einstellung, affektives Subsystem: Grad der positiven Einstellung

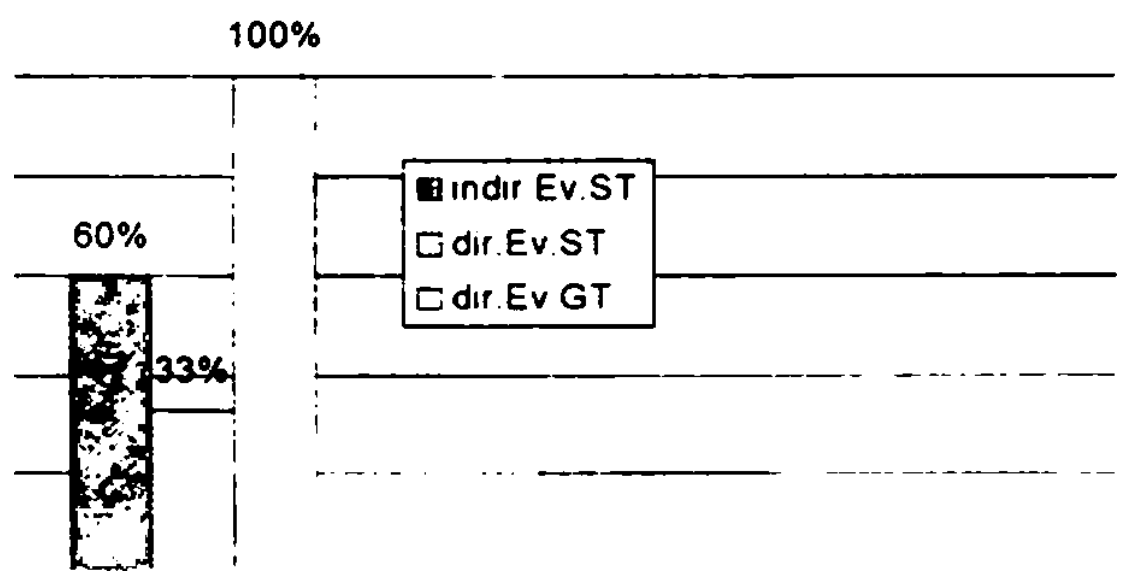

Kommentar: Jinak mluvim ve škole, jinak doma, jinak s práteli. $\mathrm{K}$ televizi: vadi mi, když komentatori koktaji (viz. pociasi, TV Prima).

\section{Student, 22 Jahre (3. Studienjahrgang)}

Proijjste si uybral pránè lento studijmi obor?

- Protože je zajimavý.

Máre je.šc cjimé denrody?

- Dalšim dúvodem bylo to, že jsem chodil ityrii roky na stredni školu, no a potom - v podstatě jsem chtêl navázat na to, co už jsem studoval. To byl dủvod. A dalšim důvodem je snad uplatnẻni v oboru - myslim si, że technika by méla bỵt to nejlepši, co by mélo byyt. Základ toho státu A jaky mále iyhled do budoucina?

- Vỷhled do budoucna neni tak rưžový, no - $v$ souçasné chvili. Ale myslim si, że se to zlepši Takì mále dobré perspekrivy?

- Vỷhled do budoucna je kladný - bych iekl. Nebo aspoñ doufäm, že bude kladny். a že se ve svem oboru uplatnim.

Ano, a jake se "cile cizi jazyky?

- No, učil jsem se nèmecký jazyk, $v$ soucasnè dobè se učim anglický jazyk. Myslim si, że $k$

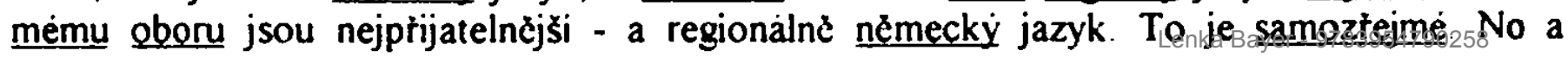


anglický jazyk - manuály, jestli je tr̉eba ještě nèco $\mathrm{k}$ tomu komentovat. Musi se studovat $v$ podstatê $v$ těchto jazycich - vêtš̉inou. Většina literatury je napsána $i \mathrm{v}$ anglickèm jazyce. Tr̉eba $\checkmark$ japonštinè nebo $v$ jinych jazycich je taky, ale vêtšinou bývá $v$ angličtinè

A ted' ješté otȧzka z jiné oblasti. Jak se Vam osobne libila letošni teplá zima?

- Jak se mi libila letošni teplá zima. No, nekvitoval jsem ji s povděkem. Samoziejmè ne, jelikož ċasto a rảd jezdim na lyže, a tak bych rekl, že moc ne. Mảm radeji zimu, kdy je snih, kdy mohu jezdit na lyže a uživat zimnich radovánek. Stavêt sněhuláka, koulovat.

Sprachverhalten

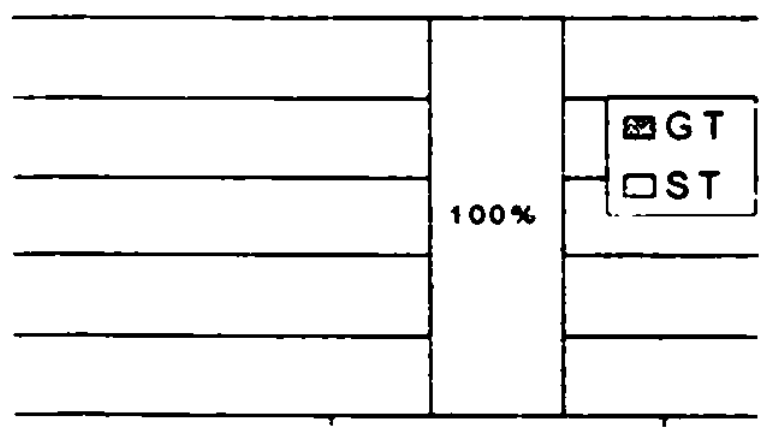

form ell

Einstellung kognitives Subsystem:

Derkant I nicht exkent
Einstellung, konatives Subsystem:

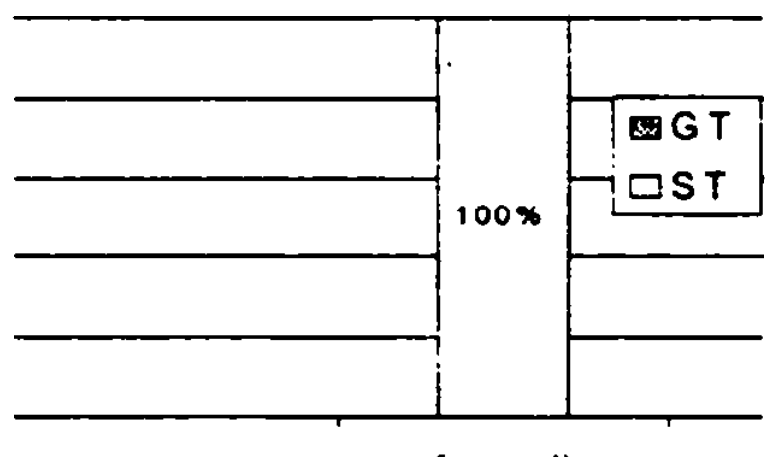

form ell

Evaluation der eigenen Kognition:

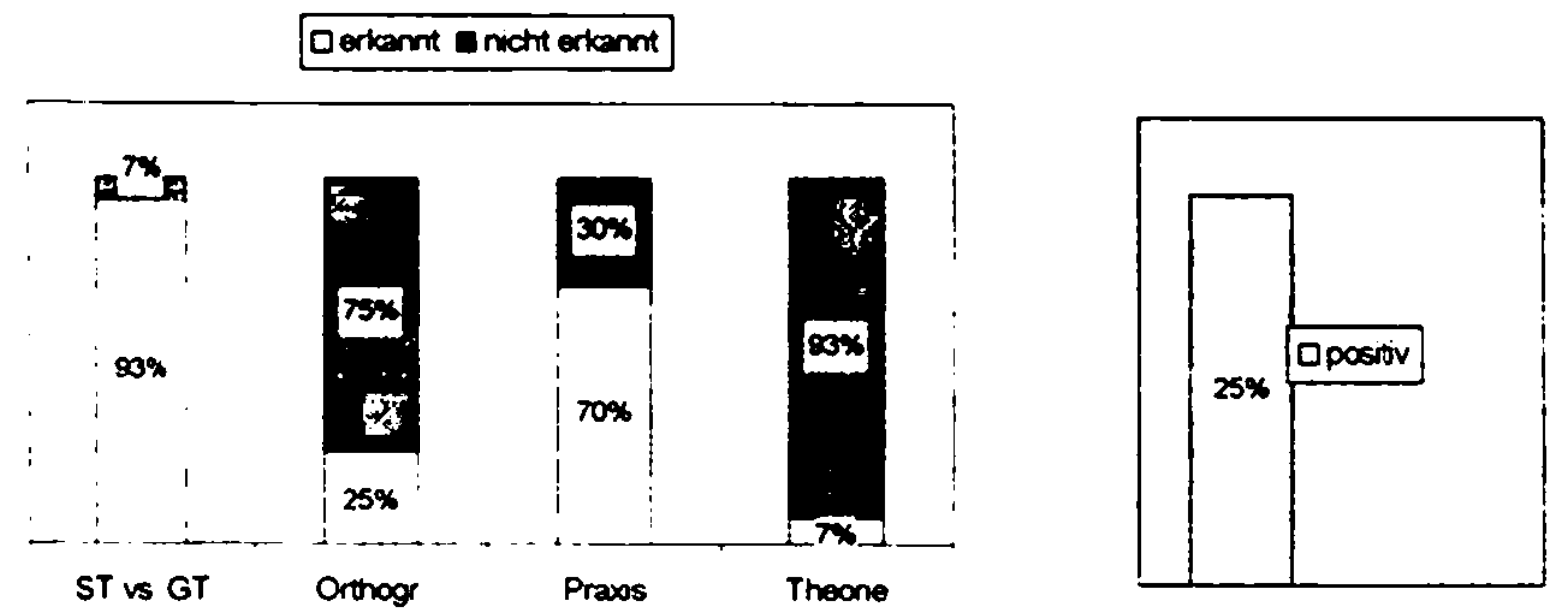

Einstellung, affektives Subsystem. Grad der positiven Einstellung

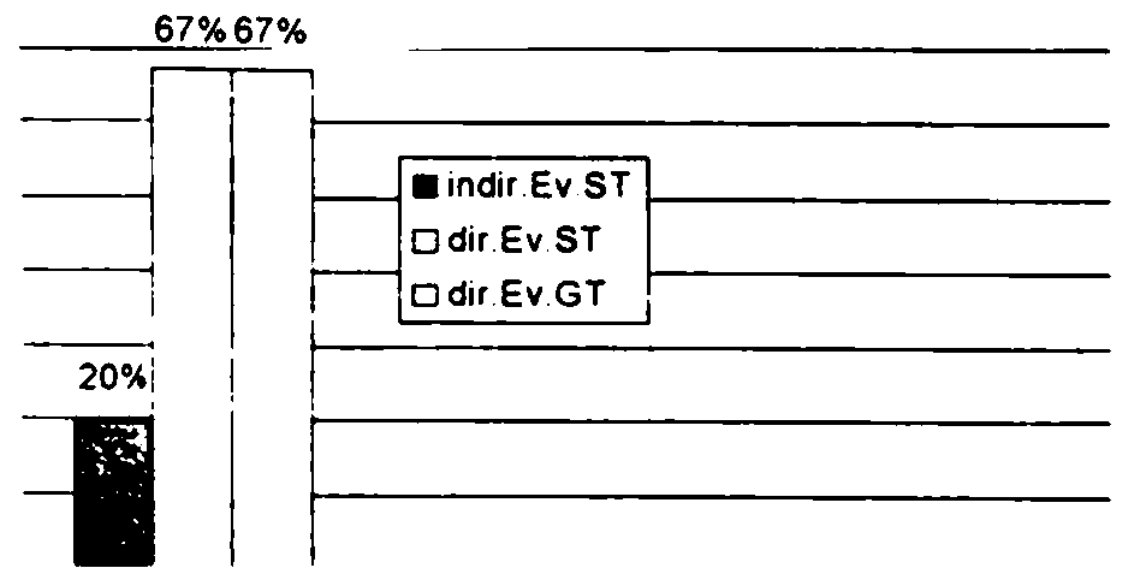

Kemmentar ohne Kommentar 


\section{Student, 22 Jahre (3. Studienjahrgang)}

Proc̀ jste si vybral právè temo studijni obor?

- Jelikoż mné nic jinýho nezbývalo. Ano, a dostal jsem to doponučeno od svèho nejlepšiho kamaráda, tak jsem se nechal inspirovat timto oborem a šel jsem studovat na tuto školu.

A jaky máte iyhled do budoncna?

- Bohužel hodně špatný, jelikož uplatněni $v$ této oblasti je sice dobré, ale platové podminky jsou špatný, tak mi nic jinèho zṙejmé nezbyjvá, než hledat jimé zamèstnáni v jiným oboru. A jake se "cite cizi jazyky?

- To je otazka sama pro sebe. Začal jsem ruštinou, po tłech letech - ne, vlastñ po ètyìech letech jsem ji prerušil, zahajjil jsem studium nẻmeckýho jazyka, které jsem taky po čtyrech letech ukoncil. Šest let jsem se učil anglický jazyk - a v souçasné dobè se uêim zase nuský jazyk. A jes̀t lè ózka z jimé oblasti. Jaky je láś názor na posledni teplou zimu?

- Posledni teplá zima - to je zajimavć. Klanêl bych se $k$ tomu, že to bude zrejme vlivem „El niña" a ekologických katastrof.

A jak vidite naši budoucnost, ţikajici se zim?

- Jelikož meteorologưm moc nevěrim, ocekávám lepši vývoj. To znamená chladnčjši zimy, teplejši léta.

Sprachverhalten:

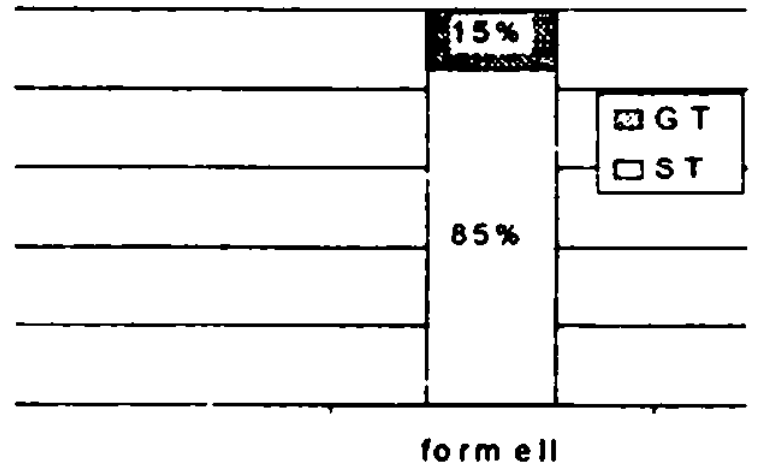

Einstellung, kognitives Subsystem:

Derkannt D nicht erkannt

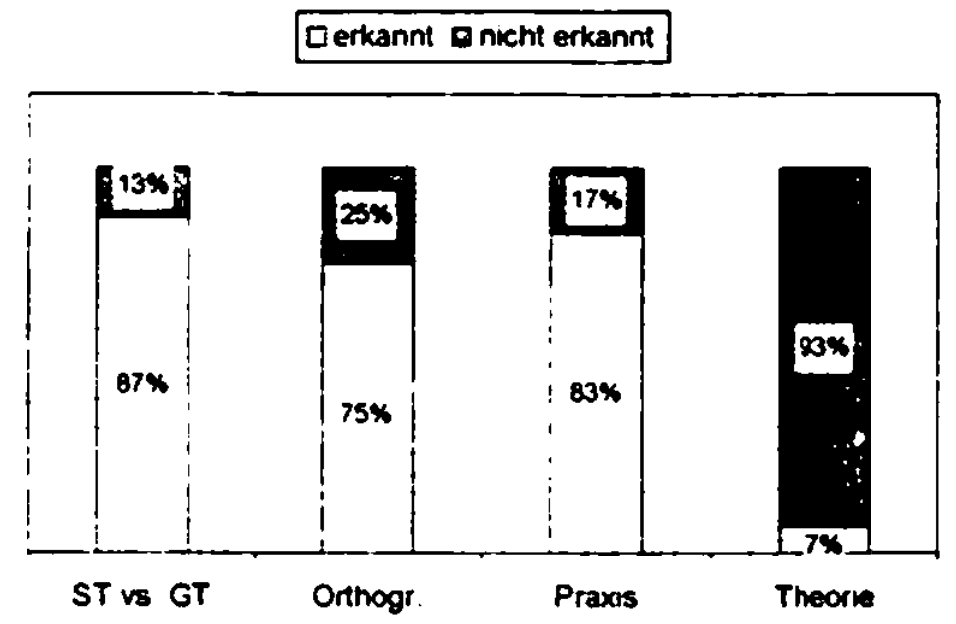

ST ve GT Orthogr. Praxs Theorve
Einstellung, konatives Subsystem:

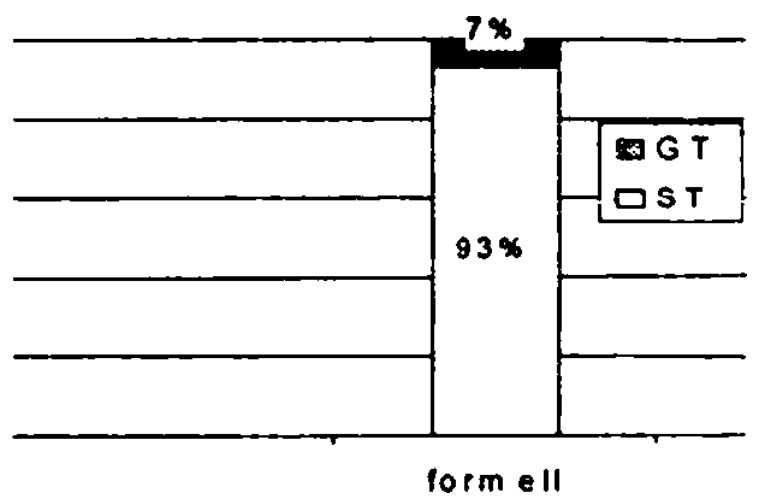

Evaluation der eigenen Kognition:

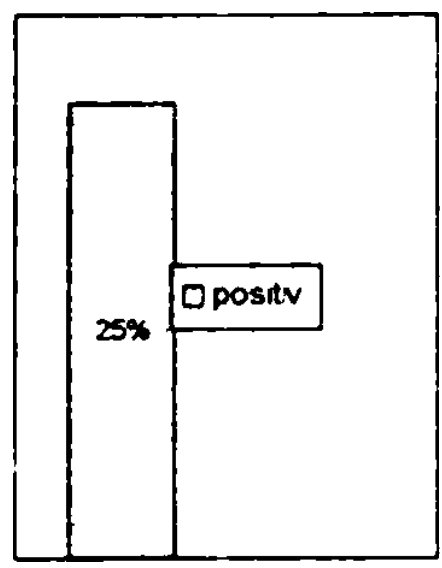


Einstellung, affektives Subsystem: Grad der positiven Einstellung

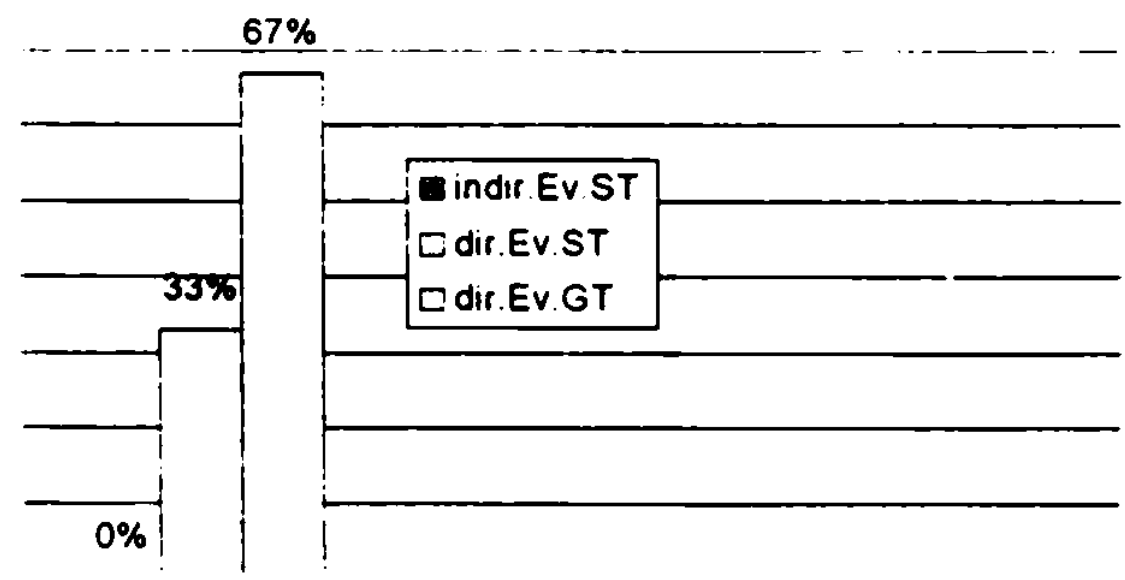

Kommentar: Jsem rảd, že se vưbec ještẻ nẻkdo tímto (myslim našim rodným jazykem) zaby்và. Chtêlo by to možná trochu vice času, a preji Vám hodnê ủspêchủ.

\section{Student, 22 Jahre (3. Studienjahrgang)}

Proc jste si vybral práve è temo studijmi obor?

- Tudleten - tento studijni obor jsem si vybral z toho důvodu, že - $v$ novinách jsem se dočetl $\underline{Q}$ nedostatku inženýru obrábżcu a inženýrú, který jsou urěený $k$ r̀izeni jakosti, $z$ c̀ehož se dảle odvinul müj zajem o tento obor.

A jaky mate vihled do budoucna?

- Vỷhled do budoucna - rád bych se prosadil $v$ nejakem strojirenském podniku. právê $v$ tomto oboru. ktery studuii.

Jake jazyky studnjete?

- Studoval jsem na základni škole ruštinu, pak asi sedm let němčinu a nčjaké znalosti anglictiny

A proci priv'e tylo jazyky?

- Dá se rict, že jsou to svêtové jazyky, mluvi s nimi - anglic̀tinou a nèmčinou - mluvi dá se rict osmdesát procent celèho svêta. A komunikace je dnes velice dủležità. takže je tr̉eba umêt tyto jazyky.

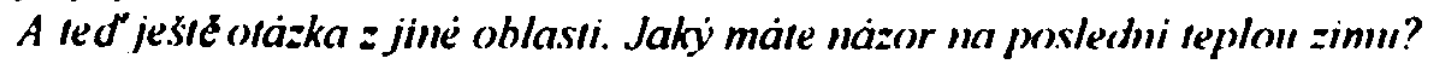

- Posledni teplá zima, no byl to presný opak zimy loñské. Nedà se presné rici, co bylo prijjemnejjisi, jestli ty obrovské mrazy, které postihly naši republiku loni, nebo zima teplà, která byla letos. Tẻzko rici. Na tuto otázku je têżko odpovèddèt.

Budou budouci zimy podle l'ašeho nazoru replejši a nebo zase porádne sfmdene?

- No, meteorologové predpovidaji, že $v$ budoucich ityriceti letech by msly bỹt zimy studené. ale jestli se tyto prognózy potvrdi - těžko rici. 
Sprachverhalten:

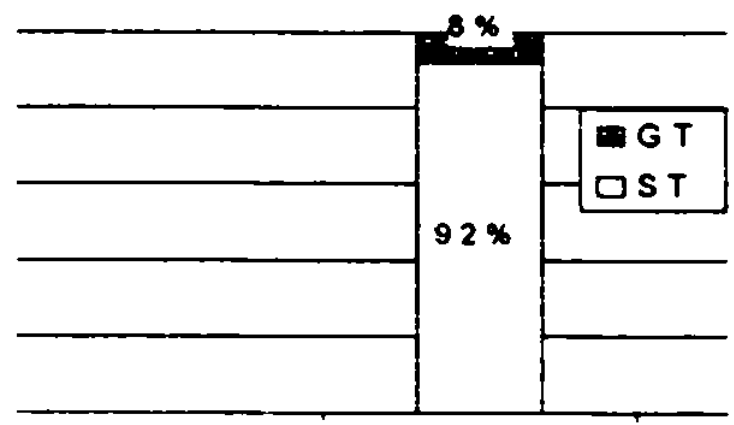

form ell

Einstellung kognitives Subsystem:

Derkannt o nicht erkannt

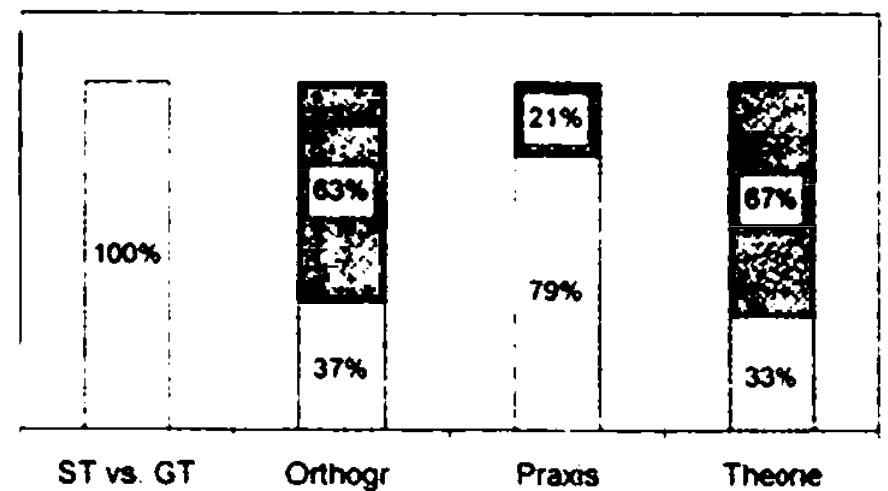

Einstellung, konatives Subsystem:

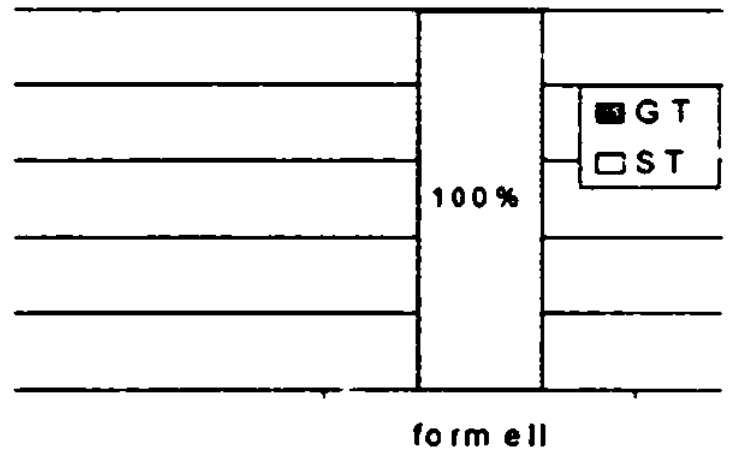

Evaluation der eigenen Kognition:

Einstellung, affektives Subsystem Grad der positiven Einstellung

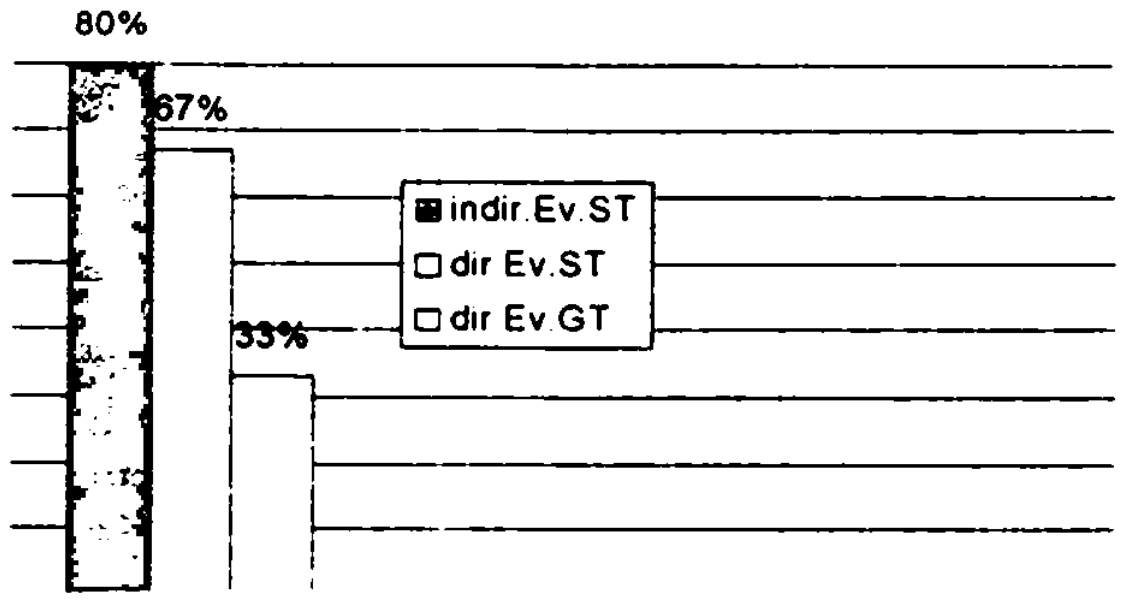

Kommentar: Tato anketa slouži spiše k osobnimu ověreni a provẻreni svých znalosti ceskèho jazyka, ale nedává stoprocentni obraz o tom, jak bychom se $v$ dané situaci zachovali (mluvili). Prii každdodennim hovoru se na nás vice, ċi méné odráżi volba slov $\Rightarrow z$ toho se odviji i kvalita hovoru

\section{Student, 20 Jahre (1. Studienjahrgang)}

Procijste si iybral pràve lemo studijni obor?

- Tento studijni obor jsem si vybral, protoże jsem vlastnè studoval středni prumyslovou školu strojni a libi se mi technika. 
A jaky mále vihled do budoucna?

- Vỷhled do budoucna - rảd bych někde zủstal $v$ nęjakèm strojar̉skèm podniku, pravdépodobně $\checkmark$ mistẻ bydlištẻ.

Ano, a jake jazyky' studujete? Jake cizi jazyky?

- Ted' momentảlnẻ studuji nèmčinu, studoval jsem angličtinu, tu jsem ukonciil zkouškou. Takže jenom tyto dva.

A proc práa étyo ctia jazyky?

- Tyto dva jazyky asi proto, protože jsou nejpouživanějši a jsou nejžảanějši.

Diknji. A red'ješté otázka z jime oblasti. Jaky màte názor na posledni teplou zimu?

- No, názor - że to je špatný, no. Asi tak.

Nelibila se I"àm? A proc, z jakého dinnodu?

- No, tak v zimè prece jenom má bỹt zima, aby si êlověk užil têch zimnich radovánek.

Sportujete, psstujete "ějaky zimni sport?

- Taky, mimo jinè. Vêtšinou bežzy a z jiných sportů potom volejbal.

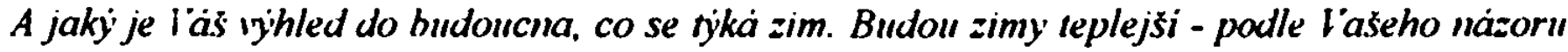
- anebo budou zase porádné studené jako driv?

- No, co se vlastnè týče oteplováni planety, tak předpokládam, že asi budou teplejši.

Sprachverhalten:

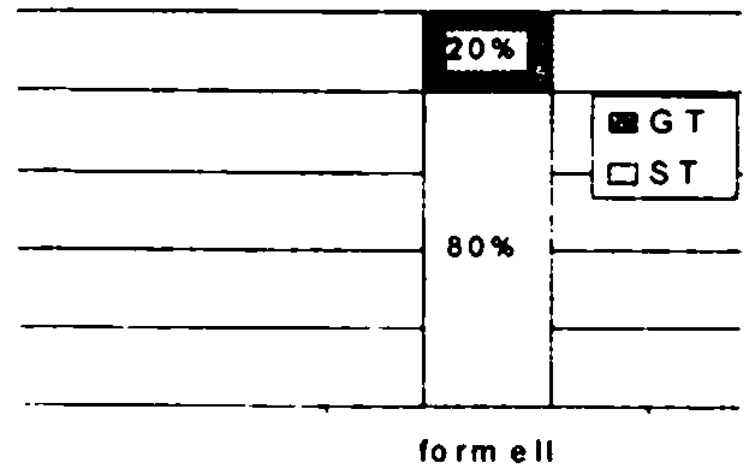

Einstellung, kognitives Subsystem:

Gerkannt Dicht erkannt

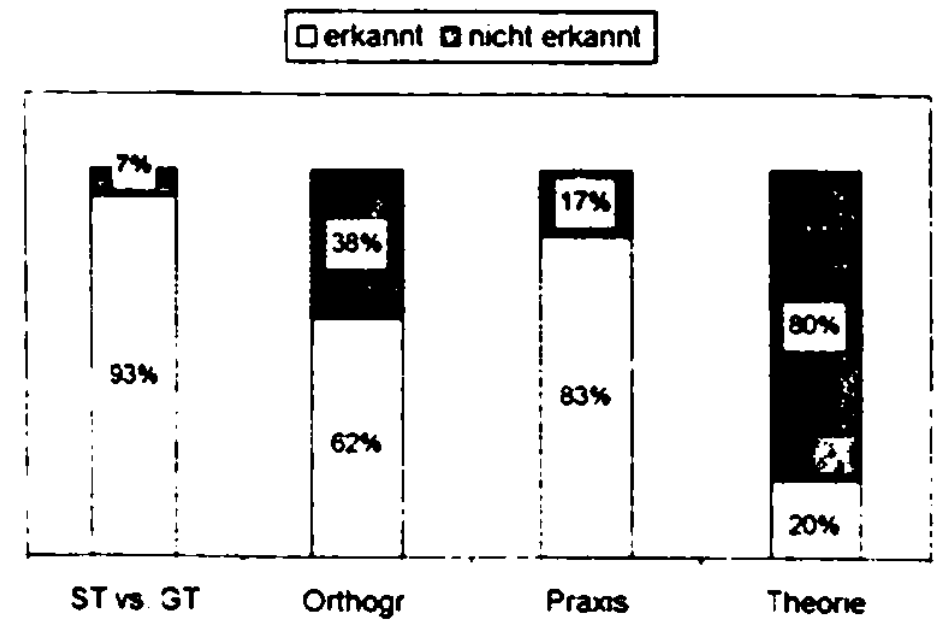

Einstellung, konatives Subsystem:

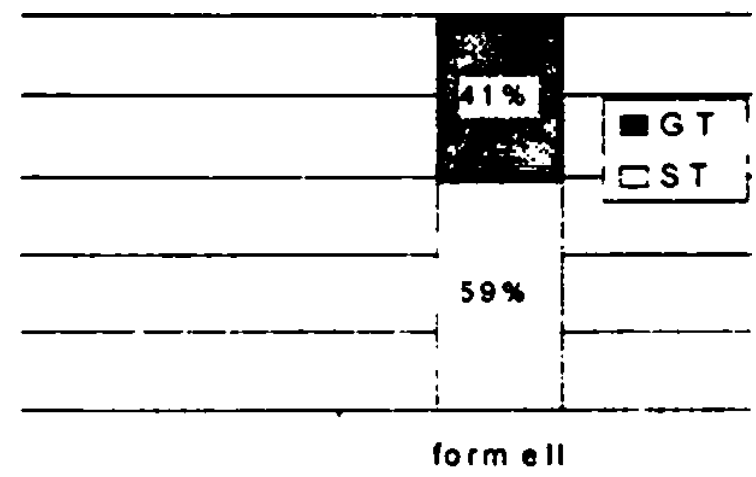

Evaluation der eigenen Kognition:

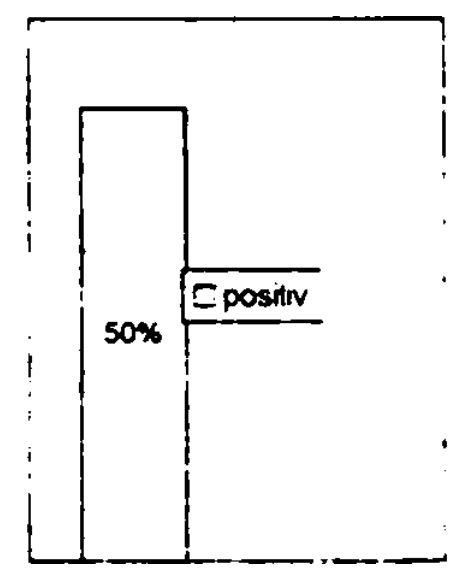


Einstellung, affektives Subsystem: Grad der positiven Einstellung

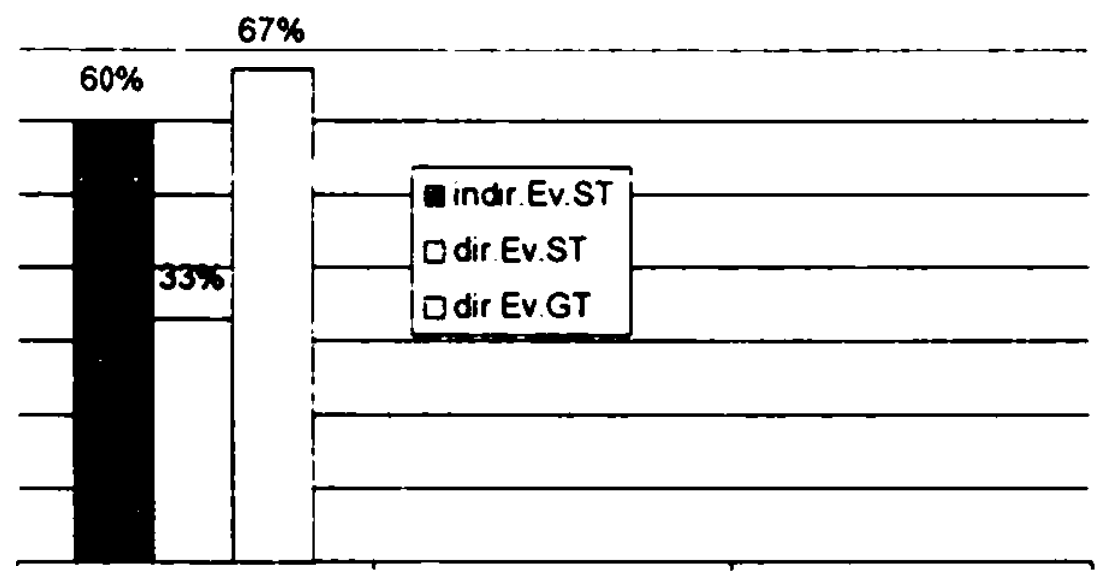

Kommentar: Anketa je velmi zajimavá, ale myslim si, že $v$ ni chybi některé výrazi ${ }^{\prime \prime \prime}$, kterými se predevšim odlišuji nẻkterả náreči. Priklad - kudy pudeme - Plzeñáci - kudypa pudem.

\subsubsection{Simdentimmen der Pädagogischen Fakultät, Bohemistik}

Die Studentinnen ${ }^{112}$ wurden in der Fakultät während einer Lehrveranstaltung aufgenommen Insgesamt wurden 5 Aufnahmen durchgefuhrt.

\section{Studentin, 22 Jahre (4. Studienjahrgang)}

Proc jste si uybrala právẻ temo studijni obor?

- Protože čeština a nèmčina už na gymnazziu mé dost bavila - jak ċeština, tak i némčina a taky oba dva predmèty mi nejvic šly. Mam $k$ nim blizky vztah a pedagogickou fakultu jsem si vybrala, protože chci bỷt ửitelka. Takže právê proto jsem se prihlảsila na tuhle fakultu. Ne za

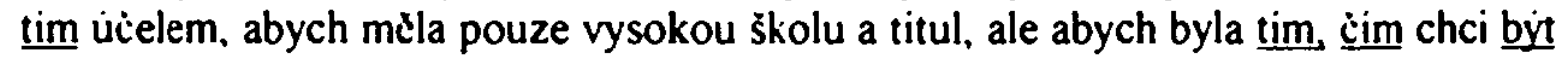
A jake mate vyhledy do budoucna, týkajici se vašseho povolani?

- No tak, $v$ soucasne dobs je ta situace ve školstvi - $i$ je dost nešastná, ale doufám, že dostanu bud' tady v Plzni anebo ve Stribrie, což je mèsto deset kilometrů od mého bydlištê, doufám, že tam dostanu misto. Pokud bych nezústala ve školstvi, tak bych asi uplatnila znalost némeckého jazyka. Takže bych bud' preklädala, anebo - prostẻ bych se vênovala jazyku.

Sinchujete jestc jiny jazyk mimo nónciny?

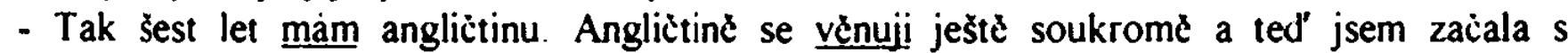
francouštinou. Kromé toho na gymnáziu jsem mêla latinu, se kterou jsem pokračovala tady na vysokẻ škole. Màm z toho zkoušku. Samozỉejmè ruština byla kdysi u nas hlavnim svêtovyjm jazykem, ale to už jsem tak trošku i zapomnela.

A ted' ješlć otázka z jime oblasti. Jaky je vàs názor na posledni mirnou zimu?

- No, názor na posledni mirnou zimu. Já nejsem meteorolog, odbornik, abych to nejjakjum zpúsobem mohla komentovat. Rikalo se. že nastávà oteplovani planety, takže snad to $s \underline{\text { tim }}$ souvisi Nevim. co bych $k$ tomu mohla rict. (...) Takhle, ja jsem milovnik bileho sportu. Ja jsem milovnik zimnich sportú, ale samozrejmc jako każdý clověk nemám rảda ty kruté mrazy. To

"II Dieser Ausdruck wurde von deın Respondenten niclı korrekt aufgeschricben. Die richtige Form ware: ivirazl.

11: Es handelt sich um Studierende (siche auch Kap. 6.3.1.4). die das Tschechische (Sprachwissenschaft bzi Literatur) für das Lchramt an Gymnasien und Fachoberschulen in Kombination mit mindestens einem weiteren Fach studieren. 
znamená tèch deset stupñủ pod nulou, ale nicménè - pro mé je určitẻ lepši, kdyż je zima taková. jaká má bỳt. Takže když bych to mêla zhodnotit, tak jsem z té letošni zimy nějak nadšená nebyla.

Sprachverhalten:

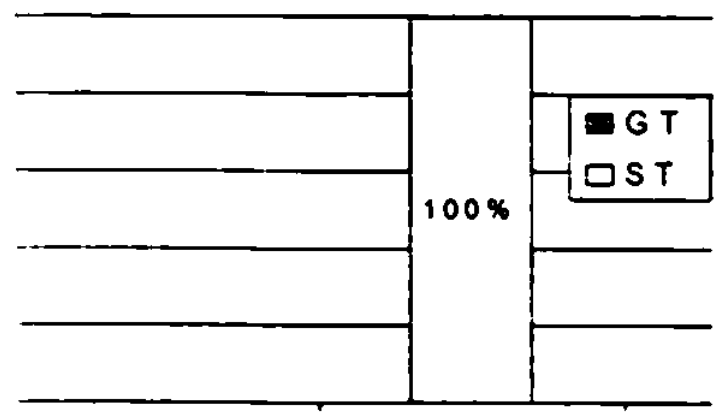

lorm ell

Einstellung, kognitives Subsystem:

Derkannt Enicht erkannt

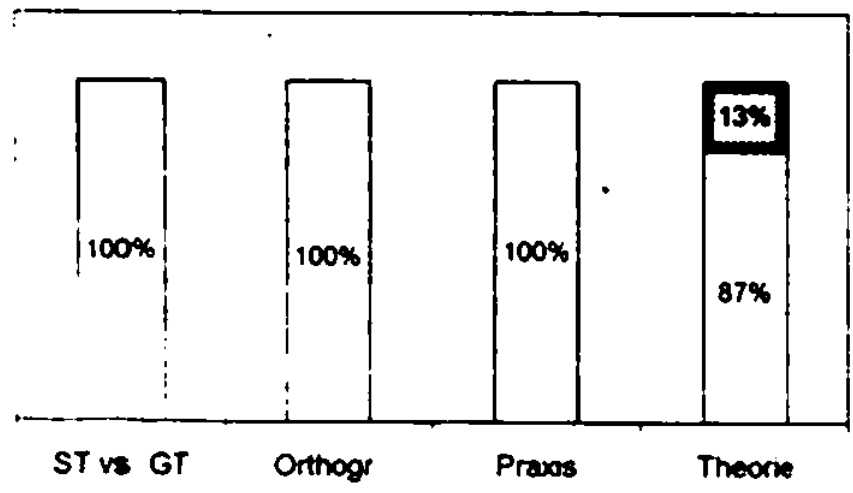

Einstellung, konatives Subsystem

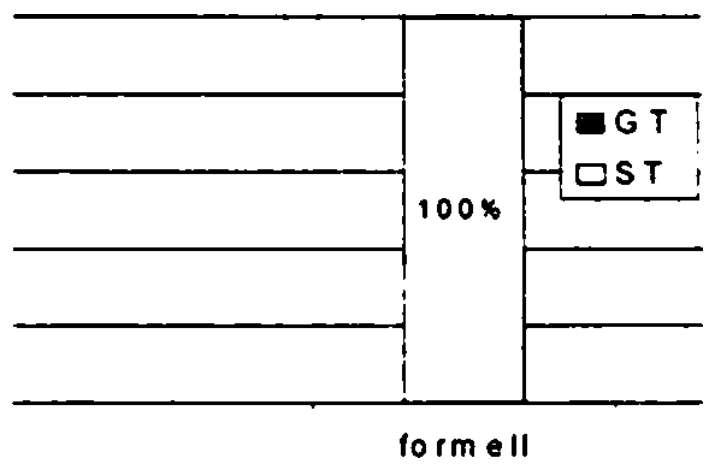

Evaluation der eigenen Kognition:

Einstellung, affektives Subsystem: Grad der positiven Einstellung

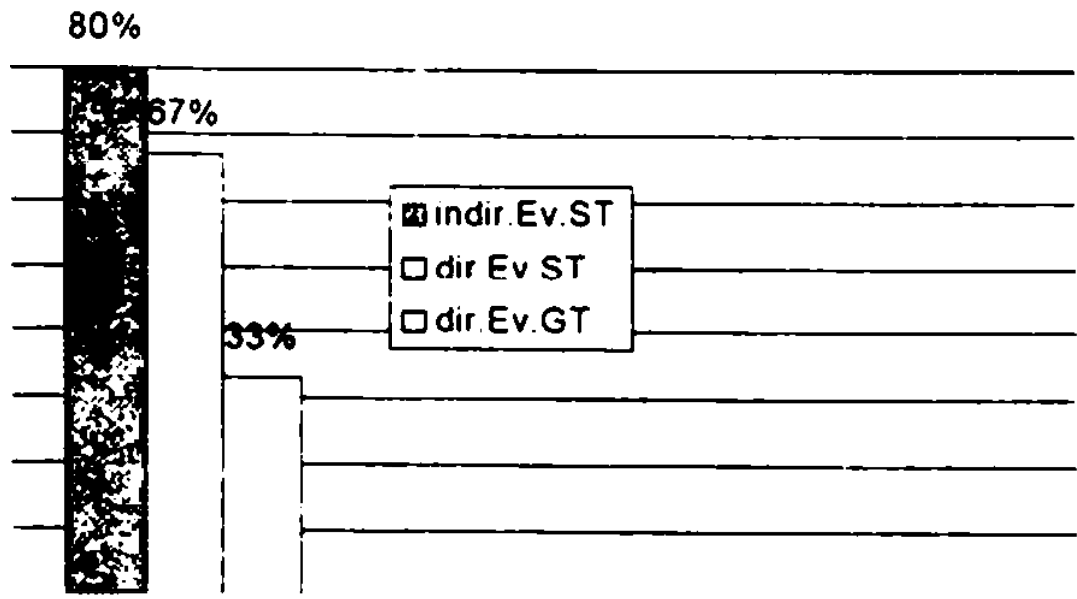

Kommentar: Situace spisovné češtiny je $v$ dnešni dobẻ, myslim, velmi kritickả. Markantni je to ve školách. Nejvic jsou postiženi ${ }^{113}$ déti a dospivajici mlädeż. Maji problèm s vyjadrovánim. Promluvit spisovnou ceštinou je pro nê obrovskỷ problèm. To. že nêkterým politikủm a verejnè cinným lidem dêlá potiže promluvit spisovné je zrejmé a někdy i dost viditelné.

"I" Dieser Ausdruck wurde von der Respondentin nicht korrekt aufgeschricben. Die riclutige For ıI ware pextituny. 


\section{Studentin, 22 Jahre (4. Studienjahrgang)}

Proc jste si uybrala právex temo studijmi obor?

- Protože mé čeština odmalička zajimala - vlastné vedli mé $k$ tomu trochu $i$ rodiče a vybrala jsem si kombinaci ještể s ruštinou, takže já bych łekla, že u mě je ten zảjem vủbec $o$ jazyky už odmalicka.

A jake máte vihledy do budoucna?

- No, moc dobré ne. Vzhledem $k$ tomu, že ruština porád ještê neni perspektivni. Jà bych chtêla učit češtinu i ruštinu, ale bohužel v současne dob̌̉ na školách ruština se moc neuči. Takže uvidime.

Studujete mimo rušstiny a čstiny jest é dalsi jazyky?

- Studuji angličtinu ješté.

Proc práve angliçimu?

- Protože se mi angličtina libi. To je asi tak všechno.

A ještc jimá otázka. Jaký máte názor na posledni mirnou zimu?

- No, mnè se nelibila vủbec. Vzhledem $k$ tomu, že jsme byli lyžovat na Slovensku a ani tam nebyla studená zima a snih $\vee$ Tatrách všechen roztả, takže jsme si moc nezalyžovali a deštivà zima - to neni ono.

Màte dojem, ¿z momentálni chripková epidemie s touı mirnou zimou néjak souvisi?

- Jà ani nevim vo tom, že je chr̉ipková epidemie. U nás neni - tak. Ale myslim - byla i minulý rok, a byla i predminuly rok - myşlim. že nèjakou souvislost to mit musi, když se zimy postupné otepluji - a drive tady tolik chripkovych epidemii nebylo.

Sprachverhalten:

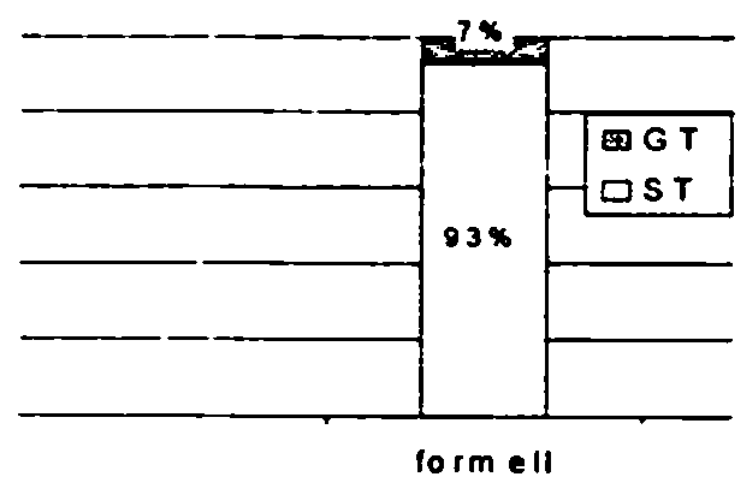

Einstellung, kognitives Subsystem:

Qerkannt Encht erkannt

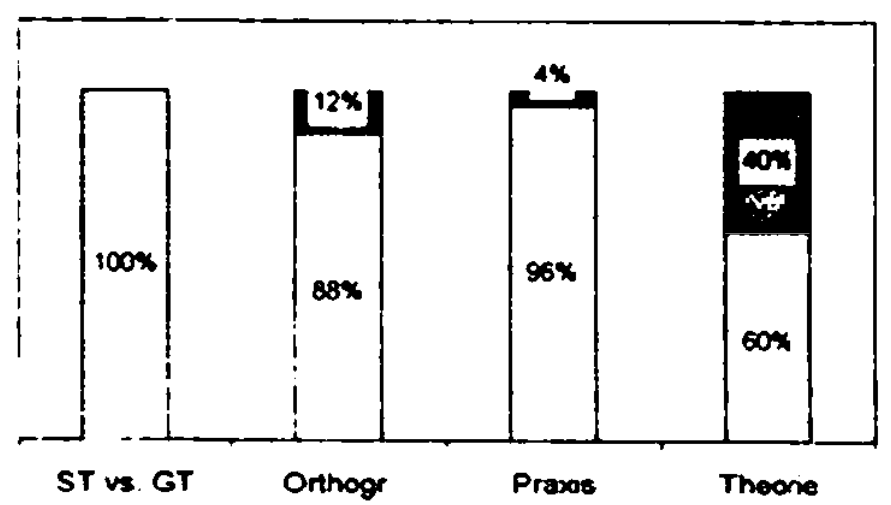

Einstellung konatives Subsystem.

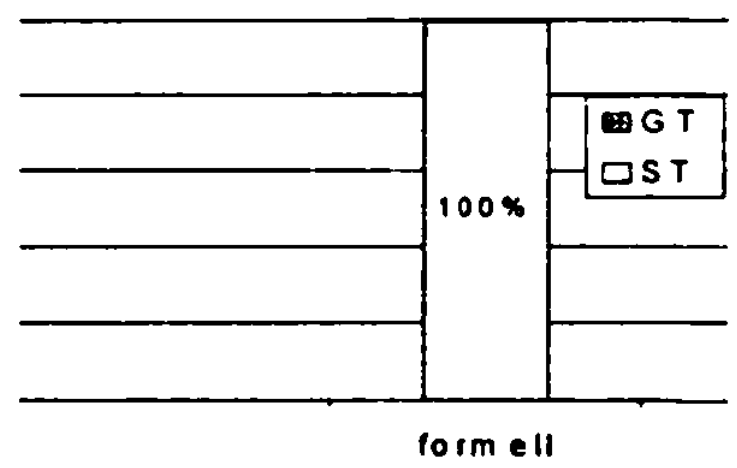

Evaluation der eıgenen Kognition:

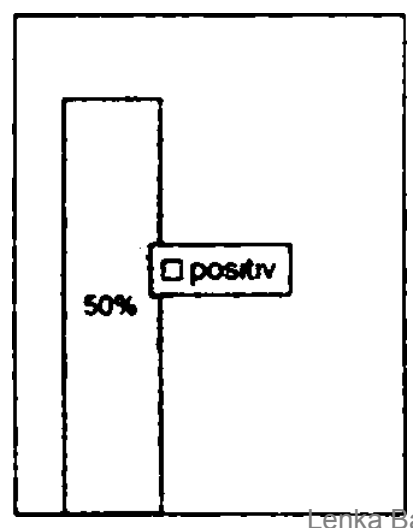


Einstellung, affektives Subsystem: Grad der positiven Einstellung $100 \%$

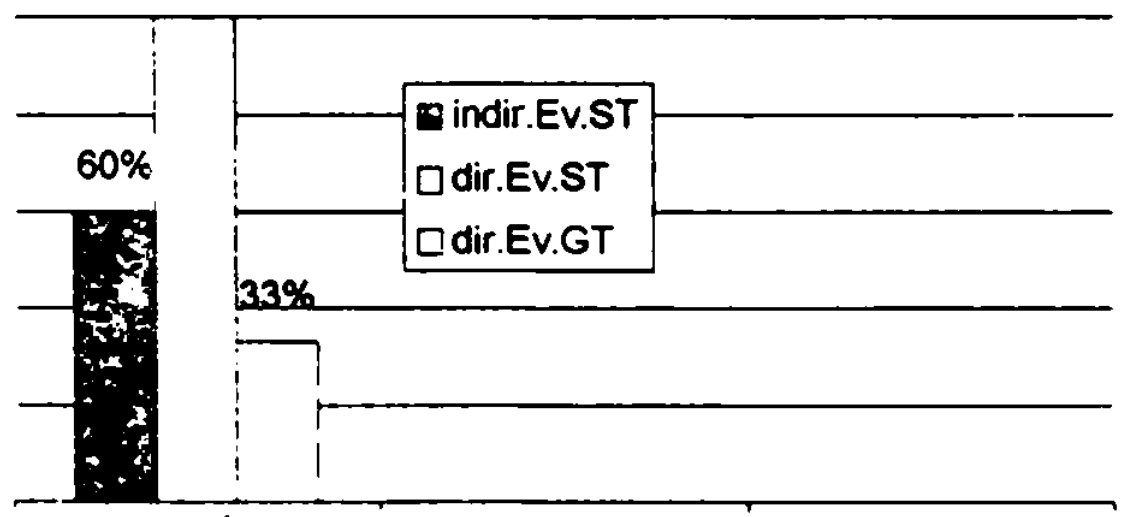

Kommentar: Úroveň vyjadłováni ve spisovném jazyce i na hodinách ceského jazyka vyrazne klesá. Žàci nejsou vedeni $k$ vyjadrováni se ve spisovném jazyce ani doma ani ve škole. Casto nedokážou rozlišovat, který výraz je spisovný a který nikoliv.

\section{Studentin, 24 Jahre (3. Studienjahrgang)}

Proc studujete pràne bohemistiku?

- Protože mẻ zajimala už na středni škole literatura.

A jake máte ujhlecty do buctoucna, jake máte plány?

- No, vỷhledy jsou špatnê., protože učitelè jsou vlastné k nepotrebẻ dnes, a málo placený. Jake se "isire cizi jazyky?

- No, zadaè, protože já na to moc nemám hlavu, tak mi to moc nejde. Já umim anglicky, ale jinak se nevzdělávám dále.

Máre v plainu se "cit cizim jazyk im v budoucmu?

- Cizim jazykủm asi ano, protože $k$ tomu budu asi prinucená prosté vỷbęrem pracovniho mista. že mè to asi prinuti se ucit.

A ted" jes̀tẻ otäza z jimé oblasti. Jaky máte näzor na posledni replou zimu?

- Ľàdny

Libila se vam amebo jsste byla zklamana?

- No, tady v Plzni je vždycky teplá zima, takže já to nijak nehodnotim. Spiš se mi libila, já nenıam zimni boty.

A jaké máte vihledy do budoncria. Budon se podle vašeho názorn zimy oteplovat

- Myslim. že budou studenčjži. Uż ted'ka napadl snih.

Sprachverhalten:

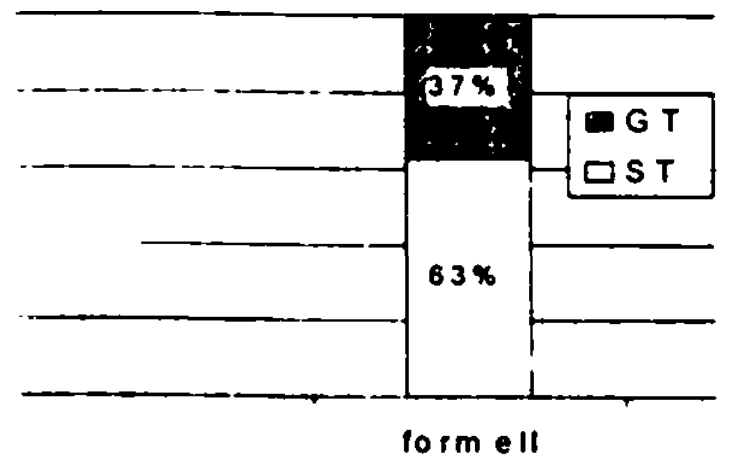

Einstellung, konatives Subsystem

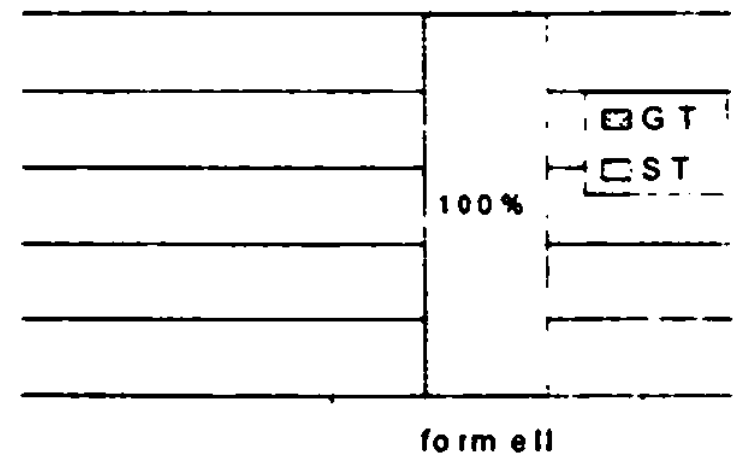


Einstellung, kognitives Subsystem:

Derkannt oncht erkannt

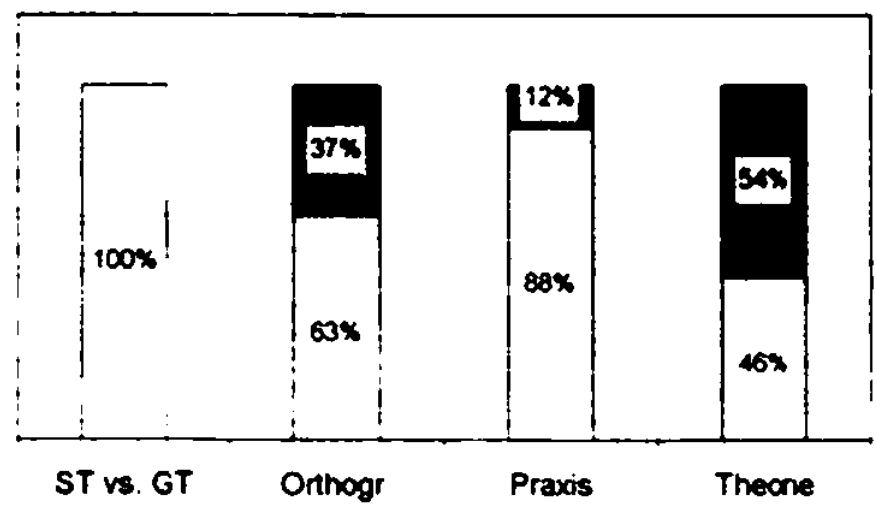

Evaluation der eigenen Kognition:

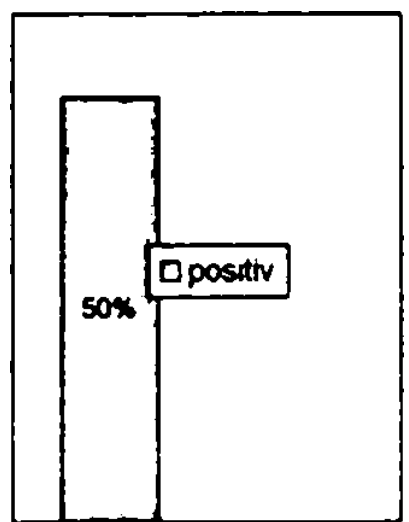

Einstellung, affektives Subsystem: Grad der positiven Einstellung $80 \%$

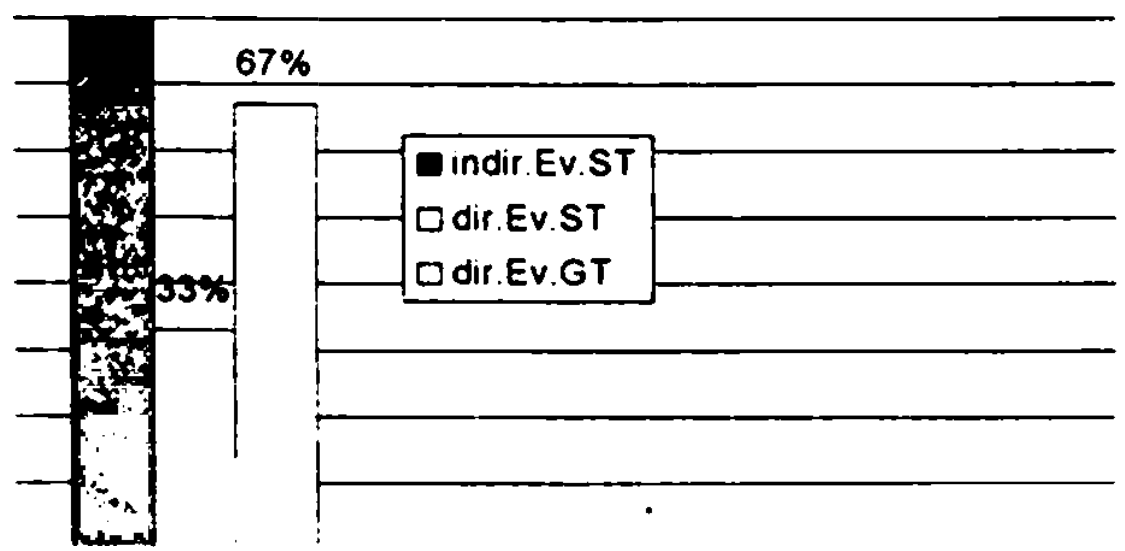

Kommentar: Mluva $v$ televizi a $v$ rozhlase spiše směruje $k$ použiváni hovorových, nespisovných prvkü jazyka; což. považuji za chybu a znehodnoceni jazyka.

\section{Studentin, 21 Jahre (4. Studienjahrgang)}

Procjsste si iybrala práde temo studijmi obor?

- Tenhleten studijni obor jsem si vybrala hlavné kvili divadlu - jsem deset let hrála divadlo - a kvủli recitováni, protože mam strašné ráda básničky. Tak hlavnè to mé pritiáhlo $k$ češtiné. No. a pak druhý predmèt mam nẻmčinu. tu už jsem dẻlala hodné na stredni škole a bavila mé. Jaky maite vyhled do budoucna. tykkjici se vašeho povolani?

- No tak, doufam, že u nás misto najdu. Bylo mi tečeno, že nèmčinár̆u - že nèmčináre potrebujou, takže doufam, že néco najdu. Rảda bych zủstala $v$ nęjaké odborné stredni škole. A divadlo "ż vás neláká?

- Láká mé porad a ráda bych ho délala jednou s mýma studentama Simdujele ješsı dalši cizi jazyky?

- Dẻlala jsem hodnê dlouho angličtinu, ale ted̛ už bohužel - ruštinu jsem taky dêlala -, ale oba dva jazyky úspešně zapominam.

A ted' ješı đ̇ otȧka z jimé oblasti. Jaky máte názor na posledmi mirnou zimu? Libila se vám?

- No, pokud byla teplá, tak se mi libila, ale ted'ka uż by to zase chtélo, aby se to teplo vratilo, protože snih moc rảda nemám. A nerada lyżuju. takže radß̌i to teplo 
Spojujete chrïpkovou epidemii, která momemálne rádi v Evropè, s touto mirnou zimou?

- No, asi možný to bude. Nejsem teda odbornik, ale myslim si, že jo, že to néco má do sebe.

Sprachverhalten:

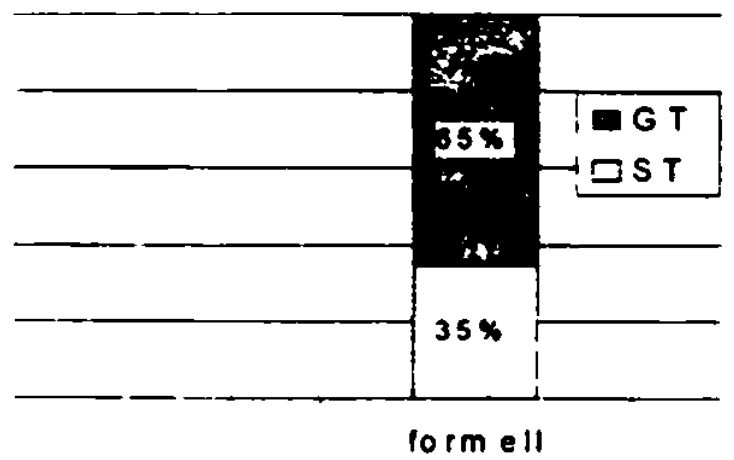

Einstellung, kognitives Subsystem:

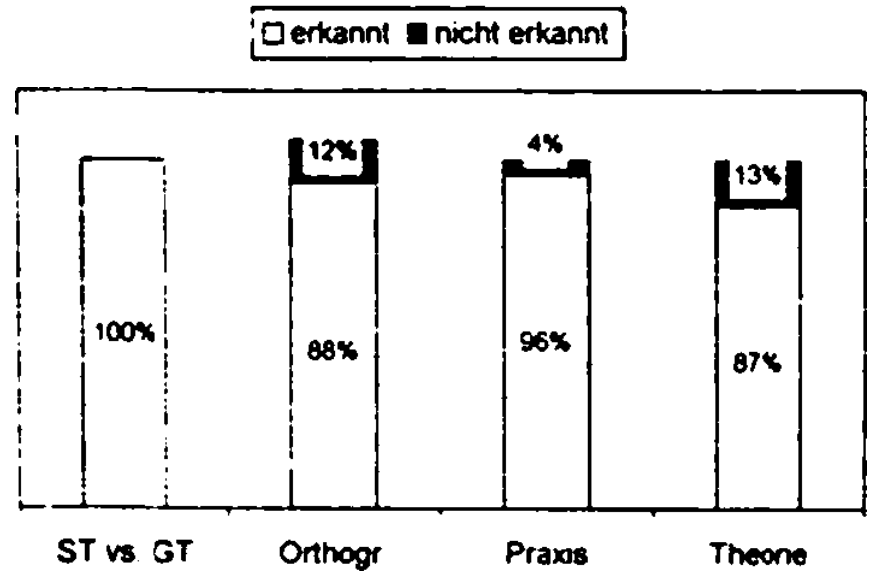

Einstellung, konatives Subsystem:

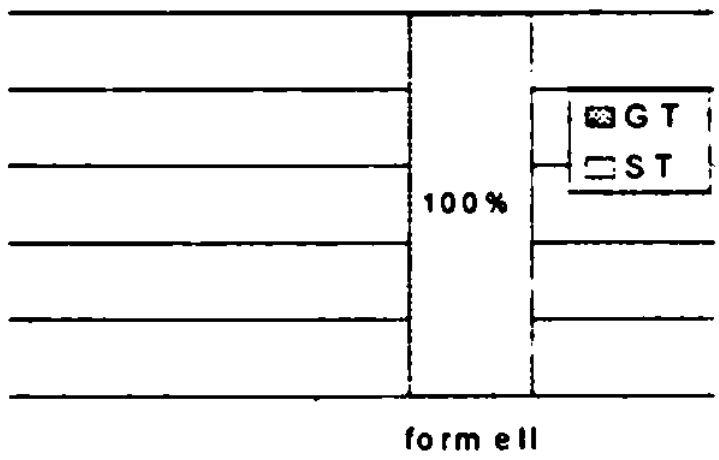

Evaluation der eigenen Kognition:

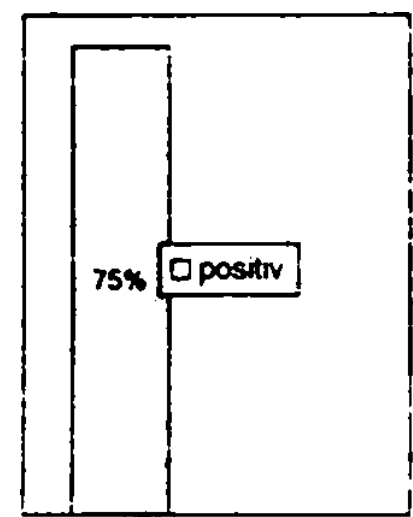

Einstellung, affektives Subsystem: Grad der positiven Einstellung

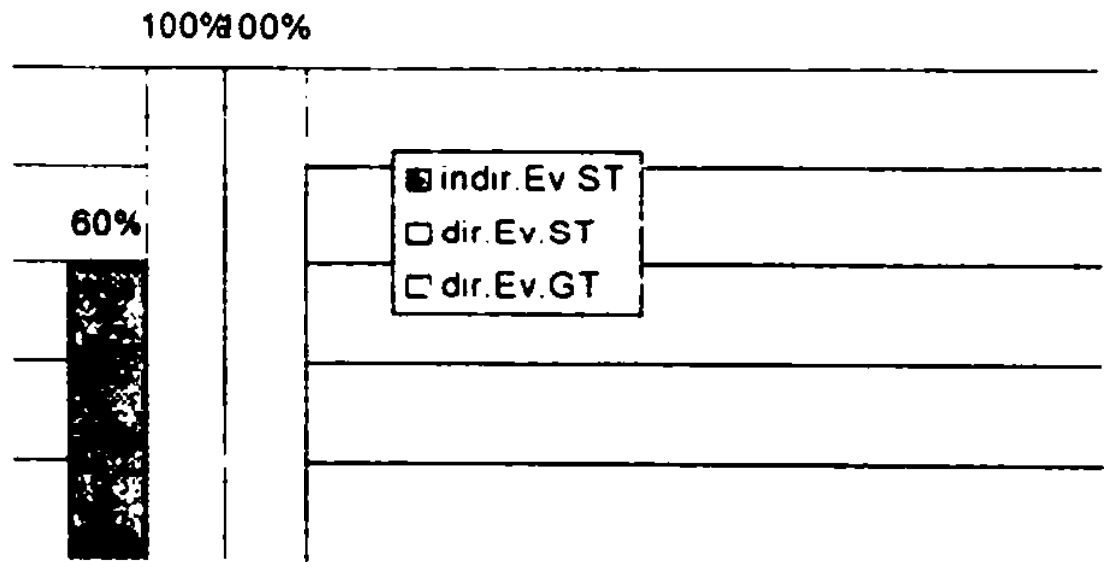

Kommentar Velice mi vadi použiváni nespisovné ceštiny hlavnẻ $v$ komerčni televizi Pro mne sanotnou je velice těžke mluvit spisovne, ale prì hodinach ceštiny se o to budu snažit a budu chtit $i$ od mých ${ }^{11+}$ žákủ. aby spisovně mluvili.

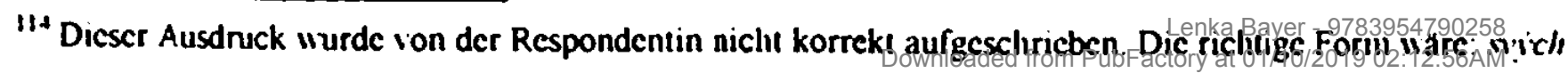




\section{Studentin, 22 Jahre (4. Studienjahrgang)}

Proc jste si vybrala právè tento studijni obor?

- Ceštinu jsem si vybrala kvůli literatữe, protože ta mẻ vždycky zajimala a néměinu jsem si vybrala úplnẻ nảhodou, protože jsem se učila prosté líp na gymnazziu némćinu nebo ta výuka byla kvalitnejjši, takže żejmé proto. Je to nahoda.

A jaky máte vihled do budoucna, týkajici se vašeho povoláni?

- Co se tỳče učitelství, tak situace moc rǐžová neni, ale já už vyučuju - jo, takže vim jako, co to obnáši. Vim, jaký jsou problémy a nejsem si jistá. jestli $v$ tom budu pokračovat na celej żivot jako vyhlidka

$Z$ jakeho dinvodu?

- Hlavne z finančniho. Pŕesto, že teda uěim na soukromé škole, tak ty platy o moc lepši nejsou a podminky pro vyučováni taky až tak dobrý nejsou - pomúcky, vybaveni třid, všechno možný - takže to si člověk všechno musi udêlat sàm. No tak, to zabere hodné času.

Studujete kromé nconciny ješte jiné cizi jazyky?

- Délala jsem angličtinu, ruštinu a ted’ dêlám francouštinu.

Proc zrovika tyto jazyky a tolik?

- Jsou príbuzný, takže tam jako to tak velkej problèm neni a kvưli literature všechny potrebuju, protože to potřebuju naẻist v originale - že jo, hlavné básničky.

A ted" ješı č otázka z jiné oblasti. Jaký máte názor na posledni mirnou zimu. Libila se vám?

- Ne, mné byla strašnč neprijemná. Je to nepriirozený pro organizmus, takže se vyskytlo hodnê chřipek a tak. Tohodle já jsem byla ušetrená, ale neodpovidá to prosté tomu organizmu Fungujeme trošku jako zimni spánek, no a to teplo jako nebylo moc dobrý z tohodle hlediska.

Sprachverhalten:

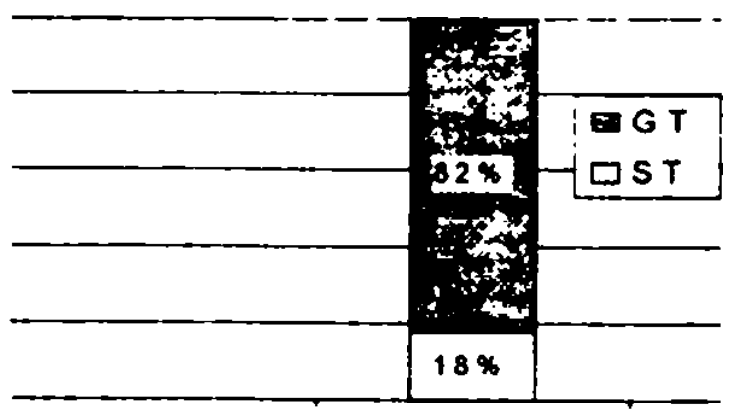

form ell

Einstellung kognitives Subsystem:

Derkannt Dicht erkanm

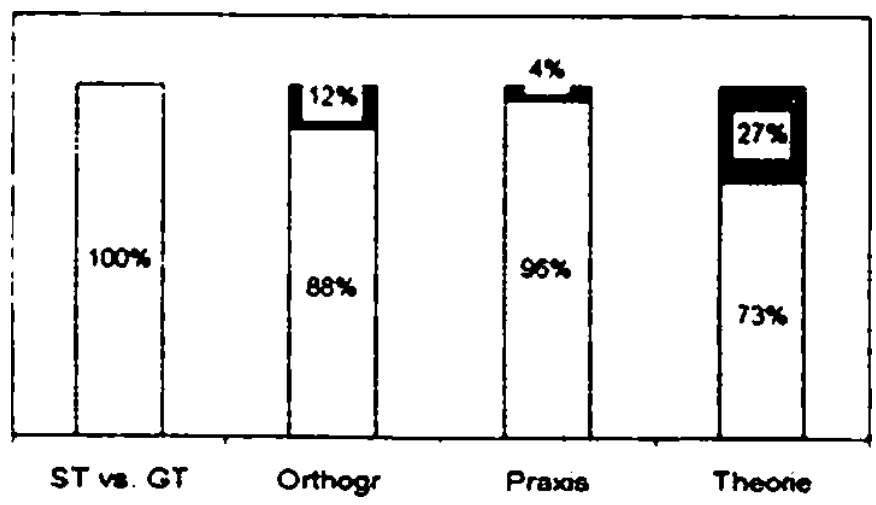

Einstellung, konatives Subsystem:

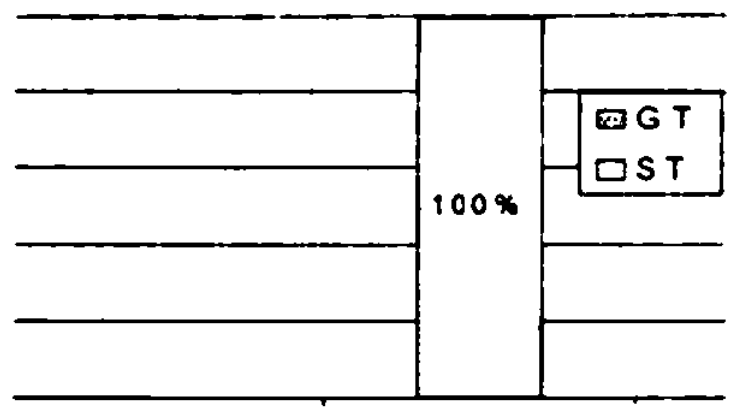

lo rm ell

Evaluation der eigenen Kognition:

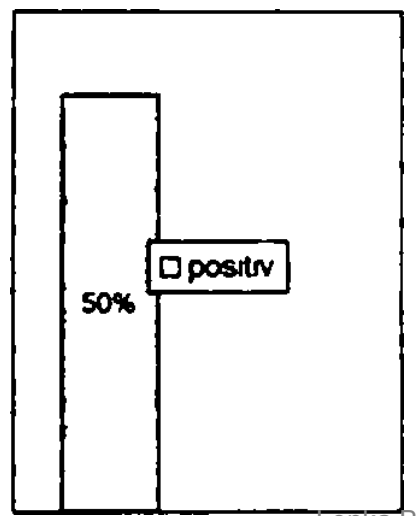


Einstellung, affektives Subsystem: Grad der positiven Einstellung

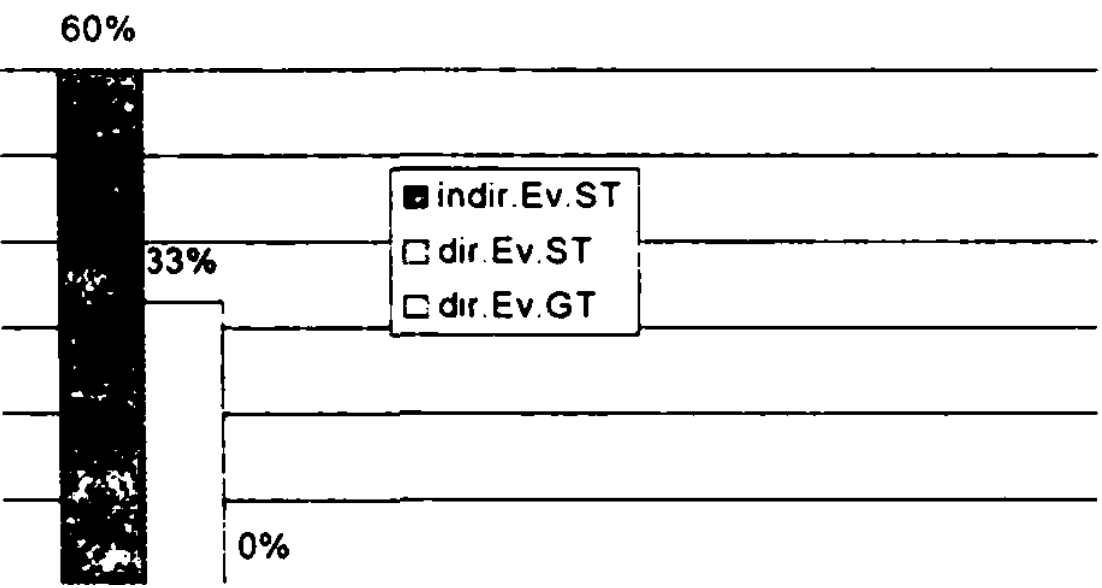

Kommentar: Neni mi żejmý účel této práce. Existuji knihy, které popisuji jak náreči, tak běžnẻ mluvenou ieštinu.

\subsection{I Studenten der Pädagogischen Fakullät. Bohemistik}

Die Studenten wurden in der Fakultät während einer Lehrveranstaltung aufgenommen. Insgesamt wurden 3 Aufnahmen durchgeführt.

\section{Student, 19 Jahre (2. Studienjahrgang)}

Proc jste si uybral práe e tento studijni obor?

- Tak jả jsem si vybral češtinu proto, protože jsem mél na stredni škole a vủbec i na základni škole - mé učili takovi lidé, kteri tu ceštinu ovlàdali, ale dalo by se leccos ještê zlepsit na jejich - treba mluvenem projevu. A ja si myslim, právě proto, že lidè by méli mluvit opravdu spisovně a asi tu ċestinu dobrie ovládat, protože je to jejich rodný jazyk.

A jake máte 'yihledy' do budoucna, tỷkajici se vašeho povoláni?

Tak, týkajici se mého povolàni. Jả bych strašnè rảd - treba učil svijj obor - ¿eštinu, obċanskou vychovu, ale zaleži na tom, právê kde, protože myslim si, že tr̉eba na úrovni tr̉eba učñovské treba ta literatura ty studenty určité moc nezajimá, maji tr̉eba jiné obory, které jsou pro né dủležitejjši, ale proto bych jako tu češtinu chtęl ucitit.

Sindujere rake cizi jazyky?

- Ano. Tak zdokonaluji se $v$ anglic̀tiné a trochu $v$ nèmčiné

Proci prác ctylo dia jazyky?

- Tak angliçtina je vlastnè dnes nezbytná pro komunikaci $v$ celém svêtě̉ a vlastné je to univerzáln jazyk, $s$ kterým se ve svêtę̌ i človêk domluvi. A nèmčina je $z$ toho dủvodu. že vlastnê - já jsem pủvodné z Klatov, takže $v$ sousedstvi. Je to blizko hranic a vlastné tam je spoustu nêmeckỳch návštevnikư, takže se človêk s tou nẻmčinou takẻ domluvi.

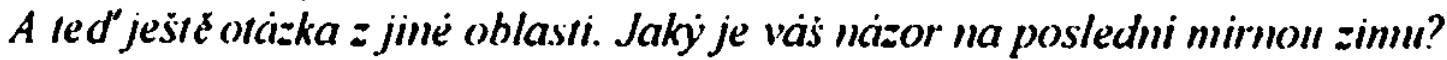

- Tak jả konkrètné mam rảd hodné léto a teplo, protože - jednak kvưli oblecieni. že c̀lovêk - je to jednodušš - múże se obléci lehce a pohodlné a $z$ hlediska - treba globálniho oteplováni je to

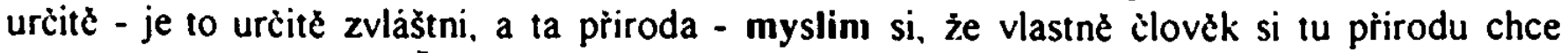
ochociit. ale ta se nedá. Že prostě si jednou - stejnê človêka jednou potrestá za to, jak s ni naklada. A vlastné tim pociasim - $v$ tom počasi se to projevuje. 
Sprachverhalten:

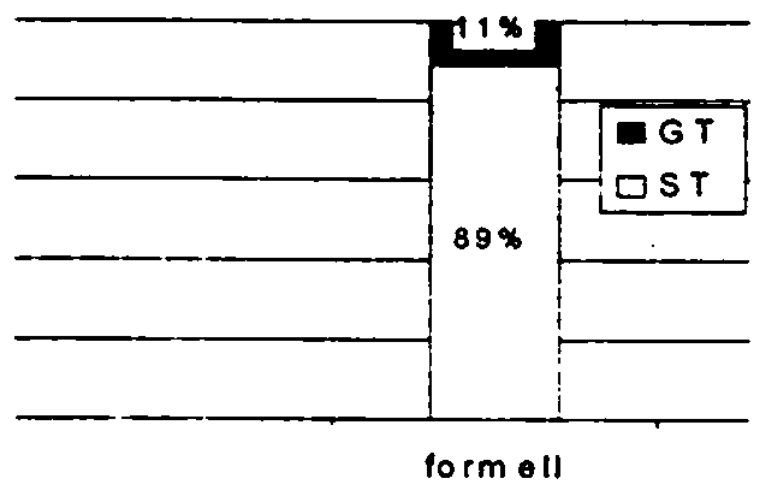

Einstellung kognitives Subsystem: Derkannt ancht erkannt

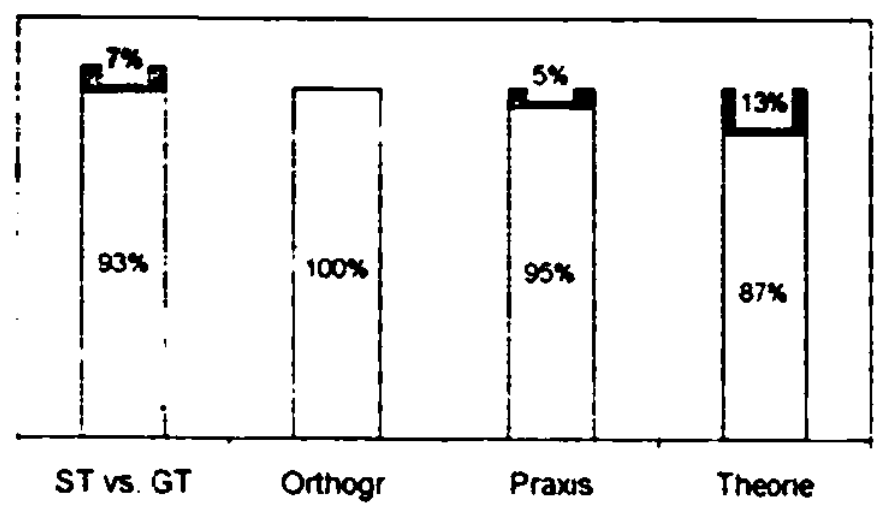

Einstellung, konatives Subsystem:

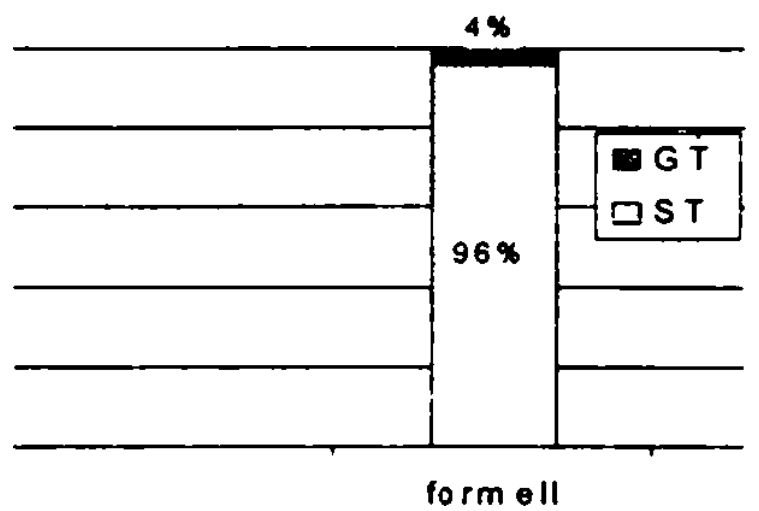

Evaluation der eigenen Kognition:

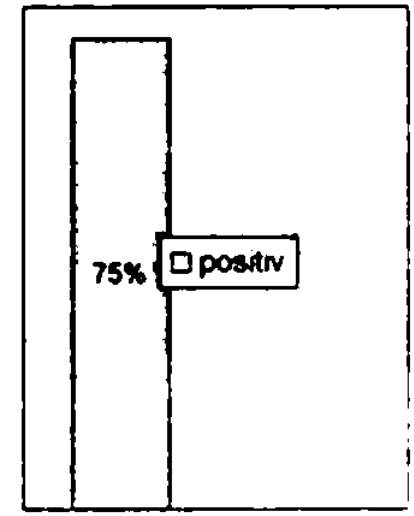

Einstellung, affektives Subsystem. Grad der positiven Einstellung

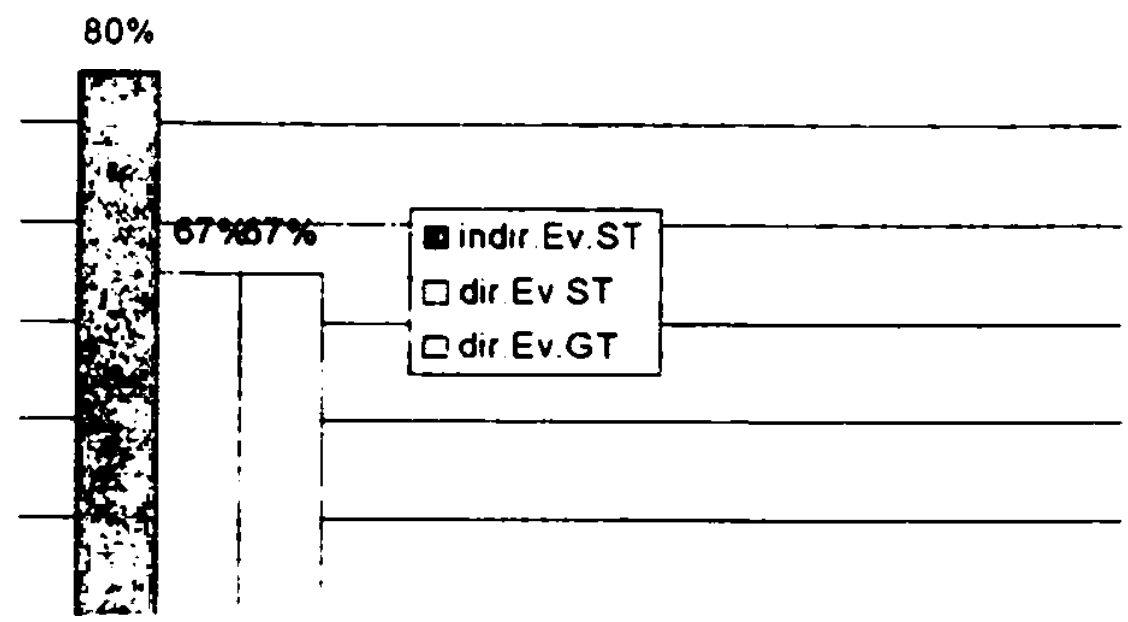

Kommentar: Mnè osobnè nejvice vadi, že se vyskytuji pravopisne chyby $v$ dennim tisku. Také reportèri $v$ médiich by méli zkultivovat svoji mluvu.

Názor na anketu: určité by si ji mêli vyzkoušet všichni, kteři maji co do činěni s ċeským jazykem jako oborem 


\section{Student, 20 Jahre (2. Studienjahrgang)}

Procijste si vibral práe é tento studijni obor?

- Tak, jeden důvod je proto, protože mam rád literaturu, predevšim tedy českou literaturu. A samoż̉ejm respektuju to, že člověk potrebuje $k$ literatừe nejenom tu pisemnou formu, ale $i$ normálnè se nauči gramatiku a mluvnici.

A jake máre vihlecty do budoucna?

- Abych pravdu ṙek, tak moc dobrie nevim. Myslim si, že bych ešte̊ moh jit studovat slovanské jazyky däle, predevšim jihoslovanské jazyky.

A studujere mimo déstiny' rake "ejake cizi jazyky?

- Tak mimo cešstiny studuju eštê nèmčinu a predevšim tedy ruštinu.

A proc prave tyto jazyky?

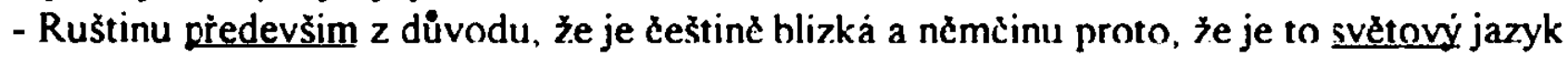
A ted'otäzka z jimé oblasti. Jaký máte názor na posledni mirnou zimu?

Mnè osobnè je to ùplnê jedno, jestli je teplà nebo studená. Protože nelyżuju. A jaký je vás̆ nazor na hudouci zimy. Budou se ochlazovat nebo oreplovar?

- Teda já si myslim. że spiš naopak, že priijdou studené zimy.

Sprachverhalten:

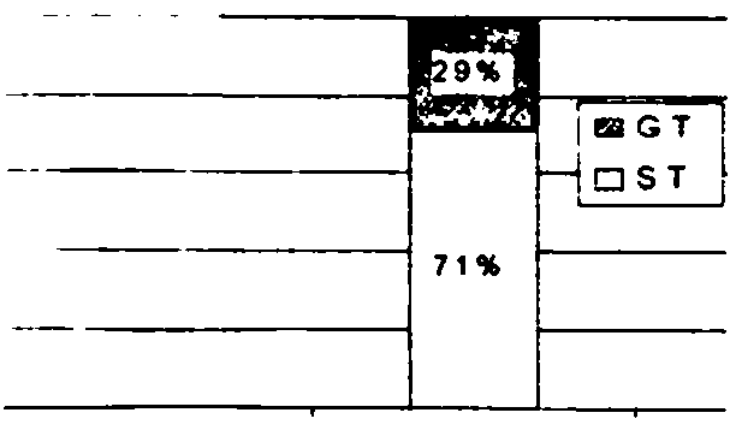

form ell

Einstellung, kognitives Subsystem:

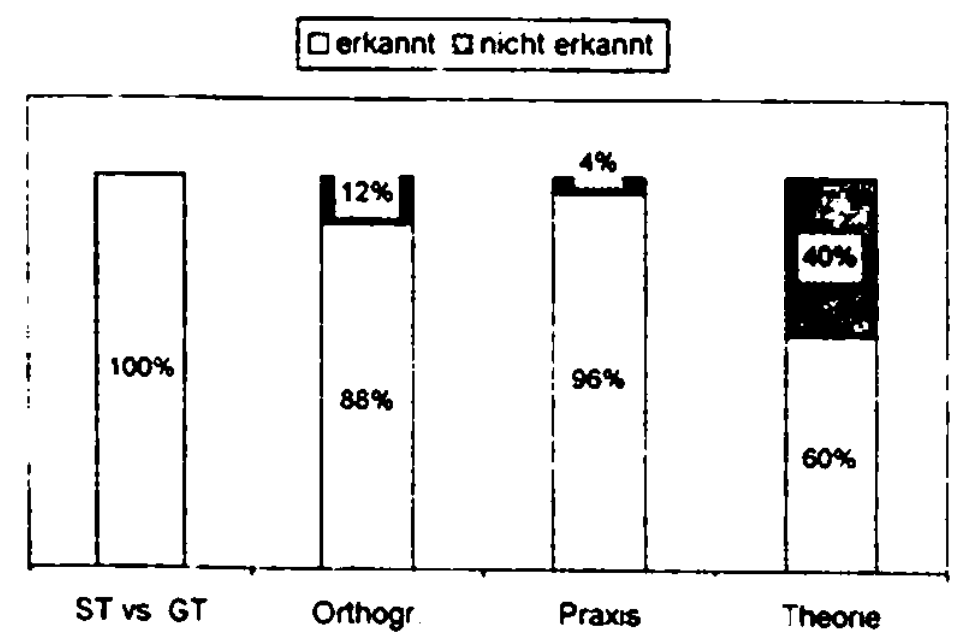

Einstellung, konatives Subsystem:

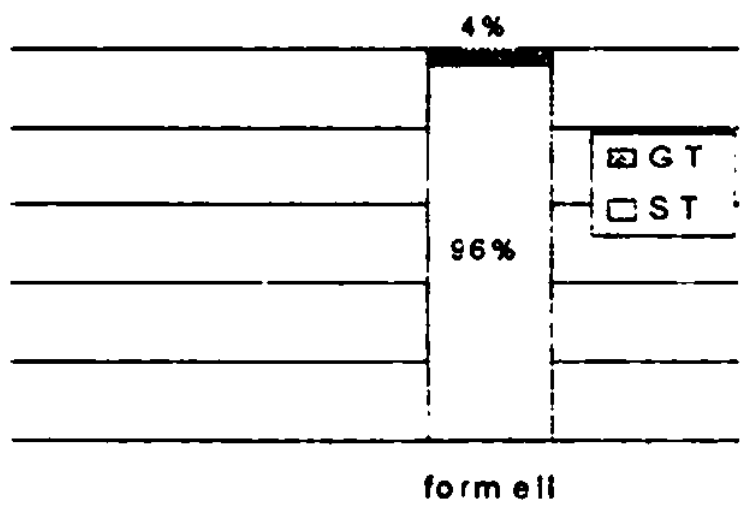

Evaluation der eigenen Kognition: 
Einstellung, affektives Subsystem: Grad der positiven Einstellung

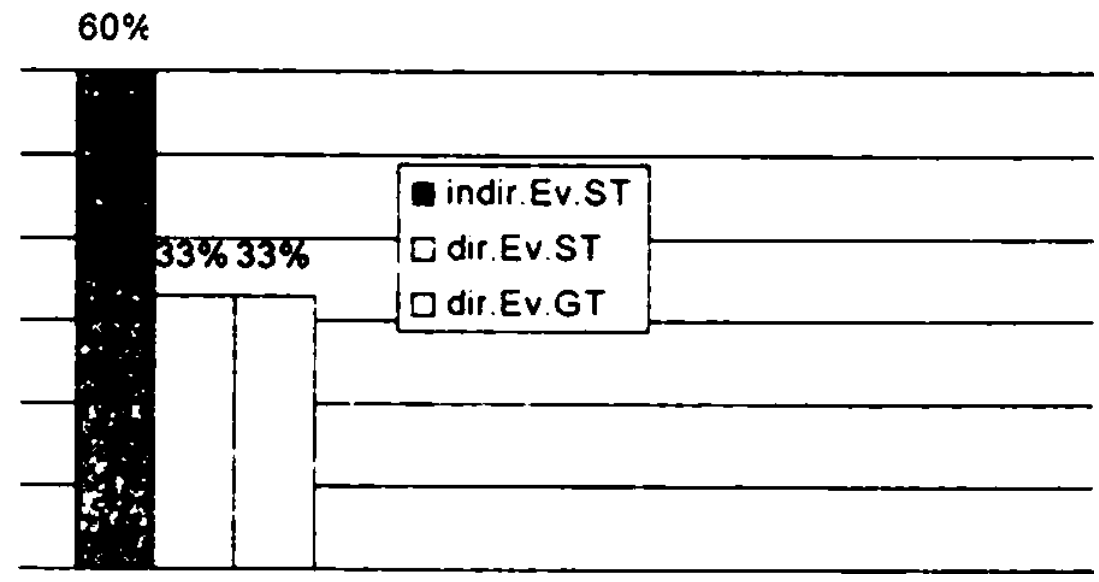

Kommentar: ohne Kommentar

\section{Student, 20 Jahre (2. Studienjahrgang)}

Procijste si iybral prá's temto studijni obor?

- No. çeský jazyk se mi odmalicka libil a moji rodiče - teda moje matka - je učitelkou a taky uči ces̀tinu.

Jake mále vihledy do budoucna. týkajici se vaseho povolani?

- No, chtêl bych učit a stát se úspěšným ucitelem.

Sirudujele raky cizi jazyky"?

- Angliçtinu na stredni škole jsem studoval - angličtinu i nẻmčinu. Jsou to svétovè jazyky a ve vêt sinè státủ se pomoci jich domluvim

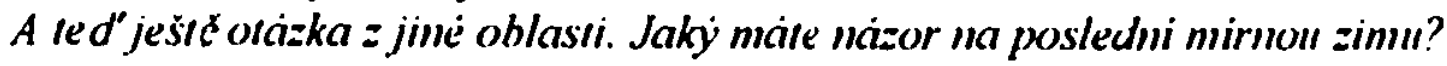

- Jả nejsem pìiliš priznivcem zimy, takže jsem byl docela rảd, že nemrzlo a že jsem nemusel chodit moc zimné oblečen. protože chodim rảd nalehko.

Budou se poelle vašeho nazoru ziny ochlazovat nebo oteplovat?

- No, myslim si, že budou spiše podobné têm, takové, jaká byla letos, ale doufäm, że to nebude moc rapidnê a rychle, protože rảd bych také ješté lyžoval. A nechtêl bych, aby moje déti tr̉eba nevêdžly, jak vypadà snih.

Sprachverhalien:

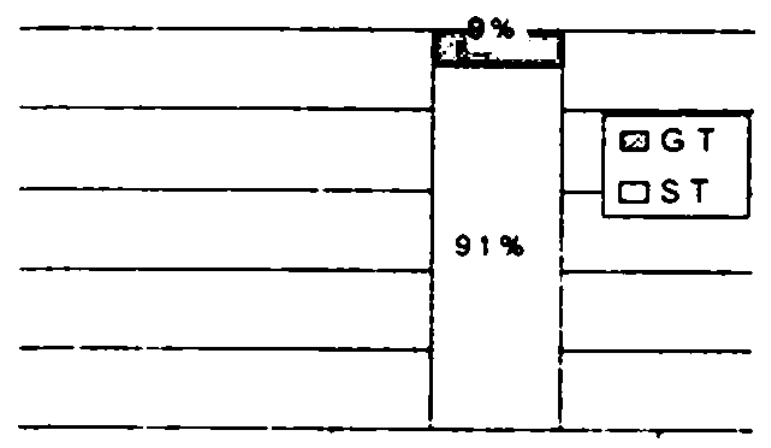

form ell
Einstellung, konatives Subsystem:

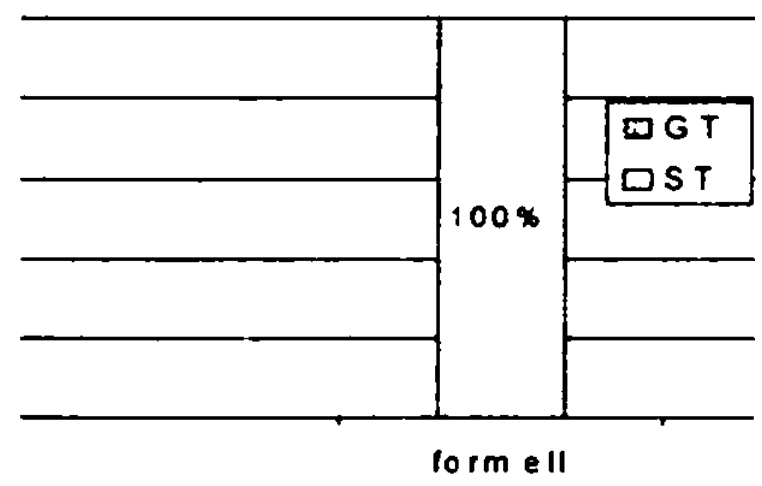


Einstellung kognitives Subsystem:

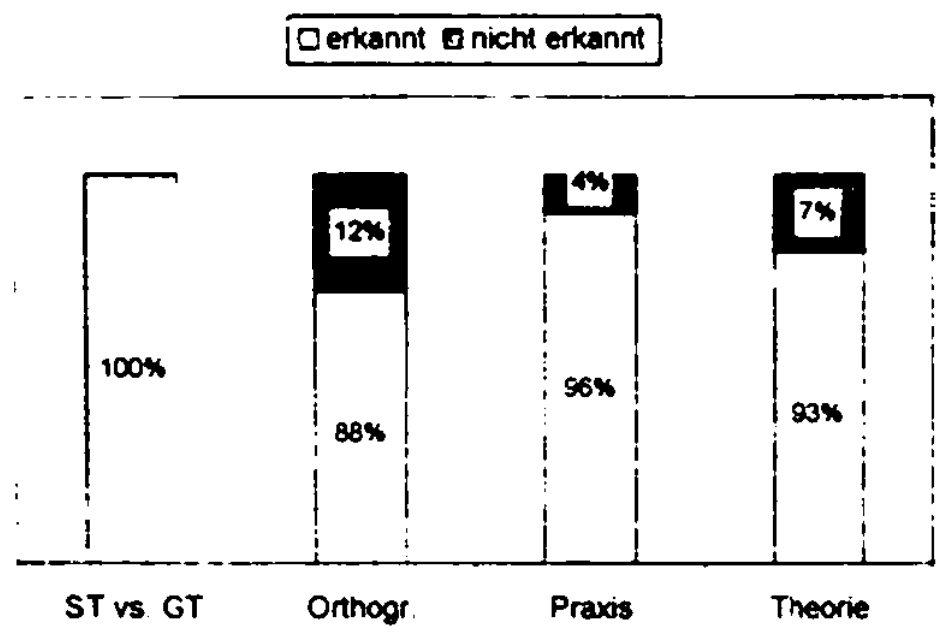

\section{Evaluation der eigenen Kognition:}

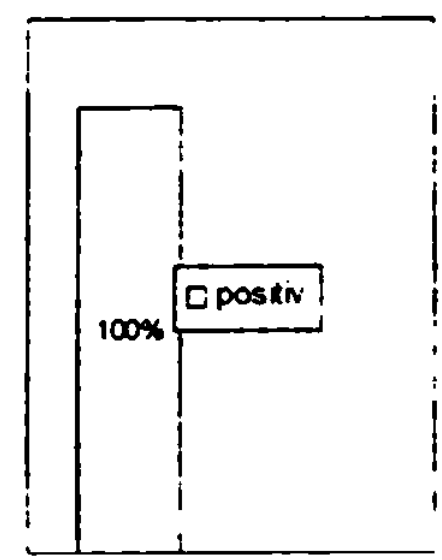

Einstellung, affektives Subsystem: Grad der positiven Einstellung

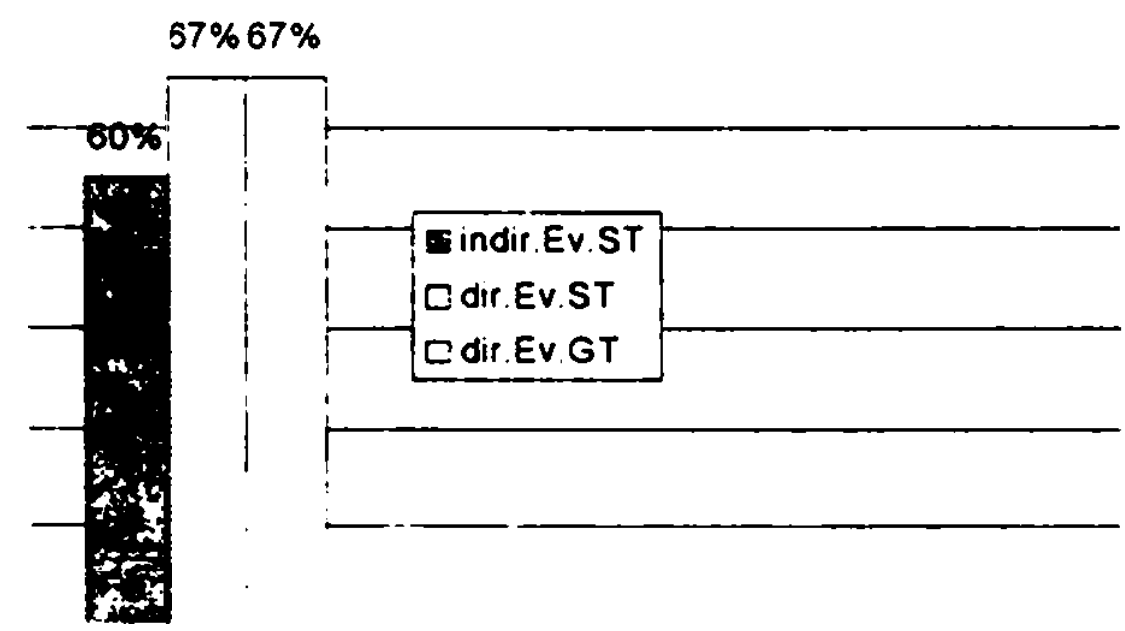

Kommentar: Myslim si, že všichni, kteri vystupuji v televizi nebo rozhlase, by mêli se snažit mluvit spisovnou ceštinou.

\subsubsection{Schiler der Techmischen Oberschule, lerkehrswesen}

Es handelt sich um Schüler im 3. Schuljahr, ca. ein Jahr vor dem Fachabitur. Die Schüler wurden in der Schule während der Deutschstunde aufgenommen. Insgesamt wurden 5 Aufnahmen durchgeführ

\section{Schüler aus Železná Ruda, 17 Jahre}

Procijsle si iybral pràué dopranni primyslowku?

- Protože tady se studoval obor ekologie. Byl nově votev̌̌enej. Když jsem šel do prváku, kdyż. jsem podával prihlašky - a mé to zajimalo, já bydlim v Železný Rudé - takže $k$ tomu mam takovej trošku vztah, a tak se mi to libilo, ten vobor, tak jsem jsem šel - jsem se s mim prihlásil A jaki mait ijhledy do budoucna? Jaké màte pläny?

- No, eštč bych chtêl jit do Prahy na zemédélskou vysokou. Tam je vlastnč pokraiovani toho mýho oboru. No, a pak se uplatnit jako ekolog. treba no. u Sumavskýho národniho parku nebo u ñákího vêtšsiho podniku. 
A proci se ucite "cóncimu?

- Nêmčinu. Jả jsem s ni začal už na základce. Vlastnè vybral jsem si ji jako hlavni jazyk - tady. Abych - jä jsem - já bydlim na Železný Rudẻ, to je u hranic Takže se mi to hodi asi vic než angličtina

Sprachverhalten:

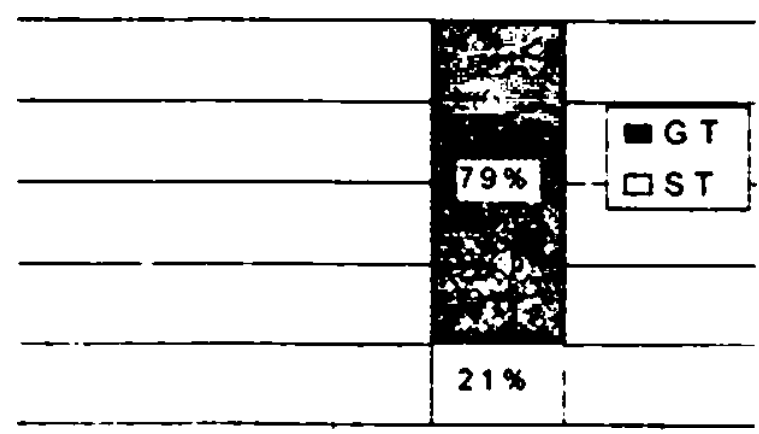

form ell

Einstellung, kognitives Subsystem:

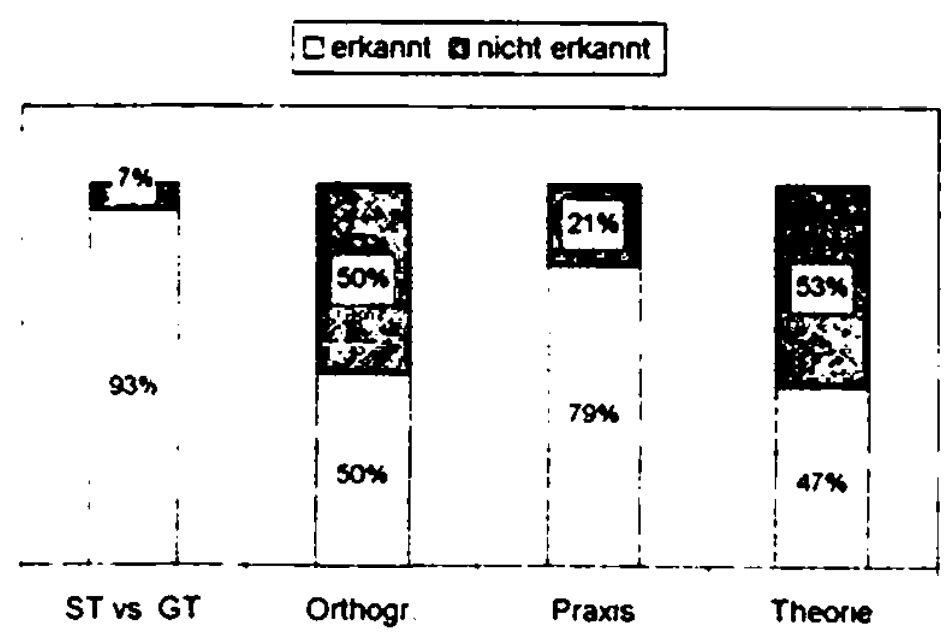

Einstellung, affektives Subsystem: Grad der positiven Einstellung

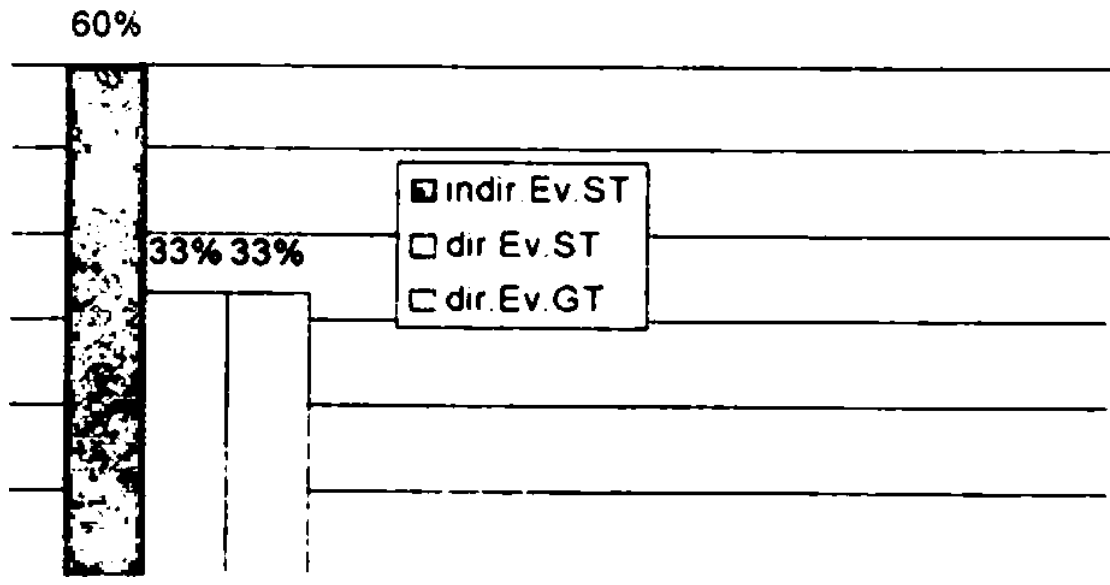

Kommentar Bylo to zábavné. Vyplñoval jsem svêdomité, ale obças mi dêlalo problemy se rychle rozhodnout Doufäm, že jsem pomohl. 


\section{Schüler aus Pilsen, 17 Jahre}

Proci studujele prà'é dopravni primyslovku?

- Myslim si že je to docela dobrá škola, a je to aspoñ s maturou - $s$ maturitou - než nẻjaké jiný ućebni obory. Naprìklad - nejdriv jsem chtêl na truhlàre, ale priece jenom prümyslovà škola je prümslovà škola.

Jaky máte rýhled do budoucna? Jaké máte plàny?

- To ješté vübec nevim. To všechno ukáže c̀as.

A proć studujete "čmcinm??

- Protože už jsem studoval na základni škole od pátý trłidy, tak jsem nechtêl precházet na jinyy jazyk.

A studujere ješ é dalsi jazyky?

- No, studuji akorát anglictinu, kterou máme povinnè na této škole.

A te d' jeślc jiná otázka. Jakj' máte názor na letošni zimu?

- No, docela dost bylo sněhu a lyžováni bylo naprd, protože lyžujem. Když jsme byli na lyžał́skym kurzu, tak to docela šlo.

Sprachverhalten:

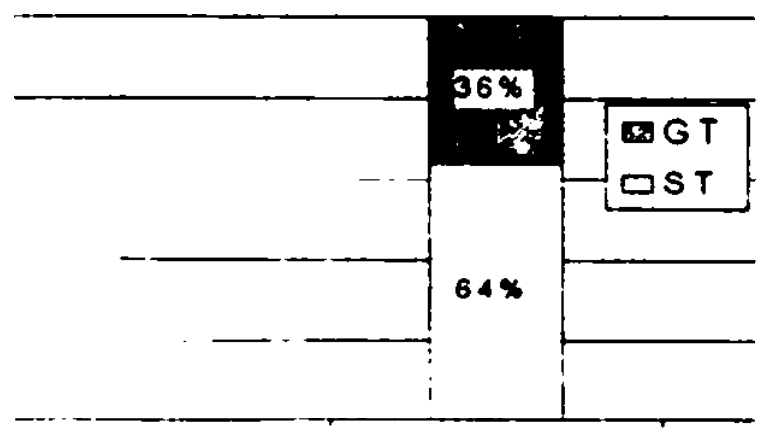

form ell

Einstellung, kognitives Subsystem:

Eerkannt w nicht erkannt

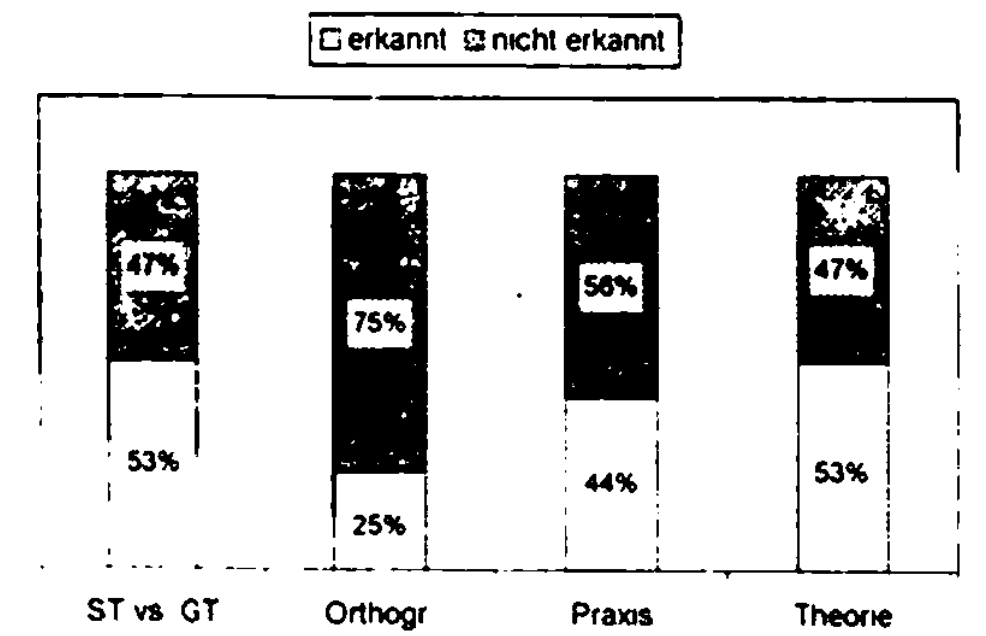

Einstellung, konatives Subsystem:

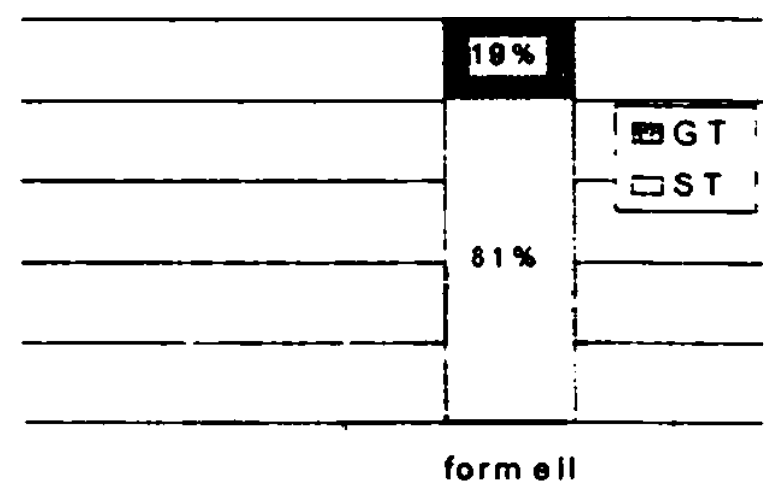

Evaluation der eigenen Kognition:

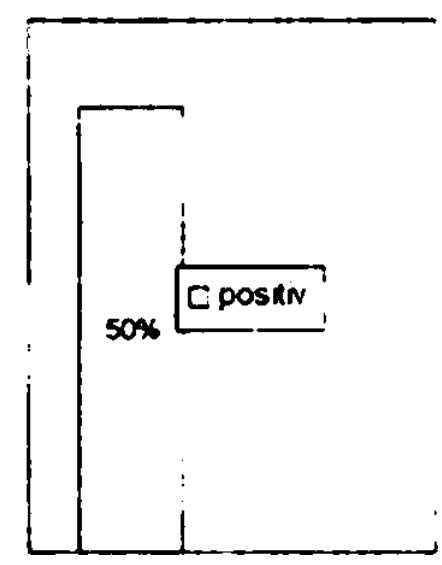


Einstellung, affektives Subsystem: Grad der positiven Einstellung

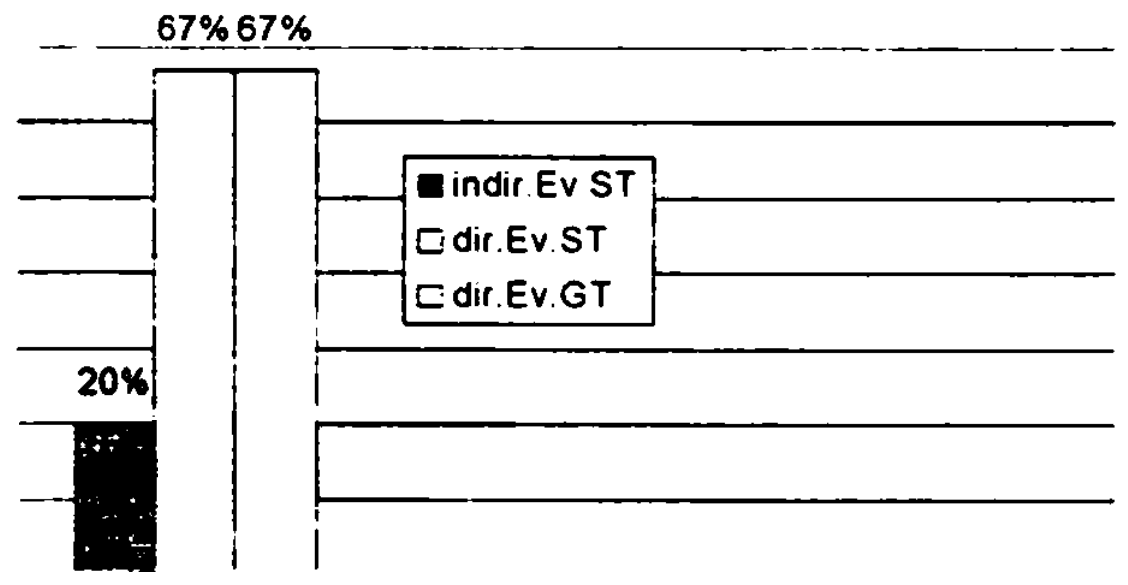

Kommentar: Ve škole by se mêlo mluvit spisovne, hlavnê pri českèm jazyce. Jinak mi na cestine nic nevadi, je to docela dobry jazyk. Tento test byl docela zajimavý a docela se mi libil.

\section{Schüler aus Pilsen, 16 Jahre}

Proc'studujele prá E dopranmi prímyslorku?

- Protołe tady byl obor ekologie a moji rodice pracujou v tutom oboru.

Jaki máte ujhled do budoucria?

- No, zatim žádnej, protože musim dostudovat tuto školu.

Mále 'e vihledu iystudovat iysokon skolu?

- No, nèjak se rozmejšlim, a myslim si, že ne.

A proc s/mdujele nimecky, jazyk?

- No, protože si myslim, že $k$ Nêmecku máme blizko a do Anglie a do anglicky mluvicich zemi se tak brzo nedostanu.

lakx sindujete pouze "imcim!?

- No, ted'ko jsem zaçal loni studovat i angličtinu. Protože jsme méli povinnej druhej jazyk. A red' ještc otázka z jimého oboru. Jak se vám libila posledmi zima?

- No, bylo to skromný s tim snchem, no. Mohlo ho bejt vic. Ale lyžoval jsem.

Sprachverhalten.

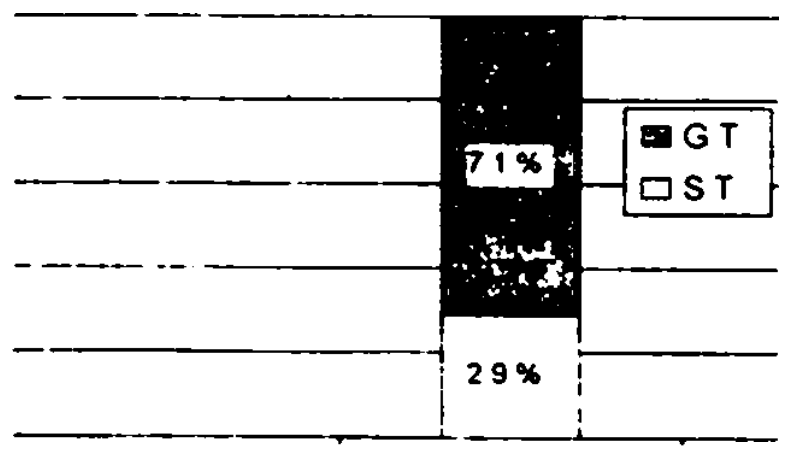

form ell
Einstellung, konatives Subsystem:

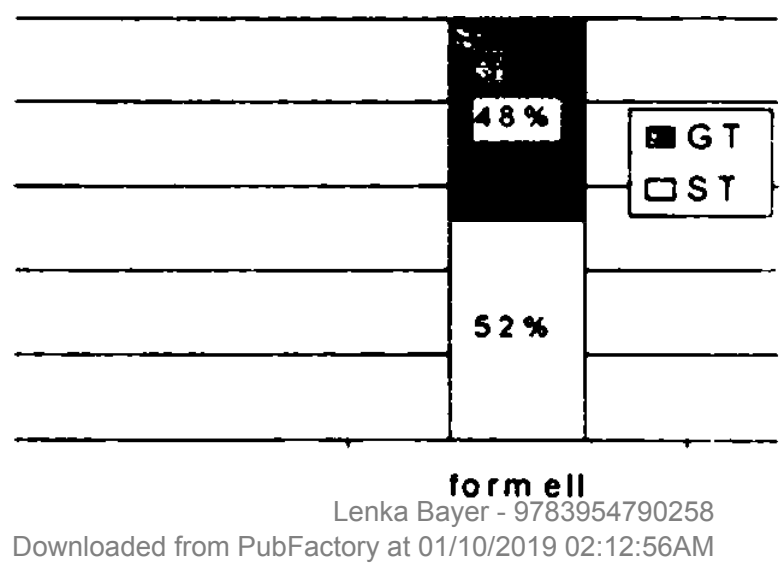


Einstellung, kognitives Subsystem:

Lierkannt a nicht erkannt

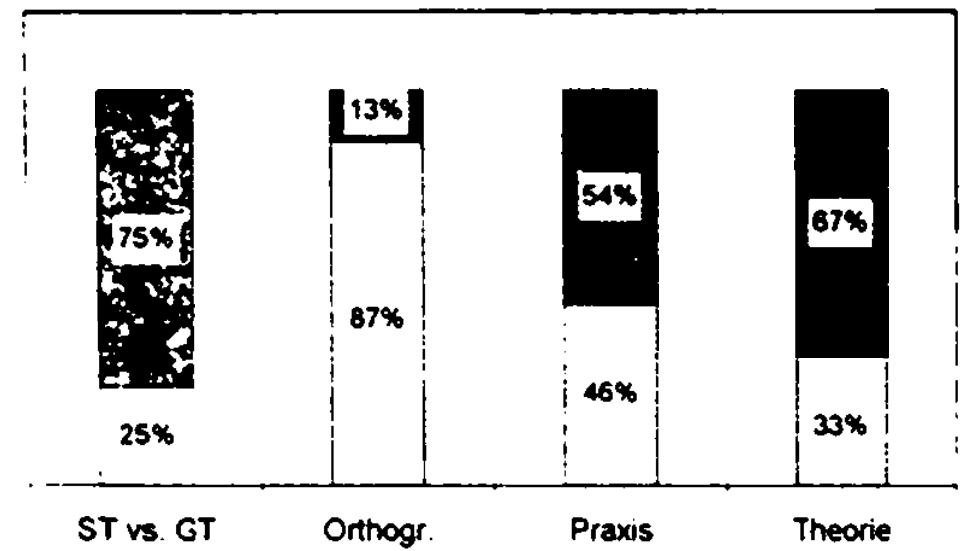

Evaluation der eigenen Kognition:

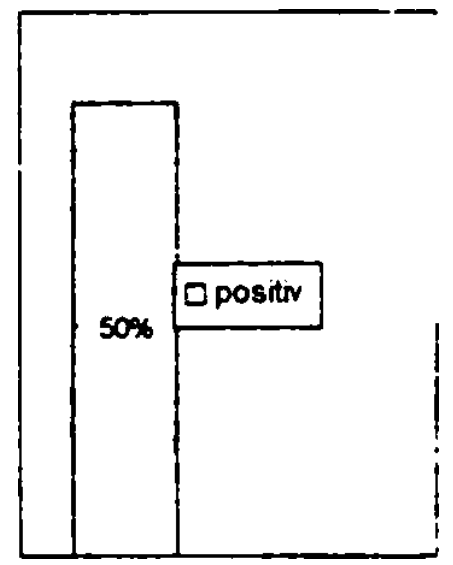

Einstellung, affektives Subsystem: Grad der positiven Einstellung $67 \%$

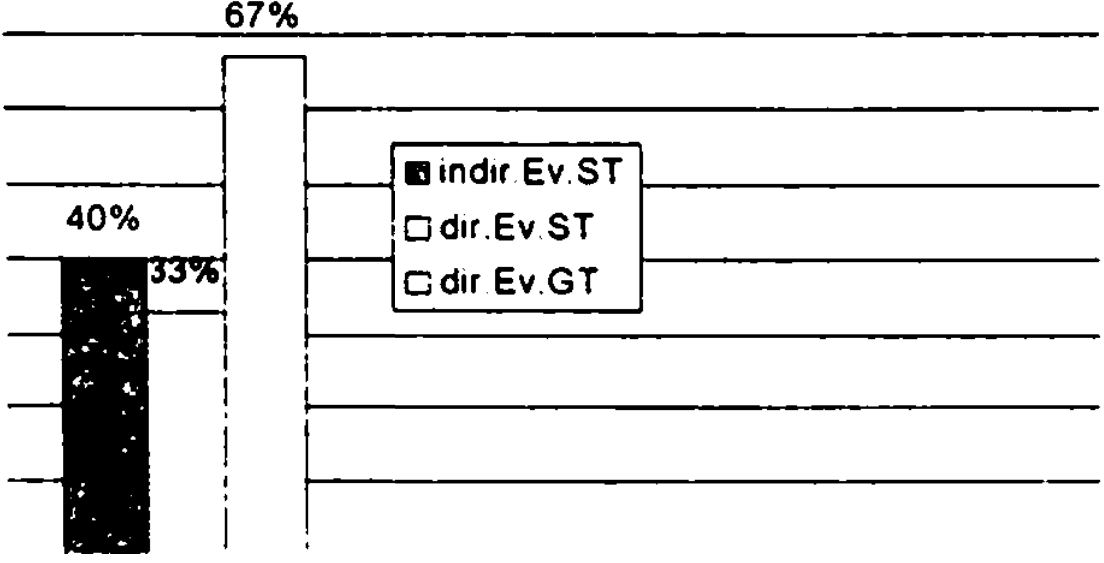

Kommentar: Bylo to zajimavé, ale je težzkè si vzpomenout na slovni spojeni, které ${ }^{11 s}$ použivàme doma. a do televize nebo do rozhlasu jsem ještě nikdy nemluvil

\section{Schüler aus Pilsen, 17 Jahre}

Proc studujete próne dopran'mi prümy'slovku?

- No, tak ja jsem se zrovna na ni dostal, protože jsem ñảk nevêdèl, kam mam jit. Kamarád mi to nabidnul, abych jsem šel na tu školu.

A jake maite konkreimi plany do budoucna?

- No, to zatim ještě nevim.

Sindium ıysoké školy?

- No, możnà taky.

A proci studujere nomecky jazyk?

- No, já už jsem ho studoval na základce, tak jsem ho - tak ho studuju ještẽ ted'ko, no

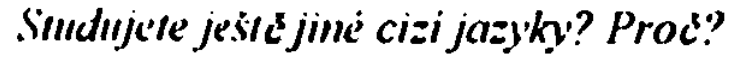

11s Diescr Ausdruck ist morphologisch-sỵntaktisch nicht korrekt. Kontcilablıăngig ist in diesem Sat/. dils Akkusiturobjekt spejeni im Plural gemeint. Der Relativanscliluß muß dann cbenso in Akk Pl stehen. Dic richtige Form wäre kteró. 
- No, angličtinu ještě. Protože jsme si museli vybrat ještè druhej cizi jazyk a jinej tady na tej škole už asi neni.

Ted' ješté otázka z jimého oborı. Jak se vám libila posledmi zima?

- No tak, mnè se zima nèjak moc nelibi, także - ale byla docela dobrá. Já jsem byl na horách. Zalyžoval jsem si tak trošku, no.

Sprachverhalten:

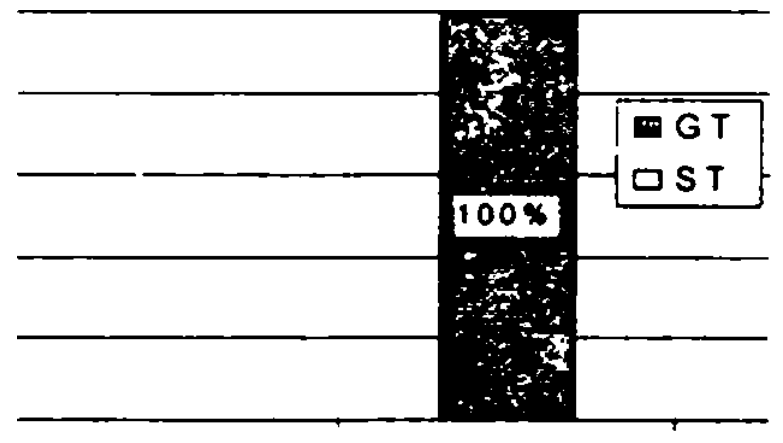

form ell

Einstellung, kognitives Subsystem:
Einstellung, konatives Subsystem:

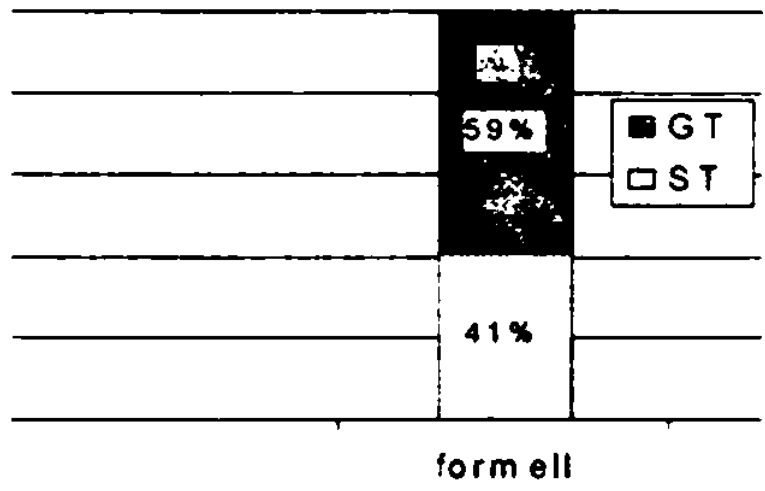

Evaluation der eigenen Kognition:

Qerkannt Enicht erkannt
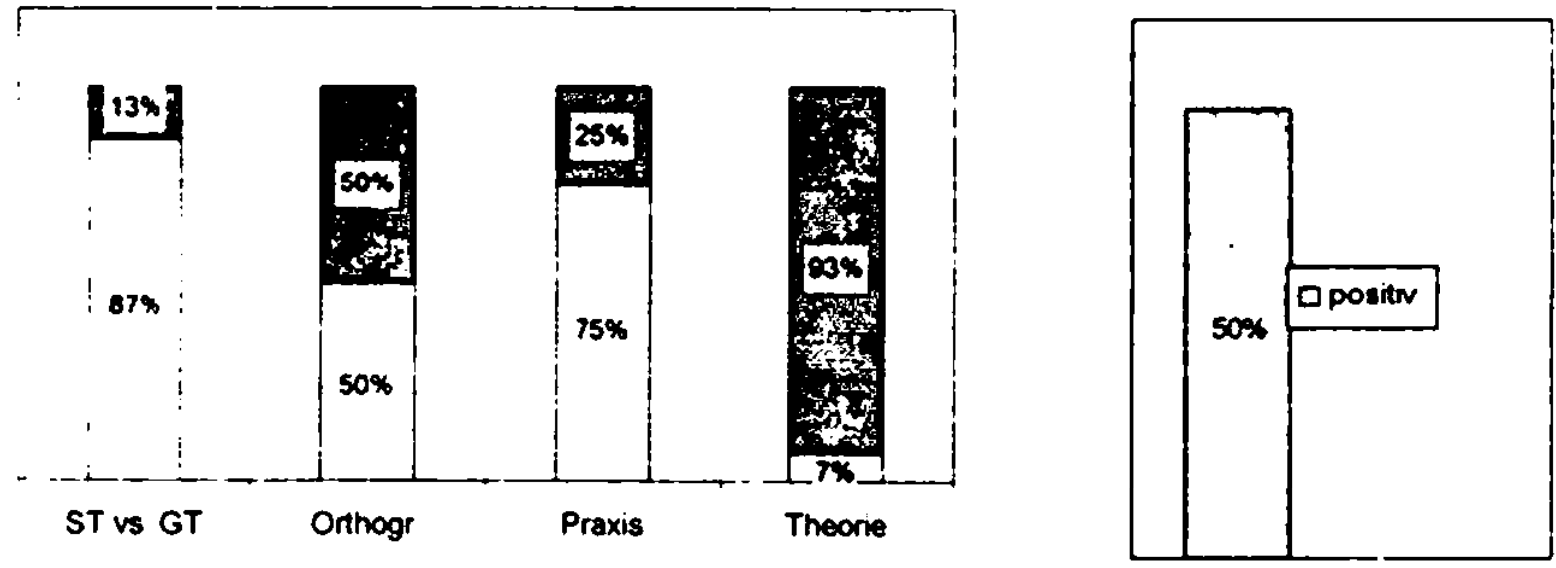

Einstellung, affektives Subsystem: Grad der positiven Einstellung

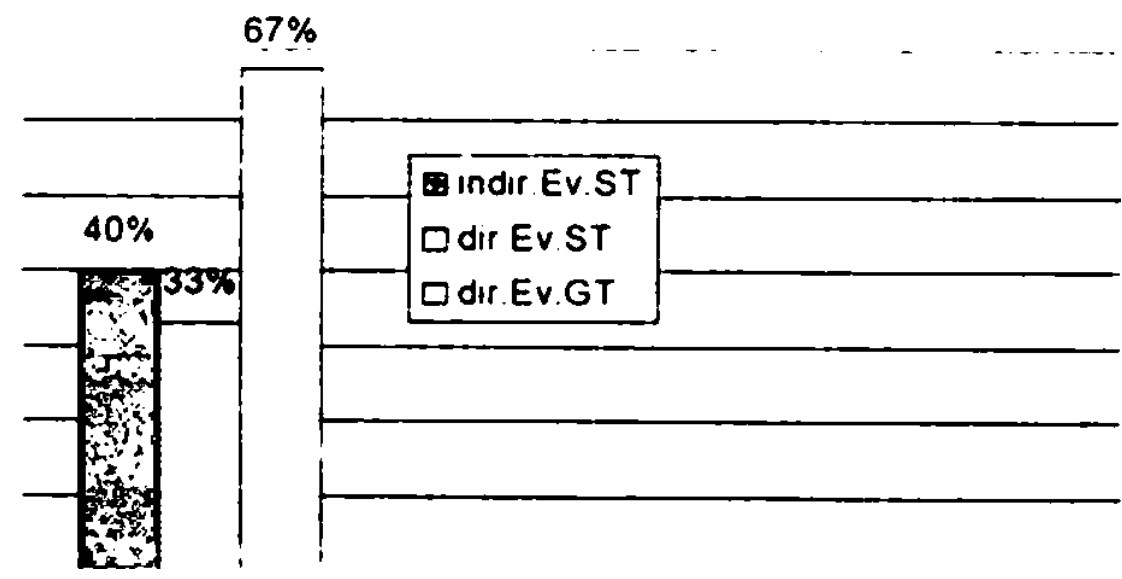

Kommentar: Myslim si, že tento prỉzkum je zbytečnỳ, protože podle mèho nảzoru bude každỳ mluvit svym nárecim, tak jak je zvykly. 


\section{Schüler aus Pilsen, 17 Jahre}

Procistudujete prán'é dopravni prünyslovku?

- Protože vlastné jsem nevědèl jaký obor si vybrat, tak jsem se rozhod tady na to protože si myslim, že - já mam obor silnični doprava a ochrana životniho prostredi - tak si myslim, že snad eště néco tady na tom - na tomto svêté zachránim.

A jakè máte konkrétmi plány do budoncna?

- Chtell bych zkusit vysokou školu zemédélskou na - v Praze.

A potom. jaké zam Esmáni?

- Zamèstnáni, takhle, já se nebojim žádný práce, hlavně aby za to byly penize.

A proci se "cite práné nćncimm?

- Protože je to vlastně nảš nejbližši stảt. Takže jako, dost tam budeme jezdit a takhle, si myslim.

Situdujete i jine jazyky?

- Ano, studuji ještč angličtinu, protože s angličtinou se vlastnê - je to svêtovej jazyk, s kterym se domluvim všude.

A jaky' máte názor na posledni zimu? Byla teplà nebo studená?

- Tak, chvilku studená a chvilku teplá, ale bỵl jsem na horách, a tam jsem si docela užil. Jezdil jsem na snowboardu.

Sprachverhalten:

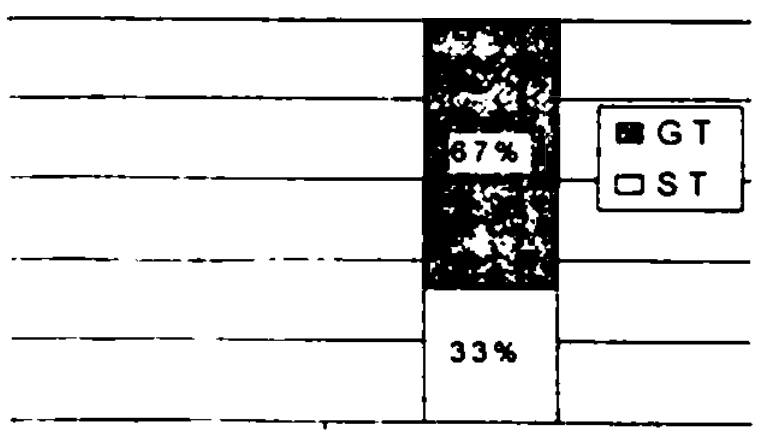

formell

Einstellung, kognitives Subsystem.
Einstellung, konatives Subsystem:

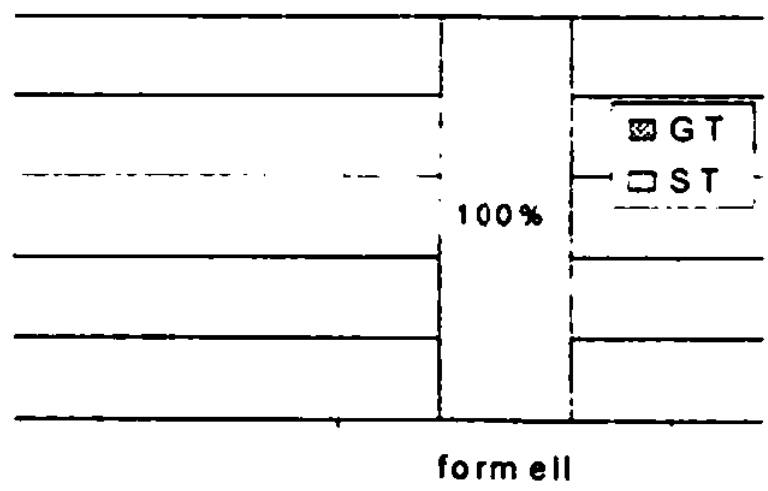

Evaluation der eigenen Kognition:
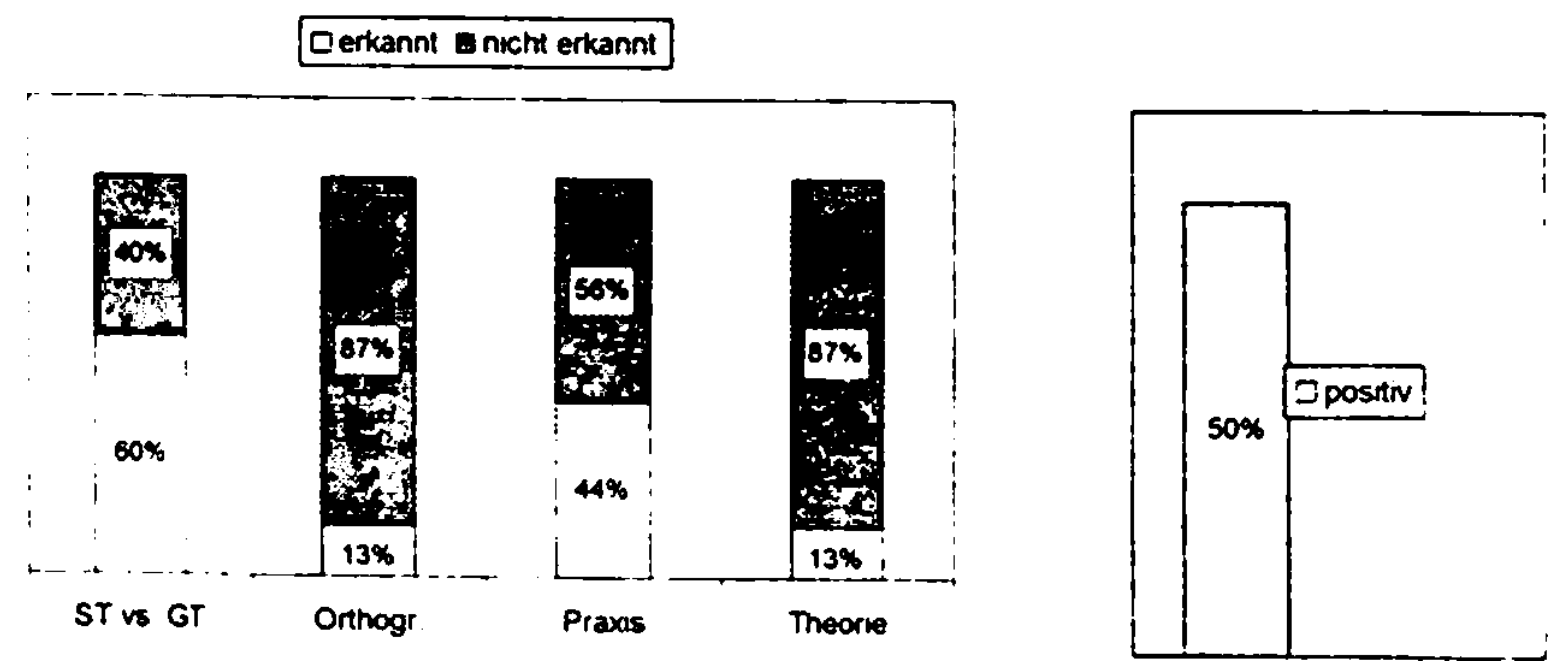
Einstellung, affektives Subsystem: Grad der positiven Einstellung

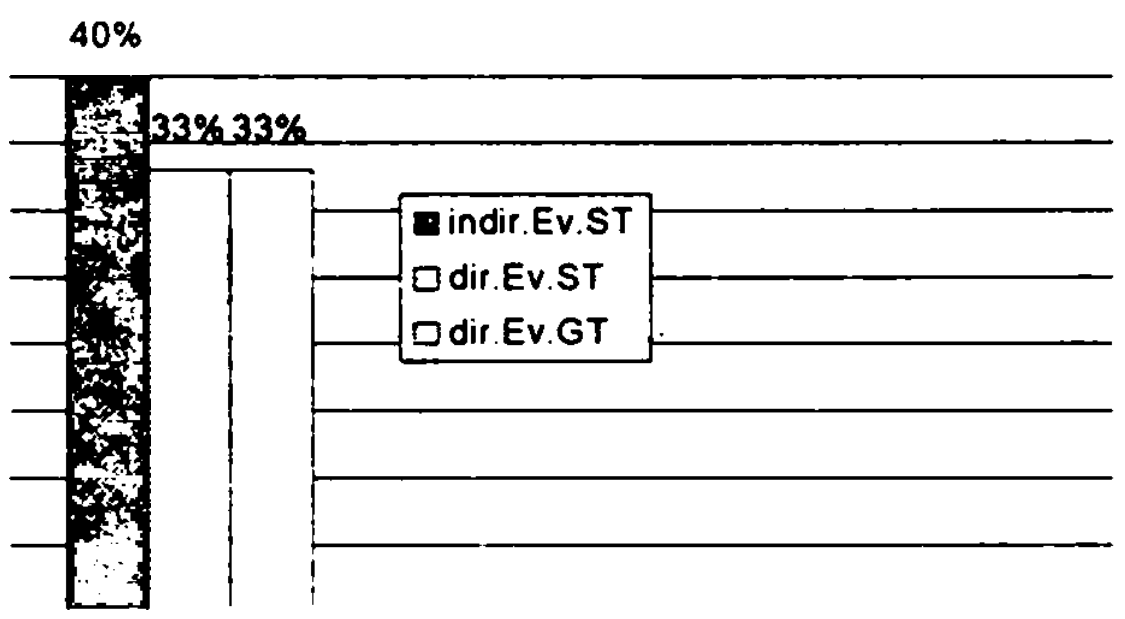

Kommentar: Je rozdil mezi výukou na základnich školách a na str̉ednich školách a kdyż. základni školy špatnê pripravi žáka na vstup do stredni školy. Tak žăk nemá šanci se na té škole uchytit. Je dobré, že se nêkdo o náš jazyk zajimá! ${ }^{116}$

\subsubsection{Prag}

\subsubsection{Studentimmen der Philosophischen Fakultät, Bohemistik}

Die Studentinnen wurden in der Fakultät während einer Lehrveranstaltung aufgenommen. Insgesamt wurden 5 Aufnahmen durchgeführt.

\section{Studentin, 24 Jahre (5. Studienjahrgang)}

Proc jste si vybrala prán'è tento studijni obor?

- Protože jsem se vlastnê už od středni školy zajimala $Q$ literaturu a vždycky byla moje touha studovat tento $\underline{Q b o r}$. Tak proto jsem si to vybrala.

A jake mále plany do budoucna?

- No, bud' bych chtêla učit češtinu nékde na stredni škole, anebo mojim zamčrenim je i novinárstvi, takže spiš psaná forma projevu - psát ċlänky nebo pripadnč piekládat, także práce s jazykem a se slohem.

A ješ̀c jimá orcizka. Jakj mále názor na posledmi zimu?

- No, jà musim priznat, jà jsem - myslite všeobecně, nebo vzhledem $k$ jazyku, ke studiu? Ne, vübec, v'seobecné Libila se vàm?

- No, mñ se libila, i kdyż. musim tict, że jsem ji nevênovala moc pozornosti, protože jsem méla ț̌žke zkoušky, takže jsem se na nẻ zejmèna pripravovala doma. Ale myslim si. že je vždycky fajn, když napadne alespoǹ trošku sněhu. Teda pro nás Pražáky. Jà, protože jsem mestský ditč, tak mảm nejradši, kdyż napadne trochu sněhu a mohu odjet nékam na hory alespoñ na týden. 
Sprachverhalten:

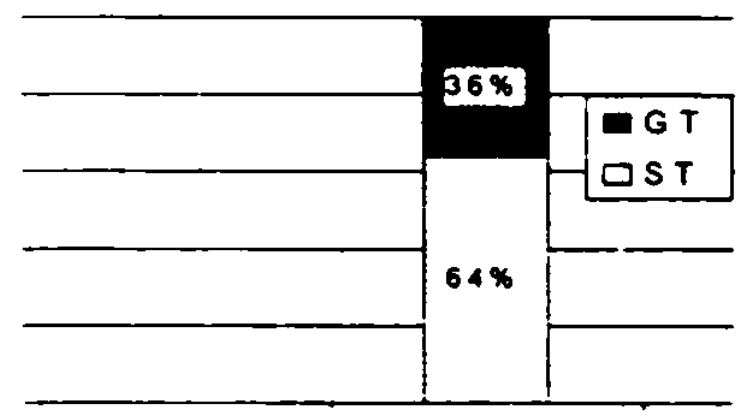

form ell

Einstellung, kognitives Subsystem:

\section{Derkannt E nicht erkannt}

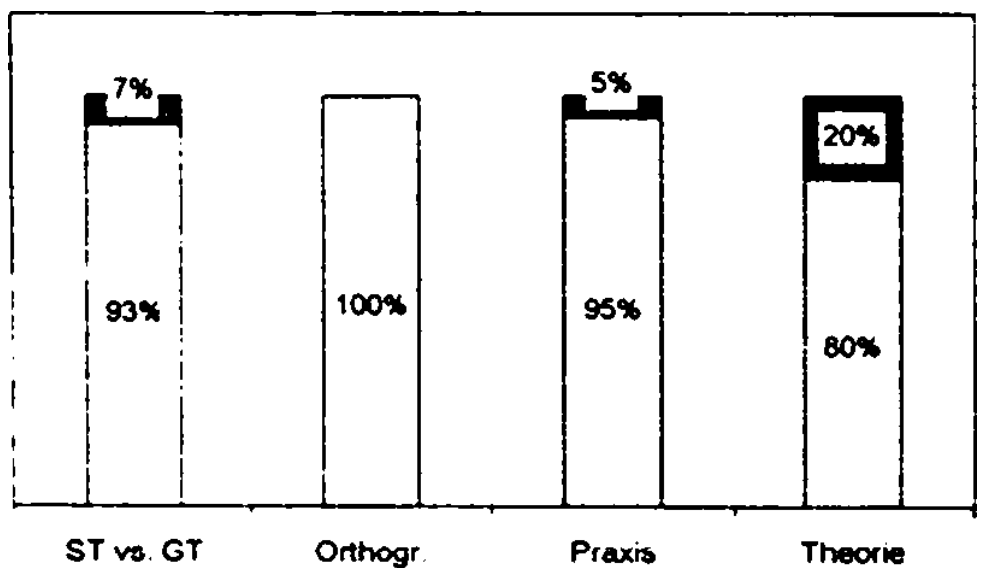

Einstellung, affektives Subsystem: Grad der positiven Einstellung

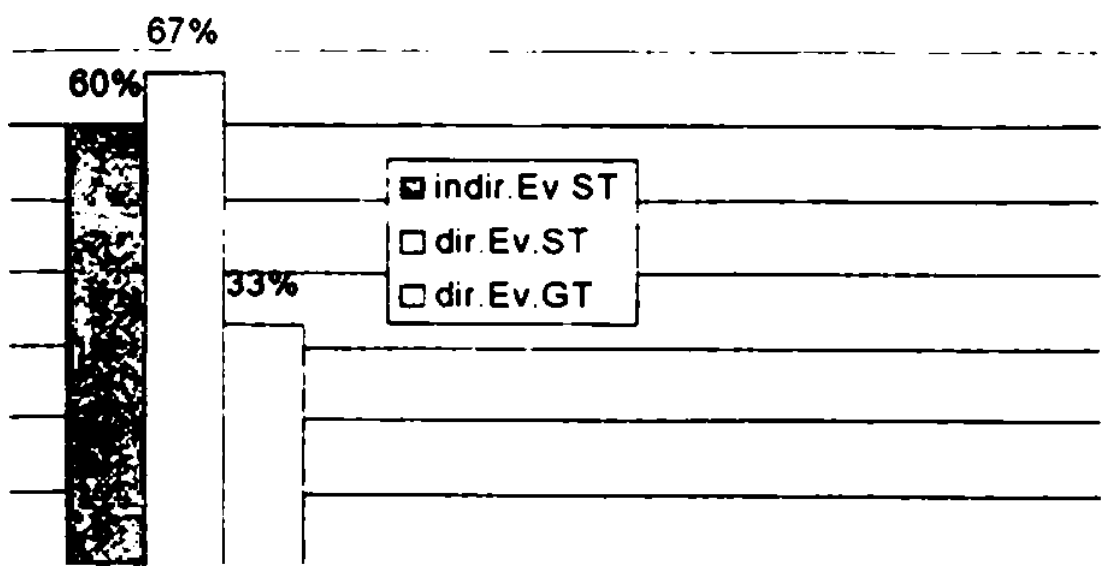

Kommentar: ohne Kommentar

\section{Studentin, 24 Jahre (5. Studienjahrgang)}

Procijste si uybrala prán'e temo studijmi obor?

- No, jả jsem vỉdycky chtêla studovat češtinu, protože jsem ráda četla $v$ détstvi a méla jsem Takže když budu studovat ceštinu, tak budu mit dostatek casu, abych ty kniżky cist mohla. Jake máre plany do budoucna? 
- No tak, v nejbližši dobẻ bych chtêla dodélat diplomku a potom teda nêjaké stätnice. ... Tak to zatim těžko tict.

Màte v plànu zưstat v Praze, anebo jit eventuálné do jiného mesta?

- No, v podstatẻ bych asi zủstala v Praze, ale samoż̉ejmé kdyby se naskytla nęjaká nabidka zajimavá, tak bych ji neodmitla

A ješt c jima otázka. jak se vám libila posledni zima v Praze nebo i na horäch?

- No tak, zima byla pẻknả Bylo tolik sněhu jako už dlouho nebylo.

Užvala jste si zimnich radovánek?

- No, ještẻ ne. Já pojedu ted’ teprve na hory. Takže zatim ještẻ ne.

\section{Sprachverhalten:}

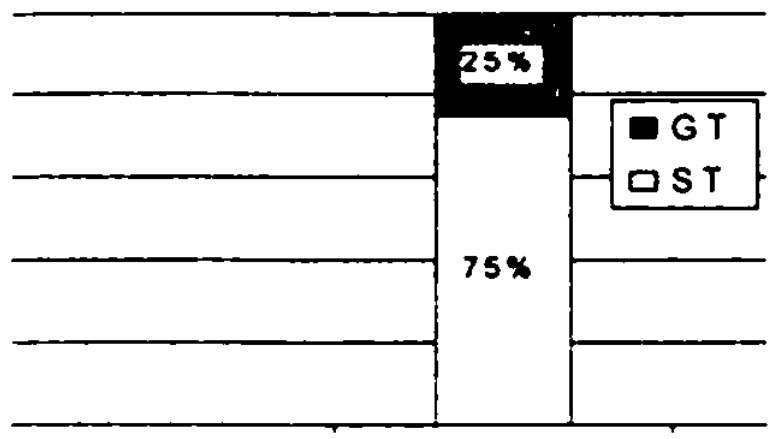

form ell

Einstellung kognitives Subsystem:

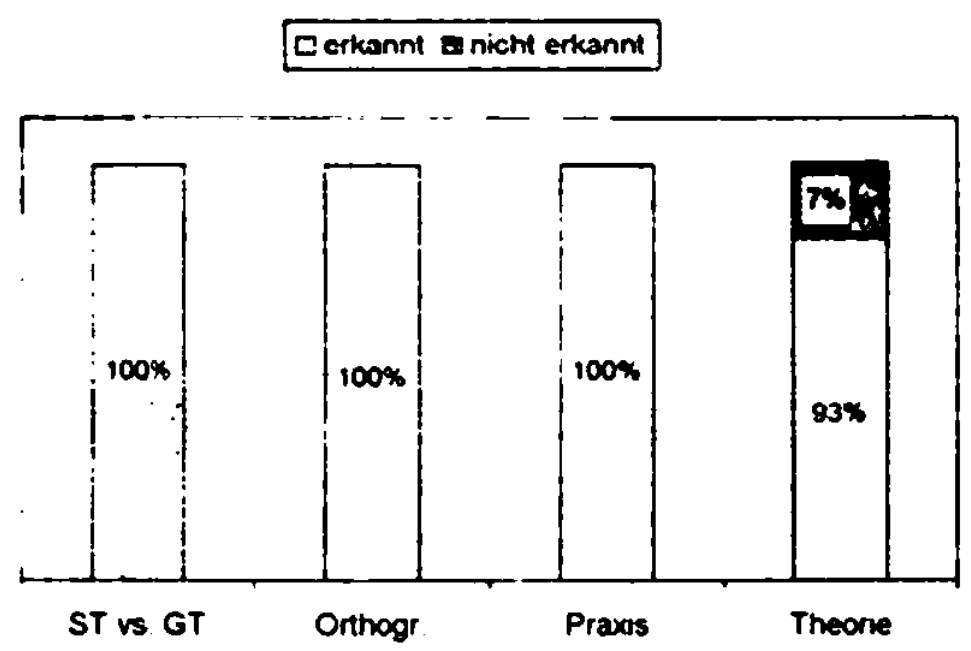

Einstellung, konatives Subsystem:

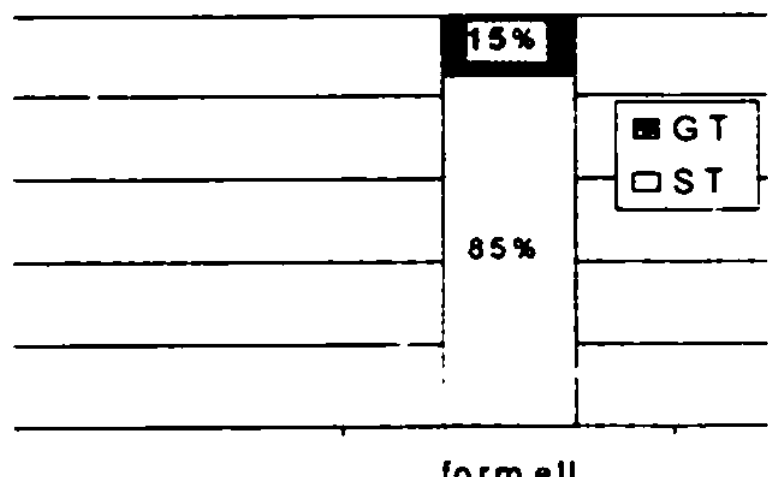

Evaluation der eigenen Kognition:

Einstellung, affektives Subsystem Grad der positiven Einstellung

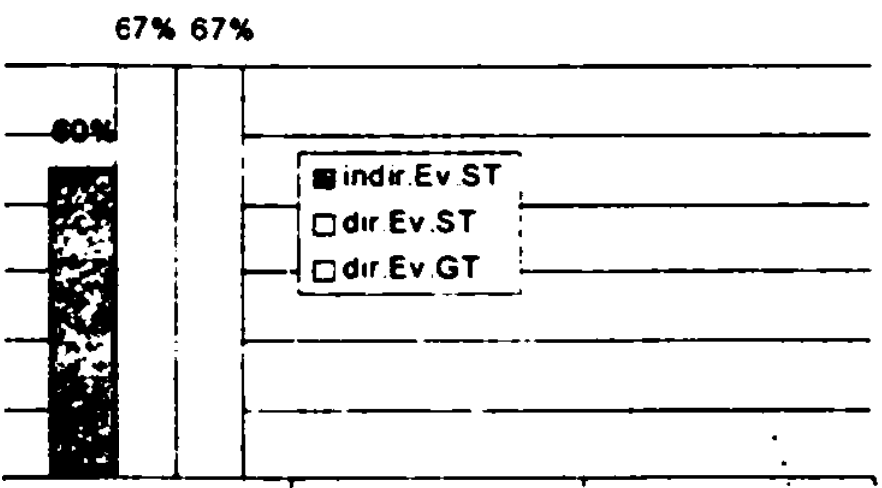




\section{Studentin, 24 Jahre (5. Studienjahrgang)}

Proc jste si 'ybrala prón'e tento studijni obor?

- Protože se mi moc libi a obdivuju, když nékdo mluvi spisovnẻ česky a chtěla bych, aby spisovná ceština se udržela a rozširitla do komunikace i mezi běžné normálni lidi.

Ale to znamena, myslite do jimych mest i na vesnici?

- Myslim tim to, ano, ale určitě se nedosáhne toho, aby se tak mluvilo i $v$ normálni béżné mluvené komunikaci doma, ale aby se vice rozširiila - urěité bych chtěla, aby se vice rozširiila do rozhlasu a televize, do médii. A to mi vadi, nespisovná ceština $v$ médiich, velmi.

A mäte ambice pracovat v tomto oboru, napríklad v televizi, $v$ rádiu a tak dále. Jaké máte plany' do budoucna po ukondeni svého studia?

- Ano mám tendence zkoušet, zkusit. bỳt rozhlasovou komentátorkou, a tak pủsobit na recepci spisovné ceštiny tak, aby se to vnimalo jako normalni a ne jako exotický výrazy.

Dobir. A ted' ješt é otäza z jime oblasti. Jak se vám libila posledni zima?

- Zima se mi libila vice neż minulé zimy, protože byla tak jak má zima vypadat. Byl v Praze snih, kupodivu, a nebyla brečka. Takže se mi libila.

Jak jste si "živala této zimy??

- Ješté jsem nevyuživala, ale prìšsti týden se chystám na hory lyžovat.

Sprachverhalten:

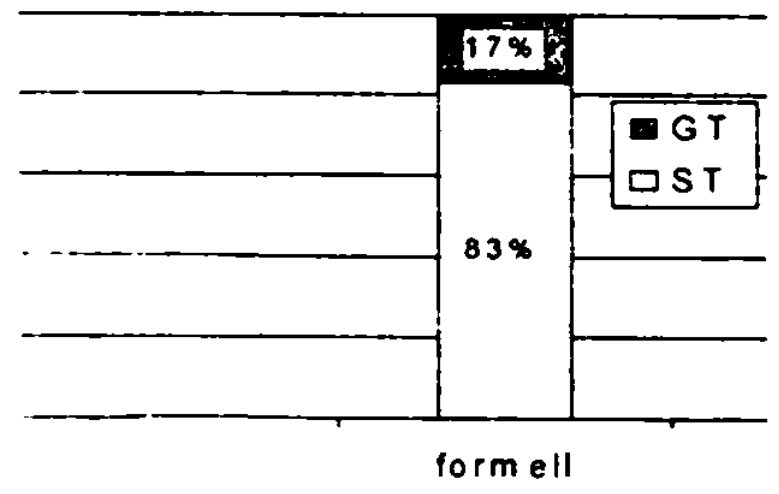

Einstellung, kognitives Subsystem:
Einstellung, konatives Subsystem:

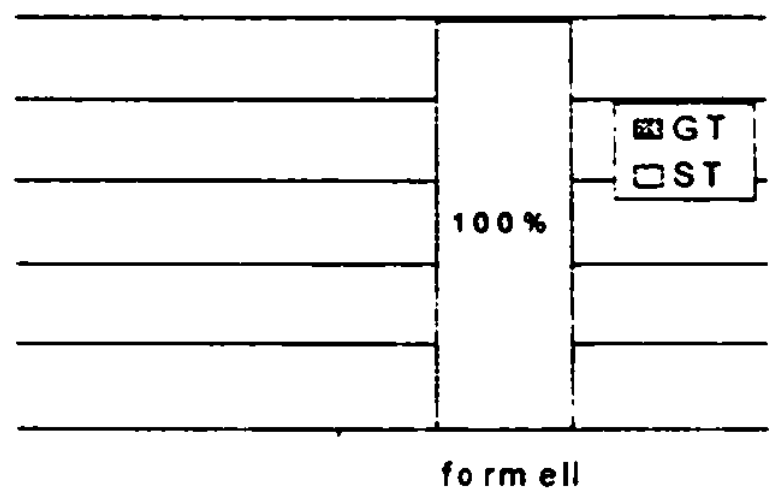

Evaluation der eigenen Kognition:

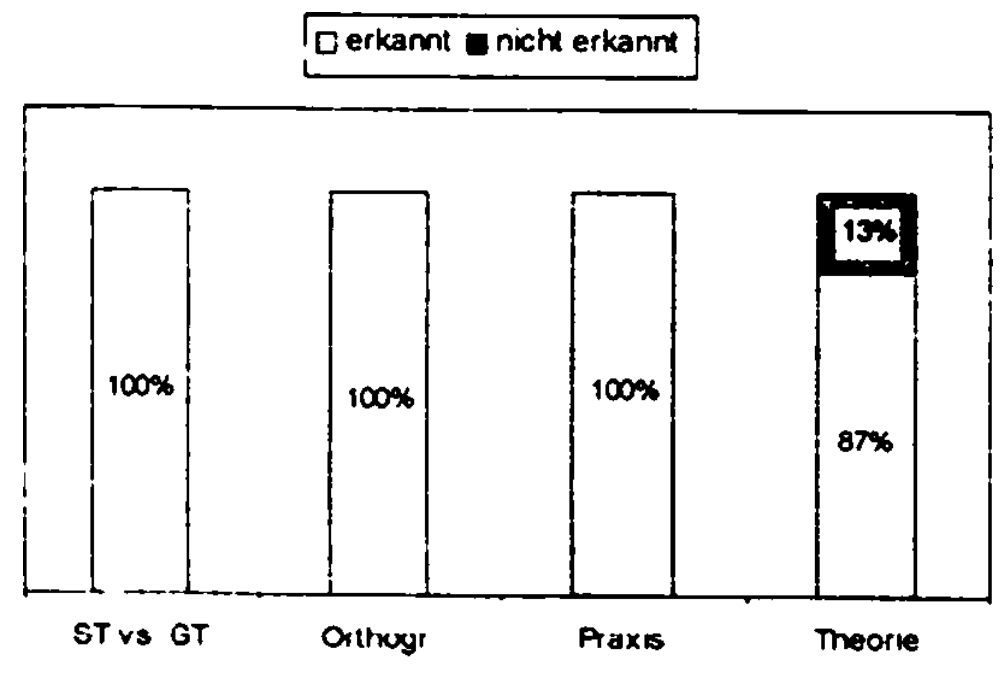

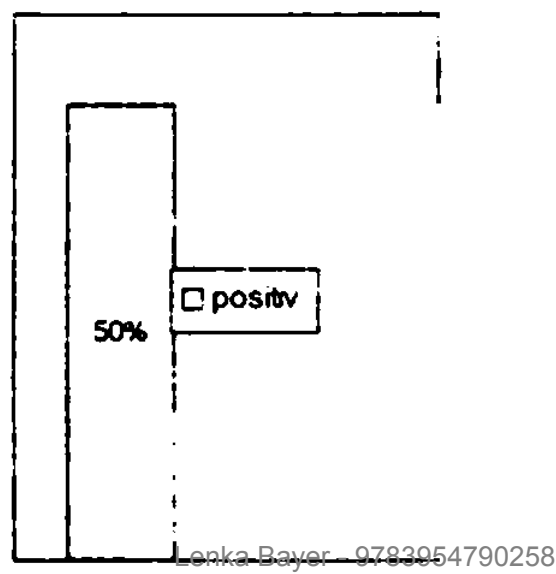


Einstellung, affektives Subsystem: Grad der positiven Einstellung

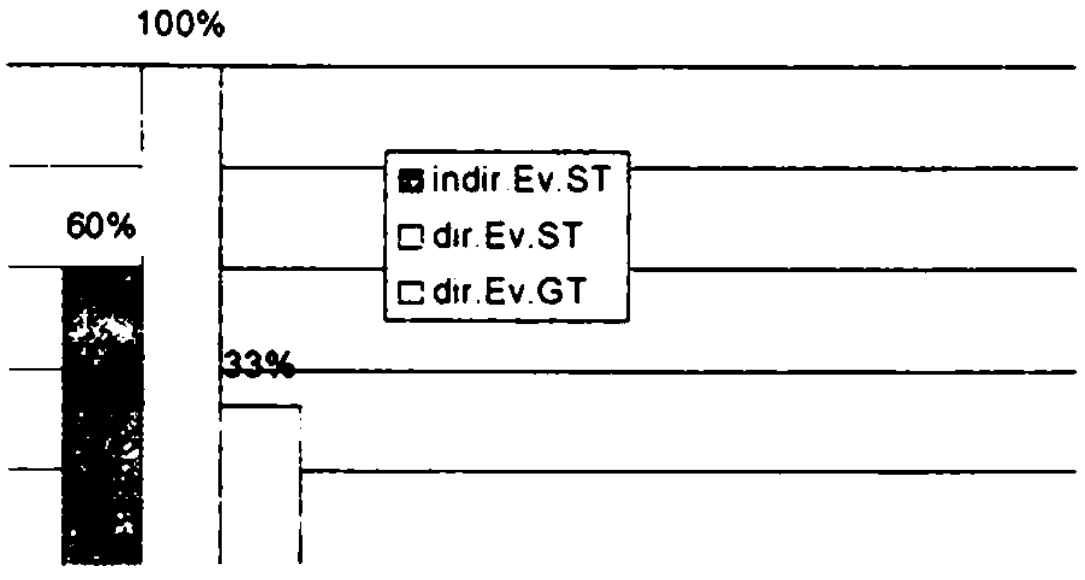

Kommentar: ohne Kommentar

\section{Studentin, 24 Jahre (5. Studienjahrgang)}

Proc jste si iybrala prón'ê temo studijni obor?

- Protoże jsem mêla na gymnaziu moc hodnou pani učitelku nebo zajimavou pani učitelku. která nanı, nás dokázala hrozné moc nadchnout a nosila nám do trìdy knižky a vždycky $z$ každý knižky udẻlala prostê vrcholnou zảležitost. Takže jsme mysleli, že si to musime precist a že to je hroznč zajimavý.

Takze yy se vinujete hlane literature. jestli tomu dob he rozumim.

- No, ani hlavné ne. To byl ten prvotni podnčt a ted'ka jà nemủžu rict. Já ešte̊ studuju historii s ceštinou a vlastnê mym diplomnim oborem je historie. Ale v podstaté musim rict, že ten zajem se tak kolisavs pohybuje a hlavnim asi rozhodujicim momentem je, jaky jsem treba poznala učitele a jaký jsem měla seminàre. Takže vždycky, kdyż byl nčjakej zajinıavej seminár, tr̉eba, tak se muj zajem priklonil na stranu toho a pak zase nècho jinýho.

A jake máte konkrémi plány do budoucna po ukoncenni studia?

- No tak, s têma plánama je to docela takový nerozhodný, protože to hodné záleži na mym osobnim životê, protože vlastnê muj partner, už docela dlouholetej, je cizinec a já nevim. jestli my budeme żit tady nebo kde vlastnê nakonec skončim. Takže jà vlastnè nevim - nevim.

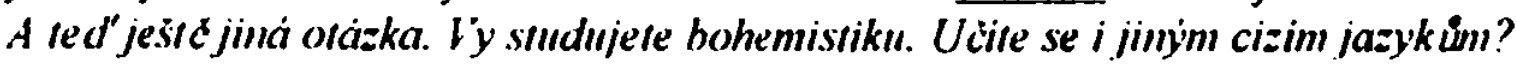

- No tak. v současný dobẻ se neuẻim néjak aktivnẻ nebo tak. Já umim anglicky anebo dlouho jsem se uciila anglicky a $v$ podstaté, protoże ten muj partner je Angličan. tak $s$ nim mluvin anglicky $A$ jinak eštce, protože on $v$ şouçasnè dobe żije $v$ Nêmecku, tak, když ho navštčvuju.

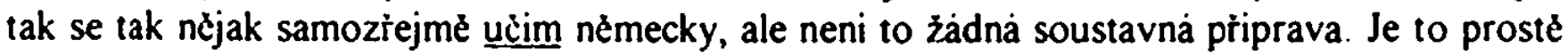
$\mathrm{z}$ televize a $\mathrm{z}$ rozhovori z pobytu tam.

A red ješr ć posledni otázka. Jak se väm libila posledni zima?

- To myslite tu, co ted'ka zrovna skoncila? No, moc se mi nelibila, ale mné se vlastné Zadná zima nelibi. Já zimu nemam vủbec ráda. A tahle mnẻ prỉšla taková zvlášt né prijiemná. protože tady nebyly nèjaký takový - zimni vrchol - prostê - a bylo to takový moc dlouhý a takový nevrcholový, kolisavý. 
Sprachverhalten:

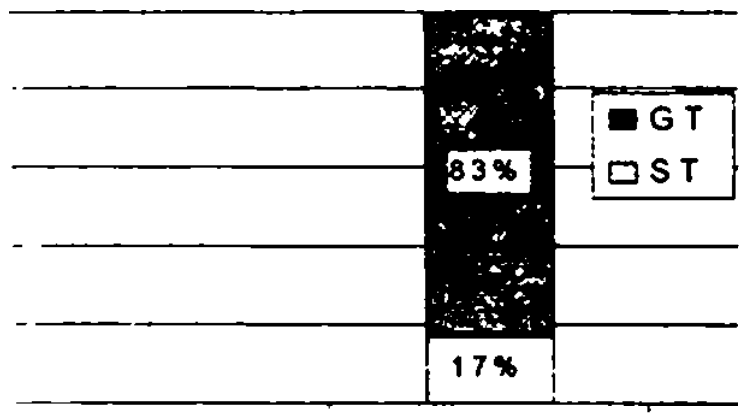

form ell

Einstellung, kognitives Subsystem:

Derkannt Dicht erkannt

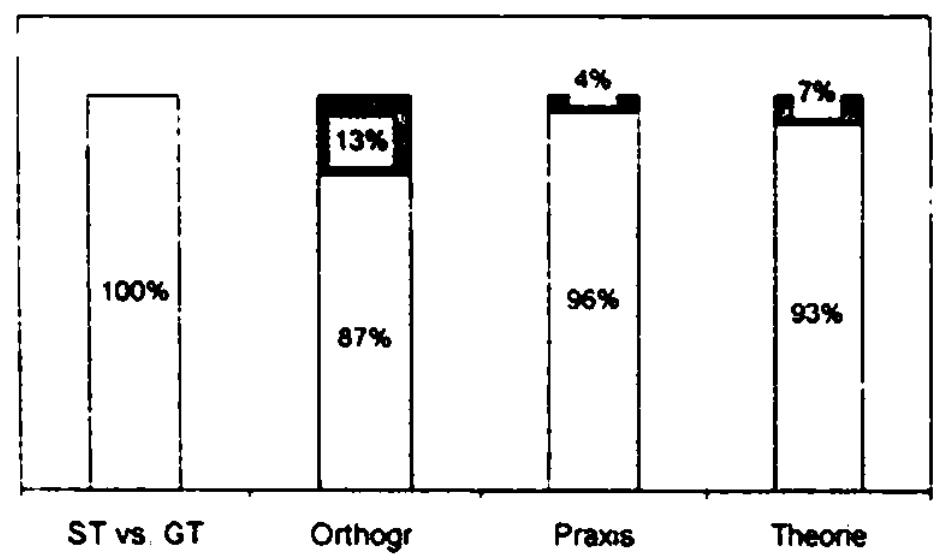

Einstellung, affektives Subsystem: Grad der positiven Einstellung

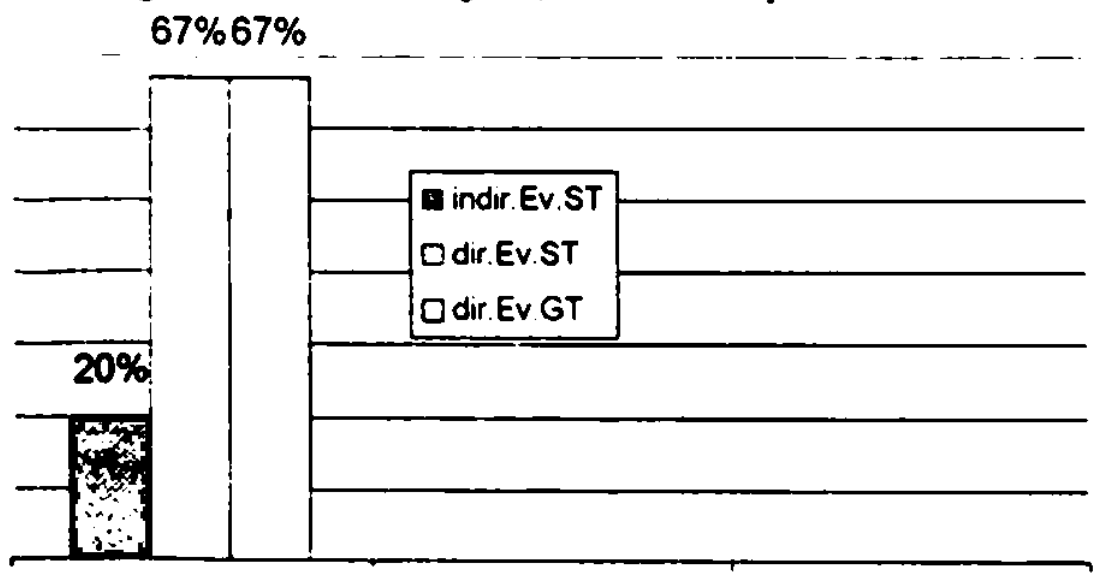

Kommentar: ohne Kommentar

\section{Studentin, 26 Jahre (5. Studienjahrgang)}

Proc jsle si iybrala právé tento siudijni obor?

- Vybrala jsem si ho z nékolika důvodủ. Protože jsem chtěla studovat jazyky, dostala jsem se na filozofickou fakultu, dostala jsem se na éeštinu a bavi mé literatura. To je asi všechno.

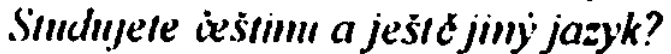

- Ne, studuji pouze češtinu. Chtêla jsem studovat španělštinu, ale to se mi nepovedlo

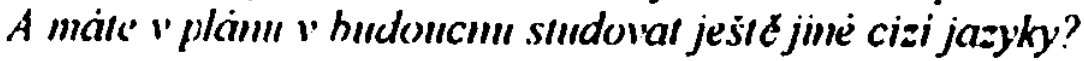


- No, umim dobte rusky a anglicky a docela dobre క̌panẻlsky, francouzsky a učim se srbsky. Takžc myslim. že už to stači.

A jaké máte plány do budoucna, tyjkajici se vašeho povoláni?

- Chtěla bych dêlat lektorku někde na nêjaké zahranični univerzitě. No, tak pro nejbližši dobu. Toto asi. Takže néjaká ta pedagogická práce by mé docela zajimala.

Takze pracujete ráda s dçmi. nebo radeji s dosp dymi?

- Radéji s vêtšsimi détmi a s dospếlỳmi. Už mám zkušenosti $s$ tim. že jsem učila Čiñany, to znamena dospélè, ceštinu.

To je velice zajimave. ''y jste ucila Ciñany cesstimu? A jaké máte zkusenosti?

- Velmi špatnè. Moc jim to nešlo, protože to byli vétšinou lidé, kteti neuméli żảdný jiný cizi jazyk neż cinštinu, takže bylo velice teč̌ké jim približit vủbec gramatický system nebo vưbec systèm evropského jazyka. indoevropskèho.

A nancili se trosk" desky? A po jaki dobe?

- No, záleželo na jejich pily taky. Ti, co se hodné snažili, tak se naučili dorozumét docela dobre $\checkmark$ tẻch zakladnich situacich a byli schopni porozumét a nèco odpovêdè̃t. Ten kurz trval trii

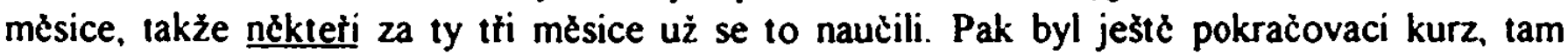
vydrželi jen tị nejvètši zajemci. Takovi ti. jako hodnẻ vesnické typy, nechci je teda uražet, ale tak ty vêtšinou ani nemohli čist. Nebo když neméli zkušenost $s$ latinkou vưbec, tak to pro né byl velký problèm víbec cist a vỉbec se orientovat.

A ješt é jiná otázka. Jaký máte názor na posledni zimu? l'idim. ž̉ máte zrovna rýmu.

- No, byla jsem rada, že se mi celou zimu všechny choroby vyhỷbaly a ted'ko, jak byla zase ta zmẽna $\mathrm{z}$ teplèho počasi na studené, tak mê rýma nẻjak zachvátila.

Sprachverhalten:

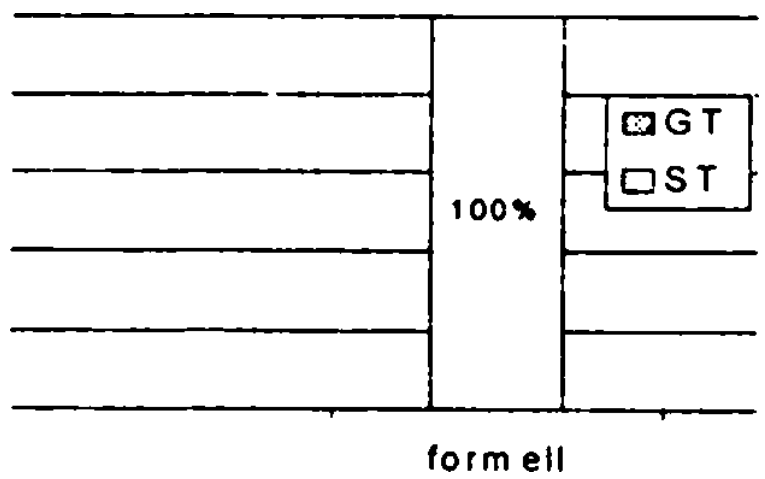

Einstellung kagnitives Subsystem:

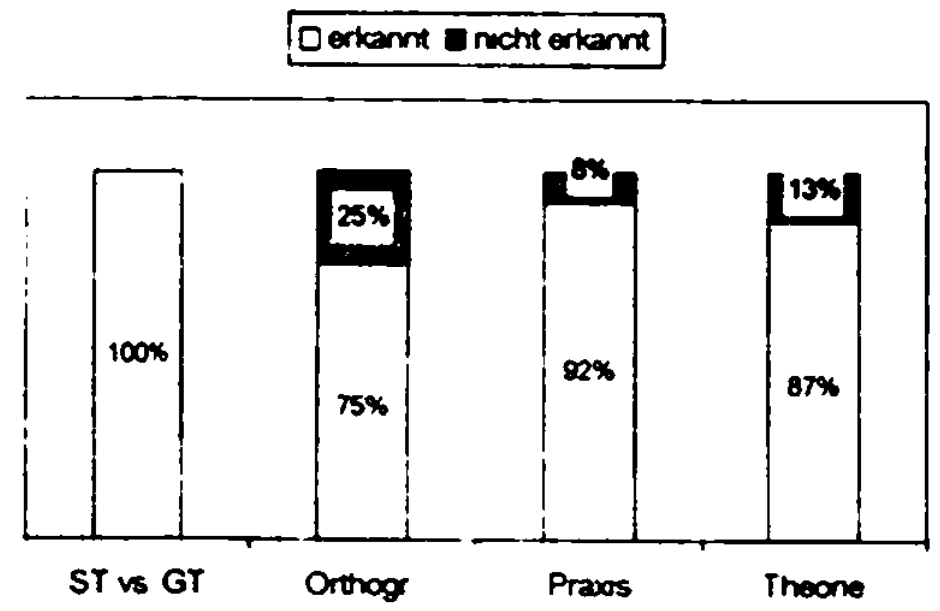

Einstellung, konatives Subsystem:

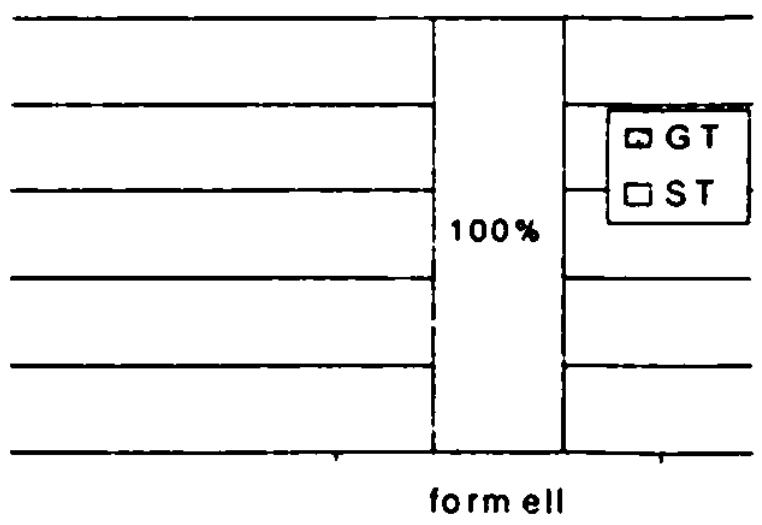

Evaluation der eigenen Kognition:

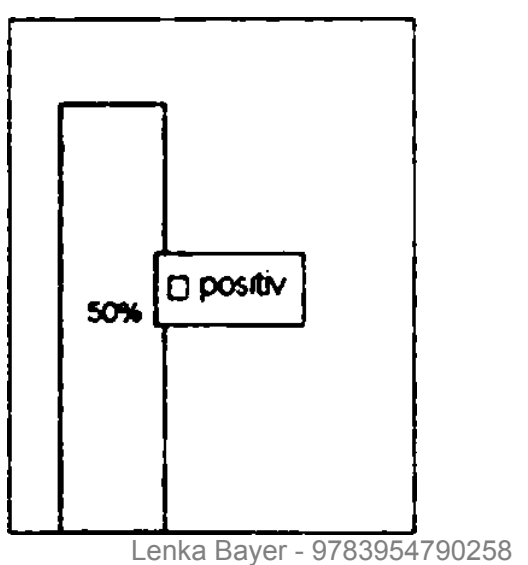

Lenka Bayer - 9783954790258 
Einstellung, affektives Subsystem: Grad der positiven Einstellung

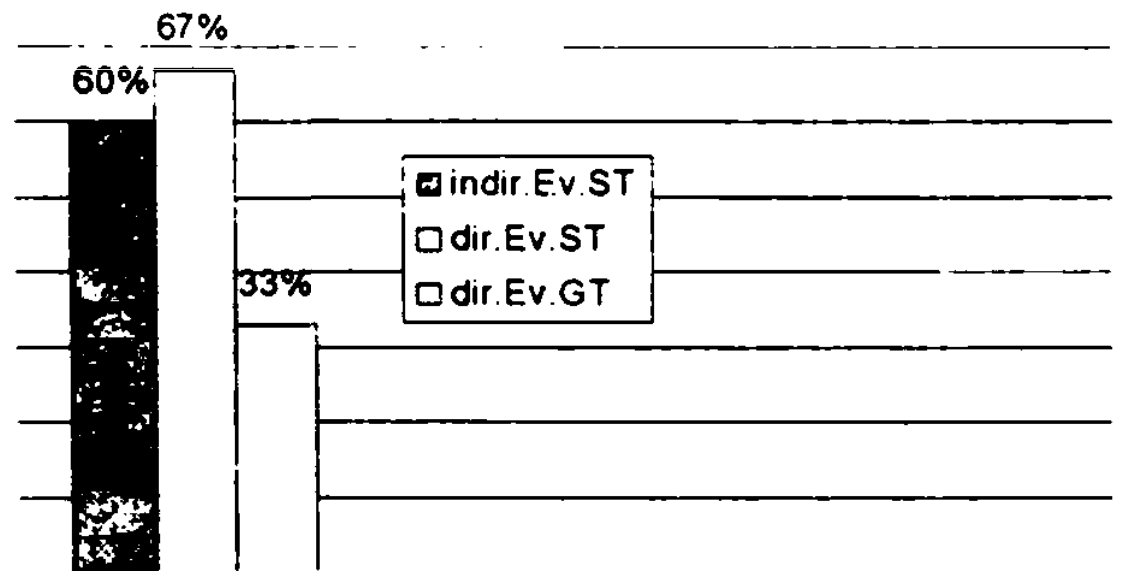

Kommentar: ohne Kommentar

\subsubsection{Sindenten der Philosophischen Fakulıät, Bohemistik}

Die Studenten wurden in der Fakultät während einer Lehrveranstaltung aufgenommen. Insgesamt ivurden 2 Aufnahmen durchgeführt.

\section{Student, 24 Jahre (4. Studienjahrgang)}

Proc jste si vybral práde temo studijni obor?

- Protože miluju ċeský jazyk a literaturu. Já jsem preedtim už studoval teologickou fakultu a protože jsem nechtêl jit pracovat, tak jsem si zvolil to, co mé bavilo už na gymnáziu

Akcemujete literaturu, nebo linguistiku?

- Spiše mé bavi linguistika. Literatura mé prestala bavit, už mé bavi jenom c̀ist.

A ukterim rociniku jste ted"?

- Teư' jsem ve îtvrtém rociniku.

A studujete pauze céstimu, nebo ješte néjaky cizi jazyk?

- Studuju jednooborovê ceský jazyk a literaturu. A cizi jazyk délám jenom z povinnosti. Jak se vyžaduje tady. Angličtinu a nuský jazyk.

A jake mále plany do budoncria, tjkajici se vašeho povoláni?

- Co se tỳce povoláni, tak to jsem si zatim nevybral. Možnà, możnà budu zkoušet doktorat To ještč tčžko rict zatim

Zatim żidrki konkrétmi plàny nemáte?

- Ne, nevim o tom, že bych chtêl nęjaké urçité povoläni vykonávat.

A ted' ješt $\mathfrak{c}$ jiná otázka. Jak se rám libila posledni zima?

- Posledni zima. Posledni zima se mi libila. protože koneiné byly laviny. A koneiné bylo na horách dost snčhu. Ale bohužel jsem nelyžoval, tak jsem si ji moc neužil

Tak jste neby/ v Rakousku ' dobe lavin?

- Ne. to jsem bohužel nebyl. 
Sprachverhalten:

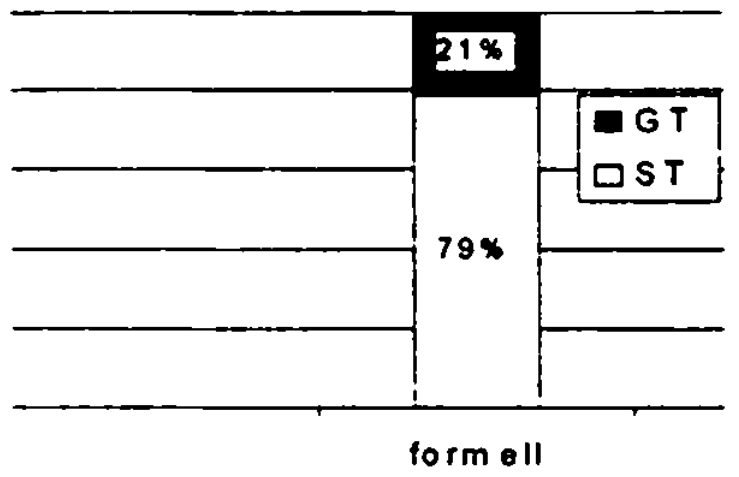

Einstellung, kognitives Subsystem:

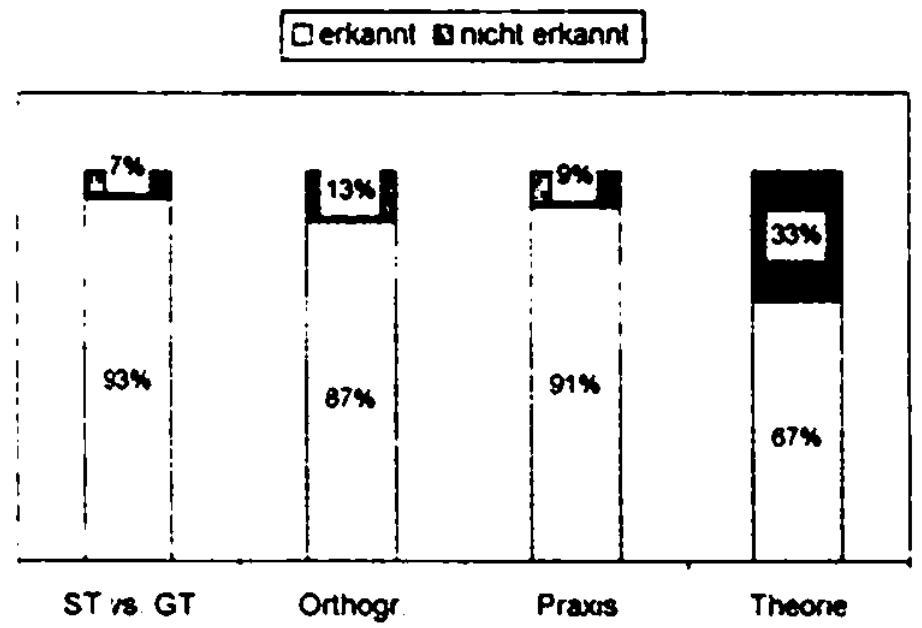

Einstellung, konatives Subsystem:

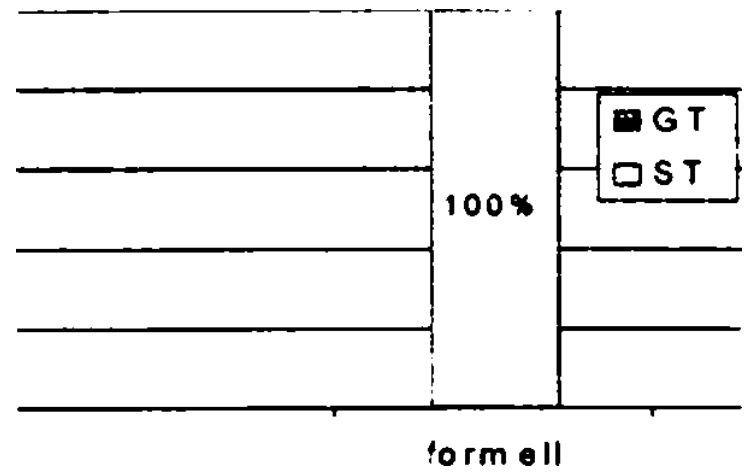

Evaluation der eigenen Kognition:

Einstellung, affektives Subsystem: Grad der positiven Einstellung

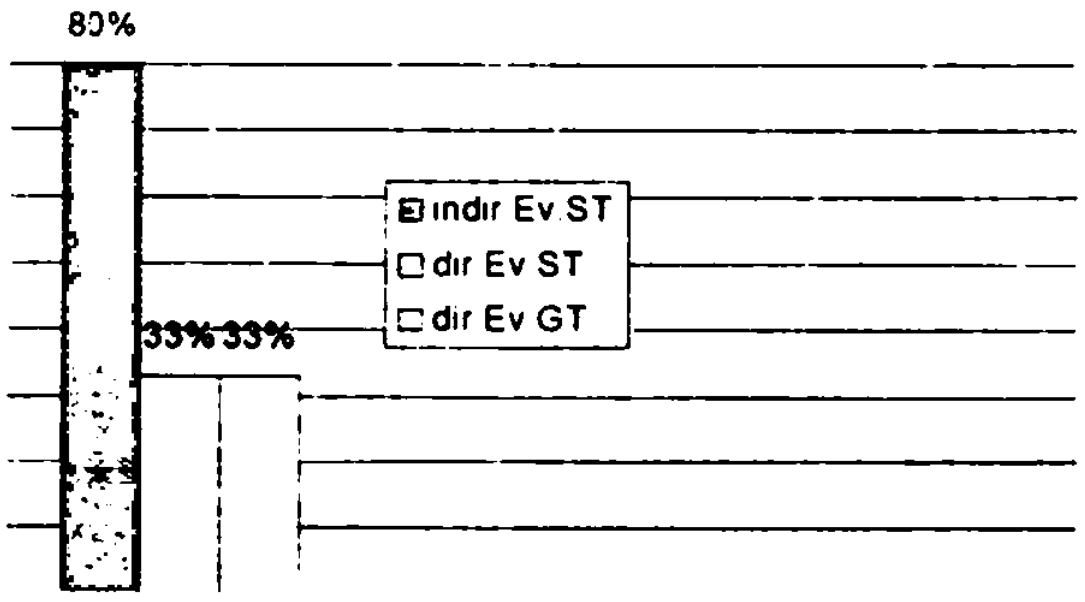

Kommentar: Libi se mi jednoduchost dotazniku.

\section{Student, 26 Jahre (5. Studienjahrgang)}

Prot'jste si uybral právé tento studijmi obor?

- Protoże mé zajimá literatura, tak jsem si vybral právê českỷ jazyk a literaturu Pak v prübčhu ċasu jsem se zamšril spiše na jazyk a na linguistiku. Takže müj zajem se presunul spiše timto smírem No, nicmend literatura stäle zủstává mẏm konickem.

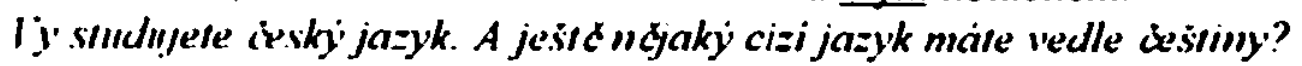


- Máme jako $v$ povinnych, jako ve studijnim ráa máme, že musime mit zkoušky ze dvou jazykủ. Ale mam, já mam bohemistiku sólovè. Tak maximálnè mam zkoušku z ruštiny a $z$

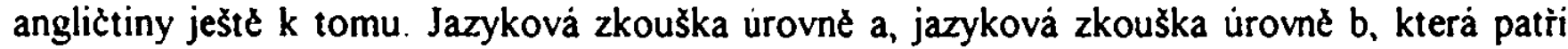
prosté $\mathrm{k}$ povinnému, tomu penzu, které musime vyplnit ve studiu.

A jake máte pläny do budoucna, týkajici se vaseho povoláni?

- Jestli se mi podari úspěňně složit - složit státni zkoušku, tak bych se pokusil postoupit do postgraduálniho studia a $v$ ideálnim prípadẹ zústat tady na akademické pủdẻ. Pravdèpodobnè primo tady v Praze.

A ješt e jiná otäzka. jak se vám libila posledni zima?

Zima. No, tak já jsem si ji moc primo neužil - zimy, protože nelyžuju. Priimo na horách jsem nebyl, vlastné až na tři dny. Tak jsem byl celou dobu v Praze. Priliž sněhu nebylo, cili zima pro

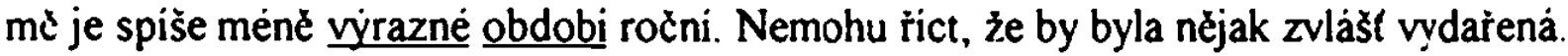

Sprachverhalten:

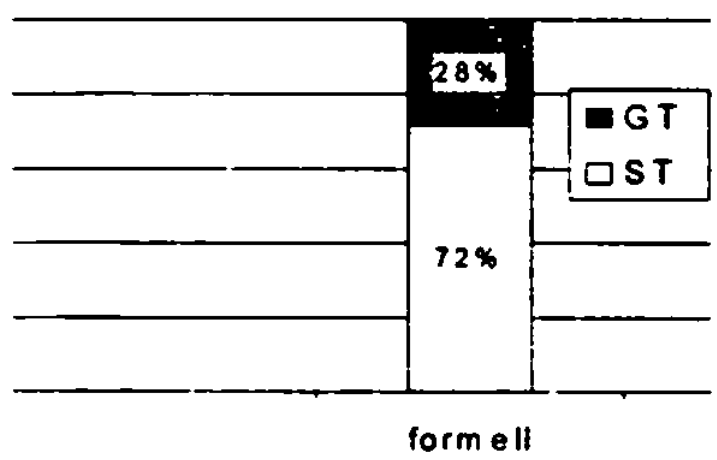

Finstellung, kognitives Subsystem:

Derkannt D nicht erkannt

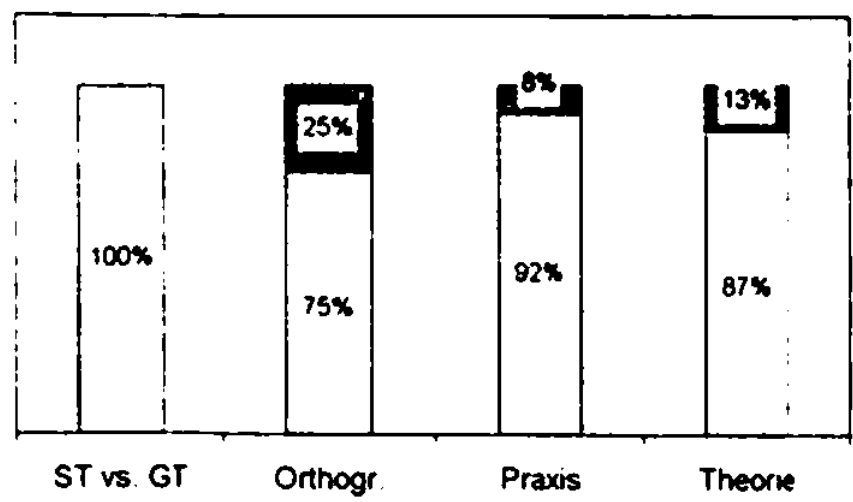

Einstellung, konatives Subsystem:

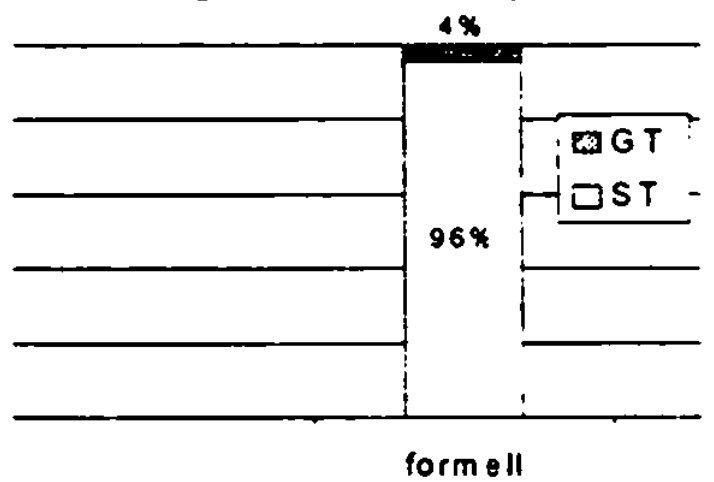

Evaluation der eigenen Kognition:

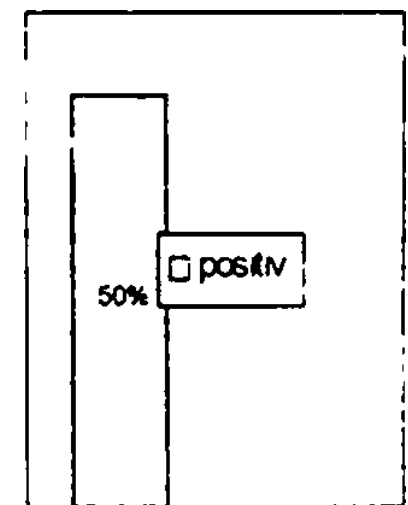

Einstellung, affektives Subsystem: Grad der positiven Einstellung $: 00 \%$

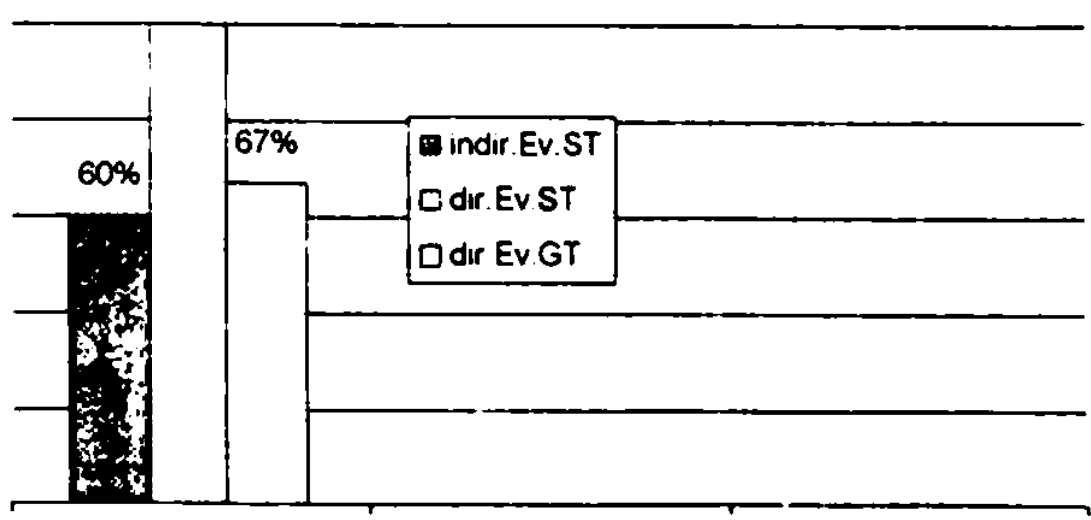




\subsubsection{Studentinnen der Pädagogischen Fakultät. Bohemistik}

Die Studentinnen ${ }^{117}$ wurden in der Fakultät während einer Lehrveranstaltung aufgenommen. Insgesamt wurden 5 Aufnahmen durchgefuhrt.

\section{Studentin, 19 Jahre (2. Studienjahrgang)}

Procijste si vybrala pràvè temo studijni obor?

- Protože bych byla ráda ucitelkou.

Máte ješte jine motiny?

- Zajimám se $Q$ çeský jazyk.

Hlame o jazyk. anebo o literaturu?

- Spiše $\mathrm{Q}$ jazyk.

A jaké máte cile do budoucna?

- Ráda bych zlepsila napriklad výslovnost, nebo zlepsit kvalitu jazyka u mladých lidi.

A s jakou skupinou byste cht da nejradeji pracovat?

- Asi se studenty strednich skol.

Takž studujere pedagogiku pro stredni školy?

- Pro druhý stupeñ a středni školy.

A jake cizi jazyky studujere?

- Momentálnè żảdný, ale studovala jsem nèmčinu.

$A$ z jakeho dinodu?

- Nevejde se do rozvrhu.

$A$ z jakeho dinodu jste studovala nóncimu?

- Vênovala jsem se ji asi od svých šesti let, tak asi proto.

A ted' ješte jiná otázka. Jak se vám libila posledni zima?

- Byla jiná než ostatni. Byla hezìi.

Z jakeho dincodu?

- Bylo hodnẽ snčhu, tak asi proto.

\section{Sprachverhalten:}

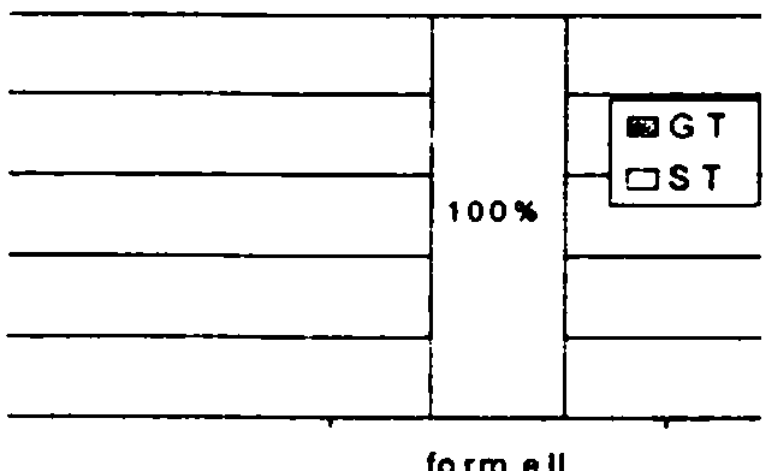

Einstellung, konatives Subsystem:

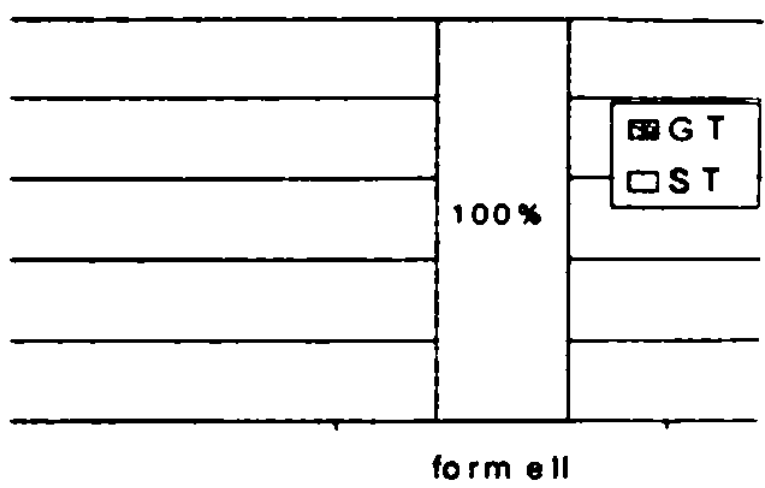

"- Es handelt sich um Studierende (sielic auch Kap. 6.3.2.4). die das Tschechische (Sprachwissensclaft bzw:

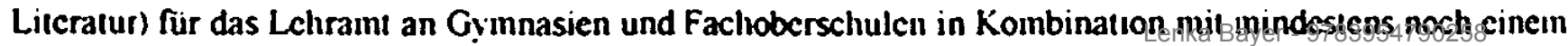
weileren Fach sludieren. 
Einstellung kognitives Subsystem:

Evaluation der eigenen Kognition:

D erkannt a nicht erkannt
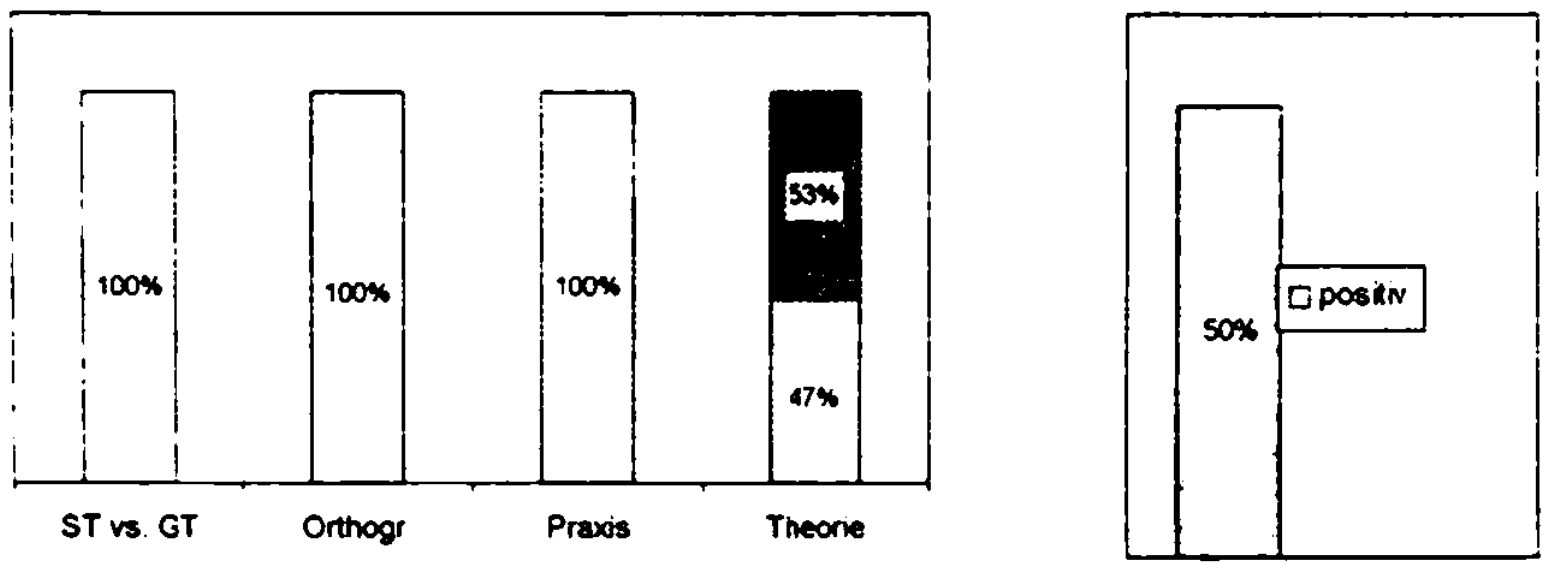

Einstellung affektives Subsystem: Grad der positiven Einstellung $80 \%$

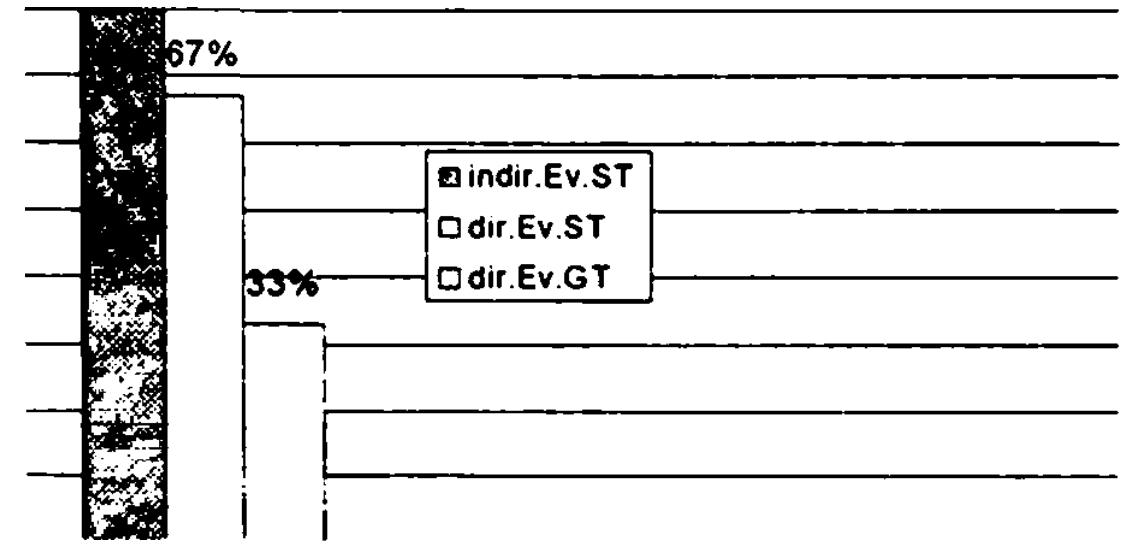

Kommentar: Myslim, że napì. $v$ médiich (televize, rozhlas) by se mêl dávat vêtši pozor na vyslovnost a na plynulost reci.

\section{Studentin, 19 Jahre (2. Studienjahrgang)}

Procijste st vybrala právé temto studijni obor?

- Tak to je priliš têžke na to - anebo ne priliš têžké ... Protože mé ceština a jazyky zajimaji už od základni školy a moje rodina je humanitniho zamêteni, takže to taky hrálo velkou roli, že $v$ tomhletom smèru mẻ to posunovalo jako už od dêtstvi.

A akcentujele spis literaturu, anebo jazyk?

- Spiše jazyk a možná, že to je i tim, že mam určitý hendikep proti literature, že toho nemam tolik naciteno. Když by se mẻlo mluvit takhle hodnè osobnê. protože - a vlastnê ten jazyk vidim $v$ tom vêtši uplatněni, které by se mohlo - i mé to zajimá.

A vaše plány do budoucna. tykajici se vaseho povoláni?

- Chtela bysem dodélat bakalaŕský stupeñ a potom prerušit studium a jet bud' jako na studium na stipendium, nebo jako au-pair naučit se druhý jazyk pořảnž Protože myslim, že kdyż. člověk neżije $v$ tom prostredi, tak nikdy se tomu cizimu jazyku nemúže tak dokonale nauciit. A jaky jazjk to je ve vašem pripadd?

- No, ještể nejsem rozhodnutà, vảhảm mezi angličtinou a nêmčinou. 
A ted' jiná otázka. Jaký máte názor na letošni zimu?

- No, už je hodnè dlouhá

Co byste na ni zmúnila?

- No, už bysem chtěla, aby bylo jaro. A co bych na ni změnila? No, asi aby odešla v klidu tr̉eba kvůli tomu, kolik je sněhu na horách. Aby nebyly żádné záplavy nebo tak.

Sprachverhalten:

Einstellung, konatives Subsystem

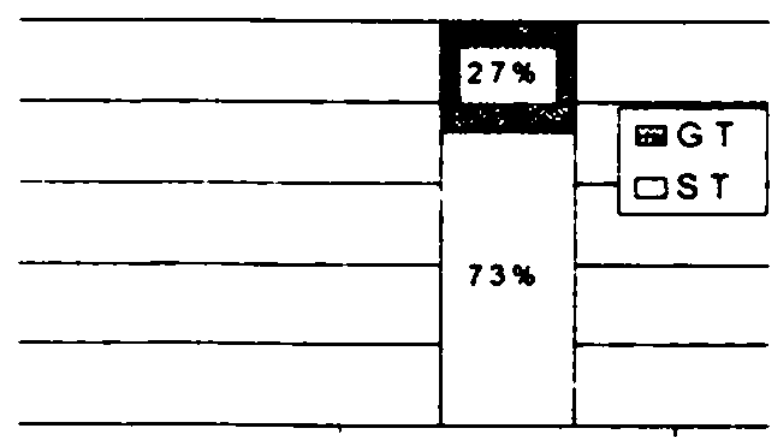

form ell

Einstellung, kognitives Subsystem

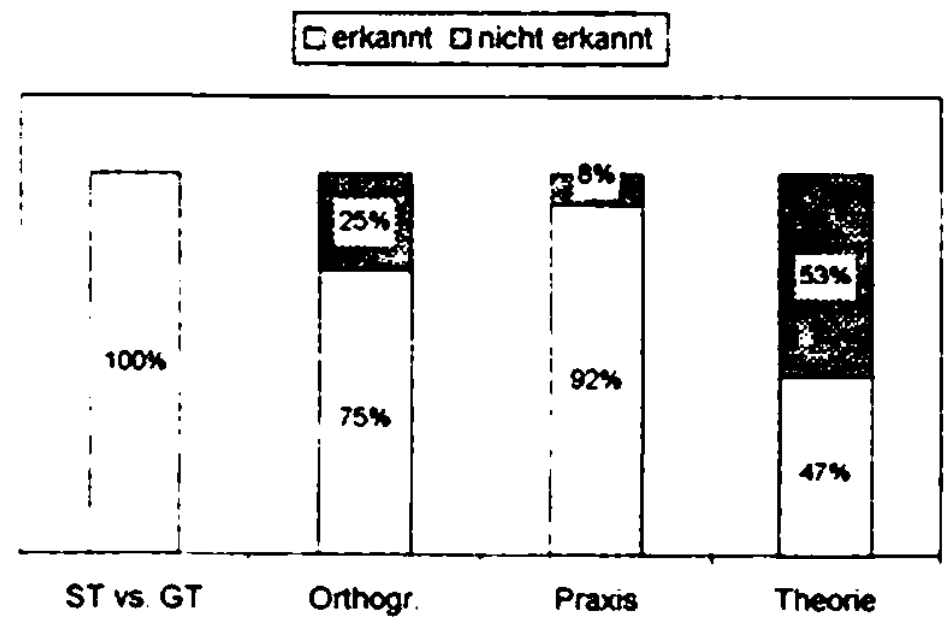

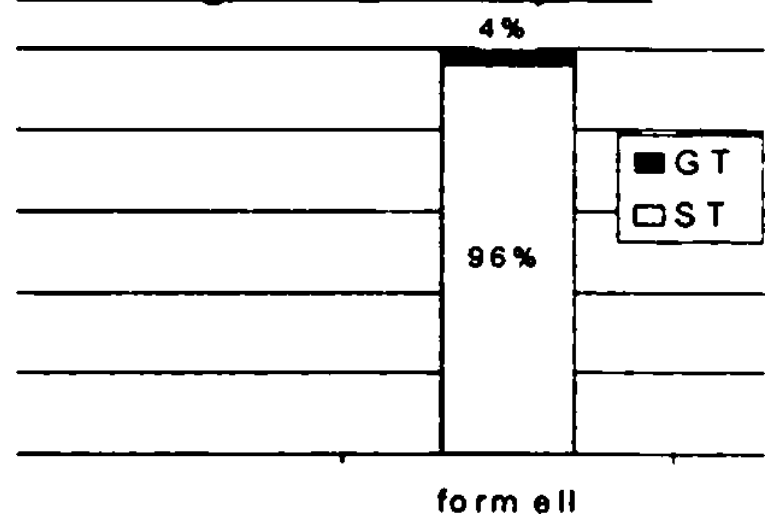

Evaluation der eigenen Kognition

Einstellung, affektives Subsystem: Grad der positiven Einstellung

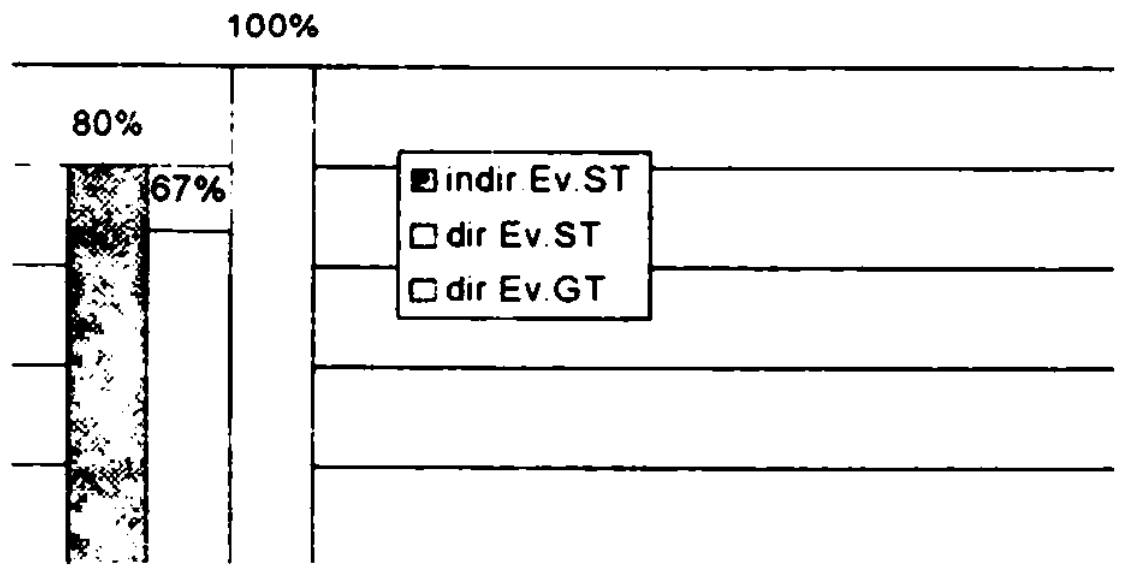




\section{Studentin, 20 Jahre (2. Studienjahrgang)}

Proc̀ jste si vybrala právé ıento studijni obor?

- Protože mé bavi ceština a ceský jazyk a literatura.

A bavi vás vic literatura, anebo jazyk?

- Bavila mé vic literatura, ale poté, co tady vlastnê studuju, tak jazyk.

A jake máte plány do budoucna, tykajici se vašeho povoláni?

- Nechci jit učit. No, jả bych radéji nékde $v$ rozhlase nebo $v$ televizi pracovala.

Nemáte ráda práci s dami? Nebo z jakèho dinodu?

- To rozhodnè ne. Práci s dètmi mám rảda. ale kdybych šla učit, tak bych šla učit nêkam na gymnazium nebo tak. Ale treba na základni škole bych nechtẻla. Ne kvưli tomu, že bych nemêla ráda déti, ale vủbec kvưli tomu prostiedi a tak.

Tak zad raji práce s dospdymi nebo s vašimi dèmi?

- Rozhodnè s vêtšimi dètmi.

A jaky cizi jazyk studujete?

- Nemám jako oborovej - oborovy cizi jazyk.

A na skole jste se ucila jakj' jazyk?

- Učila jsem se angličtinu, nèmčinu, latinu a ruštinu. Momentảlnê se učim angličtinu - jako angliçtinu a ruštinu, ale ne nějak $v$ kontextu s touhle školou.

$A$ z jakèho din'odu angliçimu?

- No tak, angličtina je $v$ dnešni dobẻ vlastnè nejdůležitęjši jazyk podle mého názoru a bez ni vlastnê ta naše generace už nemá mnoho sanci.

A ted' ješt čjiná otäzka. Jak se vám libi nebo jak se vám libila posledni zima?

- Posledni zima se mi moc libila, protože bylo venku hodně snẻhu a mohlo se jezdit lyžovat.

Sprachverhalten:

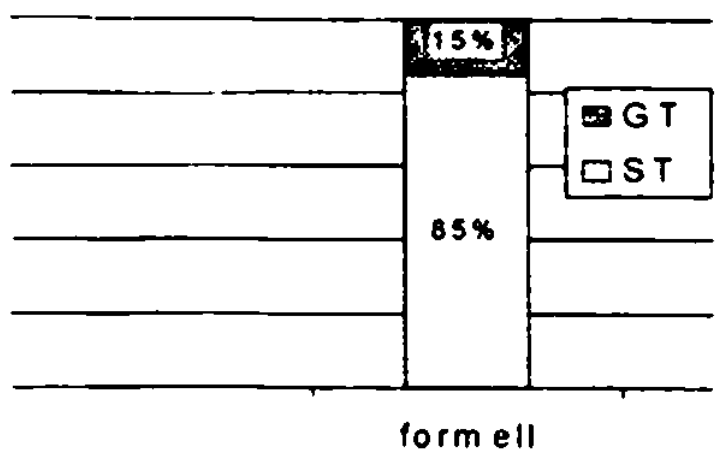

Einstellung, kognitives Subsystem:

Cerkannt Bincht erkanmt

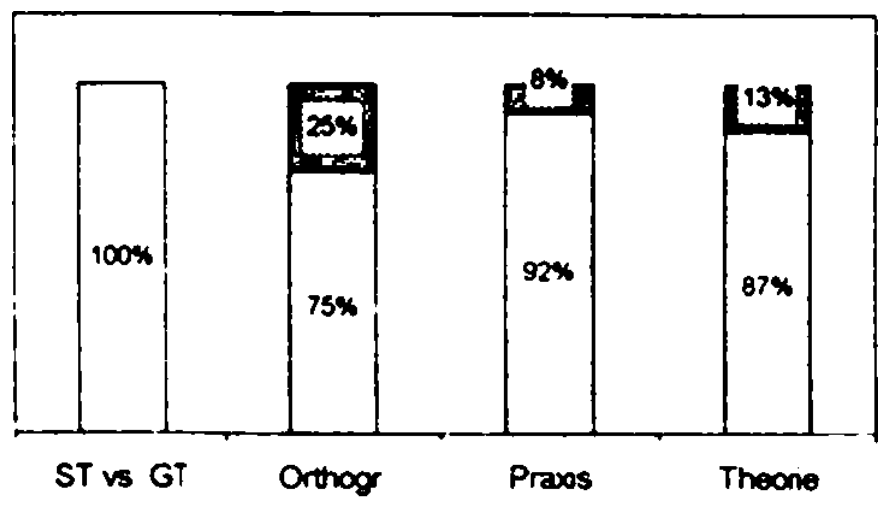

Einstellung, konatives Subsystem:

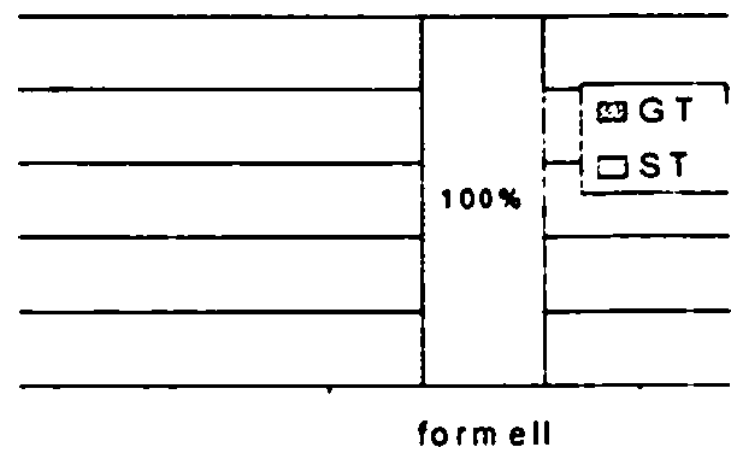

Evaluation der eigenen Kognition:

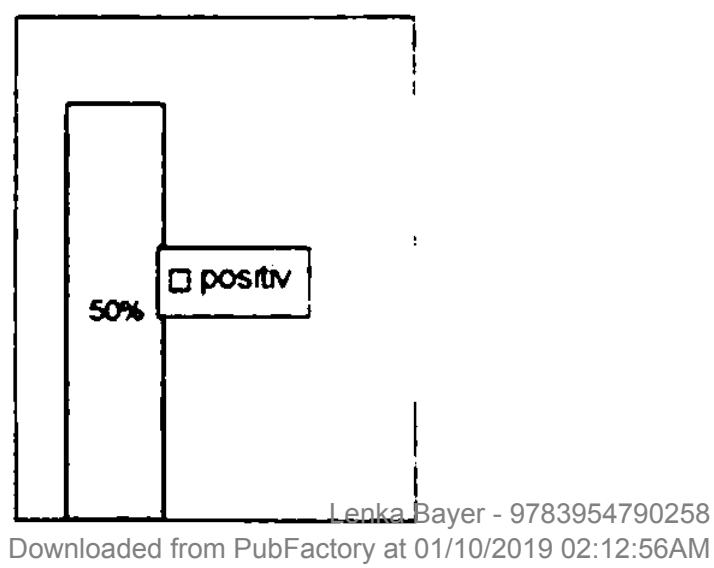


Einstellung, affektives Subsystem: Grad der positiven Einstellung

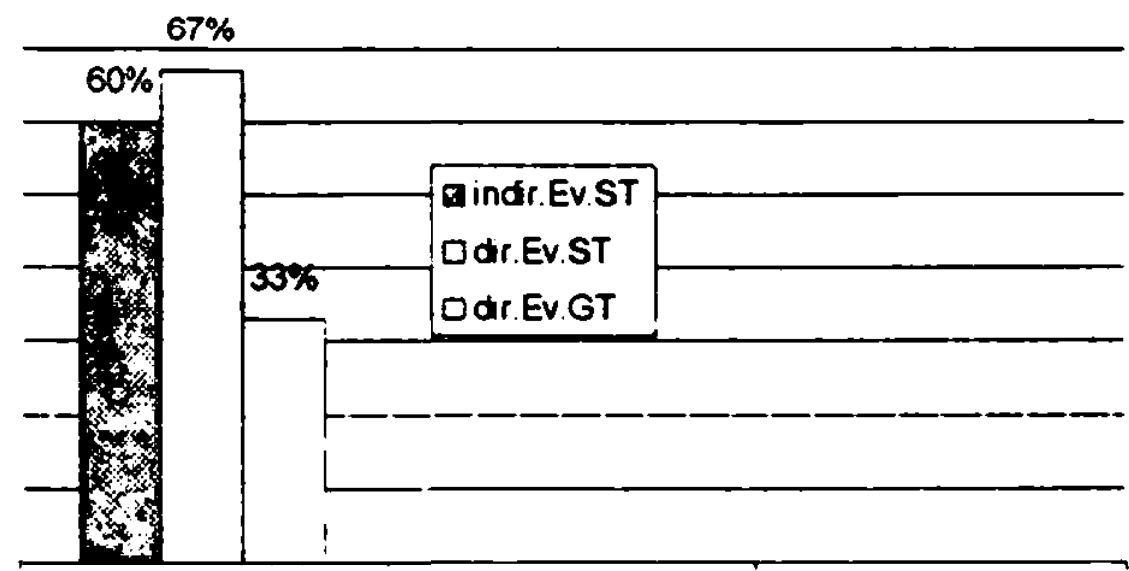

Kommentar: ohne Kommentar

\section{Studentin, 20 Jahre (2. Studienjahrgang)}

Procijste si uybrala právé temto studijni obor, bohemistiku?

- Popravdé ṙečeno, protoże byla $v$ kombinaci $s$ hudebni výchovou, a prece jenom jsem ráda chodila do divadla. cetla jsem, tak jsem myslela, že by to bylo vhodné a potom až vlastnè $v$ rámci studia mê zac̀la vic bavit ceština.

A bani vás vic jazyk, anebo literatura?

- Vic literatura, ale i jazyk mé bavi.

A vase pläny do budoucna, tjkajici se vašeho povolani jako ceśtináika?

- Chtêla bych učit na stredni škole a spiš neż nacpàvat hlavy, tak dẻlat nèjakou osvẽtu a aby deti cetly, chodily do divadla a zajimaly se o kulturu

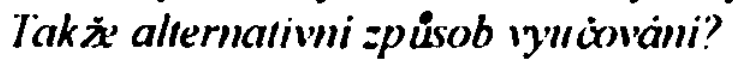

- Néco takoveho.

A jakj' stmdujete cizi jazyk? Studujele ncjjakj?

- Studuji v rámci univerzitniho základu nèmčinu a chystàm se na ruštinu prišti rok.

Némčinu už jsem délala od základni školy a protože to je svêtový jazyk. človék se s nim domluvi a ruștinu, protoże to je slovanský jazyk a je zajimavý $v$ ramei trieba studia staroslovènštiny.

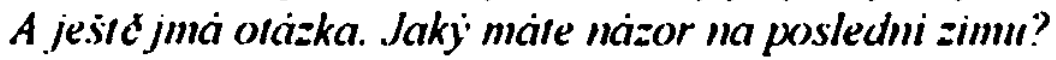

- Zima se vydarila, snčhu bylo dost. Byla jsem na horach lyžovat. Nemam ráda mráz, mam ráda naopak takové jarni poćasi, kdy sviti sluničko a vzduch voni travou, ptáckové zpivaji. Ale když sviti to sluničko i $v$ zimê a neni vylơ̌enê mráz, tak mam ráda i zimu.

Sprachverhalten.

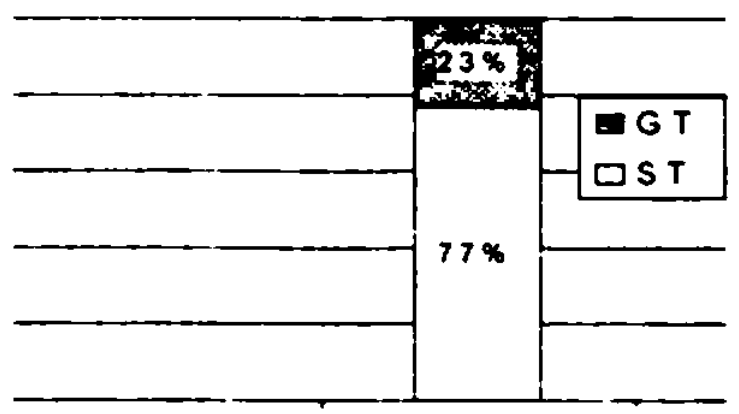

form ell
Einstellung, konatives Subsystem:

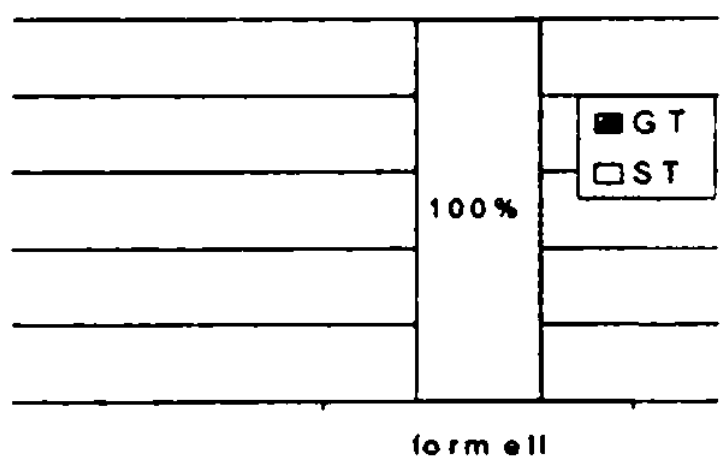


Einstellung. kognitives Subsystem:

G erkannt es nicht erkannt

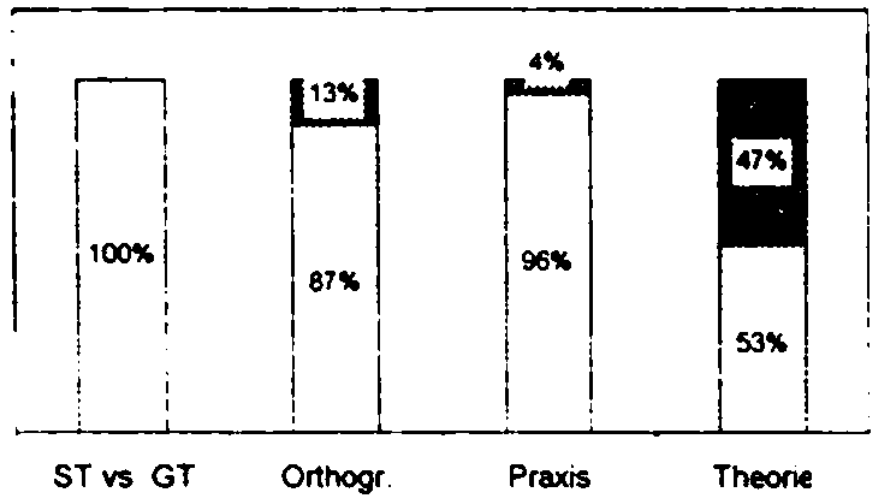

Evaluation der eigenen Kognition:

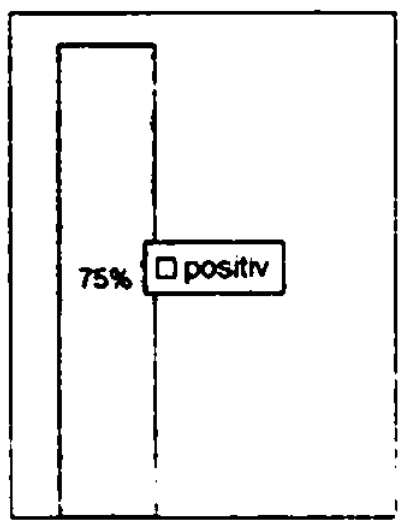

Einstellung, affektives Subsystem: Grad der positiven Einstellung

$67 \% 67 \%$

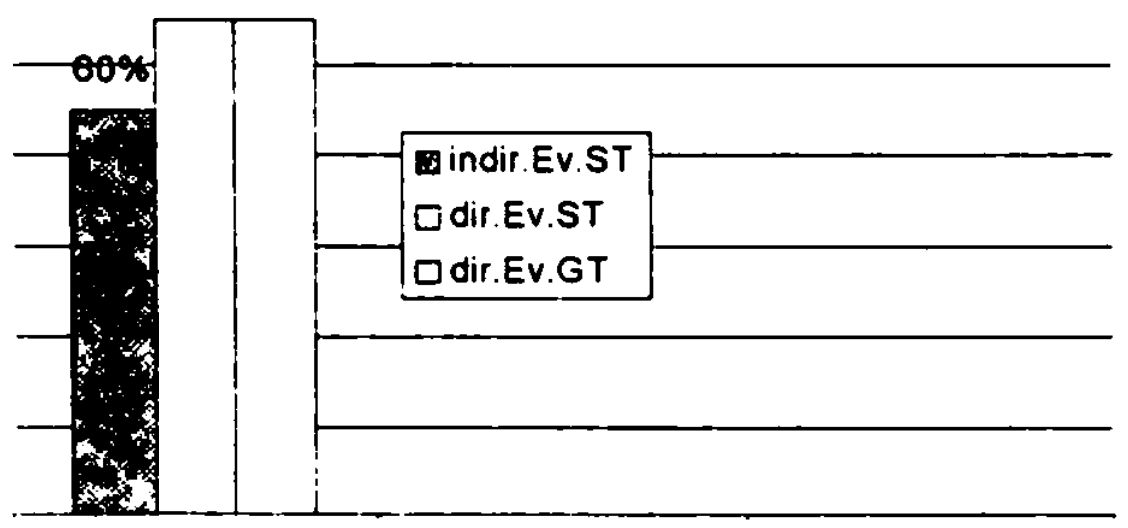

Kommentar: Anketa byla fajn, je dobíe, že nèco takovèho se vúbec organizuje. Prii vyplñováni mé napadlo, ž v Praze se opravdu mluvi hrozně, na druhou stranu si nedovedu predstavit, že by se mluvilo jinak. Rozhodnẻ bych ale nechtêla, aby se takhle mluvilo $v$ médiich. Nekkdy se $v$ médiich nespisovnà slova objevi a nepúsobi to dobrie.

\section{Studentin, 21 Jahre (2. Studienjahrgang)}

Proc jste si iybrala právè remo studijmi obor?

- No tak. já studuju vlastnž ceštinu a výtvarku - výtvarnou výchovu. A vybrala jsem si to z toho dủvodu, že jsem chtêla dẻlat právě výtvarnou výchovu, a ta čeština mé bavila jako taková. A tady otevirali tenhlecten - tuhlectu kombinaci. Takže proto. Jinak jako češtinu bych asi normálnê studovat nešla.

A zajimá vás vice literatura, anebo jazyk?

- Spiš asi literatura. A ten jazyk, no. Jako zajímavý to určitě je, ale zas takhle jako se $v$ tom hrabat, to zase mé nebavi.

A práce s darmi? Jaký je vás názor na práci s dámi?

- No, s tim moc zkušenosti nemám, takže to nemúžu tict. Každopádné déti mi lezou dost na nervy. Ale zase. co si vzpominám, tak jsem vedla skautskej kroužek, no vlastné takovou jenom družinu tam. A to mé vcelku bavilo.

Takize vaše plany do budoucna konkréme? A jaki cizi jazyky studujele 
- To eštể vủbec žádný nemám, ale pravděpodobnẻ učit nebudu chtit. Tady ve škole? Tady studuju angličtinu a to mi prijjde dost hloupé tadyto iešeni, protože vlastně oni otevieli hrozně málo seminàiù, a zajemcủ je tady mnohem vic. A to hlavně u tý angličtiny je to hodné znàt. Takový ty jazyky, jako francouština, tam jich tolik neni, takže tam ta kapacita staci. Ale u tý angličtiny je to vopravdu špatný. A ta úroveñ, no ta je docela dobrá. No, člověk se tam néco naucii, kơyż se teda naucit chce.

A ted" ješté jiná otázka. Jak se vám libila posledmi zima?

- Posledni zima? Ješté neskoncila. No, tak vcelku teplá byla, no, nevim.

Sprachverhalten:

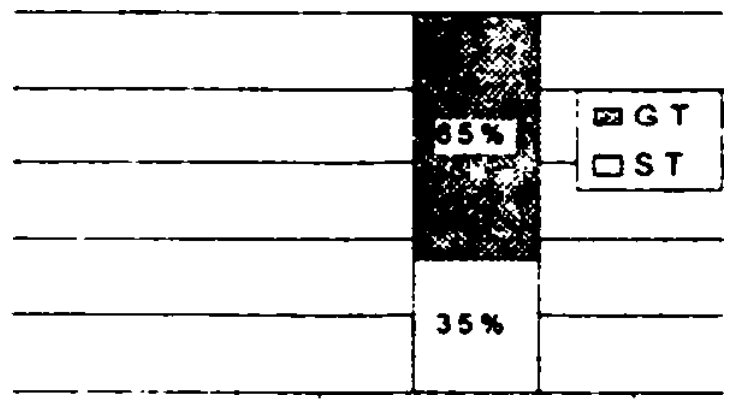

form ell

Einstellung, kognitives Subsystem:

Cierkannt 0 nicht erkannt

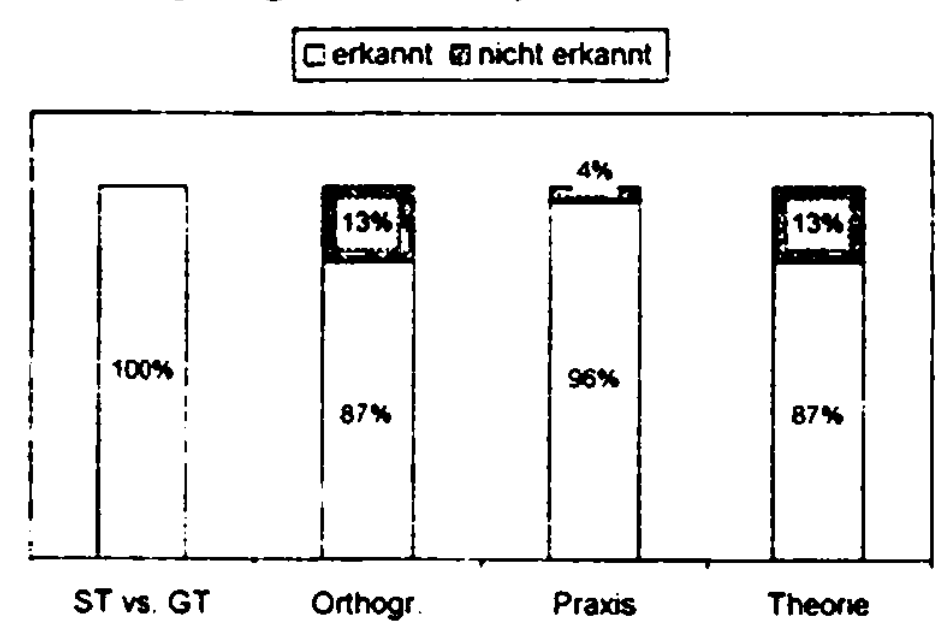

Einstellung, konatives Subsystem:

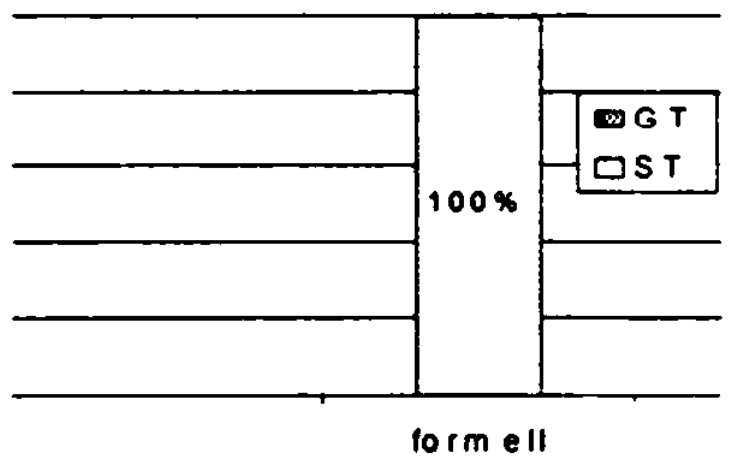

Evaluation der eigenen Kognition:

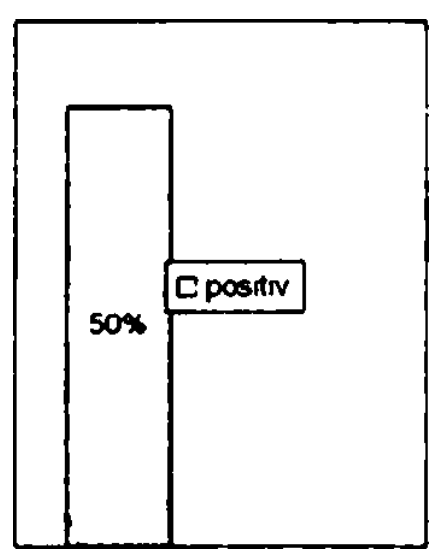

Einstellung, affektives Subsystem: Grad der positiven Einstellung

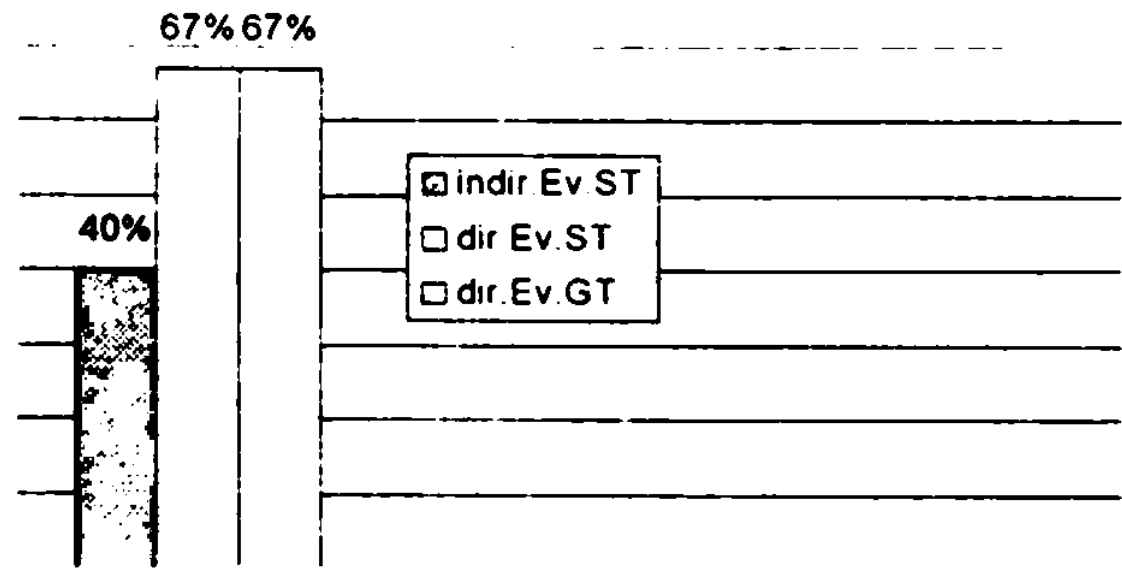




\subsection{Studenten der Pädagogischen Fakultät, Bohemistik}

Die Studenten wurden in der Fakultät während einer Lehrveranstaltung aufgenommen. Insgesamt wurden 3 Aufnahmen durchgefuihrt.

\section{Student, 20 Jahre (2. Studienjahrgang)}

Proc jste si vybral pràve temto studijni obor?

- Protože čeština je mủj rodný jazyk, rảd se češtinè naučim, a dnes je velký príiklon a zajjem o cizi jazyky a na tu ceštinu se tak trochu zapominá.

A bavi vás spiš literatura, anebo spiš jazyk?

- Když. jsem priišel na školu, tak jsem mêl hlavni těžištê sveého zajjmu v literature, tak jako vîtšina studentů A ted’ bych rek, že $k$ tomu jazyku ziskávám lepši vztah.

A jakyं máte vzlah k cizim jazykim? Jaky jazyk se "čite, ucil jste se?

- Ucil jsem se anglický jazyk a $k$ cizim jazykủm mám vztah kladný, ačkoli je trochu zanedbávám, práve̊ na úkor jiných záležitosti a zajmủ.

A jaké máte vỷhledy do budoucna? Jake máte plány, týkajici se vašeho povoláni?

- Chci byt ucitelem.

To znamena, práce s malymi děmi, anebo s visimi, anebo s dospdyimi?

- Jak mi dovoluje aprobace. Druhý stupeñ a středni školy. Chtêl bych začit na druhèm stupni.

A ted' ješt é jimá otázka. Jak se vám libi tato sima?

- Zima se mi libi, protože neni zima a začiná jaro. A jả jsem teplomil. Takže se téšim, až skutec̉nè bude svitit sluničko kaž̀dý den.

Sprachverhalten:

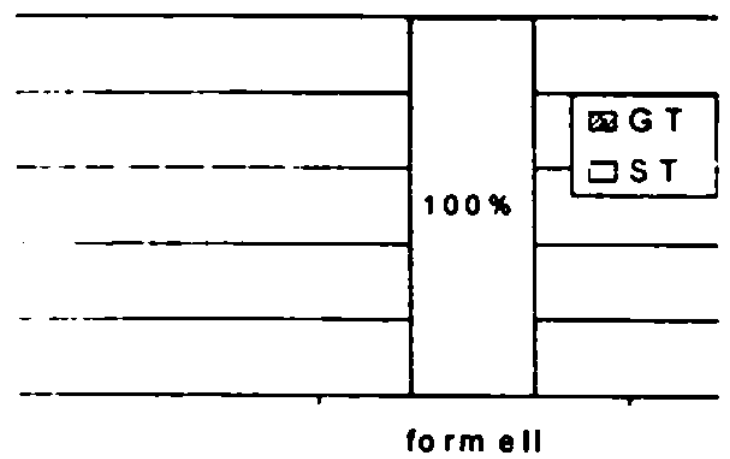

Einstellung, kognitives Subsystem:

Oerkannt B nicht erkannt

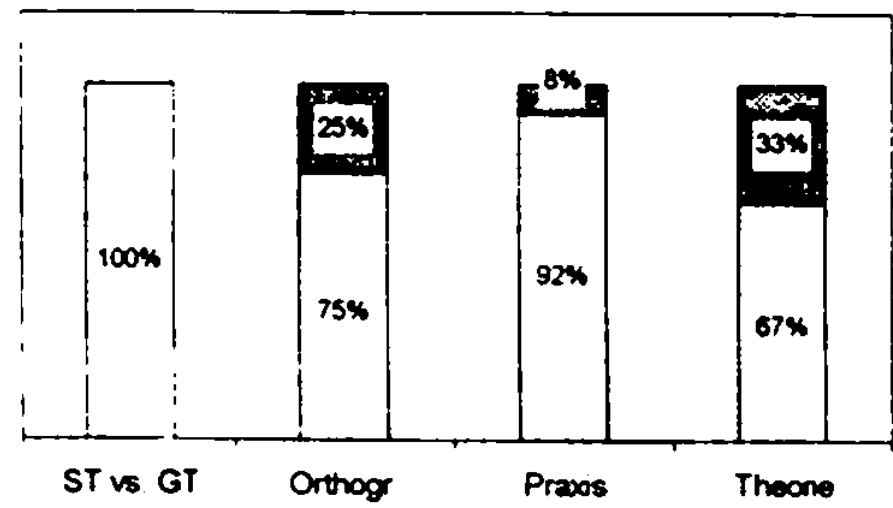

Einstellung, konatives Subsystem:

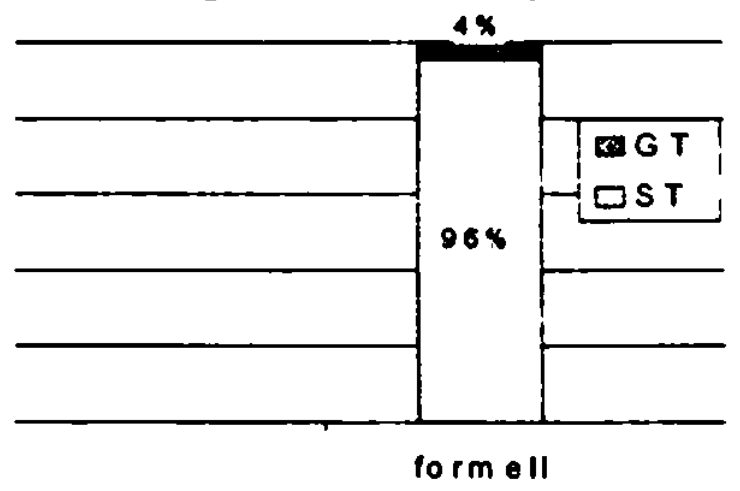

Evaluation der eigenen Kognition:

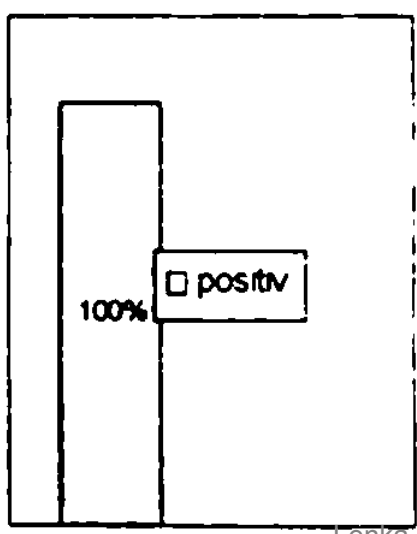


Einstellung, affektives Subsystem: Grad der positiven Einstellung

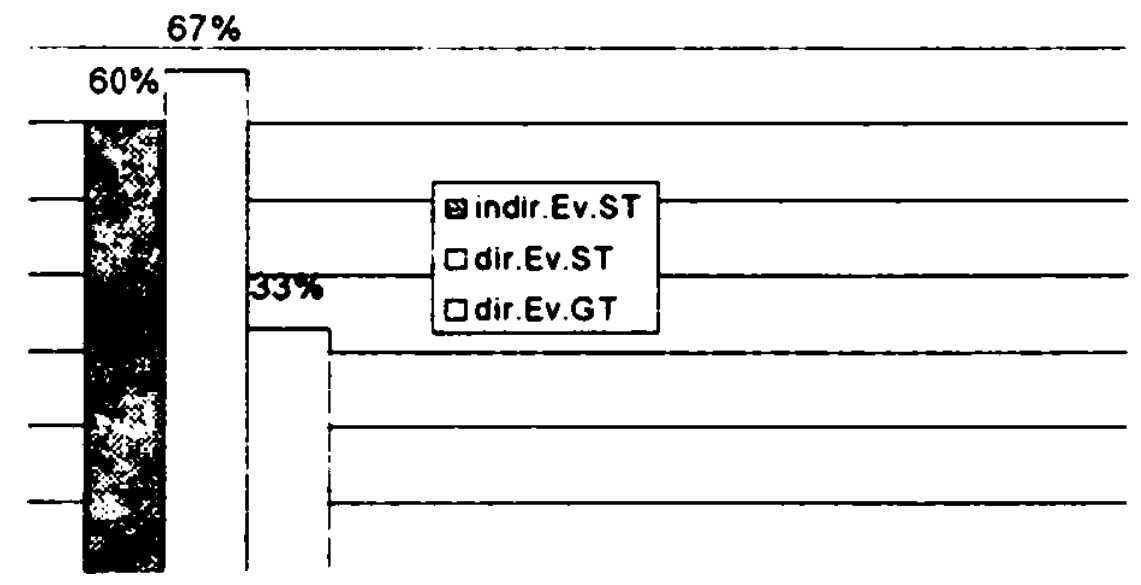

Kommentar: ohne Kommentar

\section{Student, 20 Jahre (2. Studienjahrgang)}

Proc'jste si vybral práne temlo studijni obor, bohemistiku?

- Zajimam se o nẻj. Mẻl jsem k nẻmu vždycky pozitivni vztah

$A$ vice k literature, anebo $k$ jazyku?

- Zpocáatku to bylo spiše $\mathbf{k}$ jazyku a poslèze jsem se pak věnoval vice literature. Tak literatura.

A jaky' je vás oblibený cesky antror?

- To si netroufäm rict. No, ono jich je vic. To se nedá takhle - nemohl bych jednoho vypichnout mezi ostatnimi.

Jaky cizi jazyk studıjete

Studoval jsem angličtinu, francouštinu, no a jako my všichni asi, trošicku tu ruštinu. $A$ z jakiho din'octu franconsisimm?

- Mnè prijde neobyciejne hezký.

A jake máte pläny do budoncna. tjkajici se vašeho povolaini?

- To se mé na moc ptate. To ješté nevim.

A ted' ješl jina otázka. Jak se lám libila tato zima?

- Ta zima. No, byla mimorádné studená nebo $v$ tom smyslu, že bylo hodnẻ snêhu.

Sprachverhalten:

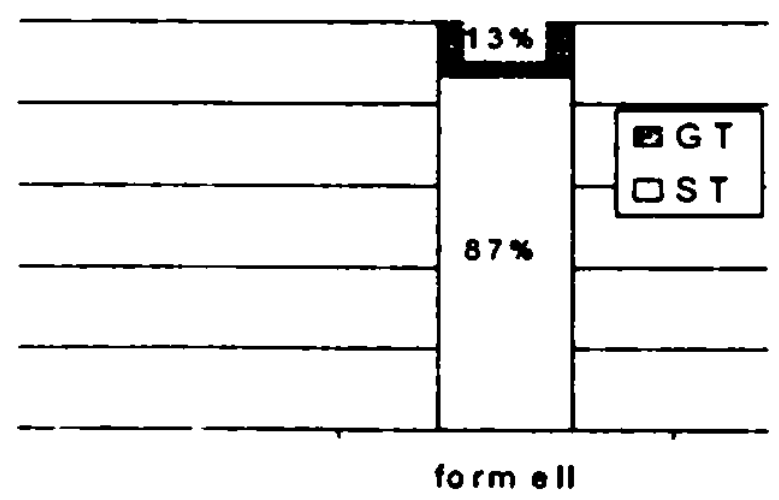

Einstellung, konatives Subsystem.

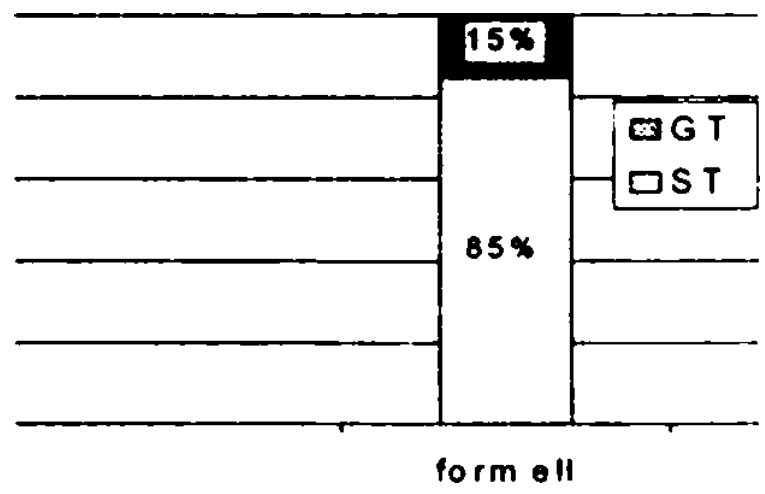


Einstellung, kognitives Subsystem:

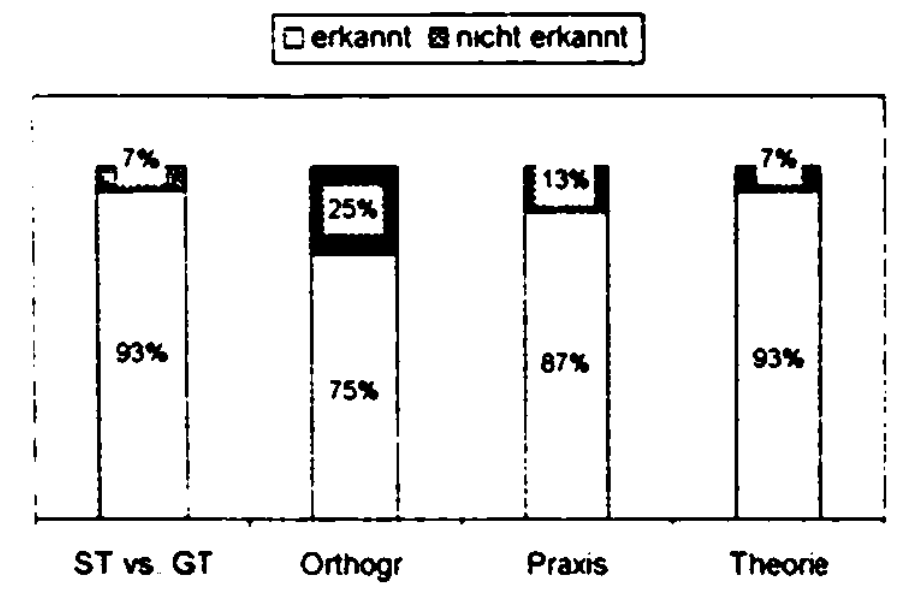

\section{Evaluation der eigenen Kognition:}

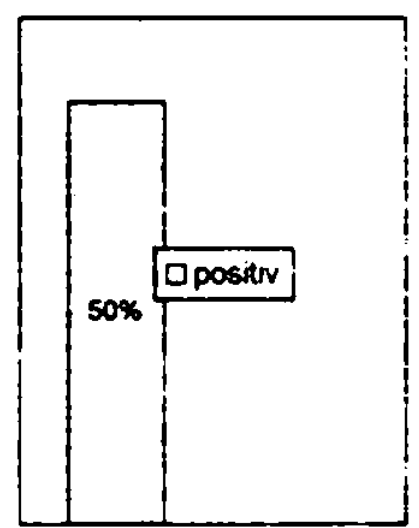

Einstellung, affekektives Subsystem: Grad der positiven Einstellung

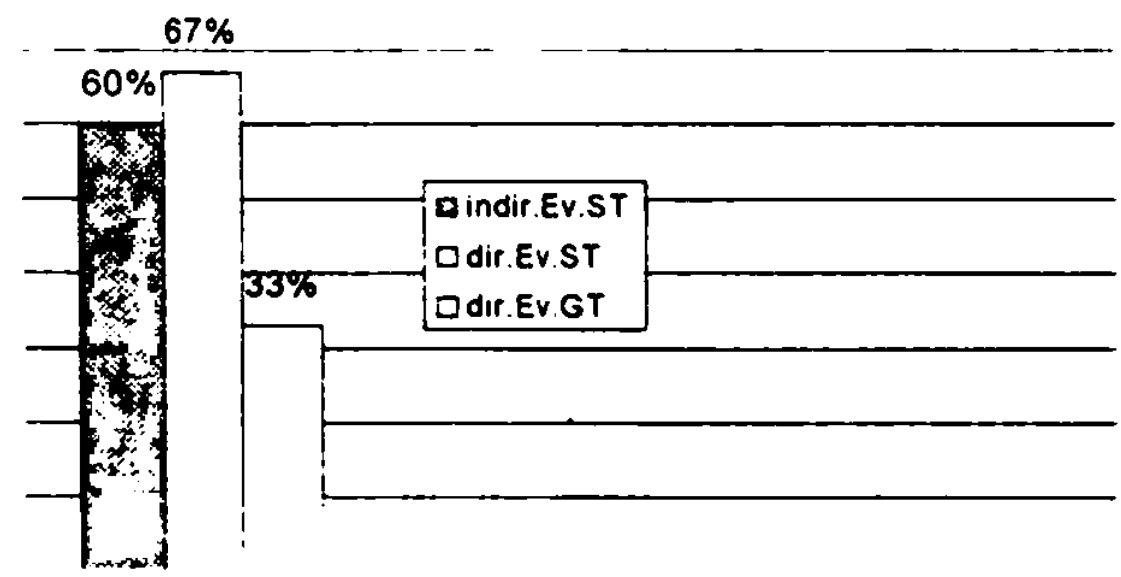

Kommentar ohne Kommentar

\section{Student. 20 Jahre (2. Studienjahrgang)}

Procijste si iybral právé lemto studijni obor?

- To byla naprostá náhoda. Jà jsem chtêl studovat pouze historii, a ta cešstina byla nejperspektivncjjši V souçasne chvili je to naprosto obrácené. Ceština mé bavi, dà se tici, nejvic a historie ustupuje do pozadi.

A akcentujete spise ieskou literaturu, anebo cesky jazyk?

- V souçasne dobé je to naprosto vyvážené Drive jsem akcentoval hlavnẻ teda literaturu, ted' se začinám orientovat i na mluvnici.

A jake máte vihledy do hudoucna? Jake máte pläny. tjkajici se vašeho povolani?

- No, rád bych pracoval nékde $v$ nejjakem archivu nebo ve vẻdeckém ustavu, kde bych se rád zabyval ċeśtinou.

Tak ż práce s dămi ani rak ne?

- Dá se rici, że o tom neuvažuji.

Dobiv. Jaké cizi jazyky studujele?

- Angliçtina, nêmčina. Ràd bych se učil ještê ruštinu. Samozṙejmé povinnà je latina a staroslovènšstina

A jaké máte povinmé jasyky v bohemistice? 
- To pouze tu staroslovẻnštinu.

Rikal jste anglichim a ncincims. Proc práve tyto dva jazyky?

- Asi už z té základni skoly, kde to bylo povinné.

Dobre. A red" jiná otázka. Jak se vám libi posledmi zima?

- Jà osobné zimu rảd nemám, takže se mi vübec nelibila.

Sprachverhalten:

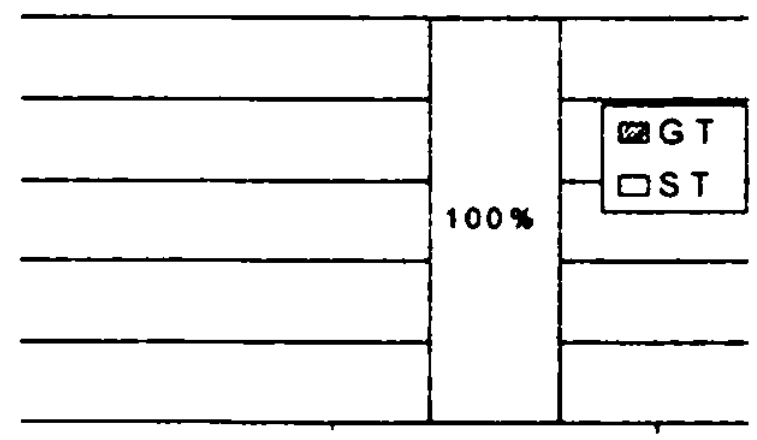

form ell

Einstellung, kognitives Subsystem:

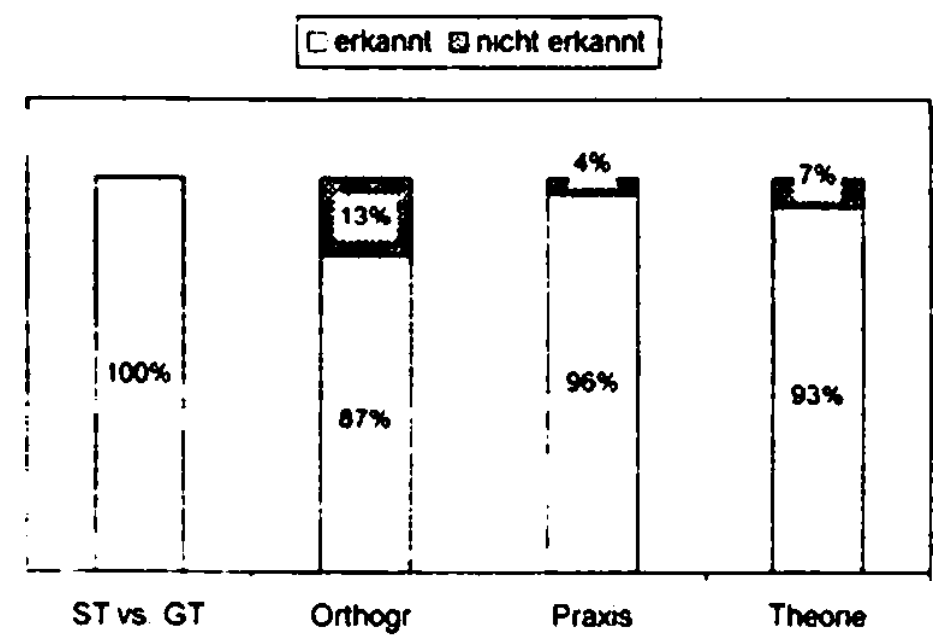

Einstellung, konatives Subsystem

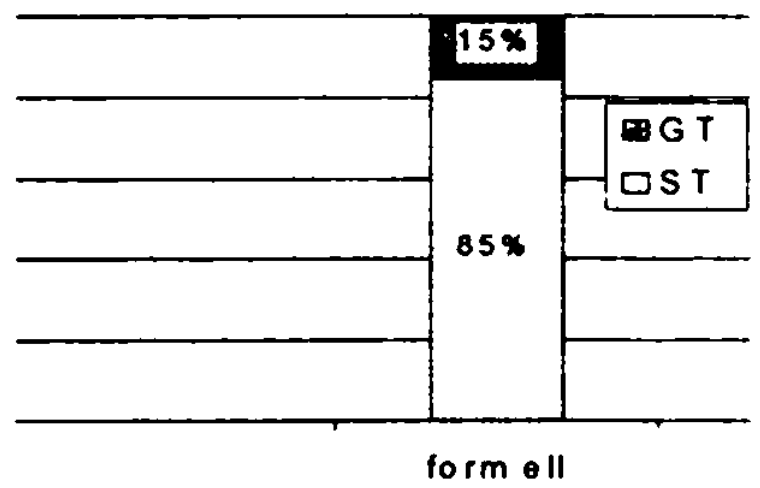

Evaluation der eigenen Kognition

Einstellung, affektives Subsystem: Grad der positiven Einstellung

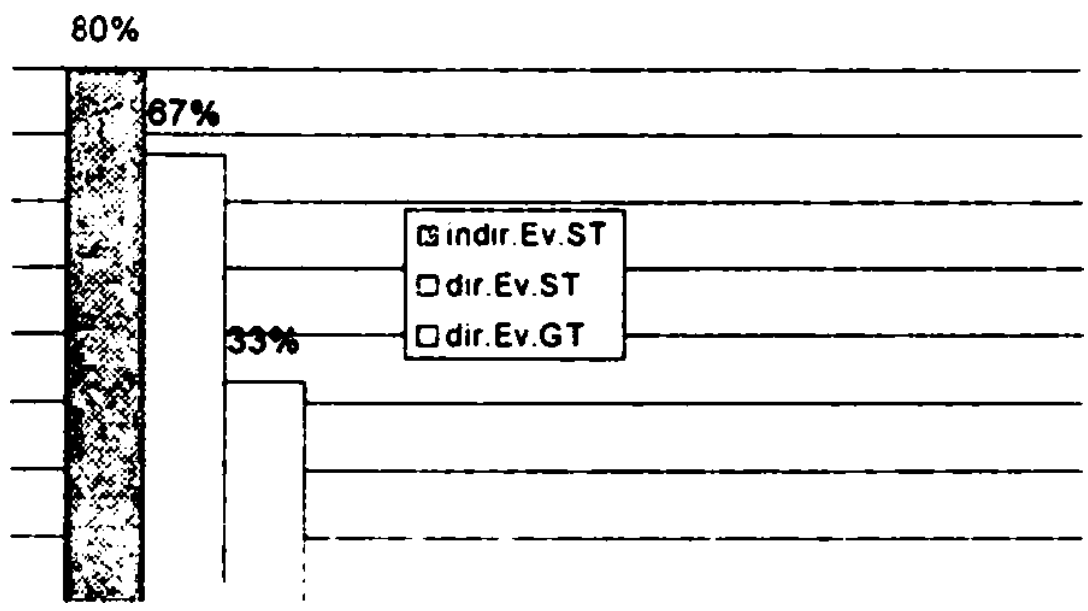




\section{Exkurs: Sprache der audiovisuellen Medien}

Während unserer Enquete stellte sich heraus, daß viele Tschechen unabhängig von ihrem Geschlecht, Bildung und Wohnor die gegenwärtige Sprache der tschechischen Audiomedien mit einem kritischem Blick betrachten. Auf die im Fragebogen aufgeführte Frage "ladi läm. kdyż televizmi a rozhlasovi hlasatele mluvi pri vysiläni nespisovne?" antwortete die absolute Mehrheit aller Respondenten mit "ano".

Die Sprache der tschechischen Rundfunk- bzw. Fernsehsender war in inserer Bitte um einen Kommentar zu unserer Enquete nicht thematisiert. ${ }^{118}$ Vielmehr erwarteten wir kritische Worte über ihre Konzeption und Durchführung. Dennoch nutzten viele Respondenten die Gelegenheit, ihre Unzufriedenheit mit der gegenwärtigen sprachlichen Form der audiovisuellen Medien an dieser Stelle zum Ausdruck zu bringen:

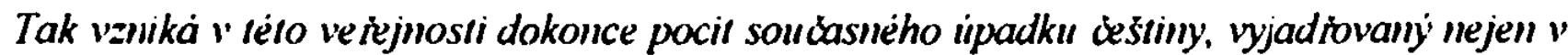
dopisech citenárí médiim, jazykovym poradnam a vysokym školám. ale $i$ v projevech prezidema republiky, viznammého dramatika l'áclava Havla. (ULICNY 2000, 129)

Die Sprache der tschechischen Rundfunk- bzw. Fernsehsender ist zwar nicht das primäre Objekt unserer Untersuchung, sie gehört aber dennoch zu den wichtigen Drittvariablen, die vor allem in der Phase der sekundären Sozialisation - neben der Schule - zwischen dem Sprachgebrauch und der sprachlichen Attitude der Sprecher intervenieren. Aus diesem Grund soll hier ein kurzer Exkurs unternommen werden, mit dem Ziel, die Anteile der in dieser Studie untersuchten sprachlichen Variablen - ST und GT - in der Sprache der tschechischen Audiomedien - zu skizzieren

Um den Rahmen dieser Arbeit zu wahren, ist es an dieser Stelle nicht möglich. Ausschnitte aus allen Gattungen der Fernseh- bzw. Rundfunksendungen zu präsentieren. Dies erscheint auch nicht notwendig, denn in allen offiziellen Sendungen wie Nachrichtensendungen, Wetterberichten, populärwissenschaflichen Sendungen u.ä. wird ausschließlich das Standardtschechische verwendet bzw. angestrebt.

In Unterhaltungssendungen - Spielfilmen, Märchen, Kabaretts, und Talkshows sowie Werbesendungen - wird häufig das Gemeintschechische verwendet, welches hier eine ungezwungene, informelle und gelassene Atmosphäre vermitteln soll. Es ist keine Seltenheit. $\mathrm{da} ß$ in den tschechischen Rundfunksendern ein berühmter Sänger oder Schauspieler - nicht selten sogar ein Politiker - interviewt wird, welcher ausschließlich bzw. zum großen Teil gemeintschechisch spricht, während der Moderator seine Fragen konsequent auf standardtschechisch stellt. In manchen Fällen versucht der Moderator im Laufe des Interviews den Dialog sprachlich zu homogenisieren, indem er den ungezwungenen Kode, das Gemeintschechische, von seinem Gast zumindest partiell übernimmt. Nicht selten verwenden jedoch die Gesprächsteilnehmer während der gesamten Sendung unterschiedliche Varietäten: der Moderator das ihm von der Redaktion vorgeschriebene Standard- und der prominente Gast das für ihn usuelle ungezwungene Gemeintschechische.

Von den vielen trivialen ausländischen, meistens schnell und sowohl morphologisch, lexikalisch als auch syntaktisch mangelhaft ins Tschechische übertragenen Filmen und Serien. die zur Zeit das Tschechische Fernsehen überschwemmen, wird hier völlig abgesehen. Sich mit

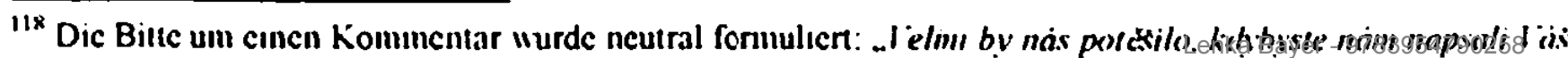

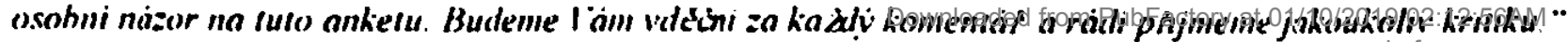


dieser sprachlichen Landschaft auseinanderzusetzen würde diese Studie sprengen. Wir hoffen, daß diese unerfreuliche Welle eine nur vonübergehende Erscheinung in den tschechischen Massenmedien darstellt und daher als das Objekt einer näheren Untersuchung irrelevant ist.

\section{Sendung im Tschechischen Fernsehen (Unterhaltung, Quiz)}

Sängerin: A tam prìšel papirek a tam bylo napsáno: Kolik máme v životẻ milenců. Jà zpozornela protože, ne, że bych to nemohla..

Moderator: To by mé zajimalo taky.

Sängeriin: No prảvê!! Počkej! Jả to rozkošatim. No tak, prostê já jsem někde četla, že průmèrnè je jako, za život každej člověk jako - Cínan, Japonec, Čech, Američan - vystřídả prej asi dvacet partneru. Tak jsem si rikala: No, já to tam క̌oupnu, abych je nezklamala. Možná bych mohla i pridat, aby si nemysleli, že jsem ňảká chudinka, że jo. Tak jsem rekla pètadvacet. Voni tak na mé koukali, ale spiš jako, že jsem ta chudinka. Vopravdu, já nevim, jak se ted' zije, že jo. No, ale vo to nejde. Já jsem tekla těch pêtadvacet, za chvili takhle zezadu se priroloval ten papirek bilej. Já to votevřu, a tam bylo napsano ...

Moderator: Kdybych si moh vzpomenout, to bylo takový. Vy jste tady vesmès jako moc mladý. Ale jako nčktcrii ho určitě znáte. To byl krasavec, milovnik padesátých, šedesátých let Robert Vrchota. Byl to opravdu takovej Don Chuan jak vo nèm vypravesli?

Schanspieler: Super, super. Jà jsem s nim byl v angažmá v Pardubicich Dokonce si predstav, my jsme byli takový kamaradi, že jsme si tam navzäjem jaksi všelijak pomảhali. že pr̉esto, že celej soubor v Pardubicich - pač mèli všichni malè gáže - tak bydlel po podnajmech Já jsem si musel držet kvůli Robertovi Vrchotovi pokojový hotel v Grandhotelu. Von ho denné potreboval. i̇li, já jsem poràd vysedával jenom v kavảrně na kafi, který nikdy nepiju, nenávidim Ale já jsem denodenné musel bỹt v kavárné a nemoh jsem domu. Ale to chci rict, Robert Vrchota super super Don Chuan. Von taky ale vlastnè to byl takovej krasavec, że na potkáni holky padaly na záda. Rozumiš. to nebylo nic jednoduchýho. (...)

Moxderator: Kolik let to je, rekne-li se Kristova leta?

Sïngerin: Tady už napovidaji Já to slyšim.

Moxderator: Mluvte, až budete tázáni.

Sängerim: Jo promiñ, já jsem se zamyslela. Jo, dva to vêdèt budou.

Schauspieler: Jà myslim tr̃i. My už jsme malomysIný, rozumiš

Moderator: Tak, jak tak koukám, prátelè, dneska se tady sešla intelektuálni elita. Takže, já si myslim. že tohleto budete veddét. Slečno? Tak otázka zni: Kolik let je, rekne-li se Kristova lèta? Schauspicler: No, tak tohleto, i když jsem mimớadnð̌, mimớádn̊̊ netalentovanej na jakoukoli elektroniku a cokoli, tak to vim $i$ já. A to je co rict. Kolik voltủ je v zásuvce?

Sprachverhalten: Sangerin

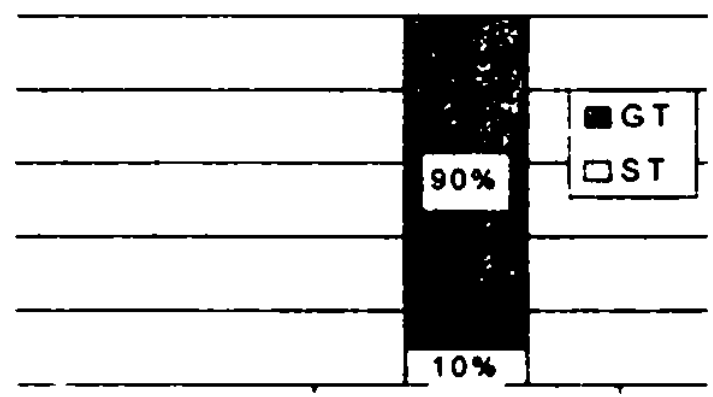

form ell
Sprachverhalten: Moderator

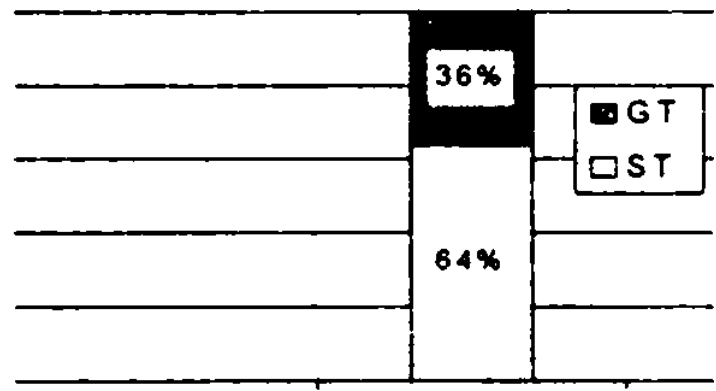




\section{Sprachverhalten: Schauspieler}

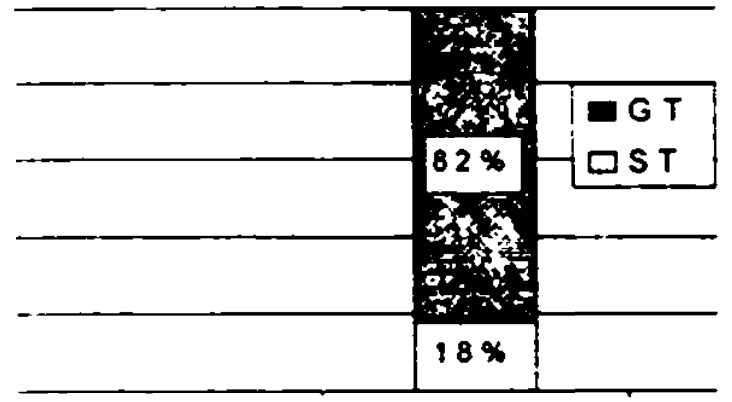

form ell

\section{Sendung im Tschechischen Fernsehen (Unterhaltung)}

Unterhalier. To je proti moucham, vopravdu. ... To je to, cemu Australani tikaji australskej bumerang. To je typickả australská zbrañ, je to bumerang. Jà když jsem se $s$ tim učil hảzet, já vam reknu - já mẻl osobniho instruktora - mủžu vảm rict, ze všech sportủ mi to nejvic pripominalo golf. Jà jsem se $v$ životè tolik nenachodil, jako pro bumerang. To je zbrañ, která se má vracet, když má člověk stát na mistě. Tak bumerang samozł̌ejmě se musi vracet, jestliže to je originàl bumerang australskej. To byl originál. No, chtêl jsem nechat kolovat, ale bojim se, ze by se mi nevratil.

Prodavac ukazoval, že ty plody jsou, von to teda ukazoval néco jako melouny. Sazenice stála stovku, tak ja jsem rikal, tak mi jednu prodejte a von tikal, to nejde, musite si vzit dvé, voni se navzajem opylujou. Tak já jsem rikal. tak dobr̉e. tak kdyż teda bez sebe nemì̌ou bejt, tak mi dejte vobẻ, jo. Zaplatim dvě stovky, ł́ikam, co s tim ted" mam dẻlat. A von tiká, zasadit. Já jsem řikal, dčkuju, já jsem myslel, že to budeme doma grilovat. Jà jsem zacátećnik, rozumite. Mnć musite vysvêtlit, jak to mám zasadit. Von tiká, musite tam mit hrabanku z lesa. Já jsem rikal, pockejte. jà žiju ve mćsté. Kde vemu hrabanku $z$ lesa? Von tikà, v lese. Rikam, a kolik si mám navozit tý hrabanky. A von tiká, hodnc, hodnẻ musite zaplnit celou tu diru pod tou sazenici Jà jsem rikal, jak je velká ta dira? Von povidà, hodnè, hodné. Musite mit dvé daleko vod sebe a udslejte dvé takový diry, aby byla dlouhá asi tak metr sedmdesát, široká asi metr a hluboká asi vosmdesát centimetrù. Já jsem rikal, co? To je hrob.

\section{Sprachverhalten Unterhalter:}

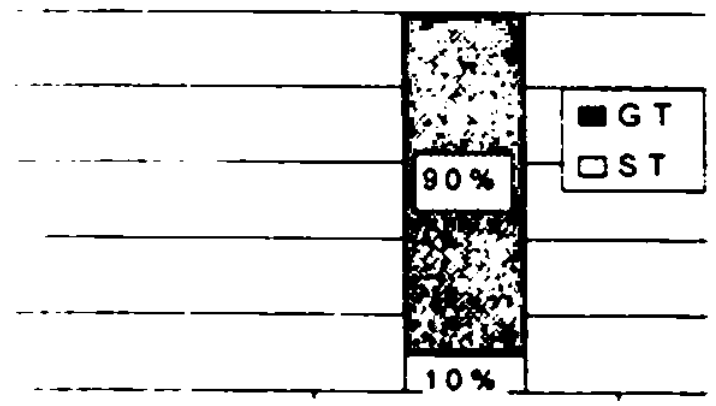

form ell 


\section{Sendung im Tschechischen Fernsehen (Sportinterview)}

Trainer: ... momentálnê, takže když se tomu brankári nedarailo úplně stoprocentnê, tak musel zaskocit okamžitex druhy. Proto jsme tam dali ... a myslim, że chytal velice dobre.

Reporler: Dá se řict, že v každèm utkảni vêtši, menši mèrou rozhoduje nęjaký váš puk. Myslite si, že. ... vaše velká zbrañ vlastnê $v$ té sérii, že jste dokázali vždycky, że nékdo dokázal ten provaz a vlastnè dotähnout to mužstvo $k$ tomu vitězstvi

Traincr. Tak byly nêkdy velmi kvalitni pètky. A tydlety pêtky se vlastnẻ podélily o to vitězstvi ... takový ten cas, ktery jsme potřebovali pro to odbyti těch dvou pétek a myslim si, žc dneska hlavnẻ ta pruni pêtka, že ten zápas rozhodla.

Reporter: Posledni otazka. Ostatni zápasy ještě nejsou rozhodnuty. Cili nevite vlastnè, kdo vás ceká $v$ semifinále. Nicméné, jak budete ted'ka pracovat $s$ mužstvem a jak ho budete motivovat na dalši utkáni?

Trainer: Tak my máme zitra ... A ted' se sejdem na lehkèm tréninku, udéläme regenereci a samoziejmé sobota, nedẻle budeme trénovat, budem se pripravovat na soupere, kterèho uż budeme potom vlastné znàt.

Sprachverhalten: Trainer

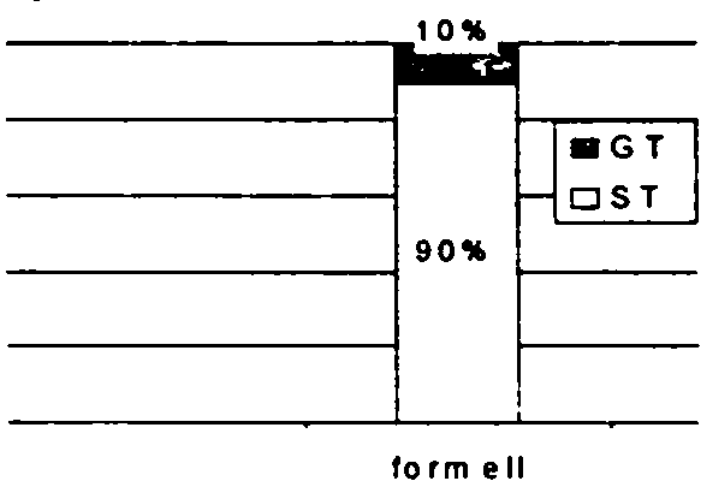

Sprachverhalten: Reporter

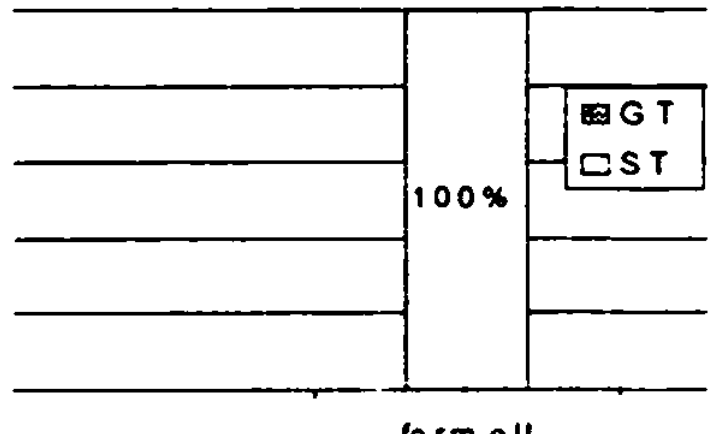

form ell

\section{Sendung im Tschechischen Fernsehen (Unterhaltung, Laien-Singwettbewerb)}

Schan.yieler: ... anebo vždycky, kdyż zpivali, jà jsem dêlal to kr̉ovi. No tak určité jsem v tý poroté zasloužcné.

Moderator: Tak Michal bude hodnotit piedevšim projev pohybovy

Moxterator: A vy jste poetická duše?

L.aiensaingerin: No, trochu.

Moxterator: Trochu jo Studentka?

Lanensängerim: Ano, studuju drogistickou školu v Mariänských Länich

Modcrator. Aha, to znamena., ze budete cim?

l.alensingerin: Kosmetickou.

Moxlerator. Vy jste z hudebni rodiny? Hrajete na nčco?

l.cienxingeriin: Ne, nehraju na nic

Moxlerator Rada zpivate?

Iaiensaingerin: Ràda zpivàm

Moxlerator. A z rodiny? Máte sourozence?

l.aiensaingerim: Nemám sourozence, ale müj otec mả štyry bratry a ty radi hrajou. Chodi hrát do rưzných klubủ, a moje matka taky rada si zazpivà 
Moderator: Takže to máte takzvaně v krvi.

Moderator: Velice těžká pisnička. Jitko, co ty $k$ tomu?

Schanspielerin: No, mé tady zaujalo to pohybový nadáni, teda. Protože tam byly teda moc pékný solistavy.

Schanspieler: No, jả jsem se chtêl zeptat, jestli se taky dảvaji půlky? Jako bodováni pủlky? Moderator: Pưlky nedá. Pủlky, je to neotł̌elý, nedávaj. Ukažte, jak to vidite vy.

Sprachverhalten: Schauspieler

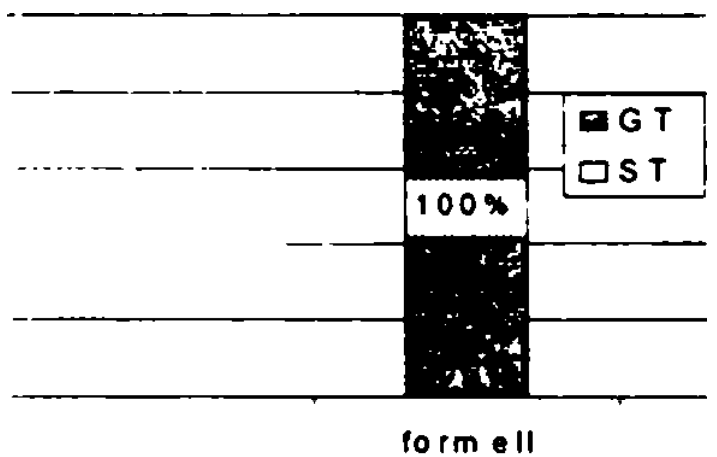

Sprachverhalten: Laiensängerin

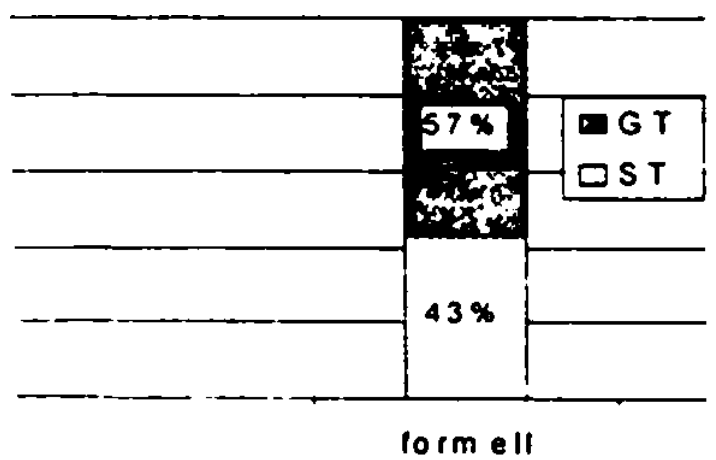

Sprachverhalten: Moderator

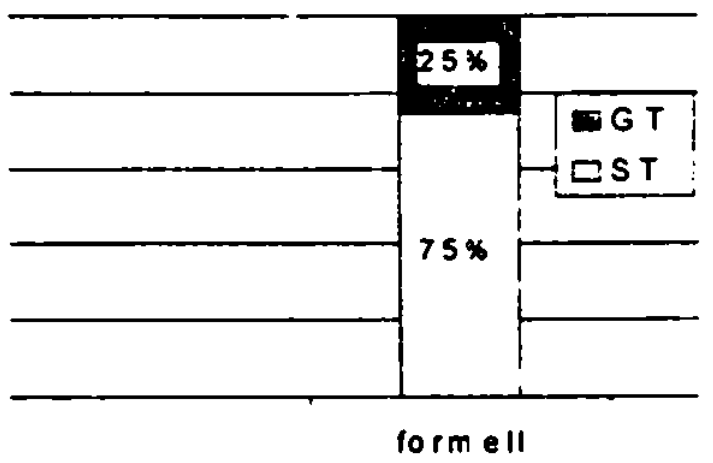

Sprachverhalten: Schauspielerin

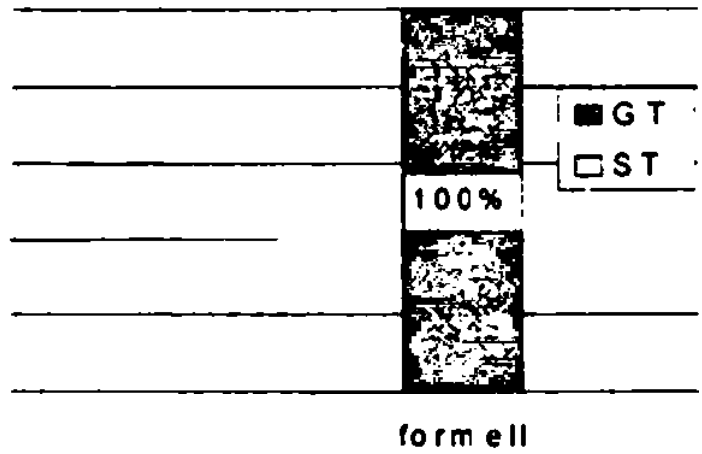

Moxterator: Z Prahy, rikám to dobre?

l.aıensänger. $Z$ Prahy, ano

Moderalor: Vek?

Laiensänger: Śstadvacet

Moxlerator Šestadvacet. Takže svobodný?

Laiensanger: Svobodny, ano.

Moderator. Budete se ženit? Piemýšlite o tom nékdy?

Laiensanger No, to je vymyšlený.

Moderator Moment, jak vymyšlený?

Laiensainger: To právẻ nesmim rict. Voni by to slyšeli.

Moxderator. Tak jä budu tak hádat. Vymyšlený to màte tak, że se oženite asi tak za rok?

Laiensänger: No ne, nejdriv vyhraju ve sportce

Mcxleralor: Jo prachy, to je zaklad toho. To je predpoklad. Dobre, jà vám rozumim. Muzika je vaše vảšn - zpiváni Jaký styl muziky? Country?

l.alen.ximger: Country hlavne.

Moxderator: Hlavne, hlavné. A vzor? Zpèvak?

Iariensinger: No, spiš ty ceský, no. 
Moderator: Takhle. Máte sourozence?

Laiensänger: Mám jednoho bratra. Staršiho, vo hodnd.

Moxlerator: $Q$ hodné, $Q$ kolik?

Laiensänger: Vo dvanáct let.

Moxlerator: Vo dvanáct let. Takže on vás vychovával, taky ručne??

Laiensänger: No, tak to by si mohl zkusit, no. ...

Moderator: Tak co tiká porota?

Schanspieler. Skvêlý. Vlk celej a ta piseñ zủstala celà.

Moderator: Pìesnẻ tak. Także kolik daváš? Kolik bys to tak vidẻl. Osmičkou. Jitka taky osmicku, Michala vedle mé celou dobu vzdychala jä jsem ovlivnèn. Vzdychala ... Trikràt osm.

Schauspielerin: Jà to vysvêtlim, jà totiž jsem prošla - mé zaujalo to country, protože já jsem v sedmnacti letech zpivala ve folkový kapele, a taky tam bylo néjaký country.

Moderator: Tak zazpivejte neco.

Schauspielerin: Ježiš, to raději ne, raději ne.

Sprachverhalten: Moderator

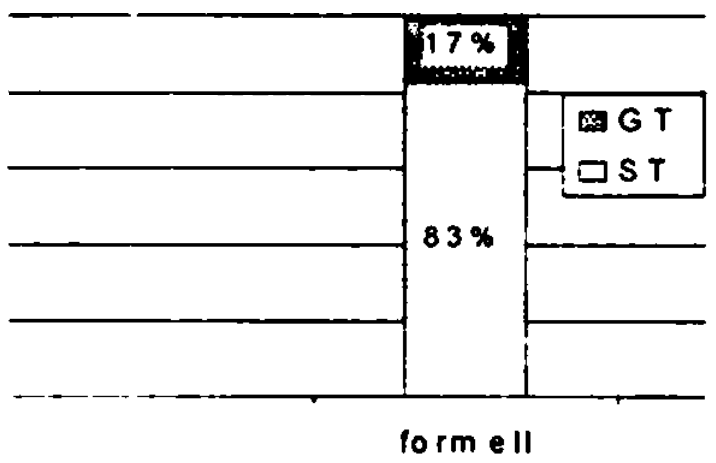

Sprachverhalten: Schauspieler

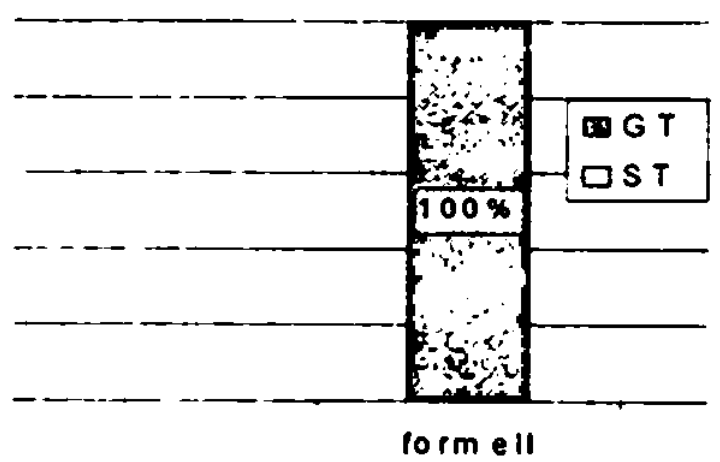

Sprachverhalten: Laiensänger

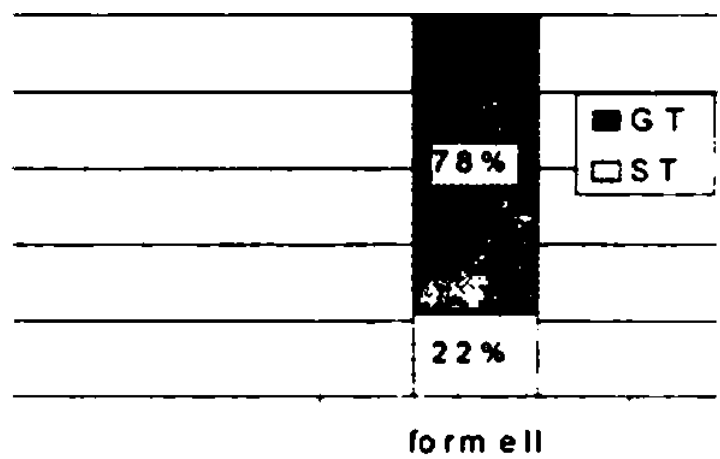

Sprachverhalten: Schauspielerin

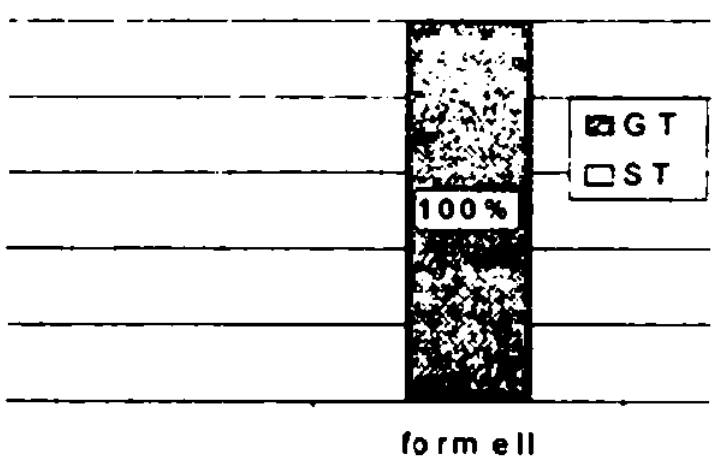

Moxderator: Odkud?

Laiensangerin: Z Litvinova.

Moxteraır $Z$ Litvinova. Litvinov, hokej, chemickè závody. Fandite hokeji?

Laiensangerin: No, fandim. ale nic moc.

Moxlerator: Dukle fandite jako nic moc?

laiensangerin: Neni moje hobby.

Moxkeratorr. Dalo by se rici, že jste tak malinko sportovec duši nebo i têlem?

Laiensangerin: No, i trošku tčlem

Moxderator Máte ješté nčjakou zálibu kromè zpiváni? 
Laiensängerin: Mảm doma sedmiletou dceru Barču a mimoto mám osmimésièni štěnẻ Baseta Charliho. Takže to je hobby samo $Q$ sobe.

Moderator Charli se jmenuje? Baset? Baset, to je nádhera. Je, ukažte nám na kameru, jak se tvàĭi, když je smutnej.

laiensängerin: Von porảd koukả stejnè, kdyż je smutnej, když je veselej

Sprachverhalten: Moderator

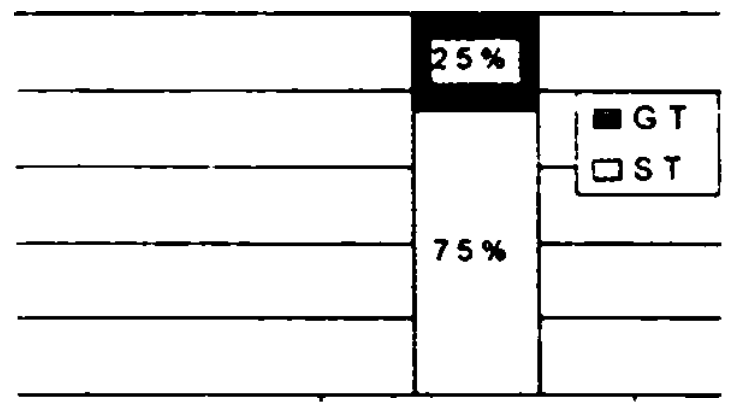

formell
Sprachverhalten: Laiensängerin

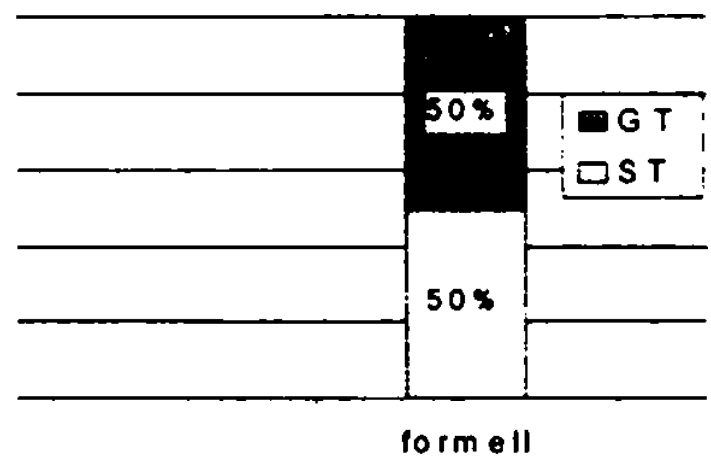

Laiensänger: Na nảdraži na Žižkovể ve velkoobchodu s nápoji

Moderator. To je zajímavý povoláni. To mé zajimá, pozor. Oskare, velkoobchod s nápoji. Hlavnê nękteré nápoje mé zajimaji. Jaký tam jsou nápoje?

Laiensänger: Veškerý druhy.

Moderator A samozíejmè velkoobchod levnějši, že?

l.aiensänger: Samoż̉ejmé je to o hodné levnéjš̉ než v obchodech.

Moclerator Potom se domluvime, až to tady skonci. C.im jste chtêl bỵt nebo co jste délal.

Laiensänger: Vodjakživa mam rảd sport. Dvanáct let jsem piskal ledni hokej. Także jako hokej, fotbal Dneska hraju kopanou, takže aspoǹ nẻjak se udržuju v tý fyzický kondici.

Moderator: Vy jste rozhodèi. To jsme tady ješté neméli. Umite piskat? A ted' s pravdou ven. Rozhodìi je úplatnej někdy?

Laiensänger. Jà se s tim nesetkảm.

Moxderalor Nikdy vàm nikdo nic nevnucoval?

laienscinger: Jednou jsme prìijeli na utkảni a vedouci mužstva povidá: 'Pảnové, po utkáni jste zvaný na zabiječku'. Oni prohráli, zabijačka byla, ale takovej jako spiš funus Zvaný mužstvo prohrálo, zabijaçka samozíejmé byla, ale nebylo to takový, rozumite prosté. Hosté si odvezli body, takže jsme tam sedẻli. snèdli jsme nẻco a odjeli jsme domù

Sprachverhalten: Laiensänger

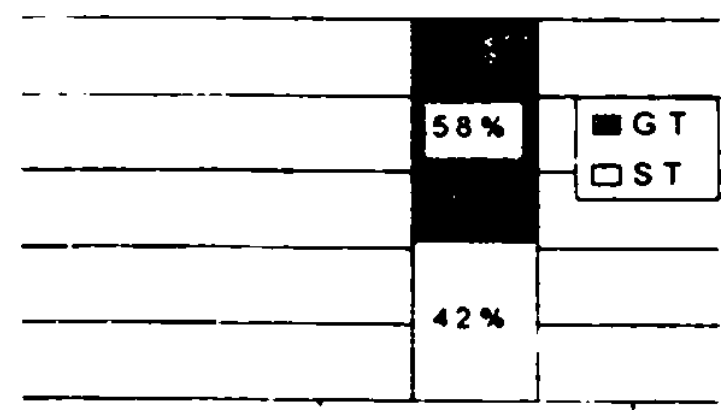

form ell

\section{Sprachverhalten: Moderator}

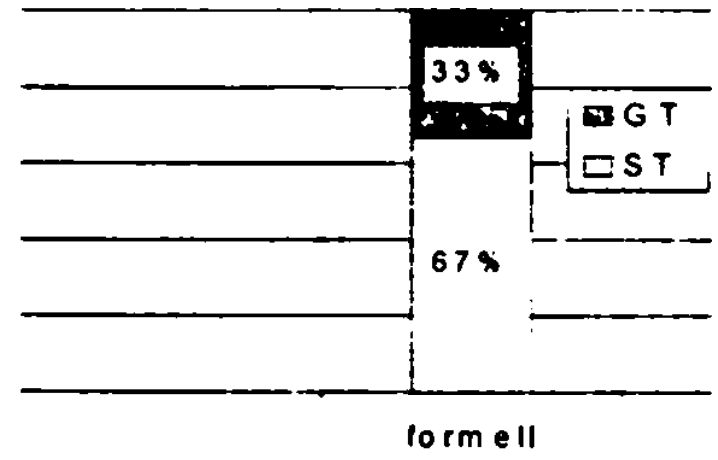




\section{Auswertung der Umfrage}

Bei einem genaueren Blick auf das gesammelte Material unserer Umfrage, das im Kapitel 7 präsentiert und ausgewertet wurde, wird deutlich, daß die soziologischen ${ }^{119}$ und diatopischen Variablen mit den Ergebnissen im kognitiven, evaluativen und konativen Subsystem der sprachlichen Einstellung im Tschechischen korrespondieren und daß sie das sprachliche Verhalten der Tschechen in verschiedenen sprachlichen Situationen hic et nunc beeinflussen Um die Konturen dieser ad hoc Beobachtung zu schärfen, werden in den folgenden Kapiteln die Durchschnittswerte in den Bereichen der Einstellung und des Verhaltens systematisch dargestellt und bewertet

Im Kapitel 8.1 werden die Werte der einzelnen Respondenten aus dem Kapitel 7 auf verschiedenen Ebenen bzw. Stufen nach der Working-up-Methode gebündelt und die jeweiligen Durchschnittswerte graphisch dargestellt.

Im Kapitel 8.2 werden die im Kapitel 8.1 ermittelten Durchschnittswerte im Bereich des kognitiven und des affektiven Subsystems der Einstellung mittels Graphischer Darstellungen kontrastiv nebeneinander gestellt und bewertet.

Anschließend werden im Kapitel 8.3, dem thematischen Kern dieser Studie, die im Kapitel 8.1 ermittelten Durchschnittswerte im Bereich des sprachlichen Verhaltens in den beiden untersuchten Situationen - soweit vorhanden - und dem konativen Subsystem der Einstellung nach dem selben Prinzip wie im Kap. 8.2 erläutert und verglichen. Der Akzent liegt hier auf dem direkten kontrastiven Vergleich des sprachlichen Verhaltens der Tschechen mit dem konativen Subsystem ihrer sprachlichen Einstellung. Das Verhältnis der beiden Variablen, die sich im Mittelpunkt unserer Untersuchung befinden, wird hier anhand der vorhandenen Daten konkretisiert und kommentiert.

\subsection{Ermittlung der Durchschnittswerte}

Die folgenden Auswertungen geben nach der Working-up-Methode die Durchschnittswerte der einzelnen Respondentengruppen wieder, die nach dem Kriterium der soziologischen und diatopischen Variablen ermittelt wurden ${ }^{120}$. Auf der ersten Working-up-Ebene werden die Daten der einzelnen Respondenten nach dem Kriterium des Geschlechts in Verbindung mit dem Bildungsgrad innerhalb einer untersuchten Region zu einer relativ homogenen Gruppe gebundelt und die Durchschnittswerte innerhalb dieser Gruppe ermittelt

Auf der zweiten Working-up-Ebene werden die Respondenten:

1. nach dem Kriterium des Geschlechts ohne Rücksicht auf Bildung.

2. nach dem Kriterium der Bildung ohne Rücksicht auf Geschlecht

119 Besonders signifikant ersclicint hicr dic Diastratic. d.h. dic Bildungsgrade - oline Abitur. mit Abitur. mit Hochischulabschluß b/w. Schüler und Studenien.

120 Wic bereits erwahnt. war es im Bercich des Sprachverhalıens niclut imuner moglich. dic Aufnalunen in den beiden untersuclıen Siluationen durchzufuliren. Aus diesem Grund wurde auch im Bercich des konalıven Subsysteıns auf dic Auswertung in der gegebenen Siluation verzıchtel. da dic Vergleiclısgrundlage nicht vorkanden war. In den Auswertungen im Bereich des Verhaltens werden in der jeweiligen Situation in der Klammer die Zahlen der beteiligien Respondenten aufgefülıt. die sich cbenfalls auf das konative Subsistem bezichen 
zu übergreifenden Gruppen gebündelt und die Durchschnittswerte ermittelt. Die abschließende Auswertung auf der zweiten Working-up-Ebene gibt die Durchschnittswere aller Respondenten innerhalb einer untersuchten Region wieder ohne Rücksicht auf Bildung und Geschlecht.

Die dritte Working-up-Ebene ist regionübergreifend. Hier werden die Angaben aller Respondenten ohne Rücksicht auf ihren Wohnsitz nach dem Kriterium des Geschlechts und der Bildung graphisch dargestellt. Die letzte Auswertung der dritten und somit höchsten Workingup-Ebene gibt die Durchschnittswerte aller im Rahmen unserer Studie befragten Respondenten als einer geschlossenen Gruppe - ohne Rücksicht auf Geschlecht, Bildung und Wohnort wieder.

Auf allen drei Working-up-Ebenen gehen wir bei der Auswertung der Angaben stets von den Werten der einzelnen Respondenten aus. Die einzelnen Werte der zu einer Gruppe zugehörigen Respondenten werden addiert und durch die Anzahl der Respondenten dividiert. Nach dem folgenden Beispiel für die Berechnung des Sprachverhaltens - Anteile des ST in der informellen Situation - werden analog alle Auswertungen auch im Bereich der Einstellung durchgefuhr:

\section{Beispiel, erste Working-up-Ebene:}

Westböhmen, Frauen ohne Abitur, insg. 7 Respondentinnen, informelle Situation, (alle 7 Respondentinnen wurden in der informellen Situation aufgenommen):

Summe der Werte im Bereich des Gebrauchs des ST bei jeder cinzelnen Respondentin in \%. $0+0+0+3+9+10+0=22 \%$.

Die Summe aller Respondentinnen (22\%) wird dividiert durch die Anzahl der Respondentinnen: $22 \%: 7=3,14 \%$ (abgerundet $3 \%$ )

Der in der Graphik abgebildete Durchschnittswert - Gebrauch des ST in der informellen Situation - gibt die errechneten $3 \%$ wieder.

Demonstration der obigen Berechnung: Sprachverhalten in der informellen Situation

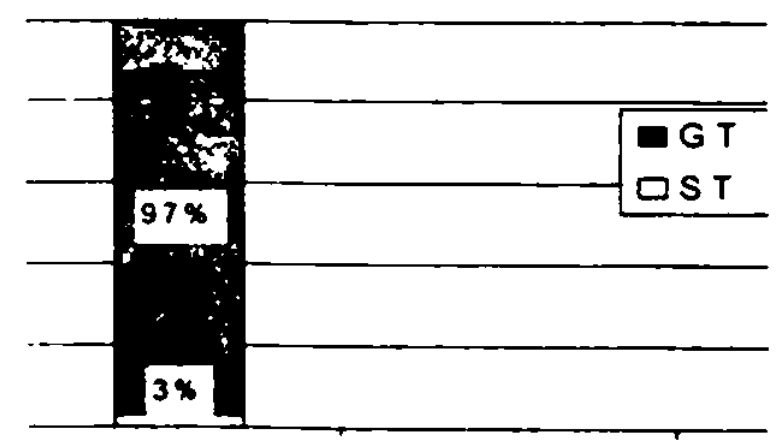

in form ell (7) 


\section{I.I Erste Working-ıp-Ebene: Wesıböhmen}

\section{Frauen}

Frauen ohne Abitur: insgesamt 7 Respondentinnen, Alter 38 bis 65 Jahre

Sprachverhalten:

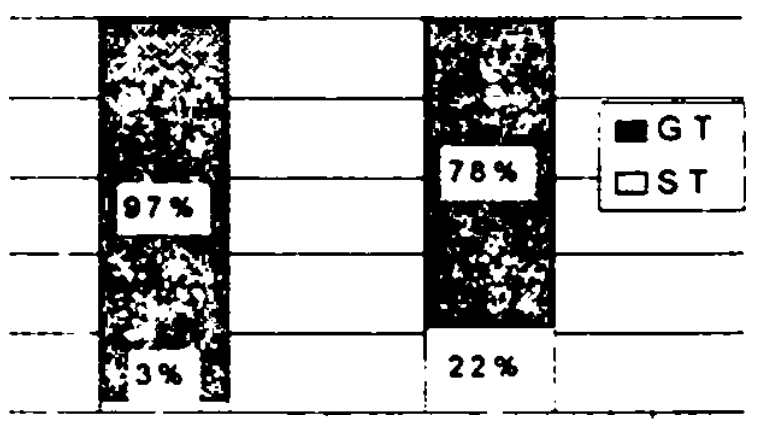

informell (7) formell (7)

Einstellung, kognitives Subsystem:

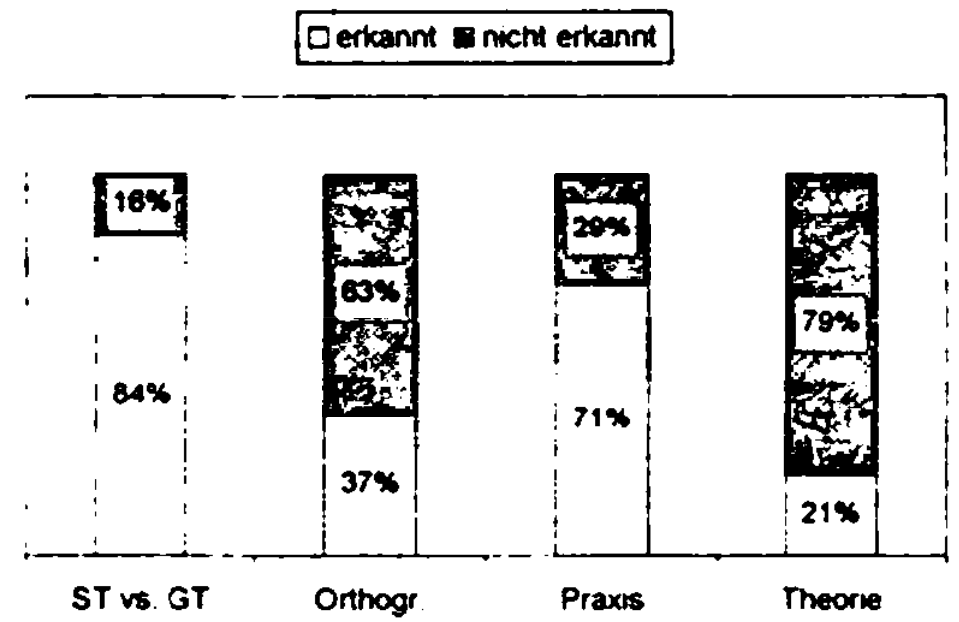

Einstellung, konatives Subsystem:

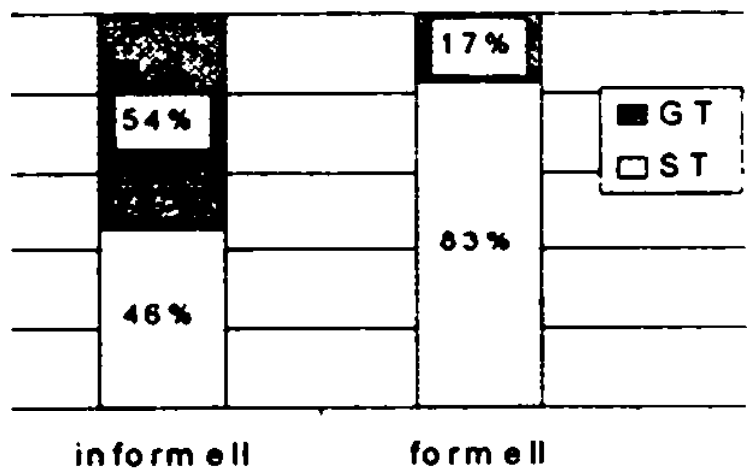

Evaluation der eigenen Kognition:

Einstellung, affektives Subsystem: Grad der positiven Einstellung

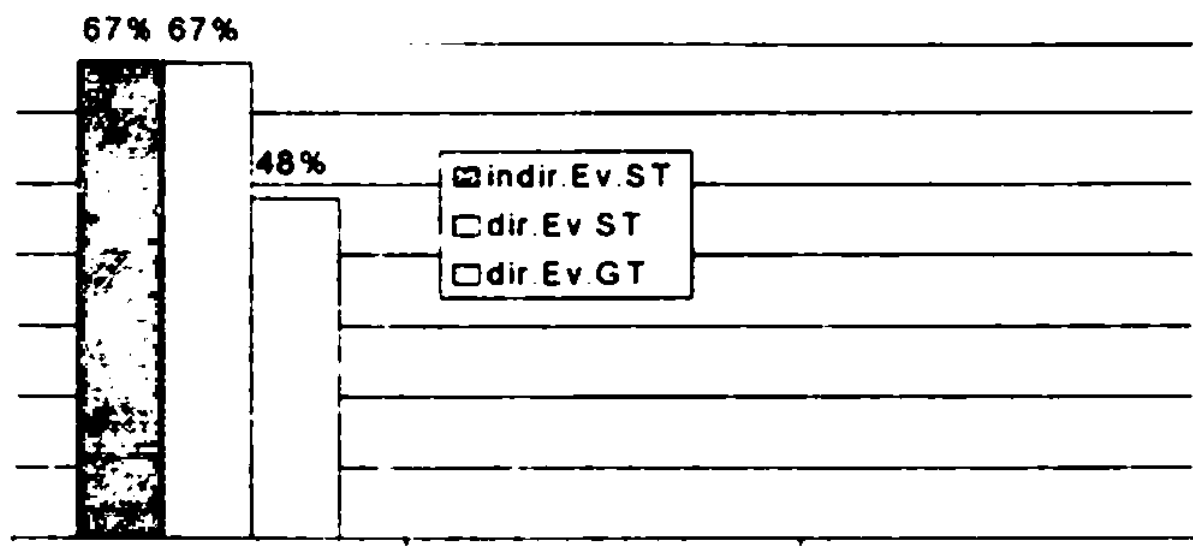


Frauen mit Abitur: insgesamt 7 Respondentinnen, Alter 20 bis 62 Jahre

Sprachverhalten:

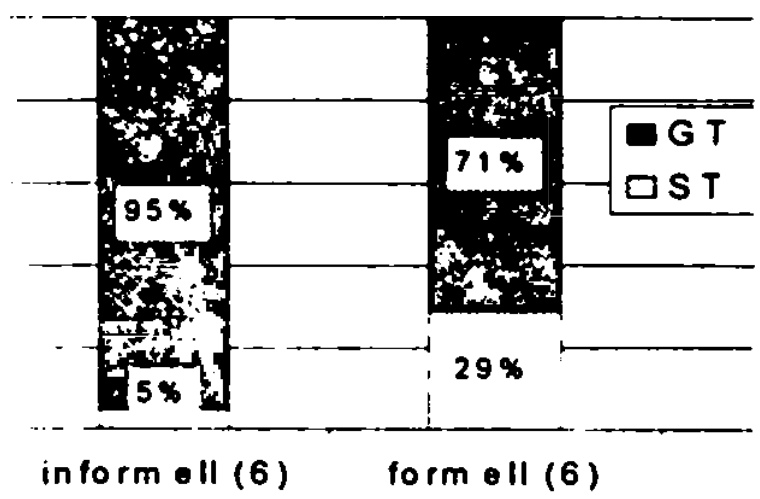

Einstellung, kognitives Subsystem:

Q erkannt E nicht erkannt

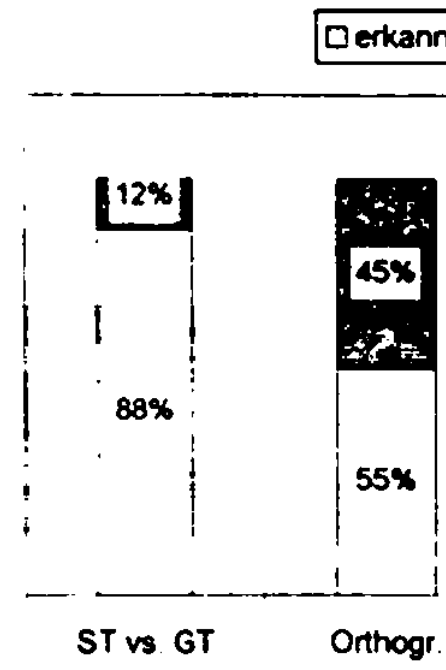

Einstellung, konatives Subsystem:

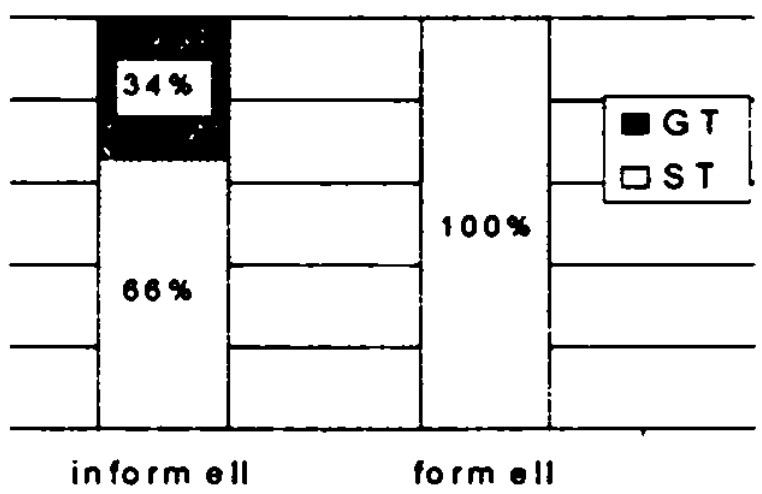

Evaluation der eigenen Kognition:
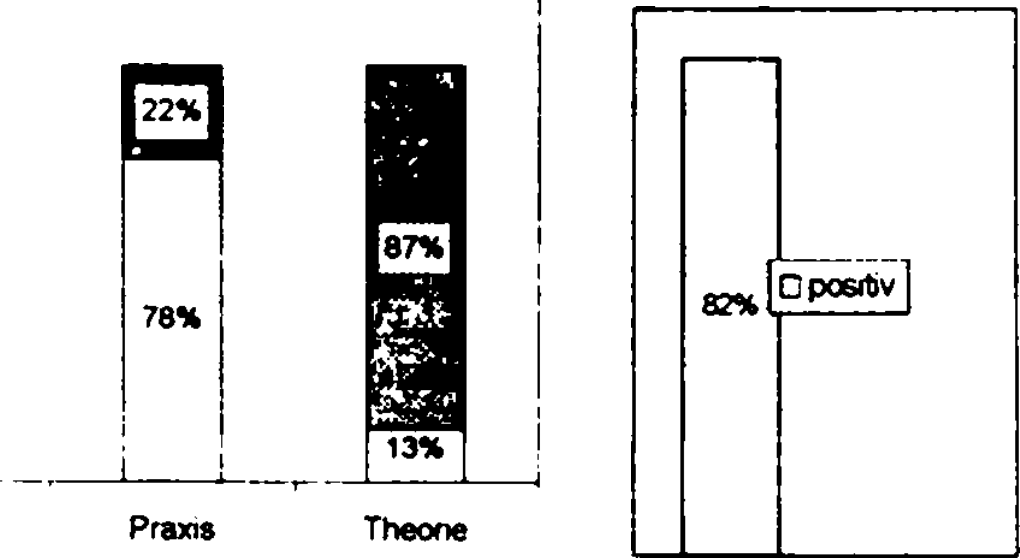

Einstellung, affektives Subsystem: Grad der positiven Einstellung

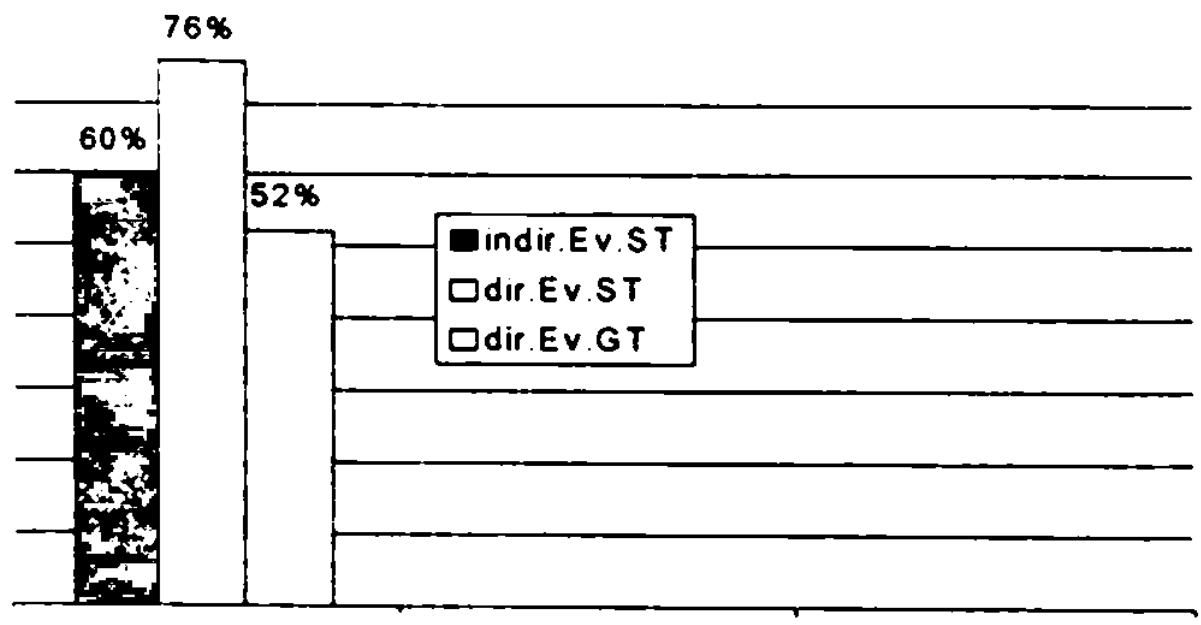


Frauen mit Hochschulabschluß: insgesamt 7 Respondentinnen, Alter 25 bis 63 Jahre

Sprachverhalten:

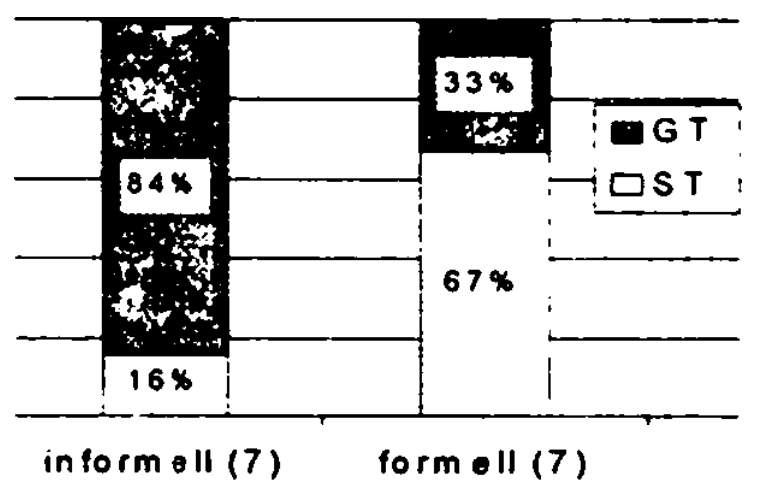

Einstellung, kognitives Subsystem:

Derkannt I nicht erkannt

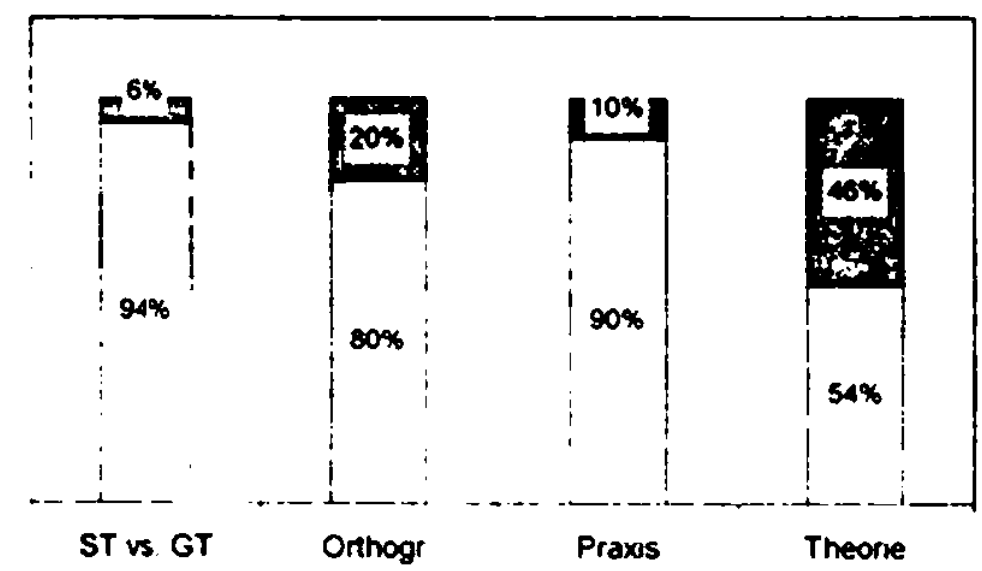

Einstellung, konatives Subsystem:

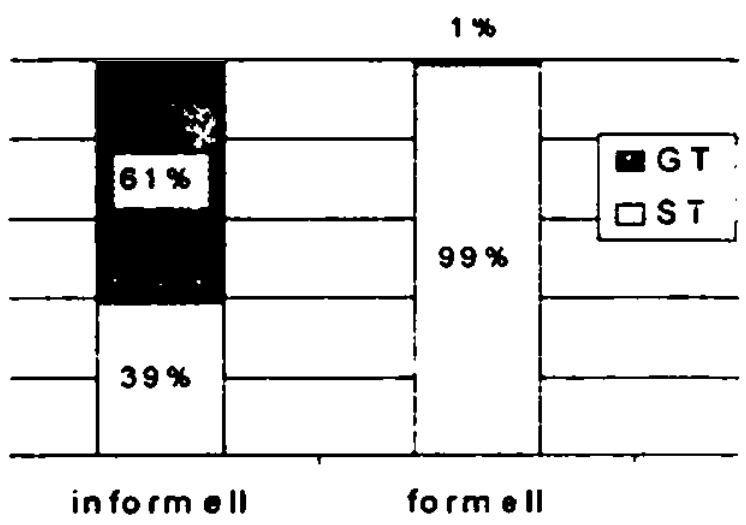

Evaluation der eigenen Kognition.

Einstellung, affektives Subsystem: Grad der positiven Einstellung

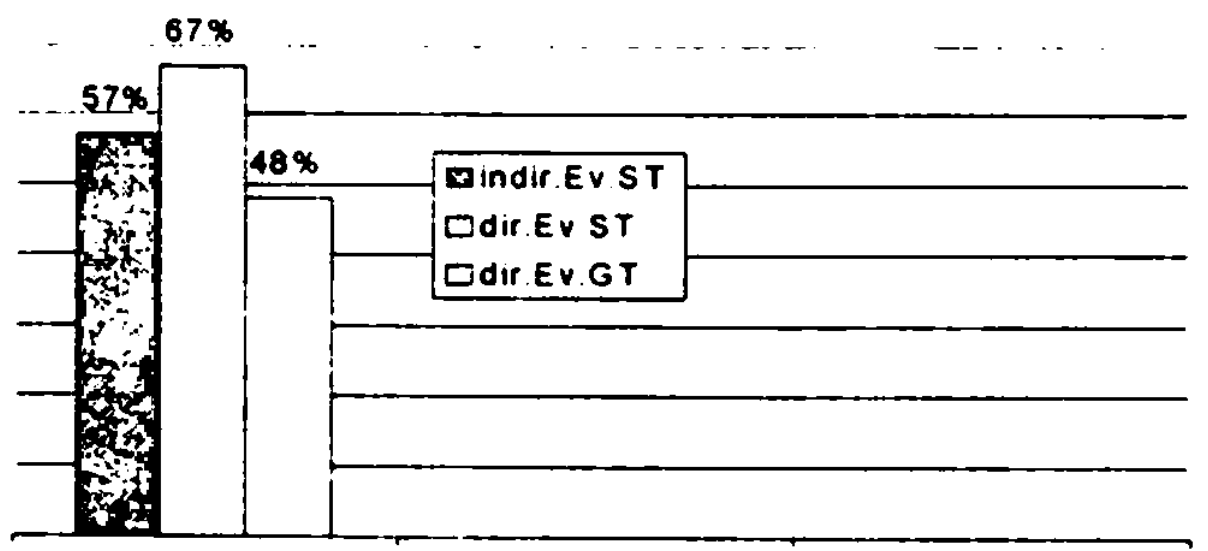




\section{Männer}

Männer ohne Abitur: insgesamt 8 Respondenten, Alter 26 bis 68 Jahre

Sprachverhalten:

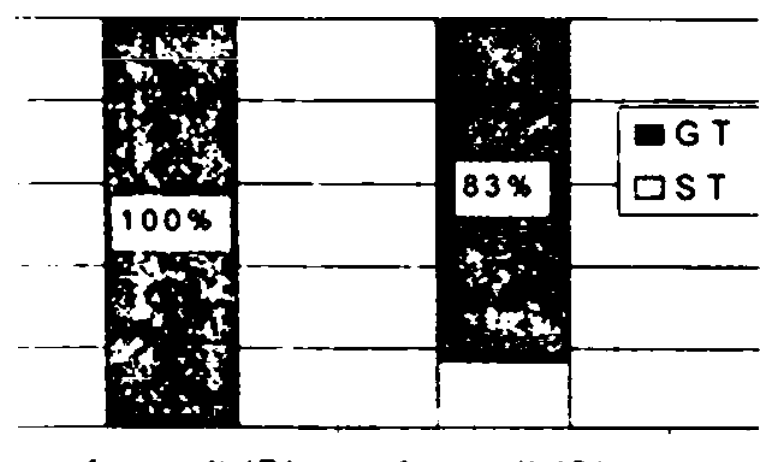

informell (7) formell (8)

Einstellung, kognitives Subsystem:

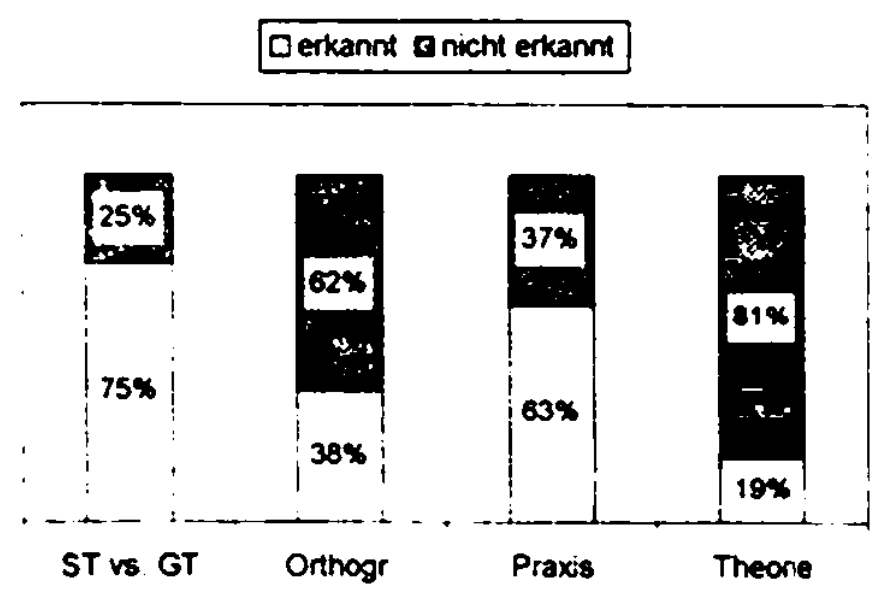

Einstellung, konatives Subsystem:

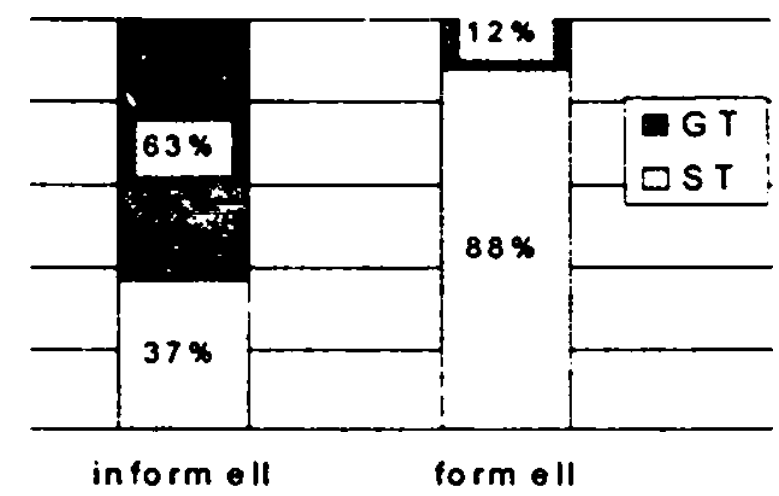

Evaluation der eigenen Kognition:

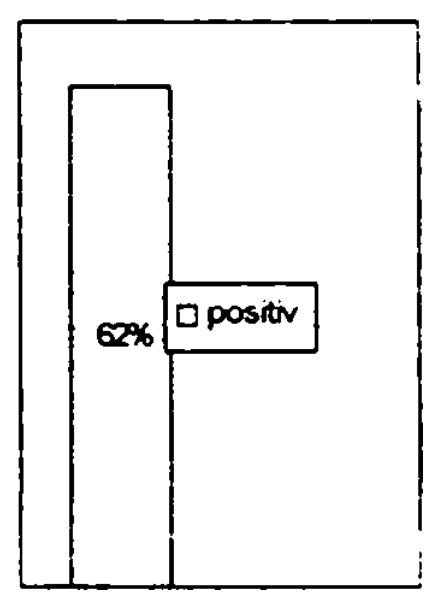

Einstellung, affektives Subsystem. Grad der positiven Einstellung

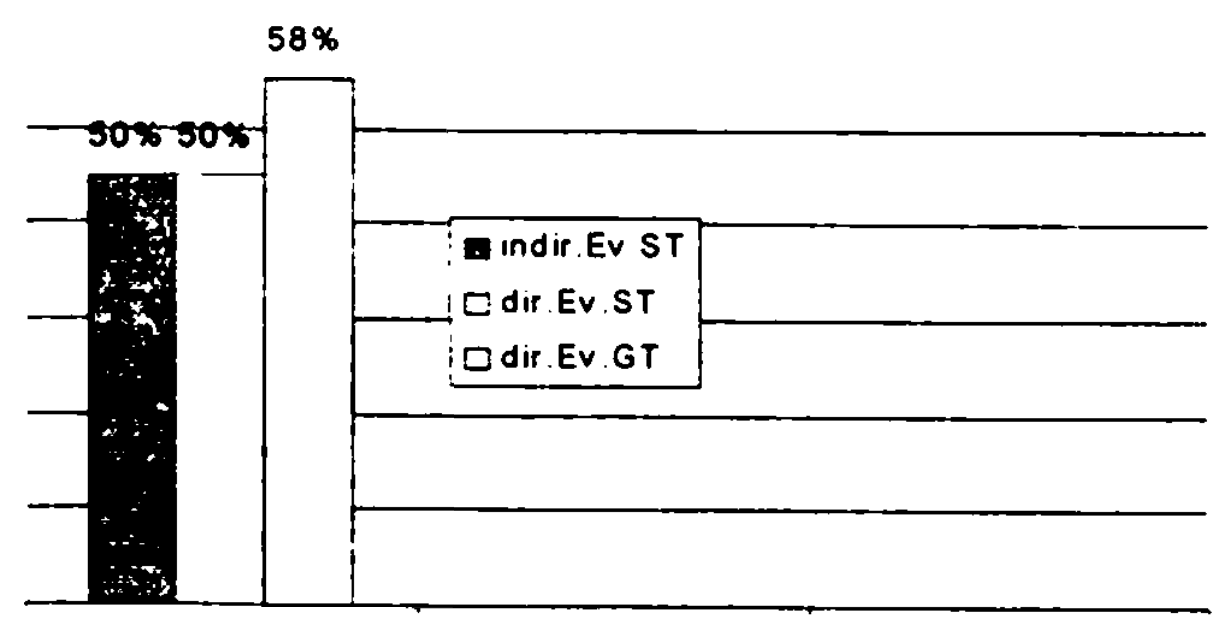


Männer mit Abitur: insgesamt 10 Respondenten, Alter 29 bis 69 Jahre

Sprachverhalten:

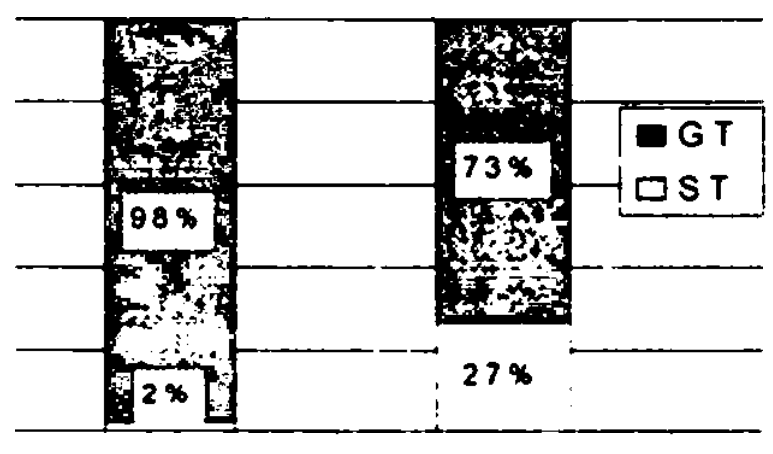

informell (6) formell (10)
Einstellung, konatives Subsystem:

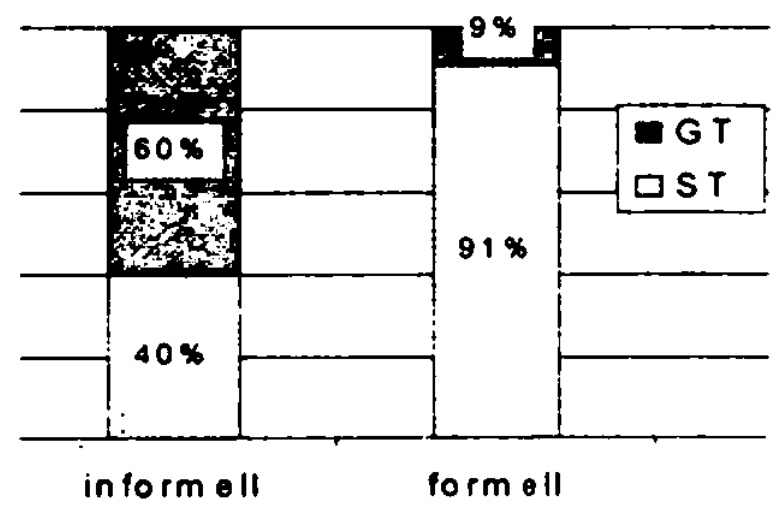

Evaluation der eigenen Kognition:
Einstellung, kognitives Subsystem:

\section{Derkannt E nicht erkannt}

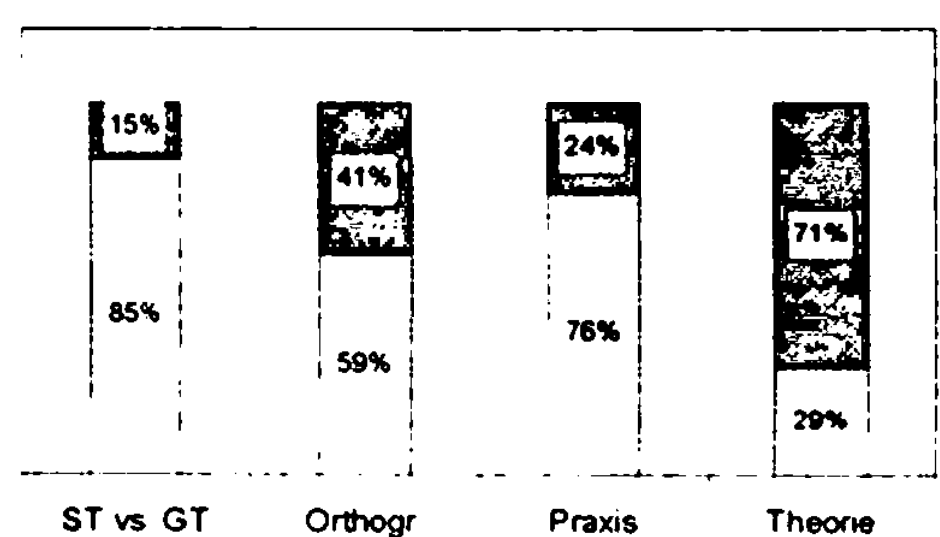

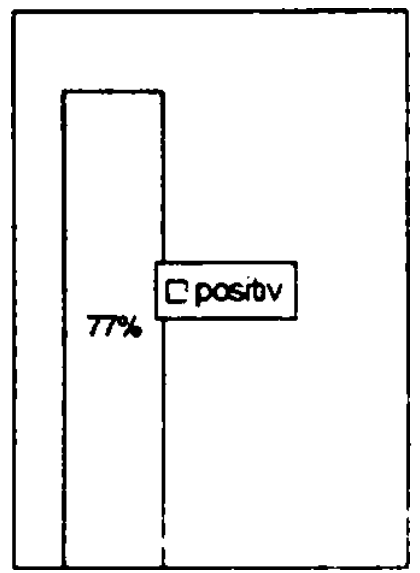

Einstellung, affektives Subsystem: Grad der positiven Einstellung

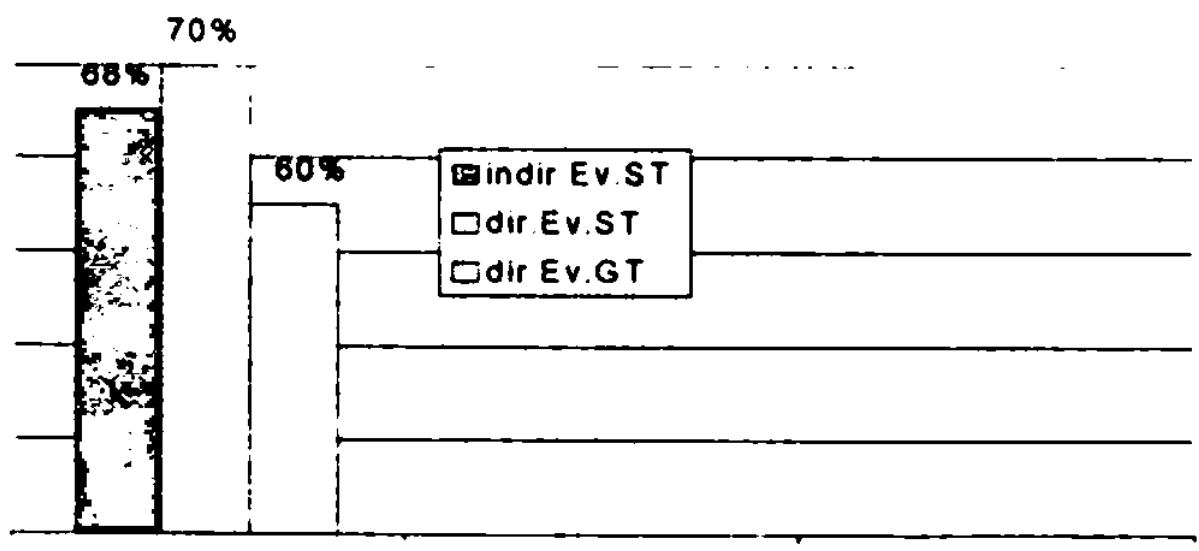


Männer mit HochschulabschluB: insgesamt 7 Respondenten, Nter 25 bis 61 Jahrc

Sprachverhalten:

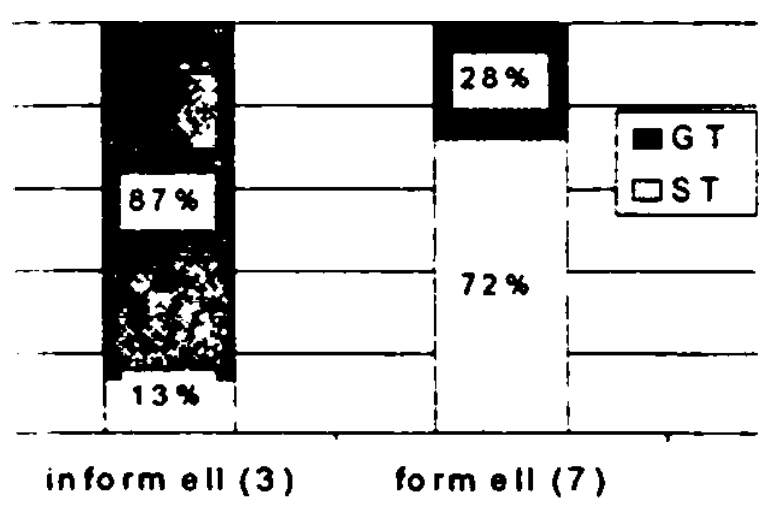

Einstellung kognitives Subsystem:

Derkannt a nucht erkannt

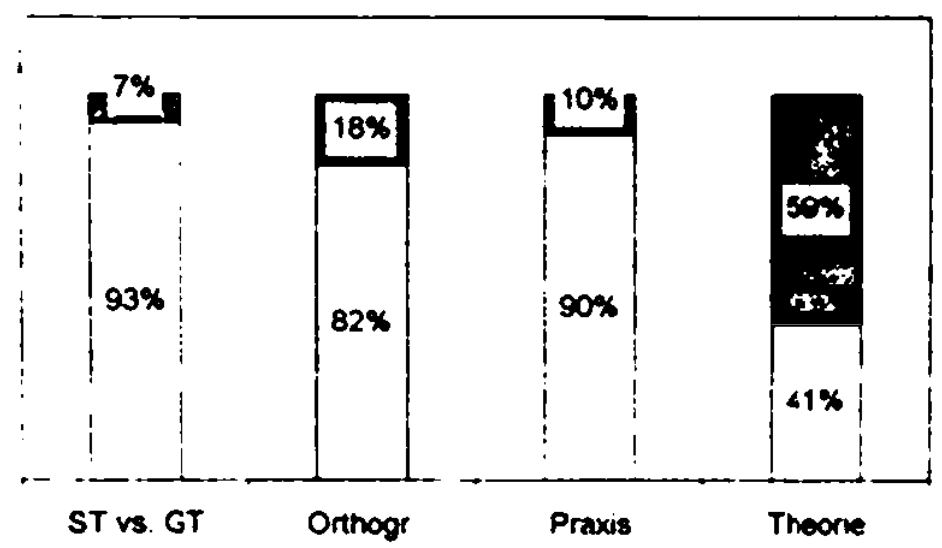

Einstellung konatives Subsystem:

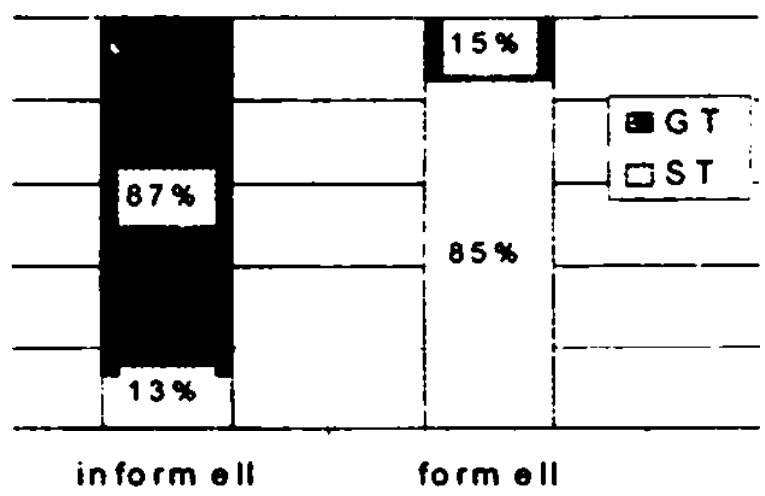

Evaluation der eigenen Kognition:

Einstellung, affektives Subsystem: Grad der positiven Einstellung

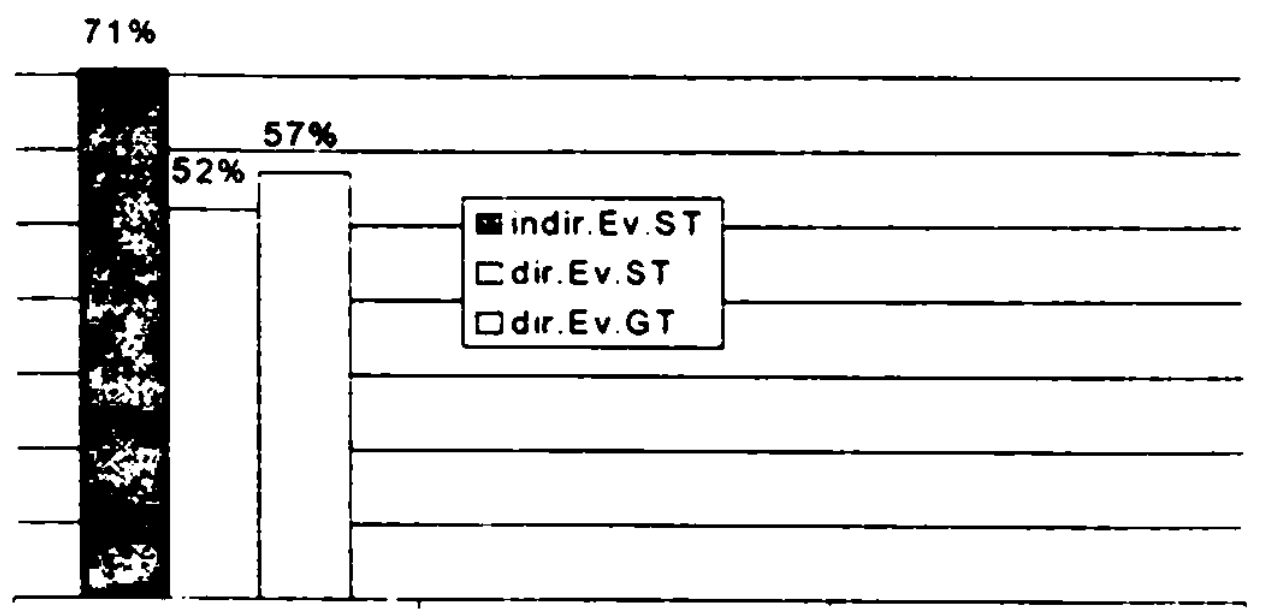




\section{Studentinnen/Studenten}

6 Studentinnen, Geisteswissenschaften ${ }^{121}$

Sprachverhalten:

Einstellung, konatives Subsystem:

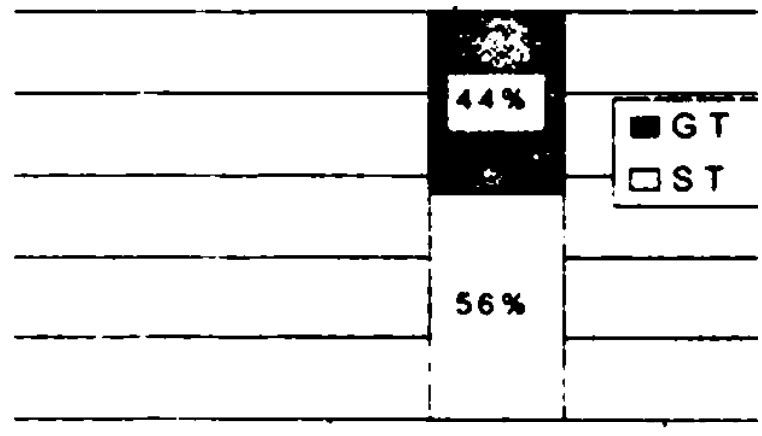

form ell (6)

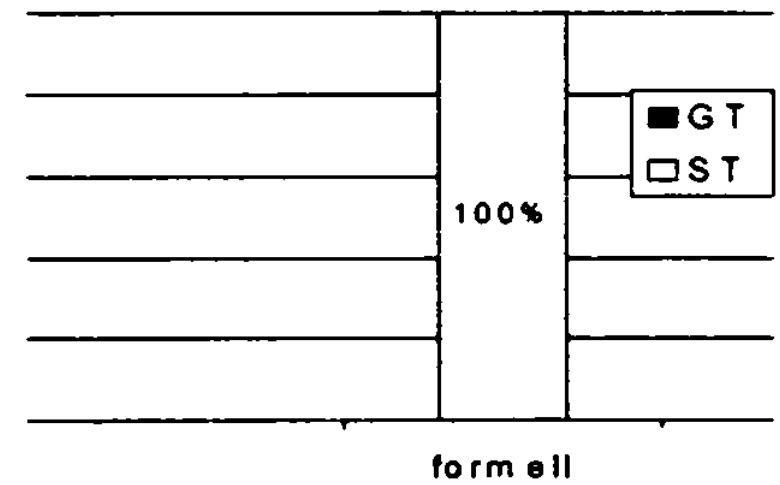

Evaluation der eigenen Kognition:

Einstellung, kognitives Subsystem:

Derkannt E nicht erkannt
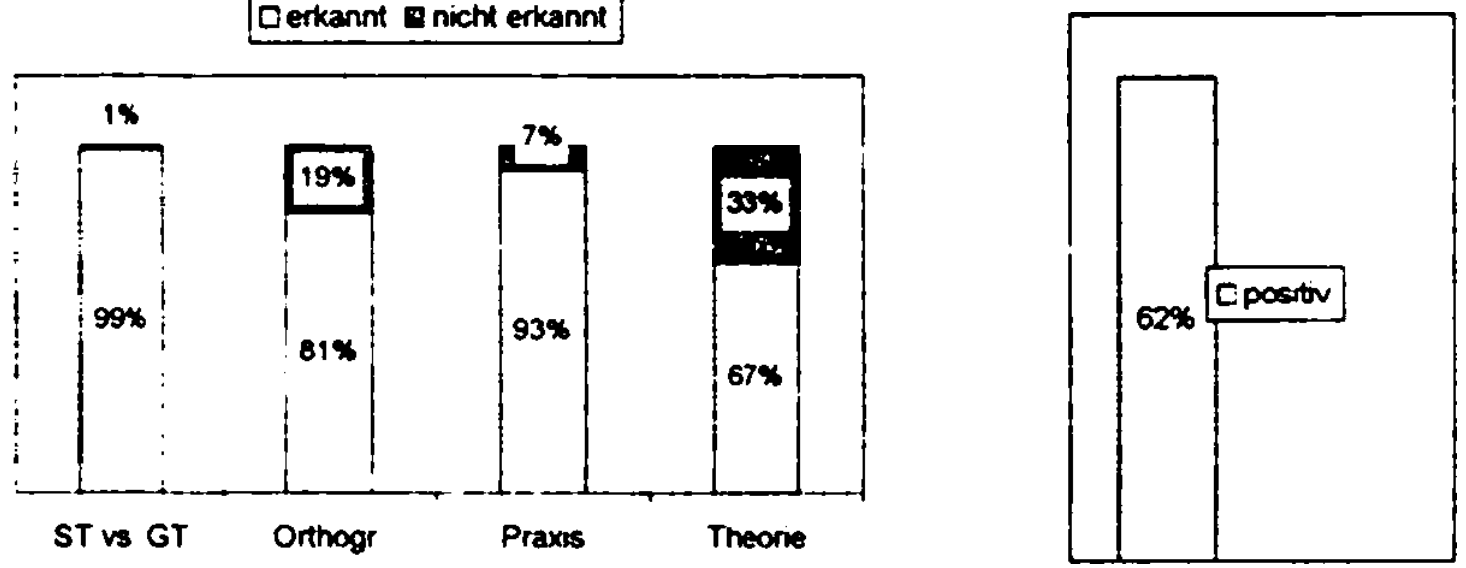

Einstellung, affektives Subsystem: Grad der positiven Einstellung

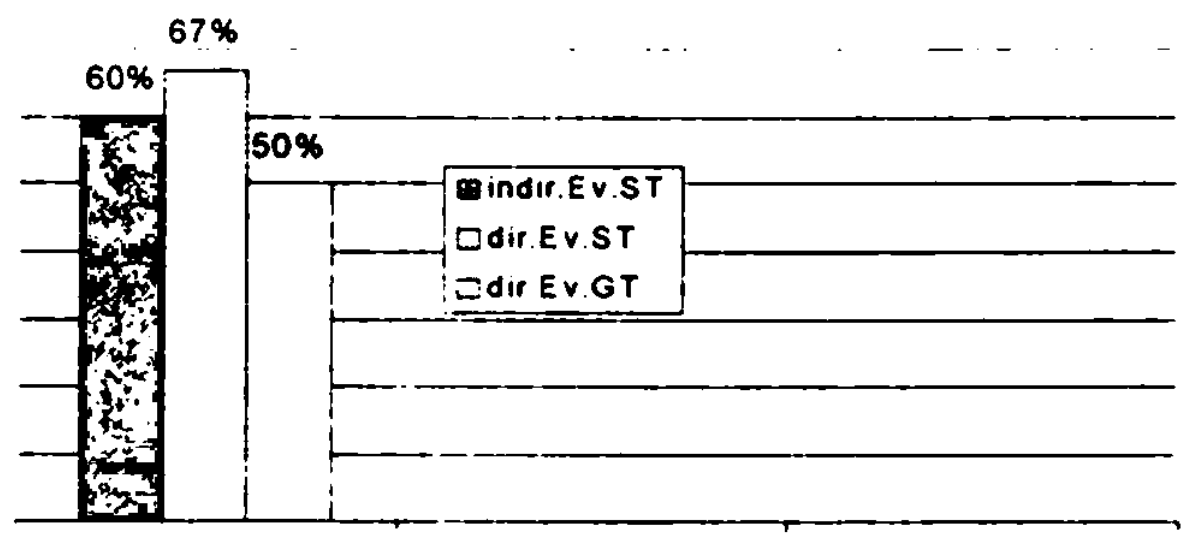

121 Diese Gruppe selzt sich дusamsıen aus ciner Jurastudentin und S Studentinnen der Padagogisclien Fakultät. Fachrichtung Bolkemistik. Alle studieren in Pilsen. 
4 Studenten, Geisteswissenschaften ${ }^{122}$

Sprachverhalten:

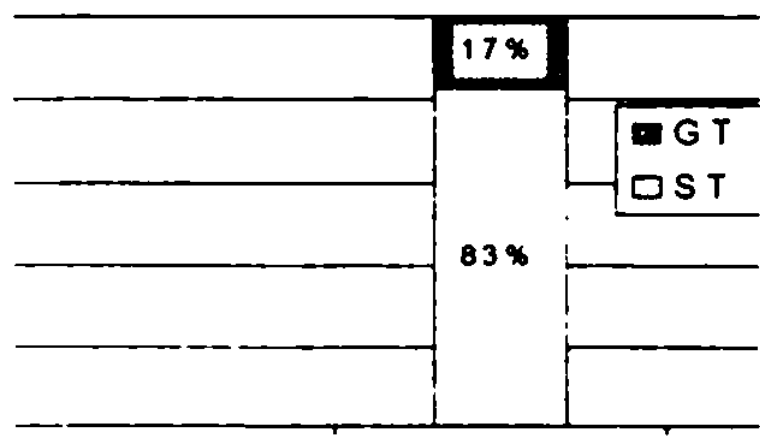

form ell (4)

Einstellung, kognitives Subsystem:

Derkannt Enicht erkannt

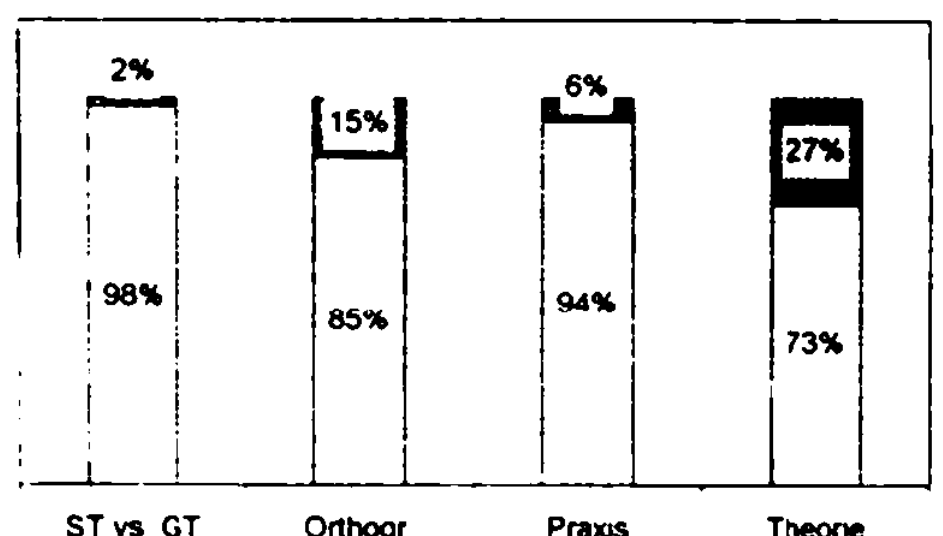

ST vs GT

Orthogr

Praxis

Theorre
Einstellung, konatives Subsystem:

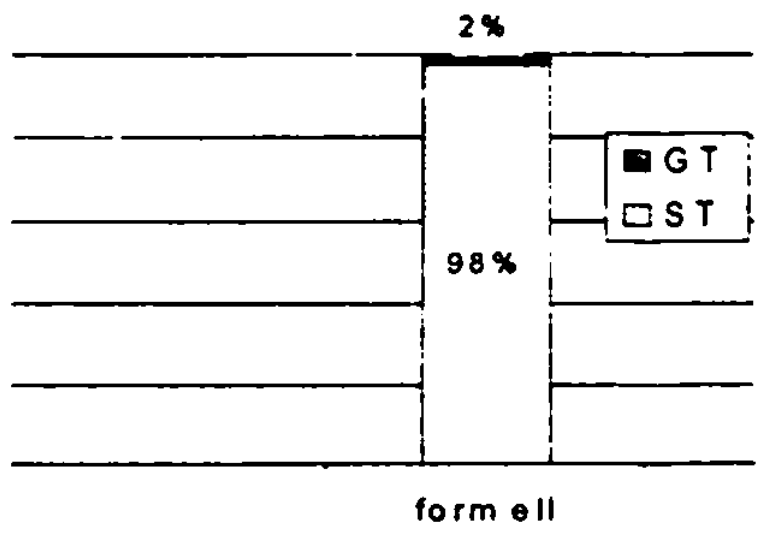

Evaluation der eigenen Kognition:

Einstellung, affektives Subsystem: Grad der positiven Einstellung

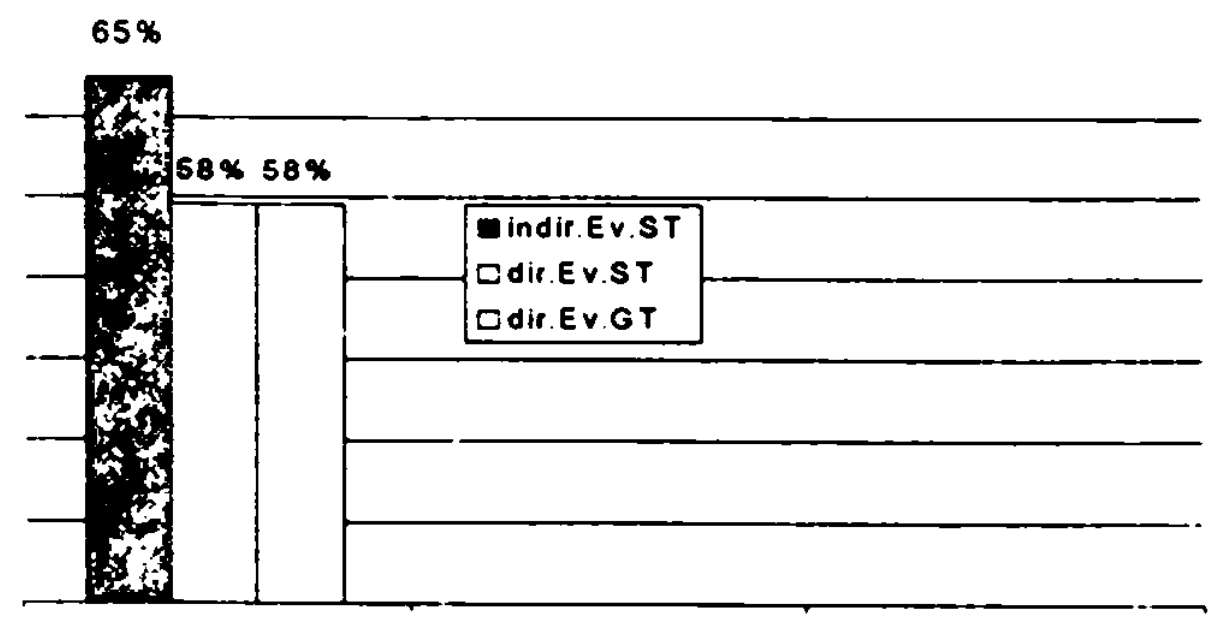

122 Diese Gruppe setzt sich zusammen aus einem Jurastudent und 3 Studenten der Pädigogısclien Fakultăt. Fachrichtung Bolicmıstik. Alle studieren in Pilsen. 
5 Studenten der Technischen Fakultät in Pilsen

Sprachverhalten:

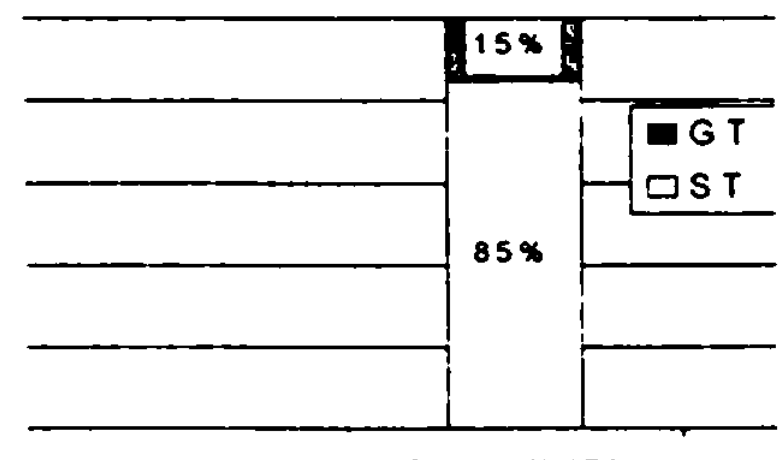

form $\bullet \| 11(5)$

Einstellung, kognitives Subsystem:

Derkannt Dnicht erkannt

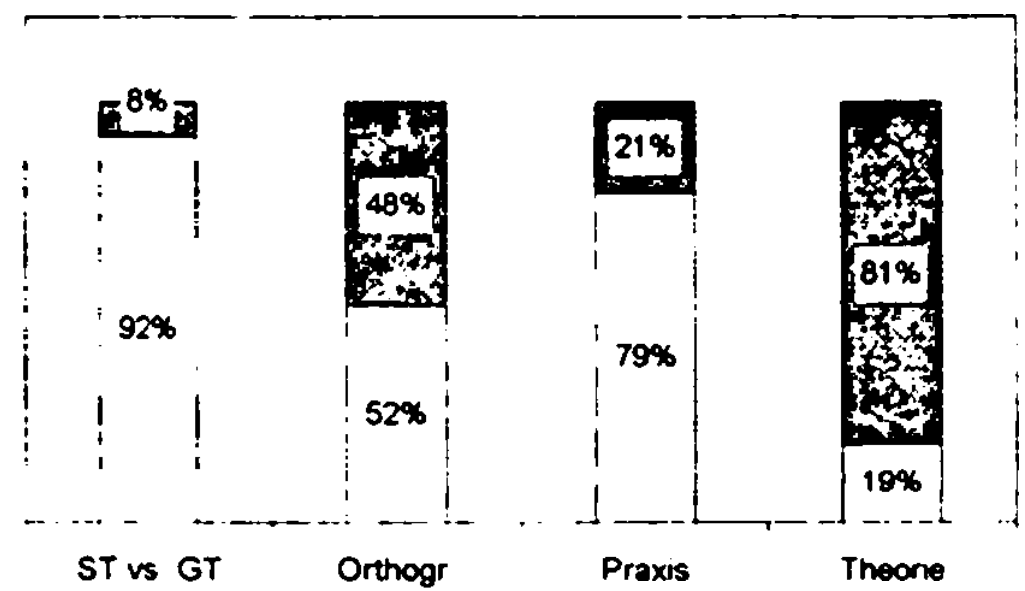

Einstellung, konatives Subsystem.

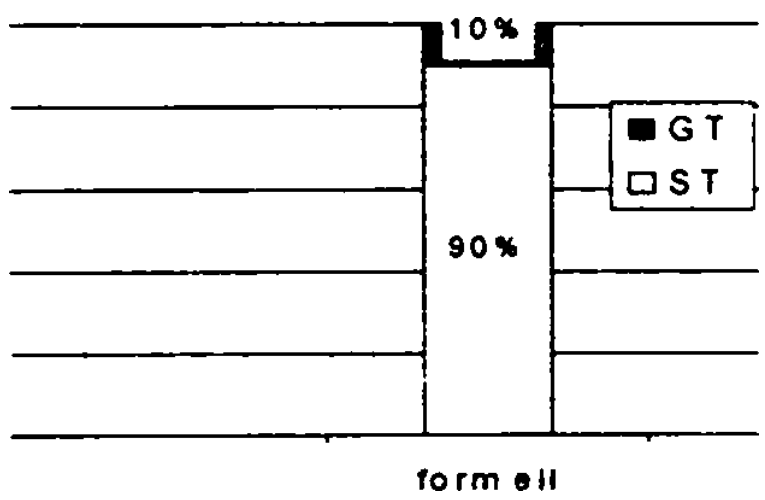

Evaluation der eigenen Kognition:

Einstellung, affektives Subsystem: Grad der positiven Einstellung

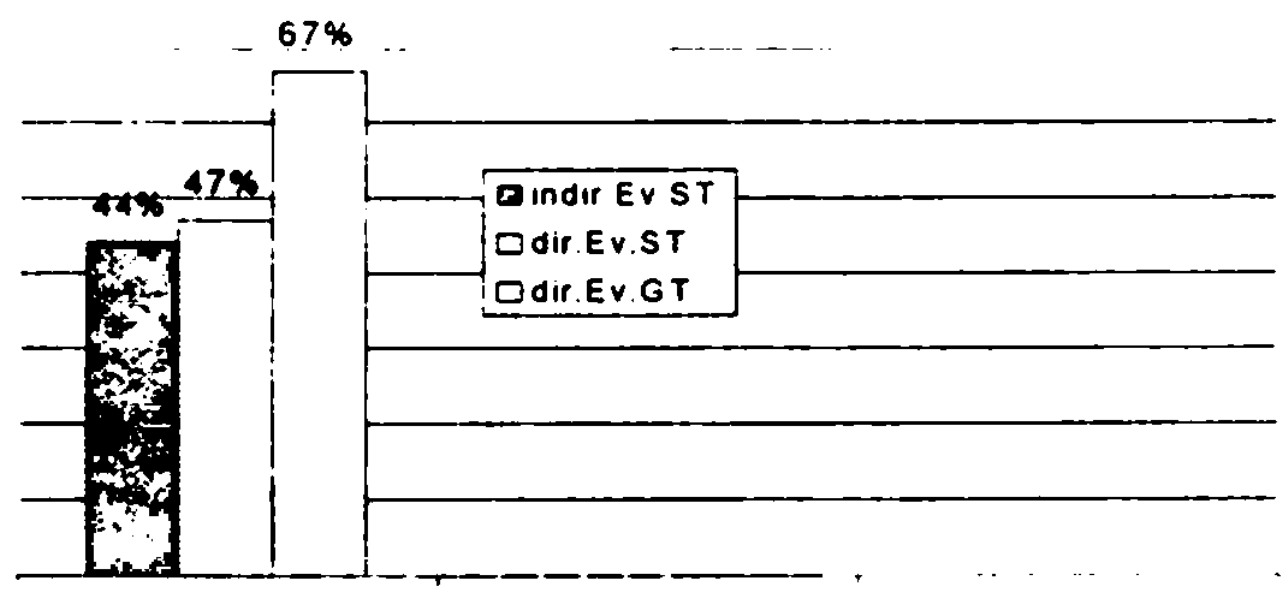




\section{Schüler}

5 Schüler der Technischen Oberschule in Pilsen

Sprachverhalten:

Einstellung, konatives Subsystem:

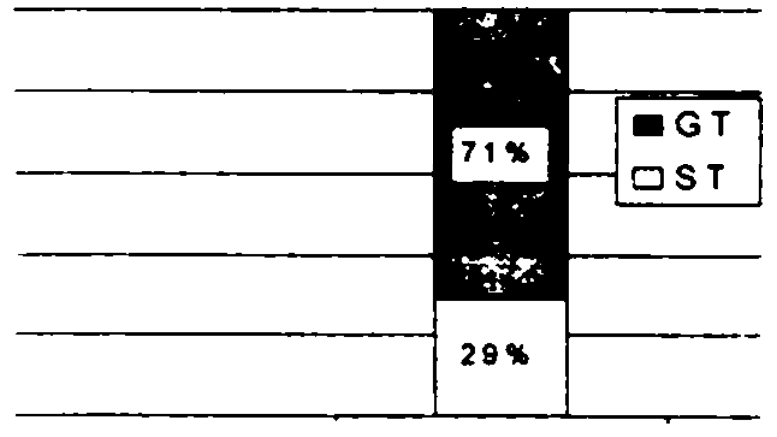

form $\bullet$ II (5)

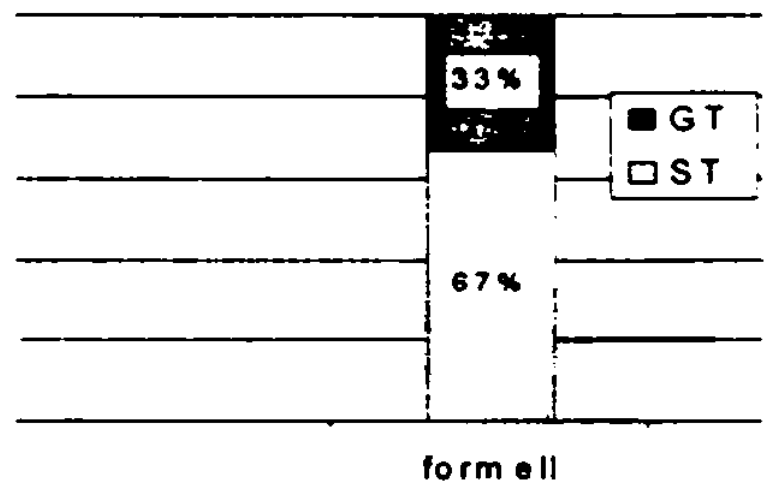

Evaluation der eigenen Kognition:
Einstellung, kognitives Subsystem:

Derkannt D nicht erkannt

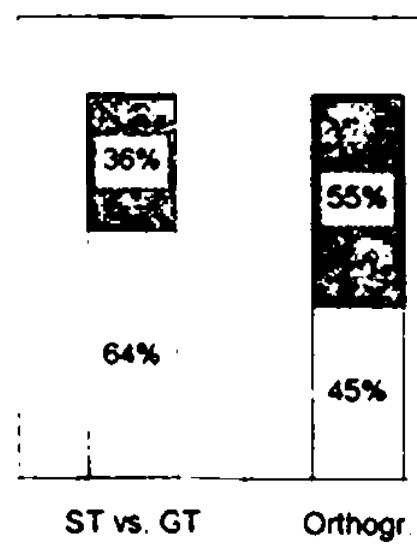

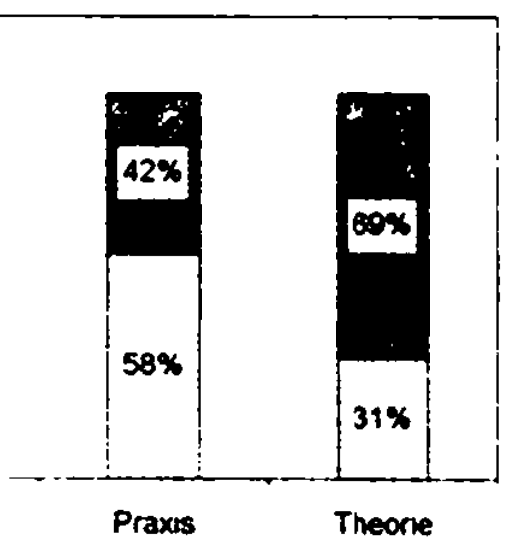

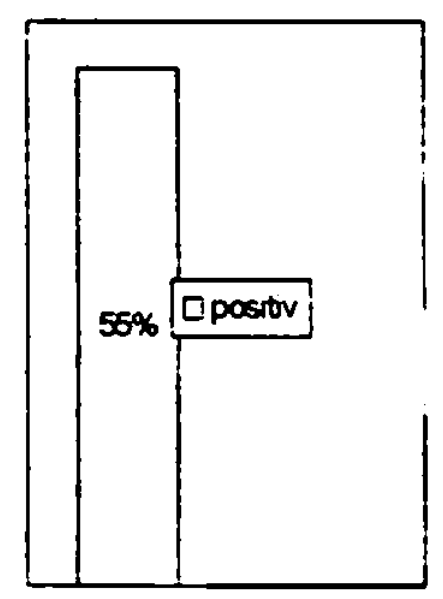

Einstellung affektives Subsystem: Grad der positiven Einstellung

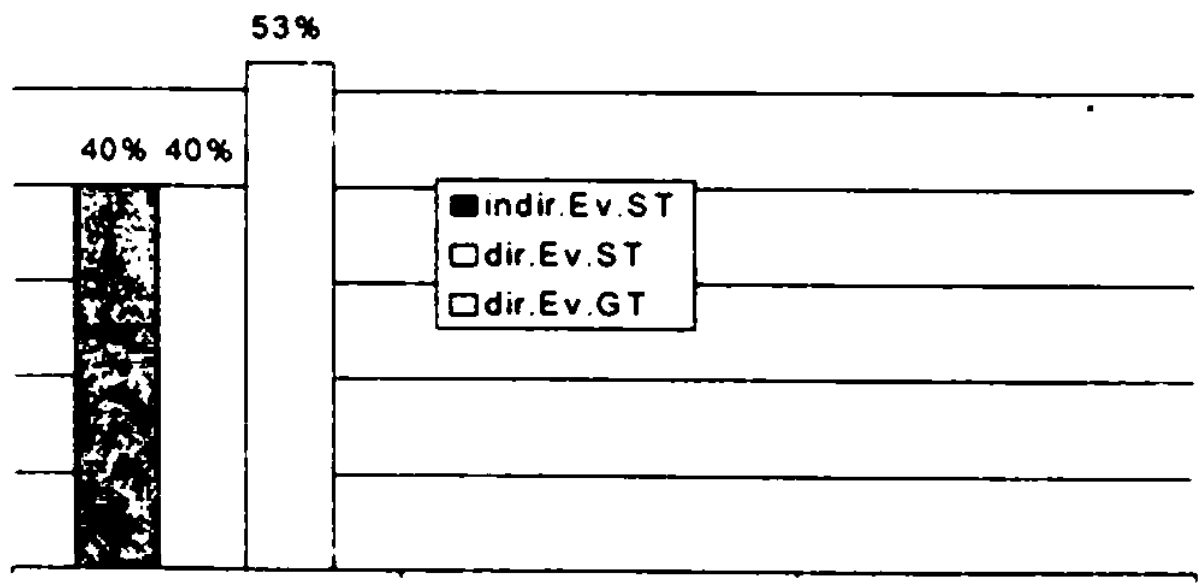


8.1.2 Erste Working-ıp-Ebene: Prag ${ }^{123}$

\section{Frauen}

Frauen ohne Abitur: insgesamt 4 Respondentinnen, Alter 38 bis 65 Jahre J $^{124}$

Sprachverhalten:

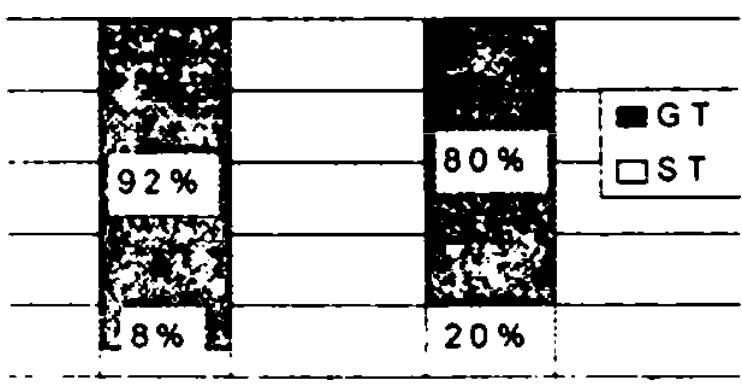

informell (1) formell (3)

Einsteliung, kognitives Subsystem:

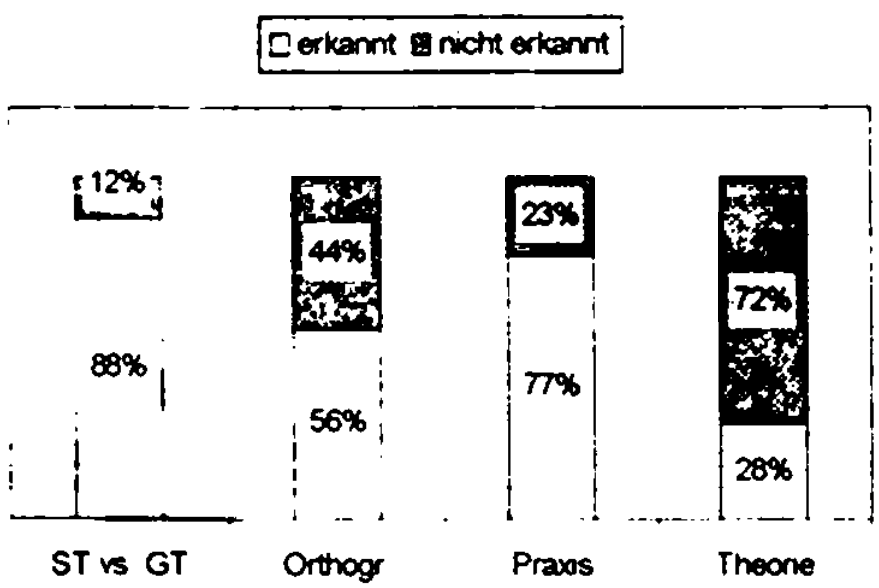

Einstellung, konatives Subsystem:

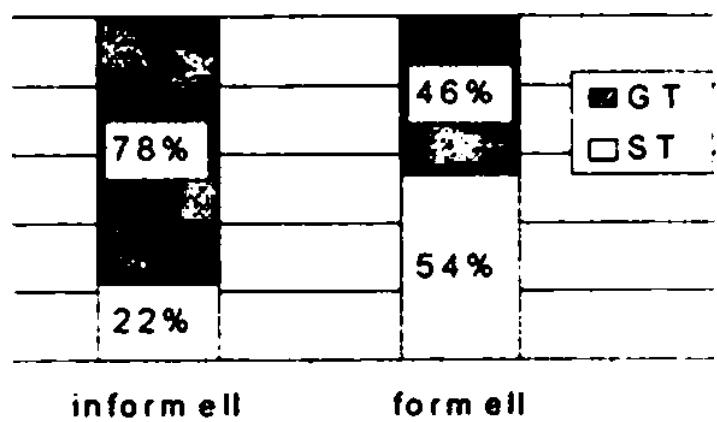

Evaluation der eigenen Kognition.

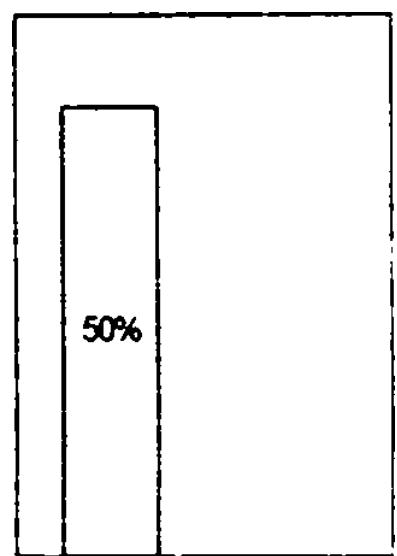

Einstellung, affektives Subsystem: Grad der positiven Einstellung

(58\%

12.3 Die Gnippe der in Prag befragien Respondenten ist um ca. $\$ 2 \%$ kleiner als die in Westbolumen.

124 Bei dieser Gnuppe konnte nur eine Frau in der informellen Situation aufgenommen werden Somit sind dic Angaben im Spracliverhalten und dem konativen Subststem keinc Durchsclinittswerte- 9783954790258 
Frauen mit Abitur: insgesamt 5 Respondentinnen, Alter 29 bis 54 Jahre

Sprachverhalten:

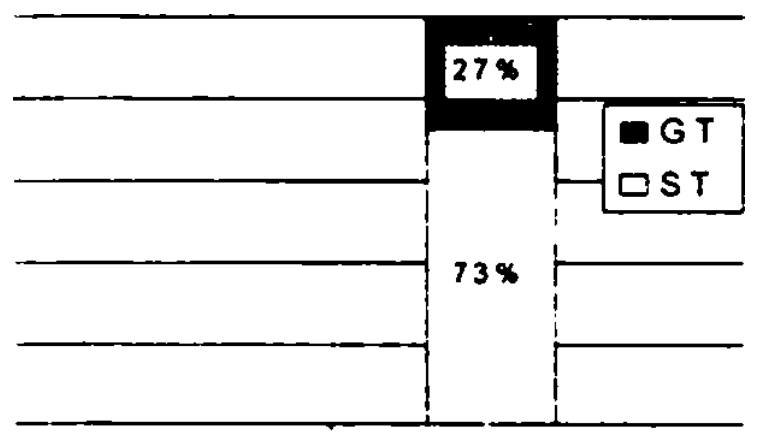

form ell (5)

Einstellung kognitives Subsystem:

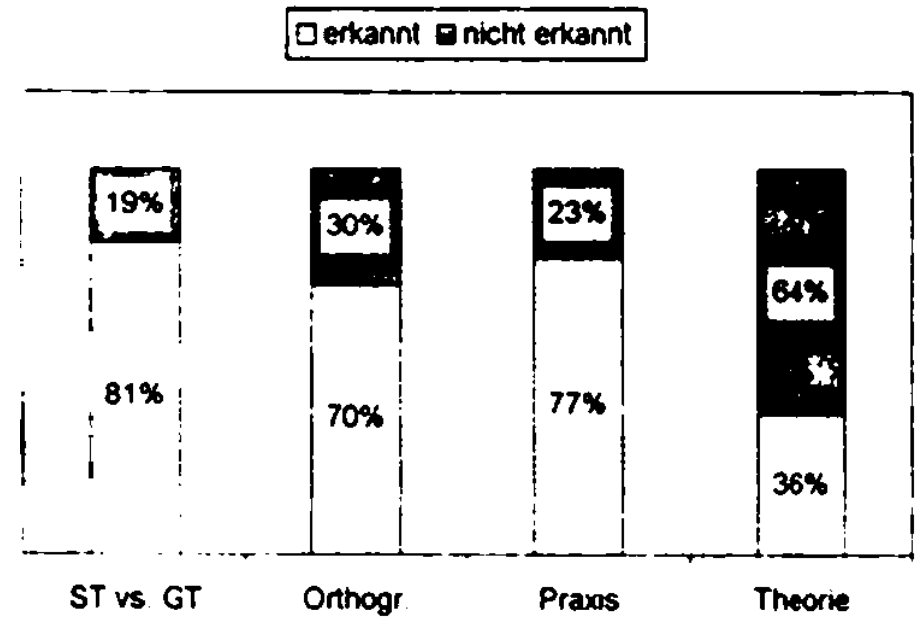

Einstellung, konatives Subsystem:

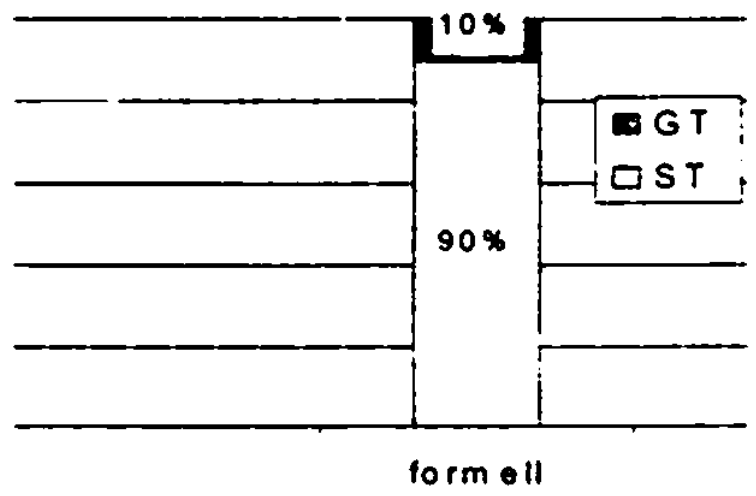

Evaluation der eigenen Kognition:

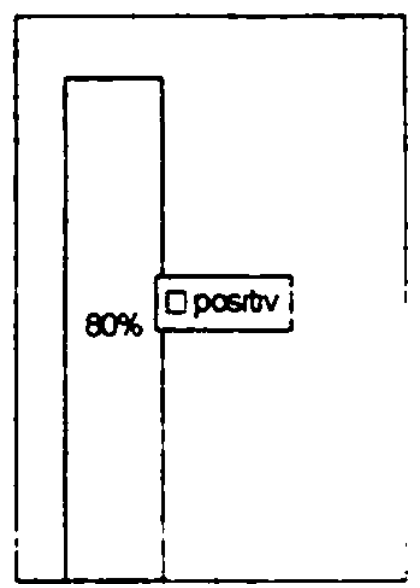

Einstellung affektives Subsystem: Grad der positiven Einstellung $80 \%$

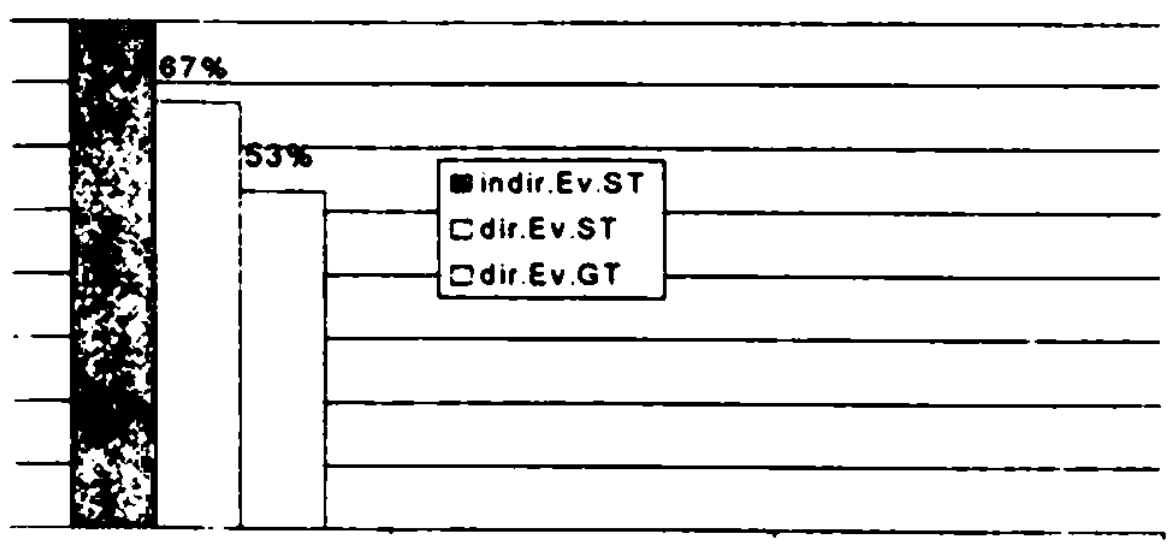


Frauen mit HochschulabschluB: insgesamt 2 Respondentinnen, Alter 37 und 39 Jahre

Sprachverhalten:

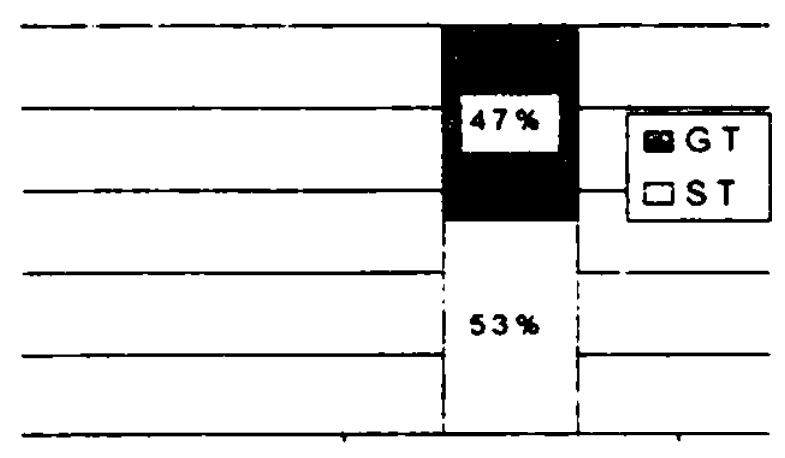

form ell (2)
Einstellung, konatives Subsystem:

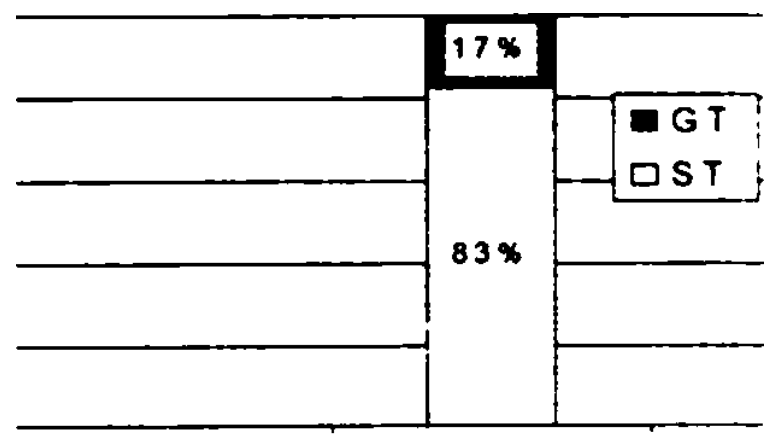

formell
Einsteliung kognitives Subsystem:

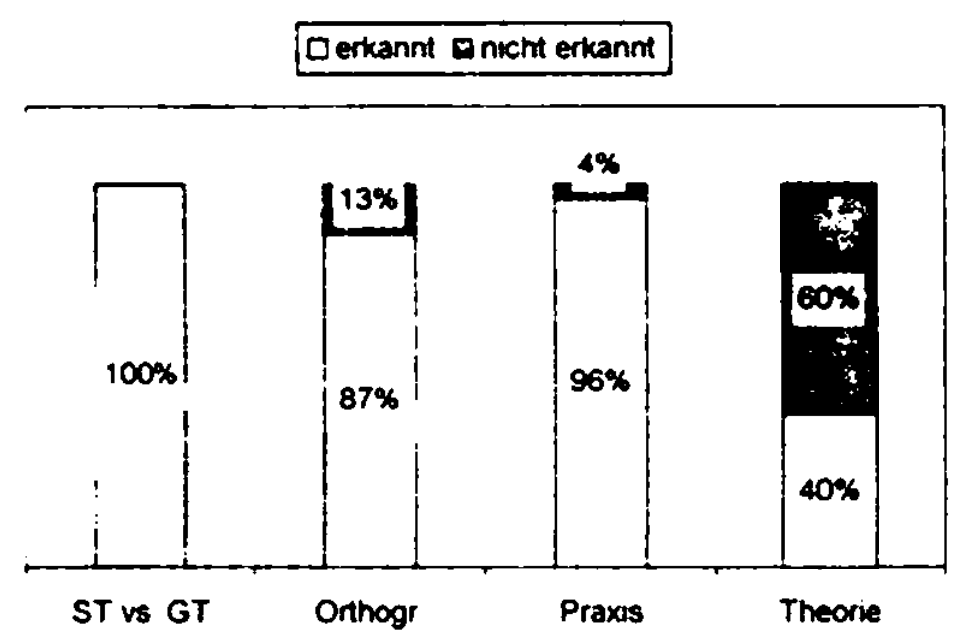

Evaluation der eigenen Kognition:

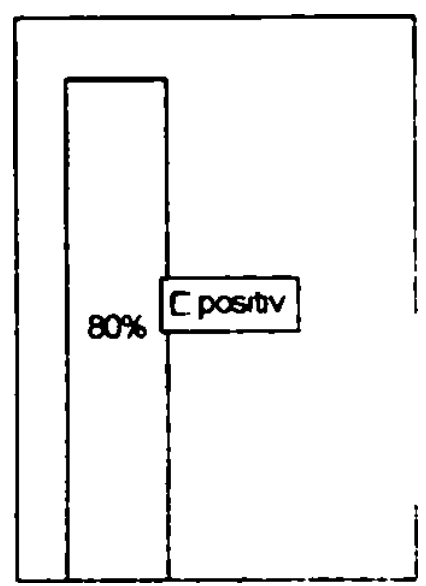

Einstellung, affektives Subsystem: Grad der positiven Einstellung

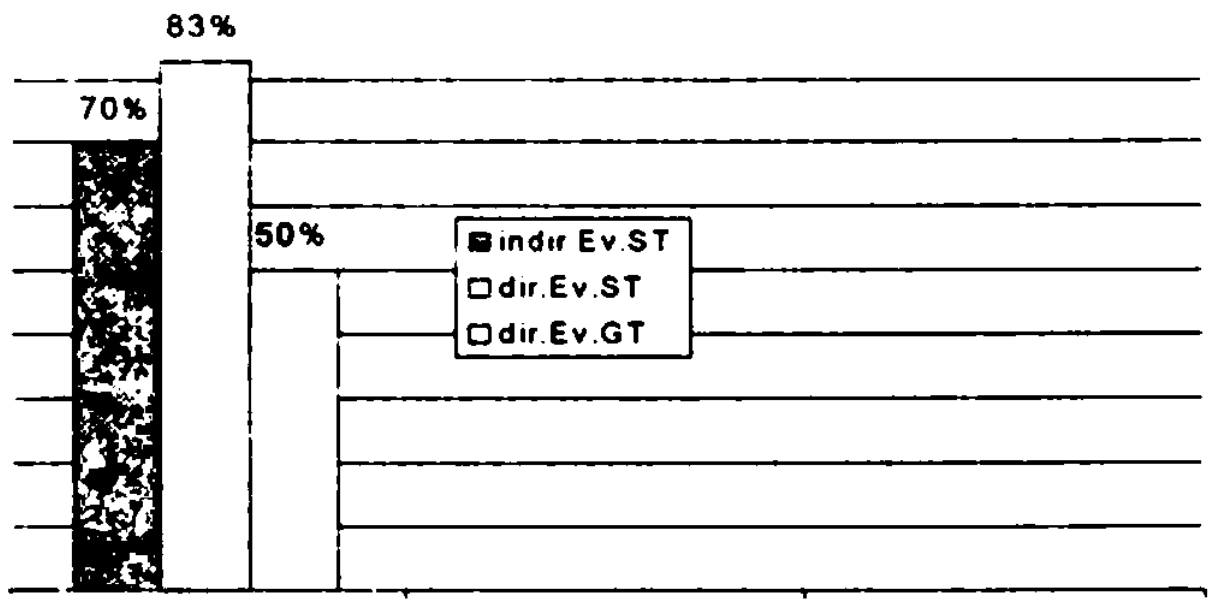




\section{Männer}

Männer ohne Abitur: insgesamt 6 Respondenten, Alter 37 bis 49 Jahre

Sprachverhalten:

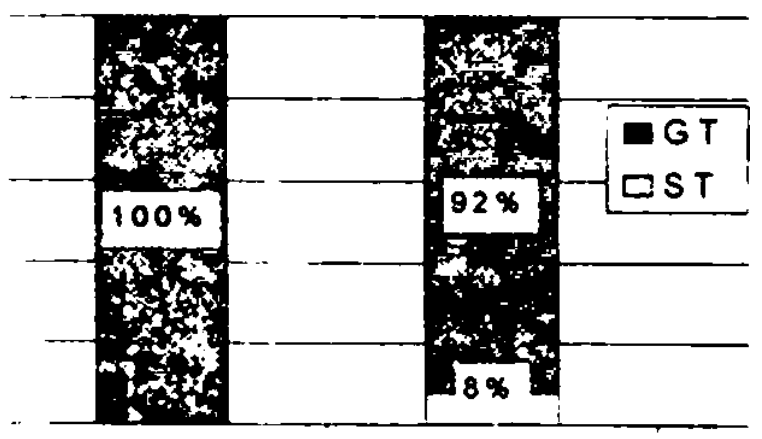

in form ell (2) form ell (4)
Einstellung, konatives Subsystem:

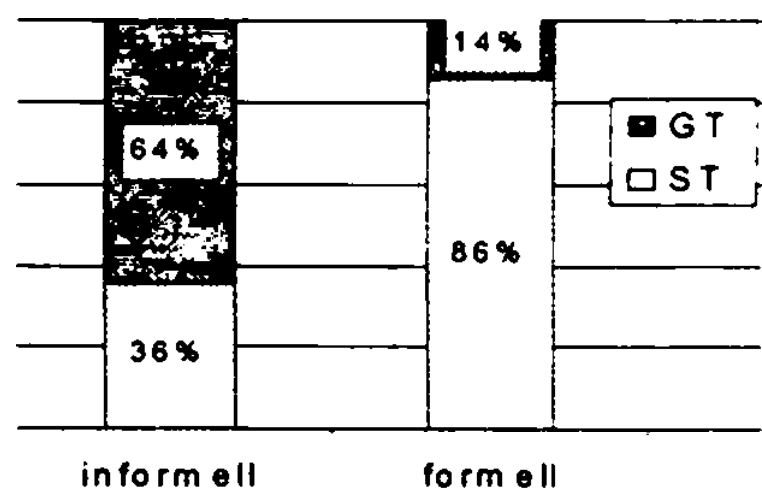

Evaluation der eigenen Kognition

Einstellung, kognitives Subsystem:

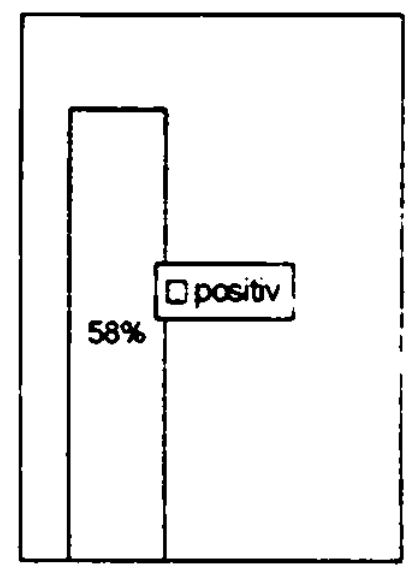

Einstellung, affektives Subsystem: Grad der positiven Einstellung

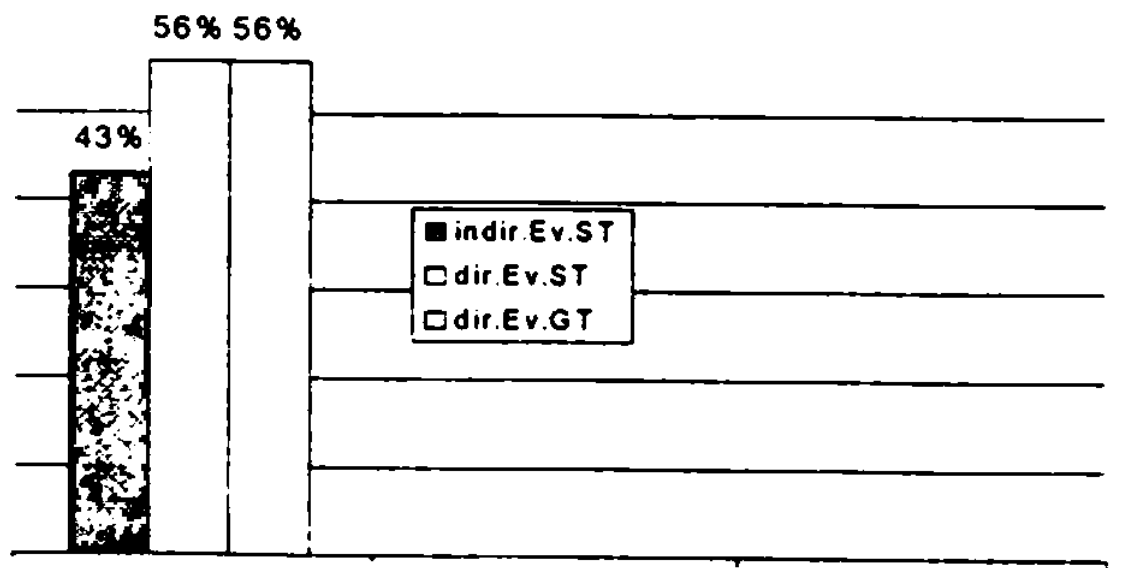


Männer mit Abitur: insgesamt 5 Respondenten, Alter 33 bis 67 Jahre $^{12 s}$

Sprachverhalten:

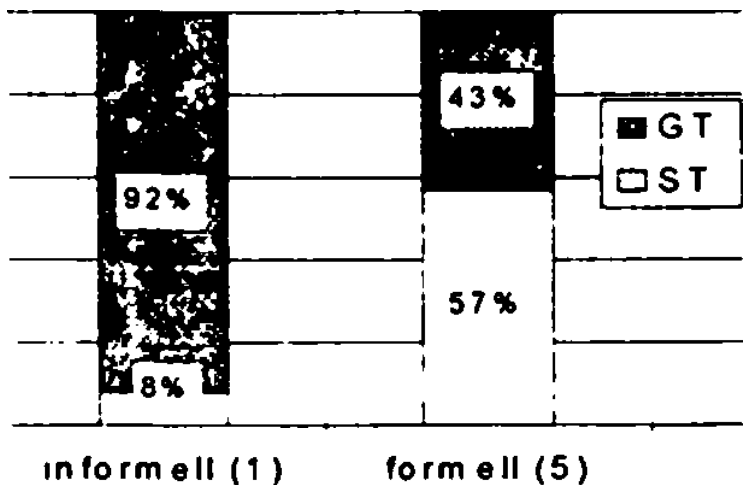

Einstellung, kognitives Subsystem:
Einstellung, konatives Subsystem:

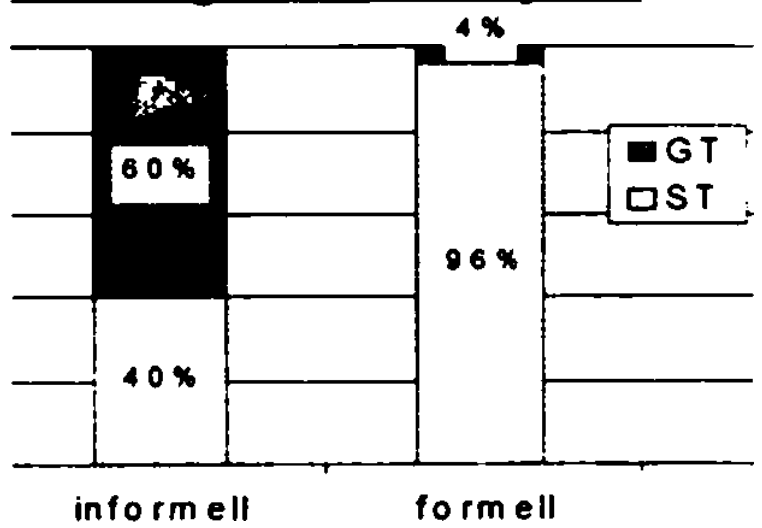

Evaluation der eigenen Kognition

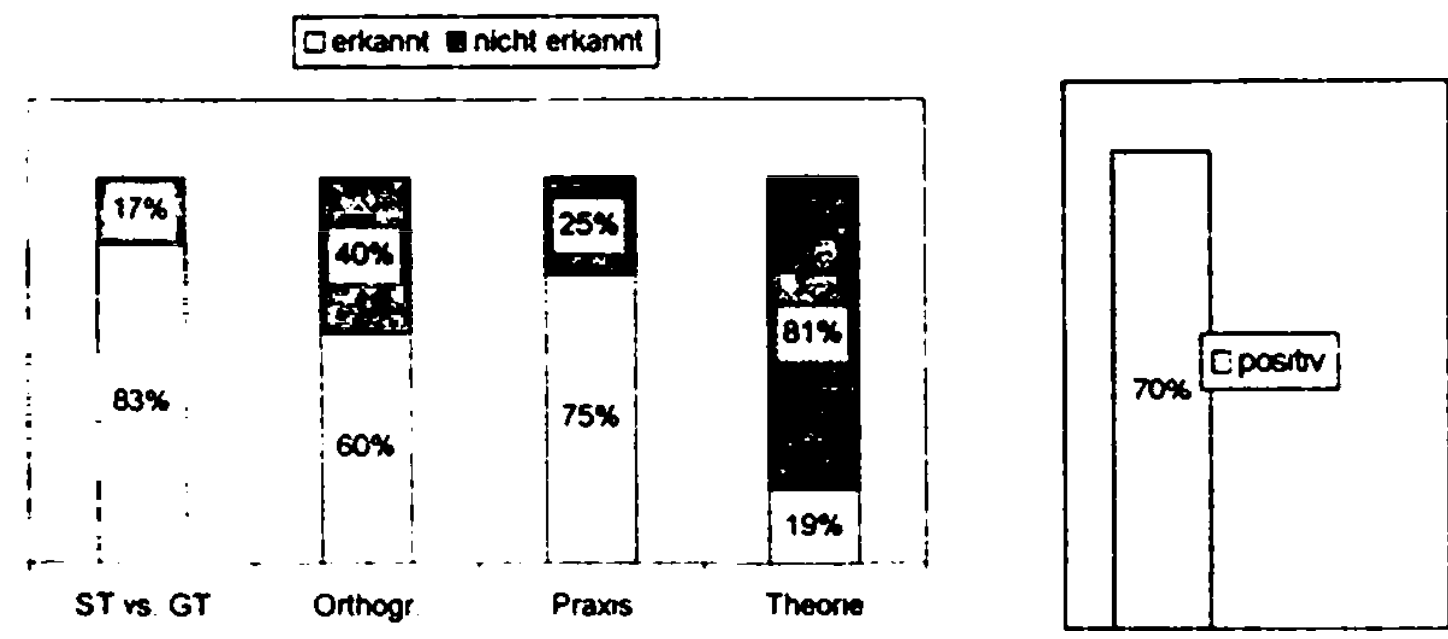

Einstellung, affektives Subsystem: Grad der positiven Einstellung

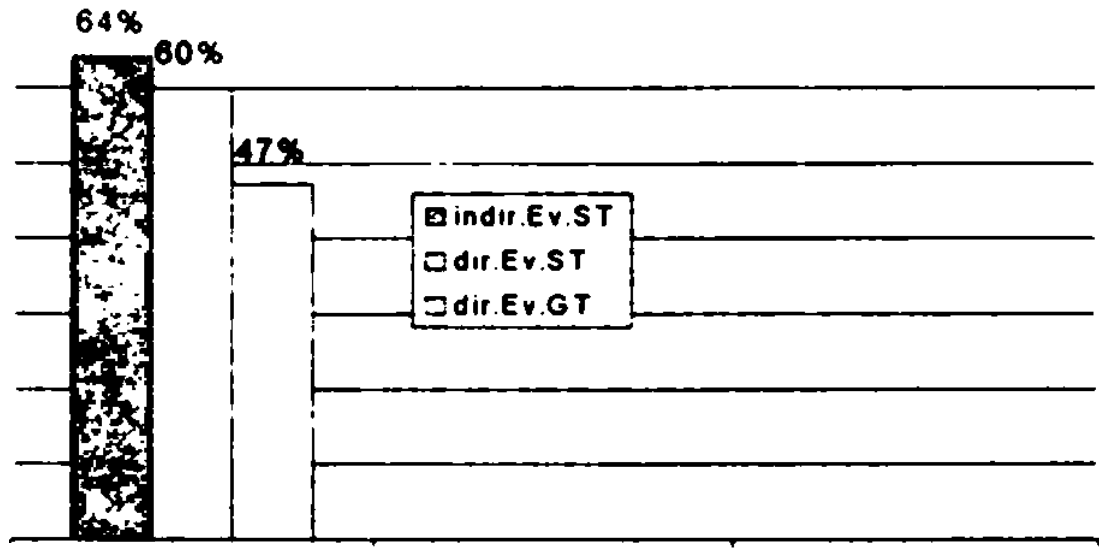

125 Bei dieser Respondentengnuppe konnte nur cin Mann in der informellen Situation aufgenonmen werden. Soniil sind die Angaben im Sprachicrhalten und dem konativen Subsystem keine Durchschnittswerte und dalice nur nuarginal zu beacliten. 
Männer mit Hochschulabschluß: insges. 2 Respondenten, Alter 49 und 60 Jahre

Sprachverhalten:

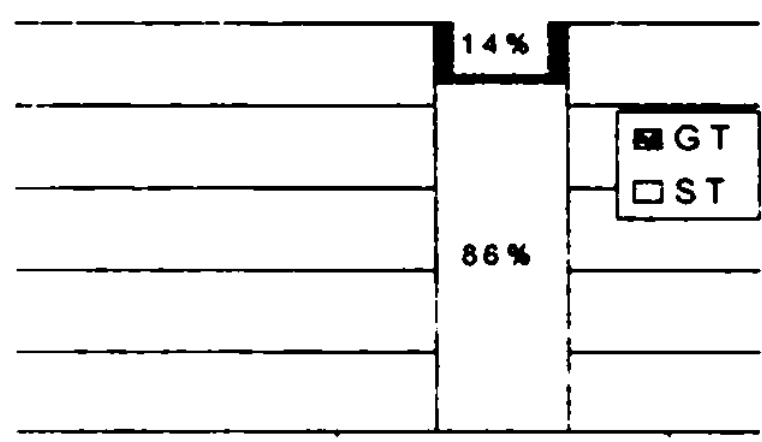

form ell (2)
Einstellung, konatives Subsystem:

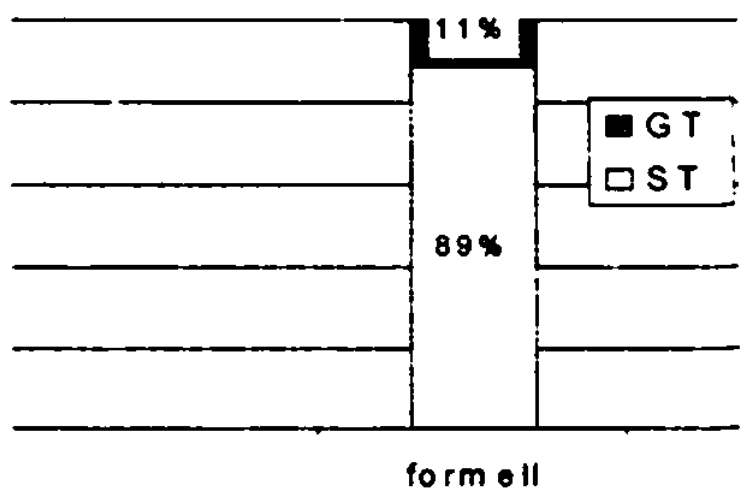

Evaluation der eigenen Kognition:
Einstellung, kognitives Subsystem:

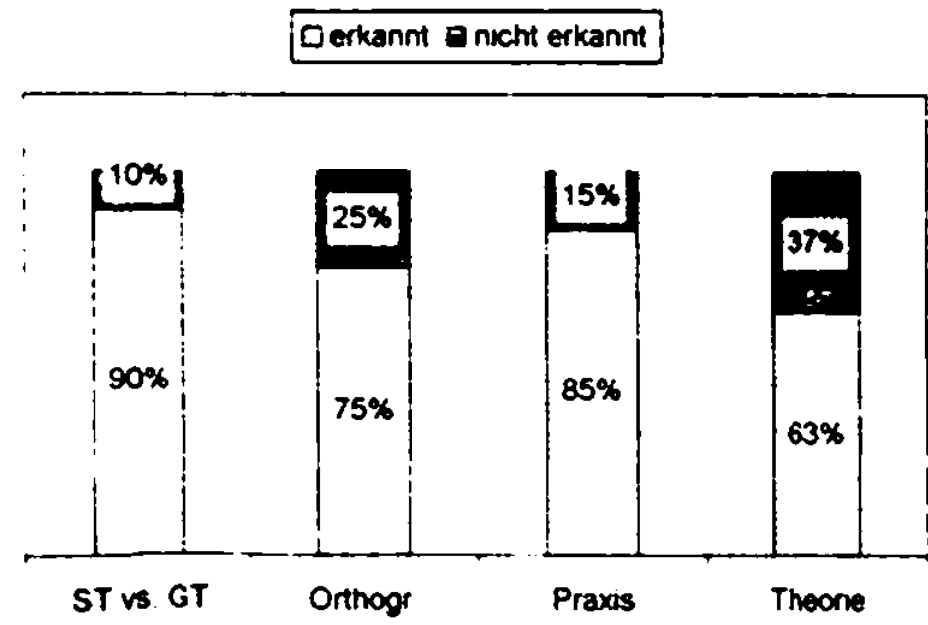

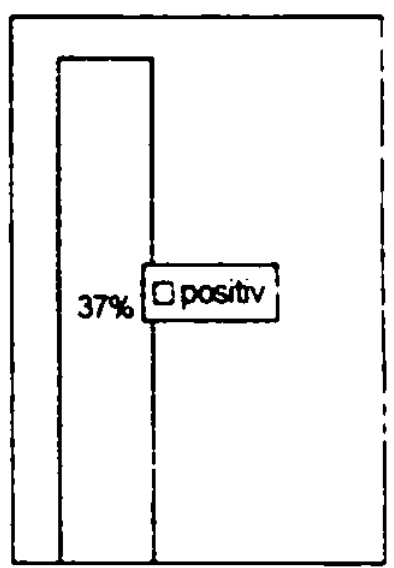

Einstellung, affektives Subsystem: Grad der positiven Einstellung

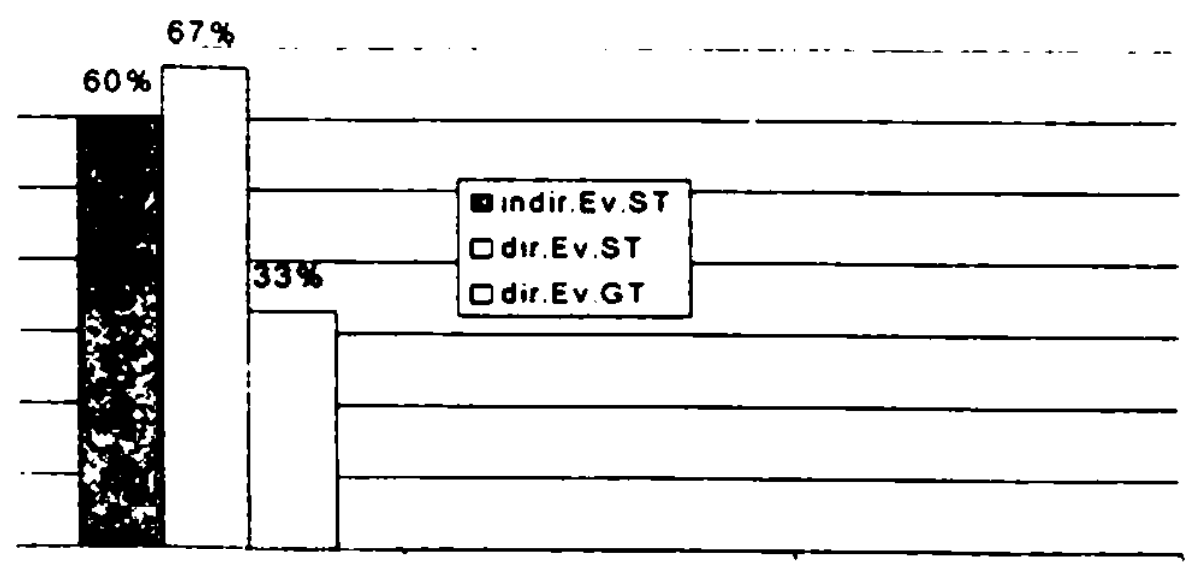




\section{Studentinnen/Studenten}

10 Studentinnen, Geisteswissenschaften ${ }^{126}$

Sprachverhalten:

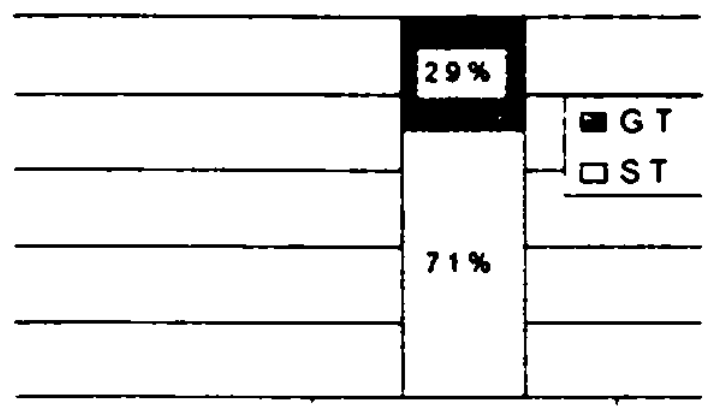

form ell $(10)$
Einstellung, konatives Subsystem:

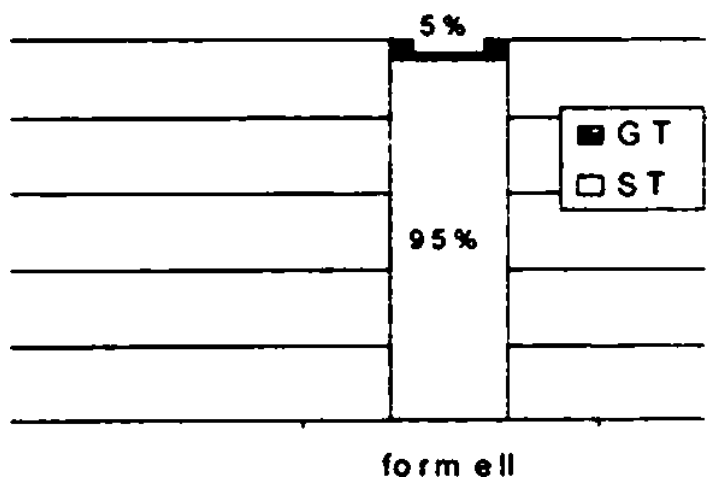

Evaluation der eigenen Kognition:

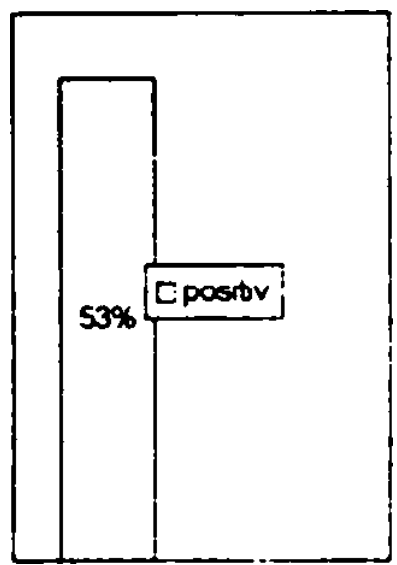

Einstellung, kognitives Subsystem:

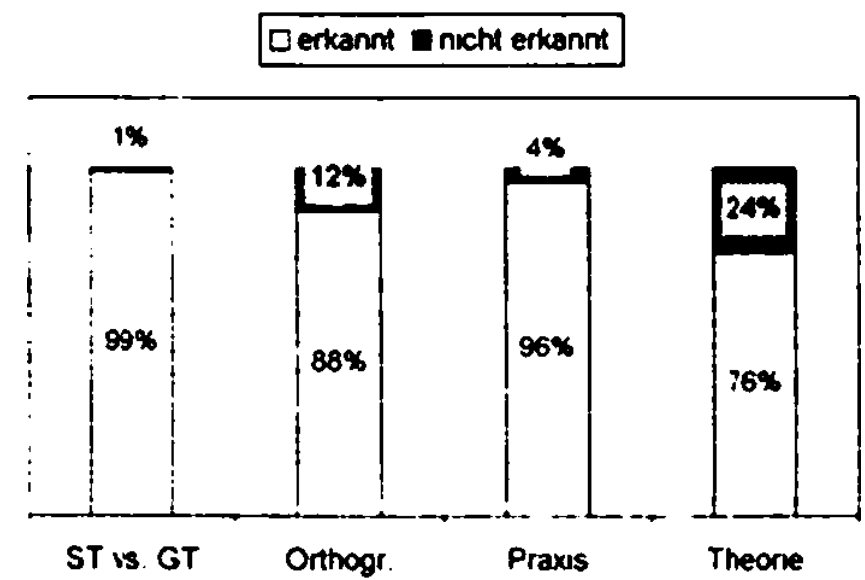

Einstellung, affektives Subsystem: Grad der positiven Einstellung

10\%

126 Diese Gruppe setzt sich zusammen aus 5 Studentinnen der Philosophischen Fakultaı in Prag. Fachriclitung Bolsemistik und S Studentinnen der Padagogısclien Fakultă in Prag. Fachrichtung Bohemegussijk 
5 Studenten, Geisteswissenschaften ${ }^{127}$

Sprachverhalten:

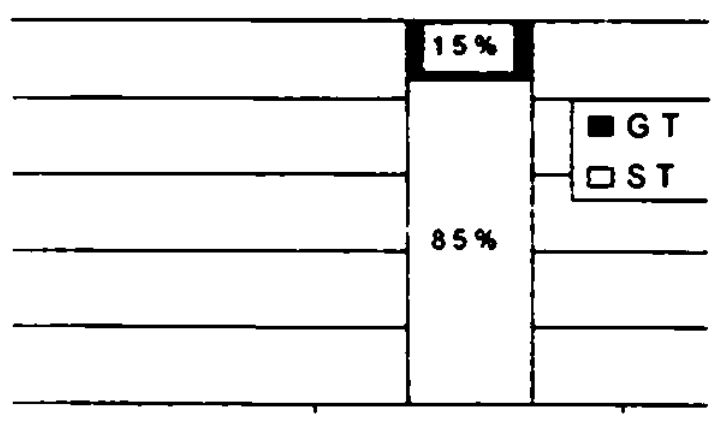

form ell (5)
Einstellung konatives Subsystem:

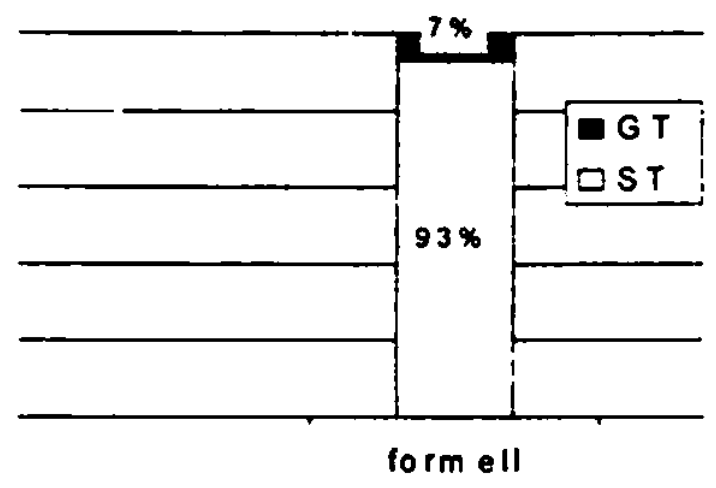

Evaluation der eigenen Kognition:
Einstellung kognitives Subsystem:

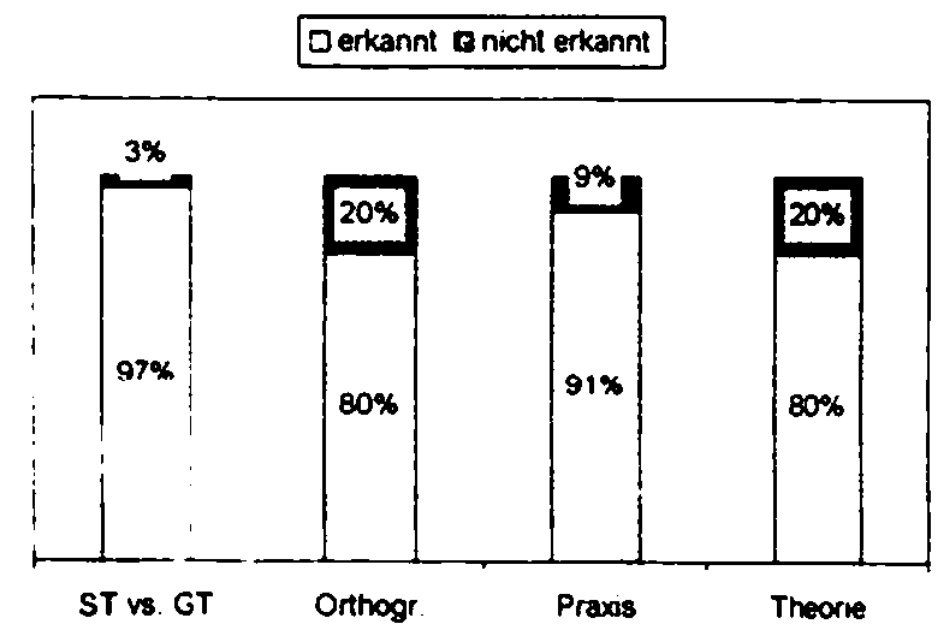

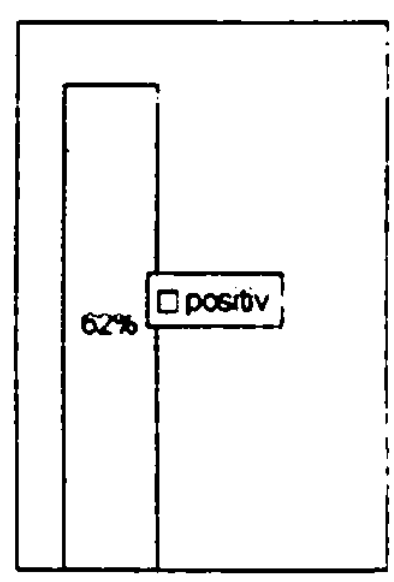

Einstellung, affektives Subsystem: Grad der positiven Einstellung

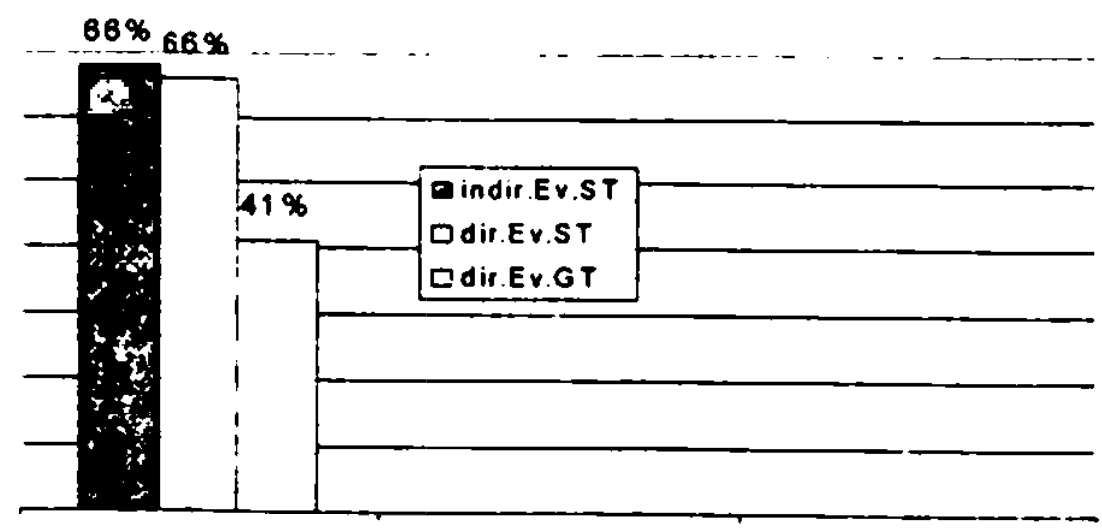

127 Diese Gruppe setzt sich zusammen aus 2 Studenten der Philosophischen Fakultăt in Prag. Fachirichtung Bolıemistik und 3 Studenten der Padagogischen Fakultăt in Prag. Fachrichtıng Bolicnistik. 


\subsubsection{Zweite Working-up-Ebene: Westböhmen}

Durchschnitt aller Frauen außer Studentinnen, insg. 21 Respondentinnen ${ }^{128}$

Sprachverhalten:

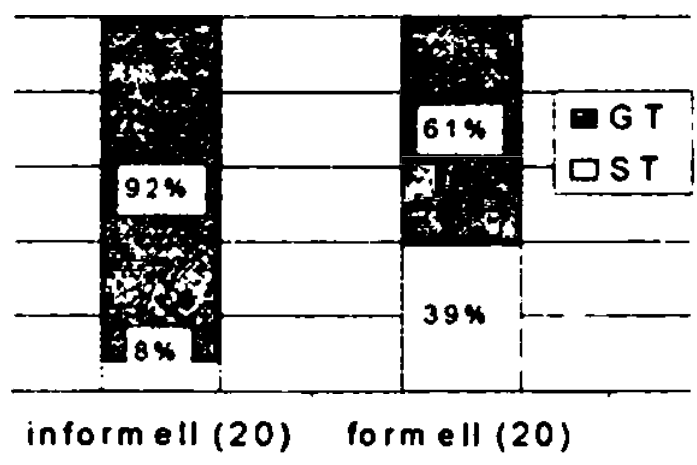

Einstellung, kognitives Subsystem:

Derkannt a nicht erkannt

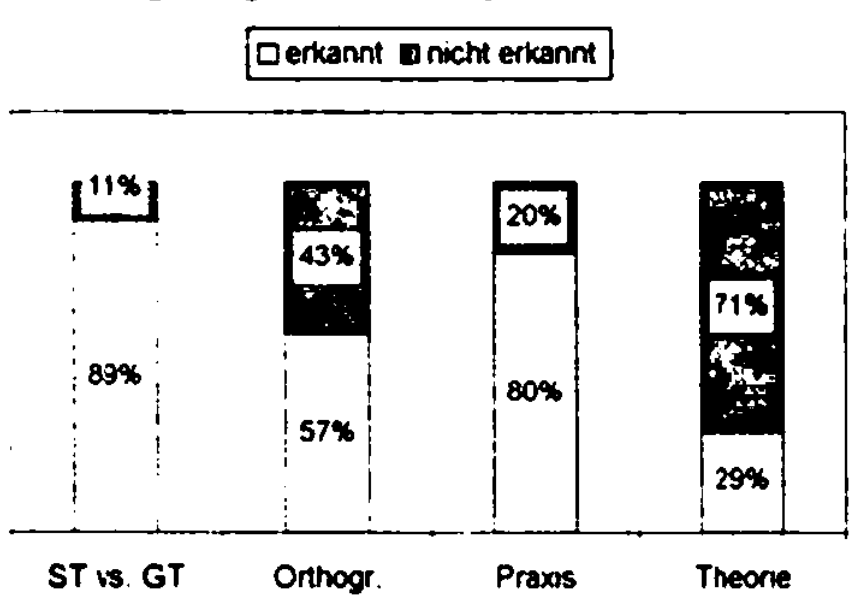

Einstellung konatives Subsystem:

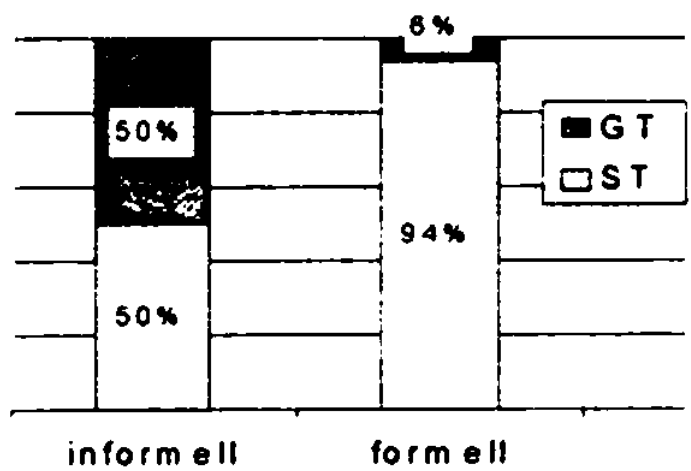

Evaluation der eigenen Kognition:

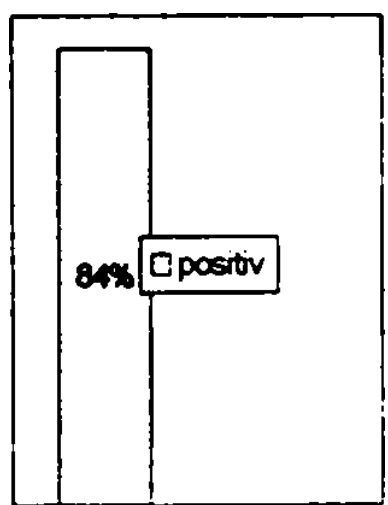

Einstellung, affektives Subsystem: Grad der positiven Einstellung

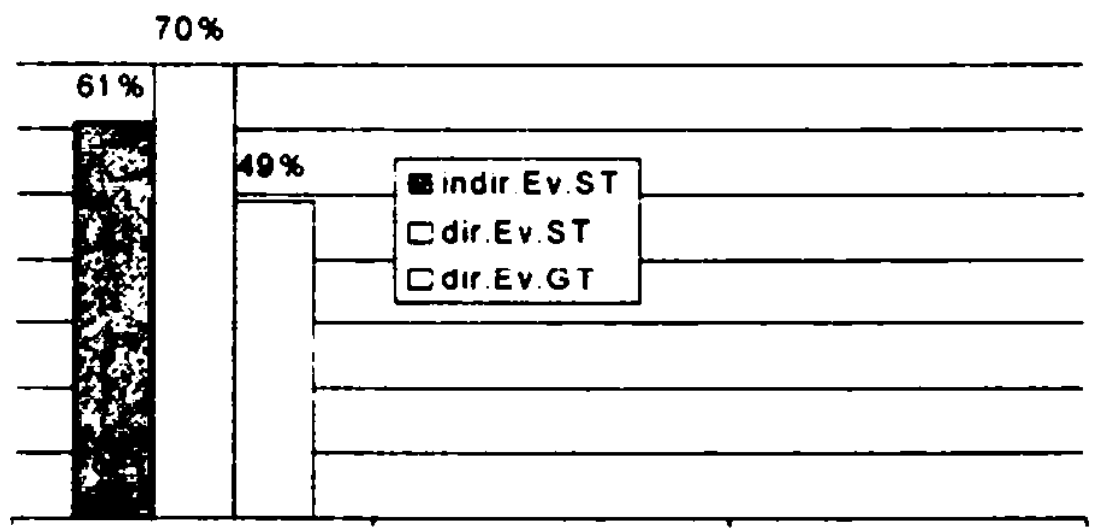

128 Auch auf der zweiten und dritıen Working-up-Ebene wird sorgfâltig darauf geaclitet. daß die tatsăcliliclie Relation der einzelnen Sprechergnuppen bei der Bildung der generalisienen (gebündelien) Respondentengruppen. z.B. der Anteil der Frauen init und ohne Abitur, nicht verzern wird. Aus diesem Grunde gingen wir auch hier jeweils von den Basiswerten aus. d.i. von den Werten jedes einzelnen Respondenten (siche Beispicl S. 237) 
Durchschnitt aller Männer außer Studenten, insg. 25 Respondenten

Sprachverhalten:

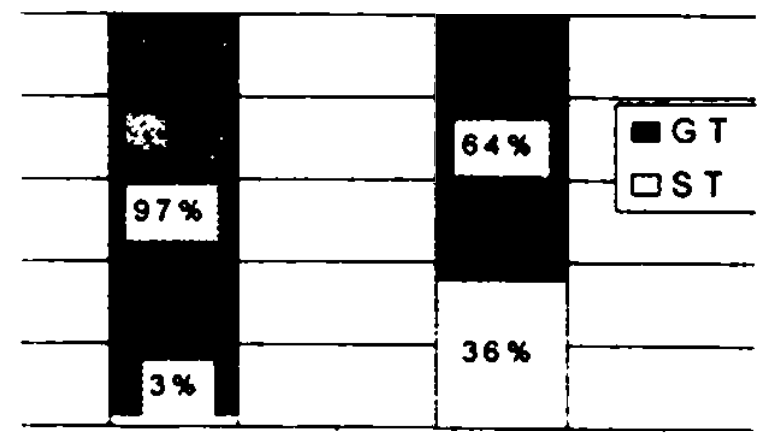

inform ell (16)

Einstellung, konatives Subsystem:

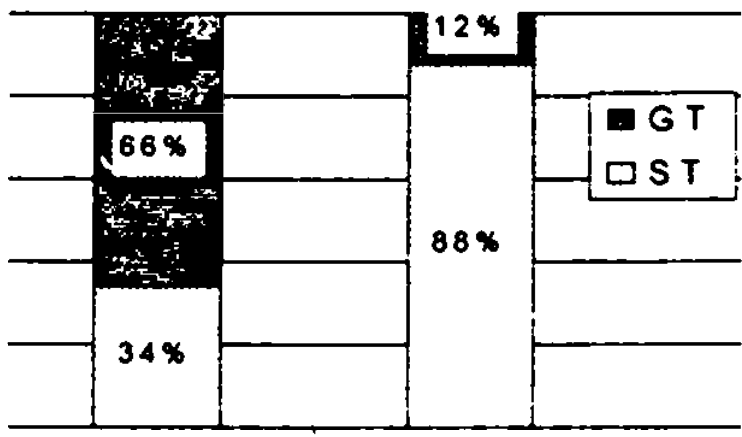

in form ell

form oll

Evaluation der eigenen Kognition:

Einstellung, kognitives Subsystem:

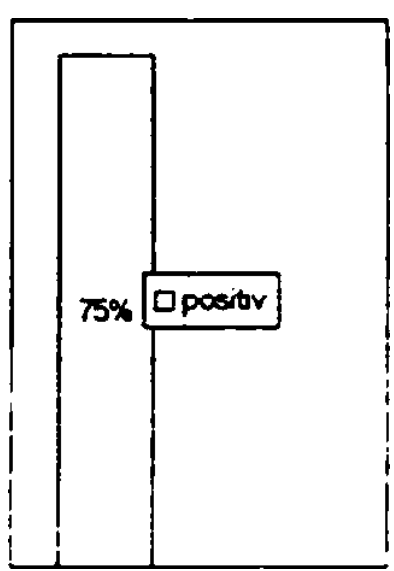

Einstellung, affektives Subsystem: Grad der positiven Einstellung

$63 \%$

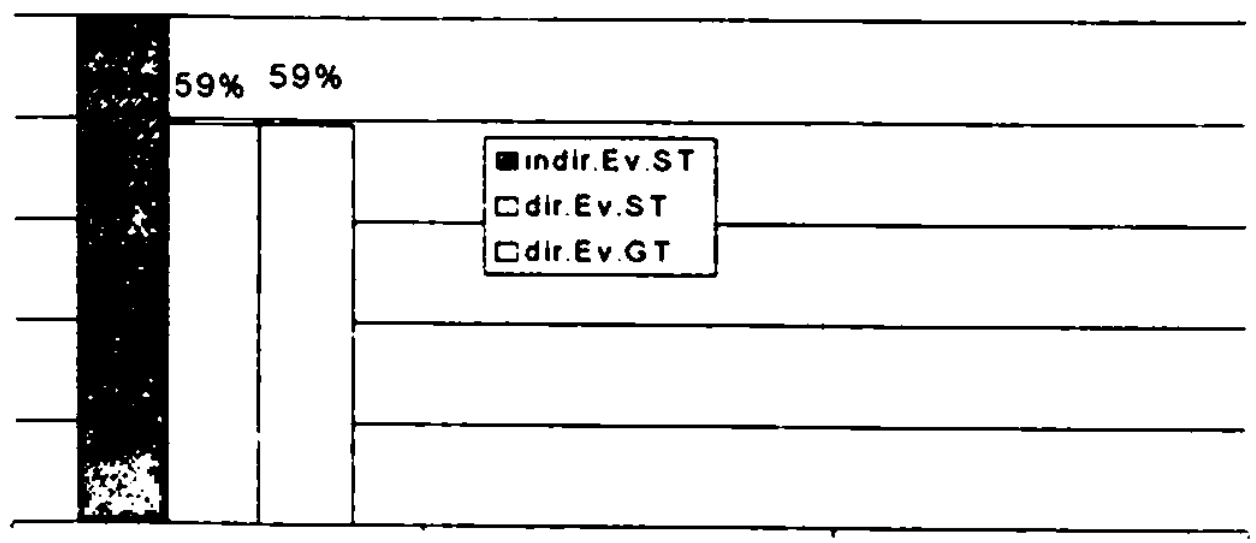


Durchschnitt aller Respondenten (Frauen. Männer) ohne Abitur, insg. 15 Respondenten

Sprachverhalten:

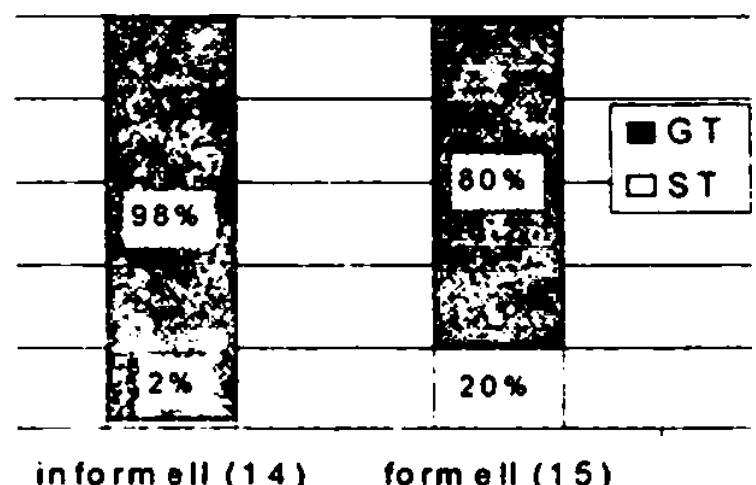

Einstellung, kognitives Subsystem:

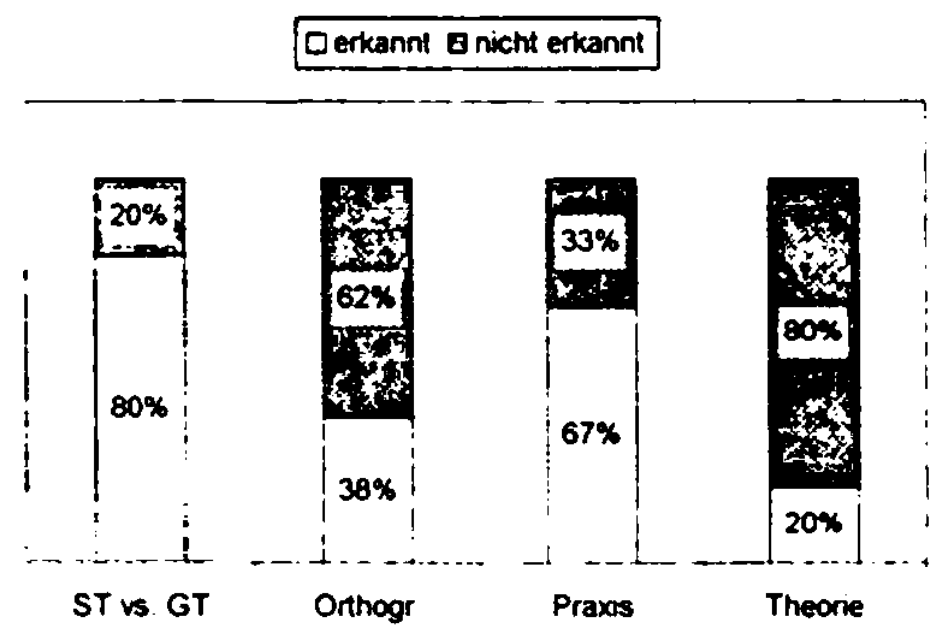

Einstellung konatives Subsystem:

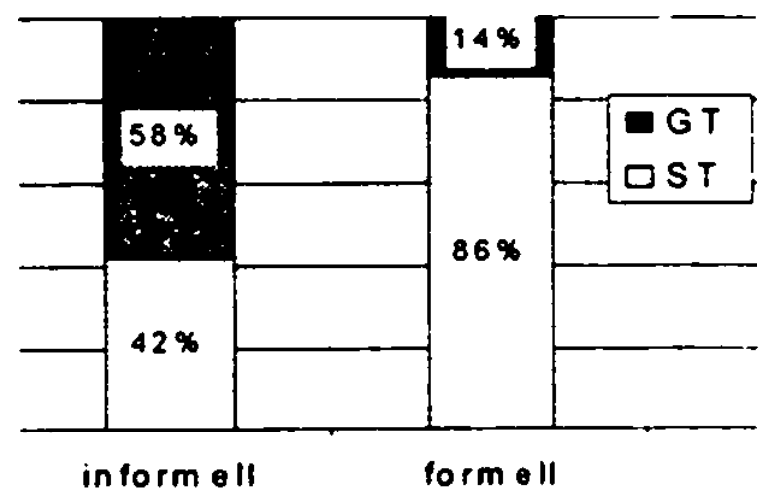

Evaluation der eigenen Kognition.

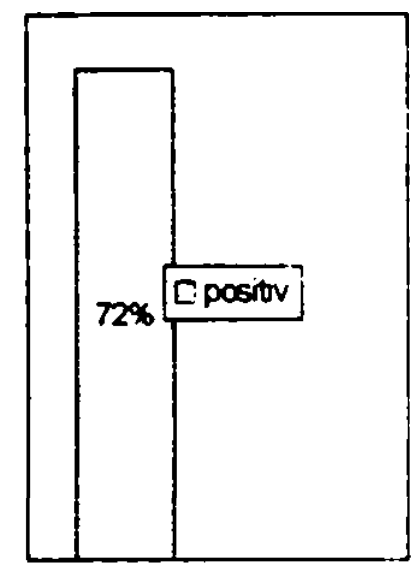

Einstellung, affektives Subsystem: Grad der positiven Einstellung 
Durchschnitt aller Respondenten (Frauen, Männer) mit Abitur, insg. 17 Respondenten

Sprachverhalten:

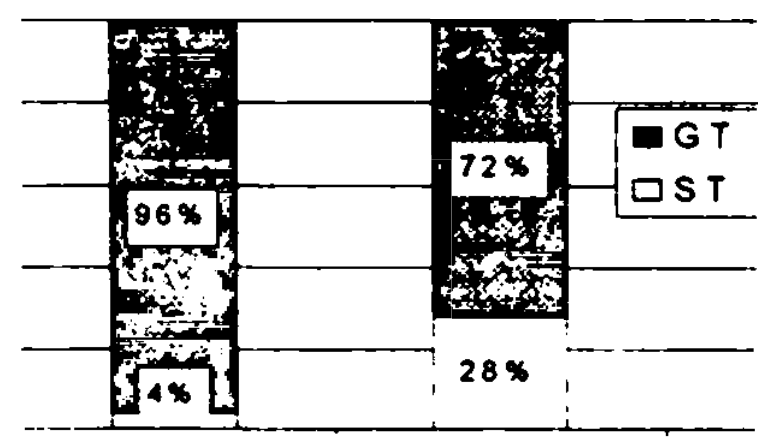

in formell (12) formell (16)

Einstellung, kognitives Subsystem:

Gerkannt D nicht erkanmt

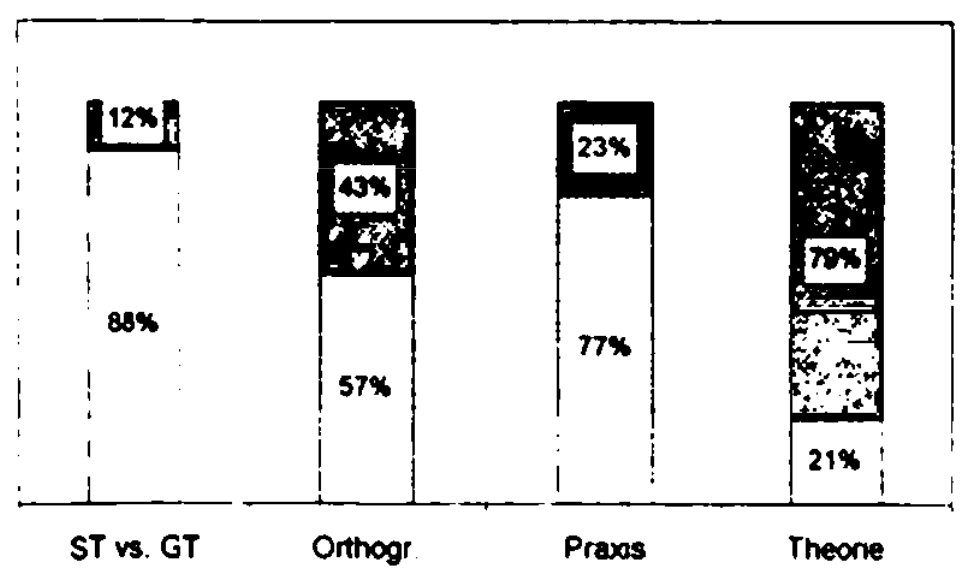

Einstellung, affektives Subsystem: Grad der positiven Einstellung

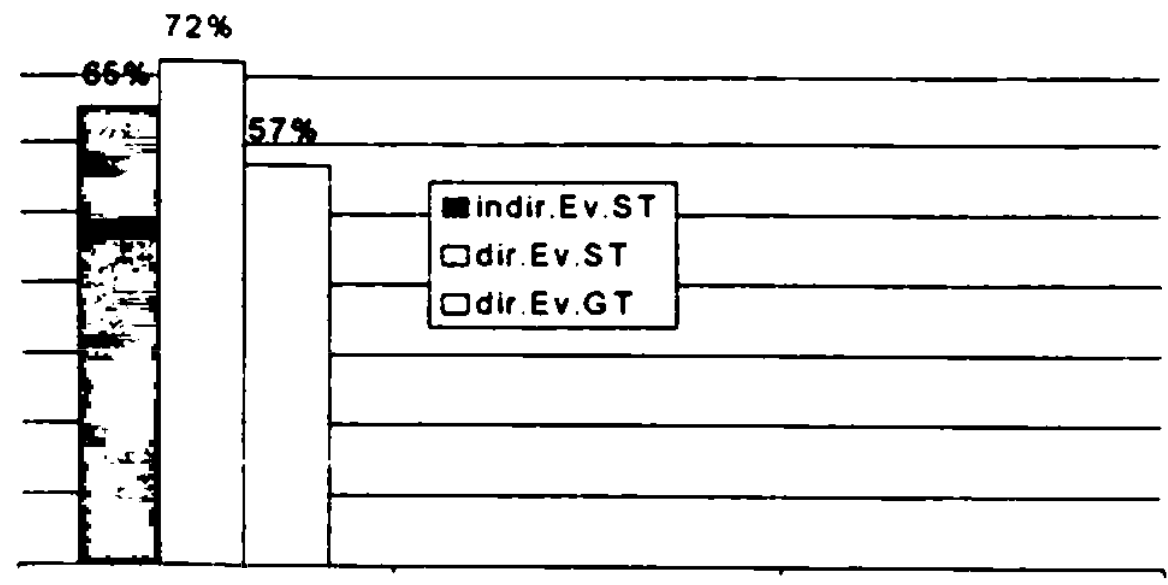

Einstellung, konatives Subsystem:

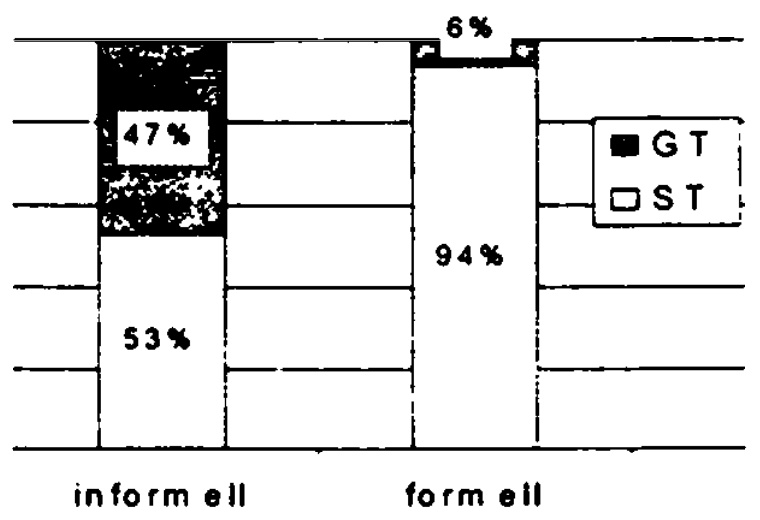

Evaluation der eigenen Kognition:

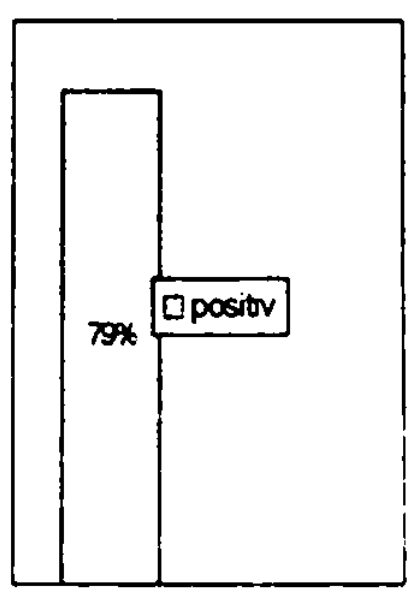


Durchschnitt aller Respondenten (Frauen, Männer) mit Hochschulabschluß (ohne Studenten), insg. 14 Respondenten

Sprachverhalten:

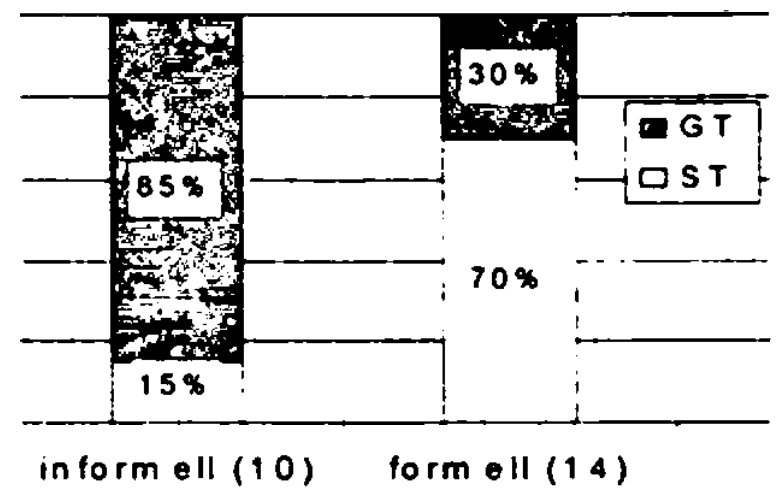

Einstellung, kognitives Subsystem:

Qerkannt Enicht erkannt

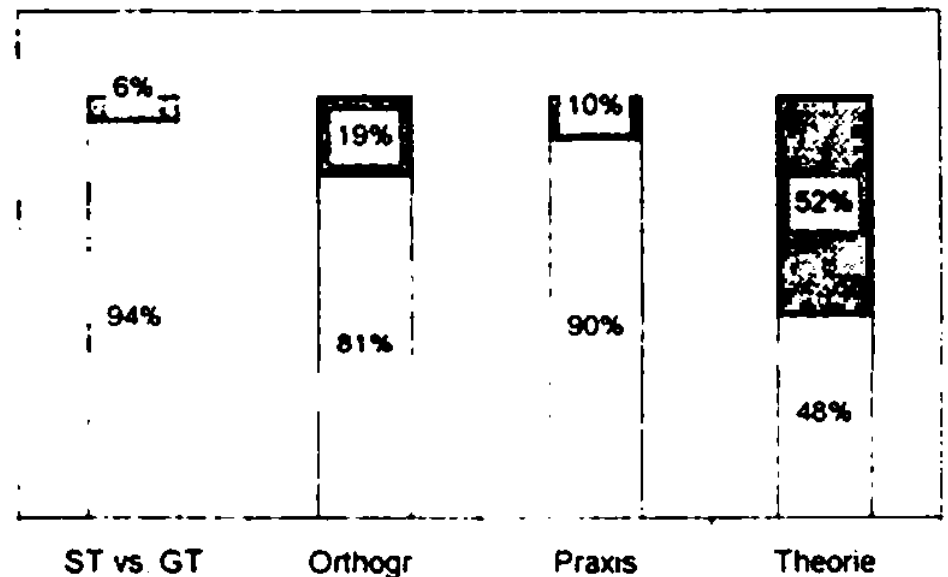

Einstellung, affektives Subsystem. Grad der positiven Einstellung

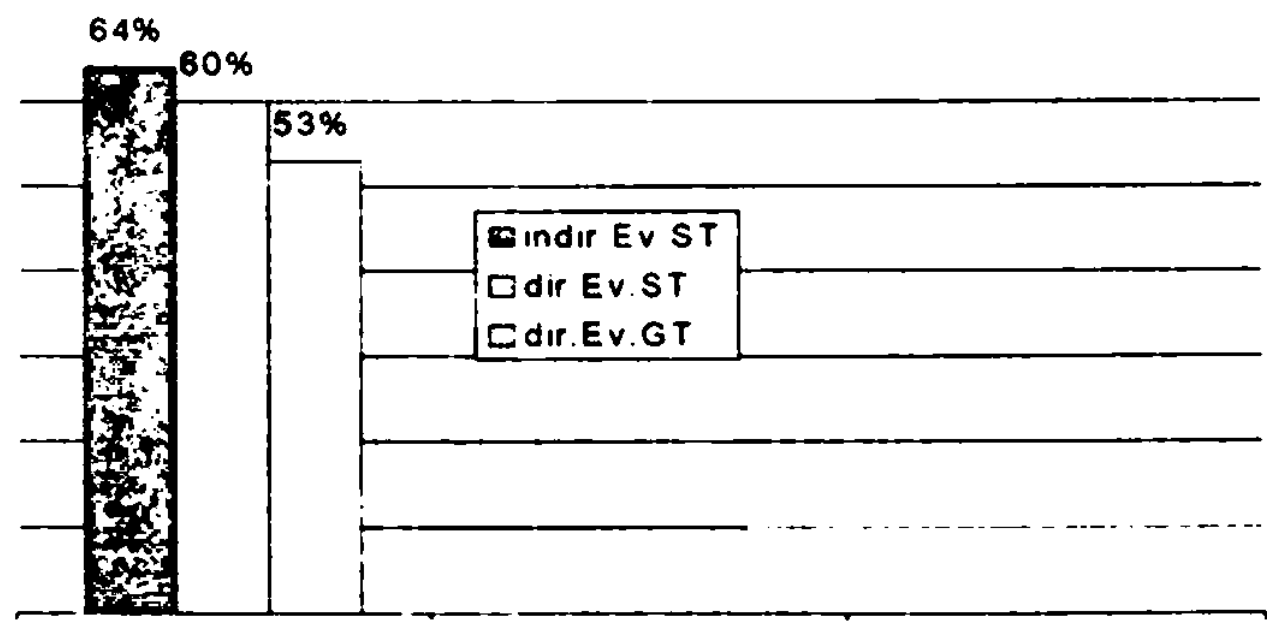

Evaluation der eigenen Kognition:

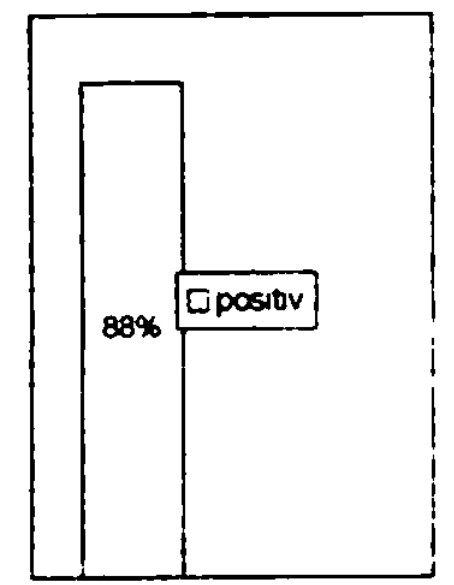


Durchschnitt aller Respondenten (Frauen, Männer) außer Studierende, insg. 46 Respondenten

Sprachverhalten:

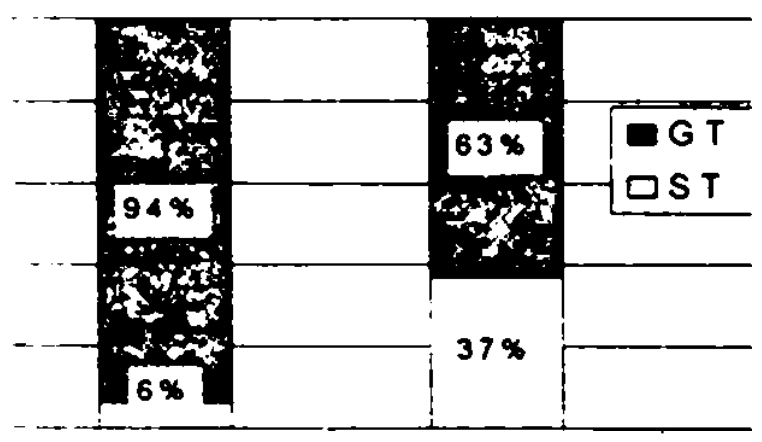

informell (36) formell (45)

Einstellung, kognitives Subsystem:

Derkannt B nicht erkannt

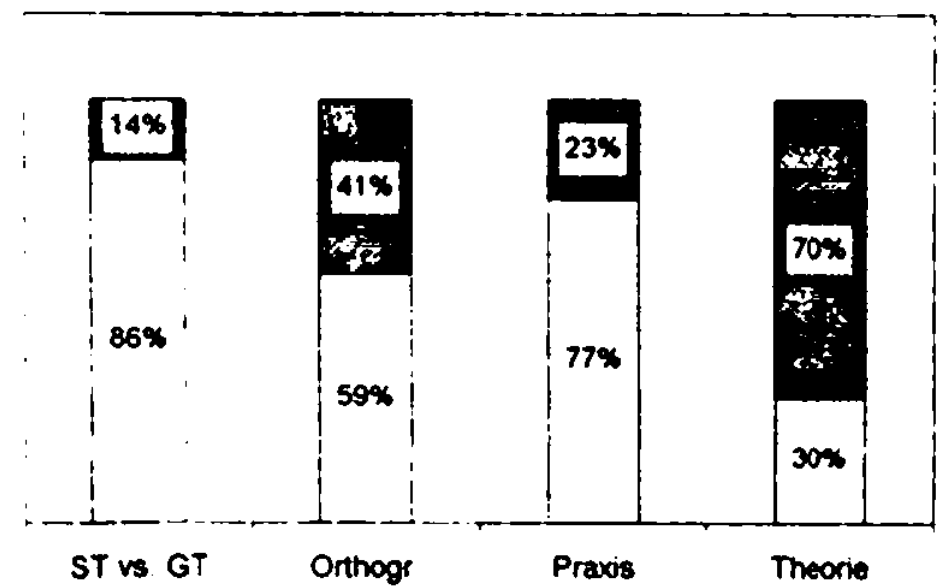

Einstellung, konatives Subsystem:

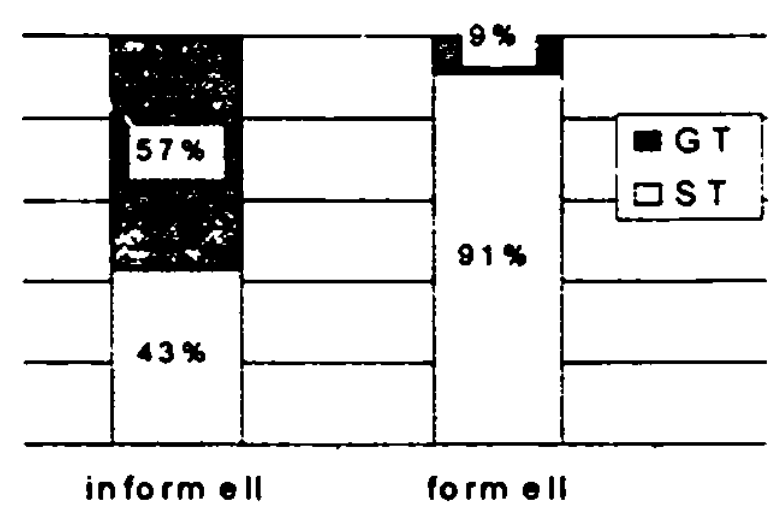

Evaluation der eigenen Kognition:

Einstellung, affektives Subsystem: Grad der positiven Einstellung

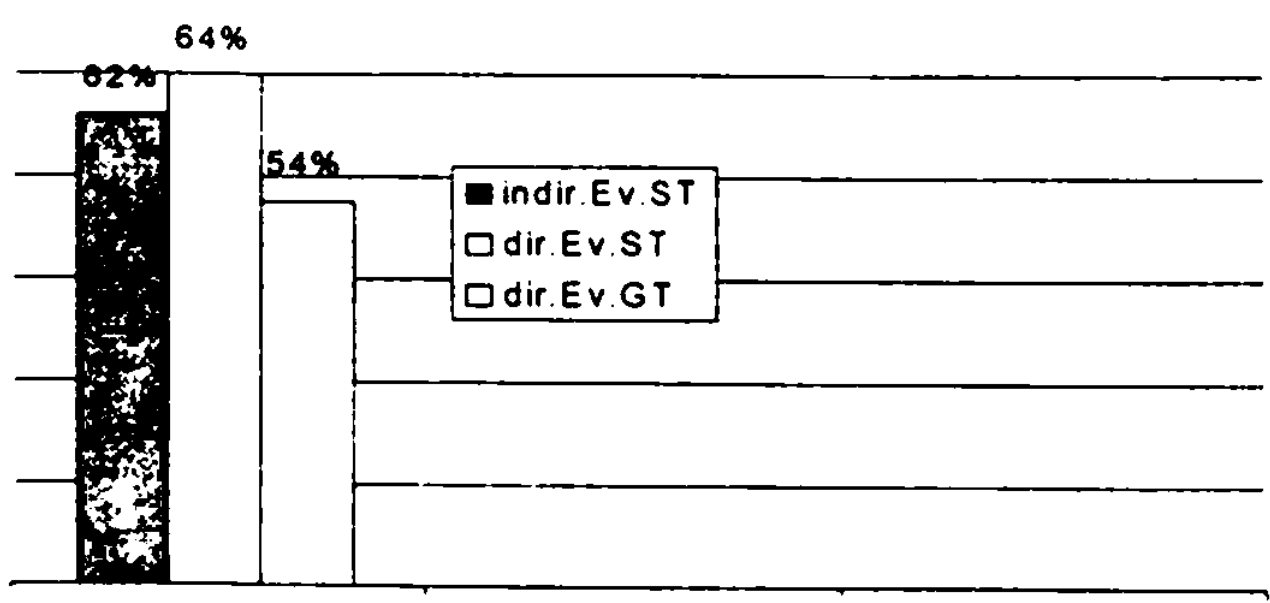


Durchschnitt aller Studierenden der Geisteswissenschaften (männlich, weiblich) ${ }^{129}$, insg. 10 Respondenten

Sprachverhalten:

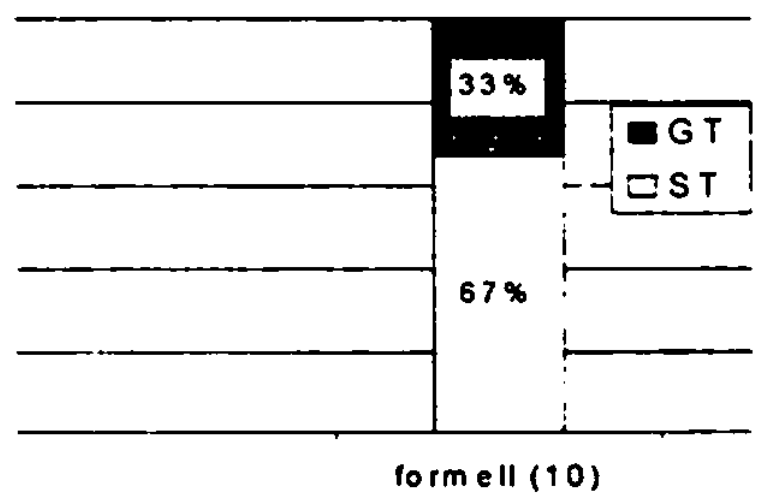

Einstellung kognitives Subsystem:

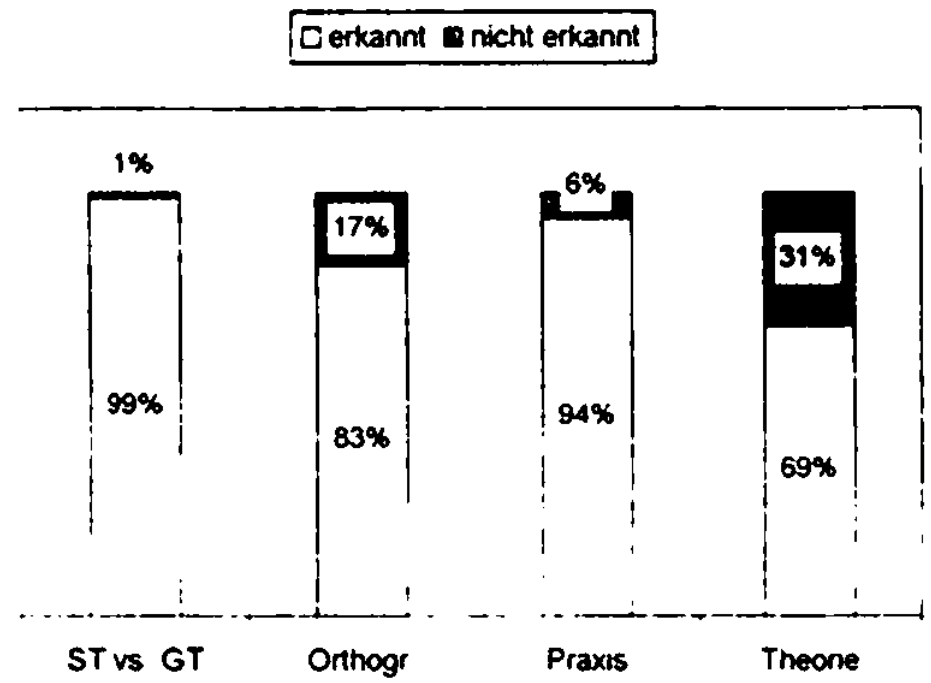

Einstellung, konatives Subsystem:

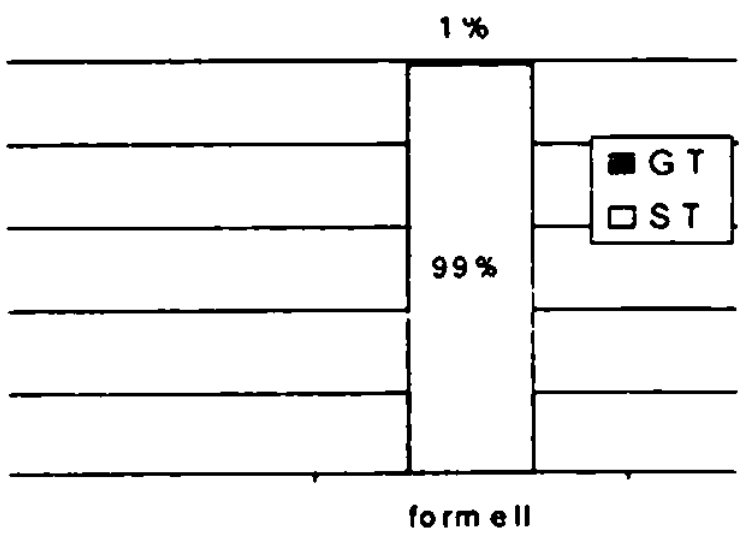

Evaluation der eigenen Kognition:

Einstellung, affektives Subsystem: Grad der positiven Einstellung

63\%




\section{1. + Zweite Working-up-Ebene: Prag}

Durchschnitt aller Frauen außer Studentinnen ${ }^{130}$, insg. 11 Respondentinnen

Sprachverhalten:

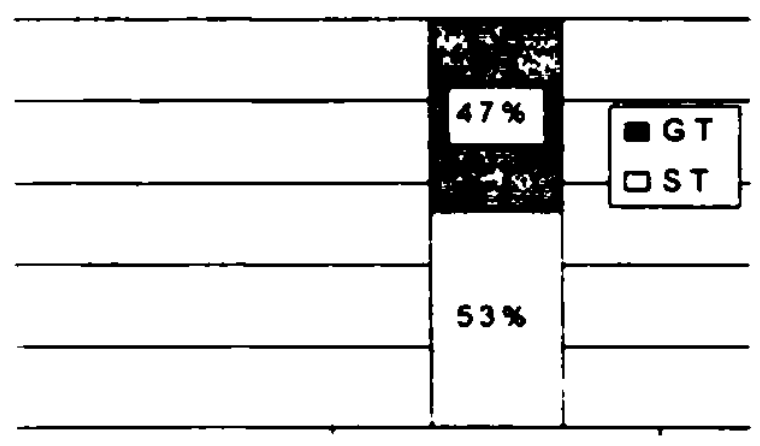

form ell (10)

Einstellung kognitives Subsystem:

Qerkannt a nicht erkannt

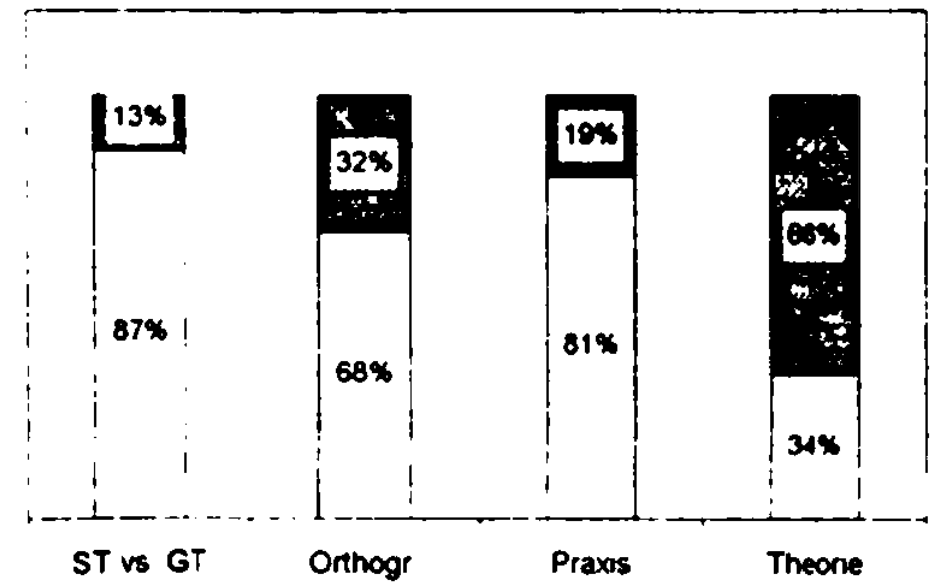

Einstellung, affektives Subsystem: Grad der positiven Einstellung

(18\%

130 Die cinzige Frau. die in Prag in der informellen Situation aufgenommen wurde. wird hier nicht berücksichtigt. 
Durchschnitt aller Männer außer Studenten, insg. 13 Respondenten

Sprachverhalten:

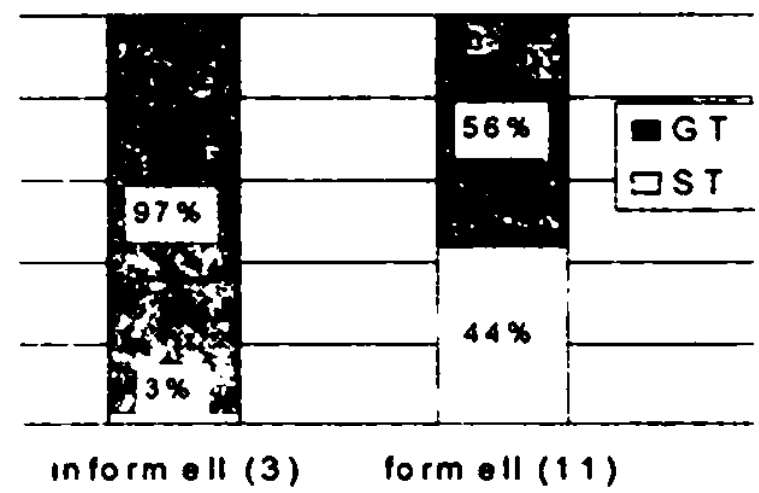

Einsteliung, kognitives Subsystem:

Derkannt E nicht erkannt

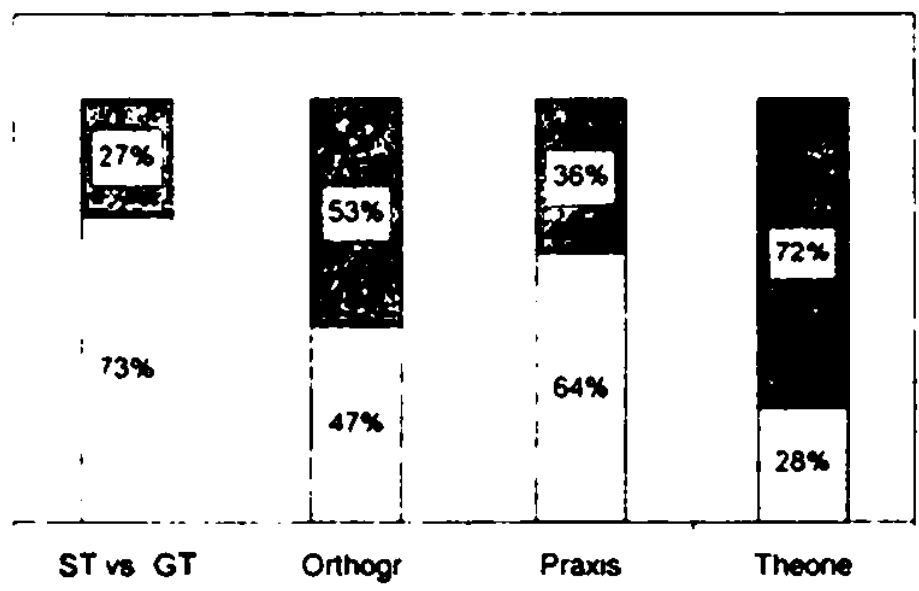

Einstellung, konatives Subsystem:

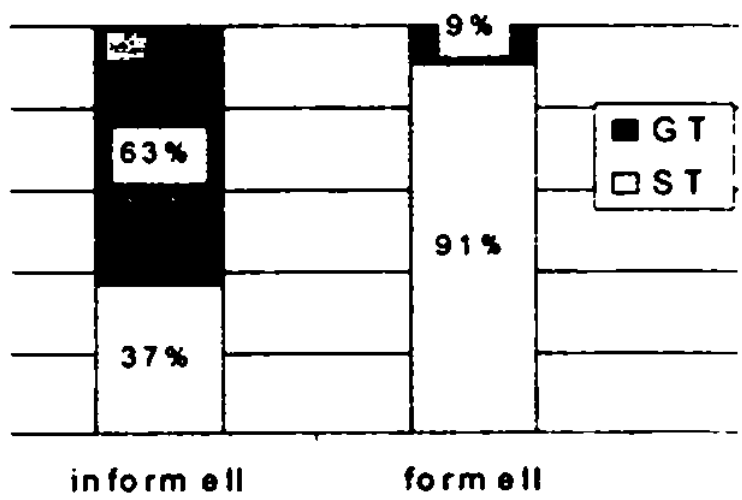

Evaluation der eigenen Kognition.

Einstellung, affektives Subsystem: Grad der positiven Einstellung

| Eindir.Ev.ST


Durchschnitt aller Respondenten (Frauen, Männer) ohne Abitur, insg. 10 Respondenten

Sprachverhalten:

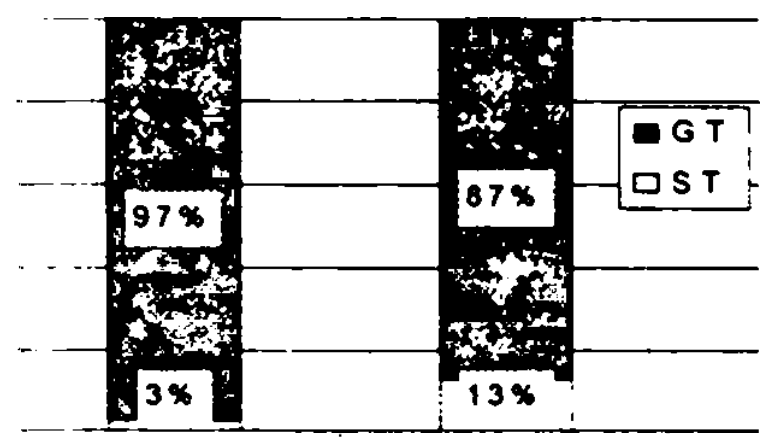

inform ell (3) form ell (7)
Einstellung, konatives Subsystem:

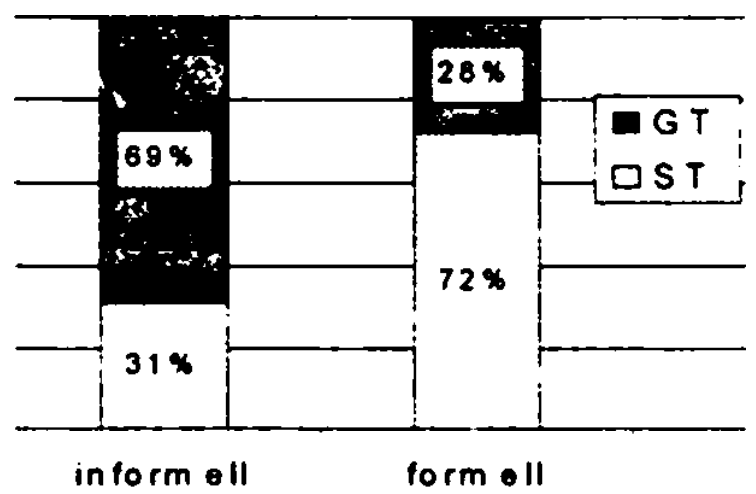

Evaluation der eigenen Kognition:

Einstellung kognitives Subsystem:

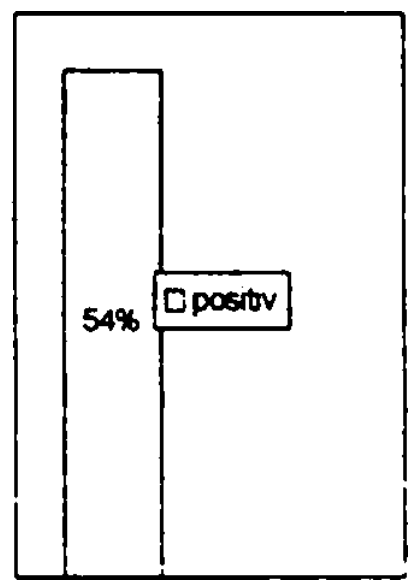

Einstellung, affektives Subsystem: Grad der positiven Einstellung

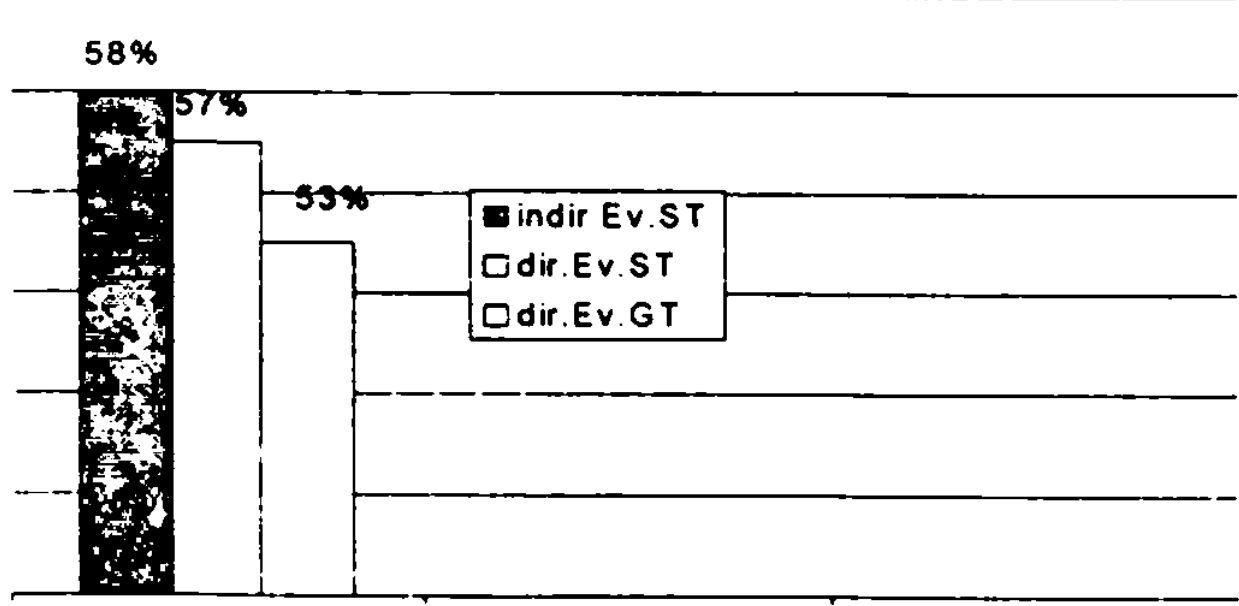


Durchschnitt aller Respondenten (Frauen, Männer) mit Abitur, insg. 10 Respondenten

Sprachverhalten: ${ }^{13 !}$

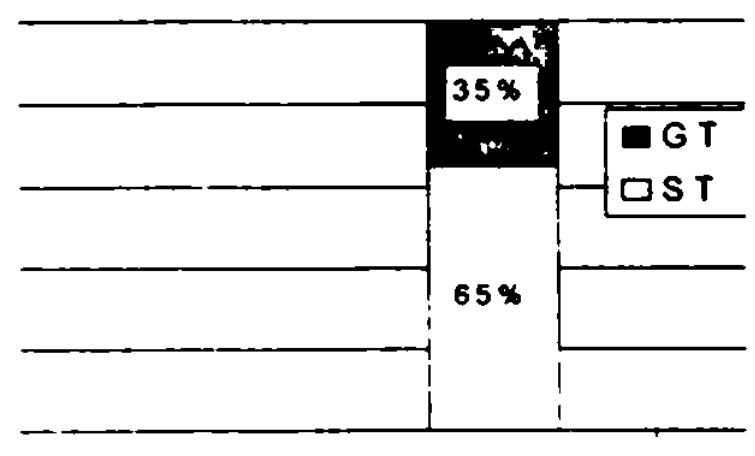

form oll $(10)$
Einstellung, konatives Subsystem:

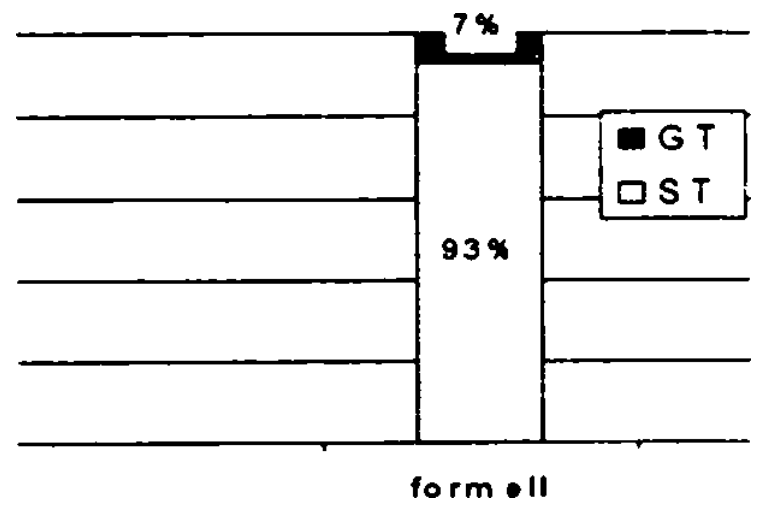

Evaluation der eigenen Kognition:
Einstellung, kognitives Subsystem:

Derkannt E nicht erkannt
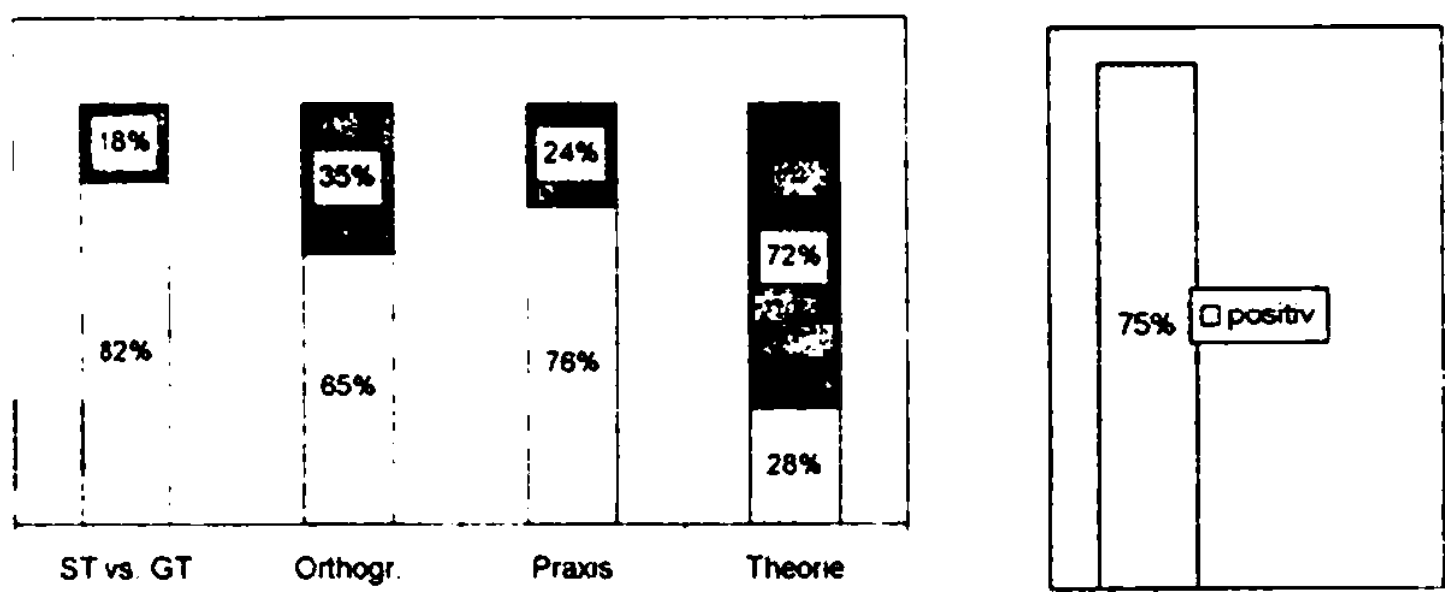

Einstellung, affektives Subsystem: Grad der positiven Einstellung

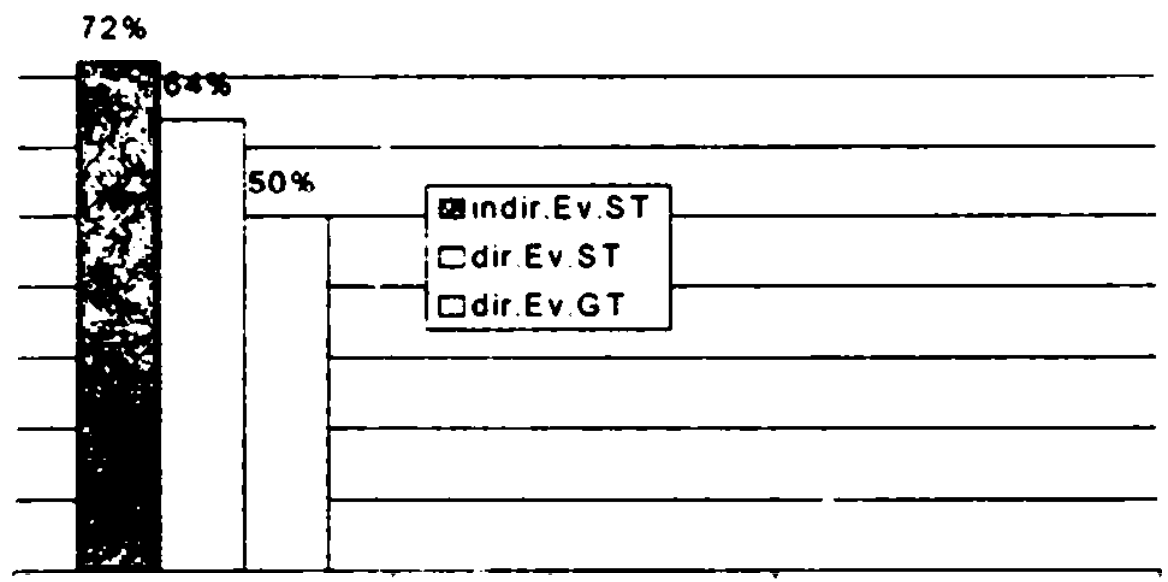

131 Der cinzige Spreclier mit Abıtur, der in der inforınellen Situation aufgenoinınen wurde. bleıbl in der graphisclien Darstellung unbcrücksichligt. 
Durchschnitt aller Respondenten (Frauen, Männer) mit Hochschulabschluß (ohne Studenten), insg. 4 Respondenten

Sprachverhalten:

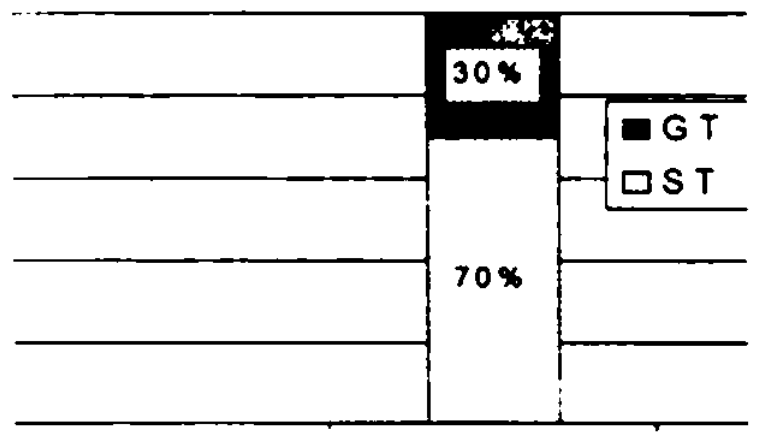

form ell (4)
Einstellung, konatives Subsystem:

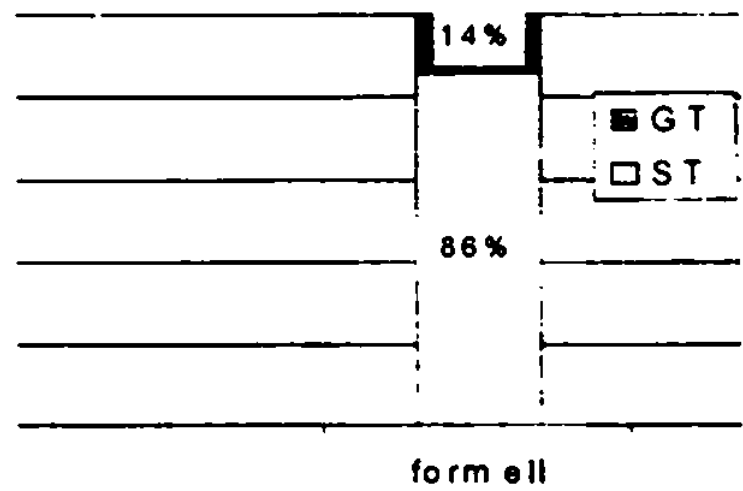

Evaluation der eigenen Kognition
Einstellung, kognitives Subsystem:

\section{Derkannt a nicht erkanmt}

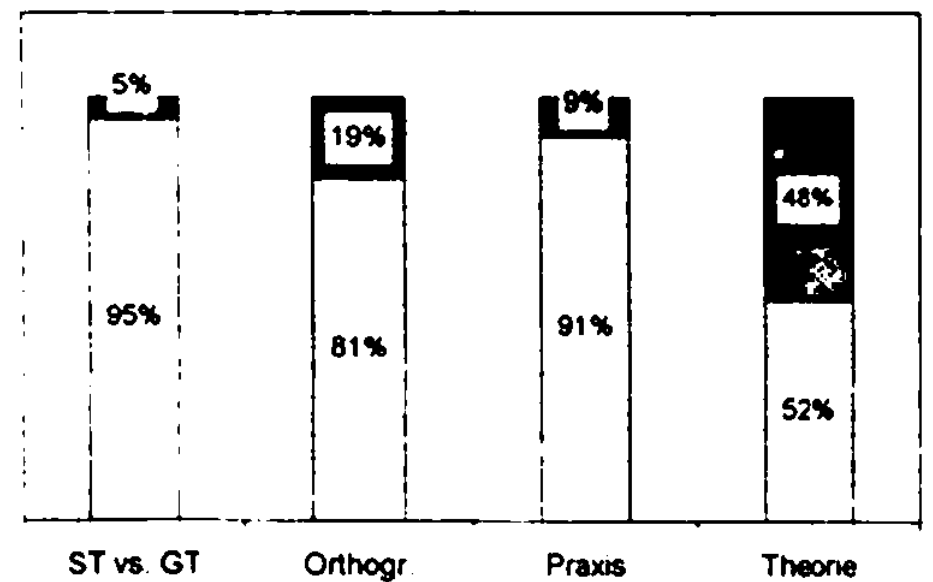

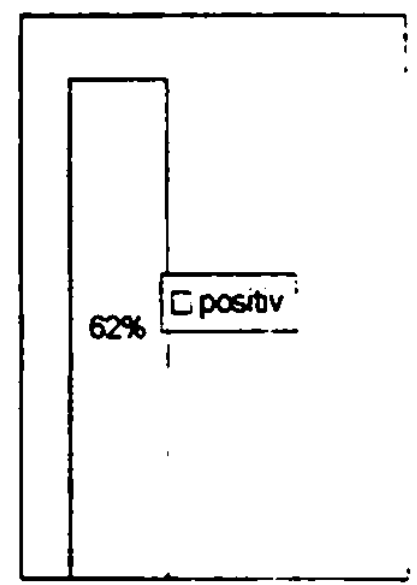

Einstellung, affektives Subsystem: Grad der positiven Einstellung

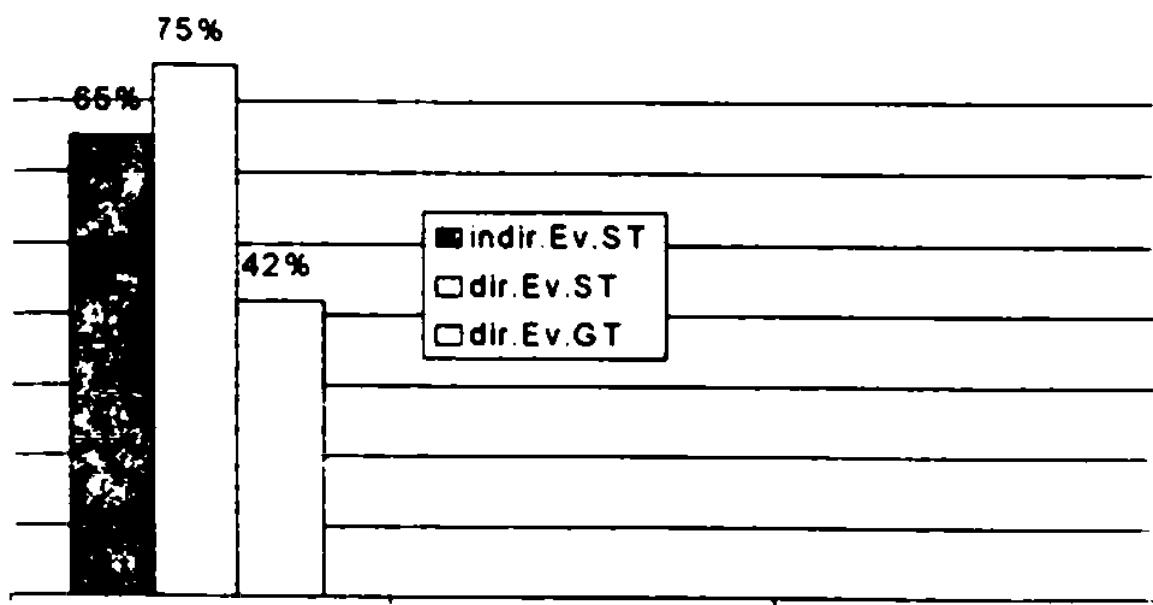


Durchschnitt aller Respondenten (Frauen, Männer) außer Studierende, insg. 24 Respondenten ${ }^{132}$

Sprachverhalten:

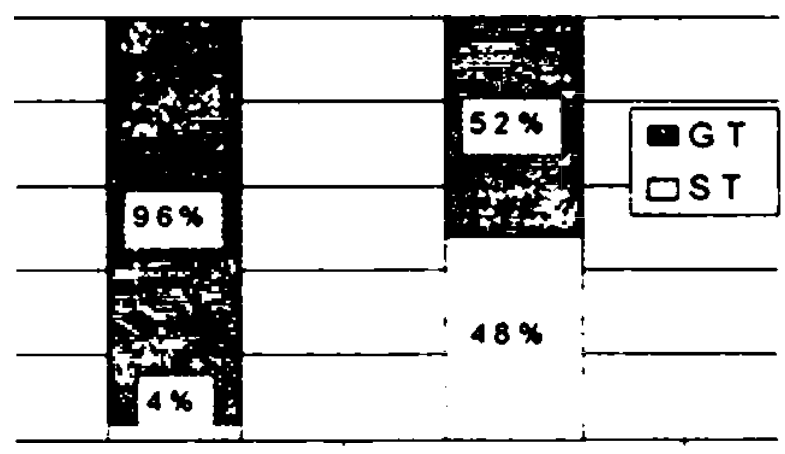

inform ell (4) form ell (21)

Einstellung, kognitives Subsystem:

Derkannt Enicht erkannt
Einstellung, konatives Subsystem:

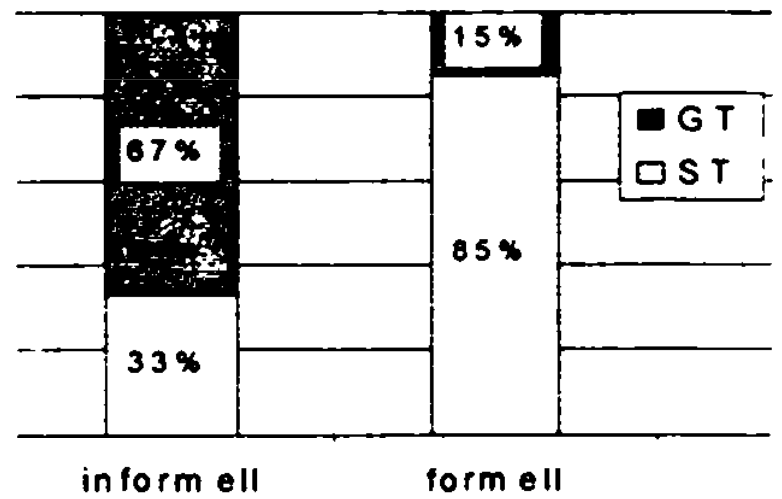

Evaluation der eigenen Kognition:

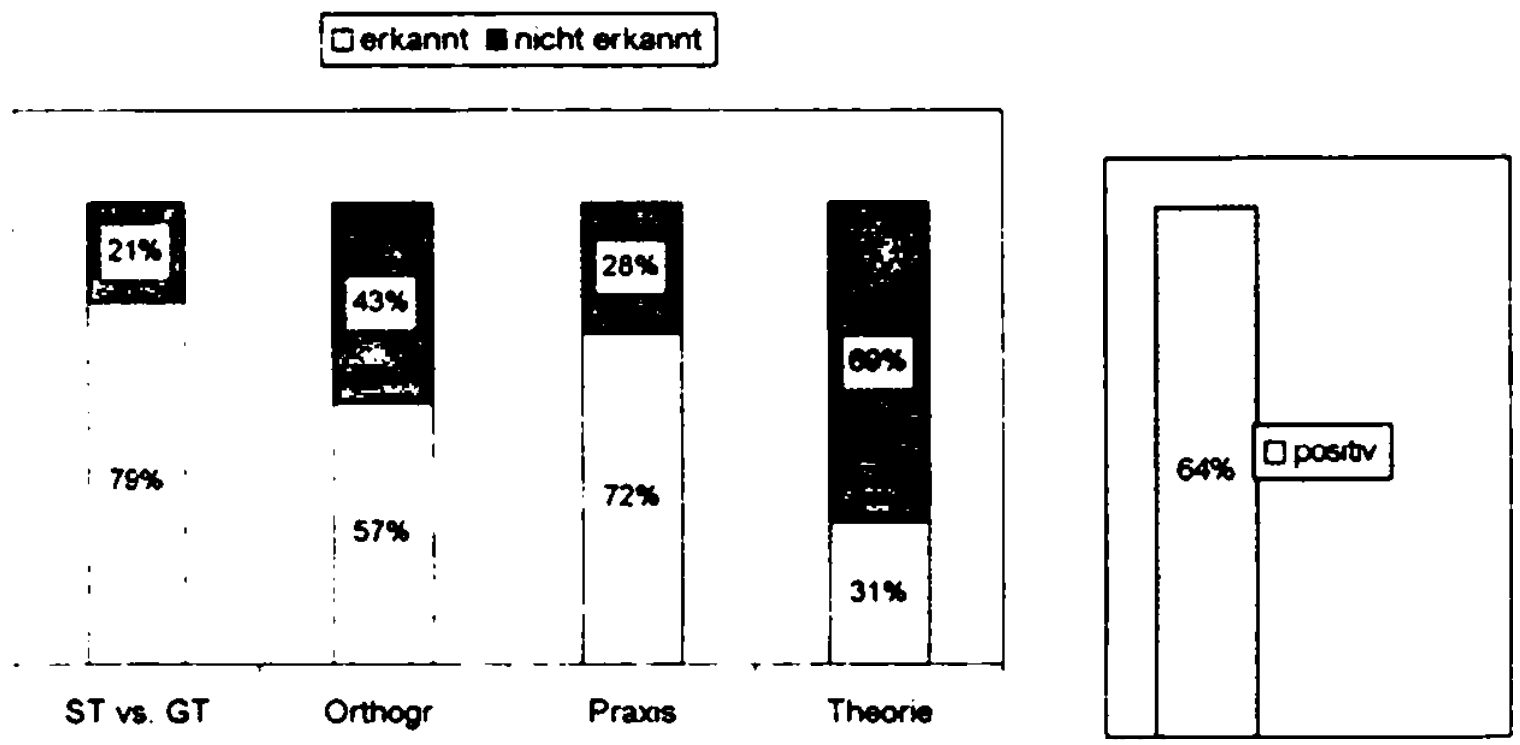

Einstellung, affektives Subsystem: Grad der positiven Einstellung

| 10

132 An dieser Stelle ist anzumerken. daß die + Respondenten aus Prag. die in der informellen Situation aufgenoınınen wurden. der Kategorie Sprecher mit niedrigerem Bıldungsnivcau angelioren (3 ohne Abitur. I mit Abitur). 
Durchschnitt aller Studierenden (männlich, weiblich), insg. 15 Respondenten

Sprachverhalten

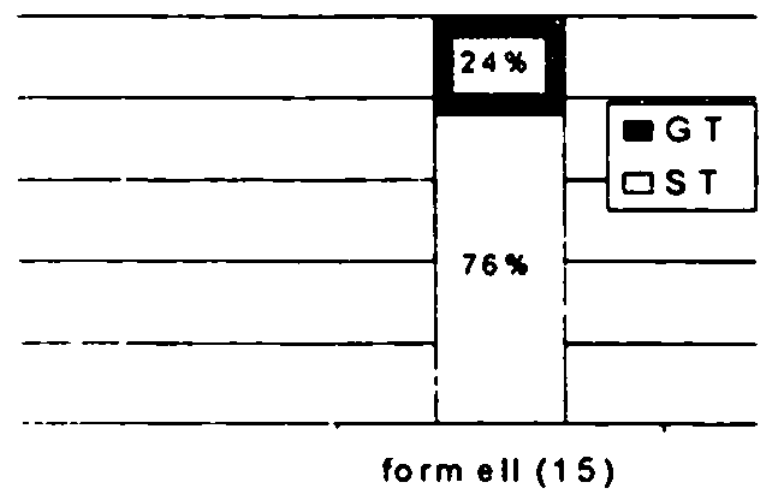

Einstellung, kognitives Subsystem:

Derkannt I nicht erkannt

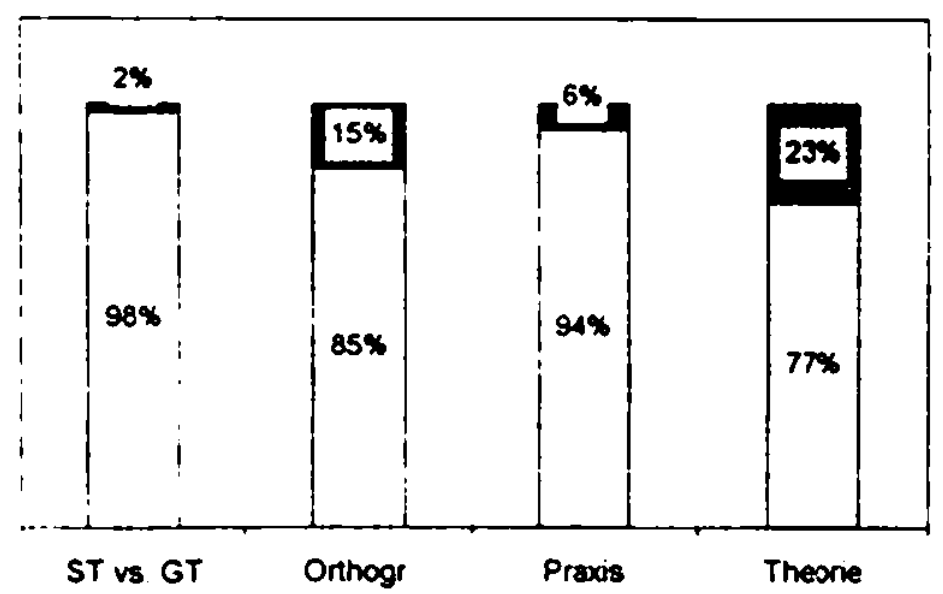

Einstellung, konatives Subsystem:

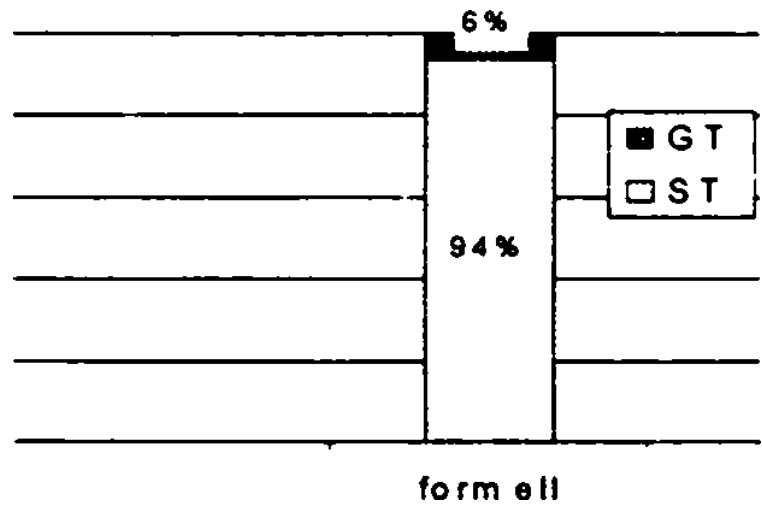

Evaluation der eigenen Kognition:

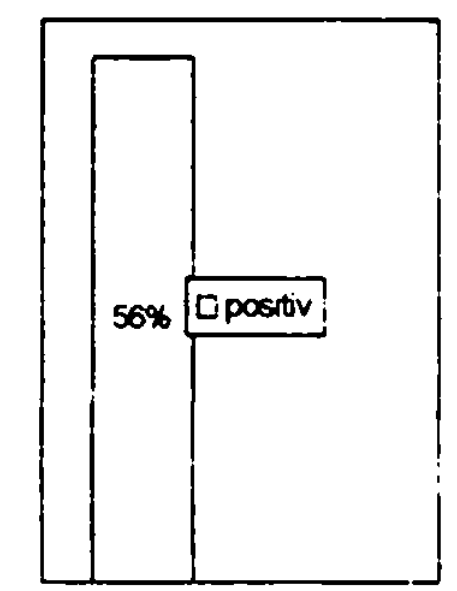

Einstellung, affektives Subsystem: Grad der positiven Einstellung

\begin{tabular}{c|c|}
\hline \\
\cline { 2 - 3 }
\end{tabular}




\subsubsection{Dritte Working-up-Ebene: Westböhmen. Prag}

Durchschnitt aller Frauen außer Studentinnen, insg. 32 Respondentinnen ${ }^{133}$

Sprachverhalten:

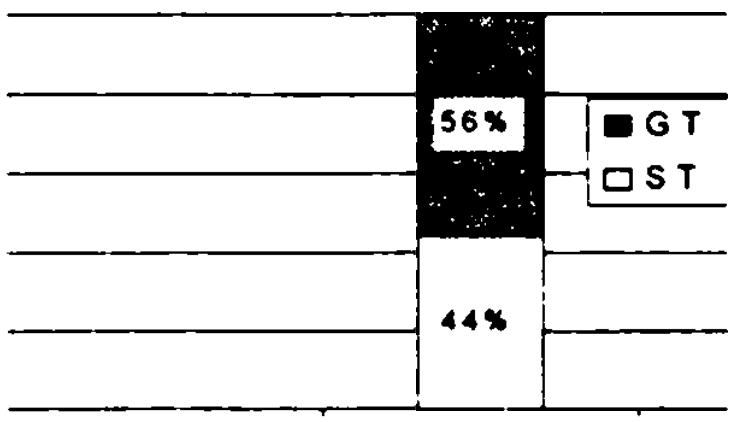

form ell $(30)$

Einstellung, kognitives Subsystem:

\section{Q erkant a nicht erkant}

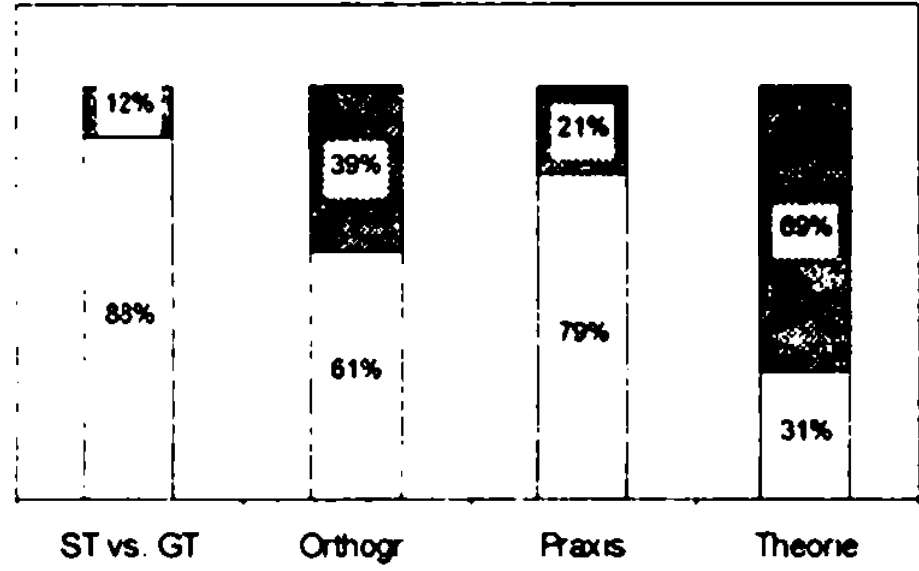

Einstellung, konatives Subsystem:

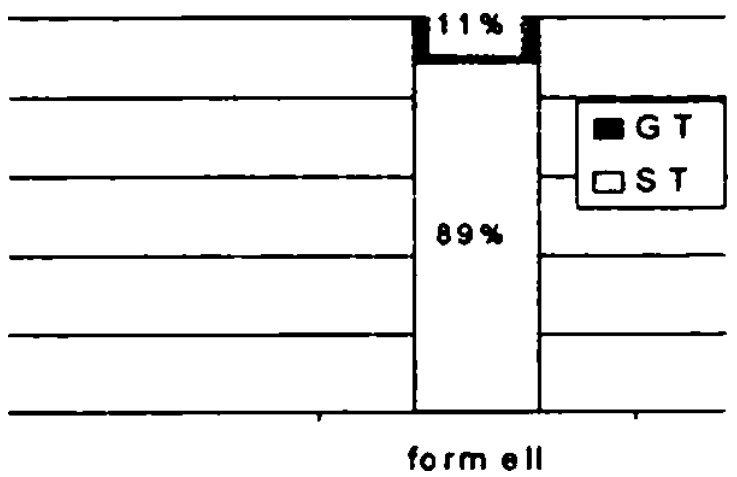

Evaluation der eigenen Kognition:

Einstellung, affektives Subsystem: Grad der positiven Einstellung

10

${ }^{133}$ Da wir in Prag nur cine cinzige Frau in der informellen Situation aufnalumen. ließen wir diese unbericksichtigt. Für die Bereclınung des Durchschnitts aller Frauen mußien dann auclı dic Ergebnisse der in Westbohmen aufgenommenen Frauen außer acht bleiben. da das Prager Äquivalent ing der infogngelleag Situation niclit vorhanden ist. 
Durchschnitt aller Männer außer Studenten, insg. 38 Respondenten

Sprachverhalten:

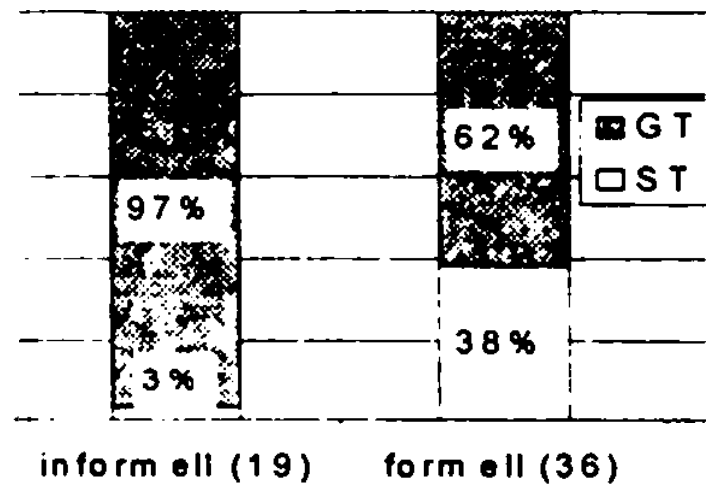

Einstellung, kognitives Subsystem: Derkannt encht erkannt
Einstellung, konatives Subsystem:

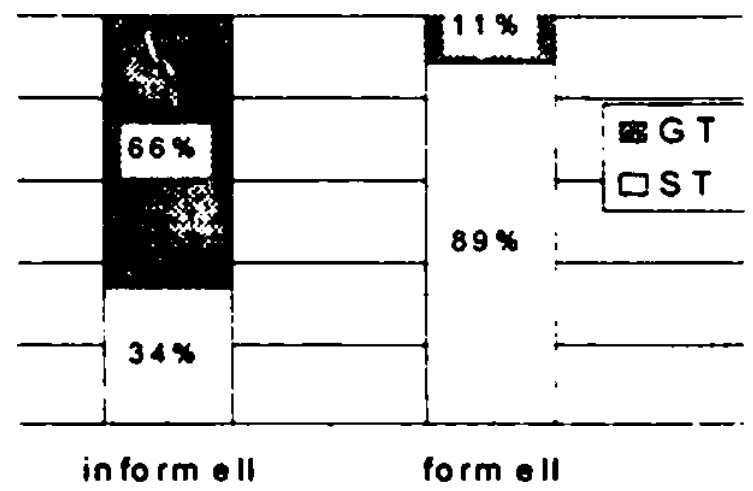

Evaluation der eigenen Kognition:

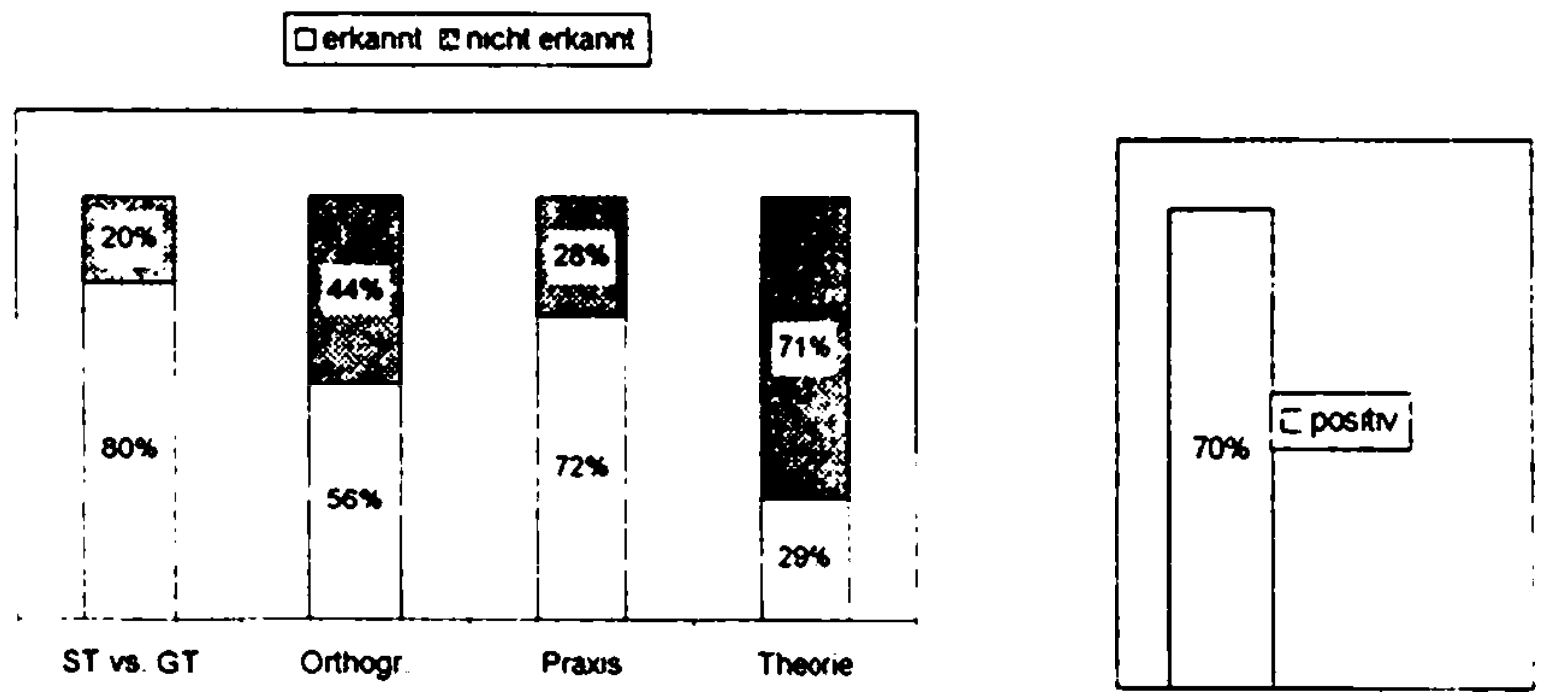

Einstellung, affektives Subsystem: Grad der positiven Einstellung

(50\%


Durchschnitt aller Respondenten (Frauen, Männer) ohne Abitur, insg. 25 Respondenten

Sprachverhalten:

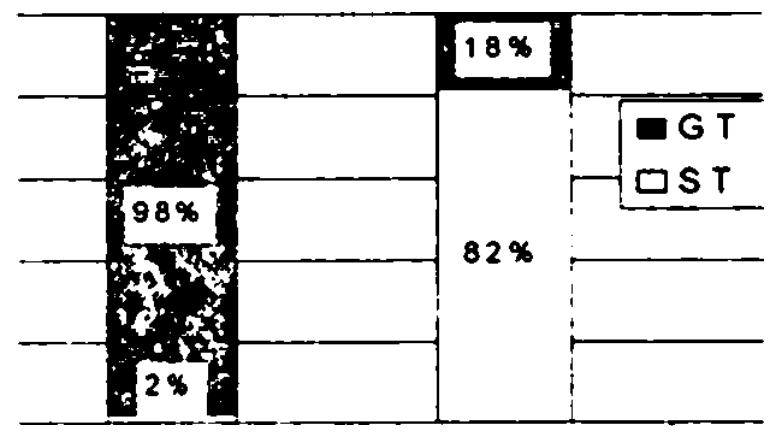

inform $\bullet \| 11(17)$ form $\in$ ll (22)
Einstellung, konatives Subsystem:

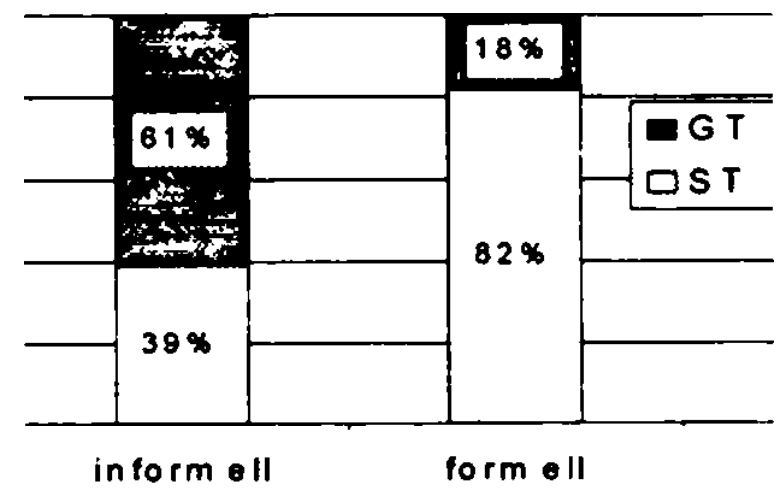

Evaluation der eigenen Kognition:

Einstellung, kognitives Subsystem:

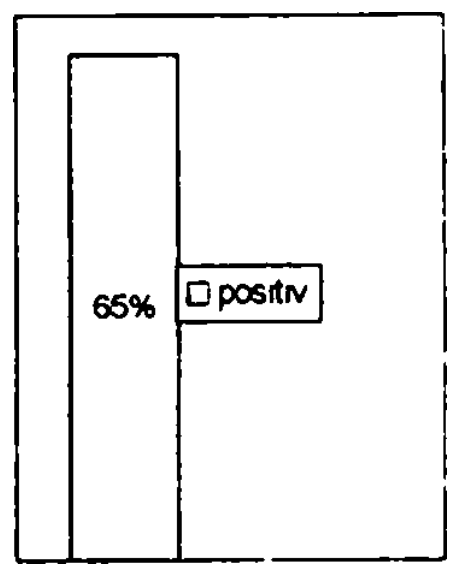

Einstellung, affektives Subsystem: Grad der positiven Einstellung

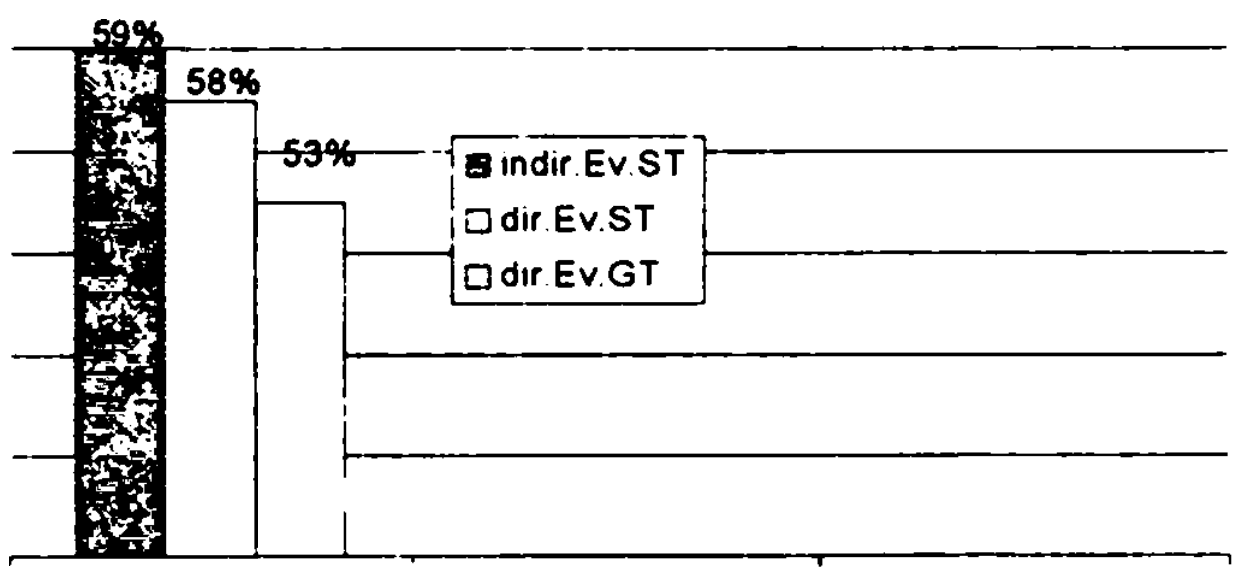


Durchschnitt aller Respondenten (Frauen, Männer) mit Abitur, insg. 27 Respondenten

Sprachverhalten:

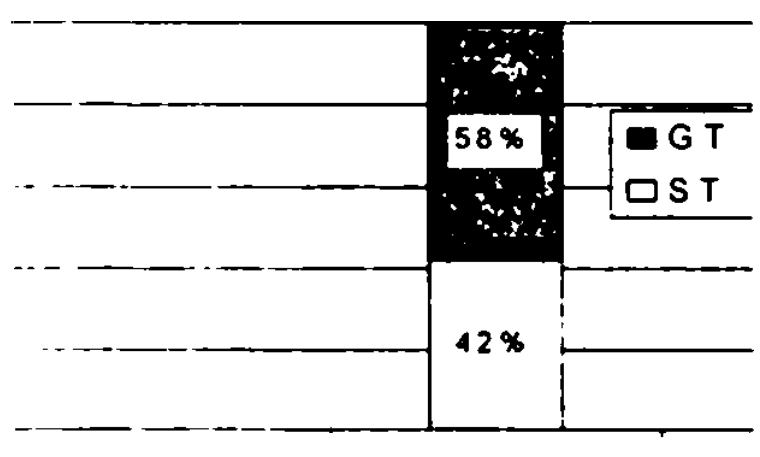

form $e \|(26)$

Einstellung, kognitives Subsystem:

Derkannt onkht erkannt

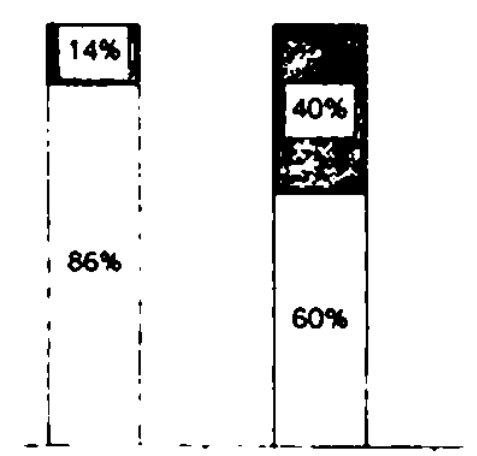

ST vs GT

Orthogr

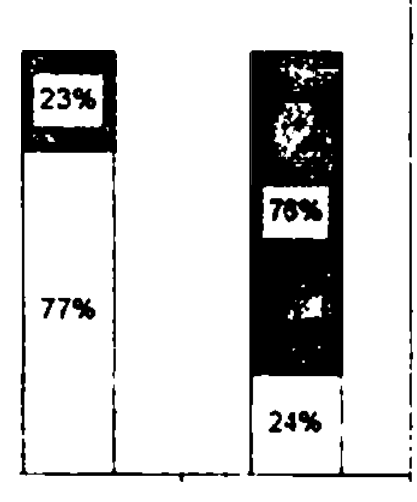

Evaluation der eigenen Kognition:

Einstellung, konatives Subsystem:

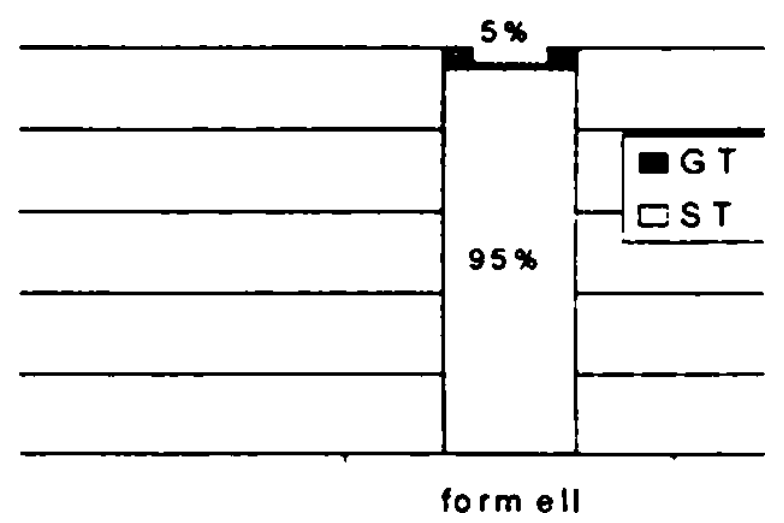

form ell

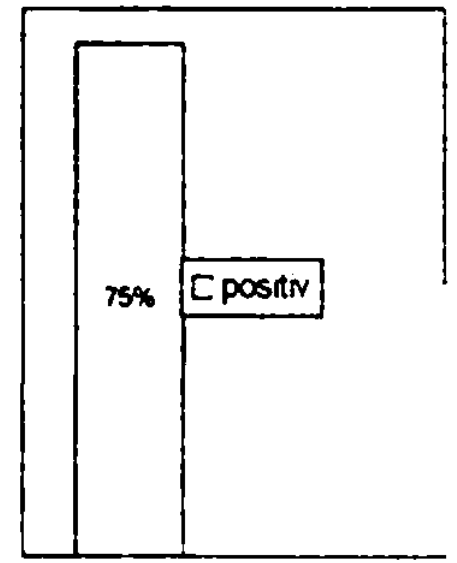

Einstellung, affektives Subsystem: Grad der positiven Einstellung

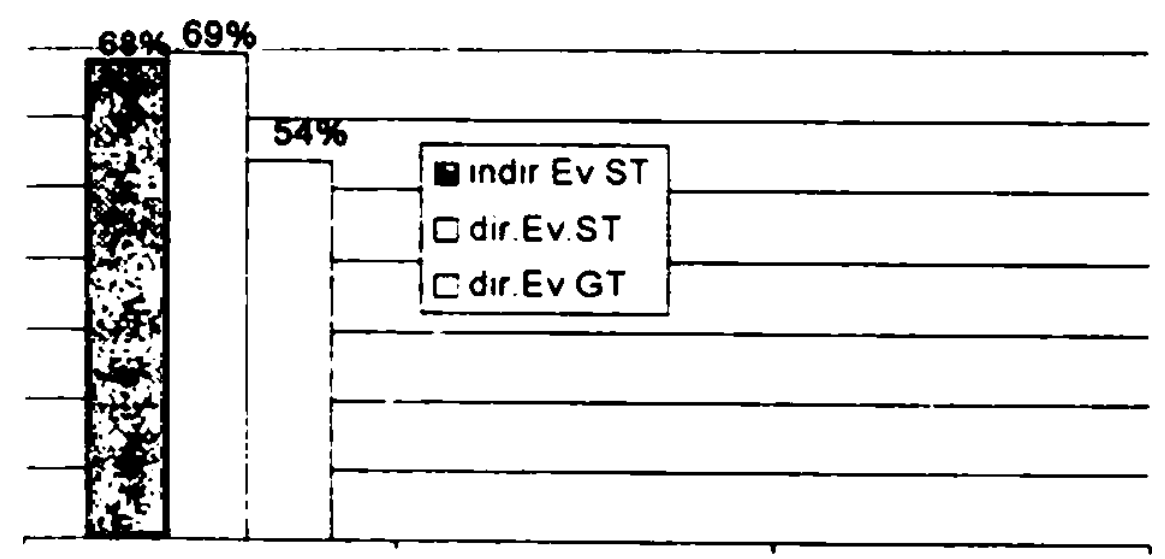


Durchschnitt aller Respondenten (Frauen, Männer) mit Hochschulabschluß (ohne Studenten), insg. 18 Respondenten

Sprachverhalten:

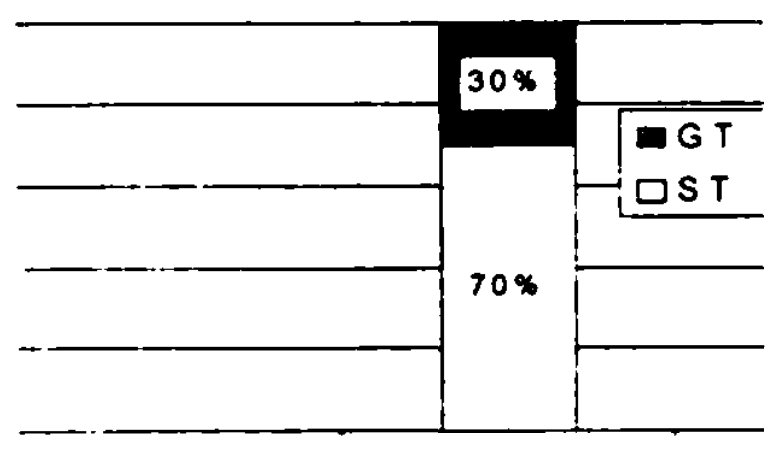

form ell (18)
Einstellung konatives Subsystem:

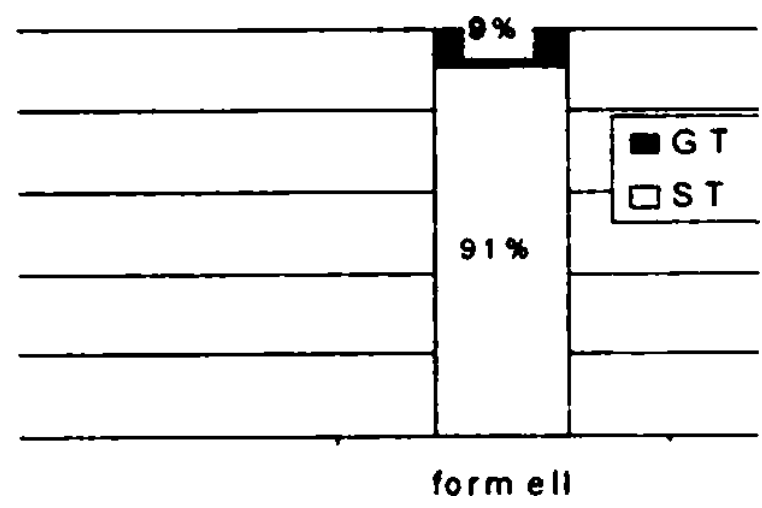

Evaluation der eigenen Kognition

Einstellung kognitives Subsystem:

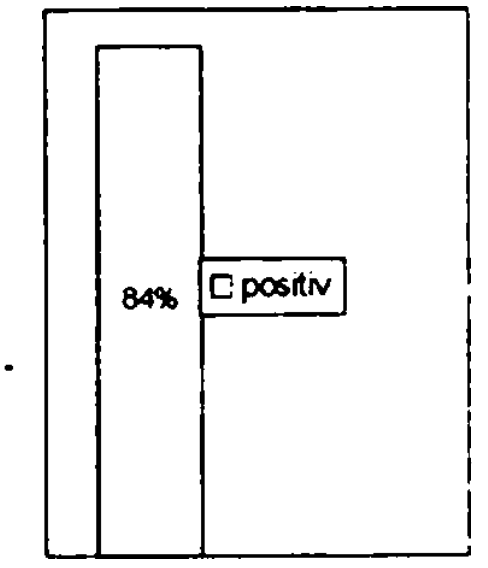

Einstellung, affektives Subsystem: Grad der positiven Einstellung

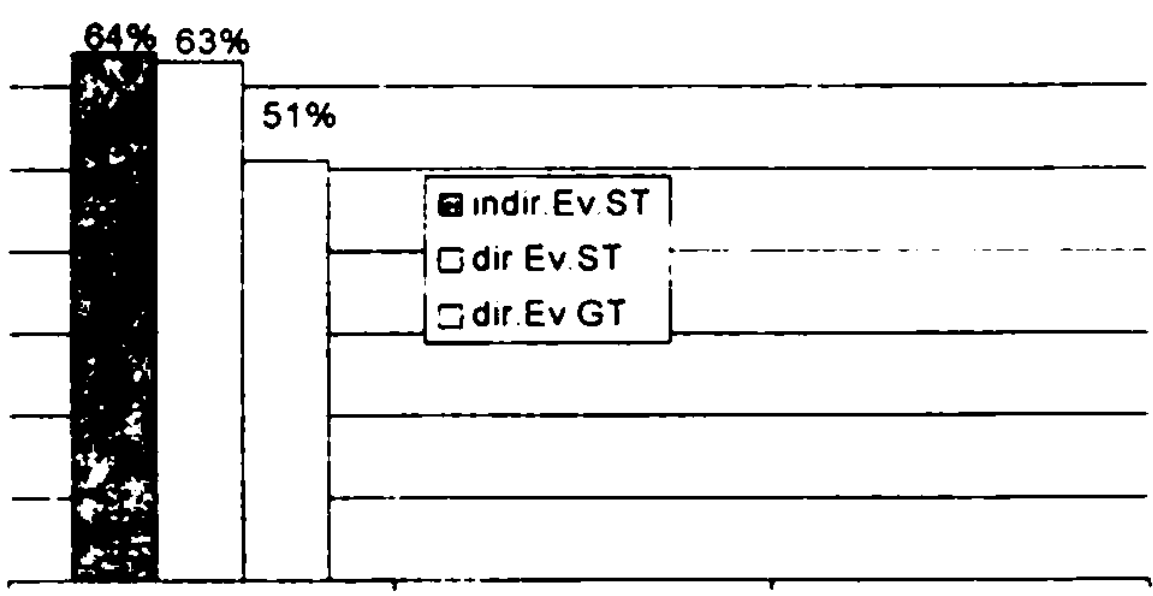


Durchschnitt aller Respondenten (Frauen und Männer) außer Studierende, insg 70 Respondenten

Sprachverhalten:

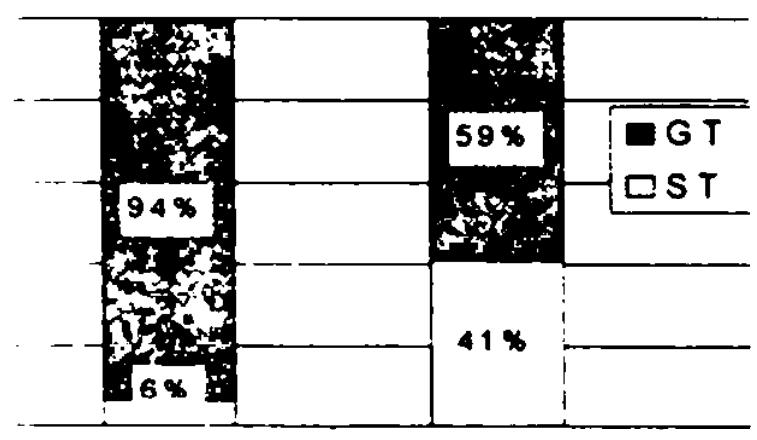

in form $\bullet l l(40) \quad$ form $\bullet l l(66)$

Einstellung, kognitives Subsystem:

Derkannt o nicht erkannt
Einstellung, konatives Subsystem.

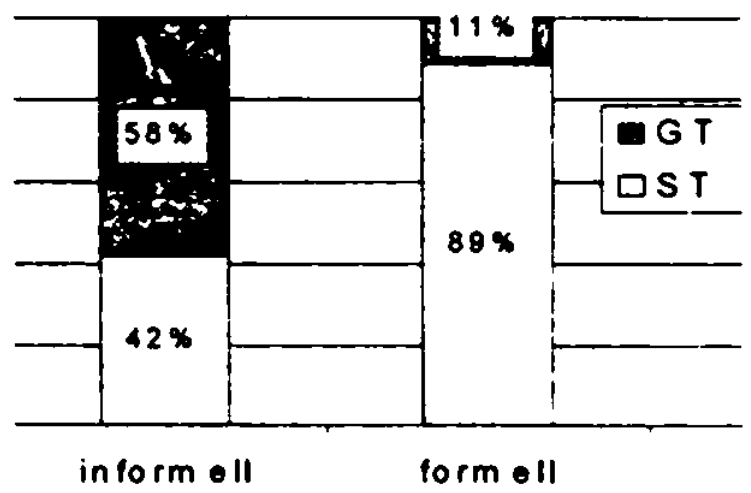

Evaluation der eigenen Kognition:

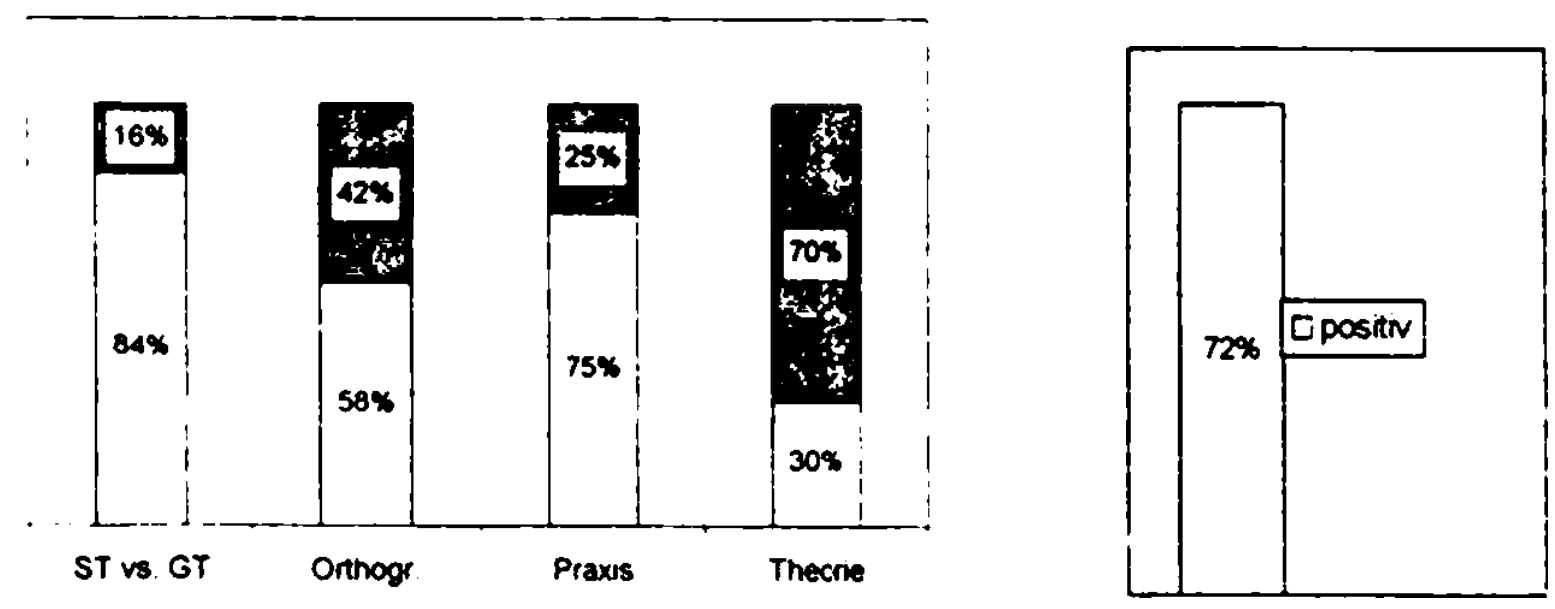

Einstellung, affektives Subsystem: Grad der positiven Einstellung

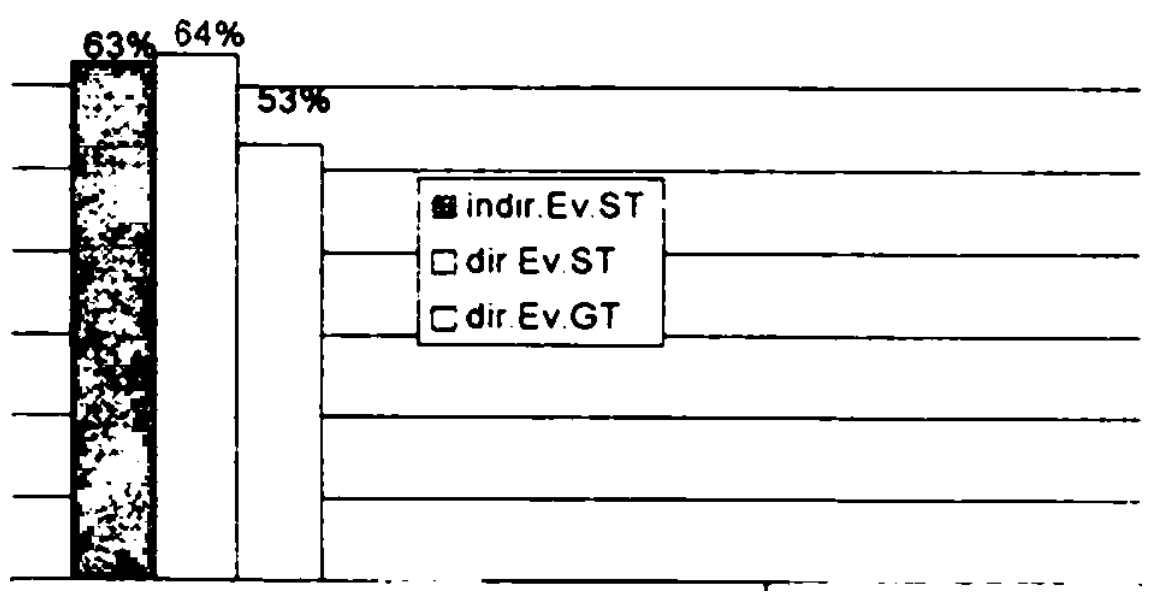


Durchschnitt aller Studierenden der Geisteswissenschaften (männlich, weiblich), insg. 25 Respondenten ${ }^{1: 4}$

Sprachverhalten:

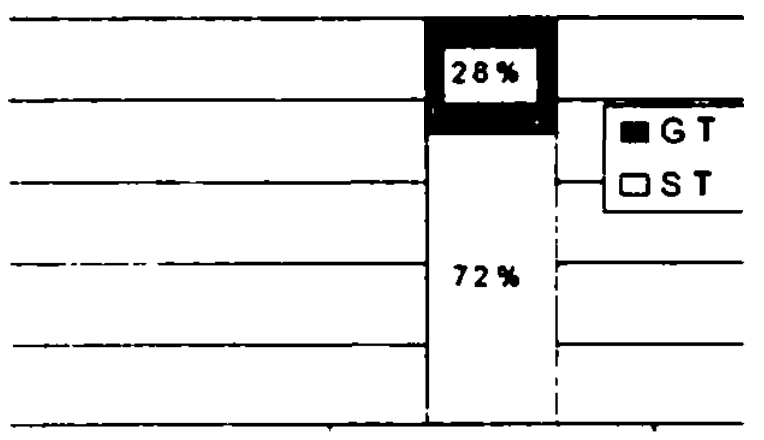

form ell (25)

Einstellung, kognitives Subsystem:
Einstellung, konatives Subsystem:

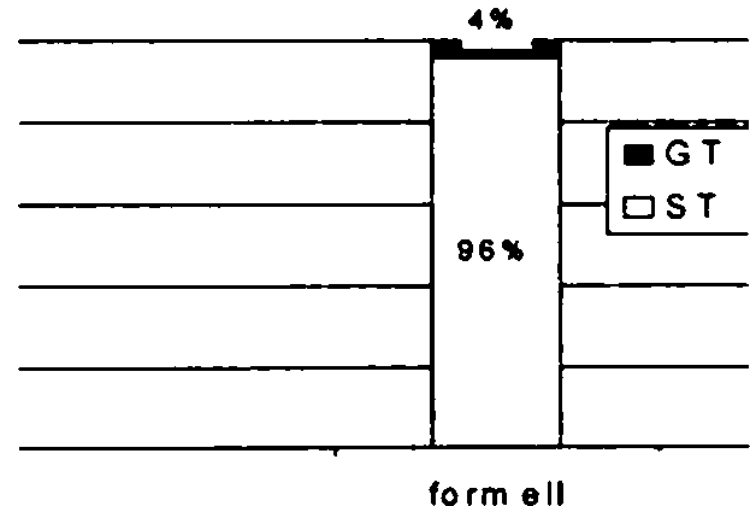

Evaluation der eigenen Kognition:

Derkannt 2 nicht erkannt
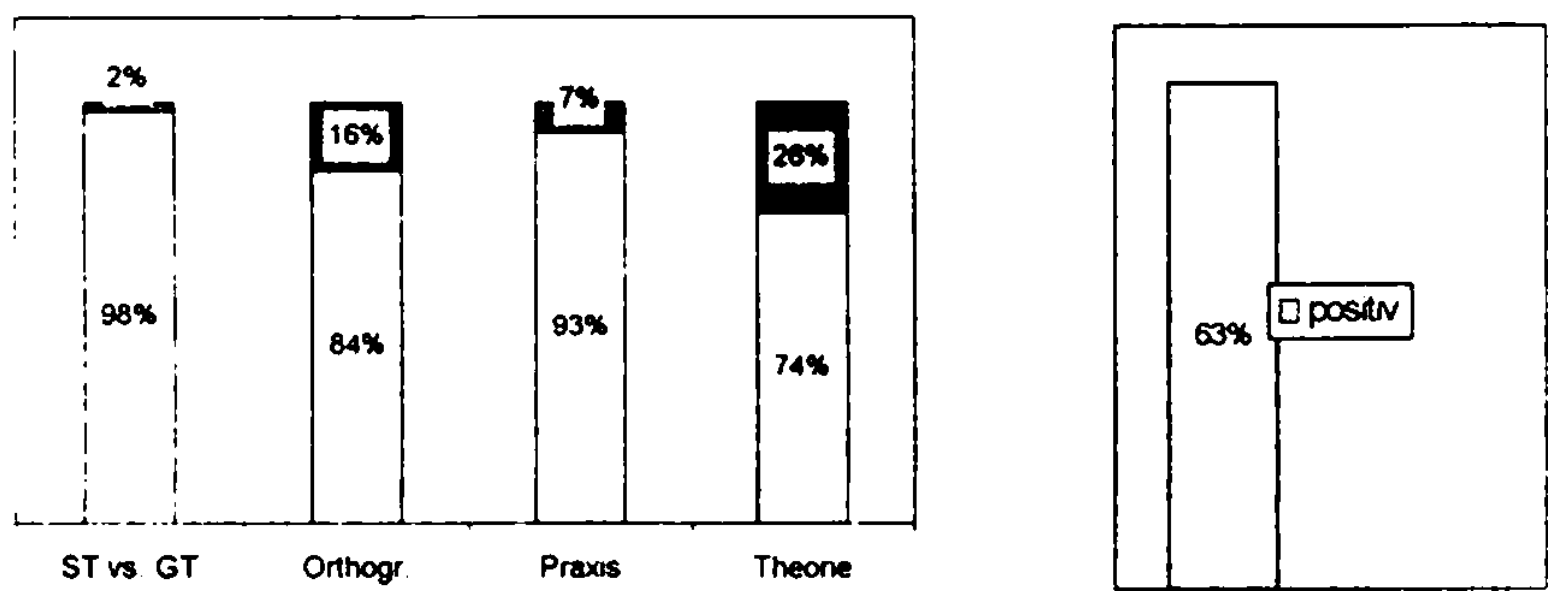

Einstellung, affektives Subsystem: Grad der positiven Einstellung

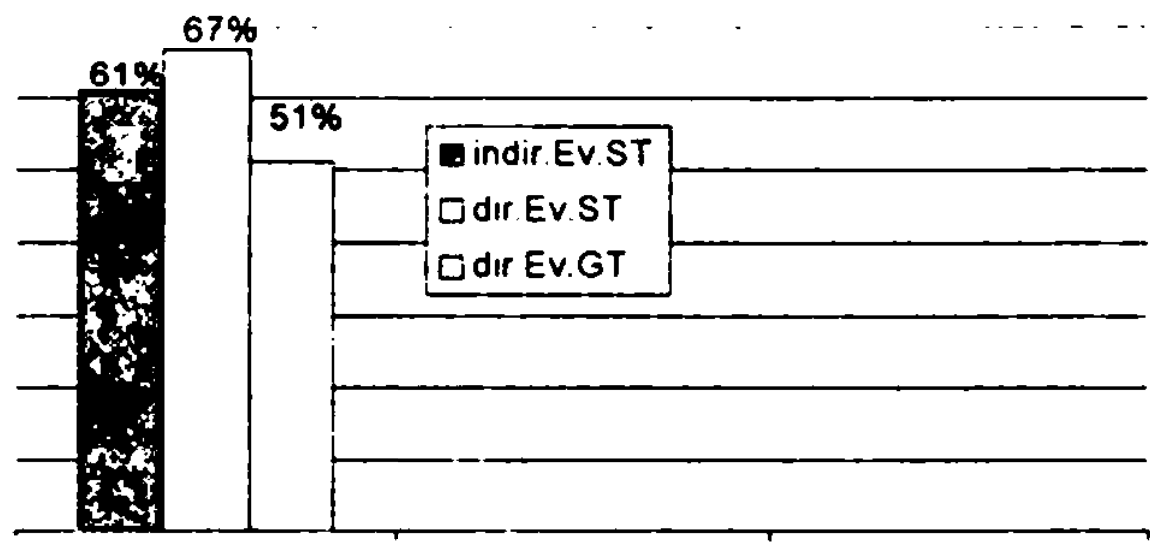


Durchschnitt aller Studierenden (männlich, weiblich), insg. 30 Respondenten

Sprachverhalten:

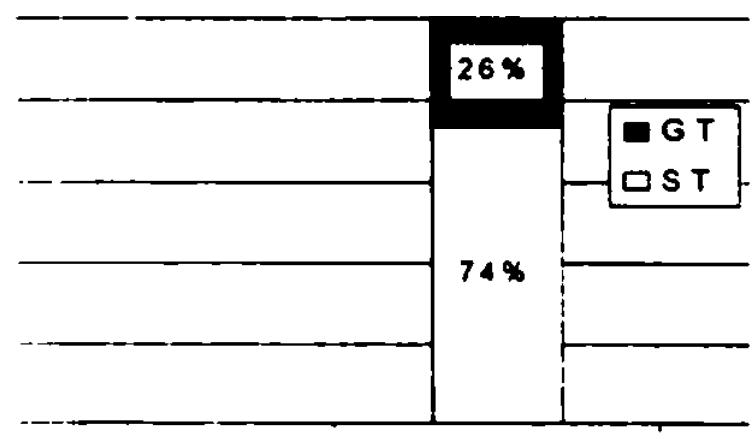

form oll (30)
Einstellung, konatives Subsystem:

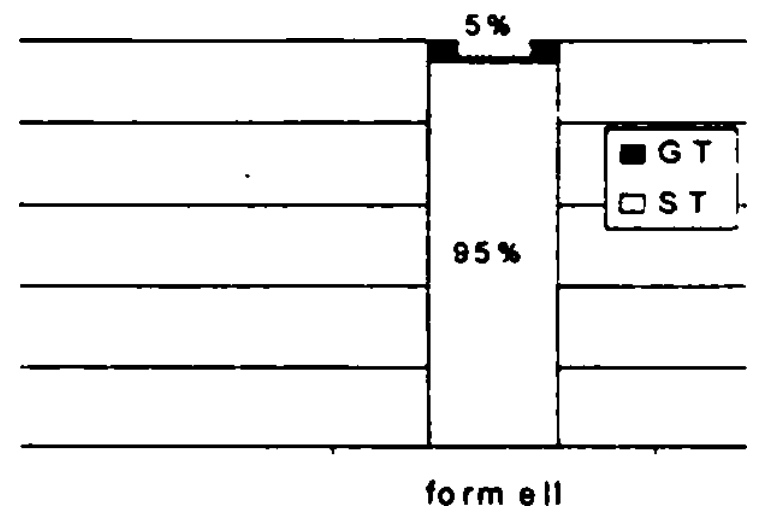

Evaluation der eigenen Kognition:
Einstellung, kognitives Subsystem:

Derkannt I ncht erkannt

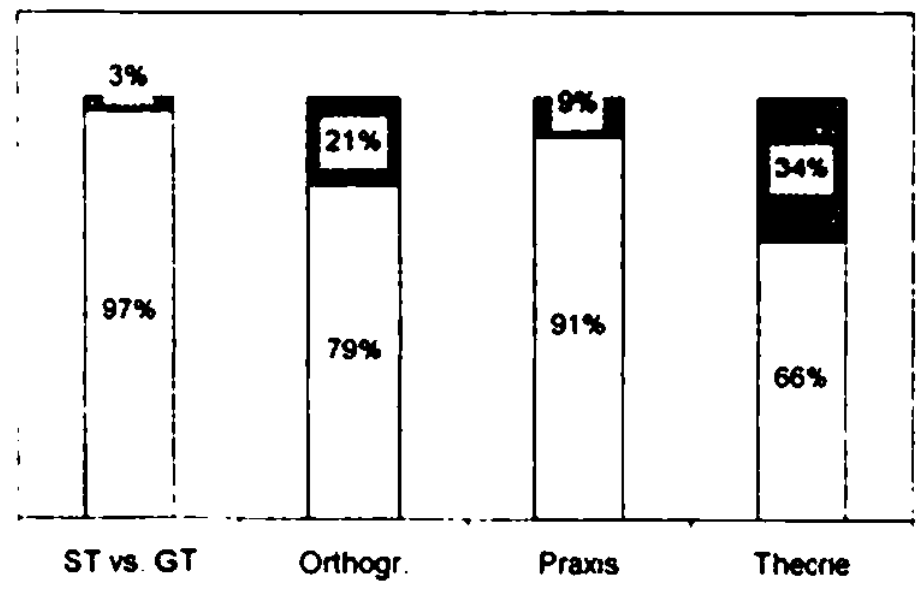

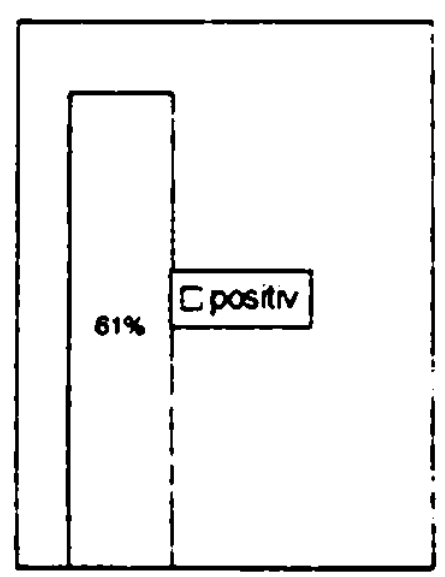

Einstellung, affektives Subsystem: Grad der positiven Einstellung

10




\subsection{Vergleich des kognitiven und des affektiven Subsystems}

Die im Kapitel 8.1 nach der Working-up-Methode ermittelten Durchschnittswerte der einzelnen nach den angegebenen soziologischen und diatopischen Variablen kategorisierten Respondentengruppen sollen in diesem Kapitel im Bereich des kognitiven und des affektiven Subsystems der Einstellung bewertet und in gegenseitige Relation gebracht werden. Es wird nachfolgend versucht, anhand möglichst übersichtlicher zusammenfassender Liniendiagramme, die Auswirkung der soziologischen Variablen auf die beiden Subsysteme darzustellen und zu erläutern

Vergleiche im kognitiven Subsystem: in der Praxis erkannt ${ }^{135}$

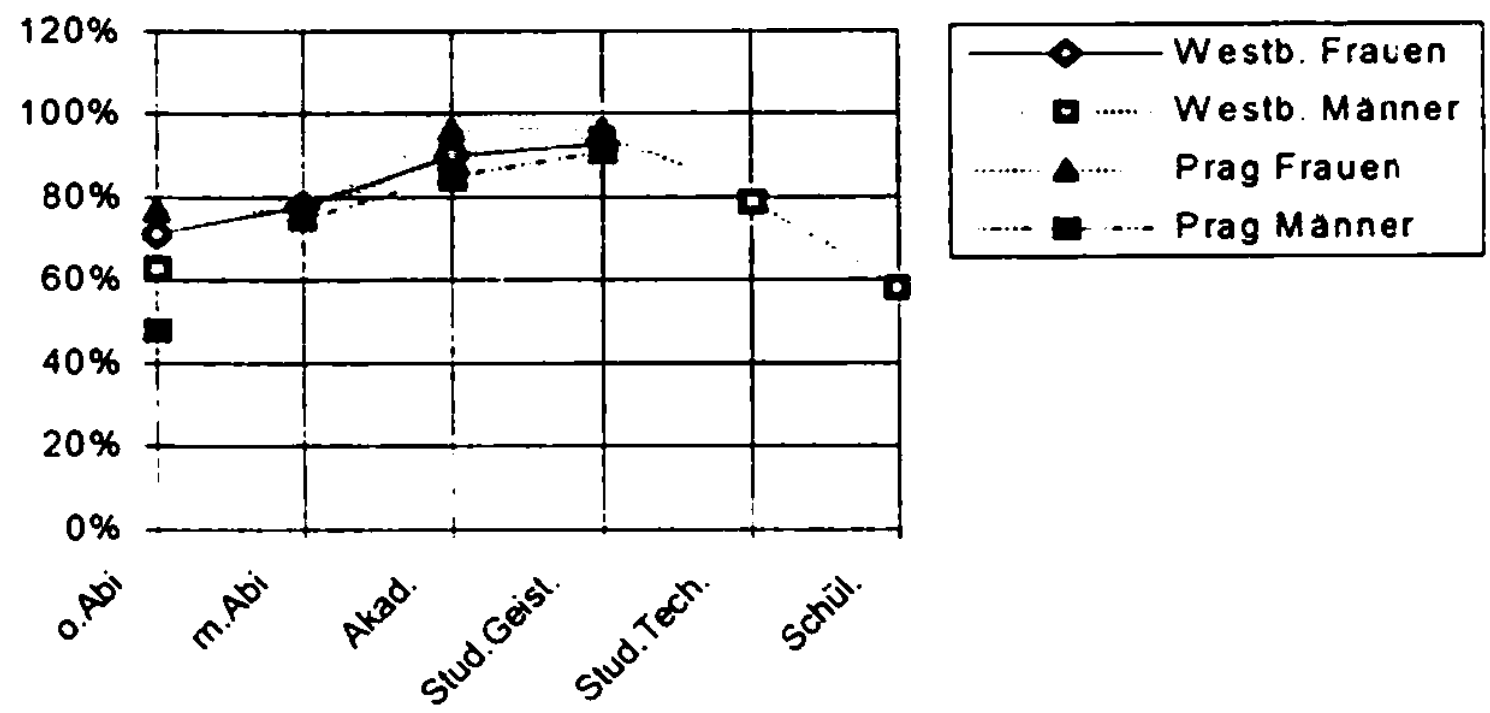

Der durchschnittliche Wert aller Befragten außer Studenten betragt im Bereich der Kognition in der Praxis $75 \% \%^{1: 6}$. In Westböhmen erreichten die Respondenten ohne Studenten $\mathbf{7 7 \%}$, in Prag etwas weniger - 72\%. Auch im Bereich des Geschlechts (ohne Rücksicht auf Region) sind Unterschiede zu verzeichnen: Frauen (ohne Studentinnen) erkannten das Standardtschechische in der Praxis zu 79\%, Männer (ohne Studenten) nur zu 72\%.

Die Bildung der Respondenten ist erwartungsgemäß der wichtigste Faktor im Bereich der Kognition des ST in der Praxis. Wie aus der obigen Graphik zu ersehen, zeichnen sich die niedrigsten Werte im Bereich der Respondenten ohne Abitur ab $(63 \%)^{137}$. Die Kurve steigt in Richtung "mit Abitur" (77\%) und gipfelt bei den Werten der Akademiker (90\%).

Die Sludenten der Geisteswissenschaften erreichten $93 \%$, d.i. $18 \%$ mehr als der allgemeine Durchschnitt. Die Kognition bei den Technikstudenten ist deutlich niedriger (79\%) und liegt nur $4 \%$ über dem allgemeinen Durchschnitt. Der Unterschied zwischen den Studentinnen und

135 Setzt sicli zusammen aus der Kognition im ST vs. GT - der in dieser Studic untersuchten sprachliclien Variablen (siche Kap. 3) - und der Kognition in der Orthographic in der Relation 21 (igl. Kap. 5.1.1)

1.6. Der allgemeine Durchschnitswert schließt jewcils alle Respondenten in Westbolumen und Prag außer Studenten und Sclıülcr cin. Geachict wird auch hier auf dic de facto Antcile der cinzelnen Respondentengruppen. so daß der allgemeine Durchschnitt niclıt aus Westböhunen und Prag im Verhälınis 1:1 gereclinet wird. sondern anteilig nach der Anvahl der Respondenten in der jewesiligen Regie954790258

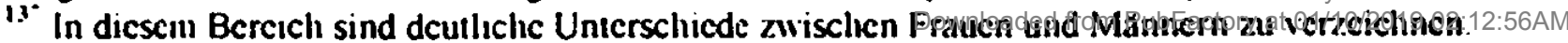


Studenten - direkt vergleichbar sind nur die Studenten der Geisteswissenschaften - ist minimal (94\% zu 93\%). Auch das diatopische Kriterium bei den Studentengruppen steht unseren Ergebnissen nach nicht in unmittelbarer Verbindung mit ihrer Kognition im ST (Prag, Pilsen je $94 \%)$.

Der Durchschnittswert der Schüler der Technischen Oberschule (58\%) liegt deutlich unter dem allgemeinen Durchschnitt, obwohl diese zu den Respondenten mit Abitur gezählt werden könnten ${ }^{138}$.

Vergleiche im kognitiven Subsystem: in der Theorie erkannt ${ }^{139}$

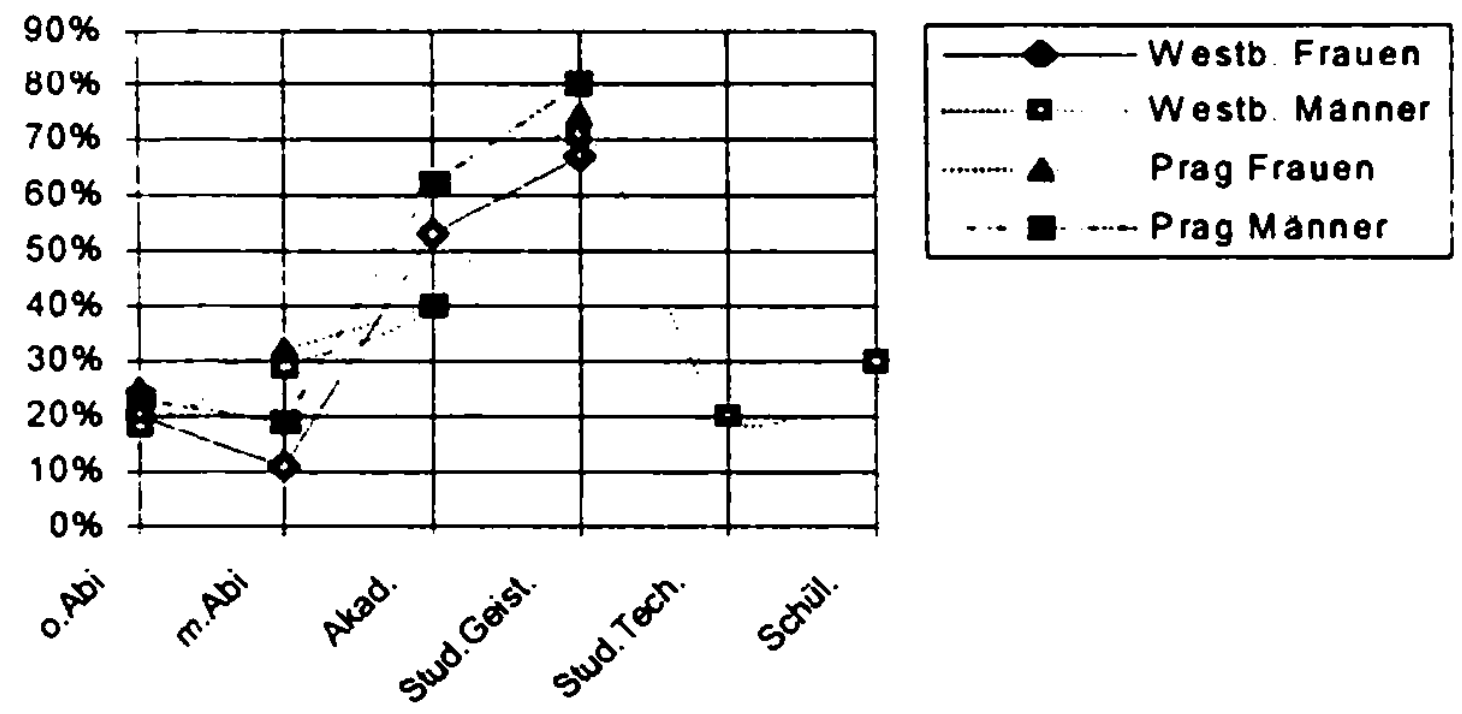

Erwanungsgemäß ist das theoretische Wissen der Tschechen über ihre Sprache, wesentlich niedriger als ihre praktischen Kenntnisse Der allgemeine Durchschnitt - ohne Studenten - liegt hier nur bei 30\%. Der Unterschied zwischen Westböhmen und Prag ist auch in diesem Bereich, ahnlich wie in der Kognition in der Praxis, minimal (30\% zu 31\%). Auch das Geschlecht bildet hier keine signifikante Variable: Frauen erreichten $31 \%$, Männer $29 \%$.

Die Bildung spiegelt sich deutlich im Bereich der Kognition in der Theorie wider. Der Unterschied zwischen den Sprechern ohne und mit Abitur ist zwar sehr gering: Die Sprecher mit Abitur erreichten im Durchschnitt 24\%, nur $2 \%$ mehr als die Sprecher ohne Abitur ${ }^{1+0}$. Die Akademiker liegen aber mit $49 \%$ weit über den beiden niedrigeren Bildungsgraden.

Interessant erscheint der Bereich der Studenten und Schuler. Die Studenten der Geisteswissenschaften erreichten erwartungsgemäß die besten Ergebnisse ${ }^{141}$ (74\%). Die Prager liegen weit vorne vor den Pilsner Studenten $\left(77 \%\right.$ zu 69\%) ${ }^{142}$. Die Kognition in der Theorie bei den Technikstudenten liegt mit nur 19\% gegen unsere Erwartungen deutlich unter dem allgemeinen

138 Alle Schüler lernten zur Zeit unserer Enquete im 3. Schuljahr. d.h. sic sollten in cincin Jahr das Fachabitur ablcgen

139 Die Ergebnisse in diescin Bereich wurden ermittelt anhand von 5 theoretischen Fragen uber das ST bzו das Tschechisclie allgemein (vgl. Kap. 5.1.1).

1+1) Dies becinträchtigt sicherlich dic Gruppe "Ilestbohmen. Frauen mit .tbitur". in welcher der Grad der Kognition wahrscheinlich durch Zufall sehr niedrig war.

141 Die absolute Mehrheit bilden Studenten der Bohemistik.

14. Margınal set hier lingewiesen auf den etwas niedngeren Wen bei der Studentinnen (71\%) drm Vergleieh au den Studenten (76\%). 
Durchschnittswert. Dies könnte etwa damit erklärt werden, daß, wie wir während unserer Enquete erfuhren, an der Technischen Fakultät in Pilsen kein Tschechischunterricht mehr stattfindet und das Interesse der Studenten sich zum größten Teil auf technische Bereiche konzentriert. Die Schüler dagegen liegen trotz ihrer technischen Orientierung $1 \%$ über dem allgemeinen Durchschnitt (31\%), was sicherlich dem noch stattfindenden Tschechischunterricht zu verdanken ist.

Vergleiche im affektiven Subsystem: indirekte positive Evaluation des $\mathrm{ST}^{1+3}$

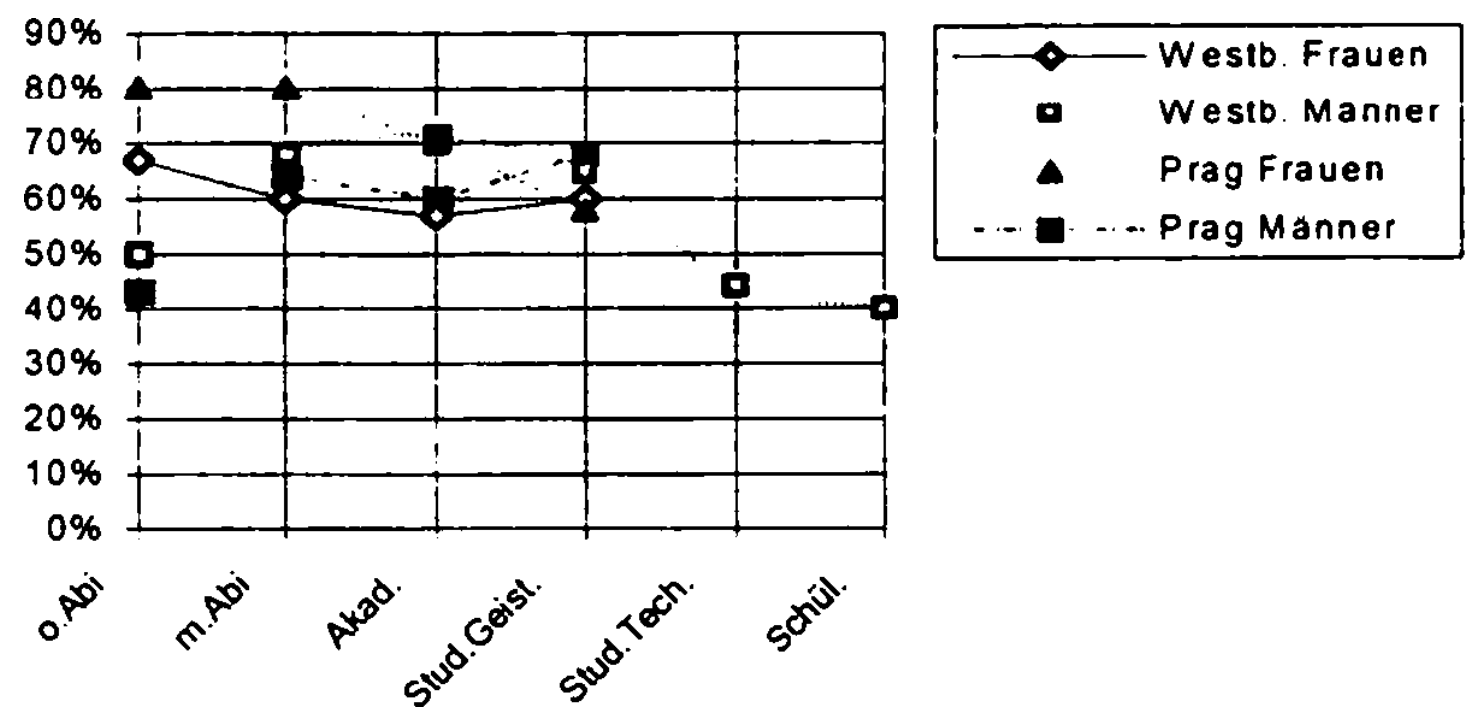

Der Durchschnittswert der indirekten positiven Bewertung des ST liegt bei den Sprechern ohne Studenten bei $63 \%$. Der Unterschied zwischen den westböhmischen und Prager Sprechern (62\% zu 65\%) deutet auf eine positivere Evaluation des ST in Prag. Auch im Bereich des Geschlechts zeichnet sich eine deutliche Differenz ab (Frauen 67\%, Männer 60\%). die auf eine positivere Einstellung zum ST bei den Frauen hinweist.

Wie der Kurvenverlauf in der Graphik verrät, steigt der Grad der indirekten positiven Bewertung des ST - im Gegensatz zur Kognition - nicht parallel mit dem erreichten Bildungsgrad. Der Durchschnittswert bei den Sprechern ohne Abitur (59\%) liegt etwas unter dem Durchschnitts der Akademiker (64\%). Die Sprecher mit Abitur nehmen dennoch in der Evaluation ihrer Standardsprache mit $68 \%$ die führende Position ein ${ }^{1+4}$

Die Angaben der Studierenden der Geisteswissenschaften (63\%) kongruieren mit dem allgemeinen Durchschnittswert. Die Variable des Geschlechts tritt hier in den Vordergrund, denn die Studenten der Geisteswissenschaften evaluieren das ST deutlich höher (67\%) als ihre Kommilitoninnen $(59 \%)^{1 \text { ss }}$. Auf der diatopischen Ebene bestehen im Bereich der Studenten der Geisteswissenschaften ein nur minimaler Unterschied (Prag 61\%. Pilsen 62\%). Die Techniker sowohl die Studenten als auch die Schüler - sind ihren Angaben nach in ihrer positiven Bewertung des ST zurückhaltend. Sie liegen mit $44 \%$ bzw. $40 \%$ an den letzten Stellen

143 Der Grad der indirckten Evaluation des ST wurde crinittelt anhand von 5 Fragen (vgl. Kap. 5.1.2)

is Insgesamt bewerieten die Frauen ohne und mit Ahitur das ST ain positivsten

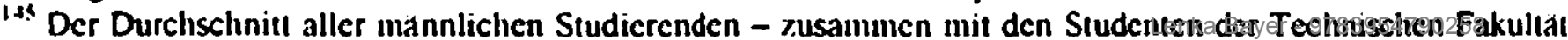


Die Frage, die zusammen mit vier anderen die Bewertung der indirekten Evaluation des ST ermoglichte:

Souhlasili byste s reformou spisovmé cestiny, pri které by byly mluvene proky uznainy za spisovme, tak zy bozdily mezi spisovnou a mluvenou deštinou rychle zanikly?"

wurde vor allem aus dem Grund gestellt, um die innerhalb der Bohemistik diskutierte und von einigen Linguisten angestrebte Reform des Standardtschechischen ${ }^{1+6}$ von den Sprechern beurteilen zu lassen. Alle 105 Befragten beantworteten die obige Frage mit nein.

Vergleiche im affektiven Subsystem: direkte positive Evaluation des $\mathbf{S T} \mathrm{T}^{1+7}$

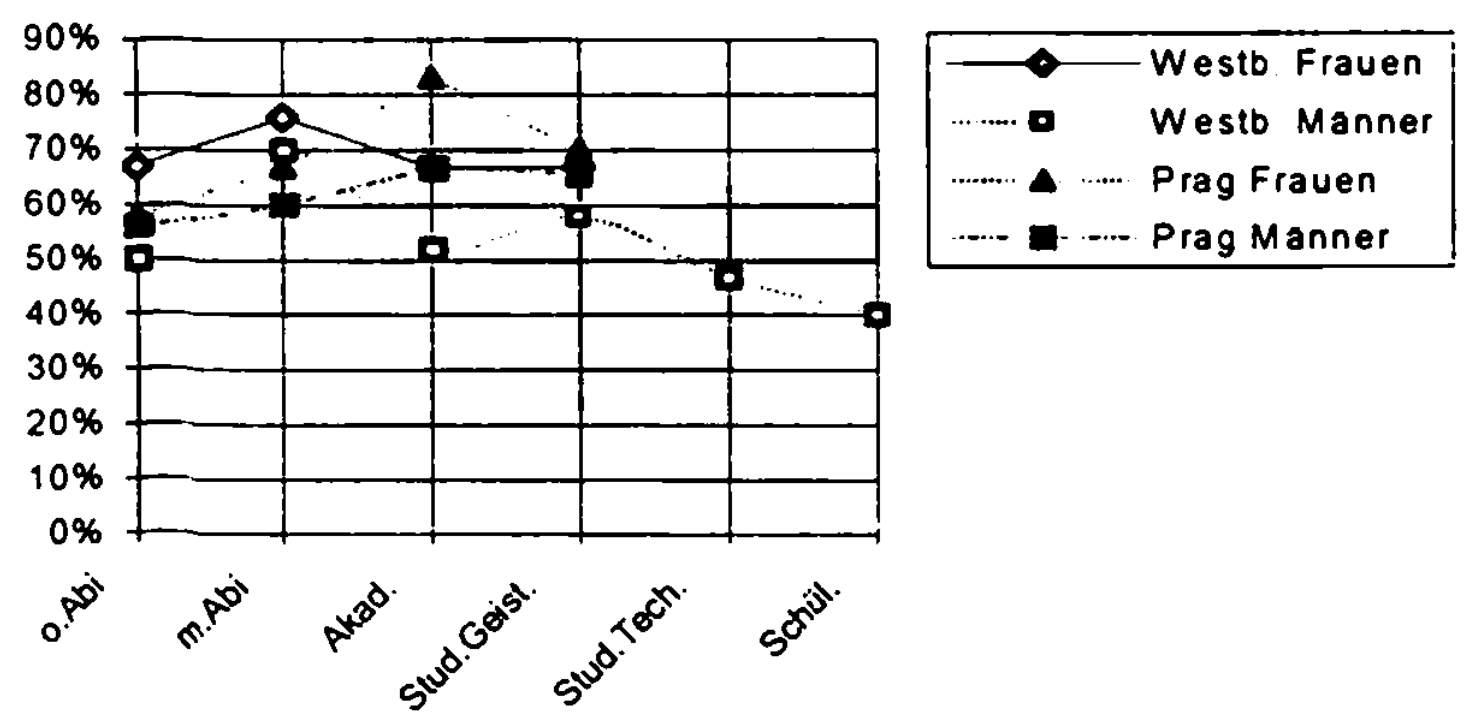

Die Werte im Bereich der direkten positiven Evaluation des ST stimmen in etwa mit denjenigen im Bereich der indirekten Evaluation des ST überein. Der Durchschnittswert aller Respondenten - ohne Studenten - ist im Vergleich mit der indirekten Evaluation des ST nur ein Prozent höher $(64 \%)$. Die Werte im Bereich der Diatopie unterscheiden sich ebenso nur unbedeutend (Prag 63\%, Westböhmen 64\%). Die Frauen bewerten dagegen - ebenso wie bei der indirekten Evaluation des ST - ihre Standardsprache deutlich positiver als die Männer $(69 \%$ zu $59 \%)$.

Auch im Bereich der Bildung sind keine auffallenden Differenzen zwischen den Werten im Bereich der indirekten und der direkten positiven Evaluation des ST festzustellen. Die Sprecher mit Abitur bewerten das ST mit $69 \%$ am positivsten. An der zweiten Stelle stehen die Werte der Akademiker mit $63 \%$. Die Reihe schließen ebenso wie bei der indirekten positiven Evaluation des ST die Respondenten ohne Abitur mit 58\%.

Die Werte der einzelnen Studentengruppen bzw. der Schüler sind mit den im Bereich der indirekten Evaluation des ST nahezu identisch. Die Geisteswissenschaftler erreichten $67 \%$. ${ }^{18}$

1*6 Vgl. Kap. 1

it: Die Respondenten sollten ihre Eınstellung direkt cinstufen unter sehr positiv, pessill: neutral octer megati. (vgl. Kap. 5.1.2).

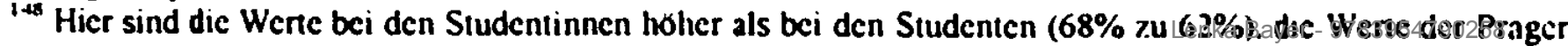
Studenten höher als die der Pilsner (68\% zu 62\%). 
deutlich unter diesem Wert liegen die Techniker mit 47\%. Die Reihe schließen die Schüler mit $40 \%$.

Vergleiche im affektiven Subsystem: direkte positive Evaluation des $\mathrm{GT}^{1 * 9}$

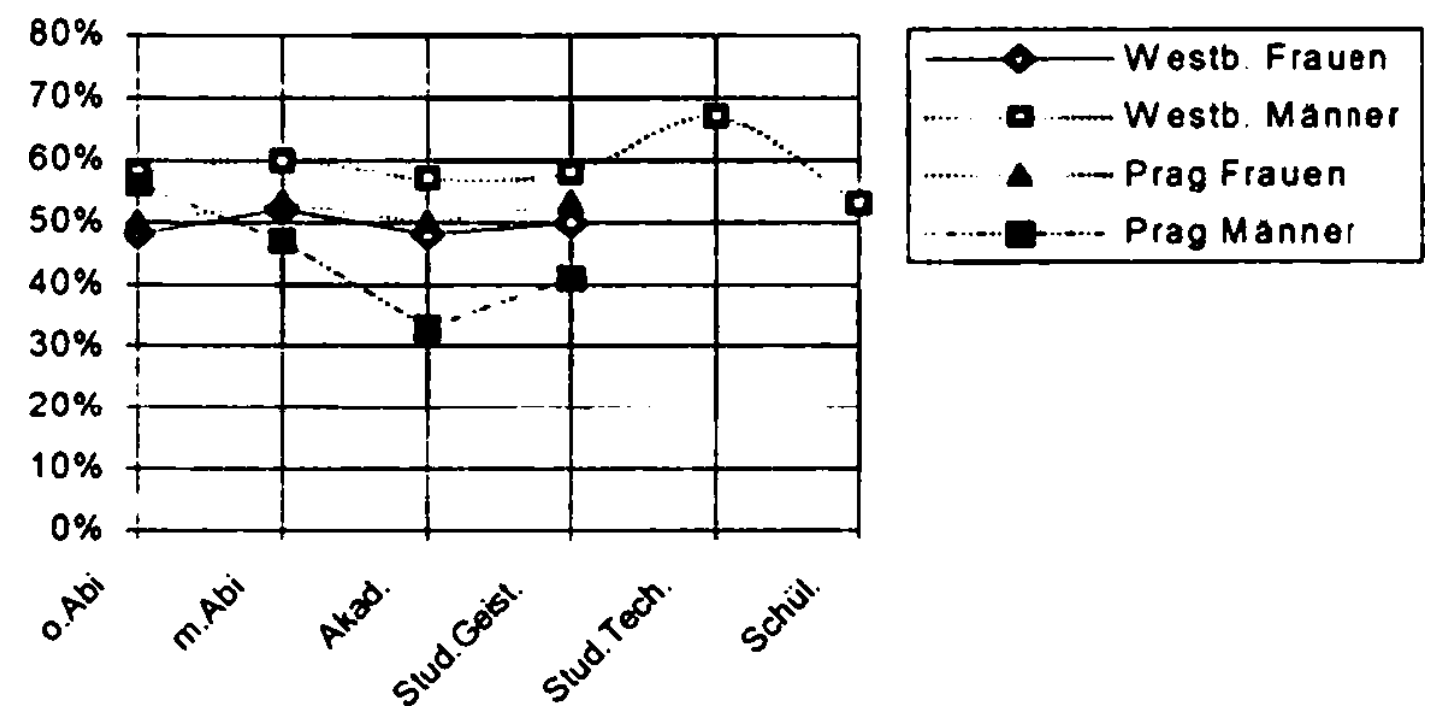

Der Durchschnittswert der direkten positiven Evaluation des GT (53\%) liegt im Vergleich zu den Werten der positiven Evaluation des ST bei den Nichtstudenten um $11 \%$ tiefer. Die Ergebnisse in Prag und in Westböhmen gehen hier etwas auseinander (50\% zu $54 \%$ ) und deuten auf eine starkere Ablehnung des gesprochenen Nonstandards in Prag ${ }^{150}$. Der Unterschied zwischen Frauen und Männern (50\% zu 56\%) ist in diesem Bereich deutlich, demnach stehen Männer dem GT gegenüber positiver als die Frauen.

Auf der Ebene der Bildung zeichnen sich die Akademiker mit nur $51 \%$ als die Gruppe, die das GT am geringsten schätzt. Somit liegen die Akademiker sowohl unter dem ailgemeinen Durchschnitt als auch unter dem Wert der Respondenten ohne Abitur (56\%) bzw. mit Abitur (54\%).

Die Studenten der Geisteswissenschaften bewerteten das GT auch nicht positiv. Die bei dieser Sprechergruppe ermittelten $51 \%$ liegen $2 \%$ unter dem allgemeinen Durchschnitt und kongruieren somit mit dem Wert der Akademiker. Die Technikstudenten bewerten dagegen die bohmische Koine Respondentengruppen mit Abstand am positivsten (67\%). Auf der diatopischen Ebene liegen die Prager Studenten der Geisteswissenschaften mit nur $47 \%$ deutlich hinter den Pilsner Studenten der Geisteswissenschaften (54\%). Die Unterschiede zwischen den Studentinnen und Studenten sind dagegen unbedeutend $(51 \%$ zu $50 \%)$. Der erreichte Grad der positiven Evaluation des GT bei den Schülern $(53 \%)$ kongruiert mit dem allgemeinen Durchschnitt

Etwas marginal, zwischen dem kognitiven und affektiven Subsystem der Einstellung gelagert, befindet sich ein weiteres Objekt unserer Untersuchung, die subjektive Bewertung der eigenen Kognition im Bereich des Standardtschechischen. Im Vorderpunkt steht hier die

149 Ebenso wie bei der expliziten Evaluation des ST sollten hier die Respondenten ihre Einstellung direkı cinstufen unter sehr positi:. prositiv. neutral oder negativ (vgl Kap. S. I.2).

19" Besonders deutlich wird dies bei den Mănnern in Westböhmen (siche obige Graphił 
Bewertung der in der Schule erworbenen Kenntnisse, gefolgt von der subjektiven Einschätzung der eigenen Fähigkeiten im gesprochenen $\mathrm{ST}^{131}$.

Die Ergebnisse in diesem Bereich bilden zusammen mit den Sprecherkommentaren und den Beobachtungen innerhalb und außerhalb der Enquete die theoretische Grundlage für das Bestimmen der Drittvariablen, die zwischen dem sprachlichen Verhalten und dem konativen Subsystem der Einstellung intervenieren und somit die Diskrepanzen zwischen diesen beiden Variablen bewirken.

\section{Positive Evaluation der eigenen Kognition der Respondenten:}

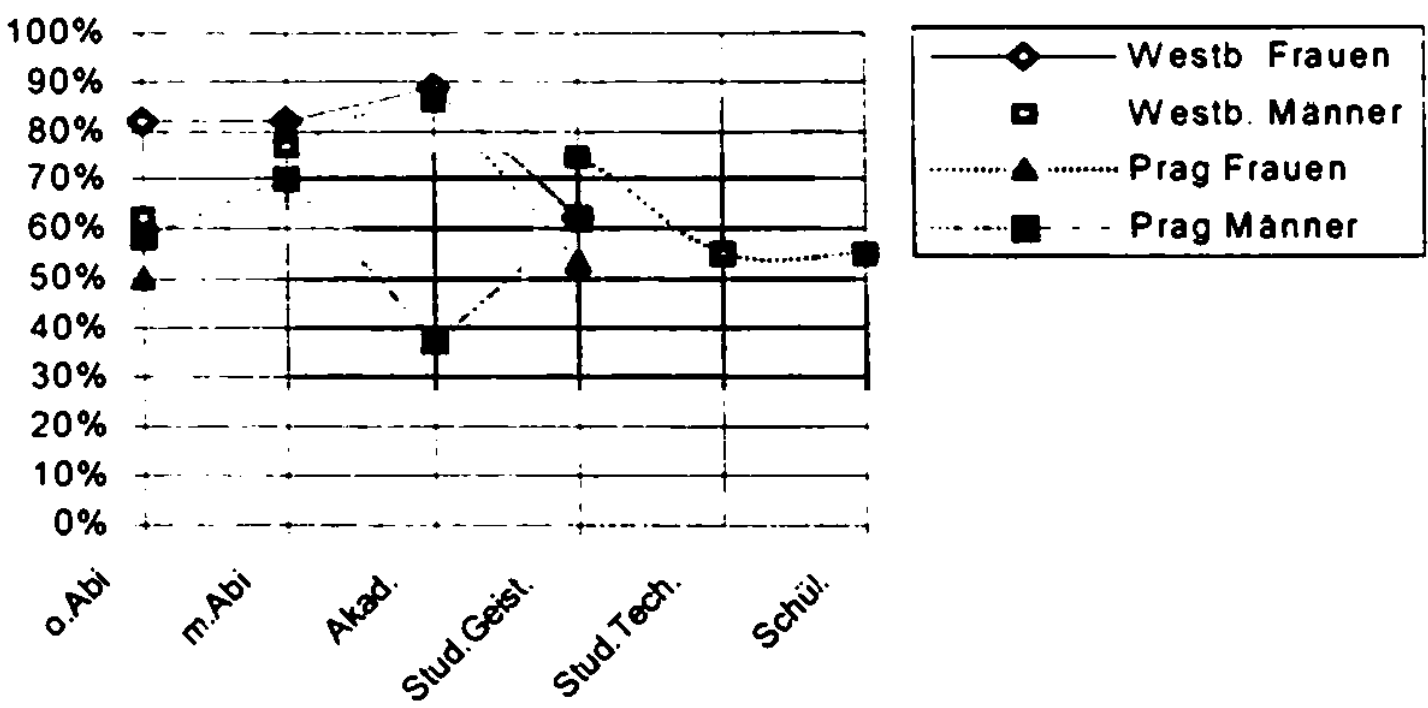

Der allgemeine Durchschnittswert bei den Nichtstudenten ist $72 \%$. Die Werte auf der diatopischen Ebene gehen deutlich auseinander, indem die westböhmischen Sprecher ihre Kenntnisse im ST verbunden mit der schulischen Vorbildung viel höher (80\%) bewerten als die Prager (64\%). Auch im Bereich des Geschlechts sind größere Diskrepanzen zu verzeichnen Frauen erreichten $80 \%$, Manner dagegen nur $70 \%$.

Auf der Ebene der Bildung stellt sich heraus, daß die Sprecher ohne Abitur in der subjektiven positiven Bewertung der eigenen Kenntnisse sehr zurückhaltend sind und mit $65 \%$ deutlich unter dem allgemeinen Durchschnitt liegen. Der Wert der Sprecher mit Abitur (75\%) steht nur leicht über dem allgemeinen Durchschnitt, die Sprecher mit Hochschulbildung überragen dagegen mit $84 \%$ die beiden niedrigeren Bildungsgrade.

Uberraschend - und für unsere Untersuchung überaus wichtig - erscheint die vergleichsweise negative Bewertung der eigenen Kenntnisse in Verbindung mit der schulischen Bildung seitens der Studenten und Schüler. Vor allem die Bewertung der Bohemisten, d.h. angehender Tschechischlehrer, die den größten Anteil an der geisteswissenschaftlichen Studentengruppe bilden und die anhand ihrer Qualifikation die schulische Situation sicherlich sehr gut reflektieren, ist für unsere Studie von großer Bedeutung. Die Geisteswissenschaftler erreichten nur $63 \%$, d.i um $9 \%$ weniger als der allgemeine Durchschnitt. Die Werte der Technikstudenten und Schüler bilden mit jeweils 55\% die unterste Grenze. Die Prager Studenten - diese Gruppe besteht nur aus Bohemisten - weisen mit 57\% nach den Technikern die niedrigsten Zahlen auf.

1s1 Die Respondenten sollien mach des Fragebogenmethode + Fragen beantwonen (vgl. Kap. 5. I.1) 
Nach dem Kriterium des Geschlechts liegen Studentinnen bei der Bewertung der eigenen Kenntnisse hinter ihren männlichen Kommilitonen ( $57 \%$ zu 68\%). Demnach wird deutlich, daß die zukünftigen Bohemistinnen - Lehrerinnen und Wissenschaftlerinnen im Bereich des Tschechischen -, die an der renommiertesten Universität Tschechiens studieren, ihre in der Schule erworbenen Kenntnisse im Bereich ihrer Bildungsdomäne, nämlich der tschechischen Standardsprache, mit 57\% deutlich negativer bewerten als der Durchschnittssprecher.

Zusammenfassend betrachten wir die Kognition im schriftichen Tschechisch als gut. Die lautlichen und morphologischen Unterschiede zwischen dem ST und dem GT werden unseren Ergebnissen nach von den Tschechen sicher erkannt. Im Bereich der Orthographie stellten wir bei den Respondenten größere Lücken fest. Dieser Bereich liegt dennoch an der Peripherie unserer Arbeit und wurde eine gesonderte eingehende Untersuchung erfordern.

In der Theorie des Tschechischen sind die Kenntnisse, wie sich in unserer Studie herausstellte, sehr gering. Mit der Ausnahme der Bohemisten ist der Begriff "obecná cestina" dem durchschnittlichen Tschechischsprecher gänzlich unbekannt. Demnach können die Tschechen die Frage nach ihrem sprachlichen Kode nur bedingt beantworten, denn sie haben für die von ihnen gesprochene und sie ständig umgebende Varietät keine Bezeichnung. Die meisten wissen zwar oder vermuten, daß sie nicht "spisovwá ceština" sprechen - dieser Begriff ist jedem geläufig - können aber nicht genau sagen, wie sie sprechen. Für manche ist ihr sprachlicher Kode ein Dialekt, für andere "hovorovä" oder "mluvená cestina"1s2. Dieses Phänomen bezieht sich nur auf die böhmischen Gebiete, denn die meisten Respondenten orientierten sich in der mährischen Sprachlandschaft gut. Die meisten Respondenten konnten mehr als einen der mährischen Dialekte nennen. Hier drängt sich die Frage auf, warum der seit HAVRANEK (1934) in der Bohemistik etablierte Terminus "obecná ceśtina" nicht in den Schulen, in den Medien etc. thematisiert wurde und bis heute nicht wird?

Der Einfluß der Bildung auf die Kenntnisse im Tschechischen war und ist unbestritten. Die Positionen der drei Bildungsgrade in der Skala entspricht dem Postulat je besser die Bildung. desto besser die Kenntnisse im Tschechischen.

Die Geschlechtzugehörigkeit bzw. die sprachliche Prägung einer Region spiegelt sich dagegen im Bereich der Kognition im Tschechischen nur bedingt wider. Die Frauen erreichten, vor allem im Bereich der Kognition in der Praxis, etwas bessere Ergebnisse als die Männer. Die westböhmischen Sprecher bewiesen etwas fundiertere Kenntnisse ihrer Standardsprache als die Prager.

Im Bereich der Evaluation wird die allgemein positive Einstellung zum ST deutlich. Dies erscheint keineswegs überraschend, denn wie bereits im Kap. 5.1.2 erläutert, wurde das ST seit dem 19. Jh. seitens der tschechischen Politik und Literatur mit positiven Attributen besetzt Das Bildungssystem und die Medien helfen auch in den letzten Jahren diese Einstellung weiterhin aufrecht zu erhalten.

Auf der Ebene der Bildung zeichnen sich deutliche Unterschiede ab. Die Sprecher mit Abitur stehen in der positiven Evaluation des ST an der ersten Stelle, gefolgt von den Akade-

15: An dieser Stelle drängt sıch der vielleicht cthas skurrile. dennoch nicht ganz. abwegige Vergleich thit Brot auf. Wie ware es wohl. wenn wir für das Brol. das wir taglich cssen. keinc Bezeiclinung wüBten und es stall Brol als "enias aus.l/eh/ ba.. enwas wie Brotchen, aher großer" bezcichnen würden" 
mikern an der zweiten und den Sprechern ohne Abitur an der letzten Stelle ${ }^{153}$. Wie sich in unserer Studie herausstellte, spielt auch die Diatopie bei der Bewertung des ST eine Rolle Die Prager Sprecher evaluieren das ST positiver als die westböhmischen. Auch das Geschlecht bildet eine prägnante Variable. Die Tschechinnen bewerten ihre Standardsprache deutlich positiver als ihre männlichen Pendants.

Die Bewertung des GT fiel im Vergleich zu der des ST deutlich negativer aus ${ }^{154}$. Auf der diatopischen Ebene evaluieren die Prager Sprecher das GT weniger positiv als die Sprecher in Westböhmen ${ }^{\text {iss }}$. Ebenso deuten die Ergebnisse der Frauen auf eine negativere Einstellung zum GT als die der Männer.

Im Bereich der Bildung demonstrierten die Akademiker und die Studenten der Geisteswissenschaften mit ihren Angaben eine deutlich ablehnende Haltung dem GT gegenüber. Uberraschend implizieren die Ergebnisse der Technikstudenten dagegen eine weit über dem Durchschnitt liegende positive Einstellung zu ihrem sprachlichen Nonstandard ${ }^{136}$.

Nach dem Motto "Weiß ich, was ich weif?" stellten wir den Respondenten 4 Fragen, die die Bewertung der subjektiven Evaluation der eigenen Kenntnisse der Respondenten ermöglichten. Insgesamt außerten sich die Tschechen über ihre Kenntnisse im Bereich des ST positiv. Den Angaben nach sind die meisten Sprecher der Meinung, sie wären im Tschechischunterricht ausreichend ausgebildet und sie wären in der Lage - wenn sie wollten - eine Konversation auf Standardtschechisch zu führen. Die Bewohner Westböhmens sind sich laut der Ergebnisse ihrer Kenntnisse wesentlich sicherer als die Prager, ebenso die Frauen im Vergleich zu den Männern. Die Sprecher mit Hochschulabschluß nehmen in diesem Bereich erwartungsgemäß die führende Position ein, gefolgt von den Sprechern mit Abitur an der zweiten und den Sprechern ohne Abitur an der letzten Stelle.

Nach dem Motto "Ich weiß. daß ich nichts weiß" (SOKRATES) mußten wir feststellen, daß gerade die Fachleute, die sich in ihrem Werdegang dem Studium des Tschechischen verschrieben und die de facto über die besten Kenntnisse im Tschechischen verfugen, ein unzureichendes in der Schule erworbenes Wissen anprangern. Sie geben an, sie würden über das Tschechische in der Schule nicht ausreichend unterrichtet sein und sie wären nicht sicher, ob sie überhaupt einen Dialog im Standardtschechisch führen könnten.

\footnotetext{
${ }^{13}$ Interessant ersclieinen hier die auffallend niedrigen Wente der jungen angelienden Techniker. Studenten der Technisclien Fakultăt und der Schüler der Technischen Fachoberscliule.

${ }^{14}$ Wic sich auch in vielen Kommentaren zu unserer Enquete niederschlug.

15s Es ist cin wenig Schade in Anbetracht der Tatsaclie. daß sie in der Ursprungsregion des GT leben.

1.ss Dieses Ergeconis kongruier mit der etwas ablehnenden Haltung dem ST gegenuberenka Bayer - 9783954790258
} 


\subsection{Sprachverhalten vs. konatives Subsystem der Einstellung}

Dieses Kapitel bildet den thematischen Kern der vorliegenden Arbeit. Nach dem immer engeren Umkreisen des Hauptthemas, das mit zahlreichen peripheren Untersuchungen bzw. Auswertungen verbunden war, soll nun der direkte Vergleich zwischen dem sprachlichen Verhalten und dem konativen Subsystem der Einstellung der Respondenten erfolgen.

Wie bereits im Kap. 5.2.1 beschrieben, erwiesen sich die verdeckten Aufnahmen in der informellen Situation trotz sorgfaltiger Vorbereitung als schwierig. Abgesehen von der inneren Spannung, was wäre, wenn die jeweilige Aufnahme seitens des Respondenten bzw. der Respondentin aufgedeckt worden wäre, traten Komplikationen mit der Aufnahmequalität auf. So mußten wir of eine Enttauschung hinnehmen, wenn sich nach der scheinbar gelungenen Aufnahme herausstellte, daß die Lautkulisse, v.a. in Restaurants, Cafés u.ä., so stark war, daß sie die Stimme der aufgenommenen Person übertönte. Nicht selten kam es vor, daß unsere Anspannung, sich gleichzeitig mit dem Respondenten ungezwungen zu unterhalten und dabei heimlich das sich in der Einkaufstasche ${ }^{157}$ befindende Aufnahmegerät einzuschalten, so groß war, daß wir statt der Aufnahmetaste eine andere betätigten.

$\mathrm{Zu}$ unserem Bedauern stellte sich beim Sortieren des gesammelten Materials heraus, daß wir in Pilsen in der informellen Situation nur 36 Aufnahmen auswerten konnten - d.i. ca. $55 \%$ aller in Westbohmen durchgeführten Aufnahmen. In Prag waren es sogar nur 4 - nur etwa $11 \%$ aller in Prag durchgefuhrten Aufnahmen ${ }^{158}$. Bei den Studenten und Schülern mußten wir auf die Tonaufnahmen in der informellen Situation leider gänzlich verzichten ${ }^{159}$.

Trotz der relativ geringen Anzahl der Proben in der informellen Situation wird aus den folgenden Auswertungen deutlich, daß die Tschechen in einem Privatgespräch mit Freunden, Bekannten aber auch mit einer unbekannten Person, mit der sie zufallig ins Gesprach kommen. das ST - wie der Durchschnitt von $6 \%$ demonstriert - nur sehr partiell verwenden ${ }^{(6)}$. Diese Tatsache wird schließlich auch innerhalb der tschechischen Bohemistik anerkannt ${ }^{161}$

Es steht fest, dass die Standardsprache (im Tschechischen] micht in der Funksion der Sprechsprache oxder Imgangssprache oder Sinbstandards (welchen Termmms man anch vorzieht) vencendel wird. (D.A.ES 1997. 206)

15" Wic bereits im Kap. 5.2.1 beschrieben. versteckten wir das Aufnahmegerăt in ciner leiclıten Stofftasclic (Einkaufstasche).

${ }^{1: 8}$ Wie bereits im Kap. 5.2 .1 geschilder. waren wir in Prag mıt Ausnahıne der Studenten auf die Hilfe eines Tutors angewiesen. Trotz sciner Anstrengungen konnte er nur sehr wenige Privalaufnalimen durchführen.

1s9 Wie bereits im Kapitel +.1 cnwähnt. wurden die Studenten und Scliuler an ihrer Ausbildungsstatte interviewt. Da diese Inteniews quasi wălırend des Schul- bzw. Universităısbetriebs liefen. ergab sich vor und danach keine Gelegenheit zu einem ungezwungenen Privatgesprăch

IN' Obwohl wir im Ralımen unserer Sludie niclı in allen Settings Tonaufnalınen durchführen konnten. Inacliten wir die Erfalıning. dißB auch in den Gesclıaften beim Einkaufen aber auch beim Arzt fast ausschließlich GT gesprochen wird. Ausfürlicher dazu siehe Kap. 9.

inl Vgl. aucli Kap. I 
Vergleiche im Sprachverhalten: Anteile des ST in der informellen Situation
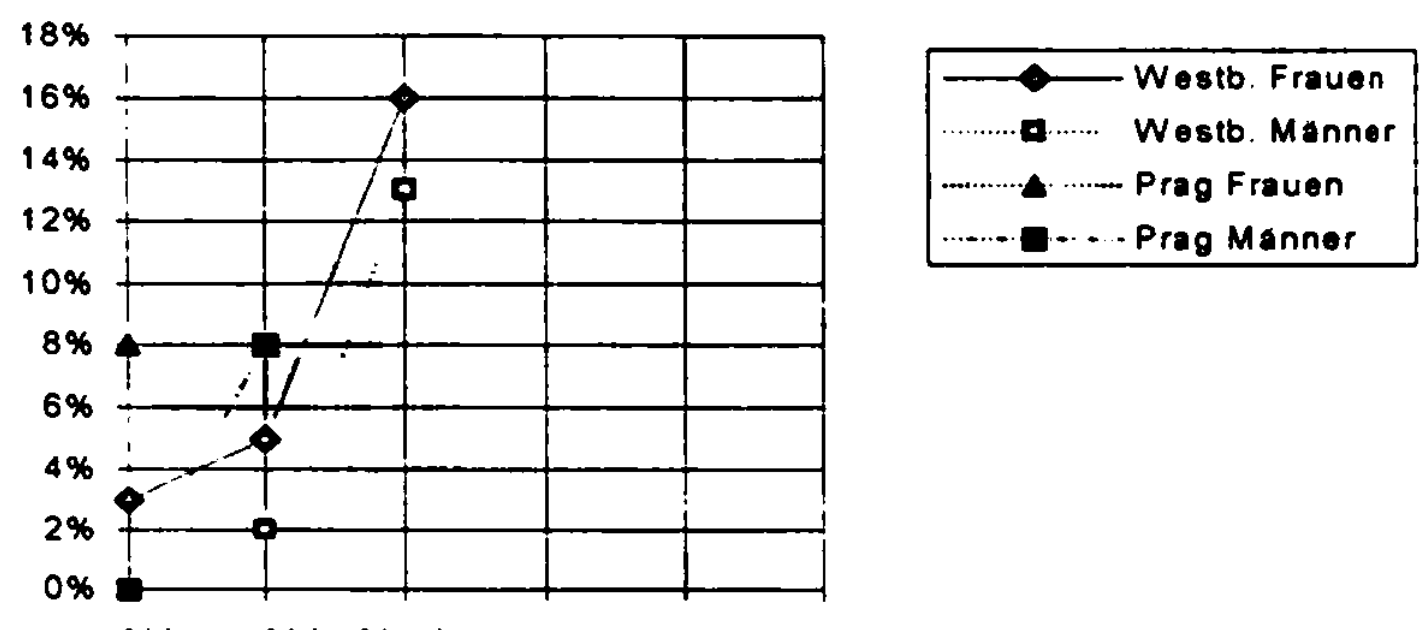

- Abi m.Abi Akad

Der allgemeine Durchschnittswert (ohne Studenten) im Bereich des Sprachverhaltens in der informellen Situation ist $6 \%$. Dieser Wert besteht fast ausschließlich aus den Aufnahmen westböhmischer Sprecher. Die (westböhmischen) Frauen verwenden mehr standardtschechische Elemente als die Männer ( $8 \%$ zu 3\%). Auf der Ebene der Bildung greifen erwartungsgemäß die Sprecher mit einem hoheren Bildungsgrad deutlich häufiger zu den standardtschechischen Mitteln (ohne Abitur 2\%, mit Abitur 4\%, Akademiker 15\%).

Prımär wichtig erscheinen uns bei den Ergebnissen im Sprachverhalten in der informellen Situation dennoch nicht die einzelnen Durchschnittswerte, sondern die empirische Bestätigung des obigen Danešschen Zitats.

Vergleiche im konativen Subsystem: Anteile des ST in der informellen Situation
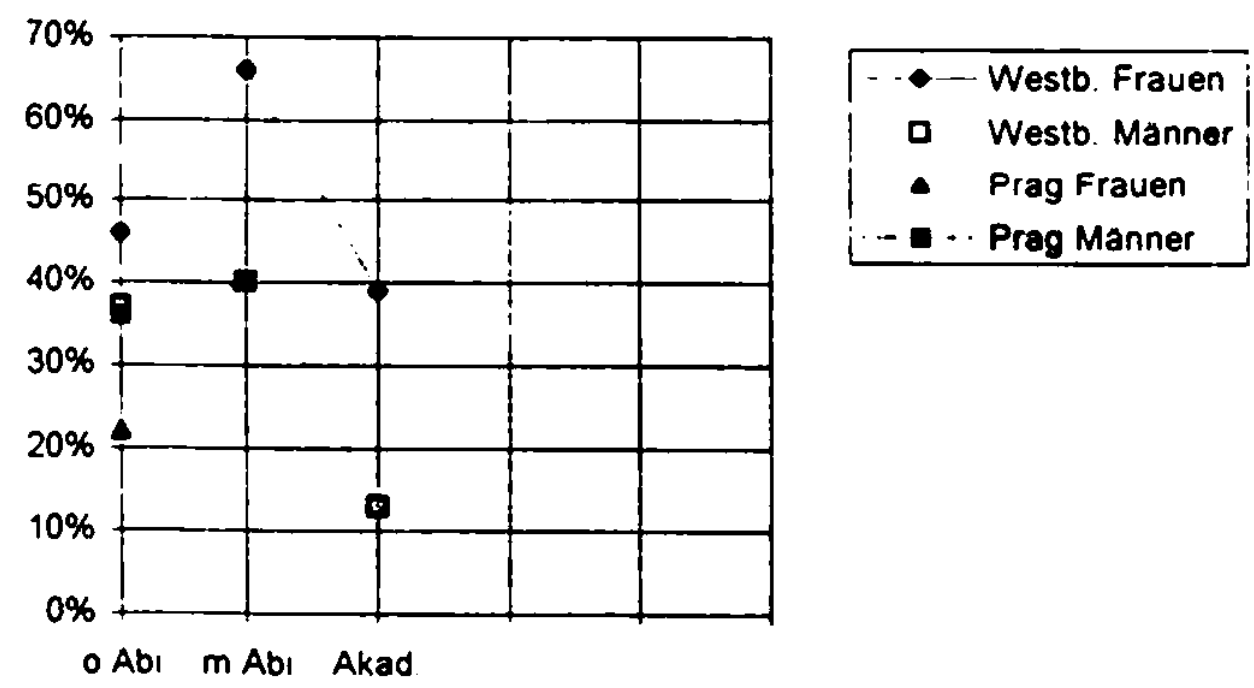
Im Bereich der Konation fielen die Werte deutlich positiver aus als im Bereich des sprachlichen Verhaltens. Der allgemeine Durchschnittswert bei den Nichtstudenten ${ }^{162}$ beträgt $42 \%$. Die Frauen zeigen eine deutlich größere Bereitschaf, das ST zu verwenden als die Männer (50\% zu 34\%). Auf der diastratischen Ebene sind überraschender Weise die Werte der Hochschulabsolventen am niedrigsten (31\%), an der zweiten Stelle stehen die Werte der Sprecher ohne Abitur (39\%). Die höchsten Werte weisen die Sprecher mit Abitur auf (53\%).

Ein wichtiges Moment ist der Vergleich der Ergebnisse im sprachlichen Verhalten mit den Ergebnissen im konativen Subsystem der Einstellung. Wie die Ergebnisse in der folgenden Graphik belegen, klaffen die beiden Variablen - hier in der informellen Situation - deutlich auseinander:

Vergleich Verhalten vs. Konation, allg. Durchschnitt (ohne Studierende):

informelle Situation

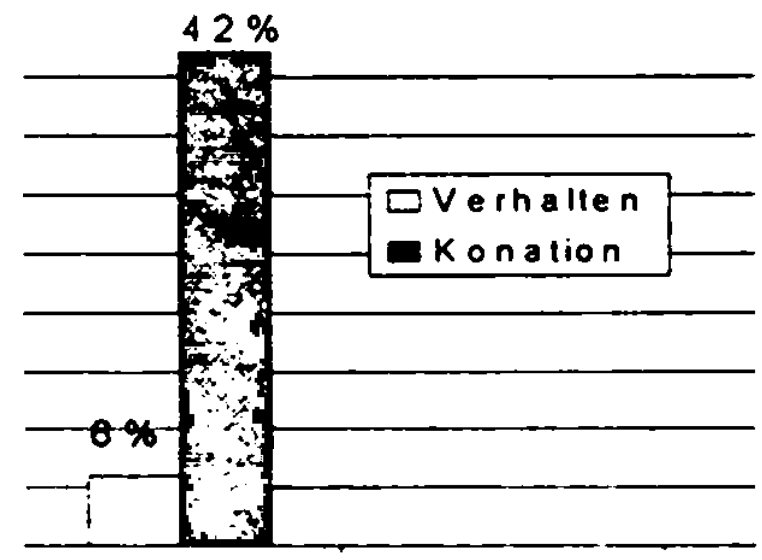

\section{Vergleich Verhalten vs. Konation. Geschlecht:}

informelle Situation

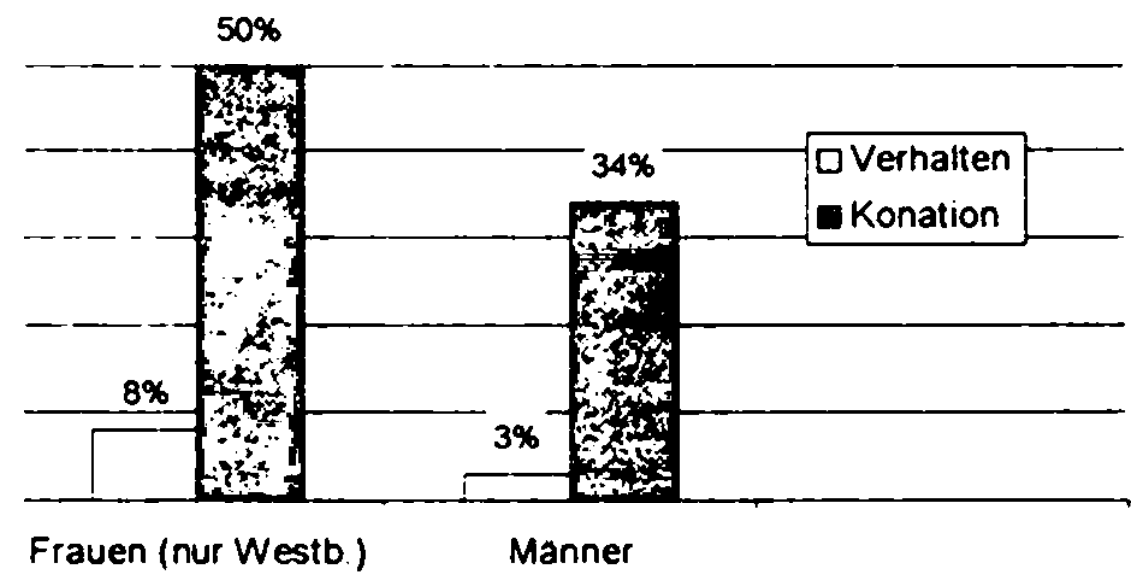

16: Auch hicr wird auf den Vergleich Westbohmen vs. Prag verzichtet. da der Vergleich im Bereich des Sprachverhaliens aufgrund zu weniger Proben nicht durchgeführt werden konnte. Lenka Bayer-9783954790258 


\section{Vergleich Verhalten vs. Konation Bilduns}

Informelle Situation

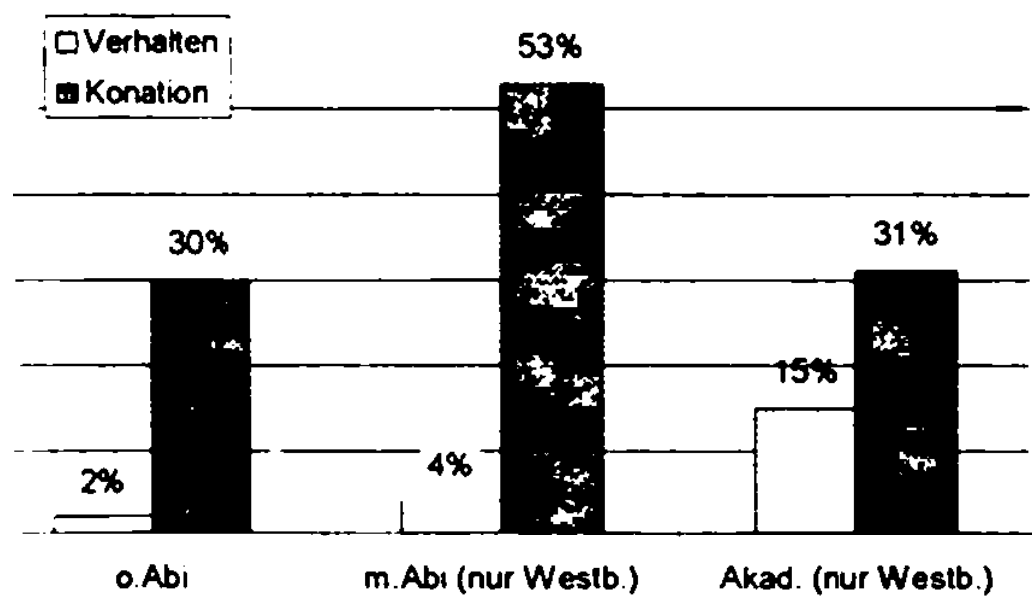

Wie aus unseren Graphiken ersichtlich, würde ein durchschnittlicher Tscheche seiner Vorstellung nach in einer informellen Situation etwa $7 \mathrm{mal}$ (Verhältnis 1:7) häufiger zum ST greifen als er es in Wirklichkeit tut. Die hier festgestellten Diskrepanzen zwischen dem sprachlichen Verhalten und dem konativen Subsystem der Einstellung übertreffen bei Weitem unsere Erwartungen.

Sowohl das Geschlecht als auch die Bildung der Sprecher beeinflussen laut der Ergebnisse das Verhältnis Sprachverhalten vs. Konation. Die Diskrepanz zwischen den beiden Variablen ist bei den Frauen geringer $(1: 6,25)$ als bei den Männern (1:11,33). Auch auf der diastratischen Ebene ergeben sich deutliche Unterschiede. Das Verhältnis bei den Sprechern ohne Abitur weist die größten Diskrepanzen auf (1.19,5), an der zweiten Stelle stehen die Sprecher mit Abitur (1:13,25). Die Sprecher mit Hochschulabschluß können dagegen ihren Sprachgebrauch wesentlich realistischer einschätzen. Das Verhältnis Verhalten vs. Konation ist bei dieser Sprechergruppe nur 1:2,06. Dies beweist den direkten Einfluß der Bildung auf die richtige subjektive Einschätzung des sprachlichen Verhaltens. Somit sind die Akademiker - im Vergleich zu den anderen Bildungsgraden - gut in der Lage, ihre Bereitschaft, das ST zu sprechen in ihrem sprachlichen Verhalten zu realisieren.

Im Gegensatz zu der relativ geringen Anzahl der Proben in der informellen konnten in der formellen Situation fast alle Respondenten ${ }^{163}$ mit Mikrofon interviewt werden. Die Ergebnisse in dieser Situation erscheinen uns von großer Bedeutung, denn gerade die formellen Kontexte so die Mehrheit der tschechischen Bohemisten - sollten die Domäne des Standartschechischen darstellen. Das folgende Zitat spiegelt die Haltung der meisten tschechischen Bohemisten wider ${ }^{1 / 4}$ :

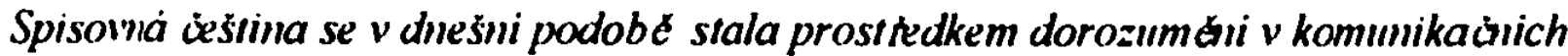
silmacich verejmych a oficiälwich, kde to v ostatmich, $t$ j. imimmich sitmacich se ji "tiva vice menč okrajove. (ULLCNY 2000a, 209)

163 Insgesame 101 Respondenten. davon 65 in Westbolimen und 36 in Prag.

${ }^{1 \text { ks }}$ Weitere Beitrage. igl. Kap. 1. 
Die Ergebnisse der folgenden Auswertungen in der formellen Situation können das obige Zitat nicht bestätigen. Es stellte sich heraus, daß auch in einer formellen Situation zum größten Teil das GT verwendet wird:

Vergleiche im Sprachverhalten: Anteile des ST in der formellen Situation

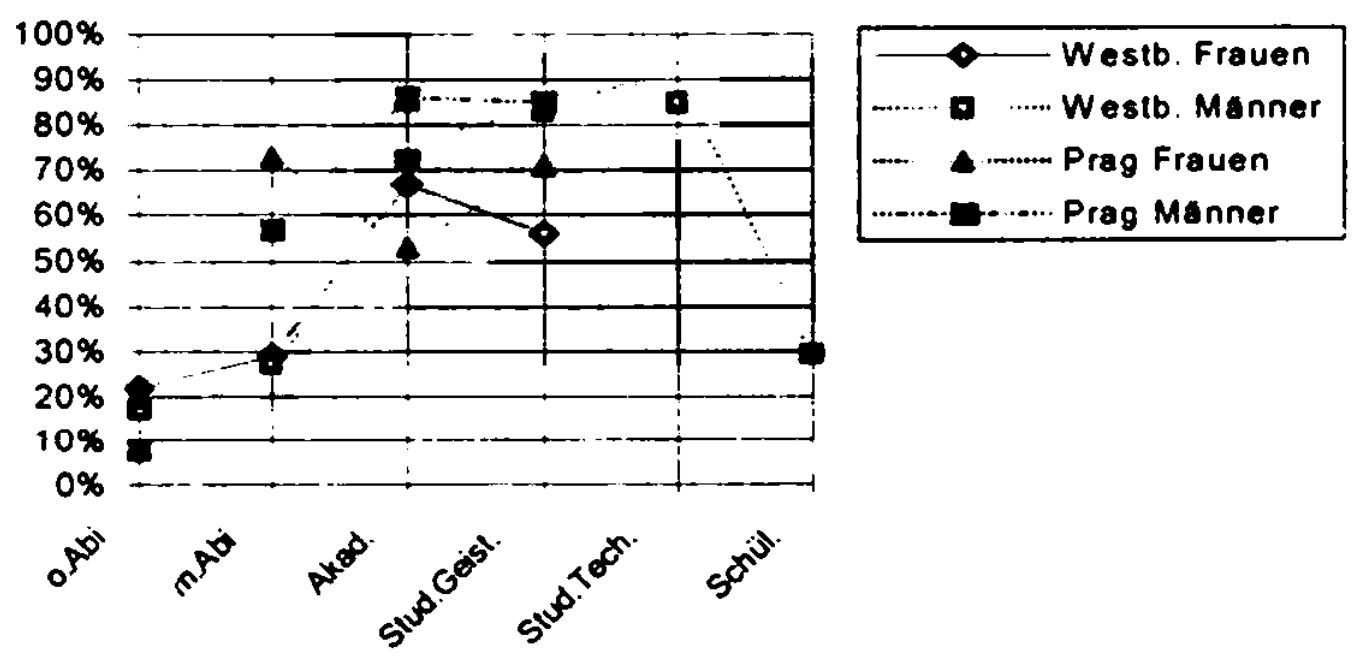

Der Durchschnittswert im Bereich des Verhaltens bei den Nichtstudenten erreichte $41 \%$. In Prag wird das ST häufiger verwendet als in Westböhmen (48\% zu 37\%). Ebenso greifen Frauen häufiger zu ihrer Standardsprache als Männer (44\% zu 38\%). Die Bildung spielt erwartungsgemäß auch hier die wichtigste Rolle. Die Sprecher ohne Abitur verwenden das ST in einer formellen Situation zu 18\% ${ }^{165}$, die Sprecher mit Abitur zu 42\% ST und die Akademiker zu $70 \%$.

Die Studenten der Geisteswissenschaften erreichten einen relativ hohen Wert (72\%). wurden aber - gegen unsere Erwartungen - von den Studenten der Technischen Fakultät überholt $(85 \%)^{166}$. Die Schüler der Technischen Fachoberschule in Pilsen liegen, wie in der Graphik gut erkennbar, mit dem Durchschnittswert von $29 \%$ auf der letzten Stelle, was sicherlich mit dem jugendlichen Alter erklärbar ist.

Vergleiche im konativen Subsystem: Anteile des ST in der formellen Situation

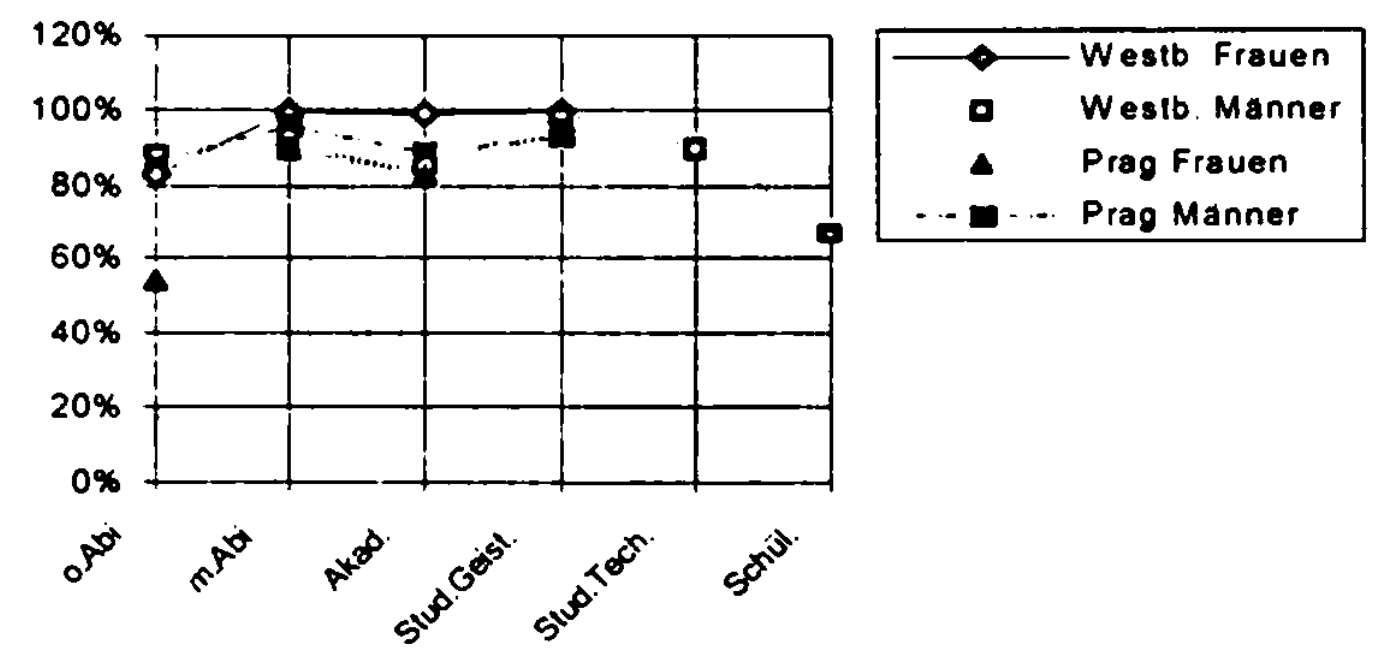

16s In diescin Bercich ist die Differenz zwischen Frauen und Mănnern außergewơhnlich groß. 21\% zu 6\%. Dicse Fesistellung erfolgt hier jedoch nur tnarginal. denn auf solche Vergleiche detaillien einzugehen. würde den Ralumen unserer Arteit sprengen.

${ }^{16}$ Für diese Tatsache fanden wir keine plausible Erklănung. 
Der allgemeine Durchschnittswert im Bereich der Konation (bei den Nichtstudenten) ist deutlich höher $(\mathbf{8 9 \%})$ als im Bereich des Sprachverhaltens. Die westböhmischen Sprecher zeigen mehr Bereitschaft das ST zu verwenden als die Prager (91\% zu 85\%). Zwischen den Geschlechtern besteht dagegen kein Unterschied (à 89\%).

Im Bereich der Bildung stellt sich heraus, daß die Sprechergruppe mit Abitur - ähnlich wie in der informellen Situation - am meisten bereit ist, das ST zu verwenden (95\%). Die Akademiker nehmen in der formellen Situation die zweite Stelle ein (91\%), gefolgt von den Sprechern ohne Abitur (82\%).

Der Durchschnittswert bei den Studenten der Geisteswissenschaften liegt bei $96 \%$, di. nur um 6\% höher als bei den Studenten der Technischen Fakultät. Die Differenz zwischen den weiblichen und männlichen Studierenden ist in diesem Bereich nur minimal (98\% zu 96\%). Ebenso scheinen die Unterschiede in der Diatopie nicht von großer Bedeutung zu sein. Die Prager Studierenden der Geisteswissenschaften würden in einer formellen Situation das ST zu 94\% verwenden, die Pilsner Studierenden zu 99\%.

Der Durchschnittswert der Schüler der Technischen Fachoberschule in Pilsen (67\%) liegt 22\% unter dem allgemeinen Durchschnitt. Dieses Ergebnis korrespondiert mit den Ergebnissen der Schuler in der Kognition in der Praxis, in der Evaluation des ST und im Sprachgebrauch des ST.

Beim Vergleich der Ergebnisse im Bereich des Verhaltens und des konativen Subsystems der Einstellung in der formellen Situation ergeben sich folgende Schemata:

Vergleich Verhalten vs. Konation, Durchschnittswerte: formelle Situation G $\mathrm{CVetat}$ aten

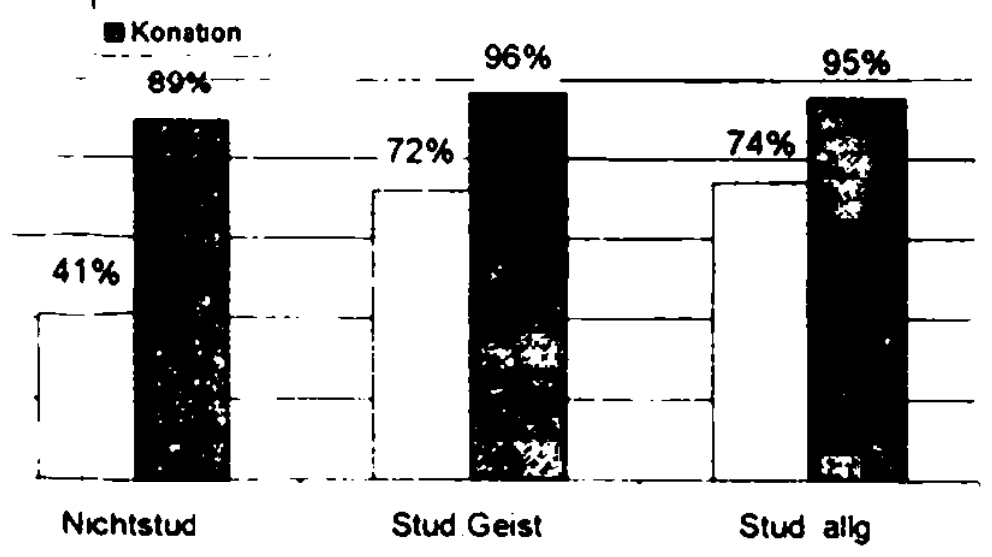

Vergleich Verhalten vs. Konation, Diatopie, Nichtstudenten: formelle Situation

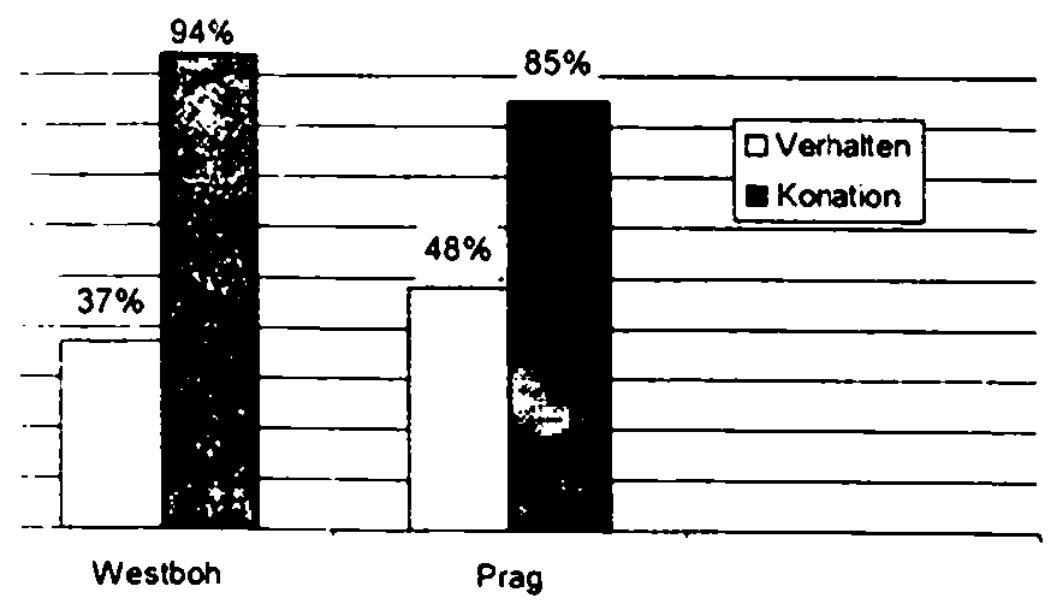


Vergleich Verhalten vs. Konation, Diatopie, Studenten der Geisteswissenschaften: formelle Situation

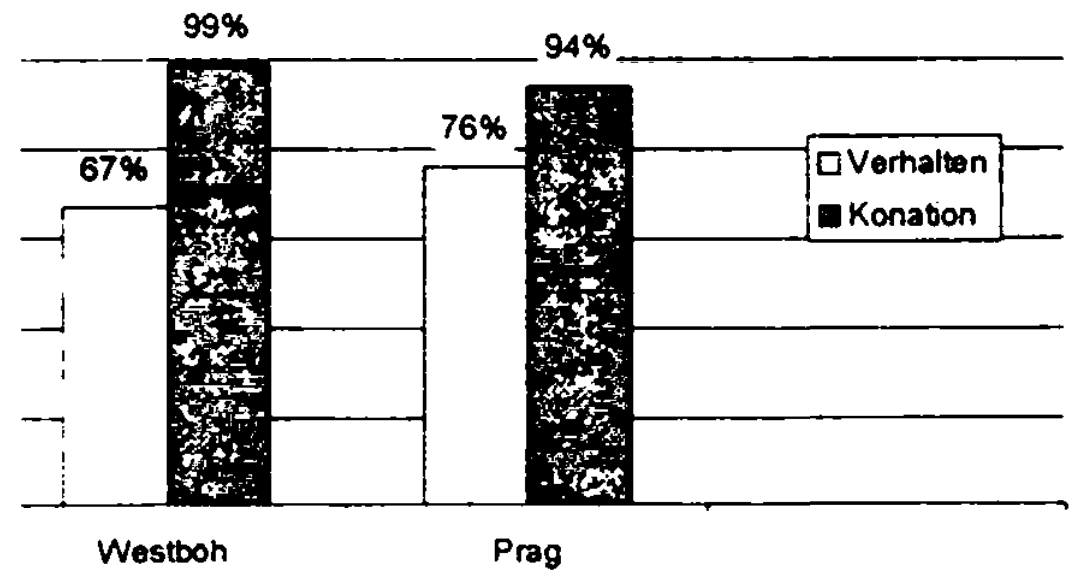

Vergleich Verhalten vs. Konation. Geschlecht, Nichtstudenten: formelle Situation

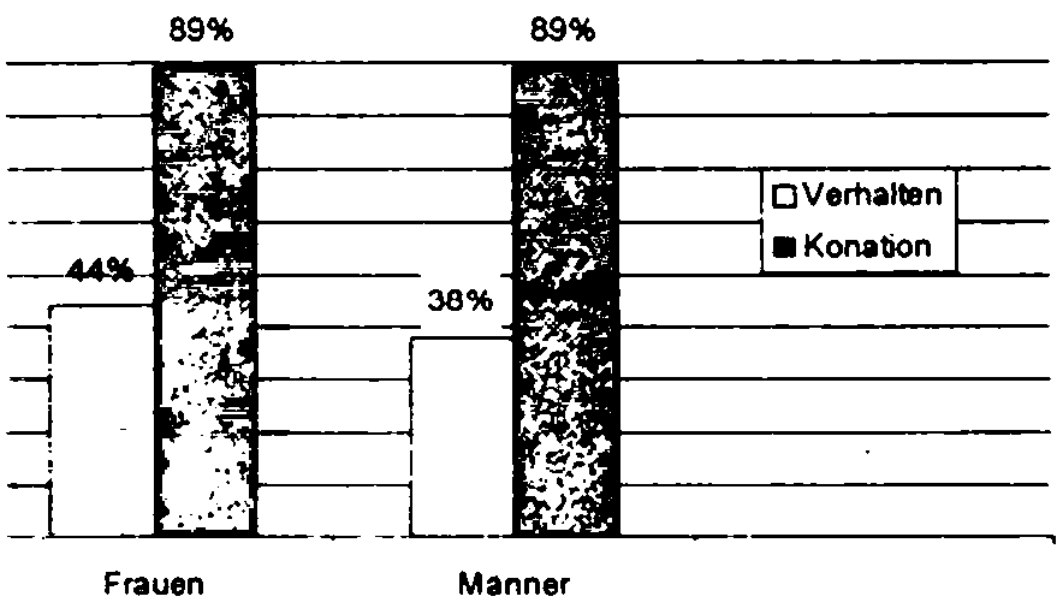

Vergleich Verhalten vs Konation, Geschlecht, Studenten (Geisteswissenschaften). formelle Situation

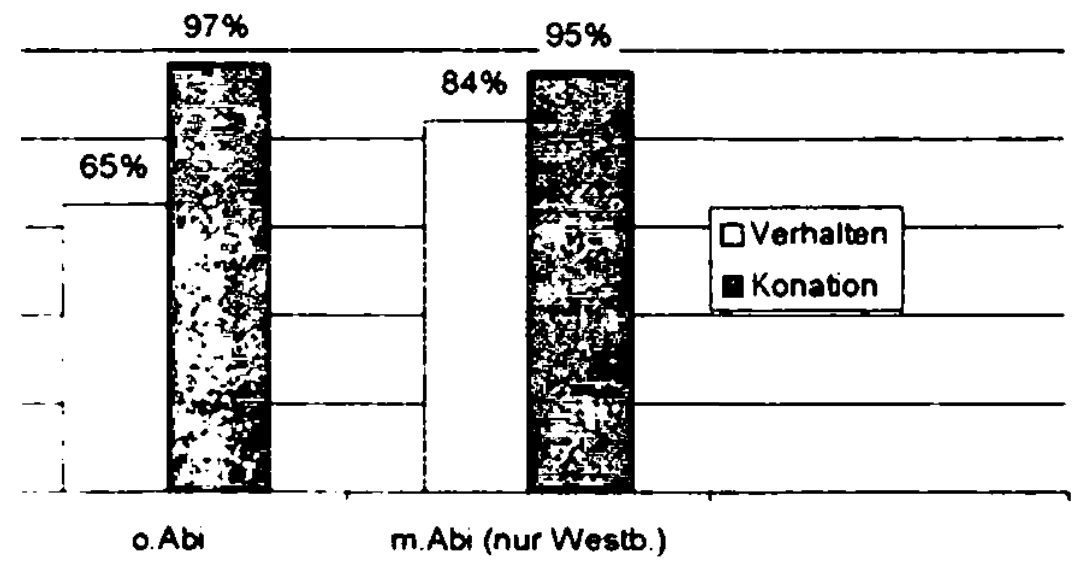


Vergleich Verhalten vs. Konation, Bildung: formelle Situation

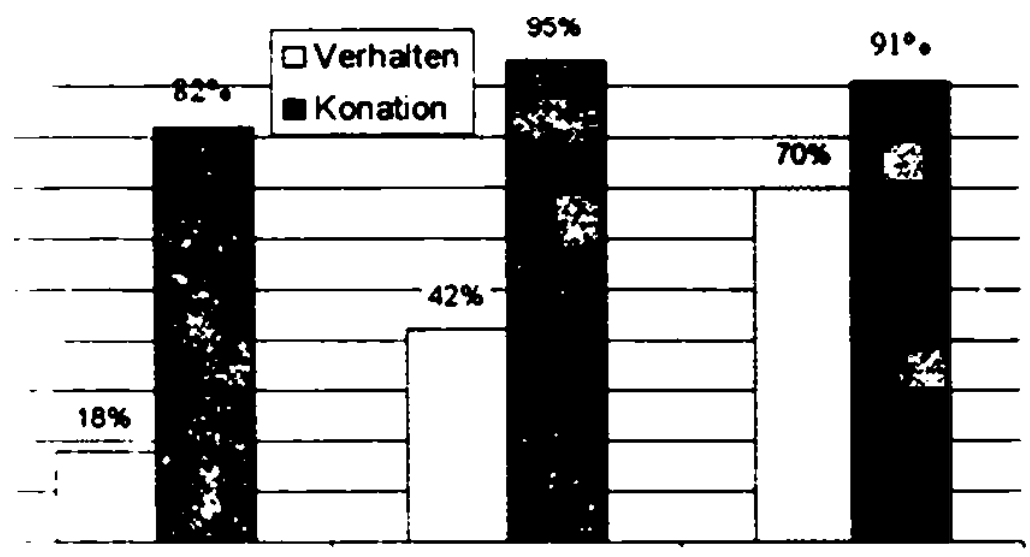

O. Abi m. Abi Acad.

Wie aus den obigen Graphiken zu ersehen, bestehen auch in der formellen Situation im Verhältnis Sprachverhalten vs. konatives Subsystem der Einstellung zum ST größere Diskrepanzen. Ein durchschnittlicher Tscheche zeigt in einer formellen Situation eine wesentlich größere Bereitschaft zum ST zu greifen als es in der Realität der Fall ist (Verhältnis 1:2,2). Bei den Studenten sind die Werte der beiden Variablen homogener (Verhältnis 1:1,3).

Auf der diatopischen Ebene bestehen laut unserer Untersuchung deutlichere Unterschiede zwischen dem Verhalten und der Konation in Westböhmen (Nichtstudenten 1:2.5 / Studenten 1:1,5). In Prag ist das Verhältnis homogener (Nichtstudenten 1:1,8 / Studenten 1:1,2).

Auch das Geschlecht stellt eine Variable dar, die das Verhältnis Gebrauch des ST vs. Bereitschaft hierzu beeinflußt. Die Diskrepanzen bei den Frauen sind kleiner als bei den Männern (Frauen 1:2/Männer 1:2,3). Die Situation im Bereich des Geschlechts bei den Studenten ist - gegen unsere Erwartungen - geradezu gegensätzlich. Das Verhältnis bei den Studentinnen ist 1:1,5, bei den Studenten nur 1: 1,1. Demnach besteht bei den mannlichen Studierenden die geringste Diskrepanz zwischen ihrer Verwendung des ST und ihrer Bereitschaft hierzu Dies bestätigen auch die Werte der Studenten der Technischen Fakultät $(1: 1,05)$ Das Verhältnis Verhalten vs. Konation bei den in Pilsen befragten Schülern ist 1:2,3 . Dieses tangiert den allgemeinen Durchschnitt.

Auch die Ergebnisse auf der diastratischen Ebene deuten bei den Nichtstudenten darauf hin. daß die Bildung der Sprecher die wichtigste Variable darstellt, die das Verhaltnis Sprachverhalten vs. Bereitschaft standardsprachliche Mittel zu verwenden am stärksten beeinflußt Das Verhältnis bei den Sprechern ohne Abitur ist 1:4,5, bei den Sprechern mit Abitur 1:2,3 und bei den Sprechern mit Hochschulabschluß 1:1,3. Dies deutet darauf hin. daß die Sprecher mit höheren Bildungsgraden durchaus in der Lage sind, ihre Bereitschaft, sprachliche Mittel des ST anzuwenden, in ihrem mündlichen Ausdruck zum größten Teil realisieren können. 


\section{Beobachtungen und Respondentenkommentare}

Als gebürtige Tschechin, in Pilsen aufgewachsen, möchte ich an dieser Stelle einige meiner eigenen Erfahrungen und Beobachtungen aus dem sprachlichen Alltag in der heutigen Tschechischen Republik sowie in der ehemaligen Tschechoslowakei zum Ausdruck bringen. Im Vordergrund steht auch in diesem Kapitel der Gebrauch der beiden hier untersuchten Varietäten sowie die Einstellung der Sprecher zu denselben. Besondere Aufmerksamkeit soll in diesem Kapitel der sprachlichen Erziehung in der Schule gewidmet werden ${ }^{167}$

Obwohl alle Respondentenkommentare zusammen mit den Aufnahmen und Auswertungen bereits im Material der Umfrage präsentiert wurden ${ }^{168}$, sollen in diesem Kapitel die in den Fragebögen festgehaltenen Meinungen der Sprecher systematisiert und einige von ihnen genauer untersucht werden. Anhand mancher Respondentenkommentare werden für uns wichtige Tendenzen in der Meinung der Sprecher sichtbar und können gezielt hervorgehoben werden Die beiden Aspekte - die eigenen Erfahrungen bzw. Beobachtungen einerseits und die Meinungen der Respondenten andererseits - sollen hier komplementär zu den Ergebnissen unserer Studie zu einem moglichst komplexen Bild des Gebrauchs des Standard-bzw. Gemeintschechischen sowie der Einstellung zu diesen Varietäten beitragen

Der familiäre sprachliche Kontext in Böhmen wird ausschließlich vom Gemeintschechischen geprägt. Somit wird ein Kind im Vorschulalter, d.h. in der Phase der primären Sozialisation, im aktiven Sprachgebrauch ausschließlich, im passiven zum größten Teil ${ }^{169}$ mit dem GT konfrontiert Auch im Kindergarten ist der sprachliche Umgang sowohl der Kinder untereinander als auch mit den Erzieherinnen vom GT beherrscht. Demnach beschreibt ein in Bohmen aufwachsendes Kind bis zum Antritt des Schulalters scine Welt primär mit den sprachlichen Mitteln des GT. Von einer Reflexion der lautlichen und morphologischen Unterschiede zwischen den Varietäten kann im Vorschulalter noch nicht die Rede sein.

Der Schulbeginn und somit die Einleitung der sekundären Sozialisation, die eine Vervielfaltigung der sprachlichen Kontexte evozient, bildet sicherlich ein wichtiges Moment im sprachlichen Wahrnehmen des Kindes. Die ersten geschriebenen Texte, die ja ausschließlich im ST vertaßt sind, werden von ihm selbst laut vorgelesen Das Kind hört zum ersten Mal sich selbst standardtschechische Merkmale auszusprechen. Dennoch basiert auch in dieser Entwicklungsphase der mündliche Umgang mit seiner Umgebung vorwiegend auf der Ebene des GT Denn außerhalb des Vorlesens, Zitierens und der Erklärung der Fachwörter wird im Unterricht zum größten Teil das GT verwendet. Eine kleine Demonstration enthalt unsere Studie. Eine 35jährige Grundschullehrerin aus einem Dorf unweit von Pilsen bemüht sich zwar in einer formellen Situation ins Mikrofon standardtschechisch zu sprechen, es gelingt ihr dennoch nicht". Ihr Kommentar"", in dem sie die gemeintschechischen Variablen als "Prager larianlen" bezeichnet, als auch ihre Meinung, in Pilsen spreche man mehr Standard als in

16. Die Zeit der primären sowic sckundären Sozialisation in der chemaligen Tschechoslowakei in Verbindung mit meiner spăteren Tătigkeit im Bereich der deutschen Bohemistik - und die dadurch bedingten vielfaltigen Kontakte zur Karlsuniversıtät - bilden cine günstige Grundlage. die spracliliche Situation im heutigen Tschechisclien eu verstelien und wiederzugeten.

IA* Kommentare im Original siche Kap. 6.

169 Im passiven Spracligebrauch kommt ein Kind in Beruhrung mII dem Standardiscliechischen in gerıngem Unifang nur durch dic audiovisuclien Medicn.

$1 \cdots V_{\text {gl. S. }} 91 \mathrm{ff}$.

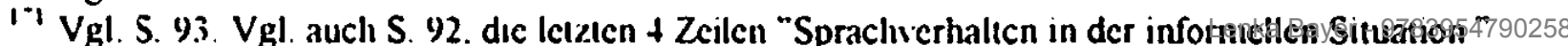


Prag, deuten darauf hin, daß sie sich in der sprachlichen Situation im Tschechischen nur ungenügend orientiert

Auch in den spateren Phasen der Schulausbildung beschrankt sich der Gebrauch des $\mathrm{SI}$ im Unterricht vorwiegend auf das Vorlesen. Auswendiglernen und die Wiedergabe geschriebener Texte. Während unserer Enquete in der Technischen Fachoberschule in Pilsen, die zum Teil direkt im Unterricht verlief, sprach zwar die Dozentin ins Mikrofon und beim Erklären des Unterrichtsstoffes standardtschechisch"?, im Gespräch mit ihren Schulern verwendete sie dennoch fast ausschließlich das $\mathrm{GT}^{1-3}$. Auch meine eigene Erfahrung aus der Schulzeit, bestätigt die Beobachtungen während der Enquete. Im Unterricht wurde das ST im mündlichen Gebrauch auch am Gymnasium "1 nur in unmittelbarer Verbindung mit dem Unterrichtsstoff verwendet.

Diese Beobachtungen und eigene Erfahrungen untermauert ein Kommentar, in dem eine zukunftige Lehrerin im vorletzten Jahr ihres Studiums an der Pädagogischen Fakultat in Pilsen ihre Meinung über die Situation des ST in der Schule abgibt:

Die Sitmation des ST ist in der heutigen Zeit, denke ich, sehr kritisch. Signifikam ist es in den Schulen. Am meisten sind Kinder und Jugendliche betroffen. Sie haben ein Problem sich auszudriicken. Etwas auf ST z" sagen, ist fuir sie ein großes Problem. Daß einige Politiker und offentich wirkende Personen Schwierigkeiten mit dem ST haben, ist eindentig und offensichtlich"is.

Ein ernstzunehmendes Moment in der schulischen Ausbildung ist sicherlich die sprachliche Aufklärung in der eigenen Nationalsprache. Die Schüler sollten seitens der Lehrenden rechtzeitig angeleitet werden, die Varietäten ihrer Sprache zu erkennen und somit ihr eigenes sprachliches Verhalten richtig einzuordnen. Wie aus den Ergebnissen unserer Enquete hervorgeht, ist die kognitive Orientierung der Sprecher in der mährischen Dialektlandschaft obwohl Mähren eine deutlich kleinere Region ist - wesentlich besser als die Orientierung in der sprachlichen Situation in Böhmen. Alle Respondenten konnten mindestens einen der mahrischen Dialekte nennen. Das Bewußtsein jedoch, daß in ganz Böhmen die gesprochene Sprache von der schriftlichen Form abweicht, daß diese mündliche Varietat bereits in den $30 \mathrm{er}$ Jahren von HAVRANEK untersucht und als "obecnd ceština" benannt wurde, ist auch heute nicht vorhanden. Ich kann mich noch sehr gut daran erinnern, daß den mahrischen Dialekten im Tschechischunterricht an unserem Gymnasium viel Zeit gewidmet wurde. Mit dem Begriff "obecna iesstina" kam ich erst in Erlangen als Slavistikstudentin in Berührung ${ }^{1 * 6}$.

Den zweiten Kommentar, der diese Problematik tangiert, gab cine weitere zukünftige Lehrerin aus Pilsen im vorletzten Jahr ihres Studiums ab:

$1=$ Vgl. S. $95 f$

19 Dieselbe Dozentin erlebıe ich auch in einem Seminar an der Padagogıschen Fakultăt in Pilsen. Auch hier "wurden sowiohl ihrerseits als auch scitens der Studenten selır häufig gemeintschechisclie Mittel ventendet.

$1 \cdot$ Das Abitur legte ich an cincın wcsiböhmischen G!̣mnasium ab.

1.3 Vgl. S. I91.

${ }^{1-6}$ Im Jahre 1982. cin Jahr nach dem Abitur - inn Alter von 19 Jahren - verließ ich dic danalige Tschechoslowakei und ubersiedclte nach Deutschland. Erst einige Jahre später. Walırend meines Slavistikstudiums in Erlangen. begann ich allmăhlich die sprachliche Realităt in meiner Heinat au reflekticren. Bercits im Hauptstudium entwickelte sich dieser Forschungsbercich zum Mitlelpnnkı meines wissenschaftlıchen Interesses. 
Das Niveau des Ausdrucks im ST sinkt deutlich auch in den TschechischUnterrichtsstunden. Die Schïler werden weder au Hause noch in der Schule angeleitet. sich im ST anszudrïcken. Oft kömien sie mcht unterscheiden, welcher Ausdruck standardischechisch ist und welcher nicht"

Die mangelhafte sprachliche Information ist sicherlich der dogmatischen Sprachpolitik in der ehemaligen Tschechoslowakei zuzuschreiben. Allerdings stellt sich hier die Frage, warum seit dem politischen Umschwung, der bereits mehr als 10 Jahre zurückliegt, auf dem Gebiet der sprachlichen Information und Ausbildung so wenig geschah. Wie aus den Ergebnissen dieser Studie erkennbar, ist auch unter den Studenten - ausgenommen linguistisch qualifizierte Bohemistikstudenten - und den Schülem, der Begriff "obecná cešrina" und die mit dieser Varietat verbundene Thematik bzw. Problematik weitgehend unbekannt.

Eine klare Unterscheidung der sprachlichen Kontexte in formell bzw. informell ist im sprachlichen Alltag sicherlich nicht möglich. Jeder Sprecher wird tagtäglich mit vielfältigen sprachlichen Situationen konfrontiert, die sich außerhalb einer klaren Kontextdefinition befinden, da sie von jedem Einzelnen subjektiv bewertet werden. Dazu gehört das Einkaufen. Kommunikation im Beruf, z.B. mit Vorgesetzten, Besuche der Ämter, beim Arzt etc

Für die vorliegende Studie wählten wir möglichst typische Situationen: für die informelle Situation den sprachlichen Kontext zu Hause oder bei Freunden / Bekannten, für die formelle Situation den sprachlichen Kontext im Rundfunk, der neben dem Fernsehen die Domäne des ST darstellen sollte. Obwohl der Rahmen der Untersuchung keine weiteren Aufnahmen erlaubte, soll hier das sprachliche Verhalten in einigen mehr oder weniger "halbformellen" Situationen anhand von Beobachtungen bzw. eigenen Erfahrungen skizziert werden

Grundsätzlich vertreten wir die Meinung, daß auch in den "halbformellen" Situationen die Kommunikation vorwiegend auf der gemeintschechischen Basis verläuft. Bei Gesprächen mit den Kunden sprechen z.B Verkäuferinnen zum größten Teil gemeintschechisch' ${ }^{\prime 3}$. Die Ausdrucke aber, die sie quasi als Termini Technici des Verkaufs verwenden, werden in einer bereits automatisierten Form im ST verwendet ${ }^{139}$. Ahnlich ist die Situation in Friseursalons ${ }^{181}$. Gaststätten und Restaurants, wobei sich das Niveau der Einrichtung auch auf der sprachlichen Ebene widerspiegelt. Der Ober, der im Rahmen unserer Enquete interviewt wurde, verwendete nur sehr partiell das ST, allerdings sprach er ins Mikrofon nicht über seine Tätigkeit, sondern uber ein politisches Thema ${ }^{181}$. Ich selbst konnte in einem der gehobenen Prager Restaurants, in dem vorwiegend Unternehmer und sozial bessergestellte Prager verkehren, die verbalen Umgangsformen beobachten. Das gut geschulte Personal verwendete strikt als "Markenzeichen" das ST. In einem Gespräch jedoch, in dem einige Fragen mehr als üblich thematisien wurden, hielt auch hier der Ober die standardtschechische Form nicht ein. Bei einigen Fragen uber das

\footnotetext{
$\because$ Vgl. S. 193

$1^{-8} \mathrm{Vgl}$. S. 78f. Gespräclı der Verfasscrin mit ciner Boutiquererkăuferin

${ }^{1: 9}$ Zu solehen Ausdrücken gehoren z.B. "dekujı, halèr. riden." Wie in der Aufnahme einer Verkäuferin in der informelien Situation festgelialten. veniendete diese fast ausschlieBlich das GT Als sie jedoch aus ihrem

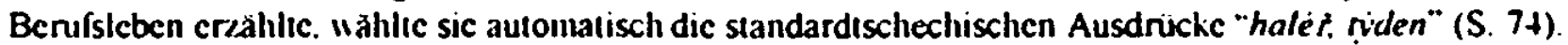

18: Dic ungezwungenen Gespricke zwischen einer Friseuse und Kundin verlaufen wic in einer informelien Situalion in GT.
}

${ }^{181} \mathrm{Vgl}$. S. $167 \mathrm{ff}$. 
Mineralwasserangebot meinerseits antwortete er mit der gemeintschechischen Form "s bublinkama"18:.

In Prag wurden einige Beamtinnen in der formellen Situation, direkt am Rathaus ${ }^{183}$ interviewt. Ihr sprachlicher Ausdruck hebt sich deutlich von den übrigen Aufnahmen in der selben Bildungsklasse - Frauen mit Abitur - ab. Da diese Frauen zum größten Teil über ihre Tätigkeit interviewt wurden, verwendeten sie Formen, die sie bereits automatisch beim taglichen Publikumsverkehr verwenden. Diese Formen waren jeweils standardtschechisch. Darüber hinaus war ihr sprachlicher Ausdruck kontrollierter und dadurch im höheren Maße standardtschechischer als bei den Respondentinnen, die nicht in einem Amt arbeiten. Die von uns interviewte Standesbeamtin äußerte sich im Standardtschechisch, das sie bedingt durch ihren Beruf sehr gut beherrschte

Eine ähnliche Beobachtung machten wir im Gerichtssaal. Die Richterin, die nur im privaten Kontext aufgenommen wurde $e^{i s}$, sprach während einer Gerichtsverhandlung ausschließlich ST. Die Rechtsanwalte verwendeten zum größten Teil ebenso das ST, obwohl ab und zu ein gemeintschechisches Wort fiel. Die Streitparteien und die Zeugen verwendeten dagegen häufig das GT. Diese Beobachtungen deuten darauf hin, daß Personen mit Berufen, die den Gebrauch des ST voraussetzen, durchaus in der Lage sind, standardtschechische Formen zu verwenden ${ }^{185}$. Diese Tatsache impliziert die an sich problemlose Erlernbarkeit des ST und deutet wiederum auf das ungenügende Einüben dieser Varietät in der Schule.

Die Kommunikation mit Ärzten kann in etwa mit der auf den Ämtern verglichen werden Die meisten Ärzte sind ohne Zweifel in der Lage, das ST zu verwenden, die Individualität spielt hier dennoch eine größere Rolle. In der Regel konzentriert sich ein Arzt in einem Gespräch mit seinem Patienten mehr auf die inhaltlichen Probleme als auf die formale Seite der Sprache. Ich habe keinen Arzt in der Erinnerung, der ausschließlich standardtschechisch gesprochen hälle.

Ein interessantes Phänomen, das einer eirgehenden Untersuchung unterzogen werden sollte, ist die Sprache der erst nach der politischen Wende entstandenen Unternehmerschicht ${ }^{186}$. Während dieser Untersuchung sowie unserer Aufenthalte in der Tschechischen Republik fiel und fallt auf, daß sich die Sprecher dieser gesellschaftlichen Gruppe von den anderen Sprechern immer deutlicher abheben. In den formellen Situationen sind sie durchaus in der Lage, sich sowohl auf den sprachlichen Inhalt als auch auf die standardtschechische formale Norm zu konzentrieren. Die meisten von ihnen beherrschen ihre Standardsprache sicherer als die Mehrheit der Bevölkerung. Ihr Ausdruck wirkt elaboriert und trotzdem natürlich. Deutlich spurbar ist dieses Phänomen z.B. in den Privatkliniken, in denen das Empfangspersonal sowohl am Telefon als auch im persönlichen Gespräch mit den Patienten gepflegtes Standardtschechisch verwendet und dieses auch souverän beherrscht. Diese Beobachtungen lassen darauf schließen, daß diese innerhalb der tschechischen Gesellschaft neu entstandene soziale Schicht, die ihr positives Image - gepflegtes Outfit und selbstbewußtes Auftreten - zu ihrem Erfolgsprinzip und gleichzeitig Statussymbol macht, das Standardtschechische unter einem neuen Sichtwinkel betrachtet und verwendet Nämlich als die Varietät. die zu ihrem Image paßt, als ein Statussymbol, ein Werkzeug, das zu ihrem Erfolg beitragen kann.

18: Gemeintsclieclisclic Form des Instr.Pl.. vgl. Kap 3.2

18' Es handelt siclı um cine Referentin im Bereicli Umwelischutz. cine Beamtin am Finanzamı und cin Standesbcamun Vgl. S. 1+5//1+6//149f.

Ixs Im Gerichtssaal war es uns niclıt möglich. Audiozufnahmen zu machen Vgl. S 9isf.

${ }^{18}$ 'Dafuir spriclit auch das Inten iew eines Schauspiclers. sielie S. 169ff

ikn In Kontakt kaınen wir vor allem mit den kleineren bau. Initteiständischen Unternclunern. dic Pancicıverkehr haben. Z.B. Ingenieurbüros. Produktionsfirmen. Autohăuscr. Privatklimkerthęeyer - 9783954790258 
Wie aus den Ergebnissen dieser Studie sowie unseren Beobachtungen hervorgeht, verläuft der größte Teil der Kommunikation im Tschechischen auf der Ebene des GT. Somit kann das GT nicht nur auf der diatopischen, sondern auch auf der diastratischen Ebene als die böhmische Koine definiert werden. Reziprok zu der sprachlichen Wirklichkeit zeichnet sich anhand der Ergebnisse eine positive Einstellung zum ST ab. Offensichtlich schätzen die Tschechen ihre Standardsprache und erwarten, daß das ST als die Sprache der formellen Situationen in den Medien verwendet und in den Schulen unterrichtet wird. Sie wünschten eine Kultivierung des mündlichen Ausdrucks, damit jeder Einzelne fähig wäre, sich im ST zu äußern. Sie selber würden in bestimmten Situationen gerne das ST verwenden bzw. sie denken, daß sie dies tun. Die allgemeine Bereitschaft, das ST zu sprechen, ist unseren Ergebnissen nach hoch.

Diese Schlußfolgenung über die positive Einstellung zum ST untermauern einige Respondentenkommentare, die wir über die Fragebögen gewannen. Insgesamt erhielten wir 51 Kommentare. In 16 davon äußerten sich die Respondenten - häufig Frauen - unzufrieden über die Sprache der Medien. Die meisten kritisieren die nichtstandardliche Sprachform im Fernsehen (und Rundfunk) ${ }^{18:}$. Dieses Phänomen erscheint interessant, denn wie sich in unserer Studie herausstellte, können die meisten Sprecher nicht ausreichend unterscheiden, wann sie selbst standard- bzw. gemeintschechisch sprechen. Im Zusammenhang mit der Sprache der Medien zeigen sie jedoch eine ausgeprägte Sensibilisierung für die Unterschiede zwischen den beiden Varietäten.

Vier Respondenten äußerten sich in ihren Kommentaren kritisch über die Schule und ihre Rolle bei der sprachlichen Erziehung der Kinder. Vier der Respondenten meinten, daß sich jeder bemühen sollte standardtschechisch zu sprechen. Weitere drei Respondenten kritisierten die häufige Verwendung von Fremdwörtern im Tschechischen, zwei wendeten sich gegen die Vulgarismen. Einige weitere Kommentare lobten die Enquete, die ihnen - ihren eigenen Worten nach - half, die sprachliche Situation im Tschechischen bzw. ihren eigenen Sprachgebrauch besser zu reflektieren. Die übrigen Kommentare tangierten unsere Problematik nicht

Abschließend sei an dieser Stelle ein Kommentar zitiert, in dem neben der Selbstreflexion des Respondenten auch das generelle Verhätnis im Gebrauch der beiden hier untersuchten Varietaten zum Ausdruck kommt:

Bei diesem Test wird eimem klar, w'le vielfällig das Tschechische ist und wie schwer. Wer spricht denm mir standardtschechisch? Ein solcher Mensch wurde noch nicht geboren. Es mißre ein fiur das ST programmierter Roboler sein ${ }^{188}$.

1** Vgl dazu Fikurs Sprache der audiovisucllen Medien 


\section{Zusammenfassung und Ausblick auf die weitere Forschung}

Die vorliegende Untersuchung knüpft an die nach der politischen Wende in der Tschechischen Republik wiederaufgenommene linguistische Diskussion um die Stratifikation des Tschechischen sowie das Verhältnis der tschechischen Standardsprache zu der böhmischen Koine, dem Gemeintschechischen an.

Bereits in den 60er Jahren wurden innerhalb der tschechischen Bohemistik die ersten Ansätze für diese Diskussion geschaffen, die jedoch bald nach dem Prager Frühling unterbunden wurde. Die stark präskriptiv ausgerichtete Sprachpolitik des damaligen sozialistischen Machtapparats lehnte den böhmischen Nonstandard ab und distanzierte sich folglich von Diskussionen über diese Varietät. Erst in der liberalen Atmosphäre nach der politischen Wende in der ehemaligen Tschechoslowakei Anfang der 90er Jahre wurde ein fruchtbarer Boden für neue Beiträge zur sprachlichen Situation im Tschechischen geschaffen. Die Diskussion der 60er Jahre erlebte ein Comeback.

Einen der wichtigsten Diskussionspunkte bildete und bildet die von einigen namhaften Bohemisten geforderte Reform des Standardtschechischen, d.h. eine formale Anpassung des sprachlichen Standards an die böhmische Koine, an das Gemeintschechische. Die lautliche und die morphologische Ebene stehen dabei im Vordergrund.

In der Einleitung zu dieser Studie wurden drei Ziele formuliert, die einen Beitrag zu einem allgemeinen Verständnis der aktuellen Situation im heutigen Tschechisch leisten sollten:

1. Das erste Ziel der Studie ist es, anhand eines Sprachkorpus, die Situation im zeitgenössischen gesprochenen Tschechisch ausreichend zu dokumentieren ${ }^{189}$. Das Material für dieses Korpus wurde im Jahre 1998 in Westböhmen und 1999 im Großraum Prag gesammelt. Die Wahl der insgesamt 105 Respondenten verlief nach ausgewählten soziologischen Parametern - dem Geschlecht, dem Wohnort und der Bildung der Sprecher. Aufgenommen wurden Gesprache bzw Monologe in einer informellen Situation, $d h$ in einer von dem Respondenten als privat und ungezwungen empfundenen Atmosphäre. Diese Aufnahmen wurden ohne Kenntnis der Respondenten durchgefuhrt. Dieselben Sprecher wurden nach dem Durchfuhren der verdeckten Aufnahmen in der informellen Situation in eine formelle versetzt. indem sie um ein Interview für eine (fiktive) Radiosendung gebeten wurden. Obwohl der Úbergang von einer informellen in eine formelle Situation bereits in der präexperimentellen Phase methodisch sorgfältig vorbereitet wurde, stellte sich dieser für den Interviewer dennoch als äußerst schwierig heraus. In der Regel gelang es schließlich doch, die meisten Respondenten zu einem formellen Interview zu motivieren ${ }^{100}$.

2. Nachdem die empirische Grundlage geschaffen wurde, konnten wir die zweite Zielsetzung unserer Studie realisieren, nämlich die sprachliche Analyse des gesammelten Materials. Diese erfolgte nach dem Vorkommen der vier signifikantesten lautlichen und morphologischen Merkmale des Tschechischen, deren Form im ST und im GT variiert. Das quantitative

${ }^{159}$ Die Vorbercitung und Durclifulinung der Enquete sowie dic Auswertungen lagen zum großıen Teil in der Regie ciner Person. Aus diesem Grunde konnte die gesprochene Spracle lediglich in zwei böhmisclien Regionen gesammelt werden Trotz dieser regionalen Einsclirankung sind die Sprachproben - kleine regionale Abweichungen ausgenommen - reprassentativ fur den mundlichen Umgang aller bolumischen Regionen. Vgl. SGiNL/Hronlk 1992. 20.

${ }^{100}$ Frauen zeıgten melır Hemmungen. ins Mikrofon zu sprechen als Mănner. 
Verhältnis zwischen den standard- und gemeintschechischen Variablen wurde hier im Zusammenhang mit den von uns festgelegten soziologischen (Geschlecht, Bildung ${ }^{191}$ ), diatopischen (Wohnort ${ }^{19}$ ) und diaphasischen (informelle und formelle Situation) Variablen akzentuiert.

Die Ergebnisse dieser Untersuchung bestätigen einerseits Meinungen der meisten Bohemisten, daß in Böhmen in den informellen Situationen fast ausschließlich gemeintschechisch gesprochen wird. In den von uns durchgefürten Aufnahmen wurde das Standardtschechische durchschnittlich ${ }^{193} \mathrm{zu} 6 \%$, das Gemeintschechische zu $94 \%$ verwendet. Andererseits widerlegen die Ergebnisse unserer Studie die Ansichten und Behauptungen vieler Bohemisten, das ST sei die Varietät, die in den formellen Situationen verwendet würde. Laut der Ergebnisse verwendet der durchschnittliche Tscheche das ST in formellen sprachlichen Kontexten zu $41 \%$. Deutlich häufiger, nämlich zu $59 \%$, greift er auch hier zum GT.

Interessante und sicherlich wichtige Ergebnisse zeichnen sich bei Berücksichtigung der soziologischen und diatopischen Variablen ab. Es stellt sich heraus, daß sowohl das Geschlecht der Sprecher als auch ihr Wohnort und ihre Bildung ihren sprachlichen Ausdruck bzw. Gebrauch der hier untersuchten Varietäten beeinflussen kann.

Laut der Ergebnisse verwenden Frauen in den beiden untersuchten Situationen deutlich

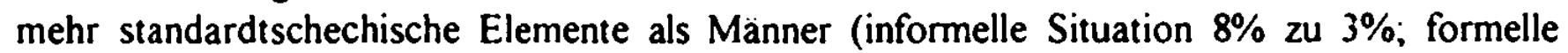
Situation $44 \%$ zu 38\%). Ebenso greifen die Prager Sprecher häufiger zum ST als die westböhmischen (formelle Situation $48 \%$ zu $37 \%$ ) ${ }^{194}$.

Im Bereich der Bildung ergaben sich im Gebrauch des ST die signifikantesten Unterschiede Die Sprecher ohne Abitur erreichten die niedrigsten Werte (informelle Situation 2\%; formelle Situation 18\%). Die Sprecher mit Abitur stehen an der zweiten Stelle (informelle Situation 4\%; formelle Situation $42 \%$ ). Die Akademiker heben sich vor allem in der formellen Situation deutlich von den beiden nuedrigeren Bildungsgraden deutlich ab (informelle Situation 15\%; formelle Situation $70 \%$ ).

Die im Rahmen dieser Studie interviewten Studenten und Schüler wurden stets als eine selbständige Kategorie betrachtet und ausgewertet. Leider war es uns nicht möglich, diese Sprechergruppe in der informellen Situation aufzunehmen In der formellen Situation erreichten sie jedoch erwartungsgemäß die besten Ergebnisse. Bemerkenswert ist, daß nicht, wie erwartet, die Studenten der Geisteswissenschaften (vorwiegend Bohemisten, haufig zukünftige Tschechischlehrer) ${ }^{19}$, sondern die Technikstudenten im mündlichen Ausdruck am haufigsten das ST verwenden (Geisteswissenschaftler $72 \%$. Techniker $85 \%$ ).

Anhand der Ergebnisse der vorliegenden Studie sowie der eingehenden Beobachtungen und Respondentenkommentare wird deutlich, daß die Vertreter einiger Berufsgruppen das Standardtschechische als ihr Werkzeuy betrachten und dementsprechend auch verwenden. Die Vertreter solcher Berufe heben sich von den übrigen Sprechern ab. Sie zeichnen sich durch

${ }^{191}$ Untersuclit wurden alle dreı Bildungsgrade: olıne. mit Abitur und mit Hochschulabschluß. Weitere Differenzienıngen innerhalb dieser Bıldungsgrade nach Fachriclitungen wurden den Ralımen unserer Arbeit sprengen. Besondere Gruppen bilden Studenten der Bolıemistik (Padagogik in Pilsen und Prag: Philosophic in Prag) und der Technischen Fakultăt in Pilsen sowie Schüler der Techuischen Fachoberschule in Pılsen.

19: Aufgenommen b/w: untersuclit wurden nur die Spreclier. dic unindestens 15 Jahre am selben Or leben

193 Die Studenten und Schüler wurden in dic Durchschnittswerte nicht einbezogen. Sie werden stets als selbstandige Gruppen aufgefulin

19. Die Unterschicde zwischen den Regionen konnten im Bereich des Spracliverhaliens nur in der formellen Siluation untersuclu werden. denn nur + der Respondenten in Prag konnten in der informellen Situation aufgenomumen werden.

19: Der erreichte Wert innerhalb dieser Sprechergnuppe war deutlich nedriger als-erkasiaef - 9783954790258 
einen sicheren Umgang mit dem ST aus. Zu solchen Berufsgruppen gehören z.B. Vertreter der Justiz, Beamte in gehobener Position mit häufigem Parteienverkehr sowie die sich nach der politischen Wende neu herausgebildete Schicht der Unternehmer. Gegen unsere Erwartungen gehoren zu diesen Berufsgruppen nicht unbedingt die angehenden bzw. bereits berufstätigen Lehrer

3. Die dritte Zielsetzung dieser Studie bildet eine mit sozialpsychologischen Methoden durchgefuhrte experimentelle Untersuchung. Die Einstellung der Tschechen zu ihrer Standardsprache, ferner auch zu ihrer Koine, dem Gemeintschechischen, steht hier im Mittelpunkt. Das Material für diese Untersuchung wurde mittels einer indirekten Enquete gewonnen, die an die sprachlichen Aufnahmen gekoppelt wurde. Jeder der Befragten sollte nach dem Interview einen Fragebogen ausfüllen, der für die Analyse der Einstellung zu den beiden untersuchten $\mathrm{Va}$ rietäten konzipiert wurde Angestrebt war eine möglichst umfassende Analyse aller drei Subsysteme der sprachlichen Einstellung nach dem in der modernen Sozialpsychologie etablierten Drei-Komponenten-Prinzip.

Die von uns entworfenen thematischen Bereiche des Fragebogens lieferten die Grundlage fur die Auswertung aller drei Komponenten (Subsysteme) der Einstellung: des kognitiven, evaluativen, primär aber des konativen Subsystems. Das zuletzt genannte Subsystem der Einstellung wurde anschließend dem sprachlichen Verhalten gegenübergestellt. Das Verhältnis zwischen den beiden Variablen - dem konativen Subsystem der Einstellung vs. Sprachgebrauch - bildet den thematischen Kern unserer Untersuchung.

Im Rahmen der Analyse des kognitiven Subsystems der Einstellung wurde die praktische Beherrschung des schriftichen ST - vor allem die Fähigkeit, das ST von dem GT zu unterscheiden - sowie das theoretische Wissen über das ST bzw. das Tschechische allgemein fokusiert $^{\text {is }}$. Die praktische Beherrschung des schriftlichen ST ist unseren Ergebnissen nach zufriedenstellend. Die meisten Tschechen erkennen sicher gemeintschechische Formen im Text und konnen sie meistens ohne Probleme korrigieren. Schwächen in der Orthographie sind angesichts ihrer Komplexität ein häufigeres Phänomen. Die Ergebnisse halten sich jedoch auch hier im normalen Bereich. Ein durchschnittlicher Tscheche erkennt das ST in der Praxis zu $75 \%$. In Westböhmen wurden sogar etwas bessere Ergebnisse erreicht als in Prag. Ebenso bewiesen Frauen mehr Sicherheit im schriftlichen ST als Männer.

Die Bildung spielt beim Beherrschen des schriflichen ST freilich eine wichtige Rolle. Die Sprecher ohne Abitur zeigten erwartungsgemäß - $v a$. in der Orthographie des Tschechischen großere Schwächen. Die Sprecher mit Abitur erreichten deutlich bessere Ergebnisse, wurden jedoch von den Hochschulabsolventen und Studenten der Geisteswissenschaften weit übertroffen

Die Studenten der Technischen Fakultät in Pilsen zeigten dagegen im schriftlichen Bereich des ST ein leichtes Defizit, gefolgt von den Schülern der Technischen Fachoberschule in Pilsen, die den letzten Platz einnahmen. Diese Sprechergnuppe erreichte im schriftlichen Tschechisch die schlechtesten Ergebnisse.

Der Stand der theoretischen Kenntnisse der Tschechen über ihre Nationalsprache - primär uber das ST und GT - ist nach unseren Ergebnissen ungenügend: Ein durchschnittlicher Tscheche weist nur etwa $30 \%$ des von uns angenommenen Wissens ${ }^{19}$ auf. Die Variable des Geschlechts sowie die diatopischen Variablen zeigen keine prägnanteren Unterschiede

19 Dicses wurde anhand eines Sprachtests und theoretischer Fragen uberpruft.

19" Das Niveau unserer Fragen cnisprach in clwa cineil Bildungsgrad olhnc Abitur 
zwischen den einzelnen Sprechergruppen. Innerhalb der Bildungsgrade ergeben sich dagegen einige Differenzen. Die Sprecher ohne und mit Abitur können sich in der Theorie der Sprache Geschichte, Schichtung etc. - nur mit deutlichen Schwierigkeiten orientieren (22\% zu 24\%). Die Akademiker bewiesen bessere Kenntnisse. Der Durchschnitt ist aber auch hier mit $49 \%$ unserem Urteil nach relativ niedrig.

Die Studenten der Geisteswissenschaften - zum größten Teil Bohemisten - zeigen sich in den theoretischen Fragen des Tschechischen erwartungsgemäß am sichersten (74\%). Die Techniker - Studenten und Schüler - weisen dagegen eine begrenzte Orientierung auf: Die Schüler liegen im allgemeinen Durchschnitt. Die Studenten nehmen mit nur 19\% sogar den letzten Platz ein.

Das theoretische Wissen über die einzelnen Varietäten des Tschechischen - über die Entstehung des ST etc. - ist sicherlich für einen nicht Involvierten von keiner gravierenden Bedeutung, obwohl es als ein Teil der Allgemeinbildung gilt. Sehr wichtig ist dennoch für jeden Sprecher eine Mindestorientienung in der Sprachsituation seiner Heimat. Jeder Tscheche sollte die wichtigsten Varietäten seiner Sprache kennen. Er sollte wissen, wie er spricht, welcher Dialekt bzw. welche Koine seine Region prägt ${ }^{18 s}$

Wie unsere Ergebnisse zeigen, wissen die Tschechen ${ }^{199}$ nur sehr wenig über die Varietat, die seit den 30er Jahren „obecnà cestina" bezeichnet wird und die de facto ihre Muttersprache ist. Sie können nicht genau sagen, wie in Böhmen gesprochen wird und verwenden für ihren eigenen mündlichen Ausdruck unklare Bezeichnungen wie ,mluvená cestina", .mespisovmá ¿ešsina", "nárec ci" etc. Auch die Tatsache, daß es in Böhmen quasi keine Gegend gibt, in der standardtschechisch gesprochen wird, wird nur sehr selten reflektiert ${ }^{\text {s*" }}$. Diese Defizite sind in einem modernen Land, das seine Sprachpolitik nach einer langen Periode des ungesunden Praskriptivismus in eine neue Richtung lenken mochte, sicherlich anachronistisch.

Eine wichtige Komponente der sprachlichen Einstellung bildet die Evaluation der beiden untersuchten Varietäten. Anhand einiger indirekten Fragen sowie einer direkten Bewertung des ST und des GT wurde es möglich, die positive bzw. negative Haltung der Tschechen zu den beiden Varietäten zu skizzieren.

Generell bewerten die Tschechen ihre Standardsprache positiv. Die Unterschiede auf der diatopischen Ebene sind nur minimal. Ebenso das Geschlecht bildet keine signifikante Variable"' Interessant erscheint jedoch die diastratische Ebene. Die Sprecher mit Abitur bilden die gesellschaftliche Gruppe, die das ST am meisten schätzt Akademiker stehen auf dem zweiten. Sprecher ohne Abitur auf dem dritten Platz. Die Werte der Studierenden der Geisteswissenschaften kongruieren in etwa mit den Werten der Akademiker.

Uberraschend stellte sich heraus, daß die Studenten der Technischen Fakultat in Pilsen sowie die Schüler der Technischen Fachoberschule in Pilsen ihre Standardsprache im Vergleich zu den ubrigen Sprechergruppen deutlich negativer bewerten. Ihre Angaben stehen im direkten Zusammenhang mit ihrer positiven Bewertung des GT und implizieren eine realitatsnahe Einschälzung der sprachlichen Situation im Tschechischen

1'* Hier soll ein kurzer Vergleich init der sprachlichen Siluation im Deutschen gewagt werden. Unabliangig von der Bildung und deın Geschleclıt weiB z.B. jeder Franke. daB er frănkisch spricht. Er kann den von ihmı gesproclienen Dialekt erkennen und benennen unabhängıg von sciner persónliclien Einstellung zu diesem

199 Unablıăıgig ıon ilırer Bildung. Wolınort und Gesclileclıt.

:'* Paradover Weise sind die málırischen Dialekıc. dic an sıch für einen durchschnittlichen Spreclier in Bölumen keıne größcre Bedeutung haben. für jeden cin Begriff.

st Frauen bew crien das ST clwas positiver als Manner. 
Das Gemeintschechische ließen wir von den Respondenten mit einer direkten Frage bewerten. Erwartungsgemäß wird diese Varietät ${ }^{212}$ von der Mehrheit deutlich weniger positiv angesehen als die Standardvarietät. In Prag wird das GT etwas negativer bewertet als in Westböhmen. Die Frauen stehen dieser Varietät negativer gegenüber als die Männer. Innerhalb der drei Bildungsgraden wird das GT am positivsten von den Sprechern ohne Abitur evaluiert. Die Sprecher mit Abitur schätzen ihren Nonstandard etwas geringer, gefolgt von den Akademikern und den Studenten der Geisteswissenschaften.

Als nicht unwichtige Marginalien betrachten wir einige in unserem Fragebogen integrierte Fragen, die mit der sprachlichen Einstellung zwar nicht in unmittelbarem Zusammenhang stehen, die aber einen Einblick in die subjektive Einschätzung der sprachlichen Fähigkeiten sowie der in der Schule erworbenen sprachlichen Kenntnisse eines jeden Sprechers gewähren.

Die meisten Sprecher bewerten beides positiv. Die Differenzen innerhalb der einzelnen Sprechergruppen sind für unsere Untersuchung nicht von größerer Bedeutung, dafür um so mehr die Angaben der Bohemistikstudenten Die zukünftigen Lehrer reflektieren sehr kritisch ihre eigenen sprachlichen Fähigkeiten sowie den Stand ihrer in der Schule erworbenen Kenntnisse. Die Antworten sowie auch einige der Kommentare deuten auf eine unzureichende sprachliche Ausbildung in den tschechischen Schulen hin. Ihren Angaben nach seien die Schulen nicht ausreichend in der Lage, den Sprecher auf eine im ST gefuhrte mündliche Kommunikation vorzubereiten.

Die dritte und für unsere Untersuchung wichtigste Komponente der sprachlichen Einstellung ist ihr konatives Subsystem, konkret die Bereitschaft der Sprecher, das ST in ihrem mundlichen Ausdruck zu verwenden. Die in der modernen Sozialpsychologie fest etablierte Konzeption des Drei-Komponenten-Prinzips der Einstellung postuliert, daß jeder Sprecher, der über Kenntnisse in einer Varietät vertügt und in der Lage ist, diese Varietät positiv oder negativ zu bewerten, auch bereit ist, diese Varietät in der Praxis zu verwenden.

Die Ergebnisse dieser Studie im Bereich der Konation im ST deuten auf eine ausgeprägte Bereitschaft der Tschechen, das Standardtschechische nicht nur in den formellen, sondern auch in den informellen Situationen zu verwenden. Ein durchschnittlicher Tscheche würde seinen Angaben nach das ST in einer informellen zu $42 \%$, in einer formellen Situation sogar zu $89 \%$ verwenden. Auch hier sind es die Frauen, die prozentuell hoher liegen.

Interessant zeichnet sich hier die diastratische Ebene ab. Die Akademiker nämlich stehen mit ihren Angaben zur Verwendungsbereitschaft des ST in der informellen Situation an der letzten. in der formellen an der zweite Stelle. Somit ist die Diskrepanz zwischen dem Verhalten und der sprachlichen Konation innerhalb dieser Sprechergruppe - zusammen mit den Studenten - am geringsten.

Insgesamt stellten wir zwischen der Konation und dem Sprachverhalten der Tschechen deutliche Diskrepanzen fest. In der sprachlichen Praxis wird das ST in Böhmen nur zu einem Bruchteil der festgestellten allgemeinen Bereitschaft hierzu verwendet. Diese Tatsache prägt die sprachliche Situation im heutigen Tschechisch: Das Verhältnis Konation vs. Gebrauch des ST in einer informellen Situation ist bei einem durchschnittlichen Tschechen 1:7, in einer formellen Situation 1:2,2. In Prag fielen die Unterschiede zwischen den beiden Varietäten in der formellen Situation etwas milder aus, ebenso bei den Frauen.

:" In unserem Fragebogen war nucht dic Rede von ..obecne cestına“. denn es wäre nicht deutlich. "

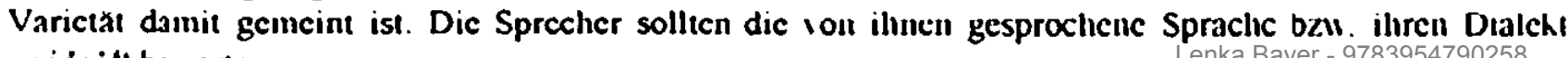
.náfect" bewerten. 
Wie bereits erwähnt, ist die Bildung die Variable, die das Verhältnis Gebrauch vs. Konation am stärksten beeinflußt. Die Sprecher mit Hochschulabschluß sowie die Studenten, unabhängig von der Studienfachrichtung, können im Vergleich zu anderen Sprechern ihre Bereitschaft zur Verwendung des ST in der Praxis am besten umsetzten.

Zum Abschluß unserer Studie möchten wir nun die sich anhand der Ergebnisse herauskristallisierenden Fragen formulieren:

Aus welchem Grumd sind die Tschechen micht in der Lage. ihre ausgeprägte Bereitschaft zum Gebrauch ihrer Standardsprache in ihrem mindlichen Ausdruck z"I realisieren? Wo liegen die Ursachen fiur die signifikanten Diskrepanzen? Welche Dritnariablen intervenieren zwischen diesen zwei Bereichen und verhindern ihre Ammäherung?

Diese Fragen können wir hic et nunc freilich nur hypothetisch beantworten. Die festgestellte positive Einstellung zum Standardtschechischen, die Respondentenkommentare sowie unsere langjahrigen Beobachtungen und Erfahrungen, die während des alten und neuen politischen Regimes gesammelt wurden, deuten darauf hin, daß die Tschechen ihre Standardsprache im heutigen Zustand sehr schätzen. Sie erwarten und verlangen deren Gebrauch seitens der audiovisuellen Massenmedien. Sie bringen sie in Verbindung mit formellen Situationen des öffentlichen Lebens. Sie verpönen Vulgarismen und wehren sich gegen den zur Zeit starken Import von Anglizismen in den Massenmedien. Sie würden sich entschieden gegen eine Reform stellen. die das Standardtschechische an die gesprochene Sprache anpassen würde ${ }^{2 n}$. Trotzdem sprechen sie ihre Standardsprache nicht:

... prisuzovat jim. $x$ imyslnç a vesele delaji chyby a "žvaji cosi oskliveho, je absurdmi.

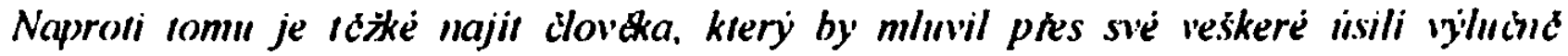
sposovinc a ani profesionalnim bohemistüm to casto jaksi nejde; siálo by sa to si je muhràt, jak mluvi zilcistd doma. (CFRMÁk 1996, 14)

Dieses Phänomen führen wir im Einklang zum obigen Zitat zurück auf eine unzureichende Vorbereitung der Sprecher, sich in der sprachlichen Praxis per Standardtschechisch auszudrüken Die Hauptursache dafur ist wohl in erster Linie im fruheren aber auch im heutigen Schulsystem zu suchen. Die Schule sollte die Institution sein, in der das ST nicht wie bisher fast ausschließlich in seiner schriftichen Form vermittelt, sondern auch im mundlichen Umgang eingeübt wird - ohne die frühere ideologische Präskription und ohne den erhobenen Finger des Lehrers ${ }^{2 *}$. Vor allem die Absolventen höherer Schulen und Universitäten sollten in der Lage sein, in den fur das ST adäquaten Situationen frei und ungezwungen per ST zu kommunizieren

Die nächste nicht minder wichtige Aufgabe der Schule aber auch der Medien sollte die sprachliche Information sein Nach mehr als einem Jahrzehnt Demokratie wissen die Tschechen immer noch nicht, daß sie eine Varietät sprechen, die in ganz Böhmen verbreitet ist und

213 In unserem Fragebogen stellien wir dic direkte Frage nach der Meinung der Respondenten über cine evtl. formale Reform des Standardischechischen.

I4 Vgl. CERN.iK 1996. 1+ff. 
innerhalb der Linguistik als „obecná ceštind“ bezeichnet wird. Den Sprechern sollte dennoch nicht - wie zur Zeit des diktatorischen Regimes - suggeriert werden, daß jeder, der nicht ..spisowna "estina" verwendet, schlecht spricht ${ }^{20}$. Im Gegenteil, jeder in Böhmen lebende Tscheche sollte wissen, daß in Böhmen im täglichen sprachlichen Alltag nicht der sprachliche Standard verwendet wird, daß dieser Zustand bereits Tradition ist und daher durchaus normal und natürlich. Es wäre längst an der Zeit die künstlich aufgesetzte, stigmatisierende Note, die dem GT lange Zeit seitens der (Sprach)Politik gegeben wurde, zu tilgen. Wie schon HAVRANEK erkannte, ist die Standardsprache

jazykovym vyrazem kulturmiho a civilizachiho żvota, vyjadrije postup a visledky myšleni filosofickonábożenskèho, vateckeho, politickèho a auministrativné pránniho ... (HAVRANEK 1963b, 11)

Es besteht also kein Bedarf und keine Notwendigkeit, zu Hause, mit Freunden, mit Kollegen an der Arbeitsstelle etc. standardtschechisch zu sprechen; denn die sprachlichen Mittel, über die das Gemeintschechische verfügt, sind diesen Bedürfnissen durchaus gerecht. In den Kontexten aber, in denen elaborierte, überregionale bzw. repräsentativere sprachliche Mittel erforderlich bzw. angebracht sind, sollten die Sprecher - so der heutige europäische Standard über ihre Standardsprache verfügen können ${ }^{\text {int }}$.

Im Rahmen der Globalisienung sollten die sprachpolitischen Institutionen mittels des Schulsystems und der Massenmedien verstärkt das Wissen vermitteln, daß die sprachliche Situation im Tschechischen innerhalb Europas durchaus keine „ungesunde" Ausnahme darstellt. Auch in anderen Ländern bzw. deren geographischen Teilen unterscheidet sich. ahnlich wie in Tschechien, der sprachliche Standard von dem altäglichen sprachlichen Usus. Im benachbaren Deutschland Z.B. werden die Dialekte gepflegt. Sie sind auch heute noch ein Ausdruck der regionalen Zugehörigkeit. Auch bei gebildeten Sprechern wirkt ihr Heimatdialekt - gesprochen in informellen Kontexten - durchaus natürlich und trägt of sogar eine charismatische Note $e^{x-1}$

Abschließend möchten wir uns der Warnung von „novodobém brusistvi, prehnane a pritom arbiträrmi preskripci“ (CERMAK 1996, 14) anschließen. Nicht eine Reform ist notwendig, um das Standardtschechische zum tatsächlichen sprachlichen Standard zu erheben, sondern

1. eine bessere sprachliche Information der Tschechen über ihre Sprache

2. eine praxisorientierte Vermittlung des yesprochenen ST in den - v.a. hoheren - Schulen und an den Universitäten

3. mehr sprachliche Toleranz statt Präskription

4. mehr Information über die sprachliche Situation anderer Länder.

\footnotetext{
rs Wie aus den Kommentaren deutlich, ist dieses Bewußtsein ticf venwurzelt.

3* Wăhrend meiner Lehrtătigkeit an der Universilăt erlebte ich cinen Studenten. Sol̆n cines Emigrantenclicpaares. der in Deutschland getoren und aufgewachsen. das ST nicht belicrrsclit. Er spriclit perfekt GT Als er ein Referat über Jan Hus auf Tschechisch vortrug. verwendete er nur die ihm eigenen sprachlichen Mittel. Hier wurde deutlich. daß das GT als die Sprache des Alltags nicht über die erforderlichen lexikalischen und syntaktischen Mittel verfugt. Dementsprochend erscheinen auch die morphologischen und lantlichen Mittel des GT in cinem wissensclaftichen Kontext als unpassend und restringien.
}

s' Denken wir doch an den baverischen Ministerpräsidenten Franz Joseph Strauß. Lenka Bayer - 9783954790258 
An dieser Stelle wird uns bewußt, daß die Bohemistik an der Schwelle einer aus der sprachlichen Sicht neuen Zeit steht. Die „ahsence noveho vizkumu“ (CERMAKK 1996, 14) kann mit einer Untersuchung dieses Umfangs nicht behoben werden. Sehr viel Hoffnung legen wir in das bereits weit vorgeschrittene Projekt "Cesky närodni korpus", das auch eine große Sammlung des gesprochenen Tschechisch beinhalten wird und das eine gute Grundlage fur weitere Untersuchungen gewährleistet. Aus diesem Grund überließen wir das gesamte sprachliche Material, das wir im Rahmen der direkten Enqueten in Westböhmen und Prag gesammelt haben, diesem Projekt.

Unserer Auffassung nach liegt die Zukunft in der Empirie, in der Interdisziplinarität und im Teamwork Das gesprochene Tschechisch, das Verhältnis Standard-vs. Gemeintschechisch in Böhmen aber auch in Mähren sowie die Einstellung der Sprecher zu den verschiedenen Varietäten des Tschechischen - die mährischen Dialekte nicht ausgeschlossen - bieten eine Vielfalt an Themen ${ }^{3 \times}$, deren wissenschaftliche Verarbeitung für die Gegenwart und Zukunft des Tschechischen sicherlich von überaus großer Bedeutung ist.

Y* Zum Beispicl die Spraclie der Lelırer die Sprache in Unierriclu in den Schulenka Bayer - 9783954790258 


\section{Literaturverzeichnis}

ALLP()RT, G.W. (21959): Persönlichkeit. Struktur. Entwicklung und Erfassung der menschlichen Eigenart. Meisenheim/Glan.

AltMMANN, G./ GROTJAHN, R. (1988): Linguistische Meßverfahren. In: AMMON, U./ DITTMAR, N./ MATTHEIER, K. J. (ed.) (1988): Soziolinguistik. Halbband 2 (HSK 3.2), S. 1026-1039, Berlin-New York.

AMMON, U./ DItTMAR, N./ MATTHEIER, K. J. (ed.) (1987): Soziolinguistik. Halbband / (HSK 3.1), Berlin-New York

dies (ed) (1988): Soziolingnistik. Halbband 2 (HSK 3.2), Berlin-New York

ATTESLANDER, P. (1988): Befragung In: AMMON, U./ DITTMAR, N./ MATTHEIER, K. J. (ed.) (1988): Soziolinguistik. Halbband 2 (HSK 3.2), S. 940-951, Berlin-New York.

AUWARTER, M. (1988): Das Experiment in der Soziolinguistik. In: AMMON, U./ DITTMAR, N./ MATTHFIER, K. J. (ed.) (1988): Soziolinguistik. Halbband 2 (HSK 3.2), S. 922-931, BerlinNew York.

BECIIERT, J./ WILDGEN, W. (1991): Einfühnung in die Sprachkontaktforschung. Darmstadt.

BÉLIC. J. (1953): .Zảkonodärce novè spisouné ceštiny“. In: Naše feč (36), S. 193-201

ders. (1955): Sedm kapitol o čèstind. Prispecky k problematice národmiho jazyka. Praha.

ders. (1958a): K otázce obecné ceštiny. In. Studie ze slovanské jazykovêdy. Sbornik k 70. narozeninam akademika FRANTISKA TRAVNICKA, S. 429-434, Praha

ders. (1958b): Vznik hovorové ċeštiny a jeji pomèr $k$ ceštinê spisovné. In: Ceskoslovenské pr̉ednášly pro IV. mezinárodni sjezd slavistủ v Moskvê, S. 59-71, Praha.

ders. (1968): „Nalèhavé ùkoly ċeské dialektologie“. In: Slovo a slovesnost (29), S. 287-294.

ders. (1972): Nástın české dialekıologie. Praha

BELIĆ J./ HAVRÁNEK, B./ JedLICKA, A./ TRÁVNIĆEK F. (1961a): “K voprosu ob „obichodnorazgovornom" cešskom jazyke $\mathrm{i}$ jego otnošenii k literaturnomu cešskomu jazyku". In: l'oprosy jazykoznanija (3), S. 44-51.

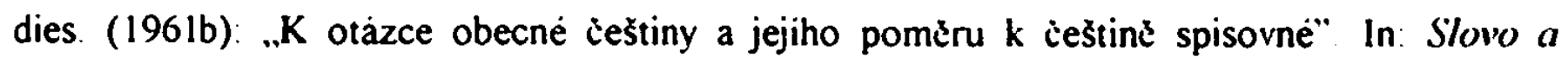
slovesnost (22), S. 98-107.

BERNSTEIN, B (1972): Studien zur sprachlichen Sozialisation. (Sprache und Lernen. Bd 7). Düsseldorf. 
BERRUTO, G. (1987): Varietät. In: AMMON, U./ DITTMAR, N./ MATTHEIER, K. J. (ed.) (1987): Soziolinguistik. Halbband I (HSK 3.1), S. 263-268, Berlin-New York.

BIERHOFF, H.W. ('1998): Sozialpsychologie, ein Lehrbuch. Stuttgart.

Bielefeld, H. U. et al. (ed.) (1977): Soziolinguistik und Empirie. Beiträge zu Problemen der (orpusgewinmming und - auswernung. Wiesbaden.

Bolssevain, J. (1987): Social Network. In: AMMON, U./ DITTMAR, N./ MATTHEIER, K. J. (ed.) (1987): Soziolinguistik. Halbband 1 (HSK 3.1), S. 164-169, Berlin-New York.

BRABCovi, R. (1973): Mestská mluva v Branctyse nad Labem. Praha.

dies. (1985): Slovesné vyjadrováni v mluvených projevech. In: Sbornik Pedagogické fakulty University Karlovy. Filologické studie (XIII), S. 41-59, Praha.

dies. (1996): Novinky z pravopisu a waroslovi. Dobrichovice.

BUSSMANN, H. ( $\left.{ }^{2} 1990\right)$ : Lexikon der Sprachsissenschaft. Stuttgart.

CFRMAK, F (1987): Relations of spoken and written Czech. In: Wiener slawistischer Almanach. Bd. 20, S. 133-150, Wien.

ders. (1993): Spoken Czech. In: ECKERT, E. (ed.) (1993): Varieties of Czech. Studies in Czech Sociolinguistics, S. 27-41, Amsterdam-Atlanta.

ders. (1996): Obecná a spisovná čeština: Pomèr, funkce a metodologie. In: ŠrAMMK. R (ed.) (1996). Spisovnost a nespisovnost dnes. Sbornik Pedagogicke fakulty Masarikovy university. Band 133, S. 14-18, Brno.

ders. (1997): "Obecná ceština: je součásti české diglosie"? In. Jazjkové aktıcality (34), S. 34 43.

Cl:RMAK, F/ S(iAl.l. P (1997) „Výzkum mluvené ceštiny: jeho situace a potreby“. In: Slovo a slovesnosi (58). S 15-25

CHLoIfPEk, J. (1954): K otázce interdialektu. In: ADOLfu KLlLLNERoVI Sbornik jazykovèdnych studii, S 145-153, Opava.

ders. (1974): Knizka o ix.sime. Praha

ders. (1980). „35 let noveho vỳvoje češtiny”. In: Slovo a slovesnost (41), S. 178-184

ders. (1986): Dichotomie spisornosti a nespisonnosti. Brno.

CMI:JRKOVȦ, S / DANFS, F (1993): "Jazyk maleho národa". In: Slovo a slovesnost (54), S. $19-$ 30. 
CONFORTIOVA, H. (1993): "Relations between written and oral forms of language in teaching Czech to foreigners". In: Slovo a slovesnost (54), S. 165-168.

CURiN, F. (ed.) ("1975): lÿvoj ceskèho jazyka a dialekıologie. Učebnice pro pedagogické fakulty. Praha.

CURIN, F./ NOvOTNÝ, J. (1981): l'ývojove tendence soudasné spisovné dešstiny' a kultura jazyka. Praha.

DANES, F. (1963): Jak jsou utvárena ċeská slova, In: DANES, F. et al. (ed.) (1963): O ceštinè pro Cechy. Jazyková príručka, S. 61-100, Praha.

ders. (1964): Malý prinodce po dnešni češtinex. Praha.

ders. (1969): „Kultura mluvených projevi̊. (Jeji základni predpoklady a aktuàlni problemy)“ In: Naše réc(52), S. 95-109.

ders. (1988a): Herausbildung und Reform von Standardsprachen. In: AMMON, U./ DITTMAR, N./ MATTHEIER, K. J. (ed.) (1988): Soziolinguistik. Halbband 2 (HSK 3.2), S. 1506-1515, Berlin-New York.

ders. (1988b): Sprachkultur. In: AMMON, U./ DITTMAR, N./ MATTHEIER, K. J. (ed.) (1988): Soziolinguistik. Halbband 2 (HSK 3.2), S. 1697-1703, Berlin-New York.

ders. (1995a): Situace ceštiny: perspektiva i retrospektiva. In: Spisovná ceština a jazyková kultura 1993. Sbornik z olomoucké konference 23 - 27.8.1993. Band 1, S. 23-31, Praha.

ders. (1995b): O spisovnè a obecnè çeštině. In: Spisovná ceština a jazyková kultura 1993. Sbornik z olomoucke konference 23. - 27.8.1993. Band 1, S. 91-92, Praha.

ders. (1996): Preskripce - anebo "nechte svüj jazyk na pokoji“"? In: Jazyk a jeho uživáni. Sbornik k zivotnimu jubileu OL.DRICHA UıICNEKHO, S. 166-173, Praha.

ders (1997): Was geschieht mit dem heutigen Tschechischen (Triebkräfte und Perspektiven). In: MATHEIER, K.J./ RADTKE, E. (ed.) (1997): Standardisierung und Destandardisierung europaischer Nationalsprachen. S. 201-213, Frankfurt a.M.

DANES, F et al. (ed.) 1963): O češtin̊̉ pro Cechy. Jazykovả prirucka. Praha.

DANEŚ. F./ SGall., P. (1964): Jazyk a souċasná společnost. In: SGial.l. P et al. (ed.) (1964): Cesty moderni jazykovèdy, S. 7-30, Praha.

Di:IM:K, B (1981): Mlıva nejstarši generace Hradce Krälové se samerienim na diferenini jevy hláskove a morfologicke. Hradec Krälové.

ders. (1987): Beżı̉ mluvenyं jazyk nejmladsi generace Hradce Krälovi (hläskoslovi a morfologie). Hradec Králové. 
DFNZ, H. (1987): (Zeitliche) Längs- und Querschnittsuntersuchungen. In: AMMON, U./

DITTMAR, N./ MATTHEIER, K. J. (ed.) (1987): Soziolinguistik. Halbbandl (HSK 3.1), S. 6165. Berlin-New York.

DePREZ, K./ PERSOONS, Y. (1987): Attitude. In: AMMON, U./ DitTMAR, N./ MATTHEIER, K. J. (ed.) (1987): Soziolinguistik. Halbband I (HSK 3.1), S. 125-132, Berlin-New York.

DESERIEV, J.N. (1987): Wechselbeziehung zwischen Soziologie, Linguistik und Soziolinguistik. In: AMMON, U./ DITTMAR, N./ MATTHEIER, K. J. (ed.) (1987): Soziolinguistik. Halbband 1 (HSK 3.1), S. 2-8, Berlin-New York.

DITTMAR. N. (1988): Quantitative Methoden. In: AMMON, U./ DITTMAR, N./ MATTHEIER, K. J. (ed.) (1988): Soziolinguistik. Halbband 2 (HSK 3.2), S 879-893, Berlin-New York.

DeBRowsky, J. (1809): Ausfiihrliches Lehrgebaude der Bohmuschen Sprache. Prag. ND 1940.

ders (1819): Lehrgebaude der Böhmischen Sprache. Prag. ND 1940

DekULIL. M. (1963). „Vyvojové tendence casováni v soucasné spisovné ceštine“. In: DANES, F. et al. (ed.) (1963) O ceštiné pro Cechy. Jazyková prínucka, S. 210-239, Praha.

DUMASIII:V. A.J. (1987): Umgangssprache/ Slang/ Jargon In: AMMON, U./ DITTMAR, N./ MATtHFIER, K J. (ed.) (1987): Soziolinguistik. Halbband I (HSK 3 1). S. 308-315. BerlinNew York

DVoRak, E (1979):"Umélá pravidla' Josefa Dobrovskeho". In: Slovo a slovesnost (40), S. $32-35$.

E(KKRT, E. (ed ) (1993): Iarieties of ("zech. Sindies m Czech Siciolmgunistics. AmsterdamAtlanta.

ENGiEl, U./ SCHWENK1:, O. (ed.) (1972): Gegemwartssprache und Gesellschaft. Beiträge zu akme'llen Fragen der Kommmmikation. Düsseldorf

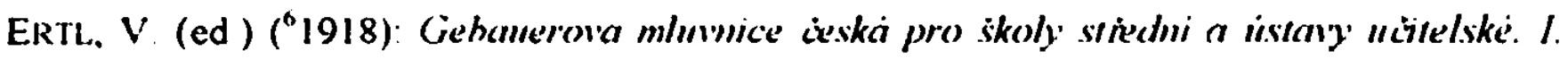
hlaskoslowi - nauku o slow's. Praha.

FILIPEC. J / DANES, F. (ed. ) (1994): Slovmik spisovme čsstiny pro skolu a verejmost. Praha

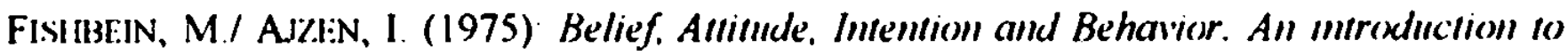
theory and research. Addison-Wesley.

dies. (1980): Inderstanding antindes and predicting social behavior. Englewood Cliffs.

FoRst, V. (1985-1993): Lexıkon ceskéliteratury. Osobmosti, dila, instituce. Bd. I bis 2/2, AL Praha 
FRIEDRICHS, J. ( $\left.{ }^{13} 1980\right)$ : Methoden empirischer Sozialforschung. Opladen

GFBAIJFR, J (21963): Historická mlınnice jazyka ceskèho. Dil l. Hláskoslovi. Praha.

ders. ("1958): Hislorická mlınnice jazyka čského. Dil III. Tvaroslovi II. Casováni. Praha.

ders. (21960): Historickà mlınnice jazyka ceskèho. Dil III. Tvaroslovi l. Sklonováni. Praha.

GILES, H. et al. (1987): Research on Language Attitudes. In: AMMON, U./ DITTMAR, N./ MATTHEIER, K.J. (ed.) (1987): Soziolinguistik. Halbband l (HSK 3.1), S. 585-597, BerlinNew York.

G JEBL, H. (1988): Forschungsethische Probleme. In: AMMON, U./ DITTMAR, N./ MATTHEIER, K.J. (ed.) (1988): Soziolinguistik. Halbband 2 (HSK 3.2), S. 855-866, Berlin-New York.

GRAUMANN, C.F. (1987): Sozialpsychologie In: AMMON, U./ DITtMaR, N./ MATTHEIER, K.J. (ed.) (1987): Soziolinguistik. Halbband I (HSK 3.1), S. 487-494, Berlin-New York.

GREPl. M./ KARL.ik, P. (ed.): (21997): Prirnchi mlunnivce ceśstiny: Brno

GUMPERZ. J (1975): Sprache, lokale Kultur und soziale Identitait. Theoretische Beiträge und Fallstudien. Düsseldorf.

ders. (1976): The sociolinguistic significance of conversational code-switching. In: Papers on language and context. Bd. 46, S. 3-46. Berkeley (California)

ders. (1982): Discourse strategies. Cambridge

ders (1988): Directions in socioliniguisrik. The ethnography of commmmications. Oxford u.a.

H^MMl:R, L. (1985): Prague (olloquial Czech: A case study in code-swirching. Bloomington.

dies. (1986): Code-switching in Colloquial Czech. In: MEY, J.L. (ed.) (1986): Language and discourse: Test and protest, S. 455-473, Amsterdam.

HaRric, M. (1985): Angewandte Linguistik des Deutschen. In: Soziolinguistik. Germanische Lehrbuchsammlung Bd 16. Bern.

HARTUNG, W. (1984): „Der Einfluß sozialer Faktoren auf die Entwicklung der Sprache in der sozialistischen Gesellschaft". In: Slovo a siovesnost (45), S 204-211.

HAUSENBLAS, K. (1962): "Styly jazykových projevů a rozvrstveni jazyka. (K diskusi o obecnè a hovorove ceštinê)". In: Slovo a slovesnost (23), S. 189-201.

ders. (1963): O jazykové kulture. In: DANFS, F. et al. (ed.) (1963): O ceštinê pro Cechy Jazykova priručka. S. 7-25, Praha. 
ders (1968): "K pojeti 'souiasnèho jazyka"”. In: Slovo a slovesnost (29), S. 348-354

hausendlas, K./ Kuchak̉, J. (ed.) (1979): Cestina za školou. Praha.

HAUSENBLAS, O. (1993a): "K tzv. pronikảni obecné češtiny do spisovného jazyka". In: Slovo a sloresnost (54), S. 97-106.

ders. (1993b): „Nevšednost a formálnost jako podstatnè rysy spisovne ceštiny”. In: Naše iec (76). S. 72-74.

HAVRANI:K, B. (1932): Úkoly spisovneho jazyka a jeho kultura. In: HAVRANEK, B./ WEINGART, M. (ed.) (1932): Spisovná ceștina a jazyková kultura, S. 32-84, Praha.

ders. (1934): Nářcči ècská. In: DÉdINA, V. (ed.) (1934): Československá vlastivęda Dil III Jazyk. S 84-218, Praha

ders. (1963a). „Na závèr dvouleté diskuse o obecnè a hovorové ceštine”. In: Slovo a slovesnost (24). S. 254-261.

ders. (1963b): Studie o spisovmem jazyce. Praha.

HAVR.iNEK, B./ JEDLICKA, A. (1960): Českà mlinnice. Praha.

HAVRANEK, B./ WEINGiART, M. (ed.) (1934): Spisovná ceština a jazykovà kultura. Praha

HFLCL. M. (1963): Slovni zásoba ceštiny a jeji zmèny. In: DANES, F et al. (ed.) (1963): O ¿eštin̉̇ pro Čechy. Jazykovà priručka. S. 26-60, Praha

HI:RKNIR. W. ('1991). Eimfuhrung in die Sozialpsychologie Bern

Hil.1., P (1977): Was ist Umgangssprache? In: GIRKI, W./ JACHN(1), H (ed.) (1977): Slavistische Linguistik (Slavische Beiträge. Bd. 120). S. 41-62.

HIRSCHOVȦ, M. (1984): „K jednomu typu výpovẻdi běžnè mluvenè ceštiny“. In: Slovo a slovesnost (45), S. 273-276.

HLASOVA. J. (1988) "O protikladu spisovnosti a nespisovnosti v ceštinč. (JAN CHI.OUPEK. Dichotomie spisovnosti a nespisovnosti)". In: Slovo a slovesnost (49), S. 220-226.

Hiavsa, Z./ Hruskova, Z./ hủrkova, J. et al. (ed.) (1993): Pravidla deského Pravopisu Praha

Hol.tuss, G./ RADTKI: E. (ed.) (1986): Sprachlicher Substandard. Tübingen

Holus, Z / JaneCKova, M. (1993): lihod do české dialektologie. Ceskè Budcjovice

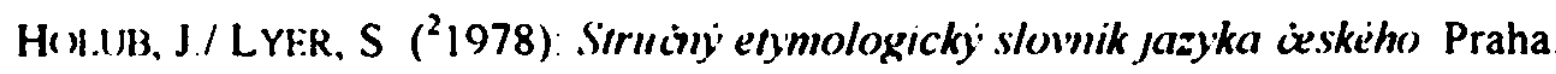


HORALEK, K. (1954): K problematice dẻjin spisovnèho jazyka. In: Studie a práce linguistické. Band 1, S. 369-375, Praha.

HORECKÝ, J. (ed.) (1979): Východiská k teórii spisovnèho jazyka. In: RủżıCKA, J. (1979): $\mathrm{Z}$ teórie spisovneho jazyka, S. 13-22, Bratislava.

HRONEK, J. (1971): „K otảzkảm hlảskoslovi obecnè češtiny”. In: Slavica Pragensia (13), S. 227-239.

ders. (1972): Obecná ceśrina. Praha.

HUJeR, O (1934): Vývoj jazyka československèho. In: DÉDINA, V. (ed): Ceskoslovenskà vlastivèda. Dil III. Jazyk, S. 1-83. Praha.

Hůrkova, J. (1995): Ceskà vyislovmostmi norma. Praha.

JACHNOW, H. (1987): Sprachfunktionsforschung. In: AMMON, U./ DITTMAR, N./ MATTHEIER, K.J. (ed.) (1987): Soziolinguistik. Halbband I (HSK 3.1), S. 612-626, Berlin-New York

ders. (1994): "Bohemistik und Substandardforschung". In: Zeitschrift fiir slanische Philologie (54), S. 358-381.

JEDIICKA, A. (1954): „K otäzce jazykové kultury v tricátých a ìtyricátých letech XIX. stoleti“. In: Stuctie a práce linguistické (1), S. 459-472, Praha.

ders. (1963a). "K problematice normy a kodifikace spisovnè ceštiny (oblastni varianty ve spisovné norme)". In: Slovo a slovesnost (24), S. 9-20.

ders. (1963b): Sklon̉ováni jmen, jeho dnešni stav a vỳrojové tendence In: DANEs. $F$ et al (ed.) (1963): O češtiné pro Cechy. Jazyková prinučka, S. 102-129, Praha.

ders (2078): Spisovnyj jazyk v souciasné kommmikaci. Praha.

ders. (1982): „Typy norem jazykové komunikace”. In: Slovo a slovesnost (43), S. 272-281.

ders. (1990) "Ceská teorie spisovnèho jazyka ve vyvojovych souvislostech linguistického myšleni" In. Slovo a slovesnost (51), S.210-219.

ders. (1994): Josef Jungmann a obrozeneckà terminologie literärné vatmá a linguistickà. Praha

JFDLIČKA, B (ed.) (1936): DOBROI SKX', J.: Geschichte der böhmischen Sprache. Redaktionen von 1791, 1792 und 1818. Prag.

JEDLLCKA, A./ CHLOUPEK, J. (1988): Sprachnormierung und Kodifizierung. In: AMMON, U / Ditrmar, N./ MATTHEIER, K.J. (ed.) (1988): Soziolinguistik. Halbband 2 (HSK 3.2), S 1650-1659, Berlin-New York. 
JeLINEK, J./ STYBLik, V. $\left({ }^{2} 1980\right)$ : Cleni o ceskèm jazyku. Praha.

JelineK, M. (1962): „K normälnimu zpủsubu vyjadłováni”. In: Slavica Pragensia (4), S. 629634.

ders. (3̈1973): Zápisky. Lychäzi k 200. výroci narozeni Josefa Jungmama. Praha

ders. (1995): Kultura jazyka a kultura ieči. In: Spisovná ceština a jazyková kultura 1993. Sbornik z olomoucké konference 23. - 27.8.1993. Band 1, S. 31-40, Praha.

KARI.iK. P et al. (ed.) (1995): Príruchi mlunnice cestiny. Brno

KLANN-Delius, G. (1987): Sex end Language In: AMMON, U./ DITTMAR, N./ MATtHEIER, K.J. (ed.) (1987): Soziolinguistik. I lalbband I (HSK 3.1), S. 767-780, Berlin-New York

KI.AUER, K.C. (1991): Einstellungen. Der Einfluß der affektiven Komponemte auf das kognitive Lirteilen. Göttingen.

KIIEN, W./ WUNDERIICH, D. (ed.) (1971): Aspekte der Soziolinguistik. Schwerpunkıe Linguistik und Kommumiaktionswissenschaft. Bd. 1. Frankfurt/M.

KLIMES, L (1992): Zajpadoceskà vlassivdda. Jazyk. Plzeň.

K(X.HAN. D.C. (ed.) (1973): Sprache und kommumikative Kompetens. Theoretische und empurische Beiträge zur sprachlichen Sozialisation und Primärsprachdidaktik. Stuttgart.

KoRnadt, H.J. et al. (ed.) (1994): Sprache und Kognition. Perspektiven moderner Sprachpsychologie. Heidelberg- Berlin- Oxford

KRAPPMANN, L. (1987): Identität. In: AMMON, U./ DITTMAR, N./ MATTHEIER, K.J. (ed) (1987): Soziolinguistik. Halbband I (HSK 3.1), S. 132-139, Berlin-New York.

Kraus, J (1993): "Rez: SGall., P. e.a.: Variation in Language. Amsterdam/ Philadelphia 1992" In Slovo a slovesnost (54), S. 145-150.

KRALIS, J/ KIICHAR, J/ STICH, A (1981): "Současný stav a vývojové perspektivy kodifikace spisovné cestiny". In: Slovo a slovesnost (42), S. 228-238.

KRAVĊISINNOVA, K. / BEDNÁROVÁ, B. (1968): "Z výzkumu běžně mluvené češtiny". In: Slavica Pragensia (X), S. 305-319.

KRF.MNIT7. G. (1987): Diglossie / Polyglossie. In: AMMON, U./ DITTMAR, N./ MATTHEIER, K.L. (ed.) (1987): Soziolinguistik. Halbband 1 (HSK 3.1), S. 208-218, Berlin-New York.

KRISTR.K. V. (ed.) (1973): Josef Jumgmanm dnešku (1773-1973). Praha 
KROMREY, H. ('1994): Empirische Sozialforschung. Modelle und Methoden der Datenerhebung und Datenauswertung. Opladen.

KUBCZAK, H. (1987): Soziolekt. In: AMMON, U./ DITTMAR, N./ MATTHEIER, K.L. (ed.) (1987) Soziolinguistik. Halbband I (HSK 3.1), S. 268-273, Berlin-New York

KUČERA, H. (1955): Phonemic variations of spoken Czech. In: Slavic Word. Suplement to Word 11, S. 575-602, The Hague.

ders. (1961): The phonology of Czech. The Hague.

KudélKA. M./ ŠIMČEK, Z.I ŠtASTNÝ, V. (1977): Ceskoslovenskà slavistika v letech 19181938. Praha.

KUMPRECHT, K./ OSTMEYER, J. (1994): Cesko-nčmecky' a némecko-českj' slovnik. Praha.

LABOV, W. (1972): Sociolinguistic Pattern. Philadelphia.

ders. (1976/78): Sprache im sozialen Kontext. Beschreibung und Erklarung struktureller und sozialer Bedeutung von Sprachvariation. Bd. 1-2. Herausgegeben von DITTMAR, N./ RIECK, B.O. Kronberg/Ts.

ders. (1994): Principles of Linguistic Change. Voluma I: Imternal Factors. OxfordCambridge.

LAMPRECHT, A./ ŠloSAR, D. (1962): Lỷoj ceského hláskoslovi a tvaroslovi. Praha.

LAMPRECHT, A./ ŠloSAR, D./ BAUER, J. (1977): Historicky vinoj čstiny. Hlaskoslovi. naroslowi, skladha. Praha.

LLEUUWEN-TIRNOVCOVA, J. VAN (1994): Kultursemantisches zur Lexik des Nonstandards. In REITtR. N. (ed.) (1994): Sprachlicher Standard und Substandard in Südost- und Osteuropa (Balkanologische Veroffentlichungen. Bd. 25), S. 165-183, Wiesbaden.

dies. (ed.) (2002): Gender-Forschung in der Slawistik. Beiträge der Konferenz „GenderSprache-Kommunikation-Kultur". 28. April bis 1 Mai 2001, Institut für Slawistik, Friedrich-Schiller-Universität Jena. (Wiener slawistischer Almanach. Sonderband 55). Wien.

LINDENl.AuB, S. (1984): Einstellungen und Handeln. Neue Sicht eines alten Problems. Gottingen.

MARCELESSI, J.B / ElimaM, A. (1987): Language and Society from a Marxist Point of View. In. AMMON, U./ DitTMAR, N./ MATTHEIER, K.J. (ed.) (1987): Soziolinguistik. Halbband I (HSK 3.1), S. 443-452, Berlin-New York.

MARKARD, M. (1984): Einstellung - Krutik eines sozialpsychologischen Grumdkonzeptes. Frankfurt a. M. 
MATHESIUS, V. (1932): O požadavku stability ve spisovném jazyce. In: HAVRÁNEK, B./ WEINGART, M. (ed.) (1932): Spisovná čeština a jazyková kultura, S. 14-31, Praha

ders. (1933): „Probleme der iechischen Sprachkultur“. In: Slavische Rundschau (5), S. 70-85. ders. (1947): Cesstina a obecny jazykospyt. Soubor stati. Praha.

MATtTEIER, K.J. (1987): Alter, Generation. In: AMMON, U./ DITTMAR, N./ MATTHEIER, K.J. (ed.) (1987): Soziolinguistik. Halbband I (HSK 3.1), S. 78-82, Berlin-New York.

ders. (1997): Uber Destandardisienung, Umstandardisierung und Standardisiereung in modernen europäischen Standardsprachen. In: MATTHEIER, K.J./ RADTKE, E. (ed.) (1997): Standardisienung und Destandardisienung europäischer Nationalsprachen, (VarioLingua. Bd 1). S. 1-9, Frankfurt a. M.

MATTHEIER, K.J./ RADTKE, E. (ed.) (1997): Standardisierung und Destandardisierung europäischer Nationalsprachen, (VarioLingua. Bd. 1), Frankfurt a. M.

MUMMENDEY, H.D. (ed.) (1977): Einstellung und V'erhalten. Psychologische Untersuchungen in natirlicher Umgebung. Wien.

ders. (1987): Die Fragenbogen-Methode. Grumdlagen und Anwendung in PersönlichkeitsEinstellumgs- und Selbstkonzeptforschung. Göttingen.

ders. (1988): Verhalten und Einstellung. Untersuchung der Einstellungs- und Selbstkonzeptsänderning nach Änderung des allıäglichen Verhaltens. Berlin u.a.

MÚllerovi. O. (1994): Zur Beziehung der Schriftsprachlichkeit und Nichtschriftsprachlichkeit im gegenwartigen gesprochenen Tschechisch. In: REITtR, N. (ed.) (1994): Sprachlicher Standard und Substandard in Südost- und Osteuropa, (Balkanologische Veröffentlichungen. Bd. 25), S. 211-223, Wiesbaden.

Múlerová, O./ HofFMANNOVA, J./ SCHNEIDEROVȦ, E. (1992): Mlunená déstima v autentickych textech. Jinoiany.

NekVAPIL, J. (1994): Standard und Nonstandard im Tschechischen unter dem Aspekt der Erforschung von Slangs. In: REITER. N. et al. (ed.) (1994): Sprachlicher Standard und Substandard in Südost- und Osteuropa. (Balkanologische Veröffentlichungen. Bd 25), S. 224-235, Wiesbaden.

NÉMEC, I (1990): „Historie matersského jazyka a nảrodni sebevẻdomi“. In: Slovo a slovesnost (51), S 177-184

ders. (1993): "Ceština jako nositel národni svébytnosti a nadnárodnich hodnot". In Slavia (62), S. 9-17. 
NERIUS, D. (1987): Gesprochene und geschriebene Sprache. In: AMMON, U./ DITTMAR, N./ MATTHEIER, K.J. (ed.) (1987): Soziolinguistik. Halbband I (HSK 3.1), S. 833-841, BerlinNew York.

NOVÁ, P. (1962): “O smyslu diskuse o mluvené ceeštinę". In: Slovo a slovesnost (23), S. 266272.

ders. (1992): "K poválečným osudủm české linguistiky". In: Slovo a slovesnost (52), S. 183193.

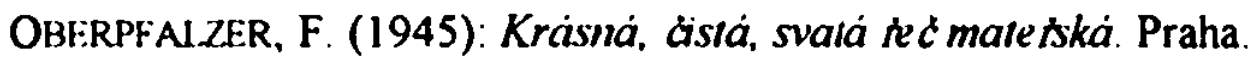

ODLožllik, O. ('1946): Nástin československých déjin. Praha.

Ou.IVuvÁ, V. (1995): Dejiny nové doby 1850-1993. Praha.

OTro, J. (ed.) (1888-1908): Ottưv slovnik naučný. Ilustrovanà enzyklopedie obecných vêdomosti. Bd. 1-27. Praha.

PAI.KOVA, Z (1995): Spisovnỳ standard jazyka v mluvené komunikaci. In: Spisovná ceština a jazyková kultura 1993. Sbornik z olomoucké konference 23. - 27.8.1993. Band 1, S. 76-80, Praha.

PANEvoví, J. (1993): “Ještẻ pàr slov k poválečným osudưm ceské linguistiky". In: Slovo a slovesnost (54), S. 129-132.

PETFRMANR, F. (1980): Einstellungsmessung. Einstellungsforschung. Göttingen.

PETR, J. (1988): „Ke Gebauerovu pojeti jazyka“. In: Slovo a slovesnost (49), S 3-29.

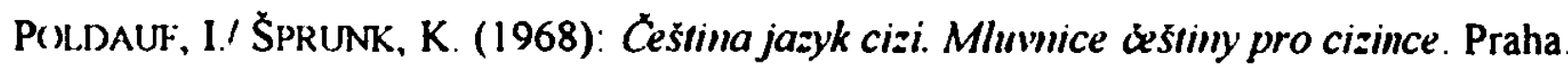

P(IPLACK, S./ SANKOFF, D. (1988): Code-Switching. In: AMMON, U./ DITTMAR, N./ MATTHEIER, K.J. (ed.) (1988): Soziolinguistik. Halbband 2 (HSK 3.2), S. 1174-1180, Berlin-New York.

REHDER, R (1988): Weiteres zum Problem Standardsprache und sprachliche Norm: diachronische Aspekte In: Slavistische Lingıistik (Slavistische Beiträge. Bd. 230), S. 375384.

RrITER, N. (1994): Der standardisierte Substandard im postindustriellen Zeitalter. In: REITER, N. et al. (ed.) (1994): Sprachlicher Standard und Substandard in Südost- und Osteuropa. (Balkanologische Veröffentlichungen. Bd. 25), S. 224-235, Wiesbaden.

Rossi, P. (ed.) (1988): Programm - Evaluation. Einfiihrung in die Methoden angewandter Sozialforschung. Stuttgart. 
RoTH, E. (1967): Einstellung als Determination individuellen Verhaltens. Die Analyse eines Begriffs und seiner Bedeutung für die Persönlichkeitspsychologie. Göttingen.

Rusinova, Z. (1993): Rez.: SGAll, P.i HroneK, J.: Ceština bez prikras, Praha 1992. In: Sbornik praci Filozofické fakulty Brnènské university. Ročnik 36. Rada jazykovědnà (A) Nr. 35, S. 151-156, Brno.

dies. (1995): Spisovná a obecná čeština. In: Spisovná ceština a jazyková kultura 1993. Sbornik $z$ olomoucké konference 23. - 27.8.1993. Band 1, S. 72-76, Praha.

RủžıcKA, J. (ed.) (1979): $Z$ teórie spisovnèho jazyka. Bratislava.

RYAN, E.B. (1987): The Measurement of Language Attitudes. In: AMMON, U./ DITTMAR, N./ MATTHELtE. K.J. (ed.) (1987): Soziolinguistik. Halbband 1 (ISK 3.1), S. 821-832, BcrlinNew York.

SANKOFF, D. (1988): Problems of Representativeness. In: AMMON, U./ DITTMAR, N./ MATTHEIER. K.J. (ed.) (1988): Soziolinguistik. Halbband 2 (HSK 3.2), S. 899-903, BerlinNew York.

SCHIEFELE, U. (1990): Einstellung, Selbstkonsistenz und Verhalten. Göttingen.

SCHMITZ, U. (1987): Sprache und Massenkommunikation. In: AMMON, U./ DITTMAR, N./ MATTHEIER. K.J. (ed.) (1987): Soziolinguistik. Halbband 1 (HSK 3.1), S. 821-832, BerlinNew York.

SCHONBACH, P. (1970): Sprache und Attitüden. Uber den Einfluß der Bezeichmungen "Fremdarbeiter" und "Gastarbeiter" auf Einstellungen gegenüber ausländischen Arbeitern. Bern.

SCHONFELD, H. (1988): Hauptphasen des Forschungsprozesses. In: AMMON, U./ DITTMAR, N./ MATTHEIER. K.J. (ed.) (1988): Soziolinguistik. Halbband 2 (HSK 3.2), S. 893-899, Berlin-New York.

SCHUTZE, F. (1987): Situation. In: AMMON, U./ DIrTMAR, N. MATTHEIER, K.J. (ed.) (1987): Soziolinguistik. Halbband 1 (HSK 3.1), S. 157-164, Berlin-New York

ŠEBESTA, K. (1992): „Obecná ceština v Gebauerově mluvnici ceské pro školy středni a ústavy ucitelskè". In: Slavia Pragensia (35), S. 95-97.

SGALl, P. (1960): „Obichodno - razgovornyj cešskij jazyk”. In: Voprosy' jazykoznanija (2), S. $11-20$.

ders. (1962): "Znovu o obecné ceštinę". In: Slovo a slovesnost (23), S. 37-46.

ders. (1963): „K diskusi o obecné a spisovné ceštine”. In: Slovo a slovesnost (24), S. 244-254. 
ders. (1981): „K některým otázkảm naši jazykové kultury”. In: Slovo a slovesnost (42), S 299-306.

ders. (1990): "Chceme spisovnou ceštinu ochuzovat a cinit nemluvnou? (Na okraj jedné recenze)". In: Slovo a slovesnost (51), S. 60-63.

ders. (1991): "Sbornik z konference o dynamice soucasnè ceštiny". In: Slovo a slovesnost (52), S. 134-137.

ders. (1994): "Spisovnost a kultura vyjadrováni". In: Slovo a slovesnost (55), S. 34-47.

SGiAl.l. P./ HRONeK, J. (1992): Cešrtina bez prikras. Praha.

SGAll, P.i HRONEK, J./ STICH, A./ HORECKY, J. (1992): Variation in Language. Code Switching in Czech as a (hallenge for Sociolingiustics. Amsterdam-Philadelphia.

SGill, P./TRNKOVÁ, A. (1963): "K metodám zkoumáni běžnè mluvenè cešstiny". In: Naše reč (46), S. 28-35.

SIX.. B. (1992): Neuere Entwicklungen und Trends in der Einstellung-Verhaltens-Forschung. In: WITTE, E.H. (ed.) (1992): Einstellung und Verhalten. Beiträge des 7. Hamburger Symposiums zur Methodologie der Sozialpsychologie. (Braunschweiger Studien zur Erziehungs- und Sozialarbeitswissenschaft. Bd. 32), S. 9-34, Braunschweig.

SKALICKA, V. (1962): „Poznámky o obecné ceštine””. In: Slovo a slovesnost (23), S. 201-205.

S̉loSAR, D/ VECERKA, R. (1979): Spisovmý jazyk v déjinaich ceské spole chosti. Praha

ŠMILAUER, V. (1954): Ceske historicke traroslovi s pridankem skladebnim. Praha.

ŠnkOVA, J. (2000): „Mluvená čeština a korpusová lingvistika”. In: Slovo a slovesnost (61), S. $190-202$.

SPOLSKY, B. (1988): Tests in Sociolinguistics. In: AMMON, U./ DITTMAR, N./ MATTHEIER. K.J. (ed.) (1988): Soziolinguistik. Halbband 2 (HSK 3.2), S. 932-939, Berlin-New York.

STtGER, H. (ed.) (1982): Soziolinguistik. Ansätze zur soziolinguistischen Theoriebildung. (Wege der Forschung. Bd. 144). Darmstadt.

STI:NKE, K. (1993): „Die Entstehung des slavischen Schriftums und die Frage der Schriftsprache“. In: Zeitschrift fïr Slawistik (38), S. 53-60.

ders (1995): „Rez:: SGilL, P. e.a.: Variation in Language, Amsterdam - Philadelphia 1992“. In: Die Well der Slaven (40), S. 372-374. 
Śticha. F. (1995): K pojeti spisovnosti. In: Spisovná čeština a jazyková kultura 1993. Sbornik $z$ olomoucke konference 23. - 27.8.1993. Band I, S. 57-60, Praha.

SUK. J. (1991): NEkolik slangoiých slovnikü. Praha.

SVÉRAK, F. (1954): „Ptispèvek k dẻjinàm spisovnè ceštiny“. In: Studie a pràce lingvistickè. Bd. I, S. 405-419. Praha

THOMAS, A. (1991): Grumdriss der Sozialpsychologie. Band 1. Grumallegende Begriffe und Prozesse. Göttingen.

ders. (1992): Grundriss der Sozialpsychologie. Band 2. Individumm. Gruppe. Gesellschaft. Göttingen.

THUSTONE, L.L. (1927): "A law of comparative judgment". In: Psychological revieu (34), S. 273-286.

TiIJstont, L.L./ Chave, E.J. (1929): The measurement of attitude. Chicago.

ToMS, J. (1994): Prehled izioje desko-nómeckych valahü na izemi Ceske republiky od 12. stoleti do roku 19+7. Plzeñ.

ToWnsend), CH.E. (1990): A Description of Spoken Prague (zech. Columbus.

TRAVNIC̈EK, F. (1940): Nástroj myšleni a dorozumcrni. Hrst iwah o spisoimé céṡinex. Praha

ders (1942): O jazykové správnosti In HAVRÁN:K, B / MURAROVSKÝ. J. (ed.) (1942): Cteni o jazyce a poesii. S. 105-228. Praha.

TRosr, P. (1976): "Stridáni kódu". In: Slovo a slovesnost (37), S. 1-3.

UL.KČNY, O. (1995): Spisovnà ceština a hodnotovà orientace. In: Spisovna ceština a jazyková kultura 1993 Sbornik z olomoucke konference 23. - 27.8.1993. Band 1, S. 65-71, Praha.

ders. (2000a): O funkỉnich aspektech některych morfologickych prostredkủ ceskèho narodniho jazyka. In: GAJDA (ed.) (2000): Stylistika Bd. 9, S. 209-215, Opole

ders. (2000b): Dynamika současné spisovné ceštiny: stav, problémy, axiologickè aspekty. In Wiener Slavistisches Jahrbuch. Bd. 46, S. 129-136, Wien.

UTESENẎ, S. (1990): “K jazykovèmu vỳvoji v pohraniči českých zemi”. In: Slovo a slovesnost (31), $S$ 44-57.

ders. (1962): "O územnim rozrüznènı bẻžne mluvenè češtiny na Moravê". In. Slanica Pragnesia (4), S. 577-585 
ders. (1979): "K integračnim procesủm $\mathbf{v}$ bẻżné mluvě ceského venkova (Na okraj sborniku 'souc̀asná vesnice')". In: Slovo a slovesnost (40), S. 164-168.

ders. (1980): "K rozrünẻnosti ¿eskèho národniho jazyka". In: Slovo a slovesnosi (41), S. 7 16.

VACHEK, J. (1942): Psaný jazyk a pravopis. In: HAVRÁNeK, B./ MUKARovskÝ, J. (ed.) (1942): Cteni o jazyce a poesii, S. 231-306, Praha.

VaGAdyova, M. (1988): The Czech Language Situation "Sag mir, was du sprichst..." Ein Beitrag zur sprachlichen Situation in der CSR. In: Standard Language in the Slavic World (Slavistische Beiträge. Bd. 235), S. 33-57, München.

VEY, M. (1946): Morphologie du tchèque parlé. Paris.

VORWERG, M. (ed.) (1971): Psychologische Probleme der Einstellungs- und Verhaltensänderung. Berlin.

WANDRUSZKA, M. (1979): Die Mehrsprachigkeit des Menschen. München.

WEHNER, E.G. (1980): Einfiihrung in die empirische Psychologie. Stuttgart.

WIEHN, E.R. (1987): Schicht. In: AMMON, U./ DITTMAR, N./ MATTHEIFR. K.J. (ed.) (1987): Soziolinguistik Halbband 1 (HSK 3.1), S. 109-114, Berlin-New York.

WII.DGEN, W. (1987): Theorie-Empirie. In: AMMON, U./ DITTMAR, N./ MATTHEIER. K.J. (ed.) (1987): Soziolinguistik. Halbband 1 (HSK 3.1), S. 45-51, Berlin-New York.

Wirte, E.H. (1989): Sozialpsychologie, ein Lehrbuch mit Tabellen. München.

ders (1992a): Das Einstellungskonzept: Alte Themen, neue Klärungsversuche und ein theoretisches Modell. In: WITTE, E.H. (ed.) (1992): Einstellung und Verhalten. Beiträge des 7. Hamburger Symposiums zur Methodologie der Soziapsychologie. (Braunschweiger Studien zur Erziehungs- und Sozialarbeitswissenschaft. Bd. 32), S. 35-60, Braunschweig.

ders (ed ) (1992b): Einstellung und Verhalten. Beiträge des 7. Hamburger Symposiums zur Methodologie der Sozialpsychologie. (Braunschweiger Studien zur Erziehungs- und Sozialarbeitswissenschaft. Bd. 32). Braunschweig. 


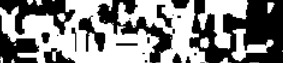

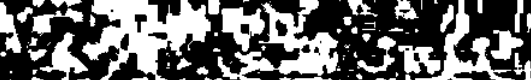

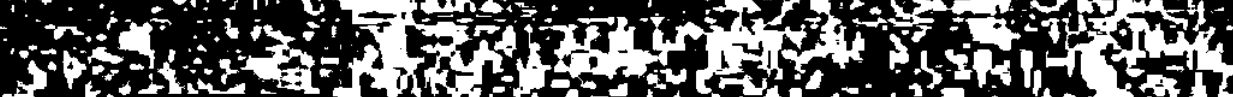

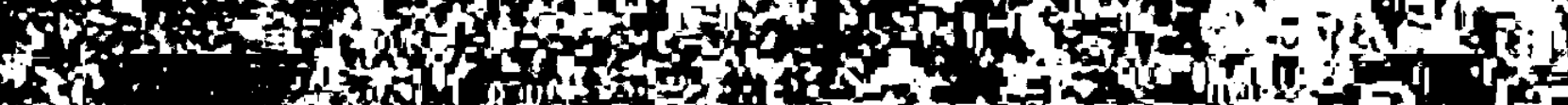

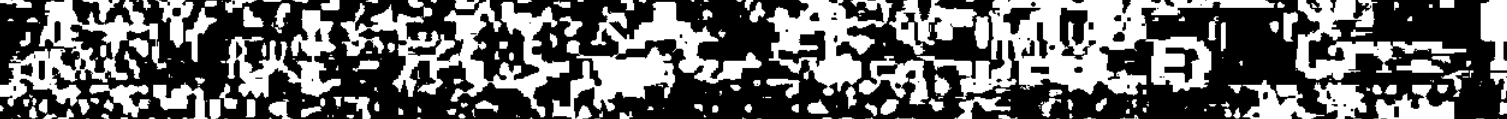

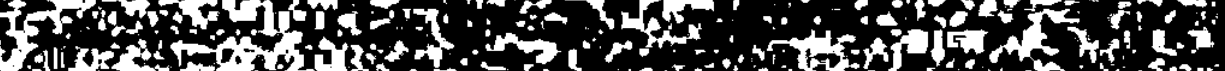

$\because 50$ is

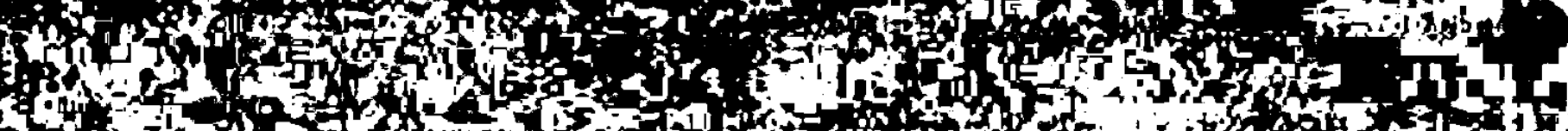
a

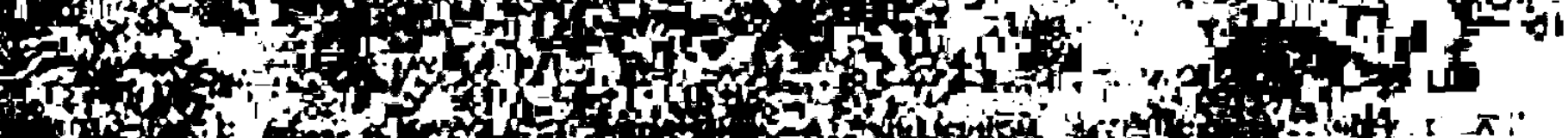

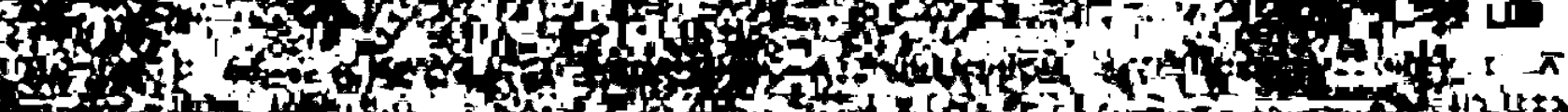

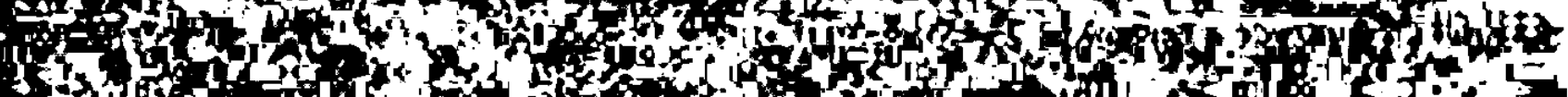

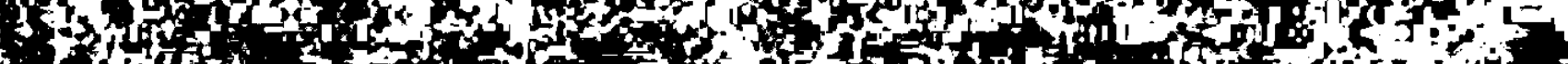

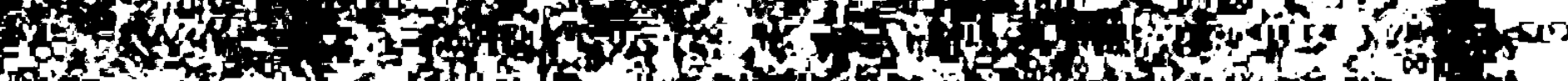
son S

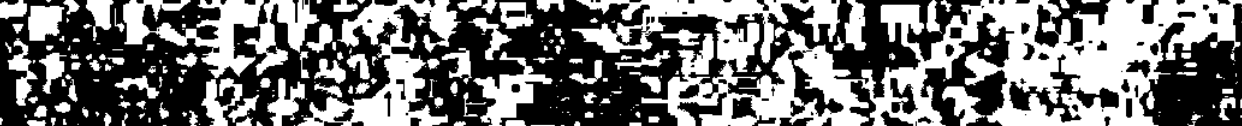

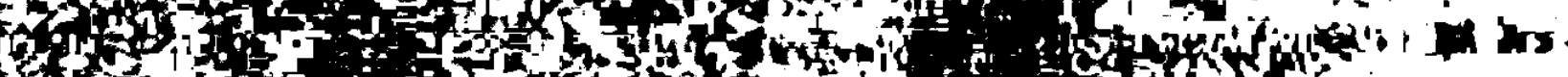

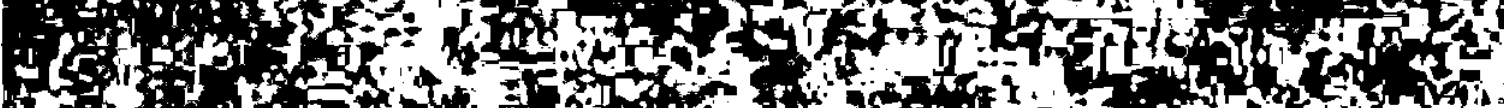
3.5. (1) L t

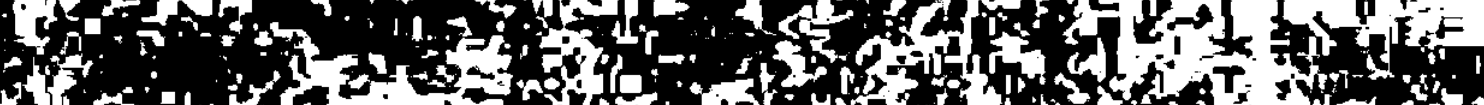
ry

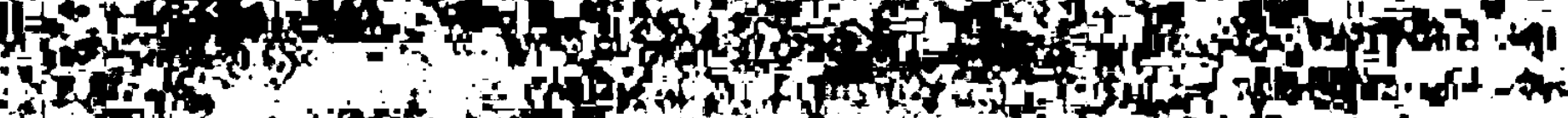

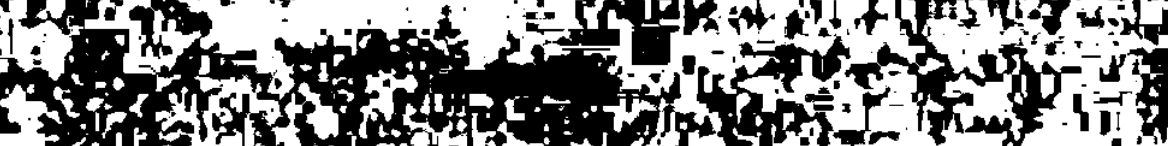

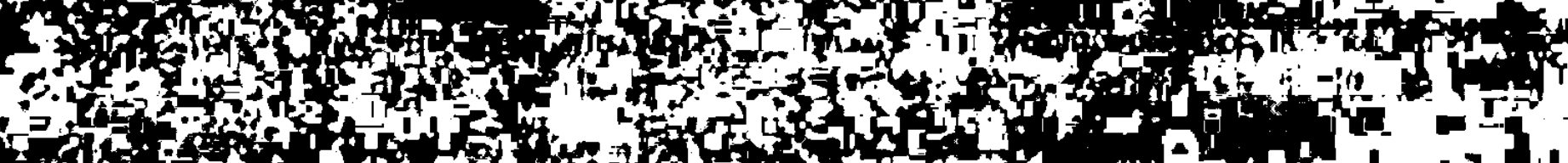
A.

lyes o

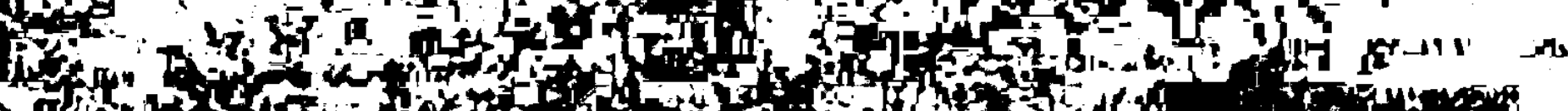

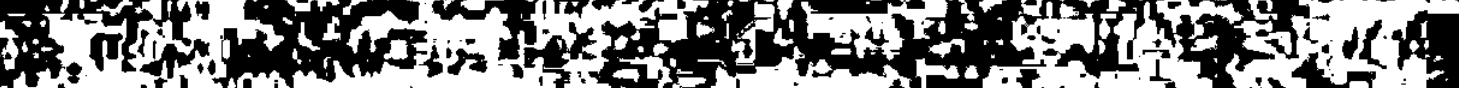

1.

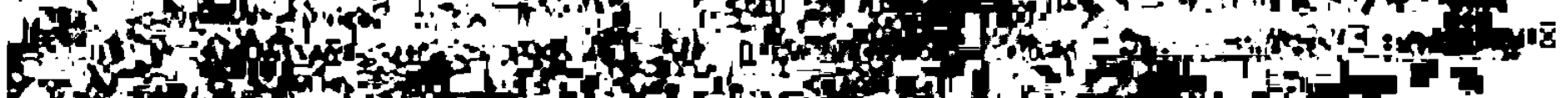

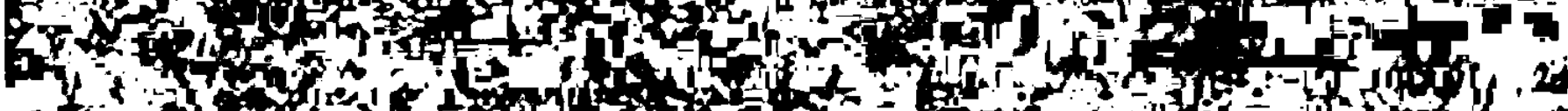

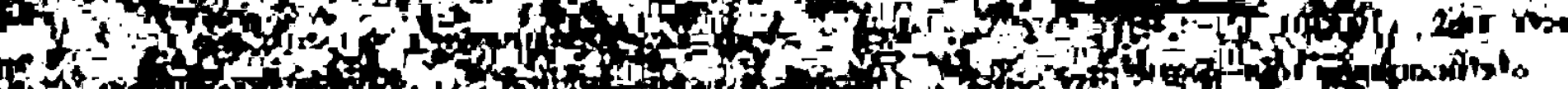
30 to 4 (a) of for 1. ficher 


\section{A N L A G E}




\section{Dotaznik $\mathbf{k}$ vědecké práci $z$ českého jazyka}

Téma: „Znaky mluveného jazyka v Cechách"

Prosime všechny účastniky této akce o svědomité zpracováni tohoto dotazniku a o uvedeni pravdivých údajủ. Pł̉edem dčkujeme všem za vynaloženou námahu a obětovaný c̀as.

Studenti filozofické fakulty (obor bohemistika)

Naše anketa je naprosto anonymni, jen následujíci údaje jsou pro sociolingvistické vyhodnoceni dotaznikủ velmi dúležité:

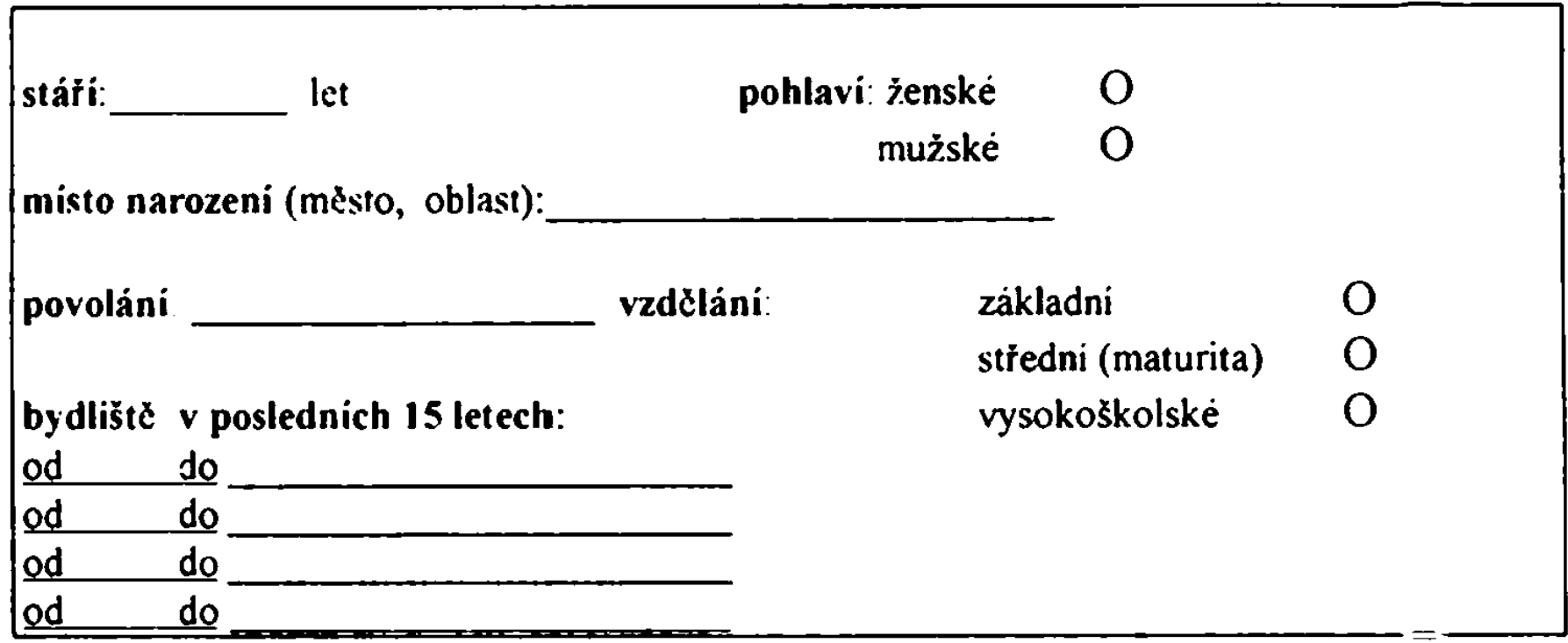

A) Pìedstavte si, že jste učitel nebo učitelka, a že máte opravit následujici text - jsou v nèm totiž. chyby:

Naši mèstský pożảrnici koupili trì nové požảrnické auta $s$ navÿjecima hadicema a poloautomatickými regulatorami tlaku vody. Starosta m̊ssta řek $v$ rozhlasu: „Naši chlapci pracujou nad miru spolehlivě, jsme š́astny, že jich mäme, a jsme na nč velmi hrdý. Mč osobně se libi jejich objetavost. Velmi jsi vážim jejich prace, vždyd' oni chrảnęji naše mèsto pred vohnêm a zachrañujou lidsky životy. Bez nich bysme nemély klidnej život. Doufám, že si budeme i nadále dobre rozumnct."

B) Prosime Vás o zodpovêzení následujicich otázek:

1. Kdy si myslite, že vznikla spisovnả čeština? 
3. Jakà náreči existuji na Moravê?

4. Jak se nazývá mluvený nespisovný jazyk, kterým se mluvi v Čechách?

5. V které oblasti v Čechách nebo na Moravæ̌ se mluvi jen spisovnẽ?

6. Myslite si, že jste byli ve škole dostatec̀nẻ informováni o naši ṙeči: o spisovné češtiné i o nespisovných formach našeho jazyka; o vzniku a vyvoji češtiny?

$$
\text { O ano } \quad \text { ne }
$$

7. Myslite si, Že jste se ve škole naučili dobł̉e ovlàdat pisemnou formu spisovné éeštiny?

$$
O \text { ano } O \text { ne }
$$

8. Myslite si, že jste se ve škole naučli dobře ovládat mluvenou formu spisovné češtiny?

$$
O \text { ano } O \text { ne }
$$

9. Jste si jisti, že dovedete - kdybyste chtęli - mluvit čistou spisovnou češtinou?

$$
\text { O ano O ne }
$$

10. Vadi Vảm, když s Vámi cizi človêk mluvi nespisovnę?

$$
\text { O ano } \quad \text { ne }
$$

11. Vadi Vàm, když televizni a rozhlasovi hlasatelè mluvi pr̆i vysiláni nespisovně?

$$
O \text { ano } O \text { ne }
$$

12. Pràli byste si, aby se nespisovná mluvená ceština postupně príibližila $\mathrm{k}$ češtinê spisovné, takže by jednou zanikla?

O ano $\quad$ ne

13. Płáli byste si, aby se spisovná čeština postupnẻ približzila $\mathrm{k}$ nespisovnè mluvené ceštinê, także bychom jednou psali tak, jak dnes mluvime?
O ano
O ne

14. Souhlasili byste $s$ reformou spisovné češtiny, prì které by byly mluvenè prvky uznány za spisovne, takže by rozdily mezi spisovnou a mluvenou ceštinuu rychle zanikly?

$O$ ano $O$ ne

15. Jakỷ je Vả̌ vztah ke spisovné češtinđ??

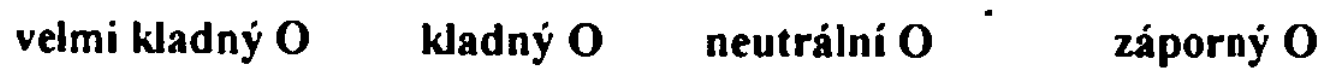

16. Jakỷ je Vảš vztah $k$ nespisovné mluvené èeštinè (Vašemu nảreči)?

$$
\text { velmi pozitivni } O \text { pozitivni } O \text { neutrálni } O \text { negativni } O
$$


C) Nảsledujici tři strany tvơ̌i velmi dủležitou součást naši ankety: Jak mluvíte doma a jak byste mluvili pr̀i oficiálni besedx̉ $v$ rozhlase nebo $v$ televizi?

Tento príklad Vám pomůže pł̆i vyplñování:

Príklad vyplnèni:

\begin{tabular}{|l|c|c|}
\hline & doma & $\begin{array}{l}\mathbf{v} \text { televizi /v } \\
\text { rozhlase }\end{array}$ \\
\hline $\begin{array}{l}\text { 1. dobri vecier } \\
\text { 2. dobrej večer } \\
\text { 3. (misto pro Vaši } \\
\text { osobni variantu. napri. } \\
\text { dobrej vecir) }\end{array}$ & 3 & 1 \\
\hline $\begin{array}{l}\text { 1. stari midlo } \\
\text { 2. stari mejdlo } \\
\text { 3. (stini midlo) }\end{array}$ & 3 & 1 \\
\hline
\end{tabular}

Prosime Vás, vyplňte následujici polička tak, jak opravdu v dané situaci mluvite, popř. jak byste mluvili!

Nespisovné tvary se Vàm jistě zdaji na prvni pohled ponẻkud nezvyklè. To je zpủsobeno tim, że je nejste zvykli vnimat vizuálnê, t.j. v pisemné podobẻ. Proto je dủležité vyslovit si kaźdý spisovny i nespisovny vyraz pro sebe nahlas, abyste ho vnimali akusticky. Pritom je nutne vcitit se $v$ dané situaci (doma, pri besedê $v$ rozhlase nebo televizi) do role mluvici osoby.

S chuti do toho a púl je hotovo!

\begin{tabular}{|c|c|c|}
\hline & doma & $\begin{array}{l}\mathbf{v} \text { televizi / v } \\
\text { rozhlase }\end{array}$ \\
\hline $\begin{array}{l}\text { 1. kulaty stůl } \\
\text { 2. kulatej stül } \\
\text { 3. }\end{array}$ & & \\
\hline $\begin{array}{l}\text { 1. pracuji každẏ tiden } \\
\text { 2. pracuju każdej tcjden } \\
\text { 3. }\end{array}$ & & \\
\hline $\begin{array}{l}\text { 1. mluvil o novem autể } \\
\text { 2. mluvil o novim autẻ } \\
\text { 3. mluvil vo noṿm autẻ } \\
\text { 4. }\end{array}$ & & \\
\hline $\begin{array}{l}\text { 1. dům s maḷ̣mi oknỵ } \\
\text { 2. dưm s malcjma oknama } \\
\text { 3.dủm s maḷ̣ma voknama } \\
\text { 4 }\end{array}$ & & \\
\hline $\begin{array}{l}\text { 1. rảno piji teplé mlèko } \\
\text { 2. rano piju teply mliko } \\
\text { 3. }\end{array}$ & & \\
\hline
\end{tabular}




\begin{tabular}{|c|c|c|}
\hline & doma & $\begin{array}{c}v \text { televizi / v } \\
\text { rozhlase }\end{array}$ \\
\hline $\begin{array}{l}\text { 1. prisli bychom } \\
\text { 2. prisli byssme } \\
\text { 3. }\end{array}$ & & \\
\hline $\begin{array}{l}\text { 1. s mladími pány } \\
\text { 2. s mladejma pánama } \\
\text { 3. } s \text { mladíma pảnama } \\
\text { 4. }\end{array}$ & & \\
\hline $\begin{array}{l}\text { 1. bez velkழ̣ch problèmú } \\
\text { 2. bez velkejch problémú } \\
\text { 3. }\end{array}$ & & \\
\hline $\begin{array}{l}1 \text { musim se umit mídlem } \\
\text { 2.musim se umejt mejdlem } \\
\text { 3. }\end{array}$ & & \\
\hline $\begin{array}{l}\text { 1. rodice pracuji doma } \\
\text { 2. rodice pracujou doma } \\
\text { 3. }\end{array}$ & & \\
\hline $\begin{array}{l}\text { 1. jdeme ke známím } \\
\text { 2. deme ke známejm } \\
\text { 3. deme ke znám!m } \\
\text { 4. }\end{array}$ & & \\
\hline $\begin{array}{l}\text { 1. déti maluji barevnịmi } \\
\text { tužkami } \\
\text { 2.déti malujou barevnụma } \\
\text { tužkama } \\
\text { 3.déti malujou barevnejma } \\
\text { tužkama } \\
\text { 4. }\end{array}$ & & \\
\hline $\begin{array}{l}\text { 1. potrebuji nove brile } \\
\text { 2. potrebuju novy' brejle } \\
\text { 3. }\end{array}$ & & \\
\hline $\begin{array}{l}\text { 1. miluji ruchlá auta } \\
\text { 2. miluj̣i rochlé auta } \\
\text { 3. miluju ruchḷ auta } \\
\text { 4. }\end{array}$ & & \\
\hline $\begin{array}{l}\text { 1. mladi ččsti maliři } \\
\text { 2. mladì ceský malirì } \\
\text { 3. }\end{array}$ & & \\
\hline $\begin{array}{l}\text { 1. musim bit doma } \\
\text { 2. musim bejt doma } \\
\text { 3. musim bejt doma } \\
\text { 4. }\end{array}$ & & \\
\hline $\begin{array}{l}\text { 1. mám hodneho kolegu } \\
\text { 2. mám hodnịho kolegu } \\
\text { 3. }\end{array}$ & & \\
\hline $\begin{array}{l}\text { 1. mluvila o svém životé } \\
\text { 2. mluvila o sı̣̂m żivoté } \\
\text { 3. mluvila vo sṿm żivoté } \\
\text { 4. }\end{array}$ & & \\
\hline
\end{tabular}




\begin{tabular}{|c|c|c|}
\hline & doma & $\begin{array}{l}v \text { televizi / v } \\
\text { rozhlase }\end{array}$ \\
\hline $\begin{array}{l}\text { 1. vidéli jsme staré hrady } \\
\text { 2. videli sme starỵ hrady } \\
\text { 3. }\end{array}$ & & \\
\hline $\begin{array}{l}\text { 1. znám dobré kuchare } \\
\text { 2. znam dobrị kuchare } \\
\text { 3. }\end{array}$ & & \\
\hline $\begin{array}{l}\text { 1. boli mể ocii } \\
\text { 2. bolej mé vocii } \\
\text { 3. }\end{array}$ & & \\
\hline $\begin{array}{l}\text { 1. kabát je v nové sktini } \\
\text { 2. kabát je v noṿi sktini } \\
\text { 3. }\end{array}$ & & \\
\hline $\begin{array}{l}\text { 1. šli ke staremu mlinu } \\
\text { 2. šli ke staṇimu mlejnu } \\
\text { j. }\end{array}$ & & \\
\hline $\begin{array}{l}\text { 1. musim prinést pivo } \\
\text { 2. musim prinýst pivo } \\
\text { 3. }\end{array}$ & & \\
\hline $\begin{array}{l}\text { 1. trvá to dèle } \\
\text { 2. Irvá to dịl } \\
\text { 3. }\end{array}$ & & \\
\hline $\begin{array}{l}\text { 1. nemohu dichat } \\
\text { 2. nemižu dejchat } \\
\text { 3. }\end{array}$ & & \\
\hline $\begin{array}{l}\text { 1. malè déti piji caj } \\
\text { 2. malỳ déti pijou caj } \\
\text { 3. }\end{array}$ & & \\
\hline
\end{tabular}

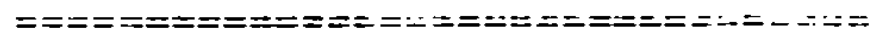

D) Velmi by nás potčšilo, kdybyste nám napsali Váš osobni názor na tuto anketu a na současnou situaci v češtinč. Co byste $V y$ osobñ $v$ češtinč zmčnili a co se Vám libi. Budeme Vám vděčni za každý komentáł a rádi prijmenıe jakoukoliv kritiku. 